

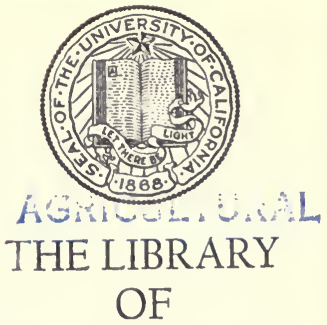

THE UNIVERSITY

OF CALIFORNIA RIVERSIDE

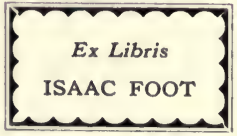


m.m. aiefó ys $1920^{2}$ chepsetis. 


\section{HANDBOOK \\ OF}

\section{THE BRITISH FLORA:}

A DESCRIPTION OF

THE FLOWERING PLANTS AND FERNS

INDIGENOUS TO, OR NATURALISED IN,

The Jaritisb łales.

FOR THE USE OF BEGINNERS AND AMATEURS.

BY

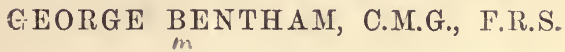

REVISED BY

SIR J. D. HOOKER, K.C.S.I., C.B., F.R.S.

LATE DIRECTOR OF THE ROYAL GARDENS, KEW.

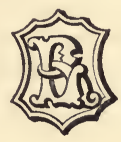

LONDON :

L. REEVE \& CO., LTD.

6, HENRIETTA STREET, COVENT GARDEN, W.C. 2. 


\section{ILLUSTRATIONS OF THE BRITISH FL_ORA.}

A series of 1315 Wood Engravings, with dissections of British Plants, drawn by W. H. FITCH, F.L.S., with additions by W. G. SMITH, F.L.S., forming an illustrated companion to "Bentham's Handbook of the British Flora and other Floras." Crown 8vo., pp. $x v i+338$. Price 12s. net

\section{Outlines of Botany, as Introductory to} Local Floras. By George Bentham, F.R.S., F.L.S. Separately from the Handbook. Is. net.

Flora of Hampshire, including the Isle of Wight, with localities of the less common species. By F. Townsend, M.A., F.L.S. Second Edition. With Map, 2 Plates, Index of Orders, \&c., and of popular English names. 18 s. net.

The Potamogetons (Pondweeds) of the Brltish Isles; Descriptions of all the Species, Varieties, and Hybrids. By Alfred FRYER, A.L.S., completed by A. BENNETT, A.L.S. With 6o Plates by Robert Morgan, F.L.S., and Miss M. SMrrh. Royal 4 to. Coloured, $\ell_{5}$ 5s. net; incoloured, $£_{3} \times 5$ s. net. 


\section{PREFACE.}

WuEN revising the fourth edition of my late friend's "Handbook of the British Flora," I abstained from making other additions or alterations than appeared to me to be absolutely necessary, and consistent with the object of the work, which is, as stated in the title-page, "for the use of beginners and imateurs." In the Preface to the first, 1858, but in no sub. sequent edition, Mr. Bentham explained his motives for precenting his work to the public, and the method he followed in preparing it: and inasmuch as he therein gives his reasons for adopting a different treatment of British plants from what obtains in other works devoted to our native Flora, it appears to me to be expedient, now that the editorship has passed into other hands, to repeat what he there says in his own werds :-

"In adding to the number of British Floras already before the public, it is not attempted to enter into competition with either of the standard scientific works whose merits have been tested through several successive editions. The Author's object has been rather to supply a deficiency which he believes has been much felt. He has been frequently applied to, to recommend a work which should enable persons having no previous knowledge of Botany to name the wild flowers they might gather in their country rambles. He has always been much embarrassed how to answer this inquiry. The book he had himselt used under similar circumstances in a foreign country, the 'Flore Française' of De Candolle, is inapplicable to Britain, and has long been out of print even in the country 
for which it was written. Our standard Floras, ${ }^{1}$ whatever their botanical merit, require too much previous scientific knowledge for a beginner or mere amateur to understand without assistance the characters by which the plants are distinguished from each other.

"In the endeavour to comple a more practical guide to the botanical riches of our islands, the Author has recalled to his mind the process by which he was enabled, nearly torty yaars since, without any previous acquaintance with the subject, to determine the wild plants he gathered in the neighbourhood of Angoulême and of Montauban, the difficulties he had to surmount, and the numerous mistakes he was led into. Keeping these points in view, and taking, in some measure, De Candolle's 'Flore' as his model, he has here attempted a descriptive enumeration of all the plants wild in the British Isles, distinguished by such characters as may be readily perceived by the unlearned eye, and expressed, as far as lay in his power, in ordinary language, using such technical terms only as appeared indispensable for accuracy, and whose adopted meaning could be explained in the work itself.

"In commencing this process the Author originaily considered that a mere compilation might be sufficient. The British plants are so well known, they have been so repeatedly described with so much detail, they are mostly so familiar to the Author himself, that it appeared to him only necessary to select from published descriptions the characters that suited his purpose. But he soon found that no satisfactory progress could be made without a careful comparison and verification of the characters upon the plants themselves; and, during five vears that the present work has been in hand, the whole of the

1 The Floras here alluded to are Hooker and Arnott's "British Flora," of which the last (eighth) edition was published in 1860, and Babing. ton's "Manual of British Botany," ed. 7th, which has advanced to ast eighth edition, published in 1881. - J. D. H. 
lescriptions have been drawn up in the first instance from British specimens (except in the few cases of doubtful natives). They have been then compared with the characters given in Hooker and Arnott's 'British Flora,' and Babington's 'Manual,' or with detailed descriptions in some of our best local Floras. They have, in almost all cases, been verified upon continental specimens from various parts of the geographical range of each species; and a considerable number have been checked by the examination of living specimens. The works of the best French, German, Swedish, Italian, or other botanists have also been consulted wherever the occasion required it. The dried specimens made use of have been chiefly those of the rich collections at Kew, including the unrivalled herbarium of Sir William Hooker; but the Author has also availed himself of numerous and repeated observations made during forty years' herborisations in various parts of Europe.

"Taking into account the omission of all plants erroneously indicated as British, it will still, no doubt, be a matter of astonishment that, whilst the last edition of Hooker and Arnott's 'Flora' contains 1571 species, and that of Babington's 'Manual' as many as 1708 (exclusive of Chara), that number is reduced in the present work to 1285.1 This is not owing to

1 The number of species (exclusive of Chara) described in the last (eighth, 1881) edition of Babington's "Manual" is 1758 , that in this edition of Bentham's "Handbook" is 1296 ; that in the third edition (1884) of my "Student's Flora" (which replaces Hooker and Arnott) is 1413. The difference between the Manual and Handbook is not (as it is here stated by Bentham to be) "wholly owing to a different appreciation of the value of the species," but in a great measure to there being inclnded in the "Manual" many avowedly introduced and naturalised plants. Nearly $150 \mathrm{such}$ are enumerated in the Appendix to the "Student's Flora," nearly all of which appear in the "Mannal," but not in the "Handbook." Of the 462 more species in Babington's than there are in Bentham's work, 162 are comprised in the nine genera Ranunculus, Rubus, Rosa, Hieracium, Rumex, Salix, Juncus, Potamogetom, Carex, genera the limits of whose species are notorious subjects of con- 
any real difference of opinion as to the richness and diversity of our vegetable productions, but is occasioned by a different appreciation of the value of the species themselves. The Author has long been persuaded that the views originally enter tained by Linnæus of what really constitutes a species were far more correct than the more limited sense to which many modern botanists seem inclined to restrict the term; and that in most cases where that great master had good means of observation, he succeeded admirably in the practical application of his principles. At any rate, if those minute distinctions by which the innumerable varieties of Brambles, of Roses, of Hawkweeds, or of Willows have of late years been characterised, are really more constant and more important than the Author's experience has led him to conclude, they cannot be understood without a more complete acquaintance with trifling, vague, and sometimes theoretical characters than he has himself been able to attain, or than can ever be expected from the mere amateur. It is considered, therefore, that such details would be out of place in the present work, and those who feel sufficient interest in the subject to devote their leisure hours to the investigation, can only hope to master it by a close and patient study of the numerous, often very carefully elaborated monographs published in Germany, Swcden, and France, as well as in this country. The species are here limited according to what are conceived to have been the original principles of Linnæus, and the Author, in submitting his views to the judgment of the scientific world, trusts that they will not be attributed to hasty generalisations or conjectural theories, but that they will be generally recognised as founded on personal observation of living plants, made during many years' residence on the Continent as well as in this country, and on repeated comparison of specimens collected

troversy ; leaving 300 to be accounted for by the inclasion of doubtful and introdnced species, and by a subdivision of the species of varions small genera.-J. D. H. 
from the most varied and distant points of the geographicall areas of the several species."

In respect of the views here advanced as to the limitation of the species of our indigenous Flora, it must be remembered that they are those of a great master of systematic and descriptive Botany who had collected and studied a large proportion of the prevalent forms of British plants in a living state, not only in our three kingdoms, but in France, Scandinavia, Russia, Germany, Switzerland, and Turkey. Bentham's conclusions were not critical, but neither were they superficial; he was an acute and indefatigable observer, gifted with remarkable synthetic powers, and as conscientious as judicious in the uses he put them to. The result he arrived at was, that the specific term should have a much wider application than prevailed in most local Floras.

It remains that I should explain the course I have adopted in the delicate task of rendering a new edition of my late friend's work as complete as possible without tampering with his views. I have not amplified or modified the descriptions of orders, genera, and species, except in rare cases of error or omission. The very few species recently added to the British Flora, and which I think that he would have admitted, are entered between brackets [ ]. In cases where I think he would have regarded them as varieties I have briefly described them (in brackets) as such under the species to which, I believe, he would have attached them. With regard to certain well-marked varieties admitted as species by most botanists, but which he has dismissed with a mention, I have added their characters; in all such cases especially as where I think that the absence of such characters would lead the beginner to suppose that he had a different species under his eye.

In many instances I have been compelled to revise and materially add to the localities, and especially the contirentai and exotic distribution of the species. It is evident that this 
part of the Handbook had not been revised by Mr. Bentham since the publication of the first edition, and that the later works of Watson, Nyman, \&c., and many local Floras of the north temperate regions, had not been consulted.

June 30, 1886.

J. D. HOOKER.

\section{NOTE TO EDITION VI.}

Is revising Bentham's work for a sixth edition I have endeavoured to follow the course pursued in regard to its predecessor, and which is explained at p. vii. of the Preface. The only material modification which I have introduced has been the omitting many of the duplicate English names of the species, especially those that are mere translations of the Latin names. The greater number of them was invented or adopted by the late Professor Hensow, and generally settled in consultation with Mr. Bentham and myself (see Preface, edition 1, p. xiv.), for the use of village school-children, who were not as a rule supposed to recognise the Latin names.

The space thus obtained has enabled me in many cases to introduce the characters of more of these well-marked forms of variable species that were not differentiated in earlier editions, and which forms, if not specially alluded to, mislead beginners; as also briefly to introduce the few species new to the British Isles that have been discovered since the appearance of the last edition (1886). It further enables me to bring the work more into harmony with the "London Catalogue of British Plants," edition 8, a most reliable index to all known species and varieties of the flowering plants and ferns of our islands, and in accordance with which most British botanists arrange their herbaria.

J. D. HOOKER. 


\section{CONTENTS.}

\section{INTRODUCTION.}

OUTLINES OF BOTANY, WITI SPECIAL REFERENCE TO LOCAL

FlorAS . . . . . * , . , xi

Chap. I. Definitions and Descriptive Botany * * xi

$\S$ 1. The Plant in General . . . . . . . xii

$\S$ 2. The Root . . . . . . . . . . xiv

\& 3, The Stock . . . . . . . . . . $\mathrm{xv}$

$\$$ 4. The Stem . . . . . . . . . . . $\mathrm{xV}$

§ 5. The Leaves . . . . . . . \& . xvii

§ 6. Scales, Bracts, and Stipules . . . . . . . xxí

$\S 7$. Inflorescence and its Bracts . . . . . . xxii

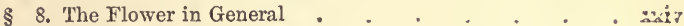

$\S$ 9. The Calyx and Corolla, or Perianth . . . . . xxvii

$\S 10$. The Stamens . . . . . . . . . xxix

$\S$ 11. The Pistil . . . . . . . . . . $\mathrm{xxx}$

\$ 12. The Receptacle and Relative Attachment of the Floral

Whorls . . . . . . . . . . xxxiii

$\S 13$. The Fruit . . . . . . . . . . $\mathrm{xxxv}$

$\S$ 14. The Seed . . . . . . . . . . xxxvii

§ 15. Accessory Organs . . . . . . . . . xxxvii

Ciap. II. Classification, or Systematic Botaxy . . xl 
PAGE

Chap. III. Vegetable Axatomy and Physiology • • xlii

$\S 1$. Structure and Growth of the Elementary Tissues . . xlii

§ 2. Arrangement of the Elementary Tissues, or Structure of the Organs of Plants . . . . . . . xliii .

§3. Growth of the Organs . . . . . . . xlvi

\$ 4. Functions of the Organs . . . . . . xlviii

Chap. IV. Collection, Preservation, and Determination of Plants . . . . . . . . . . 1

II. INDEX OF TERMS, OR GLOSSARY . . . . . . lvi

JiI. Arrangement of the Text, and Abbreviations . Ixi

IV. ANalytical Key to the Natural ORders ANd ANomaLOUS GeNerA OF the BRITISH FlorA. . . . Ixiii

V. Arrangement of the Natural Orders in the Present WORK . . . . . . . . . . Ixxv

FLORA.

Class I. Dicotrledons . . . . . . . . I

Class II. Monocotyledons . . . . . . . 418

Class III. Criptogans . . . . . . . . . 547

Index of Substantive Names . . . : , , 572 


\section{OUTLINES OF BOTANY.}

\section{Chap. I. Definitions and Descriptive Botany.}

1. The principal object of a Flora of a country, is to afford the means of determining (i.e. ascertaining the nams of) any plant growing in it, whether for the purpose of ulterior study or of intellectual exercise.

2. With this view, a Flora consists of descriptions of all the wild or native plants contained in the country in question, so drawn up and arranged that the student may identify with the corresponding description. any individual specimen which he may gather.

3. These descriptions should be clear, concise, accurate, and characteristic, so as that each nne should be readily adapted to the plant it relates to, and to no other one; they should be as nearly as possible arranged under natural (184) divisions, so as to facilitate the comparison of each plant with those nearest allied to it; and they should be accompanied by an artificial key or index, by means of which the student may be guided step by step in the observation of such peculiarities or characters in his plant, as may lead him, with the least delay, to the individual description belonging to it.

4. For descriptions to be clear and readily intelligible, they should be expressed as much as possible in ordinary well-established language. But, for the purpose of accuracy, it is necessary not only to give a more precise technical meaning to many terms used more or less vaguely in common conversation, but also to introduce purely technical names for such parts of plants or forms as are of little importance except to the botanist. In the present chapter it is proposed to define such technical or technically limited terms as are made use of in these Floras.

5. At the same time mathematical accuracy must not be expected. The forms and appearances assumed by plants and their parts are infinite. Names cannot be invented for all; those even that have been proposed arc too numerons for ordinary memories. Many are derived from supposed resemblances to well-known forms or objects. These resemblances are differently appreciated by different persons, and the same term is not only differently applied by two different hotanists, but it frequently happens 
that the same writer is led on different occasions to give somewhat different meanings to the same word. The botanist's endearours shonld always be, on the one hand, to make as near an approsch to precision as circumstances will allow, and, on the other hand, to svoid that prolixity of detail and overloading with technical terms which tends rather to confusion than clearness. In this he will be more or less successful. The aptness of a botanical deccription, like the beauty of a work of imagination, will always vary with the style and genins of the suthor.

\section{1. The Plant in General.}

6. The Plant, in its botanical sense, inclndes erery being which has regetable life, from the loftiest tree which adorns our landscapes, to the humblest moss which grows on its stem, to the mould or fungus which attacks our provisions, or the green scum that floats on our ponds.

7. Every portion of a plant which has a distinct part or function to perform in the operations or phenomens of regetable life is called an organ.

8. What constitutes vegetable life, and what are the functions of each organ, belong to Vegetable Physiology; the microscopical structure of the tissues composing the organs, to Vegetable Anatomy; the composition of the substances of which they are formed, to Vegetable Chemistry; under Descriptive and Systematic Botany we hsre chiefly to consider the forms of organs, that is, their Morphology, in the proper sense of the term, and their general structure so far as it affects classification and specific resemblances and differences. The terms we shall now define belong chiefly to the latter branch of Botany, as being that which is essential for the investigation of the Flora of a conntry. We shall add, however, a short chapter on Vegetable Anatomy and Physiology, as a general knowledge of both imparts an additional interest to and facilitates the comparison of the characters and affinities of the plants examined.

9. In the more perfect plants, their organs are comprised in the general terms Root, Stem, Ieaves, Flowers, and Fruit. Of these the first three, whose function is to assist in the growth of the plant, are Organs of Vegetation; the flower and fruit, whose office is the formation of the seed, are the Organs of Reproduction.

10. All these organs exist, in one shape or another, at some period of the life of most, if not all, flowering plants, technically called phonogamous or phanerogamous plants; which all bear some kind of flower and fruit in the botanical sense of the term. In the lower classes the ferns, mosses, fungi, moulds or mildews, seaweeds, etc., called by botanists cryptogamous plants, the flowers, the fruit, and not unfrequently one or more of the organs of regetation, are either wanting, or replaced by organs so different as to be bardly capable of bearing the same name.

11. The observations comprised in the following pages refer exclusively to the flowering or phrenogamous plants. The study of the cryptogamous classes has now become so complicated as to form almost a separate science. They are therefore not included in these introductory observations, nor, with the exception of ferns, in the present Flore.

\section{Plants are}

Monocarpic, if they die after one flowering-season. These include Annuals, which flower in the same year in which they are raised from seed; and Biennials, which only flower in the year following that in which they are nown. 
Caulocarpic, if, after flowering, the whole or part of the plant live through the winter and produces fresh flowers another season. These include Herbaceous perennials, in which the greater part of the plant dies sfter flowering, leaving only a small perennial portion called the Stock or Caudex, close to or within the earth ; Undershmibs (suffruticose or suffrutescent plant8) in which the flowering branches, forming a considerable portion of the plant die down after flowering, but leave a more or less prominent perennial and woody base; Shrubs (frutescent or fruticose plants), in which the perennial woody part forms the greater part of the plant, but branches near the base, and does not much exceed a man's height; and Trees (arboreous or arborescent plants) when the height is grester and forms a woody trunk, scarcely branching from the base. Bushes are low, much branched shrubs.

13. The terms Monocarpic and Caulocarpic are but little used, but the other distinctions enumerated above are unirersally attended to, although more useful to the gardener than to the botanist, who cannot always assign to them any precise character. Monocarpic plants, which require more than two or three years to produce their flowers, will often, under certain circumstances, become herbaceous perennials, and are generally confounded with them. Truly perennial herbs will often commence flowering the first year, and have then all the appearance of annuals. Many tall shrubs and trees lose annually their flowering branches like undershrubs. And the same botanical species may be an annual or a perennial, an herbaceous perennial or an undershrub, an undershrub or a shrub, a shrub or tree, according to climate, treatment, or variety.

14. Plante are usually terrestrial, that is, growing on earth; or aquatic, i.e. growing in water; but sometimes they may be found attached by their roots to other plants, in which case they are epiphytes when simply growing upon other plants without penetrating into their tissue, parasites when their roots penetrate into and derive more or less nutriment from the plant to which they are attached.

15. The simplest form of the perfect plant, the annual, consists of-

(1) The Root, or descending axis, which grows downwards from the stem, divides and spreads in the earth or water, and absorbs food for the plant through the extremities of its branches.

(2) The Stem, or ascending axis, which grows upwards from the root, branches and bears first one or more leares in succession, then one or more flowers, and finally one or more fruits. It contains the tissues or other channels (217) by which the nutriment absorbed by the roots is conveyed in the form of $\operatorname{sap}(192)$ to the leares or other points of the surface of the plant, to be elaborated or digested (218), and afterwards redistributed over different parts of the plant for its support and growth.

(3) The Ieaves, usually flat, green, and horizontal, are rariously arranged on the stem and its branches. They elaborate or digest (218) the nutriment bronght to them throngh the stem, absorb carbonic acid gas from the air, exhaling the superfluous oxygen, and returning the assimilated sap to the stem.

(4) The Flowers, usually placed at or towards the extremitics of the branches. They are destined to form the future seed. When perfect and complete they consist:-1st, of a pistil in the centre, consisting of one or more carpels, each containing the germ of one or more seeds; 2nd, of one or more stamens outside the pistil, whose action is necessary to fertilize the 
pistil or enable it to ripen its seed; 3rd, of a perianth or flural entelopa, which usually encloses the stamens and pistil when young, and expands and exposes them to riew when fully formed. This complete perianth is double; the outer one, called Calyx, is usually more green and leaf-like; the inner one, called the Corolla, more conspicuons, and variously coloured. It is the perianth, and especially the corolls, as the most showy part, that s generally called the flower in popular language.

(5) The Fruit, consisting of the pistil or its lower portion, which persists or remains attached to the plunt after the remainder of the flower has withered and fallen off. It enlarges and alters more or less in shape or consistence, becomes a seed-vessel, enclosing the seed until it is ripe, when it either opens to discharge the seed or falls to the ground with the seed. In popular language the term fruit is often limited to such seed-vessels as are or look juicy and eatable. Botanists giro that namo to all seedressels.

16. The herbaceous perennial resembles the annual during the first year of its growth; but it also forms (usually towards the close of the season), on its stock (the portion of the stem and root which does not die), one or more buds, either exposed, and then popularly called eyes, or concealed smong leaves. These buds, called leaf-buds, to distinguish them from flower-buds or unopened flowers, are future branches as yet undereloped; they remain dormant through the winter, and the following spring grow out into new stems bearing lesres and flowers like those of the preceding year, whilst the lower part of the stock emits fresh roots to replace those which had perished at the same time as the stems.

17. Shrubs and trees form similar leaf-buds either at the extremity of their branches, or along the branches of the year. In the latter case these buds are usually axillary, that is, they appear in the axil of each leaf, i.e. in the angle formed by the leaf and the branch. When they appear at any other part of the plant they are called adventitious. If these buds by producing roots (19) become distinct plants before separating from the parent, or if adrentitious leaf-buds are produced in the place of flowers or seeds, the plant is said to be viviparous or prolifcrous.

\section{§2. The Root.}

18. Roots ordinarily produce neither buds, leaves, nor flowers. Their branches, called fibres, when slender and long, proceed irregularly from any part of their surface.

19. Althongh roots proceed usually from the base of the stem or stock, they may also be produced from the base of any bud, especially if the bud lies slong the ground, or is otherwise placed br nature or art in circumstances farourable for their development, or indeed occasionally from almost any part of the plant. They are then often distinguished as adventitious, but this term is by oome spplied to all roots which are not in prolongation of the original radicle.

\section{Roots are}

fibrous, when they consist chiefly of slender fibres.

tuberous, when either the main root or its branches are thickened into one or more short fleshy or woody masses called tubers (25).

taproots, when the main root descends perpendicularly into the esrth, -mitting only very smsll fibrons branches.

21. The stock of an herbaceous perennial, or the lower part of the stem 
of an annual or perennial, or the lowest branches of a plant, are sometimes underground and assume the appearance of a root. They then take the name of rhizome. The rhizome may always be distinguished from the true root by the presence or production of one or more buds, or leaves, or scales.

\section{\$ 3. The Stock.}

22. The stook of an herbaceous perennial, in its most complete state, includes a small portion of the summits of the previous year's roots, as well as of the base of the previons year's stems. Snch stocks will increase yearly, so as at length to form dense tufts. They will often preserve through the winter a fow leaves, amongst which are placed the buds which grow out into stems the following year, whilst the under side of the stock emits new roots from or amongst the remains of the old ones. These perennial stocks only differ from the permanent base of an undershrub in the shortness of the perennial part of the stems and in their texture nsually less woody.

23. In some perennials, however, the stock consists merely of a branch which proceeds in autumn from the base of the stem either aboveground or nnderground, and produces one or more buds. This branch, or a portion of it, alone survives the winter. In the following year its bnds produce the new stem and roots, whilst the rest of the plant, even the branch on which these buds were formed, has died away. These annual stocks, called sometimes hybernacula, offsets, or stolons, keep up the communication between the annual stem and root of one year and those of the following year, thus forming altogether a perennial plant.

24. The stock, whether annual or perennial, is often entirely underground or root-like. This is the rootstock, to which some botanists limit the meaning of the term rhizome. When the stock is entirely root-like, it is popularly called the crown of the root.

25. The term tuber is applied to a short, thick, more or less sncculent rootstock or rhizome, as well as to a root of that shape (20), although some botanists propose to restrict its meaning to the one or to the other. An Orchis tuber, called by some a knob, is an annual tuberous rootstock with one bud at the top. A potato is an annual tuberous rootstock with several buds.

26. A bulb is a stock of a shape approaching to globular, usually rather conical above and flattened underneath, in which the bud or buds are concealed, or nearly so, under scales. These scales are the more or less thickened bases of the decayed leaves of the preceding year, or of the undeveloped leaves of the future year, or of both. Bulbs are annnal or perennial, usually underground or close to the ground, but occasionally buds in the axils of the upper leaves become transformed into bulbs. Bulbs are said to be scaly when their scales are thick and loosely imbricated, tunicated when the scales are thinner, broader, and closely rolled round each other in concentric layers.

27. A corm is a tuberous rootstock, usually annnal, shaped like a bulb, but in which the bud or bnds are not covered by scales, or of which the scales are very thin and membranous.

28. Stems are

\section{4. The Stem.} erect, when they ascend perpendicularly from the root or stock; 
swiggy or virgate, when at the same time they are slender, stiff, and scarcely branched.

decumbent or ascending, when they spread horizontally, or nearly so, at the base, and then turn upwards and become erect.

procumbent, when they spread along the ground the whole or the greater portion of their length; diffuse, when at the same time very much and rather loosely branched.

prostrate, when they lie still closer to the ground.

crecping, when they emit roots at their nodes. This term is siso frequently applied to any rhizomes or roots which spread horizontally.

tufted or caspitose, when very short, close, and many together from the same stock.

29. Weak climbing stems are said to twine, when they support themselves by winding spirally round any object; such stems are also called voluble. When they simply climb without twining, they support themselves by their leaves, or by special clasping organs called tendrils (169), or sometimes, like the Ivy, by small root-like excrescences,

30. Suckers are young plants formed at the end of creeping, undergronnd rootstocks. Scions, runners, and stolons or stoles, are numes given to young plants formed at the end or at the nodes (31) of branches or stocks creeping wholly or partially aboreground, or sometimes to the creeping stocks themselres.

31. A node is a point of the stem or its branches at which one or more leaves, branches, or leaf-buds (16) are given off. An internode is the portion of the stem comprised between two nodes.

32. Branches or leaves are the stem.

opposite, when two proceed from the same node on opposite sides of

whorled or verticillate (in a whorl or verticil), when several proceed from the same node, arranged regularly around the stem; geminate, ternate, fascicled or fasciculate when two, three, or more proceed from the same node on the same side of the stem. A tuft of fasciculate leares is usually in fact an axillary leafy branch, so short that the leaves appear to proceed all from the same point.

alternate, when only one proceede from each node, one on one side and the next above or below on the opposite side of the stem.

decussate, when opposite, but each pair placed at right angles to the next pair abore or below it; distichous, when regularly arranged one above another in two opposite rows, one on each side of the stem; tristichous, when in three rows, etc. (92).

scattered, when irregularly arranged round the stem ; frequently, howover, botanists apply the term alternate to all branches or leaves that are neither opposite nor whorled.

secund, when all start from or are turned to one side of the stem.

33. Branches are dichotomous, when several times forked, the two branches of each fork being nearly equal; trichotomous, when there are three nearly equal branches at each division instead of two; but when the middle branch is evidently the principal one, the stem is usually said to have two opposite branches; umbellate, when divided in the same manner into several nearly equal branches proceeding from the same point. If however the central branch is larger than the two or more lateral ones, the atem is said to have opposite or whorled b-anches, as the case may be. 
34. A culm is a name sometimes giren to the stem of Grasses, Sedges, and some other Monocotyledonous plants.

\section{5. The Leaves.}

35. The ordinary or perfect Ieaf consists of a flat blade or lamina, nsually green, and more or less horizontal, attached to the stem by a stalk called a footstalk or petiole. When the form or dimensions of a leaf are spoken of, it is generally the blade that is meant, without the petiole or stalk.

36. The end by which a leaf, a part of the fluwer, a seed, or any other organ, is attached to the stem or other organ, is called its base, the opposite end is its apex or summit, excepting sometimes in the case of anther. cells (115).

\section{Ieaves are}

sessile, when the blade rests on the stem without the intervention of a petiole.

amplexicaul or stem-clasping, when the sessile base of the blade clasps the stem horizontally.

perfoliate, when the base of the blade not only clasps the stem, but closes round it on the opposite side, so that the stem appears to pierce throngh the blade.

decurrent, when the edges of the leaf are continned down the stem so as to form raised lines or narrow appendages, called wings.

sheathing, when the base of the blade, or of the more or less expanded petiole, forms a vertical sheath round the stem for some distance abore the node.

38. Leaves and flowers are called radical, when inserted on a rhizome or stock, or so close to the base of the stem as to appear to proceed from the root, rhizome, or stock; cauline, when inserted on a distinct stem. Radical leaves are rosulate when they are spread in a circle on the ground.

\section{Leaves are}

simple and entire, when the blade consists of a single piece, with the margin nowhere indented, simple being used in opposition to compound, entire in opposition to dentate, lobed, or divided.

ciliate, when bordered with thick hairs or fine hair-like teeth.

dentate or toothed, when the margin is only cut a little way in, into what have been compared to teeth. Such leaves are serrate, when the teeth are regular and pointed like the teeth of a $8 \mathrm{aw}$; crenate, when regular and blunt or rounded (compared to the battlements of a tower); scrrulate, and crenulate, when the serratures or crenatures are emall; sinuate, when the teeth are broad, not deep, and irregular (compared to bays of the coast); wavy or undulate, when the edges are not flat, but bent up and down (com. pared to the waves of the sea).

lobed or cleft, when more deeply indented or divided, bnt so that the incisions do not reach the midrib or petiole. The portions thus divided take the name of lobes. When the lobes are narrow und very irregular, the leaves are said to be laciniate. The spaces between the teeth or lobes are called sinuses.

divided or dissected, when the incisions reach the midrib or petiole; but the parts so divided off, called segments, do not separate from the petiole, oven when the leaf falls, without tearing.

compound, when divided to the midrib or petiole, and the parte so 
divided off, called leaplets, separate, at least at the fall of the leat, from the petiole, as the whole leaf does from the stem, without tearing. The com. mon stalk upon which the lesflets sre inserted is called the common petiole or the rachis; the separate stalk of each leaflet is a petiolule.

40. Leaves are more or less marked by veins, which, starting from the stalk, direrge or branch as the blade widens, snd spread sll over it more or less visibly. The principal ones, when prominent, are often called ribs or werves, the smsller branches only then retsining the nsme of veins, or the latter are termed veinlets. The smsller reins are often connected together like the meshes of a net, they are then said to anastomose, and the lenf is said to be reticulate or net-veined. When one principal vein runs direct from the stalk towrrds the summit of the leaf, it is called the midrib. When several start from the stalk, diverge slightly without branching, and converge again towards the summit, they are said to be parallel, although not mathemstically so. When 3 or 5 or more ribs or nerres diverge from the base, the leaf is said to bo 3-nerved, 5-nerved, etc., but if the lateral ones diverge from the midrib a little above the base, the leaf is triplinerved, quintuplinerved, etc. The arrangement of the veins of a leaf is called their venation.

\section{The Ieaflets, Segments, Iobes, Velns of leaves are}

pinnate (feathered), when there sr.9 sereral succeeding each other on each side of the midrib or petiole, comparel to the branches of a feather. A pinnstely lobed or divided leaf is called lyrate when the terminal lobe or segment is much larger gnd 3made: than the lateral ones, compared, by a stretch of imagination, to a lyre; runcinate, when the lateral lobes are surved bsckwsrds towsrds the base of the leaf; pectinate, when the lateral lobes are numerous, narrow, snd regular, like the teeth of a comb.

palmate or digitate, when several diverge from the same point, compared to the fingers of the hand.

ternate, when three only start from the same point, in which case the distinction between the palmste and pinnate arrangement often ceases, or can only be determined by anslogy with allied plant8. A leaf with ternate lobes is called trifid. A lesf with three leaflets is sometimes improperly called a ternste leaf; it is the lesflets that are ternate; the whole lesf is trifoliolate. Ternste leaves are leaves growing three together.

pedate, when the division is at first ternate, but the two onter branches are forked, the outer ones of each fork again forked, and so on, and all the branches are near together at the base, compared vaguely to the foot of a bird.

42. Leaves with pinnate, palmate, pedate, etc.. leaflets, are usually for shortness called pinnate, palmate, pedate, etc., leaves. If they are so cut into segments only, they are usually said to be pinnatisect, palmatisect, pedatisect, etc., althongh the distioction between segments and leaflets is often unheeded in descriptions, and cannot indeed slways be ascertained. If the leares are so cut only into lobes, they sre said to be pinnatifid, pal matifid, pedatifid, otc.

43. The teeth, lobes, segments, or leaflets, may be again toothed, lobed, divided, or compounded. Some leares are even three or more times divided or compounded. In the latter case they sre termed decompound. When twice or thrice pinnate (bipinnate or tripinnate), each primary or secondary divisior, with the leaflets it comprises, is called a pinna. When the pinno of ast or the loaflets of a pinns are in psirs, without an odd terminal 
pinna or leaflet, the leaf or pinna so divided is said to be abruptly pinnate; if there is an odd terminal pinna or leaflet, the leaf or pinns is unequally pinnate (imparipinnatum).

44. The number of leaves or their parts is expressed adjectively by the following numerals, derived from the Latin:-

uni-, bi-, tri-, quadrl-, quinque-, sex-, septem-, octo-, novem-, decem-, multi-, 1-, 2-, 3-, 4-, $\quad$ 5-, 6-, 7-, 8- 9-, $10-$, many-

prefixed to a termination, indicating the particular kind of part referred to. Thus :-

unidentate, bidentate, multidentate, mean one-toothed, two-toothed, many-toothed, etc.

bifid, trifid, multifid, mean two-lobed, three-lobed, many-lobed, etc.

unifoliolate, bifoliolate, multifoliolate, mean having one leaflet, two leaflets, many leaflets, etc.

unifoliate, bifoliate, multifoliate, mean having one leaf, two leaves, many leares, otc.

biternate, and triternate, mean twice or thrice ternately divided.

unijugate, bijugate, multijugate, etc., pinnæ or leaflets, mean that they are in one, two, many, etc., pairs (juga).

45. Ieaves or their parts, when flat, or any other flat organs in plants, are

linear, when long and narrow, at least four or five times as long as broad, falsely compared to a muthematical line, for a linear leaf has always a perceptible breadth.

lanceolate, when ahout three or more times as long as broad, broadest below the middle, and tapering towards the summit, compared to the head of a lance.

cuneate, when broadest abore the middle, and tapering towards the base, compared to a wedge with the point downwards; when very broadly cuneate and rounded at the top, it is often called flabelliform or fanshaped.

spathulate, when the broad part near the top is short, and the narrow tapering part long, compared to a spatula or flat ladle.

ovate, when scarcely twice as long as broad, and rather broader below the middle, compared to the longitudinal section of un egg; obovate is the same form, with the broadest part above the middle.

orbicu'ar, oval, oblong, elliptical, rhomboidal, etc., when compared to the corresponding mathematical figures.

transversely oblong, or oblate, when conspicuously broader than long. falcate, when curved like the blade of a scythe.

46. Intermediate forms between any two of the above are expressed by combining two terms. Thus, a linear-lanceolate leaf is long and narrow, yet broader below the middle, and tapering to a point; a linear-oblong one is scarcely narrow enough to be called linear, yet too narrow to be strictly oblong, and does not conspicuously taper either towards the summit or to. wards the base.

47. The apex or summit of a leaf is acute or pointed, when it forms an acute angle or tapers to a point. obtuse or blunt, when it forms a very obtuse angle, or more generally when it is more or less rounded at the top.

acuminate or cuspidate, when suddenly narrowed at the top, and then 
more or less prolonged into an acumen or point, which may be acnte or obtuse, linear or tapering. Some botanists make a slight difference between the acuminate and cuspidate apex, the acumen being more distinct from the rest of the leaf in the latter case than in the former; but in general the two terms are used in the same sense, some preferring the one and some the other.

truncate, when the end is cut off square.

retuse, when very obtnse or truncate, and slightly indented.

emarginate or notched, when more decidedly indented at the end of the midrib; obcordate, if at the same time approaching the shape of a heart with its point downwards.

mucronate, when the midrib is produced beyond the apex in the form of a small point.

aristate, when the point is fine like a hair.

48. The base of the leaf is liable to the same variations of form as the apex, but the terms more commonly uked are tapering or narrowed for acute and acuminate, rounded for obtuse, and cordate for emarginate. In all cases the petiole or point of attachment prevents any such absolute termination at the base as at the apex.

49. A leaf may be cordate at the base whatever beits length or breadth, or whatever the shape of the two lateral lobee, called auricles (or little ears) formed by the indenture or notch; but the term cordiform or heart-shaped leaf is restricted to an orate and acute leaf, cordate at the base, with rounded auricles. The word 'auricles' is more particnlarly used as applied to sessile and stem-clasping leaves.

50. If the anricles are pointed, the leaf is more particularly called auriculate; it is moreover said to be sagittate, when the points are directed downwards, compared to an arrow-head; hastate, when the points diverge horizontally, compared to a halbert.

51. A reniform leaf is broader than long, slightly but broadly cordate at the base, with rounded auricles, compared to a kidney.

52. In a peltate leaf, the stalk, instead of proceeding from the lower edge of the blade, is attached to the under aurface, nsually near the lower edge, but sometimes in the very centre of the blade. The peltate leaf has nsually several principal nerres radiating from the point of attachment, being, in fact, a cordate leaf with the auricles united.

53. All these modifications of division and form in the leaf pass so gradually one into the other that it is often difficult to say which term is the most applicable-whether the leaf be toothed or lobed, dirided or compound, oblong or lanceolate, obtuse or acute, etc. The choice of the most apt expression will depend on the skill of the describer.

54. Zeaves, when solld, Stems, Frults, Tubers, and other parts of plants, when not flattened like ordinary leaves, are

selaceous or capillary, when very slender like bristles or hairs. acicular, when very elender, but stiff and pointed like needles. oubulate, when rather thicker and firmer like awls.

linear, when at least four times as long as thick; oblong, when from about two to about four times as long as thick, the terms having the same sonse so when applied to flat surfaces.

ovoid, when egg-ehaped, with the broad end downwarde; obovoid, if the broed and is upwards: these torms corresponding to ovate and obovate shapes in flat surfaces. 
globular or spherical, when corresponding to orbicular in a flut surface. Round applies to both.

turbinate, when shaped like a top.

conical, when tapering upwards; obconical, when tapering downwards; if in both cases a transverse section shows a circle.

pyramidul, when tapering upwards; obpyramidal, when tapering downwards ; if in both cases a transverse section shows a triangle or polygon.

fusiform, or spindle-shaped, when tapering at both ends; cylindrical, when not tapering at either ond; if in both cases the transverse section shows a circle, or sometimes irrespective of the transverse shape.

terete, when the transverse section is not angular; trigonous, triquetrous, if the transverse section shows a triangle, irrespective in both cases of longitudinal form.

compressed, when more or less flattened laterally; depressed, when more or les 8 flattened vertically, or at any rate at the top; obcompressed (in the achenes of Composite), when flattened from front to back.

articulate or jointed, if at any period of their growth (usually when fully formed and approaching their decay, or in the case of fruits when quite ripe) they separate, without tearing, into two or more pieces placed end to end. The joints where they separate are called articulations, each separate piece an article. The name of joint is, in common language, given both to the articulation and the article, but more especially to the former. Some modern botanists, however, propose to restrict it to the article, giving the name of joining to the articulation.

didymous, when slightly two-lobed, with rounded obtuse lobes.

moniliform, or beaded, when mnch contracted at regular intervals, but not separating spontaneously into articles.

55. In their consistence Ieaves or other organs are

fleshy, when thick and soft; succulent is generally used in the same sense, but implies the presence of more juice. leather.

coriaceous, when firm and dry, or very tough, of the consistence of

membranous, when thin and not stiff.

scarious or scariose, when very thin, more or less transparent and not green, yet rather stiff.

56. The terms applied botanically to the consistence of solids are those in general use in common language.

57. The mode in which nnexpanded leares are disposed in the leaf-bud is called their vernation or prafoliation; it varies considerably, and technical terms have been proposed to express some of its varieties, but it has been hitherto rarely noticed in Descriptive Botany.

\section{§ 6. Scales, Bracts and Stipules.}

58. Scales (Squame) are leares very much reduced in size, usually sessile, seldom green or capable of performing the respiratory functions of leaves. In other words, they are organs resembling leaves in their position on the plant, but differing in size, colour, texture, and functions. They are most frequent on the stock of perennial plants, or at the base of annual branches, especially on the buds of future shoots, when they serve apparently to protect the dormant living germ from the rigour of winter. In the latter case they are usually short, broad, close together, and more or less imbricated, that is, overlapping each other like the tiles of a roof. It is 
this arrangement as well as their usual shape that has ouggested the name of scales, borrowed from the scales of a fish. Imbricated scales, bructs, or leaves, are said to be squarrose, when their tips are pointed, and very spreading or recurved.

59. Sometimes, however, most or all the leaves of the plant are reduced to small scales, in which case they do not appear to perform any particular function. The name of scales is also given to any small broad scale-like appendages or roduced organs, whether in the flower or any other part of the plant.

60. Bracts (Bractea) are the upper leares of a plant in flower (either all those of the flowering branches, or only one or two immediately under the flower), when different from the stem-leaves in eize, shape, coluur, or arrangement. They are generally much smaller and more sessile. They often partike of the colour of the flower, although they rery frequently also retain the green colour of the leaves. When small they are often called scales.

61. Floral leaves or leafy bracts are generally the lower bracts or the upper leaves at the base of the flowering branches, intermediate in size, shape, or arrangement, between the stem-leaves and the upper bracts.

62. Bracteoles are the one or two last bracts under each flower, when they differ materially in size, shape, or arrangement from the other bracts.

63. Stipules are lanf-like or scale-like appendages at the base of the leaf-stalk, or on the node of the stem. When present there are generally two, one on each side of the leaf, and they sometimcs appear to protect the young leaf before it is developed. They are, however, exceedingly variable in size and appearance, eometimes exactly like the true leaves except that they hare no buds in their axils, or looking like the leaflets of a compound leaf, sometimes apparently the only leaves of the plant; generally smull and narrow, sometimes reduced to minute scales, spots, or scurs, sometimes nnited into one opposite the leaf, or more or less united with, or adnate to the petiole, or quite detached from the leaf, and forming a ring or sheath round the stem in the axil of the leaf. In a great number of plants they are entirely wanting.

64. Stipelle, or secondary stipules, are similar organs, sometimes found on compound leaves at the points where the leaflets are inserted.

65. When scales, bracts, or stipules, or almost any part of the plant besides leaves and flowers, are stalked, they are said to be stipilate, from stipes, a stalk.

\section{\$ 7. Inflorescence and its Bracts.}

66. The Inflorescence of a plant is the arrangement of the flowering branches, and of the flowers upon them. An Inflorescence is a flowering branch, or the flowering summit of a plant above the last stem-leares, witn its branches, bracts, and flowers.

67. A single flower, or an inflorescence, is terminal when at the summit of a stem or leafy branch, axillary when in the axil of a stem-leaf, leafopposed when opposite to a stem-leaf. The inflorescence of a plant is -aid to be terminal or determinate when the main stem and principal branches end in a flower or inflorescence (not in a leaf-bud), axillary or indeterminate when all the flowers or inflorescences are axillary, the stem or branches onding in leaf-buds.

68. A Peduncle is the stalk of a solitary flower, or of un influruscence ; 
that is to $88 y$, the portion of the flowering branch from the last stem-leat to the flower, or to the first ramification of the inflorescence, or even ap to its last ramifications; but the portion extending from the first to the last ramification or the axis of inflorescence is often distinguished under the name of rachis.

69. A Scape or radical Peduncle is a leafless pednucle proceeding from the stock, or from near the base of the stem, or apparently from the root itself.

70. A Pedicel is the last branch of an inflorescence, supporting a single flower.

71. The branches of inflorescences may be like those of eteins, opposite, alternate, etc. $(32,33)$, but very often their urrangement is different from that of the lesfy branches of the same plant.

72. Inflorescence is

centrifugal, when the terminal flower opens first, and those on the lateral branches are snccessively dereloped.

centripetal, when the lowest flowers open first, and the main stem continues to elongate, developing fresh flowers.

73. Determinate inflorescence is nsually centrifugal. Indeterminate inflorescence is always centripetal. Both inflorescences may be combined on one plant, for it often happens that the main branches of an inflorescence are centripetal, whilst the flowers on the lateral branches are centrifugal ; or vice $2: t r s h$

74. An Inflorescence is

8 Spike, or spicate, when the flowers are sessile along a simple undivided axis or rachis.

a Raceme, or racemose, when the flowers are borne on pedicels along a single undivided axis or rachis.

a Panicle, or paniculate, when the axis is divided into branches bearing two or more flowers.

a Head, or capitate, when several sessile or nearly sessile flowers are collected into a compact head-like cluster. The short, flat, convex or conical sxis on which the flowers are seated, is called the Receptacle, a term also used for the torus of a single flower (135). The very compret flowerheads of Composite are often termed compound flowers.

an Umbel, or umbellate, when several branches or pedicels appear to start from the same point and are nearly of the same length. It differs from the head, like the raceme from the spike, in that the flowers are not sessile. An umbel is said to be simple, when erch of its branches or rays bears a single flower; compound, when each ray bears a partial umbel or umbellule.

s Corymb, or corymbose, when the branches and pedicels, although starting from different points, all attain the same level, the lower ones being much longer than the upper. It is a flat-topped or fastigiate panicle.

a Cyme, or cymose, when branched and centrifugal. It is a centrifugal panicle, and is often corymbose. The central flower opens first. The lateral branches successively developed sre usually forked or opposite (dichotomous or trichotomons), but sometimes after the first forking the branches are no longer divided, but produce a succession of pedicels on their upper side forming apparently unilateral centripetal racemes; whereas, if attentively examined, it will be found that each pedicel is at first terminal, but becomes lateral by the derelopment of one outer branch only, 
immediately under the pedicel. Such branches, when in bud, are generally rolled back at the top, like the tail of a ecorpion, and are thence called scorpioid.

a Thyrsus, or thyrsoid, when cymes, usually opposite, are arrranged in a narrow pyramidal panicle.

75. There are numerous cases where inflorescences are intermediate between some two of the above, and are called by different botanists by one or the other name, according as they are guided by apparent or by theoretical similarity. A spike-like panicle, where the axis is divided into very short branchee forming a cylindrical compact inflorescence is called sometimes a spike, sometimes a panicle. If the flowers are in diatinct clusters along a simple axis, the inflorescence is described as an interrupted spike or raceme, according as the flowers are nearly sessile or distinctly pedicellate; although when closely examined the flowers will be found to be inserted not on the main axis, but on a very short branch, thus, strictly opeaking, constituting a panicle.

76. The Catkins (Amenta) of Amentacee, the Spadices of several Monocotyledons, the Ears and Spikelets of Grasses, are forms of the spike.

77. Braots are generally placed singly under each branch of the inflorescence, and nnder each pedicel; bracteoles are usually two, one on each side, on the pedicel or close under the flower, or eren upon the calyx itself; but bracts are also frequently scattered along the branches without axillary pedicels; and when the differences between the bracts and bracteoles are trifling or immaterial, they are usually all called bracts.

78. When three bracts appear to proceed from the same point, they will, on examination, be found to be really either one bract and two stipules, or one bract with two bracteoles in its axil. When two bracts appear to proceed from the same point, they will usually be found to be the stipules of an undereloped bract, unless the branches of the influrescence are opposite, when the bracts will of course be opposite also.

79. When several bracts are collected in a whorl, or are so close together as to appear whorled, or are closely imbricated round the base of a head or umbel, they are collectively called an Involucre. The bracts composing an involncre are described nnder the name of leaves, leaflets, bracts or scales, according to their appearance. Phyllaries is a useless term, lately introduced, for the bracts or scales of the involucre of Composite. An Involucel is the involucre of a partial umbel.

80. When several very small bracts are placed ronnd the base of a calyx or of an involucre, they have been termed a Calycule, and the calyx or involnere said to be calyculate; but these terms are now falling into disuse, as conveying a false impression.

81. A Spatha is a bract or floral leaf enclosing the inflorescence of some Monocotyledons.

82. Palea, Pales, or Chaff, are the inner bracts or scales in Composita, Graminee, and some other plants, when of a thin yet stiff consistence,

83. Glumes are the bracts enclosing the flowers of Cyperacea and
Gramine.

\section{The Flower in General.}

84. A complete Flower (15) is one in which the calyx, corolla, s'xmens, and pistils are all present; a perfect flower, one in which all these organs. 
or such of them as are present, are capable of performing their several functions. Therefore, properly speaking, an incomplete flower is one in which any one or more of these organs is wanting; and an imperfect flower, one in which any one or more of these organs is 80 altered as to be incapable of properly performing its functions. These imperfect organs are said to be abortive if much reduced in size or efficiency, rudimentary if so much 80 as to be scarcely perceptible. But, in many works, the term inoomplete is specially applied to those flowers in which the perianth is simple or wanting, and imperfect to those in which either the stamens or pistil are imperfect or wanting.

85. A rlower is

dichlamydeous, when the perianth is double, both calyx and corolla being present and distinct.

monochlamydeous, when the perianth is eingle, whether by the union of the calyx and corolla, or the deficiency of either.

asepalous, when there is no calyx.

apetalous, when there is no corolla.

naked, when there is no perianth at all.

hermaphrodite or bisexual, when both stamens and pistil are present and perfect.

male or staminate, when there are one or more stamens, but either no pistil at all or an imperfect one.

female or pistillate, when there is a pistil, but either no stamens at all, or only imperfect ones.

neuter, when both stamens and pistil are imperfect or wanting.

barren or sterile, when from any sause it produces no seed.

fertile, when it does produce seru. In some works the terms barren, fertile, and perfect are also used respectively as synonyms of male, female, and hermaphrodite.

86. The flowers of a plant or species are said collectively to be unisexual or diclinous when the flowers are all either male or female.

monacious, when the male and female flowers are distinct, but on the same plant.

dicecious, when the male and female flowers are on distinct plants.

polygamous, when there are male, female, and hermaphrodite flowers on the same or on distinct plants.

87. A head of flowers is heterogamous when male, female, hermaphrodite, and neuter flowers, or any two or three of them, are included in one head; homogamous, when all the flowers included in one head are alike in this respect. A spike or head of flowers is androgynous when male and female flowers are mixed in it. These terms are only used in the case of very fow Natural Orders.

88. As the scales of buds are leares undeveloped or rednced in size and altered in shape and consistence, snd bracts are leaves likewise reduced in size, and occasionally altered in colour; so the psrts of the flower are considered as leaves still further altered in shape, colour, and arrangement ronnd the axis, and often more or leds combined with each other. The details of this theory constitute the comparatively modern branch of Botany called Vegetable Metamorphosis, or Homology, sometimes improperly termed Morphology (8).

89. To understand the arrangement of the floral parts, let $\mathrm{ns}$ take a complete tlower, in which moreover all the parts are free from each other, definite 
in number, i.e. always the same in the sume species, and symmetrical of isomerous, i.e. when each whorl consists of the same number of parts.

90. Such a complete symmetrical flower consists usually of either four or five whorls of altered lesves $(88)$, placed immediately une within the other.

The Calyx forms the outer whorl. Its parts are called sepals.

The Corolla forms the next whorl. Its parts, called petals, usually alternate with the sepals; that is to say, the centre of each petal is immodiately orer or within the interval between two sepals.

The stamens form one or two whorls within the petals. If in two whorls, those of the outer one (the outer stamens) alternate with the petals, and are consequently opposite to, or over the centre of the sepals; those of the inner whorl (the inner stamens) alternate with the outer ones, and are therefore opposite to the petals. If there is only one whorl of stamens, they most frequently alternate with the petals; but sometimes they are opposite the petals and alternate with the sepals.

The Pistil forms the inner whorl; its carpels usually alternate with the inner row of stumens.

91. In an axillary or lateral flower the upper parts of each whorl (sepals, petals, stamens, or carpels) are those which are next to the main axis of the stems or branch, the lower parts those which are furthest from it ; the intermediate ones are said to be lateral. The words anterior (front) and pasterior (back) are often nsed for lower and upper respectively, but their meaning is sometimes reversed if the writer supposes himself in the centre of the flower instead of ontside of it.

92. The number of parts in each whorl of a flower is expressed adjectively by the following numerals derived from the Greek :-

mono-, dil, tri-, tetra-, penta-, hexa-, beptar, octo-, ennea-, deca-, etc., poly-

1-, 2-, 3-, 4-, 5-, 6-, 7-, 8-, 9-, 10-,

prefixed to a termination indicating the whorl referred to.

93. Thus, a rlower is

disepalous, trisepalous, tetrasepalous, polysepalous, etc., according as there are 2, 3, 4, or many (or an indefinite number of) sepuls.

dipetalous, tripetalous, polypétalous, etc., according as there are 2, 3, or many petals.

diandrous, triandrous, polyandrous, ete., according as there are 2, 3 , or many stamens.

digynous, trigynous, polygynous, etc., according as there are 2,3 , or many carpels.

And generally (if symmetrical), dimerous, trimerous, polymerous, ote., accurding as there are 2,3 , or many (or an indefinite number of) parts to euch whorl.

94. Flowers are unsymmetrical or anisomerous, strictly speaking, when any one of the whorls has a different number of parts from any other; but when the pistils alone are reduced in number, the flower is still frequently called symmetrical or isomerous, if the calyx, corolla, and staminal whorls have all the sime number of parts.

95. Flowers are irregular when the parts of any one of the whorls are unequal in size, dissimilar in shape, or do not spread regularly round the sxis at equal distances. It is, howerer, more especially irregularity of the corolls that is referred to in descriptions. A slight inequality iu size or 
direction in the other whorls does not prevent the flower being classed as regular, if the corolla or perianth is conspicuous and regular.

\section{§ 9. The Calyx and Corolla, or Perianth.}

96. The Calyx (90) is usually green, and smaller than the corolla; sometimes very minute, rudimentary, or wanting, sometimes very indistinctly whorled, or not whorled at all, or in two whorls, or composed of a large number of sepals, of which the outer ones pass gradually into bracts, and the inner ones into petals.

97. The Corolla (90) is usually coloured, and of a more delicate texture than the calyx, and in popular language is often more specially meant by the flower. Its petals are more rarely in two whorls, or indefinite in number, and the whorl more rarely broken than in the case of the calyx, at least when the plant is in a natural state. Double flowers are in most cases an accidental deformity or monster in which the ordinury number of petals is multiplied by the conversion of stamens, sepals, or even carpels, into petals, by the division of ordinary petals, or simply by the addition of supernumerary ones. Petals are also sometimes very small, rudimentary, or entirely deficient.

98. In very many cases, a so-called simple perianth (15) (of which the parts are usually called leaves or segments) is one in which the sepals and petuls are similar in form and texture, and present apparently a single whorl. But if examined in the young bud, one half of the parts will generally be found to be placed ontside the other half, and there will frequently be some slight difference in texture, size, and colour, indicating to the close observer the presence of both calyx and corolla. Hence much discrepancy in descriptive works. Where ove botanist describes a simple perianth of six segments, another will speak of a donble perianth of three sepals and three petals.

99. The following terms and prefixes, expressire of the modifications of form and arrangement of the corolla and its petals, are equally applicable to the calyx and its sepals, and to the simple perianth and its segments.

100. The Corolla is said to be monopetalous when the petals are united, either entirely or at the base only, into a cup, tube, or ring; polypetalous when they are all free from the base. These expressions, established by a long usage, are not strictly correct, for monopetalous (consisting of a single petal) should apply rather to a corolla really reduced to a single petal, which would then be on one side of the axis; and polypetalous is sometimes used more appropriately for a corolla with an indefinite number of petal8. Some modern botanists have, therefore, proposed the term gamopetalous for the corolla with united petals, and dialypetalous for that with free petals; but the old-established expressions are still the most generally nsed.

101. When the petals are partially united, the lower entire portion of the corolla is called the tube, whatever be its shape, and the free portions of the petals are called the teeth, lobes, or segments (39), according as they are short or long in proportion to the whole length of the corolla. When the tube is excessively short, the petals appear at first sight free, but their slight union at the base must be carefully attended to, being of importance in classification.

10\%. The Fsstivation of a corolla is the arrangement of the petule, or of such portion of them as is free, in the unexpanded bud. It is 
valvate, when they are strictly whorled in their whole length, their edges being placed against each other without orerlapping. If the edges are much inflexed, the sestivation is at the same time induplicate; involute, if the margins are rolled inwards; reduplucate, if the margins project outwards into salient angles; revolute, if the margins are rollod outwards ; plicate, if the petals are folded in longitudinal plaits.

imbricate, when the whorl is more or less broken by some of the petals being outside the others, or by their overlapping each other at least at the top. Five-petaled imbricate corollas are quincuncially imbricate when one petal is outside, and an adjoining one wholly inside, the three others intermediute and overlapping on one side; bilabiate, when two adjoining ones are inside or outside the three others. Imbricate petals are described as crumpled (corrugate) when puckered irregularly in the bud.

twisted, contorted, or convolute when each petal overlaps an adjoining one on one side, and is overlapped by the other adjoining one on the other side. Some botanists include the twisted astivation in the general term imbricate: others carefully distinguish the one from the other.

103. In a few cases the overlapping is so slight that the three restivations cannot easily be distinguished one from the other; in a few others the astivation is variable, even in the same species, but, in general, it supplies a constant character in species, in genera, or even in Natural Orders.

104. In general shape the Corolla is

tubular, when the whole or the greater part of it is in the form of a tube or cylinder. or bell.

campanulate, when approaching in some measure the shape of a cup

urceolate, when the tube is swollen or nearly globular, contructed at the top, and slightly expanded again in a narrow rim.

rotate or stellate, when the petals or lobes are spread out horizontally from the base, or nearly eo, like a wheel or star.

hypocrateriform or salver-shaped, when the lower part is cylindrical and the upper portion expanded horizontally. In this case the name of tube is restricted to the cylindrical part, and the horizontal portion is called the lamb, whether it be divided to the base or not. The orifice of the tube is called its mouth or throat.

infundibuliform or funnel-shaped, when the tube is cylindrical at the base, but enlarged at the top into a more or less campanulate limb, of which the lobes often spread horizontally. In this case the campanulute part, ap to the commencement of the $1 \mathrm{~b}$ bes, is sometimes considered as a portion of the tube, sometimes as a portion of the limb, and by some botanists again described as independent of either, under the name of throat (fauces). Generally speaking, however, in campanulate, infundibuliform, or other corollas, where the lower entire part passes gradually into the upper divided and more spreading part, the distinction between the tube and the limb is drawn either at the point where the lobes separate, or at the part where the corolla first expands, according to which is the most marked.

115. Irregular corollas have received various names according to the more familiar forms they have been compared to. Some of the most important are be

bilubiate, or two-lipped corolla, when, in a four- or five-lobed corolls, the two or three apper lobes stand obviously apart, like an upper lip. from 
the two or three lower ones or under lip. In Orchidec and some other families the name of lip, or labellum, is given to one of the divisions or lobes of the perianth.

personate, when two-lipped, and the orifice of the tube closed by a projection from the base of the upper or lower lip, called a palate.

ringent, when very strongly two-lipped, and the orifice of the tube very open.

spurred, when the tube or the lower part of a petal has a conical hollow projection, compared to the spur of a cock; saccate, when the spur is short and round like a little bag; gibbous, when projecting at any part into a slight owelling.

resupinate or reversed, when a lip, spur, etc., which in allied species is usually lowest, lies uppermost, and vice versá.

106. The above terms are mostly applied to the forms of monopetalous corollas, but several are also applicable to those of polypetalous ones. Terms descriptire of the special forms of corolla in certain Natural Orders, will be explained under those Orders respectively.

107. Nost of the terms used for describing the forms of leaves $(39,45)$ are also applicable to those of individual petals ; but the flat expanded portion of a petal, corresponding to the blade of the leaf, is called its lamina, and the stalk, corresponding to the petiole, its claw (unguis). The stalked petal is said to be unguiculate.

\section{10. The Stamens.}

108. Although in a few cases the onter stamens may gradually pass into petals, yet, in general, stamens are very different in shape and aspect from leares, sepals, or petals. It is only in a theoretical point of view (not the less important in the study of the physiological economy of the plant) that they can be called altered leaves.

109. This usual form is a stalk, called the filament, bearing at the top an anther divided into two pouches or cells. These anther-cells are filled with pollen, consisting of minute grains, usually forming a yellow dust, which, when the flower expands, is scattered from an opening in each cell. When the two cells are not closely contiguous, the portion of the anther that unites them is called the connectivum.

110. The filament is often wanting, and the anther sessile, yet still the stamen is perfuct; but if the anther, which is the essential part of the stamen, is wanting, or does not contain pollen, the stamen is imperfect, and is then said to be barren or sterile (without pollen), abortive or rudimentary (84), according to the degree to which the imperfection is carried. Imperfect stamens are often called staminodia.

111. In unsymmetrical flowers, the stamens of each whorl are sometimes reduced in number below that of the petals, even to a eingle one, and in several Natural Orders they are multiplied indefinitely.

112. The terms monandrous and polyandrous are restricted to flowers which have really but one stamen, or an indefinite number respectively. Where several stamens are united into one, the flower is said to be synandrous.

113. Stamens are

monadelphous, when united by their filaments into one cluster. Thi eluster either forms a tube round the pistil, or, if the pistil is wanting, occupies the centre of the flower. 
diadelphous, when so united into two clusters. The term is more especislly applied to certain Leguminose, in which nine stamens are united in s tube slit open on the upper side, snd s tenth, placed in the slit, is free. In some other plants the stamens are equally distributed in the two clusters.

triadelphous, pentadelphous, polyadelphous, when so united into three, fire, or many clusters.

syngenesious, when nnited by their anthers in a ring round the pistil, the filaments usually remaining free.

didynamous, when (usually in a bilabiate flower) there are four stamens in two pairs, those of one pair longer than those of the other.

tetradymamous, when (in Crucifere) there are six, four of them longer than the two others.

exserted, when longer than the corolla, or eren when longer than its tube, if the limb bevery spreading.

114. An Anther (109) is adnate, when continuous with the filament, the anther-cells appear ing to lie their whole length along the upper part of the filament. innate, when firmly attached by their base to the filament. This is an adnate anther when rather more distinct from the filament.

versatile, when attached ky their back to the very point of the filsment, so as to swing loosely.

115. Anther-cells msy be parallel or diverging at a less or grester angle; or divaricate, when placed end to end so as to form one straight line. The end of each anther-cell placed nearest to the other cell is generally called its apex or summit, and the other end its base (36); but some botanists roverse the sense of these terms.

116. Anthers hare often, on their connectivum or cells, appendages termed bristles (setæ), spurs, crests, points, glands, etc., according to their appearance.

117. Anthers heve occasionally only one cell: this may take place either by the disappearance of the partition between two closply contiguous colls, when these cells are said to be confuent; or by the abortion or total deficiency of one of the cells, when the snther is said to be dimidiate.

118. Anthers will open or dehisce to let out the pollen, like capsules, in valves, pores, or slits. Their dehiscence is introrse, when the opening faces the pistil ; extrorse, when towards the circumference of the flower.

119. Pollen (109) is not always in the form of dust. It is sometimes collected in each cell into one or two little wax-like masses. Special terms used in describing these masses or other modifications of the pollen will beexplained nuder the Orders where they occur.

\section{The Pistil.}

120. The carpels (91) of the Pistil, although they may occasionally assume, rather more than stamens, the appearance and colour of leaves, are still more different in shspe and structure. They are usually sessile; if stalked, their stalk is called a podocarp. This stalk, upon which each separate carpel is supported above the receptacle, mnst not be confounded with the gynobasis (143), upon which the whole pistil is sometimes raised.

121. Each carpel consists of three parts :

(1) the ovary, or enlarged base, which inclndes one or more cavities or celle, containing one or more small bodies called ovules. These are the earliest condition of the future seeda. 
(2) the style, proceeding from the summit of the ovary and supporting -

(3) the Stigma, which is sometimes a point (or punctiform stigma) or small head (a capitate stigma) at the top of the style or ovary, sometimes a portion of jts surface more or less lateral and variously shaped, distinguished by a looser texture, and covered with minute protuberances called papille.

122. The style is often wanting, and the stigma is then sessile on the orary, but in the perfect pistil there is always at least one ovule in the orary, and some portion of stigmatic surface. Without these the pistil is imperfect, and said to be barren (not setting seed), abortive, or rudimentary (84), according to the degree of imperfection.

123. The ovary being the essential part of the pistil, most of the terms relating to the number, arrangement, etc., of the carpels, apply specially to their oraries. In some works each separate carpel is called a pistil, all those of a flower constituting together the gynecium; but this term is in littie nse, and the word pistil is more generally applied in a collective sense. When the ovaries are at all united, they are commonly termed collectively a componnd ovary.

124. The number of carpels or ovaries in a flower is frequently reduced below that of the parts of the other florsl whorls, eren in flowers otherwise symmetrical. In a very few genera, however, the ovaries are more numerous than the petals, or indefinite. They are in that case either arranged in a single whorl, or form a head or spike in the centre of the flower.

125. The terms monogynous, digynous, polygynous, etc. (with a pistil of one, two, or more parts), are vaguely used, applying sometimes to the whole pistil, sometimes to the ovaries alone, or to the styles or stigmas only. Where a more precise nomenclature is adopted, the flower is

monocarpellary, when the pistil consists of a single simple carpel.

bi-, tri-, etc., to poly-carpellary, when the pistil consists of two, three, or an indefinite number of carpels, whether separated or united.

syncarpous, when the carpels or their ovaries are more or less united into one compound ovary.

apocarpous, when the carpels or ovaries are all free and distinct.

126. A compound ovary is

unilocular or one-celled, when there are no partitions between the orules, or when these partitions do not meet in the centre so as to divide the cavity into several cells.

phurilocular or several-celled, when completely divided into two or more cells by partitions called dissepiments (septa), usually vertical and radisting from the centre or axis of the orary to its circumference.

$b i$-, tri-, etc., to multi-locular, according to the number of these cells, two, three, etc., or many.

127. In general the number of cells or of dissepiments, complete or partial, or of rows of ovules, corresponds with that of the oarpels, of which the pistil is composed. Bnt sometimes each carpel is divided completely or partially into two cells, or has two rows of orules, so that the number of carpels sppears double what it really is. Sometimes again the carpels are so completely combined and reduced as to form a single cell, with a single ovule, although it really consists of several carpels. Bnt in these cases the orary is usually described as it appesrs, as well as such as it is theoretically supposed to be.

128. In apocarpou pistils the styles are usually free, each bearing its 
own stigma. Very rarely the greater part of the styles, or the stigmas alone, are nnited, whilst the ovaries remain distinct.

129. Syncarpous flowers are said to have

several styles, when the styles are free from the base.

one style, with several branches, when the styles are connected at the base, but separate below the point where the stigmas or stigmatic surfaces commence.

one simple style, with several stigmas, when united up to the point where the stigmas or stigmatic surfaces commence, and then separating.

one simple style with a branched, lobed, toothed, notched, or entirs stigma (as the case may be), when the stigmas slso aro more or less nnited. In many works, however, this precise nomenclature is not strictly adhered to, and considerable confusion is often the result.

130. In general the number of styles, or branches of the style or stigma, is the same as that of the carpels, but sometimes that number is doubled, especially in the stigmas, and sometimes the stigmas are dichotomonsly or pinnately branched, or penicillate, that is, divided into a tuft of hair-like branches. All these variations sometimes make it a difficult task to determine the number of carpels forming a compound ovary, but the point is of considerable importance in fixing the affinities of plants, and, by careful consideration, the real as well as the apparent number has now in most cases been agreed upon.

131. The Placenta is the part of the inside of the ovary to which the orules are attached, sometimes s mere point or line on the inner surface often more or less thickened or raised. Placentation is therefore the indication of the part of the ovary to which the ovules are attached.

\section{Placentas are}

axile, when the ovules are attached to the axis or centre, that is, in plurilocular ovaries, when they are attached to the inner angle of each cell ; in unilocular simple ovaries, which have almost always an excentrical style or stigma, when the ovules are attached to the side of the ovary nearest to the style; in unilocular compound ovaries, when the orules are attached to a central protuberance, column, or axis rising up from the base of the cavity. If this column does not reach the top of the cavity, the placenta is said to be free and central.

parictal, when the ovules are attached to the inner surface of the carity of a one-celled compound ovary. Parietal placentas are usually slightly thickened or raised lines, sometimes broad surfaces nearly covering the inner surface of the cavity, sometimes projecting far into the carity, and constituting partial dissepiments, or even meeting in the centre, but withont cohering there. In the latter case the distinction between the onecelled and the several-celled ovary sometimes almost disappears.

133. Each Ovale (121), when fully formed, usually consists of a central mass or mucleus, enclosed in two bag-like coats, the outer one called primine, the inner one secundine. The chalaza is the point of the ovule at which the base of the nnclens is confluent with the coats. The foramen is a minute aperture in the coats over the apex of the nuclens.

134. Orules are

orthotropous or straight, when the chalaza coincides with the base (86) of the ovule, and the foramen is at the opposite extremity, the of the ovale being straight.

campylatropous or incurved, when the chalaza still coinciding 
base of the ovile, the axis of the ovule is curved, bringing the foramen down more or less towards that base.

anatropous or inverted, when the chalaza is at the apex of the ovule, and the foramen next to its base, the axis remaining straight. In this, one of the most frequent forms of the ovule, the chalaza is connected with the base by a cord, called the raphe, adhering to one side of the ovule, and becoming more or less incorporated with its coats, as the ovulo enlarges into a seed.

amphitropous or half-inverted, when the ovule being as it were attached laterally, the chalaza and foramen at opposite ends of its straight o1 curved axis are about equally distant from the base or point of attachment.

\section{\$ 12. The Receptacle and Relative Attachment of the Floral Whorls.}

135. The Receptacle or torus is the extremity of the pednncle (above the calyx), upon which the corolla, stamens, and ovary are inserted. It is sometimes little more than a mere point or minute hemisphere, but it is often also more or less elongated, thickened, or otherwise enlarged. It must not be confonnded with the receptacle of inflorescence (74).

136. A Disk, or disc, is a circular enlargement of the receptacle, usually in the form of a cup (cupular), of a flat disk or quoit, or of a cushion ( $p u l$ vinate). It is either immediately at the base of the ovary within the stamens, or between the petals and stamens, or bears the petals or stamens or both on its margin, or is quite at the extremity of the receptacle, with the ovaries arranged in a ring round it or under it.

137. The disk may be entire, or toothed or lobed, or divided into a number of parts, usually equal to or twice that of the stamens or carpels. When the parts of the disk are quite separate and short, they are often called glands.

138. Nectaries, are either the disk, or small deformed petals, or abortive stamens, or appendages at the base of petals or stamens, or any small bodies within the flower which do not look like petals, stamens, or ovaries. They were formerly supposed to supply bees with their honey, and the term is frequently to be met with in the older Floras, but is now deservedly going out of nse.

139. When the disk bears the petals and stamens, it is frequently adherent to, and apparently forms part of, the tube of the calyx, or it is adherent to, and apparently forms part of, the orary, or of both calyx-tube and ovary. Hence the three following important distinctions in the relative insertion of the floral whorls.

140. Petals or, as it is frequently expressed, flowers, are

hypogynous (i.e. under the ovary), when they or the disk that bears them are entirely free both from the calyx and ovary. The ovary is then described as free or superior, the calyx as free or inferior, the petals as being inserted on the receptacle.

perigynous (i.e. round the ovary), when the disk bearing the petals is quite free from the ovary, but is more or less combined with the base of the calyx-tube. The ovary is then still described as free or superior, even though the combined disk and calyx-tnbe may form a deep cup with the ovary lying in the bottom; the calyx is said to be free or inferior, and the petals are described as inserted on the calyx.

eprgynous (i. e. upon the ovary), when the disk bearing the petals is combines both with the base of the calyx-tube and the base outside of the 
ovary; either closing over the ovary so as only to leave a passage for the style, or leaving more or less of the top of the orary free, but always adhering to it above the level of the insertion of the lowest orule (except in a very fow cases where the ovules are absolutely suspended from the top of the cell). In epigynous flowers the ovhry is described as adherent or inferior, the calyx as adherent or superior, the petals as inserted on or above the ovary. In some works, however, most epigynous flowers are included in the perigynous ones, and a very different meaning is given to the term epigynous (144), and there are a few cases were no positive distinction can be drawn between the epigynous and perigynous flowers, or again between the perigynous and hypogynous flowers.

141. When there are no potals, it is the insertion of the stamens that determines the difference between the hypogynous, perigynous, and epigynous flowers.

142. When there are both petals and stamens,

in hypogynous flowers, the petals and stamens are usually free from each other, but sometimes they are combined at the base. In that cuse, it the petals are distinct from each other, and the stamens are monadelphous, the petals are often said to be inserted on or combined with the staminal tube; if the corolla is gamopetalous and the stamens distinct from each other, the latter are said to ke inserted in the tube of the onrolla.

in perigynous flowers, the stamens are usually inserted immediately within the petals, or alternating with them on the edge of the disk, but occasionally much lower down within the disk, or even on the nnenlarged part of the receptacle.

in epigynous flowers, when the petals are distinct, the stamens are usually inserted as in perigynous flowers; when the corolla is gamopetalous, the stamens are either free and hypogynous, or combined at the base with (inserted in) the tnbe of the corolla.

143. When the receptacle is distinctly elongated below the ovary, it is often called a gynobasis, gynophore, or sialk of the ovary. If the elongation tukes place below the stamens or below the petals, these stamens or petals are then said to be inserted on the stalk of the ovary, and are ocedsionally, but falsely, described as epigynous. Really epfgynous stamens (i.e. when the filaments are combined with the ovary) are very rare, unless the rest of the flower is epigynous.

144. An epigynous disk is a name given either to the thickened summit of the ovary in epigynons flowers, or very rarely to a real disk or enlargement of the receptacle closing over the ovary.

145. In the relative position of any twn or more parts of the flower, whether in the same or in different whorls, they are

connivent, when nearer together at the summit than at the base.

divergent, when further apart at the summit than at the base.

coherent, when united together, but so slightly that they can be aeparated with little or no laceration; and one of the two coherent parts (ubually the smallest or least important) is said to be adherent to the other. Grammatically speaking, these two terms convey nearly the same meaning, but require a different form of phrase; practically, howerer, it has been found more convenient to restrict cohesion to the union of parts of the same whorl, and: adhesion to the union of parts of different whorls.

connate, when so closely united that they cannot ke separated withoet laceracion. Each of the two connate parts, and especially that one 
which is considered the smaller or of the least importance, is said to be adnate to the other.

free, when neither coherent nor connate.

distinct is also used in the same sense, but is also applied to parts distinctly visible or distinctly limited.

\section{\$ 13. The Firuit.}

146. The Fruit (15) consists of the ovary and whatever other parts of the flower are persistent (i.e. persist at the time the seed is ripe), usually enlarged, and more or less altered in shape and consistence. It encloses or covers the seed or seeds till the period of maturity, when it either opens for the seed to eseape, or falls to the ground with the seed. When stalked, its stalk has been termed a carpophore.

147. Fruits are, in elementary works, said to be simple when the result of a single flower, compound when they proceed from several flowers closely packed or combined in a head. But as a fruit resulting from a single flower, with several distinct carpels, is compound in the sense in which that term is applied to the ovary, the terms single and aggregate, proposed for the fruit resulting from one or several flowers, may be more appropriately adopted. In descriptive Botany a fruit is always supposed to result from a single flower unless the contrary be stated. It may, like the pistil, be syncarpous or apocarpous (125); and as in many cases carpels united in the flower may become separate as they ripen, an apocarpous fruit may result from a syncarpous pistil.

148. The involucre or bracts often persist and form part of aggregate fruits, but very seldom so in single ones.

149. The receptacle becomes occasionally enlarged and succulent; if when ripe it falls off with the fruit, it is considered as forming part of it.

150. The adherent part of the calyx of epigynous flowers always persists and forms part of the fruit; the free part of the calyx of epigynous flowers or the calyx of perigynous flowers, either persists entirely at the top of or round the fruit, or the lobes alone fall off, or the lobes fall off with whatever part of the calyx is above the insertion of the petals, or the whole of what is free from the ovary falls off, including the disk bearing the petals. The calyx of hypegynous flowers usually falls off entirely or persists entirely. In general a calyx is called deciduous if any part falls off. When it persists it is either enlarged round or under the fruit, or it withers and dries up.

151. The corolla usually falls off entirely; when it persists, it is usnally withered and dry (marcescent), or very seldom enlarges round the fruit.

152. The stamens either fall off, or more or less of their filaments persists, usually withered and dry.

153. The style sometimes falls off or dries up and disappears; sometimes persists, forming a point to the fruit, or becomes enlarged into a wing or other appendage to the fruit.

154. The Pericarp is the portion of the fruit formed of the ovary, and whatever adheres to it exclusive of and outslde of tha seed or seeds, exclusive also of the persistent receptacle, or of whatever portion of the calyx persists ronnd the ovary without adhering to it.

155. Fruits have often external appendages called wings (alæ), beaks. crests, awns, etc., according to their appearance. They are either formed by persistent part of the flower more or less altered, or grow ont of the 
ovary or the persistent part of the calyx. If the appendage be a ring of hairs or scales round the top of the fruit, it is called a pappus.

156. Fruits are generally divided into succulent (including fleshy, pulpy, and juicy fruits) and dry. They are dehiscent when they open at matnrity to let out the seeds, indehiscent when they do not open spontaneously but fall off with the seods. Succulent fruits are nsually indehiscent.

157. The principal kinds of succulent fruits are

the Berry, in which the whole substance of the pericarp is fleshy or pulpy, with the exception of the outer skin or rind, called the Epicarp. The seeds themselves are usually immersed in the pulp; but in some berries the seeds are separated from the pulp by the walls of the carity or cells of the ovary, which form as it were a thin inner skin or rind, called the Endocarp.

the Drupe, in which the pericarp, when ripe, consists of two distinct portions, an outer succulent one called the Sarcocarp (covered like the berry by a skin or epicarp), and an inner dry endocarp called the Putamen, which is either cartilaginous (of the consistence of parchment) or hard and woody. In the latter case it is commonly called a stone, and the drupe a stone-fruit.

158. The principal kinds of dry fruits are

the Capsule or Pod,* which is dehiscent. When ripe the pericarp usually splits longitudinally into as many or twice as many pieces, called valves, as it contains cells or placentas. If these valves separate at the line of junction of the carpels, that is, along the line of the placentas or dissepiments, either splitting them or leaving them attached to the axis, the dehiscence is termed septicidal; if the valves separate between the placentas or dissepimont, the dehiscence is loculicidal, and the valves either bear the placentas or dissepiments alorg their middle line, or leare them attached to the axis. Sometimes also the capsule discharges its seeds by alits, chinks, or pores, more or less regularly arranged, or bursts irregularly, or separates into two parts by a horizontal line; in the latter case it is said to be circumsciss.

the Nut or Achene, which is indehiscent and contains but a single seed. When the pericarp is thin in proportion to the seed it encloses, the whole fruit (or each of its lobes) has the appearance of a single seed, and is so called in popular language. If the pericarp is thin and rather loose, it is often called an Utricle. A Samara is a nut with a wing at its npper end.

159. When the carpels of the ovary are distinct (125), they may severally become as many distinct berries, drupes, capsules, or achenes. Separate carpels are usually more or less compressed laterally, with more or less prominent inner and onter edges, called sutures, and, if dehiscent, the carpel nsually opens at these sutures. A Follicle is a carpel opening at the inner suture only. In some cases where the carpels are united in the ovary, they will separate when ripe; they are then called Cocci if oneseeded.

160. The peculiar fruits of some of the large Orders have received special namen, which will bo explained nnder each Order. Such are the Siliqua and Silicule of Cruciforæ, the Legume of Legnminosæ, the Pome of Pyrus and its allies, the Pepo of Oucurbitacer, the Cone of Coniferæ, the Grain or Caryopois of Graminem, otc.

- In Fnglish descriptlons, pod is more frequently used when it ts long and narrow:

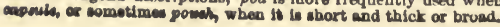




\section{\$ 14. The Seed.}

161. The seed is enclosed in the pericarp in the great majority of flowering plants, called therefore Angiosperms or angiospermous plants. In Coniforce and a very few alliod genera, called Gymnosperms or gymnospermous plants, the seed is naked, without any real pericurp. These truly gymnospermous plants must not be confounded with Labiate, Boraginea, etc., which have also been falsely called gymnospermous, their small nuts having the appearance of seeds (158).

162. The seed when ripe contains an embryo or young plant, either filling or nearly filling the cavity, bnt not attached to the outer skin or the seed, or more or less immersed in a mealy, oily, fleshy, or horn-like aub. stance, called the albumen, or perisperm. The presence or absence of this albumen, that is, the distinction between albuminous and exalbuminous seeds, is one of great importance. The embryo or albumen can often only be found or distinguished when the seed is quite ripe, or sometimes only when it begins to germinate.

163. The shell of the seed consists neuslly of two separable coats. The onter coat, called the testa, is usually the principal one, and in most cases the only one attended to in descriptions. It may be hard and orustaceous, woody or bony, or thin and membranous (skin-like), dry or rarely succulent. It is sometimes expanded into wings, or bears a tuft of hair, cotton, or wool, called a coma. The inner coat is called the tegmen.

164. The funicle is the stalk by which the seed is attached to the placenta. It is occasionally enlarged into a membranous, pulpy, or fleshy appendage, sometimes spreading over a considerable part of the seed, or nearly enclosing it, called an aril. A strophiole or caruncle is a similar appendage, proceeding from the testa, by the side of or near the funicle.

165. 'The hilum is the scar left on the seed where it separates from the funicle. The micropyle is a mark indicating the position of the foramen of the ovule (133).

166. The rmbryo (162) consists of the Radicle or base of the future root, one or two Cotyledons or future seed-leares, and the Plumule, or future bud within the base of the cotyledons. In some seeds, especially where there is no albumen, these several parts are very conspicuous, in others they are very difficult to distinguish until the seed begins to germinate. Their observation, however, is of the greatest importance, for it is chiefly npon the distinction between the embryo with one or with two cotyledons that are founded the two great classes of phrnogamous plants, Monocotyledons and Dicotyledons.

167. Althongh the embryo lies loose (nnattached) within the seed, it is generally in some determinate position with respect to the seed or to the whole fruit. This position is described by stating the direction of the radicle next to or more or less remote from the hilum, or it is said to be superior if pointing towards the summit of the fruit, inferior if pointing towards the base of the fruit.

\section{\$ 15. Accessory Organs.}

168. Under this name are included, in many elementary works, various external parte of plants which do not appear to act any essential part either in the regetation or reproduction of the plant. They may be classed nnder four heads: Tendrils and Hooks, Thorns and Prickles, Hairs and Glands, 
169. Tendrils (cirrhi) are nsually abortive petioles, or abortive peduncles, or sometimes abortive ends of branches. They are simple or more or less branched, flexible, and coil more or less firmly round any objects within their reach, in order to support the plant to which they belong. Hooks are similar holdfasts, but of a firmer consistence, not branched, and less coiled.

170. Thorns and Prickles have been fancifully called the weapons of plants. A Thorn or Spine is the strongly pointed extremity of a branch, or abortive petiole, or abortive peduncle. A Prickle is a sharply pointed excrescence from the epidermis, and is usually produced on a branch, on the petiole or veins of a leaf, or on a peduncle, or even on the caly $x$ or corolla. When the teeth of a leaf or the stipules are pungent, they are also called prickles, not thorns. A plant is spinenes if it has thorns, aculeate if it has prickles.

171. Eairs, in the general sense, or the indumentum (or clothing) of a plant, inclade all those productions of the epidermis which have, by a more or less appropriate comparison, been termed bristles, hairs, down, cotton, of wool.

172. Hairs are often branched. They are said to be attached by the centre, if parted from the base, and the forks spread along the surface in opposite directions; plumose if the branches are arranged along a common axis, as in a feather; stellate, if sereral branches radiate horizontaliy. These stellate hairs have sometimes their rays connected together at the base, forming little flat circular disks attached by the centre, and are then ealled scales, and the surface is said to be scaly or lepidote.

173. The Epidermis, or outer skin, of an organ, as to its surface and in. dumentum, is

smooth, when withont any protuberance whatever.

glabrous, when without hairs of any kind.

striate, when marked with parallel longitudinal lines, either slightly raised or merely discoloured.

furrowed (sulcate) or ribbed (costate) when the parallel lines are more distinctly raised. lines.

rugose, when wrinkled or marked with irregular raised or depressed

umbilicate, when marked with a small round depression.

umbonate, when bearing a small boss like that of a shield. exudation.

viscous, viscid, or glutinous, when covered with a sticky or clammy

scabrons, when rongh to the touch.

tuberculate or warted, when covered with small, obtuse, wart-like protuberances.

muricate, when the protuberances are more raiked and pointed but yet short and level. prickly.

eckinate, when the protuberances are longer and sharper, almost

setnse or bristly, when bearing very stiff erect straight hairs.

glandular-setose, when the setæo or bristles terminate in a minnte resinous hesd or drop. In some works, especially in the case of Roses and Rubus, the meaning of sete has been restricted to such as are glapdular.

glochidiqte, when the setre are booked sat the top. 

hairs.

pilose, when the surface is thinly sprinkled with rather long simple

kispid, when more thickly covered with rather stiff hairs.

hirsute, when the hairs are dense and not so stiff.

downy or pubescent, when the hairs are short and soft; puberulent, when slightly pubescent.

strigose, when the hairs are rather short and soft, and lie clowe along the surface all in the same direction; strigillose, when slightly strigose.

tomentose or cottony, when the hairs are very short and soft, rather dense and more or less intricate, and usually white or whitish.

woolly (lanate), when the hairs are long and loosely intricate, like wool. The wool or tomentum is said to be fhocose when closely intricate and readily detached, like fleece.

mealy (farinose), when the hairs are excessively short, intricate and white, and come off readily, having the appearance of meal or dust.

canescent or hoary, when the hairs are so short as not readily to be distinguished by the naked eye, and yet give a general whitish hue to the epidermis.

174. The meanings here attached to the above terms are such as ap-

glaucous, when of a pale bluish-green, often covered with a fine pear to have been most generally adopted, but there is much vagueness in the nse practically made of many of them by different botanists. This is especially the case with the terms pilose, hispid, hirsute, pubescent, and tomentose.

175. The name of Glands is given to several different productions, and principally to the four following:-

1. Small wart-like or shield-like bodies, either sessile or sometimes stalked, of a fungous or somewhat fleshy consistence, oceasionally secreting a small quantity of oily or resinous matter, but more frequently dry. They are generally fow in number, often definite in their position and form, and occur chiefly on the petiole or principal veins of leaves, on the branches of inflorescences, or on the stalks or principal veins of bracts, sepsls, or petals.

2. Minute raised dots, usually black, red, or dark-coloured, of a resinous or oily nature, always superficial, and apparently exudations from the epidermis. They are often numerous on leaves, bracts, sepals, and green branches, and occur even on petals and stamens, more rarely on pistilsa When raised npon slender stalks they are called pedicellate (or stipitate. glands, or glandular hairs, according to the thickness of the stalk.

3. Small, globular, oblong or even linear vesicles, filled with oil, imbedded in the substance itself of leaves, bracts, floral organs, or fruits. They are often very numerous, like transparent dots, sometimes fow and determinate in form and position. In the pericarp of Umbellifere they are remarkably regular and conspicuous, and take the name of vitte.

4. Lobes of the disk (137), or other small fleshy excrescencen within the flower. whether from the raceptacle, calyx, corolls, stamens, or pistil. 


\section{Crap. II. Cunsimcation, on Srstematic Botany.}

176. It has already been observed (3) that descriptions of plants shonld, as nearly as possible, be arranged under natural divisions, so as to facilitate the comparison of each plant with those most nearly allied to it. The descriptions of plants here allnded to are descriptions of species; the natural divisions of the Flora refer to natural groups of species.

177. A species comprises all the individual plants which resemble each other sufficiently to make ns conclude that they are all, or may have been all, descended from a common parent. These individnals may often differ from each other in many striking particulars, such as the colour of the flower, size of the leaf, etc., bnt these particulars are snch as experience teaches us are liable to vary in the seedlings raised from one individual.

178. When a large number of the individuals of a species differ from the others in any striking particular they constitute a variety. If the variety generally comes true from seed, it is often called a Race.

179. A Variety can only bo propagated with certainty by grafts, cuttings, bulbs, tnbers, or any other method which produces a new plant by the development of one or more buds taken from the old one. A Race may with care bo propagated by seed, althongh seedlings will always be liable, under certain circumstances, to lose those particulars which distinguish it from the rest of the species. A real Species will always come true from seed.

180. The known species of plants (now near 100,000) are far too numerous for the human mind to study without classification, or eren to give distinct single names to. To facilitate these objects, an admirable system, invented by Linnæus, has been universally adopted, viz. one common substantive name is given to a number of species which resemble each other more than they do any other species; the species so collected under one name are collectively called a Genus, the common name being the generic name. Each species is then distinguished from the others of the same genus by the addition of an adjective epithet or specific name. Every species has thus a botanical name of two words. In Latin, the language usually need for the purpose, the first word is a substantive and designates the genus; the second, an adjective, indicates the species. In English, the adjective or epecific name comes before the snbstantive or generic one.

181. The geners thus formed being still too numerous (above 6000) for study without further arrangement, they have been classed npon the same principlea; viz. geners which resemble each other more than they do any other genera, have been collected together into gronps of a higher degree called Families or Tratural Orders, to each of which a common name has been giren. This name is in Latin an adjective plural, usually taken from the name of some one typical genus, generally the best known, the first discovered, or the most marked (ө.g. Ranunculacee from Ranunculus). It is rendered in English by the addition of the word plants to a plural adjective, or by adding the word family or order to the name of the typical genus taken adjectively, as Ranunculaceous Plants, or the Ranunoulus Family (or Order). This is, however, for the purpose of stady and comparison. To speak of a species, to refer to it and identify it, sll that is veressary is to give the generic and specifio names. 
182. Natural Orders themselves (of which we reckon near 200) are often in the same manner collected into classes, and where Orders contain a large number of geners, or genera a large number of species, they require further classification. The genera of an Order are then collected into minor groups called Tribes, the species of a genus into Sections, and in a few cases this intermediato classification is carried still further. The names of these several groups the most generally adopted are as follows, beginning with the most comprehensive or highest :-

Classes.

Subclasses or Alliances.

Natural Orders or Families.

Suborders.

Tribes.

Subtribes.

Divisions.

Subdivisions.
Genera.

Subgenera.

Sections.

Subsections.

Species.

Varieties.

183. The characters (3) by which a species is distinguished from all other species of the same genus are collectively called the specific character of the plant; those by which its genus is distinguished from other genera of the Order, or its Order from other Orders, are respectively called the generic cr ordinal characters, as the case may be. The habit of a plant, of a species, a genns, etc., consists of such general characters as strike the eye at first sight, such as size, colour, ramification, arrangement of the leaves, inflorescence, etc., and are chiefly derived from the organs of vegetation.

184. Classes, Orders, Genera, and their several subdivisions, are called natural when, in forming them, all resemblances and differences are taken into account, valuing them according to their evident or presumed importance; artificial, when resemblances and differences in some one or very fow particulars only are taken into acconnt independently of all others.

185. The number of species included in a genns, or the number of genera in an Order, is very variable. Sometimes two or three or even a single species may be so different from all others as to constitute the entire genus; in others, several hundred species may resemble each other so much as to be all included in one genus; and there is the same discrepancy in the number of genera to a Family. There is, moreover, unfortunately, in a number of instances, great difference of opinion as to whether certain plants differing from each other in certain particulars are varieties of one species or belong to distinct species; and again, whether two or more groups of species should constitute as many sections of one genus, or distinct genera, or tribes of one Order, or even distinct Natural Orders. In the former case, if a species is supposed to have a real existence in nature, the question may be susceptible of argument, and sometimes of absolute proof. But the place a group should occupy in the scale of degree is very arbitrary, being often a mere question of convenience. The more subdivisions upon correct principles are multiplied, the more they facilitate the study of plants, provided always the main resting-points for constant use, the Order and the Genus, are comprehensive and distinct. But if every group into which a genus can be divided be erected into a distinct genus, with a substantive name to be remembered whenever a species is spoken of, all the advantages derived from the besutiful simplicity of the linnsean nomenelsture are gone. 
The definitions abore given of Varieties, Races, Species, Sections, etc., must be taken in a genersi sense, as the distinctions between them are not al ways so absolute as they were onee thought to be.

\section{Chap. III. Vegitable Anatomy and Physiology.}

\section{\$ 1. Structure and Growth of the Elementary Tissues.}

186. If a very thin slice of any part of a plant be placed under a microscope of high magnifying power, it will be found to be made up of variously shaped and arranged ultimate parts, forming a sort of honeycombed structure. These ultimate parts are called cells, and form by their combination the elementary tissues of which the entire plant is composed.

187. A cell in its simplest state is a closed membranous sac, formed of a substance permeable by fluids, though usually destitute of visible pores. Fach cell is a distinct individual, separately formed and separately acting, though cohering with the cells with which it is in contact, and partaking of the common life and action of the tissue of which it forms a part. The membranes separating or enclosing the cells are also called their walls.

188. Botanists usually distinguish the following tissues :-

(1) Cellular tissue, or parenchyma, consists usually of thin-walled cells, more or less round in form, or with their length not much exceeding their breadth, and not tapering at the ends. All the soft parts of the leares, the pith of stems, the pulp of fruits, and all young growing parts, are formed of it. It is the first tissue produced, and continnes to be formed while growth continues, and when it ceases to be active the plant dies.

(2) Woody tissue, or prosenchyma, differs in having its cells considerahly longer than broad, usually tapering at each end into points and overlapping each other. The cells are commonly thick-walled; the tissue is firm, tenacions, and elastic, and constitutes the principal part of wood, of the inner bark, and of the verves and veins of leaves, forming, in short, the framework of the plant.

(3) Vascular tissue, or the vessels or ducts of plants, so called from the mistaken notion that their functions are analogous to those of the ressels (veins and arteries) of animals. A vessel in plants consists of a vertical row of cells, which have their transverse partition walls obliterated, so as to form a continuous tube. All phænogamous plants, as well as ferns and a fow other cryptogamous plants, have vessels, and are therefore called varcular plants ; so the majority of cryptogams having only cellular tissue are termed cellular plants. Vessels have their sides very variously marked; some, called spiral vessels, have a spiral fibre coiled up their inside, which unrolls when the vessel is broken; others are marked with longitudinal slits, cross bsrs, minute dots or pits, or with transverse rings. The size of vessels is also very variable in different plants; in some they are of considerable size and visible to the naked eye in cross-sections of the stem, in others they are almost absent or can only be traced under a strong magnifier.

189. Various modifications of the abore tissnes are distinguished by vegetable anatomists under names which need not be enumerated here ss oot boing in general practical use. Air-vessels, cysts, turpentine-vessels, 
oil-reservoirs, etc., sre either carities left between the cells, or large cells filled with peculiar secretions.

190. When tissues are once formed, they increase, not by the general enlargement of the whole of the cells already formed, but by cell-division, that is, by the division of young and vitally active cells, and the enlargement of their portions. In the formation of the embryo, the first cell of the new plant is formed, not, by division, but around a segregate portion of the contents of a previously existing cell, the embryo-sac. This is termed fres cell-formation, in contradistinction to cell-division.

191. A young and vitally active cell consists of the outer wall, formed of a more or less transparent substance culled cellulose, permeable by fluids, and of ternary chemical composition (carbon, hydrogen, and oxygen); and of the cell-contents, usually riscid or mucilaginous, consisting of protoplasm, a substance of quaternary chemical composition (carbon, hydrogen, oxygen, and nitrogen), which fills an important part in cell-division and growth. Within the cell (either in the centre or excentrical) is usually a minute, soft, subgelatinous body called the nucleus, whose functions appear to be intimately connected with the first formation of the new rell. As this cell increases in size, and its walls in thickness, the protoplasm and watery cellsap become absorbed or dried up, the firm cellulose wall alone remsining as a permanent fabric, either empty or filled with various organised substances produced or secreted within it.

192. The principal organised contents of cells are

sap, the first product of the digestion of the food of plants ; it contains the elements of vegetable growth in a dissolved condition.

sugar, of which there are two kinds, called cane-sugar and grape-sugar. It usually exists dissolved in the sap. It is found abundantly in growing parts, in fruits, and in germinating seeds.

dextrine, or vegetable mncilage, a gummy substance, between mucilage and starch.

starch or fecula, one of the most universal and conspicnous of cellcontents, and often so abundant in farinaceous roots and seeds as to fill the cell-cavity. It consists of minute grains called starch-granules, which vary in size and are marked with more or less conspicnous concentric lines of growth. The chemical constitution of starch is the same as that of cellulose; it is unaffected by cold water, but forms a jelly with boiling water, and turns blue when tested by iodine. When fully dissolved it is no longer starch, but dextrine.

chlorophyll, very minute granules, containing nitrogen, and coloured green under the action of sunlight. These granules are most abundant in the layers of cells immediately below the surface or epidermis of leares and young bark. The green colouring matter is soluble in alcohol, and may thus be removed from the granules.

chromule, a name given to \& similar colonring matter when not green.

wax, oils, camphor, and resinous matter, are common in cells or in cavities in the tissues between the cells, also various mineral substances, either in an amorphons state or as microscopic crystals, when they are called Raphides.

\section{Arrangement of the Elersintary Tissues, or Structure of the Organs of Plants.}

193. Laares. young atems. and branches, and most parts of ohæno 
gamous plants, during the first year of their existence consist anatomically of

(1), a cellular rystem, or continuons mass of collular tissue, which is developed both vertically as the stem or other parts increase in length, and horizontally or laterally as they increase in thickness or breadth. It eurrounds or is intermixed with the fibro-vascular system, or it may exist alnne in some parts of phænogamous plants, as well as in cryptogamous ones.

(2), a fibro-vascular system, or continuous mass of woody and vascular tissue, which is gradually introduced vertically into, and serves to bind together, the cellular system. It is continued from the stem into the petioles and veins of the leaves, and into the pedicels and parts of the flowers, and is nerer wholly wanting in any phænogamous plant.

(3), an epidermis, or outer skin, formed of one or more layers of flattened (horizontal), firmly coherent, and usually empty cells, with either thin and transparent or thick and opaque walls. It covers almost all parts of plants exposed to the ontward air, protecting their tissues from its immediate action, but is wanting in those parts of aquatic plants which are constantly submerged.

194. The opidermis is frequently pierced by minute spaces between the cells, called Stomates. They are oval or month-shaped, bordered by lips, formed of two or more elastic cells so disposed as to cause the stomate to open in a moist, and to close up in a dry state of the atmosphere. They communicate with intercellular cavities, and are obviously designed to regulate eraporation and respiration. They are chiefly found upon leaves, especially on the under surface.

195. When a phænogamons plant has outlived the first season of its growth, the anatomical structure of its stem or other perennial parts becomes more complicated and very different in the two great classes of phænogamous plants called Exogens and Endogens, which correspond with very few exceptions to the two classes Dicotyledons and Monocotyledons (167), founded on the structure of the embryo. In Exogens (Dicotyledons) the woody system is placed in concentric layers between a central pith $(198,1)$, and an external separable bark $(198,5)$. In Endogens (Monocotyledons) the woody system is in separate small bundles or ficres running through the cellnlar system without apparent order, and there is usually no distinct central pith, nor onter separable bark.

196. The anatomical structure is also somewhat different in the different organs of plants. In tho 220ot, although it is constructed generally on the same plan as the stem, yet the regular organisation, and the difference between Exogens and Endogens, is often disguised or oblitersted by irregularities of growth, or by the production of large quantities of cellular tissue filled with starch or other substances (192). There is seldom, if ever, any distinct pith, the concentric circles of fibro-vascular tissue in Exogene ara often very indistinct or have no relations to seasons of growth, and the epidermis has no stomates.

197. In the stem or branches, during the first year or senson of their growth, the difference between Exogens and Endogens is not-always rery conspicuous. In both there is a tendency to a circular arrangement of the fibro-vaseular aystem, leaving the centre either vacant or filled with cellular tissue (pith) only, and a more or less distinct onter rind is observable even in several Endogens, More frequently, however, the distinction is slready 
rery apparent the first season, especially towards its close. The flbrovascular bundles in Endogens usually anastomose but little, passing continuously into the branches and leaves. In Exogens the circle of fibrorascular bundles forms a more continuous cylinder of network emitting lateral offsets into the branches and leaves.

198. The Exogenous stem, after the first year of its growth, consists of

1 , the pith, a eylinder of cellnlar tissue, occupying the centre or longitudinal axis of the stem. It is active only in young stems or branches, beconies dried up and compressed as the wood hardens, and often finally disappears, or is scarcely distinguishable in old trees.

2 , the medullary sheath, which surrounds and encases the pith. It abounds in spiral vessels $(188,3)$, and is in direct connection, when young, with the leaf-buds and branches, with the potioles and veins of leares, and other ramifications of the system. Like the pith, it gradually disappears in old wood.

3 , the rood, which lies immediately outside the medullary sheath. It is formed of woody tissue $(188,2)$, through which, in most cases, vesscls $(188,3)$ variously disposed are interspersed. It is arranged in annual concentric circles (211), which usually remain active during several years, but in older stems the central and older layers become hard, dense, comparatively inactive, and nsually deeper coloured, forming what is called heartwcod or duramen, the onter, younger, and usually paler-coloured livins layers constituting the sapwood or alburnum.

4 , the medullary rays, which form vertical plates, originating in the pith, and, radiating from thence, traverse the wood and terminate in the bark. They are formed of cellular tissne. keeping up a communication between the living portion of the centre of the stem and its outer surface. As the heart-wood is formed, the inner portion of the medullary rays ceases to be active, bnt they usually may still be seen in old wood, forming what carpenters call the silver grain.

5, the bark, which lies outside the wood, within the epidermis. It is, like the wood, arranged in annual concentric circles (211), of which the oater older ones become dry and hard, forming the corky layer or outer bark, which, as it is distended by the thickening of the stem, either cracks or is cast off with the epidermis, which is no longer distinguishable. Within the corky layer is the cellular, or green, or middle bark, formed of loose thin-walled pulpy cells containing chlorophyll (192); and which is usually the layer of the preceding eeasnn. The innermost and youngest circle, next the young wood, is the liber or inner bark, formed of long tongh woody tissue called bast-cells.

199. The Endogenous stem, as it grows old, is not marked by the con centric circles of Exogens. The wood consists of a matrix of cellular tissue irregularly traversed by vertical cords or bundles of woody and vascular tigeue, which are in connection with the leaves. These vascular bundles change in structure and direction as they pass down the stem, losing their ressels, they retain only their bast- or long wood-cells, nsually curving outwarde towards the rind. The old wood becomes more compact and harder towards the circnmference than in the centre. The epidermis or rind either hardens so as to prevent any increase of diameter in the stem, or it jestends, withont increasing in thickness or splitting or casting off any onter layers.

200. In the Ieaf, the structure of the petioles and principal ribs or 
veins is the same as that of the young branches of which they are ramis. catione. In the expanded portion of the leaf the fibro-rascular system becomes usually very much ramified, forming the smaller veins. These are surrounded and the interstices filled up by a copious and very active cellular tissue. The majority of leaves are horizontal, having a differently constructed upper and under surface. The cellular stratnm forming the npper surface consists of closely set cells, placed vertically, with their smallest ends next the surface, and with few or no stomates in the epidermis. In the stratum forming the under surface, the cells are more or less horizoutal, more loosely placed, and have generally empty spaces between them, with stomates in the epidermis communicating with these intercellular spaces. In vertical leaves (as in a large number of Australian plants) the two surfaces are nearly similar in structure.

201. When leares are reduced to scales, acting only as protectors of young buds, or without taking any apparent part in the economy of vegetable life, their structure, though still on the same plan, is more simple; their fibro-vascular system is less ramified, their cellular system more uniform, and there are few or no stomates.

202. Bracts and floral envelopes: when green and much developed, resemble leaves in their anatomical structure, but in proportion as they are reduced to scales or transformed into petals, they lose their stomates, and their systems, both fibro-rascular and cellular, become more simple and uniform, or more sleuder and delicate

203. In the stamens and pistils the saructure is still nearly the same. The fibro-vascular system, surrounded by and intermixed with the cellular tissue, is usually simple in the filaments and style, more or less ramified in the flattened or expanded parts, such as the anther-cases, the walls of the ovary, or carpellary leaves, etc. The pollen consists of granular cells variously shaped, marked, or combined, peculiar forms being constant in the same species, or often in large genera, or even Orders. The stigmatic portion of the pistil is a mass of loosely cellular substance, destitute of epidermis, and usually is in communication with the ovary by a chanuel running down the centre of the style.

204. Tubers, fleshy thickenings of the stem or other parts of the plants, succulent leaves or branches, the fleshy, woody, or bony parts of fruits, the albumen, and the thick fleshy parts of embryos, consist chiefly of largely developed cellular tissue, replete with starch or other substances (192), deposited apparently in most cases for the eventual future use of the plant or its parts when recalled into activity at the approach of a new season.

205. Hairs (171) are usually expansions or processes of the epidermis, and consist of one or more cells placed end to end. When thick or hardened into prickles, they still consist usually of cellnlar tissue only. Thorns (170) contain more or less of a fibro-vascular aystem, aceording to their degree of development.

206. Glands, in the primary sense of the word $(175,1)$, consist nsually of a rather loose cellular tissue without epidermis, and often replete with resinous or other substances.

\section{\$ 3. Growth of the Organs.}

207. Roots grow in length constantly and regularly at the extremities only of their fibres, in proportion as they find the requisite nutriment. I'bey form no buds cuntaining the germ of future branches, but their filres 
proceed irregularly from any part of their surface without previous indication, and when their growth has been stopped for a time, either wholly by the close of the season, or partially by a deficiency of nutriment at any particular spot, it will, on the return of favonrable circumstances, be resumed at the same point, if the growing extremities be uninjured. If during the dead season, or at any other time, the growing extremity is cut off, dried up, or otherwise injured, or stopped by a rock or other obstacle opposing its progress, lateral fibres will be formed on the still living portion; thus enabling the root as a whole to diverge in any direction, and travel far and wide when lured on by appropriate nutriment.

208. This growth is not however by the successire formation of terminal cells attaining at once their full size. The cells first formed on a fibre commencing or renewing its growth, will often dry up and form a kind of terninal cap, which is pushed on as cells are formed immediately under it; and the new cells, constituting a greater or lesser portion of the ends of the fibres, remain some time in a growing state before they hare attained their full size.

209. The roots of Exogens, when perennial, increase in thickness like stems by the addition of concentric layers, but these are nsually much less distinctly marked; and in a large number of perennial Exogens and most Endogens the roots are annual, perishing at the close of the season, fresh adventitious roots springing from the stock when vegetation commences the following season.

210. The Stem, including its branches and appendages (leaves, floral organs, etc.), grows in length by additions to its extremity, but a much greater proportion of the extremity and branches remains in a growing and expanding state for a much longer time than in the case of the root. At the close of one season, leaf-buds or seeds are formed, each containing the germ of a branch or young plant to be produced the following season. At a very early stage of the development of these buds or seeds, a commencement may be found of many of the leaves it is to bear; and before a leaf unfolds, every leaflet of which it is to consist, every lobe or tooth which is to mark its margin, may often be traced in miniatnre, and thenceforth till it attains its full size, the branch grows and expands in every part. In some cases however the lower part of a branch and more rarely (e.g. in some Meliacee) the lower part of a compound leaf attains its full size before the young leaves or leaflets of the extremity are yet formed.

211. The perennial stem, if exogenous (198), grows in thicknese by the addition every season of a new layer or ring of wood between the outermost preceding layer and the inner surface of the bark, and by the formation of a new laver or ring of bark within the innermost preceding layer and outside the new ring of wood, thus forming a succession of concentric circles. The sap elaborated by the leaves finds its way, in a manner not as yet absolutely ascertained, into the cambium-region, a zone of tender thin-walled cells connecting the wood with the bark, by the division and enlargement of which new cells (190) are formed. These cells separate in layers, the inner ones constituting the new ring of wood, and the outer ones the new bark or liber. In most exogenons trees, in temperate climates, the seasons of growth correspond with the years, and the rings of wood remain suffieiently distinct to indicate the age of the tree; but in many tropical and a me erergreen trees, two or more rings of rood are formed in one year.

212. In endogenous perennial stems (199), the new wood or woody fibs 
is formed towards the ond of the otem, or irregularly mingled with the old. The stem consequently either only becomes more dense without increasing in thickness, or only increases by gradual distention, which is never very considerable. It affords therefore no certain criterion for judging of the age of the tree.

213. Flowers have generally all their parts formed, or indicated by protuberances or growing cells at a very early stage of the bud. These parts are then nsually more regularly placed than in the fully developed flower. Purts which afterwards unite are then distinct, many are present in this rudimentary state which are never further developed, and parts which are afterwarde very nnequal or dissimilar are perfectly alike at this early period. On this account flowers in this rery early stage are supposed by some modern botanists to be more normal, that is, more in conformity to a supposed type ; and the study of the early formation and growth of the floral organs, called Organogenesis, has been considered essential for the correct appreciation of the affinities of plants. In some cases, however, it would appear that modifications of development, not to be detected in the very young bud, are yet of great importance in the distinction of large groups of plants, and that Organogenesis, although it may often assist in clearing up a doubtful point of affinity, cannot nevertheless be exclusively relied on in estimating the real value of peculiarities of structure.

214. The flower is considered as a bud (flower-bud, alabastrum) until the perianth expands, the period of flowering (anthesis) is that which elapses com the first expanding of the perianth, till the pistil is set or begins to onlarge, or, when it does not set, until the stamens and pistil wither or fall. After that, the enlarged ovary takes the name of young fruit.

215. At the close of the season of growth, at the same time as the leafbuds or seed are formed containing the germ of future branches or plants, many plants form also, at or near the bud or eeed, large deposits, chiefly of starch. In many cases-such as the tubers of a potato or other rootstock, the scales or thickened base of a bulb, the albumen or the thick cotyledons of a seed-this deposit appears to be a store of nutriment, which is partially absorbed by the young branch or plant during its first stage of growth, before the roots are sufficiently developed to supply it from withont. In some cases, however, such as the fleslyy thickening of some stems or peduncles, the pericarps of fruit which perish long before germination (the first growth of the seed), neither the use nor the cause of these deposits has as yet been clearly explained.

\section{Functions of the Organs.}

216. The functions of the root are:-1. To fix the plant in or to the soil or other substance on which it grows. 2. To absorb nourishment from the soil, water, or air, into which the fibres have penetrated (or from other plants in the case of parasites), and to transmit it rapidly to the stem. The absorption takes place through the young growing extremities of the fibres, and through a peculiar kind of hairs or absorbing organs which are formed at or near those growing extremities. The transmission to the stem is through the tissnes of the root itself. The nutriment absorbed consists shiefly of carbonic acid and nitrogen or nitrogenuus compounds dissolved in water. 3. In some cases roots secrete or exude small quantities of matter in a manner and with a purpose not satisfactorily ascertained.

217. The Stom and its branches support the leaves. flowers, and fruit, 
transmit the crude sap, or nntriment absorbed by the roots and mixed with previously organised matter, to the leaves, and re-transmit the assimilated or elaborated sap from the leaves to the growing parts of the plant, to be there used up, or to form deposits for future use (204). The transmission of the ascending crude sap appears to take place chiefly throngh the elongated cells associated with the vascular tissnes, passing from one cell to another by a process but little nnderstood, but known by the name of endosmose.

218. Leaves are functionally the most active of the organs of vegetation. In them is chiefly conducted digestion or Assimilation, a name given to the process which sccomplishes the following results:-1, The chemical decomposition of the oxygenated matter of the sap, the absorption of carbonic acid, and the liberation of pure oxygen at the ordinary temperature of the air. 2. A counter-operation by which oxygen is absorbed from the atmosphere and carbonic acid is exhaled. 3. The transformation of the residue of the crude sap into the organised substances which enter into the composition of the plant. The exhslation of oxygen appears to take place under the influence of solar heat and light, chiefly from the nnder surface of the lesf, and to be in some measure regulated by the stomates; the absorption of oxygen goes on always in the dark, and in the daytime also in certain cases. The transformation of the ssp is effected within the tissues of the leaf, and continues probably more or less throughout the active parts of the whole plant.

219. The floral organs seldom contribute to the growth of the plant on which they are produced; their functions are wholly concentrated on the formation of the seed with the germ of a future plant.

220. The perianth (calyz and corolla) acts in the first instance in protecting the stamens and pistils during the early stages of their development. When expanded, the nse of the brilliant colours which they often display of the sweet or strong odours they emit, has not been adequately explained. Perhaps they may have great influence in attracting those insects whose concurrence has been shown in many cases to be necessary for the due transmission of the pollen from the anther to the stigma.

221. The pistil, when stimulated by the action of the pollen, forms and nourishes the young seed. The varied and complicated contrivances by which the pollen is conreyed to the stigma, whether by elastic action of the organs themselves, or with the assistance of wind, of insects, or other extraneous agents, have been the subject of numerous observations and experiments of the most distinguished naturalists, and are yet far from being fully investigated. Their details, however, as far as known, would be far too long for the present outline.

222. The fruit nourishes and protects the seed until its maturity, and then often promotes its dispersion by a great variety of contrivances or apparently collateral circumstances, e.g. by an elastic dehiscence which casts the seed off to a distance; by the development of a pappus, wings, hooked or other appendages, which allows them to be carried off by winds, or by animals, etc., to which they may adhere; by their small specific gravity, which ensbles them to float down streams; by their attractions to birds, etc., who taking them for food drop them often at great distances, etc. Appendages to the seeds themselves also often promote dispersion.

223. Hairs have various functions. The ordinary indumer tnm (171) of stein and lesves indeed seems to take little part in the economy of the 
plant besides perhaps some occusional protection against injurious atmoapheric influences, but the root-hairs (216) are active absorbents, the hairs on styles and other parts of flowers appear often materially to assist the transmission of pellen, and the exudations of glandular buirs $(175,2)$ are often too copious not to exercise some influence on the phenomena of vegetation. The whole question, h.swever, of vegetable exudations and their influence on the econumy of vegetable life, is as yet but imperfuctly understoud.

Chap. IV. Collection, Preagration, and Determination of Plants.

224. Plants can undoubtedly be most easily and satisfactorily examined when freshly gathered. But time will rarely admit of this being done, and it is moreover desirable to compare them with other plants previously observed or collected. Specimens must, therefore, be selected for leisurely observation at home, and preserved for future reference. A collection of such specimens constitutes an Herbarium.

225. A botanical Specimen, to be perfect, should have root, stem, leaves, flowers (both open and in bud) and fruit (both young and mature). It is not, however, always possible to gather such complete specimens, but the collector should aim at completeness. Fragments, such as leaves without flowers, or flowers withont leaves, are of little or no use.

226. If the plant is small (not exceeding $15 \mathrm{in}$.), or can be reduced to that length by folding, the specimen should consist of the whole plant, including the principal part of the root. If it be too large to preserve the whole, a good flowering branch should be selected, with the foliage as low down as can be gathered with it; and one or two of the lower stem-leaves or radical leaves, if any, should be added, so as to preserve as much as possible of the peculiar aspect of the plant.

227. The specimen should be taken from healthy uninjured plants of a medium size. Or if a specimen be gathered because it looks a little different from the majority of those around it, apparently belonging to the same species, a specimen of the more prevalent form should be taken from the same locality fur comparison.

228. For bringing the specimens home, a light portfolio of pasteboard, covered with calico or leather, furnished with straps and buckles for closing, and unother for slinging on the shoulder, and containing a few sheets of stout coarse paper, is better than the old-fashioned tin box (except, perhaps, for stiff, prickly plants, and a fow others). The specimens as gatlered ure pluced between the lesves of paper, and may be crowded together if not left long without sorting.

229. If the specimen brought home be not immediately determined when fresh, but dried for future examination, a note should be taken of the time, place, and situation in which it was gathered; of the stature, habit, and utwer particulars relating to any tree, shrub, or herb of which the specimen is only a portion; of the kind of root it has; of the colour of the tlower; or of any other particulars which the specimen itself cannot supply, or which may be lust in the prucess of drying. These memoranda, whether sken down in the field, or from the living specimen when brought home, abuuld be written on a label attarhed to the specimen or preeerved with it. 
230. To dry specimens, they are laid flat between several sheets of bibulous paper, and subjected to pressure. The paper is subsequently changed at intervals, until they are dry.

231. In laying out the specimen, care should be taken to preserve the natural position of the parts as far as consistent with the laying flat. In general, if the specimen is fresh and not very slender, it may be simply laid on the lower sheet holding it by the stalk and drawing it slightly down. wards; then, us the upper sheet is laid over, if it be slightly drawn downwards as it is pressed down, it will be found, after a few trials, that the specimen will have retained a natural form with very little trouble. If the specimen has been gathered long enough to have become flaceid, it will require more care in laying the leaves flat and giving the parts their proper direction. Specimens kept in tin boxes, will also often have taken unnatural bends which will require to be corrected.

232. If the specimen is very bushy, some branches must be thinned out, but always so as to show where they have been. If any part, such as the head of a Thistle, the stem of an Orobanche, or the bulb of a Lily, be very thick, a portion of what is to be the under side of the specimen may be sliced off. Some thick specimens may be split from top to bottom before drying.

233. If the specimen be succulent or tenacious of life, such as a Sedum or an Orchis, it may be dipped in boiling water all but the flowers. This will kill the plant at once, and enable it to be dried rapidly, losing less of its colour or foliage than would otherwise be the case. Dipping in boiling water is also useful in the case of Heaths and other plants which are apt to shed their leares during the process of drying.

234. Plants with very delicate corollas may be placed between single leaves of very thin unglazed tissue-paper. In shifting these plants intodry paper the tissue-paper is not to be removed, but lifted with its contents on to the dry paper.

235. The number of sheets of paper to be placed between each specimen or sheet of specimens, will depend, on the one hand, on the thickness and humidity of the specimens; on the other hand, on the quantity and quality of the paper one has at command. The more and the better the paper, the less frequently will it be necessary to change it, and the sooner the plants will dry. The paper ought to be coarse, stout, and unsized. Common blotting-paper is much too tender.

236. Care must be taken that the paper used is well-dried. If it be likewise hot, all the better; but it must then be very dry; and wet plants put into hot paper will require changing very soon, to prevent their turning black, for hot damp without ventilation produces fermentation, and spoils the specimens.

237. For pressing plants, various more or less complicated and costly presses are made. None is better than a pair of boards the size of the paper, and a stone or other heary weight upon them if at home, or a pair of strong leather straps round them if travelling. Each of these boards should be double, that is, made of two layers of thin boards, the opposite way of the grain, and joined together by a row of clenched brads nund the edge, without glue. Sush boards, in deal, rather less than half an inch thick (each layer about 21 lines) will be found light and durable.

238. It is useful also to have extrs boards or pasteboards the size of the paper, to separate thick plants from thin ones, wet ones from those uesrly 
dry, etc. Open wooden frames with crose-bars, or frames of strong wirework lattice, are still better than boards for this purpose, as accelerating the drying by promoting ventilation.

239. The more frequently the plants are shifted into dry paper the better. Excepting for very stiff or woody plants, the first pressure shculd be light, and the first shifting, if possible, after a few hours. Then, or at the second shifting, when the specimens will have lost their elasticity, will be the time for putting right any part of a specimen which may have taken a wrong fold or a bad direction. After this the pressure may be gradually increased, and the plants left from one to several days without shifting. The exact amount of pressure to be given will depend on the consisteuce of the specimens, and the amount of paper. It must only be borne in mind that too much pressure crushes the delicate parts, too little allows them to shrivel, in both cases interfering with their future examination.

240 . The most convenient specimens will be made, if the drying-paper is the same size as that of the herbarium in which they are to be kept. That of writing demy, rather more than 16 inches by $10 \frac{1}{2}$ inches, is a common and very convenient size. A small size reduces the specimens too much, a large size is both costly and inconvenient for use.

241. When the specimens are quite dry and stiff, they may be packed up in bundles with a single sheet of paper between each layer, and this paper need not be bibulons. The specimer.s may be placed very closely on the sheets, but not in more than one layor on each sheet, and care must be taken to protect the bundles by sufficient covering from the effects of external moisture or the attacks of insects.

242. In laying the specimens into the herbarium, no more than one species shonld ever be fastened on one sheet of paper, although several specimens of the same species may be laid side by side. And throughout the process of drying, packing, and laying in, great care must be taken that the labels be not separated from the specimens they belong to.

243 . To examine or dissect flowers or fruits in dried specimens it is necessary to soften them. If the parts are very delicate, this is best done by gradually moistening them in cold water; in most cases, steeping then in boiling water or in steam is much quicker. Very hard fruits and seeds will require boiling to be able to dissect them easily.

244. For dissecting and examining flowers in the field, all that is necessary is a pen-knife and a pocket lens of two or three glasses from 1 to 2 inches focus. At home it is more convenient to have a mounted lens or simple microscope, with a stage holding a glass plate, upon which the flowers may be laid ; and a pair of dissectors, one of which should be narrow and pointed, or a mere point, like a thick needle, in a handle; the other should have a pointed blade, with a sharp edge, to make clean sectiona across the ovary. A compound microscope is rarely necessary, except in cryptogamic botany and vegetable anatomy. For the simple microscope, lenses of $\frac{1}{1}, \frac{1}{2}, 1$, and $1 \frac{1}{2}$ inches focus are sufficient.

245. To assist the student in determining or ascertaining the name of a plant belonging to a Flora, analytical tables are in this work prefixed to the Orders, Genera, and Species. These tables are so constructed as to contain, under each bracket, or equally indented, two (rarely three or more) alternatives as nearly as possible contradictory or incompatible with each other, each alteruative referring to another bracket, or having nnder it sucther pair of alternatives further indented. The student having a 
plsnt to determine, will first take the general table of Natural Orders, snd examining his plant at each step to see which alternative agrees with it, will be led on to the Order to which it belongs, he will then compare it with the detailed character of the Order giren in the text. If it agrees, he will follow the same course with the table of the genera of that Order to find the genus, and again with the key of the species of that genus to find the species.

Suppose the plant to be a Dandelion, a Daisy, or a Thistle. On opening what appears to be the flower, we see at once that each part, which we may at first have taken for a petal, contains a separate style, and has a separate ovary (appearing like a seed) under it, but no sepsrate calyx, all these florets being collected within a common involucre. The flower is therefore componnd. Our attention is also called to the anthers. They may at first escape the beginner, but with a little care they will be discovered forming a ring round the style. We may then conclude that our plant agrees with the first alternative which refers to the second bracket. We must now look to the ovary under any one of the florets, cut it open, and, finding but a single ovule or seed, we are referred to the great Order of Compositæ. This second bracket is only necessary to exclude two or three Campanulaceæ (Phyteuma and Jasione), which have the united anthers and heads of flowers of Compositæ, but are most readily known by the numerous small ovules or seeds in their ovary or fruit. On turning to the deseription of the Order Compositæ, we are cautioned against confonnding with them two ur three other plants which have similar heads of flowers, and being satisfied we are right, we proceed in the asme manner to find ont the genns of our plant.

Suppose the plant to be a Violet. Arthough the anthers are united in a ring, the flowers are quite separate, each with its own calys, and we are referred by the second alternative to the third bracket, the double perianth refers us to the fourth the free ovary to the eixth, the single ovary to the eventh, the irregular corolla to the forty-first, the spur to one of the petals to the forty-second, the five stamens to the forty-third, under which the five sepals and petals indicate at once the genus Viola. We then compare our plant with the description of the genns in the Flora, before we proceed to ascertain the species. In making use of these descriptions, the beginner must be careful not to be misled by the popular meaning of terms to which a technical sense has been given by botanists, and in all cases of doubt he should refer to the definitions through the Index of Terms.

After a little habit, this mechanical process will be much abridged. The great, divisions of the general analytical table will be at once recognised, and very soon the large Orders and genera will become so familiar, that in most cases the amateur will only have to commence with them. Yet in all cases of doubt and hesitation, wherever the plant does not agree perfectly vith the generic character and description, he must revert to the beginning, and carefully go through every step of the investigation before he can be satisfied.

And notwithstanding the care that has been bestowed on the framing of the analytical keys of the present work, and the number of cases in which they have been verified, specimen in hand, through every stage, it cannot be hoped that they have been rendered so precise as to preclude doubt. The beginner especially will often be at a loss as to which alternative agrees the best with the plant he is examining, and one false atep may lead him far away from the object he is seoking. But let him not be discouraged: 
perseverance, a fresh examination of his specimen, or of othere of the same plant, a critical consideration of the mesning of every expression in the characters given, may lead him to detect some minute point overlooked or mistaken, and pot him in the right way. Even experienced botanists, provided with the most detailed descriptions in systematic works of the highest repute, are occasionally led into false determinations. Spccies vary within limits which it is often rery difficult to express in words. In making an Bnalytical tal;e, it often proves impossible so to divide the genera or species which hare to come under one bracket, ss that each alternative must exclude all that come under the other one. In such eases it has been found expedient to make both alternatires lead to the doubtful genus or species, although for lorerity's sake this has been sroided when not thought absolately necessary.

246. In those Floras where analytical tables are not giren, the student is nsually guided to the most important or prominent characters of each genus or species, either by a general summary prefixed to the genera of an Order or to the speries of the genus, for all such gencra or species; or by a special summary immediately preceding the detailed description of each genus or species. In the latter case this summary is called a diagnosis. Or sometimes the important characters are only indicated by itulicising them in the detailed description.

247 . It may also happen that the specimen gathered may present some occasional or accidental anomalies peculiar to that single one, or to a rery few individusls, which may prevent the species from being at once recognised by its technical characters. It may be useful here to point out s few of these anomalies which the botanist will b.a most likely to meet with. For this purpose we may diride them into two classes, viz.:

(1) Aberrations from the ordinary type or appearance of a sprcies for which some general canse may be assigned.

A bright, light, and open situation, particularly at considerable elerations alove the sea, or at high latitudes, without too much wet or drought, tends to increase the size and heighten the colour of flowers, in proportion to the stature and foliage of the plant.

Shade, on the contrary, especially if accompanied by richness of soil and sufficient moistnre, tends to increase the foliage and draw up the stem, but to diminish the number, size, and colour of the flowers.

A hot climate and dry eituation tend to incresse the hairs, prickles, and other productions of the epidermis, to shorten and atiffen the branches, rendering thorny plants yet more spinous. Mloisture in a rich soil has s contrary effect.

The neighbourhoed of the sea, or a saline snil or atmosphere, imparts a thicker and more succulent consistence to the foliage and almost erery part of the plant, and appears not unfrequently to enable plants usually annual to live throngh the winter. Flowers in a maritime variety are often much fower, but not smaller.

The luxuriance of plants growing in a rich soil, and the dwarf stunted character of those crowded in pocr scils, are too well known to need particularising. It is also an ereryday observation how gradually the specimens of a species become dwarf and stunted as we advance into the cold damp regions of the summits of high monntain ranges, or into high northern latitudes; and yet it is froquently from the want of attention to these circum. otances that numbers of false species have been added to our Enumerationa 
and Floras. Luxuriance entails not only an increase in the size of the whole plant, or of particular parts, but often also an increase of number in branches, in leaves, or leaflets of a compound leaf; or it may diminish the hairiness of the plant, induce thorns to grow out into branches, etc.

Capsules which, while growing, lie close upon the ground, will often become larger, more succulent, and less readily dehiscent, than those which are not so exposed to the moisture of the soil.

Herbs eaten down by sheep or cattle, or crushed underfoot, or other wise checked in their growth, or trees or shrubs cut down to the ground, if then exposed to favourable ciroumstances of soil and climate, will send up luxuriant side-shoots, often so different in the form of their leaves, in their ramification and inflorescence, as to be scarcely recognisable for the same species.

Annuals which have germinated in spring, and flowered without check, will often be very different in aspect from individuals of the same species, which, having germinated later, are stopped by summer dronghts or the approach of winter, and only flower the following season npon a second growth. The latter have often been mistaken for perennials.

Hybrids, or crosses between two distinct species, come under the same category of anomalous specimens from a known cause. Frequent as they are in gardens, where they are artificially prodnced, they are probably rare in nature, slthough on this subject there is much diversity of opinion, some believing them to be very frequent, others almost denying their existence. Absolnte proof of the origin of a plant found wild, is of course impossible; but it is pretty generally agreed that the following particulars must always co-exist in a wild hybrid. It partakes of the characters of its two parents; it is to be found isolated, or almost isolated, in places where the two parents are abnndant; if there are two or three, they will generally be dissimilar from each other, one partaking more of one parent, another of the other; it seldom ripens good seed; it will never be found where one of the parents grows alone.

Where two supposed species grow together, intermixed with nnmerous intermediates bearing good seed, and passing wure or less gradually from the one to the other, it may generally be concluded that the whole are mere varieties of one species. The beginner, however, mnst be very cautious not to set down a specimen as intermediato between two species, becanse it appears to be so in some, even the most striking characters, snch as stature and foliage. Extreme varieties of one species are connected together by transitions in all their characters, but these transitions are not all observable in the same specimens. The observation of a single intermediate is therefore of little valne, unless it be one link in a long series of intermediate forms, and, when met with, should lead to the search for the other connecting links.

(2) Accidental aberrations from the ordinary type, that is, those of which the cause is unknown.

These require the more attention, as they may sometimes lead the beginner far astray in his searcb for the genus, whilst the aberrations above-mentioned as reducible more or less to general laws, affect chiefly the distinction of species.

Almost all species with coloured flowers are liable to occur occasionally with them all white.

Many may be found even in a wild state with double flowers, that is, with 8 multiplication of petals: 
Plants which have usually conspicuous petals will oceasionally appear without any at all, either to the flowers produced at particular seasons, or to all the flowers of individual plants, or the petals may be reduced to narrow slips.

Flowers asually very irregular, may, on certain individuals, lose more or less of their irregularity, or appear in some very different shape. Spurs, for instance, may disappear, or be produced on all instead of one only of the petals.

One part may be occasionally added to, or subtracted from, the usual number of parts in each floral whorl, more especially in regular polypetalous flowers.

Plants usually monœcious or diœcious may become oceasionally hermaphrodite, or hermaphrodite plants may produce oceasionally unisexual flowers by the abortion of the stamens or of the pistils.

Leares cut or divided where they are usually entire, variegated or spotted where they are usually of one colour, or the reverse, must also be classed amongst those accidental aberrations which the botanist must always be on his guard against mistaking for specific distinctions.

\section{INDEX OF TERMS, OR GLOSSARY.}

\section{(The figures refer to the Paragraphs of the Outlines.)}

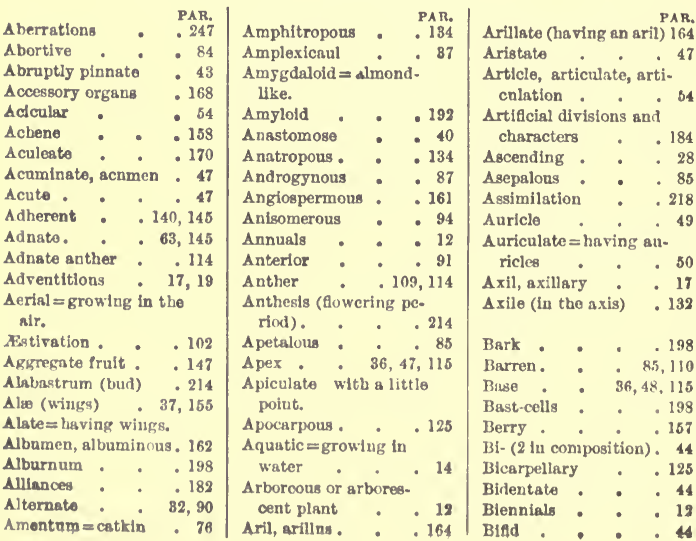




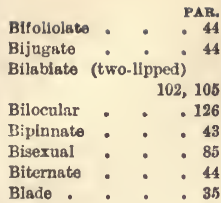

Bracts, bractea $60,77,202$

Bracteate $=$ having bracts.

Bracteoles • . 62

Bristles, bristly . $\quad 173$

Bud . . . . 16

Bulb . . . 26

Bush . . . 12

Cespitose $=$ tufted $\quad 28$

Callous $=$ hardeued and usually thickened.

Calycule, calyculate . 80

Coiyx - . 15, 90,96

Cembinm-region . . 211

Campanulate $\quad .104$

Campylotropous . . 134

Canescent . . 173

Capillary $=$ hair-like $\quad$. 54

Capitato • . 74

Capsule . . 158

Carpel . . 15, 123

Carpophore . . 146

Cartilaginous $=$ of the consistence of carti-

lage or of parchment.

Caruncle, carunculate 164

Caryopsis . . 160

Catkins . . 76

Cauline (on the stem). 38

Caulocarpic . . 12

Cells (elementary) $\quad 186$

Cells (of anthers). $\quad .109$

Cells (of the ovary) . 121

Cellular system . . 193

Cellular tissue $\quad$. 188

Cellulose . . . 191

Centrifugal . $\quad$. 72

Centripetal : . . 72

Chaff . . 82

Chalaza . . . 133

Character . . 183

Chlorophyll . . . 192

Chromule - . 192

Oulste.

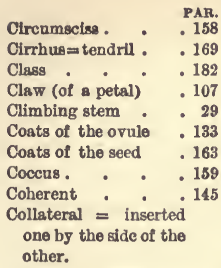

Collection of specimens 224

Coma . . . 163

Common petiole. $\quad .39$

Complete flower . $\quad$. 89

Compound leaf . $\quad$. 39

Compond tower . 74

Compound fruit . $\quad 147$

Compound ovary . $\quad .126$

Compound umbel $\quad 74$

Compressed . . . 54

Cone . 1.160

Confluent . . . 117

Conical - . 54

Connate . . . 145

Connective, connecti-

vum . . . 109

Connivent . . 145

Contorted, convolute . 102

Cordiste . . . 49

Cordiform . . . 49

Coriaceons . . . 55

Corky layer. . . 198

Corm - . . 27

Corolls . 15, 90,97

Corrugate (crumpled) 102

Corymb, corymbose . 74

Costate . . 173

Cotton, cottony . $\quad .173$

Cotyledons . . . 166

Creeping . . . 28

Crenate, crenulate . 39

Cristate $=$ having a

crest-like appendage.

Crown of the root .24

Crumpled . . 102

Cryptogamous plants . 10

Culm - . . 34

Cuneate . . 45

Cupular (cup-shaped). 136

Cuspidate . . . 47

Cylindrical . . . 54

Cyme, crmose
Deca- or decem. (10 in

composition) . 44,92

Deciduous calyx . $\quad 152$

Decompound . . 43

Decumbent . . 28

Decurrent . . . 87

Decussate - . . 32

Definite . . 89

Definitions . . (p. xi.)

Dehiscence, dehiscent

118,160

Dentato . . . 39

Depressed . . . 54

Descriptive Botany (p. xi.)

Determinate $\quad .67$

Determination of plants 245

Dextrine . . . 192

Di- (2 in composition). 92

Diadelphous. . . 113

Diagnosis . . . 246

Dislypetalous . $\quad 100$

Diandrous . . . 93

Dichlamydeons . . 85

Dichotomous - . 33

Diclinous . . 86

Dicotsledonous plants. 167

Dldymous . . . 54

Didynamous $\quad . \quad 113$

Diffuse. - . 28

Digitate - . . 41

Digynous . . 93, 125

Dimerous . . 98

Dimldiate . . 117

Dicecious . . . 86

Dipetalous . . . 93

Disepalous . . . 93

Disk . . . . 136

Dissepiment $\quad .126$

Dissected . . . 39

Distlchous . . 32

Distinct . . 145

Divaricate . . . 115

Diverging, divergent

115,145

Divided . . . 39

Dorsal =on the back.

Double fiowers . . 97

Down, downy $\quad . \quad 173$

Drupe . . . . 157

Dry fruits . . . 158

Ducts . . . 188

Duramen . . 198 


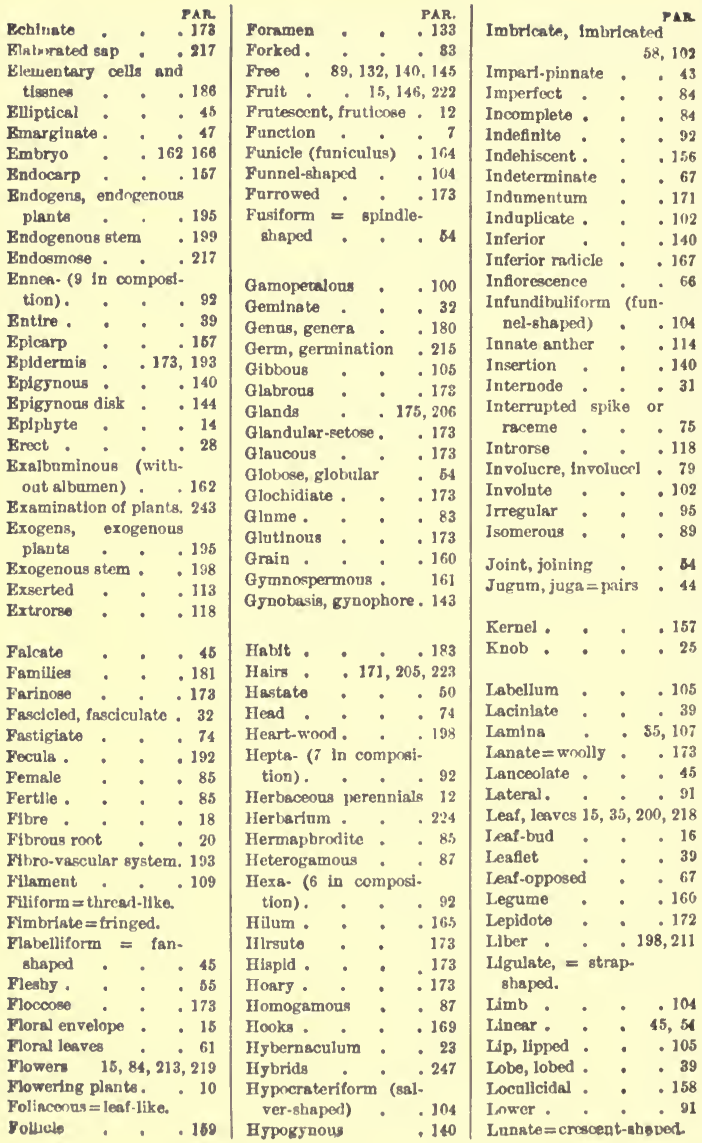




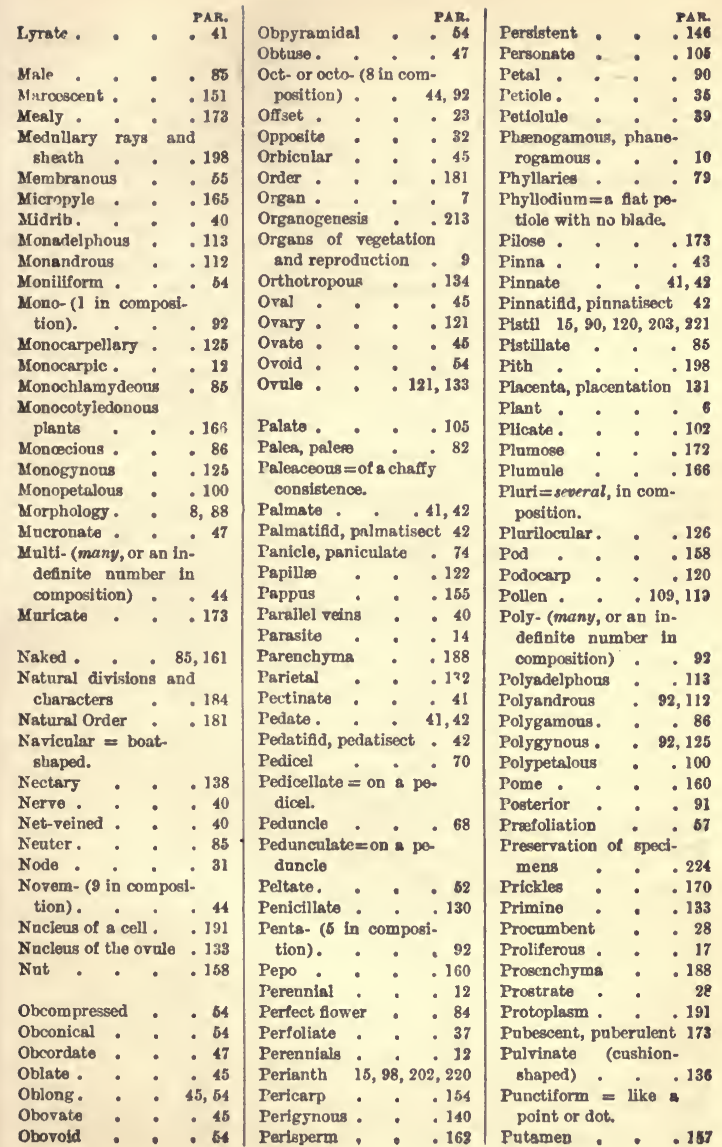




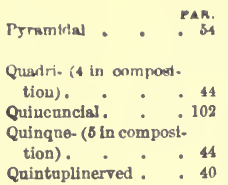

Race - . .178

Raceme, racemose . 74

Rachis .

Radical

Radicle

Raphe .

Receptacle.

Reduplicate.

Regular .

Reniform - . 51

Resupinate . . 105

Reticulate . . 40

Retuse . . . 47

Revolute . .102

Rhachis $=$ rachis . $\quad 39,68$

Rhaphe= raphe . 134

Rhizome . . 21,24

Rhomboidal . . 45

Ribs . 40

Ribbed. . . 178

Ringent . . 105

Root 15, 18, 196, 207, 216

Rootstock . . . 24

Rostrate $=$ beaked.

Rosulate . .

Rotato . .104

Rudimentary . $\quad 84$

Rugose . . . 178

Runcinate . . . 41

Runner . . 30

Bareate 105

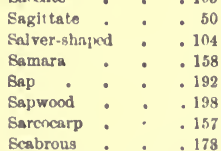

Bcales - 58, 69.172, 201

Scaly buib . 26

Bcaly surtace $\quad, 172$

Bcape . . . . 69

Ecariose, scertone

\begin{tabular}{|c|c|c|}
\hline Bcsttered & . & \\
\hline Scion . & . & \\
\hline Sentuloid cy & $y \mathrm{me}$ & \\
\hline Section. & . & \\
\hline Secund. & - & \\
\hline Secundine & - & \\
\hline Seed. & - & \\
\hline Segment & - & \\
\hline Sepals . & . & \\
\hline
\end{tabular}

Septem- (7 in conprosition)

- 44

Septicidal . $\quad 158$

Septum $=$ partitiou $\quad .126$

Serrate, serrulato $\quad .39$

Sessile . . . 37

Seta, setæ (bristles) . 173

Setaceons (bristle-like) 54

Setose (bearing

bristles) . . . 173

Sex- (6 in composition) 44

Sheathing . . 37

Shrubs . . . 12

Silicule, siliqua . $\quad .160$

Silver grain. . . 198

Simple • . . $\quad 39$

Sinuste . $\quad$. 89

Sinus . . . 39

Smooth . . 173

Spadix . . . 76

Spatha. 81

Spatulato . . . 45

Species . . . . 177

Specimen . . . 825

Spberical . 54

Spike, spicate _ . 74

Spikelet . . . 76

Spinous . . . 170

Spiral vessels $\quad . \quad 188$

Spur, spurred . . 105

Squamæ $=$ scales . $\quad .58$

Squarrose - . $\quad 58$

Stameng $15,90,108,203$

Staminate - . 85

Staminodia . . .110

Starch . . . 192

Stellate . . . 104

Stellate bairs $\quad .172$

Stem $15,28,197,210,217$

Stem-clasping - . 37

Sterile . . . 85

Stigma. . . 121

Stipells . . . 6

Stipes, stipitato . . 65

8tipales

63 $\begin{array}{lr}\text { Sturk } & \text { PAR. } \\ \text { Stole, stolon. } & 16,22 \\ \text { Stomates } & 23,30 \\ \text { Stone, stone frult } & \cdot 194 \\ \text { Striste. } & 157 \\ \text { Strigose, strigillose } & \cdot 173 \\ \text { Strophiole strophiolate } 164 \\ \text { Style } 164 \\ \text { Sub=almost, or inder, } \\ \text { in composition. }\end{array}$

Subclass, suborder $\quad 182$

Submerged $=$ under water.

Subulate ..$\quad 54$

Succulent . . . 55

Succulent fruits . $\quad 157$

Sucker . . . 30

Suffrutescent, suffruti.

cose . . . 12

Sugar . . . 192

Sulcate. . . . 173

Superior . . 140

Superior radicle . . 167

Buperposed $=$ inserted one above the other.

Snture . . . 159

Symmetrical . 89

Synandrous . . . 112

Syncarpous . . . 125

Syngenesious . . 113

Systemstio Botany (p. Ii).

Taproot

20

Teeth . . 39, 101

Tegmen . . 163

Tendril . $\quad 29,169$

Terete . . . 54

Ternste - . 32, 41

Terrestrial = growing

on the esrth . . 14

Testa . . . 163

Tetra-(4 in composition) 92

Tetradynamous . . 113

Thorns . . . 170

Throat. . . 104

Thyrsus, thyrsoid $\cdot 74$

Tissues (elementary) $\cdot 186$

Tomentose . . . 173

Toothed . . . 39

Torus . . . . 138

Trees . . . . 12

Tri-(3 in composition)44, 98

Tribe . 189 
GLOSSART OF TERMIS.

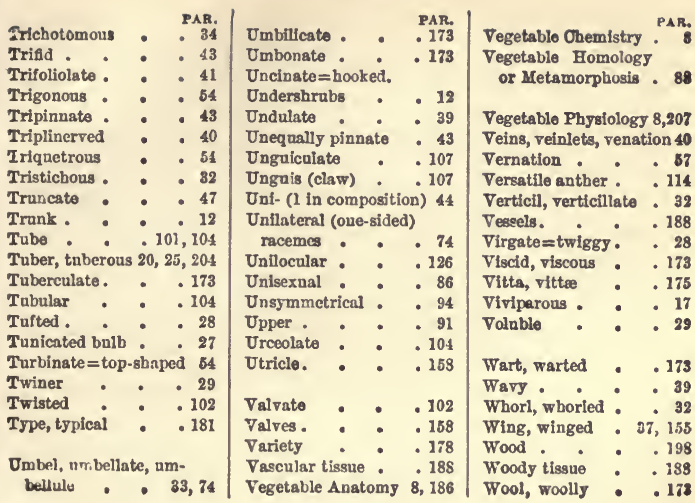

\section{ARRANGEMENT OF THE TEXT, AND ABBREVIATIONS USED IN THE PRIESENT WORK.}

In the following pages the name of each Family or Order (for the two words may be indiscriminately used) is given in Latin and in English. The English name is always in two words, exclusive of the particle. Where the first word is not the name of a genus also, it may be used alone to designate the family by putting it in the plural, as Crucifers for the Ciucifer family, Waterlilies for the Waterlily family. Where, however, it is also the name of a genus, and it is wished to designate the family hy a single word, in order to aroid confusion, either the Latin name must be taken, or it must be Anglicised by some of the modes which have been proposed, such as substitnting the terminations ids for idea, and anths or ads for acea, as: Orchids for Orchidacea, Ranunculanths or Ranunculads for Ranunculacea.

After the name of the family, the first paragraph, in large type, is the character of the family; the second, in ordinary type, contains remarks on its geographical distribution and affinities.

This is followed, in small type, by the analytical key of the British genera belonging to the Order, as above explained, (p. lii., par. 245); and short memoranda are occasionally subjoined on commonly cultivated plants belonging to exotic genera.

Each genus commences with the name, in Latin on the left, in English on the right. Where there is no English name suitable for the genus, the Latin one is repeated, as it must in that case be used as English. 
Then follow the generic character, a paragraph of remaris, an analytical key of species, and occasional memoranda on exotic cultivated species, all in the same form as in the case of the families.

Each species commences with the name, consisting, both in Latin and in English, of two words. In Latin, the first word indicates the genus, the second the species; and the name is generally followed by the indication, in abbreviation, of the botanist who first fixed the name for the species in question. In these abbreviations, Linn. stands for Linnceus; Br. for Robert Brown; DC. for De Candolle; Sm. for Sir James Smith. Other names are usually abbreviated by giving the first syllable with the first letter of the second syllable, as Hook. for Ilooker. In English, the first word indicates the species, the second the genus; but both must be used in naming the plant, excepting in cases where the only word is a popular name applied to no other plant.

After the name a reference is given in a parenthesis to the figure of the species in a companion volume of wood engravings and dissections, entitled "Illustrations of the British Flora" (drawn by the late W. H. Fitch and W. G. Smith); which engravings, \&c., were inserted in the second edition of the Handbook, but now appear in a separate form. After the description of the species a reference is given to any name or names, different from the one here adopted, under which the species may be described in other works descriptive of British plants. Thus, under Brassica muralis, p. 36, "Diplotaxis muralis, DC.; B. brevipes, Syme," means that the plant is described as a Diplotaxis in the "Student's British Flora," and as Brassica brevipes by Dr. Syme, in the new edition of "English Botany."

The next paragraph contains : 1st. The indication of the geographical area of the species. This has only been done in a very general manner, and more especially with regard to its distribntion in countries the nearest to Britain; for it would have been quite foreign to the purpose of this work to attemptito fix, with any precision, the limits of the areas remote from Britain. Generally speaking, the species indicated as extending to southern Europe penetrate more or less into Africa; if reaching the Caucasus, they often advance more or less into Persia and Arabia, \&c. 2nd. The distribution in Britain. This is also given in general terms, the object being to give the reader some indication whether the species to which he refers the plant is likely to have been found growing in the places indicated. Directions to precise localities occupy too much space for any but very local Floras or Botanists' Guide-Books. Exceptions are of corrse made for plants only known in a single locality. In all these indications Britain is meant to include Ireland. The Channel Island plants are only mentioned when they are not also found on the main British Isles.

These stations are followed, in the same paragraph, by the period of flowering, printed in italics. The season is generally given rather than the month, as the flowering of plants always varies with the season. A spring flower which may appear in the beginning of March in a favoured situation on the south coast of England may not open till May in the Highlands of Scotland. These periods of flowering, derived from personal observation or from the best sources I had to hand, nust, however, be taken with considerable allowance, for they are liable to much variation, according to local or temporary influences; and at 
any rate they can never be depended on for specific distinctions. In general, spring fiowers may be said to blow in March, April, or May, In the south of England; summer flowers in June, July, or part of August ; autumnal ones in the end of August, September, or part of October. After the middle of October, and until the beginning of March, there are but few besides occasional stragglers in flower; towards the north the flowering season is much shorter, and particularly the early flowers open later.

Observations on varieties, \&c., are reserved for the conclusion of the paragraph. The plants described as species in other "British Floras," and not adopted as such in the present work, are mentioned or referred to either in these concluding observations or among the synonyms immediately under the specific name above referred to. All other species inserted in the above works and not included or allnded to in the present one, are omitted, because they are believed not to grow wild in the British Isles.

\section{ANALYTICAL KEY TO THE NATURAL ORDERS AND ANOMALOUS GENERA OF THE BRITISH FLORA.}

The heads of division adopted in the following Key are necessarily artificial, being solely intended to assist the beginner in finding out the name of his plant, and its place in the system, like the letters of the alphabet in an index. They are not classes or groups of Orders, for the same Order will be found repeated under different heads. At the same time, it has been the endeavour so to frame them as to call the student's attention to some of the most prominent characters of the great natural divisions.

\section{FLOWERING PLANTS.}

Flowers compound, consisting of several florets in a common 1 involucre, without separate calyces. Anthers united in a

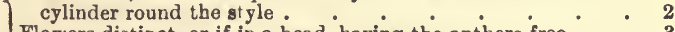

Flowers distinct, or if in a head, having the anthers free : $\quad 3$

$2\left\{\begin{array}{l}\text { Ovary and fruit containing a single seed, and appearing like a } \\ \text { seed under the floret }\end{array}\right.$

Ovary and fruit 2-celled, with several seeds . JASIONE (p. 272).

Perianth double, consisting of a calyx (sometimes reduced to

$3\left\{\begin{array}{l}\text { a scarcely prominent ring) and a corolla } \\ \text { prol }\end{array}\right.$

Perianth single (its segments all calyx-like, or all petal-like) or none

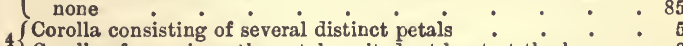

$4\left\{\begin{array}{l}\text { Corolla of one piece, the petals united, at least at the base } \\ \text { Co }\end{array}\right.$

Ovary free, within or above the petals 6

5 Ovary inferior, adherent to the base of the calyx, and below the petals . . . . . . . . 46

$6\left\{\begin{array}{l}\text { Ovaries several in the same flower, the carpels distinct or deeply } \\ 6\end{array}\right.$

$\left\{\begin{array}{c}\text { divided } \\ \text { Ovary solitary (simple or compound) antir } s \text { or sightly divided }\end{array}\right.$ 
$7\{$ Corolıa regular, the petals equal and similar to each other $\quad 15$

Corolla irregular. . . . . . . . 41

8 Ovary inferior or adherent, below the insertion of the corolla . 51

Ovary superior or free, within the tube or base of the corolla . 57

\section{Polypetals with several free, distinct oraries or carpels.}
$\left\{\begin{array}{l}\text { Stamens united in a ring or column enclosing the style. } \\ \text { Ovaries in a ring round the axis }\end{array}\right.$
$9\left\{\begin{array}{l}\text { Ovaries in a ring round the axis } \\ \text { Stamens free. Ovaries quite free, each with a distinct style or }\end{array}\right.$
stigma, withont a central axis
$10\left\{\begin{array}{l}\text { Stamens } 5 \text { or } 10 \text {, shortly nnited at the base GERANIACE } \text { (p. 88). } \\ \text { Stamens indefinite, united in a column }\end{array}\right.$

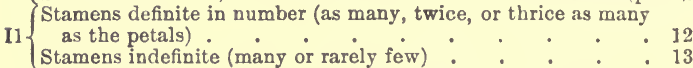
Leaves fleshy. Sepals and petals 4 or more Crassulaces (p. 158).
$12\{$ Aquatic plants not fleshy. Sepals and petals 3 each.
13 Leaves without stipules. Stamens inserted on the receptacle 14 Leaves with stipnles. Stamens on the calyx ROSACEN (p. 127).

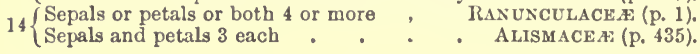

Regular Polypetals with one free, simple, or compound ovary.

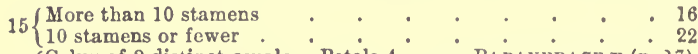

Calyx of 2 distinct sepals. Petals 4 . PAPAveraces (p. 17). Calyx of one piece, with 5 or more teeth. Petals 5 or 6.

16 Stamens about 12 . . . . 17

Calyx of 3 to 5 sepals or lubes. Petals 5. Stamens numerous 18

Calyx of several sepals. Petals and stamens numerons. Aquatic plants . . . . . NYMPHAACEÆ (p. 16).

$17\left\{\begin{array}{l}\text { Petals distinct. Ovary sessile. } \\ \text { A pparent petals really appendages to the involucre. Ovary ap. }\end{array}\right.$ parently stalked . . . . EUPHorbIA (p. 391).

$18\{$ Leaves opposite . . . . . . . . . . . 19

Leaves alternate . $\quad . \quad$. . . . . . 20

$19\left\{\begin{array}{l}\text { Sepals } 3 \text {, with or without } 2 \text { small outer ones. Style simple } \\ \text { CistaCE } 2 \text { (p. 51). }\end{array}\right.$

(Sepals 5, nearly equal. Styles 3 or 5, distinct. HyPERICINE 2 (p. 79).

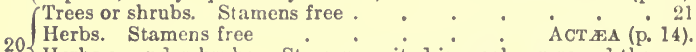

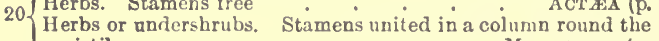
pistil . . . . MALVACEX (p. 84).

$21\left\{\begin{array}{l}\text { Petals and stamens inserted on the receptacle. Flower-stalk } \\ \text { winged by an nhlong bract } \\ \text { Petals and stamens inserted on the calyx. Flower-stalk not }\end{array}\right.$ winged . . . . ROSACEA (p. 127). 
$22\{$ Leaves opposite

Leaves alternate, or radical, or none:

$23\left\{\begin{array}{l}\text { Trees or shrubs } \\ \text { Herbs }\end{array}\right.$

Stamens 2. Leaves pinnate

Stamens 4 or 5 . Leaves ovate, toothed

Stamens about 8 . Leaves broadly lobed or angular.

. OLeACEAe (p. 297).

24

Petals Inserted on the tubular calyx near the top.

ACERACEAS (p. 96).

25

Petals inserted within the base of the calyx . . . $20^{\circ}$

26 Leaves divided, cut, or toothed . . - GRRANIACEA (p. 88).

26 Leaves quite entire . . . . . . . . 27

Capsule 1-celled, with a central placenta and several seeds.

27 Capsule with a single seed CARYOPHYLLACEA (p. 58),

Capsule and ovary divided into several cells . . . . 28

(Petals 3 or 4, with twice as many stamens. Flowers very

28 minute • • • • . Elating (p. 78).

Petals 4 or 5. Stamens the same, or rarely one or two additional ones. . . . . . . . 29

Calyx tubular, 5-toothed : : Frankrania (p. 57).

29 Calyx many-toothed. Hlowers very small. - RADIOLA (p. 84).

Sepals 5, quite free - . . LINUM catharticum (p. 84).

Trees or shrubs . . . . 31

30 Low procumbent heath-like undur-ahrub, with 3 petals and

stamens - • EMPETRUM (p. 396),

Herbs rarely slightly woody at the base . . . . . 34

31 Petals and stamens 6. Berry 1-or 2-seeded - BERBERIs (p. 15).

Petals 4 or 5. Stamens as many, or twice as many . • . 32

Branches twiggy, with small green scale-like leaves. Capsule

32 1-celled. Seeds cottony.

Shrubs or trees, with flat leaves. Ovary and fruit (usually a

berry) divided into cells . . . . . . . 33

(Petals white, alternating with the stamens - . ILEx (p. 97).

83 Petals very small, green and behind the stamens, or none.

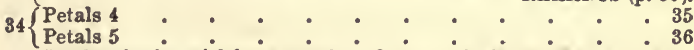

RHAMNUS (p. 99).

Leafless herbs, with brown scales. Stamens 8. Monotropa (p. 286).

85 Herbs with entire or divided leaves. Stamens 6 , of which 2

are shorter, or rarely wanting . - CrUCIFER $A$ (p. 22).

Herb with componnd leaves. Stamens 4. EPIMEDIUM (p. 15).

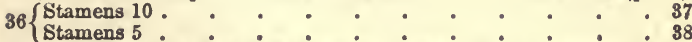

Style single, with a broad stigma. Leaves entire or minntely

toothed? PxROLA (p. 285).

87 Two styles or 2 distinct stigmas, Leaves often toothed or divided . . . . . . SAXIPRAGA (p. 165)

Five styles. Leaves of 3 leaflets : - Oxams (p, 94).

88 Leaves all radical, or only one on the stem . . . . 89

Stem-leares several, entire. . . . . . . 40 


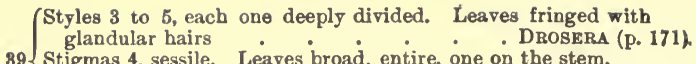
89 Stigmas 4, sessile. Leaves broad, entire, one on the stem. Styles 5. Leaves all radical, entire - Plumbaginese (p. 363). Styles 3. Procumbent plant, with very small white and green

Irregular Polypetals with one free, simple, or compound ovary.

$41\left\{\begin{array}{l}\text { Flowers with a spur or pouch at the base } \\ \text { Flowers not spurred }\end{array}\right.$

Stamens numerous

42

Stamens 5 . . . .

Sepals 5. Petals 5, spreading, one of them spnrred Viou (p. 53)

43 Outer sepals 2. One inner sepal, large, hooded, and spurred. Petals 1 outer, entire, 2 inner lobed - IMPATIENS (p. 95). (Petals small, deeply cut. Stamens more than 8, free RESEDA (p. 50). Petals 5, papilionaceous. Stamens 10, all or 9 united.

Petals and sepals in pairs or in fonrs, Stamens 6.45 Sepals 5, of which 2 are large. Petals 3 or 5, small. Stamens 8 , united in two clusters

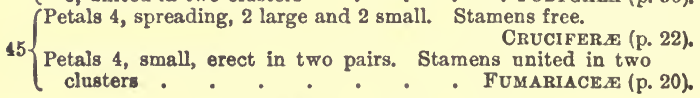
- Polygala (p. 56). Polypetals with an inferior ovary.

Stamens 10 or fewer, of the same number as or twice the petals 47 Stamens 12 .

Stamens indefinite, nsually numerous .

Petals 5. Stamens 10

- LYTHRUM (p. 155).

Petals 5. Stamens 5 .

Petals 3. Aquatic plants with diclinous flowers.

Petals 2 or 4 . Stamens 2,4 , or 8

HYDROCHARIDEX (p. 433).

Herbs. Fruit separating into 2 dry $\dot{1}$-seeded carpels.

- $\quad 50$

SAxifraga (p. 165).

DelphiNium (p. 13). 
Shrubs. Stamens 8 or 10. Fruit a berry VAccinium (p. 278). Climber. Flowers diœcious. Stamens 5, combined into 3. Fruit a berry . . . . BRYONIA (p. 157). Herbs with ternately divided leaves. Stamens 8 or 10 . Fruit a berry

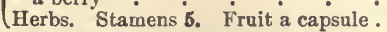
Stamens inserted within the base of the corolla.
Stamens inserted in the tube of the corolla. Flowers small, CAMPANULACEA (p. 271). ADoxA (p. 206).

• $\div 53$ white

$54\left\{\begin{array}{l}\text { Leaves in whorls of four or more } \\ \text { Leave }\end{array}\right.$ - Samolus (p. 294).

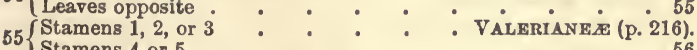
Stamens 4 or 5 . . . . . . . 56 Flowers numerous, in heads, with a common involucre. Fruit dry, 1-seeded. Stem herbaceous . DIPSACE 66 Flowers distinct or few together, without a common involucre. Fruit often succulent. Stem usually shrubby or climby.

Caprifoliaces (p. 205).

\section{Monopetals with a free ovary.}

57 Stamens twice as many as the lobes of the corolla . . . 58 Stamens equal in number to the lobes of the corolla or fewer . 61 $58\{$ Flowers regular. Stamens distinct . . . . . . 60 Flowers very irregular. Stamens nnited . . . : $\quad 59$ Leaves much divided . . . . FüAriacé (p. 20). 59 Leaves with 3 leaflets . . . . . TRIFoLIUM (p. 109). Leaves entire . . . . . . Polygala (p. 56). $\int_{60}$ Ovary single, of several cells. Leaves not peltate. Ovaries several, distinct. Radical leaves peltate, fleshy. Cotruedon (p. 159). $61\left\{\begin{array}{l}\text { Ovaries divided into two or four resembling naked seeds, in the } \\ \text { bottom of the calyx, with the style arising from between them }\end{array}\right.$ Ovary entire, of 1 or more cells, the style or stigma at the top 63

$62\left\{\begin{array}{l}\text { Leaves all opposite. Corolla 2-lipped, or seldom nearly regular } \\ \text { LABIAT } \text { (p. 342). }^{2} \text {. }\end{array}\right.$

Leaves alternate (except sometimes the floral ones). Corolla

regular or rarely oblique . . . . BORAGINEx (p. 307). 63 Corolla regular • • . • . • • • • • 64 Corolla irregular . . . . . . . . 80

(Stamens opposite the lobes of the corolla, and of the same

64 number - * - Primulacese (p. 287). Stamens alternating with the lobes of the corolla, or fewer in number . . . . . . . . . 65

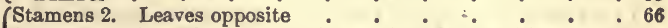
$65\left\{\begin{array}{l}\text { Stamens 3. Small berb, with minute white flowers Montra (p. 77). } \\ \text { Stamens 4 }\end{array}\right.$ Stamens and divisions of the corolla 5 or more. . . 72 Herb. Corolla rotate: $: \vdots:$ - Veronica (p. 393) 


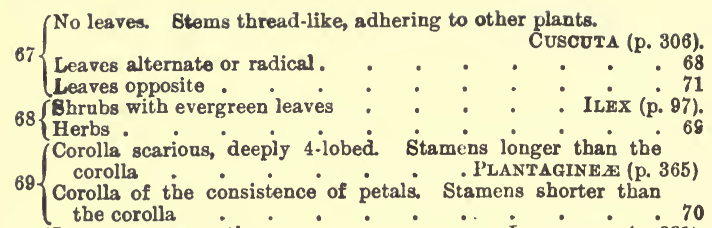
$70\{$ Leaves narrow, entire . . . . - LImosella (p. 331). $70\{$ Leaves orbicular, crenate . . . . SIBTHORPIA (p. 332). 71 Leaves entire . . . . . .GhNTIANACEA (p. 299),

71 Leaves toothed or cut . . . . . . VerbeNa (p. 362).

7 Fruit a berry . . . . . . . . . 73

$72\{$ Fruit a capsule : . . . . . . . 74

73 Shrubs with evergreen leaves . . . . ILEX (p. 97).

3 Stem or branches herbaceous . . . Solanack (p. 316).

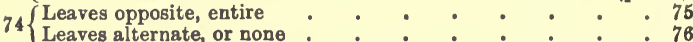

Trailing plants with evergreen leaves. Two ovaries joining at

75e top into one style - ${ }^{\circ} \cdot{ }^{\circ}$ Vincs (p. 298)

$75\{$ Small procnmbent shrubs, with very small evergreen leaves. Ovary single . . . . . . LOIsEleuria (p, 281). Herbs. Ovary single . . . . GentianaCeze (p. 299).

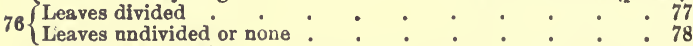

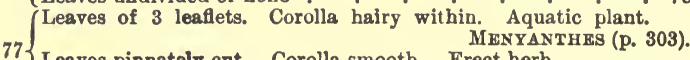

Leaves pinnately cut. Corolla smooth. Erect herb.

$78\left\{\begin{array}{l}\text { Aquatic plant, with floating orbicular leaves LimsanthemUM(p.3 } \\ \text { Twining or procumbent plants. Corolla campanulate. Seeds }\end{array}\right.$

2 or 4 in each capsule . . . Convolvulacese (p. 305).

Tall erect plants. Seeds numerous . . . . . . 79

$79\left\{\begin{array}{l}\text { Corolla nearly rotate, the upper lobes overlapping the lower ones. } \\ \text { VERBASCUM (p. 324). }\end{array}\right.$ $79\left\{\begin{array}{c}\text { Corolla campanulate, or with a distinct tube, the lobes folded } \\ \text { in the bud }\end{array}\right.$

SOLANACEA (p. 316).

Stamens 5, free . . . . . . . 79

80 Stamens 3. Small plant with minute white flowers. Montu (p. 77).

Stamens 2 or 4 . . . . . . . . . . 81

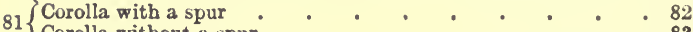

Corolla without a spur . . . . . . . 83

82 Two stamens. Capsule 1-celled - Lentibulacese (p. 294).

Four stamens. Capsule 2-celled Scrophularinks (p. 323).

One or two seeds in the ovary or capsule. VERBENACEN (p, 362).

83 Several seeds in the capsule, or at least several ovules in the

$84\left\{\begin{array}{l}\text { Plant leafless, except scales of the colour of the stem. Capsule } \\ \text { 1-celled }\end{array}\right.$ Leaves green. Capsule 2-celled. Acrophularinks (p. 323). 
Perianth rimple or none.

Floating or submerged plants

Terrestial herbs, or, if aquatic, erect from the bottom of the water, and projecting from it.

Trees or shrubs

\section{Floating Aquatic Plants.}

(Small leaf-like fronds, attached two or three together, and

86 floating without any stem . . . LEMNA (p. 421). Leaves and flowers growing out of a distinct stem . . . 87

$87\{$ Leaves deeply divided into capillary lobes . . . . 88

Leaves pinnately divided. Periantb 4-lobed. MŕmophyL- 89

Leaves repeatedly forked. Perianth nowe or many-lobed.

LUM (p. 173).

C'ARATOPHYLLUA (p. 397).

Leaves opposite or whorled $\quad . \quad$. . 90

89 Leaves in a radical submerged tuft : : : : : : 136

Leaves radical in floating tufts . . . HYDROCHARIS (p. 434).

Leaves alternate . . . . . . . . . . 92

Tube of the flower long and thread-like, resembling a pedicel.

90 Elowers sessile, or nearly so, in the axils of the leaves, or in

stalked heads or spikes, without any stalk-like tube . . 91

(One 4-lobed ovary. Two styles . . . Caluitriche (p. 397).

91 Four ovaries, with distinct styles or stigmas NAIADEe (p. 423).

One simple ovary and style . . . . HIPPURIs (p. 174).

Flowers axillary. Periarth none, or of 4 small scales.

Flowers in globular heads, the npper head male, the lower female.

92 Perianth none, or of 1 to 6 small scales SPARGANIUM (p. 419)

Flowers glumaceous. Stamens 2 or 3 ScIRPUS fluitans (p. 484).

Perianth of 6 parts. Stamens 6. . Juncus articulatus (p. 471).

Perianth of 5 parts. Stamens about 5 Polygonum amphibium (p.386).

2. Terrestial Herbs, or, if Aquatic, erect.

Flowers hermaphrodite, containing one or more ovaries and one or more stamens . . . . . . . .

93 Flowers diclinous, the stamens and ovaries either in separate perianths, or intermixed or variously arranged on the same spike, or within the same involucre, but separated by single

scales only, without distinct perianths . . . . . 125

$94\{$ Stamens more than 6 . . . . . . . . 95

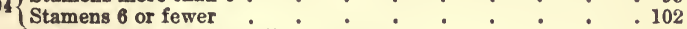

(Stamens indefinite, nsually numerous _ • • . . 96

95 Stamens about 12 . . . . . . . . . 97

Stamens 7 to 10 . $\quad . \quad \cdot \quad \cdot \quad \cdot \quad \cdot 98$

Stamens inserted on the receptacle. Ovaries numerous.

RANUNCULACHE (p. I

Stamens on the calyx. Ovaries few or single ROsACEAs (p. 127).

Perianth 8-lobed. Capsule sessile . . ASARUM (p. 390).

97 Perianth (involucre) with 5 small lobes or teeth. Capsule stalked 
98 Leaves radical, or in a single whorl on the stem . 9 ? Leaves alternate or opposite . . . . . 100 (Leaves once or twice ternately divided. Flowers in a small terminal head . . . . ADoxA (p. 206).

99 Leaves entire, rush-like, radical. Flowers in a terminal umbel. Plant aquatic . . . . Buton us (p. 431), Leaves entire, in a single whorl of four or five. Flowers solitary, terminal . . . . . PARIS (p. 456).

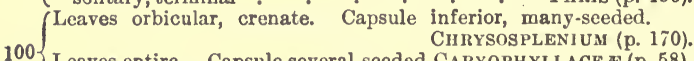

100 Leaves entire. Capsule several-seeded CARYOPHYLLACEA (p. 58). Leaves entire. Capsule 1-seeded . . . . . . 101 101 Leaves small, opposite. Capsule inferior SclerantuUs (p. 370).

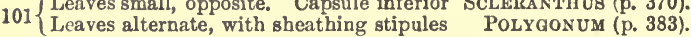

(Perianth coloured, and looking like a corolla . . . 103

102 Perianth herbaceous, and looking like a calyx or scales, or entirely wanting . . . . . . . . . 111 One or two anthers sessile on a central column or style. One

103 of the six divisions of the perianth different from the others.

Three to slx stamens distinct from the style . . . . 104

$104\{$ Leaves opposite or in whorls . . . . . . . . 105

Leaves alternate or radical $\quad . \quad 0 \quad . \quad 0 \quad . \quad 07$

Stamens 6. Capsule 2-celled, with several seeds Perlis (p. 156).

105 Stamens 5 or fewer. Ovary inferior. . . . . . 54 Stamens 5. Ovary superior . . . . . . . . . 106

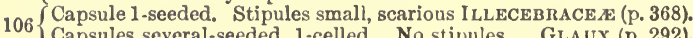
Capsules several-seeded, 1-celled. No stipules Gla UX (p. 292). (Leaves pinnate, with stipules . . . SANGUisorBA (p. 140).

107 Leaves pinnate or divided, without stipules UMBELLIFER A (p. 174). Leaves entire . . . . . . . . 108 Stipules forming sheaths or rings round the stems. Nut

108 superior, 1-seeded . . . . PolygONACEN (p. 379). No stipules . . . . . . . . . . 109 Stamens and divisions of the flower 4 or $5 \quad . \quad . \quad .110$

109 Stamens and divisions of the flower 3 or 6 . Leaves with parallel veins . . . . . . . . . . 154 Styles 5. Ovary and capsule superior PuUMBainedi (p. 363). 110 Styles 2. Ovary inferior . . . UM BELLIFERA p. 174). Style 1. Ovary inferior. . . . . . THESIUM (p. 389).

$111\left\{\begin{array}{l}\text { Leaves opposite or whorled } \\ \text { Leaves alternate or radical } \\ \text {. }\end{array}\right.$ Fleshy, articulate, maritime plants, without leaves. Stamens 1 or 2 . . . . SAliconNIA (p. 371). $112\left\{\begin{array}{l}\text { Leaves linear, whorled. Stamen } 1 \text { - Hippunis (p. 174). } \\ \text { Leaves opposite. Stamens 4, 5, or } 6\end{array}\right.$

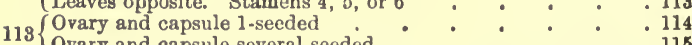
Ovary and capsule several-seeded : . . . . . 115

$114\{$ Leaves small, with scarious stipules ILLECEBRACE $($ p. 368). 115 Ovary inferior. Stamens 4 . $\quad$. Chenopodiacke (p. 370).

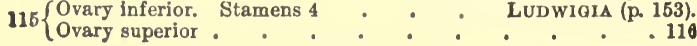


Calyx 6-toothed. Stamens 6. Capsule 2-celled PePLIS p. (156). Calyx 5-lobed. Stamens 5. Capsule 1-celled, several-

116 seeded . . . . . GLAUX (p. 292).

Calyx of 4 or 5 sepals. Stamens 4 or $\dot{b}$. Capsule 1-celled several-seeded . . . CAkYOPHYLLACExs (p. 58)

Flowers glumaceous, consisting of chaffy scales alternating with each other, enclosing the stamens, Leaves linear.

$117 \begin{gathered}\text { Stamens } 2 \text { or } 3 \\ \text { Perianth entire, oblique projecting on one side into a lip. Sta. }\end{gathered}$ mens 6 . . . ARISTOLOCHIACEX (p. 389).

Perianth 4-, 5-, or 6-merous. Stamen 4,5 , or 6 . . . 118

118 Two or more ovaries. . . . RosAcE 1 (p. 127).

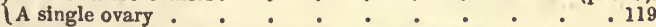

$119\{$ Perianth of 4 or 5 parts or teeth. Stamens usually 4 or $5 \quad 120$

Perianth of 6 divisions. Stamens 6. . . . 124

120 Ovary inferior . . . . . . . TH rsium (p. 389).

Ovary superior . . . . . . . . . . . 121

121 Seeds several in the capsule : : Plantago (p. 366).

Seeds solitary . $\quad . \quad$. $\quad . \quad . \quad . \quad .122$

Stipules leafy. Leaves broadly lobed or divided RosACE $x$ (p. 127).

122 Stipules membranous, sheathing the stem PoLYGONACEA (p. 379).

Stipules minute or none . . . . . . . . 123

123 Stamens 4 . . . . . . . PARIRTARIA (p. 400).

Stamens 5 : - . C Cilenolrodiaces (p. 370).

Stem leafy. Stipules sheathing. Nut enclosed in three of

124 the perianth-lobes.

Leaves linear, mostly radical. Capsule with 3 or more seeds 161

Stamens and pistils in distinct globular or cylindrical masses without separate perianths . . . . . . 166

125 Stamens about 12 , with one pistil in a calyz-like involucre.

EUPHORBIA (p. 391).

Flowers, male or female, each with a distinct perianth . . 126

Stems long and climbing . 127

126 Stems parasitical on trees with hard green forked branches.

(Stems terrestrfal or aquatic, but neither climbing nor floating 130

127 Leaves opposite. Capsules in a head concealed by leafy bracts

Leaves alternate. Berries red . . . . . 128

$128\left\{\begin{array}{l}\text { Leaves angular or lobed. Stem climbing by tendrils. Perianth } \\ \text { 5-lobed }\end{array}\right.$

Leaves entire, shining. Stem twining, without tendrils. Perianth 6-lobed : . . . TAMUS (p. 155).

$129\{$ Male and female flowers on the same plant : . . . 131

Male and female flowers on different plants : $\quad . \quad$. 139

Flowers glumaceous, consisting of chaffy scales enclosing

$130\{$ the stamens : . . . . . . 165

Howers of both sorts, or at least the males, with a distinct perianth of 3,4 , or more divisions . . . . . 129

181 Male perianth of 3 to 5 divisions . . . . . . 132

Male perianth of 6 divisions $\quad . \quad 0.0138$

$132\left\{\begin{array}{l}\text { Stamens as many as the divisions of the perianth : } \\ \text { 8tamens indefinite }\end{array}\right.$ 
$133\left\{\begin{array}{l}\text { Male flowers in globular heads in a terminal raceme. Females } \\ \text { axillary, joined two together in a large prickly burr, with } \\ \text { incurved points } \\ \text { Flowers, male and female, distinct, or in heads, not prickly . 134 }\end{array}\right.$ 134 Male perianth of 4 parts . . . . . . . . 135

Male perianth of 5 or 3 parts . CHenopodiacex (p. 370).

Leaves all radical, linear and fleshy, or transparent. Marsh

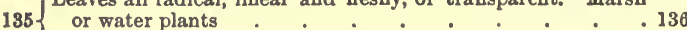

Stems leafy. Leaves flat . . . . URTICACEA (p. 398).

${ }_{136}\left\{\begin{array}{l}\text { Male flowers une or two on a stalk, with very long stamens. } \\ \text { Females sessile }\end{array}\right.$

Male and female flowers minute, mixed together in small

terminal head . . . . KriocauloN (p. 476).

137 Leaves opposite, simple . . . M ERcurialis (p. 395).

Leaves alternate, pinnate . . . . Poterium (p. 141).

Leaves alternate, with sheathing stipules. Stamens 6 . Nut

enclosed in the calyx . . . . RUMEx (p. 379).

Leaves small and fine, in tufts. Stamens 6 . Fruit a berry

138 Asparagus (p. 459).

Leaves small and heath-like. Stamens 3. Fruit a berry

EMPETRUM (p. 396).

Leaves radical, long, arrow-shaped. Stamens and carpels

(numerous. Aquatic plant . . . SAGITTARIA (p. 431).

139 Flowers all male (a male specimen). . . . . . 131

Flowers all female (a female specimen) . . . . 140

(Perianth 6-cleft, the 3 inner segments larger. Styles 3, with short fringed stigmas. Leaves alternate or radical.

RUMEX (p. 379).

140 Perianth 2- or 4-cleft. St ḩma single, sessile, tufted. Leaves opposite, stinging . . . . URTICA (p. 399).

Perianth 3-cleft. Styles 2, simpie. Leaves opposite, not stinging. . . . . . MRRCURIALIS (p. 395),

\section{Trees or Shrubs.}

Leaves opposite . • • • • • • . 142

Leaves alternate or in tufts . . . . . . . . . . . . . .

$142\{$ Leaves divided, lobed or angular, deciduous . . . 143

Leaves lobed or angular. Stamens about 8 . Fruit with two

143 diverging wings • : $: A C K R$ (p. 96).

Leaves pinnate. Stamens in pairs, collected in clusters. Fruit with one erect wing . . . FrAxnNus (p. 297).

Parasitical shrub with green dichotomous stems. Fruit a berry

144

Erect branching shrub with shining leaves. Fruit a few. seeded capsule . . . . . BuXus (p. 396).

Male flowers in catkins, separated by scales only. Females

145 solitary or in clusters, or in catkins, usually different from

the males i. . 146

Flowers hermaphrodite or diclinous, each with a distinct perianth 
(Leaves entire and mostly evergreen, needle-like, or narrow or scale-like. Anthers sessile on the catkin-scales.

Leaves flat, mostly toothed. Strmens distinct from the scales.

CONIFERA (p. 115).

AMENTACRA $(p, 402)$.

Flowers diceions. Male perianth of 2 or 6 scales . . 148

147 Flowers hermaphrodite or polygamous. Perianth regular, of 3 to 5 divisions

$148\{$ Erect shrub. Male perianth of 2 scales . HiPPOPHAE (p. 388).

Procumbent undershrub. Perianth of 6 scales EMPETRUN (p. 396).

Trees. Stamens opposite the lobes of the perianth. Fruit

149 thin, like a small leaf . . . . ULMUS (p. 401).

Evergreen climber. Fruit a berry . . . HedERA (p. 203).

Shrubs. Fruit a berry . . . . . 150

$150\left\{\begin{array}{l}\text { Flowers on the under side of the leaves . : Ruscus (p. 459). } \\ \text { Flowers on the stem or branches }\end{array}\right.$

$151\left\{\begin{array}{l}\text { Flowers very small, green and open. Stamens } 4 \text { or } 5 \text {, alternat- } \\ \text { ing with the lobes of the perianth. }\end{array}\right.$

Flowers with a conspicuons tube, often coloured. Stamens 8.

DAPHN (p. 387).

\section{Monocotyledone.}

Perianth, or at least the inner segments, colonred and looking

$152\left\{\begin{array}{l}\text { like a corolla, or, if green, soft and yellowish } \\ \text { Perianth green or brown, or reduced to mere scales, or none } \\ \text { at all }\end{array}\right.$

One or two anthers sessile on a central column or style. One

153 of the six divisions of the perianth different from the others.

Three or more distinct stamens 154

(Ovaries several, quite distinct, or, if cohering, each with a

154 distinct style " r stigma* . - . AlisMaces (p. 430).

Ovary single, 3-celled . . . . . . . . 155

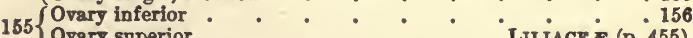

Ovary superior . . . . . LILIACE (p. 455).

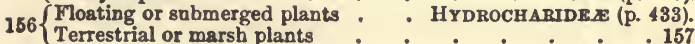

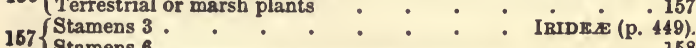

158 Climbing plant with alternate net-veined leaves TAMUs (p. 155 ).

Bulbons herbs . . . . AMARYLlidese (p. 452).

159 Floating or submerged plants . . . * . 86

Terrestrial plants, or, If aquatic, erect from the bottom of the water and projecting above it

$160\left\{\begin{array}{l}\text { Leaves in a single whorl of } 4 \text { or } 5 \text {, with netted veins. Perianth- } \\ \text { segments, and stamens, } 8 \text { or } 10 \\ \text { PARIS (p. }\end{array}\right.$

Leaves radical or alternate, linear or cylindrical, with parallel veins [reins netted in drum.] 
Perianth of 6 or 4 segments. Stamens as many or half as many 162 Flowers glumaceous, consisting of alternate chaffy scales, en-

161 closing the stamens and pistil in the same or separate scales 165

Stamens and pistils in dense heads or spikes, without distinct

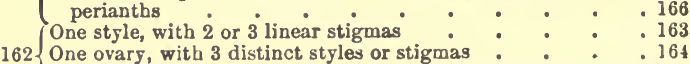

Three distinct ovaries . . . Scheuchzeria (p. 42y).

Flowers minute, unisexual, in a globular head ErIOCAULON (p. 176).

163 Flowers complete, distinct, or clustered, or panicled

$164\{$ Three short styles - . . . TUrLLLDIA (p. 468).

Three sessile stigmas . . TRIGLOCHIN (p. 430).

(Flowers with a single scale under each set of stamens and pistil.

Sheath of the leaves closed round the stem CyPERACE $(p .477$ ).

16: Flowers enclosed in 2 or more scales. Sheath of the leaves usually split open on the she opposite the blade - Aroidene (p. 420).

Fruit a dry nut. Leaves linear and sedge-like TYPHACEs (p. 118).

11. CRYPTOGAMS. (No Stamens or Pistil.)

(Plants with distinct roots and stems or rootstocks, with leaves

$1\left\{\begin{array}{l}\text { or green branches } \\ \text { Plants variously shaped, without distinct roots, stems, and }\end{array}\right.$ leaves, seldom green unless aquatic

Fructification in terminal spikes

Cellula Cryptogams (p. 547).

. $\cdot$. 3

Fructification radical or in the axils of small leaves . . . 4

2\{

Fructification on the whorled leaves. Aquatic plant Filicks (p. 554)

Stems leafless, jointed, simple, or with whorled branches

EQUisetuM (p. 551).

Stems bearing numerous small leaves. Spores of one kind

3 LYcopodiuM (p. 547),

Stems bearing numerous small leaves. Spores of two kinds

Stem bearing a simple or branched leaf below the spike

Selaginelia (p. 549). Filices (p. 554).

4 Spore-cases sessile • • • • • • • • • 5

Spore-cases stalked : $: \quad \div \quad \div \quad 0$

(Spore-cases small, in the axils of small leaves or bracts

LYCOPODIUM (p. 547).

Spore-cases in the enlarged base of linear submerged leaves

ISOETES ( $\mathrm{p}$. 542)

Spore-cases (or involucres) globular on the rootstock at tho base of linear leaf-like fronds

Pilularia (p. 550

(Spore-cases globular or urn-shaped, opening with a lid 


\section{ARRANGEMENT OF THE NATURAL ORDERS IN, THE PRESENT WORK.}

The very unequal manner in which the several Natural Orders are represented in the British Isles renders it impossible, in a work confined to British Plants, to give any fair idea of the subclasses into which these Orders have been grouped, or of the principles which have guided the authors of the linear arrangement the most generally followed. The following recapitulation is therefore merely intended as a sort of table of contents, showing the order in which the families follow each other in the present work; at the same time that the attention is called to one or two of the most striking, tce most important, or the easiest observed features of each one. These characters are, however, general, not always without exception, and sometimes specially applicable to British genera only.

\section{CLASS I. -DICOTYLEDONS.}

In the germination of the seed che plumula arises between two (rarely more) lobes or cotyledons of the embryo, or from a terminal notch. ['The vascular tissue of the stem forms a ring or rings between the bark and pith. The nerves of the leaf are branched and netted (see also Arum, Tamus and Paris in Monocotyledons). The parts of the flower are usually in fours or fives.]

Subclass 1. Thalamiflorde.-Petals distinct from the calyx, and from each other, seldom wanting. Stamens usually hypogynous, or nearly so. [Exceptions. - The calyx or corolla is absent in some Rannn. culaceæ, Cruciferæ, Violaccæ, Caryophyllaceæ. The petals cohere more or less in some Fumariaceæ, Polygalaceæ, Portulaceæ, Tamariscineæ, Malvaceæ. The stamens are epigynous or perigsnous in Nfmphacere and some Caryophyllaceæ.]

\section{- Ovary apocarpous.}

I. Ranunculaceæ. Petals definite. Stamens indefinite.

II. Berberidex. Perianth and stamens in twos or threes, or their multiples. Anthers opening by recurved valves.

11I. Nymphracer. Aquatio plants with indefinite petals and stamens, the inner petals passing gradually into the outer stamens.

-* Ovary syncarpous. Placentas parietal (except in Polygalaceæ).

IV. Papaveraces. Perianth regular, in twos or fours. Stamens indefinite.

V. Fumariaceæ. Perianth very irregular, in twos or fours. Stamens 6 , in two sets.

VI. Cruciferæ. Sepals and petals 4 each. Stamens 6, of which 2 shorter.

VII. Resedacex. Petals small, unequal, some divided. Stamens few but indefinite. Capsule open at the top before it is ripe.

VIII. Cistacer. Sepals 3, equal, or with additional small ones. Petals 5 , regular. Stamens indefinite.

IX. Violacea. Stamens 5 ; the anthers on the inner face of very short broad filaments, nsually united in a ring. Capsule 3-valved. 
X. Polygalacer. Perianth very irregular. Stamens 8, In two parceis, petals united with them. Capsule 2-celled.

XI. Frankeniacer. As in Caryophyllaces, except the parietal pla. centis.

\section{**" Ovary syncarpous. Placentas axile.}

XII. Caryophyllacex. Leaves opposite, entire. Flowers regular. Btamens definite. Capsule 1-celled, with a free central placenta.

XIII. Portulaceæ. As in Caryophyllaceæ, but only 2 sepals and 5 or more petals.

XIV. Tamariscineæ. Shrubs with alternate green scale-like leaves. Flowers regular. Capsule 1-celled. Seeds with a tuft of wool.

XV. Elatinaceæ. As in the Pink family, but the capsule divided into cells.

XVI. Hy pericineæ. Leaves opposite. Flowers regular. Sepals im. bricate. Flowers indefinite, in 3 or 5 clusters or bundles.

XVII. Linaceæ. Leaves entire. Petals convolnte, distínct. Stamens definite. Capsule separating into carpels without leaving a central axis.

XVIII. Malvacex. Sepals valvate. Petals convolute, adhering at the base to the staminal tube. Stamens indefinite, monadelphus, with 1-celled anthers.

XIX. Tiliacez. Trees, Sepals valvate. Petals free. Stamens indefinite.

XX. Geraniaceæ. Petals convolute or very irregular. Stamens definite. Capsule with several cells and lobes round a persistent central axis.

XXI. Aceraceæ (genus or tribe of Sapindacca). Trees. Leaves opposite. Stamens definite, but seldom isomerous. Fruit separating into 2 (rarely 3 ) winged nuts.

Subclass 2. CALYCIFLORJE.-Petals usually distinct, and stamens perigynous or epigynous. [Exccptions.-The petals are absent in some Rosacex, Onagraceæ, Lytharieæ, Saxifragaceæ, Halorageæ, and Loranthaceæ. The petals cohere more or less in some Aquifoliacen, $\mathrm{Cu}$ curbitacex and Crassulacer. The stamens are hypogynous in some Saxifragaceæ, in Droseraceæ, and are epipetalons in some Crassulaceæ.]

- Stamens and petals mostly perigynous (except in the Crassulacea, Cucurbitacea, and Ribcriacece families).

XXII. Aquifoliacex. Shrubs or trees with small flowers. Petals shortly united at the base. Stamens alternating with them. No disk. Ovary syncarpous, free.

XXIII. Celastraceæ. Shrubs or trees, with small regular green flowers. Stamens alternating with the petals, on a disk lining the base of the calyx.

XXIV. Rhamnaces. As in Celastracer, but the stamens are opposite the small concave or scale-like petals.

XXV. Papilionaceæ (a tribe of Leguminosæ). Flowers very irregular, papilionaceous. Stamens 10, all, or 9 of them, combined. Ovary of one carpel.

XXil. Rusacen. Flowers regular. Stamens indefiuite. Ovary (at least when young) apocarpous. 
XXVII. Onagracese. Perianth in twos or t,..... Stamens definite. Ovary inferior. One style.

XXVIII. Lythariez. Stamens usually definite, inserted with the petals at the top of the calyx-tube. Ovary syncarpons within the base of the tube One style. Lower leaves opposite.

XXIX. Cuburbitacez. Climbers with tendrils. Flowers unisexual. Ovary inferior.

XXX. Crassulacer. Leaves succulent. Sepals, petals, stamens of one or two rows, and free carpels, all isomerous.

XXXI. Ribesiacez. Shrubs. Flowers regular. Stamens definite. Ovary inferior. Placentas parietal. One style.

XXXII. Saxifragaceæ. Flowers regular. Stamens definite. Ovary syncarpous at the base, bnt a separate style for each carpel.

XXXIII. Droseraces. Herbs with radical leaves covered with long glandular hairs. Flowers regular. Stamens definite. Placentas parietal. Styles distinct.

XXXIV. Halorager. Aquatio herbs with very small flowers. Calyx. lobes and petals 4, 2, or none. Stamens definite. Ovary inferior. Stรles or stigmas distinct.

\section{- Petals and stamens epigynous (round an epigynous disk).}

XXXV. Umbellifers. Leaves alternate. Fruit dry, separating from the axis into seed-like carpels.

XXXVI. Araliaces. Leaves alternate. Frnit succulent. Carpels often more than 2 , and not separating.

XXXVII. Loranthaceæ. Parasites. Stamens on, or opposite to the petals. Leaves usually opposite. Ovary 1-celled.

XXXVIII. Cornaces. Leaves nsually opposite. Stamens alternate with the petals. Style one.

Subclass 3. MONOPETALE.-Petals united (at least at the base) into a single corolla. [The petals are absent in some Primulaceæ and Oleaceæ, and are free in some Ericace» and Plumbagineæ.]

\section{\$1. Corolla epigynous, bearing the stamens.}

XXXIX. Caprifoliacea. Leaves opposite. No stipules. Ovary 2. or more-celled.

XL. Stellatæ (a tribe of Rubiaceæ). Stipules like the leaves in appearance, and forming whorls with them round the stem. Ovary 2-celled, with 1 seed in each cell.

XLI. Valerianex. Stamens fewer than the lobes of the corolla. Ovary and fruit l-seeded.

XIII. Dipsaceæ. Florets in compact beads or spikes. Stamens isomerous. Anthers free. Ovary and fruit 1-seeded.

XLIII. Composite. Florets in compact heads. Stamens isomerons. Anthers united in a ring round the style. Ovary and fruit 1-seeded.

\section{Stamens free from the corolla.}

XLIV. Campanulaces. Herbs. Stamens as many as the corolla. lobes. Anthers opening longitudinally.

XLV. Ericacese. Shrubs. Stamens usually twice as many an the corolla-lobes. Anthers opening in pores or cross-valves. 
83. Corolla hypogynous, bearing the stamena.

* Placenta free central.

XLVI. Primulaceæ. Stamens isomerous and opposite the corollalobes.

XLVII. Lentibulaceæ. Corolla very irregular. Stamens fewer than the lobes, and alternate with them.

* Placentas porietal, or in the axial angle of the cells.

a. Corolla regular, or nearly so.

XLVIII. Oleaceæ. Trees or sbrubs. Stamens 2, alternating with the 2 ovary-cells, and having no constant relation to the corolla.lobes.

XLIX. Apocynaceæ. Corolla contorted. Stamens isomerons. Ovary of 2 carpels, usually distinct, whilst the styles are nnited at the top.

L. Gentianacex. Bitter plants. Corolla contorted. Stamens isomerous. Placentas parietal, rarely meeting in the axis.

LI. Polemoniaceæ. Corolla contorted. Stamens isomerous. Ovary 3-celled, with several seeds.

LII. Convolvulacex. Corolla plaited. Stamens isomerous. Ovary 2 - or 3-celled, with 2 ( rarely 1) ovules in each, often separated by an additional false partition.

LIII. Boragineæ. Stamens isomerous. Ovary 2- or 4-lobed, with one ovule in each lobe.

LIV. Solanacer. Stamens isomerous. Corolla plaited or imbricate. Ovary 2-celled, with several ovules in each cell.

\section{B. Corolla irregular. Stamens 1 less or 3 less than the lobes.}

LV. Orobanchaceæ. Leafless parasites. Placentas parietal, or rarely meeting in the axis.

LVI. Scrophularineæ. Ovary 2-celled, with several cvules in each cell.

LVII. Labiatæ. Ovary 4-lobed, with 1 ovule in each lobe.

LVIII. Verbenaceæ. Ovary entire, 2- or 4-celled, with I ovule in each cell.

\section{*** Anomalous familics.}

LIX. Plumbaginex. Ovary with 1 cell and ovule, but several styles. LX. Plantagineæ. Corolla scarious. Stamens isomerous.

Subclass 4. MONOCHLAMYD乎.-Perianth really or apparently simple or none. [Exceptions.-Petals are present in some Illecebraceæ.

LXI. Illecebraceæ. Perianth small, rarely double. Orary with 1 cell and ovule, but 2 or 3 styles or stigmas. Leaves usually opposite, with scarious stipules.

LX1I. Chenopodiacer. Perianth small; stamens opposite to its lobes. Ovary with 1 cell and ovule, but 2 or more styles or stigmas. No stipnles.

LXIII. Polygonacex. Perianth small. Ovary with I cell and ovule, but 2 or more styles or stigmas. Stipules sheathing.

LXIV. Thymeleacex. Stamens inserted in the tube of the perianth, and usually double the number of its lobes. Ovary free, with I pendulons ovule. One style. 
LXV. Elreagnacex. Shrubs or trees, with scurfy leaves. Flowers mostly unisexual. Ovary free in the bottom of the perianth-tube, with 1 erect ovule.

LXVI. Santalacex. Perianth-lobes valvate. Ovary inferior, 1-celled, with 2 or 4 pendulous ovules. Spike simple.

LXVII. Aristolochiaceæ. Perianth irregular, or 3-lobed, Stamens 6 or 12. Ovary inferior, 3- or 6-celled, with numerous ovules.

LXVIII. Euphorbiaceæ. Flower unisexual. Fruit separating into $\mathbf{3}$ (rarely 2 or more) carpels, leaving a persistent axis, each carpel conaining 1 or 2 pendulous seeds.

LXIX. Empetraceæ. Differs from Euphorbiacer in the ovnles and seeds erect.

LXX. Ceratophyllum and Callitriche. Anomalous aquatic genera. Perianth none. Ovary with 1 or 4 cells, and 1 seed in each.

LXXI. Utricacex. Flowers unisexual, smalı and green. Stamens opposite the perianth-divisions (usnally 4). Ovary free, with a single ovule, and 2 (rarely 1 ) styles or stigmas.

LXXII. Ulmaceæ. Trees. Flowers often bisexual, the stamens opposite the lobes. Ovary free, 2-celled, with 1 erect ovule in each cell.

LXXIII. Amentacere. Trees or shrubs. Flowers unisexual, the males in catkins with an imperfect perianth, or none at all. Fruit of the females 1-celled.

LXXIV. Coniferæ. Trees or shrubs with stiff or scale-like leaves. Flowers unisexual, the males in catkins without perianth. Ovules and seeds in the females not enclosed in any ovary or pericarp.

CLABS II. - MONOCOTYLEDONS.

In germination the plumule is developed from a sheath-like cavity on one side of the embryo. [The vascular tissue of the stem occurs in scattered bundles amongst the cellular. The nerves of the leaves are more or less parallel (except in Aroideæ, Dioscorideæ, Paris, and in 8ome Liliaceæ). The parts of the flower are usually in twos or threes.]

\section{- Perianth none, or of 4 small sepals or bracts.}

LXXV. Typhaceæ. Flowers nnisexual, intermixed with bracts in dense heads or spikes. Fruit a dry nut.

LXXVI. Aroidex. Flowers nnisexual, often intermixed with bracts in dense heads or spikes, mostly in a spatha. Fruits usually succulent,

LXXVII. Lemnaceæ. No distinct stem. Flowers (very scarce) on the edge of the small leaf-like floating fronds.

LXXVIII. Naiadeæ. Floating or submerged plants. Flowers distinct or in loose spikes. Stamens 1, 2, or 4. Ovaries 1, 2, or 4.

** Perianth wholly or partially petal-like. Ovary apocarpous.

LXXIX. Alismacex; the only British family of the group.

** Perianth wholly or partially petal-like. Ovary inferior.

LXXX. Hydrocharidex. Floating or submerged plants, Flowers usually unisexual. Perianth regular, with a slender tube.

LXXXI. Orchidaceæ. Perianth very irregular. Anther 2-celled, combined with the style in an axile column.

LXXXII. Iridex. Like the Amaryllis family, but stamens 3 Leaver oftep in two opposite rows, 
LXXXIII. Amaryllidex. Terrestial plants. Perianth of 6 divisions Stamens 6.

LXXXIV. Dioscorideæ. Twining plants. Flowers unisexual. Perianth regular, of 6 divisions.

"... Perianth regular. Ovary synearpous, superior.

LXXXV. Liliaces. Perianth petal-like.

LXXXVI. Juncaces. Perianth stiff, or calyx-like. Capsule 3-celled, with several seeds, or 1 erect seed in each cell.

LXXXVII. Restiaceæ. Perianth calyx-like. Flowers nnisexnal. Ovary with I pendulous ovule in each cell.

"**** Perianth rudimcntary or none, replaced by chaffy scales or bracts enclosing the fluwers.

LXXXVIII. Cyperaces. Leaf-sheafs entire. Each flower in the axil of one bract.

LXXXIX. Graminex. Leaf-sheaths split open opposite the blade. Each flower enclosed in two bracts.

\section{CLASS III. - VASCULAR CRYPTOGAMS.}

No true flowers ; that is, no stamens or pistils.

XC. Lycopodiacez. Spores of one form only, in closed capsules, in the axils of the leaves, or of the bracts of a terminal spike, or in the base of the leaves.

XCI. Selaginellaceæ. Spores of two forms, in closed capsules in the axils of the leaves, or of the bracts of a spike.

XCII. Marsileacez. Spores in minute cases enclosed in globular or ovoid utricles (or involucres) placed on the rootstock.

XCIII. Equisetaceæ. Stems jointed, with whorled branches. Spores under peltate scales, in terminal heads or spikes.

XCIV. Filices. Spores in minute cases clustered on the back or margin of the fronds.

The remaining famllies of British Cryptogams [called cellular, from having no vascular tissue (see p. xlii, par. 186)] are not included in the present Flora. [They are the Charas, Mosses, Liverworts, Hepatica, Fung, Lichens, and Alga.] 


\section{Class I. DICOTyLedons.}

STEM, when perennial, consisting of a pith in the centre, of one or more concentric circles containing fibrous tissue, and of the bark on the outside. Seeds with two cotyledons, the young stem in germination proceeding from between the two lobes of the embryo, or from a notch in its summit.

The above characters are all that can be said to be constant to separate Dicotyledons from Monocotyledons. They are, however, in most cases very difficult to observe, and yet the distinction is essential, for these two great classes have each their peculiar aspect, which, after a very little habit, the botanist will in most cases recognise at a glance. All British trees and shrubs are Dicotyledons, so also are all plants with opposite, or whorled, or netted-veined leaves (except Paris and a few aquatic plants), and almost all those which have the parts of the flower in fours, fives, or eights. [For other characters see p. lxxv.]

\section{RANUNCULACEE. THE RANUNCULUS FAMILY.}

Herbs with alternate or radical leaves, or, in one genus, climbers with opposite leaves, the leafstalk generally dilated at the base without stipules, the leaf often cut, and the flowers solitary or in terminal racemes or panicles. Sepals distinct, more than 2 (usually 5). Petals distinct, usually 5 , but sometimes deformed, or very minute, or wanting. Stamens indefinite, usually numerous, inserted on the receptacle. Carpels several, distinct or partially united (very rarely solitary), each enclosing a single cell, with 1 or more ovules or seeds attached to the base or to the inner angle of the cavity. Seed containing a copious albumen, with a minute embryo.

Althongh, from the variable nature of the flowers, especially of the petals, the above characters may be somewhat vague, yet the great majority of Ranunculacee are easily distinguished by their numerous, free, hypogynous stamens, and by their distinct carpels. Where, as in Myosurus, the stamens are few, the carpels are numerous; and, on the other hand, if in Actcea and some Delphinia the carpels are solitary, they are unilateral, with the ovules attached to one side or angle of their single cell, showing that they are simple, not composed of the nnion of several, as is the case with the central ovaries of Papaveraceex and Cistacea, which have either several cells or several rows of ovules. Another very distant Order, which may at first sight be confounded 
with the present one, is that of Alismacea, among Monocotyledons ; but besides the microscopical character derived from the embryo, there are but three petals and sepals, as in most other Monocotyledons, a rare circumstance in Ranunculacece.

Ranunculacece are widely diffused over the globe, but more especially in temperate or cool climates. Within the tropics they are, with the exception of Clematis, almost confined to high mountain-ranges. Most of the principal genera are represented in our Flora.

Climber with opposite leaves. Carpels 1-seeded. Sepals coloured Herbs with alternate or radical leaves, rarely opposite on runners.

Carpels several or numerous, one-sceded. Flowers always regular.

Sepals 4, 5, or more, often coloured and petal-like, but no rcal petals.

An involucre of 3 leaves outside the flower or on the stalk .

No involucre. Floral leaves alternate. Stamens longer than

the sepals
Petals 5 or more, usually more consplcuous than the sepals.
Carpels very numerous, in a long, cylindrical column.

Petals very small, with a tubular claw
Carpels in a globose or oblong head. Petals flat.

Yetals (usually yellow or white) wlth a little scale, or a thlckened hollow spot at the base of each

Petals (usually red) without any scale or thickened spot at the base

Carpels several, each with several seeds.

Flowers very irregular or spurred.

Upper sepal helmet-shaped, withont a spur . . . . 12. AcoNiTum.

Upper sepal with a long spur at the base

Sepals flat and regular. Petals with a ppur at the base of each 10 . AQUILEGIA.

Flowers regular.

Sepals large, often coloured. Petals small or none.

Sepals bright yellow and petal-like. Real petals none

Bepals pale yellow and petal-like. Petals small, flat, and linear

Bepals greenish. Petals smail and tubular : $\dot{*}^{-}$:

Sepals green, smaller than the large red or wlite petals 9 . HrLLEBoros

Carpels solitary, with several seeds.

Frult s capsule. Flowers spurred

Fruit a berry. Flowers nearly regular, small : $:$ : $^{-}$13. ACTAA.

Among old inbabitants of our gardens, which have spread spon. taneonsly, are the exotic genera Eranthis (Winter Aconite) and Isopyrum, both closely allied to Helleborus; and Nigella (Devil-in-the-bush), which differs from Helleborus in the more petal-like sepals, and the carpels connected together in the middle, but diverging at the top into 5 long points.

\section{Clematis. Clematis.}

Stem usually climbing, and often woody at the base. Leaves opposite. Sepals 4 or 5 , valvate in the bud, coloured and petal-like. No real petals. Stamens numerous. Carpels numerous, 1-seeded.

A numerous genus, well characterised, widely spread over the globe, and almost the only representative of the Order in tropical climates. Beveral exotic species are among the hardy climbers cultivated in our gardens.

1. C. Vitalba, Linn. (fig. 1"). Traveller's Joy, Old Man's Beard.-

- These flgures refer to the companion vol., "I!ustrations of the British Flora," by ntch and smith. 
A larger climber, its woody stems attaining even the thickness of the wrist and a length of several yards, whilst the young branches spread to a great extent over shrubs, clinging by their twisted petioles. Leaves pinnate, usually with 5 ovate stalked segments. Flowers greenish-white, in loose panicles at the ends of short axillary or terminal branches. Carpels, when ripe, very conspicuous from the persistent styles, which grow out into long feathery awns.

In hedges, thickets, and open woods in central and southern Europe to the Caucasus. Abundant in several of the southern and some of the central counties of England, and naturalised in Ireland. Fl. summer.

\section{THALICTROM. THALICTRUM.}

Herbs with a short perennial rootstock, annual, erect stems, and much divided leafstalks, bearing distinct segments or leaflets. Sepals 4 or 5, small, coloured, and petal-like, but no real petals. Stamens numerous, with long anthers projecting beyond the calyx. Carpels several, 1-seeded, furrowed, and usually acute at both ends.

A considerable genus generally diffused over the northern hemisphere, distinguished from Actcea by the distinct 1-seeded carpels, from all others of the Order by the thin texture of the sepals, the large anthers, and peculiar foliage. The species are very variable and difficult to characterise. They have also been much multiplied by modern botanists, but if the British forms be limited to three species, their characters are more striking.

Stem simple, seldom 6 Inches high _ . . . . . . 1. T. alpinum.

Stem 1 or more feet high.

Leaflets roundish; panicle diffuse; flowers mostly drooping . 2. $T$. minus.

Leaflets obovate or wedge-shaped; panicle compact; flowers mostly erect.

3. T. flavum

Some foreign European species are to be met with in old gardens, especially the tall handsome $T$. aquilegifolium.

1. T. alpinum, Linn. (fig. 2). Alpine T.-Stem usually simple and almost leafless, from 4 to 6 inches high. Leaves mostly radical, about half the height of the stem, with the footstalk twice divided into 3 or 5 branches; leaflets small, roundish, and crenate or lobed. Panicle nearly reduced to a simple raceme. Flowers few and drooping, each with 4 small sepals. Stamens from 10 to 20. Carpels generally reduced to 2 or 3. Pedicel of the fruit recurved, as well as that of the flower.

An alpine plant, native of the mountains of northern Europe and Asia, and at greater elevations in the mountains of central and southern Europe, Asia, and North America. Abundant in the Highlands of Scotland; very rare in Ireland, local in northern England and North Wales. Fl. summer.

2. T. minus, Linn. (fig. 3). Lesser T.-A very variable species; in dry limestone soils often only a foot high, of a glaucous bue, or slightly downy; in moist, rich situations (where, however, it is seldom found) it is much larger and greener, but readily distinguished from $T$. flavum by its loose panicle occupying a great part of its height; the pedicel also is as long or longer than the flower, and recurved in bud, although it becomes erect as the fruit ripens. Stem usually in zigzag, making a bend at everv node. Petioles, especially of the lower and rootleaves, 
thres or four times divided, with very numerous small leaflets roundish or broadly wedge-shaped, trifid and toothed. Flowers usually of a pale greenish-yellow, with a pink tinge on the sepals. Stamens numerous, with long narrow anthers. Carpels from 3 to 5 or 6 , very acute and strongly furrowed.

In dry situations, chiefly in limestone countries, throughont Europ,e and Russian Asia, except the extreme north. Scattered over Britain and Ireland, but not common. Fl. summer. Several varieties have keen described as species, and three or four of these are British, but their characters are vague and nncertain.

[The two most marked forms are minus proper, which is 6 to 18 in. high, often glaucous and glandular, with the stem naked below; and 1'. majus, Sm., with a stem 2 to 4 feet higl, more leafy below, and larger leaflets. The latter is most common in the north.]

3. T. flavum, Linn. (fig. 4). Ycllow T., Meadow Rue.-The largest British species, being generally 2 to 3 feet high, and deeper green than the last. Stem stout, furrowed. Leaves large, petiole twice or thrice divided, the leaflets much fewer than in $T$. minus, but larger, often an inch long, obovate or wedge-shaped at the base. Panicle compact, rather corymboso. Pedicels short and ereet even before the flower expands. Flowers, especially the stamens, decidedly yellow.

In moist meadows, and along ditches, in Europe and North Asia, scarcely extending so far north as T'. minus. Found in England, Ireland, and southern Scotland, but not very common. Fl. summer. Here, again, some botanists distinguish several species by size, colour, and pubescence, and according as the rootstock is more or less creeping, or whether sessile leaflets resenbling stipules are or not formed at the base of the branches of the petiole.

\section{ANEMONE. ANEMCiNR.}

Rootstock perennial. Leaves radical. Flower-stem naked, excepting an involucre of three leaves usually at a considerable distance from the flowers. Sepals 5 or more, frequently 6 , coloured and petal-like, longer than the stamens. No petals. Stamens numerous. Carpels numerous, 1-seeded, pointed or ending in a long feathery awn.

A large genus, found in almost all temperate regions of the globe, chiefly characterised by the 3 leaves placed in a whorl, from halfway up the flowering stem to very near the flowers. When much divider, these leaves may appear more numerous, but they always form a single whorl, and are always united at the base into three.

Flowers purple, silky outside. Carpels ending in feathery awns 1. A. Pulsatilla Flowers white or pink, glabrous. Carpels ending in a point . 2 . nemorosa

Several Continental species are cultivated in our gardens, especially A. pratcnsis, and the Hepatica (A. Hepatica), in which the involucre is so close to the flower as to resemble a calyx. 'Two South European species, the blue-flowered A. apennina and the jellow-flowered $A$. ranunculoidcs, both with the habit and carpels of $A$. nemorosa, have been established in plantations, and are bence included in some British Floras.

1. A. Pulsatilla, Linn. (fig. 5). Pasque-flower.-Rootstock thick aul moody. liadical leaves on long stalks, covered when young with lisj hairs, and two or tinree timse divided into iong, linear segments. 
Flowerstalk 5 to 8 inches bigh, with the involucre at first near the flower, but becoming more remote as the fruit ripens, its 3 sessile leaves deeply cut into linear segments. Flower solitary, large, with 6 sepals of a dull violet-purple, very silky outside. Awns of the carpels long and feathery, like those of a Clematis.

In open limestone pastures, in the greater part of Europe and Russian Asia, but not very far northwards. Occurs in several parts of England, but not in Wales, Scotland, or Ireland. Fl. spring.

2. A. nemorosa, Linn. (fig. 6). Wood A.-Rootstock black and horizontal, emitting from its extremity 2 or 3 leaves and a single flowerstalk, all glabrous or but slightly downy. Leafstalks long, with 3 ovate or lanceolate leaflets, toothed or lobed, or often divided al. most to the base into 3 similarly shaped segments. Peduncle 3 to 6 or 8 inches high, the involucral leaves at about two-thirds of its height, like the radical ones, bnt smaller, with shorter stalks. Sepals 6 , white bluish or reddish outside, and perfectly glabrous. Carpels downy, with a point nearly as long as themselves, but not feathery.

Common in and near woods, throughout Europe and North-west Asia and North America. Abundant in Bitaln. Fl. early spring.

\section{ADONIS. ADONIS.}

Annual, or, in foreign species, perennial herbs. Leares divided. Flowers red cr straw-coloured. Sepals 5. Petals 5 or more; sometimes more deeply coloured at the base, but without the nectary of Ranunculus. Stamens usually numerous. Carpels numerons, withont awns, in a globular or oblong head each containing a single pendulous ovule.

The species are few, chiefly from southern Europe and western Asia.

1. A autumnalis, Linn. (fig. 7). Pheasant's Eye. -An erect annual, from 8 to 12 inches, or more, glabrous or slightly downy. Leaves finely divided into numerous narrow linear segments. Sepals green or slightly coloured. Petals 5 to 8 , rather longer than the calyx, of a bright scarlet, with a dark spot at the base. Carpels numerous, and rather large, arranged in a head at first ovate or oblong, but which often lengthens and becomes cylindrical.

In cornfields, in central and southern Europe and western Asia. Not very common in Britain, but appears occasionally, especially in the warmer counties of England and Ireland, and sometimes in Scotlanil. Fl. summer and early autumn. A variety with larger flowers was formerly much cultivated in flower-gardens under the name of Flos Adonis.

\section{MYOSURUS, MOUSETAIL.}

Annuals with entire leaves. Sepals 5. Petals 5, small, linear, with tubular claws. Stamens few. Carpels small, 1-seeded, very numerous, arranged in a long and dense cylindrical spike. Ovule attached near the top of the cell.

A genus containing one European and one western America species chiefly distinguished from the small-flowered Ranunculuses by the tubular claw of the petals, by the attachment of the ovule.

1. 3i. minimus, Linn. (fig. 8). Common Mousetail.-A small annual with linear radical leaves, 1 to 3 inches, including their long footstalk 
Peduncles also radical, rather longer than the leaves, often enlarged and hollow at the top, with a single small yellowish flower. Sepals prolonged below their insertion into a kind of spur. Petals rarely longer than the calyx, and very narrow. Carpels very numerous, forming a head which lengthens into a close slender spike, 1 or even 2 inches in length.

In moist sandy or gravelly fields and waste places, in Europe, Russian Asia, naturalised in America and Australia. Most common in the south and south-east of England; not found in Scotland or Ireland. $\mathcal{~}$. spring.

\section{RANUNCULUS. RANUNCULUS.}

Annnal or perennial herbs, sometimes entirely aquatic. Leaves entire, or more or less divided. Flowers usually yellow or white. Sepals 5, very rarely reduced to 3 . Petals 5 , or sometimes more, each with a thickened hollow spot (nectary) at the base, often covered by a minute scale. Stamens usually numerous. Carpels numerous, without awns, in a globular or oblong head, each containing a single ovule attached near its base.

A numerous genus widely spread over the temperate regions of the globe, and even found under the tropics. It is easily distinguished from Anemone by the want of the involucre. The so-called nectary at the base of the petals, which separates it from Adonis, is sometimes reduced to a slightly discoloured, concave spot. In the small-flowered species one or more of the petals are often wanting, and the stamens reduced to very few.

Flowers white. Carpels transversely wrinkled. Plants float ing ln water or creepiug in mud. (Batrachium.)

Lower leaves or all the leaves finely cut. Receptacle

All the leaves rounded with broad lobes. Receptacle glabrous ${ }^{\circ}$ Carpels smooth or tuberculate. Plant Flower's yellow. Carpels sm
terrestrial or not floating.

Leaves all undivided

J'etals 5 or fewer.

Carpels with a stout beak. Stem erect, 2 feet or more. Flowers large $\dot{0}$. 'Stems geldom alrove a

Carpels with a short point. Stems seldom alove a
foot, often decumbent. Flowers little more that half an inch in diameter or smaller.

P'etals much longer than the calyx .

Petals very small .

Petals more than 5 , usually 8 or 9

Leaver divided or deeply cut.

Carpels smooth or slightly tuberculate near the edge. Rootstock (In all but 7 and 13) peremnial.

Leaves glabrous or very slightly downy.

l'etals very small. Carpels amall, uumerous, In an ovate or oblong head

Petals consplcuons, bright jellow. Carpels downy, in a globular head.

1. $R$. aquatilis.

2. $\boldsymbol{R}$. hederacens.

\section{R. Lingua.}

4. R. Flammula.

6. R. ophioglossifolius

6. R. Ficaria.

Leaves hairy.

Calyx spreadlng, but not reflected.

Stems erect without runners. Lower leaves palm. ately divided. Carpels in a globular head

Runners creeplng and rooting. Central division of the lower leaves projectiog beyond the others

7. R. sceleratus.

8. $R$. auricomus.

\section{R. acris.}

10. $R$ rewors 
Thickenedl base of the stem bulb-like. Leaves radical. Carpels numerous in an oblong or cylindrical head

Calyx closely reflected on the peduncle.

Kootstock or thickened base of the stem perennial. Carpels perfectly smooth within the margin . . . . 13. R. hirsutue.

Carpels covered with tubercles or prickles. Annnals.

Leaves bairy, segments broad. Carpels tuberculate.

Stems weak
Leaves glabrous, segments narrow. 'Carpels very

11. $R$. charophyllas.

prickly. Plant erect

14. $R$. parviflorus.

15. $R$. arvensis.

The showy double Ranunculus of our gardens belongs to a Levant species (R. asiaticus). Donble-flowered varieties of several others, especially of our common yellow Buttercups, and of the white-flowered Continental $R$. aconitifolius, are known as Bachelor's Buttons.

1. R. aquatilis, Linn. (fig. 9). Water R.-A most variable species, but easily known by its stem either floating in water, or creeping along mud, by its white flowers, and very small ovoid carpels marked with transverse wrinkles. It is glabrous in all its parts excepting sometimes the carpels and their receptacle. The lower leaves and sometimes all, if submerged, are divided into numerous very fine linear segments, whilst those which float are rounded and more or less cut into 3 or 6 wedge-shaped, obovate, or rounded lobes. Flowerstalks axillary and 1-flowered. Petals 5 or sometimes more, withont any scale over the spot at their base.

In ponds, streams, and fresh and brackish ditches thronghont all temperate regions. Abundant in Britain. Fl. the whole season. Many of the forms it assumes are striking, and have been distinguished as species, but the characters, although often to a certain degree permanent, are at times so inconstant, and so depend on the situation the plant grows in, that I can only consider them as varieties. Twelve of them are admitted by Babington as species, of which the following are the most prominent.

a. fluitans ( $R$. fluitans, Lam.). All the leaves submerged and finely cut, the segments long and parallel. Flowers large, on long stalks.Chiefly in running streams.

b. circinatus ( $R$. circinatus, Sibth.). All the leaves submerged and finely cut, but with shorter segments spreading in a perfect circle. Flowers large. - Chiefly in deep still waters.

c. vulgaris. Lower leaves submerged and finely cut; npper leaves floating, rounded and broadly lobed. Flowers very variable in size.The commonest state of the plant.

2. R. hederaceus, Linn. (fig. 10). Ivy R.-Very closely allied to $R$. aquatilis, and probably a variety of that species; but as in our own country, at least, it is very constant, I here admit it in deference to the opinion of others. It never appears to produce the finely cut leaves of $R$ aquatilis, but, creeping on mud or floating in shallow water, it roots at every joint, bearing angular and broadly lobed leaves like the npper ones of $R$. aquatilis; the flowers are usually very small, the petals scarcely exceeding the sepals, and the carpels and receptacles are quite glabrous.

Chiefly in wet ditches in western and northern Kurope, common in 
Britain. R. cenosus is a floating variety with much larger flowers, rare in Britain, but more common in western Europe, where forms occur also connecting $R$. hederaceus with $R$. aquatilis. $R$. tripartitus is a form with 3-lobed or partite leaves and longer narrow 3-nerved petals [and Lenormand $i$ is another with reniform or orbicular leaves and longer 5 nerved petals].

3. R. Lingua, Linn. (fig. 11). Great Spearwort.-Rootstock emitting a dense mass of fibrous roots, and perenuial by means of creeping runners. Stems erect, stout, and hollow, 2 or 3 feet high, the lower nodes emitting whorls of fibrous roots. Leaves long, lanceolate, entire or with a few small teetb, glabrous, with a few nearly parallel veins. Flowers above an inch in diameter, in a kind of loose panicle, bright shining yellow. Carpels ending in a short broad flat beak.

In marshes, wet ditches, and edges of lakes, in Europe and temperate Asia, but not Arctic. Found, but not common, in England, Ireland, and Scotland, as far north as Moray. Fl. summer.

4. R. Flammula, Linn. (fig. 12). Lesser Spearwort.-A glabrous annual, or a perennial, much smaller and more slender than $R$. Lingui. Stems usually rooting and decumbent at the base, seldom above a fou high, with a few loose branches. Lowest leaves often ovate, the remainder lanceciste or linear, and all entire or slightly toothech Flowers yellow, on long peduncles, seldom more than half an inch in diameter, and often much smaller. Carpels in a small globular head each with a very short, usually hooked beak.

In marshes and wet pastures, and on the borders of lakes and poncls, common throughout Europe, except perhaps the southern extremity North Asia, and North America. Abundant in Britain. Fl. the who summer. It varies much in the size of its parts; the breadth of the leaves, \&c. $\quad R$. reptans, Linn., is a very slender creeping form of species, with arching internodes, minute achenes and recurved styles, found only on the sandy shores of Loch Leven in Britain.

5. R. ophioglossifolius, Vill. (fig. 13). Snakctongue R.-Very nearly allied to $R$. Flammula, but always annual. The stem is more erect and branched, the lower leaves broadly orate, and sometimes slightly cordate, and all broader in proportion than in $R$. Flammula, and the flowers smaller, the petals scarcely exceeding the calyx. Carpels minutely granulated.

In marshes in South and West Europe. Hampshire only in Britain, and formerly St. Peter's Marsh in Jersey, where it is extinct. Fl. June.

6. R. Ficaria, Linn. (fig. 14). Figwort R., Lesser Celandine.Rootstock small, emitting oblong or cylindrical tubers, which are renewed annually. Leaves mostly radical, cordate, obtuse, angular or crenate, thick, smooth, and shining. Flower-stems usually scarcely longer than the root-leaves, bearing one or two small leaves and a single flower, with 3 sepals and 8 or 9 oblong glossy yellow petals. Carpels rather large, in a globular head.

In fields, pastures, and waste places, a very common weed through$\rightarrow$ at Europe and western Asia. Abundant in Britain, except perhaps the west Highlands of Scotland. Fl. spring, one of the earliest that eppears. It varies occasionally with a slightly branched, creeping stem of 8 or 9 inches or even more, with most of the leaves orposite.

7. R. sceleratus, Linn. (fig. 15). Celery-leaved R.-An erect, much 
branched annual, 6 inches to near 2 feet high, glabrous or nearly so. Stem thick and hollow. Lower leaves stalked, divided into 3 or more obtusely toothed or lobed segments, the upper ones sessile, with 3 narrow segments. Flowers small and numerous, the petals pale sellow, scarcely longer than the calyx, and without any scale over the nectary. Carpels very small in a dense head, which becomes oblong as the fruit ripens.

On the sides of pools and wet ditches, over Europe and temperate Asia, occnrring even in Bengal, and now spread into North America. Scattered through Britain. Fl. summer.

8. R. auricomus, Linn. (fig. 16). Wood R., Goldilocks.-A perennial, with the large bright yellow flowers of $R$, acris, but not so tall, more glabrous, having only a few appressed hairs, especially in the upper parts, and the lower leaves less cut and more obtuse. Stem seldom above a foot bigh, erect and branched. Radical leaves on long stalks, rounded or reniform, and but little cut. Stem-leaves few, sessile, divided to the base into narrow, entire, or slightly toothed segments. Carpels as in $R$. acris, but downy.

In woods and bushy places in uorthern and central Europe and northern and western Asia to N. India. Frequent in England, rarer in Ireland and Scotland, and scarce in the Highlands. Fl. spring. [A variety with deformed petals or with none, is $R$. apetalus, Wallr.]

9. R. acris, Linn. (fig. 17). Meadow R., Crovfoot, Buttercups. ${ }^{*}-\mathbf{A}$ softly hairy perennial, very variable in size, but generally one of the tallest of our species; hairs mostly spreading, but deflexed on the lower parts of the stem, and appressed on the peduncles. Stems erect, often 2 or 3 feet high, but in poor or mountain stations sometimes not 6 inches. Leaves nearly all stalked and 3eeply divided into 3, 5, or 7 palmate segments, which are again cut into 3 toothed lobes, the divisions lanceolate and acute, those of the lower leaves broader and sometimes wedge-shaped, the nppcr ones narrower and fewcr. Flowers rather large, bright yellow, on long terminal peduncles, forming usually large loose panicles. Sepals yellowish-green, concave, shorter than the petals, spreading horizontally, but not reficcted on the peduncle. Carpels ovate, compressed, glabrous, in a globular head.

In meadows and pastures, cultivated and waste places, very common in Europe and Russian Asia, and naturalised in North America. Very abundant in Britain. Fl. early summer, ani till late in autumn.

10. R. repens, Linn. (fig. 18). Crceping $R$. -With the flowers and fruit of $R$. acris, this species is easily distinguished by the runners shooting from among the radical leaves, rapidly rooting and forming fresh plants at every node, by the flowering stems seldom above a foot high and less branched, by the hairs generally longer and looser, and by the leaves divided into 3 stalked segments, each one lobed and toothed, but the central one projecting considerably besond the others, so as to gire the whole leaf an ovate form, not the rounded one of $R$. acris.

In cultivated and waste places throughout Europe, and North Asin, introduced in N. America. In Britain as abundant as $R$. acris, and a very tronblesome weed. Fl. all summer, and often till late in autumn.

- These names are popularly applied to nearly all the specles of Ranunousus aith bright yellow flowers and divided leavea. 
11. R. flabellatus, Desf. (fig. 19). Fine-leaved R.-A hairy perennial, with the habit of the smaller specimens of $R$. bulbosus. Stem nsually 6 to 9 inches high, thickened at the base into a kind of bulb, covered with the fibrous remains of old leaves, and emitting small tubers from the base amongst the fibrous roots. Leaves radical, the early outer ones often rounded and toothed only, the more permanent ones once or twice ternately divided into cut segments. Flowers few, rather large, bright yellow, the sepals spreading, but not reflected. Carpels numerous, glabrous, collected in an oblong or cylindrical head. R. Charophyllos, Linn., of former editions.

In rather dry, waste, and cultivated places, and hilly pastures, especially in western and southern Europe, and formerly occurring near St. Aubin's, in Jersey. Fl. early summer.

12. R. bulbosus, Linn. (fig. 20). Bulbous R.-A perennial, much smaller and usually more hairy than the $R$. acris, of which it has the bright yellow petals. Stem seldom above a foot high, and usually thickened at the base into a kind of bulb. Leaves more like those of $R$. repens, but smaller, divided into 3 segments more or less cut, but broader than in $R$. acris. It is distinguished from all but $R$. hirsutus by the sepals, which, as soon as the flower expands, are closely reflected on the peduncle. Carpels glabrous and smooth, in a globular head.

In meadows, pastures, and waste places over the greater part of Europe, but disappearing in the north-east, rare in western Asia; naturalised in North America. Abundant in Britain. Fl. early summer.

13. R. hirsutus, Curtis. (fig. 21). Hairy R.-An erect annual, much branched from the base, 6 inches to near a foot bigh, with the foliage and reflexed calyx of $R$. bulbosus, but the flowers more numerous, rather smaller, and of a paler yellow, and the hairs of the stem usually fewer and looser, although in this respect both species are variable. Carpels with a series of tubercles (visible especially when dry) within the rather broad margin.

In fields, cultivated and waste places, in central and southern Europe, extending eastward to the Caucasus, and northward to southern Sweden. In most parts of England and southern Scotland, but not generally common, and unknown in Ireland. Fl. summer. [R. Philonotis, Ehr., the name adopted in earlier editions of this work, is of later date than hirsutus. $\quad R$. Sardous, Crantz, and parvulus, Linn., are earlier than either, but are quite misleading.]

14. R. parviflorus, Linn. (fig. 22). Small-flowered R.-A hairy annual, with weak, prostrate or ascending stems, from a few inches to about a foot in length. Leaves nearly orbicular, the lower ones 5-lobed or crenate, the upper ones divided into 3 or 5 segments, which are more or less lobed, but generally less so than in $R$. hirsutus. Peduncles short, mostly opposite to the leaves. Flowers small and yellow, the petals narrow, seldom exceeding the calyx. Carpels coverea with small tubercles.

In cultivated and waste places in Europe and Asia; introduced into N. America. Not common in Britain, although occurring bere and there in England and Ireland; not in Scotland. Fl. spring and summer.

15. R. arvensis, Linn. (fig. 23). Corn R.-An erect, branching nearly glabrous annual, of a pale green, 6 to 18 inches high. Leaves 
deeply cut into narrow segments. Flowers small, of a pale yellow. Carpels few, rather large, much flattened, covered on both sides with conical, straight, or hooked prickles.

A common and troublesome cornfield weed, in central and southern Europe, and extending to North India. Very abundant in slovenly farms in southern England, but decreasing northwards, and of rare occurrence in Ireland. Fl. and ripens its seed with the corn.

\section{CALTha CALTHA.}

Glabrons herbs, with a perennial stock, and annual stems. Sepals about 5, large and yellow like the petals of Ranunculus, but no real petals. Stamens numerous. Carpels 5 to 10 , laterally compressed, each with several seeds.

A genus of very few species, inhabitants of temperate and cold regions in both the northern and sonthern hemispheres.

1. C. palustris, Linn. (fig. 24). Marsh Marigold.-A perennial, forming large tufts, with a thick almost tuberous rootstock. Stems about a foot long, erect or decumbent, often rooting at the lower nodes, and but slightly branched. Leaves mostly radical, on long stalks, orbicular or kidney-shaped, cordate at the base and crenate on the margin. Flowers large, of a bright golden-yellow.

In marshy places, the sides of brooks, \&c., throughout Europe and temperate Asia to North India, and North America. Abundant in Britain. Fl. spring, commencing early and often lasting till summer.

[There are three British forms : 1. vulgaris proper, with large flowers and spreading carpels. 2. C. Guerangerii, Boreau, with smaller flowers and spreading carpels. 3. Var. minor, Syme, procumbent, with solitary rather large flowers and erect carpels-a mountain plant. A second species, $C$. radicans, Forst., with the stem rooting at the nodes and deltoid acutely toothed leaves, was once found in Forfarshire, but ha long been extinct.]

\section{TROLLIOS. TROLLIUS.}

Perennial herbs, with divided leaves and yellow flowers. Sepals 5 to 15, large and coloured like petals. Real petals about as many, small, linear, and flat. Stamens numerous. Carpels several, each with several seeds.

Besides our species, the genus comprises but very few, all from northern Asia or America.

1. T. europæus, Linn. (fig. 25). Globe T., Globeflower.-A glabrous, erect plant, 1 to 2 feet high, the stem simple or nearly so. Radical leaves not unlike those of Ranunculus acris, palmately divided into 3 or 5 segments, which are again lobed and cut. Stem-leaves few, smaller, and nearly sessile. Flowers large, pale yellow, with 10 to 15 broad concave sepals converging into a 'globe, usually concealing the petals, stamens, and carpels.

In moist woods and montain pastures, in northern and central Kurope, eastwards to the Caucasus. Pretty frequent in Britain, from Wales to the Grampians, very rare in Ireland. Fl. summer. 


\section{HELLEBORUS. HELLEBORE.}

Perennial herbs, with palmately or pedately divided leaves, of a paler green and more rigid than in most other Ranunculaceous plants. sepals 5, large, greenish (in the British species), remaining till the fruit is nearly ripe. Real petals 8 to 10 , very small, tubular, 2-lobed at the top. Stamens numerous. Carpels several, rather large, each with several seeds.

A well-marked genus, but not numerous in species, chiefly south European and west Asiatic.

Flowers usually 3 or 4 . Sepals spreading . . . . . 1, U. viridis. Flowers many, in a large panicle, with large ovate bracts. Sepals

converging .

The Winter Aconite (see p. 2) was formerly considered as a species of IIclleborus. It is a small plant, with narrow, petal-like, yellow sepals, surrounded by an involucre of green divided leaves. The white Christmas Rose is a true Helleborus (II. niger) from south-eastern Europe.

1. H. viridis, Linn. (fig. 26). Green $H$., Bear's-foot.-Radical leaves large, on long stalks, divided into 7 to 11 oblong, acute, toothed segments, 3 to 4 inches long, the central ones free, the lateral ones on each side connected together at the base so as to form a pedate leaf. Stem scarcely exceeding the leaves, bearing usually 2,3 , or 4 large drooping flowers of a pale yellowish-green, and at each ramification a sessile leaf, much less divided than the radical ones, and the segments usually digitate.

In pastures and thickets, especially in calcareous soils, and about old walls and ruins in western and central Europe, but not extending to the eastern frontier, nor far to the north. A native of the south and south. east of England, and naturalised elsewhere. Fl. early spring.

2. H, fœtidus, Linn. (fig. 27). Fetid H., Setter-wort.-Lower leaves not all radical, but mostly raised on the short perennial base of the stems, forming a larger and thicker tuft than in II. viridis, their segments narrower, less toothed, stiffer, and more shining, their outer lobes at a less distance from the central ones. Flower-stem above a foot higl, with a large close panicle of drooping flowers, of a pale green, often tinged with purple, the concave sepals giving them a globular form. Bracts at the ramifications of the panicle ovate and entire, or shortly 2 -lobed at the summit.

In stony places, chiefly in limestone districts, in southern Furope, extending here and there into central Europe, but neither a northern nor an eastern plant. In England it is wild in Tiampshire and Sussex, but, like the last, it is in most cases an introduced plant. Fl. early spring.

\section{AQUILEgIA. COLUMBINE.}

Perennial berbs, with the leaves chiefly radical, ternately divided, with distinct stalked segments or leaflets. Sepals 5, coloured. Petals 5 , each terminating below in a born-shaped spur, projecting below the calyx. Stamens numerous. Carpels 5, each with several seeds.

A small but very distinct genus, widely spread over the north tem. perate regions of both hemispheres, especially in mountain districts.

1. A. vulgaris, Linn. (fig. 28). Common C.-Radical and lower leavcs in a large fuft, each with a long stalk, once, twice or even 
three times ternately divided, the segments broad, 3-lobed, and crenate, of a glaucous-green, glabrous, or with a few hairs underneath. Flowerstem $1 \frac{1}{2}$ to 2 feet or more high, bearing a loose panicle with a few leaves at its ramifications much less divided than the lower ones. Flowers large, drooping, blue, or of a dull purple.

In coppices and open woods in Europe and temperate Asia, extending northwards into Scandinavia, and eastwards to the Himalaya. In britain often introduced, bnt believed to be indigenous in several counties of England, Ireland, and southern Scotland. Fl. early summer. In gardens it sports much in the form and colour of the flowers.

The 4. Canadensis, and some other exotic species, are occasionally cultivated in our flower-gardens.

\section{DELPHINIUM. LARKSPUR.}

Annual or percnnial herbs, with much divided leaves, the segments usually palmate and narrow. Sepals 5 , coloured, terminating below in a hollow spur. Petals, in the British species 2, combined into 1, which is lengthened into a spur within that of the calyx; in some exotic species the petals are 4, the two upper ones forming a spur. Carpels 1 to 5, each with several seeds.

A considerable genus, widely spread over the northern hemisphere without the tropics. It is as well marked as Aquilegia and Aconitum, by the peculiar irregularities of the calyx and corolla.

1. D. Ajacis, Linn. (fig. 29). Common L.-An erect annual, 1 to $1 \frac{1}{2}$ feet high, glabrous or slightly hairy, the branches few and spreading. Radical leaves shortly stalked, the stem ones sessile, all divided into fine, linear, deeply cut segments. Flowers showy blue, reddish or white, not numerous, in terminal racemes, forming sometimes an irregular panicle. Spur of the calyx as long as the rest of the flower or rather shorter (each about 6 lines). Petals 2 only, their appendages united on the under side into an inner spur open along its upper edge. Carpel solitary, glabrous or pubescent.

A native of the east Mediterranean region, long cultivated in Europe, has become a common weed of cornfields. In Britain in Cambridgeshire, but appears occasionally in cornfields in other parts of England. In the first edition of this work, as in the earlier British Floras, the Continental $D$. Consolida had been described for this. $F$. will the corn, or later, on the stubble. Some marks at the base of the united petals, which have been compared to the letters A I A I, have given rise to the name of $D$. Ajacis. Some larger pcrennial species are also cultivated in llower-gardens.

\section{ACONITUM. ACONITE.}

Perennial herbs, with much divided leaves, the segments palmate. Sepals 5, coloured, the upper one helmet-shaped, the two lateral ones broader than the two lower. Petals 2 to 5 , concealed within the calyx, the two upper ones forming small and irregular spurred bodies, on long stalks within the upper sepal, the three lower very small and linear, or wanting. Stamens numerous, Carpels 3 to 5 , each with several seeds. 
A natural genus, consisting chiefly of monntain plants, spread over the greater part of Europe and central Asia, represented also in northern America by a very few species. Two or three exotic species are often cultivated in our perennial borders.

1. A. Napellus, Linn. (fig. 30). Monkshood, or Wolfsbane.-Stem firm and erect, $1 \frac{1}{2}$ to 2 feet high. Leaves stalked, or the upper ones nearily sessile, of a dark-green, glabrous or slightly downy, divided to the base into 5 or 7 deeply cnt, linear, pointed segments. Flowers large, dark blue, on erect peaicels, forming a handsome, dense, terminal raceme. The upper helmet-shaped sepal at first conceals the lateral ones, but is ultimately thrown back. Spur of the small upper petals short, conical, and more or less bent downwards. Carpels 3, often slightly united at the base.

In moist pastures and thickets and waste places, in mountainous districts, in Europe and temperate Asia, extending northwards into Scandinavia, and eastwards to the Himalaya. In Britain apparently wild in some shady places in western England and South Wales. Fl. summer.

\section{ACT ÆA. BANEBERRY.}

Perennial herbs, with the leaves chiefly radical, their stalk divided, the segments or leaflets distinct. Sepals 4, small, petal-like. Petals 4, small, distinctly clawed. Stamens numerous, as long as or longer than the petals, with small anthers. Carpel solitary, becoming a berry when ripe, with several seeds.

A small genus, spread over the northern hemisphere, with much of the general habit of Thalictrum, but differing in the presence of both sepals and petals, in the anthers, and fruit.

1. A. spicata, Linn. (fig. 31). Baneberry, Ilerb Christopher.-Radical leaves large, not unlike those of several U'mbellifers, the stalk usually twice divided into 3 or 5 pinnately arranged branches, the segments or leaflets ovate, pointed, often 3-lobed and coarsely toothed, of a deep green, and quite glabrous. Stem 1 to 2 feet high, with few leaves, much smaller than the radical ones. Flowers small, nearly white, in a short, loose, oblong, terminal raceme. Berries small, nearly black.

In mountain woods and pastures, in central and eastern Europe, Russian Asia, and northern America, extending to the Arctic circle. In Britain very local, and only in northern England. Fl. May.

\section{PAIONIA. PEONY.}

Large perennials, the leaves chiefly radical, with divided stalks and distinct segments or leaflets, the flowers large and handsome. Sepals 5 , herbaceons. Petals 5 or more, much larger. Stamens numerous, inserted on fleshy disk. Carpels 2 to 5 , each with several seeds.

A very distinct genus, consisting of but very few species, indigenons in southern Europe and temperate Asia.

1. P. officinalis, Linn. (fig. 32). Common P.-Rootstock emitting a cluster of thick.tuberous roots. Stem 1 to 2 feet high. Radical leaves twice ternate, the segments ovate, entire or divided into two or three deep lobes. Flowers deep red. Carpels large and thick, very downs, and, when ripe, more or less recurved. 
In hilly districts, in southern Europe and central Asia, from the Pyrenees to the Caucasus and Himalaya. Not indigenous to Britain, but naturalised in the rocky clefts of the "Steep Holme" Island, in the Severn. Fl. May or June. The variety there found is usually considered as a species ( $P$. corallina), the name of $P$. officinalis being reserved for some of the garden Pæonies, which are, however, mostly varieties produced from this by cultivation. The half-shrubby Moutan is a very distinct species, from China.

The Magnolias and Tulip-trees of our plantations belong to the Magnotia family, which has no European representative. They have, like the Ranunculacea, several distinct sepals, petals, stamens, and pistils, but they are always trees, or shrubs, their leaf-buds are enclosed in membranous stipules, and the carpels usually cohere in a kind of cone.

\section{BERBERIDE无. THE BARBERRY FAMILY.}

Shrubs or herbs, with alternate or radical leaves, and no stipules. Sepals and petals distinct, $2,3,4,6$, or 8 each, but never 5. Stamens the same number as the petals, and opposite to them. Anthers opening by valves or lids turned upwards. Ovary of a single carpel, with two or more ovules attached to the bottom or to one side of the cavity. Seeds albuminous.

A small family, spread over the temperate regions or tropical mountains of the globe. It is universally admitted by botanists, although the connection between the Barberry and the herbaceous genera associated with it appears at first sight rather artificial. These are, however, none of them British. The Epimedium alpinum (Linn.), a native of south-eastern Europe, has indeed been admitted into our Floras as growing about old castles, \&c., but only where it had been planted. Some Japanese Epimediums are also cultivated in our gardens.

\section{BERBERIS. BARBERRY.}

Shrubs, with usually prickly leaves. Sepals 8 or 9 , yellow, outer minute. Petals 6 , in 2 series, with honeyed glands at their bases. Stamens 6. Fruit a berry.

A rather numerous genus, chiefly Asiatic and American. Many exctic species are cultivated in our gardens, either with simple leaves, like our own, or belonging to a section with pinnated leaves, sometimes considered as a genus under the name of Mahonia.

1. B. vulgaris, Linn. (fig. 33). Common B.-A glabrons acid pale green shrub with yellow wood, attaining 6 or 8 feet, the branches arched and hanging at the ends, armed with 3-lobed thorns at the base of the tufts of leaves. Leaves alternate or clustered, obovate, rather stiff, sharply toothed. Flowers yellow, in elegant drooping racemes, with a disagreeable smell. Berries small, red, oval or oblong, contain. ing 2 or 3 seeds.

In hedges, thickets, and open woods, over the greater part of Europe and temperate Asia, to the Himalaya. In Europe it extends north. 
wards into Scandinaria, but has been so frequently planted that the real limits of its area cannot be ascertained. Scattered over Britain, but probably not really indigenous. $F l$. spring or early summer.

\section{NYMPHAACE无. THE WATERLILY FAMILY.}

Aquatic herbs, with a submerged rootstock, orbicular or peltate floating leaves, and large solitary flowers. Sepals few. Petals numerous, in several rows, passing gradually into the stamens, which are also very numerous, their anthers adnate. Carpels numerous, but either imbedded into the receptacle, or combined together so as to form a single ovary with many cells, each with a sessile stigma. Seeds albuminous, in the British genera, with a very small embryo.

Waterlilies, although not numerous in species, are to be found floating on shallow, still, or gently running waters in almost all parts of the world. They form an exceedingly natural group, of which several are in cultivation in our hothonses, including the gigantic Victoria, from tropical Ameriea, and the elegant Nelumbo, from tropical Asia.

Sepals greenish outside, about the size of the onter (white) petals . 1. NYMPIFA. Sepals yellow, concealing the much smaller (yellow) petals

2. NUPHAR.

\section{NYMPH王A. NYMPHAA.}

Sepals about 4 , like the outer petals, but greenish outside. Carpels numerous, imbedded in the thick receptacle so as to form as many cells, radiating from a common centre, whilst the petals and stamens are attached to the outside of the receptacle, nearly as high as the top of the cells. Stigmas as many as the cells, radiating on the surface of the ovary, each one extended into an erect, incurved, linear appendage, whilst the centre of the flower is occupied by the small conical summit of the receptacle. Fruit slightly pulpy, indehiscent.

This genus, generally spread over the globe, includes the greater number of the species of the Order, with white, blue, or red flowers.

1. N. alba, Linn. (fig. 34). White Waterlily.-Leaves deeply cordate, glabrous, usually about 6 or 8 inches in diameter. Flowers lying on the surface of the water, white, scentless, usually 3 to 4 inches in diameter.

In lakes or still waters, and slow rivers, extending all over Europe and northern and central Asia, although absent from particular localities. Generally distributed in Britain. Fl. summer. Smaller flowered states occur, and several varieties have been distinguished by minute but uncertain characters in the forms of the anthers and stigmatic appendages.

\section{NUPHAR. NUPHAR.}

Sepals about $\mathbf{5}$ or 6 , concave, yellow, much larger than the onter petals. Carpels numerous, and radiating as in Nymphcca, but united into an ovary, raised on the top of the receptacle, and not imbedded in it. Stigmas as many as the colls, their appendages united into a flat disk npon which the stigmas themselves radiate. 
Besides the European species, there are but two N. Amcrican oncs.

1. N. Luteum, Sm. (fig. 35). Yellow Waterlily.-Leaves very nearly as in Nymphaca alba. Flowers yellow, raised 2 or 3 inches above the water, much less expanded and faintly scented, the concave sepals assuming a more globnlar form. Petals and stamens very numerous, but scarcely more than half the length of the sepals. Fruit globular, crowned by the stigmatic disk, indehiscent or bursting irregularly.

As common, and in many places more so, than Nymphaza alba, with the same geographical range; certainly more general in Britain. $\mathrm{Fl}$. all summer. It varies much in size, and in the number of the stigmatic rays. A very small form, with few stigmatic rays, found in some lakes of Scotland, has been distingnished nnder the names of $N$. pumilum and $N$. minimum.

\section{PAPAVERACE正. THE POPPY FAMILY.}

IIerbs, with milky juice, alternate or radical leaves, usually much divided, and no stipules. Flowers regular. Sepals 2, rarely 3, falling off as the flower expands. Petals (in the European genera 4) crumpled in the bud. Stamens numerous, distinct. Ovary really 1-celled, with several many-seeded parietal placentro but these placentæo often project so far into the cavity as sometimes to meet in the centre, dividing the ovary into as many imperfect cells. Fruit capsular, opening by pores or valves. Seeds albuminous, with a small embryo.

Papaveracexe belong almost exclusively to the north temperate zone, in both the Old and New World, a single species, the Mexican Aryemone or Prickly Poppy, having spread as a weed all over the tropics. The combination of 2 sepals and 4 petals easily distinguishes the British genera from all other polyandrous plants.

Ovary and fruit globular or ollong.

Stigmas radiating on a sessile flat disk . . . . 1. PAPAVRR.

Stigmas supported on a short but distinct style : $\quad: \quad$ : 2 MrCONOPSIS. ovary and fruit linear.

Seeds crested. Flowers small, yellow . . - . . . 3. Chrmidonium.

Seeds not crested.

Sea-cosst plant, with thickish leaves and large yellow flowers 5. GLAOCIUM.

Cornfleld weed, with rather large violet flowers . . . 4. Rasirria.

The Californian Eschscholtzias, now so common in our gardens, belong to this family. Platystemon, a curious annual from the same country, also not unfrequently cultivated, is intermediate, as it were, betwcen Papaveracee and Ranunculacea.

\section{PAPAVER POPPY.}

Capsule globular ovoid or slightly oblong, crowned by a circular disk, upon which the stigmas radiate from the centre, internally divided nearly to the centre into as many incomplete cells as there are stigmas, and opening by as many pores immediately under the disk. Flowers rather large, red, white, or purplish in the British species, or pale yellow in some exotic ones.

A small genus, extending over Europe, Asia, Sonth Alrica, and 
Australia, and introduced as weeds of cultivation into other parts of the world.

Vlant glabrous and glaucous. Leaves toothed or slightly lobed, clasping the stem at their base

Plant green, usually with stiff hairs. Leaves once or twice pin.

\section{P. somniforum} natiflaly divided.

Capsule glabrous.

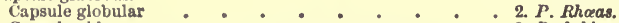

Capsule oblong . : : $\quad 3$. P. dubium.

Capsule more or less hlspid with stiff halrs or bristles.

Capsule nearly giobular. Bristles numerous and spreading . 4. P. hybridum.

Capsule oblong or obovid. Bristles few aud erect - : 5. P. Argemone.

The yellow-flowered $P$. nudicaule, from the mountains of northern and central Europe and Asia, is much cultivated in our gardens.

1. P. somniferum, Linn. (fig. 36). Opium P.-An erect annual, of a glaucous green, glabrous, or with a few hairs on the peduncle, scarcely branched, about 2 feet high or more. Leaves clasping the stem by their cordate base, oblong, irregularly toothed, and slightly sinuate or lobed. Flowers large, usually of a bluish white, with a purple base. Filaments slightly dilated at the top. Capsule large, globular, and glabrous.

A native of southern Europe and the Levant, but much cultivated in Europeari gardens, and occasionally establishes itself in waste places. In Britain it assumes the appearance of a wild plant in several parts of England, especially near the sea, and in the fens of the eastern counties. Fl. summer. It supplies Opium and Poppy heads, and in our gardens varies much in the colour of the flowers, which are often very double.

2. P. Rhœas, Linn. (fig. 37). Field P.-An erect, branched annual, 1 to 2 feet high, with stiff spreading hairs or bristles. Lower leaves large, stalked, once or twice pinnately divided, the lobes lanceolate, pointed, and more or less cut. Flowers large, of a rich scarlet, with a dark eye, the filaments of the stamens not dilated. Capsule perfectly smootb, globular, or slightly top-shaped, with 8 to 12 stigmatic rays.

In waste and cultivated places, in central and southern Europe and western Asia, rare in the north. Abundant in cornfields in England and Ireland, less so in Scotland, and scarce in the IHighlands. Fl. all summer. Double-flowering varieties are often cultivated.

3. P. dubium, Linn. (fig. 38). Long-headed P.-Very near P. Rhoeas, but generally smaller and more slender, the leaves more cut, with narrower lobes, the hairs less spreading, and the flowers rather smaller. It is more essentially distinguished by the capsule, which is oblong, often twice as long as broad, and narrowed at the base.

In waste and cultivated places in Europe and western Asia, extending further north than $P$. Rhoeas, but not so generally common. In Eingland and Ireland less frequent, but in Scotland more so than $\boldsymbol{P}$. Rhoeus. Fl. summer. [The sap varies in colour, white in true dubium, and yellow in a variety or species called Lecoqii, Lamotte.]

4. P. hybridum, Linn. (fig. 39). Rough $P$. - Nearly as tall as $P$. Rhocas, but generally less branched, the leaves smaller, with stiffer and shorter segments, the hairs few and short. Flowers smaller, of a purplish red, usually with a dark spot in the centre. Filaments of the stamens dilated from the middle upwards. Capsule nearly globular, covered with stiff spreading bristles a little turned upwards at their points; rags 4 io 8. 
In waste and cultivated places in central and southern Europe to the Caucasus, disappearing in northern Germany. In Britain rather rare, chiefly in sandy and chalky fields in England and Ireland. Fl. summer.

5. P. Argemone, Linn. (fig. 40). Pale P.-The weakest, and often the smallest of our red Poppies, the segments of the leaves few and narrow, the flowers rather small, of a pale ted, often with a dark spot. Filaments of the stamens dilated as in $P$. hybridum. Capsule oblong, contracted at the base, bearing, especially towards the top, a few stiff hairs or bristles, more erect from the base than in $P$. hybridum.

Stations and geographical range about the same as those of $P$. Rhoeas, but much less common in Britain and central Europe. Fl. summer.

\section{MECONOPSIS. MECONOPSIS.}

Ovary ovoid, with a short but distinct style, and a slightly dilated stigma of 4 to 6 rays. Capsule opening at the top in as many short valves, the placentas inside lining the cavity, but not projecting to the centre.

A small genus, containing, besides the European species, a few others from central Asia and north-western America.

1. M. cambrica, Vig. (fig. 41). Welsh $P$. - Stock perennial, forming, when old, large tufts with thick, tapering roots. Stems erect, about a foot high. Leaves on long stalks, pale green and slightly hairy, pinnate, the segments distinct or slightly decurrent along the leafstalk, ovate or lanceolate, toothed or pinnately lobed. Flowers rather large, pale yellow, on long peduncles. Capsules narrow, ovate, or oblong, glabrous.

In rocky woods and shady places, in the hilly districts of western Europe, from Spain to Ireland, Wales, and the western counties of England. $F l$ summer.

\section{CHELIDONIUM. CELANDINE.}

Ovary linear, ending in a short style, with a small, slightly 2-lobed stigma. Capsule long, linear, opening from the base upwards, in two valves, the placentas slender. Seeds with a small crest-like appendage next the hilum.

A genus now reduced to a single spccies.

1. C. majus, Linn. (fig. 42). Common Celandine.-Rootstock perennial. Stems erect, slender, branching, 1 to 2 feet high, full of a yellow fetid juice, and generally bearing a few spreading hairs. Leaves thin, glancous underneath, once or twice pinnate, the segments ovate, coarsely toothed or lobed, the stalks often dilated into a kind of false stipules. Flowers small and yellow, 3 to 6 together, in a loose nmbel, on a long peduncle. Pod nearly cylindrical, glabrous, $1 \frac{1}{2}$ to 2 inches long.

On roadsides and waste places, throughout Europe and Russian Asia except the extreme north. In Britain, chiefly near houses. Frequent in England and some parts of Ireland, less so in Scotland. Fl, all summer.

\section{RCEMERIA. ROEMERIA.}

Ovary linear, with a sessile stigma of 3 or 4 short rays. Capsule long and lirear, opening from the summit downwards in 3 or 4 valves, the placentas slender. Seeds without any crest-like appendage. 
A genus of two or three species, from the east Mediterranean region, perhaps all varieties of one.

1. R. hybrida, DC. (fig. 43). Common R.-An annnal very much resembling Papaver Argemone in habit and foliage, and in its pale red. purplish flowers, but differing widely in its linear capsule, $1 \frac{1}{2}$ to 2 or 3 inches long, bearing a few erect, stiff bairs, and not divided into cells inside.

A Mediterranean species, appearing occasionally as a cornfield weed in central Europe, and established as such in Norfolk and Cambridgeshire. Fl. with the corn.

\section{GLAUCIUM. GLAUCIUM.}

Ovary linear, contracted at the top into a 2-lobed stigina. Capsule linear, opening in 2 valves, leaving 2 free linear placentas, forming a thin, dry, spongy substance, in which the seeds are more or less im. bedded.

The very few species comprised in the genus besides the British one are from the Mediterranean region.

1. G. Iuteum, Scop. (fig. 44). IIorned Popmy, Sea Poppy.-A stout annual, with spreading branches, very glaucous in all its parts. Leaves thick, the radical ones stalked, pinnately lobed or divided, the lobes ovate or lanceolate, sinuate or lobed, rough with short thick bairs, the upper ones shorter, broader, less divided, and smoother. Flowers on short peduncles, large and yellow, the petals very fugacious. Pods 6 to 10 or 12 inches long, crowned by the spreading lobes of the stigma.

On sandy seashores, common all round the Mediterranean, and up the western coast of Europe to Scandinavia. Frequent on the coasts of England and Ireland, but decreasing much in Scotland. Fl. summer.

\section{FUMARIACE尼. THE FUMITORY FAMILY.}

Delicate glabrous herbs, either annual or with a perennial rootstock; the leaves much divided into distinet segments, and no stipules. Flowers very irregular. Sepals 2, small and seale-like. Petals 4, in two pairs, the two outer united at the base and often one or both spurred; the two inner narrow, their crested tips united over the stigma. Stamens 6, hypogynous, united into 2 sets of 3 each, the middle anther of each set having 2 cells, the lateral ones 1 cell each. Ovary of a single cell, with 2 placentas and several ovules, at least in a very young stage. Fruit a 1-seedel nut, or a pod with several seeds. Embryo small, at the base of the albumen.

A small family, spread over the temperate regions of the northern hemisphere, scarcely penetrating into the tropics, but reappearing in southern Africa. It is now generally referred as a tribe to Papaveracee, wlth which it agrees in the parts of the flower being in twos and in the structure of the ovary, but it differs so strikingly from the British 
genera of that family in the irregular flowers and definite stamens, that it may be more convenient in this work to retain it as a distinct Order. Fruit a small roundish nut with one seed . . . . . . 1. Fumaria. Fruit an elongated pod with several seeds $: \vdots \quad \vdots \quad: \quad 2$ CORYDALIs.

Some species of Dicentra or Dielytra, a North American and east Asiatic genus, are cultivated for the beauty of their flowers.

\section{FUMARIA. FUMITORY.}

One of the onter petals has a pouch or spur at its base. Fruit a small roundish green 1-seeded nut, although the very young ovary has two ovules, of which only one remains at the time of flowering.

A genus of few species, chiefly natives of the Mediterranean region, of which the common one is now widely spread over the globe.

1. F. officinalis, Linn. (fig. 45). Common $F$. - A delicate pale green annual, perfectly glabrous, usually forming, when it commences flowering, a dense tuft of a few inches in height, but the stem often grows out from 1 to 3 feet; it is then generally weak or trailing, and sometimes slightly climbing, supported by the twisted petioles. Leaves much divided into numerous segments, generaily 3 -lobed, the lobes varying in shape from narrow-linear to broadly lanceolate or oblong. Flowers in racemes of 1 to 2 inches, either terminal or opposite the leaves, dense at first, but often lengthening much as the flowering advances. Pedicels short, in the axil of a very small, scale-like, white or coloured bract. Sepals small, white, or coloured like the bracts, and often toothed. Petals oblong-linear, forming a tubular corolla, with dark-coloured tips, the spar at the base giving it the appearance of being attached laterally to the pedicel. Nut usually about a line in diameter, somewhat compressed laterally.

Common in cultivated and waste place in Europe and Asia, disappearing at high northern latitudes, bnt occurring as a weed of cultivation in many parts of the globe. Abundant in England and southern Scotland, but decreases much in the north. Fl. all summer and autumn. It varies much in the form of the leaf-segments, in the size and colour of the flower, white or red, in the size and shape of the sepals, and in the shape of the nuts; and several species are generally admitted, but they run so much one into another, that there is every probability of their bcing mere varieties. The most prominent British forms are-

a. $F$. capreolata, Linn. ( $F$. pallidiflora, $F$. confusa, and $F$. muralis, of authors). A luxuriant climber, attaining a length of 2 or more feet; leaf-segments broad; flowers 4 or 5 lines long, white or pale red, the sepals rather large, the nuts nearly orbicular. A bout bedges and walls, more common and more marked in southern Europe than in Britain.

b. $P$. officinalis, Linn. Leaf segments neither very broad nor very narrow ; flowers red, abont 3 lines long; nnts very blunt, or depressed at the top, rather broader than long. Connected both with the preceding and the following by numerons intermediates, some of which are considered as species under the names of $F$. media, $F$. agraria, \&c.

c. $F$. densiflora, DC. ( $F$. micrantha, Lag.). Leaf-segments usually gmall; flowers smaller, and in closer racemes than in the common variety, the sepals remarkably large in proportion to the corolla; nuts 
with two slabllow pits at the top. Not uncommon in southern Europe, and here and there over Britain and other parts of the area of the species.

d. $F$. parviflora, Lamk. ( $F$. Vaillantii, Loisel., $F$. tenuiseeta, Syme). Leaf-segments narrow; flowers scarcely 2 lines long, white, or rarely red, sepals very small, sometimes quite minute; nuts with two pits at the top. Common in hot countries; rare in Britain. A very distinct form.

\section{CORYDALIS. CORYDAL.}

One of the outer petals has a pouch or spur at the base as in Fumaria, but the fruit is a narrow pod, opening by two valves and containing several seeds, bearing near their hilum a little erest-like appendage.

The species are rather numerous, spread over Europe, temperate Asia, and northern America. The two British ones belong to the section Capnoides, in which the stems are branched and leafy, without tubers to the root. C. solida, from continental Europe, often met with in our flower-gardens, has occasionally remained from cultivation in groves and shady places in some parts of England. It is a small plant, with a tuberous rootstock, simple stems, and rather large purplish flowers, belonging to the section Bulbocapnos.

Stcm short, erect, much branched. Flowers yellow 1 . C. lutea. Stem long, slender, climbing. Flowers whitish . . . 2. C. claviculata,

1. C. Iutea, DC. (fig. 46). Yellow C.-An erect or spreading plant, 6 or 8 inches high, either annual or forming a tufted stock of several years' duration. Leaves delicate and pale green, much divided, the segments ovate or wedge-shaped, and cut into 2 or 3 lobes. Flowers in short racemes, pale yellow, about 6 lines long, with a sbort broad spur. Pod 3 or 4 lines long.

In stony places, in southern Europe, but having been long cultivated in flower-gardens it has become naturalised on old walls and rubbish in northern Europe, as well as in some parts of England. Fl. summer.

2. C. claviculata, DC. (fig. 47). Climbing C.-An annual with slender intricate stems, 1 to 2 feet long, climbing by means of the leafstalks, which usually terminate in delicate tendrils. I,eaf-segments small, ovate or oblong, and often toothed or cut. Racemes or spikes short and compact at the extremity of the peduncles. Flowers small white, with a slight yellow tinge, and a very short spur. Pod 2 or 3 lines long.

In hilly distrícts and stony situations, in western Europe, penetrating eastward into northern Germany, and along the Mediterranean. Widely distributed over Britain, most common in western and northern England and southern Scotland, rare in Ireland. Fl, summer.

\section{CRUCIFER止. THE CRUCIFER FAMILY.}

Herbs, or rarely undershrubs, with alternate leaves and no stipules; the flowers in terminal racemes, which are generally very short or reduced to a corymb when the flowering com- 
mences, but lengthen out as it advances. Sepals 4. Petals 4, equal, or 2 (on the outer side) larger. Stamens 6, of which 2 are generally shorter or very rarely deficient. Ovary solitary, 2-celled. Style single, often very short or almost none, with a capitate or 2-lobed stigma. Fruit a pod, divided into 2 cells by a thin partition, from which the valves generally separate at maturity; or, in a few genera, the pod is 1-celled or indehiscent, or separates transversely into several joints. Seeds without albumen, attached, in each cell, alternately, to the right and left edges of the partition.

An extensive and very natural farmily, widely spread over the globe, but chiefly in the northern hemisphere; scarce within the tropics, and in some districts entirely nnknown. The number of sepals, petals, and stamens readily distinguish Crucifers from all other British plants, but the discrimination of the numerous genera into which they are distri. buted is a very difficult task. The characters are derived chiefly from the pod and the seed, and are often very minute. It is therefore absolutely necessary, in order to name a Crucifer, to have its fruit; and to examine the seed, it must be ripe; it shonld then be soaked, and the outer coating removed, in order to lay bare the embryo, and observe the position of the radicle on the cotyledons, which affords the most essential among the generic characters.

A few terms specially made use of in describing plants of this family may require some explanation. The calyx is said to be bisaccate when two of the sepals, a little ontside the two others, are broader at the base, forming little protuberances or pouches. The pod is termed a silique or siliquose when linear, at least three or four times as long as broad; a silicule or siliculose when short and broad-not twice as long as broad; and a lomentum or lomentose when it does not open its valves. The nerves on the pod, often used as a generic character, can be best seen on dried specimens; they are sometimes quite imperceptible on the fresh pod. The seeds are said to be in one row when, from the narrowness of the pod or the length of the seed-stalk, they occupy the centre of the cell, the two rows being as it were blended into one; or in two rows, when the two rows are distinct without overlapping. In the embryo the radicle is said to be accumbent when it is bent down on the edges of the cotyledons, incumbent when bent over the back of one of them; in the latter case the cotyledons are either flat or conduplicate, that is, folded longitudinally over the radicle.

Notwithstanding all these nice distinctions, the genera of Crucifcrs as at present defined are often as artificial as they are difficult, under which circumstances I have selected those adopted in the best modern Floras, or such as have appeared to me the most natural. The following table is founded, as much as possible, on less minute characters, but even in the few British species the examination of the seed cannot ! ways be dispensed with.

I $\left\{\begin{array}{l}\text { Pnd with a longitudinal partition, generally opening in } 2 \text { valves } \\ \text { Poil not dehiscent, with } 1 \text { seed, or with several seeds separated by traos: }\end{array}\right.$ 
$2\{$ Pod at least 3 or 4 times as long as broad (SILIQUOS $x$ ) , - , . 8

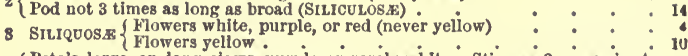

Petals large, on long claws, purple or rarely white. Stigmas 2, very siort,

$4\left\{\begin{array}{l}\text { erect and parallel } \\ \text { Petals small, or the claws scarcely longer tian the calyx "Stigma entire }\end{array}\right.$

(Leaves hoary and soft. Stigmas thickened at the base. (Radicle ac-

5 cumbent), 0 1. MatTHiola.

Leaves green, with coarse hairs. Stigmas not thickened. (Radicle in-

6 feaves all undivided ${ }_{6}$.

7 Leaves all stalked, large and broad $: 0^{*}::^{*}:$ 9. ALLIARIA $^{8}$

7 Upper leaves sessile or auricled.

Seeds in two distinct rows in each ccll. Pod rather short and curved.

8 \{

$\{$ Stem-leaves undivided, narrowed at the base

9 Leaves all pinnate or divided

All the leaves entire, or toothed only. Plant pale or hoary, with minute

$10\left\{\begin{array}{l}\text { appresscd hairs } \\ \text { Leaves, at least the Jower or radical oncs, pimate or ubed at the base. }\end{array}\right.$ llant glabrous, or hairy with rough or spreading hairs

$11\left\{\begin{array}{l}\text { Pod flattened. Radicle accumbent } \\ \text { Pol neariy quadrangular. Radicle incumbent }\end{array}\right.$

Radicle accumbent. Pods ending in a style seldom above a line along. Plant glabrous, with iyrate or pinnate leaves

Radicle incumbent. Valves of the pod opening to close under the stigma.

12 Plant hairy or glabrons, the leaves deeply pinnate. . 8. SisY MBRiU.

liadicle conduplicate. Pod ending in a beak or conical style, 1 to 6 lines long. Leaves irregularly pinnate, or lyrate, or the upper ones un. divided . 11. BRASSICA.

$13\{$ l'ods not 6 lines long, on slender spreading pedicels: : : 4. NASTURTIUM.

3 lods an tucli or more, on stiff short pedicels

14 S Liculos $\left\{\begin{array}{l}\text { Pod globular or oblong, or compressed. The valves flat or } \\ \text { convex, parallel to the broad partition. }\end{array}\right.$ 14 LICUlOS $\left\{\begin{array}{c}\text { Pod compressed or flattened laterally, at right angles to the } \\ \text { narrow partition. The valves boat-shaped }\end{array}\right.$

15 Pod nearly globular or cylindrical

$15\{$ Pol evidentiy compressed or flattened $\quad \cdot \quad \cdot \quad \cdot \quad \cdot 20$

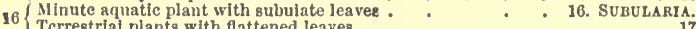

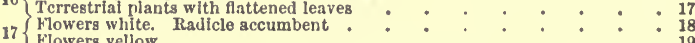

Flowers yellow $4 . \quad \cdot \quad \cdot \quad \cdot \quad \cdot 19$

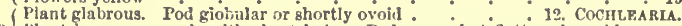

18 Plant hoary or rough with short hairs. Pod somewhat flattened or oblong

$19\left\{\begin{array}{l}\text { Leaves pinnately lobed, or, if entire, narrowed at the base. (Cotyledons } \\ \text { accumbent) } \\ \text { Ieaves linear, in dense radical tufts. Flower-stem leafless : 4. NASTURTIum. } \\ \text {. 14. DrabA. }\end{array}\right.$

$19\left\{\begin{array}{l}\text { Leaves linesr, in dense radical tufts. Flower-stem leafless } \\ \text { Leaves entire or toothed, the upper ones auricled and clasping the stem. }\end{array}\right.$ (Radicle incumbent)

$20\left\{\begin{array}{l}\text { Petals deeply divlded. (Dwarl annual) } \\ \text { Petals entire or notched }\end{array}\right.$

$21\left\{\begin{array}{l}\text { l'od nearly orblcular } \\ \text { Pod considerably longer than broad }\end{array}\right.$

22 Two or more seeds in each ceil of the pod:

One seed only in each cell

23 I feaves entire.

Leaves more or less pinnate.

24 l'od winged alt round. (Radicie sccumbent)

24. Pod obcordate or wedge-shaped, not winged. (Radicle incunbent)

25 Two seeds in each cell . . . . . . . . . 26

15. Camklina.

14. DRABA.

13. AltSSUM.

14. DRABA.

. . 23

- 27

- 24

25

\section{5} (1) . 
26 Pod eliglıtly winged, orbicular. (Radicle accumbent)

18. TEESDALIA,

Pod not winged, oval. (Radicle obllque)

20. HUTOHINSIA.

(Pod opening in two valves. Upper leaves undivided

27 Pod indehlacent, or separating laterally into two nuts. Trailing plant, with

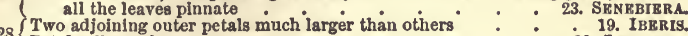

$28\{$ Petals all equal

22. LEPIDIUM.

29 LOMENTosas $\left\{\begin{array}{l}\text { Pod fiattened } \\ \text { Pod globular, cylindrical, or conical : }\end{array}\right.$

80 \{ Pod oblong, pendulous. Tall plant, with yellow flowers .

Pod small, broad. Trailing plants, with small white tlowers .

Pod globular, 1-seeded, raised on a short thick stalk within the calyx.
26. CRAMBR.

81 Pod of two joints, the upper mitre-shaped and 1-seeded, the lower pikeshaped, with an imperfect ovule.

Pod of several seeds, separated by transverse partitions

These Genera are distributed into the following Tribes :-

1. ARABIDE. Pod siliquose. Radicle accumbent. Genera:-1. Mitruioua;

2. Cheiranthus; 3. Barbarea ; 4. Nasturtium; 5. Arabis; 6. Cardamink.

2. SISYMBris

8. SistmbriUM; 9. Alliaria; 10. ERTSIMUM.

3. Brassicez. Pod siliquose. Radicle conduplicate. Genus:-11. Brassica.

4. ALYSSINEx. - Pod siliculose, the partition across the broadest diameter.

Radicle accumbent. Genera:-12. Cochlearia ; 13. AlySSUM; 14. DRABA.

5. CAMELINEx. Pod siliculose, the partition across the broadest diameter.

Radicle incumbent. Genera:-15. Casielisa; 16. Subularia.

6. THLASPIDEE. Pod siliculose, tlie partition across the narrowest diameter.

Tadicle accumbent. Genera:-17. ThLASPI ; 18. TRESDALIA; 19. I BKRIS.

7. LEPIDINR.e. Irod siliculose, the partition across the narrowest diameter.

Radicle incumbent or nearly 80. Genera :-20. "IIUTCHINSIA; 21. CAPSELLA; 22

LEPIDIUM ; 23. SENEBIERA.

8. Iomentos A. Pod lomentose. Genera :-24. Isatis; 25. Cakile; 26. Crambe;

27. RAPHANUS.

Several European and Asiatic Crucifers belonging to other genera are cultivated in our gardens; among them the most common are the IIonesty (Lunaria) and an Eastern species of Aubrietia, both belonging to the Alyssinea.

\section{MATTHIOLA. STOCK.}

Annuals or perennials, more or less hoary with stellate hairs, the leaves entire or sinuate, the flowers rather large, usually purple, never yellow. Calyx erect, distinctly bisaccate. Petals spreading, on long erect claws. Pod long and narrow, compressed or nearly cylindrical. Stigmas sessile, short, but erect, and parallel to each other, having sometimes a horizontal horn at the base of each. Seeds more or less flattened, usually surrounded by a narrow wing forming one row. Radicle accumbent.

Mostly sea-coast plants from western Europe and the Mediterranean. They formerly formed one genus with Cheiranthus, from which they are chiefly distinguished by the erect stigmas, and the colour of the flowers.

3tem erect, mnch branched. Leaves entire . . . . 1. Br. incana.

\$tem spreading. Lower leaves sinuate, or coarsely toothed : $: 2$. M. sinuata.

1. M. incana, Br. (fig. 48). Common or Queen S., Gilliflower.-Erect, usnally perennial, and more or less woody at the base, but not of long duration; 1 to 2 feet high, with hard, slightly spreading branches. Leaves oblong-linear, obtuse, quite entire, soft and hoary on both sides, with short crisped hairs. Flowers purple or reddish, rather large, tho 
petals obovate. Pod 4 or 5 inches long, crowned by the short stigmas, which are rather thickened at the base.

On cliffs and stony places on the sea-coast round the Mediterranean, and up western Europe, at least to Bayonne. In Britain fully established on cliffs in the Isle of Wight, and perhaps some other parts of the south coast, but probably an escape from cultivation. $\mathrm{Fl}$. summer.

2. M. sinuata, Br. (fig. 49). Sea Stock.-Like the last, but more herbaceous and diffuse, and covered all over with a short hoary down, which is, however, much softer and more dense. Branches very spreading. Lower leaves deeply sinuate. Flowers nearly as in $\mathbf{M}$. incana, but the pods more compressed, usually more or less covered with glandular protuberances, and the stigsas very short, scarcely thickened at the base.

On sandy seashores, common all round the Mediterranean, and up the west coast of Europe to Ireland, and some points of the south and west coasts of England and Wales. Fl. summer. [Very fragrant at night.]

\section{CheiranthUS. WALLFLOWER}

Habit and character of Matthiola, except that the hairs are bipartite and appressed, the flowers are orange or yellow, or under cultivation, red, purple, or brown, the pod more distinctly flattened, the very short stigmas spreading horizontally, not erect, and usually borne on a distinct style, and the seeds not winged.

The genus is reduced by some to a single species, by others made to include a very few species from southern Europe and the Canary Islands.

1. C. Cheiri, Linn. (fig. 50). Wallflower.-A perennial of longer duration and more woody than the common Stock, more branched and less hoary, the hairs forked at the base, and closely pressed on the surface, or often quite green and nearly glabrous. Leaves narrow, pointed, quite entire. Flowers rather large, generally of a rich orangeyellow, and sweet-scented, but varying from pale yellow to a deep red. Pods 2 to 3 inches long, the valves with a slightly prominent midrib.

A native of rocky situations, in southern Europe, but spreads rapidly from cultivation, and is now abundant, apparently wild, on walls, old buildings, and rocky places near habitations, in many parts of central and even northern Europe. In Britain very frequent under the latter circumstances. Fl, spring.

\section{BARBAREA. WINTERCRESS.}

Herbs, only differing from the yellow-flavoured Nasturtia by their longer pod, the midrib more conspicuous, and the seeds apparently arranged in a single row, and from Erysimum and Sisymbrium by accumbent, not incumbent radicle.

A very small genus, spread over the temperate regions of the globe.

1. B. vulgaris, Br. (fig. 51). Wintercress, Yellow Rocket.-A perennial of short duration, stiff and erect, green and glabrous, sparingly branched, 1 to 2 feet high. Leaves mostly pinnate, with the terminal lobe large, broad, and very obtuse, while the lower ones are few, small, and narrow; 
very rarely all the lobes are narrow, or some of the leaves oblong and nndivided, bnt deeply toothed at the base. Flowers rather small, bright yellow. Pods usually very numerous, erect or slightly spreading, and crowded in a long dense raceme, each 3 to 3 inches long, terminated by an erect, usually pointed style, varying from $\frac{1}{2}$ a line to 2 lines in length.

Hedges, or pastnres and waste places, common all over Europe, in Russian Asia and northern America. Frequent in Britain. Fl. spring and summer. It varies much in the relative size of the lobes of the leaves, in the size of the flowers, in the length and thickness of the pod, in the length of the style, \&c. A form with a very short and thick style is often considered as a different species, nnder the names of $B$. procox and $B$. intermedia, but it passes by every gradation into those which have a pointed style of 2 lines, and which have again been distinguished nnder the name of $B$. stricta. [Five forms or species are recognised by botanists :-

a. B. vulgaris proper. Flowers large, petals twice as long as the sepals, pods in a dense raceme, erect, acute, three or more times as long as their pedicels. Common.

b. B. arcuata, Reichb. Flowers large, as in a.; pods acute, large, spreading on very long pedicels, style slender. Rare; Armagh in Ireland.

c. B. stricta, Andrz. Flowers smaller, pods dense erect in a narrow raceme, style slender. Uncommon.

d. B. intermedia, Boreau. Leaves mnch cut, petals twice as long as the sepals, pods acute erect in a dense raceme much longer thañ their pedicels, style stouter. Cultivated fields.

e. B. proecox, Br. (American Cress). Leaves pinnatifid, segments narrow, flowers large, pods long distant obtuse, pedicels short stout, style very short and stout, seeds large. A garden escape; an excellent salad.]

\section{NASTURTIUM. WATERCRESS.}

Glabrous perennials or annuals, with the leaves often pinnate, or pinnately lobed, and small white or yellow flowers. Calyx rather loose. Stigma capitate, nearly sessile. Pod linear or oblong, and usually curved, or in some species short like a silicule, the valves rery convex, with the midrib scarcely visible. Seeds more or less distinctly arranged in two rows in each cell, and not winged. Radicle accumbent.

A small genus, but widely spread over the whole area of the family. It differs from Sisymbrium only in the position of the radicle in the embryo; and the white-flowered species are only to be distinguished from Cardamine by the seeds forming two distinct rows in each cell of the pod.

Pod usually it an inch long or more.

Flowers white. . . . 1. N. officinale.

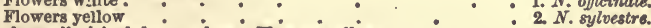

Pod usually $f$ inch long or less. Flowers yellow.

Pod oblong, curved. Petals scarcely longer than the calyx . 3. N. palustre.

Pod ovold, straight. Petals longer than the calyx . : 4. N, amphibium

1. N. officinale, Br. (fig. 52). Common W.-Stem much branched, nometimes very short and creeping, or floating in shallow water: 
sometimes scrambling on wet banks or bushes to tle length of 2 feet or more. Leaves pinnate, with distant segments, the terminal one usually longer, ovate or orbicular. Flowers small and white, in short racemes. Pod about 6 or 8 lines long or rather more, on spreading pedicels, but slightly curred upwards, the double rows of the seeds very distinct.

Along brooks and rivulets, throughout Europe and Russian Asia, except the extreme north, naturalised in America and the Colonies. Abundant in Britain except in the Highlands. Fl, the whole summer.

2. N. sylvestre, Br. (fig. 53). Crccping W.-Stem creeping at the base, the flowering branches erect or ascending, a foot high or more. Leaves all or most of them deeply pinnatifid or almost pinnate, the lower lobes distinet and narrow, the terminal one often larger and broader. Flowers yellow and small, although the petals are considerably longer than the calyx. Pod nearly that of $N$. officinale, but rather more slender, and the two rows of seeds rather less distinct.

On river-banks and in wet places, distributed over Europe and Russian Asia, but apparently not so far north as $N$. officinale. Sparingly scattered over England and Ireland, and still more rare in Scotland. $F l$ summer.

3. N. palustre, DC. (fig. 51). Marsh IV.-Mnch resembles $N$. sylvestre, but usually weaker and not so tall, the lobes of the leaves rather broader and more toothed, the petals seldom exceed the calsx, and the pod is seldom above 3 lines long, slightly curved, the seeds much crowded, in 2 distinct rows in each cell. $N$. terrestre, Sm.

In muddy and watery places, throughout Europe and Russian Asia, from the Mediterranean to the Arctic regions, in North America, and in Australia. Pretty frequent in England and Ireland, but decreasing considerably in Scotland. $\mathrm{Fl}$. summer and winter.

4. N. amphibium, Br. (fig. 55). Great W.-A taller and more erect plant than any of the preceding, attaining 2 or \& feet. Leaves less divided, sometimes narrow lanceolate 3 or 4 inches long, and only slightly toothed, more frequently deeply toothed or pinnately lobed, sometimes divided to the midrib into narrow segments. Flowers yellow, larger than in the two last, the petals longer than the calyx. Pod straight, elliptical, about 2 lines long, or sometimes shorter and almost globular, the style much longer than in the other species.

In moist meadows and watery places, throughout Europe and Russian Asia. Generally distributed over England and Ireland, but not very common. $\mathrm{Fl}$. summer. The shortness of the pod in this and in some varieties of $N$. palustre has induced some botanists to remove them to the genus Armoracia (the Ilorse-radish), a junction which is purely artificial.

\section{ARABIS. ROCKCRESS.}

Annuals or perennials, nsually erect and hairy, at least at their base, - ith a spreading tuft of radical leaves, which are occasionally lobed, the stem-leaves undivided, sessile or stem-clasping; the flowers white, or, in a few exotic species, purple. Pod long and linear, the stigma nearly sessile, the valves flat or slightly convex, often with a distinet midrib or several longitudinal reins. Seeds more or less flattened, pften winged. Radicle accumbent, rarely obliquely incumbent. 
A numerous genus, spread over the temperate regions of the northern hemisphere, with a few extra-tropical species in the southern one.

Stem-leaves undivided, rounded, or auricled at the base.

Tall plants, with pods 3 inches or more long.

Ripe pods erect or spreading. Plant glabrons.

Auricles of the leaves pointed. Pods numerous, erect,

crowded, the valves flat
Auricles of the leaves rounded. Pods loosely spreading, valves with a promlnent midrib

Ripe pods turned downwards. Plant usualiy hairy

Plants seldom above a foot. Pod seldom 2 inches long.

Upper leaves clasping the stem entirely
Upper leaves clasping the stem, coarsely toothed

Upper leaves sessile, but not clasping the stem.

Nearly simple perennial, with erect pods .

Slender branching annual, wlth spreading pods

Slender branching annual, wlth spreading pods
stem-leaves narrowed at the base, the lower often pinnately lobed.

1. A. perfoliata.

Erysimum orientale

2. A. Turrita.

3. A. hirsuta.

4. A. alpina.

5. A. ciliata.

6. A. Thaliana.

7. A. stricta.

8. A. petraea.

8tem branching at the base, in a loose tuft

Arabis albida or grandiflora, a South Russian species or variety of the A. alpina, is common in our gardens among the early-flowering perennials. Erysimum orientale, which might be mistaken for $A$. perfoliata, is described under that genus, of which it has the pods and seeds.

1. A. perfoliata, Lam. (fig. 56). Glabrous, R., Touer Mustard.-An erect annual or biennial, 2 feet or more high, perfectly glabrous except a few soft hairs at the very base, and nsually glaucous. Radical leaves spreading but withering early, obovate-oblong, sinuate or pinnately lobed, with a few forked hairs. Stem-leaves oblong-lanceolate, entire, clasping the stem by pointed auricles. Flowers small, white or pale straw-colour. Pods very long and narrow, erect and crowded in a long narrow raceme. Turritis glabra, Linn.

On banks and roadsides and in open woods, generally distributed over Europe and Russian Asia, except the extreme north in northern America, and in Anstralia. Irregularly scattered uver England and southern Scotland, very rare in Ireland. $F l$. summer. The genus Turritis, which formerly comprised many species of Arabis, is still maintained by some botanists for this species and a few American ones, which have the two rows of seeds rather more distinct than in other species of Arabis.

2. A. Turrita, Linn. (fig. 57). Tower R., Touercress.-A tall, stiff, erect biennial, approaching in size and appearance to the last species, but rough and somewhat hoary with very short forked or stellate hairs. Radical leaves spreading and stalked, stem-leaves oblong-lanceolate, sessile and clasping the stem by their rounded auricles, all slightly toothed. Flowers small, of a dirty yellowish white. Pods above 3 inches long, on short erect pedicels, but all curved downwards to one side, forming a long dense, nodding raceme. Secds oblong, with a membranous border.

In hedges, or shady banks, and under rocks, in the hilly districts of central and southern Europe, and establishes itself readily on old walls further north. Indicated at Oxford, at Cambridge, and in Kent, but evidently only introduced into Britain. Fl. spring or early summer.

8. A. hirsuta, Br. (fig. 58). Hairy R.-A rather stiff erect annual or biennial, attaining a foot or rather more in height, but often shorter, 
usually simple, and rough with short hairs. Radical leaves spreading, obovate or oblong, slightly toothed; stem-leaves generally erect, oblong, or lanceolate, entire or nearly so, all, or at least the upper ones, clasping the stem by short auricles. Flowers small and white. Pods slender, $I$ to 2 inches long, erect and crowded in a long raceme. Seeds without any wing. A. sagittata, DC., Turritis hirsuta, Linn.

On walls, banks, and rocks, common in the greater part of Europe and Russian Asia, but not in high northern latitudes. Not an abundant plant in Britain, although occurring in numerous localities, even in the north of Scotland. Fl. summer [Var. glabrata, Syme, has nearly glabrous leaves.]

4. [A. alpina, Linn. (fig. 59). Alpine R.-Very near A. hirsuta, but less stiff; stem-leaves coarsely toothed, flowers larger and fruiting racemes shorer, with more spreading pods.

A native of the Alps and Arctic regions of Europe, Asia, and North America, lately discovered by Mr. H. C. Hart on the Cuchullin mountains in Skye.]

5. A. ciliata, Br. (fig. 60). Fringed R.-Very near $A$. hirsuta, but not above 6 inches high; the stem usually glabrous, and the leaves only fringed with a few stiff hairs on their edge, the upper ones rounded at the base and not auricled. The flowers are rather larger, and the pods less erect.

In stony and rocky places, in the monntains of central Europe. In Britain only at a few stations in $\mathrm{S}$. Wales and the west coast of Ireland. Fl. summer. There is some doubt whether the British and the Continental plants are the same, but probably both are mere varieties of the common $A$. hirsuta.

6. A. Thaliana, Linn. (fig. 61). Thale R., Thalecress, Wallcress.-A slender, erect, branching annual, usually about 6 inches high, but sometimes attaining a foot, clothed with short, spreading stiff hairs, or sometimes nearly glabrous. Leaves mostly radical and spreading, oblong, with a few coarse teeth, from $\frac{1}{2}$ to 1 inch long. Stem-leaves few, small, and sessile. Flowers small and white. Pods on spreading pedicles, in slender racemes, narrow linear, varying from 4 to 5 inches long to twice that lengtb. Seeds small, the two rows blended into one; the cotyledons placed obliquely, so that the radicle is almost incumbent on the back of one of them. Sisymbrium 'Thaliana, Hook.

On old walls, dry banks, and stony waste places throughout Europe and Iussian Asia, extending into northern America. Frequent in Britain. $F$. early spring, and occasionally also in summer and autumn. On account of the position of the radicle this species is referred by some to Sisymbrium, with which it has little else in common.

7. A. stricta, Huds. (fig. 62). Bristol Rockcress.-A perennial, but probably of few years' duration, resembling in some respects the $A$. petrcea. Radical leaves in a small spreading tuft, pinnately lobed, and hispid with stiff hairs. Stems about 6 inches high, erect, nearly simple, with a very few small leaves narrowed at the base. Petals narrow and erect. Pods erect, about an inch long.

The Continental distribution of this species is uncertain, as the name is often given to plants quite different from ours; but it appears to be a native of limestone rocks in the mountains of western Europe. In Britain only on St. Vincent's rocks, near Bristol, where it is becomin 
very scarce, and it will probably soon have to be expunged from ou: Floras. Fl. spring.

8. A. petræa, Lam. (fig. 63). Northern $R$.-A small perennial, in some respects intermediate between Arabis and Cardamine. Stems branched at the base, loosely tufted, or shortly diffuse, or almost creeping, but seldom above 6 inches long. Radical and lower leaves obovate or oblong, stalked glabrous or with a few stiff hairs, most pinnately divided, with the terminal lobe largest, or some of them nearly entire; the upper leaves few, narrow, almost entire, tapering at the base. Flowers few, considerably larger than in A. hirsuta, white, or slightly purplish. Pod spreading, rather more than half an inch long, the seeds apparently in single rows.

In the mountains of northern and central Enrope, extending across $\mathrm{N}$. Asia to N. America. In Britain frequent on the higher mountains of northern and western Scotland, and has been found also in Cumberland and North Wales, and very rarely in North-west Ireland. Flo summer.

\section{CARDAMINE. BITTERCRESS.}

Herbs, either annual or with a perennial rootstock, glabrous, or bearing only a few simple hairs; the leaves pinnate, or, if undivided, on long stalks; the flowers white or pink. Stigma capitate, or small. Pod narrow-linear; the valves flat without any conspicuous midrib, and usually opening with elasticity. Seeds apparently in a single row in each cell; radicle accumbent on the edge of the cotyledons.

A large and natural genus, widely spread over the temperate and colder regions of both the northern and southern hemispheres. The white flowers and pinnate leaves distinguish it from all British Crucifers, except Nasturtium officinale, which differs in its pods.

Petals large, obovate or oblong, spreading.

Stem weak. Segments of the stem-leaves broad.

Rootstock slender, with creeping offsets. All the leaves pinnate 1. C. amara.

Rootstock thick and knotted. Upper leaves nearly entire, often

with a bulb in their axil . . . 5. C. bulbifera

Stem stifl and erect. Segments of the stem-leaves narrow $\quad$ - 2. C. pratensis.

Petals small, nearly erect.

Stem tall and erect. Leafstalk with stipule-like appendages at the base

Stem low and weak, or much branched. No stipular appendages

3. C. impatiens. 4. C. hirsuta.

1. C. amara, Linn. (fig. 64). Large B.-Rootstock slender, with creeping offsets. Stem a foot high or more, weak and ascending, or nearly erect. Leaves pinnate, with 5 or 7 distinct segments, all ovate or orbicular, irregularly angled or toothed, the terminal one often an inch long. Racemes few-flowered. Petals nearly as large as in $\boldsymbol{C}$. pratensis, slightly spreading, of a pure white. Pod about an inch long.

In wet meadows, and along brooks and streams, generally distributed over Europe and North Asia (except the extreme north), and the western Himalaya, becoming a mountain plant in the south. Widely spread over Britain, but not a common plant. $F l$. spring and early oummer.

2. C. pratensis, Linn. (fig. 65). Meadow B., Ladies' Smock, Cuckoofower.-Rootstock short and perennial, often bearing small fleshy scales or tubers. Stem erect, simple or branched, near a foot high. Leaves pinnate, the segments of the lower radical ones ovate or orbicular, the 
terminal one the largest, those of the stem-leaves narrow-oblong of linear. Flowers large and showy; the petals obovate and spreading, pure white, frequently tinged with a pinkish purple. Pod more than an inch long.

In moist meadows, and along brooks and streams, con.mon through. out Europe, Russian Asia, and Arctic America. Abundant in Britain. $F l$ spring and early summer. [There are two remarkable varieties, $C$. dentuta, Schult., a tall plant with fewer larger angled and toothed leaflets; and var. Heyneana, Neilr., with the liabit of C. hirsuta, many small leaflets, small white flowers, and narrow petals; found in Surrey and Lancashire.]

3. C. impatiens, Linn. (fig. 66). Narrov-lcaved B.-An annual, with a stiff, erect, leafy stem, 10 to 18 inches high, simple, or with a few erect branches. Leaves pinnate, with numerous lanceolate or almost ovate segments, $\frac{1}{4}$ to $\frac{1}{2}$ inch long, and often deeply toothed or cut ; the common leafstallk has, on each side, at its base, a curved linear appendage embracing the stem, and resembling a stipule. Petals very minute, and sometimes wanting. Pods numerous, about an inch long, the valves rolling back at maturity, with much elasticity.

On moist rocks, and in shady waste places, over a great part of Europe and Russian Asia. In Britain scattered over central and northern England, very rare in Ireland. Fl. summer.

4. C. hirsuta, Linn. (fig. 67). Lairy B.-An annual, of a deep green colour, often much branched at the basc, with ascending or erect stems, sometimes a foot ligh, but usually not half so much, with a few scattered hairs. Leaves pinnate, the segments small, those of the lower leaves ovate or rounded, and angularly toothed, the upper ones narrower and more entire. Flowers small and white, the petals seldom twice the length of the very small sepals. Pods in a rather loose racemc, about 6 lines to 1 inch long.

On moist or shady banks, waste and cultivated places, throughout the temperate regions of the globe. Abundant in Britain. Fl. spring and all summer. It varies much, like otber Cardamincs, in the length and thickness of the style. The common form is a small annual with the stamens usually reduced to 4. A large perennial variety, with 6 stamens and slender style, is distinguished as a species, under the name of C. flexuosa, With. (sylvatica, Link).

5. C. bulbifera, Br. (fig. 68). Bulbiferous B., Coralroot.-Stem weak, 1 to $1 \frac{1}{2}$ feet ligh, bearing several leaves, often with a small ovoid bulb in their axils, the lower ones pinnate, with 5 or 7 segments, the upper ones with fewer segments, or quite undivided; all the segments lan. ceolate, entire, or toothed, tapering at the base, mostly $1 \frac{1}{2}$ to 2 inches long. Flowers few, rather large. The pod is seldom formed, as the plant usually propagates by the axillary bulbs falling to the ground, and there growing. Dentaria bulbifcra, Linn.

In damp woods and shady places, chiefly in the mountain districts of Europe from Scandinavia and central France to the Cancasus. In Britain occurring from Stafford southwards to Kent and Sussex. Flo spring.

This species, with a few exotic ones, formed the genus Dentaria, Linn., kept up in the first edition of this work, but the supposed characters are slight, resting on the rather broader pod, and the little scedstalks being usually, but not always, flat and broau. 


\section{HESPERIS. HESPERIS.}

Coarse, erect herbs, more or less hairy, with toothed leaves, and rather large purple flowers, resembling those of Matthiola. Calyx erect. Petals on long claws. Pods long and linear, nearly cylindrical; the stigma oblong, erect, and very shortly divided into two parallel lobes. Seeds not winged, apparently in a single row in each cell; the radicle is incumbent.

A genus confined to Europe and northern Asia, nearly allied to Matthiola, but with a somewhat different habit, and an incumbent radicle.

1. H. matronalis, Linn. (fig. 69). Dame's Violet.-Stems 2 to 3 feet high, usually slightly branched. Leaves shortly stalked, or tapering at the base, ovate-lanceolate or lanceolate, 2 to 3 inches long, or the upper ones smaller. Flowers usually fragrant in the evening. Pods 2 to 4 inches long, nearly cylindrical, but much contracted between the seeds.

In hedges, bushy places, and open woods, in central and southern Europe, and all across Russian Asia, and, having been long cultivated in cottage gardens, is frequently met with, apparently wild, further to the north. In Britain only as an escape from gardens. $F$. early summer.

The Virginia Stock of our gardens, a sea-coast plant of sonthern Europe, is said to have been found on our own shores near Dover. It belongs to the genus Malcolmia, only differing from Hesperis in the more pointed lobes of the stigma, and the pod shightly thickened at the base.

\section{SISYMBRIUM. BISYMBRIUM.}

Annnal, or rarely perennial, erect herbs, glabrous, or with spreading hairs; the flowers small, yellow, or, in some exotio species, white. Pod linear, nearly cylindrical, the lateral nerves of the valves more or less distinct; the stigma entire, small or capitate, closely sessile on the summit of the ovary. Seeds apparently in a single row, ovoid or oblong, not flattened; the radicle incumbent.

A numerous genus, spread over the northern hemisphere, with the yellow flowers and habit of Barbarea and Brassica, but differing essentially from both in the position of the radicle. Several species of the three genera are popularly known by the name of Rocket.

Leaves deeply pinnatifid.

Terminal lobe of the leaves broad and very obtuse, much larger

than the others
Lobes of the leaves lanceolate, the lower ones often curved backwards Pods short, downy, closely pressed against the axis . 1. S. oficinalo.

Fods long, glabrous, spreading, and often turned to one side 2 S. Irio.

Lpaves twice or thrice plnnate, with numerous small linear seg. mente

Besides the above, the $S$. polyceratium, from continental Europe, is established in the streets of Bury, in Suffolk, and on ballast hills in Fife. It has the foliage of S. Irio, with numerous shorter pods crowded in the axils of the upper leaves.

1. S. officinale, Scop. (fig. 70). Hedge Mustard.-An erect annual, more or less downy, a foot high or rather more, with very rigid, spreading branches. Leaves deeply pinnatifid, with few lanceolate, 
alightly toothed lobes, the terminal one 1 to 1 if inches long, the others smaller, often curved backwards; the upper leaves sometimes undivided and hastate. Flowers very small and yellow. Pods about 6 lines long, thick at the base, tapering to the point, more or less hairy, almost sessile, and closely pressed against the axis, in long, slender racemes, the midribs of the valves almost as prominent as in Erysimum.

In waste places, and by roadsides, common throughout Kurope and Russian Asia, except the extreme north. Abundant in Britain, rarer in " the north of Scotland. Fl. summer.

2. S. Irio, Linn. (fig. 71). London Rocket.-An erect annual, with a hard stem, a foot high or more, and glabrous or nearly so. Leaves deeply pinnatifid or pinnate, the lobes or segments lanceolate, more numerous and larger than in $S$. officinale. Flowers small and yellow. Pods on more or less spreading pedicels, $1 \frac{1}{3}$ to 2 inches long, often all turned to one side, forming a dense, erect raceme.

In waste places, and by roadsides, in central and southern Kurope to the Caucasus. Rare in Britain, and chiefly recorded from the neighbourhood of London, Berwick, and Dublin. Fl. summer. [Called London Rocket from having sprung up amongst the ruins of the Fire of London in 1666.]

3. S. Sophia, Linn. (fig. 72). Flixweed.-An erect annual, a foot high or rather more, not so coarse as the last two, and somewhat hoary with a very short down. Leaves two or three times divided into numerous short linear segments. Flowers small and yellow. Pods slender and glabrous, 9 to 12 lines long, on slender, spreading pedicels, forming loose, terminal, erect racemes.

In waste places, by roadsides, \&c., in Europe and northern Asia, from the Arctic Circle to the Mediterranean, the Caucasus, and Himalaya, and in northern America; thinly scattered through Britain. Fl. svermer.

\section{ALLIARIA. ALLIARIA.}

A single species, associated by some with Sisymbrium, by others with Erysimum; differing from the former by the valves of the pod, with a prominent midrib, as in Erysimum; from the latter by white flowers, and a more cylindrical pod; from both by a pecullar habit of foliage, and by the striate seed, of which the short stalk is more distinctly expanded (within the pod) into a broad white membrane.

1. A. officinalis, Andrz. (fig. 73). Garlic-Mustard, Sauce-alone.An erect annual or biennial, or sometimes of longer duration, 1 to 3 feet high, smelling strongly of garlic when rubbed, glabrous, or with a few long hairs on the stem and the edges of the leaves. Lower leaves on long stalks, orbicular and crenate; those of the stem on shorter stalks, cordate, ovate, or triangular, coarsely toothed, 2 to 3 inches long and broad. Flower small and white. Pods on short, spreading stalks, stiff and glabrous, 1 to $1 \frac{1}{2}$ inches long, nearly cylindrical, but with a very prominent midrib on each valve. Sisymbrium Alliaria, Scop. Erysimum Alliaria, Linn.

Under helges, in shady waste or cultivated places, over the greater part of Europe and western Asia, but not Arctic. Frequent in Britain, but decreasing much in northern and western Scotland. Fl. epring. 


\section{ERYSIMUM. ERYSIMUM.}

Erect annuals or perennials, pale or hoary with closely appresed hairs, rarely quite glabrous; the leaves entire, or slightly toothed. Flowers yellow, or rarely yellowish-white. Pod linear, nearly quadrangular from the very prominent midrib of the valves. Stigma broadly capitate, or with short; spreading lobes. Seeds ovoid or oblong, the seedstalk not flattened, the radicle incumbent on the back of one of the cotyledons.

A rather numerous genus in the northern hemisphere, differing from Cheiranthus in the seeds, from Sisymbrium by the midrib of the valves of the pod being more prominent than in all the species of that genus except $S$. officinale.

Plaut slightly hoary. Leaves tapering at the base

Plant glabrous and glaucous. Leaves clasping the stem, and rounded at the base . - . 2. E. orientale.

1. E. cheiranthoides, Linn. (fig. 74). Treacle M/ustard.-A stiff, erect annual, 1 to 2 feet high, slightly hoary with closely appressed hairs. Leaves numerous, of a pale green, broadly lanceolate, entire or slightly toothed, tapering into a short stalk at the base. Flowers small, pale yellow. Pods numerous, on spreading pedicels, seldom an inch long, the stigma slightly dilated.

In waste and cultivated places, in northern and central Europe, Asia, and northern America. Diffused over a great part of Britain, but probably introduced. $F l$ summer and autumn.

2. E. orientale, Br. (fig. 75). IIare's-ear.-An erect, perfectly glabrous, and somewhat glaucous annual, a foot high or rather more. Radical leaves obovate and stalked, the stem-leaves oblong, 2 or 3 inches long, quite entire, and embracing the stem with prominent rounded auricles. Flowers pale yellow, or whitish. Pods 3 or 4 inches long, slender, in a loose raceme, the midrib of the valves very prominent.

In stony fields and waste places, in central and southern Europe, and western Asia, extending northwards to the Baltic. In Britain it has been gathered occasionally near the southern and eastern coasts of England, but appears scarcely to be permanently established. $F l$. spring and summer.

\section{BRASSICA. BRASSICA.}

Annuals or perennials, either glabrous or with stiff or rough hairs, the lower leaves usually deep pinnate, or lyrate, the upper ones sometimes entire, the flowers yellow. Pod linear, cylindrical or nearly so, more or less beaked at the top beyond the end of the valves, the beak consisting either of the conical style alone, or including a portion of the pod itself, with one or more seeds in it. Seeds globular, ovoid, or somewhat flattened, the cotyledons folded longitudinally over the radicle.

A numerous genus, spread over Europe and northern and central Asia, comprising the Brassica and Sinapis of Linnæus, and divided by other botanists into from three to six or even more genera, variously defined, according to the peculiar views entertained by each, but all aptly united into one by Boissier. It is distinguished from Sisymbrium and Barbarea essentially by the folded cotyledons, and in most cases by the beak of the pod. Even in the first two species, and in $B$. nigra, where the beak 
Is not so distinct, the persistent style is more conical at the base than in Barbarea, and very much longer than in Sisymbrium.

Upper stem-leaves entire, sessile, or clasping the stem.

All the leaves glabrous and glaucous, the upper ones not

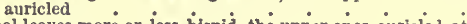

Radical leaves more or less hispid, the upper ones auricled at the base

All the leaves pinnately cut or stalked.

Six or fewer seeds in each cell of the pod.

Pods slender and short, closely pressed against the axis of the raceme. Beak small.

Pods ending in a slender style, slightly conical at the base

Pods ending in a distinct beak, thickened at the base .

Pods more or less spreading in a loose raceme. Beak large. Pod very hispid, rather sliorter than the long flat beak Pod glabrous, or rough, rather longer than the conical beak Ten, twelve, or more seeds in each cell of the pod.

Pod 1 to 2 inches, the beak distinct, with 1 or 2 seeds .

Pod slender, not $1 \frac{1}{2}$ inch long. The beak very short, witl. out seeds.

Branched and leafy perennial, a foot high or more

Low annual, the leaves mostly radical .

4. B. oleracea.

5. B. campestris.

8. B. nigra.

9. B. adpressa.

6. B. alba.

7. B. Sintapis.

3. B. monensis.

1. B. tenuifolia.

2. B. muralis.

Besides the above, a variety of $B$. Erucastrum, Vill., a common roadside weed in some parts of continental Europe, has been fourd near Saffron Walden, and is said to have sown itself in the neighbourhood, but can scarcely claim as yet to be admitted in our Floras. It is an erect annual, with the habit and pinnatifid or pinnate leaves nearly of $B$. monensis, but the pod has a very short seedless beak.

1. B. tenuifolia, Boiss. (fig. 76). Wall B., Rocket.-A loosely branched or bushy perennial, 1 to 2 feet high, perfectly glabrous and somewhat glaucous, emitting a disagreeable smell when rubbed. Leaves very variable, mostly irregularly pinnate, 2 to 4 or 5 inches long, with a few lanceolate or oblong, entire or coarsely toothed segments, the upper leaves often entire or nearly so. Flowers rather large, lemon-coloured. Pods in a loose raceme, about $1 \frac{1}{2}$ inches long, slender, spreading, with numerous small seeds distinctly arranged in two rows. Diplotaxis tenuifolia, D.C.

On old walls, ruins, and waste places, in central and southern Europe to the Caucasus, extending nortbwards to southern Sweden. In Britain chiefly in southern England. $F l$. the whole summer.

2. B. muralis, Boiss. (fig. 77). Sand B.-An annual, branching from the base, usually about 6 inches high, with the same smell as the last. Leaves mostly radical, or crowded at the base of the stems, less deeply divided than in $B$. tenuifolia, and often only sinuate. Flowers much smaller, the pods and seeds similar, but also smaller. B. brevipes, Syme. Diplotaxis muralis, D.C.

In fields, cultivated and waste places, very common in southern and scattered over central Europe. In Britain abundant in some of the of uthern counties of England, and near Portmarnock, in Ireland, and appearing occasionally further north, especially near the sea. $F$, all summer. [Var. viabinglonii, Syme, is a biennial or perennial variety.]

3. B. monensis, Huds. (fig. 78). Isle of Man B.-Either an annual or forming $\mathrm{h}$ stock of longer duration, glabrous, or bearing a few stiff hairs at its base. Stems sometimes barely 6 inches bigh, with the laires tiostly ralical, scmetimes loosely branche?, sbove a foot high, 
and more leafy. Radical leaves pinnatifid or pinnate, the lobes or segments short and broad, and marked by a few coarse teeth, the upper leaves more deeply divided, with narrower segments. Flowers rather large, pale yellow. Pods spreading, $1 \frac{1}{2}$ to above 2 inches long, with a thick beak, from a fifth to above a third of the whole pod, anc usually containing 1 to 3 seeds above the valves.

In western Europe, and chiefly in the Pyrenees and sonth-western Alps, but extending up the west coast of France to Britain. Flo summer. The smaller state is the most frequent in sandy places on the western coasts of Great Britain as far north as Bute, but the more luxuriant variety, often distinguished as a species, under the name of Sinapis or Brassica Cheiranthus, occurs in Cornwall and the Channel Islands.

4. B. oleracea, Linn. (fig. 79). Cabbage.-In the wild state the Cabbage has a thick, almost woody stock, probably of two or three years' duration, branching into erect stems, 1 to 2 feet high. Leaves glabrous and glancous, the lower ones large, stalked, broad, sinuate, or lobed at the base, the upper ones oblong, usually sinuate, clasping the stem by their broad base, but not projecting into auricles. Flowers rather large, pale yellow. Pod spreading, $1 \frac{1}{2}$ inches or more in length.

On maritime cliffs, round the Mediterranean, and on the coasts of northern France and of sonthern England, as well as in some more northern localites, but there probably escaped from cultivation. $F$ early summer. The cultivated forms of this species include the Cabbage, Cauliflower, Broccoli, Kale, Kohlrabbi, \&c., of gardeners. [This and the following are doubtless forms of one species, the varieties of which are variously classed under one or the other. Another division of the aggregate species is founded on the leaves and flowers, one having leaves glaucous beneath, and flowers pale orange, whilst the other has leaves not glaucous, and smaller bright yellow flowers. The Cabbage is a type of the first, the Turnip of the other.]

5. B. campestris, Linn. (fig. 80). Field B.-In its wild state this is an erect, simple, or scarcely branched annual, 1 to 2 feet high. Lower leaves green and slightly glaucous, more or less pinnately divided, with a large terminal lobe, and rough with stiff hairs, which are sometimes very copious, and rarely entirely wanting; upper leaves narrow-oblong or lanceolate, clasping the stem with rounded projecting auricles. Flowers and pods much like those of $B$. oleracca, but the petals are usually of a brighter yellow. B. polymorpha, Syme.

On borders of fields, and waste places, thronghout Europe and Russian Asia. A frequent weed of cultivation in Britain. $F l$. spring and summer. The cultivated varieties include the Turnip (B. Napus), the Rape or Colza (B. Rapa), and probably also the Swedish Turnip (B. Rutabaga).

6. B. alba, Boiss. (fig. 81). Cultivated Mustard.-Stem 1 to 2 fe:si high, glabrous, or with spreading, stiff bairs. Leaves pinnately lobed or divided, more or less rough, the lobes ovate or oblong, coarsely toothed, the terminal one the largest. Flowers rather large, fruit-pedicels spreading. Pod s to 1 inch long, but more than half occupied by a stont flattened beak, often curved, with a single seed in its base, the valves and lower part of the beak very hispid with stiff white hairs concealing the prominent nerves. Sinapis alba, Linn.

In waste and cultivated places, in Europe and westẹn Asia, and 
of ten cultivated for salad or forage. Not unfrequent in some parts of England and Ireland, more rare in Scotland. Fl. all summer.

7. B. Sinapis, Visiani. (fig. 82). Charlock, Wild Mustard.-A coarse annual, 1 to 2 feet high, with a few stiff spreading hairs. Leaves rongh with very short hairs, the lower ones usually with one large oval or oblong coarsely toothed segment, and a few smaller ones along the leafstalk, the upper ones often undivided, oblong or lanceolate. Flowers rather large. Pods more or less spreading, $\frac{1}{2}$ to $1 \frac{1}{2}$ inches long, of which rather more than a third is occupied by a stout beak, often containing a seed in its base; the valves glabrous, or rough with stiff reflexed hairs, the lateral nerves prominent. Sinapis arvenis, Linn. B. Sinapistrum, Boiss.

A native probably of southern Europe, but now one of the most abundant weeds of cultivation thronghout Europe and Asia, and but too common all over Britain. Fl. all summer.

8. B. nigra, Koch. (fig. 83). Black Mustard.-Less hairy than the last two species, and sometimes entirely glabrous, especially in the upper part, but the lower leaves and stem are generally slightly hispid. Stem 2 feet high or more. Leaves mostly deeply divided, with one large terminal ovate or oblong| lobe and a few small lateral ones, the upper leaves often small and entire. Flowers rather smaller than in B. Sinapis. Pods on short pedicels, closely pressed against the axis of the long slender racemes, glabrous, seldom more than half an inch long, with a slender style, slightly conical at the base, the valves marked with a strong midrib. Sinapis nigra, Linn.

On banks, under hedges, in waste and cultivated places, in central and southern Europe and temperate Asia, and much cultivated for its seed. Scattered over England, and apparently wild on some points of the south coast; rare in Scotland. Perhaps introduced only into Britain. Fl, summer.

9. B. adpressa, Boiss. (fig. 84). Hoary B.-Very like B. nigra in habit and foliage, but more frequently biennial, the stem stiffer and harder at the base, the leaves less divided, and more or less hoary with short rough hairs. Pods short and closely pressed against the axis, as in $B$. nigra, but terminating in a short, thick, 1 -seeded beak, instead of a slender style. Seeds rather ovoid, not globular. Sinapis incana, Linn.

On sandy or arid places near the sea, in southern Furope, extending up the west coast to the Channel Islands, and rarely to Ireland. Fl. summer.

\section{COCHLEARIA. COCHLEARIA.}

Annnals or perennials, usually glabrous, with undivided leaves, and white flowers. Filaments of the stamens without appendages. Pod globular, ovoid or shortly oblong, with a broad partition; the valves very convex. Seeds several in each cell, not bordered, the radicle accumbent.

Besides the common northern species, the genus contains several Asiatic and south European ones, some of them intermediate, in appearance, between the two very dissimilar ones here associated. The pod is verv different from that of any other British white-flowered Crucifer. 
Tall erect plant, with very large oblong radical leaves Low diffuse plant, the leaves small and thick

1. C. armoracia.

1. C. armoracia, Linn. (fig. 85). Horseradish.-Rootstock tapering inte a long root. Radical leaves on long stalks, often 6 inches to a foot long, and 4 to 6 inches broad, sinuate and toothed at the edges, glabrous, but rough. Stems 2 to 3 feet high, erect; the leaves smaller and narrower than the radical ones, the lower ones often deeply toothed or almost pinnatifid. Flowers small and white, in numerous racemes, forming a terminal panicle. Pods on slender pedicels, ovoid or elliptical, without any prominent nerve. Armoracia rusticana, Rupp.

A plant of sonth-eastern Europe, introduced by cultivation into northern and western Europe. It is naturalised in several parts of Britain. Fl. summer. The pod seldom comes to perfection in this country.

2. C. offlinalis, Linn. (fig. 86). Scurvy-grass.-A low, diffuse, quite glabrous, and somewhat fleshy annual or biennial, the stems seldom above 6 inches long. Lower leaves stalked, orbicular, deltoid, or reniform, entire or angularly toothed; the upper ones sometimes similar, sometimes ovate or oblong, and often quite sessile. Flowers in short racemes, the petals obovate and spreading. Pods globular or ovoir, varying from 2 to 3 lines in diameter, pointed by the short style, the midrib of the valves very prominent when dry. C. polymorpha, Syme.

In stony, muddy, or sandy soils, in the Arctic Circle, on the seacoasts of northern and western Europe, and at considerable elevations in the great mountain-chains of Europe. Not nncommon on the shores of England and Ireland, still more abundant on those of Scotland, penetrating inland along some of its rivers, and in the Highland mountains. $F l$. all summer. It varies much in the size and shape of the leaves, in the size of the flowers, and the size and shape of the pods, and has been divided into many species. . [The most prominent forms are-

a. C. nfficinalis proper. Root-leaves orbicular or reniform, deeply cordate, pods nearly globose.

b. C. alpina, Wats. Leaves as in a, pods narrowed at both $\mathrm{ends}$. C. greenlandica, Sm. Mountains.

c. C. danica, Mill. Leaves deltoid, pods as in b.

d. C. anglica, Linn. Much larger in all its parts. Leaves oblong. homboid or ovate, not cordate, pods inllated, constricted at the suture.]

\section{ALYSSUM. ALYSSUM.}

Annnals or low branching perennials, with a hoary or short stellate down, and white or yellow flowers. Filaments of the stamens, or the shorter ones only, usually winged near the base, or thickened, or furnished with small teeth. Pod sessile within the calyx, orbicular or oval, the partition broad, the valves convex, and not veined. Seeds 1 to 4 , or very rarely more, in each cell. Radicle accumbent on the edge of the cotyledons.

An extensive genus, in Europe and northern Asia, and tolerably natural, distinguished from Draba chiefly by the short few-seeded pod, with more convex valves, or by the appendages to the base of the 
filaments, one or other of these characters being observable in all the species. They have also usually a stiffer, more leafy habit, and even the annuals often look woody.

Sepals persisting round the pod. Petals minute, yellowish-white.

Seeds 2 in each cell $\dot{0}$. Petals spreading, pure white.

1. A. calyeinum

Seeds 1 in each cell

2. A. maritimum.

The $A$. incanum, often separated as a genus under the name of Berteroa, having longer pods with more seeds, a common European annual, has been occasionally found near Lewes and near Weymouth, but does not appear to be permanently established. The yellow-flowered A. saxatile, from southern Europe, is a long established perennial in our rock-gardens.

1. A. calycinum, Linn. (fig. 87). Small A.-A small hard annual, often simple, 3 or 4 inches high, or, when very luxuriant, branching at the base, and 6 inches high. Leaves oblong-linear, much narrowed at the base. Petals inconspicuous, of a pale yellow. Pods in a long raceme, on short pedicels, nearly orbicular, the narrow herbaceous sepals persisting round them till they are ripe. The filaments of the shorter stamens have each a small fine tooth or appendage at their base.

In waste places, on the edges of fields, \&c., in central and southern Finrope, from Sweden to the Caucasus. In Britain it occurs rarely in England, I reland, and southern Scotland. Fl. spring and early summer.

2. A. maritimum, Linn. (fig. 88). Sweet A.-A hard annual or perennial, with much-branched procumbent or ascending stems, from 4 or 5 inches to near a foot long. Leaves narrow-lanceolate or linear, narrowed at the base, or stalked. Flowers white with a honey scent, rather small, but the petals obovate, spreading, and conspicuous. Pods orbicular or slightly oval, with only one seed in each cell; the calyx deciduous. The filaments are without appendages, Koniga maritima, $\mathrm{Br}$.

In waste places and dry pastures, chiefly near the sea ; very abundant round the Mediterranean. Much cultivated in gardens, and established as a weed of cultivation in some parts of England. Fl. all summer.

\section{DRABA. DRABA.}

Small annuals or perennials, usually hairy or hoary with spreading or tufted radical leaves, entire or toothed, the stem-leares few or none, rarely many. Flowers white or yellow. Filaments of the stamens without appendages. Pod oblong or elliptical, from one and a half to near three times as long as broad, more or less flattened; the partition broad; the valves flat or convex, their midrib usually distinct. Seed several in each cell. Radicle accumbent.

A considerable genus, ranging over the northern bemisphere, ascend. ing to the greatest elevations and to high Arctic latitudes, and extending along the great monntain-chain of America into the southern bemisphere. The species most? differ from Alyssum in their longer pod, and in a peculiar habit approaching that of Arabis; from the latter genus they se distinguished by the pod which, though long for a siliculoes 
Crucifer, is still much shorter, in proportion to its wiuth, than in the shortest Arabis.

Flowers yellow (stiff tzfted perennial)

Hlowers white.

Biennials or perennials. Pedicels short and stiff.

Stem with a few leaves, the radical ones spreading

1. D. aizoides.

Stem almost leafless, the radlcal ones tufted .

Annuals. Pedlcels slender, spreading.

Stem dwarf, erect, leafless. Petals deeply divided

Steam weak, ascending, leafy. Petals entire . .

1. D. aizoides, Linn. (fig. 89). Yellow D.-Stock perennial and branched, covered with closely packed leaves, forming dense tufts of 2 or 3 inches diameter. The leaves 3 or 4 lines long, sessile, linear, of a bright green, edged with stiff white hairs. Peduncles leafless, 1 to 4 or even 5 inches high, bearing a few rather large yellow flowers. Pods about 4 inches long, glabrous or slightly hairy, with a rather long style; the valves more convex than in the rest of the genus.

In clefts of rocks, and stony places, in the mountain districts of central and southern Europe. Long cultivated in our rock-gardens, it has established itself in considerable abundance on rocks and old walls about Penard Castle, near Swansea. Fl. spring.

2. D. hirta, Linn. (fig. 90). Rock D.-Stock shortly tufted and perennial, but not of long duration. Leaves crowded, 3 to 5 or 6 lines long, narrow, oblong, or lanceolate, entire or slightly toothed, with a few stiff, simple or stellate hairs. Peduncles usually 1 or 2 inches, and leafless; in luxuriant specimens twice as long, with 1 or 2 small ovate leaves. Flowers few and small, but larger than in D. incana. Pods 2 to 3 lines long, on short stiff pedicels, usually slightly hoary with a few very minute hairs. $D$, rupestris, $\mathrm{Br}$.

In the mountains of the northern or Arctic regions of Europe, Asia, and North America. Rare on some of the higher mountain summits of Scotland and North-west Ireland. $F l$. July. The specimens with slightly hoary pods (as are the Scotch ones) are by some distinguished, under the name of $D$. rupestris, from the original $D$. hirta of Linnæus (not found in Britain), in which they are almost or quite glabrous.

8. D. incana, Linn. (fig. 91). IIoary D.-Nearly allied to D. hirta, but very different in appearance. Often only a biennial, with the radical leaves spreading, and seldom forming branched tufts; the whole plant hoary with short, simple, and stellate hairs. Stems erect, 6 inches high or more, with several small, sessile, oblong, or lanceolate leaves. Flowers small, and white. Pods 3 to 5 lines long, on short stiff pedicels, glabrous, or sprinkled with a few stellate hairs; the valves flat, or the whole pod slightly twisted. $D$. confusa, Ehrh.

In rocky situations, in northern and Arctic Europe and Asia, far more common than D. hirta, and descending to lower elevations. Frequent in the Scotch Highlands, and extending into northern England, North Wales, and Ireland, where it also occurs on maritime sandhills. $F l$. summer.

4. D. muralis, Linn. (fig. 92). Wall D.-A slender, erect, but weak annual, from a few inches to a foot high, simple or slightly branched, green, but rough with short hairs. Radical leaves spreading, ovate or oblong, toothed, $\frac{1}{2}$ to 1 inch long. Stem-leaves smaller, ovate, clasping the stem by their cordate or auricled basse. Petals white, entire, and 
very minute. I'ods about 2 lines long, on spreading pedicels, in a long, slender raceme, each containing about 6 seeds.

On rocks and walls, in limestone hilly districts, in Europe and northern Asia, from the Mediterranean to Scandinavia. In Britain sparingly scattered over several parts of England, and introduced into Scotland and Ireland. Fl. spring.

5. D. verna, Linn. (fig. 93). Whitlow grass.-A dwarf annnal, lasting but a few weeks, the leaves all radical, ovate or oblong, seldom above half an inch long, and closely spreading on the ground. Peduncles slender, erect, 1 to 3 or rarely 4 inches high. Petals small, white, and deeply cleft. Pods on rather long slender pedicels, about 3 lines long, containing numerous minute seeds, on stalks of very unequal length. Erophila vulgaris, D.O.

On walls, rocks, dry banks, and stony places, throughout Europe and western Asia, except the extreme north. Abundant in Britain. Fl. early spring. Distinguished by some as a genus, under the name of Erophila. An alpine variety with remarkably inflated ovoid-oblong pods ( $E$. inflata, Wats.) occurs on Ben Lawers and Glen Shee in Scotland. [There are three well marked British forms or species: 1. The above-mentioned inflata ; 2. E. brachycarpa, with orbicular-oblong fewer-seeded pods, as long as broad; 3 . E. vulgaris proper, with obovate-oblong pods, twice as long as broad.]

\section{CAMELINA. CAMELINA.}

Frect and more or less hispid annuals, with sagittate or anricled stemleaves, and small yellow flowers. Pod obovoid, the partition broad, the valves very convex, with the midrib distinct, the edges flattened, forming a narrow margin round the pod. Style slender. Seeds several. The radicle incumbent on the back of one of the cotyledons.

A genus of $t$ wo or three European and north Asiatic species, perhaps reducible to one, separated from Cochlearia by their yellow flowers and incumbent radicle.

1. C. sativa, Crantz (fig. 94). Gold of Pleasure.-Stem simple, or slightly branched, 1 to 2 feet high. Lowest leaves stalked, upper oncs sessile, clasping the stem with pointed auricles, lanceolate, entire, or toothed, 1 to 2 inches long. Pods about 3 lines long, on pedicels about twice that length, in a long loose raceme. C. fotida, Bab.

In cultivated and waste places, in central and southern Europe, and temperate Asia ; further north only as a weed of cultivation. In Britain it occurs in flax-fields in England and Ireland. Fl. with the corn.

\section{SUBULARIA. AWLWORT.}

A dwarf aquatic annual, with the pod of a Draba, but the valves more convex, and the radicle incumbent on the back of the cotyledons, which are linear, and the bend is, as in Senebiera, above the base of the cotyledons, not at their junction with the radicle, as in the rest of Crucifers.

The genus is limited to a single species.

1. S. aquatica, Linn. (fig. 95). Avolwort.-The whole plant is but I to 2 , rarely 3 inches high, and perfectly glabrous, usually growing entirely under water. Leaves all radical, nearly cylindrical, slender 
and pointed, $\frac{1}{2}$ to 1 inch long. Flowers few, with minnte white petals. Pods about a line and a half long, and oblong, or sometimes shorter, and nearly globular, with 5 or 6 seeds in each cell.

In the shallow edges of alpine ponds and lakes, in northern Europe, Asia, and America, and more rarely in central Europe. Scarce in Britain, in the monntains of Scotland, north-western England, North Wales, and western Ireland. Fl. summer.

\section{THLASPI. PENNYCRESS.}

Annuals or low perennials, the leaves nsually undivided, the upper ones clasping the stem, the flowers small and white. Petals equal, or nearly so. Pod orbicular or obovate, flattened laterally at right angles to the narrow partition, the valves boat-shaped, their midrib or keel more or less expanded into a green wing surrounding the pod. Seeds 2 or more in each cell. Radicle accumbent.

A small genus, spread over Europe, northern and central Asia, and North America, distinguished from Iberis and Lepidium by having more than 1 seed in each cell of the pod, from all others by the winged pod.

Pod (including the broad wing) orbicular, about 6 lines broad

Pod obovate or obcordate, not 3 lines broad.

Biennial or perennial. Pod longer than broad, with 6 or 8 seeds

in each cell
Annual. Pod nearly as broad as long, with about 4 seeds in

1. T. arvense. each cell

3. T. alpestre.

2. T. perfoliatum

1. T. arvense, Linn. (fig. 96). Mithridate Mustard.-An erect, glabrons annual, 6 inches to a foot high or rather more, simple or branched in the upper part. Radical leaves stalked, but soon disappearing. Stemleaves oblong or lanceolate, usually marked with a few coarse teeth; the lower ones narrowed at the base, the upper clasping the stem with prominent auricles. Pods in a long raceme, about half an inch in diameter, including a very broad wing, deeply notched at the top, with a very minute style in the notch. Seeds usually 6 in each cell.

In cultivated and waste places, throughont Europe and Russian Asia to N.W. India. Widely scattered over various parts of Britain, but not so common with us as on the Continent. Fl, spring and summer.

2. T. perfoliatum, Linn. (fig. 97). Perfoliate P.-A glabrous annnal, branching at the base, or nearly simple, the stem ascending or erect, 3 to 6 inches high. Radical leaves spreading or tufted, stalked, ovate or orbicular; upper stem-leaves ovate or oblong, clasping the stem with rather large rounded auricles. Pods not half the size of those of $T$. arvense, with narrower wings, and the notch much broader and more open. Style nearly as long, or longer than the notch. Seeds nsually 4 in each cell.

In stony pastures and waste places, chiefly in limestone districts, in central and sonthern Europe, and temperate Asia. In Britain apparently confined to a few localities in E. Gloucestershire. Fl. spring.

3. T. alpestre, Linn. (fig. 98). Alpine P.-A glabrous biennial or perennial, forming a shortly branched or tufted stock, with obovate oval or oblong, stalked, radical leares. Stems simple, erect or ascending, about 6 inches high; the leaves narrow, clasping the stem witb 
small auricles. Flowers nsually larger than in the last two. Pod about 3 lines long, but not so broad as in T. perfoliatum, especially at the base, the wings rounded at the top, leaving a broad but not a deep notch between them. Style prominent. Seeds 6 or 8 in each cell.

In mountain pastures, in limestone districts, in Europe, extending northward to southern Sweden, and eastward to the Himalaya. In Britain chiefly on the hilly mountains of England, in Wales and Scotland. Fl. summer. [Slight varieties, depending on the depth of the noteh of the pod and length of the style, have been regarded as species by вome authors.]

\section{TEESDALIA. TEESDALIA.}

Dwarf annuals, with white flowers, two petals larger than the two others, as in Iberis; but the longer filaments bave a scale-like appendage near their base, and the pod has 2 seeds in each cell.

A genus confined to two Kuropean species.

1. T. nudicaulis, Br. (fig. 99). Common T.-Leaves radical and spreading, about half an inch long or but little more, usually pinnate, the terminal lobe larger, obovate or orbicular, glabrous or with a few stiff hairs. Flower-stems 2 or 3 inches high, erect and leafless, or the lateral ones ratler longer, ascending, with 1 or 2 small entire or pinnate leaves. Flowers very small. Pods in short racemes, nearly orbicular, about $1 \frac{1}{2}$ lines in diameter, flat, narrowly winged round the edge, and notched at the top.

On sandy and gravelly banks and waste places, in central and southern Europe and western Asia. Rather generally distributed over England and southern Scotland, though not a very common plant, and not in Ireland. Flo at any time from spring to autumn.

\section{IBERIS. CANDYTUFT.}

Glabrous or minutely downy annuals or branching perennials, with narrow or pinnatifid leaves, and white or pink flowers ; two adjoining exterior petals larger than the two others. Filaments without appendages. l'od orbicular or oval, laterally flattened (at right angles to the narrow partition), notched at the top, the valves boat-shaped, the keel or midrib expanded into a wing; the cells 1 -seeded, the radicle accumbent.

A genus of several south European and western Asiatic species, some of which are cultivated in our flower-gardens under the name of Candytufts, and all readily known by the unequal petals.

1. I. amara, Linn. (fig. 100). Bitter C.-An erect, rather stiff, very bitter annual, 6 to 12 inches high, with a few erect branches forming a terminal flat corymb. Leaves oblong-lanceolate or broadly linear, with a few coarse teeth, or slightly pinnatifid, seldom quite entire. Flowers white. Pod nearly orbicular, the long style projecting from the notch at the top.

Common as a weed of cultivation in western, central, and southern Europe. Appears occasionally in cornfields in England and Scotland especially in limestope districts, $F l$, with the corn 


\section{HUTCHINSIA. HUTCHINSIA.}

Dwarf annuals or perennials, with pinnate leaves and white flowers separated from Lepidium by having 2 seeds in each cell of the pod.

A genus limited by some to one species, by others extended to a few allied ones from southern Europe and Russian Asia, or also to some perennials from the ligh mountains of central and southern Europe.

1. H. petræa, Br. (fig. 101). Rock H.-A glabrous, delicate, erect annual, seldom 3 inches high, branching at the base. Radical leaves about half an inch long, and pinnate; stem-leaves few and smaller, with fewer and narrower segments. Flowers very minute. Pod oval, rather more than a line long. Radicle of the seeds incumbent on the back of one of the cotyledons, but very near its edge.

On limestone rocks, old walls, and stony places, in central and southern Europe, from Sweden to the Crimea. Confined, in Britain, to the limestone tracts of the west of England, Dumfries, and Wales, the walls of Eltham churchyard and of a cemetery at Cork in Ireland. Fl. spring.

\section{CAPSElla. CAPSELL.}

Annuals, with entire or pinnate leaves and small white or purplish flowers, distinguished from Lepidium and Hutchinsia by having several seeds in each cell of the pod, from 'Thlaspi by the pod not winged, and the radicle incumbent on the back of one of the cotyledons.

A genus of a single one, or of two or three, European and Asiatic species, according to the limits assigned to it by different botanists.

1. C. Bursa-pastoris, Moench. (fig. 102). Shepherd's-purse.-Root tapering, often to a great depth. Radical leaves spread on the ground, pinnatifid, with a larger ovate or triangular terminal lobe, or sometimes entire. Stem erect, from a few inches to above a foot high, rather rough and often hairy, with a few oblong or lanceolate, entire or toothed leares, clasping the stem with projecting auricles. Pods in a long loose raceme, nsually triangular, truncate at the top, with the angles slightly rounded, and base narrowed, sometimes notched at the top and almost obcordate. Seeds 10 to 12 in each cell.

Probably of European or west Asiatic origin, but now one of the commonest weeds in cultivated and waste places, nearly all over the globe withont the tropics. Abundant in Britain. Fl. ncarly all the year round.

\section{LEPIDIUM. CRESS.}

Annuals or perennials, glabrous or hairy, with numerous small white flowers. Petals equal. Stamens without appendages. Pods ovate or shortly oblong, rarely orbicular, compressed laterally (at right angles to the narrow partition); the valves boat-shaped, either without wings or the keel expanded into a narrow wing at the top. Seeds one in each cell, the radicle usually incumbent on the back of the cotyledons.

A numerous and rather natural widely diffused genus. It is readily distinguished from Iberis by the small petals all equal, and from all other British siliculose Crucifers, with laterally compressed pods, except Sencbicra, by the single secds in each cell. 
Pods winged at the wp.

Tall annual with a single stem. Style short

Perennial, branching at the base. Style longer than the notch of the pod.

Pod not winged.

Stem stout and erect. Leaves oblong or broadly lanceolate.

Upper leaves auricled and clasping the stem. Pud 2 lines broad

Upper leaves narrowed at the base. Pod 1 line brosi :

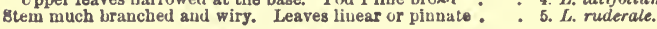

\section{L. Smithii.}

The common Cress of onr gardens is the $L$. sativum, a native of west central Asia.

1. L. campestre, Br. (fig. 103). Mithridate Pepperwort.-An annual or biennial, nearly a foot high, more or less ho.ury with minute scaly hairs, or rarely quite glabrous; the stem solitary, erect or nearly so, usually branched in the upper part. Radical leaves stalked, oblong, entire or pinnatifid, with a large terminal lobe; the upper ones oblong or lanceolate, entire or slightly toothed, clisping the stem with short, pointed auricles. Flowers very small. Anthers yellow. Pods numerous, on spreading pedicels, broadly ovate, thick when ripe, nearly surrounded by the wing, which is narrow at the base, but broad and slightly notched at the top, with a short, often very minute style.

In hilly pastures, cultivated and waste places, over the greater part of Europe, from Sweden to the Caucasus. Generally distributed over England, Ireland, and southern Scotland. Fl. summer.

2. I. Smithii, Hook. (fig. 104). Smith's C.-Very near L. campestre, but forms a more or less perennial stock. The stems are several together, much shorter, and decumbent at the base; the foliage more hairy, the flowers rather larger, the anthers violet, and the pod glabrous.

In hilly pastures, cultivated and waste places in western Europe, from Spain and Portugal, up western France, to England, Ireland, and southern Scotland. Fl. spring and autumn. It should perhaps be united as a mere variety with the L. hirtum from south-western Europe, which is hairy all over, including the pods, and the L. heterophyllum from western Europe, which is glabrous all over.

3. L. Draba, Linn. (fig. 105). Houry C.-A perennial about a foot high, more or less hoary with a minute down. Stems stout and erect, branching above. Leaves oblung or broadly lanceolate, usually slightly toothed, $1 \frac{1}{2}$ to 2 inches long, the lower one stalked, the upper ones clasping the stem with projecting auricles. Racemes not much lengthened, forming a broad flat corymb. Pods about 2 lines broad and not quite so long, very thick, the valves sharply keeled, but not winged, the style prominent.

In waste places, by $10 a d s i d e s, ~ \& c . ;$ common in central and southern Europe, and temperate Russian Asia. Rare in Britain, and only as an introduced plant in a few English counties. Fl. spring or early summer.

4. L. latifolium, Linn. (fig. 106). Ditlander.-A stout, erect perennial, attaining 2 feet or more in height, of a pale green, but glabrous. Stems much branched above, but forming a large loose panicle, not a flat corymb as in L. Draba. Radical leaves large, ovate, toothed, on long stalks; stem-leaves oblong or broadly lanceolate, 2 or $\$$ inches long, the lower ones stalked and mostly toothed, the upper 
sessile, but tapering at the base, and often entire. Pods about 1 line long and broad, the valves scarcely keeled and not winged, the stylo almost imperceptible.

In waste places, especially near the sea, widely distributed over central and sonthern Europe and temperate Asia, extending northwards to Sweden. In Britain indigenous on the coasts of England from Wales to Norfolk, and near Cork in Ireland, introduced in other localities. Fl. summer.

5. I. ruderale, Linn. (fig. 107). Narrow-leared C.-A glabrons annual, 6 inches to a foot high, with very much branched wiry stems. The radical and lower leaves pinnatifid, with narrow lobes; the npper ones entire or nearly so, and linear. Flowers very minute, generally withont petals, and only 2 stamens. Pods small, nearly orbicular; the valves keeled or sometimes slightly winged at the top; the style minute.

In dry gravelly soils, waste places, on rubbish and old walls, chiefly near the sea, nearly all over Europe and northern Asia, except the extreme north. In Britain along the coast of England, but scarcely wild inland, or in Scotland. Fl. early summer, and often on till autumn.

\section{SENEBIERA. SENEBIERA.}

Prostrate annuals, with pinnate leaves, and short racemes of small white flowers opposite the leaves. Petals and stamens as in Lepidium. Pod laterally compressed (at right angles to the narrow partition), orbicular or broader than long, either indehiscent or separating into two nuts, each with a single seed. Radicle incumbent, but the bend is, as in Subularia, a little above the base of the cotyledons, not at their junction with the radicle.

A genus of very few species, but widely diffused over nearly the whole range of the Order.

Pods 2 lines broad, deeply wrinkled, sessile, or nearly so

Pods 1 liue broad, slightly wrinkled, on slender pedicels

1. S. Coronopus.

- 2. S. didyna.

1. S. Coronopus, Poir (fig. 108). Swine-cress, Wartcress.-A pale green, glabrous or glaucous annual, the stems, when first flowering, forming a short, close tuft, afterwards spreading along the ground to the length of 6 inches or more. Leaves once or twice pinnately divided, the segments not numerons, linear, or wedge-shaped, entire or toothed. Racemes at first forming close sessile heads, but, as the fruit ripens, lengthening out to $I$ or 2 inches. Pedicels seldom a line long. Pod about 2 lines broad and not quite so long, scarcely notched at the top, marked with deep wrinkles, which form a kind of crest round the edge; it usually remains entire when ripe. Coronopus procumbens, Gilib.

In cultivated and waste places, in central and sonthern Europe to the Caucasus, extending into Sweden. Rather plentiful in soutbern England, decreasing northwards, and local in Scotland and Ireland. Fl. summer and autumn.

2. S. didyma, Pers. (fig. 109). Lesser S.-Much like S. Coronopus in habit and foliage, but generally more slender, often sprinkled with a few hairs; the leaves rather smaller and more divided; the flowers 
smaller, in looser racemes. Pod scarcely more than a line broad, but slightly wrinkled, and separating into two ovoid nuts. Coronopus didyma, $\mathrm{Sm}$.

[Supposed to be indigenous only in the Argentine provinces of South America, and thence to have been introduced into the Old World.] In Britain on the coast $\mathbf{s}$ from Fife southwards, and S.W. Ireland. In inland districts only as an occasional straggler. Fl. all summer.

\section{ISATIS. WOAD.}

Erect annuals or biennials, with undivided leaves, the upper ones clasping the stem, and auricled. The flowers small, yellow, and numerous. Pod flat, pendulous, obovate or oblong, with a strong rib on each side, indehiscent and containing a single seed. Radicle incumbent.

A genus, spread over southern Europe and western Asia.

1. I. tinctoria, Linn. (fig. 110). Dyer's W.-Stems 18 inches to 2 or 3 feet high, branched in the upper part, glabrous and glaucous, or with a few hairs in the lower part. Radical leaves obovate or oblong, coarsely toothed and stalked, 2 to 4 inches long; the npper ones narrow and lanceolate, with prominent auricles. Pods hanging from slender pedicels, generally about 7 or 8 lines long and 2 to $2 \frac{1}{2}$ broad, and tapering to the base, but somewhat differing in size and shape.

Of south-eastern origin, formerly much cultivated in many parts of Europe and Asia, and has thence become established in stony or waste places, as far north as Sweden. Repeatedly found in several localities in Britain, but scarcely fully naturalised [except near Tewkesbury, where indeed it appears to be indigenous]. Fl. summer.

\section{CAKILE. CAKILE.}

Maritime branching annuals, with fleshy leaves and purplish or white flowers. Pod oblong-linear, somewhat compressed, without any longitudinal partition or valves, but, when ripe, separating transversely into 2 articles, the upper one mitre-shaped, deciduous, containing one erect seed ; the lower one persistent, divided into two points, and containing a pendulous ovule, which seldom enlarges into a seed. Radicle obliquely incumbent on the back or towards the edge of the coty. ledons.

A genus consisting of two species, spread over the sea-coasts of the northern hemisphere, both in the New and Old World.

1. C. maritima, Scop. (fig. 111). Sea C., Sea Rockct.-Stems hard at the base, with loose straggling branches a foot long or more, and glabrous. Leaves few, thick and fleshy, with a few distant, oblong or linear lobes. Flowers not unlike those of a Stock, but smaller. Pods on short thick pedicels, distant from each other in long racemes, when young linear or lanceolate and entire but when ripe forming the two peculiar articles above described. Radicle remarkably large.

In maritime sands and salt-marshes; on all the sea-coasts of Europe and western Asia, except the extreme north. Common all round Britain. ii. sumncr and aulumin. 


\section{CRAMBE. CRAMBE.}

Erect, stout perennials, or, in some foreign species, annuals, with toothed or divided leaves, and loose panicles of white flowers. Pod apparently stalked in the calyx (that is, supported on a stalk-liko abortive lower article), globular, indehiscent, with one sced. Radicle incumbent on the back of the cotyledons, which are folded over it as in Brassica.

A well-characterised and natural genus, containing several south European, west Asiatic, and Canary Island species.

1. C. maritima, Linn. (fig. 112). Seakale.-A glabrous plant, of a glaucons grecn, forming a thick, hard, perennial stock. Stems branched, about 2 feet high. Lower leaves stalked, large, rather thick, broadly oblong or rounded, waved and coarsely toothed or pinnatifid; the upper leaves few and smaller. Panicle large and much branched. Filaments of the longer stamens forked. Pod 3 or 4 lines diameter; the abortive article or stalk within the calyx about a line long or rather more.

In maritime sands and stony places in western Europe, and Baltic, reappearing on the Black Sea. In Britain, scattered along all the coasts. Introduced into our gardens two centuries ago from Devonshire. Fl. early summer.

\section{RAPHANOS. RADISH.}

Coarse, often hairy annuals or biennials; the lower leaves pinnatifid or pinnatc, the flowers rather large. Pod more or less elongated, thick, pointed, indehiscent, more or less contracted or even jointed between the seeds, without any longitudinal partition whon ripe, but containing several seeds, separated by a pithy substance filling the pod. Radicle incumbent on the back of the cotyledons, which are folded over it.

A genus well characterised by the pod, but consisting of very few species, or perhaps of more or less permanent races of one species. Our garden Radish is unknown in a wild state, but some Mediterranean varieties of the wild one come so near to it as to suggest its being a cultivated race of that species, although placed by some botanists in a distinct genus.

1. R. Raphanistrum, Linn. (fig. 113). Wild $R$., Jointed or White Charlock.-An erect or spreading annual or biennial, 1 to 2 feet high, much branched, with a fow stiff hairs on the base of the stem. Leaves pinnately divided or lobed, the terminal segment large, obovate or oblong, and rough with short hairs; the upper leaves often narrow and entire. Flowers of the size of those of the Charlock, the calyx very erect, the petals either white, with coloured veins, or pale yellow, or lilac. Pod usually 1 to $1 \frac{1}{2}$ inches long, nearly cylindrical when fresh, and terminating in a long, pointed, or conical style, when dry more or less furrowed longitudinally, and often separating in joints between the seeds.

A common weed of cultivation, throughout Europe and temperate Asia, and equally abundant in Britain. Fl. summer and autumn. A sea-coast variety, particularly abundant round the Mediterranean, but e stending up the shores of western Europe to those of England, 
Ireland, and southern Scotland, has been distinguished as $R$. maritimus, Sm. It has the leaves usually more divided, the pods often longer, and is more apt to last a second year, but all the other characters derived from the colour of the flower, the comparative length of the strle and pod, the depth of the furrows, \&c., occur also on inland fpecimens, at least on the Continent. [R. maritimus, Sm., is confined to the sea-coast, and no doubt indigenous; $R$. Raphanistrum is a cornfield plant, the origin of which is doubtful.]

\section{RESEDACE\&. THE MIGNONETTE FAMILY.}

A small family, limited in Britain to tho single genus Reseda. The exotic genera, of very few species each, associated with it, originally formed part of it, but have been separated on account chiefly of the slight differences in the structure of the fruit.

\section{RESEDA. MIGNONETTE.}

Herbs, either annual or with a short perenntal stock, alternate leaves, no stipules, and small greenish-yellow or white flowers, in long terminal racemes or spikes. Sepals 4 to 6 . Petals as many, small, narrow, and some or all of them deeply divided. Stamens indefinite, but not numerous (about 8 to 24), inserted under the ovary on a glandular disk. Ovary single, with short teeth, each terminating in a very short style or sessile stigma. Capsule green, open at the top long before maturity, containing several seeds, arranged along as many parietal placentas as there were styles. Seeds without albumen.

The species are rather numerous, and chiefly confined to Europe, northern Africa, and western Asia. 'The narrow, insignificant, divided petals, and open capsule, are sufficient to distinguish them from all other British plants.

Jeaves entire . . . . . . . . . 1. R. luteola.

Leaves cut or divided.

Petals white, sll divided. Leaves pinnate, with many entire seg-

ments
Petals greenish-yellow, one or two of them undivided. Leaves trifid or pinnate, with few segments, often again divided $\quad$ 2. R. lutea.

The sweet Mignonctte of our gardens ( $R$. odorata) is a native of Egypt, neariy allied to $R$. lutca.

1. R. luteola, Linn. (fig. 114). Weld, Yellow W'eed, or Dyer's Rocket. -An erect glabrous annual or biennial, with a hard, stiff, searcely branched stem, 1 to 2 feet high. Leaves linear or lanceolate, 2 to 3 inches long, entire, but slightly waved on the edges. Flowers of a yellowish green, in long stiff spikes. Sepals 4 . Petals 4 or 5 , very unequal, the 1 or 2 lower ones entire, the upper ones divided into 2 to 5 lobes. Capsules nearly globular, with 3 or sometimes 4 teeth, and twice as many external furrows.

In waste places, throughout temperate and southern Europe, from Sweden to the Caucasus. Extends over the greater part of Britain, but decreases northward, although found occasionally as far as Rossshire. Loug cultivated for the use of dyers, it may not improbably be 
an introduced plant with us, as in northern Europe generally. Fl. summer.

2. R. Iutea, Linn. (fig. 115). Cut-leaved M.-Not so tall as R. Luteola, much more branched, and less erect. Leaves very variable, but always deeply divided, most of them once or twice trifid, but occasionally pinnatifid, with few oblong or linear segments, much waved on the margins. Flowers on slender pedicels, in long racemes. Sepals usually 6 , but sometimes only 5 . Petals as many, of a greenish yellow, the lowest entire or 2-cleft, the others irregularly divided into 2,3 , or 4 . Capsule oblong, with 3 , rarely 4, very short teeth.

In waste places, especially in limestone districts, in central and southern Europe, to the Caucasus. In Britain, in south-eastern England, on the limestones of the western and northern counties of Ireland, and on the east of Scotland to Aberdeen. Fl summer.

3. R. alba, Linn. (fig. 116). White M.-A tall perennial, the lowe. leaves crowded on the stock or base of the stem, and all deeply pinnate, with numerous (9 to 21) linear or lanceolate segments, entire, but waved on the margins. Flowers on short pedicels, much whiter than in the last two species. Sepals 5 or 6 . Petals as many, all equal, and 3-cleft. Capsule ovoid, with 4 , or sometimes 3,5 , or 6 teeth. $R$. fruticulosa, Linn.

A Mediterranean species, long since introduced into gardens, and occurs as an outcast on the south coasts of England and Ireland. Fl. oummer.

\section{CISTACE正. THE CISTUS FAMILY.}

Shrubs or herbs, with opposite, or, in a few exotic species, alternate leaves, with or without stipules; the flowers in ter. minal racemes. Sepals 3, nearly equal, overlapping each other in the bud, with or without 2 smaller outer ones. Petals 5, or rarely fewer, broadly spreading. Stamens numerous, hypogynous, and free. Ovary and style single. Capsule 1-celled, or incompletely divided into several cells, opening in 3,5 , or 10 valves, which bear along their centre as many placentas or imperfect partitions. Seeds several, the embryo curved, imbedded in albumen.

A small Order, spread chiefly over southern and western Europe and northern Africa, with a few American species. It corresponds with the old Linnean genus Cistus, which is now limited to the large-flowered species with 5 valves to the capsule. They are none of them British, but include the well-known Gum-Cistuses of our gardens.

\section{HELIANTHEMUM. ROCKROSE.}

Low or diffuse undershrubs or herbs, with the flowers smaller than an the true Cistuses, and the capsule opening in 3 valves only. The ceaves in the British species are all opposite, and the 2 outer sepals ery seldom wanting. 
The geographical range is the same as that of the family.

Erect annual

Diffuse, much brsnched nndershrubs.

No stipules to the lesves (flowers small)

A pair of stipules at the base of each leat.

Ieaves green above, nearly fist. Flowers ususlly yellow

Leaves whitish on both sides, the edges rolled back. Fiowers always white .
1. H. guttatum.

2. H. canum.

3. $\boldsymbol{H}$. vulgare.

4. II. potifolium.

1. H. guttatum, Mill. (fig. 117). Spotted R.-An erect, hairy annual, often branched at the base, from a few inches to ncar a foot high. Leaves narrow-oblong or lanceolate, or the lower ones obovate and very obtuse ; the upper ones more pointed, and often bearing stipules, which are wanting to the lower ones. Racemes loose, with small flowers on slender pedicels. Petals very fugacious, yellow, with or without a dark spot at their base, varying in size, and in being entire or jagged. Style straight.

In pastures, fields, and waste places, very common in western and southern Europe, extending northward through France to the Channel Islands, Cork in Ireland, and Holyhead mountain in Anglesea. Fl. summer. The Anglesea specimens are rather stunted, with broader leaves and usually bracteate pedicels (those of guttatum proper being ebracteate); they form the $H$. Breweri, Planch.

2. H. canum, Dun. (fig. 118). Hoary R.-A much smaller and more compact undershrub than $H$. vulgare. The leaves much smaller, seldom 6 lines long, white underneath, or sometimes on both sides, and all without stipnles. Racemes numerous and short, with small bracts at the base of the pedicels. Flowers yellow, very much smaller than in II. vulgare. Style sigmoid. $I I$. marifolium, Mill., the earliest name.

1n rocky, hilly districts, in central, western, and southern Europe, extending to Sweden. Rather rare in Britain, on limestone rocks in western and north-western England, and a form with the leaves nearly glabrous above, $\boldsymbol{H}$. vineale, Pers., in Clare and the isle of Aran on the coast of Ireland. Fl. summer.

3. H. vulgare, Gærtn. (fig. 119). Common R.-A low, diffuse under* shrub, with a short, much branched, woody stem, and annual procumbent or ascending flowering branches, from a few inches to near a foot long. Leaves shortly stalked, mostly oblong, but varying from ovate to lanceolate, scarcely curved down on the edges, glabrous or slightly hairy, green above, and more or less hoary or white underneath. Stipules linear-lanceolate, 1 to 2 or even 3 lines long. Racemes loose, the pedicels defleeted before and after flowering. The 3 larger sepals marked with 3 very prominent ribs, and often scarious between them ; the 2 outer very small. Petals broad spreading, bright yellow, near 6 lines long and broad. Style bent npwards.

In dry meadows and pastures, throughout Europe and western Asia. Common in England and eastern Scotland, but unknown in Ireland. $F l$. all summer. A curious accidental deformity, H. surrejanum, Mill., occasionally seen in gardens, and supposed to have been originally found near Croydon in Surrey, has small, narrow, deeply cut petals. The Rockroses of our gardens are chiefly varieties of this species, which, under cultivation, varies much in the colour of its flowers.

4. H. polifolium, Mill. (fig. 120). White R.-Very near H. vulgare, and by some considered as one of its numerous varieties. It is less straggling 
the leaves are narrow, much rolled back on the edges, and hoary on both sides, and the flowers are always white.

On limestone, rocky wastes, common in south-western and some parte of central Enrope. In Britain only on Brean Downs in Soworsetshire, and Babbicombe, near Torquay, in Devonshire. Fl. aummer.

\section{VIOLACEE. THE VIOLET FAMILY.}

A family limited in Europe to the single genus Viola. The exotic genera associated with it agree with it in their 5 sepals and petals, their 5 anthers placed on the inner surface of the short broad filaments, their 1-celled ovary with three parietal placentas, and their albuminous seeds with a straight embryo. They are chiefly tropical, and many are trees or shrubs, with small, almost regular flowers.

\section{VIOLA. VIOLET.}

Low annuals or perennials, with stipulate, radical or alternate leaves, and (in the British species) axillary or radical 1-flowered peduncles. Sepals 5, produced at the base beyond their insertion. Corolla irregular, of 5 spreading petals, the lowest produced into a spur at the base. Stamens 5, the filaments very short and broad, bearing the anthers on their inner surface, and more or less cohering in a ring round the ovary, the 2 lower ones lengthened into a short spur at the base. Style single, with a dilated or thickened or hooked stigma. Ovary 1-celled, with several ovules, inserted on 3 parietal placentas. Fruit a capsule, opening in 3 valves, which become folded lengthwise so as to clasp tightly the shining seeds.

A considerable genus, widely spread over the greater part of the globe, and readily distinguished by the stamens and spurred flowers from all British Polypetals except Impatiens, which is at once known by the number and shape of the sepals and petals. In all the British species, except $V$. tricolor, the showy, perfect flowers seldom set their fruits. The capsules and seeds are generally produced by minute flowers, almost without petals or stamens, which appear later in the year.

Sepals obtuse. Flowers and leaves apparently radical. Stem very short.

Leaves glabrous, reniform. Flowers small, scentless . . . 1. V. palustric.

Leaves more or less downy or hairy.

Flowers sweet-scented. Lateral scions creeping . . . 2. V. odorata

Flowers scentless. No creeping scions. Leaves very hairy : 3. V. hirta. Senals acute. No creeping scions. Leaves pubescent : 4. V. arenaria. Sepals acute. Annual flowering branches more or less elongated.

Stipules narrow, entire, ciliate or toothed. Stigma hooked and pointed.

stipules deeply divided. Stigma thickened, with a tuft of hairs below it.

\section{V. canina.}

6. V. tricolor.

The $V$. calcarata from the Alps, the $V$. cornuta from the Pyrenees, and a few other exotic species, occur in our gardens, and from some of them, especially $V$. cornuta, many showy varieties have been produced.

1. V. palustris, Linn. (fig. 121). Marsh V.-The stock occasionally emits runners or scions, like $\boldsymbol{V}$. odorata, but it is a smaller plant, and perfectly glabrous. excent, very rarely a few hairs on the peduncles 
Leaves reniform or orbicular, and cordate at the base, very slightly crenate. Flowers smaller than in $V$. odorata, pale blue, with purple streaks, and scentless; the sepals obtuse, the spur very short. Stigma broad, oblique.

In marshy grounds and bogs, over northern and central Europe, Asia, and North America. Abundant in Scotland, but decreasing southwards, and local in southern England. Common in some parts of Ireland. Flo spring and early summer; the petalless flowers in summer.

2. V. odorata, Linn. (fig. 122). Sweet V.-Perennial stock short, but sometimes branched, knotted with the remains of the old leaf-stalks and stipules, and usually emitting creeping runners or scions. Leaves in radical (or rather terminal) tufts, broadly cordate, rounded at the top, and crenate, downy or shortly hairy, with rather long stalks. Stipules narrow-lanceolate or linear, and entire. Peduncles about as long as the leaf-stalks, with a pair of small bracts about half way up. Flowers nodding, of the bluish-purple colour named after them, or white, more or less scented. Sepals obtuse. Spur of the lower petal short. Stigma pointed, horizontal or turned downwards.

On banks, under hedges, in woods, and on the borders of meadows, widely spread over Europe and Asia, extending northward to temperate Sweden. Common in many parts of Britain, but absent over large districts, and only a doubtful native of Ireland. Fl. early spring, or some garden varieties in autumn; the small petalless flowers that produce the seeds may be seen nearly all summer. Some botanists distinguish several species from minute differences in the shape and hairs of the petals.

[ $V$. permixta, Jord., is a form with scentless flowers, and scions that do not root. $\boldsymbol{V}$. sepincola, Jord., is another scentless one with darker flowers, more hairy leaves, and rooting scions. Both of them are supposed hybrids with $V$. hirta.]

3. V. hirta, Linn. (fig. 123). Hairy V.-Very near V. odorata, and most probably a mere variety, seldom producing runners, more hairy in all its parts, with narrower and less obtuse leaves, and scentless flowers.

Chiefly in limestone districts, in rocky places, open woods, and pastures, with a more extended area than $\boldsymbol{V}$. odorata, penetrating further north in Scandinavia, and yet more common in sonthern Europe to the Caucasus. Appears more frequent in eastern Britain, and less so in the west than $V$. odorata; very rare in Ireland. $F l$. rather later than $\boldsymbol{V}$. odorata. [V. calcarea, Bab., is a stunted form from very dry places in England.]

4. V. arenaria, Dec. (fig. 124). Sand $\nabla$.-A small, tufted, pubescent or hoary stemless perennial. Leaves orbicular-ovate, obtuse, much rounder than in $\boldsymbol{V}$. canina. Flowers pale blue, on short axillary branches from a compact rosette of leaves; stipnles small, fimbriate. Sepals lanceolate; acute, bases square in fruit. Petals broad, spur short. Capsule oblong, pubescent.

A native of sandy and stony places in Europe from Norway south. wards, and in North Asia. In Britain, found only in the mountains of Upper Teesdale, and there extremely rare. Fl. summer.

5. V. canina, Linn. (fig. 125). Dog V.-Stock short, with the radicai leaves tnfted, and the flowering branches at first so short as to give the plant much resemblance to the sweet $V_{\text {. }}$; but as the season advances the lateral flowering branches are always more or less elongated, ascend. 
ing or erect, from a few inches to near a fcot long. Leaves ovatecordate, varying from nearly orbicular to broadly lanceolate, and pointed. Flowers much like those of $V$. odorata, but usually paler, always scentless, and the sepals pointed. The complete flowers set their fruit more frequently than in $V$. odorata, but yet the greater number of capsules are produced by the later petalless flowers.

Very common in a variety of situations, thronghont Europe and northern Asia. Abundant in Britain. Fl. spring and early summer; the petalless flowers all summer. It varies much in size, in the shape of the leaves, and in the mode of development of the flowering branches, and has been divided into a number of species, which may be reduced to three principal varieties, viz:-

a. V. pumila, Hook, and Arn. Usually only 2 or 3 inches high, the flowering branches frequently perennial at the base, and the capsules almost always obtuse, being produced by the petalless flowers. Grows in open, dry, or sandy situations.

b. V. sylvatica, Fries. Common Dog V.-Six inches bigh or more; the flowering branches all lateral. Leaves ovate-cordate. Capsules often pointed, and produced by the complete flowers. Hedge-banks and thickets. V. Riviniana, Reichb.

c. V. stagnina, Kit. Flowering branches more erect than in the common variety, often much longer, although sometimes short. Leaves ovate-lanceolate, from one and a balf to three times as long as broad, and cordate at the base. Flowers very pale or white. Very luxuriant on boggy heaths, dwarf near the seaside. Baker distinguishes two British forms of this variety, $\boldsymbol{V}$. stagnina, with, and $V$. lactea, without creeping stolons.

6. V. tricolor, Linn. (fig. 126). Ileartsease. - A most variable plant, but easily recognised by the branching stem, the large leaf-like stipules deeply divided into several linear or oblong lobes, the central or terminal one the largest, broadest, and most obtuse, and by the style thickened at the top into an almost globular oblique stigma. The plant is glabrous, or slightly downy. Leaves stalked, from narrow oblong to ovate or cordate, always obtuse and slightly crenate. Flowers purple, whitish, or yellow, or with a mixture of these colours ; the two upper pairs of petals slightly overlapping each other, and usnally more coloured, the lower petals always broadest, and generally yellow at the base.

On hilly pastures and banks, in cultivated and waste places throughout Europe and Asia, and abundant in Britain, especially as a weed of cultivation. Fl. from spring till autumn. This is the most variable of all our Violets, and has been divided into more than a dozen species. The following are the most prominent forms, which, however constantly different they may sometimes appear, at others pass gradually into each other.

a. V. arvensis, Murr., or Field Pansy. A slender annual, from 2 or 3 inches to 6 inches or a foot long. The lobes of the stipules and leaven narrow; the petals small, sometimes shorter than the calyx, pale yellow nearly white, or the upper ones pale purple. A very common weed of cultivation.

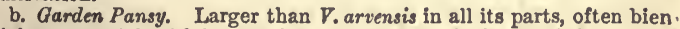
nial or perennial, with broader leaves. The terminal lobe of the stipule larger; the petals much larger than the calyx, very variable in colour, It sows itself readily, but is apt to degenerate into $V$. arvensis. 
c. V. lutea, Huds. Usually perennial. Foliage of the compact forms of the garden Pansy. Flowers large, and richly coloured, often yellow. In mountain pastures in Wales, northern England, and western Scotland. V. Curtisii, Forst., is an intermediate form between this and the garden Pansy. [Var. hamulata, Baker, is a small-flowered form of this from Yorkshire, which resembles a perennial arvensis.]

\section{POLYGALACE尼. THE MILKWORT FAMILY.}

$\Lambda$ family represented in Europe only by Polygala itself. The other genera associated with it are chiefly tropical or natives of the southern hemisphere, differing from Polyyala in the form and consistence of their fruit, or in minor details in the structure of their flowers.

\section{POLTGALA. MILKWORT.}

Herbs or shrubs, with entire lcaves, usually alternate, no stipules, and very irregular flowers in terminal racemes. Sepals 5 , of which the 2 inner are large, usually petal-like, and commonly called wings. l'etals 3,4 , or 5 , the lowest very small and subulate, and all more or less united with the stamens. Stamens united in 2 parcels, each with 4 anthers opening by pores at the summit. Style 1, with a single stigma. Ovary and capsule flat, 2 -celled, with a single pendulous seed in each cell. Seeds albuminons and cotyledons thin in the British species; cotyledons fleshy and no albumen in some exotic ones.

A very numercus genus, widely diffused over most parts of the globe. Several were formerly showy South African species cultivated in our greenhouses.

1. P. vulgaris, Linn. (fig. 127). Common Mlilkwort.-A glabrous or nearly glabrous perennial, with a short tufted or almost woody stock, and numerous diffuse or ascending branches, from an inch or two to near a foot long, occasionally flowering the first year, so as to appear annual. Leaves crowded at the base, the lowest obovate or even orbicular, especially in young plants, the upper ones oblong-lanceolate, or even lincar, 2 or 3 lines to near an inch long. Flowers usually bright blue or pink, hanging on short pedicels in elegant terminal racemes, with a small bract at the base of each pedicel. Three outer sepals small, linear, and greenish, the 2 wings twice as large, obovate or oblong, coloured and elegantly veincd; after flowering they lie flat on the capsule, but become greener. Petals much smaller, the 2 lateral oblong-linear, the lowest keel-shaped, and tipped with a little crest. Style dilated at the top. Capsule green, orbicular, surrounded by a narrow wing, notched at the top. Seeds oblong, downy.

In meadows and pastures, heaths, under bedges, \&c., throughont Europe and Russian Asia, except the extreme nortb. Abundant in Britain. Fl. all summer. It varies much in the relative size of the lower and npper leaves, in the size and colour of the flowers, in the veins and the breadth of the wings, \&c., and many forms which have oppeared constant in particular localities have at various times been 
characterised as species. The most remarkable is $P$. amara, Linn. ( $P$. uliginosa, Reichb.), a small plant, with the lower leaves obovate and spreading, precisely like some forms of the common variety, except that the flowers are rosy, and the inner sepals or wings are narrower, with their veins all simply branched, not anastomosing, as in all other British varieties. It is a Continental variety, which had only been found in Britain on Cronkley Fell, in North Yorkshire; but a blueflowered form ( $P$. austriaca, Crantz) has been detected in Kent by Mr. Duthie. [Five British species of Polygala (or three, with two varieties of one of them) are now generally recognised: 1. P. vulgaris, Linn., with scattered leaves, and the veins of the wings copiously netted; of this there are two varieties, $P$. oxypter $a$, Reichb., with flexuous branches, linear leaves, and cuneate wings shorter than the capsule; found in dry sandy and rocky places; and $P$. depressa, Wend (serpyllacea, Weih., ciliata, Lebel), with sub-opposite distribons leaves, and broad wings ; a common form. 2. $P$. calcarea, F. Schultz, with rosulatc radical leaves, branches umbellately spreading from the root, the vefas of the wings sparingly or not at all netted, and an obcordate capsule; a native of dry rocky places in Scuth-east England. 3. P. amara, Linn., much the sinallest species, with rosulate spathulate radical leares, axillary flower. ing branches, narrow wings, with nearly simple veins, and an orbicular capsule. Of this there are two very different looking forms, namely, $P$. amara, Linn. (uliginosa, Fries.), a mountain plant with pink flowers, found only on Cronkley Fell in Yorkshire, where it is extremely rare, and a larger blue-flowered plant, $P$. austriaca, Crantz, found only in Kent. Owing to the variability of their characters, as found in exotic specimens, Bentham regarded all these as forms of $P$. vulgaris.]

\section{FRANKENIACEA. THE FRANKENIA FAMILY.}

An Order limited to the genus Frankenia, which differs from the Caryophyllacece in the parietal placentas of its ovary and capsule, and from Hypericinece in its valvate calyx and definite stamens, and in its habit.

\section{FRANKENIA. FRANKENIA.}

Prostrate or spreading sea-coast herbs or undershrubs, with opposite often clustered, small leaves, and no stipules, the flowers sessile in the upper axils. Sepals combined into a tubular calyx with 4 or 5 teeth. Petals 4 or 5, with long claws and spreading laminas. Stamens 4 or 5, alternating with the petals, and nsually 2 or 3 additional ones opposite the petals. Ovary single, with one style, shortly 2-, 3-, or 4-cleft. Capsule opening in 2,3 , or 4 valves. Seeds attached to the centre of the ralves, very small, with a straight embryo imbedded in albumen.

A genus of few species, but widely spread over the sea-coasts of nearly all the temperate and warmer regions of the globe.

1. F. løvis, Linn. (fig. 128). Sea-heath.-A diffuse, much-branched perennial, spreading to the extent of 6 or 8 inches; glabrons or nearly so in the British specimens. Leaves crowded in little opposite clusters along the branches, small, rather thick, and appearing linear from theis edges being closely ralled down. Flowers few, sessile among the upper 
leaves, forming little terminal leafy heads or short spikes. Caylx furrowed, about the length of the leaves. Petals small, pink.

In maritime sands and salt-marshes, common round the Mediterranean and in Asia, extends up the western coasts of Spain and France, and varieties are abundant in similar localities in the southern hemisphere. In Britain it is only on the south-eastern coasts of England, from Yarmouth to Kent. Fl. summer. The hairy variety, $F$. pulverulenta, of ten distinguished as a species, common in the south, does not appear to extend to Britain.

\section{CAROPHYLLACEA. THE PINK FAMILY.}

Annual or perennial herbs, with opposite entire lcaves and no stipules, or, in a vory few genera, small scarious stipules; the branches usually knotted at each pair of leaves; the flowers not yellow, usually in dichotomous cymes or panicles. Sepals 4 or 5 , free, or united into a tubular calyx. Petals as many, twisted in the bud, sometimes minute or wanting. Staniens free, twice as many as the petals, or fewer, inscrted under the ovary. Styles 2 to 5, linear, stigmatic along their whole lengtl. Capsule 1-celled, or divided into cells at the base only, opening at the top into as many, or twice as many teeth or valves as there are styles. Seeds several, attached to a shorter or longer central column; embryo curved round a mealy albumen or very rarely nearly straight.

A considerable family, widely spread over the globe, most numerous in temperate regions, especially in the northern hemisphere, extending into the Arctic Circle, and to the summits of the Alps, but rare within the tropics. The species are readily distinguished by their foliage and habit from all British polypetalous plants, except Frankenia, Elatine, and Linum catharticum, which have their ovary and capsule completely divided into cells, and Paronychiacea, which have but one seed in the ovary and capsule.

The genera into which the species are distributed are often very arti. ficial, depending on the number of sepals, petals, stamens, or styles. These numbers are not indeed strictly constant, even in different flowers of the same individual; but in general by far the greater number of flowers in each individual will be found to agree in this respect with the characters assigned to the genus to which it belongs. Care must therefore be taken, especially in the smaller-flowered Alsinece, to count the number of parts in several flowers wherever any hesitation is felt as to the genus it should be referred to.

\section{Sub-order 1. SILIN $\mathbf{R}$.}

\section{Sepals united in a tubular or campanulate calyx.}

Two or four scales or bracts closely embraclng the base or

the whole of the calyx

No scales at the base of the calyr.

Styles 2

Btyles 3 :
Btyles 6 (rarely 
Sub-order 2. ALSIN 2 a.

Sepals free, or only very slightly connected at the base.

imall, white, scaly stipules at the base of the leaves.

Styles 3. Leaves linear, cylindrical, opposite, not clus-

tered
Styles 3 . Leaves flat, the upper ones apparently 4 in

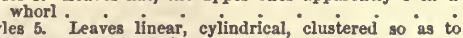

appear many in a whorl . . . 12. SYerouls.

11. SPERGULARIL.

13. Polycakpon.

Leaves without any scales or stipules at the base.

'etals entire, or slightly jagged, or none.

Sepals 4 or 5 , with the same number of stylex.

Capsule opening in 4 or 5 valves. Small, matted, fine leaved plants

Capsule opening at the to $\dot{p}$ in $\dot{8}$ or $\dot{10}$ teeth.

Plant glabrous, stiff, and erect. Petals quite entire - 7. Marchl A.

Plant downy, much branched. Petals slightly notched

Sepals 5. Styles 3 (rarely 4).

Petals quite entire or 0

Petals slightly jagged

Petals 2-cleft.

Styles 3.

Capsule opening to below the middle, in 6 valves.

Capsule opening at the top, in 6 short teeth. Aljine plant, with narrow leaves.

Styles 5 (rarely 4 ).

Stem-leaves sessile. Capsule opening in 10 or 8 short

teeth-leaves cordate, stalked. Capsule opening in entire or shortly split valves

5. SAGINA.

9. Cerastil y.

6. ArENARIA.

8. Holostel y.

10. Stellaria.

Cerastiou trijynum

\section{Cerastiux,}

STRLLARIA aquatica.

Among exotic genera, several Gypsophylla, from south-eastern Europe, are occasionally cultivated in our flower-gardens, and c'uculalus baccifer, from central and southern Europe, is said to have been formerly found in the Isle of Dogs, introduced with ballast.

\section{DIANTHUS. PINK.}

Stiff perennials, or more rarely annuals, with narrow leaves. Calyx tubular, 5-toothed, clasped at the base or covered by 2, 4, or 6 broad scales or bracts. Petals nsually crenate, or jagged. Stamens 10. Styles 2. Capsule stalked within the calyx, opening in the top in 4 teeth or short valves.

A considerable genus, spread over Enrope and Asia, with a few Sonth African species. It is also one of the most natural in the family, readily known by the scales nnder the calyx.

Annuals. Flowers small, clustered together, the scales as long as the calyx.

Plant glabrous. Scales broad, dry, and scarious .
Plant slightly downy. Scales narruw, herbaceous, with long points Fiowers few on each stem, distinct, the scales much Perennials. Fiowers few on
shorter than the calyx.

Lower leaves not half an inch long, green, and loosely tufted. Calyx-teeth and scales pointed. Flowers scentless .

Iower leaves near an inch, stiff, and glaucous. Calyx teeth and
scales broad, obtuse, or with minute points. Flowers scented

1. D. prolifer.

2. D. Armeria.

Among the exotic species cultivated in gardens, are the SweetWilliam (D. barbatus), the Carnation and Clove Pink (varieties of $D$. Curyophylus), the Pheasant's-eye Pink (D. plumarius), all from central 
or southern Furope, and the last two said to establish themselves occasionally half wild on old walls, the Indian Pink (D. sinensis), \&c.

1. D. prolifer, Linn. (fig. 129). Proliferous P.-A stiff, erect, wiry, glabrous annual, simple, or with a few erect branches, 6 inches to a foot high or rather more. Leaves few, narrow, erect, and mostly pointed. Flowers small, in compact, oblong or ovoid, terminal heads, the calyx quite concealed by broad, dry, shining, almost scarious, im. bricated scales, from the top of which appear the small, spreading, pink petals.

On dry, hilly pastures, roadsides, \&c., in central and southern Europe from southern Sweden to the Caucasus. In Britain, found wild in various localities in southern and eastern England, extending northward to mid-Scotland, but not indigenous. Fl. summer and autumn.

2. D. Armeria, Linn. (fig. 130). Deptford P.-An erect annual or biennial, rather more than a foot high, slightly branched, and more or less downy with very short hairs. Leaves more herbaceous than in most Dianthi, 1 to 2 or even 3 inches long, obtuse, or the upper ones pointed. Flowers small and scentless in terminal clusters. Calyx 8 or 9 lines long, the teeth fine and pointed, the outer scales broad at the base, but tapering into fine green points, often projecting beyond the calyx. Petals narrow, pink, with white dots, crenate on the edge.

On pastures, in waste places, under hedges, \&c., in central and southern Europe to the Cancasus, and northward to southern Sweden. Not common in Britain, although it has been found in several English and $a$ few of the southern Scotch counties. Fl. summer.

3. D. deltoides, Linn. (fig. 131). Maiden P.-A low perennial, forming a loose, diffuse, leafy tuft; not of many years' duration, the flowering stems ascending glabrous, or slightly hoary, 6 inches to near a foot long, usually forked above the middle. Leaves seldom half an inch long, green and glabrous, obtuse, or the upper ones scarcely pointed. Flowers not large, scentless, pink or spotted with white, solitary or two together, on short peduncles. Calyx 6 or 7 lines long, with pointed teeth, the outer scales broad, with a narrow point reaching to a third or near a half of the length of the calyx.

On banks, open pastnres, \&c., in Europe and western Asia, penetrating further north into Scandinavia than the last two. More generally distributed over Britain, from Inverness southwards, and abundant in some localities, but wanting in many counties, and not known in Ireland, except as an introduced plant. Fl. all summer. It varies with 2 or 4 scales to the calyx, and has often white flowers.

4. D. cæsius, Linn. (fig. 132). Cheddar P.-A perennial, of a very glaucous hue, forming a short, densely tufted, often almost woody stock. Lower leaves crowded, stiff, seldom above an inch long, narrow-linear, but obtuse. Flower-stems erect, 5 or 6 inches or rarely near a foot high, simple and 1-flowered, or rarely forked, bearing a few leaves more pointed than the lower ones. Flowers rather large, fragrant. Calyx rather thick, with short teeth, the outer scales 4 , broad, very shortly pointed, not half so long as the calyx. Petals broad, irregularly crenate, usually with a few hairs on the inside.

On limestone or volcanic rocks, in varions parts of western, central, and southern Europe, but usually very local. In Britain, confined to the Cheddar rocks in Somersetshire. Fl. June and July. 


\section{SAPONARIA. SAPONARIA.}

Calyz, corolla, and stamens of Lychnis. Styles 2. Capsule opening at the top in 4 teeth or short valves.

This genus, artificially distinguished by the number of styles, comprises sereral European and west Asiatic species, among which the $S$. ocymoides and calabrica are frequently cultivated in our flower-gardens, and $S$. Vaccaria, a common cornfield weed in continental Europe and central Asia, remarkable for its angular calyx and small pink flowers, appears occasionally in our own cornfields, especialls in the southern counties of England.

1. S. officinalis, Linn. (fig. 133). Soapwort.-A glabrous or pubernlons perennial, with several stout, leafy, erect stems, from 1 to 2 feet ligh. Leaves ovate or elliptical, 2 to 3 inches long, strongly marked with 3 or 5 ribs, and narrowed at the base into a very short, broad stalk. Flowers large and handsome, of a pale pink, or nearly white, in dense corymbs or heads at the summit of the stems, surrounded by small lanceolate floral leaves or bracts. Calyx tubular, about 9 or 10 lines long. Petals obcordate.

On banks, roadsides, and waste places, thronghout central and southern Europe and western Asia. Abundant in some parts of England, Ireland, and southern Scotland, about villages and babitations, probably introduced from cultivation, but perhaps really native on the coasts of Cornwall and Devon. Fl. summer.

\section{SILENE. SILENE.}

Calyx, corolla, and stamens of Lychnis. Styles 3. Capsules opening at the top in 6 teeth or short valves.

A very numerons genus, widely spread over Europe, Russian and central Asia, and North America, with a few South African species. It is very artificially distinguished from Saponaria and Lychnis by the number of styles, and the popular names of Caichfly and Campion each include species of both Silene and Lychnis. It has been proposed to abandon the character derived from the styles, and to distinguish these two genera by the number of the teeth or valves of the capsule, the same as that of the styles in Lychnis, twice as many in Silene, thus transferring Lychnis vespertina and S. diurna to Silcne, but this would scarcely render the genera less artificial.

Calyx glabrous. Leaves glabrous or slightly downy.

Jioss-like alpine plant, with very short tufted stems .

1. S. acaulis.

Stem elongated.

Calyx much inflated after flowering, ovoid or globular

Calyx short, not inflated. Flowers numerous, small

2. S. Cucubalus.

Calyx and foliage downy or hairy.

Perennials.

Caly $x$ short. Flowers small, numerous, in opposite bunches or

Calyx tubular. Flowers rather large, nodding, on opposite

peduncles, forming loose panicles with narrow teeth.
Annuals. Calyx contracted at the top, with

Flowers axillary, forming unilateral spikes. Calyx 10-ribbed 5. S. gallica.

Flowers in terminal dichotomous panicles, or solitary.

Calyx conlcal, 25- to 30-ribbed .

Caiyx long and tubular, 10-ribbed

3. S. Otites.

4. S. nutans.

3. S. Otiles.

Two south Furopean species, S. italica and the Lobel's Catchly (A 
Armeria), appear to have occasionally escaped from gardens, and sown themselves in some localities. Several other exotic species, especially S. compacta, $S$. vespertina, $S$. rubella, $S$. Schafla, \&c., are frequent ornaments of our flower-beds.

1. S. acaulis, Linn. (fig. 134). Dwarf S., Mfoss Campion.-This beantiful little mountain plant forms dense moss-like tufts, often many, inches' diameter, consisting of a much branched perennial stock, the very short branches covered with the remains of old leaves, and crowned by dense spreading clusters of short, green, linear, and glabrons leaves. From the centre of these arise the numerous flowers, either sessile or on 1-flowered peduncles, which seldom attain an inch in length. Calyx broadly tubular or campanulate, quite glabrous, with rather obtuse teeth. Petals reddish-purple, obovate, slightly notched, with a small scale at the base of the lamina.

In the mountains of northern and Arctic Europe, Asia, and America, and, at considerable elevations, on the great mountain-ranges of central and southern Europe. Abundant in the mountains of Scotland, extending more sparingly into the Lake district of England and into North Wales; in Ireland found only in Donegal. Fl. summer.

2. S. Cucubalus, Wibel. (fig. 135). Campion.-A perennial, loosely branched at the base, with ascending or seldom erect stems, from 6 inches to above a foot long, of a glaucous green, and usually glabrous. Leaves ovate, oblong, or rarely nearly linear, and usually pointed. Flowers few, white, erect or slightly drooping, in loose terminal panicles. Calyx rather more than half an inch long, becomes at length almost globular, inflated, and much veined. Petals more or less deeply 2-cleft, with a small scale at the base of the lamina, which sometimes disappears altogether, $S$. inflata, Sm.

In fields, on banks, roadsides, and waste places, throughout Europe and Russian and central Asia, extending into the Arctic regions and to high alpine summits. Generally spread over Britain, but not very common. $\mathrm{Fl}$. all summer. A sea-coast variety, more frequent in England and Ireland, with short diffuse stems, thicker, more obtuse leaves, almost solitary flowers, and larger scales on the petals, has been distinguished as a species, under the name of S. maritima.

3. S. Otites, Sm. (fig. 136). Spanish S.-Perennial stock short and tufted, with narrow leaves, as in $S$. nutans; the stems simple, erect and stiff, with few leaves, about a foot high. Flowers diœcious, small and numerous, of a pale yellowish-green, arranged in loose opposite clusters, having the appearance of whorls, and forming a long, narrow panicle. Calyx scarcely $1 \frac{1}{2}$ line long. Petals narrow and entire. Style and stamens projecting beyond the flower.

In sandy fields and pastures, in central, sonthern, and especially castern Europe, and all across Russian Asia ; not so common in western Furope, although extending to the sandy shores of the Atlantic. In Britain only in Norfolk, Suffolk, and Cambridgeshire. Fl. summer.

4. S. nutans, Linn. (137). Nottingham Catchfy. - Stock tufted and perennial, with a rather thick taproot, short, procumbent barren shoots, and erect flowering stems, 1 to 2 feet high, more or less hoary with short hairs, usually viscid in the upper part. Lower leaves oblongobovate, pointed, narrowed into a long stalk, the stem-leaves few, narrow, and sessile. Flowers nodding in a loose, rather narrow panicle, 
3 or 5 together on short opposite peduncles. Calyx tubular, 4 or 5 lines long. Petals white or greenish underneath, deeply 2-cleft, with long claws, the style and stamens projecting beyond the flower

On hilly or stony pastures, and in rocky districts, ovor nearly the whole of Europe and Russian Asia to the Arctic Circle. Distribnted over several parts of England and southern Scotland, but in some places introduced only, and not recorded from Ireland. Fl. summer.

5. S. gallica, Linn. (fig. 138). Small-flowered S.-A hairy, slightly viscid, much branched annual, 6 inches to near a foot high, erect or decumbent at the base. Lower leaves small and obovate, upper ones narrow and pointed. Flowers small, nearly sessile, generally all turned to one side, forming a simple or forked terminal spike, with a linear bract at the base of each flower. Calyx very hairy, with 10 longitudinal ribs and 5 slender teeth, at first tubular, afterwards ovoid, and much contracted at the top. Petals very small, entire or notched, pale red or white.

Probably of south European origin, but now a common weed in sandy or gravelly fields and waste places, especially near the sea, in most parts of the cultivated world; pretty frequent in sonthern England, and appearing occasionally in other parts of Britain. Fl. summer. [There are three very distinct varieties of this:-S. gallica proper, with white or pink large 2-fid petals; S.quinquevulnera, Linn., with white entire petals, each with a red spot (formerly cultivated); and S. anglica, Linn., with spreading branches and small white, often jagged petals.]

6. S. conica, Linn. (fig. 139). Striated S.-An erect, simple, or slightly branched annual, about 6 inches high, slightly hoary with minute, soft, and glandular hairs. Radical leaves obovate, spreading, those of the stem narrow and erect. Flowers few, in a small, compact, terminal panicle. Calyx conical, about 6 lines long, marked with 25 to 30 longitudinal veins, the mouth always contracted, with 5 slender teeth. Petals small, pale pink notched or 2-cleft.

In sandy fields and waste places, especially near the sea, common in central and southern Europe and central Asia, but not reaching into northern Germany. In Britain, confined to the eastern counties of England, or appearing occasionally on ballast.bills further north. $F$. summer.

7. S. noctiflora, Linn. (fig. 140). Night-flovering S.-A coarse, erect, hairy, and viscid annual, 1 to 2 feet high, simple or branched. Lower leaves ovate or ovate-lanceolate, and shortly stalked, the upper ones narrow-lanceolate and sessile. Flowers 2 or 3, or sometimes several together, in a loose, terminal, dichotomous panicle. Calyx above an inch long, tubular, with 10 ribs and 5 slender teeth, swelling, as the fruit ripens, rather below the middle. Petals rather large, 2-cleft, pale pink or nearly white, opening at night.

Probably of sonth European origin, now a common cornfield weed in central Europe, and found occasionally as such in various parts chiefly of eastern Kngland, Ireland, and southern Scotland. Flo with the corn.

\section{LYCHNIS. LYCHNIS.}

Caly $x$ tubular or inflated, with 5 teeth. Petals 5, with erect claws, and a spreading lamina, entire or 2-cleft, usually with a small double or notched scale at its base. Stamens 10. Styles 5, or very rarely 4. 
Capsule 1-celled, or divided at the base into 5 cells, and opening in 5 or 10 teeth or short valves at the top.

Far less numerons than Silene, the species of this genus are, however widely spread over the northern hemisphere without the tropics. Some botanists break up the genus into several small ones, referring the British species to Melandrium, Agrostomma, Lychnis, and Viscaria.

Calyx with long, narrow, green lobes, projecting beyond the petals.

Calyx-teeth shorter than the petals.

Calyx after flowering mnch swollen, ovoid and globular.

Plant glabrous and glancous. Calyx veined.

Flowers white. Capsule ovold

Flowers red. Capsule nearly globular : ${ }^{\circ}$ :

Calyx tubular or short, not swollen.

Flowers in loose panicles. Petals cut into narrow strips

Hlowers in heads, or dense oblong panicles.

Stems very viscid. Calyx narrow, tubular. Petals notched . . . . 5. L. Viscaria.

Stems not viscid, Calyx short. Petals 2-cleft: $: \quad$ : 6. L. alpina.

Among the exotic species most frequently cultivated for ornament may be mentioned the $L$. chalcedonica, $L$. coronaria or Rose Campion, $L$. Cali-Rosa, and $L$. ocellata, from the Mediterranean region or the Levant, and $L$. fulgens from Mexico.

1. L. vespertina, Sibth. (fig. 141). White L. -A rather coarse, hairy biennial, more or less viscid, 1 to 2 feet high, and loosely branched. Leaves oval-oblong, usually pointed, tapering at the base, the lower ones stalked. Flowers few, in loose panicles, rather large, white, or rarely pale pink, opening in the evening (when they are slightly scented), and usually diœcions. Calyx 7 to 9 lines long, softly hairy, with 10 ribs and 5 lanceolate-linear teeth, swelling as the capsule ripens, so as to assume an ovoid shape. Petals 2-cleft. Capsule ovoid, opening at the top in 10 teeth, which remain erect, or curve slightly outwards.

Under hedges, in fields and waste places, throughout Europe and Russian Asia. Abundant in Britain. Fl. all summer.

2. L. diurna, Sibth. (fig. 142). Red L.-Very near $L$. vespertina, and perhaps a mere variety, but the plant is less viscid, the leaves and calyzes usually shorter, the flowers red, scentless, opening in the morning, and the capsule more globular, the 10 teeth very spreading, or rolled back.

In moist, shady places, woods and hedge-banks, with the same geographical range as $L$. vespertina. Equally common in Britain. $F l$, all summer, commencing in spring.

3. I. Githago, Scop. (fig. 143). Corn Cockle.-A tall, erect annual, simple or slightly branched, clothed with long, soft, whitish appressed hairs. Leaves long and narrow. Flowers on long leafless peduncles, rather large, red, and inodorous, remarkable for the long, green, linear lobes of the calyx, projecting much beyond the petals; the latter are broad, undivided, and without any scales on the lamina. Capsule opening in 5 teeth. Agrostemma Githago, Linn. Githago segetum, Desf.

Probably of sonth-eastern origin, but now a common cornfield weed, all over Furope and Russian Asia, except the extreme north. Abundant in British cornfields. $F$, with the corn.

4. L. Flos-cuculi, Linn. (fig. 144). Ragged Roben.-Stock short and perennial, but not of long duration, stems erect, not mich branched, 
to 2 feet high, slightly downy below and viscid above. Leaves few, narrow-lanceolate, the lower ones stalked. Flowers in loose terminal panicles, red and scentless, but remarkable for their petals cut into 4 linear lobes, the two middle ones the longest. Calyx short, glabrous, with 10 ribs and 5 short teeth. Capsule nearly globular, opening in 5 teeth.

In moist or marshy meadows and pastures, ditches, \&c., throughont Europe and Russian Asia, except the extreme north. Abundant in Britain. Fl. spring and summer.

L. Viscaria, Linn. (fig. 145). Viscid L.-Stock perennial, nsually tufted, the flowering stems erect, 6 inches to a foot higb, glabrous, but very viscid in the npper part. Leaves long and narrow, the lower ones contracted into long stalks, which are often fringed with a few woolly hairs. Flowers red, in close, sessile or shortly stalked, opposite clusters, forming an oblong panicle, or sometimes a terminal head. Calyx tubular, about 6 lines long, with 10 veins and 5 short teeth, rather swollen above the middle as the fruit ripens. Petals slightly notched.

On rocks and rather dry hilly pastures, in northern and central Enrope and a great part of Russian Asia, but not an Arctic plant, and yet rare in southern Europe. In Britain, confined to a few localities in North Wales and Scotland, especially about Edinburgh and in Perthshire. Fl. June.

6. I. alpina, Linn. (fig. 146). Alpine L.-Like L. Viscaria in habit and foliage, but smaller and not riscid. Stems seldom 6 inches high. Flowers pink, smaller than in $L$. Viscaria, in compact heads, the calyx much shorter, and the petals narrow and deeply 2-cleft.

In rocky sitnations, at high latitudes or great elevations, in Arctic and northern Europe and Asia, and in the bigher mountains of central Europe. In Britain, only known on the summit of Little Kilrannoch, in Forfarshire, on Hobcartin Fell in Cumberland, and in Lancashire. Fl. summer.

\section{SAGINA. PEARLWORT.}

Small, matted or tufted herbs, with subulate leaves and small flowers. Sepals 4 or 5 . Petals 4 or 5 , small, entire or slightly notched, sometimes entirely deficient. Stamens 4 or 5 , or twice those numbers. Styles 4 or 5. Capsule opening in as many valves.

A small genns, with nearly the geographical range of Arenaria, from which it only differs in the number of styles. The 5-styled species were formerly included in Spergula, which is now reduced to one or two species easily distinguished by their apparently whorled foliage.

Sepals, stamens, and styles usually 4. Petals as many or none $\quad$ 1. S. procumbens. Sepals, petals, and styles 5. Stamens usually 10.

Sepals obtuse.

Petals not longer than the calyx. Leaves not clnstered

Petals longer than the calyx. Upper leaves with clusters of very small ones in their axils

Bepals pointed

1. S. procumbens, Linn. (fig. 147). Procumbent P.-A minute annual, or perennial, 1 to 2 inches or seldom 3 inches high, sometimes erect from the base, especially at first, but usnally branching and decumbent at the base, forming little spreading tufts, usually glabrous, but having often an exceedingly minute glandnlar down. Leaves small and 
subulate, joined at the base in a short, broad, scarions sheath, the radical ones longer, and often tufted. Flowers very small, on capillary pedicels much longer than the leaves. Sepals about a line long, and obtuse. Petals much shorter, often wanting. Valves of the capsule as long as, or rather longer than, the sepals. All parts are usually in fours, but often fives.

In a great variety of situations, but especially in waste or stony places, wet or dry heaths, sandy marshes, \&c., throughout Europe, in Russian and central Asia, North America, Anstralia, \&c. Abundant in Britain. Fl. from spring till autumn. It varies considerably, and has been divided into many supposed species. Small, slender, but little branched specimens, with the petals very minnte or wanting, constitute the $S$. apetala, Linn.; in the $S$. ciliata, Fries., the branches are more diffuse, glandular-pubescent, and the sepals appressed to the capsule. A sea. coast variety, S. maritima, Don., presents the nsual maritime differences of firmer and thicker stems and leaves, is glabrous, and bas broad obtuse sepals, suberect in fruit.

2. S. Linnæi, Presl. (fig. 148). Alpine P.-Very near S. procumbens, but it forms an undoubtedly perennial stock (although often flowering the first year so as to appear annual), the radical leaves are rather longer, the petals are more conspicuous, usually nearly as long as but not longer than the sepals, and there are almost always 5 sepals, 5 petals, 10 stamens, and 5 styles and valves of the capsule.

In mountain pastures, and stony places, in Arctic and northern Europe, Asia, and America, and in most mountain districts of central and southern Europe to the Caucasus, descending occasionally to the sea-coast in western Europe, when it is very difficult to distinguish it from S. procumbens. In Britain, in the Scotch Highlands, in the west and south of England, and in Ireland. Fl. summer. [There are three very distinct forms included here-

a. S. Linnai proper (S. saxatilis, Wimm.; Spergula saginoides, Sm.), prostrate, branches rooting, pedicels curred, erect in fruit.

b. S. nivalis; Fries. Densely tufted, leaves broader, pedicels always erect, and petals shorter. Confined to some of the loftiest Scotch mountains.

c. S. subulata, Wimm. (Spergula subulata, Swartz). Tufted, more or less pubescent and glandular, leaves narrowed to the awned tip, petals not longer than the sepals. Common.]

3. S. nodosa, Fenzl. (fig. 149). Knotted P.-Like the last, this forms little perennial tufts, but as it often flowers the first year, it then appears annual. Stems numerous, decumbent, or nearly erect, 2 to 3 or rarely 4 inches high, and not much branched. Lower leaves like those of $S$. Linnai, or rather longer, but the stem leaves are much shorter, with little clusters of minute ones in their axils. Flowers few on each stem, on pedicels from 3 to 6 lines long, and more conspicnous than in the other species, the white obovate petals being twice as long as the calyx. Sepals obtuse, a line long, the parts of the flower usually in fives, with 10 stamens.

In wet, sandy places, marshes and bogs, in northern and central Europe Asia, and America. Generally distributed over Britain. Fl. summer, 


\section{ARENARIA. SANDWORT.}

Small, branched annuals, or tufted or prostrate perennials, glabrous, or rarely shortly hairy, with white flowers. Sepals 5. Petals 5, entire, rarely wanting. Stamens 10 , or rarely fewer. Styles 3, very rarely 4. Capsule opening in as many or twice as many valies.

A very numerous genus in the northern hemisphere without the tropics, with a few species also in the southern hemisphere; distinguished from Sagina by the number of styles, from Cerastium and Stellaria by the entire petals. The British species are usually distributed into four sections, often considered as independent genera, viz., Alsine, with the valves of the capsule as many as the styles, and many seeds, including A. verna, $A$. uliginosa,'and A. tenuifolia; Honckenya, with the capsular valves as many as the styles, and few large seeds, for A. peploides ; Arenaria, with the capsular valves twice as many, and no appendage to the seeds, including A. ciliata and A. serpyllifolia and Mahringia, with the capsule of Arenaria, but with shining seeds, having a little appendage to their hilum.

Leaves linear or subulate.

Tufted perennials.

Petals minute or 0

Petals equalling or exceeding the sepals.

Pedicels 2 to 4 lines long

Pedicels 6 or 12 lines long or more : : : : 3. A. uliginosa.

Leaves ovate.

Leaves thick and fleshy. Capsules large, globular, 5-valved . 5. A. peploides.

Leaves small or thin. Capsule 10-valved, amall.

Leaves scarcely 2 lines long. Sepals with 3 nerves.

Annual, much branched, and downy. Petals shorter or scarcely longer than the calyx

Alpine, procumbent, perennial. Petals mnch longer than

the calyx
Leaves mostiy half an inch, thin, and 3 -nerved. Sepals 1. nerved.

6. A. serpyllifolia.

7. A. ciliata.

8. A. trinervis.

1. A. Cherleri, Benth. (fig. 150). Cyphel.-Stock rery densely matted, often several inches diameter, with long roots, the very short branches completely covered with closely packed linear leaves, rather stiff, and 2 or 3 lines long. Pedicels slender, from the summit of the tufts, with a single erect flower. Sepals about a line long, with 3 prominent veins. Stamens shorter than the calyx. Capsule slightly protruding, opening to the base in 3 valves, and containing but few seeds. Cherleria sedoides, Linn.

An alpine plant, not uncommon at considerable elevations in the Pyrenees and Alps, extending to Greece and Transylvania, and reappearing in the Scotch Highlands, especially in the Breadalbane range, and in Sutherland, but neither an Arctic nor a Scandinavian plant. Fl. summer.

2. A. verna, Linn. (fig. 151). Vernal S.-Stock perennial, short, becoming densely tufted and thickly covered with old leaves; the flowering stems erect or decumbent, 2 to 4 inches high, and branched. Leaves subulate, rather stiff, the upper ones short and broader. Flowers in rather loose forked cymes, the pedicels usnally slightly downy, and seldom above 3 or 4 lines long. Sepals $1 \frac{1}{2}$ to near 2 lines long, pointed, with 3 very prominent nerves. Petals obovate, spreading beyonä ine points of the sepals. Capsule 3-valved. Alsine verna, Wahlb.

In stony or mountain pastares, almost all over the continent of Kiurope 
and Russian Asia and in North America. Much less frequent in Britain, and chicfly in Scotland, northern England, Wales, Cornwall, and Ireland. $\mathrm{Fl}$. spring and summer. An Arctic variety, extending to some of the highest mountains of Scotland, has been distinguished under the name of $\boldsymbol{A}$. sulsata, Schlecht. (hirta, Wormsk., rubella, Hook.). It is more stunted, with shorter and rather broader leaves, few flowers, smaller and narrower petals, and sometimes 4 or even 5 styles and capsular valves. [Another variety, A. Gerardi, Wahlb., occurs in Cornwall; it has less pointed leaves, the lower of which are appressed.

3. A. uliginosa, Schleich. (fig. 152). Bog S.-Perennial tufts like those of $A$. verna, but the subulate leaves are rather thicker, almost succulent, the stems longer, with very few distant pairs of leaves, the pedicels much longer, often an inch or even more, and always glabrous, the sepals broader. Petals about the length of the calyx. Capsule 3valved. Alsine stricta, Wahl.

In bogs or mountain marshes, in Arctic and northern Europe and Asia, and in some mountainous parts of central Europe, but never common. In Britain, only known on Widdybank Fell, in Durbam. Fl. summer.

4. A. tenuifolia, Linn. (fig. 153). Finc-lcaved S.-A very slender, erect, much branched annual, glabrous or very minutely downy or glandular above, 3 or 4 inches high. Leaves finely subulate. Pedicels very slender, usually about half an inch long. Sepals narrow-lanceolate, finely pointed. Petals obovate or oblong, usually scarcely half the length of the sepals. Capsule opening in 3 valves. Alsine tenuifolia, Crantz.

On old walls, stony wastes, or sandy fields, in central and southern Europe, from southern Sweden to the Caucasus. In Britain, apparently confined to some of the eastern counties of England. Fl. summer.

5. A. peploides, Linn. (fig. 154). Sea Purslane.-Rootstock creeping, with short, procumbent, usually forked flower-stems. Leaves numerous, thick and somewhat fleshy, ovate or elliptical, half an inch long or more, the upper ones smaller and broader. Flowers few, on short pedicels, in small, leafy, terminal cymes, usually more or less unisexual. Sepals thickish, about $2 \frac{1}{2}$ lines long. Petals scarcely longer. Capsule large, nearly globular, opening in 3 (or sometimes 4 or 5 ) broad valves, with fewer and larger seeds than in the other Arenarice. Honckcnya peploiles, Ehrh.

In maritime sands, in northern and Arctic Europe, Asia, and America, extending down western Europe to Portugal. Rather common all round Britain. Fl. summer, rather carly.

6. A. serpyllifolia, Linn. (fig. 155). Thyme-leaved S.-A very much branched, slender, and slightly downy annual, seldom attaining 6 inches. Leaves very small, ovate and pointed. Pedicels from the upper axils or forks of the stem, 2 or 3 lines long, and slender. Sepals pointed, about $1 \frac{1}{2}$ lines long. Petals usually mucb shorter, but variable in size, obovate. Capsule opening in 6 narrow valves.

On walls and dry sands, or stony, waste places, throughout Europe and central and Russian Asia, except the extreme north. Common in Britain, but more so in the south than in the north. Fl.summer. [A very variable plant, of which there are three British forms.

a. A. serpyllifolia proper. Rigid, sepals ovate-lanceolate, capsule ovoid, pedicel ascending.

b. A. glutinosa, Koch. Shorter, stonter, more glandular. 
c. A. leptoclados, Guss. Flaccid, sepals lanceolate, capsule narrower, pedicels spreading.]

7. A. ciliata, Linn. (fig. 156). Fringed S.-Stems perennial at the base, short, diffuse, generally much branched and matted, the flowering branclies 2 or 3 inches high, and more or less downy. Leaves small and ovate, more distinctly stalked than in $A$. serpyllifulia, veined underneath, and usually fringed with a few stiff hairs, near the base. Flowers much larger than in the last species, on slender pedicels, 3 to 6 lines long, the obovate petals considerably longer than the sepals. Capsule opening in 6 valves.

In mountain pastures, in northern and Arctic Europe, and at considerable elevations, in the higher ranges of central and southern Europe. In Britain, only on limestone cliffs near Ben Bulben, in Sligo, Ireland, and in the Orkneys and Shetlands. Fl.summer. The Scottish specimens belong to an Arctic (maritime?) nearly glabrous variety, with more succulent leaves, seldom fringed, shorter peduncles, and rather broader sepals, distinguished as a species under the name of $A$, norvegica, Gunn. [An annual or biennial variety of this species has been recently discovered on Ribblehead, Yorkshire; with It is the A. gotthica, Fries.]

8. A. trinervis, Linn. (fig. 157). Three-nerved S.-A tender, much branched, decumbent or spreading annual, from 4 or 5 inches to a foot long, resembling in some respects Stellaria media, but very different in flower. Leaves stalked, ovate, pointed, half an inch long or more, thin, of a light green, with 3 distinct nerves. Pedicels from the upper forks of the stem, rather longer than the leaves. Sepals very pointed. Petals not quite so long, obovate and entire. Capsule opening in 6 valves, the seeds few, shining, with a little white appendage at their hilum.

In shady woods, along ditches and moist places, throughout Europe and the greater part of Russian Asia, except the extreme north. Frequent in England and Ireland, less so in Scotland. Flo spring and summer.

\section{MOENCHIA. MOENCHIA.}

Small, but rather stiff, erect annuals. Sepals 4. Petals 4, entire. Stamens 4 or 8 . Styles 4 . Capsule opening at the top, with 8 short teeth.

A genus of two or three European species, with the numbers of parts of the flower and entire petals of Sagina, the babit and calyx rather of Stellaria, and the capsule of a Cerastium.

1. M. erecta, Sm. (fig. 158). Upright $M$. - A glabrous and glaucons annual, 2 to 4 or rarely 6 inches high. Leaves linear, the radical ones slightly spathulate and stalked, the upper ones few and sessile. Flowers few, white, rather large for the size of the plant, on long, erect pedicels. Sepals nearly 3 lines long, broadly lanceolate, pointed, with white scarious margins. Petals rather shorter. Capsule ovate. Cerastiun quaternellum, Fenzl.

In stony or sandy wastes and pastures, over the greater part of central and southern Europe, but not extending to its eastern limits, nor into the north of Germany. Spread over England as far north as the Cheriots. $F l$ spring or early summer. 


\section{HOLOSTEUM. HOLOSTEUM.}

Small annuals. Sepals 5. Petals 5, more or less toothed or jagged, but not cleft. Stamens usually 5. Styles 3. Capsule opening in 6 short valves or teeth.

Besides our species, there are but one or two from the Levant, all differing from Cerastium in the less divided petals, and generally fewer stamens and styles.

1. H. umbellatum, Linn. (fig. 159). Umbellate H.-A slightly downy, more or less viscid annual, seldom above 6 inches high, divided at the base into several erect or ascending stems. Radical leaves spreading, oblong or elliptical; thuse of the stem sessile, varying from ovate to linear, often half an inch long or more. The upper part of the stem forms an almost leafless peduncle, bearing an umbel of 3 to 8 flowers, on long pedicels, erect at the time of flowering, then turned down, and erect again when the capsule is ripe. Sepals near 2 lines long, white and scarious at the edges. Petals white, rather longer.

On sandy and stony wastes, fields, and roadsides, very common in southern Europe and western A sia, less so over central Europe, but reaching southern Sweden. In Britain, only on old walls or roofs in Norfolk and Suffolk.

\section{CERASTIUM. CERAST.}

Annual or perennial herbs, usually downy or hairy, and branching at the base, with white flowers in terminal forked cymes, or rarely solitary ; the upper bracts often, like the sepals, scarious on the edges. Sepals 5 , rarely 4. Petals 5, rarely 4, usually 2 -cleft, sometimes minute or wanting. Stamens 10 , or occasionally 5 or fewer. Styles 5 , rarely 4 or 3. Capsule opening at the top in twice as many short teeth as there are styles.

A considerable genus, widely diffused over the whole range of the fimily, and rather a natural one, differing generally from Stellaria in its capsule, from the other British Alsinece by the cleft petals.

Annual or blennial. Petals shorter or scarcely longer than the calyx

Perennials. Petals considerably longer than the calyx.

Styles always 5 .

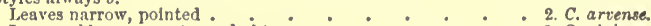

Leaves oblong or ovate, and obtuse $\quad \vdots \quad \vdots \quad \vdots \quad \vdots 3$ C. alpinum.

Styles mostly 3. Leaves narrow - : : : : 4. C. trigynum.

An Eastern species, with cottony leaves, C. tomentosum, is not un. frequently cultivated in our cottage gardens.

1. C. vulgatum, Linn. (fig. 160). Mouse-car Chickweed.-A coarsely downy, usually more or less viscid annual, branching at the base, sometimes dwarf, erect, and much branched; at others, loosely ascending to a foot or even two, occasionally forming, at the end of the season, dense, matted tufts, which may live through the winter, and give it the appearance of a perennial. Radical leaves small and stalked; stemleaves sessile, from broadly ovate to narrow-oblong. Sepals 2 to $2 \frac{1}{2}$ lines long, green, and downy, but with more or less conspicuous scarions margins. Petals seldom exceeding the calyx, and often much chorter, sometimes very minute, or even none. Stamens often reduced 
to 5 or fewer. Capsule, when dry, cylindrical, often curved, and projecting beyond the calyx.

In cultivated and waste places, pastures, and woods, wet or dry, over nearly the whole of the civilised world. Most abundant in Britain. $F$ the whole season. Its protean forms have much puzzled the botanists of many countries to distinguish them into from 2 or 3 to 20 or 30 supposed species. The most conspicuous observable in Britain are-

a. C. glomeratum, Thuill. Tall and luxuriant, the leaves broad, almost orbicular, the flowers (somctimes apetalous) in a compact head, the pedicols shorter than the calyx, the stamens usually 10 . In rich soils, in moist, shady situations, but often later in the season assuming the inflorescence of the narrower-leaved varieties.

b. C. viscosum, Linn. Much branched at the base, but usually rather tall. Leaves oblong or narrow. Stamens usually 10. The commonest form in rather moist and rich meadows and pastures. Pedicels often elongated in this and the two following varieties. C. triviale, Link.

c. C. semidecandrum, Linn. (C. pumilum, Curtis). Stems short and often slender, more branched and more erect as the situation is drier. Leaves rather small, thicker near the sea, more viscid in hot situations. Stamens usually about 5, but often more. Capsules usually long. Very common in dry, poor, open situations.

d. C. tetrandrum, Curtis. Like the last, but more branched, and the parts of the flower usually rcduced to fours. Pedicels often long. Less common than the last two, and generally near the sea.

[The above classification of the puzzling British forms of the common Mouse-ear Chickweed does not quite accord with that of any other author; it was, however, founded on a very long and careful observation of living plants over a great area of the British Isles.]

2. C. arvense, Linn. (fig. 161). Field C.-Stem perennial, and much branched at the base, often very intricate and prostrate; the flowering branches ascending to about 6 inches, or more when very luxuriant. Leaves crowded in the lower part, narrow, lanceolate-linear, more glabrous and less viscid than in $C$. vulgatum. Flowers large and white, in loose cymes, on rather long pedicels. Sepals near 3 lines long. Petals twice that length, cleft to near the middle. Capsule oblique, usually longer than the calyx.

In dry, hilly fields, pastures, and banks, throughont Europe and Russian Asia, except the extreme north, in North America, and down the Andes of South America. In numerons localities in Britain, but not at all common. Fl. spring and early summer.

3. C. alpinum, Linn. (fig. 162). Alpine C.-Stems shortly perennial, much branched, prostrate and rooting at the base; the flowering branches ascending to $a$ few inches, with 1 or 2 large flowers on long peduncles; the whole plant nearly glabrous, or more frequently covered with long woolly hairs, and occaslonally viscid. Leaves ovate, elliptical, or oblong, always broader for their length than in $C$. arvense. Petals rather longer than in that species; styles 5. Capsule not much longer than the calyx, straight or nearly so.

In alpine, moist pastures, and wet, rocky situations, in all the great mountain ranges of Europe and Russian Asia, and all round the Arctio Circle. Pretty abundant in the Highlands of Scotland, less so in northern England, and rare in Wales; not recorded from Ireland. $\mathrm{Fl}$. summer. 
The nearly glabrous form, which is the $C$. alpinum of most Continental botanists, is not so common in Britain as the woolly one, the C. lanatum of some foreign botanlsts. These two were formerly distinguished by British botanists as $C$. alpinum and $C$. latifolium, but the latter name is now generally given to a variety with a shorter pubescence, and usually with a shorter and broader capsule and larger seeds, but these differences often appear quite inappreciable. The C. latifolium, Linn. ? of the Alps of central Europe is not British. [A Cerastium occurs in the Shetland Isles, $C$. nigrescens, Edmonstone, which has seeds larger than those of $C$. alpinum, covered with a loose testa as in true latifolium. It is the alpinum, var. Edmonstonei, of Mr. N. E. Brown.]

4. C. trigynum, Vill. (fig. 163). Starwort C.-Stems shortly perennial, prostrate and intricately branched, but much more slender than in $C$. alpinum; the whole plant glabrous, except minute hairs down one side of the branches, or rarely generally hairy. Leaves narrow, usually curved to one side. Flowering branches shortly ascending, with 1 or 2 large flowers, on rather long peduncles, as in C.alpinum; but the styles are 3 , very seldom 6,4 , or even 5 , the tecth of the capsule always double the number of the styles.

In moist, alpine situations, in Europe and Russian Asia to the Arctic Circle. Frequent in the Breadalbane range in Scotland, and other mountains to the northward. Near Bantry in Ireland. $\mathrm{Fl}$. summer.

\section{STELLARIA. STARWORT.}

Annuals or perennials, generally more glabrous than Cerastium, the leaves usually pointed and often cordate, the sepals more pointed and less distinctly scarious at the edge. Sepals 5 . Petals 5 , deeply bifid. Stamens 10 , occasionally reduced to 5 or fewer. Styles 3 , or rarely 5 . Capsule opening to the middle, or lower down in as many or twice as many valves.

A large genus, extending over nearly the whole geographical range of the family, and generally a natural one, although some species, especially $S$. media and $S$. uliginosa, resemble Arenaria trincrvis, and can only be distinguished by a close inspection of the minute petals and capsules. Most of the species are occasionally, though rarely, apetalous.

Lower leaves atalked, ovate or heart-shaped.

Petals much longer than the calyx.

Five styles in most of the flowers . . . . . . . 1. S. aquatica.

Three styles : : : : : 2. S. nemorum.

Petals shorter or scarccly longer than the calyx.
Iower leaves ovste, cordate, on long stalks. - . . 3. S. media.

All the leaves narrowed at the base, sessile or shortly stalked: 4. S. uliginosa.

All the leaves narrow-lanceolate or linear, and sessile or nearly ao.

Petals shorter or scarcely longer than the calyx.

llant annual. Leaves oblong or lanceolate, short - 4. S. uliginosa.

Stock pcrennial. Leaves narrow-lanceolate or llnear . E. S. graminea.

Petals considerably longer than the calyx.

J.eaves very narrow. Sepsls distlnctly 3-nerved . * 6. glauca.

Leaves lanceolste or linear-lanceolate. Nerves of the sepais

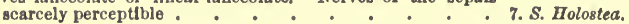

1. S. aquatica, Scop. (fig. 164). Water S.-A perennial with much of the habit and the heart-shaped leaves of $S$. nemorum, but on a rather larger scale, nsually more pubescent, and slightly viscid, the flowers smaller, and always known by all or most of them having 5 styles, and 
the capsule opening in 5 valves, which are entire or shortly bifid, seldom deeply cleft as in the other Stellarice. Stems weak, often a foot or more long. Lower leaves small, on long stalks, upper ones more sessile or stem-clasping, often 1 to 2 inches long, thin and flaccid, with a prominent midrib, and very pointed. Flowers in the forks of leafy cymes, the pedicels turned down after flowering. Sepals about 2 lines long at the time of flowering, enlarged when in fruit. Petals narrow, deeply cleft, about one half longer than the calyx. Malachium aquaticum, Fries.

In wet places, along ditches and streams, \&c., very widely diffused over Europe, and Russian and central Asia, except the extreme north, and migrating with man to several other parts of the world. Not common in Britain, and not occurring south of Yorkshire and Clieshire. Fl. summer. The flowers have occasionally, but seldom, only 3 styles.

2. S. nemorum, Linn. (fig. 165). Wood S.-Rootstock creeping, of some years' duration. Stems weak, emitting creeping branches from the base, the flowering branches ascending to 6 inches or a foot, with a few short spreading hairs. Leaves heart-shaped, pointed, of a thin texture, usually glabrous or slightly ciliated on the edges, the lower ones small, on long stalks, the upper 1 to 2 inches long, with much shorter stalks or nearly sessile. Flowers in elegant, loose, spreading cymes, on long, slender pedicels, with small bracts at their base. Sepals about 3 lines, the petals nearly twice as long, narrow, and deeply cleft. Styles 3. Capsule straight, opening to near the base into 3 bifid or 6 entire ralres.

In moist woods, throughout northern Europe and the hilly districts of central, and some parts of soutbern Europe, and across Russian Asia to western North America. In Britain, chiefly in northern and western England and southern Scotland. Not recorded from Ireland. Fl. summer.

3. S. media, Cyrill. (fig. 166). Chickweed.-A weak, much branched annual, glabrous, with the exception of a line of hairs down one side of the stem, and a ferv long ones on the leafstalks. Leaves small, ovate and pointed, the lower ones stalked and often heart-shaped, the upper sessile and narrower. Flowers small, on rather long, slender pedicels, in irregularly forked leafy cymes. Petals shorter than the calyx, deeply cleft, with narrow, slightly diverging lobes. Stamens often only $\mathbf{5}$. Styles 3.

In cultivated and waste places, roadsides, and edges of streams throughout Europe and northern Asia, and carried out as a weed to all the temperate and colder regions of the globe. Abundant in Britain. Fl. the whole season. [There are two varieties: S. media proper, with obtusely tubercled seeds; S. umbrosa, Opitz, with these acutely tubercled.]

4. S. uliginosa, Murr. (fig. 167)。 Bog S.-A weak, slender, glabrons ankinal, in some measure intermediate between $S$. media and $S$. graminea. Stems usually about 6 inches, rarely near a foot long, much shorter and tufted when on dry ground. Leaves much narrower than in $S$. media, but much shorter and broader than in S. graminea, oblong or lanceolate. Flowers small, in loose, slender, forked panicles, which, as in S. graminea, soon become lateral. Sepals about $1 \frac{1}{2}$ lines long. Petals shorter, with very narrow spreading lobes. Styles 3.

In marshes and wet ditches, widely spread over liurope, Russian 
Asia, and northern America, but not an Arctic plant, although in southern Europe generally confined to mountains. Almost universal in Britain. Fl. spring and summer.

5. S. graminea, Linn. (fig. 168). Lesser Stitchwort.-A glabrous perennial, with a creeping rootstock and slender quadrangular stems, diffuse or nearly erect, of ten above a foot long. Leaves sessile, linearlanceolate and pointed. Flowers small, in long, loose panicles, which often become lateral as the flowering advances, the bracts small and scarious. Sepals 3 -ribbed. Petals narrow, deeply cleft, seldom exceed. ing the calyx.

In meadows and pastures, along hedges, throughout Europe and Russian Asia. Very common in the low grounds of Britain, and up the mountain valleys as far as cultivation extends. $F l$. all summer.

6. S. palustris, Ehrh. (fig. 169). Marsh S.-Intermediate between $S$. graminca and $S$. Holostea, having the 3-ribbed sepals and deeply cleft petals of the former, with the flowers nearly as large as in the latter. It differs also from both, in being generally more glaucous, and the leaves are more regularly linear, not so lanceolate nor so pointed. The flowers are fewer than in S. graminea, with more leafy bracts. S. glauca, With.

In marshy and wet places, generally diffused over temperate Europe and Russian Asia ; it, or perhaps a variety, occurs in Australia. Not very common in Britain, but recorded from several parts of England, Ireland, and southern Scotland. Fl. summer.

7. S. Holostea, Linn. (fig. 170). Great S., Stitchwort.-A perennial, usually glabrous, with a creeping rootstock, and nearly erect though weak stems, 1 to 2 feet high, quadrangular, rather brittle, and sometimes slightly downy. Leaves sessile, lanceolate, tapering to a fine point, often 2 inches long or more. Flowers large, in loose, terminal, forked panicles, with leafy green bracts. Sepals about 3 lines long, scarious at the edge, scarcely ribbed. Petals near twice as long, rather broad, and cleft to about the middle.

In hedges, open woods, and bushy places, thronghout Europe and Russian Asia, except the extreme north. Abundant in Britain. Flo spring and early summer.

\section{SPERGULARIA. SANDSPURRY.}

Low, generally prostrate herbs, with opposite, linear, or subulate leaves, with smaller ones often clustered in their axils, and scaly scarious stipules. Sepals 5. Petals 5, undivided. Stamens 10 or occasionally fewer. Styles 3, rarely 4 or 5 . Capsule opening in as many entire valves.

A genus of very few, chiefly Mediterranean species, differing from Arenaria only in the stip:'es, which give them a strong resemblance to Illecebracea. [It has many synonyms, as Buda, Adans., Lepigonum, Fries., and $T$ issa, employed by various anthors.]

1. S. rubra, Pers. (fig. 171). Common S.-An annnal or biennial, glabrous or with a short viscid down in the npper parts, with numerous atems branching from the base, and forming spreading or prostrate tufts, 8 or 4 inches, or, when very luxuriant, 6 inches long. Leaves narrow-linear: the scarious stipules at the base short, but very con- 
spicuous. Flowers very variable in size, usually pink, or rarely nearly white, on short pedicels, in forked cymes, usually leafy at the base. Petals shorter, or rarely rather longer than the sepals. Seeds more or less flattened, often surrounded by a narrow, scarious wing or border.

In sandy or gravelly heaths and waste places, cbiefly in maritime countries, widely spread over Europe, Russian Asia, North America, and Australia. Common in Britain. Fl. all summer. There are two marked varieties; one, chiefly occurring inland, has slender leaves, small flowers (the sepals 1 to 2 lines long), short capsules, and the seeds rarely bordered; the other, generally growing near the sea, often distinguished as S. marina, has thicker, somewhat fleshy leaves, larger flowers (the sepals 2 to 3 lines long), larger capsules, and the seeds usually bordered, but both varieties occur with bordered and with unbordered seeds.

[Most authors distinguish four British species, of which two are annuals or biennials. 1. S. rubra, Pers., with linear flat acute leaves, short capsules and tubercled seeds with thick margins. 2. S. salina, Presl., with semicylindric acuminate leaves, longer capsules, and seeds usually smooth, winged or not; and two are perennials, both with semicylindric leaves. 3. S. media, Pers., glabrous with long capsules and winged seeds. 4. S. rupestris, Lebel, with short capsules and pyriform seeds not winged, All are maritime except $S$. rubra.]

\section{SPERGULA. SPURRY.}

Slender herbs, with narrow-linear leaves in opposite clusters, so as to appear whorled, and minute, scarious stipules. Sepals 5. Petals 5, undivided. Stamens 10, or occasionally 5 or fewer. Styles 5. Capsule opening in 5 entire valves.

A very small European and Asiatic genus, differing from Sagina, as Spergularia does from Arenaria, by the presence of scarious stipules.

1. S. arvensis, Linn. (fig. 172). Corn S.-A slender annual, branching at the base into several erect or ascending stems, 6 inches to a foot high, glabrous or slightly downy. Leaves almost subulate, 1 to 2 inches long, growing 6 or 8 together in two opposite clusters, and spreading so as to appear whorled. The scarious stipules much smaller than in Spergularia, and sometimes obscure. Flowers small, white, on long slender pedicels, turned down after flowering in terminal, forked cymes. Sepals $1 \frac{1}{2}$ to 2 lines long. Petals generally shorter. Stamens frequently 10 or 5 in the same plant. Seeds slightly flattened, with or withont a narrow, scarious border.

In cultivated and waste places, all over Enrope, and temperate Asia; but in the northern districts, as in many other parts of the world, only as a cornfield weed. Common in British cornfields. Fl. all summer.

\section{POLYCARPON. POLYCARP.}

Low annuals, with opposite, or apparently whorled, flat leaves, and scarious stipules. Sepals 5. Petals 5, very minute. Stamens 8 to 5. Styles very short, with 8 short linear branches. 
A genus of two or three Mediterranean species, very near to Sy,rgularia, but, in their minute petals and very short styles combined at the base, showing a further approach to Illecebracece.

1. P. tetraphyllum, Linn. (fig. 173). Four-leaved P.-A glabrous, much branched, spreading or prostrate annual, seldom more than 3 or 4 inches long. Leaves obovate or oblong, really opposite, but placed as they usually are, under the forks, two pairs are so close together as to assume the appearance of a whorl of 4. Flowers very small and numerous, in loose, terminal cymes; the sepals barely a line long. and rather concave. Petals much shorter, and very thin. Stamens usually 3 .

In sandy situations, generally not far from the sea, in south-western Europe, round the Mediterranean, along the Atlantic, and as an introduced weed over the world, perhaps indigenous in Australia. In Britain, only in the Channel Islands and from Cornwall to Dorset. Fl. summer.

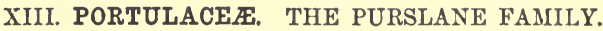

More or less succulent herbs, with entire leaves, usually opposite. Sepals 2 or rarely 3 . Petals 5 or rarely more, sometimes slightly united. Stamens either equal in number and opposite to the petals, or indefinite. Styles 2 to 8 , united at the base. Capsule 1-celled, with a free central placenta, and , several seeds with a curved embryo and mealy albumen, as in Caryophyllacece.

The family has a very wide geographical range, especially in North and South America, with a few species dispersed over the other quarters of the globe. It is nearly allied to the smaller species of Caryophyllacea, and to the Illecebracea, but easily known by the calyx. Several species belonging to the exotic genera Portulaca (Purslane) and Calandrinia, as well as to Claytonia, are cultivated in our gardens.

Petals 5, distinct. Stamens 5, opposite the petals . . . . 1. Chaytonia Petals united in a corolla, split open on one side. Stamens 3 2. MONTIA.

\section{Claytonia. claytonia.}

Petals 5, free. Stamens 5, opposite to the petals and adhering to them at the base. Stigmas 3. Capsule opening in 3 valves, and containing 3 seeds.

The genus comprises several species natives of North America or northern Asta, and is only admissible into the British Flora amongst naturalised aliens.

1. C. perfoliata, Don (fig. 174). Perfoliate C.-A glabrous, green, somewhat succulent annual, with numerous spreading prostrate or ascending stems, from a few inches to nearly a foot long. Radical leaves on long petioles, small, broadly ovate or almost reniform. Flowering stems with a single leaf below the flowers, nearly orbicular, concave, and quite perfoliate, the stem passing through the centre, evidently formed by the union of two opposite leaves. Flowers very 
small, in one, two, or more clusters or short racemes along one common peduncle above the leaf. Petals white, notched, scarcely longer than the calyx.

A native of north-western America, now so common a weed in many English counties that it cannot be omitted from our Flora Flo spring and summer.

[C. Sibirica, Linn. (alsinoides, Sims), with ovate acuminate root-leaves and sessile orbicular stem-leaves, also a North American species, is naturalised in various places, and threatens to be as common as $C$. perfoliata.]

\section{MONTIA. MONTIA.}

Flowers minute, with the 5 petals united into one corolla, split open in front. Stamens 3. Stigmas 3. Capsule opening in 3 valves, and containing 3 seeds.

The genus consists but of one species.

1. M. fontana, Linn. (fig. 175). Blinks, or Tater Chickweed.-A little, glabrous, green, somewhat succulent annual, forming dense tufts, from 1 to 4 or 5 inches in height, the stems becoming longer and weaker in more watery situations. Leaves opposite or nearly so, obovate or spathulate, from 3 to 6 lines long. Flowers solitary or in little drooping racemes of 2 or 3 , in the axils of the upper leaves; the petals of a pure white, but very little longer than the calyx. Capsules small and globular.

On the edges of rills, and springy, wet places, where the water is not stagnant, throughout Europe, in north Russian Asia, in North America, and down the Andes to the southern extremity, in Australia and New Zealand, but not in central Asia. Extends over the whole of Britain. Flo spring and summer.

\section{TAMARISCINE压. THE TAMARISC FAMILY.}

A very small European, North African, and central Asiatic family, with one Mexican genus, all differing from Caryophyllacece in their frequently shrubby habit, alternate leaves, and the ovules and seeds inserted on 3 distinct placentas, arising from the base of the cavity of the ovary, and adhering sometimes to its sides, forming incomplete dissepiments, almost as in Frantieniacea. A single species claims admission into a British Flora, but only as a naturalised plant.

\section{TAMARIX. TAMARISO.}

Maritime shrubs, with slender, twiggy branches, covered with small, green, alternate, scale-like leaves ; the Howers small, in terminal spikes or racemes. Sepals 4 or 5 . Petals as many. Stamens as many, or twice as many, hypogynous. Ovary free, with 3 , rarely 2 or 4 styles. Capsule 1-celled; opening in as many valves as styles. Seeds several, erect, crowned each with a tuft of cottony hairs. No albumen.

1. T. gallica, Linn. (fig. 176). Common T.-An eiegant shrub of 
to 5 or 6 feet ; the slender branches erect, or slightly pendulous at the extremities; the numerous scale-like, pointed leaves scarcely above a line long ; flowers pink or white, very small, crowded in spikes of from $\frac{1}{2}$ to $1 \frac{1}{2}$ inches long, forming frequently branching terminal panicles, the petals persisting till the fruit ripens. T. anglica, Webb.

Very common on the sandy or marshy sea-coasts of the Mediterranean, and extending up the Atlantic shores of Spain and France. Now esta. blished on several parts of the southern coast of England, but believed to be only where it has been planted. Fl. early summer.

\section{ELATINACE\&. THE ELATINE FAMILY.}

A very small family, confined in Europe to the single genus Elatine, but comprising two or three others from hotter or tropical climates. They differ from the tribe Alsinea, of Caryophyllacea, in their capitate stigmas, in their ovaries and capsules completely divided into 3 or more cells, and in their seeds usually without albumen.

\section{ELATINE. ELATINE.}

Minnte, glabrons, aquatic or marsh annuals, with opposite, entire leaves, minute, almost microscopical stipules, and very small, axillary, solitary flowers. Sepals 3 to 5 , sometimes united at the base. Petals as many, hypogrnous, entire. Stamens as many, or twice as many. Styles 3 to 5, with capitate stigmas. Ovary and capsule divided into as many cells as styles, opening when ripe in as many valves, leaving the dissepiments adhering to the axis. Seeds several.

A small genus, spread over the northern bemisphere, in the New as well as the Old World.

Flowers stalked. Petals 3. Stamens 6. Styles 3 . $\quad$ 1. E. hexandra. Flowers sessile. Petals 4. Stamens 8. Styles 4 - . - 2. E. Ilydropiper.

1. E. hexandra, DC. (fig. 177). Six-stamened Waterpepper.-This little plant forms small, matted, creeping tufts, often under water; the stems seldom above 2 inches long, and often not balf an inch. Leaves small, obovate or oblong, tapering at the base. Pedicels 1 to 2 lines long. Flowers globular, with 3 rose-coloured petals scarcely longer than the calyx. Seeds numerous, beautifully ribbed and transversely striated under the microscope. $E$. tripetala, Sm.

Spread over a wide range, in Europe and North $\mathbf{A s i a}$, but its known stations alwass few and scattered. In Britain, recorded from several parts of England, Scotland, and Ireland, and probably frequently overlooked from its minuteness. Fl. summer.

2. E. Hydropiper, Linn. (fig. 178). Eight-stamened Waterpepper.Inclnded by the older authors with the last, under the name of $E$. $\boldsymbol{H} y$ dropiper, but differs in having sessile flowers, with 4 sepals, petals, and styles, and 8 stamens, a more deeply divided calyx, and fewer and larger seeds.

Scattered over the range of $E$. hexandra, and something mixed with 1t, but more rare. In Britain it has only been observed near Farnliam in Surrey, in Worcestershire, and in Anglesea ; and in Ireland in Lough Neagh ond the Lagan Canal. Fl. summer. 


\section{HYPERICINEX. THE HYPERICUM FAMILY.}

A family confined in Britain to the single genus Hypericum. The tropical genera associated with it differ slightly in the number of parts, or in the arrangement of the stamens or of the seeds, and some are tall shrubs or even trees. The chicf distinction of the Order from those nearest allied to it lies in the stamens, either very numerous or arranged in 3 or 5 clusters or bundles.

\section{HYPERICUM. HYPERICUM.}

Herbs, nsually perennial (in some exotic species shrubs) often marked with glandular dots; the leaves opposite and entire, and no stipules; the flowers regular, usually yellow. Sepals 5. Petals 5, hypogynons, usually oblique. Stamens indefinite, clustered or shortly united at the base into 3 or 5 bundles. Capsule more or less completely divided into 3 or 5 cells by as many placentas projecting from the sides to the axis, and usually opening in 3 or 5 valves. Seeds numerous, small, without albumen.

An extensive genus, particularly abundant in southern Evrope, western Asia, and North America, but found also within the tropics, and in the southern hemisphere, both in the New and the Old World. The glandular dots are of two kinds, the pellucid ones, which can be seen by holding up the leaves against the light, and the black ones, which are usually on the under side of the leaves round the edge, or on the flowers themselves.

Undershrubs, with large ovate leaves, few flowers, broad round sepals, and stamens in 5 bundles.

Styles 5 . Flowers very large.

8tyles 3. Petals not much longer than the calyx
erbs with numerous flowers, small or narrow sepala, and Herbs with numerous flowers, smal
stamens in 3 bundles or clusters.

Sepals quite entire, or with very few teeth, without black date Stems erect, above a foot high, bearing a corymb of bright yellow flowers.

stems cylindrical or slightly angled.

Sepals pointed. Leaves with numerous pellucld dots Sepals blunt. Leaves with few or no pellucid dots . stems distinctly four-sided.

Sepals broad and blunt, or acarcely pointed

Sepals narrow and very polnted. Petals pale yellow stems diffuse, not 6 inches long, and much branched. Flowers small, in leafy cymes

Sepals fringed with black or red glandular teeth or dots.

Whole plant perfectly glabrous.

Stems diffuse, or, if erect, growing in tufts, seldom above 6 inches high.

Leaves oblong or ovate. Stems low and diffuse

Leaves linear.

1. $I$. calycinum.

2. H. Androscemum.

stems erect and stiff, usually a foot or more high.

Stem-leaves broad-cordate, rarely above inch long.

Panicle oblong, loose
stem-leaves ovate or oblong, it to 2 inches long. Panicle compact

stems or leaves hairy.

stem tall and erect, sllghtly hairy. Leaves oblong or

stems diffuse, very woolly. Leaves orbicular

3. II. perforatum.

4. II. dubium.

4. H. dubium.

5. H. quadrangulum

6. H. humifusum.

6. H. humifusum.

7. II. linarifolium

8. H. pulchrum.

10. H. montanum.

9. H. hirsutum.

11. $\boldsymbol{H}$. Elodes. 
Sereral half-shrubby or shrubby species, from sonthern Europe, America, or the Canary or Azores Islands, are occasionally cultivated in our flower-gardens or shrubberies.

1. H. calycinum, Linn. (fig. 179). Large-flowered $1 /$.-Rootstock extensively creeping and woody. Stems scarcely a foot high, simple or branching at the base only, with large, almost sessile, ovate or oblong leaves, very obtuse, green and glabrous, with very small pellncid dots. Flowers bright yellow, 3 or 4 inches diameter, 1 or 2 at the top of each stem, or, in our gardens, in a corymb of 5 or 6 . Sepals nearly 6 lines long, orbicular, with longitudinal glandular lines. Stamens very numerous, long and slender, united at the base into 5 bundles. Styles 5 .

A sonth-east European species, long cultivated, and now naturalised in bushy places in several parts of England and Ireland. Fl. summer.

2. H. Androsæmum, Linn. (fig. 180). II. Tutsan.-Stock sbort, somewhat woody; the flowering stems usually numerous, erect, $1 \frac{1}{2}$ to 2 feet high, simple or slightly branched. Leaves sessile, ovate, obtuse, cordate at the base, 2 to 3 inches long, glabrous, with very minute pellucid dots. Flowers few, in small corymbs, shorter than the last pair of leaves. Sepals broad, 3 or 4 lines long. Petals scarcely longer. Stamens numerous, slightly connected at the very base into 5 clusters. Styles 3. Capsule globular, slightly succulent before it is ripe, not usnally opening in valves.

In shrubby places and open woods, in western and southern Europe, extending also far into central Asia. In Britain, all along the west side of Great Britain, in Ireland, and sonthern England, but rare on the eastern side. Fl. summer. The plant recently added to our Flora

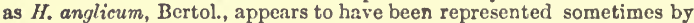
a long-styled state of the Tutsan, sometimes by exotic species escaped from cultivation.

3. H. perforatum, Linn. (fig. 181). St. John's-wort.-Stock perennial, with short runners or decumbent barren shoots and erect stems, 1 to $1 \frac{1}{2}$ feet high, branching in the upper part, cylindrical or with 2 slightly prominent opposite angles, and quite glabrous. Leaves sessile, oblong, seldom above 6 lines long, marked with pellucid dots, and occasionally a few black ones on the under side, the nerves are opaque. Flowers bright yellow, in a handsome terminal corymb. Sepals lanceolate, pointed, quite entire, but with a few glandular lines or dots. Petals twice as long, marked, as well as the anthers, with black dots. Stamens numerous, shortly united into 3 bundles. Styles 3.

In woods, hedges and thicket:, roadsides, \&c., throughout Europe, extending to the Himalaya and central and Russian Asia, except the extreme north, and now introduced into other countries. Abundant in Britain. Fl. summer and autumn.

4. H. dubium, Leers (fig. 182). Imperforate H.-Very much like H. perforatum, but the stem is slightly quadrangular, the leaves rather larger and broader, and nearly destitnte of pellucid dots, but with a few black ones along the margin on the under side and pellucid nerves; the sepals mnch broader, obtuse or scarcely pointed, and the petals and stamens much less dotted.

In similar situations as $I$. perforatum, almost over all Enrope, espe. cially in hilly districts, extending far into Scandinavia, but not an urctic plant. Generally spread over England, southern Scotland and 
Ireland, but not near so frequent as $H$. perforatum. Fl. summer. [Usually regarded as a variety of $H$. quadrangulum.]

5. H. quadrangulum, Linn. (fig. 183). Square-stalked $H$.-With the general habit of the last two species, this one is readily known by the four very prominent angles of the stem, and the rather smaller and paler flowers. Leaves ovate, often an inch long, clasping the stem at the base, with numerous pollucid nerves and dots, and a few black dots round the margin on the under side. Sepals lanceolate and pointed. Petals and anthers with very few black dots, or entirely withont them.

In moist pastures, by hedges and ditches, in central and sonthern Kurope to the Caucasus, extending northward to southern Sweden. Common in England, Ireland, and southern Scotland, but decreasing in frequency towards the north. Fl. summer. H. undulatum, Schousb., (H. baticum, Boiss.), found in bogs of Devonshire and Cornwall, appears to be a slight variety of $H$. quadrangulum, with glandular sepals, narrower petals, and styles only half the length of the capsnle. $[H$. quadratum, Stokes; (tetrapterum, Fries.), is a common form or species allied to quadrangulum; it has glandular acuminate sepals, and short styles.]

6. H. humifusum, Linn. (fig. 184). Trailing H.-A low, decumbent, much branched, almost trailing plant, from 2 or 3 to near 6 inches long, sometimes forming dense spreading tufts, with a perennial rootstock, but often flowering the first year, so as to appear annual. Leaves of $\boldsymbol{H}$. perforatum, but smaller. Flowers few, small, of a pale yellow, in short, loose, leafy cymes. Sepals oblong, often unequal, entire or with a few glandular- teeth, and generally bordered by black dots. Petals scarcely so long, with very few black dots. Stamens few.

In stony heaths, pastnres, bogs, and waste places, in central Europe, extending northward to sonthern Sweden, and carried out to some other countries with European weeds; frequent in England and Ireland, less so in Scotland. Fl. summer and autumn.

7. H. linarifolium, Vahl. (fig. 185). Flax-leaved H.-Intermediate in some measure between $H$. humifusum and $H$. perforatum; taller and more erect than the former, much smaller and more slender than the latter, seldom above 8 or 10 inches high. Leaves linear or narrowoblong, 6 to 8 lines long, rarely marked with pellucid dots, but with a few black ones underneath. Flowers in a loose corymb, larger and brighter than in $H$. humifusum; the sepals oblong or broadly lanceolate, with numerons black dots, and a few glandular tceth on the edge. Petals twice or thrice as long as the sepals. Stamens not numerons.

On dry, hilly wastes and rocky places, in western Spain, Portugal, and France, extending to the Channel Islands and to Cape Cornwall, in south-western England, and the Teign, in Devonshire. Fl. summer

8. H. pulchrum, Linn. (fig. 186). Slender H.-Perennial stock, shortly decumbent, the stems erect and stiff though slender, 1 to near 2 feet high, with short lateral branches, all perfectly glabrous. Leaves of the main stem broadly cordate and clasping the stem at the base, seldom above 6 lines long, those of the lateral branches smaller and much narrower, all marked with pellucid dots, but nsually without black ones. Flowers rather smaller than in $\boldsymbol{H}$. perforatum, forming 
an oblong or pyramidal panicle, not a flat corymb. Sepals broad and obtuse, united to near the middle, without black dots outside, but fringed at the top with black, glandular teeth.

In dry woods, on open heaths and wastes, almost all over Europe, but scarcely extending to the Asiatic frontier. Frequent in Britain. Fl. summer.

9. H. hirsutum, Linn. (fig. 187). Hairy H.-A stiff, erect perennial, with an oblong or pyramidal panicle like $H$. pulchrum, but rather taller, and the stems always more or less downy or hairy. Leaves often above an inch long, oblong or elliptical, narrowed at the base into a very short stalk, more or less hairy underneath on the veins, and marked with numerous pellucid dots. Flowers of $H$. pulchrum, but of a paler yellow; the sepals narrow, fringed with rather long, glandular teeth ; the petals fully twice as long.

In woods and thickets, generally spread over Europe and Russian Asia, except the extreme north. Frequent in Great Britain. Very rare is Ireland. Fl. summer.

10. H. montanum, Lian. (fig. 188). Mountain H.-Stock perennial, the stiff, erect stems about 2 feet high, usually simple, with the upper leaves small and distant, the lower leaves rather large, ovate, and stem-clasping, quite glabrous, with or without pellucid dots, but with a row of black ones round the margin underneath. Flowers in a close compact cyme, often reduced to a head; the sepals lanceolate, fringed with black, glandular teeth; the petals twice as long, narrow, and paler than in $H$. perforatum.

In woods, in central and southern Europe to the Caucasus, and northwards into southern Sweden. Not so frequent in England as the other species, and in Ssotland only found in Ayrshire; only once found in Ireland near Belfast. Fl. summer.

11. H. Elodes, Linn. (fig. 189). Marsh H.-Stems diffuse, often rooting at the base, and attaining 6 to 8 inches, or, when very luxuriant, a foot in length, covered with loose, woolly, whitish hairs. Leaves orbicular, stem-clasping, woolly on both sides. Flowers pale yellow, few together in a leafless cyme, at first terminal, but afterwards becoming lateral. Sepals small, ovate, copiously fringed with glandular teeth. Petals three times as long, with a small fringed appendage at their base. Stamens united to above the middle in 3 bundles.

In spongy and watery bogs, in western Europe, from Spain and Portugal to north-western Germany. Extends over the west of England, Wales, and Ireland, and in Scotland to Argyllshire. FL summer.

\section{LINACEE. THE FLAX FAMILY.}

Herbs or undershrubs, with entire leaves, no stipules, and regular flowers. Sepals 5, rarely fewer, overlapping each other in the bud, rarely partially united. Petals as many, twisted in the bud. Stamens as many, free, or the filaments very shortly united at the base, with small teeth between each (or, in exotic genera, 10 stamens). Styles 5, rarely fewer, often 
slightly connected at the base, with capitate stigmas. Ovary with as many cells as styles, or incompletely divided into twice as many. Capsule separating into as many carpels as cells, without any central column; each carpel opening inwards by longitudinal slits, and containing 2 seeds, often separated by an incomplete partition. No albumen.

A small Order, widely spread over the globe, differing from Geraniacea chiefly in the foliage and the absence of any persistent axis to the fruit, from Caryophyllacee by the capitate stigmas and the fruit.

Parts of the flower in fives

Parts of the flower in fours
1. LINUM.

2. RADIOLA.

\section{LINUM. FLAX.}

Sepals, petals, and stamens 5 . Cells of the capsule apparently 10 but really 5 , each divided into two by a nearly complete partition.

A rather numerous genus, spread over nearly the whole of the temperate and warmer regions of the globe, but chiefly abundant in the Mediterranean region and western Asia.

Flowers small, white. Lower leaves opposite - * - $\quad$ 4. $L$. catharticum.
Flowers blue. Leaves all alternate.

Root annnal. Sepals pointed.

Stem erect. Leaves lanceolate. Petals 7 or 8 lines long . 1. L. usitatissimum.

Stem decumbent. Leaves short and linear. Petals not 6 lines long .

Rootstock perennial.

Sepals obtuse. Petals deep blue, 7 or 8 lines long - . 2. L. perenne.

Sepals pointed. Petals pale blue, not 6 lines long : : 3. L. angustifolium.

The L. flavum, a south European perennial, with yellow flowers, and some other exotic species, are to be met with in our gardens.

1. I. usitatissimum, Linn. (fig. 190). Common P., Linseed.-A tall, erect annual, perfectly glabrous, and usually branched only at the top. Leaves alternate, erect, narrow lanceolate, pointed and entire, $\frac{1}{2}$ to $1 \frac{1}{2}$ inches long. Flowers of a rich blue, in a loose terminal corymb. Sepals obovate or lanceolate, all pointed. Petals obovate, entire or slightly crenate, 7 or 8 lines long. Capsule globular or slightly depressed.

An extensively cultivated plant, whose origin is unknown, but it readily sows itself as a weed of cultivation in Europe, Asia, and other parts of the world, and as such it is met with in some parts of England. Fl. summer.

2. L. perenne, Linn. (fig. 191). Perennial $F$. - A very variable plant, sometimes resembling much $L$. usitatissimum, but it forms a perennial stock, either tufted or rootlike; the stems are usually more slender, and not so erect, and sometimes quite procument, the leaves smaller and narrower, and the sepals, or at least the inner ones, are always obtuse.

In dry chiefly limestone pastures and waste lands, or sometimes in rich mountain pastures, varying much according to soil or situation, and widely diffused over central and southern Europe, and southern Russian Asia, but not extending into northern Germany. Common in western N. America. Occurs in some of the eastern counties of England, but in other localities $L$. angustifolium is often mistaken for it. $F$. summer.

3. L. angustifolium, Huds. (fig. 192). Pale $F$.-Usually a perenniai, with the decumbent stems and narrow leaves of some varieties of $L$ 
percnne, but with the pointed sepals of $L$. usitatissimum. It is occasionally annual, but always differs from both the preceding species in its much smaller pale blue flowers, the petals seldom exceeding 5 lines in length.

In waste places, chiefly in limestone districts, very common in southern Europe and western Asia, and extending up western France to southern and western England, as far as Lancashire ; rare in Ireland. Fl. summer

4. L. catharticum, Linn. (fig. 193). Cathartic $R$.-A very slender, erect, or slightly decumbent glabrous annual, from 3 or 4 to 6 or 8 inches high, with small, opposite, obovate or oblong leaves, and very small flowers, of a pure white, on long, slender pedicels. Sepals all pointed. Petals obovate, scarcely 2 lines long.

In meadows and pastures, common throughout Europe, except the extreme north, and in West Asia. Abundant in Britain. Fl. all summer.

\section{RADIOLA. ALLSEED.}

A single species, separated from Flax on account of the parts of the flower and fruit being in fours instead of in fives, and the sepals united to near the middle in a several-toothed calyx.

1. R. Millegrana, Sm. (fig. 194). Allseed.-A minute, erect annual, with very numerous, repeatedly forked branches, forming dense corymbose tufts, 1 to 2 inches high, with minute globular flowers, on short pedicels. Leaves small, opposite. Calyx-tecth 8 or I2. Petals 4, about the length of the calyx. [ $R$. linoides, Roth., is an earlier name, but quite inapplicable.]

On sandy heaths and waste places, in central and southern Europe to the Caucasus, extending northward into southern Scandinavia. Generally spread over Britain, and very abundant in some localities, though scarce in other districts. Fl. summer.

\section{MALVACE无. THE MALLOW FAMILY.}

Herbs or soft-wooded slırubs, with alternate, stipulate, palmately-veined leaves, and regular flowers. Calyx of 5 divisions, valvate in the bud, and (in the British genera) 3 or more bracts at the base, forming an involucre or so-called outer calyx. Petals 5 , twisted in the bud, and adhering by their short claws to the staminal tube. Stamens numerous, their filaments united in a tube round the pistil, the anthers 1-celled. Ovaries (in the British genera) several, arranged in a ring round a common axis. Styles or style-branches as many as ovaries. Fruit (in the British genera) separating into as many carpels as ovaries. Seeds 1 or several in each carpel, attached to the inner angle, kidney-shaped, with a curved embryo and little albumen.

A very extensive and generally natural family, widely distributed, chiefly over the warmer climates of the globe. The three British genera, all closely allied to each other, only represent one of the two forms of ovary and fruit prevailing in the Order. In Hibiscus, Abutilon, and cereral other exotic genera, the carpels are all united into a single several- 
velled ovary and fruit; in Pavonia and some others there are twice as many style-branches as ovaries.

Exterior bracts united at the base into an involucre or outer calyx.

Involucre 3 -lobed .
Involucre of 5 or more divisions

Exterior bracts 3, distinct from each other, fiserted on the calyx

1. LAVATRRA.

3. ALTH AKA.

2. MALVA.

Among Malvacea, grown in our gardens and belonging to exotic genera, the most frequently to be met with are species of Malope, Hibiscus, or $\Delta$ butilon.

\section{LAVATERA. LAVATERA.}

Involucre 3-lobed, often larger than the 5-lobed calyx. Ovary and fruit of Malva.

A genus of very few species, from the Mediterranean region, western Asia, southern Africa, and Australia.

1. L. arborea, Linn. (fig. 195). Tree Mallow.-Stem woody at the base, with thick, hard, annual flowering branches, forming an under shrub, 1 to 4 or 5 feet high. Leaves on long stalks, the lower ones broadly orbicular, palmately divided into 5 to 9 broad, short, crenate lobes, and softly downy on both sides, rarely nearly glabrous. Flowers numerous, of the size of those of Malva sylvestris, of a pale purple-red, on short pedicels, collected into clusters, forming a long terminal raceme or narrow panicle. Involucre divided to below the middle into 3 broad leaf-like lobes.

On maritime rocks, in sonth-western Europe, from Greece, westwards to the British Isles, where it is very local, chiefly on the south and west coasts of England and Ireland, and in the Firths of Forth and Clyde. Fl. summer.

L. Olbia, a south European species, often cultivated in our gardens, has appeared along the sides of a new embankment in Epping Forest, and may occasionally sow itself in other parts of England. [L. oretica, Linn., a Mediterranean species, is naturalised in waste places rear Penzance, and in the Scilly Isles. It closely resembles Malva sylvestris.]

\section{MALVA. MALLOW.}

Involucre of 3 small distinct bracts, inserted on the lower part of the calyx. Calyx divided to near the middle into 5 broad lobes. Stylebranches 10 or more, subulate. Carpels as many, arranged in a ring round a thickish axis, and separating from it when ripe, each one containing a single seed.

A rather numerous genus, widely dispersed over Europe, northern and central Asia, North America, and South Africa.

Stem decumbent or prostrate. Petals not above twice as long as the calyx.

Stem erect or ascending. Petals 3 or 4 times the length of the calyx.

Leaves with short, broad lobes, not reaching to the middle.

Flowers in axillary clusters
Leaves deeply cut into narrow lobes. Fowers crowded at the summits of the brasuhes.

2. M. sylvestric.

3. M. moschata

The tall tree mallow ( $M$. mauritiana) from the Mediterranean, sad the 
curled mallow ( $M$. crispa) from central Asia, are often to be met with in cottage gardens. Several Cape species are also in cultivation.

1. I. rotundifolia, Linn. (fig. 196). Dwarf M.-A procumbentannual, with a hard, sometimes woody-looking hase, the stem 6 inches to a foot long, tough, and slightly downy. Leaves on long stalks, orbicular, cordate at the base, with 5 to 7 very short and broad crenate lobes. Flowers clustered in the axils of the leaves, small, and of a pale bluist. colour, on pedicels $\frac{1}{2}$ to 1 inch long. Petals 4 to 5 lines long. Carpelr about 15, downy, and rounded on the back, so as to form together a disk-shaped fruit, slightly furrowed on the margin between each two carpels.

On roadsides and in waste places, throughout Europe and western Asia, except the extreme north. Common in England, rarer in Ireland and southern Scotland, still more so further north. Fl. spring to autumn.

M. parviflora, Linn. (M. pusilla, With., borealis, Wallm.), from southern Europe and extending north into Scandinavia; has been introduced with ballast. It has the small flowers of $\boldsymbol{M}$. rotundifolia, but is chiefly distinguished by the carpels not rounded, but flat on the back, with angular edges, as in the $\boldsymbol{M}$. sylvestris. M. verticillata, Linn., from southern Europe and central Asia, with the flowers and fruit of $\boldsymbol{M}$. parviflora, but erect stems, and the flowers in close clusters, has appeared occasionally in cornfields.

2. M. sylvestris, Linn. (fig. 197). Common M.-A biennial, with several erect or ascending stems, 1 to 2 or even 3 feet high, more or less clothed witl spreading hairs, especially in the upper part. Leaves on long stalks, orbicular, slightly cordate at the basc, with 5 or 7 lobes, broad and short, but always deeper than in $M$. rotundifolia, and the middle one often longer than the otlers. Flowers in axillary clusters, usually of a reddish-purple; the petals about 9 or 10 lines long. Carpels usually 10, flat on the back, with angular edges, so that the fruit has rather projecting ribs than furrows between the carpels.

In waste places, on roadsides, \&c. Common in Europe, except at high northern latitudes, and extending all across Russian Asia. Abundant in England and Ireland, decreasing to the northward, and probably not indigenous north of the Grampians. Fl. summer.

3. M. moschata, Linn. (fig. 198). Musk MI.-A perennial, with several erect, simple or slightly branclied stems, about 18 inches ligh, covered with long, spreading hairs. Radical leaves orbicular, with short, broad lobes, but those of the stem deeply divided into linear or wedge-shaped segments, which are again pinnatifid or 3 -lobed. Flowers large, rosecoloured, or rarely white, crowded at the summits of the stem and branches. Carpels rounded on the back, and very hairy.

On hedge-banks, roadsides, and in gravelly pastures, in western, central, and southern Europe, extending northwards to South Sweden, and eastwards to Dalmatia. Not uncommon in England, Ireland, and southern Scotland. $\mathrm{Fl}$. summer.

\section{ALTHÆA. ALTIXA.}

Involucre of more than 5 bracts, more or less united together at the base. Calyx 5-lobed. Ovary and fruit of Malua. 
A small genus, chiefly from the Mediterranean region and western Asia, with one or two South African species.

Tall perennial, covered with a short, velvety down .

1. A. ofloinalis. Annual, with long, spreading, stiff hairs

2. A. hirsuta.

The Hollyhock of our gardens is an Althaca from the Mediterranean region. The Althoea Frutcx of our gardeners is improperly so called, for it is a species of Hibiscus (II. syriacus, Linn.).

1. A. offlinalis, Linn. (fig. 199). Marsh Mallowo.-Stock perennial, the flowering stems erect, branched, 2 to 3 feet high, covered, as well as the foliage and inflorescence, with a soft, dense, velvety down. Leaves stalked, broadly ovate, undivided or 3-lobed, the lower ones often cordate at the base, the upper ones narrow. Flowers not large, of a pale rose-colour, on short pedicels in the upper axils, or the greater number forming almost leafless terminal spikes. Involucre divided into several linear segments, much shorter than the 5-lobed calyx. Carpels 15 to 20 , rounded on the back.

In marshes, especially in maritime districts, in southern Europe, and northern Asia, extending to nortbern Germany, but not into Scandinavia. Not uncommon in southern England and some parts of Ireland, but not found north of Lincolnshire or Arran. Fl. rather late in summer.

2. A. hirsuta, Linn. (fig. 200). Hispid A.-An erect, stiff, but rather slender annual, seldom above a foot high, hispid with long, spreading hairs. Leaves few, the upper ones divided into 3,5 , or 7 narrow segments. Flowers of a pale purplish-blue, on long axillary peduncles. Involucre of 8 to 10 lanceolate lobes, nearly as long as the calyx, the petals about one-half longer. Carpels numerous, somewhat angular on their edges.

In waste and cultivated places, common in southern Europe, up to the Palatinate of the Rhine, and occasionally carried to the northward as a weed of cultivation. Introduced as such into Hertfordshire and Kent, where it has fully established itself near Cobbam. It has also been lately found apparently indigenous in North Somersetshire. Fl. summer

\section{TILIACE尼. THE LIME FAMILY.}

A rather large tropical Order, but limited in Britain to a single species. It differs from Malvacece by the petals imbricated but not twisted in the bud; the stamens free or shortly united into several bundles; the anthers 2-celled, and the carpels completely consolidated into a several-celled ovary.

\section{TILIA. LIME.}

Trees with alternate leaves, deciduous stipules, and small cymes of flowers on an axillary peduncle, to which is attached a long leaf-like bract. Sepals 5, valvate in the bud. Petals 5. Stamens numerous, very shortly cohering in several clusters. Ovary globular, 5-celled, with 2 ovules in each cell, attached to the inner angle. Style single, with a 5-toothed stigma. Fruit, a small globular nut, containing 1 or 2 seeds.

A genus of very few species, widely distributed over the northern temperate zone, where it is the only representative of the family.

1. T. europøa, Linn. (fig. 201). Common L., Lime-trce.-A handsome. 
long-lived tree, attaining sometimes as much as 120 feet,in height, but generally not above half that size. Leaves stalked, broadly heartshaped or nearly orbicular, often oblique, and always pointed, serrate on the edge, glabrous above and more or less downy underneath, especially in the angles of the principal veins. Peduncles hanging amongst the leaves, bordered or winged half-way up by the long, narrow, leaflike bract. Flowers sweet-scented, of a pale whitish-green. Not downy when young, but often glabrous when ripe.

In woods, over nearly the whole of Europe, except the extreme north, and extending eastward across Russian Asia to the Altai. Much planted in Britain, and probably truly wild in southern and western England. Fl. summer. It varies much in the size of the leaves, in the degree of down on their nnder surface and on the fruits, in the greater or less prominence of the 5 filiform ribs of the fruit, \&c. The truly indigenous form in northern Europe is always a small-leaved one. The largeleaved variety which we commonly plant ( $T$. grandifolia, Ehrh.) is of south European origin, with the leaves still further enlarged by cultivation. [The Limes are very puzzling, and no two authors are agreed as to their specific limits. The only certainly indigenous British one is T. cordala, Mill. (parvifolia, Ehrb.), with glabrous twigs, small leaves glaucous beneatl, and downy crustaceous globose or ellipsoid faintly ribbed fruit. Then there is the possibly indigenous $T$. platyphyllos, Scop. (T. grandifolia, Ehrh.), with hairy twigs, leaves large and downy beneath, and obovoid or globose fruit with prominent ribs, said to be a native of W'est England. Lastly the T. vulgaris, Hayne (T. intermedia, Dc.), commonly planted, with glabrous twigs, leaves pnbescent in the axils of the nerves beneath, and a woody pubescent fruit, not ribbed when ripe.]

\section{GERANIACER. THE GERANIUM FAMILY.}

Annual or perennial herbs, or, in exotic species, low shrubs, with opposite or rarely alternate leaves, usually more or less livided or compound, toothed, and furnished with stipules. Flowers regular in the principal British genera, irregular in Impatiens and some exotic ones. Sepals in the regular flowers 5 , overlapping in the bud. Petals 5 , twisted in the bud. Stamens 5 to 10 , often united at the base. Ovary 5-lobed and 5-celled, with one or several seeds in each, all attached to the central axis. Styles 5. Fruit 5-lobed, the carpels opening or partially falling off when ripe, leaving a central persistent axis. In the genera with irregular flowers these characters are much modified. (Sce Impatiens.)

Geraniacca resemble Caryophyllarca and Malvacea in the twisted arrangement of their petals, but differ from the former in foliage as well as in fruit, and from the latter in the definite stamens. The species are distributed nearly all over the globe, but most numerous in the temperate regions of the northern hemisphere, and more especially in south-western Africa. The limits of the Order are as yet scarcely 
settled, some botanists exclnding Impatiens, Oxalis, and Tropaolum, thus confining it to the old Linnæan genus Geranium.

Flowers regular.

Leaves opposite, cut or toothed. Carpels 1-seeded, round the base of a long-beaked receptacle or axis.

Ten stamens

Five stamens

Leaves radical or alternate, with 3 entire leaflets. Receptacle

or axis not beaked. Carpels with several seeds . .

Fowers irregular, with \& large conical spur

1. Graniviu.

2. Erodiom.

3. OXALrs.

4. IMPATIXNS.

The Cape Pelargoniums, so frequent in our greenhouses, belong to Geraniacea. The South American Tropaeolums, including the common Nasturtium of gardeners, are also very nearly allied.

\section{GERANIUM. GERANIUM.}

Herbs, with forked stems often swollen at the nodes, opposite, palmately divided leaves, and purplish flowers, solitary or 2 together, on axillary peduncles. Stamens 10, of which 5 shorter, but generally with anthers. Ovary 5-lobed, terminating in a long beak with 5 short stigmas on the top, the lobes being all whorled round the long-beaked receptacle. Capsule separating into 5 l-seeded carpels, which curl upwards, with a long elastic awn, detached from the beak, and glabrous inside.

A genus spread over the northern bemisphere, witb a few species in the southern, but always without the tropics. It is easily distinguished from all but Erodium by the long beak of the fruit, which has given to the two genera Geranium and Erodium the popular name of Crane'sbill.

Rootstock perennial. Flowers usually large.

Pedunclea 1-flowered .

Peduncles with 2 (rarely 3 ) flowers.

Petals deeply notched. (Flowers not so large.) . . . 5. G. pyrenaicum.

Petals entire or slightly notched.

Petals dark purple, very apreading or slmost reflexed. Points of the sepals very short

Petals blulsh-purple. Sepals with long fine points.

Pedicels of the fruit erect. Flowers numerous, corym.

Pedcels of the fruit spreading or reflexed. Flowers in a loose panicle .

Annuals, with small flowers.

2. G. pharum.

3. G. sylvaticum.

4. G. pratense.

Leaves of 3 distinct segments, which are pinnately cut or divided ${ }^{\circ}$ valmately cut or divilded into 5 or more lobes or seg.

Leaves palr
ments.

Calyx pyramidal, with projecting angles. Petals entire,

much longer than the sepals
Calyx scarcely sngular. Petals about as long, unicss deeply notehed.

Leaves dlvided to the base into 5 or more narrow cut seg. ments.

Peduncles much ahorter than the leafstalks.

Leaves much divided. Seeds dotted.
Leaves small, the lower ones divided to the middle

only. Seeds smooth
Peduncles and pedicels long and slender. Leaves much

divlded
Leaves orbicular, seldoom divlded below the middla.

6. G. Robertianum.

7. G. lucidum.

Petals deeply notched.

Petals twlce as long as the calyx .

11. G. dissectum

9. G. pusillum.

12 G. columbinum

6. G. pyrenaicum 
Petals not longer than the calyx .

8. G. molle.

Petals entire or slightly notched.

Leaves shortly divided into broad lobes. Seeds dotted 10 . G. rotundifolium Leaves divided to the middle. Seeds smooth . . 9. G. pusillum

Two other Continental perennial species are included in some of onr Floras as having occasionally strajed from gardens: G. striatum, with long hairs on the stems, and rather large flowers, the petals very pale, elegantly veined, and rather deeply notched; and $G$. nodosum, a glabrous plant, the lobes of the leaves very pointed, and the petals of a purplish red, much less notched. G. macrorhizon and several other exotic perennials are also cultivated in our flower-gardens.

1. G. sanguineum, Linn. (fig. 202). Blood-red G.-Rootstock thick and woody, sometimes creeping. Stems numerous, about a foot long, decumbent or rarely erect, with spreading hairs. Leaves nearly orbicular, but divided to the base in 5 or 7 segments, which are again cut into 3 or $\mathbf{5}$ narrow lobes. Flowers large, of a dark purple, growing singly on long, slender peduncles. Sepals hairy, with a fine point. Petals twice as long, oborate, slightly notched, and very spreading.

In dry woods and pastures, in temperate and southern Europe to the Caucasus, penetrating far into scandinavia. In Britain, it occurs in many localities, and yet is not very general. Fl. summer. A more hairy variety with more flesh-coloured flowers, and of shorter growth, originally found in the Isle of Walney, Lancashire, is the $G$. lancastriense, With.

2. G. phæum, Linn. (fig. 203). Dusky G.-Rootstock and general mode of growth of $G$. sylvaticum, but the stems are weaker, with fewer flowers, the leaves less deeply iut, with broader lobes, and the petals, of a dark, dingy purple colour, are broadly obovate, quite entire, and spread very open from the base, or are almost reflexed.

In woods and mcadows, in hilly districts, in central and western Europe, not extending to its eastern limits, and in northern Europe only as an introduced plant. In Britain also an introdnced plant, although said to be wild in Westmoreland and Yorkshire. Fl. all summer.

3. G. sylvaticum, Linn. (fig. 204.) Wood G.-Rootstock very short, covered with the brown scarious stipules of the old leaves. Stems erect or ascending, 1 to 2 feet high or rather more. Radical leaves on long stalks, palmately divided almost to the base with 5 or 7 pointed lobes more or less cut and serrated. Stem-leaves few, on much shorter stalks. The upper part of the stem is repeatedly forked, forming a rather dense, corymbose panicle of handsome purplish flowers. Peduncles short, each with 2 flowers, on short pedicels, which remain erect when the fruit ripons. Sepals ending in a fine point above a line long. Petals obovate, slightly notched, scarcely twice as long as the calyx. Filaments of the stamens hairy, scarcely flattened.

In moist woods and thickets, and mountain meadows, thronghout Europe and Russian Asia, extending to the Arctic regions. In Britain, not found south of Stafford and Carnarvon; common in Scotland and northern Ireland. Fl. summer.

4. G. pratense, Linn. (fig. 205). Meadow G.-Distinguished from a. sylvaticum chiefly by its more cut leaves, and larger bluish-purple flowers loosely panicled on longer peduncles; the pedicels always more 
or less spreading or reflexed after flowering. The filaments are also much flattened in their lower part, and the claws of the petals ciliated on the edge, not bearded inside.

In meadows, woods, and thickets, roadsides, \&c., widely spread over Europe and Russian Asia, but not Arctic, although, like the last, chiefly a mountain plant in southern Earope. In Britain, not so frequent as $G$. sylvaticum, not extending so far north in Scotland, but more widely spread in southern England; very rare in Ireland. Fl. summer.

5. G. pyrenaicum, Burm. f. (fig. 206). Mountain G.-A perennial, like the last four species, but with smaller flowers, and much of the habit of the annual ones. Stems often 2 feet long or more, and branched, more or less covered with short, soft hairs. Leaves orbicular, deeply cut into 5 or 7 coarsely toothed, usually obtuse lobes. Flowers numerous, on slender pedicels, 2 together on each peduncle. Sepals scarcely 2 lines long. Petals about twice their length, pale purple and veined, deeply notched.

A native of the hilly districts of central and southern Europe to the Caucasus, but frequently naturalised on roadsides and waste places further to the north. In Britain it appears to be fully established in several parts of England, southern Scotland, and Ireland. Fl spring and summer.

6. G. Robertianum, Linn. (fig. 207). Herb-Robert.-An erect or spreading much-branched annual, 6 inches to near a foot high, generally bearing a few soft hairs, often turning bright red in all its parts, and smelling disagreeably when rubbed. Leaves divided into 3 pinnate or twice pinnate segments, never orbicular or palmate (except the 3 primary divisions). Flowers rather small. Sepals bairy, with long points. Petals reddish-purple or rarely white, sometimes nearly twice the length of the calyx, obovate and entire, with glabrous, erect claws. Carpels glabrous, with a few transverse wrinkles.

In stony and waste places, open woods, \&c., very common throughout Europe, Russian and central Asia, and northern America, short of the Arctic Circle. Abundant in Britain. Fl. the whole season. A maritime variety, with thicker leaves and smaller flowers, is $G$. purpre'eum, Willd.

7. G. lucidum, Linn. (fig. 208). Shining G.-An annual, often turning red like $G$. Robertianum, but always glabrous and shining, and the leaves are orbicular and palmately lobed, with broad segments usually obtuse, or rarely slightly pointed. It is easily distinguished from all our Geraniums by the pyramidal calyx, the edges of the erect sepals forming very projecting angles. Petals like those of $G$. Robertianum, but smaller.

In stony and waste places, on old walls, \&c., in Europe and central Asia, extending northwards into Scandinavia. Generally distributed over Britain, rarer in northern Scotland. Fl. spring and summer.

8. G. molle, Linn. (fig. 209). Dove's-foot G.-An annual, often tufted at the base, more or less covered with rather long, soft, spreading hairs; the stems weak and spreading, very short when first flowering, and seldom attaining a foot. Radical leaves numerous, on very long stalks, orbicular, rather above an inch diameter, divided to below the middle into 7 to 11 obovate or wedge-shaped lobes, which are again 
3 or 5-lobed; the npper leaves few, small, with fewer but deeper and narrower divisions. Peduncles shorter than the leaves, each with 2 small purplish flowers; the sepals obtuse or scarcely pointed; the petals deeply notched, scarcely longer than the calyx. Carpels usually distinctly marked with transverse wrinkles. Seeds quite smooth without dots.

In waste and cultivated places, throughout Europe, except perhaps the extreme north, and spread orer many other countries as a weed of cultiration. Abundant in Britain. Fl. the whole season. [Var. aequale, Bab., a native of Hampshire, has no wrinkles on the carpels.]

9. G. pusillum, Linn. (fig. 210). Small-flowercd G.-Very near $G$. molle, but less hairy, and the leaves usually smaller and more deeply divided. Sepals with a short but distinct point. Petals but slightly notched. Carpels not wrinkled, but hairy as in $G$. rotundifolium, while the seeds are as smooth as in $G$. molle. Five of the stamens hare usually, and perhaps constantly, no anthers, as in Erodium. The upper leaves are sometimes divided to the base; the species is then distinguished from $G$. dissectum by the smaller leaves and smooth seeds.

In waste and cultivated places, throughout Europe, except the extreme north, but not generally so common as $G$. molle. In Britain certainly not so abundant as that species, but perhaps sometimes mis. taken for it, and thus overlooked. Fl. all summer.

10. G. rotundifolium, Linn. (fig. 211). Round-leaved G.-Usually rather a stouter plant than $G$. molle, but with the same orbicular leaves and soft hairs; the lobes of the leaves rather broader, more obtuse, and not so deep; the peduncles shorter ; the flowers still smaller, with entire, obovate petals, scarcely extending the sligk:tly pointed sepals. Carpels hairy, without wrinkles, and the seeds dotted, as in the two following species.

In waste and cultivated places, recorded as common in Europe and Russian Asia, and certainly so in the south, but much less frequent in the north, $G$. molle being probably frequently mistaken for it. In Britain rather scarce, only occurring in southern and central England, and some parts of Ireland. Fl. summer.

11. G. dissectum, Linn. (fig. 212). Cut-leaved a.-An annual, like the last three, but often more erect, and usually more branched, and the leaves much more deeply divided into 5,7 , or 9 narrow segments, which are again deeply trifid or lobed. Peduncles very short, bearing two small purple flowers; the sepals rather larger than in the last three species, with distinct subulate points; the petals about their length, slightly notched. Carpels hairy, without wrinkles. Seeds beautifully and minutely retioulated or dotted. The hairiness of the plant is variable; usually the stems are clothed with long, reflexed hairs, the leaves with a short, soft down.

In dry pastures, waste and cultivated places, common over Europe, Russian Asia, and North America, except the extreme north; a slight variety equally common in North America under the name of $G$. carolinianum, and a larger-flowered perennial variety extends over western America, southern Australia, and New Zealand. The common smallflowered form is abnndant in Britain. Pl. spring and summer.

12. G. columbinum, Linn. (fig. 213). Long-stalked $(.,-$ An annual. 
with slender, decumbent, slightly hairy stems ; the leaves deeply divided as in $G$. dissectum, but the segments still narrower, mostly linear; the peduncles and pedicels long and slender ; the calyx considerably longer, with long, slender points. Petals entire or notched, seldom exceeding the calyx. Carpels but slightly hairy, or quite glabrous, not wrinkled. Seeds dotted as in $G$. dissectum.

In dry pastures, on banks and waste places, over Europe and Russian Asia, except the extreme north. Not so common as $G$. dissectum in Britain, and very local in Scotland and Ireland. Fl. spring and summer.

\section{ERODIUM. ERODIUM.}

Prostrate or decumbent herbs, differing from Geranium in the divisions or nerves of the leaves being pinnate, not palmate; in the stamens always reduced to 5 , the 5 alternate ones being rudimentary only; in the awns of the carpels bearded with a few long hairs on the inside, and spirally twisted after they are detached from the axis. The flowers are also frequently more than 2 together, in an umbel on the summit of the peduncle.

The geographical range is nearly that of Geranium, in which genus it was included by Linnæus. But the greater number of the species are maritime plants from the Mediterranean regions, or roadside weeds: with flowers so insignificant that but few have ever been cultivated.

Leaves pinnate, with distinct segments.

Segments deeply pinnatifld, with toothed lobes. Flowers of a reddish purple.

Segments ovate, coarsely toothed or shortly lobed. Fowers

Leaves toothed or lobed, but not divided into distinct segments.

Leaves ovate

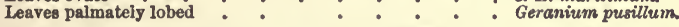

1. E. cicutarium, L'Hér. (fig. 214). Common E.-Usually an annual, but often forming a dense tuft, with a thick taproot, and in some situations lasting at least a second year, always more or less covered with spreading hairs, which are sometimes viscid. Stems sometimes exceedingly short, sometimes lengthening out to 6 inches or near a foot. Leaves mostly radical, pinnate, on long stalks, the segments distinct and deeply pinnatifid, with narrow, more or less cut lobes. Peduncles erect, bearing an umbel of from 2 or 3 to 10 or 12 small purple or pink flowers. Sepals pointed, about the length of the obovate, entire petals. Carpels slightly hairy, the beak varying from 16 to 18 lines in length.

In waste and cultivated lands and dry pastures, especially near the sea, and on roadsides; very common in Europe, northern Asia, and North America, short of the Arctic Circle. Generally distributed over Britain. Fl. spring and summer. A maritime, more viscid, and hairy variety, known in southern Europe as $E$. hirtum, is also found on our own coasts.

2. E. moschatum, L'Hér. (fig. 215). M M sk B. - A much larger and coarser plant than $\boldsymbol{B}$. cicutarium, often strongly smelling of musk. Stems often a foot long. Leaves on long footstalks, with from 9 to 11 distinct, ovate segments or leaflets, often cordate at the base, and deeply toothed or shortly pinnatifid. Flowers generally numerous in the umbel, of a bluish-pnrple, rather larger than in E. cicutarium, 
although the petals are scarcely longer than the calyx. Peduncles often 6 or 8 inches long.

In sandy waste places and heaths, especially near the sea, in western and southern Europe. Abundant in the Channel Islands, found also on the southern and western coasts of England and South Wales; local in Ireland. Fl. summer.

3. E. maritimum, L'Hér. (fig. 216). Sea E.-A small, softly hairy, often viscid annual, with the same varying habit as $E$. cicutarium, but easily distinguished by the simple, not pinnate leaves, often not above half an inch long, orate-cordate, more or less toothed or even lobed, but seldom beyond half-way to the midrib. Peduncles seldom longer than the leaves, with 1,2, or rarely more, small, reddish-purple flowers. Beak of the fruit seldom above 6 lines long; the bairs of the inside of the awn very few, or perhaps sometimes entirely wanting.

In maritime sands, in western Europe, and on the Mediterranean, where it varies much more than with us, and sbould probably include several species of modern botanists. Not uncommon on the south and west coasts of England, up to the south of Scotland, all round Ireland. Has been found also in some inland situations in England. Fl. all summer.

\section{OXALIS. OXALIS.}

Herbs, either annual, or with a tuberous or creeping, perennial rootstock, and, in European species, palmately trifoliate, long-stalked leaves. Flowers solitary, or several in an umbel, on radical or axillary peduncles. Sepals 5. Petals 5. Stamens 10. Ovary angular, not beaked, 5-celled, with several ovules in each cell. Styles 5, short, scarcely united at the base. Capsule with 5 angles, opening in as many valves.

A very numerous genus, widely diffused over the temperate and hotter regions of the globe. A few tropical species have entire or pinnate leaves, and are occasionally undershrubs; but the great mass of the genus, like the few European species, are remarkable for their leaves, with 3 obovate leaflets like those of a Trifolium.

Flowers white. Peduncles radical, 1-flowered . . . . 1. 0 . Acetosella. Flowers small, yellow. Stem elongated. Peduncles axillary $: 2.0$. corniculata.

Many exotic species, with yellow or reddish flowers, have at various times been cultivated, either in our flower-gardens, or, for their tuber. ous rootstocks, as esculents.

1. O. Acetosella, Linn. (fig. 217). Wood-sorrel--Rootstock shortly creeping, slender, but often knotted with thickened scales. Leaves radical, with long stalks, and 3 obovate, delicately green leaflets, with a slightly acid flavour. Peduncles radical, long and slender, bearing a single, rather large white, rarely pink or purplish flower, and 2 small bracts, about half-way up. Sepals small, ovate, obtuse, thin. Petals obovate, about 6 lines long. Capsule ovoid, with 2 shining black seeds in each cell.

In woods, throughout Europe, Russian and central Asia, and northern America. Abundant in Britain. Fl. early spring. This is believed to be the original of the Irish Shamrock, although that emblem is now represented by Trifolium repens.

2. O. corniculata, Linn. (fig. 218). Procumbent 0.-A more or less 
downy annual, or, in warmer climates, a perennial, with slender, spread. ing branches, seldom above 6 inches long. Leaves of 3 deeply obcordate leaflets, with small stipules at the base of the leafstalks. Peduncles slender, axillary, bearing an umbel of from 2 to 4 , or rarely 5, pale yellow flowers, much smaller than in 0 . Acetosella.

A common weed in all the hotter and most of the temperate regions of the globe. In Britain, only in a few localities in southern England, except where accidentally introduced into gardens. Fl. the whole scason. A closely allied American species, the 0 . stricta, with a more erect stem and no perceptible stipules, is also an occasional garden weed.

\section{IMPATIENS. BALSAM.}

Herbs, mostly glabrous or almost succulent, with alternate, undivided leaves, no stipules, and very irregular flowers. Sepals and petals all coloured, and consisting usually of 6 pieces, viz., 2 outer, opposite (sepals), flat and oblique; the next (upper sepal, although by the twisting of the pedicel it hangs lowest) large, hood-shaped, ending below in a conical spur; the fourth (lower petal, but uppermost from the twisting of the pedicel) much smaller, but yet very broad, and somewhat concave; the 2 innermost (petals) very oblique and irregularly shaped, more or less divided into two unequal lobes. Stamens 5, with very short, thick filaments, the anthers cohering in a mass round the pistil. Ovary 5 celled, with several ovnles in each cell. Stigmas 5, minute, sessile or nearly so. Capsule bursting elastically in 5 valves, which roll inwards, scattering the seeds.

A numerous genus, chiefly East Indian, with a few North American species.

Flowers yellow. Spur of the calyx loosely bent back, and entire . calyx, and notched at the extremity . . 2. I. fulva.

Several East Indian species are cultivated for their flowers, and amongst them the well-known garden Balsam ( 1 . Balsamina), whose flowers become donble with great readiness. The $I$. parviflora, a native of eastern Europe and Russian Asia, has more or less established itself as a weed in some of the southern counties of England. It is a rather tall species, with many flowered peduncles, and very small flowers, with a very short spur.

1. I. Noli-me-tangere, Linn. (fig. 219). Yelloro B., Touch-me-not.An erect, glabrous, branching annual, 1 to 2 feet high; the stem rather succulent, and swollen at the nodes. Leaves stalked, ovate, pointed, toothed, of a pale green, and very flaccid. Peduncles axillary, slender, bearing 1 or 2 perfect flowers, which are large and showy, yellow, spotted with orange; the hooded sepal ending in a long spur, curved npwards, and bent back upon the flower. These flowers seldom set their seed in this country; the pods are chiefly produced by minute, imperfect flowers, of which there are several on the same peduncles as the perfect ones.

In moist woods and shady places, in the hilly districts of Khurope and Russian Asia, extending northwards into Scandinavia. In Britain 
chiefly in northern England and North Wales, extending neither into Scotland nor Ireland. Fl. summer till rather late.

2. I. fulva, Nutt. (fig. 220). Orange B.-An annual closely resembling the last species, except that the flowers are of a deeper orange-colour, spotted with reddish-brown, and the spur is very closely bent back upon the calyx, and slightly notched at the extremity.

A North American plant, fnlly established along the Wey in Surrey, and some other streams. Fl. summer. [I. biflora, Walt., is a much earlier name, but it has not been adopted by American botanists.]

The Rue (Ruta graveolens), and Fraxinclla (Dictamnus Fraxinclla), both from southern Europe, belong to the very large family Rutacce, chiefly numerous within the tropics, and in the soutbern hemisphere, but unrepresented in Britain. The Diosmas, Correas, and many other South African and Australian plants in our plant-houses, are members of the same family.

\section{ACERACE屟. THE MAPLE TRIBE.}

(A Tribe of Sapindacea, or the Sapindus family.)

The Maple tribe corresponds to the Linnæan genus Acer, which modern botanists have broken up into two or three by the separation of a few North American or East Indian species. The whole group consists, however, but of very few species, ranging over the temperate zone of the northern hemisphere.

The true Sapindacca are mostly tropical trees or lofty climbers, and are seldom to be met with even in our hothouses; but the Horsechestnuts (Asculus, Linn.), form a distinct tribe of the same family, or, according to some botanists, the small adjoining family of Hippocastanece, which, like Aceracea, contains a small number of trees or shrubs from the northern hemisphere. The Bladder-nut of our shrubberies (Staphylea pinnata, Linn.), from central and eastern Europe, is the type of the third tribe or Sapindacea, in which, as in Aceracce and Hippocastanea, the leaves are always opposite, whilst in the true Sapindacea they are generally alternate.

\section{ACER. MAPLE.}

Trees, with opposite, palmately-veined and lobed leaves, no stipnles, and small greenish flowers, in axillary corymbs or racemes. Sepals nsually 5 , overlapping each other in the bud, and more or less united at the base. Petals 5, or sometimes 4, or entirely wanting. Stamens abont 8 , inserted on a thick disk below the ovary. Ovary 2-lobed or rarely 3 -lobed, each lobe enclosing one cell with 2 ovules suspended from the inner angle. Styles 2, rarely 3, often united at the base. Fruit separating when ripe into 2 , rarely 3 , indehiscent carpels or nuts, produced into a wing at the top, and called keys or samaras. Seeds 1 or 2 in each carpel, without albumen.

A genus not numerous in species, but extending over Europe, Russian and central Asia, the Himalaya, and Nortb America. It differs from all British trees, except the $A s h$, by its opposite leares, and from that genus by the flowers, and by the palmate not pinnate leaves. 
Flowers on short, loose, erect corymbs. Wings of the car pels diverging horizontally

Howers in pendulous racemes. Wings of the carpels erect, or slightly diverging .

1. A. campestre.

The Norway Maple, A. platanoides, and A. monspessulanum from eastern or southern Europe, the sugar Maple (A. saccharatum) from North America, and some other exotic true Maples, besides the ash-leaved Maple, forming the genus Negundo, from North America, may be met with in our parks and plantations.

1. A campestre, Linn. (fig. 221). Common M.-When full-grown, a rather handsome, round-headed, though not very tall tree, with a dense dark-green foliage, but, as it is of slow growth and flowers when young, it is often seen as a small scraggy tree, or mere bush, in onr hedges. Leaves on slender stalks, 2 to 3 inches broad, divided to about the middle into 5 broad, nsually obtuse lobes, entire or sinuate, glabrous above, often downy nnderneath. Flowers few, on slender pedicels, in loose, erect corymbs, shorter than the leaves. Carpels downy or rarely glabrons, the wings spreading horizontally, so as to form together one straight line.

In European woods, extending eastward to the Cancasus, and northward to sonthern Sweden. In Britain, abundant in sonthern England, and apparently truly indigenous as far north as Cheshire and the Tyne, rare in the wild state in Ireland. $F$. spring.

2. A. Pseudo-platanus, Linn. (fig. 222). Syeamore-A mnch handsomer and freer-growing tree than $\boldsymbol{A}$. campestre, the leaves larger, with more pointed and toothed lobes, not unlike those of a Plane-tree. Flowers in loose, oblong, hanging racemes. Wings of the carpels nearly parallel, or diverging so as to form a right angle, not spreading into one straight line.

A native of the monntains of central Europe and western Asia, naturalised in Britain. $F l$ spring.

\section{AQUIFOLIACE无. THE HOLLY FAMILY.}

A small Order, widely spread over the globe, limited in Britain to a single genus, from which the few exotic ones differ slightly in the number of parts of the flower and fruit. They nearly all approach Celastracece, but have the petals usually very shortly united into a monopetalous corolla, and the stamens inserted on its base, without any fleshy disk round the ovary.

\section{ILEX. HOLLY.}

Shrubs or trees, with alternate leaves, and small flowers in axillary clusters. Calyx of 4 or rarely 5 small teeth. Corolla regular, deeply divided Into as many segments or petals. Stamens as many, inserted on the corolla, and alternating with its segments. Ovary sessile, 4-celled, with one pendulons ovule in each cell, and crowned by 4 minute sessile stigmas. Fruit a berry, or rather a small drupe, including 4 stones or nzts, each containing a single seed.

The species are numerous in the warmer parts of the northern hemi. 
sphere, as well as in the tropics, but reduced to very few in the more temperate regions.

1. I. Aquifolium, Linn. (fig. 223). Common H.-An erect, much branched evergreen shrub or bushy tree; the leaves shortly stalked, ovate, thick and shining, some quite entire, others much waved, and bordered with strong, very prickly coarse teeth. Flowers white, in dense clusters in the axils of the leaves, often unisexual. Berries bright red or yellow.

Common in hedges and woods in western and southern Europe, extending to the Cancasus, but will not bear the winters of northeastern Europe or northern Asia. Found all over Britain. Fl. summer.

\section{CELASTRACER. THE CELASTRUS FAMII,Y.}

A rather numerous family, in warm climates of both the New and the Old World, and in the southern hemisphere, but confined in Britain to the single genus Evonymus. The exotic genera associated with it differ chiefly in the shape of the parts or the flowers, or in the various forms the fruit assumes as it ripens.

\section{EVONYMUS. SPINDLE-TREE.}

Shrub, with opposite, undivided leaves, and small green or purplish regular flowers, in loose, axillary cymes. Calyx small and flat, with 4 or 5 broad, short lobes, overlapping each other in the bud. Petals as many, also overlapping each other. Stamens as many, alternating with the petals, and united with them on a slightly thickened disk, which covers the base of the calyx. Ovary immersed in the disk, with a very short, protruding style. Capsule with 4 (rarely 3 or 5 ) angles or lobes, enclosing as many cells, and opening, when ripe, in as many valves along the middle of each cell. Seeds solitary in each cell, enclosed in a coloured, fleshy arillus. Embryo in a fleshy albumen.

A genus widely diffused over Europe, Asia, and North America, and easily recognised by its fruit.

The E. latifolius, from the continent of Europe, the E. atropurpureus, from North America, and some other exotic, especially Japanese, species, are occasionally planted in our shrubberies.

1. E. europæus, Linn. (fig. 224). Common S.-A glabrous shrub, about 3 to 5 feet high. Leaves shortly stalked, ovatc-oblong or lanceolate, pointed, and minutely toothed. Peduncles shorter than the leaves, with seldom more than 3 or 5 flowers, of a yellowish-green colour. Petals 4, obovate, about 2 lines long, the stamens half that length. Pod red when ripe, opening at the angles so as to show the secds enclosed in a brilliant orange-coloured aril.

In hedges and thickets, in temperate and southern Europe, and western Asia, extending into southern Scandinavia. Frequent in many parts of England, local in Ireland, rare in Scotland. Fl. spring or early summer

XXIV. RHAMNACEE. THE BUCKTHORN FAMILY.

An extensive family widely dispersed over the globe, but confined in Britain to the single genus Rhamnus. The exotic 
genera all agree with that one, and differ from the adjoining families in the position of the stamens, alternating with the sepals, the petals either small and opposite to (or underneath) the stamens, or wanting.

The Ceanothuses of our gardens belong to this family. The Grape Vine. the Virginian creeper, and other species of Vitis and Cissus, have the same relative position of the stamens and sepals; but the stamens being more decidedly hypogynous, and the habit different, they form the independent family Vitacece (or Ampelidece).

\section{RHAMNUS. BUCKTHORN.}

Shrubs, with alternate undivided leaves, and small green flowers on short pedicels, usually clustered in the axils of the leaves. Calyx with 4 or 5 short deciduous teeth or sepals. Petals none or very small. Stamens 4 or 5 , alternating with the teeth of the calyx and opposite the petals, inserted on a disk which lines the base of the calyx. Ovary free, 3- or 4-celled, with 1 erect ovale in each cell. Style very short. Fruit a small berry (or drupe) enclosing 3 or 4 small 1-seeded nuts. Embryo in a fleshy albumen.

A considerable genus, widely spread over the northern hemisphere, both in the New and the Old World, penetrating into the tropics, with a few southern species.

The evergreen Alaternus of our shrubberies is a species of Rhamnus (R. Alaternus) from southern Europe.

Leaves minutely toothed. Branches often thorny. Flowers diocious; stamens 4 . 1. R. catharticus. Leaves entire. No thorns. Flowers hermaphrodito; stamens $\dot{5}$ 2. $R$. Franyula.

1. R. catharticus, Linn. (fig. 225). Common B.-A glabrous shrub with spreading branches, the smaller ones often ending in a stout thorn. Leaves stalked, ovate, acuminate or pointed, rarely obtuse, $1 \frac{1}{2}$ to 2 inches long, bordered by very small regular teeth, marked with a few prominent veins, obliquely diverging from the midrib, and mostly proceeding from below the middle. Flowers diœcious, very small, usually thickly elustered in the axils of the leaves. Petals 4, very narrow, and not longer than the teeth of the calyx. Fruit black, about the size of a pea.

In hedges and bushy places, over Europe, Russian A sia, and naturalised in North America, but not Arctic. Not abundant in England or Ireland, and very rare, if native, in Scotland. Fl. spring or early summer.

2. R. Frangula, Linn. (fig. 226). Alder B.-A more erect shrub than $R$. catharticus, not thorny, the leaves broader and more obtuse, entire or slightly sinuate, having sometimes a minute down on the under side, and the lateral veins more numerous, diverging equally from the midrib almost the whole of its length. Flowers 2 or 3 together in each axil, all hemaphrodite; the minute petals, the teeth of the calyx, and the stamens, in fives. Fruit dark purple, the size of a pea.

In hedges and bushy places, throughout Europe and Russian Asia, except the extreme north. In Britain rather more frequent than $R$. eatharticus, but still rare in Scotland and Ireland. Fl. spring or curly nummer. 
The Sumachs of our shrubberies (species of Rhus) belong to the large family of T'erebinthacece, widely spread over the temperate and hotter regions of the globe, but unrepresented in Britain. They are usually shrubs or trees, with mostly compound leaves, small regular flowers, definite stamens, inserted under a perigynous disk, quite free from the ovary, and no albumen in the seed.

\section{PAPILIONACE压. THE PEAFLOWER TRIBE.}

(A Tribe of the Leguminous family, or Leguminosa.)

Herbs, shrubs, or trees; the leaves alternate (or, in a few exotic genera, opposite), usually furnished witl stipules, simple or more frequently compound; the leaflets either pinnately or digitately arranged on their common stalk. Flowers in axillary or terminal racemes or spikes, rarely solitary. Sepals combined into a single calyx, more or less divided into 5 or fewer teeth or lobes. Corolla very irregular, consisting of 5 petals; the upper one, called the standard, is outside of all in the bud, and usually the broadest; the two lateral ones, called wings, are between the standard and the two lower onez, which are inside of all, and united more or less by their outer edge into a single one called the keel; the claws of all 5 petals remaining free. Stamens 10, the filaments in the British species either monadelphous, all united in a sheath round the ovary, or diadelphous, when the upper one is free and the other nine united in a sheath. Ovary single, 1-celled, with 1, 2, or more ovules arranged along the inner or upper angle (the one next the standard) of the cavity. Style simple. Fruit a pod, usually opening in 2 valves. Seeds with 2 large cotyledons and no albumen.

A very numerous tribe, widely distributed over the whole surface of the globe, and easily known by the peculiar form and arrangement of the petals, constituting the well-known peaflower called by botanists papitionaceous, comparing it, by a not very intelligible stretch of imagination, to a bntterfly. 'The whole family comprises two other tribes or sub-orders, chiefly tropical or southern: the Casalpinia tribe, represented in our plantations by the Judas-tree (Cercis) and the Gleditschia, or, in our plant-houses, by Cassias, Bauhinias, and others; and the Mimosa tribe, to which belong the Sensitive-plant (Mimosa pudica), the Calliandras, and the numerous Australian Acacias. The Leguminosa thus form, after the Composites, the most extensive of all the Natural Orders of flowering plants.

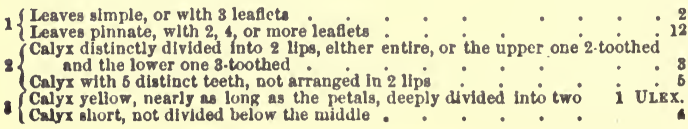


flips of the calyx deeply toothed

Teeth of llps very short

5 Keel of the corolla very pointed

Keel of the corolla obtuse

(Leaves with 1 or 3 leaflets.

rilowe delphous

$6<$ dladelphous 17. LATHYRUB.

Leaves with a pair of leaflets at the base of the stalk besicles the 3 at the top. Flowers in umbels. Stamens diadelphous .

9. LOTUE.

7 Shrubs or undershrubs, Stamens monadelphous

Herbs. Stamens diadelphous

$8\{$ Leavcs simple or reduced to a tendril :

$8\{$ Leaves with 3 leaflets

of Pod much curved or spirally twisted. Flowers in short racemes

Pod straight or nearly so

$10\{$ Flowers in long racemes

$10\{$ Flowers in heads or short racemes

11\{

Pod several-seeded, much longer than the calyx:

Pod 1. to 4-seeded, seldum exceeding the calyx .

12 Flowers in umbels or globular heads

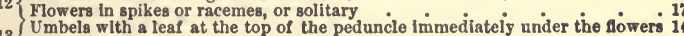

13 Umbels leafleas

14 Calyx inflated, enclosing the pod .

14 Calyx not inflated, shorter than the pod

15 Leaflets 5. Keel pointed or beaked. Pod not jointed

Leaflets many. Keel obtuse. Pod jointed.

16 Keel very pointed

Keel small, obtuse. Flowers minute:

Common stalk of all the leaves ending in a terminal leaflet. Stipules not

Common stalk of the leaves, at least some of them, ending in a tendril or fine point. Stipules sagittate, or half-sagittate.

18 Pod short, flat, with 1 seed

15. ONOBR YCHIS.

, with several seeds

19

Keel with a short. distinct point

Keel with a short. distinct point
Keel obtuse, without any point $:$ on the outer side or all round. Leaflets small

Style numerous (except in V. bithynica) . Style flattened, hairy on the inner side only. Leaflets usnally few, and rather large

Among the very numerous Peaflowers cultivated in our gardens, and belonging to genera entirely exotic, the most common are, amongst trees, -two species of Laburnum, the Robinias (cornmonly called Acacias, but not the Acacias of botanists); among shrubs, - the bladder Senna (Colutea arborescens), the Spanish Broom (Spartium junceum), sereral species of Caragana, Coronilla, \&c.; in flower gardens,-several Lupines, the French Honeysuckle (Hedysarum coronarium), \&c.; and in kitchengardens, - the French Bean (Phaseolus vilgaris), the Scarlet runner (Phaseolus coccineus), \&c. ; whilst the Anstralian Chorozemas, Kennedyas and others, the New Zealand Edwardsias and Clianthus, the East Indian Piptanthus, Indigos, \&c., the Chinese Millettia (Wistaria or Glycine of gardeners), and many others, from various parts of the world, are con spicuous in our plant-houses or on garden-walls.

\section{ULEX FURZk.}

Much branched, very thorny, green shrubs, with simple, prickle. shaped leaves, and yellow flowers. Calyx coloured like the petals, divided nearly to the base into two concare segments or lips, which 
are entire or minutely toothed at the top. Stamens all united into a complete sheath. Pod few-seeded, scarcely longer than the calyx.

A genus of very few species, confined to western and central Europe and north-western Africa.

Calyx very hairy, with the bracts of the base about a line long Calyx nearly glabrous, the bracts scarcely perceptible .

1. 0 . europous. 2. U. nanus.

1. U. europæus, Linn. (fig. 227). Furze, Gorse, Whin.-A shrub of 2 to 3 feet, or even twice that height when old and luxuriant, and more or less hairy, especially on the main branches; the numerous short, intricate, small branches all ending in a stout thorn. Lower leaves occasionally lanceolate, but the greater number reduced to thorns, 2 to 6 lines long. Flowers abont 6 lines long, solitary in the axils of the leaves on the preceding jear's shoots, forming showy racemes, intermixed with thorns at the end of the branches. Calyx yellow like the petals and but little shorter, clothed with brownisb hairs, with a small, broad bract about a line long on each side at the base, besides a similar bract under the short pedicel. Petals narrow.

On heaths and sandy and stony wastes in western Europe, extending eastward to northern and central Germanr, but not a Mediterranean species. Abundant in England, Ireland, and southern Scotland, more searce in the north. Fl. spring and early summer, commencing occasionally in winter, or even late in autumn. A double flowering variety, and another with compact ercet branches, commonly called Irish Furze ( $U$. strictus) are frequent in gardens.

2. U. nanus, Forst. (fig. 228). Duarf F.-Very near U. europacus, and perhaps a mere variety. It is of much smaller stature, less hairy, and of a deeper green; the flowers of a deeper golden yellow, and smaller; the calyx glabrous, or with only a few short, scattered hairs, and the bracts at its base very much smaller, sometimes quite microscopic.

On heaths and sandy or stony wastes, more strictly western tban $U$. europeus, as it does not cross the Rhine, but often intermixed with that species. Very abundant in Britain. Fl, summer and autumn, whilst the common $F$, is in fruit. There are two forms, sometimes very distinct, at others running much one into the other; one, the original $U$. nanus, found chiefly in the plains of eastern England, is very dwarf and procumbent, with the calyx about 4 lines long; the other, $U$. Gallii, Planch, is more ereet, with the calyx about 5 lines long, and is more frequent in western England, often covering large tracts in the Welsh mountains.

\section{GENISTA. GENISTA.}

Low branching green slurubs or undershrubs, with simple (or in a very few exotic species trifoliolate) leaves and yellow flowers. Calyx with 5 teetli, the 2 upper ones much longer than the 3 lower. Standard oblong; keel usually reflexed after flowering. Stamens all united in a complete sheath. Stigma usually oblique. Pod longer than the calyx. Seeds several, not strophiolate.

A numerous genus chiefly in the Mediterrancan region and western Asia, the few British species easily distinguished by their foliage and the shape of the petals. Manj exotic species, however, present so much variety, that the general circumscription of the genus, and ite 
distinction from Cytisus and other allied genera, are very differently viewed by different botanists.

No thorns. Pod narrow, mnch flattened.

Corolla and pod without hairs. Branches erect or sscending . 1. G. tinctoria

Corolla and pod hairy. Branches mostly prostrate : . 2 G. pilosa.

Lower branches very thorny. Pod short and inflated $: \vdots \quad$ \& G. anglica.

1. G. tinctoria, Linn. (fig. 229). Dyer's G., Greenweed.-Stems woody, branching and decumbent at the base, the flowering branches erect or ascending, 1 to $1 \frac{1}{2}$ feet high, hard and stiff, but green. Leaves sessile, from narrow-lanceolate to broadly elliptical or nearly ovate, glabrous or nearly so, and often shining. Flowers in short racemes at the ends of the branches, each one shortly stalked in the axil of a lanceolate bract, with very small bracteoles below the flowers. Calyx short, all the teeth ending in a short, fine point, the npper 2 broadly lanceolate, the 3 lower very narrow. Petals about 6 lines long. Pod nearly an incb long, flattened, and quite glabrous.

In pastures, thickets, and waste places, throughout central and southern Europe, across Russian Asia to the Baikal, and northward to southern Sweden. Frequent in the greater part of England, south of Scotland only, and rare in Ireland. Fl. summer, rather early. The common form is erect, with lanceolate leaves; in rich meadows it becomes very luxuriant with ovate leaves; in dry rocky soils the stem is more branched, and almost prostrate, like the $G$. pilosa, from which it is always known by its more pointed leaves, and glabrous flowers and pods. [A decumbent hairy form found in Dorset and Cornwall is var. prostrata, Bab.]

2. G. pilosa, Linn. (fig. 230). IIairy G.-Stems woody and prostrate, with numerous short, hard branches. Leaves shortly obovate or lanceolate, obtuse, glabrous above, but covered underneath with short, silky hairs. Flowers smaller than in $G$. tinctoria, of a bright yellow, on short pedicels in the axils of the last year's leaves. Calyx silky. Petals also covered outside with silky hairs. Pod rather shorter and broader than in $G$. tinctoria, thickly covered with longish hairs, which are appressed and silky when young, more spreading as the pod ripens.

In pastures, heaths, and dry, gravelly or stony places, common in central and souther Europe to the Caucasus, extending northward to sonthern Sweden. Rare in Britain, and only found south of Pembrokeshire on the west, and Suffolk on the east of England. Fl. spring or early summer.

3. G. anglica, Linn. (fig. 231). Needle G., Petty Whin.-A small, loosely branched, spreading shrub, seldom a foot high, perfectly glabrous, the lower branches converted into short, but slender, simple or branched thorns. Leaves small, lanceolate or ovate. Flowers few, in short, leafy, racemes, paler and smaller than in $G$. tinctoria; the teeth of the calyx less unequal; the petals narrow, and often turning green in drying. Pods about 6 lines long, broad, and much inflated.

On beaths, moors, and bushy pastures, in western Europe, extending eastward to Denmark and north-western Germany. Frequent in England and the greater part of Scotland, but not recorded from Ireland. F spring and early summer, and sometimes again later in the year. 


\section{CYTISUS. BROOM.}

Shrubs, with stiff, green branches, the leaves mostly with 3 digitate leaflets. Calyx campanulate, with 2 short, broad lips, minutely toothed at the top. Petals broad, the keel obtuse and slightly incurved. Stamens all united into a complete sheath. Pod flat, much longer than the calyx. Seeds several, with a strophiole at the hilum.

A large genus, extending over Europe and the Mediterranean region to the Canary Islands. The most constant character to distinguish it from Genista is the strophiole of the seed, but in the case of most species it is also known by the 3 -foliolate, not simple leaves, broader petals, \&c. The only British species has been by some modern botanists separated under the name of Sarothamnus, chiefly on acconnt of the spiral style; but some European species show a gradual passage from the long spiral to the short and straight style.

The Irish Broom of our gardens is the C. patens from Portugal, not a native of Ireland. The Spanish Broom belongs to the genus Spartium. Several other south European true Cytisi are cultivated in our gardens.

1. C. scoparius, Link. (fig. 232). Common B.-A shrnb, of 3 to 5 feet, glabrous or nearly so, with numerous long, straight and erect, green, wiry branches prominently angled. Lower leaves shortly stalked, with 3 small, obovate leaflets; upper leaves sessile; the leaflets often reduced to a single one. Flowers large, bright yellow, solitary or in pairs, on slender pedicels, in the axils of the old leaves, forming handsome leafy racemes along the upper branches. Petals all broad, the standard broadly orbicular, the keel often deflected as in Genista. Style very long and spirally incurved. Pod $1 \frac{1}{2}$ to 2 inches long, flat, hairy on the edges, but glabrous on the sides, the seeds attached to a line considerably within the edge of the pod. Sarothamnus scoparius, Koch.

On dry, hilly wastes and bushy places, chiefly in western Enrope, but extending more sparingly to its eastern limits, and northward into southern Sweden. Common in Britain. Fl. spring and early summer. [A prostrate, var. (prostrata, Hanb.), occurs in Cornwall and the Channel Islands.]

\section{ONONIS. ONONIS.}

Herbs or low andershrubs, with pinnately trifoliolate, or rarely simple leaves; the leaflets generally toothcd; the stipules leafy, adhering to the lcafstalk; the flowers solitary, on axillary peduncles, often forming terminal leafy racemes. Calyz with 5 narrow segments. Standard large and striate. Keel terminating in a pointed beak. Stamens all united in a sheath. Pod inflated, with few seeds.

A rather numerous genus, chiefly from the Mediterranean region. The toothed leaves are like those of the Trifolium group, whilst the stamens are monadelphous, as in Genista and its allics.

A much branched perennial or undershrub, often thorny . . . 1. O. arvensis. A small, erect annual

1. O. arvensis.

1. O. arvensis, Linn. (fig. 233). Restharrono.-Very variable in aspect, generally a low, spreading, much branched undershrub, often rooting at the base or creeping underground, sometimes nearly erect, a foot high or more, rarely glabrous, usually thinly clothed with sof silreading hairs, and more or less glutipous; th.c hairs cither coverink 
the branches all round or chiefly or entirely in two opposite lines; in dry situations many of the small branches end in a thorn. Leaflets obovate or oblong, the lateral ones smaller or sometimes wanting. Flowers sessile or shortly stalked, solitary, on short branches, or forming short, leafy racemes. Flowers pink, the standard streaked with a deeper shade. Pod shorter or rather longer than the calyx, with 2 or 3 sceds.

In barren pastures and poor ill-cultivated fields, throughout Europe and central and Russian Asia, except the extreme north. Common in Britain. $F l$ summer and antumn. A glabrous, more erect, and thorny variety is often admitted as a species, under the name of $O$. antiquorum, or 0 . campestris. It is more common in the south of Europe than in Britain. [There are two principal British forms of this plant:-

a. O. spinosa. Erect, spinous, not foetid, without stolons, leaflets usually narrow, pod equalling the calyz. Absent from Ireland.

b. O. repens, Linn. Prostrate or ascending, viscidly villous, stoloniferous, spinous or not, leaflets broader, flowers large, pod usually shorter than the calyx. A seaside form.]

2. O. reclinata, Linn. (fig. 234). Small Ononis.-An erect annual, 3 or 4 inches high, slightly hairy, and often viscid, the lateral branches decumbent at the base. Leaflets small, varying from broadly obovate to very narrow. Flowers small, pale pink, hanging from short erect pedicels, forming short, terminal, leafy racemes. Petals scarcely exceeding the calyx, or shorter. Pod rather smaller, containing 10 or 12 seeds.

On sands and dry banks near the sea, very common lound the Mediterranean, and bere and there on the shores of the Atlantic, up to Alderney in the Channel Islands, and again on sea cliffs in Devon, and near the Mull of Galloway, on the south-west coast of Scotland. Fl. early summer.

\section{MEDICAGO. MEDICK.}

Herbs (with one exotic shrubby species), with leares pinnately trifoliolate; the leaflets usually toothed; the leafy stipules adhering to the leafstalks; the flowers small, in short spikes or loose heads, on axillary peduncles. Calyx 5-toothed. Keel obtuse. Stamens diadelphous, the upper one entirely free. Pod small, with few seeds, very much curved or spirally twisted, and indehiscent.

A ratber numerous genus in the Mediterranean region and a portion of central Asia, with a few species extending as weeds over a great portion of the globe. To determine the annual species it is absolutely necessary to have the fruit, as some cannot be distinguished by any other character.

Perennials, with conspicuous purple or pale yellow flowers.

Stems mostly erect. Flower purple. Pod forming 2 or 3 spires

Stems decumbent. Flower pale yellow. Pod not forming a complete spire .

Aunuals, with very small, bright yeliow flowers,

Pol small, 1-seeder, not forming a complete spire .

Pod several-seeded, spirally twisted, edged with prickles.

Plant downy. Stipules nearly entire

Plant nearly glabrous. Stipules finely toothed.

Pod nearly globular, of 3 or 4 spires, furrowed at the edge between the prickles

Pod of 2 or 3 flat, luose, strongly-velied splres, not furrowed at the edge

2. M. sativa.

1. M. falcata.

2. M. lupulina.

6. Y. minima.

5. I. maculata.

4. M. denticulata 
The shrubby $M$. arborea, and one or two annual species from southern Europe, have been occasionally cultivated in gardens as curiosities, especially the so-called Snail-plant ( $M$. soutcllata).

1. M. falcata, Linn. (fig. 235). Sickle M.-Stock perennial, with decumbent or rarely erect stems 1 to 2 feet long. Stipules narrow and entire. Leaflets obovate oblong or nearly linear. Peduncles axillary, bearing at their extremity a short, close raceme of flowers, rather large for the genus, nsially yellow, but sometimes passing into blue or violet. Pod much longer than the calyx, flat, more or less curved, but never forming more than one complete ring. Secds 2 or 3 .

On dry banks and open places in central and southern Europe, and central Asia, extending eastward to the Baikal and northward to Sweden. In Britain confined to the eastern counties of England, and rare even there. $F l$. summer. [M. sylvestris. Fries., with yellower flowers and annular or semicircular pods, is probably a hybrid.]

2. M. sativa, Linn. (fig. 236). Luecrn.-Much like M. falcata, and perhaps only a variety produced by cultivation. It is usually more erect, the flowers are almost always violet or blue, and the pod is spirally twisted so as to form 2 , or sometimes 3 , complete rings or coils.

A pparently of south-eastern origin, but so generally cultivated, that no station is known for it where it may not have escaped from cultiva. tion. In Britain, certainly introduced only on the borders of fields, and in pastures. $F$. summer.

3. M. lupulina, Linn. (fig. 237). Black M., Nonsuch.-An annual, branching at the base into spreading stems 1 to 2 feet long, and more or less clothed with short, soft hairs. Stipules broad and sbortly toothed. Leaflets obovate. Peduncles longer than the leaves, bearing a compact raceme or oblong head of very small bright yellow flowers. Porls small, 1-seeded, black when ripe, glabrous or slightly hairy, kidney-shaped, but marked with veins, curved almost into a complete spire.

In pastnres and waste places, thronghont Europe and central and Russian Asia, except the extreme north, and often cultivated among "artificial grasses." Frequent in Britain, extending to northern Scotland. Fl. the whole scason.

4. M. denticulata, Willd. (fig. 238). Toothed $M$. - An annual, branch. ing at the base into spreading stems from a few inches to above a foot long, glabrous, or with a very few appressed hairs. Stipules bordered with fine teeth. Leaflets obovate or obcordate. Flowers very small, in little heads, on peduncles rather longer than the leaflets. Pod spirally twisted, formed of 2 or 3 loose, flat coils, elegantly veined on the surface, and usually edged with 2 rows of more or less hooked or curved prickles, but not furrowed between them.

In cultivated and waste places, especially near the sea, very abnndant in the Mediterranean region and west central $\Lambda$ sia, and carried out with cultivation to many parts of the world. In Britain it appears to have established itself in some of the southern and eastern counties of England. Fl. spring and summer. A variety with smaller pods, with the prickles very short and not hooked, is $M$. aniculata, Willd. [Another with prickles longer than the semi-diameter of the subglobnlar pod is M. lappacea, Lamk.]

\%. M. maculata, Willd. (fig. 239). Spotted $M$.-An almost glabrous 
annual, so like the last in foliage, stipules, and flowers, that, without the fruit, it can be scarcely distinguished but by a few spreading hairs on the leafstalks, visible when held up against the light. It is often also more luxuriant, the leaflets have usually a dark spot in the centre, and the flowers are fewer in the raceme. The pod has 3 or 4 spires, much more compact than in $\boldsymbol{M}$. denticulata, giving the whole pod a more globular form, the surface is less veined, and the edge thicker, more or less furrowed between the prickles, which are finer and more curved. Al. arabira, All.

In cultivated and waste places, in western and southern Europe to the Caucasus and Persia, rarely extending into Germany. Not uncommon, especially in southern England; found also in southern Ireland, but not in Scotland. $\mathrm{Fl}$. spring and summer.

6. M. minima, Lam. (fig. 240). Bur M.-An annual, like the last two, but usually smaller and more compact, and clothed with short, soft hairs or down. Stipules entire or very shortly toothed. Flowers few, minute, on short peduncles. Pod smaller than in the last two species, nearly globular, of 2,3 , or 4 compact spires edged each with a double row of hooked prickles.

In open pastures and waste places, widely spread over Europe and western Asia, extending northwards to southern Sweden. Rare in Britain, and only in some of the southern and eastern counties of England. $F$. spring and summer. Like other species, it varies much in the size of the pods and the length of the prickles; in Britain they are usually small.

\section{MELILOTUS. MELILOT.}

Herbs with leaves pinnately trifoliolate, the leaflets usually toothed, the stipules slightly adhering to the loafstalks, and small yellow or white flowers, in long, loose racemes on axillary peduncles. Calyx 5toothed. Petals falling off after fading, the keel obtuse. Stamens diadelphous, the upper one entirely free. Pod of 1 or very few seeds, straight, thick, small, but longer than the calyx, and indehiscent.

A genus of few species, all sonth Earopean or west Asiatic, but some spreading over most parts of the world. They were formerly united with I rifolium, but their inflorescence gives them a very different aspect. From Trigonella they differ chiefly in the short, thick pod, usually with only 1 or 2 seeds.

Flowers white

Flowers yellow.

Pod irregularly net-veined and wrinkled. Stem usually 2 or

3 feet high
Pod transversely wrinkled. Stem usually nnder 2 feet high

The $M$. parviflora, Desf., common in almost all warm countries, espe. cially near the sea, has appeared occasionally as an introduced weed in the neighbourhood of London and of Liverpool. It is near $M$. officinalis, but a smaller weaker plant, the flowers and fruits very much smaller, the pod very obtuse and prominently net-veined.

1. M officinalis, Willd. (fig. 241). Common M. -An annual or biennial, usually erect, 2, 3, or even 4 feet high, branched and glabrous; the leaves nsually distant, on long leafstalks. Stipules narrow. Leaflets of the lower leaves obovate or nearly orbicular, those of the upper ones 
narrower, often linear. Flowers numerous, 2 or 3 lines long, of a bright jellow, in long, axillary racemes. Pod oval, about 2 lines long, obtuse or pointed, marked with Irregularly netted veins. M. altissima, Thuill.

On roadsides, banks and bushy places throngbout Europe and central and Russian Asia, except the extreme north. Not frequent in Britain, and only as an introduced plant, excepting in southern England and on the east coast of Ireland. Fl. summer.

2. M. arvensis, Wallr. (fig. 242). Ficld M.-Very near M. officinalis, and perhaps a mere variety. It is usually smaller, seldom attaining 2 feet, the leaflets rather broader, and the racemes looser, with fewer flowers, but the only positive distinction is in the fruit, which is smaller, more like that of $M$, alba, and marked with transverse wrinkles. In flower only it is often impossible to distinguish it from $M$. officinalis.

In cultivated and waste places, in central and southern Europe. In Britain, only in some of the eastern counties of England. Fl. summer.

3. M. alba, Desr. (fig. 243). White M.-Very like $M$. officinalis, but usnally taller and of longer duration, with a harder, more wiry stem, and narrower leaflets, and the flowers always white. Pod variable, but usually smaller and more obtuse than in $M$. officinalis, with the transverse wrinkles of $\boldsymbol{M}$. arvensis, - $\boldsymbol{H}$. vulyaris, Willd., MI. leucantha, Koch.

As widely spread as $M$. officinalis over continental Europe and Asia, and more abundant in the south, where it is a tronblesome weed in fields and vineyards. Occasionally found in England, Ireland, and Scotland, but probably introduced with corn or ballast. Fl. vather late in summer.

\section{TRIGONELLA. TRIGONEL.}

Herbs, with leaves pinnately trifoliolate; the leaflets usually toothed; the leafy stipules adhering to the leafstalks, the flowers axillary, solitary or in heads, spikes, or short racemes. Calyx 5-toothed. Keel obtuse. Stamens diadelphous, the upper one entirely frec. Pod protruding from the calyx, several-seeded, either thick and narrow or elongated, or in exotic species flat and broad, straight or slightly curved.

The genus is widely spread over southern Europe, Asia, and the Mediterranean region, witb one Australian species. The only British species is somewhat anomalous, and had formerly been referred to Trifolium, but the petals are all quite free from the staminal tube, and the pod is much longer than in any Trifolium, differing from some exotic true Trigonellas of the section Buceras only in being less prominently veined.

1. T. purpurascens, Lam. (fig. 244). Bird's-foot Trigonel.-A little annual, with thickly matted spreading stems, rarely more than 2 or 3 inches long, and usually glabrous. Leaflets inserted close together at the summit of the stalk, obovate or obcordate, and toothed. Flowers small, nearly white, solitary or 2 or 3 together in each axil, the lower ones nearly sessile, the npper ones on stalks of 2 to 4 or even 5 lines. Caly $\mathrm{x}$-teeth slender. Pod narrow, slightly curved, glabrous, surrounded nt the base by the persistent petals as in Trifolium, but much exceed. ing them. Seeds 6 to 8 . T. ornithopodioides, DC.

In dry sandy pastures, chigefly near the sca, in western and southern 
Europe, extending northward to Denmark. In several marltime counties of England, Ireland, and southern Scotland. Fl. carly summer.

\section{TRIFOLIUM. CLOVER.}

Herbs, with stipules adhering to the leafstalks. Leaves pinnately or almost digitately trifoliolate; the leaflets often toothed. Flowers red, white or yellow, in close heads. Calyx 5-tootbed. Petals narrow, often connected together, and attached to the staminal tube by the claws, and usually remaining round the pod after fading. Stamens diadelphous, the npper one entirely free. Pod enclosed in the calyx, or in the persistent petals, containing from 1 to 4 seeds, and usually indehiscent.

A very widely spread and numerous genus in the northern hemisphere, both in the New and the Old World, deficient in several tropical regions, but reappearing in southern America and Africa. It is readily distinguished from Medicago and Trigonella by the pod, from Melilotus by the compact heads of flower, and most of the species differ from all allied genera by the petals, either all or the three lower ones only, connected by their claws with the staminal tube.

Heads of flowers pedunculate in the axils of the leaves, or above the last

$1\left\{\begin{array}{l}\text { leaves of the stem } \\ \text { Ileads of flowers closely sessile in the axils, or within the last leaves of the }\end{array}\right.$ stem .

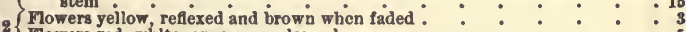

Flowers red, whlte, or cream-coloured $\quad \vdots \quad \vdots \vdots 5$

Flowers 30 to 40 , in a compact head. Standaril distlnctly furrowed when

faded .
Fowers not more than 20 in the head. Standari scarcely striate. T. procumbens.

Flowers usually 10 to 20 in the head, sessile or on very siort pedicels.

Central leaflet usually raised above the others - . 20.T. minus

Fowers 2 or 3 , rarely 6 or 6 in the head. Pedicels as long as the calyxtube. Central leaflet naually sessile between the others : 21. T. filiforme

6 Flowers pedlcellate in the head, reflexed after fading

Flowers sessile, erect

o $\left\{\begin{array}{l}\text { Stem creeping and rooting at the nodes } \\ \text { Stem ascending or erect and branched, without roots at the nodes. }\end{array}\right.$

7 Stem creeping and rooting at the nodes, or closely prostrate . 18. T. hybridum.

Heads globular. Flowers small. Calyx much lniflated after fiowering.

8 Eleads of few rather large flowers. Peduncles turned down into the gronnd after flowering . . . . . 15. T. sibterraneum.

Uleads oblong or cylindrical when fully out : : : $: 10$

Healls ovoid or globular $\quad: \quad \vdots \quad \vdots \quad 0_{11}$

10 Corulla small, shorter than the long, flie calyx-teeth : 2. T. arvense.

10 Corolla showy. Standard longer than the calyx-teeth $\quad$ i. $T$. incarnatum.

11 Corolla small, 1 to 3 lines long

Corolla showy, 5 to 6 lines long or more $\quad \vdots \quad \vdots \quad \vdots \quad \vdots \quad \vdots \quad \vdots 13$

Calyx-teeth short, lanceolate, glightly clliate $\quad \vdots \quad \vdots \quad$ 7. T. maritimum

Calyx-teeth short, subulate, glabrous : $: \vdots \quad$ 11. T. strictum.

12 Calyx softly hairy, the teeth longer than the corolla spreading after flowering. . 3. T. stellatum. Calyx Inflated after flowering. Standard turned outwards 14. T. resupinatum.

$13\left\{\begin{array}{l}\text { Annual. Teeth of the calyx nearly equal } \\ \text { Perennials. Lower tooth of the calyx longer than the others }\end{array}\right.$
Flowers red

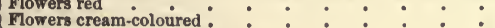

1. T. incarnatum.

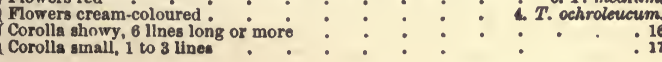


$16\{$ Flowers red

Flowers czeam-coloured

b. T. pratense.

1. T. ochroleucum.

17 Heads ovoid or oblong when fully out. Calyx more or less bairy, with rigid, erect, or spreading teeth.

Headsecth 19

18 Heads crowded at the vase of the very short prostrate stems 13. T. suffocatum . Heads distinct or distant aloug the branches . . . 12. T. glomeratum.

19 Calyx-teeth rigid and spreading after flowering, almost lanceulate . . . 20

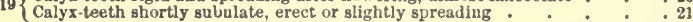

20 Stems ascending or erect, a foot high or more - i. T. maritimum

$2\left\{\begin{array}{l}\text { Stems spreading, seldom above } 6 \text { inches } \\ \text { Stem }: \vdots\end{array}: 10\right.$. T. scabrum.

21 Leaflets obovate. Upper stipules very broad . . . . 8. T. striatum.

21 Leaflets narrow-oblong or linear. Stipules narrow. Stem erect 9. T. Bucconi.

1. T. incarnatum, Linn. (fig. 245). Crimson C.-A softly hairy annual, erect or nearly so, often perennial, slender and starved-looking when wild, with ovoid or shortly oblong terminal flower-heads; but in rich soils, or when cultivated, attaining $1 \frac{1}{2}$ to 2 feet in height, with oblong or cylindrical flower-heads sometimes 2 inches long. Stipules broad and membranous. Leaflets very broadly obovate or obcordate. Calyx softly hairy, with narrow pointed teeth nearly equal in length. Corolla of a rich crimson, or of a pale cream colour, 4 to 6 lines long.

In open places, especially near the sea, in southern Europe, and, having been long cultivated for fodder, has become naturalised in various parts of central and even northern Europe. In Britain, a pale sellow perennial form, $T$. Molinerii, Balb., the most common in a wild state on the Continent, is indigenous near the Lizard Point; the cultivated crimson variety is established only in a few places in soutbern England. $\mathrm{Fl}$. summe?.

2. T. arvense, Linn. (fig. 246.) IIare's-fwot C.-A slender, branching, erect annual, seldom reaching a foot in height, aud clothed with short soft bairs. Stipules and leaflets narrow. Flowers small,'in pedunculate heads, which are at first nearly globular, but soon become oblong or cylindrical, 6 to 9 lines long, appearing very soft and feathery owing to the fine hairy teeth of the calyx projecting bejond the small corolla.

In cornfields, dry pastures, on sandy banks, \&c., throughout Europe and western Asia, except the extreme north. Abundant in Britain, but wore in the south than in the north. $F$. summer and autumn.

3. T. stellatum, Linn. (fig. 247). Starry C.-A low but rather coarse annual, covered with soft hairs, and seldom above 6 inches high. Leaves broadly obovate or obcordate. Flower-heads globular, softly hairy, on rather long peduncles above the last leaves. Calyx remarkable for the long subulate-lanceolate teeth, spreading like a star after flowering, whilst the mouth is closed over the pod by a tuft of hairs. Corolla shorter than the calyx-teeth, of a palc cream-colour.

In dry pastures and waste places, in southern Europe, common round the Mediterranean, reappearing in south-western France, and on the coast of Sussex near Shoreham, and perhaps in a few other localities, introduced with ballast. $F l$. early summer, and sometincs again in autumn.

4. T. ochroleucum, Huds. (fig. 248). Sulphur C.-A perennial, with the habit and foliage as well as the inflorescence of $T$. pratense, and the same-sized flowers, but the leaflets are usually rather narrower, the flower-heads more ovoid, and the flowers cream-coloured, with rather shorter teeth to the calyx, the lowest tooth twice as long as the others. 
In pastures, dry meadows, and open woods, in central and southern Europe to the Caucasus, but not crossing the Baltic. In Britain, confined to a few of the eastern counties of England. Fl. summer.

5. T. pratense, Linn. (fig. 249). Red or Purple C.-Stock usually perennial, but of few years' duration. Stems decumbent or nearly erect, I to 2 feet long, and hairy. Stipules rather large, ovate, veined, with long green points. Leaflets obovate or obcordate. Flowers of a reddish purple, about 6 lines long, in dense terminal, ovoid or globular heads, with 2 sessile, trifoliolate leaves close at their base, or very rarely the heads are shortly stalked above them. Calyx-teeth subulate and hairy, the lowest longer than the others. After flowering, the petals turn brown, the calyx remains erect, enclosing the usually single-seeded pod.

In meadows and pastures, throughout Europe and central and northern Asia, from the Mediterranean to the Arctic Circle, ascending high up into mountain regions. It has, however, been so long cultivated, that in some localities it may not be truly indigenous. Abundant in Britain. $\mathrm{Fl}$. the whole summer. [The common form is that cultivated as a fodder plant (var. sativum, Schreb.); the presumed indigenous state is a small one with a shorter corolla, var. parviflora, Bab.]

6. T. medium, Linn. (fig. 250). Zigzag or Meadow C.-Very much resembles $I$ '. pratense, and may be a-mere variety. It is a handsomer plant, with narrower stipules and leaflets; the heads of flowers are always more or less pedunculate above the last floral leaves, and the corolla rather larger, of a brighter and richer colour. The zigzag stem is not a very constant differential character, and even the pedunculate flower-heads may be occasionally observed also in $T$. pratense.

In open woods, bushy pastures, on banks and roadsides, in northern and central Europe, and across Russian Asia, becoming a mountain plant in southern Europe. Generally spread over Britain, but more common in southern Scotland and northern England than further north or south; extends also into Ireland. $\mathrm{Pl}$. summer.

7. T. maritimum, Huds. (fig. 251). Sea C.-A pubescent annual, with spreading or decumbent stems, seldom above a foot high, and more slender than the' last three, with much smaller flowers. Stipules long and narrow. Leaflets narrow-obovate or oblong. Flower-heads at first globular, then ovoid, shortly pedunculate above the last leaves. Calyxteeth at first subulate, the lower one longer than the others, but all much shorter than in $T$. pratense, and after flowering they are somewhat enlarged, stiff, and slightly spreading. Corolla pale pink, rather longer than the calyx. T. squariosum, Linn.

In salt-marshes and rich meadows near the sea, in southern and western Europe, rarely extending inland along great rivers. In Britain, confined to southern England, and has been occasionally found in Ireland. Fl. summer, rather early.

8. T. striatum, Linn. (fig. 252). Knotted C.-A small, tufted, more or less spreading annual, covered with short, soft hairs. Stipules ovate, ending in a fine point. Leaflets obovate. Flower-heads small, ovoid or globular, chiefly terminal, and closely sessile within the last leaves, of which the stipules are very broad and thin, with occasionally 1 or 2 heads sessile in the axils of the upper leaves. Calyx softly hairy, with short but subnlate teeth, which remain erect after flowering. Corolla very small and pale red. 
In dry pastures, on banks and waste places, in central and southern Europe to the Cancasus, extending northward into southern Sweden. Diffused over nearly the whole of England and southern Scotland, very rare in Ireland. Fl. all summer.

9. T. Bocconi, Savi. (fig. 253.) Boccone's C.-Very near T. striatum, but the stems are erect or nearly so, 2 to 6 inches high; the stipnles narrower; the leaflets narrow-oblong, spathnlate, or nearly linear; the flower-heads more oblong, usually 2 together at the summit of the stem, and sometimes 1 or 2 besides, on short, lateral branches. Flowers much like those of $T$. striatum, of a very pale colour, the calyx rather less hairy.

In dry pastures and waste places in southern Europe, and here and there up western France. In Britain only on the Cornwall coast, nea: the Lizard Point. Fl. summer.

10. T. scabrum, Linn. (fig. 254). Rough C.-Very near T. striatum, and not always easy to distinguish from it. Usually more procumbent and less hairy, the leaflets not so broad, the flower-heads more in the axils of the leaves, and the stipules of the floral leaves less prominent; but the chief distinction lies in the calyx, of which the teeth are broader, more rigid, and usually spreading or recurved after flowering, giving the plant a stiffer appearance. Flowers small and whitish.

In dry pastures and waste places, in central and southern Europe to the Cancasus, scarcely extending into northern Germany. In Britain, chiefly near the sea, in England, eastern Ireland, and eastern Scotland, but less common than $T$. striatum. Fl. all summer.

11. T. strictum, Linn. (fig. 255). Upright C.-An erect annual, seldom 6 inches high, and perfectly glabrous. Stipules very broad and thin. Leaflets narrow. Flower-heads solitary, or 2 or 3 on each stem, pedunculate above the last leaves, small and globular. Flowers very small. Calyx campanulate, the teeth subulate, quite glabrous, and about the length of the corolla. Pod ovoid, generally 1-seeded, projecting from the calyx.

In dry pastures and waste places, scattered over central and southern Europe, from the Atlantic to Transylvania. In Britain, confined to the Channel Islands and the coast about the Lizard Point. Fl. carly summer.

12. T. glomeratum, Linn. (fig. 256). Clustered C.-A small, slender, spreading annual, glabrous or nearly so. Stipules short, with a subulate point. Leaflets broadly obovate. Flower-heads small, globular, closely sessile in the axils of the leaves or at the ends of the branches. Calyxteeth short, broad, very pointed, and rigidly recurved as the pod ripens. Corolla of a bright pink, very small, but longer than the calyx-teeth.

On dry heaths, pastures, and waste places, very abundant in sonthern Europe to the Cancasus, and extending more sparingly along western France to the southern and eastern counties of England, and Wicklor in Ireland. Fl. early summer.

13. T. suffocatum, Linn. (fig. 257). Suffocated C.-A very small tufted annual, with procumbent stems often scarcely developed, and seldom more than 2 , or at most 3 , inches long. Leaflets glabrous, obovate on long, slender footstalks. Flowers small, closely sessile, in little dense heads, crowded along the short stems, close to the ground. Calyx thin, with fine recurved teeth; the corolla very minute.

In dry pastures and sandy or gravelly places, especially near the sed 
in southern Europe to the Cancasus, extending up western France to the shores of the Channel. Rare in England, on the sonthern coasts, extending eastward up to Norfolk, and westward to Anglesea; not recorded from Ireland, but perhaps overlooked. Fl. spring or early summer.

14. T. resupinatum, Linn. (fig. 258). Reversed (J.-A glabrons annual, with numerons stems, leafy and tufted at the base, lengthened ont to a foot or more. Stipules rather broad, with narrow points. Flowerheads small, on short axillary peduncles. Calyx glabrous or hairy on the upper side, the teeth short, but after flowering the npper part becomes very much inflated, arched, membranous and veined, with the 2 upper teeth at the top, the 3 lower ones remaining at the base of the inflated part. Corolla small, pink, the sides of the standard turned outwards instead of inwards as in other Trifolia.

In meadows and pastures, especially near the sea, in southern Europe to the Caucasus, and up western France to the shores of the Channel. Not indigenous in Britain, but bas occasionally appeared in some of the southern counties of England. Fl. spring and early summer.

15. T. subterraneum, Linn. (fig. 25y). Subterrancan C.-A small, prostrate anuual, more or less clothed with long spreading hairs; the stems usually short and tufted, but occasionally lengthened out to 6 or 8 inches. Stipules broad. Leaflets obovate, on long leafstalks. Flowers white or pale pink, long in proportion to the plant, 2 or 3 together on axillary peduncles, which lengthen considerably after flowering, and turn down almost into the ground; the fruiting calyx then turns back npon the peduncle, and is usually surrounded by short thick fibres, each with 5 spreading, subulate teeth, showing that they are undeveloped calyxes.

In dry, gravelly or sandy pastures, common in southern Europe to the Caucasus, and up western France to the Channel. Abundant in many parts of southern and central England, and in co. W'icklow in Ireland, but not in the north, nor in Scotland. Fl. spring and early summer.

16. T. fragiferum, Llnn. (fig. 260). Stravoberry C.-The perennial stock, creeping stcms, foliage, and peduncles are those of $T$. repens, but the flowers are closely sessile in the head, surrounded by an involucre of lobed bracts as long as the calyx-tubes, and the calyx, after flowering, becomes much inflated, thin, and reticulate, with short fine teeth; the flower-head is then very compact, half an inch or more in diameter, and often assumes a pink tint, so as to have been compared to a strawberry. Corolla small and red.

In rather dry meadows and pastures, common in Europe and central and Russian Asia, penetrating far into Scandinavia. Frequent in England, local in Ireland and Scotland. Fl. summer and autumn.

17. T. repens, Linn: (fig. 261). White or Dutch C.-A glabrous or slightly hairy perennial, the stems creeping and rooting at the nodes. Stipules small. Leaflets obovate, distinctly toothed, and usually bearing a mark in the centre, which has been compared to a horseshoe, the leafstalks often very long. Peduncles axillary, long, and erect, bearing a globular head, or rather umbel, of white flowers, often tinged with pink; the pedicels, after flowering, more or less elongated and recurved. Calyxteeth scarcely so long as the tube, the lowest one usually the shortest. Pod containing 2 to 4 sceds, usually protruding from the calyx, but enclosed in the withered corolla. 
In meadows and pastures, throughout Europe and Russian Asia, from the Mediterranean to the Arctic Circle, and having been long cultivated, $t$ is now common in most temperate regions. Abundant in Britain. In Ireland believed to be of comparatively recent introduction, although it is now taken as the national emblem, in substitution of Oxalis Acetosella, which some writers regard as the original shamrock. Fl. the vhole season. [A deep purple-flowered variety, $7^{\prime}$. elegans, Savi., occurs in the Scilly Isles.]

18. T. hybridum, Linn. (fig. 262). Alsike C.-A glabrous perennial, allied to $T$. repens, but never rooting at the joints, the stems ascending or erect, branched, and attaining, when luxuriant, nearly 2 feet. Stipules rather large. Leaflets obovate, bearing occasionally a mark in the centre, as in $T$. repens. Peduncles axillary, longer than the leaves, bearing a globular head of pedicellate flowers, with rather more pink in their colour than in the common $T$. repens, the pedicels similarly elongated and recurved after flowering. Calyx and pod as in T. repens.

In rich pastures and on the edges of woods, almost all over Europe, except the extreme north. Abundant in Sweden, but not indigenons to Britain. It has, however, of late years been much cultivated, and has fully established itself in several parts of England. Fl. summer.

1.9. T. procumbens, Linn. (fig. 263). Hop C.-A slender annual, much branched at the base, glabrous or slightly downy, procumbent or nearly erect, 6 inches to a foot long, or rather more. Stipules broad and pointed. Leaflets obovate or obcordate, the central one at some distance from the others. Flower-heads loosely globular or ovoid, on rather long axillary peduncles, containing 30 to 50 small yellow flowers on very short pedicels; in fading the flowers become reflexed, and turn pale brown, with a broadly obovate standard, distinctly marked with longitudinal furrows, and completely concealing the small, 1-seeded pod.

In rather dry pastures and meadows, on the borders of fields, \&c., throughout Europe and western Asia, except the extreme north. Abundant in Britain generally, but rare in northern Scotland. Fl. the whole season. In the first edition of this work I regarded this as the 'T. agrarium of Linnæus, but the subsequent investigations of M. Puel and others having induced me to examine carefully Linnæus's specimens, and the MS. notes in his "Species Plantarum," I find that I was in error, and that Linnæus included both $T$. procumbens and $T$. minus under his $T$. procumbens, as one species, in which he is probably right ; but as the two forms are usually very different in aspect, at least in this country, I have retained them under Smith's names. The true $T$. agrarium is but little more than a variety of $T$. spadiccum; neither of them is British.

20. T. minus, Relh. (fig. 264). Lesser C.-Very near T. procumbens, and perhaps a variety only, but more slender and procumbent; the flowers smaller, nsually 12 to 20 in a head, and of a paler colour; the standard not so broad, more folded, and only faintly striated. The central leaflet of each leaf is usually at some distance from the others, as in T. procumbens, excepting sometimes in the lower leaves. Pedicels of the flowers much shorter than the tube of the calyx. T. dubium, Sibth.

As common as $T$. procumbens over the greater part of Europe, but does not extend so far to the east or to the north. In Britain also as 
abundant as $T$. procumbens, excepting perhaps in the north. Fl. the whole seasom. Starved specimens of this species are much like the more luxuriant ones of $T$. filiforme, and chiefly distinguished by the shortness of the pedicels.

21. T. flliforme, Linn. (fig. 265). Slender C.-Still more slender than $T$. minus; the stems decumbent, ascending, or erect, seldom 6 inches long. Leaflets usually narrower than in the last two species, the central one inserted immediately between the two others, excepting in the npper leaves of very luxuriant specimens. Flowers 2 or $\mathbf{3}$ in each head, or very seldom as many as 5 or 6 , smaller than in $T$. minus; the pedicels usually about as long as the calyx.

In sandy or stony pastures and waste places, chiefly near the sea, in southern Europe; very common round the Mediterranean, and extending $\mathrm{np}$ western France. Rare in Britain, but found as far north as Roxburghshire, and doubtfully wild further north. Fl. early summer.

\section{LOTUS. LOTUS.}

Herbs, with pinnate leaves of 5 (rarely 4 ) leaflets of which 2 (or 1), close to the stem, take the place and appearance of stipules. Peduncles axillary, bearing 1 or several yellow or reddish flowers in an umbel, with a leaf of 3 leaflets close under it. Calyx 5-toothed. Keel pointed. Stamens diadelphous, the upper one free from the base, and 5 of the flaments flattened at the top. Pod cylindrical, with several seeds.

A well-marked genus, not very numerous in species, chiefly abundant in southern Europe and northern Africa, but widely spread over the temperate regions of the Old World and Australia.

Perennial. Flowers usually 5 or more in the unbel . . . 1. L. corniculatus. Annual. Flowers small, seldom above 2 in the umbel $: \quad 2 . L$. angustissimus

1. I. corniculatus, Linn. (fig. 266). Bird's-foot T'refoil.-Stock perennial, with a long taproot. Stems decumbent or ascending, from a few inches to near 2 feet long. Leaflets nsually ovate or obovate, and pointed, but sometimes narrow; those which take the place of stipules broader than the others. Peduncles much longer than the leaves. Umbels of from 5 or 6 to twice that number of bright yellow flowers; the standard often red on the outside. Calyz-teeth about the length of the tube. Pod usually about an inch long. Seeds globular, separated by a pithy substance, which nearly fills the pod.

In meadows and pastures, whether wet or dry, open or shaded, widely spread over Europe, Russian and central Asia, the East Indian Peninsula, and Australia, but not reaching the Arctic Circle. Abundant all over Britain. Fl. the whole summer. It is a very variable species, accommodating itself to very different stations and climates; and some of the races appear so permanent in certain localities as to have been generally admitted as species, but in others they run so much into one another as to be absolutely undistinguishable. The most distinct British forms are-

a. L. uliginosus, Schk. Tall, ascending or nearly erect, glabrons or slightly hairy, and luxuriant in all its parts, with 6 to 8 flowers in the nmbel. Calyx-teeth nsually, but not always, finer and more spreading than in the smaller forms. In moist meadows, along ditches, under hedges, and in rich, bushy places. L. major, Sm.; L. pilosus, Beeke. 
b. L. crassifolius, Pers. Low and spreading, often tufted at the base, glabrous or nearly so, usually with 5 or 6 rather large flowers to the umbel. Leaflets broad, and often glaucous, especially near the sea, where they become much thicker. In open pastures and on dry, sunny banks.

c. L. villosus, Coss. and Germ. Like the common variety, but covered with long spreading hairs. In dry, sunny situations, common in sonthern Europe, but in Britain found only in Kent and Devon.

d. L. tenuis, Waldst and Kit. Slender and more branched than the common form, with very narrow leaflets. In poor pastures and grassy places, chiefly in south-eastern Europe. Rare in Britain, and always i unning much into the common form. L. decumbens, Forst.

2. L. angustissimus, Linn. (fig. 267). Slender L.-An annual, more slender and branched than $L$. corniculatus, always hairy, and with smaller leaflets. Peduncles short, the flowers scarcely above half the size of those of $L$. corniculatus, often solitary or 2 together, very seldom 3 or even 4 in the umbel. Calyx-teeth longer than the tube. Pod slender, 8 or 9 lines long.

In meadows, pastures, and fields, very common in southern Europe, extending eastward in southern Russia to the Altai, and northward along the coasts of western Europe to the Cbannel. In Britain, only on the south coast of England, extending eastward to Kent. Fl. early in summer, and often again in autumn. L. hispidus, Desf., is a larger, more hairy variety, having often 3 flowers to the umbel, with a thicker pod, often less than 6 lines long. It has the same range as the more slender variety.

\section{ANTHYLLIS. ANTHYLLIS.}

Herbs, with pinnate leaves, and yellow, red, or purple flowers in crowded heads or umbels, with a deeply divided bract close underneath. Calyx inflated, with 5 small teeth. Stamens all united in an entire sheath. Pod enclosed in the calyx, with few seeds.

A genus of fer species, chiefly from the Mediterranean region, allied to Lotus in inflorescence, to Genista in its stamens, and éasily distinguished by the calyx.

1. A. Vulneraria, Linn. (fig. 268). Kidney Vetch, Lady's-fingers.Stock perennial, and often tufted, with spreading or ascending stems, from a few inches to a foot long; the whole plant more or less clothed with short, appressed, silky hairs. Leaflets narrow and entire, 6 lines long or more; in the upper leaves often numerous and not very unequal; in the lower leaves the terminal leaflet is nsually oblong, an inch long or more, with very few much smaller ones along the stalk; or in the first leaves the terminal one stands alone. Flower-heads usually in pairs at the ends of the branches, each one surrounded by a digitate, leafy bract; the flowers numerous and closely sessile. Calyx hairy, much inflated, and contracted at the mouth. Corolla small, varying from a pale or bright yellow to a deep red.

In dry pastu as and rocky stony places, chiefly in hilly districts, tr.reughout Europe and western Asia, from the Mediterranean to the A retic Circle. Ranges generally over Britain, although here and there considerable districts may be without it. $F l$, summer, commencing early. 


\section{ASTRAGALUS. ASTRAGAL.}

Herbs, with pinnate leaves, and pink, purple, bluish, pale yellow, or white flowers, in axillary racemes or spikes, without leafy bracts. Stipules entire at the base (not sagittate). Calyx with 5 teeth. Petals usually narrow. Keel obtuse. Stamens diadelphous, the npper one entirely free. Pod cylindrical or inflated, usually more or less divided lengthwise by a complete or partial partition proceeding from the side next the keel. Seeds several.

A very numerous genus, distributed all orer Europe, central and northern Asia, North America, and down the Andes of South America; penetrating far into the Arctic regions, ascending to high alpine ummits, and abundant in the hot rocky districts of the Mediterranean region.

Stems 2 or 3 feet long, with large leaflets, and dingy yellow flowers 3. A. glycyphyllos.

Low plants, with small leaflets, and bluish-purple flowers.

Flowers 8 or 9 lines long. Puds erect, not twice the leugth of the calyx .

Fowers not 6 lines long. Pods pendulous, 3 or 4 times the length of the calyx .

\section{A. danicus}

2. A. alpinus

1. A. danicus, Retz. (fig. 269). Purple A.-A low, slightly hairy perennial, the stem prostrate, branching at the base, 2 to 5 or 6 inches long. Stipules free from the leafstalk, but more or less united together on the opposite side of the stem. Leaflets usually in 10 to 12 pairs, witl an odd one, 2 or 3 lines long. Flowers of a bluish purple, in short spikes, on long axillary peduncles. Calyx sessile, erect, about 3 lines long, more or less downy with short black hairs. Standard near 3 times as long as the calyx. Pod shortly stalked witlin the calyx, ovoid, erect, hairy, seldom 6 lines long, and completely divided by a longitudinal partition into 2 cells, usually with only 1 seed in each cell. Hypoglottis, DC. (not Linn.).

On dry hilly pastures, in central and northern Europe, Russian Asia, and northern America, but not an Arctic plant. In Britain, chiefly in eastern, central, and northern England, and southern Scotland; in Ireland, only indicated in the south isles of Aran on the west coast. Fl. summer.

2. A. alpinus, Linn. (fig. 270). Alpine A.-A small, prostrate, slightly hairy perennial, the stems branching at the base, a few inches or rarely nearly a foot long. Stipules slightly connected with the leafstalk, but quite free from each other. Leaflets 8 to 12 pairs, with an odd one, ovate or oblong. Flowers drooping, of a bluish purple, or white tipped with purple, in short close racemes, on rather long peduncles; the calyx little more than 1 line; the corolla about 5 lines long, with petals broader in proportion than in A. danicus. Pod pendulous, about 6 lines long, on a stalk about the length of the calyx, covered with short black hairs, and partially divided inside by a narrow projection from the side next the keel. Seeds 3 to 6 .

An alpine plant, common in the great mountain-ranges of central and northern Europe and Russian and central Asia, and extending far into the Arctic regions. In Britain, only in the mountains of Perthshire, Clova, and Braemar in Scotland. Fl. summer.

3. A. glycyphyllos, Linn. (fig. 271). Milkvetch.-A glabrous perennial, of a light green colour; the zigzag stems spreading along the 
ground to the length of 2 feet or even more. Stipules free. Leaflets 11,13 , or more, ovate, 1 to $1 \frac{1}{2}$ inches long, the common leafstalk fully 6 inches long. Flowers about 6 or 7 lines long, of a dingy yellow, spreading or pendulous, in racemes rather shorter than the leaves. Pods erect, curved, glabrous, above an inch long, completely divided into 2 cells by a thin double partition, with 6 to 8 seeds in each half.

In rather dry, open woods, and bushy places, over the greater part of Europe and Russian Asia, except the extreme north. Not common in Britain, although it ranges over a great part of England, especially the eastern counties, and southern Scotland, rarer in the north; not recorded from Ireland. $F l$. summer.

\section{OXYTROPIS. OXYTROPE.}

Low, tufted perennials, only differing from Astragalus in the keel, which has a small point at its extremity, either erect or slightly recurved, and in the pod, which has an incomplete longitudinal partition projecting into the cavity from the angle next the vexillum (the one which bears the seeds), not from the angle next the keel.

A considerable genus, but not so numerous nor so widely spread as Astragalus, and chiefly confined to mountain stations or high latitudes in Europe, Asia, and North America.

Flowers yellowish. . . . . . . . . . . 1. 0 . campestris.

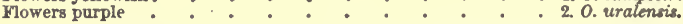

1. 0. campestris, DC. (fig. 2خ2). Yellow 0.-Stock short and tufted, covered with the old stipules and leafstalks, seldom lengthening into shortly ascending branches; the leaves and peduncles usually proceeding from the stock. Leaficts 10 to 15 pairs, with an odd one, oblong or lanceolate, and hairy; the common leafstalk 2 or 3 inches long. Peduncles rather longer, with a short spike of pale yellow flowers tinged with purple. Calyx hairy, 4 or 5 lines long; corolla twice that length; the point of the keel short, straight, and erect. Pod erect, ovoid, covered with short, usvally black, hairs ; the partition projecting to about the centre of the cavity.

In mountain pastures, and on alpine rocks, common in the great mountain-ranges and Arctic regions of Europe, Russian Asia, and northern America. In Britain only in one spot, among the Clova mountains of Scotland. Fl. summer.

2. O. uralensis, DC. (fig. 273). Purple O.-Stock short and tufted, with the foliage, inflorescence, and pod of $O$. campestris, but the whole plant is much more densely covered with soft, silky hairs; the flowers are of a bright purple, and the pod is more completely divided into 2 cells. The point of the keel is short and straight, as in 0 . campestris.

In monntain pastures, in central Europe and Russian Asia, descending to a low level in the north, and penetrating far into the Arctic regions. Not uncommon in Scotland, in dry, hilly pastures, chiefly near the sea, but does not descend to England. $F l$. summer.

\section{ORNITHOPUS. BIRD'S-FOOT.}

Slender, spreading annuals, with pinnate leaves and axillary poduncles, bearing a bead or umbel of small pink or white flowers. Calys 
tubular. Keel obtuse. Stamens diadelphous, the upper one quite free. Pod cylindrical or slightly flattened, much longer than the calyx, often curved, separating when ripe into 1-seeded articles.

A genus of few, chiefly south European, with one sonth American species, differing from Coronilla chiefly in their slender habit and obtuse keel.

Plant glabrous. Umbel without any bract. Pod slender, tereto . 1. 0. ebracteatus. Plant hairy. Umbel with a pinnate leaf-like bract at the base.

Pod somewhat flattened.

1. O. ebracteatus, Brot. (fig. 274). Sand B.-Stems very slender, spreading on the ground to the length of 6 incties. Leaflets 9 to 15, small, obovate or oblong, the lowest pair at some distance from the stem. Stipules very small. Peduncles very slender, with an umbel of from 2 to 5 minute, yellow flowers. Pods about an inch long, slender, curved, ending in a short, hooked beak, and separating into linear articles.

In sandy situations, near the sea, chiefly in south-western Europe, extending nearly all round the Mediterranean, and up western France, to the Channel Islands and to the Scilly Jsles. Fl. spring, and often again towards autumn. This species has been separated as a genns, under the name of Arthrolobium, adopted in the first edition of this work; but the character relied on, the absence of the leafy bract, is a very unimportant one.

2. O. perpusillus, Linn. (fig. 275). Common B.-Stems spreading on the ground, or slightly ascending, to the length of 6 or 8 inches. Leaflets 5 to 10 or sometimes more pairs, with an odd one, small, oval or oblong, and softly hairy, the lowest pair close to the stem. Flowers usually 2 or 3 only on the peduncle, closely sessile over a small, pinnate leaf; the keel short and obtuse. Pods slightly downy, about 6 lines long, ending in a curved beak; the articles short and oval.

In dry pastures, in central and sonthern Europe, scarcely extending to its eastern limits, and northward only into southern Sweden. Abundant in many parts of England and the sonth of Scotland; very rare in Ireland, and found on the east side only. Fl. spring and summer.

\section{HIPPOCREPIS. HIPPOCREPIS.}

Herbs or low shrubs, usually glabrons, with pinnate leaves and axillary peduncles, bearing an umbel of yellow flowers, withont any leaf. Stamens diadelphous, the upper one quite free. Pod much flattened, of numerous articles, each of them curved like a horseshoe, so that the pod has as many deep notches on one side.

A genus of but few species, chiefly natives of south-western Enrope. In flower they cannot well be distinguished from Coronilla, but the pod is very different.

1. II. comosa, Linn. (fig. 276). Common H.-Stock perennial, with numerous stems branching at the base, and either short and tufted, or spreading along the gronind to the length of 6 inches to a foot. Leaflets 9 to 15 , small, obovate, oblong, or linear, and glabrous, the lowest pair at a distance from the stem. Flowers 5 to 8 in the umbel, resembling those of Lotus corniculatus, and with nearly the same pointed keel, but rather smaller and paler. Pod about an inch long, ending in $n$ fine point. the notches of the inner edge broad and deep. 
In pastures, on banks, \&c., cliiefly in limestone distriets, in central and southern, especially western Europe, not extending to nort hern Germany. Abundant in some parts of England, extending to the south of Scotland, but not to Ireland. $F l$. spring and summer.

\section{ONOBRYCHIS. SAINFOIN.}

Herbs, with pinnate leaves, without tendrils, and spikes of flowers asually pink, on long axillary peduncles. Stamens diadelphous, the upper one quite free. Pod sessile, flat, hard, 1-seeded and indehiscent, strongly veined or pitted, and usually either prickly, crested, or winged.

A genus of several species, chiefly from the eastern Mediterranean region and west central Asia, very distinct from any other British Peaflower, but only differing from Hedysarum (a large European and Asiatic genus, which includes the so-called French Honeysuckle of our gardens) in the pods being reduced to a single article.

1. O. sativa, Lam. (fig. 277). Common Sainfoin.-Stock perennial, but of few years' duration, with several ascending stems, 1 to $1 \frac{1}{2}$ or rarely 2 feet long. Stipules brown, thin, and finely pointed. Leaflets numerous, oblong, slightly downy underneath, glabrous above. Peduncles longer than the leaves, bearing in their upper half a spike of pale pink flowers, at first closely packed, but lengthening out as the flowering advances. Calyx-teeth long and slender. Wings of the corolla shorter than the keel and standard. Pod twice as long as the calyx, the npper edge nearly straight, the lower semicircular, bordered with short teeth, sometimes prickly, the flat surface marked with raised veins. O. viciafolia, Scop.

In limestone districts, in central and southern Europe, and temperate Asia ; much cultivated for forage, and occasionally naturalised further northward. In Britain, believed to be truly indigenous in southern and eastern England, but not recorded from Ireland. Fl. early summer.

\section{VICIA. VETCH.}

Herbs, with weak stems, often sliglitly climbing, half-sagittate stipules, and pinnate leaves; the leaflets usually numerous: the common leafstalk ending in a simple or branched tendril, or at least in a small point. Flowers in the axils of the leares, solitary, clustered, or in pedunculate racemes, blue, purplish, white, or pale yellow. Petals usually rather narrow. Upper stamen quite free, or connected with the others, at least in the middle. Style cylindrical or sliglitly flattened, with a tuft of hairs below the stigma on the outer side, or shortly downy all round under the stigma, or rarely quite glabrous. Pod more or less flattened, opening in 2 valves, with several, or rarely only 2 seeds, either globular or slightly flat tened.

A numerous genus, widely spread, but most abundant in temperate regions; in the tropies almost confined to mountain districts, and unknown in Australia. The tendrils distinguish it from all our Leguminous plants, except Lathyrus, from which it is absolutely separated chiefly by the style; but also in all our species, except $V$. bithynica, the more numerous and smaller leaflets, and the general shape of the flowers, give 
it a peculiar aspect easily recognised. The staminal tube is usually much more oblique at the top than in Lathyrus. The common Bcan is a Vicia supposed to be a variety produced by cultivation of the south Europeas $V$. narbonensis.

Leaflets above an inch long, 1 or 2 pairs to each leat . . . 10. V. Vithynica.

Leaflets more than 2 palrs to each leaf, usually small.

Peduncles elongated (at least half as lony as the leaf).

Howers few and amall, on slender peduncles. Pod acarcely 6 lines long.

Plant glabrous or nearly so. Fod with 4 to 6 seeds . . 2. V. tetrasperma.

Plant halry. Pod witl 2 seeds . . . 1. V. hirsuta.

Mowers at least 6 lines long. Pod an inch or more.

Leafstalks ending in a short point. Racemes short and close.

Plant quite glabrous, drying black. Stipules quite entire Lathyrus niger.

Plant slightly hairy. Stipules usually toothed. . . b. V. Orobus.

Leafstalks ending in a tendril. Racenies long.

Flowers white, with purplish velns. Stipules deeply divided at the base

divided at the base

Peduncles not longer than the calyx, or flowers quite sessile.

Klowers pale yellow. Pod hairy

Flowers purple, blue, or red. Pod glabrous.

Flowers 3 or 4 together, shortly stalked.

Flowers sessile, solitary or rarely 2 together.

Howers large. Seeds smooth

Flowers small. Seeds granulated

7. $V$. lutea.

6. V. sepium

8. V. sativa.

9. V. lathyroides.

$\therefore$ V. hirsuta, S. F. Gray (fig. 278). Hairy V., Tare.-A more or less hairy annual, with slender, weak stems, 1 to 3 feet long, of ten climbing by means of the branched tendrils. Stipules small, narrow, often divided. Leaflets small, oblong, 6 or 8 pairs to each leaf. Peduncles slender, with very few, usually 2 or 3 , insignificant, pale blue flowers, the fine teeth of the calyx almost as long as the standard. Style glabrous. Pod nearly 6 lines long, flat and hairy, containing 2 slightly compressed sceds, with a long, linear hilum.

In hedges, cornfields, and waste places, common in Europe and Russian Asia, from the Mediterranean to the Arctic Circle. Extends all over Britain, but is rare in the Highlands of Scotland. Fl. the whole summer.

2. V. tetrasperma, Mœnch. (fig. 279.) Slender V. - A slender annual, glabrons, or nearly so, the weak stems often climbing, from 6 inches to near 2 feet long. Leaflets narrow, the lower ones obtuse, 3 to 6 pairs in each leaf, the tendrils simple or branched. Peduncles slender, with 1 to 6 or 7 pale bluish flowers, larger than in $V$. hirsuta, but much smaller than in any other British Vicia, seldom exceeding 3 lines. Calyxteeth much shorter than the standard. Pod flat, not above 6 lines long, usually containing about 4 seeds, but sometimes 5 or 6 . V. gemella, Crantz.

In fields, bedges, and waste places, all over temperate Europe and Russian Asia. Not nncommon in England, hardly wild in Scotland, and very rare in Ireland. $\mathrm{Fl}$. the whole summer. A variety with more pointed leaflets, and with the number of seeds more frequently 5 or 6 , has been distinguished nnder the name of $\nabla$. gracilis, Loisel. ; it is confined to the middle and south of England, and is a doubtful native.

3. V. Cracca, Linn. (fig. 280). Tufted V.-Rootstock perennial, the annual stems weak, and climbing by means of the branched tendrils to the length of 2 or 3 feet or rather more; the whole plant hairy, or nearly glabrous. Stipules narrow and entire. Leaflets numerous, oblong or linear, the largest 8 or 9 lines long. Flowers numerous, in 1-sided 
racemes, on peduncles rather longer than the leares, of a fine bluishpurple, each one about 5 lines long. Style hairy, all round below the stigma. Pod flattened, glabrous, about an inch long, with 6 or 8 seeds.

In hedges and bushy places, throughout Europe and Russian Asia, from the Mediterranean to the Arctic Circle, and in northern America. Common in Britain. Fl. summer.

4. V. sylvatica, Linn. (fig. 281). Wood V.-A handsome, usually glabrous species, climbing over shrubs and small trees, sometimes to the length of 6 or 8 feet. Stipnles deeply divided at their base. Leaflets fewer and broader than in $V$. Cracca, usually 8 or 10 pairs to each leaf, oblong, or the lower ones ovate, obtuse or notched at the top. Flowers considerably longer than in $V$. Cracca, white with bluish streaks, loosely drooping in long racemes. Pod glabrous, broad, an inch long, 4-6 veeded.

In open woods and bushy places, in the hilly, and especially the northern districts, of Europe and Russian Asia to the Arctic Circle, and in the moun. tains of southern Europe and central Asia. Not uncommon in Scotland, and in most hilly, wooded districts of England and Ireland. Fl. summer.

5. V. Orobus, DC. (fig. 282). Upright V.-A slightly hairy branching perennial, with a somewhat creeping rootstock; the stems more erect than in otber Vicia, and the tendrils all reduced to a fine point terminating the leafstalk, or in the upper leaves replaced by a terminal leaflet, as in Lathyrus niger, but the plant does not usually dry black, as in that species, and the style is that of Vicia Cracca. Stipules broader than in the last two species, and slightly toothed. Leaflets 8 to 10 pairs to each leaf, narrow-oblong, with a fine point. Peduncles about the length of the leaf, with a close raceme of 6 to 10 rather large purplish-white flowers. Pod flattened, about an inch long, with 3 or 4 seeds, or rarely more.

In mountain pastures and woods, in western Europe, from the Pyrenees to southern Norway, reappearing eastward in Bavaria and Transylvania. In Britain, spread over Wales, northern England, and a great part of Scotland, very rare in Ireland. Fl. early summer.

6. V. sepium, Linn. (6q. 283). Bush V.-A slightly hairy perennial; the stems 1 to 2 feet high, weak and straggling but scarcely climbing. Stipules small and entire, or larger and toothed. Leaflets 4 to 6 pairs in each leaf, ovate or oblong; the leafstalk ending in a tendril, usually branched. Flowers smaller than in $V$. sativa, of a light reddish-purple, 2 to 4 together in the axils of the upper leaves, drooping from short pedicels, and forming a sessile cluster or a very short raceme. Style with a dense tuft of hairs under the stigma on the onter side, with a few short hairs on the opposite side. Pod glabrous, about an inch long. Seeds few, half encircled by the long, linear hilum.

In woods and shady places, and bedges, extending over Europe and Russian Asia, from the Mediterranean to the Arctic Circle. Common in Britain. Fl. all summer.

7. V. Iutea, Linn. (fig. 284). Yellow V.-A glabrous or slightly hairy annual, said, however, by some to form a perennial rootstock; the stems spreading, branched, nsually low, but sometimes ascending to a foot or more. Stipules, foliage, and solitary flowers of $V$. sativa, but the corolla is of a pale yellow, and the rather broad pods are roflezed, and covered with long hairs. Seeds few, with a short hilum. 
In dry, stony, waste, or cultivated places, in central and southern Europe to the Caucasus, not extending into northern Germany. In Britain, chiefly near the sea in southern England, and again on the rocky coasts of eastern Scotland. Not recorded from Ireland. $F$. early summer.

8. V. sativa, Linn. (fig. 285). Common V.-An annual or biennial, glabrous or hairy; the stems short and spreading, or nearly erect, or almost climbing, 1 to 2 feet high. Stipules toothed, and nsually marked by a dark spot in the centre. Leaflets usually 4 to 7 pairs to esch leaf, varying from obcordate to obovate to narrow-linear, the tendrils usually branched. Flowers sessile and solitary, or rarely 2 together in the axils of the leaves, usually large, of a reddish or bluish purple. Pod glabrous, 1 to 2 inches long, rather narrow, with 10 to 12 smooth, globular seeds.

In dry pastures, open woods, and waste places, throughout Europe and Russian Asia, and having been long cultivated for forage, is now widely spread over the temperate regions of the globe. $F$. spring and early summer. In the cultivated state the stems are 1 to 2 feet high, the leaflets usually broad, and the flowers large; in the more common wild form, often distinguished as $V$. angustifolia, Linn., the leaflets are narrower, the flowers rather smaller and pod shorter; and the low spreading variety, $\boldsymbol{V}$. Bobartii, Forst., is only to be distinguished from $V$. lathyroides by the smooth seeds, and somewhat larger flowers and pods.

9. V. lathyroides, Linn. (fig. 286). Spring V.-A low spreading annual or biennial, glabrous or nearly so; the stems branching at the base, seldom 6 inches long; the foliage, solitary flower, and general appearance those of the smaller specimens of $V$. sativa, the flowers are, however, smaller, usually of a richer purple, the calyx less decidedly oblique at the base, and the pods seldom an inch long. The seeds are also rough with raised dots, a distinction believed to be constant.

In dry pastures, open woods, banks, \&c., over the whole of Europe, except the extreme north, extending eastward to the Cancasus. Not uncommon in England and Scotland, very rare in Ireland. Fl. spring.

10. V. bithynica, Linn. (fig. 287). Bithynian V.-A glabrous or slightly downy annual, with weak angular stems, 1 to 2 feet long. Leaves more like those of a Lathyrus than of a Vicio, having usually only 2 pair of leaflets, obovate in the lowest leaves, oblong or lanceolate, and above an inch long in the others, the tendrils branched. Stipules rather broad and toothed. Flowers solitary or 2 together, on peduncles sometimes very short, sometimes half as long as the leaves, rather large, of a bluish-purple with very pale wings, and shaped like those of $V$. sativa. Style with a tuft of hairs under the stigma on the outer side. Pod 1 to $1 \frac{1}{2}$ inches long about 4 lines broad, usually more or less hairy. Seeds 4 to 6 .

In bushy or stony waste places, chiefly near the sea, but spreading inland as a cornfield weed, in southern Europe to the Caucasus, extending up western France to Bordeanx, and reappearing in various counties of England, but not in Scotland or Ireland. Fl. Summer, 


\section{LATHYRUS. PEA.}

Herbs, with weak stems, sometimes climbing, and half-sagittate, or sagittate stipules; the leaves usually pinnate, with few leaflets, larger than in Vicia, the common leafstalk ending in a simple or branclied tendril or in a small point, the leaflets sometımes wanting. Flowers solitary or in racemes, on axillary peduncles, purple, red, white, or bright yellow. Petals usually broad, especially the standard. Upper stamen free, or more frequently connected with the others, at least in the middle. Style flattened below the stigma, quite glabrous on the outer side, but more or less downy on the inner face for some way below the stigma. Pod cylindrical or flattened. Seeds several, usually globular or angular.

A considerable genus, with the wide geographical range of Vicia, differing from them chiefly by the style, and in most cases by the fewer and larger leaflets and broader petals. The calyx is usually more oblique, the upper teeth shorter than the lower ones. Severa] species are very apt to dry black, which is seldom the ease in Vicia.

Leafstalks without real leaflets.

stipules large and leaf-like. Leafstalk a mere tendril. Flowers yellow

Stlpules none. Leafstalk fiattened, resembling a grass-leaf. Flowers pale red

Leaves with one pair of leaflets.

Annual, with snall red flowers. Pods hairy . . . . 3. L. hirsutus.

Perenufal, with large red or purplish flowers. Pods glabrous.

Rootstock tuberous. Stens not winged

Rootstock without tubers. Stem winged :

Perennith

Leaves with two or more pairs of leaflets.

Stipules deeply divided

Stipules entire.

Leafstalk ending in a simple or branched tendril.

Leaflets lanceolate. Stlpules narrow, half-sagittate

Leaflets ovate or elliptical. Stipules large, broadly ovate, sagittate.

Leaflets ending in a short flne polnt.

Leaflets 2 or 3 pairs, rarely 4 pairs, lanceolate or linear . 9. L. macrorrhizus. Leaflets 5 or 6 pairs, rarely 4 pairs, ovate . . . . 10, L. niger.

The Sicilian sweet Pea, the Tangiers Pca, the Sonth American Anson's $P e a$, and some other exotic species of Lalhyrus, are cultivated in our flower-gardens. The $\mathrm{Pca}$ of our kitchen-gardens and fields is usually distinguished as a genus, under the name of Pisum, but upon elaracters which are hardly sufficient for the separation of a solitary species.

1. L. Nissolia, Linn. (fig. 288). Grass Velchling.-An erect, glabrous annual, branching from the base, about a foot high. Leaves all reduced to a long, linear, grass-like, flattened leafstalk, ending in a fine point, without leaflets or stipules. Peduncles long, bearing immediately below their summit 1 or rarely 2 small pale red flowers. Pod long, narrow, and straight.

In bushy places, grassy borders of fields, and stony pastures in central and sonthern Europe to the Cancasus, but not extending into northern Germany. In Britain, spread over central and southern England, but rare and not known in Ireland or Scotland. Pl. early sumer.

2. L. Aphaca, Linn. (fig. 289). Yellow Vetchling.-A weak, branching, glabrous annual, about a foot long, without real leaflets, but the 
2 large, broadly heart-shaped or sagittate stipules assume the appe:rance of simple opposite leaves, with a slender branching tendril be:ween them. Peduncles long and slender, with 1 or rarely 2 small yellow flowers. Pod rather more than an inch long, flattened, glabrous, containing 4 to 8 seeds.

In waste and cultivated places, in central and southern Europe, and central Asia, spreading northwards as a cornfield weed, and, as such, appearing occasionally in the midland and southern counties of England. Fl. early summer.

3. I. hirsutus, Linn. (fig. 290). Rough Pea.-A weak annual, much branched at the base, a foot long or more, with the young shoots slightly hairy. Stipules narrow. Tendrils branched, with a single pair of linear-lanceolate leaflets. Peduncles long, with 1 or 2 rather small tlowers. Standard bright red, the keel and wings paler. Pod hairy.

In cultivated and waste places, in southern Europe to the Caucasus, spreading northwards as a cornfield weed, and as such found, but very rarely, in York, Essex, Kent, Surrey, and Somersetshire. Fl.carly summer.

4. L. pratensis, Linn. (fig. 291). Mcadono Pea.-A weak, much branched, glabrous perennial, straggling or half climbing to the length of 1 to 2 feet or rather more. Stipules large, broadly lanceolate, and sagittate. Tendrils branched, with one pair of narrow-lanceolate or linear leaflets. Peduncles elongated, with a short raceme of 6 to 10 or rarely more yellow flowers. Pod glabrous.

In moist meadows and pastures, throughout Europe and Russian Asia, from the Mediterranean to the Arctic Circle. Abundant in Britain. Fo all summer.

5. L. tuberosus, Linn. (fig. 292). Earth Nut Pea.-Rootstock peren. nial, slender, forming small tubers; the annual stems weak, branching, ascending to the height of the corn in which it grows, glabrous, tbe angles not winged. Leafstalks ending in a branched tendril, and bearing a single pair of obovate, oblong, or broadly lanceolate leaflets. Stipules lanceolate, half-sagittate. Peduncles 3 to 6 inches long, bearing a loose raceme of red handsome flowers, although not usually so numerous as in L. sylvestris, and rather smaller. Pod glabrous, rather more than an inch long.

In grassy wastes and hedge-banks, but more especially in cornfields, frequent in many parts of central Europe and Russian Asia. In Britain, only in cornfields around Fyfield in Essex, where it is abundant, and probably an ancient denizen. Fl. summer.

6. L. sylrestris, Linn. (fig. 293). Evcrlasting Pca.-A glabrous perennial, with a creeping rootstock, and straggling or climbing stems, attaining 3 to 5 or even 6 feet, the angles expanded into narrow green wings. Leafstalks also flattened or winged, ending in a branched tendril, and bearing a single pair of long lanceolate leaflets. Stipules narrow. Peduncles 6 inches long or more, bearing a loose raceme of rather large flowers of a pale reddish-purple; the standard very broad, with a green spot on the back, and the keel also partially grcen. Pod 2 or 3 inches long or even more. Seeds numerous, slightly flattened.

In hedges, thickets, and bushy or rocky places, scattered over the greater part of Europe except the extreme north, but chiefly abundant in the south. Occurs in many localities in England and Scotland, but probably not indigenous in Scotland, and not recorded from 
Ireland. Fl. summer, often lasting late. The everlasting Pea of onr gardens, $L$. latifolius, Linn, is a broad-leaved variety from southern Europe, with larger, more richly coloured flowers, and some slight difference in the seeds. As an escape from cultivation, it will often establish itself in the vicinity of gardens.

7. I. palustris, Linn. (fig. 294). Marsh Pea.-A glabrous, somewhat climbing perennial, not half the size of the $L$. sylvestris, and the wings of the stem much narrower. Stipules half-sagittate. Leaflets oblong-lanceolate, 2 to 4 pairs to each leaf, the tendril usually branched. Flowers smaller and not so broad as in $L$. sylvestris, of a bluish-purple colour, from 2 to 8 in the raceme. Pod glabrous, rather more than an inch long.

In moist meadows and boggy places, in northern and central Europe, Russian Asia, and northern America. Dispersed over a few localities in England and Ireland, but only a very doubtful inhabitant of Scotland. Fl. summer.

I. maritimus, Bigel. (fig. 295). Sea Pea.-A glabrous, rather stout, branching perennial, with a creeping rootstock, and sharply angular spreading stemsabout a foot long. Stipules broad and leaf-like, sagittate at the base, both sides nearly alike. Leaflets 5 or 6 pairs to each leaf, those next the stem often 2 inches long by 1 broad, the tendril simple or branched. Peduncles about the length of the leaves, with a raceme of 6 to 8 large flowers of a bluish-purple. Pod hairy, at least when young, 1 to 2 inches long.

On gravelly sea-coasts, in northern and Arctic Europe, Asia, and America, not extending southwards in Europe beyond the shores of Picardy. Occurs in a few localities on the coasts of southern and eastern England, of Shetland, and of Kerry in Ireland. Fl. summer.

9. I. macrorrhizus, Wimm. (fig. 296). Tuberous Pea-Rootstock perenuial, forming small tubers; the annual stems glabrous, nearly erect, simple or nearly so, 6 inches to a foot high. Leaves without tendrils; the leafstalk ending in a fine point, or sometimes in a narrow leaflet; the leaflets usually 2 pairs, sometimes 3 or even 4 pairs, oblonglanceolate or linear. Peduncles slender, bearing a loose raceme of 2 to 4 flowers of a bright reddish-purple. Pod glabrous, about $1 \frac{1}{2}$ inches long. The whole plant dries black like the following species. $L$. montanus, Bernh. Orobus tuberosus, Linn.

In thickets and open woods, nnder hedges, \&c., thronghout Europe, except the extreme north. Abundant in Britain. Fl. spring and early summer. This and $L$. niger form part of the old genus Orobus, still kept up by many botanists, but only differing from Lathy;us by the want of tendrils to the leaves.

10. I. niger, Wimm. (fig. 297). Black Pea.-A glabrous perennial, always turning black in drying; the rootstock short and not tuberous; the stems erect or ascending, branched, 1 to 2 feet high or even more. Stipales small and narrow. Leaflets 4 to 6 pairs to each leaf, ovate or elliptical, 6 lines to an inch long, the common stalk ending in a short point. Peduncles longer than the leaves, with a short raceme of 6 to 8 flowers. Pod glabrous, near 2 inches long.

In mountainous and rocky districts, throughout temperate Europe to the Caucasus, extending far Into Scandinavia. In Britain, only known from two localities, in Perth and Forfar. Fl. summer. 


\section{ROSACEE. THE ROSE FAMILY.}

Herbs, shrubs, or trees, with alternate leaves, mostly toothed or divided, the stipules seldom wanting and often leaf-like. Flowers in cymes, or solitary at the ends of the year's shoots, or more rarely in lateral bunches or racemes. Sepals 4 or 5 , united at the base into a lobed calyx, sometimes double and usually enclosing the ovary or adhering to it. Petals 4 or 5 or rarely none. Stamens usually indefinite in number, inserted with the petals on the calyx below its lobes. Ovary of 1,2 , or more carpels, usually distinct at the time of flowering, but sometimes combined even then into a single 5 -celled ovary, which is then always inferior ur combined with the calyx. As the fruit enlarges, the carpels either remain free or are variously combined with each other or with the calyx. Seeds 1 or 2 (or in Spircea 3 or 4) in each carpel. Embryo with large cotyledons and no albumen.

A numerous family, widely spread over the globe, but more in the temperate and cooler parts of the northern hemisphere than within the tropics. The indefinite stamens inserted on the calyx are sufficient to distinguish the greater number of the genera from all other British plants. In the few cases where the stamens are apparently definite, there are no petals, but they then differ widely from all other apetalous genera by their stipules and divided leaves, as well as by the structure of the ovary.

(Ovary or ovarles auperior or free from the calyx, thongh sometimes enclosed Ovary or ovaries inferior or adhering to the calyx-tube, which is ciosed over

$\{$ A single ovary :

$2\left\{\begin{array}{l}\text { Aeveral ovaries } \\ \text { Sevingles }\end{array}\right.$

$8\left\{\begin{array}{l}\text { Trees, with a deciduous calyx and succulent fruit } \\ \text { Herbs, with the calyx persiscing round the dry seed-vessel }\end{array}\right.$

No petals. (Herbs.)

ve, or more petals. (Herbs or shrubs.) - . . . 8

$5\{$ Leaves palmately lobed or digitate. Hlowers in loose panicles or cymes : 6

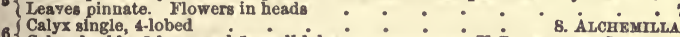

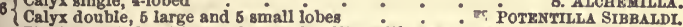
(Heads purplish. Wlowers hermaphrodite, with 4 stamens $t \quad$. 9. BANGUISORBA.

7 Heads green. Howers diccious, the males with numerous stamens.

f Calyx-tnbe short and nearly fiat, not enclosing the carpels 10. POTRRIOM.

$8\left\{\begin{array}{l}\text { Calyx-tube shor and nearly fat, not enclosing the carpels } \quad . \quad \cdot .9 \\ \text { Calyx-tube closing over the carpels or seeds }\end{array}\right.$

Calyx single

- Calyx double, having as many external bracts as divisions, and alternating with them.

10 Calyx-segments $5: \ldots$ Calyx-segments about 8. Carpels dry and distinct when ripe: $\quad$ 3. DRYAs.

$11\{$ Carpels dry, opening when ripe

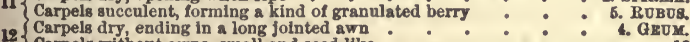

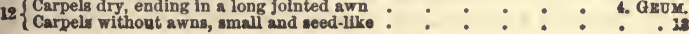


(Carpels few, on a minute dry receptacle

13 Carpels numerons, on a small, flat, dry receptacle

Carpels numerous, on a large, succulent receptacle.

Herbs, calyx-tube dry, small, enclosing 1 or 2 carpels.

$\{$ Tres or slirubs calyx-tube succulent or fleshy, at least

No petals, calyx-tube smooth

15 Petals 5, calyx-tube covered with hooked bristles, forming a burr

Fruit enclosing from 1 to 5 cells, or hard nuts, arranged round the central 16 axis, each with 1 or 2 sceds

Fruit enclosing several hairy, seed-like csrpels, irregularly placed

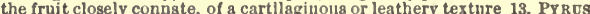

Cells of the fruit closely connate, of a harl, bony consistence . 14. CBatagus.

17

Cells of the fruit forming distinct bony nuts, but adhering to the insile of the calyx .

Cells bony, somewhat exposed at the top of the fruit, readily separable from each other.

These Genera are usually distributed into three tribes, considered by some botanists as distinct Orders, viz. :-

1. A myodalef. Calyx declduons. Carpel 1, frce. Genus:-1. Pruxus.

2. Rosaf. Calyx persistent. Carpels 1 or nore, free (but sometimes included In the clozed calyx). Genera:-2. SPIRAA; 3 . DRYAS; 4. GEUM; 5 . RUBUS; 6. Fraoaria; 7. Potrntilla; 8. Sibbaldia ; 9. Alcuemilla; 10 . Sanguisorba; 11. POTRRIUM; 12. AGRIMONIA; 13. ROSA.

3. POмACE 8 . Calyx persistent, allherent to the ovary, the carpels of which are nnited, at least in the ripe fruit. Genera:-14. Prous; 15. Cratages; 16. CotoNEASTER; 17. MIESPILUS.

The double-flowering Kerria japonica, so frequently to be met with tralned upon cottage garden-walls, formerly supposed to be a specics of Corchorus, is now known to belong to the Rosacece.

\section{PRUNUS. PRUNUS.}

Shrubs or trees, with undivided, toothed leaves, and small, free stipules, often scarcely visible; the flowers either in small bunches on a former year's wood, or in racemes in the axils of young leaves. Calyx free, 5-lobed. Petals 5. Stamens numerous. Ovary of 1 carpel, containing 2 pendulons ovules. Fruit a fleshy or juicy drupe, with a hard ctone, smooth or rugged, but not wrinkled on the surface, containing 1 , or rarely 2 seeds.

A considerable genus, distributed over the whole of the northern hemisphere, and even abundant within the tropics, both in the New and the Old World, but not extending into the south temperate zone. It is the only British genus with a stone fruit.

Flowers in axillary racenics

Howers solitary or clusterch, from leafless buds.

Flowers slingle or two together, on short pedicels .

The well-known common Laurcl and Portugal Laurel of our gardeners are species of Prunus ( $P$. Lauro-crasus and $P$. lusitanicus), and have no aflinity with the true Laurel of the ancients, which is our Bay-trce (Laurus nobilis). The Mahaleb ( $P$. Mahaleb) and the $P$. semperforens, both from the continent of Europe, are also frequently to be met with in our shrubberies. The Apricot is another Prunus ( $P$.armeniaca); the Almond, the Peach, and the Nectarine belong to the genns Amygdalus, only differing from Prunus in the wrinkled surface of the stone.

1. P. spinosa, Linn. (fig. 298). Blackthorn, Sloc.-In the common, truly wild state, this is a much branched shrub, the smaller branches often ending in a stout thorn. Leaves ovate or oblong, stalked, and 
finely toothed, usually glabrous, but occasionall 5 , espesially the oxder sides as well as the young shoots, more or less downy. Flowers small, white, nearly sessile, solitary or in pairs, appearing betore the leaves. Fruit small, globular or shortly ovoid, nearly black, with a hluish bloom. $P$. communis, Huds.

In hedges, thickets, and open woods, common in Europe and northern Asia. Abundant in Britain. Flo early spring. The Bullace, $P$. insititia, linn., is a variety of a somewhat taller growth, and less thorny, with the leaves rather more downy, and the fruit rather larger and globose. black or yellow, and less acrid. It is more abnndant and more marked in south-eastern Europe and central Asia than with us. The Damson and the numerous varieties of Plum of our gardens, although growing into thornless trees, are believed to be varieties of $P$. spinosa, pro. duced by long cultivation; they will occasionally sow themselves, and may be found apparently wild in the neighbourhood of gardens and orchards, retaining their arborescent character. Some botanists distinguish these varieties as a species, under the name of $P$. domestica, Linn. [Other anthorities regard $\boldsymbol{P}$. insititia, with globose pale fruit, as the origin of all the Plums, and $P$. spinosa, with blue-black ovoid fruit, as that of the Damson.]

2. P. Cerasus, Linn. (fig. 299). Wild Cherry.-The Cherry, when wild, is often a mere shrub of 6 or 8 feet, throwing out suckers from its creeping roots, or more properly rhizomes; but in cultivation, and often also in a really wild state, it will form a tree of considerable size. Stipules narrow, often toothed and glandular, but very deciduous. Leaves ovate or ovate-lanceolate. toothed, 2 to 4 inches long, usually with 1 or 2 glands at the top of the stalk or on the edge of the blade, near the base; but they are sometimes wanting on the same specimen. Flowers white, on pedicels from 1 to 2 inches long, in bunches of 2, 3, or more, issuing together from leafless buds, surronnded by brown scales, of which the inner ones often became green and leaf-like at the tips. Fruit globular and smooth, red or black, usually without bloom.

In woods, thickets, and hedgerows, in central and southern Kurope and temperate Asia, extending northward into Scandinavia, but has been in so many places introduced by cultivation, that its precise limits can scarcely be fixed. Generally dispersed over England, Ireland, and southern Scotland, but in many cases not truly indigenous. Fl. spring. There are several more or less permanent varieties in cultivation, which are variously distributed by different botanists into several species, of which the $P$. Avium, for the tree variety, without suckers, and $P$. Cerasus, for the shrubby form, are generally adopted; but none of the characters given appear to be constant in a wild state. [Linnæus distinguished the two species thus :-

$P$. Cerasus. Leaves sproading, crenate-serrate, glabrous, petiole short, corolla cup-shaped, petals firm suberect, fruit acid.-The Cherry.

$\boldsymbol{P}$. Avium. Leaves drooping, sharply serrate, pubescent beneath, petiole long, corolla open, petals flaccid, almost obcordate, fruit sweet or bitter.-The Gean.]

3. P. Padus, Linn. (ifg. 300). Birdcherry.-A shrub of 6 or 8 feet, or sometimes a small tree, always glabrous. Leaves oval or ovatelanceolate, finely toothed, and slightly cordate at the base. Flowerd wnita rat,her small, in loose, often drooping racemes of 2 or 3 to nearly 
6 inches, on short, leafy, or rarely leafless branches, on the last year's wood. Fruit small, nearly globular, black and bitter, with a rugged stone.

In woods, thickets, and hedges, in northern and central Europe and Asia, from the Arctic regions to the Caucasus and Himalaya, but disappearing in south-western Europe. Scattered over various parts of Britain, but absent in southern England, and a great part of Ireland. Fl. spring.

\section{SPIREA SPIREAA.}

Herbs, with pinnate leaves, or, in exotic or introduced species, shrubs, showing much diversity in foliage. Flowers usually small and nnmerous, in elegant terminal cymes or panicles. Calyx free, 5-lobed. Petals 5. Stamens numerous. Carpels 3 or more, usually 5, quite free from the calyx, forming as many dry capsules, opening, when ripe, along the inner edge, and containing 2 or more seeds.

A considerable genus, spread over the northern hemisphere both in the New and the Old World, but scarcely penetrating into the tropics. It is easily recognised by its dehiscent, capsular carpels, and among British Rosacea, by the numerous small flowers.

Shrub, with simple, serrate leaves.

Herbs with pinnate leaves.

Segments of the leaves few and large, white underneath.

Segments of the leaves numerous and small, deeply toothed

1. S. salicifolia.

- 2. S. Ulmaria.

1. S. salicifolia, Linn. (fig. 301). Willow S.-A shrub of 4 or 5 feet, with rather slender branches, usually glabrous. Leaves undivided, oblong or lanceolate, serrate, green on both sides. Flowers pink, in a dense oblong or pyramidal terminal panicle. Carpels usually 5.

A native of eastern Europe, Russian Asia and North America, long cultivated in our shrubberies, and found here and naturalised in moist woods in the north of England and south of Scotland. In some parts of North Wales it forms a principal ingredient in hedges, propagating readily by its creeping suckers. Many other shrubby species are cultivated in our gardens.

2. S. Ulmaria, Linn. (fig. 302). Meadow-sweet, Queen of the Meadows. - Stock perennial, with erect, rather stout, annual stems, 2 or 3 feet high, usually glabrous and reddish. Leaves large, pinnate, with 5 to 9 ovate or broadly lanceolate segments often 2 or 3 inches long, irregularly toothed, green above, soft and wbitish underneath, the terminal one deeply divided into three; besides which are several smaller segments along the common stalk. Stipules broad and toothed. Flowers small, of a yellowish white, sweet-scented and very numerous, in componnd corymbose cymes at the summit of the stems. Capsulos 5 to about 8, very small, and more or less spirally twisted.

In meadows, on the banks of ponds and ditches, \&c., throughout Furope and Russian Asia, except the extreme north. Common in Britain. Fl. summer.

3. S. Filipendula, Linn. (fig. 303). Droproort. - Stock perennial, the fibrous roots swollen here and there into oblong tubers. Stems erect, 1 to 2 feet high. Leaves chiefly radical or in the lower part of the stem, 3 to 5 inches long, with nimprons (above 20) small, ovale 
oblong or lanceolate segments, deeply toothed or pinnately lobed, gradually smaller as they near the stem, green and glabrons, or slightly downy. Stipules broad, adhering to the leafstalk nearly their whole length. Flowers like those of S. Ulmaria, but rather larger, and often tipped with red. Carpels 6 to 12, not twisted.

In meadows, pastures, and open woods, generally dispersed over Europe and Russian Asia, except the extreme north. Frequent in Fngland, Scotland, and in a few localities in the west of Ireland. Fl. summer.

\section{DRYAS. DRYAS.}

Tufted or creeping perennials, with undivided leaves and rather large white or yellowish flowers, growing singly on long peduncles. Calyx free, 8- to 10-lobed. Petals 8 to 10, or rarely fewer. Carpels numerous, crowded on the receptacle, 1-seeded and indehiscent, ending when ripe in long feathery awns or tails, which are not jointed.

The genus consists of but two, or perhaps three species, confined to the high mountains or Arctic regions of Europe, Asia, and North America.

1. D. octopetala, Linn. (fig. 304). White Dryas.-Stems short, much branched, prostrate or creeping, forming with their crowded foliage dense spreading tufts. Leaves but little more than 6 lines long, oblong, deeply and regularly crenate, green, glabrous, and almost shining above, white and downy underneath. Peduncles erect, 2 or 3 inches long. Segments of the calyx nsually 8 , rather shorter than the petals. Feathered awn of the carpels above an inch long.

General geographical range nearly the same as that of the genus. In Britain, not uncommon in the limestone mountain districts of northern England and northern and western Ireland, but particularly abundant in the north of Scotland. Fl. summer.

\section{GEUM. AVENS.}

Herbs, with a short perennial, sometimes slightly creeping, stock, and annual erect stems. Leaves pinnate, with few and very unequal distinct segments, and yellow or red or white flowers growing singly on long peduncles at the ends of the stems or branches. Calyx of 5 equal divisions, with 5 very small onter ones alternating with them. Petals 5. Stamens numerous. Carpels numerons, 1-seeded, indehiscent, ending in a hairy point or awn, which is hooked at the tip.

A genus of several species, widely diffused over the temperate and colder regions of Europe, Asia, and North America, and descending along the Andes to extra-tropical South America.

Stems branched. Petals small, yellow, spreading . . . 1. G. urbanum. stems simple or nearly so. Flowers drooping. Petals dull purple, scarcely spreading . ? 2 G. rivale.

1. G. urbanum, Linn. (fig. 305). Common A., Herb-Bennet.-Stems erect, slightly branched, 1 to 2 feet high, nearly glabrous. Stipules large, leaf-like, the npper ones sometimes above an inch long and broad, and coarsely toothed or lobed. Leaves thin, light green, the lower ones with several large segments intermixed with small onee, the upper ones usually with only 3 large segments, or a single one 
divided into 3 , and sometimes 2 or 3 small ones along the stalk, all coarsely toothed. Flowers yellow, with small spreading petals. Carpels in a close, sessile head, covered with silky hairs; the awn about 3 lines long, curved downwards, with a minute hook at the tip.

Under hedges, on roadsides, banks, and margins of woods, common in the greater part of Europe and Russian and central Asia, but not a high northern plant. Abundant in England, Ireland, and southern Scotland, but apparently becoming scarce towards the north.

2. G. rivale, Linn. (fig. 306). Water A.-Rootstock often shortly creeping. Stems erect or ascending, usually simple, shorter than in $G$. urbanum. Leares mostly radical, with one large, orbicular, terminal segment, coarsely toothed or lobed, or sometimes divided into 3 , and a few very small segments lower down the stalk, all more hairy than in G. urbanum. Flowers few, drooping, much larger than in $G$. urbanum; the petals less spreading, of a dull purplish colour, with a tint of orange. Carpels very hairy, in a globular head, which is shortly stalked above the calyx.

In marshes and wet ditches, in Europe, Russian Asia, and northern America, extending into the Arctic regions, and almost confined to mountainous districts in southern Europe. Common in northern England, Scotland, and Ireland, but absent in south-western England. Fl. summer. Where this and $G$. urbanum grow together, specimens are occasionally found approaching sometimes more nearly to the one, sometimes to the other. They have been described as a species under the name of $G$. intermedium, Ehrh., but they are more generally believed to be mere accidental hybrids between the two species.

\section{RUBUS. RUBUS.}

Herbs, with a perennial stock, or more frequently weak, scrambling, prickly shrubs; the leaves pinnately or palmately divided into distinct segments or leaflets, or rarely simply lobed. Calyx free, 5-lobed. Petals 5. Stamens numerous. Fruit a kind of granulated berry, formed by the union of numerous 1-seeded succulent carpels round the conical or shortly oblong, dry receptacle.

A large genus, widely distributed over almost every part of the globe. The fruit, analogous in some respects to that of a Mulberry, is sufficient to distinguish it at once from all other Rosacea. In the Mulbcrry, however, each granule is formed by a separate flower, whilst in Rubus the whole fruit proceeds from a single one. From the Stravberry it differs in that the carpels are succulent on a dry receptacle, whilst in the Strawberry the carpels are dry, and the receptacle succnlent.

Flowering stems biennial or perennlal, woody at least at the

base, 2 or more feet long. Stipules subulate.

Iower leaves pinnate, with 5 leaflets. Rootstock creeping .

Leaves of 3 leaflets, or, if of 5 , the 4 lower ones proceed from the same point.

Branches slender, glaucous. Fruit covered with blnish

Branches not glaucous. Fruit black or reddish, without bloom.

Fowering stems herbaceous, very short, or seldom a foot high.

stipules ovate or lanceolate.

Ieaves with 3 leaflets. Howers small, axillary

1. R. Idaus.

Leaven undivided. Flowers large, terminal, solitary

2. $R$. cassius.

3. $R$. fruticosus

4. $R$. saxatilis.

5. $R$. Chamaemorue 
The Virginian Raspberry, often cultivated in shrubberies, is the $R$. odoratus from North America. $R$. arcticus, a low plant, with creeping rootstock, and short, berbaceous stems, like $R$. Chamcemorus, but with 3 leaflets and pink flowers, has been inserted in our Floras as having been found in the Scotch Highlands, but this appears to be a mistake.

1. R. Idæus, Linn. (fig. 307). Raspberry.-Rootstock perennial and creeping; the flowering stems biennial, nearly erect, 3 or 4 feet high, more or less downy, and armed with weak prickles. Stipules small, subulate, often inserted some way up the leafstalk. Leaves pinnate; leaflets 5 in the lower leaves, often 3 only in the upper ones, ovate or oblong, pointed, coarsely toothed, of a light green above and whitish underneath. Flowers white, in long panicles at the ends of the short branches. Petals narrow and short. Fruit red, sometimes white in cultivation, usually separating from the receptacle when ripe.

In woods throughout Europe and Russian Asia. Generally distributed over Britain, but perhaps in some localities escaped from cultivation. $F l$. spring or early summer. [ $R$. obtusifolius, Willd., Leesii, Bab., is a variety or hybrid with shorter crowded leaflets, found sparsely from Dumfries southwards.]

2. R. fruticosus, Linn. (fig. 308). Bramble, Blackberry.-Rootstock perennial, without nnderground creeping shoots; the flowering stems biennial, or of few years' duration, sometimes nearly erect, but more frequently arched, straggling or prostrate, often rooting, and forming fresh plants at the extremity, usually armed with prickles, either stout and hooked or thin and straight, with stiff hairs, or glandular bristles, or a short down, all varionsly intermingled or occasionally wanting. Stipules subulate or linear, inserted a short way up the leafstalk. Leaflets rather large and coarse, either 3 or 5 , the 2 or 4 lower ones inserted together at some distance below the terminal one, ovate, toothed, more or less downy, the midribs as well as the stalks nsually armed with small hooked prickles. Flowers white or pink, in panicles at the ends of the branches. Fruit black, or very rarely dull red, not separating readily from the receptacle, the calyx usually turned down under it, seldom çlosing over it as in $k$. ccesius.

In hedges, thickets, woods, and waste places, over nearly the whole of Europe, Russian and central Asia, and northern Africa, but not a high alpine nor an Arctic species. Abundant in Britain. Fl. summer, commencing early. It varies considerably, especially in the prickles and hairs, and in the shape of the leaflets, and from its propagating so readily by its rooting stems, individual variations are often extensively multiplied, and acquire an undue importance in the eyes of local observers. The consequence has been an excessive multiplication of supposed species, both in Britain and on the Continent, although scarcely any two writers will be found to agree in the characters and limits to be assigned to them. The British Flora (8th edit.) admits $\mathbf{6}$ species, but for those who adopt a further division, short characters are given for 34. Babington's Manual (8th edit.) distinguishes 45. Amongst those which have been observed in Britain, the following appear to be the most marked, although even these will very frequently be found to pass imperceptibly one into the other.

a. $R$. fruticosus communis. Leaflets covered underneath with a close, न rhite down. Hlowers usually numerous. Chiefly in bedges and thickets, 
b. $R$. corylifolius. Leaflets green underneath, usually large and broad. Flowers not so numerous as in the common variety. In hedges and thickets with the common variety, but usually flowering earlier.

c. $R$. carpinifolius. Leaflets green underneath, but not so broad, and more pointed than in the last, the stems more hairy. Flowers not so numerous. Chiefly in woods.

d. $R$. glandulosus. Leaflets as in the last variety, or sometimes broader, the stems with numerous stiff, glandular hairs mixed in with the prickles. More frequent in shady woods than in open thickets.

e. $R$. suberectus, Anders. Leaflets green, or slightly hoary underneath. Stems shorter, and more erect than in the common forms. Flowers usually few, and the fruit not so black. Occasionally found in wet woods and thickets, especially in the west.

[Mr. Baker, who has studied the genus for many years, enumerates in the Student's Flora 22 sub-species of $R$. fruticosus, including $R$. caesius as one of them. These are divided into three principal groups-

a. Stems prickly, otherwise glabrous ; includes $R$. suberectus, fruticosus communis, corylifolius, and casius.

b. Stems prickly and hairy, but hairs not glandular; includes $R$. carpinifolius.

c. Stems prickly, bristly, and glandular-hairy ; includes $R$. glandulosus.]

3. R. cæsius, Linn. (fig. 309). Dewberry.-Very near $R$. fruticosus, but distinguished by the more slender branches, more or less glaucous when young, spreading or creeping along the ground, and seldom arched; the flowers few, in small, loose panicles; the divisions of the calyx narrow, with much longer points, closing more or less over the fruit; and especially by the glaucous bloom covering the fruit when ripe. Leaves pale green on both sides. Prickles usually small, with few or no hairs intermingled.

In open fields and stony wastes, seldom penetrating into woods, or climbing up into hedges, extending over Europe and Russian Asia, but not an Arctic plant. Common in Britain. Fl. summer. It is believed by some botanists to be as much connected with $R$. fruticosus by intermediate forms as some of the above-enumerated varieties of that species are with each other, but generally speaking it is not difficult to distinguish it.

4. R. saxatilis, Linn. (fig. 310). Stone R. -The rootstock emits a few creeping runners rooting at the nodes, and erect or ascending simple stems seldom above a foot high, slender and downy, with a few small prickles, or sometimes wholly unarmed. Stipules ovate-oblong or lanceolate, scarcely adhering to the leafstalk. Leaflets usually 3 , much like those of $R$. casius, thin, and of a pale green. Flowers on slender pedicels, 2 or 3 together in the axils of the upper leaves, forming very short racemes or corymbs, seldom growing out into short, leafy flowering branches. Petals of a dirty white or greenish yellow, and very narrow. Berries red, with very few rather large carpels.

In open woods, diffused over the mountain regions of Europe and central and Russian Asia ; more abundant, and descending to lower elevations in more northern latitudes. Frequent in Scotland, in the north of Fngland, and along the western counties to South Wales; in ireiand, chiefly in the north. $F l$ summer. 
5. R. Chamæmorus, Linn. (fig. 311). Cloudberry.-Rootstock creeping. Stems simple, herbaceous, unarmed, seldom above 6 inches high. Lower stipules entire, in a short sheath, without leaves; upper ones distinct, small, and ovate. Leaves fow, rather large, simple, broadly orbicular or reniform, toothed, and often more or less deeply cut into 5,7 , or 9 broad lobes. Flowers white, rather large, solitary on terminal peduncles. Fruit rather large, of an orange red.

In turfy bogs, in northern Europe, Asia, and America, generally at high latitudes, but descenüing southwards into northern Germany. Abundant on some of the Scotch mountains, and extends also into northern England and Wales; very rare in Ireland, and found in the north only. Fl. summer.

\section{FRAGARIA. STRAWBERRY.}

Habit, foliage, and flowers of Potentilla, but the fruit is succulent, formed of the enlarged succulent receptacle, studded on the outside with the numerous minute 1-seeded carpels, looking like seeds.

A genus spread over nearly the whole of the northern hemisphere without the tropics, where it consists perhaps but of a single species, and represented again by a nearly allied but possibly distinct species in southern extra-tropical America, and by another in the Himalaya.

1. F. vesca, Linn. (fig. 312). Strawberry.-A short, perennial, tufted stock emits slender runners, rooting and forming new plants at every node. Leaves mostly radical, more or less clothed with soft, silky hairs, consisting of 3 ovate, toothed leaflets at the end of a long leafstalk. Flower-stems radical, erect, leafless, or with 1 or 2 usually undivided leaves, 3 to 6 inches high or rarely more, bearing a small number of pedicellate white flowers. Fruit usually red.

In woods, bushy pastures, and under hedges, throughout Europe and Russian and central Asia and in northern America, extending to the Aretic regions. Abundant in Britain. Fl. nearly the whole season. The kautboy, a rather taller variety, with fewer runners and flowers, usually entirely or partially unisexual, and fruit without carpels round its base, has been distinguished as a species under the name of $F$. elatior, Ehrh.; and several other wild or cultivated varieties have been proposed as species, but the great facility with which fertile cross-breeds are pro. duced gives reason to suspect that almost the whole genus, including even the Chilian Pine Strawberry, may prove to consist but of one species.

\section{POTENTILLA. POTENTIL.}

Herbs, with a perennial, tufted stock, and occasionally a creeping rootstock or runners. Flowering stems usually annual, often very short, rarely perennial or partially shrubby. Leaves of 3 or more digitate or pinnate, distinct segments or leaflets. Peduncles 1-flowered, solitary, or forming a dichotomous cyme at the ends of the stem. Calyx free, clouble, that is, of twice as many divisions as there are petals, the alternate ones outside the others, and usually smaller. Petals 5 or rarely 4. Stamens numerous. Carpels numerous, small, 1-seeded and seed-like, crowded on a receptacle which enlarges but slightly, and rarely becomes spongy, never succulent. 
The species àre numerons, extending over the whole of the northern hemisphere without the tropics, especially in Europe and Asia, penetrating into the Arctic regions, and descending along the mountain-ranges of America to its southern extremity. The genus, already extended by the admission of Tormentilla, Comarum, and Sibbaldia, would perhaps be still better defined if Pragaria were likewise included. It would then comprise all Rosacece with a double calyx, numerous, distinct, 1-seeded carpels, not enclosed in its tube, and the styles not transformed into long, feathery beaks or awns.

Leaves digitately divided.

Hlowers whlte.

Flowers yellow.

Petals 4 in all, or nearly ail, the flowers

Petals 5 in all, or nearly all, the flowers.

Leaves very white underneath.

Leaves green on both sides.

Stems creeping, and rooting at the node

Stems ahort and tufted, leaflets 5-7

Leaves plnnately dividea.

Stems short and tufted, leaflets 3 .

Hlowers dingy purple

Flowers white

Hlowers yellow.

Stem much branched, often shrubby. Leaflets few, oblong.

Stem creeping. Leaflets numerous, silky underneath

1. P. Fragariastrian

3. P. Tormentilia.

4. $P$. argentea.

2. $P$. reptans.

5. P.'verna.

6. P. Sibbaldi.

10. P. Comarum,

9. $P$. rupestris.

Two red-flowered East Indian species, with digitate leaves, $P$. nepalensis and $P$. atropurpurea, and several of their hybrids, are frequently to be met with in our gardens. [ $P$. norvegica, Linn., a hirsute erect annual with palmately 3 -foliolate leaves and yellow flowers, is naturalised in several English counties, and multiplying rapidly.]

1. P. Fragariastrum, Ehrh. (fig. 313). Strawberry-leaved P.-Resembles the Strawberry in its short, tufted stems, silky hairs, 3 leaflets regularly toothed almost all round, and white flowers; but the receptacle does not swell or become succulent as the fruit ripens. The stem itself is also often shortly creeping, either under or above ground, and the flowering branches are less erect than in the Strawberry; the petals usually smaller, although variable, sometimes narrow and scarcely so long as the calyx, sometimes nearly as large as in the common wild Strawberry.

On banks, dry pastures, and in open woods, in western and central Europe, extending northward to South Sweden, and eastward to the Crimea and the Caucasus. Abundant in England, Ireland, and southern Scotland, but becoming rare in the Highlands, $F$. early spring.

2. P. reptans, Linn. (fig. 314). Cinquefoil.-Stock seldom much tufted, with slender, prostrate stems, often rooting at the nodes, and sometimes extending to a considerable length. Stipules ovate, mostly entire. Leaves all stalked, with 5 obovate or oblong, coarsely toothed leaflets. Flowers single, on long peduncles, apparently axillary, or rarely forming a loose terminal cyme, as in $P$. Tormentilla. Petals large and yellow, mostly 5 , but occasionally 4.

In rich pastures, borders of meadows, edges of woods, and hedges, throughout Europe and Russian Asia, except the extreme north. Abunciant in England and Ireland, but decreasing much in Scotland. $F$. ismmer and autumn. Much as the common form of this species differ 
from the following one, it is by some supposec to be a mere variety, and certainly the procumbent variety of the true Tormentilla appears to be intermediate between the two.

3. P. Tormentilla, Neck. (fig. 315). Tormentil.-Rootstock thick and woody. Stems erect, or procumbent at the base, several times forked, more or less silky-hairy as well as the leaves. Lower leaves often shortly stalked, and like those of $P$. reptans, but the upper ones always sessile, consisting of 3 , or rarely 5 , deeply toothed leaflets. Peduncles in the forks of the stem, or in the axils of the upper leaves, forming a loose, leafy, terminal cyme. Flowers small, bright yellow, and mostly with 4 petals; the first one, however, of each stem has occasionaliy 5.

On heaths, moors, and pastures, in open woods, \&c., throughout Europe and Russian Asia, to the Arctic region. One of the most abundant and most generally diffused British plants. $\mathrm{Fl}$. summer. The $P$. procumbens, Sibth. (Tormentilla reptans, Linn.), is a more procumbent variety, occasionally creeping at the base, with rather larger flowers, more frequently having 5 petals, and forms some approach to $\boldsymbol{P}$. reptans; but the really intermediate forms mentioned above are of very rare occurrence.

4. P. argentea, Linn.(fig. 316). Hoary P.-Dtems decumbent at the base, ascending, and forked above. Lower leaves on long stalks, the upper ones nearly sessile, composed of 5 wedge-shaped or obovate leaflets, with a very few deep teeth or lobes, and remarkable for the close white down which covers their under side as well as the stems. Flowers in a loosely forked, leafy corymb or panicle, rather small, with 5 yellow petals.

In gravelly pastures, and on roadsides, in northern and central Europe, extending all across the Asiatic continent, but neither an Arctio nor generally a Mediterranean plant. In Britain, sparingly distributed over Engiand, and eastern Scotland; absent from Ireland. Fl. summer.

5. P. verna, Linn. (fig. 317). Spring P.--Stems generally short and tufted, sometimes procumbent at the base, and ascending above to the height of 6 or 8 inches, or shortly prostrate, but not rooting at the nodes as in $P$. reptans. Lower leaves on long stalks, with 5 or 7 obovate or oblong, toothed leaflets; the upper ones shortly stalked or nearly sessile, with 5 or rarely only 3 leaflets, all green on both sides, although sometimes greyish by the abundance of silky hairs. Flowers irregularly panicled at the ends of the short, weak stems; the petals yellow, broad, and longer than the calyx.

In pastures and waste places, chiefly in hilly and monntain districts, In Europe, and central and Russian Asia, extending to the Arctic regions, but grows also in the dry, hot regions of southern Europe. Thinly scattered over England, north of Cambridge and Somerset, and Scotland, chiefly in hilly districts, and not recorded from Ireland. Fl. spring and summer. It varies much in size and hairiness, and in the size of the flowers. A luxuriant mountain variety, with larger flowers, of a golden yellow, has been distinguished as a species, under the name of $P$. alpestris, Hall. f., or P. aurea, Sm. (not Linn.). [The mountain plant further differs from the lowland one in its ascending stem, larger less truncate leaflets, and often spotted flowers. Its earlier names are 
P. salisburgensis, Hænke, and maculata, Pourr., which were published in the same year, and $P$. rubens, Vill., the earliest of all.]

6. P. Sibbaldi, Haller f. (fig. 318). Sibbaldia.-The perennial stock forms a short, dense, spreading tuft. Leafstalk seldom above 6 lines long, with 3 obovate or wedge-shaped leaflets, 3 -toothed at the end, green, and more or less hairy on both sides. Flower-stems $\frac{1}{2}$ to $1 \frac{1}{2}$ inches long, almost leafless, bearing a cyme of small flowers, of which the green calyxes are the most conspicuous, the petals being very small and of a pale yellow, or occasionally wanting. The carpels are 5 to 7 , rarely more. The lobes of the calyx often close over the carpels after flowering, but the latter are not enclosed within the tube as in Alchemilla. (Sibbaldia procumbens, Linn.)

In the mountains of northern and Arctic Europe, Asia, and America, or at greater elevations, in the higher ranges of central Europe and Asia. Frequent in the Scotch Highlands, constituting in some places a considerable portion of the greensward, but unknown in England or Ireland. $F l$. summer.

7. P. fruticosa, Linn. (fig. 319). Shrubby P.-Differs from all other European species by the stem, the lower portion of which becomes woody, forming an erect or spreading shrub or undershrub often very low, but sometimes attaining 2 feet in height; the short flowering branches die down as in other Potentillas. Stipules narrow and thin. Leaflets usually 5, narrow and entire; the three upper ones often shortly connected at the base; the two lower inserted at some distance from them, so as to form a pinnate rather than a digitate leaf. Peduncles terminal or opposed to the leaves, each with a single rather large yellow flower.

In bushy or stony places, chiefly in mountain districts, widely diffused over Europe, central and Russian Asia, and North America, but not generally common. In Britain, only in a few localities in the north of England, and in Clare and Galway in Ireland. Fl. summer.

8. P. anserina, Linn. (fig. 320). Silver-weed.-Stock tufted, with long creeping runners rooting at the nodes, as in $P$. reptans. Leaves pinnate, with numerous oblong, deeply toothed leaflets, green or somewhat silky on the upper side, of a shining silvery white underneath from the silky down with which they are covered. Peduncles long, solitary at the rooting nodes, bearing a single rather large yellow Hower.

Common on roadsides, in stony pastures, and waste places throughout Europe, Russian and central Asia, and a great part of North America, extending to the Aretic regions, and reappearing in the southern bemisphere. Abundant in Britain. Fl. summer.

9. P. rupestris, Linn. (fig. 321). Rock P.-Stock perennial, sometimes forming a very short, woody stem, the annual flower-stems e, to 10 inches high. Leaves chiefly rarlical, pinnate; the common sidik rather long; the leaflets 5 or rarely 7, ovate, toothed, green, and somewhat glutinous. The stem-leaves few and smaller, usually with only 3 leaflets. Flowers few, rather large, of a pure white, forming a loose, irregular corymb.

In clefts of rocks, in limestone districts, in the mountain-ranges of central and southern Europe, and across the whole continent of Asia, extending northwards into southern Sweden. In Britain, only in one 
spot on the Breidden Hill in Montgomeryshire. [This very rare plant has quite recently been found in another locality in the eastern counties of Wales. Fl. May and June.]

10. P. palustris, Scop. (fig. 322). Marsh P.-A perennial, 1 to $1 \frac{1}{2}$ feet high, often assuming a bluish-purple colour, glabrous or more or less hairy in the upper part; the stems decumbent and rooting at the base. Stipules not distinct from tha enlarged base of the leafstalk. Leaflets mostly 5 , shortly pinnate at the end of the stalk, oblong, toothed, nearly glabrous above and hoary underneath, or softly hairy on both sides, and often near 2 inches long. Flowers in a loose, irregular corymb, of a dingy purple; the inner segments of the calyx broad, with long points, the outer ones narrow and much smaller. Petals shorter than the calyx. Carpels numerons and small, on a somewhat enlarged, rather spongy receptacle, on which account this plant was considered by Linnæus as forming a distinct genus, Comarum palustre, Linn.

In marshes, peat-bogs, and wet places, in northern and central Kurope, Asia, and a portion of North America, penetrating far into the Arctic regions. Widely distributed over Britain, but rare in the south of England. Fl. summer.

\section{ALCHEMILLA. ALCHEMIL.}

Tufted herbs, either annual or with a perennial, almost woody stock, and annual flowering-stems, palmately lobed or divided leaves, and small green flowers, in loose panicles or in small sessile heads. Calyx free, double, that is, of 8 divisions, of which 4 alternate ones are outside and smaller. No petals. Stamens 4 or fewer. Carpels 1 or 2, 1-seeded, and enclosed in the dry tube of the calyx.

The species are very few, but widely spread over the northern hemisphere, chiefly in mountainous districts. The palmate, not pinnate leaves, and inflorescence, readily distinguish them from the two follow: ing apetalous genera.

Perennial. Flowers in terminal panicles.

Leaves green on both sides, with short, broad, palmate lobes . 1. A. vulgaris.

Leaves silvery shining underneath, deeply paimate $:$ : A. alpina.

Small annual. Fowers minute, in sessile axillary heads : $:$ 3. A. arventis.

1. A. Vulgaris, Linn. (fig. 323). Lady's-mantle.-A perennial, either glabrous or more or less hairy, but always green, not silvery. Radical leaves large, on long stalks, broadly orbicular or reniform, divided only to a fourth or a third of their depth into 7 or 9 broad, regularly toothed lobes. Flowering-stems decumbent or ascending, seldom above 6 inches high, bearing a few small leaves on short stalks, with large, green, toothed stipules, and a loose panicle of small, green flowers, each borne on a little pedicel, generally at least as long as the tube of the calyx.

In meadows and pastures, in northern and Arctic Europe and Asia, becoming more restricted to mountain-ranges in central and southern Europe and central Asia. Generally distributed over Britain, but scarce in south-eastern England. Fl. spring and summer. [A. hybrida, Mill. (montana, Willd.), is a dwarf mountain form with very silky or pubescent leaves.] 
2. A. alpina, Linn. (fig. 324). Alpine A.-An elegant plant, with much of the general habit of $\boldsymbol{A}$. vulgaris, but known at once by the shining silvery hairs, which cover the stems and under side of the leaves. The stock often emits short, creeping runners. Leaves smaller than in $\boldsymbol{A}$. vulgaris, and divided to the base, or nearly so, into 5 or 7 oblong, almost entire segments. Flowers in little, dense corymbs, which form short, interrupted spikes or panicles at the ends of the branches.

In the principal mountain-ranges of Europe, but generally at greater elevations than A. vulgaris, and in Asia and America almost restricted to the Arctic regions. Abundant in the mountains of Scotland and northern England, and occurs also in those of Kerry and Sligo in ireland. Fl. summer. [A. argentea, Don (conjuncta, Bab.), is a curions sport, with the leaflets connate below the middle, found in a few spots in Scotland, as well as in France and Switzerland.]

3. A arvensis, Scop. (fig. 325). Parsley Piert.-A little annual, so different in appearance from the last two that Linnæus considered it as forming a distinct genus (Aphanes, Linn.), bnt the essential characters are the same as in Alchemilla. It is seldom more than 2 or 3 inches high, and often in full flower at 1 inch, much branched, green, and softly hairy. Leaves on short stalks, orbicular, more or less deeply divided and cut. Flowers very minnte, green, and sessile, forming little heads in the axils of the leaves, half enclosed in the leafy stipules.

In fields and waste gravelly places, on earthy wall tops, \&c., throughont Europe and western Asia, and carried by cultivation into other countries. Abundant in Britain. Fl. the whole season.

\section{SANGUISORBA. SANGUISORB.}

Herbs, with a perennial stock, annual, erect, or ascending stems, and pinnate leaves. Flowers in dense oval or cylindrical heads, at the ends of long peduncles. Calyx simple, of 4 coloured lobes, the tube enclosed in 2 or 4 bracts. Petals none. Stamens few. Carpels 1 or rarely 2, 1-seeded, enclosed in the dry, oblong tube of the calyx.

The genus consists but of very few European, north Asiatic, and North American species. They are closely allied to the following genus, with which they are popularly included under the name of Burnet, the chief distinction being in the small number of stamens, and the flowers usually hermaphrodite.

1. S. officinalis, Linn. (fig. 326). Great Bur:_..-A glabrous and erect perennial, attaining about 2 feet in height. Leaves chiefly radical or from the lowcr part of the stem, with 9 to 13 ovate or oblong, toothed segments; the upper part of the stem almost leafless, and divided into 3 or 4 long peduncles, each terminated by a single head of flowers, at first globular, then ovoid or oblong, rarely an inch long. Flowers much crowded, and more or less tinged with dark purple. Stamens usually 4 , but varying from 3 to 6 . Poterium officinale, Hook. $f$.

In moist meadows, chiefly in mountainous districts, almost all over Europe and Russian Asia to the Arctic Circle. In Britain, not uncommon from Ayr and Selkirk southwards; rare in Ireland. $\boldsymbol{F}$. 


\section{POTERIUM. POTERIUM.}

Herbs, with a perennial stock, ascending or erect annual stems, and pinnate leaves. Flowers without petals, in dense, globnlar or ovate heads at the ends of long peduncles, as in Sanguisorba, but most frequently monœcious. Calyx in the males 4-lobed, the stamens numerous, with long filaments. Calyx in the female tubular, contracted at the mouth, with 4 small deciduous teeth. After flowering it becomes quadrangular, closely enclosing 1 or rarely 21 -seeded carpels.

A small genus, chiefly south European and western Asiatic, generally preferring drier and more rocky situations than the Sanguisorbas.

1. P. Sanguisorba, Linn. (fig. 327). Salad Burnet.-A glabrous or very slightly downy perennial, much like the Sanguisorba but smaller, the stem seldom above a foot high. Leaflets small, ovate, deeply toothed, often 15 to 19 to each leaf. Heads of flowers smaller and more globular than in Sanguisorba, of a light green colour, very seldom acquiring a purplish tinge. Lower flowers all males, with the numerous stamens projecting in hanging tufts; upper flowers female, with a long style ending in a purple, tufted stigma. Ripe calyx from 1 to 2 lines long, more or less distinctly quadrangular, and irregularly wrinkled and pitted.

In dry pastures and clefts of limestone rocks, in central and southern Europe, and temperate Russian Asia, extending northwards into southern Sweden. In Britain, generally spread over the limestone districts of England, but scarce in Scotland and Ireland. The ripe calyx or fruit varies in size and in the prominence of the wrinkles, constituting in the eyes of southern botanists several distinct svecies; one of these, with the ripe calyx near 2 lines long, and very disinctly pitted and marked with little asperities, is $P$. muricatum, Spach.

\section{AGRIMONIA. AGRIMONY.}

Herbs, with a perennial stock, erect stems, pinnate leaves with dis. tinct segments or leaflets, and yellow flowers in long, terminal, simple, loose spikes. Calyx 5-toothed. Petals 5. Stamens few. Carpels nsually 2 , enclosed within the dry, persistent calyx, which is covered, when ripe, with hooked bristles.

The genus comprises but very few European, north Asiatic, and North American species, easily known by their inflorescence and their fruit.

1. A. Eupatoria, Linn. (fig. 328). Agrimony.-Stems 2 or 3 feet high, more or less clothed, as well as the leaves, with soft hairs. Lower leaves often 6 inches long, with from 5 to 9 distinct, ovate, coarsely toothed leaflets, about an inch long, intermized with a number of muck smaller ones; the upper leaves gradually smaller, with fewer leaflets Spike long and leafless, but each flower in the axil of a small 3-cleft bract, with 2 smaller 3-toothed bracteoles on the very short pedicel Tube of the calyx hairy and erect when in flower, tarned downward after flowering, when it becomes thickly covered at the top with hooked, green or reddish bristles, forming a small burr. Petals rather small, oblong. Stamens short, often not more than 6 or 7 , but sometimes twice that number.

On roadsides, waste places, borders of fields, \&c. over nearly the 
whole of Europe, Russian Asia, and North America, but not an Arctio plant. Frequent in England and Ireland, but becoming scarce beyond the Clyde and Forth, in Scotland. Fl. all summer. It varies considerably in the hairiness of the foliage, in the size of the flowers, and in the form of the ripe calyx, which is more or less contracted at the base, from obconical to campanulate; and from this character two European specics have been distinguished, but the differences do not appear constant enough to separate them even as marked varieties. [These are-

a. A. Eupatoria proper. Fruiting calyx obconic, deeply grooved, with the lower spines spreading.

b. A. odorata, Mill. More branched, with resinons odour, racemes denser, flowers larger, fruiting calyx bardly furrowed, with the lower spines spreading or deflexed.]

\section{ROSA. ROSE.}

Erect, scrambling or climbing shrubs, more or less prickly, with pinnate leaves, leafy stipules adhering to the leafstalk, and showy flowers, either solitary or in small corymbs at the ends of the branches. Calyx-tube globular or ovoid, contracted towards the top; the limb divided into 5 segments, often nnequal, and sometimes lobed. Petals 5. Stamens numerous. Carpels several, 1-seeded, hairy, enclosed within the tube of the calyx, which becomes succulent when ripe, and sometimes slightly pulpy between the carpels, the whole forming a rather dry red or black berry.

A well-marked genus, widely diffused over the northern hemisphere. It comprises a considerable number of true species; but several of them being of very ancient and universal cultivation, and having been hybridised and multiplied with all the skill of modern horticulturists, their more or less marked races or varieties are now reckoned by thousands. Even in the wild state, endeavours have been made to characterise so large a nnmber of proposed species, that the confusion amongst them is almost as great as in the Bramblcs. The forms indigenous to Britain appear to be reducible to five types, which are probably real species. It must, however, ve admitted, that the characters separating them are not so decided as could be wished, and that specimens will occasionally be found that the most experienced botanist will be at a loss to determine, and certainly not the less so if the number of British species be extended to 11, as in Babington's Manual.

Prickles mostly stralght, or very slightly curved, scarcely dilated at the base.

Stem seldom above a foot high when wild. Leaflets 7 or 9 , usually small, and simply toothed.

Stem 2 feet or more. Leaflets 5 or 7 , usually doubly toothed, downy on both sides.

Irickles, at least the larger ones, more or less curved, and dilated at the base.

Styles slightly protruding from the mouth of the calyx in a dense tuft, but not united. Stem scarcely trailing.

Calyx-tube globular, more or less prickly or bristly.

Calyx-tube ovold or oblong, without prickles or bristles. Leafiets very glandular, doubly toothed .

Leaflets without glands, or with very few on the edges only, simply or rarely donbly toothed

1. R. pimpinellifolia

2. R. villosa.

tyles nnited in a column, protruding from the calyx. Stem very tralling

2. R. villosa.

3. $R$. rubiginose.

4. R. canina.

5. R. arvensis. 
The most common exotic Roses in our cottage gardens are the Cabbage Rose and Moss Roses, varieties of the $R$. centifolia, of uncertain origin (perhaps not distinct from the $R$. gallica, from central and southern Europe); the Ayrshire Rose, a cultivated variety of the south European $R$. sempervirens; and the China Roses, varieties of the Asiatic $R$. indica; but several other species from Europe, Asia, and North America, are also in general cultivation, and are the parents of numerous garden hybrids.

1. R. pimpinellifolia, Linn. (fig. 329). Burnet or Scotch R.-A small, erect, very much branched shrub, usually under a foot high when wild, and seldom above 2 feet in cultivation, usually armed with numerous unequal, mostly straight, rather slender prickles, often more or less intermixed with glandular hairs. Leaflets small, 7 or 9 to each leaf, glabrous or with a minute glandular down; the teeth simple, or very rarely again toothed. Flowers rather small, white or pink, solitary at the end of the short branches; the floral stipules small. Calyx globular or slightly ovoid, and smooth; the segments lanceolate, almost always entire. Carpels all sessile, with free styles. Fruit black, or rarely red, globular or nearly so, crowned by the persistent segments of the calyx, $R$. spinosissima, Linn.

In dry, bushy wastes, either near the sea or on dry, heathy hills, widely spread over Europe and temperate Asia, ascending occasionally to considerable elevations, but not extending to the Arctic regions. Common in Scotland and in several parts of England and Ireland, generally not far from the sca. Fl. spring or early summer, and sometimes again later. This is the origin of the Scotch Roses of our gardens.

2. R. villosa, Linn. (fig. 330). Downy R.-In its ordinary state this is distinguished from the downy varieties of $R$. canina chiefly by the globular fruit, more or less covered with small, fine prickles, which are seldom entirely wanting. It is usually more erect and bushy, the prickles of the stem straight or but slightly curved; the leaflets softly downy on both sides, and almost always doubly toothed. Calyx-segments long, and often expanded near the top, sometimes all entire, sometimes, as in $R$. canina, some of them more or less pinnately lobed. Flowers white or pale pink. R. tomentosa, Sm.

In hedges and thickets, in Europe and western Asia, and chiefly in the north, or in the mountain districts of the south. Generally distributed over Britain, but chiefly in Scotland, northern and western England, and Ireland. $F l$. early summer. The $R$. pomifera from continental Europe appears to be a variety of this species, which, although generally very distinct, seems in some localities to pass into forms of R. canina.

3. R. rubiginosa, Linn. (fig. 331). Sweetbriar.-Very nearly allied to $R$. canina, but in its typical state, as cultivated in our gardens, easily recognised by the aromatic scent of the foliage when rubbed. This proceeds from small glands, copiously scattered on the leafstalks and the under side and edges of the leaflets, often giving the foliage a rusty bue. In the wild state the scent is often very faint, although the glands are still numerous. The plant is usually more slender than $R$. canina, the prickles curved or hooked, often intermixed with glandular hairs; the leaflets rather small, and almost always doubly toothed : the flowers pink, usually solitary, rather smaller than in $R$. canina 
Fruit ovoid or oblong, smooth, or rarely bearing a very few small prickles. $R$. micrantha, Sm.

In hedges and thickets, in central and southern Europe and central Asia, extending northwards into Scandinavia. In Britain, chiefly in southern and eastern England, apparently rare in northern and western England, Scotland, and Ireland. Fl. early summer.

4. R. canina, Linn. (fig. 332). Dog R.-Rootstock woody, frequently producing suckers. Stems of several years' duration, often the first year erect and simple to the beight of 3 or 4 feet; the flowering stems of two or more years branched, rather weak and straggling, attaining 6 or 8 feet in length, usually glabrous, and without glands, armed with curved or hooked prickles. Leaflets 5 or sometimes 7 , ovate, nsually simply toothed and glabrous, or downy on the nnder side, and then often doubly toothed. Flowers pink or white, usually sweet-scented, solitary or 3 or 4 together at the ends of the branches; the stipules of the undeveloped floral leaves forming elliptical bracts. Fruit ovoid or rarely nearly globular, without bristles, although there are often a few on the pedicels; the 5 divisions of the calyx persistent, spreading or reflexed, either all dilated at the top and entire, or more frequently 1 pinnate on both sides, 2 on one side only, and the other 2 entire. Styles free, but collected in a dense hairy mass scarcely protruding from the orifice of the calyx-tube. Central carpels always distinctly stalked, according to Koch, a character which requires further verification. $R$. ccesia, Sm.

In hedges and thickets, the commonest Rose throughout Europe and Russian Asia. Abundant in Britain. Fl. summer, rather early. It varies considerably in the foliage, either quite glabrous or more or less downy, especially underneath, and often glandular at the edges, but never so much so as in $R$. rubiyinosa, nor so downy as in $R$. villosa, from which it is usually readily distinguished by the prickles and the fruit. The plants usually named $R$. collina, Eng. Bot., or $R$. systyla, Bast., appear to be generally reducible to $R$. canina; the character derived from the free or cohering styles is sometimes deceptive. [These are referred to arvensis by Mr. Baker, the first authority on the genus.]

5. R. arvensis, Linn. (fig. 333). Fiehi $R$. - A much more trailing plant than $R$. canina, often extending to many feet, with slender branches. Foliage and prickles nearly as in that species, but the leaflets are usually more glabrous and shiniig on the upper side, rarely slightly downy. Prickles usually small, and much hooked. Flowers white and scentless, usually 3 or 4 together at the end of the branches, rarely solitary. Fruit globular or nearly so, without bristles; the calyx-divisions mostly entire, and falling off before the fruit is ripe. Styles usually united in a column protruding from the orifice of the calyx-tube, and the carpels all quite sessile, but neither of these characters appear to be quite constant.

In hedges and thickets with $R$. canina, in western and central Europe, and often as common, but not extending so far to the north, nor apparently into eastern Europe. Abundant in England and Ireland, but becomes scarce in Scotland. Fl. summer, lasting much later thun K. canima. 


\section{PYRUS. PYRUS,}

Troes or shrubs, with entire or pinnately divided leaves, and showy flowers, either proceeding, with a few leaves, from buds or spurs on a former year's wood, or in simple or branched corymbs at the ends of the year's shoots. Calyx-tube adhering to the ovary, the limb with 5 small divisions. Petals 5. Stamens numerous. Styles 5 or fewer. Fruit forming with the calyx a fleshy mass, divided in the centre intc 5 or fewer cells of a leathery or cartilaginous consistence, each cell containing one or two seeds or pips.

A genus of several species, widely spread over the northern heml. sphere, but chiefly in central Asia and southern Europe. This and the tliree following genera, although nniversally distinguished by modern botanists, are nevertheless separated only by characters of little importance and difficult to appreciate. The structure of the flowers is the same in all; the number of styles is variable, the distinction consists chiefly in the consistency of the lining of the cells of the ripe fruit. In Pyrus it is cartilaginous or leathery, so that the fruit can be cut across with a knife; in the three other genera the cells are hard and bony, and tend to separate from each other into distinct nuts. 'The following analytical table includes the British species of all four.

Nowers solitary or few together, in simple bunches. Lesves undivided.

Calyx-segments long and leafy. Fowers solitary, sessile . XVII. MrSPILUS.

Calyx-segments small. Howers several together.

Hlowers small, drooplng. Leaves entire, white nnderneath

Wowers showy, erect. Leaves toothed.

Styles combined at the base. Frult globular . - - 2. P. Malus,

Styles distinct. Fruit pear-shaped : : 1. P. comnmunis.

Flowers in branched corymbs. Leaves often cut or divided.

Leaves simple, toothed, lobed, or pinnate at the base only.

Ieaves very whito underneath, with a dense cotton . . 3. P. Aria.

Leaves green or loosely hairy underneath.

Leaves large, broad or almost cordate at the base, more or less pinnately lobed

Lesves narrowed or wedge-shaped at the base, $3-$ or 5 lobed

Lesves pinnately divided to the midrib into several pairs of distinct, nearly equal segments or leaflets

\section{P. torminalis.}

XV. Crateguus.

5. P. Aucuparia.

Several others are cultivated in onr gardens for their fruit or for orna. ment, especially the Quince ( $P$. Cydonia), the $P$. japonica, the Siberian Crab (P. prunifolia), \&c.

1. P. communis, Linn. (fig. 334). Pear-tree.-In favourable cir. cumstances the Pear will form a handsome tree of considerable elevation, of a somewhat pyramidal shape, with dense foliage, and showing all its flowers on the ontside; but it may often be seen as a low scrubby tree or mere bush. Leaves stalked, ovate or obovate, simple, bordered with numerous small teeth, glabrous or loosely covered, when young, with a slight down. Flowers rather large, of a pure white, on pedicels of about an inch long, in very short racemes or bunches of 6 to 10 , on the wood of a former year. Divisions of the calyx narrow and pointed. Stryles long. and distinct from the base. The fruit is so well known as to have given its name to the peculiar shape it retains through nearly the whole of its numerous cultivated varieties. 
In woods and hedgerows, in the temperate regions of Kurope and Asia, extending northwards into southern Sweden. Scattered over Britaln, but in so many instances escaped from cultivation, that it cannot be affirmed to be really indigenous. Fl. spring. $[P$. cordata, Desv. ( $P$. Briggsii, Syme), is a curious form found, apparently wild, in Cornwall, with more ovate leaves, and very small fruit.]

2. P. Malus, Linn. (fig. 335). Crab-apple.-The Apple-tree never grows to the height of the Pear, and assumes a more spreading shape. The leaves are very nearly the same, but generally downy underneath, with a shorter and stouter stalk. The inflorescence is also the same, except that the peduncles issue from nearly the same point, instead of being arranged in a short raceme along a common axis ; the divisions of the calyx are broader and downy, the flowers often assume a pinkish hue, the styles are shortly united at the base, and the fruit is nearly globular, and flat or hollowed at the base by the stalk.

As widely spread as the Pcar-tree over Europe and western Asia, it extends farther northward into Scandinavia. Equally scattered over Britain, but with more probability of its being a true native. $F l$. spring. In a wild state it produces the small acrid-fruited Crab Apple, but the Apples, Pippins, Codlins, \&c., of our orchards all belong to the same species.

3. P. Aria, Ehrh. (fig. 336). Beam-tree.-Often a mere shrub, but growing into a tree of moderate size, with a rather broad head; the inflorescence, the young shoots, and the under side of the leaves covered with a soft, white cotton. Leaves ovate or obovate, green and glabrous on the upper side, always sharply toothed, sometimes undivided, sometimes more or less pinnately lobed; the lobes rounded at the top, and not acuminate as in $P$. torminalis. Flowers white, in corymbs at the ends of short, leafy branches, but not near so numerous as in $P$. Aucuparia, and rather larger, the lateral peduncles bearing seldom more than 3 or 4 . Styles visually 2 only. Berries globular or ovoid, and red.

In woods, in central Europe, and in the mountain-ranges of southern Europe and central Asia, extending eastward to the Altai and Himalaya, and northward into Scandinavia. Generally distributed over Britain, but more frequent in England and Ireland than in Scotland. Fl. spring or early summer. The more or less cut-leaved varieties are sometimes considered as species, under the names of $P$. intermedia, latifolia, scandica, pinnatifida, and fennica; these are not uncommon in the north of Europe, and are occasionally found in the north of England, Ireland, and Scotland; and some are supposed to be hybrids between Aria and Aucuparia.

4. P. torminalis, Ehrh. (fig. 337). Wild Service-tree,-A tall shrub or moderately-sized tree, with the inflorescence and under side of the leaves, when young, clothed with a loose down, which disappears as they grow old. Leafstalks slender; leaves broad, and divided to near the middle into a few broad, pointed lobes, bordered with small teeth. Flowers in corymbs at the ends of short leafy branches, white, fewer and larger than in $P$. Aucuparia; more numerous and rather smaller than in P. Aria Styles usually 2, united to above the middle. Berries ovold or globular, small and brownish.

In woods, in central and southern Europe to the Cancasus, scarcely 
extending into northern Germany. In Britain only in southern and central England. $F l$. spring.

5. P. Aucuparia, Gærtn. (fig. 338). Rowan-tree, Mountain Ash.A moderate-sized tree, distinguished from all the foregoing by the rcgularly pinnate leaves. Leaflets 11 to 19 , in pairs along the common stalk, with a terminal one at some distance from the last pair; all narrow-oblong, toothed, from 1 to near 2 inches long, glabrous or nearly so above, more or less downy underneath. Flowers white, rather small, but very numerous, in showy corymbs at the ends of short leafy branches. Peduncles and calyx more or less downy. Styles rather short, usually 3, almost glabrous and free from the base. Berries numerous, small, globular, of a bright red.

In woods, throughout Europe and Russian Asia, especially in moun. tainous districts and at high latitudes, where it shrinks into a stunted shrub. Generally distributed over Britain in a wild state, besides being much planted. Fl. spring or early summer. The cultivated Service-tree ( $P$. domestica) has precisely the foliage of $P$. Aucuparia, of which it is believed by some to be a variety produced by cultivation. The flowers are rather larger and the styles often woolly, but the ouly real distinction is in the fruit, which is very much larger, assuming the form of a little pear. It has been inserted in Britlsh Floras on a single tree in the furest of Wyre, near Bewdley, which has, however, been in all probability planted there.

\section{CRAT EgUS. HAW'THORN.}

Shrubs, seldom growing into trees, mostly armed with stont thorns formed of abortive branches, and differing from Pyrus only in the hard bony consistence of the cells of the fruit.

The genus is, like Pyrus, spread over the temperate regions of the northern hemisphere, but the species are more vumerous in North America than in Europe and Asia. Among those most frequently cultivated in our shrubberies and gardens are the $C$. pyracantla from south-eastern Europe, and the C. Crus-galli, and some other North American ones. The evergreen $C$. glabra, from China, now forms the genus Photinia.

1. C. Oxyacantha, Linn. (fig. 339). Mawthorn, May, Whitethorn.A thorny shrub or small tree, glabrous or more or less downy on the calyxes and young foliage. Leaves stalked, narrowed at the base, and more or less divided upwards into 3 or 5 lobes or segments, which are irregularly toothed or even lobed. Flowers white or pink, sweetscented, in sessile corymbs on short leafy branches. Petals broad. Styles 1, 2, or 3. Fruit red, globular or ovoid, crowned by the short divisions of the calyz, and containing a hard, bony, 1- or 2-celled nut, each cell with a single seed.

In woods, thickets, and hedges, throughout Europe and central and Russian Asia, except the extreme north. Abundant in Britain, and universally cultivated for artificial hedges. Fl. spring or early summer. It varies much in the form of its leaves, the down of its foliage and calyx, the number of styles, and the colour and size of the flower and fruit. [A variety with more deeply cut leaves, pabescont calyz and smaller later fruits of 1 carpel, is the $C$. monogyna, Jacq.] 


\section{COTONEASTER. COTONEASTER.}

Shrubs, with leaves usually small and entire, and rather small flowers, either solitary on short peduncles, or 4 or 5 together in short drooping racemes; the generic characters those of Cratcous, except that the cells of the fruit form as many nuts, distinct from each other, but cohering to the inside of the fleshy calyx.

The species are few, chiefly from eastern Europe, the Himalaya, or central Asia, with a few North American ones.

1. C. vulgaris, Lindl. (fig. 340). Cummon C.-An irregularly growing tortuous shrub, with a dark ruddy bark; the young shoots and under side of the leaves covered with a short, dense, white cottony down. Leaves shortly stalked, small, ovate or orbicular, entire, glabrous on the upper side. Flowers greenish-white, small, solitary or few together, in short drooping racemes, on very short leafy branches or buds. Calyx glabrous, with short broad teeth. Styles usually 3 . Fruit small, reddish.

In rocky situations, chicfly in limestone regions, in central and southern, and especially eastern Europe, and in central and Russian Asia, extending to the Arctic Circle, and ascending high up into mountain-ranges, even to the edges of glaciers. In Britain, only snown on the limestone cliffs of the Great Orme's Head. Fl. spring.

\section{MESPILUS. MEDLAR.}

A single specles, distinguished as a genus from Cratcegus on account of its large flowers, with more foliaceous divisions to the calyx, and of its fruit, of which the bony cells are more exposed at the top of the fruit, and more readily separable from each other.

1. M. germanica, Linn. (fig. 341). Common M.-A slirub or small tree, more or less thorny when wild, but losing its thorns in cultivation. Leaves undivided, nearly sessile, lanceolate or oblong, with very small teeth, usually downy, especially beneath. Flowers large, white or slightly pink, solitary and sessile on short leafy branches. Styles glabrous and distinct, usually 5. Fruit nearly globular or pear-shaped, crowned by a broad hairy disk, from wheuce the 5 bony cells very slightly protrude.

In hedges and thickets, common in southern Europe to the Caucasus, extending more or less into central Europe, but in many cases only as escaped from cultivation. In Britain, apparently wild in several localities in southern England, but probably not truly indigenous. $\mathrm{Fl}$. spring.

The Calycanthus, occasionally planted in shrubberies, and Chimonanthus, often trained against walls, belong to the small North American and Asiatic Calycanthus family, allied on the one hand to Rosacece, on the other to Magnoliacece. 'The common Myrtle, a south European shrub, is one of the very large tropical family of Myrtaces, with the indefinite perigynous stamens of the Rosacece, but with opposite leaves, and a completely syncarpous inferior ovary. 


\section{ONAGRACEE. THE CRNOTHERA FAMILY.}

Herbs, or, in some exotic genera, shrubs, with the leaves, especially in the lower ones, frequently opposite, almost always undivided (except when immersed in water), and toothed, without stipules. Flowers in terminal spikes or racemes, or the lower ones solitary in the axils of the leaves. Calyx-tube adhering to the ovary, sometimes prolonged considerably above it; the limb of 4 or sometimes 2 lobes, not overlapping each other in the bud. Petals as many, inserted on the calyx below its lobes, or occasionally wanting. Stamens 8,4 , or 2 , inserted with the petals. Styles simple or divided at the top into 2 or 4 stigmas. Ovary inferior, of 2 or 4 cells, in all British genera. Fruit various, capsular in the British genera. Seeds usually small, without albumen.

A considerable Order, ranging over the whole world, but in the greatest variety in North America. It is readily known amongst European Calyciflores with an inferior syncarpous ovary, by the parts of the Hlower being all in twos or in fours. The small-flowered genera with sessile stigmas, included in the Order in the first edition of this work, are now separated under the name of Haloragea.

Stamens 8. Petals 4.

Howers purplish-red, pink, or white. Capsule long. Seeds with a tuft of hairs.

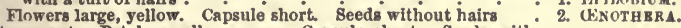

stamens 4. Petals small or none. Capsule short. Seeds with: out hairs stamens 2. Petals 2, cleft. Capsule small, hispid. 'Sceds 1 or 2 . 1. CIROAA.

The North American Clarkias, Zauschneria, and Gaura, of our flowergardens, and the South American Fuchsias of our plant-houses, all belong to the Enothera family.

\section{EPILOBIUM. EPILOBE.}

Herbs, mostly erect, with annual flowering stems, either with a creeping perennial rootstock, or, in the small-flowered species, becoming perennial by means of scions or offsets formed in autumn at the base of the decaying stem. Leaves opposite, or irregularly scattered. Flowers pink or red, rarely white. Limb of the calyx 4-cleft. Petals 4. Stamens 8. Ovary and capsule long and narrow, 4-celled. Style distinct, with a club-shaped or 4-lobed stigma. Seeds numerous, bearing a tuft of long hairs.

The genus is diffused over nearly the whole of the globe, from the extreme Arctic regions of both hemispheres to the tropics. The numerous forms the species assume in every variety of climate [together with the frequent hybrids], make it exceedingly difficult to define them upon any certain principle, and botanists seldom agree as to the number they should admit. Those here adopted are the most marked among our British forms; but in some instances intermediates are to be met with which will be found very puzzling. In all cases the style must be 
carefully observed, if possible when fresh, and a note made whether the stigma is entire or lobed.

Flowers somewhat irregular, in long, terminal, leafless racemes. Petals spreading from the base, mostly entire. Flowers regular, axillary or in short racemes, leafy at the base.

1. E, angustifolium. Petals erect at the base, mostly notched.

Stigma deeply 4-lobed.

Stem often 3 to 4 feet. Flowers large. Leaves elasping the stem

8tem seldom above $\dot{2}$ feet. Leaves, at licast the lower ones, shortly stalked.

Leaves lanceolate, the middle ones sessile. Plants softly hairy.

Ieaves ovate-lanceolate or ovate, nostly stalked. Plant glabrous or slightly hoary

Stigma club-shaped, entire (or very shortly 4 -lobed in $\mathrm{F}$. rosemim).

stem marked with 2 or 4 raised lines, dccurrent from the lower or all the leaves.

Ieaves lanceolate, sessile. Buds erect

leaves shortly stalked. Buds ereet or sllghtly nodding

Stem cylindrical. Decurrent lines none or faint. Buds nodding.

Alpine plants, not 6 inches high. Ieaves ovate. Leaves small, mostly entire. Plant little branched. leaves broad, toothed, an inch or more long. I'lant much branched

Iowland plant, often a foot high or more. Leaves narrow, nearly entire.

2. E. hirsutum.

3. E. parviflorum.

4. E. montanum.

6. F. tetragonum

5. E. roseum.

9. E. alpinum.

8. E. alsinefolium.

7. E. palustre.

1. E. angustifolium, Linn. (fig. 342). French I'illow, Rosc-bay.A handsome plant, simple or scarcely brancher, 2 or 4 feet high, glabrous or slightly hoary, but never hairy. Rootstock creeping. Leaves shortly stalked, lanceolate, entire or with very minute distinet teeth. Flowers large, purplish red, in long terminal racemes; the petals slightly unequal, entire, and spreading from the base; the stamens and styles inclined downwards. Stigma deeply 4-lobed. Pod 1 to 2 inches long, more or less hoary.

On moist banks, and in moist open woods, chiefly in light soils, in Arctic and northern Europe, Asia, and North America, extending into the mountainous districts of central Furope and Asia. Widely spread over Britain, but not common, and in many places introduced. $F l$. summer. [A cultivated forin with shorter capsules, E. brachycarpum, Leight., oceurs as a garden eseape.]

2. E. hirsutum, Linn. (fig. 343). Great Willon-herb, Codlins-andcrcam.- Stems stout and branched, 3 or 4 or even 5 feet high, the whole plant softly hairy. Leaves lanceolate, clasping the stem at the base, and bordered with small teeth. Flowers large and handsome; the petals erect at the base, spreading upwards, and deeply notched. Pod very long, quadrangular, and hairy.

On the sides of ditches and rivers, and in wet places, throughout Furope and central and Russian Asia, except the extreme north. Abundant in England, but less common in Scotland. Fl. summer.

3. E. parviflorum, Schreb. (fig. 344). Hoary K.-Some specimens of this plant look like the $\boldsymbol{E}$. hirsutum on a small scale, others approach $E$. montanum. It is distinguished from the former by its smaller stature and much smaller flowers. The lower leaves, also, and sometimes the upper ones, are shortly stalked; the middle ones usually eessile, but scarcely clasping the stem. From $E$. montanum there is 
little to separate it but the soft hairs with which it is clothed, the narrower (mostly alternate) leaves with shorter stalks, and the rather larger flowers. But none of these characters appear to be quite constant, and it may possibly prove to be a mere variety of $B$. montanum.

In Europe and western Asia, but not so common as $E$. montanum, and generally found in wetter situations. It has nearly the same range over Britain, excepting the extreme north of Scotland. $F$. summer. [ $E$. rivulare, Wahlb., is an almost glabrous form, and $E$. intermedum, Merat., one with all the leaves alternate.]

4. E. montanum, Linn. (fig. 345). Broad-leaved B.-Stems erect, simple or slightly branched, from 6 inches to a foot or more high, cylindrical, without any decurrent lines or angles, and usually glabrous or slightly hoary; the autumnal offsets usually short, and sometimes sessile. Leaves shortly stalked, or sometimes almost sessile, ovate or broadly lanceolate, and toothed. Flower-buds erect or slightly nodding; ovary downy, tapering into a stalk at the base, and crowned by a calyx 2 or 3 lines long, divided below the middle into 4 reddish lobes. Petals pink, usually nearly twice as long, but sometimes scarcely exceeding the calyx, always deeply notched. Style divided at the top into 4 oblong, spreading, stigmatic lobes. Pod slender, 2 to 3 inches long.

In waste and cultivated places, roadsides, woods, \&c., throughout Europe and Russian and central Asia, and apparently in many other parts of the globe. Very abundant in Britain. Fl. summer. It varies much in the size of the flowers, which are in dry situations often nearly as stnall as in $E$. roseum, from which it is then chiefly distinguished by the deeply-cleft stigma. [ $B$. montanum has usually opposite leaves; the closely allied $B$. lanceolatum, Sebast. and Maur., which occurs in some of the southern counties of England, has these mostly alternate. It is sometimes regarded as a variety of $B$. roseum.]

5. E. roseum, Schreb. (fig. 346). Pale E. - An erect plant, glabrous or hoary when young, much resembling at first sight a small-flowered $E$. montanum, but the leaves are narrower, on longer stalks, the lower ones generally opposite, with a raised line descending more or less along the stem from the junction of the leafstalk on each side, almost as in $E$. tetragonum. They vary from ovate-lanceolate to narrow-oblong, and from 1 to 3 inches in length. Flowers in a short, terminal, leafy, branched raceme or panicle; the limb of the calyx scarcely 2 line long, and the notched petals not mnch longer. Buds erect or slightly nodding, the style ending in a club-shaped stigma, either entire or very shortly 4-lobed. Pods from 1 to 2 inches long.

Along ditches, and in moist situations, in Europe and Russian Asia, but not so common as either the preceding or the following species, nor extending so far to the north. Scattered over several parts of Britain, from Edinburgh southwards. It is often confounded with $E$. montanum or $\boldsymbol{E}$. parviflorum. $F$. summer.

6. E. tetragonum, Linn. (fig. 347). Square $B$.-Stems erect, often much branched, 1 to 2 feet high, glabrous or hoary with a very short down, and more or less angular from raised lines descending on each side from the margins $\mathrm{cf}$ the leaves; the autumnal offsets often long and thread-like, with a fleshy bud at the extremity, more rare'y short and scaly or leafy, as in $E$. montanum. Leaves sessile or newrly so, barrow, and toothed. Flowers small, in terminal leafy racemas. the 
buds erect, the petals deeply notched. Stigma entire and club-shaped. Pod often very long.

In wet ditches and watery places, throughont Europe, Russian Asia, and a portion of North America, and extending to the Arctic Circle. and very nearly allied to a common Australian species. Common in Britain. Fl. summer. [The following forms are more or less well marked-

a. E. tctragonum proper. Scions formed in autumn and bearing rosulate leaves, leaves narrow shining above, capsule 2 to 4 inches long.

b. $E$. obscurum, Schreb. (E. virgatum, Gren. and Godr.). Scions very slender, formed in summer with few opposite leaves, leaves broader, opaque above, capsule 1 to 2 inches long.

c. E. Lamyi, Wirtg. Scions as in a, but stem-leaves narrowed into short petioles.]

7. E. palustre, Linn. (fig. 348). M/arsh E.-Very near E. alpinum, and by some believed to be a lowland form of it. It has the same flender scions, entire or not much toothed leares, short terminal racemes, small flowers, nodding buds, and club-shaped, undivided stigma; but its stature is taller, often a foot or even 2 in height, and the leaves are longer and much narrower, often linear. It sometimes also comes very near the narrow-leaved forms of $E$. roscum and $E$. tctragonum, but has the buds much more nodding, and the decurrent lines on the stem are either very faint or entirely wanting.

in wet, boggy places, and ditcbes, throughout Europe and Russian Asia, but more especially in the north, extending into the A retic regions. Generally distributed over Britain, but not very common. $\mathrm{Fl}$. summer.

8. E. alsinefolium, Vill. (fig. 349). Chickweed $E$.-Closely allied to, and perhaps a mere variety of, $E$. alpinum, but much more lnxuriant, and frequently branched, though seldom more than 6 inches high. Leares very shortly stalked, ovate, and toothed, and an inch long or more, like those of $E$. montanum, but of a thicker consistence. Flowers larger than those of $E$. alpinum, forming very short, leafy racemes. Buds nodding, and stigma club-shaped, as in E. alpinum. The autumnal scions are more frequently undergronnd than green and leafy.

Along alpine rivulets and springs, in all the great mountain-ranges of Furope and western Asia. Very common in the Scoteh Highlands, extending into the mountains of North Waies and north-western England, but not recorded from Ireland. Fl. summer.

9. E. alpinum, Linn. (fig. 350). Alpine E.-This little plant is seldom more than 4 or 5 inches high, and often much shorter, decumbent and mnch branched at the base, glabrous or nearly so; the autumnal scions usually above gronnd, slender and leafy, rarely short and tufted. Leaves more or less stalked, small, ovate or lanceolate, nsually obtnse, and entirely or obscurely toothed. The stems have not the raised decurrent lines of $E$. roseum, bnt are only marked oceasionally with faint downy lines. The flowers, although as small as in $E$. palustre, appear large in proportion to the size of the plant, they are few in the axils of the upper leaves, forming short, leafy racemes. Bnds nodding. Petals notched. Stigma club-shaped, entire or nearly so. Pod 1 to 2 inches long, narrowed at the base into a long stalk. [The stolons are rosnlate, but $\mathscr{E}$. anagallidifolium is a form in which they are olongate.] 
Along alpine rills, and wet places in the high mountain-ranges or Arctic regions of Europe, Russian Asia, and northern America. Abundant in the Scotch Highlands, but very local in England, and does not extcnd into Wales or Ireland. Fl. summer.

\section{EENOTHERA. ENOTIIERA.}

Herbs or undershrubs, with alternate leaves, and yellow, red, or purple flowers, either axillary or in terminal spikes or racemes. Calyx-tube prolonged above the ovary, 4-lobed at the top. Petals 4. Stamens 8. Orary and capsule 4-celled. Style distinet, with a capitate or 4-lobed stigma. Seeds numerons, without any tuft of cottony hairs.

A large American, and chiefly $N$ irth American genus, from whence several species are cultivated in our flower-gardens.

1. OE. biennis, Linn. (fig. 351). Evening Primrose-A biennial, 2 or 3 feet high; the stems almost simple, and more or less hairy; leaves orate-lanceolate or lanceolate, slightly toothed, hoary or downy. Flowers yellow, large, and fragrant, in a long, terminal spike, often leafy at the base. Ovary sessile, about 6 to 8 lines long, the tube of the calyx at least an inch longer, the petals broad and spreading. Capsule oblong.

A North American plant, long cultivated in European flower-gardens, and now naturalised on river banks and other sandy places in western Europe. Apparently fully established in Lancashire and some other counties of Fngland. Fl. summer and autumn, opening in the evening.

$[$ E. odorata, Jaç., which has linear-lanceolate waved leaves and a long cylindric capsule, is a Patagonian species, recently established on the S.W. coasts of England.]

\section{LUDWIGIA. LUDWIGIA.}

Marshy or almost aquatic herbs, with opposite leares, and small flowers solitary in the axils of the upper leaves. Limb of the calyx of 4 short divisions. Petals very small, or, in the British species, none. Stamens 4. Ovary and capsule 4-celled. Style distinct, with a capitate stigma. Seeds numerous, withont any tuft of hairs.

The genus consists of a considerable number of species, widely diffused over the hotter as well as the temperate regions of the globe, in the New World as in the Old. In their general habit and small flowers they resemble Peplis, and some other semi-aquatic Lythrariex. but the inferior ovary and some other characters are entirely those of Onagracea.

1. I. palustris, Ell. (fig. 352). Marsh L.-A small glabrous annual, 3 to 6 inches high or rarely more; the lower part of the stem creeping in mud or floating in water, branching and rooting at almost every node. Leaves ovate and entire, 6 lines to an inch long. Flowers closely sessile, with a small green calyz, no petals, very small stamens, and an exceedingly short style, with a comparatively large capitate stigma. The capsule rapidly enlarges, when ripe, about 2 lines long, obovate, with 4 green angles, and numeroụs minuțe seeds. Isnardịa palustrist Hinn. 
In wet ditches, bogs, and pools, in central and southern Europe, central Asia, and North America, not crossing the Baltic to the northward. In Britain only known hitherto in three localities in Hampshire and Sussex, and in Jersey. Fl. summer.

\section{CIRCEA. CIRCFA.}

Herbs, becoming perennial by creeping rootstocks from the base of the erect annual flowering stems, with opposite stalked leaves, and small flowers in terminal racemes. Limb of the calyx of 2 divisions, turned back whilst flowering. Petals 2. Stamens 2. Style distinct, with a thick stigma. Ovary and capsule globular, pear-shaped, or oblong, 2-or 1-celled, with 1 seed in each cell.

This pretty little genus consists of three or four species, spread over Europe, temperate Asia, and North America, all so nearly resembling each other, that, in the opinion of some botanists, they are varieties of one.

Plant more or less hairy. Capsule pear-shaped, with 2 seeds . Leaves perfectly glabrous. Capsule oblong, with 1 seed .

1. C. lutetiana.

1. C. Lutetiana, Linn. (fig. 353). Common C., Enchanter's Nightshade. - Stems erect or shortly decumbent, and rooting at the base, 1 to $1 \frac{1}{2}$ feet high, and, as well as the leaves and racemes, more or less clothed with very short whitish hairs. Leaves on rather long stalks, broadly ovate or heart-shaped, 2 to 3 inches long, rather coarsely toothed, of a thin texture. Hlowers white or pink, in elegant, slightly branched, leafless, terminal racemes. Pedicels abont 2 lines long, turned down after flowering. Capsule small, pear-shaped, covered with stiff, hooked hairs, forming a small burr. Seeds 2 .

In shady situations, thronghout Europe and temperate Asia, except the extreme north, and in North America. Abundant in England and Ireland, rarer in Scotland, but extending to Aberdeenshirc. Fl. summer.

2. C. alpina, Linn. (fig. 354). Alpine C.-Closely resembles the common species, of which it may be a mountain variety, but is smaller in all its parts, and usually quite glabrous, except the fruit. It is seldom above 6 inches high ; the leaves are thinner, and often glossy ; the capsules smaller, less bairy, much narrower, and usually contain only a single sced, owing to the almost constant abortion of one of the cells.

In woods, and stony places, chiefly in mountain districts, in Enrope and all across Russian Asia, often ascending to great altitudes, and penctrating farther northward than C. lutetiana, but apparently not an Arctic plant. Abundant in Scotland, extending into the midland countics of England, but disappearing in the south; in Ireland it is both in the north and in Cork connty. Fl. summer. A large variety, or hybrid, has sometimes been described as a distinct species, under the name of $C$. intermedia, Ehrh., a name also occasionally given to smaller states of C. lutetiana. 


\section{LYTHRARIEA. THE LYTHRUM FAMILY.}

Herbs, or, in some exotic genera, shrubs or trees, with leaves mostly (at least the lower ones) opposite, entire, and without stipules; the flowers either axillary or forming terminal racemes or spikes, more or less leafy at the base. Calyx free, tubular or campanulate, with as many, or twice as many, teeth as there are petals. Petals 4, 5, or sometimes more, rarely deficient, inserted at the top of the tube of the calyx, crumpled in the bud. Stamens equal to or double the number of the petals (or, in some exotic genera, indefinite), inserted in the tube of the calyx, often lower down than the petals. Style single. Ovary free from the calyx, but generally enclosed within its tube, divided into 2 or more cells, each with several ovules. Capsule of a thin texture, sometimes becoming 1-celled by the drying up of the partition, containing several small seeds without albumen.

A considerable family, some of the herbaceous semi-aquatic species dispersed over almost every part of the globe, whilst the larger shrubby or arborescent ones spread over the tropics both in the New and the Old World. They come near to some Rosacea in the insertion of the stamens, the position of the ovary, the structure of the seeds, \&c., but, independently of the structure of the ovary, they are readily known by their entire leaves, the lower ones at least always opposite. They are much more allied to the splendid and extensive tropical Order of Melastomacex, which, however, has no representative in Europe, and is even but little known in our stoves.

Calyx tubular. Petals longer than its teeth . . . . . 1. Lrthrum.

Calyx shortly campanulate. Petals minute or none - : . 2. PkPLis.

Several species of Cuphea, an American genus of this family, are now generally cultivated in our flower-gardens.

\section{LYTHRUM. LYTHRUM.}

Herbs, with sessile, axillary flowers, the upper ones forming long leafy spikes. Calyx tubular, with 8,10 , or 12 teeth, 4,5 , or 6 of them being external, and much narrower than the alternate inner ones. Petals 4, 5, or 6, longer than the calycine teeth. Stamens as many, or nearly twice as many, inserted below the petals on the tube of the calyx. Ovary and capsule 2-celled. Stigma borne on a distinct style.

The genus consists of very few species, spread over the northern hemisphere of the New as well as the Old World.

8 tems 2 feet or more. Leaves all opposite or whorled. Flowers large, in a showy, terminal raceme
stems 6 or 8 inches or less. Upper leaves alternate, narrow. Flowers small, with minute petals

1. L. Salicaria.

2. I. hyssopifolium.

1. I. Salicaria, Linn. (fig. 355). Purple Loosestrife.-Rootstock perennial, with stout, annual, erect stems, 2 or 3 feet high, slightly branched, glabrous or softly downy. Leares opposite c= sometimes in threes, sessile, and clasping the stem at the base, lanceolate and 
entire, from 2 to 3 inches long. Flowers reddish-purple or pink, in rather dense whorls, forming handsome terminal spikes, more or less leafy at the base; the upper floral leaves reduced to bracts scarcely longer or even shorter than the flowers. Calyz about 3 lines long, with as many ribs as teeth, of these the outer ones are subulate, the inner ones short and broad. Petals oblong, often near half an inch long.

In wet ditches and marshy places, throughout Europe and Russian and central Asia, in Australia, and North America. Abundant in Fingland, Ireland, and southern and western Scotland, very local in the east and north. Fl, summer. [The flowers of the Purple Looscstrife are trimorphic, differing in the comparative length of the stamens and styles. Thus individual plants have-1. Long styles and medium stamens; 2. Long styles and short stamens; 3 . Medium styles and long stamens; 4. Medium styles and short stamens; 5 . Short styles and long stamens; 6 . Short styles and medium stamens. These differences are accompanied with others in the colour of the flowers, and colour and size of the pollen grains.]

2. I. hyssopifolium, Linn. (fig. 356). Hyssop L.-A glabrous annual, seldom more than 6 or 8 inches high, the stems slightly branched, and decumbent at the base, or, in starved specimens, erect and simple. Leaves sessile, narrow, and entire, barely half an inch long; the lower ones opposite, the upper ones altcrnate. Flowers small and solitary in the axils of the upper leaves; the calyx scarcely more than a line long, with minute teeth; the petals purple, about half that length.

In moist or muddy places, especially those which are occasionally inundated. Widely spread over central and southern Europe, all across central Asia, in North and South America, South Africa and Australia, but not so common in Europe as the $L$. Salicaria. In Britain it occurs in a few of the southern and eastern counties of England. Fl. summer.

\section{PEPLIS. PEPLIS.}

Small glabrous annuals, with oppositc entire leaves, and minute axillary flowers. Calyx shortly campanulate, with 6 external and 6 internal smaller teeth. Petals very minute or none. Stamens 6. Style very short, scarcely distinct. Capsule globular.

A genus of very fow species, widely spread over Europe, Asia, and Africa.

1. P. Portula, Linn. (fig. 357). Mater Purslane.-A slightly branched annual, oreeping and rooting at the base, seldom above 2 or 3 inches high, but sometimes many plants grow together in broad tufts or patches. Leaves obovate or oblong, seldom half an inch long, tapering into a stalk at the base. Flowers sessile in the axils of ncarly all the leaves. Capsules enclosed in somewhat enlarged calyx, but seldom attaining a line in diameter.

In wet ditches, and moist, watery places, in central and southern Furope to the Cancasus, extending northward to Scandinavia, but not recorded from Siberia or central Asia. Frequent in England and Ireland, loss so in Scotland. Fl, all summer. 


\section{CUOCURBITACEבE. THE GOURD FAMILY.}

Herbs with long stems, prostrate, or climbing by means of axillary tendrils; alternate, palmately-veined leaves; and unisexual flowers, either solitary or in bunches or racemes in the axils of the leaves. Calyx 5-toothed. Petals united in a single 5-lobed corolla or rarely distinct, inserted in the margin of the calyx. Stamens in the male flowers inserted on the calyx or corolla; anthers curved, forming a wavy line on the short, thick filaments, which are sometimes free, but often so combined as that the number of stamens has been differently described as $\mathbf{5}$ or $\mathbf{3}$ only, or sometimes all the filaments form but one mass. Ovary in the females inferior, divided into 3 or 5 cells. Stigmas from 3 to 5, 2-cleft, either sessile or supported on a style. Fruit succulent or juicy, either indehiscent or bursting open elastically when ripe.

A considerable Order, chiefly tropical, and more especially African, with but very few species extending into Europe or northern Asia. It is very easily recognised, as well by its foliage and tendrils as by the structure of the flowers. The only Order at all allied to it is that of the Passifloracere or Passion-fowers, almost all of them American, and chiefly tropical, but of which some species are well known among our greenhouse or stove plants. To the Cucurbitacca belong the Cunin- Nelons, Watermelons, Ciourds, Pumpkins, Vegelable Marrows, \&c., of our gar dens, most of them of very ancient cultivation, but unknown in a wild state.

\section{BRYONIA. BRYONY.}

Caly $x$ with 5 small teeth. Corolla 5-lobed. Stamens combined into 3 , of which 2 are double and 1 single. Style 3-lobed, with capitate or 2-lobed stigmas. Fruit a globular berry.

1. B. dioica, Jacq. (fig. 358). Common B.-Rootstock perennial, thick and tuberous, sometimes branched ; the annual stems climbing to a great length, and, as well as the whole plant, rough with minute hairs, containing an acrid juice, and emitting a sickening smell in drying. Tendrils simple or branched, and spirally twisted. Leaves more or less deeply divided into 5 or 7 broad angular, and coarsely toothed lobes, of which the middle one is the longest. Hlowers diocious, the males several together in stalked racemes, of a pale yellow; the corolla broadly campanulate, about half an inch diameter; the females much smaller, generally 2 together, nearly rotate, with a globular ovary. Berries réd or orange, about 1 lines in diameter, containing several flat, nearly orbicular seeds.

Common in hedges and thickets, in central and sonthern Europe to the Caucasus. Occurs in most English counties, and common in some, but rare in the north and in Wales, and does not extend into Scotland or Ireland. Fh summer. It must not be confounded with the black Bryorg, Tamus communis, a very different plant, with entire, shining lestes 


\section{CRASSULACE㞋. THE CRASSULA FAMILY.}

Herbs or shrubs, with succulent leaves, all or only the upper ones usually alternate, rarely all opposite, no stipules, and flowers in terminal racemes or cymes. Sepals $\mathbf{3}$ or more, usually 5 , sometimes 15 to 20 , cohering at the base. Petals as many, sometimes united in a single corolla. Stamens as many or twice as many, inserted with the petals at the base of the calyx. Ovary superior; the carpels as many as the petals, and free, usually with a small, flat scale at their base, and forming as many distinct capsules, each containing several seeds attached to the inner angle. Embryo straight, with a thin, fleshy albumen.

A numerous family, extending over the greater part of the globe, but particularly abounding in south-western Africa and in the rocky districts of Europe and central Asia. The exact concordance in number of the parts of the flower of the different whorls forms the most prominent character of the family, to which the succulent leaves give a peculiar habit.

Stamens 3 or 4. Plants very small, with minute flowers

Stamens twice as wany as the petals (half of them sometimes without anthers).

Petals united in a tubular corolla, longer than the calyx .

1. TILLAa.

Petals free or nearly 8o, and spreading.

Flowers mostly with 5 or 6 petals and sepals

All the flowers with more than 6 , usually 10 or 12 petals and sepals.

Among the succulent plants in our greenhouses, the Crassulas, Echeverias, Kocheas, and a few others, belong to this family, but by far the greater proportion of "succulents" form part of the Ficoulece and Cactacece, which are entirely exotic.

\section{TILLAEA. TILLAEA.}

Very small annuals, with opposite leaves, and minute flowers in the upper axils. Sepals, petals, stamens, and carpels 3 or 4 .

Besides the European species, the genus contains several from North America, central Asia, southern Africa, and Australia, most of them amongst the smallest of flowering plants.

1. T. muscosa, Linn. (fig. 359). Mossy T.-The whole plant is seldom more than 2 inches high, and usually but an inch, or even much less. although much branched, and crowded with flowers; it is usually of a reddish colour, and slender, though succulent. Leaves narrow. lanceolate or linear. Flowers solitary in each axil, or several together in little clusters. Sepals lanceolate, pointed. Petals minute and subulate. Carpels with 2 minute seeds in exch.

On moist, barren, sandy leaths and wastes, in western and southern Kurope, extending eastward round the Mediterranean, and northward to the Netherlands. Has been found in several of the southern and eustern counties of England, but not in Ireland or Scotland. Fr summer. 


\section{COTYLEDON. COTYLEDON.}

Herbs, or succulent shrubs, with scattered leaves (rarely opposite in some exotic species), and flowers in terminal racemes or panicles. Sepals 5, small. Petals combined into a single tubular or campanulate corolla, with 5 teeth or divisions. Stamens 10, inserted at the base of the corolla, but often adnate to the top of the tube. Carpels 5, each with a scale at the base.

Taking this genus in the sense in which it was understood by Linnæeus, it includes a considerable number of south-west African, besides several south European and central Asiatic species, which, with our British ones, are considered by some modern botanists as forming a distinct genus under the name of Umbilicus.

1. C. Umbilicus, Linn. (fig. 360). Pennywoort, Navelroort.-Stock perennial, almost woody. Radical and lower leaves on long stalks, fleshy, orbicular, broadly crenate, and more or less peltate. Flowering stems erect, from 6 inches to a foot high, simple or slightly branched, leafy at the base only, and bearing a long raceme of pendulous, yellowish-green flowers. Calyx very small. Corolla cylindrical, about 3 lines long, becoming afterwards somewhat enlarged, with 5 short teeth, and enclosing the stamens and carpels.

On rocks, walls, and old buildings in western Europe, extending eastward round the greater part of the Mediterranean, southwards to the Canary Islands, and northwards to Ireland, southern and western Fngland, and the south and west counties of Scotland. Fl. summer.

\section{SEDUM. STONECROP.}

Succulent herbs, sometimes woody at the base, with scattered leaves, occasionally opposite or whorled, especially at the base, or on barren stems ; and yellow, white, reddish or blue flowers, in terminal cymes or corymbs. Sepals 4 to 6 (usually 5). Petals as many, distinct. Stamens twice as many. Carpels as many as the petals, each with an entire or emarginate scale at the base, and containing several seeds.

A widely diffused genus, numerons in species, especially in central and southern Europe and central Asia, but extending also into North America, and the monntains of South America. A large number of the snialler, thick-leaved species are found on dry rocks or stony places, whence the popular name of Slonecrop applied to several of them.

Leaves flat, broad.

Flowers dicecious, with 4 sepals and petals

Howers hermaphrodite, in large corymbs, with 5 sepals and petals .

Leaves as thick, or nearly as thick, as broad.

Flowers white or reddish.

Leaves shortly ovoid or globular.

Whole plant quite glabrous

Calyx and pedicels with a few short, glandular hairs

Leaves oblong or cylindrical.

Glabrous perennial, with numerous short barren branches, and erect flowering stems .

Viscidly downy, erect annual, without barren branche : Flonoers yellow.

Ylowering stems 1 to 3 Inche hlgh. Cymes of 2 or 3 ahort branches.

Leaves ovold or globular

Lasves crlindrical or oblong
1. S. Rhodiola.

2. S. Telephium.
3. S. anglicum.

4. S. dasyphyllum.

5. S, album

6. S. villosum. 
Flowering stems at least 6 inches high. Cymes two or threa times divided.

Leaves flattened, acuminate

Leaves cylindric with a subulate tip :

9. S. rupestre.

-10. S. rejlexum.

The S. Sieboldi, from Japan, and some exotic species, are to be met with in our gardens.

1. S. Rhodiola, DC. (fig. 361). Roservot, Midsummer-men.-Stock short, thick, and almost woody; the annual stems erect, stout, simple, 6 inches to nearly a foot high. and leafy to the top. Leaves alternate, sessile, obovate or oblong, slightly toothed, from 6 lines to an inch long, the lower ones often reduoed to brown scales. Flowers dicecious, yellow or rarely purplish, forming rather dense cymes, surrounded by the upper leaves, which often assume a yellow or purple tinge; the males with 8 stamens, rather longer than the petals and sepals; the females with 4 carpels, ending in short spreading styles.

In clefts of rocks in northern and Arctic Europe and Asia, and in the higher mountain ranges of central Europe and Asia. Abundant in the mountains of Scotland, northern England, and Ireland, descending also to maritime cliffs in western Scotland. Fl. summer. The smell of the rootstuck, when drying, has been compared to that of roses, whence its name.

2. S. Telephium, Linn. (fig. 362). Orpine, Livelong.-Rootstock perennial, the annual stems hard, erect, simple, about a foot high or rather more. Leaves scattered, obovate, or oblong, and coarsely toothed; the lower ones 2 inches long or even more, and much narrowed or even stalked at the base; the upper ones often rounded at the base. Flowers numerous, purple in the British variety, forming a handsome corymb at the top of the stem. Sepals 5, short and pointed. Petals more than twice as long. Stamens 10, rather shorter than the petals.

On the borders of fields, hedge-banks, and bushy places, in northern and central Europe and Russian Asia, chiefly confined to hilly districts in the more southern portion of its area. Occurs in most of the British counties, but has been so long cultivated in cottage gardens, and is so very tenacious of life, that it is difficult to say how far it is really indi. genous. Fl. summer, rather late. [S. Fabaria, Koch, is a more slender state, with the bases of the upper leaves cuneate, and smooth carpels.]

3. S. anglicum, Huds. (fig. 363). English S.-A small perennial, seldom more than 3 inches high, and quite glabrous in all its parts; the stems decumbent and much branched at the base, with short, thick, almost globular leaves, crowded on the short barren branches, more loosely scattered and occasionally opposite on the flowering ones. Flowers white, occasionally tinged with pink, in a short, irregular cyme. Sepals short and green. Petals more than twice as long, lanceolate, and more or less pointed.

In rocky or stony places, usually not far from the sea, in western Europe, from Portugal, to southern Norway, ascending also high into the mountains of the south-west. Abundant especially along the western coast of Scotland, in Wales, and in Ireland, and appears also occasionally, but more rarely, on the eastern coasts of Fngland. $F$ summer.

4. B. dasyphyllum, Linn. (fig. 364). Thick-leaved S.-Very nearly slied to S. anglicum, but usually rather smaller, of a glaucous s:cen, 
and the flowering summits more or less viscid, with short, glardulaf hairs; the leaves thicker, and more frequently opposite; the cymes or tlowers more compact, of a dead white tinged with rose-colour; and the petals broader and not so pointed.

Much more widely spread on rocks and walls, in western, central, and southern Europe, than $S$. anglicum, but does not extend eastward to the kussian territory, nor northward into northern Germany. In Britain, only found on old walls, \&c., in southern England, and in Cork county, Ireland, where it is not really indigenous. Fl. summer.

5. S. album, Linn. (fig. 365). White S.-Stock creeping and procumbent, bearing in winter short barren stems with crowded leaves, and in summer erect flowering branches, from 4 to 6 inches high, and perfectly glabrous. Leaves scattered, oblong or cylindrical, 3 to 6 lines long. Flowers of a pure white or slightly pink, ratber small and numerous, in elegant terminal cymos or corymbs. Sepals short oval, and obtuse. Petals nearly three times as long, oblong and obtuse.

On old walls, rocks, cottage roofs, \&c., over the greater part of Europe and Russian Asia, except the extreme north. In Britiin perlaaps truly indigenous in the Malvern Hills and in Somersetshire; and Mr. Carrol reports that a variety with short thick leaves is found on the south coast of Ireland, near Cork; in other places where the species has been observed, it had probably been introduced from gardens. Fl. summer.

6. S. villosum, Linn. (fig. 366). IIairy S.-An annual, with erect, nearly simple stems, 3 to 4 inches bigh; the upper part of the plant always more or less covered with short, viscid hairs, like S. dasyphyllum. Leaves more than twice, often 4 or 5 times, as long as thick, alternate or scattered. Flowers few, of a pale, rather dingy rose colour, in a small, rather loose, terminal cyme. Sepals ovate and green. Petals ovate, about twice as long as the calyx.

In bogs and along stony rills, in the mountains of western, central, and northern Europe, frequent in northern England and the Scotch Highlands, but not recorded from Ireland. Fl. summer.

7. S. acre, Linn. (fig. 367). Wall-Pepper.-Tufts perennial and procumbent, consisting of numerous short barren stems, and erect or ascending flowering branches, from 1 to 2 or 3 inches high; the whole plant quite glabrous, assuming a yellowlsh tinge, and biting to the taste when chewed. Leaves small, thick, ovoid, or sometimes nearly globular, those of the barren shoots usually closely imbricated in six rows. Flowers of a bright yellow, in small terminal cymes. Sepals very short. Petals much longer, narrow-oblong and pointed.

On walls and rocks, in stony and sandy places, throughout Europe and Russian Asia, from the Mediterranean to the Arctic regious. Abundant in Britain. Fl. summer.

8. S. sexangulare, Linn. (fig. 368). Tastcless S.-Very near S. acre, and by some considered as a mere variety, differing only by the more slender leaves, several times longer than thick, and by the flavour said to be less acrid.

A rather scarce plant, scattered over central and eastern Euroft. Indicated in some parts of Fingland, especially on old walls, in some of she eastern counties, but it is not indigenous. Flo summer. 
9. S. rupestre, Linn. (fig. 369). Rock S.-Stock perennial and creeping, with numerous short barren shoots, I to 3 inches long; the terminal flowering stems ascending or erect, 6 inches to a foot high. Leaves linear-lanceolate, acute, flattened, and more or less extended at the base below their point of insertion into a short spur. Flowers yellow, considerably larger than in the other British species, forming a terminal cyme of 4 or 5 to 7 or 8 recurved branches, each bearing from 3 to 5 or 6 sessile flowers. Sepals short and ovate; the petals twice as long, and linear.

On old walls and stony places, in temperate and southern Europe extending northwards to southern Sweden. In Britain, it is unloubtedly wild in several of the southern and western counties of England, Wales, and in Ireland, but has besides established itself in many places where it has escaped from cultivation. Fl. summer. A slight variety has been distinguished under the name of $S$. Porsterianum, Sm., but the characters assigned, derived chiefly from the more or less crowded, closely appressed or spreading leaves of the barren shoots, are very difficult to appreciate, and appear to depend more on station than on any real difference in the plants.

[10. S. reflexum, Linn. (fig. 370). Reflexed-leaved S.-Very near S. vupestre, but usually larger, with crowded cylindric leaves ending iu a subulate tip, and larger pedicelled often bracteate flowers.

On rocks and housetops in northern and middle Europe, extending sparingly to England, Wales, and Ireland, but often an escape or relic of cultivation, especially a garden form which has reflexed green leaves on the flowering shoots; whilst the truly wild form, S. glaucum, Sm., found in Suffolk and Devon, has glabrous leaves, erect or spreading, and paler tlowers.]

\section{SEMPERVIVUM. HOUSELEEK.}

Succulent berbs, with a perennial, often woody stock, usually larger and coarser than the Scdums; the thick, succulent leaves densely imbricated on the short, often globular, barren shoots, and scattered along the erect flowering stems. Inflorescence and flowers as in Sedum, except that the parts of the flower are inuch more numerous, the sepals, petals, and carpels varying from 6 to 20 (usually 10 to 12). Stamens twice as many, but one half occasionally abortive and very small, or sometimes transformed into extra carpels. The little scales placed under the carpels are toothed or jagged, or sometimes wanting.

Besides the common one, there are a few allied specimens in central and southern Europe, some half-shrubby ones in the Canary Islands, and several in south-western Africa. Some of these have long been in cultivation among our garden succulent plants.

1. S. tectorum, Linn. (fig. 371). Houselcek.-The barren shoots form numerous, almost globular tufts, from whence, in subsequent years, arise the stont, stcculent flowering stems to the height of about a foot. Leaves viry thick and fleshy; the lower ones $I$ to $1 \frac{1}{2}$ inches long, ending in a short point, and bordered by a line of short, stiff hairs; the npper ones as well as the cymes more or less clothed with a short, viscid down. Flowers pink, sessile along the spreading or recurved branches of the cyme. Petals linear, pointed, 2 or 3 times as long as the sepals, downy cn the outside, and ciliate on the edges, like the leaves. 
In rocky situations, in the great monntain-ranges of central and southern Europe to the Cancasns, and having been very long cultivated as a curiosity, it is widely spread over northern Europe, as an introduced plant, on cottage-roofs and old walls. It is only under such circumstances that it is to be met with in Britain. Fl. summer.

\section{RIBESIACE无. THE RIBES FAMILY.}

This family is identical with the Linnean genus libes, and nearly allied to the exotic shrubby genera of Saxifragacea, but maintained as distinct on account of the succulent fruit with parietal placentas, and the union of the styles at the base, indicating some approach to the Cactacece. [The genus Ribes is included under saxifragacese by many authors.]

\section{RIBES. RIBES.}

Shrubs, with alternate, palmately veined or lobed leaves, no stipules, and axillary flowers in racemes, or rarely solitary. Caly $x$ adnate to the ovary at the base, the limb divided into 4 or 5 segments. Petals as many, very small and scale-like, inserted at the base of the segments of the calyx. Stamens as many. Ovary inferior, 1-celled, with many ovules inserted on 2 parietal placentas. Style deeply divided into 2 or 4 lobes. Fruit a berry, filled with juicy pulp, in which the seeds are suspended by long stalks. Albumen horny, with a snall, straight embryo.

A genus spread over the whole of the temperate regions of the northern hemisphere. The species are most numerous in north-western America, and a small number extend along the Andes towards the southern extremity of that continent.

Stens prlekly. Peduncles 1-or 2-flowered . . . 1. R. Grossularia. Stems unarmed. Flowers in racemes.

fluwers all complete.

Leaves Inodorous. Pedicels all short. Fruit rell or white . 2. R. rubrum.

Leaves strongly scented. Lowest pedicels of each ruceme longer than the upper ones. Fruit black.

Flowers diceclous. Fruit red $\quad \cdot 4 . R$ nigrum.

The Scarlet Ribes and several others, now frequent in our shrubberies, are natives of north-western America.

1. R. Grossularia, Linn. (fig. 372). Gooseberry. -A much branched shrub, 3 or 4 feet high, with numerous palmately spreading prickles, either single or 2 or 3 together. Leaves small, orbicular, palmately divided into 3 or 5 crenated lobes, more or less hairy on both sides. Flowers green, hanging singly or in pairs on short pedicels from little tufts of young leaves. Calyx-tube shortly campanulate, the segments oblong, about twice the length of the petals. Berry of the wild plant rather small and yellowish, sprinkled with stiff hairs, but in cultivation varying much in size and colour, and often quite glabrons.

In thickets, open woods, and hedges, in the rocky parts of central and southern Europe, and western Asia. In Britain, well established in many places, in hedges, and even wilder places, but, except in the north of England, scarcely indigenous, having been abundantly cultivated in cctlage gardens for several centuries. Fl. early spring. [The truly wild 
European form is $R$. Uva-crispa, Linn., with small simooth fruit, which extends to Morocco and the Himalaya.]

2. R. rubrum, Linn. (fig. 373). Rcd and White C.-An erect, branching shrub, 3 or 4 feet high, without prickles. Leaves on rather long stalks, much larger and thinner than those of the Gooseberry, witn 3 or 5 rather short and broad-toothed lobes, glabrous, or more frequently sprinkled with a few minute hairs on the upper surface, and more or less downy underneath. Flowers small, greenish-white, several together ir axillary racemes at the base of the year's shoots. These racemes are either erect or pendulous when in flower, but almost always pendulous when in fruit; the pedicels all short, and do not commence at the very base of the raceme, as in $R$. nigrum, each pedicel being in the axil of a small bract. Calyx-segments broadly spreading, obovate, or rounded, twice the length of the small petals. Berries red when wild, varying in cultivation from red to white.

In rocky woods, in northern and central Europe and Russian Asia, extending to the Arctic Circle, but replaced in southern Europe and central Asia by the $R$. petrceum. Frequent in Scotland, the north of England, and occurs also in some parts of southern England and Ireland, but it has been so long and so generally cultivated, that it is difficult to say how far it is really indigenous. Fl. spring. A variety with more upright racemes has been falsely referred to the Continental $R$. pctraum, and another with the flowers almost sessile has been distinguished as $R$. spicatum, Robs.

3. R. alpinum, Linn. (fig. 374). Mountain C.-Very near R. rubrum, but the leaves are smaller, more deeply divided, smooth and shining, and glabrous underneath; the Hlowers much smaller and always diøecious; the males rather numerous, in little, erect racemes, of 1 to $1 \frac{1}{2}$ inches; the pedicels slender, but not quite so long as the bracts; the females, on separate shrubs, much fewer together, in very short racemes, and often almost sessile; the berries small and tasteless.

In rocky, hilly districts, in central and southern Europe and Russian Asia; not an alpine plant, notwithstanding its name, but said to extend to rather high northern latitudes; it may not, however, al ways have been properly distinguished from $R$. rubrum. Rather scarce in Britain, probably indigenous in the north of England, but not so in Scotland; it does not extend into the Highlands, nor into Ireland. $\mathrm{Fl}$. spring.

4. R. nigrum, Linn. (fig. 375). Black C.-Easily known from the peculiar smell of the leaves when rubbed, arising from the small glandular dots, copiously sprinkled on the under side. Stem unarmed. Leaves rather larger than in $R$. rubrum, more cordate, and usually with only 3 broad, crenate lobes, coarse and rough, but scarcely hairy. Racemes pendulous, looser than in the $R$. rubrum, the flowers larger, campanulate, on longer pedicels, of which the lowest, arising from the very base of the raceme, are much longer than the others. Calyx rather hoary outside. Berries black.

In woods, in northern, central, and eastern Europe, and Russian and central Asia, but less common in western Europe than the last two anecies. In Britain, although found in cool, shady places, and boggr tuickets, in various parts of England and Scotland, yet it is very doubttul whether it be truly indigenous, as its cultivation dates from a very earlv period. If anwwhere wild, it is in the Lake district and lorkshire

TF. surzin. 


\section{SAXIFRAGACER. THE SAXIFRAGE FAMILY.}

Herbs, or, in exotic genera, trees or shrubs, with alternate or opposite leaves, and no stipules. Calyx free, or more or less adherent to the ovary, with 4 or 5 (rarely more) lobes or segments. Petals as many, perigynous or none. Stamens as many, or twice as many (rarely more), perigynous. Ovary either adherent or inserted on a broad base, either 2- or 4-celled, or 1-celled, with 2 or more parietal placentas, often lobed at the top, with as many (rarely twice as many) styles or stigmas as cells or placentas. Fruit a capsule. Seeds several, usually many, to each cell or placenta ; the albumen usually copious, rarely none.

An extensive family, ranging over nearly the whole world, and including many shrubs and trees, such as the Hydrangeas, Escallonias, Philadelphuses (Syringas), Deutzias, \&c., of our gardens, of which the British herbaceons genera can give very little idea. The characters of the Order are moreover somewhat complicated, there being several exceptions among exotic genera, besides those alluded to in the above general character. The three British genera differ from each other in many essential points, but are all distinguished from Rosacea by the definite stamens and want of stipules, from them and from Crassulacere by the carpels united into a single ovars, and from Lythrariece by the distinct styles and the more adherent ovary.

Petals none . . . . . . . . . . . 2 Chrysosplenium.

Petals 5.

Stamens 10, all bearing anthers. Styles 2 . . SAXIFrAGA.

Stamens 5 , bearing anthers; 5 barren, with a tuit of globular-headed flaments. Stigmas 4 .

\section{SAXIFRAGA. SAXIFRAGE.}

Herbs, either annual or more commonly with a perennial tufted stock, with radical or alternate or rarely opposite leaves, no stipules, and terminal flowers either solitary or in cymes or panicles. Calyx free, or more or less adherent at the base, with 5 teeth or segments. Petals 5. Stamens 10, inserted with the petals at the base of the segments of the calyx. Ovary 2-celled, superior or more or less inferior, with 2 distinct styles. Seeds several in each cell, with a small embryo in a fleshy albumen.

A numerous genus, consisting chiefly of mountain or rock plants, abundant in all the great mountain-chains of the northern hemisphere, some ascending to the highest Alpine or most Arctic regions, others extend from the northern Andes to Tierra del Fuego, whilst still others inhabit the hot limestone rocks of the Mediterranean region.

Leaves all opposite and small. Low spreading plant. Flowers

purple

Flowers yellow.

Calyx spreading, adherent at the base. Stem bearing several flowers
Calyx reflexed, free Stems 1-fiowered: Flowers white or pink.

1. S. opprsitifolia 2. S. aizondes. 
Calyx adherent at the base, the lobes erect or spreading.

Stem much branched at the base, with procumbent or densely tufted barren shoots. Leaves narrow, simple or 3-lobed.

Jeaves or thelr lobea usually acute. Tufts loose

4. S. hypmoides.

Ieaves or their lobes obtuse. Tufts dense .

Stems simple or branched, without barren shoots at the base.

Perennlals, with the radical leaves larger, and longer stalked.

Lower leaves rounded or palmate. Flowers aolitary or panlcled.

Iowland plant. Stem erect. Iower leaves crenate Iigh alpine plants. Stems weak. Lower leaves angular or deeply lobed.

Petals at least twice as long as the calyx . . 7. S. cornua.

Petals scarcely exceeding the calyx . . 8. S. rivularis.

Radical Jeavis, ovate, toothed. Stem almost leafless, with a terminal head of small tlowers. .

with a terminal head of small towers : $\quad$ 10. S. nivalis.
Annual, with narrow leaves, entire or 3-lobed

Calyx firce, with reflexed divisions.

H'lowers white. Leaves thin, angular or acutely toothed.

Flowers pink. Leaves thlck and leathery, crenate.

leaves obovate, narrowed at the base

Ieaves orbicular, cordate or rounded at the base

\section{S. granulata.}

9. S. tridactylites.

11. S. stellaris.

12. S. чtmbrosa.

13. S. Geum.

The large, somewhat coarse Siberian $S$. crassifolin is common among herbaceous plants in our gardens. The Chinese $S$. sarmenlosa, wilh long, hanging runners, is often grown in pots in cottage windows ; ar.d several species from the great European mountain-ranges form a large proportion of all cultivated collections of alpine plants.

1. S. oppositifolia, Linn. (fig. 376). P'urple S.-Stems perennial, creeping, very much branched, forming low, straggling tufts, of several inches in diameter, seldom rising above an inch from the ground. Ieaves crowded, small, opposite, obovate, and ciliate. Flowers rather large, handsome, and purple, often so crowded as almost to conceal the foliage, although gris. ing singly on very short, erect branches. Calyxtube adhering to the ovary and capsule up to more than lialf its length; the segments ovate, green, erect or spreading, not half so long as the petals.

In moist situations, in the higher mountain-ranges of Furope, Asia, and North America, abundant in the Arctic regions. Common in the loftier Scotch, and found, but sparingly, on some of the higher Irish, Welsh, and northern English mountains. Fr. spring and carly summer.

2. S. aizoides, Linn. (fig. 37i). Yellow S.-Stock short, sometimes tufted, the flowering stems ascending to about 6 inches high. Leaves alternate, narrow, rather thick, smooth and shining, about half an inch long, entire or rarely notched with 1 or 2 teeth. Flowers yellow, in a loose panicle of from 3 or 4 to a dozen or more. Cals $\mathrm{x}$-segments not much shorter than the petals, often narrow like them, and almost as yellow, giving the flower the appearance of having ten petals with a broad circular disk in the centre. Capsule adhering, for about half its length, to the short tube of the calyx.

On wet rocks or gravel, along rills and springs, in almost all moun. tainous districts of Europe, Asia, and northern America, to the Arctic Circle, descending also much lower than the last. Abundant in Scotland. the north of England, and some parts of Ireland, but apparently wanting in Walea, Fi. summer and autumn. 
3. S. Hirculus, Linn. (fig. 378). Marsh S.-Perennial stock still shorter than in the last, and often reduced to a small tuit. Leaves alternate, narrow-oblong or linear, and entire. Flowering stems ascending, as in $S$. aizoides, to about 6 inches, but terminated by a single, rather large flower; the calyx almost entirely free, with oblong, reflexed divisions, not half so long as the erect, narrow-obovate or oblong, yellow petals. Capsule rather large, ending in 2 spreading beaks.

In wet moors, at high elevations, chiefly in the mountain-ranges of eastern Europe, Asia, and generally round the Arctic Circle; rare in western Europe. In Britain, only in a few localities in northern England, middle and southern Scotland and Ireland. Fl. August.

4. S. hypnoides, Linn. (fig. 379). Cut-lcaved S.-Perennial stock usually shortly creeping and rather slender, much branched with numerous decumbent barren shoots, attaining, in most situations, 2 or 3 inches, but sometimes contracted into a short, dense tuft. Leaves mostly entire, 2 or 3 lines long, narrow-linear and pointed, but some of the larger ones are often 3-lobed, or even 5-lobed, and attain half an inch; they are glabrous, or more or less ciliated with slender, often glandular hairs. At the ends of the shoots, and in the axils of the leaves, the leaf-tufts are often somewhat enlarged and crowded into an oblong head or bulb. Flowering stems 3 to 6 inches high, with very few leaves, and from 1 to 6 or 8 rather large, white flowers. Calyx adherent to about two-thirds the length of the capsule; the segments not one-third so long as the petals, and usually more or less pointed.

In rather moist, rocky situations, in the mountains of western Europe, descending occasionally to low, hilly districts. Not uncommon in Scotland, Ireland, Wales, and northern England, but very local in the southern connties, and only in the western of these, as in Somerset and north of it. $F l$.summer. Very sariable in the development of its stems, leaves and flowers, in the more or less viscid hairs, and in the leaves and calyx-segments. This has given rise to numerous supposed species; and to some of its varieties having been mistaken for S. geranioides, $S$. mus coides, and other Continental species. [S. Sternbergii, Willd. (hibernica Haw.), is a robust Arctic and Enropean form, found in Ireland, with obtuse lobes of the leaves and calyx. S. decipiens, Ehrh., has closer tufts acute leaf-lobes, and subacute calyx-lobes. S. sponhemica, Gmel., is alsc closely tufted, with acute leaf-lobes on long barren shoots and lanceolate acute calyx-lobes; it is the most common British form.]

5. S. cæspitosa, Linn. (fig. 380). Tufted S.-Very near to the last but never emitting the weak, precumbent barren shoots of that species; the leaves broader, more obtuse, and more frequently lobed, and the calyx-divisions also obtuse. The short, leafy stems are crowded into dense tufts; the flowering stems from 2 to 3 inches high generally covered with a short glandular down, and bearing 1 or 2 white flowers, smaller than in $S$. hypnoides.

A high northern and Arctic plant. In Britain, only on some of the highest Scotch, Welsh, and Irish mountains. Fl. summer. High alpine forms of $S$. hypnoides have been frequently mistaken for this plant, and are not indeed always easy to distinguish from it.

6. S. granulata, Linn. (fig. 381). Meadono S.-Perennial stock reduced to a number of small bulbs, covered with whitish or brown hairy ecales. Stems erect, 6 inches to a foot high, simple or slightly branched 
more or less covered with short spreading hairs, which become glandnlar in the upper part of the plant. Radical and lower leaves on long stalks, reniform, obtusely crenate or lobed, the npper ones few and small, more acutely lobed or entire. Flowers white, rather large, 3 to 6 together, in rather close terminal cymes. Calyx adherent to abont the middle of the ovary, with rather obtuse divisions, about half the length of the petals.

In meadows, pastures, and on banks, throughout temperate Enrope, extending northward into Scandinavia, and eastward into central and northern Asia. Abundant in several parts of England and southern Scotland, but scarcely penetrates into the Highlands; rare in Ireland. $\mathrm{Fl}$. spring and early summer.

7. S. cernua, Linn. (fig. 382). Drooping S.-In many respects allied to $S$. granulata, of which it may be a starved alpine variety. It is weaker, more glabrous, and slender; the stock does not always form distinct bulbs; the leaves are smaller, angular or broadly lobed, and the upper ones have often little bulbs in their axils. Flowering stems more or less drooping at the summit, with 1 to 3 flowers, rather smaller than $S$. granulata.

At great elevations, in a few of the larger mountain-ranges of Europe and Asia, and all round the Arctic Circle. In Britain, only known on the summit of Ben Lawers, where, however, it very seldom flowers, and is now almost extinct.

8. S. rivularis, Linn. (fig. 383). Brook S.-A glabrous plant, still smaller than $S$. cernua, which it much resembles in foliage. Perennial stock small, and seldom forming bulbs; radical leaves on long stalks, deeply 3-or 5-lobed. Flowering stems weak, only 2 to 3 inches long, with very few small leaves, and 1 to 3 flowers, like those of $S$. cernua, but much smaller, the petals scarcely exceeding the calyx.

A high alpine or Arctic species, with nearly the same geographical range as $S$. cernua, but not so scarce. In Britain it occurs sparingly on Ben Lawcrs and Ben Nevis, and more abundantly on Lochnagar. Fl. July.

9. S. tridactylites, Linn. (fig. 384). Rue-leaved S.-A little erect annual, 2 to 5 inches high, simple or branched, and more or less clothed with a glandular down. Radical leaves very small, entire, and stalked. Stem-leaves either entire and linear-oblong or more frequently 3-lobed. Flowers small, white, growing singly on rather long pedicels. Calyx adherent, with ovate segments not half so lorg as the petals.

On walls and rocks, throughout Europe and Russian Asia, from the Mediterranean to the Arctic Circle. Frequent in England, Ireland, and southern Scotland, less so farther north, espccially on the western side. Fl. spring and early summer.

10. S. nivalis, Linn. (fig. 385). Alpine S.-Perennial stock short and simple, but thick and hard, crowned with a tnft of spreading, obovate, toothed leaves, rather thick and leathery, and narrowed into a stalk at the base. Stems simple, erect, 2 to 5 inches high, slightly hairy in the apper part, leafless, or with 1 or 2 small leaves close under the flowers. These are small, collected together in little terminal heads. Calyx adherent to about half-way up the oxary, with shortly oblong spreading segments, about the length of the obovate, white petals.

In the mountains of northern and Arctic Europe and Asia, and on tho 
highest of the Bohemian. Not uncommon in the Scotch mountains, and found also, but much more sparingly, in the Lake districts of northern England, in North Wales, and on Ben Bulben, in Ireland. $\mathrm{Fl}$. summer.

11. S. stellaris, Linn. (fig. 386). Star S.-A perennial, but the stock is small, and has often an annual appearance; it is crowned by 1 or more tufts of spreading leaves, rather thin, varying from oblong to obovate, with a few coarse teeth, and tapering at the base. When luxuriant these tufts are elongated into leafy branches of 1 or 2 inches. Stems erect, 3 to 6 inches high, leafless, except a small, leafy bract nnder each pedicel. Flowers from 2 to 3 or 8 to 10, rather small, white and starlike, on slender, spreading pedicels, forming a loose terminal panicle. Calyx free almost to the base, the segments closely reflexed on the pedicel. Petals narrow and spreading. Capsule rather large, with 2 diverging beaks.

On wet rocks, and along rivulets and springs, in all the mountainranges of Europe, Russian Asia, from the Mediterranean to the Arctic regions, and also in northern America. Frequent in the mountains of North Wales, Ircland, and Yorkshire, and throughout Scotland.

12. S. umbrosa, Linn. (fig. 387). London-pride, St. Patrick's Cabbage, None-so-pretty.-Perennial stock shortly branched, crowned by the spreading leaves, forming dense tufts, which in our gardens will attain near a foot in diameter. Leaves rather thick and leathery, usually glabrous, obovate, an inch or more in length, bordered with cartilaginous crenatures or coarse teeth, and narrowed at the base into a short, more or less flattened stalk, ciliated at the edges. Stems erect, leafless, 6 inches to a foot high. Flowers small, pink, elegantly spotted with a darker colour, in a loose, slender panicle. Calyx free, with short segments closely reflexed on the pedicel. Petals much longer, ovate or oblong, and spreading.

In shady places, in Portugal, western Spain, and the higher Prrenees, and reappearing in western and south-western Ireland. Cultivated from an early period in our gardens, and has established itself in some localities in northern England and western Scotland. Fl. early summer.

13. S. Geum, Linn. (fig. 388). Kidncy S.-Closely allied to S. umbrosa in its habit and flowers, this species only differs in its leaves, which are orbicular, usually notched or cordate at the base, with long stalks, less flattened than in the last species, and usually very hairy; the leaves themselves also bave often a few scattered hairs on both surfaces.

The geographical range is the same as that of the $S$. umbrosa, but it appears generally to prefer lower altitudes. In Britain it is confined to the mountains of Kerry and Cork. Fl. early summer. Specimens in some measure intermediate between this and the last species, with the leaves orbicular or nearly so, but not cordate, and the stalk somewhat flattened, have been gathered near Killarney. They have been published as species, under the names of S. hirsuta, Linn. and S. elegans, Mackay, whilst others consider them as hybrids. In favour of the latter supposition there appears to be but little evidence, and they are probably mere varieties of S. umbrosa. [The late Mr. Ball, who knew the Irish forms well, regarded S. hirsuta, L., as a hairy form of umbrosa, with sharplytọtced leares, rrund or obtuse at the basẹ ; and S. elegans, Mackay, also 
with sharply-toothed leaves, bnt narrowed into a short petiole, as probable hybrid with umbrosa.]

\section{ChrYSOSPLENIUM. CIRYSOSPLENE.}

Delicate herbs, pcrennial and creeping at the base; the short flower. ing stems ascending, and often of a golden yellow at the top; with orbicular leaves, no stipules, and small yellow flowers, in short leafy terminal cymes. Calyx adherent, with 4 , or rarely 5 , short, free segments. Petals none. Stamens 8 , rarely 10 , inserted at the base of the calyx-segments. Ovary adherent to near the top, where it is divided into 2 short, conical lobes, each with a sbort style, and surrounded by a crenated disk within the stamens. Capsules 1-celled, opening at the top in 2 short valves. Seeds several, attached to 2 parietal placentas. Albumen copious, with a small embryo.

A small genus, spread over the temperate and colder regions of both the northern and southern hemispheres.

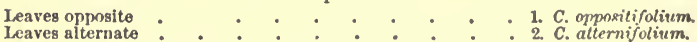

1. C. oppositifolium, Linn. (fig. 389). Golden Saxifrage.-The loose, leafy tufts often spread to a considerable extent; the stems searcely rising above 4 or 5 inches from the gronnd, simple or forked near the top. Leaves all opposite, 3 or 4 to 6 or 8 lines in diameter, slightly crenated or sinuate, and notehed at the base, with a few stiff hairs on the upper surface. Flowers small and sessile, in little compact cymes, surrounded by leaves like those of the stem, but smaller, more sessile, and often of a golden yellow. Caly $\mathrm{x}$-segments obtuse and spreading.

In moist, shady places, along the sides of rivulets, over the greater part of Europe and Russian Asia. Abundant in Britain. Fl. spring.

2. C. alternifolium, Linn. (fig. 390). Alternate-leaved C.-Closely resembles $C$. oppositifolium, but is usually of a paler colour; the leaves are always alternate, and the lower ones on longer stalks and rather more of a kidney shape.

In similar situations as $C$. oppositifolium, and much more common in continental Europe, Russian and central Asia, and northern America, extending into the Arctic regions. In Britain, on the contrary, much less common than C.oppositifolium, although pretty generally distributed. $\mathrm{Fl}$. spring. The two speeies are frequently found growing together, but appear always to retain their characters.

\section{PARNASSIA. PARNASSIA.}

Herbs, with a perennial stock, entire leaves, mostly radical, and erect, annual flowering stems, usually bearing a single leaf, and a single ter. minal flower. Calyx in the British species almost free, with 5 segments. Petals 5, perigynous. Stamens perigynous, 5 perfect and 5 imperfect, bearing, instead of anthers, a tuft of globular-headed filaments. Stigmats 4, rarely 3, sessile. Capsule 1-celled, opening in 4, or rarely 3, valves. Secds very numerous, without albumen, inserted on 4, rarely 3 , parietal placentas, opposite the styles, and in the centre of the valves.

A few species are inhabitants of bogs and wet places in Europe, Asia, and North America. The above characters are so well marked, that the 
genus is not easily confounded with any other, but its place in the Natural System has been mnch dispnted. It has been most generally placed amongst Thalamilora, with the Droseracece, next to Violacece and Polygalea; but its close affinity with Saxifraga and Chrysosplenium has now been fully proved, especially by the recent publication of several curious Himalayan species.

1. P. palustris, Linn. (fig. 391). Grass-of-Parnassus.-Stock very short. Radical leaves rather long-stalked, broadly heart-shaped, glabrous as the rest of the plant. Stems 6 inches to a foot high, with a single sessile leaf below the middle. Flowers white, rather large. Segments of the calyx ovate, spreading, 3 to $3 \frac{1}{2}$ lines long. Petals obovate, spreading, nearly twice that length. Imperfect stamens at the base of each petal short and thick, with a tuft or 10 or 12 short, white filaments, each bearing a little, yellow, globular gland. Capsule globular.

In bogs and moist heaths, throughout northern Europe and Russian Asia, becoming a mountain plant in southern Europe and west-central Asia. Frequent in Britain. Fl. end of summer and autumn.

\section{DROSERACE正. THE SUNDEW FAMILY.}

A small family, confined in Britain to the single genus Drosera, but comprising also a few exotic genera from hotter climates, all remarkable for the same glandular hairs, but differing chiefly in the number of atamens, or of the valves of the capsule, or in the insertion of the ovules. The family is usually placed amongst Thalamiflore, the majority of the species having their flowers rather hypogynous than perigynous; but there is no order there with which they are nearly connected, and altogether the group appears nuch more naturally associated with Saxifragacece, of which it was, in the first edition of this work, considered as an anomalous tribe, but, in compliance with the opinions of the majority of botanists, it is now restored as an independent family.

\section{DROSERA. SUNDEW.}

Herbs, with long-stalked radical leaves, covered with long, glandular hairs or bristles; the leafless flower-stems terminating in a simple or forked unilateral spike or raceme. Sepals 5, free from the ovary. letals and stamens 5 ; in the British species aimost hypogynous, but in many exotic ones decidedly perigynous. Styles 3 or 4, each divided into 2. Capsule 1-celled, opening into 3 or 4 valves, sometimes split into twice that number. Seeds several, with albumen, inserted on 3 or 4 parietal placentas in the centre of the valres.

'The Sundews are rather numerous in species, and found in nearly all parts of the globe where there are bogs. The curioas glandular hairs of the leaves distinguish them from all other British genera, independently of their floral characters. 
1. D. rotundifolia, Linn. (fig. 392). Common S.-Rootstock short and slender, the leaves on long stalks, nearly orbicular, 3 to near 6 lines in diameter, covered on the upper surface with long, red, viscid hairs, each bearing a small gland at the top. Flower-stems slender, erect, and glabrous, 2 or 3 to 5 or 6 inches high, the upper portion, consisting of a simple or once-forked unilateral raceme, rolled back when young, but straightened as the flowers expand. Pedicels nearly a line long, withont bracts. Calyx near 2 lines. Petals white, rather long, $\mathbf{c x}$ panding in sunshine. Seeds spindle-shaped, pointed at both ends, the loose testa several times longer than the small, ovoid albumen.

In bogs, and wet, beathy ground, throughout central and northern Europe and Russian Asia ; from northern Spain to the Arctic regions. Abundant in all parts of Britain where there are considerable bogs. Fl. summer and early autumn.

2. D. longifolia, Linn. (fig. 393). Oblong S.-Distinguished from $D$. rotundifolia by the leaves much more erect not half so broad as long, and gradually tapering into the footstalk; the flowering stem is also usually shorter, and not so slender; the styles less deeply divided, and the seeds are ovoid or oblong; the testa either close to the albumen, and taking its form, or very slightly prolonged at each end. D. intcrmedia, Hayne.

In bogs, with $D$. rotundifolia, but much less generally distributed both on the continent of Europe and in Britain. Fl. summer and early autumn.

3. D. anglica, Hnds. (fig. 394). English S.-Very like D. longifolia, but the leaves are still longer and narrower, often an inch long, without the stalk, the flowers and capsule larger, and the testa of the seed is loose and elongated, as in $D$, rotundifolia, but more obtuse at the ends.

In bogs, apparently spread over the same geographical range as the two other species, but rarer. It is often confounded with $D$. longifolia. In Britain, more frequent in Scotland and Ireland than in England. Fl. summer and early autumn.

\section{HALORAGE尼. THE MARESTAIL FAMILY.}

Aquatic herbs, or, in some exotic genera, terrestrial herbs or undershrubs. Flowers very small, often unisexual, or incomplete, axillary or in terminal racemes or panicles. Calyx-tube adnate to the ovary, the limb of 4 or 2 lobes or quite inconspicuous. Petals 4,2 or none. Stamens 8 or fewer. Ovary inferior, 2- or 4-celled, with 1 pendulous ovule in each cell, or rarely reduced to a single cell and ovule. Styles distinct, as many as cells of the ovary, in the British genera reduced to sessile stigmas. Fruit small, indehiscent; or divisible into 1-seeded nuts. Seeds without albumen.

This Order is dispersed over nearly the whole globe. It was included in the first edition of this work in Onagracea, as a very reduced type. It differs, however, essentially in the perfectly distinct styles, and otbc characters, and is much nearer allied to the Saxifrage family. 
Stamens 4 or 8 . Stigmas and seeds 4 . Stamen, stigma and seed 1

1. MrRTophyLuX.

2. HIPPURIS.

\section{MYRIOPHYLLUM. WATER-MILFOIL.}

Aquatic plants, with finely pinnated, whorled leaves, and minute, sessile, monœcious flowers. Calyx with 4 short divisions. Petals 4 in the male flowers, very minute or none in the females. Stamens in the males 8,6 , or 4 . Ovary and capsule of the females short, divided into 4 cells, with 1 seed in each.

A small genus, widely diffused over almost every part of the globe. In its finely-cut whorled leaves it bears at first sight much resemblance to Ceratophyllum, but the lobes of the leaves are pinnate, not repeatedly forked as in the latter plant.

Foral leaves or bracts not longer than the flowers . . . 1. M. spicatum. Floral leaves longer than the flowers, usually pinnate like the stem-leaves

1. M. spicatum, Linn. (fig. 395). Spiked M.-Rootstock perennial, creeping and rooting in the mud under water. Stems ascending to the surface, but usually wholly immersed, varying in length according to the depth of the water, and more or less branched. Leares whorled, in fours or sometimes in threes or in fives, along the whole length of the stem; the numerous capillary segments entire, 3 to near 6 lines long. From the summit of the branches a slender spike, 2 to 3 inches long, protrudes from the water, bearing minute flowers arranged in little whorls, and surrounded by small bracts seldom as long as the flowers themselves. The upper flowers are usually males, their oblong anthers, on very short filaments, protruding from the minute calyx and petals. The lower ones are female, very small, succeeded by small, nearly globular or slightly oblong capsules, each separating ultimately into 4.1-seeded carpels.

In watery ditches, and ponds, throughout Europe and Russian Asia. Extending all orer Britain. Flo all summer. A slender variety, with the whorls of the spike often reduced to a single flower, and the lower ones having leaves at their base like the stem-leaves, has been considered a distinct species, under the name of M. alterniflorum, DC.

2. M. verticillatum, Linn. (fig. 396). IIhorled $M$. - In deep, clear waters, the foliage is precisely that of $M$. spicatum, but the flowers are all immersed in the water, in the axils of the upper leaves. In shallow, muddy ditches, the segments of the leaves are often shorter and fewer, and the flowers form a spike protruding above the water as in $M$. spicatum, but the bracts or floral leaves are longer than the flowers, and pinnate like the stem-leaves: this form constitutes the $M$. pectinatum of some authors, but cannot be distinguished with any precision, even as a variety.

In watery ditches and ponds, with $\boldsymbol{M}$. spicatum, over the greater part of its geographical range, and in many countries as common. In Britain it appears to be rather scarce, but perhaps frequently overlooked from its flowers not appearing above the water. Fl. all summer. [H. pcctinatum, DC., is a variety with very short floral leares.] 


\section{HIPPURIS. MARESTAIL.}

A single aquatic species, distinguished as a genus frorn Myriophyllum by 1 ts entire leaves, and by its llowers always without petals, with a scarcely perceptible border to the calyx, and reduced to. 1 stamen, 1 subu. late style, and 1 ovule and seed.

1. H. vulgaris, Linn. (fig. 397). Marestail.-An aqnatic plant with a perennial rootstock, and ercet, annual, simple stems, the upper part projecting out of the water sometimes to the height of 8 or 10 inches, and crowded in their whole length by whorls of from 8 to 12 linear entire leaves; the submerged ones, when in deep streams, often 2 or 3 inches long, gradually diminishing till the upper ones are lesw than half an inch. Flowers minute, sessile in the axils of the upper leaves, cossisting of a small globular or oblong ovary, crowned by a minute, scarcely perceptible border, on which is inserted a very small stamen, and from the centre of which proceeds a short, thread-like style. Fruit a little, oblong, 1 -seeded nut scarcely a line in length.

In shallow ponds, and watery ditches, over the greater part of Europe, liussian and central Asia, and North America, especially in ligh latitudes, reappearing in Chili. In Britain, not near so frequent as Myriophyllum, except in Irelaud, where it is said to be common. Fl. summer. The whole plant has a general resemblance, although no aflinity, to some spccics of Equisetum, called Horsetails or even Mares. tails.

\section{UMBELLIFER尺. THE UMBELLATE FAMILY.}

Ilerbs, or, in a few exotic species, shrubs, with alternate leaves, often much cut or divided; the footstalk usually dilated at the base, but no real stipules. Flowers usually small, in terminal or lateral umbels, which are either compound, each ray of the general umbel bearing a partial umbel, or more rarely simple or reduced to a globular head. At the base of the umbel are often one or more bracts, constituting the involucre, those at the base of the partial umbel being termed the involucel. Calyx combined with the ovary, either entirely so or appearing only in the form of 5 small teeth round its summit. Petals 5 . inserted round a little fleshy disc which crowns the ovary, usually turned in at the point, and often appearing notched. Stamens 5, alternating with the petals. Ovary 2-celled, with 1 ovule in each cell. Styles 2, arising from the centre of the lisk. Fruit when ripe, separating into 21 -seeded, indehiscent carpels, usually leaving a filiform central axis, either entire or splitting into two. This axis, often called the carpophore, is, however, sometimes scarcely separable from the carpels. Each carpel (often called a mericarp, and having the appearance of a seed) is marked outside with 10,5 , or fower prominent 
nerves or ribs, occasionally expanded into wings, and underneath or within the pericarp are often longitudinal channels, called vittas, filled with an oily or resinous substance. Embryo minute, in a horny albumen, which either fills the seed or is dceply furrowed or excavated on tho inner face.

A numerous family, more or less represented nearly all over the globe; but the species are comparatively few in high northern latituries, as well as within the topics, their great centre being western Asia and the Mediterranean region. Their inflorescence, and the structure of their flowers, distinguish them at once from all other families, except that of the Aralias, and these have either more than 2 styles, or the fruit is a berry. But the subdivi.ion of Umbellifers into genera is much more difficult. Linnacus marked out several which were natural, but without definite claracters to distinguish them; and the modern genera, founded upon a nice appreciation of minute differences in the fruit and seed, are often very artificial, or still more frequently reduced to siogle species, and as artificial as those of Cruciferce and Compositce. These minute characters are moreover in many cases very difficult to ascertain. I have, therefore, in the following Analyticil Key, endeavoured to lead to the determination of the species, as far as possitle, by more salient though less absolute characters, which may suffice in a great measure for the few British species, although, even for them, the minute variations of the fruit cannot be wholly dispensed with. For this purpose it is essential to have the fruit quite ripe. It must then be cut across, and if a horizontal slice is placed under a lens, the general form, the ribs and furrows of the pericarp, and the vittas, will clearly appear. When the fruit is described as laterally compressed, this slice is of an oval form, the division between the carpels being across the narrow diameter; where it is fattened from front to back, (dorsally) the division is across the broadest diameter. In Seseli and other genera, where the fruit is not compressed, the horizontal slice is orbicular. Where the albumen is furrowed, its transverse section assumes a more or less half-moon or kidney shape.

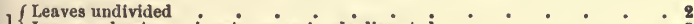

1 Leaves palmate or pinnate, or varionsly dissected $\quad: \quad \vdots \quad ; \quad ;$

Leaves quite entire, grass-like or ovate. Hlowers yeliow: 13. Buplevrum.

$2\{$ Leaves rounded, crennte or peltate. Aquatic or marsh plant, with small

heads or whorls of Howers . 1. IIYDROCOTrL.

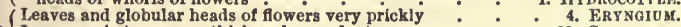

3 Leaves and stems very thick and succulent. : : : $:$ 21. CRITHMUM.

Leaves neither prickly nor fleshy .

Fruit covered with prickles or bristles or hairs, or with toothed or sinuate

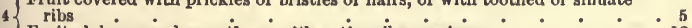

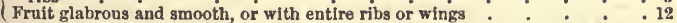

5 \{ Leaves orbicular or palmate. Umbels simple or irregularly compound : $\quad 6$

5 Leaves pinnate or much dissected. Umbels usually compound : : 7

Flowers in small heads, without involucre. Fruit prickly . 2. SANIcuis.

$6\{$ Flowers in simple or irregularly compound umbeis. Involucre of many bracts. Fruit rough, with sinuate or toothed ribs. . 3. ASTRANTIA.

7 Fruit covered with bristles or prickles or hairs.

8

Fruit glabrous, with sinuate ribs

8 Fruit fiat, with a thick border

Fruit ovold, not bordered

$\theta$ Braets of the involucre mostly pinnatifid

Bracts of the involucre entire or none.

33. Coniux

26. TORDYLIUM.

32. DA UCUS'.

.10 
Uimbels of more than 20 rays, with involucres of many bracts, and shortly

10 U downy fruits Umbels of few rays (seldom 10). Bracts few or none. Fruits burr-like or very hispid

11 Fruit contracted st the top into a very short, smooth beak 30 . Cndirophri.iux. 1 Fruit covered to the top with hooked bristles . . . 31. Caucalis.

Fruit very much flattened

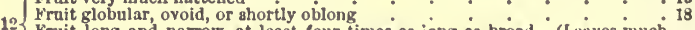

Fruit long and narrow, at least four times as iong as broad. (Leaves much cut, and often halry.)

$13\{$ Fruit rough, surrounded by a thick edge

3 Fruit smooth, with a thin or double edge.

14 Fruit bordered by 2 thin edges or wings, which are tistinct before the frult ripens.

Edges of the fruits single until the carpels separate.

15 Leaves much dissected, with narrow or anall segments - 23. PBuckdanum.

Leaves consisting of a few large, broad segnents . . . . 16

Lower leaves of 3 large, 3-lobed segments, equal to each other, and with

16 stalks of equal length . * * 23. PEUCkDANUM. Lower leaves pinnate; or, if ternaie, the mildle segment longer, with a longer stalk . . . . . . . . . . 17

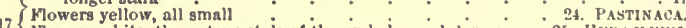

17 Flowers white, the outer petals of the umbels much larger $\quad 25$. Hkrackeux.

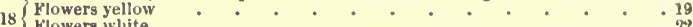

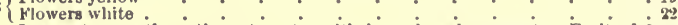

(Leaves two or three times ternate, with large broad segments. Fruit of :

$19\left\{\begin{array}{c}\text { globular carpels } \\ \text { Ieaves pinnate or much divided. Fruit ovoil or oblong : : 35. SMYкxiUм. }\end{array}\right.$

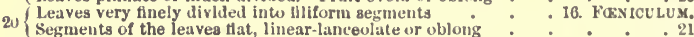

21 Ribs of the fruit very prominent, almost winged ${ }^{-}: 19$ sucics. $^{\circ}$

21 Ribs of the fruit scarcely prominent . 10. Carum Petroselinum.

Fertile flowers and fruits, at least the central ones, nearly sessile, sur-

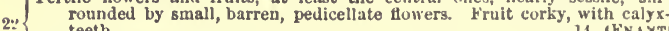

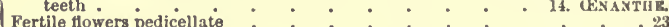

$28\left\{\begin{array}{l}\text { Fertile flowers pedicellate } \\ \text { Leaves twice or thrice ternate, with large, liroad segments (of } 2 \text { or } 3 \text { inches) }: 23 \\ \text { Leaves once pinnate, with several pairs of sessile, ovate, lanceolate, or dis- } \\ \text { sected segments }\end{array}\right.$ Leaves much dissected, with smiall or narrow segments, the lower ones stalked . . . . . . . . 30

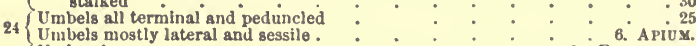

25 No involucres . . . . . . 9. FGOPOLIU.

25 Partial involucres of several bracts, general one of very few : 18. LiGusticus.

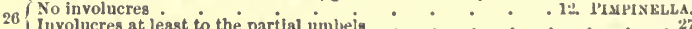

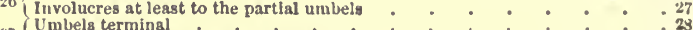

27 U mbels terminal ${ }^{2}$,

Fruit ovold, about 2 liues long or more

28 Fruit ovold, under 2 liues long

Fruit nearly globular, not 1 line long .

$29\{$ General involucre of several bracts

29 No general involucre, or only a single bract

$30\left\{\begin{array}{l}\text { Umbels mostly lateral, almost sessile } \\ \text { Umbels all terminal or pedunculate }\end{array}\right.$

(Leaves with fow ovate segments

31 Leaves twice or thrice pinnate, with numerous small segmenta.

32 Erect branched annuals (not sbove 2 feet high).

16. ENANTHE Phellandrium.

32 Perennlals or tall blennlals.

83 Partisl involucres longer than the flowers, and reflexed

11. Sivx.

7. Sison.

11. SIUX.

6. ApIUY.

- 31

6. ApIux

83 Partial involucres shorter than the flowers, or none.

Fruit globular or broader than long

fruit ovold or longer than broad. 
86

Fruit globular, not separating into two

Fruit sepsrating into 2 smsll globular carpels

Fruit of 2 little, globular, bladder-like lobes or carpels

86\{

Fruit nearly globular, or broader than long

Frult ovold, or longer than broad.

37 Partial involucre of several bracts.

No Involucres.

38

Flowers of a yellowish green. Ribs of the fruit acute, almost winged 19 . SILAUs.

38 Flowers white. Ribs of the carpels obtuse, or crisped, or not prominent . 39

39

Calyx-teeth appearing above the fruit. Leaf-segments narrow.

Caiyx-teeth not conspicuons. Leaf-segments numerous, small.

Stem erect, not much branched.

10\{ lanceolate, or linear segments

12. PIMPINELLA.

ading stiff branches. Leaves ternately divided, with subulate segments . . . . . . Trinia.

(Leaf-segments divided into numerons subulate lobes, not above 2 lines long,

41 In opposite clusters, appearing whorled along the common staik 42

Ieaf-segments oblong-lanceolate or linear, and flat . . . . . . 43

42\{

Common stalk of the leaf simple. Fruit not above 2 lines long.

Common stalk brsnched. Fruit 3 or 4 lines long

10. CARUM verticillatum.

Rootstock a globular tuber

43\{

Rootstock or root not tuberons

Styles closely reflected on the fruit. Ribs of the fruit prominent. Vittas

single. 10. CARUM Bulbocastanum

Styles erect. Ribs of the fruit scarcely vislble. Vittas several to each interstice

Umbels of 3 to 5 very nnequal rays 45

Umbels of 7 to 10 rather unequal rsys. Calyx-teeth not consplcuous.

Umbels of 10 to 20 rays. Calyx-teeth prominent

46 Fruit 10 lines to above an Inch long

Fruit not above half an inch long .

47 Fruit thick, with prominent angles or ribs the whole length

$\{$ Fruit slightly ribbed at the base, with a long smooth beak

$18\left\{\begin{array}{l}\text { Fruits mostly sessile or nearly so } \\ \text { Fruits all pedicellate }\end{array}\right.$

Besides the species here described, Ammi majus, a common Continental roadside plant, with erect branching stems, finely cut leaves, a small fruit like that of Apium, but with an involucre of a few slender, pinnate bracts, like the Carrot, has established itself on the banks of the Severn, near Gloncester. [Very lately the Milk Parsley of northern and middle Kurope, Selinum caruifolium, Linn., has been found in damp woods in North Lincoln and Cambridge, but it is extremely rare and possibly not indigenous ; it is closely allied to the Lovage, but the leaflets are narrow and the seed convex on both surfaces.]

\section{HYDROCOTYLE. PENNY-WORT.}

Herbs, mostly aquatic, with leaves often peltate. Flowers in a small simple head or umbel, or in 2 or more whorls, one above the other. Petals ovate, valvate in the bud in the British species, but not in all exotic ones. Fruit laterally compressed, the carpels flat, nearly orbicular, placed edge to edge, with one prominent rib on each side, and without any prominent calycine teeth.

A rather large genus, spread over the greater part of the globe, and, notwithstanding some rather anomalous South African and Australian species, known as well by its foliage and inflorescence as by its fruit.

1. H. vulgaris, Linn. (fig. 398). Marsh Penny-vort, White-rot.-The perennial slender stem creeps along the wet mud, or even floats in water, rooting at every node, snr amitting from the same point small 
tufts of leaves and flowers. Leaves orbicular, to 1 inch diameter, crenate or slightly lobed, and attached by the centre to a rather long stalk. Peduncles shorter than the leafstalks, with a single terminal head, or 2 or even 3 whorls of minute white flowers on very short pedicels. Fruits small, flat, and glabrous, about a line in diameter.

In bogs, marshes, edges of ponds and lakes, in temperate Europe, from southern Scandinavia to the Cancasus. Frequent in Britain. Fl. summer.

\section{SANICULA. SANICLE.}

IIcrbs, with a perennial rootstock; palmately divided leaves, mostly radical; and erect, almost leafless stems, irregularly branched at the top, each branch ending in a very small head of flowers. Fruit ovoid, covered with short, hooked prickles, and crowned by the 5 prickly teeth of the calyx. Petals minute, obovate, with an inflected point.

A genus of very few specics, but widely spread over a great part of the globe without the tropics. They are all readily distinguished among irregular Umbellifere by their burr-like fruit.

1. S. europæa, Linn. (fig. 399). Sanicle--Rootstock short, almost woody. Radical leaves on long stalks, 1 to 2 inches diameter, deeply divided into about 5 palmate segments or lobes, each one obovate or wedge-shaped, dentate or lobed, the teeth ending in a fine point, and often ciliate at the edge; the whole plant otherwise glabrous. Stems 1 to $1 \frac{1}{2}$ feet high, leafless or with small trifid leaves or bracts under the branches of the panicle. This usually consists of 3 short branches, each with a single small head of flowers, with a longer branch lower down the stem bearing 3 small heads, but sometimes there are more 3 -headed branches forming an irregular umbel. At the time of flowering, the calyx-teeth almost conceal the petals; as the fruit ripens into little burrs of about 2 lines, the prickles almost conceal the calyx-teetl.

In woods, thronghout Europe except the extreme north, extending eastward into central Asia. Frequent in Britain. Fl. summer.

\section{ASTRANTIA. ASTRANTIA.}

Herbs, with a perennial rootstock, and palmately divided leaves, mostly radical. Umbels compact, irregularly compound, with general and partial involucres of several coloured bracts. Flowers often unisexual. Fruit ovoid or oblong, somewhat crorapressed laterally, crowned by the long pointed teeth of the calyx. Carpels with 5 plaited or crumpled ribs, and without vittas.

A small genus extending over central and southern Europe to the Caucasus. The foliage and involucels, as well as the fruit, mark it out as a very distinct group in the famlly.

1. A. major, Linn. (fig. 400). Larger A.-Radical leaves like those of Sanicula, but larger, with more pointed lobes. Stems 2 feet high or more, erect, with 1 or 2 leaves, smaller, and on shorter stalks than the radical ones. General umbel very irregular, of 3 to 5 unequal rays, the involucre of as many coloured and lobed or toothed bracts, with occasionally a bract or two below the middle of each ray. Partial umbels with an involucel of 15 to 20 lanceolate pointed bracts, quite entire, as long as or longer than the flowers, either white or tinged 
with pink. Flowers small, mostly unisexual, the calyx-border campanulate, with 5 teeth about the length of the petals.

In woods and pastures, in ctutral and southern Europe, not nearer to Britain than central France. Occurs apparently wild in Stokesay Wood, near Ludlow, and between Whitbourne anä Malvern in Herefordshire; probably originally escaped from some old cottage-garden. Fl. summer.

\section{ERYNGIUM. ERYNGO.}

Stiff, hard herbs, usually perennial, and with very prickly leaves and involucrcs. Flowers in a compact spike or head, with a scale or bract on the common receptacle under each flower. Petals erect, with a long inflected point. Fruit ovoid, without vittas, crowned by the pointed or prickly teeth of the calyx.

A rather numerous and very natural genus, spread over the greater part of the temperate and warm regions of the globe. In many species the whole of the npper part of the plant as well as the flowers acquire a bluish or white tint, on which account several exotic species have been frequently cultivated in our gardens.

Radical leaves rounded, the lobes plaited and toothed. Scales of the receptacle 3-lobed

Leaves pinnately divided, the lobes pinnatifld and toothed. Scales of the receptacle entire

1. E. maritimum.

2. E. campestre.

1. E. maritimum, Linn. (fig. 401). Sea Eryngo, Sea Holly.-A stiff, erect, much branched plant, nearly a foot high, quite glabrous, and glaucous or bluish. Leaves very stiff, broad and sinuate, more or less divided into 3 broad, short lobes, elegantly veined, and bordered by coarse prickly teeth; the radical ones stalked; the others clasping the stem by their broad bases. Heads of flowers nearly globular, of a pale blne, with an involucre of 5 to 8 leaves, like those of the stem, but much smaller and narrower, the bracts within the head divided into 3 spines.

On the sea-coasts of the whole of Europe and western Asia, except the extreme north. Abundant on the maritime sands of England, Ireland, and in Scotland from Aberdeenshire and Argyleshire southward. $F$. summer, rather late.

3. E. campestre, Linn. (fig. 402). Field Eryngo.-Stems not so thick, and more branched than in $E$. maritimum, the leaves much more divided; the segments pinnate, with lanceolate lobes, waved and coarsely toothed, bordered and terminated by strong prickles. Heads of flowers more numerous and smaller; the involucre leaves more or less pinnately toothed; the scales or bracts within the heads narrow, and mostly entire.

In fields, waste places and roadsides, in central and southern Europe, extending eastward to the Caucasus and Ural, and northward to Denmark. Rare in Britain, and believed to be an introduced plant; among several stations formerly given, it is now only known near Plymouth. on the ballast bills of the Tyne, and near Waterford, in Ireland. $Y_{h}$ rummer. 


\section{CICUTA. COWBANE.}

Leaves dissected. Umbels compound, without any general involucre, or only 1 or 2 small bracts ; the partial involucre of many bracts. Calyxteeth prominent above the ovary. Petals white, obcordate. Fruit short, laterally compressed; each carpcl nearly globular, with 5 scarcely prominent, broad, flat ribs, and single vittas under the furrows.

A genus of very few species, spread over the northern hemisphere ; distinguished among the short-fruited Umbelliferce with single vittas chiefly by the prominent teeth of the calyx.

1. C. virosa, Linn. (fig. 403). Corobanc, Watcr IIemlock.-Stem hollow, somewhat branched, attaining 3 or 4 feet. Leaves twice or thrice pinnate or ternate, with narrow-lanceolate, acute segments, 1 to $1 \frac{1}{4}$ inches long, bordered with a few unequal acute teeth. General umbels of from 10 to 15 or even more rays. Bracts of the partial involucres subulate, not quite so long as the pedicels.

In wet ditches and on the edges of lakes, in northern and central Europe, Russian Asia, and northern America, disappearing in southern Europe. Very local in Britain, and never abundant, although occurring in several counties of England, Ireland, and southern Scotland. $\mathrm{Fl}$. summer.

\section{APIUM. APIUM.}

Leaves dissected. Umbels compound, mostly lateral and nearly sessile, without any general involucre, or only 2 or 3 small bracts; the partial involucres of several bracts or none. Petals entire, white, with a small inflected point ; fruit short, slightly compressed laterally, without visible calycine teeth. Carpels ovoid, with 5 slender ribs, and single vittas under the furrows; the axis or carpophore free and entire, and shortly split at the top.

In the revision of Umbellifcrce which has taken place since the early editions of this Handbook, the genus A pium has been extended so as to include Helosciadium, and is now a fairly natural genus, generally spread over the greater part of the globe.

No partial involucres. Leaves with 3 to $B$ broad crenate or lobed segments $\dot{0}$ o

Partial involucres or several bracts.
Leaves of several pairs of ovate or

Leaves of several pairs of ovate or lanceolate toothed segments.

Rays of the umbel about 5 or 6 .

Leaf-segments few, usually lobed or divided. Rays of the umbcl about 3 or 4

1. A. graveoleris

1. A. graveolens, Linn. (fig. 404). stout plant; qnite glabrous ; to 2 feet high. Leaves pinate, witl 3 or 5 distinct broad segments, crenate or 3 -lobed, from 6 to 9 lines long, the upper leaves very small. Umbels small, nearly sessile on the upper branches, opposite the leaves, or on very short terminal peduncles seldom 2 lines above the last leaves; divided into from 3 to 6 rays, and bearing numerous small flowers, on short pedicels. Fruits very small, the vittas often very indistinct.

In marshy places near the sca, on the coasts of Europe, Africa, western Asia, and America, but not in high northern latitudes. In Britain it extends as far north as the middle counties of Scotland, and is occasionally found inland, but then mostly escaped from cultivation. 
Fl. summer. The Celery of onr gardens is a cultivated variety, in which the leafstalk and base of the stem acquire a considerable size.

2. A nodiflorum, Reichb. (fig. 105). Procumbent Apium.-Stems perennial, creeping and rooting at the base, the annual flowering branches ascending or nearly erect; attaining several feet in some situations, but usually very much shorter, the whole plant glabrous. Leaves with 3 or 10 or more pairs of ovate or lanceolate toothed segments. Umbels nearly sessile or on short peduncles, either opposite to the leaves or between the upper branches, each with 5 or 6 , or rarely 2. many as 8 or as few as 4 rays. General involucre nisally 0 , but sometimes consisting of 3 or 4 narrow-lanceolate bracts; partial invo. lucre of several small, lanceolate bracts.

In marshy meadows and wet ditches, in western and southern Europe ; scarcely eastward of the Rhine, but extends nearly all round the Mediterranean. Abnndant in England, Ireland, and southern Scotland. Fl. summer. It varies much in size and foliage; when very luxuriant the leaf-segments are numerous, narrow, from 1 to $1 \frac{1}{2}$ inches long; in half dried-up open ditches the plant is small, much branched, with 3 to 5 small, broad segments; it then also creeps much more, has the peduncles rather longer, and has been considered as a distinct species (S. repens, Koch.), but both forms may be occasionally found proceeding from the same stock. [A. ochneatum, DC., is a dwarf creeping form with small obtuse leaflets, and 1 to 3 bracts, found in Surrey.]

3. A. inundatum, Reichb. (fig. 406), Lesser A.-A glabrous plant, creeping and rooting at the base like the last, but much smaller and more slender, and often balf-immersed in water, when the submerged leaves are divided into capillary'segments. Flowering stems 6 to 8 inches high, with small ternate or pinnate leares; the segments 3 . toothed or 3-lobed, each lobe again often 3 -toothed. Umbels on short peduncles opposite the leares, as in A. nodiflorin, ont generally of 2 or 3 rays only, without involncre; the partial umoeis of 5 or 6 small flowers, with 2 or 3 minute bracts.

In swamps, shallow ponds and pools, or half-dried mud, chiefly in western and central Europe, extending northwards into southern Sweden, eastwards almost to the Asiatic frontier, but rare in the south. Generally dispersed over Britain, but easily overlooked, and consequently supposed to be more rare than is the fact. Fl. summer.

\section{SISON. SISON.}

Leaves dissected. Umbels compound, with general and partial involucres. Petals broad, deeply notched, with an inflected point. Fruit of Apium, except that the axis or carpophore is deeply cleft, as in Carum, and the vittas are slightly thickened at the lower end.

A single species, formerly considered as a congener of Carum segetum. 1. S. Amomum, Linn. (fig. 407). Hedge Sison, Bastard Stone Parsley. -An erect, glabrous annual or biennial, 2 feet high or rather more, with numerous stiff, slender branches in the upper part. Leaves pinnate; the segments of the lower ones ovate or oblong, often an inch long, toothed or lobed, or the lower pair again pinnate; the upper leaves much smaller, with small, narrow segments, deeply 3-lobed, toothed or entire. Umbels on slender peduncles, of 3 to 5 rays, with but few whito 
Howers on short pedicels. Involucres of very few, linear bracts, those of the partial umbels smaller, and often turned to one side. Fruit scarcely above a line long, rather broader than long.

In hedges and thickets, chiefly in western Europe, not reaching the liline in central Europe, but spread here and there much further eastward in the Mediterranean region. In Britain, frequent in sonthern lingland; more rare in the north, not penetrating into Scotland, and not recorded from Ireland. $\mathrm{Fl}$. summer.

\section{TRINIA. TRINIA.}

Leaves dissected. Umbels compound, without involucres, or with a single bract. Flowers diøcious. Petals entire, with an inflected point. Fruit short, somewhat laterally compressed, without visible calycine teeth. Carpels ovoid, with 5 prominent ribs, and single vittas under or within the ribs themselves, not under the interstices as in most Umbelliferce.

A very small genus, chiefly south European and west Asiatic, with a peculiar habit, and differing from $A$ pium chiefly in the diocious flowers, and the position of the vittas of the fruit.

1. T. vulgaris, DC. (fig. 408). Common Trinia.-Stock perennial, short and thick, almost woody, forming a tap-root at its base. Stems annual, erect, stiff and angular, with numerous spreading branches, 6 inclies to near a foot high, the whole plant glabrous, with a glaucous hue. Leaves finely cut into stiff, narrow-linear or subulate segments ; the radical ones twice pinnate, with ternate, entire segments, 3 to 6 lines long, the upper ones twice or only once ternate. Umbels small and numerous, on slender peduncles, forming a loose panicle, each with 4 to 6 rays. Flowers white, the males with much narrower petals than the females. Pimpinella dioica, Sm.

In dry, arid, and stony wastes, chiefly in limestone districts, in western and southern Europe, to the Caucasus, scarcely extending into central Germany. Rare in Britain, and confined to South Devon and North Somerset. Fl. spring or early summer.

\section{IEGOPODIUM. GOUTTEED.}

Leares dissected. Umbels componnd, without any involucres. Petals broad, notched, with an inflected point. Fruit ovoid-oblong, somewhat laterally compressed, without visible calycine teeth. Carpels witl 5 slender ribs and no vittas.

A single species, differing from Carum in habit and in the absence of vittas.

1. 2E. Podagraria, Linn. (fig. 409). Goutweed, Bishopweed, Herb Gerard.-A coarse, erect, glabrous perennial, $1 \frac{1}{2}$ to 2 feet high, with a creeping rootstock. Radical leaves on long stalks, twice ternate; the segments ovate, or ovate-lanceolate, sharply toothed, 2 to 3 inches long, the terminal ones rounded at the base, the lateral ones obliquely cor. date, or sometimes lobed. Stem-leaves few, less divided, with smaller segments. Umbels rather large, with 12 to 20 or even more rays, with numerons white flowers. Fruit about 2 lines long, the styles closely deflected upon it. 
In moist woods and thickets, widely spread over Kurope and Russian Asia, except the extreme north. Having been much cultivated for medicinal purposes, and spreading readily by its creeping rootstocks, it is not always truly indigenous, although a troublesome weed in gardens. In Britain it is common, but chiefly about houses and gardens, and therefore, probably introduced. $F$. summer.

\section{CARUM. CARUM. \\ (Including Petroselinum.)}

Leaves dissected. Umbels compound, with general and partial involucres of several smin! bracts, or in some species without any. Petals with an inflected point, entire or 2-lobed at its base, white or rarely yellowish; fruit ovoid or oblong, slightly compressed laterally without visible calycinal teeth or with very small ones. Carpels narrower than in A pium, with 5 slightly prominent ribs, and single vittas under the furrows; the axis or carpophore splitting to the base when ripe.

The genus as extended by the recent revision is a large one, chiefly European and Asiatio; but with a few North American and South African species. The five British species have by some botanists been distributed in as many distinct genera.

Tall, biennial. Leaves twice pinnate with ovate lobed seg. ments. Flowers yellowish
Slender annual. Leaves simply pinnate with ovato iobed seg: ments. Flowers white

\section{C. Petroselinum.}

2. C. segetum.

stock short, covered with the remains of old leafstalks. Lower leaves pinnate, with many distinct segments. Flowers white.

Begments of the leaves very numerous, short, fine, nearly equal, apparently clustered or whoried along the nain leafstalk

Segments gradually diminishing in length from the base to the top of the leafstalks

Rootstock a globular tuber. Lower ieaves twice or thrice pinnate. Flowers white - . - . . . B. C. Bulbocastanum.

1. C. Petroselinum (fig. 410). Parsley.-An erect, glabrous biennial, or sometimes lasting 3 or 4 years, 1 to 2 feet high, with a thick root and stiff branches. Leaves triangular in their general outline, twice pinnate; the segments stalked, ovate, lobed and toothed; the upper leaves less divided, with narrow, often linear, entire segments. Umbels all stalked, not very large, with 15 to 20 or even more rays; the general involucre consisting of 2 to 4 or 5 short linear bracts, the partial ones of several smaller bracts. Flowers rather small, of a greenish yellow. P. sativum, Hoffm.

A native, apparently, of the eastern Mediterranean region, much cultivated, and often establishing itself in waste places. In Britain it appears quite naturalised in maritime rocks in several parts of northern and western England. F. summer.

2. C. segetum (fig. 411). Corn C.-A glabrous, much branched, slender annual, 9 to 18 inches high, sometimes more. - Leaves chiefly radical, not unlike those of Pimpinella Saxifraga; but smaller, simply pinnate, with 5 to 10 pairs of sessile, ovate, toothed, or lobed segments, 3 to 6 lines long; the npper leaves few and small, merging into linear bracts. Umbels very irregular, the rays few and very unequal; the 
partial umbels containing but few flowers, some quite sessile, others on pedicels varying from 1 to 6 lines in length. Flowers small, white. Fruit $1 \frac{1}{2}$ to 2 lines long, often curved by the abortion of one of the carpels. Petroselinum segetum, $\mathrm{H}$ off m.

In fields and waste places, dispersed over central Europe and western Asia, but apparently wanting both in the north and in the south. In Britain only in southern and central England. Fl. summer and autumn.

3. C. verticillatum, Koch. (fig. 412). Whorled C.-Perennial stock short and thick, covered with the decayed bases of old leafstalks, the fibrous roots slightly thickened, the erect annual stems 1 to $1 \frac{1}{2}$ feet high. Leaves mostly radical, consisting of from 12 to 20 pairs of opposite segments, about 2 or 3 lines long, divided to the base into a number of fine subulate lobes, so as to appear like whorls or clusters of segments placed at regular distances along the common stalk, the whole leaf being 4 to 6 inches long. Stem-leaves similar but few and small. Umbels terminal, not large, of 8 or 10 rays. Involucres, both general and partial, of several very small, linear bracts.

In heaths and bogs, in western Europe, from the Spanish peninsula to Belgium. In Britain, common in some parts of Wales and Ireland, and in Western Scotland. Fl. summer and autumn.

4. C. Carvi, Linn. (fig. 413). Carauay.-A biennial forming a tap root, and perbaps occasionally a perennial stock. Stem erect, branched, $1 \frac{1}{2}$ to 2 feet high. Leaves with a rather long sheathing footstalk, pinnate, with several pairs of segments, which are sessile, but once or twice pinnate, with short linear lobes; in a leaf of 3 or 4 inches, the lowest or next to the lowest segments are about $\frac{3}{4}$ of an inch long, the others diminishing gradually to the top. Upper leaves smaller and less divided. Umbels of about 8 or 10 rass, either without involucres, or with 1 or 2 small linear bracts. Carpels (commonly called Caravay seeds) about 2 lines long, linear-oblong, and usually curved, with the ribs prominent.

In meadows and moist pastures, in the greater part of Europe and Russian and central Asia, from the Arctic regions to the Mediterranean and Himalaya, more rare in western Europe. Naturalised in many parts of Britain; having been long cultivated for its aromatic carpels. $\mathrm{Fl}$. spring and early summer.

5. C. Bulbocastanum, Koch. (fig. 414). Tuberous C.-Resemblcs the Conopodium denudatum, and like that species, the stock forms globular underground tubers, known by the name of Earthnuts or Pignuts. Radical leaves (which usually disappear at the time of flowering) twice or three times ternate; the segments all stalked and pinnately divided into a small number of linear lobes, less unequal than in Conopodium denudatum. Involucres always present, consisting of a few very fine bracts. Carpels like those of $C$. Carvi, but more slender, with the ribs rather less prominent, although more so than in Conopodium denudatum, and the face of the seed is flat or slightly concare, not furrowed as in the Conopodium. Vittas single, under each interstice. Bunium Bulbocastanum, Linn.

In dry pastures, on banks, roadsides, \&c., especially in limestone dis. tricts, in central and southern Europe, and central Asia, scarcely extendIng into central Germany. In Britain, not generally diffused, but said to be abundant in some parts of Hertfordshire, Cambridgeshire, and adjoining counties Not recorded from Ireland. Fl. summer. 


\section{SIUM. SIUM.}

Leaves pinnate. Umbels componnd, with general and partial involucres. Calyz-teeth often prominent. Petals white, notched with an inflected point. Fruit broadly oroid, somewhat compressed laterally. Carpels with 5 slender ribs, and several vittas under each interstice.

A small genus spread over almost all temperate regions of the globe; resembling A pium in the shape of the fruit, but with the calyx-teeth usually prominent as in Cicuta, and differing from both in the more numerous vittas.

Stem usually 3 or 1 feet. Umbels all terminal; rays usually 15

stem much branched, seldom above 2 feet. Umbels mostly lateral; rays usually 10 to 15 .

1. S. latifolium.

2. S. angustifolium.

1. S. latifolium, Linn. (fig. 415). Water Parsnip.-A glabrous perennial, with a creeping rootstock, and stout erect stems 2 to 4 feet high. Lower leaves very long, with 6 to 20 pairs of ovate-lanceolate segments, sessile on the common stalk, toothed or rarely slightly lobed, often 2 to 4 inches long; the upper leaves shorter, with fewer and smaller segments. Umbels rather large, of 15 to 20 rays, and all terminal. Involucres, both general and partial, of several lancelote bracts, of ten toothed. Fruits about $1 \frac{1}{2}$ lines long and broad, the small pointed teeth of the caly $x$ usually very distinct.

In wet ditches and on the edges of streams throughout Europe, except the extreme north; replaced in A sia by a closely allied species or variety. In Britain, not unfrequent in southern and central England and in Ireland, more rare in the north, and very local in southern Scotland. Fl. summer.

2. S. angustifolium, Linn. (fig. 116). Lesser S.-Resembles the S. latifolium, but is not so tall, more branched and leafy, seldom 2 feet high, and in dried-up ditches often less than a foot, and decumbent. Segments of the leaves smaller, 8 to 10 pairs in the lower leaves, fewer in the upper ones, from ovate to ovate-lanceolate, more deeply and sharply toothed or lobed than in S. latifolium. Umbels more numerous, smaller, on shorter peduncles, mostly lateral, with 8 to 12 or 15 , rarely more, rays. Involucral bracts, varying from broad lanceolate to linear, often toothed. Fruit smaller than in S. latifolium, the ribs less prominent, the vittas less superficial, the calyx-teeth very minute. $S$. erectum, Huds.

In wet ditches and shallow streams, throughout temperate and sout hern Europe and western Asia, from south Sweden to Persia. In Britain rather more common than $S$. latifolium in the greater part of England and Ireland, but beeoming scarce in nort hern England and eastern Scotland; in west Scotland it lias been found only in Wigtown. $\mathrm{Fl}$. summer.

\section{PIMPINELLA. PIMPINEL.}

Leaves dissected. Umbels compound, without involucres. Petals broad, notched, with an inflected point. Fruit short, somewhat laterally compressed, without visible calycine tecth. Carpels with 5 scarcely prominent ribs, 2 or 3 vittas under each interstice, and several vittas on the inner face.

The genus, as now usually limited, contains a considerable number of species, chiefly from the Mlediterranean region and west-central Asia 
The shape of the fruit is nearly tbat of Apium, but the ribs are much less prominent, and the vittas more numerous.

Segments of the lower leaves elther nearly orbicular or very much divided

Segments of most of the leaves ovate or lanceolate; the teeth or lobes very polnted.

1. P. Saxifraga.

The Aniseed is the fruit of a species of this genus ( $P$. Anisum).

1. P. Saxifraga, Linn. (fig. 417). Burnet Saxifrage.-Stock short and thick, but not tuberous. Stems erect, 1 to 2 feet high, not much branched, glabrons or downy at the top. Leaves very variable, the radical ones usually pinnate, with 7 to 9 pairs of broadly ovate or orbicular segments, 6 to 9 lines long, toothed or lobed; the upper leaves small, their segments divided into a few narrow, or even linear lobes; sometimes all, even the radical leaves, have their segments once or twice pinnate, with narrow lobes; sometimes the few stem-leaves are, like the radical, simply pinnate, but much smaller, or reduced to simple bracts. Umbels terminal, with from 10 to 15 rather slender rays; the flowers white.

In pastures, on banks, roadsides, \&c., thronghout Europe and Russian Asia, except the extreme north. Abundant in Britain. F. all summer.

2. P. magna, Linn. (fig. 418). Greater P. - Very near $P$. Saxifraga, and perhaps a mere variety. It is much larger in all its parts; the stems often more than 2 feet high, and stouter; the segments of the leaves usually undivided, ovate or lanceolate, often 1 to $1 \frac{1}{2}$ inches long, with more pointed teeth, or, if divided, the lobes much longer and more pointed than in $P$. Saxifraga, the flowers frequently pink, in large umbels, and the fruit also larger.

The general range is nearly the same as that of $P$. Saxifraga, but it is more frequent in mountainous districts and shady situations, or rich soils. In Britain, chiefly in southern and eastern England and sonthern Ireland, but extending into eastern Scotland. Fl. summer, rather late. A further study of intermediate forms, which are frequent in the south of Europe, may induce its reunion with $P$. Saxifraga as a marked variety.

\section{BUPLEURUM. BUPLEVER.}

Leaves quite entire. Umbels compound, or sometimes small and irregular, with partial and usually also general involucres. Petals broad, entire, yellow. Fruit ovoid or oblong, somewhat laterally compressed, without visible calycine teeth. Carpels with 5 more or less prominent ribs, with or without vittas.

A considerable genus, widely diffused over the temperate regions of the Old World, and one of the few natural ones among Umbelliferce, but distinguished more by its entire leaves, with parallel veins and yellow Towers, than by the carpological characters, which in different species correspond to different short-fruited genera.

Leaves broad and perfollate. Bracts of the partial involucres broadly ovate.

Leaves narrow and grasslike.

1. B. rotundifolium,

Annuals. Rays of the umbel few, very short or Incon. spicuous.

Umbels of 3 or 4 short rays. Bracts lanceolate, longer than the flowers 
Flowers 2 or 3 together, in little heads along the slender wiry stems. Bracts very small

Perennials. Umbels of 4 to 8 rays. Bracts shorter than the rays.

\section{B. tenuissimum}

4. B. falcatum.

The B. fruticosum, a shrubby south European species, used formerly to be much planted in our shrubberies, but is now more seldom met with, being rather tender.

1. B. rotundifolium, Linn. (fig. 419). Hare's-ear, Throw-wax.-An erect, stiff, glabrous annual, a foot or rather more high, and remarkable for its broadly ovate leaves; the upper ones embracing the stem, and joined round the back of it, so that they appear perfoliate or pierced through by the stem, the lowest leaves tapering to a stalk. Umbels terminal, of 3 to 5 , or rarely 6 , short rays, withont any general involucre; the partial involucres very mach longer than the flowers, consisting of 4 to 6 broadly ovate yellowish bracts very nnequal in size, the largest about 6 lines long.

A cornfield weed, apparently indigenous to the Mediterranean region, but now widely spread over Europe and western Asia, and introduced into North America. Occurs in cornfields in chalky soils in eastern and southern England, but neither in Ireland nor Scotland. $F l$. with the corn.

2. B. aristatum, Bartl. (fig. 420). Narrow B.-An erect annual, slender but stiff, not much branched, from 2 or 3 inches to near a foot high. Leaves narrow-linear and grass-like, but rather stiff, 1 to 2 inches long. Umbels small, terminal, of 2 to 6 very short rays. Involucres of about 5 lanceolate, green bracts ending in a fine point; the general one usually longer than the rays; the partial ones rather shorter, but still far exceeding the flowers.

In stony wastes, very abundant in southern Europe and eastward to the Caucasus, more scarce in central Europe. In Britain only near Torquay, in East Sussex, and in the Channel Islands. Fl. summer.

3. B. tenuissimum, Linn. (fig. 421). Slender B.-A slender, wiry annual, either simple and nearly erect, or more frequently divided from the base into several decumbent or ascending branches, 6 inches to a foot high. Leaves few, narrow-linear and grass-like, the upper ones very short. Flowers in little heads of 3 or 4 , nearly sessile along the npper part of the stem and branches, sometimes forming little irregularly compound nmbels at the top. Involucres of a few small, linear, pointed bracts. Fruits more conspicnous than in the other species, and covered with little raised dots or granules between the ribs.

On heaths, barren wastes, and stubbles, common in central and southern Europe, especially near the sea, extending eastward to the Caucasus, and northwards to southern Sweden. Occurs in most of the eastern and southern maritime counties of Fngland, and occasionally also fonnd inland, but neither in Ireland nor Scotland. Fl. late in summer.

4. B. falcatum, Linn. (fig. 422). Falcate B.-Stems stiff and erect, slightly branched, 1 to 3 feet high, forming at the base a short perennial stock. Leaves linear, ribbed nnderneath, the radical ones often stalked and rather broader. Umbels terminal and compound, of 4 to 8 rays; the general involucre of 3 or 4 oblong or lanceolate bracts, very much shorter than the rays; those of the partial involucres also lanceolate, of yellowish green, scarcely as long as the flowers. 
In open woods, bushy wastes, and beaths, abundant in the hilly districts of central and southern Europe, and in central and temperate Russian Asia, but scarcely further to the north than southern Belgium. In Britain only on Norton Heath, near Ongar, in Essex, and in Surrey. It is considered to be a doubtful native. Fl. A ugust.

\section{CENANTHE. CENANTH.}

Leaves dissected. Umbels componnd, with partial and sometimes also general involucres, of several small, narrow bracts. Flowers of the circumference usually barren and with larger petals; the fertile ones in the centre sessile, or on very short, often thickened pedicels. Petals notched, with an inflected point. Fruits from ovate to narrow-oblong, crowned with the 5 small calycine teeth. Carpels somewhat corky, with 5 obtusely convex ribs, and single vittas under the furrows.

A rather natural genus, spread over Europe, Asia, and North America, most of the species frequeuting wet meadows, and marshes, or even growing in water.

segments of the upper.leaves few, long and linear.

Stems very hollow. Central umbel fertlle, of 3 rays; those

of the branches barren, of several rays
stems nearly solid. All the umbels of several rays, with fertile and barren flowers . cons, broadly cuneate, or

1. Q. fistulosa.

2. K. pimpinelloides. Segments of the ste
short and oblong.

Umbels terminal and large. Segments of the leaves at least half an inch long . . . . .

Umbels mostly opposite to the leaves. Leaf-segments smali 4 4. W. Phellandrium.

1. CE. fistulosa, Linn. (fig. 423). Water Dropwort.-Stock (probably the offset of the previous autumn) emitting creeping runners, with a cluster of fibrous roots, nsually more or less thickened into oblong tubers. Stems thick and very hollow, erect, 2 to 3 feet high, and slightly branched. Radical leaves twice pinnate, with small cuneate segments divided into 3 or 5 lobes; those of the stem have long stalks, hollow like the stems, and bear only in their upper extremity a few pinnate segments with linear lobes. Umbels terminal, the central one on the stem has only 3 rays, each with numerous sessile fertile flowers, and few or no pedicellate barren ones; those which terminate the branches have usually 5 rays, their flowers all pediccllate and barren. Partial involucres of a few small narrow bracts, the general one either entirely wanting or reduced to a single bract. Fruits in compact globular heads, each one fully 2 lines long, narrowed at the base, and crowned by the stiff, narrow teeth of the calyx, and the still longer, rigid styles.

In wet meadows, and marshes, dispersed orer temperate Europe, extending eastward to the Caucasus, and northward into southern Sweden. Common in England and Ireland, but only in the southern counties of Scotland. Fl. summer and autumn.

2. CE. pimpinelloides, Linn. (fig. 424). Parsley EE.-A perennial, with clustered fibrous roots, swelling into round, ovoid, or oblong tubers, at a greater or less distance from the stock, or, in very wet places, remaining sometimes slender throughout. Stems erect, firmer and more solid than in $C E$. fistulosa, I to 2 feet high, or sometimes more, 
with a few long branches. Leaves much more divided than in the last species, but very variable; the upper ones usually with long, narrow segments, those of the radical leaves much shorter and broader, and sometimes very numerous. Umbels of 8 to 15 rather short rays; the general involucre of a few small, linear bracts, or sometimes wanting; the partial ones of several small, linear bracts. The fertile sessile or shortly pedicellate flowers, and the distinctly pedicellate barren ones are mixed in the same umbels; the persistent styles of the ripe fruits much shorter than in $C E$. fistulosa.

In meadows, pastures, and marshes, throughout central and southern Europe, extending northwards to the Baltic, and eastward to the Cancasus. Abundant in many parts of England and Ireland, but does not penetrate far into Scotland. F. summer and autumn. The great variations in the tubers of the roots and in the form of the radical leaves has induced its division into two, three or four species. These differences have, however, been shown to depend often on soll and situation; at the same time rather more constant differences have been pointed out in the fruiting umbels, although even here intermediate states show that the three following should be considered rather as marked varieties than as true species.

a. EE. pimpinelloides, Linn. Root-fibres usually tuberous. Leaf segments entire or acutely cut. Flowers assuming occasionally a faint tinge of yellowish-green. Fruiting pedicels (although very short) enlarged at the top so as to form a callosity round the base of the fruit, which is itself fully as broad at the base as at the top. In dry or moist, but not marshy meadows and pastures, rare, found only in the southern counties of England.

b. $Q \dot{E}$. Lachenalii, Gmel. Root-fibres usually cylindrical. Leaf-segments obtusely lobed. Flowers of a purer white; the fruiting pedicels less conspicuous, but little enlarged at the top; the fruits either cylindrical or narrowed at the base. In wet marshes, and especially in maritime salt-marshes, found as far north as Argyleshire, and in Ireland.

[c. $C E$. peucedanifolia, Poll. Root-fibres usually spindle-shaped, leaves more pinnate, with cuneate 2- or 3-lobed segments. Fruiting pedicels not enlarged at the top; the fruit itself sub-cylindrical. Marshes and ditches in the southern counties of England only.]

3. $\mathbf{C E}$. crocata, Linn. (fig. 425). Hemlock $\mathscr{E}$. - A stout, branched species, attaining 3 to 5 feet; the root-fibres forming thick, elongated tubers close to the stock; the juice both of the stem and roots becoming yellow when exposed to the air. Leaves twice or thrice pinnate; the segments much larger than in the other species, always above half an inch long, broadly cuneate or rounded, and deeply cut into 3 or 5 lobes. Umbels on long, terminal peduncles, with 15 to 20 rays, 2 inches long or more; the bracts of the involucres small and linear, several in the partial ones, few or none under the general umbel. The pedicellate flowers at the circumference of the partial umbels are mostly but not always barren, the central fertile ones almost sessile. Fruit somewhat corky, the ribs broad and scarcely prominent.

In wet ditches, and along rivers and streams in western Europe, extending eastward into Italy, but not into central France. Common in England, Ireland, and Scotland. Fl. summer. 
4. CE. Phellandrium, Lam. (fig. 426). Pine-leaved $\mathscr{F}$.-Dtem rooting at the base, and either thickened or ercet, or elongated and creeping, or floating, according to the situation it grows in, the flowering branches erect or ascending. Stem-leaves twice or thrice pinnate, with small oblong and entire, or cuneate and lobed segments; or, when under water, all the lobes are narrow and long, sometimes capillary. Umbels much smaller than in $F$. crocata, and almost all on very short peduncles, either opposite to the leaves or in the forks of the branches. Rays seldom above 12. No general involucre, and but very small, narrow bracts to the partial ones. Fruits rather different from those of the other species, being shortly pedicellate, cylindrical, with scarcely pro minent, broad ribs, and the calycine teeth very minute.

In wet ditches, ponds, and along rivers and streams, throughont the temperate parts of Europe and Russian Asia. Not uncommon in England and Ireland, but rare in Scotland, where it bas not been found north of Haddington. Fl. summer. A variety growing usually in decper or running water, with the lower part of the stem much elongated and slender, has been distinguished as $E$. fluviatilis. [ $E$. Phellandrium has an erect stem, 3-pinnate leaves, with very slender segments when submerged, and styles twice as long as the fruit. $E$. fuviatilis, Colem., has an ascending stem, 2-pinnate leaves with obcuncate submerged segments and styles thrice as long as the fruit.]

\section{ITHUSA. FOOL'S PARSLEY.}

Leaves dissected. Umbels compound, with partial involucres. Petals white, notched, with an inflected point. Fruit ovoid, not laterally compressed, without visible calycine teeth. Carpels with 5 thick, prominent ribs, and narrow furrows, with a vitta under each.

A single species, differing from Seseli more in habit than in character.

1. E. Cynapium, Linn. (fig. 427). Fool's Parsley.-An erect, glabrons, leafy annual, 1 to 2 feet high, with forked branches, emitting a nauseous smell when rubbed. Leaves of a bright green, twice or thrice pinnate, the segments ovate-lanceolate, more or less deeply cut into narrow lobes. Umbels on long peduncles, either terminal or opposite to the leaves, of 8 to 12 rays, nsually without general involucres. Partial involucres of 2 or 3 long, linear bracts, turned downwards towards the outside of the umbels, a character peculiar to this species among British Umbellifcra. Fruit about $1 \frac{1}{2}$ lines long, with very small reflected styles.

A common weed in fields and gardens, throughont Europe and Russian Asia, except the extreme north. Abundant in England, but does not appear to extend beyond Elgin in Scotland; it is a native of Ireland. Pl. summer and autumn.

\section{FGEICULUM. FENNEL.}

Leaves finely dissected. Umbels compound, withont involucres. Petals yellow, entire, inflected at the top, but not pointed. Fruit oval, slightly compressed laterally, without visible calycine tecth. Carpels with $\mathbf{5}$ prominent ribs, and single vittas under the furrowe

A single, or perhaps two species, with the yellow flowers and habit of Anethum (or Dill-seed), from which it has been separated, as having tho fruit somewhat lateraliy comnresed, not flattened from front to back. 
1. F. vulgare, Gætn. (fig. 428). Common F.-Stock perennial, but nsually of short duration. Stems erect, branched, 2 or 3 feet high, or when cultivated, still taller. Leaves 3 or 4 times pinnate, with very narrow, linear or subulate segments, rather stiff in dry situations, very slender when cultivated. Umbels rather large, of 15,20 , or more rays, more or less glancous. Fruit about 3 lines long, the vittas very conspicuous, $F$. officinale, All.

On dry, rocky banks, apparently of south European origin, but has long been cultivated, and establishing itself readily in stony or arid billy sitnations, especially near the sea, it is now diffused over temperate Europe and western Asia. Ochurs in many parts of Britain, and may be indigenous on the coast of England, from North Wales to Norfolk, but not north of it; nor in Ireland. Fl. rather late in summer, and sutumn.

\section{SESELI. SESELI.}

Leaves dissected. Umbels compound, with partial and sometimes general involucres of several bracts. Petals white, usually notched, with an inflected point. Fruit ovoid or oblong, not compressed, the calycine teeth usually prominent. Carpels with 5 prominent, often thick ribs, and single, or rarely 2 or more vittas under each furrow.

A considerable genus, widely spread over the northern hemisphere in the Old World. The British species belongs to a section differing from the more common ones in babit, and in the hairy fruit, and is united by some with the southern genus Athamanta, by others considered as an independent genus under the name Libanotis.

1. S. Libanotis, Koch. (fig. 429). Mountain S.-Stock perennial, short, covered with the decayed remains of old leafstalks. Stems stout, erect, 1 to 4 feet high, slightly branched. Leaves chiefly radical, thrice pinnate, with small, ovate or lanceolate, pinnately lobed segments; the stem-leaves few and much smaller. Úmbels of 20 to 30 or more rays, with numerons narrow bracts, both to the general and the partial involucres. Flowers white, crowded. Fruits always hairy, and there is often a minute whitish down on the stems, petioles, and umbels.

In hilly pastures, in central and eastern Europe and Russian Asia, less frequent in the west, and wanting in the south. In Britain, limited to chalk-hills in Hertford, Cambridge, and Sussex. Fl. summer

\section{LIGUSTICUM. LOVAGF.}

Leaves dissected. Umbels componnd, with partial involucres of many bracts. Petals white, notched, with an inflected point. Frnit ovoid, or oblong, not compressed, the calycine teeth scarcely distinct, Carpels with 5 very prominent acute ribs, almost expanded into wings, and several vittas under each furrow.

A genus of several European, Asiatic, and North American species, chiefly mountain plants, differing from Seseli in the acute ribs of the fruit and indistinct calycine teeth.

1. I. scoticum, Linn. (fig. 430). Scotch L.-Stock perennial, descending into a tap-root. Stem erect, glabrous, thick snd hollow, 1 * 2 feet high, slightly branched. Lower leaves on long stalks, deeply 
divided into 3 , each branch bearing 3 broadly ovate or obovate toothed segments, or 1 segment deeply divided into 3 lobes, each segment above an inch long. Upper leares less divided, with short stalks. Umbels of 12 or 20 rays, with a general involucre of 2 or 3 very narrow bracts, and more numerous ones to the partial umbels. Fruit near 4 lines long.

$\Lambda$ high northern plant, extending all round the Arctic Circle. Common on the rocky sea-coasts of Scotland and northern Ireland, descending also to the north-east of England. Fl. summer.

\section{SILAUS. SILAUS.}

Leaves dissected. Umbels compound, with partial involucres of sereral bracts. Flowers yellowish. Petals scarcely notched. Fruit nearly of Ligusticum, ovoid, but slightly compressed, with the ribs scarcely acute, and the vittæ much less conspicuous.

A genus of 2 or 3 European and Asiatic species, but slightly differing from Ligusticum, chiefly in the colour of the flowers.

1. S. pratensis, Bess. (fig. 431). Peppcr Saxifrage.-A glabrons, erect perennial, 1 to 2 or sometimes near 3 feet high, slightly branched. Leaves once, twice, or three times pinnate; the segments not numerous, narrowoblong, $\frac{1}{2}$ to 1 inch long, entire or 3-lobed. Umbels all terminal, not large, of about 6 to 8 rays. General involucres usually of 1 or 2 small bracts, with several small narrow-linear ones to the partial umbels. Flowers of a pale greenish-yellow. Carpels about 2 lines long.

In meadows, and moist, bushy pastures, throughout Europe and Russian Asia, exeept the extreme north. In Britain, spread over Kngland and south-eastern Scotland, but scarce in the western counties and in Ireland. $F l$. summer, rather late.

\section{MEUM. SPIGNEL.}

Leaves finely dissected. Umbels compound, with partial involucres of several bracts. Petals white or pink, entire, with an incurved point. Fruit oblong, without distinct calycine teeth. Carpels with 5 prominent acute ribs, and 2 or 3 vittas under each furrow.

A genus of 2 or 3 Enropean species, differing by characters of very little importance from Ligusticum, with which some botanists nnite it.

1. M. athamanticum, Jacq. (fig. 432). Spignel Meu, Baldmoney.Stock short, perennial, covered with the fibrous remains of old leaves, and emitting a tuft of radical leaves; their segments decply cut into numerous very fine, but short lobes, so as to have the appearance of being whorled or clustered along the common stalk, as in Carum verticillatum, but the stalk itself is once or twice pinnately divided, not simple as in that plant. Stems 1 or rarely near 2 feet high, with a very few smaller and less divided leaves. Umbels terminal, not large, of 10 to 15 rays, with 1 or 2 narrow bracts to the general one, and partial involucres of a small number of short, slender bracts. Fruits about 4 lines long.

In mountain pastures, in western and central Europe, not extending eastward beyond the Russian frontier, nor northward into Scandinavia 
Not unfrequent in the Scotch Highlands, in northern England and North Wales, but not recorded from Ireland. Fl. summer.

\section{CRITHMUM. SAMPIIIRE.}

Leaves succulent, dissected. Umbels compound, with general and partial involucres. Petals entire. Fruit ovoid, not compressed, without distinct calycine teeth. Carpels of a thick, succulent or somewhat corky consistence, with 5 acute ribs becoming prominent wben dry, but not winged; the vittas numerous, slender, and irregular. Sceds loose in the cavity, with numerous fine vittas on the outside.

A single species, very different from any other British Umbellifera, but closely allied to the large Mediterranean and Asiatic genns Cachrys, with which some botanists unite it.

1. C. maritimum, Linn. (fig. 433). Samphire-A perfectly glabrous perennial, seldom above a foot high, almost woody at the base; the young branches, foliage, and umbels, thick and fleshy. Leaves twice or thrice ternate, with thick linear segments about an inch long. Umbels of 15 to 20 or more rays. Involucres of several small linear or lanceolate bracts. Petals very minute, fugacions. Fruits abont 3 lines long.

In clefts of rocks, close to the sea, in western Europe and northern Africa, and extending along the Mediterranean to the Black Sea. Abundant in southern and western England and southern Ireland, but rare in northern England, and in Scotland confined to Asrshire. Fl. summer.

\section{ANGELICA. ANGRLICA.}

Leaves dissected. Umbels compound, with partial involucres of several bracts. Petals white, entire. Fruit flattened from front to back; the carpels broad, with 3 ribs on the back, the edges expanded into wings, those of the 2 carpels distinct before they separate, so that the fruit is surrounded by a double wing.

A genus of few species, dispersed over Europe, Asia, and North America, distinguished from all other British Umbelliferce by the double wing round the fruit.

1. A. sylvestris, Linn. (fig. 434). Wild A.-A tall, stont, branching perennial, attaining 3 or 4 feet in height, with thick stems, slightly downy in the upper part. Lower leaves large, twice pinnate, with ovate-lanceolate segments, often about 2 inches long, sharply toothed, and sometimes 3-lobed; the upper leaves shorter stalked, with fewer segments, those under the peduncles often reduced to a broad sheath, with a few small segments at the top. Umbels large, terminal, those of the main stems often with 30 or 40 rays. General involucre of 2 or 3 linear bracts; partial ones of several fine, short bracts.

In moist woods and marshy places, especially near streams, throughont Kurope and Russian Asia to the Arctic regions, Abundant in Britain. Fl. late in summer.

The garden Angelica (Archanglica officinalis), of northern and eastern kurope, long cultivated for confectionery, is not wild in Britain. 


\section{PEUCEDANUM. PEUCEDAN.}

Leaves dissected. Umbels compound, with partial involucres of many bracts. Petals white or yellowish, entire or notched, with an inflected point. Fruit flattened from front to back; the calycine teeth very small or indistinct. Carpels broad, with 3 prominent ribs on the back, the edges expanded into a wing, those of the 2 carpels so close as to form a single edge to the fruit before the carpels separate. Vittas single under the furrows.

A large genus, widely spread over Europe, Asia, and North America, scarcely differing from IIeracleum except in the more evident ribs of the carpels, the more slender vittas, and generally in Libit.

Segments of the leaves narrow-oblong or llnear.

Leaves several times ternate. Flowers yellowish . . . 1. P. offcinale.

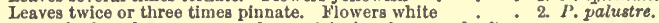

Leaves of 3 broad segments, each one 3 inches long, and often 3-lobed.

The Dillseed (Anethum gravcolens), often cultivated as a condiment, has the fruit of a Peucedanum, with the fine leaves of a Fœniculum.

1. P. officinale, Linn. (fig. 435). Hog's Fennel, Sulphur-weed.-A glabrous perennial, with erect, branching stems, 2 or even 3 feet high. Leaves 3,4 , or 5 times ternate, with narrow-linear entire segments, often above 2 inches long. Umbels large, of 20 or more rays, with pale yellow flowers. Bracts of the general involucre very few or wanting; those of the partial involucres very narrow and shorter than the pedicels. Fruit broadly oval, near 3 lines long.

In meadows and moist pastures, in central and eastern Europe and Russian Asia, or near the sea in western Europe. Very rare in Britain : forms of Enanthe pimpinclloides or of Silaus pratensis have been so frequently mistaken for it, that the only certain stations are the salt marshes of Kent and Essez, and the Cliannel islands. Fl. summer and autumn.

2. P. palustre, Mœench. (fig. 436). Hog's Fenncl, Milk Parsley.Tall and erect like the last, but often hairy at the base, and the juice is milky. Leaves twice or thrice pinnate rather than ternate with much shorter segments, varying from oblong to linear, and seldom exceeding balf an inch. Umbels not so large as in $P$. officinale although consisting of as many rays. Flowers white. Involucres both general and partial, of several lanceolate or linear bracts, with fine points. Fruit broadly oval, about 2 lines long.

In wet meadows and marshes, in central, eastern, and northern Europc, and Russian Asia, to the Arctic Circle. Apparently wanting in western France, although it extends into Spain. Like $P$. officinale, very local in Britain, and only known for certain in the marshes of eastern England, from Suffolk to Yorkshire, and in Somerset. Fl. late in summer.

3. P. Ostruthium, Koch. (fig. 437). Master-wort.-Stock perennial, with stout, erect stems, 2 to 3 feet high. Leaves divided into 3 large, broad segments, which are again deeply 3-lobed and eoarsely toothed, 3 to 4 inches long, and often rather rough with a few short hairs, but much less so than in Heracleum; the lateral segments descend mnch lower along the leafstalk on the outer than on the inner side. Umbels large, terminal, of 40 or 50 rays, without any general involncre, and 
only a few very slender small bracts to the partial ones. Flowers white. Fruit nearly orbicular, about 2 lines diameter.

A native of mountain pastures in central Europe; formerly much cultivated as a pot-herb, and now naturalised in several parts of northern Europe, in the north of England, and in Scotland. Fl. early summer.

\section{PASTINACA PARSNIP.}

Habit and fruit of Heracleum, bnt the flowers are yellow and all small. The vittas are also nsually more slender, and descend lower down on the fruit, but this character is not constant.

A genus of very few species, chiefly from the Mediterranean region and west-central Asia, now often reduced to a section of Peucedanum.

1. P. sativa, Linn. (fig. 438). Common P.-An annual or biennial, forming a tap-root, with an erect stem seldom more than 2 feet high when wild, 3 or 4 when cultivated. Lower leaves pinnate, coarse, and more or less downy, especially on the under side, with 5,7 , or 9 segments, each 1 to 3 inches long, sharply toothed, and more or less lobed, especially the terminal one; upper leaves small and less divided. Umbels not very large, of 8 to 12 rays, usually without involucres. Fruits about 3 lines long, flat and oval, with scarcely prominent ribs, the vittas very conspicuous, descending nearly to the base of the fruit.

In pastures and thickets, on banks and edges of fields, throughout central and sonthern Europe, and temperate Russian Asia, Frequent in England, extending at least as far north as Durham, an escape in Scotland, and doubtful native of Ireland. Fl. summer.

\section{HERACLEUM. HERACLEUM.}

Coarse, rough herbs, the leaves dissected with large segments. Umbels compound; the bracts few and decidnons or none. Flowers white; the outer petals of each umbel larger. Fruit flattened from front to back, with a single thin border (splitting only by the separation of the carpels). Carpels broad, with 3 very fine, scarcely prominent ribs; or if 5 , the 2 outside ones close to the border. Vittas single to each interstice, not descending to the base of the fruit, and often thickened at the lower end.

A rather natural genus, comprising a considerable number of species, from the monntains of central and southern Europe, and especially central Asia, with a single North American one. Some Asiatic species, remarkable for their size (the annual stems 12 to 15 feet, with umbels more than a foot in diameter), are occasionally grown in our gardens.

1. H. Sphondylium, Linn. (fig. 439). Cov Parsnip or Hogweed.-A tall, coarse plant, although not quite so large nor so much branched as Angelica sylvestris, and the stock of much shorter duration, but not strictly biennial as commonly supposed; the whole plant more or less rough, with short, stiff hairs. Leaves pinnate, with 3, 5, or 7 large, broad segments, usually 3 -lobed and toothed, from 3 to 5 inches long and at least as broad, sometimes more numerous and much narrower. Umbels large, of abont 20 rays, the outer petals much larger than the others. Carpels nearly orbicular, 3 or 4 lines long; the vittas very conspicuous, often only reaching halfway down the fruit. 
In meadows, pastures, hedges, and thickets, throughout Europe and Russian Asıa. In Britain, one of the commonest of our Umbelliferc. $F l$. summer and autumn.

\section{TORDYLIUM. HARTWORT.}

Leaves dissected. Umbels compound, with general and partial involucres. Flowers white or pink, the onter petals often larger. Fruits flattened from front to back, with a single thick border (splitting only by the separation of the carpels), and covered with stiff hairs or tubercles. Carpels broad, with the ribs scarcely visible, and 1 or 3 vittas under the intorstices.

A small genus, chiefly from the Mediterranean region, with the appearance of Caucalis, but readily known by the flat fruit.

1. T. maximum, Linn. (fig. 440). Great H.-An erect annual, 2 feet or rather more in lieight, rough with short, stiff hairs. Leaves pinnate, with 5,7 , or 9 segments, lanceolate or almost ovate, and coarsely toothed; the lateral ones 1 to 2 inches, the terminal ones usually longer. Umbels terminal, of 8 to 10 short rass, with a few rather long, narrow bracts to the involucres. Petals all small and pink. Fruits about 3 lines long, the thickened border very prominent.

In waste and cultivated lands, in southern Europe, and eastward to the Caucasus; more rare as a weed of cultivation in central Europe. In Britain, only in Middlesex, Oxford, and Buckinghamshire. Fl. summer.

\section{SCANDIX. SCANDIX.}

Leaves dissected. Umbels compond, with partial involucres of several bracts, and white flowers. Fruit linear, with a very long, smooth beak. Carpels (below the beak) with 5 obtuse ribs, without vittas. Albumen of the seed with a longitudinal furrow on the inner face.

A small but distinct genus, ranging chiefly over the Mediterranesn region and west-central Asia.

1. S. Pecten, Linn. (fig. 441). Shepherd's needle, Venus's comb.-A branching annual, erect or spreading, 6 inches to a foot high, and more or less hairy. Leaves twice or thrice pinnate, with short segments cut into narrow lobes. Umbels terminal, of 2 or 3 rays, without general involucres; partial involucres of several lanceolate bracts, often 2 or 3 -lobed at the top. Flowers almost sessile, small and white, with a few large outer petals. Fruits attaining near 2 inches; the carpels at the base eylindrical and ribbed, 4 or 5 lines long, the remainder occupied by a stiff, flattened beak, often compared to the tooth of a comb.

In fields and waste places, throughout Europe and west-central Asia. Frequent as a cornfield weed in England, Ireland, and the south of Scotland, but decreasing further northward. Fl. with the corn.

\section{MYRRHIS. CICELY.}

Leaves dissected. Umbels componnd, with partial involucres of several bracts, and white flowers. Fruit narrow-oblong not beaked. Carpels with 5 very prominent, acute ribs, which are hollow inside, and no vittas. Albumen of the seed with a deep longitudinal furrow on the inner face. 
A single species, scarcely distinct as a genus from Charophyllum.

1. M. odorata, Scop. (fig. 442). Sweet Cicely.-An erect, branching, hairy perennial, 2 to 3 feet high, with the foliage and habit of a Charophyllum and highly aromatic. Leares large, thin, twice or three times pinnate, with numerous lanceolate segments, deeply pinnatifid and toothed. Umbels terminal, not large, with seldom more than 8 or 10 rays, and of these but few ripen their fruits. No general involucre; bracts of the partial ones lanceolate, thin whitish, with fine points. Fruits when ripe 6 or 7 lines to near an inch long; the very prominent ribs occasionally rough with minute hairs.

A native of mountain pastures, in central and southern Europe, from the Pyrenees to the Caucasus. Of ancient cultivation in more northern Europe, it has frequently established itself in the neighbourhood of cottages. In Britain, believed by some to be truly indigenous in the hilly districts of Wales, northern England, and Scotland, where, at any rate, it is perfectly naturalised. Fl. spring and early summer.

\section{CONOPODIUM. CONOPODIUM.}

Leaves dissected. Umbels compound, either without involucres or with very few small bracts, and white flowers. Fruit oval-oblong, somewhat laterally compressed, shortly contracted at the top, with erect, or slightly spreading styles. Carpels with 5 scarcely perceptible ribs, and several very slender vittas under the interstices. Albumen of the seed, with a longitudinal furrow on the inner face.

A genus of few species, chiefly from the Mediterranean Icgion, with the habit of the tuberous Carums, but with a fruit more nearly allied to that of some Charophyllums, although shorter.

1. C. denudatum, Koch. (fig. 443). Earthnut, Pignut.-The perennial stock consists of a globular tuber, the annual stems erect, slender, glabrous, 1 to near 2 feet high, with a few forked branches. Radical leaves few and decaying early, with 3 long-stalked segments, each once or twice pinnate; the ultimate divisions short, narrow, pointed, entire or 3-lobed. Stem-leaves few, with narrow-linear divisions; the central lobe of each segment much longer than the lateral ones. Umbels terminal, or one opposite the last leaf, of 6 to 10 rays. The ribs and vittas of the fruit are scarcely perceptible. Bunium flexuosum, With.

In woods and pastures, chiefly known as a west European plant. Much more common in Britain than Carum Bulbocastanum, which is also known under the name of Pignut. Fl. summer.

\section{CH无ROPHYLLUM. CHERVIL.}

Leaves dissected. Umbels compound, with partial involucres of several bracts, and white flowers. Fruit narrow-oblong or linear, contracted at the top, and sometimes forming a beak always much shorter than the seed. Carpels with 5 ribs, sometimes only apparent at the top, either without vittas or with one vitta under each interstice. Seed marked with a longitudinal furrow on the inner face.

A considerable and rather natural genus, widely diffused over the northern hemisphere without the tropics. It is usually divided into 
two, Charophyllum, with a vitta between each rib; and Anthriscus, without vittas, and the ribs themselves scarcely visible, except at the top, when the fruit is beaked; but the distinction is purely artificial.

Umbels on short, lateral peduncles. Fruit short, hispid

3 C. Anthriecus

Úmbels terminal. Fruit long, glabrous.

Lobes of the leaves rather obtuse. Ribs and vittas of the fruit conspicuous when dry

Lobes of the leaves pointed. Fruit very smooth, without ribs or vittas

\section{C. temulum.}

2 C. sylvestre.

The garden Chervil (C. sativum, Gartn., Anthriscus Cerefolium, Hoffm.), a native of south-eastern Europe, may occasionally be found in waste places near where it has been cultivated. It is a more slender plant than $C$. sylvestre, the leaves more dissected, with shorter segments, the umbels mostly lateral and sessile, and the fruit evidently beaked.

1. C. temulum, Linn. (fig. 444). Rough C.-An ercet biennial, 2 to 3 feet high, and rough with short reflexed hairs. Leaves twice pinnate or ternate, with ovate or wedge-shaped, pinnatifid or toothed segments, more or less hairy, especially on the upper side; the lobes short and rather obtuse, never elongated and pointed as in $C$. sylvestre and Myrrhis odorata. Umbels of few rays, without a general involucre; the partial involucres of 5 or 6 broadly-lanceolate bracts, shorter than the pedicels. Outer petals of the umbel rather large. Fruit the size of that of $C$. sylvestre, but with 5 obtuse ribs and vittas between them.

In hedges and thickets, in central and southern Europe, and all across Russian Asia, extending northwards into southern Scandinavia. Frequent in England, less so in Ireland and in the Scotch Highlands. $F l$. summer.

2. C. sylvestre, Linn. (fig. 445). Wild C.-The perennial, or per. haps only biennial, stock descends into a tap-root. Stems hairy, erect, and branched, 2 to 3 feet high. Lower leaves on long stalks, twice pinnate, with ovate-lanceolate pointed segments, deeply pinnatifid and toothed ; upper leaves smaller, on shorter stalks, all more or less hairy or rarely nearly glabrous. Umbels rather numerous, not large, of 8 or 10 rays, with small white flowers. No general involucre, but the partial ones of several bracts. Fruits about 3 lines long, very smooth and shining, without ribs or vittas, narrowed at the top, but without any distinct beak. Anthriscus sylvestris, Hoffm.

Under hedges, on the borders of fields, \&c., throughout Europe and Russian Asia In Britain, one of the commonest Umbelliferce. Fl. spring.

3. C. Anthriscus, Lam. (fig. 446). Burr C.-An erect, branched, hairy annual, attaining near 2 feet in height, with nearly as much the habit of a Caucalis as of a Chorophyllum. Leaves not large, twice, or the lower ones thrice pinnate, with ovate or ovate-lanceolate segments, pinnately lobed and toothed. Umbels small, on short peduncles, opposite to the leaves, of 3 to 7 rays, without general involucres, and but few bracts to the partial ones. Fruits ovoid-oblong, not 2 lines long, covered with short, hooked bristles, and narrowed at the top into very short smooth beak. Anthriscus vulgaris, Bernh.

A weed of cultivation, probably of south European origin, but readily spreading with our crops, and now established in scattered localities 
over Rurope and Russian Asia Rather frequent in England and Scotland, more scarce in Ireland. Flo spring and early summer.

\section{CAUCALIS. CAUCALIS.}

Halry annuals, with dissected leaves. Umbels usually componnd, with partial involucres of several simple bracts, or rarely wanting. Outer petals usually larger, and deeply bifid. Fruit ovoid, covered with prickles or bristles. Carpels with 3 or 7 dorsal ribs, and 2 on the inner face; vittas single nnder each furrow. Albumen more or less furrowed on the inner face.

A small European, Asiatic, and African genus, one of the few natural ones in the family, if retained entire. It is well distinguished from Daucas by the involncre, the shape of the fruit, and the albumen; from the bristle-fruited Charo; hyllum by the want of the smooth tip to the fruit; from all other British compound nmbelled Umbelliferce by the bristled fruits.

Umbels opposite to the leaves, sessile, or on peduncles shorter than the rays.

Umbels contracted into little sesslle heads. Fruit short.

Umbels of 3 or 4 slender rays. Fruit oblong, with a short beak

Umbels terminal, or on peduncles longer than the rays

. Fruit not 2 lines long, with short bristles, mostly hooked.

General involucre of several bracts (often very small), one under each of the outer rays General involucre of a single bract or entirely wanting.

Fruit 3 or 4 lines long or more, with long prickles.

Leaves twice or thrice pinnate, with mucli cut, short segments

Leaves once pinnate, with 'ong pinnatilld segments

C. nodosa.

Charophyllum.

Anthrisctus.

\section{C. Anthriscus.}

3. C. arvensis.

4. C. daucoides. C. Latifolia.

1. C. nodosa, Sm. (fiy. 447). Knotted Caucalis.-Stems procumbent or spreading, scarcely a foot long. Leaves twice pinnate, with small, narrow, pointed segments. Umbels forming little heads, closely sessile, and opposite to the leaves; they are sometimes composed of 2 or 3 exceedingly short, scarcely distinct rays, sometimes of a simple cluster. Fruits smaller than in the other species; the onter ones covered with short, straight or hooked bristles, which on the inner ones are reduced to mere tubercles. Torilis nodosa, Linn.

On roadsides and in waste places, in the limestone districts of central and southern Europe, and eastward to the Caucasus, extending northward chiefly as a weed of cultivation. Common in sunny places in southern England and Ireland, more rare in the north and in southern Scotland. Fl. spring and summer.

2. C. Anthriscus, Huds. (fig. 448). Hedge Parsley.-Stem erect, attaining 2 or even 3 feet, with slender, wiry branches, sprinked, as well as the leaves, with appressed, stiff hairs. Leaves once, or the lower ones twice pinnate; the segments lanceolate, pinnatifid, or coarsely toothed; the lower ones of each leaf stalked, and remote from tho others. Umbels on long, slender peduncles, rather small, of from 3 to 7 or 8 rays. Involucres, both general and partial, of small, subulate bracts, one close under each ray and often readily distinguished at first sight. Petals pink or white, not very nnequal in size. Fruit a small burr, being covered with short, rough bristles, more or less curved inwards, or hooked at the top. Torilis Anthriscus, Linn. 
In hedges, on roadsides, and waste places, common throughout Kurope and central and Russian Asia, except the extreme north. Abundant all over Britain. Fl. summer and autumn.

3. C. arvensis, Huds. (fig. 449). Spreading C.-Very near C. Anthriscus, but usually a rather smaller and more spreading plant; the general involucre is either entirely wanting or reduced to a single bract, often lanceolate, and the bristles of the fruit are usually less curved, but with a minute hook at the top ; this character is not, however, so constant as that of the involucre. C. infesta, Curt.

In cultivated and waste places, on banks and in roadsides, in central and southern Europe to the Caucasus, not extending into Scandinavia. In England, chiefly amongst corn, in the midland and eastern counties and in Wales. It is said to be abundant in several local Floras, bat $C$. Anthriscus is often mistaken for it. Fl. summer and autumn.

4. C. daucoides, Linn. (fig. 450). Small C.-Erect or spreading, and much branched, seldom above a foot high. Leaves twice or three times pinnate, with rather narrow, but short, pinnatifid segments, the general outline of the leaf being broadly triangular. Umbels terminal or opposed to the leaf, on rather long peduncles, usually of 3 or 4 rays only. General involucre of one bract, partial ones of a few linear bracts. Flowers white or pink, the outer petals occasionally larger. Fruits nearly sessile, attaining, when ripe, nearly half an inch, covered with long, stout prickles. There are usually in each partial umbel a few barren flowers on longer pedicels.

A cornfield weed of sonthern origin, now widely spread over Europe and Russian Asia. Apparently well established in some of the eastern and southern counties of England, and the Channel Islands. Fl. with the corn.

5. C. Iatifolia, Linn. (fig. 451). Broad C.-Stem seldom a foot high, erect or spreading, and branched at the base. Leaves much less divided than in the other species, being simply pinnate, with oblonglanceolate segments, the lowest above an inch long, and pinnatifid, the others gradually diminishing to the top, and less deeply cut. Umbels terminal or opposite the leaves, on stout peduncles, consisting of 2 or more rays. Involucres, both general and partial, of broad, thin bracts. Flowers white or purple, the outer petals large. Fruit 4 or 5 lines long, the primary and secondary ribs equally prominent, with long, straight, or hooked prickles.

In fields and waste places, in sonthern Europe and west-central Asia, often establishing itself for a time in more northern localities. Occasionally found as a cornfield weed in several of the more southern counties of England. Fl. with the corn.

\section{DAUCUS. CARROT.}

Leaves dissected. Umbels compound, with general and partial involucres of several linear, pinnatifid or divided bracts. Fruit ovoid, prickly on tha ribs, the 4 secondary ribs more prominent than the 3 primary dorsal ones. Albumen not furrowed.

A genus of very few real species, althongh many are published; they are widely spread over most cultivated or maritime parts of the globe. 
1. D. Carota, Linn. (fig. 452). Common C.-An ercet annual or biennial, 1 to 3 feet high, with a tap-root. Lower leaves twice or thrice pinnate, with deeply 3-lobed or pinnatifid segments, usually lanceolate or linear, sometimes short and crenate; upper leaves with fewer and narrower divisions. Umbels terminal, rather large, with numerous crowded rays; the inner ones very short, the outer much longer, and usually closing over after flowering, so as to give a concave or globular form to the umbel, with the fruit inside. Bracts of both involucres usually divided into 3 or 5 long linear lobes. Fruit covered with prickles, of which the larger ones are often much flattened at the base.

Probably an original native of the sea-coasts of southern Europe, but of very ancient cultivation, and sows itself most readily, soon degenerating to the wild form with a slender root, and now most abundant in fields, pastures, waste places, \&c., throughout Europe and Russian Asia. Common in Britain, especially near the sea. Fl. the whole summer and autumn. A maritime variety, with the leaves somewhat fleshy, with shorter segments, more or less thickened peduncles, more spreading nmbels, and more flattened prickles to the fruits, is, D. gummifer, Lamck., $D$. maritimus, With., but in many seaside localities a regular passage from that to the common form may be readily traced.

\section{CONIUM. HENLOCK.}

Leaves dissected. Umbels compound, with general and partial involucres and small white flowers. Fruit broadly ovate, somewhat laterally compressed, without distinct calycine teeth. Carpels with 5 prominent ribs, which when ripe are often slightly wared or crenated. No vittas. Albumen with a deep longitudinal furrow on the inner face.

A single species, with the short fruit of an Apium or Cicuta, but differIng essentially in the deeply furrowed albumen.

1. C. maculatum, Linn. (fig. 453). Hemlock.-An erect, branching annual or biennial, 3 to 5 feet high or sometimes more, usually glabrous, and emitting a nauseous smell when bruised. Leaves large and much divided into numerous small ovate or lanceolate deeply cut segments ; the upper leaves gradually smaller and less divided. Umbels terminal, not large for the size of the plant, of 10 to 15 rays. Bracts short and lanceolate; those of the general involucre variable in number ; those of the partial ones almost always 3, turned to the outside of the nmbel. Fruit about 2 lines long.

On the banks of streams, along hedges, and the borders of fields, \&c., widely spread over Europe and temperate Asia, though not always common. Generally distributed over Britain. Fl. summer.

\section{PHYSOSPERMUM. PHYSOSPERM.}

Leaves dissected. Umbels compound, with general and partial in. volucres. Flowers white. Fruit 2-lobed, the carpels nearly globular, and attached by a narrow edge, each with 5 scarcely visible rays, and single vittas to the interstices. Albumen with a longitudinal furrow on the inner face.

A genus of very few species, from Enrope and temperate Asia.

1. P. cornubiense, DC. (fig. 454). Cornish P.-Stock perennial, 
Stcm erect, almost leafless, $1 \frac{1}{2}$ to 2 feet high, slightly branched. Radical leaves on long stalks, twice or thrice ternate; the segments ovate or cuneate, and deeply cnt. Umbels terminal, of 10 to 12 rays, with rather large, white flowers. Involucres, both general and partial, of very few linear bracts. The fruits have the appearance of two little smooth bladders placed face to face, with a loose seed in each.

A mountain plant, occurring here and there along the great European chain from the Asturias to the Cancasus, and reappearing in a few very limited localities in Cornwall and Devonshire. Fl. late in summer. The Continental plant, $P$. commutatum, Spr., is by some botanists considered is a distinct species from the British one, but the characters appear to have been derived from the examination of single specimens.

\section{SMYRNIUM. SMYRNIUM.}

Leaves entire or dissected. Umbels compound, either without in. volucre, or only a very few small bracts. Flowers yellow. Fruit 2 . lobed; the carpels ovoid, attached by the very narrow face, each with 3 prominent-angular ribs, and several vittas under the interstices. Albumen with a longitudinal furrow on the inner face. Asia.

A genus of few species, from the Mediterranean region and western

1. S. Olusatrum, Linn. (fig. 455). Alexanders.-A coarse, erect annual or biennial, 2 to 4 feet high, and nearly glabrous. Lower leaves twice or thrice, npper ones but once ternate; the segments, broadly ovate, coarsely toothed or 3 -lobed, 2 or more inches long and broad, and often of a yellowish-green. Umbels terminal, of 8 to 12 rays. Flowers of a greenish-yellow, much crowded in the partial umbels. As the fruit ripens, the peduncles are often much thickened under the umbels. Carpels above 3 lines long, very angular.

In mcadows and waste places, especially near the sea, all round the Mediterranean and up western Europe to the English Channel. Probably indigenous in several counties of southern England and Ireland; having been formerly much cultivated, it has spread into many inland parts of England and southern Scotland. Fl. spring and early summer.

\section{CORIANDRUM. CORIANDER.}

Fruit globular, not readily separating into the two carpels, crowned by the conspicuous teeth of the calyx, the ribs scarcely prominent, and no vittas.

A single species, very distinct in the form of the fruit.

1. C. sativum, Linn. (fig. 456). Coriander.-An erect, branching, glabrous annual, 1 to $1 \frac{1}{2}$ feet high, emitting a very disagreeable smell when rubbed. Lowest leaves once or twice pinnate, with broadly-ovate or cuneate, deeply-cut segments; the others more divided, with linear segments, few and slender in the uppermost leaves. Umbels terminal, rather small, of 5 to 8 rays, without general involucre, and only a few small slender bracts to the partial ones. Flowers white, the outer petals larger. Fruits about 2 lines long.

A native of the Levant, long since cultivated in Europe, and occasion. ally spreading as a weed of cultivation. Said to be established as such in some of the southern and eastern counties of England. Fl. summer. 


\section{ARALIACE⿸广 THE ARALIA FAMILY.}

Shrubs, trees, or climbers, rarely herbs, differing from most Umbelliferce in their simple (solitary or paniculate) umbels, and more generally in their fruit more or less succulent, consisting often of more than 2 (from 2 to 10 ) carpels, which do not separate so readily as in Umbelliferce, usually forming a single berry, or, more strictly speaking, a berry-like drupe, containing as many 1-seeded nuts as there are carpels. The styles also are sometimes united.

A considerable Order, widely spread over the warmer regions of the globe, represented in Europe by a single species. Some species of Aralia are cultivated in gardens.

\section{HEDERA. IVY.}

Petals not cohering at the top, valvate in the bud. Cells of the ovary 5 or 10 . Styles short, usually cohering in a single mass.

A genus, as now limited, containing only a single Australian species, besides the British one.

1. H. Helix, Linn. (fig. 457). Common 1vy.-A woody, evergreen climber; when wild the lower, slender branches spread along the ground, with small leaves, whilst the main stems climb up trees, rocks, or buildings to a great height, adhering by means of small rootlike excrescences. Leaves thick and shining, ovate, angular, or 3- or 5lobed; those of the barren stems nsually much more divided than the upper ones. Flowering branches bushy, projecting a foot or two from the climbing stems, each bearing a short raceme or panicle of nearly globular umbels. Flowers of a yellowish-green. Borders of the calyx entire, scarcely prominent, about half-way up the ovary. Petals 5, broad and short. Stamens 5. Styles united into a single very short one. Berry smooth and black, with from 2 to 5 seeds, the albumen deeply wrinkled.

In woods, on rocks and old buildings, common in western and southern Kurope, northern Africa, the Himalaya, and in Japan, scarcely penetrating into central Europe, except where the winters are very mild. Extends over the whole of Britain. Fl. late in autumn. Several varieties are in cultivation, differing chiefly in the more or less divided leaves, and one with yellow berries, introduced from the Continent, has become almost wild in some parts of southern and western England; another, the so-called Irish ivy, $H$. canariensis, Willd., with very broad thick leaves, is a very doubtful native of Ireland.

\section{LORANTHACEE. MISTLETOE FAMILY.}

Shrubby or half-succulent evergreens, parasitic on the branches of trees, with jointed branches, opposite thickish leaves, and no stipules. Calyx combined with the ovary, either entirely so, or appearing only in the shape of an entire or toothed border 
round its summit. Petils 4. Stamens 4, opposite the petals, and usually inserted on them (or, in a few exotic species, the petals are wanting, and the stamens reduced to 3,2 , or 1 ). Ovary 1-celled, with a simple style or stigma. Fruit a 1-seeded berry.

A considerable tropical family, with but very few representatives in the more temperate regions, and no exotic species are at present in cultivation. The affinities of the Order are perhaps greater with the Suntalacea among Monoclilamyda than with the Calyciflora, with which they are here associated, in compliance with the Candollean arrangement.

\section{VISCUM. MISTLETOE.}

Flowers diccions. Calyx without any prominent border. Anthers in the males sessile in the centre of the petals, opening in several pores. Stigma in the females sessile on the ovary.

The genus, taken in its most extended sense, consists of a considerable number of species, ranging over nearly the whole area of the family.

1. V.album, Linn. (fig. 458). Mistletoe.-Stems becoming woody when old, with repeatedly forked, succulent brauches, forming dense tufts of a yellowish-green, attaining 1 to 2 feet in diameter, and attached by a thickened base to the branches of trees. Leaves entire, varying from narrow-oblong to nearly obovate, thick and fleshy, and always obtuse. Flowers almost sessile in the forks of the branches; the males 3 to 5 together, in a somewhat cup-shaped, fleshy bract, with 4 short, thick, triangular petals; the females solitary, or rarely 2 or 3 together in a cup-shaped bract. The petals very minute. Berry white, semitransparent, enclosing a single seed, surrounded by a very glutinous pulp.

On a great variety of trees, but especially on the Apple, very rarely on the oak, extending over the whole of temperate Europe, from Sweden to the Mediterranean, and far into Asia, but not everywhere abundant. Common in southern and especially western England, except Cornwall; rare in the north, and not known in Scotland or Ireland. Fl. spring.

\section{CORNACEA. THE CORNEL FAMILY.}

Limited in Europe to the single genus Cornel, with which are associated two or three allied tropical gencra, scarcely differing from the Aralia family, except in their erect, not climbing habit, the more generally opposite leaves, and the more complete union of the carpels and styles.

Among the exotic genera cultivated in our gardens may be mentioned the Japanese Aucuba and the Benthamia fragifera from the Himalaya.

\section{CORNUS. CORNUS.}

Trees, shrubs, or very rarely herbs, with opposite (or in one exotio species alternate), undivided leaves, and rather small flowers in terminal corymbs without bracts, or in umbels or heads surrounded by bracts, which are sometimes coloured and petal-like. Calyx, 4 small teeth 
round the summit of the ovary. Petals 4, valvate in the bod. Stameng 4, alternating with the petals. Style simple. Ovary 2-celled, with a single pendulous ovule in each cell. Fruit a berry-like drupe; the stone 1- or 2-celled, with 1 seed in each cell. Seeds with a fleshy albumen and a rather long embryo.

A genus not numerous in species, but extending over the temperate and colder regions of the northern hemisphere, both in the New and the Old World. It was formerly included in Caprifoliacea, from which it differs chiefly in the distinct petals, valvate in the bud.

Low herb. Umbel surrounded by 4 petal-like bracts . . . 1. c. suecica. Shub. Flowers in a corymb, without bracts . : : 2 c canguinea.

Some other shrubby species of Cornus are often planted in our shrubberies, especially $C$. alba, alternifolia, and florida, from North America, and $C$. mas from southern Europe.

1. C. suecica, Linn. (fig. 459). Dwarf Cornel.-Unlike as this little herb is to $C$. sanguinea, its generic affinity may be traced throngh the exotic C. florida. It has a slender, creeping perennial rootstock, with annual stems, barely 6 inches high, and usually simple. Leaves sessile, ovate, entire, seldom abore an inch long, with 5 or sometimes 7 longitudinal nerves, and sprinkled with a few very minute, closely-appressed hairs. Flowers very small, in a little terminal umbel, surrounded by 4 large, broad, petal-like, white bracts, so as to give the whole umbel the appearance of a single flower with 4 petals. The real petals are very minute, of a dark purple. Drupes small and red, resembling berries.

In monntain moors of Northern regions, extending into the Arctic Circle nearly all round the globe. Abundant in Scandinavia, and descending southward to northern Germany. Not uncommon in the Scotch mountains, reappearing in north-eastern England, but not in Ireland. $F l$ summer, rather late.

2. C. sanguinea, Linn. (fig. 460). Dogrwood.-An erect shrub, of 5 or 6 feet. Leaves opposite, broadly ovate, and stalked; when young, hoary or silky, with closely appressed hairs; but when full grown, green and nearly glabrous. Flowers numerous, forming terminal cymes of $1 \frac{1}{2}$ to 2 inches in diameter, without bracts; the calyx and peduncles covered with a mealy down. Petals of a dull white, lanceolate, nearly 3 lines long. Drupes globular, almost black and very bitter.

In hedges and thickets, in temperate Europe and Russian Asia, extending northwards into southern Scandinavia. Abundant in southern England, becoming scarce in the north; not wild in Scotland, and only. in a very few localities in Ireland. Fl. early summer.

\section{CAPRIFOLIACEA. THE HONEYSUCKLE} FAMILY.

Trees, shrubs, or herbs, with opposite leaves, and no stipules. Flowers usually in terminal heads, corymbs, or panicles, more rarely axillary. Calyx combined with the ovary, with an entire or toothed border, sometimes scarcely prominent. Corolla monopetalous, 5- or rarely 4-lobed, regular or somewhat irre. gular, with the lobes overlapping each other in the bud. 
Stamens inserted in the tube of the corolla, and alternating with its lobes, either of the same number or one less, or rarely double the number. Ovary inferior, with 3 to 5 cells, and as many stigmas, either sessile or borne on short styles, or united on the summit of a single style. Fruit usually succulent, with 1 to 5 cells. Seeds solitary or few in each cell, with a fleshy albumen.

The Caprifoliacee do not form a very natural family, but are tolerably well defined, differing from the exotic opposite-leaved genera of the Rubiaccae family chiefly in the want of real stipules; from Valerianea and Dipsacce in the compound ovary.

Stigmas several. Corolla spreading, with a very short tube.

Jow herb. Leaves once, twice, or thrice termate . . . . 1. AdoxA.

Tall herb or tree. Leaves pinnate

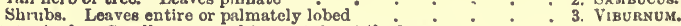

Style single. Corolla narrowed into a tube at the base.

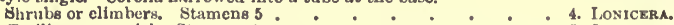

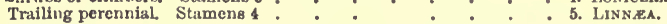

The Snowber'y (Symphoricarpos), Leycesteria, and Wcigcla, of our gardens belong also to this family.

\section{ADOXA. MOSCATEL.}

Leaves ternately divided. Calyx with 2 or 3 spreading teeth or lobes. Corolla with a very short tube, and 4 or 5 spreading divisions. Stamens 8 or 10 , in pairs, alternating with the divisions of the corolla, and inserted on a little ring at its base. Styles 3 to 5 , very short, united at the base. Ovary 3- to 5-celled, with one ovule in each cell. Fruit a berry.

A genus consisting of a single species, with very different foliage and stamens from those of other Caprifoliacce, but in other respects much more nearly allied to them than to Araliacce, among which it has until recently been classed.

1. A. Moschatellina, Linn. (fig. 461). Moscatel.-A low, glabrous herb, of a light green colour in all its parts; the rootstock covered with a few thick scales, the remains of old leafstalks, and emitting creeping, half-underground runners. Radical leaves stalked, once, twice, or even three times ternate, with broad, deeply 3 -lobed segments. Flowerstems, radical, from 4 to 6 inches high, with a single pair of leaves on short stalks, and but once ternate. Flowers pale green, in a little glo. bular head at the top of the stems, containing usually 5 ; the terminal one with 2 divisions to the calyx, and 4 to the corolla, and 8 stamens; whilst the 4 lateral flowers have three divisions to the calyx, and 5 to the corolla, with 10 stamens; but these numbers are not quite constant. Berry green and fleshy, most frequently containing but a single seed.

On moist, shady banks, and woods, in northern and central Europe, Russian Asia, and a part of North America, extending into the Arctic regions. In southern Europe, chiefly confined to mountains. Common in Great Britain, rarer in Ireland. Fl. spring.

\section{SAMBUCUS. ELDER.}

Trees, shrabs, or tall herbs, with opposite pinnate leaves, and large fist cymes or corymbs of numerous, rather small, white flowers. Calyx 
with a border of 5 small teeth. Corolla with a very short tube, and 5 spreading divisions, so as to appear rotate. Stamens 5 , inserted at the base of the corolla. Stigma sessile, 3- to 5-lobed. Fruit a berry, or, strictly speaking, a berry-like drupe, with 8, rarely 4, seed-like stones, each containing a single seed.

The genus consists of but few species, spread over Europe, temperate Asia, North America, and Australia, and is the only one in the family with pinnate leares.

Tree. Leaflets ovate, without stipular lobes.

Herb. Leaflets lanceolate, the lowest short, broad, and close to the stem, fepresenting stipules

1. S. nigra.

2. S. Bbulus.

The S. racemosa, or red-berried Elder, common in our shrubberies, is a native of the mountains of continental Europe.

1. S. nigra, Linn. (fig. 462). Common E.-A small tree, or shrub, with the stem and branches full of pith. Leaf-segments 5 to 7 , ovate, pointed, 2 to 3 inches long, regularly and sharply toothed, and nearly glabrous. Corymbs, 5 or 6 inches broad, several times branched, the first time into 4 or 5 , but the branches less numerous at each subsequent division. The bracts very minute. Flowers white or cream coloured. Fruits black.

In woods, coppices, and waste places, common in central and southern Europe to the Cancasus, and extending itself readily from cultivation further northward. Appears to be truly indigenous in England and Ireland, but only introduced into Scotland. Fl. summer, rather early. A garden variety has deeply and finely-cut segments to the leaves.

2. S. Ebulus, Linn. (fig. 463). Dwarf E., Danewort. - Stock short and perennial, with annual, erect stems, thick and pithy, slightly branched, 2 to 3 feet high. Leaf-segments 7 to 11 , lanceolate, 2 to 4 inches long, with a small one on each side of the leafstalk, on the stem itself, looking like stipules. Corymbs less regular, and rather smaller than in $S$. nigra, with only 3 primary branches. Flowers sweet-scented, of a pure white, or tinted with purple on the outside. Fruits black.

On roadsides, in rubbishy wastes, and stony places, in central and southern Europe, and west-central Asia, extending northward to southern Sweden. Occurs in many parts of Britain, and may be indigenous in some, although believed to have been everywhere introduced by the Danes. Fl. summer, later than the common $E$.

\section{VIBURNUM. VIBURNUR.}

Shrubs or small trees, with undivided or palmately-lobed leaves, and whitish flowers in terminal cymes. Calyz with a border of 5 small teeth. Corolla with a short campanulate tube (in some exotic species much longer) and 5 spreading divisions. Stamens 5 , inserted near the base of the corolla. Stigmas sessile 3 or 2, or on very short styles. Ovary 3- or 2-celled in a very young stage, but at the time of flowering 1-celled, with a single ovule. Fruit a 1-seeded berry.

A rather large and widely-spread genus, extending further into the tropical regions of both the New and the Old World than any other of the family. The flowers, at first sight very much like those of Sambucus, have yet a more distinct tube, and the foliage is very different. 
Leaves toothed, undivided, downy undcrneath. Flowers all small

Leaves 3 . to 5-lobed, glibroing. Outer flowers of the cjme large, without stamens or pistils

1. V. Lantark.

The Laurustinus of our garden is a Viburnum from southern Europe.

1. V. Lantana, Linn. (fig. 464). Wayfaring-tree.-A large, muchbranched shrub, the young shoots and leaves thickly covered with soft mealy down. Leaves ovate, 3 to 5 inches long, cordate at the base, bordered by small pointed teeth, very soft and velvety on the upper side, with a more mealy whitish down underneath, without any glands to the leafstalks. Flowers small and white, in dense cymes of 2 to 3 inches diameter. Berries somewhat oblong, of a purplish black.

In woods and hedges, all over temperate and sonthern Europe to the Caucasus, penetrating far into Scandinavia. Not unf requent in England, from York southwards, but very doubtfully indigenous north of it, or in Scotland, and not recorded from Ireland. Fl. carly summer.

2. V. Opulus, Linn. (fig. 465). Guelder Rose.-Not generally a tall shrub when wild, but it will grow into a small tree, and is always glabrous in all its parts. Leaves 2 or 3 inches broad, divided to near the middle into 3 or sometimes 5 broad angular pointed lobes, which are usually coarsely toothed or again lobed; the slender leafstalks have 2 or more sessile glands at the top, and 2 or more linear fringe-like appendages at the base. Flower-cymes like those of $V$. Lantana, except that the outer flowers become mucb enlarged, attaining often near an inch in diameter, but, having neitier stamens nor styles, they are perfectly barren. Berries globular, of a blackish red.

In hedges and coppices, in Europe and Russian Asia, extending into the Arctic regions. In Britain, mucb less frequent in Scotland than in England and Ireland. Fl. summer. T': Guelder-Rose of our gardens is a variety, or, more properly speaking, a monstrosity, in which all the flowers are enlarged and barren, giving the cyme a globular shape.

\section{LONICERA. HONEYSUCKLE.}

Shrubs, or tall climbers, with opposite entire leaves, and white, yellowish, pink, or red flowers, two or more together, in terminal or axillary heads. Calyx with a border of 5 small teeth. Corolla with a nore or less elongated tube, and an oblique limb either 5-lobed, or in two lips, the upper one 4-lobed, the lower entire. Stamens 5. Style filiform, with a capitate stigma. Ovary 2- or 3-celled, with several ovnles in each cell. Berry small, with one or very few seeds.

A considerable genus, spread over the temperate regions of Europe, Asia, and North America. It is really a natural one, and very readily distinguished from the adjoining genera by the flowers, although the two principal groups into which it is separable, the climbing true Honcysuckles and the erect shrubby fly Honcysuckles, are rather dissimilar in aspect.

climbers. Flowers long, in terminal heads.

All the leaves distinct at the base

Leaves of the one or two uppermost pars joined together at the base

yrect shrub. Flowers short, two together on short axillary veduncles .

1. L. Periclymenum

2. L. Caprifolium.

S. L. Xylosterw\%. 
Several exotic spccies of both sections are much cultivated.

1. I. Periclymenum, Linn. (fig. 4i6). Common H., Woodbine.-A woody climber, scrambling over bushes and trees to a considerable height. Leaves ovate or oblong, glabrous above, usually slightly downy or hairy underneath; the lower ones contracted at the base or stalked, the upper ones rounded and closely sessile, but not united. Flowers several together, closely sessile in terminal heads, which are always stalked above the last leaves. Corolla about $1 \frac{1}{2}$ inches long. Berries small and red.

In woods, thickets, and hedges, in western and central Kurope, from southern Scandinavia to the Mediterranean, but not extending to the Russian frontier. Common throughout Britain. Fl. summer and autumn.

2. I. Caprifolium, Linn. (fig. 467). Perfoliate H.-Very much like $\boldsymbol{L}$. Periclymenum, but quite glabrous; the leaves broader, the uppermost pairs in the flowering branches united at the base, and the heads of flowers closely sessile within a pair of leaves united into a single broadly rounded perfoliate leaf; or the flowers are sometimes separated into two tiers, with a perfoliate leaf under each.

In hedges and woods in central and south-eastern Europe, and perhaps western Asia, but often confounded with the two common southern species, $L$. implexa and $L$. etrusca. Not traly wild in Britain, but long since cultivated for ornament, and almost naturalised in some counties in England and the south of Scotland. Fl. spring and early summer.

3. I. Xylosteum, Linn. (fig. 468). Fly H.-An erect, much branched shrub, 3 or 4 feet high, of a pale green, and downy in all its parts. Leaves ovate, entire, and stalked, about $1 \frac{1}{2}$ inches long. Flowers of a pale-yellowish white, downy and scentless, only 4 or 5 lines long, hanging 2 together from short, axillary peduncles, with 2 small narrow bracts close under them. Berries bright scarlet, with 2 or 3 seeds in each.

In thickets and hedges, almost all over Europe and Russian Asia, extending northward to the Arctic Circle. Dispersed over various parts of Britain, generally as an escape from cultivation, but believed to be really indigenons in some parts of south-eastern England. It is very common in our shrubberies. Fl. early summer.

\section{LINNAEA. LINNAEA.}

Calyx with a border of 5 teeth. Corolla campanulate, 5-lobed, narrowed at the base into a short tube. Stamens 4.

A genus of a single species, dedicated to the great master of natural science, with whom it was an especial favourite.

1. I. borealis, Gronov. (fig. 469). Linncea. -A slender evergreen, creeping and trailing along the ground to the length of a foot or more. Leaves opposite, small, broadly ovate or obovate, and slightly toothed at the top. Flowering branches short and erect, with 2 or 3 pairs of leaves, and terminated by a long slender peduncle branched near the top into 2 pedicels, each bearing an elegant, gracefully drooping, and fragrant flower of a pale pink or white colour, above 5 lines long. Dvary globular and very hairy, the rest of the plant more or less 
covered with a very minute glandular down, or sometimes quite glabrous.

In woods, or rarely in more open rocky situations, in northern Europe, Asia, and North America, reappearing in the mountains of central Europe, even on the southern side of the Alps. In Britain confined to the fir-woods of some of the midland and eastern counties of Scotland and to a few localities in Yorkshire and Northumberland. Fl. summer.

\section{STELLAT\&. THE STELlate TRIBE.}

\section{(A tribe of Rubiacea.)}

Herbs, with angular stems, and entire leaves in whorls of 4, 6 , or 8 (that is, apparently so, for 2 opposite ones only of each whorl are real leaves with buds in their axils, the others, although precisely similar, are in fact stipules), rarely 2 only, the buds and branches always opposite. Flowers small, in terminal or rarely axillary panicles or heads. Calyx combined with the ovary, either entirely so or rarely with a border of 4 or 5 teeth. Corolla monopetalous, with 4 or 5 spreading lobes. Stamens as many, inserted in the tube. Ovary inferior. Style 2-cleft at the top, with a capitate stigma to each branch. Fruit indehiscent, small, dry, or rarely succulent, usually separating into 2 seed-like carpels with 1 seed in each. Albumen horny, with a small embryo.

The Stellatce are widely diffused over the globe, especially in temperate regions; in the tropics they are more rare, except in mountainous regions. They form a considerable and very natural tribe in the great Natural Order of Rubiacea, otherwise unrepresented in Britain or even in Europe. It is one of the most extensive ones within the tropics, distinguished by opposite leaves, interpetiolar stipules, an adherent calyx, and a monopetalous corolla, and includes trees and shrubs as well as herbs. Nany are cultivated in our stoves, greenhouses, or flowerbeds, including the genera Coffea, Gardenia, Luculia, Pentas, Manettia, Bouvardia, \&c.

Corolla with a distinct tube, as long as or longer than the lobes.

Fruit crowned by the 4 teeth of the calyx. Flowers in heads, surrounded by an involucre.

Caly $x$ not distinct Fiowers in panicles:

Corolla rotate, the tube very short or indistinct.

Fruit fleshy. Corolla usually 5 -lobed . . . . . . 1. RuBra.

Fruit dry. Corolla usially 4-lobed.

\section{RUBIA. MADDER.}

A genns only distinguished from Galium by the rather large succulent fruit. The European species have also larger leaves, of a firmer, more shining texture, and the flowers have often 5 instead of 4 parts, but these differences scarcely hold good in the South American species.

The species are not numerous, and miglit rather be considered as forming one or two sections of Galium, the South American species (or 
genus Relbunium) being intermediate between the two genera as usually limited.

1. R. peregrina, Linn. (fig. 470). Wild M.-A straggling herb, of a shining green, sometimes very dwarf, sometimes trailing over bushes and hedges to the length of several feet, clinging by means of short recurved prickles on the edges and midribs of the leaves, and sometimes on the angles of the stem. Rootstock and sometimes also the base of the stem perennial and creeping. Leaves 4 or 6 in the whorl, ovateoblong or lanceolate, 1 to $1 \frac{1}{2}$ inches long, on very short stalks or nearly sessile. Flowers small, greenish, in loose axillary or terminal panicles rather longer than the leaves. Corolla usually 3-lobed. Fruit a small black 2-lobed berry.

In dry woods, and stony places, in western and southern Europe, and eastward to the Caucasus, less frequent in northern France and Germany. In Britain scarcely found beyond the south-western counties of England, and the coast of South Wales, and Ireland. Fl. all summer.

The $\boldsymbol{R}$. tinctoria, or dyers' Madder, extensively cultivated in southern Europe for the scarlet dye furnished by its roots, differs but very slightly from $R$. peregrina, and may be a mere variety.

\section{GALIUM, GALIUM.}

Herbs, with weak, quadrangular stems, sessile leaves, in whorls of 4 , 6 , or 8 , and small white, yellow, or (in exotic species) red flowers, in axillary or terminal trichotomous cymes or panicles, sometimes reduced to small clusters. Calyx completely combined with the ovary, without any visible border. Corolla rotate, the tube scarcely perceptible, with 4 spreading lobes. Fruit small, dry, 2-lobed, with 1 seed in each lobe.

An extensive and natural genus, spread over the whole of the temperate regions of the New as well as of the Old World, especially abundant in Europe and northern Asia, penetrating also into the tropics, but there chiefly confined to mountain districts.

\section{Flowers yellow.}

Leaves 4 in each whorl, ovate. Cymes axillary, shorter

than the leaves
Leaves 6 or 8 in each whorl, linear. Panicles terminal :

\section{Nowers white.}

Leaves in fours.

Fruit hairy

Lesves ovste or lancoolate, very shining, and prickly at

edge
Leares linear, smooth or rough, but not prickly.
Flowers on slender pedicels. Corolla small and

rotate ${ }^{\text {rowers }}$ nearly sessile, in littlo clusters. Corolla funnel-shaped

Leaves 6 or 8 in each whorl.

Perennials. Stems smooth or rough on the angles.

Frult covered with long hairs.

Fruit small, smooth, and slightly granulated.

Lobes of the corolls onding in a fine point. Stems unuslly 1 to 2 feet, and rather firm at the base.

Lobes of the corolls scarcely pointed. Stems short, or very slender.

$y$ saves 4 or 6, very obtuse.

1. G. Cruciata.

2. G. verum.

8. G. boreale.

Rubia peregrina

3. G. palustre.

Asperula eynanehica.

Asperula odorata.

6. G. Molluga.

8. G. palustre 
Leaves 6 or 8 , mostly pointed.

Leaves nearly smooth . . . 5. G. saxatile.

Lesves very rough $:$ at adhesive hair:

4. G. uliginosum.

Annuals. Stems very rough at the edges, with adhesive hairs or minute prickles.

Small, very slender plant. Fruit very small, granulated

Coarse plants, very adhesive. Fruit rather large, usually covered with stiff hairs or tubercles.

Flowers 3 or more, in axillary panicles longer than the leares. Fruiting pedicels straight. . .

Nowers 1 or 3 , on axillary peduncles, shorter than the lesves. Fruiting pedicels rolled inwards .10 . G. tricorne.

1. G. Cruciata, Scop. (fig. 471). Crosswort or Maywort.-Stock perennial and slender, with a few short, prostrate, or creeping barren shoots; the flowering stems erect or ascending, 6 to 18 inches long, and hairy. Leaves in whorls of 4 , ovate, 6 to 9 lines long, hairy on both sides. Flowers small and yellow, in little leafy cymes or clusters, shorter than, or scarcely so long as the leaves. Many of these flowers are males only, and soon fall off, their reflexed pedicels remaining till the stem withers. Fertile flowers few, and often 5-lobed. Fruits small, smooth, almost succulent.

On hedgebanks, and in bushy places, in central and southern Europe, and eastward to the Caucasus. Common in England, and extending into mid Scotland, but very rare in Ireland. Fl. spring and early summer.

2. G. verum, Linn. (fig. 472). Ladies' bedstraw.-Rootstock woody, often shortly creeping, the whole plant glabrous and smooth, or with only a slight asperity on the edges of the leaves. Stems much branched at the base, decumbent or ascending, 6 inches to above a foot long, ending in an oblong panicle of very numerous small, yellow flowers. Leaves small, linear, numerous, in whorls of 6 or 8 . Fruits small, and smooth.

On banks and pastures, throughout Europe and central and Russian Asia, except the extreme north. Abundant in Britain. Fl. the whole oummer.

3. G. palustre, Linn. (fig. 473). Marsh $a_{\sigma}-\mathrm{A}$ weak and slender, glabrous perennial, more generally blackening in drying than any of the following. Stems a foot or more long, with few spreading branches, almost always rough on the angles. Leaves mostly 4 in a whorl, occasionally 5 , very rarely 6 , linear or oblong, obtuse, without the small point of the three following species; mostly, but not always, rough on the edges. Flowers small, and white, not very numerous, in spreading panicles; the lobes of the corolla without the fine point of G. Mollugo. Fruit rather small, slightly granulated.

In marshes and wet places, often quite in the water, but sometimes also in drier situations, and even hanging from the clefts of rocks, extending all over Europe and Russian Asia, from the Mediterranean to the Arctic Circle. Common in Britain. Fl. summer.

4. G. uliginosum, Linn. (fig. 474). Swamp G.-Differs from $G$. palustre in its leaves, either 6 or 8 in a whorl, usually narrower, terminated by a fine point, and less disposed to turn black in drying; from the slender varieties of $G$. saxatile, in its stem very rough on the angles, and often 1 to 2 feet long.

Dispersed over Kurove and Russian Asia, and occurs in varions parts 
of Britain, but not a very common plant, and very rare in Ireland, for although indicated in almost all Floras within the geographical range of $G$. palustre and $G$. saxatile, it is probable that varieties of the one or the other are often mistaken for it. Fl. summer.

5. G. saxatile, Linn. (fig. 475). Heath G.-A small perennial, much branched, leafy, and often tufted at the base; the flowering stems numerons, weak, 5 or 6 inches bigh, rarely attaining nearly a foot, and smooth, or nearly so, on the angles. Leaves nsually 6 in a whorl, sometimes 7 or 8 , and occasionally on the barren shoots only 4 or 5; the lower ones small and obovate, the upper narrow, and, when the stem lengthens much, mostly linear; all have a little point at the tip, the edges are smooth or rough, the length seldom exceeds 3 lines. Flowers numerous and white, in short terminal panicles, the lobes of the corolla scarcely pointed. Fruits small, more or less granulated.

In open heaths and pastures, very common in western and central Europe, but seldom mentioned in the more eastern Floras. In Britain, one of the most universally distributed species. Fl. summer. Varieties with narrower leaves, more often 8 in a whorl, have been distinguished as $G$. pusillum, Sm., sylvestre, Poll., montanum, Vill., commutatum, Jord., \&c. [Of these $G$. sylvestre (pusillum, Sm.) is the most distinct, having more rigid and erect stems with narrower awned and ciliate leaves.]

6. G. Mollugo, Linn. (fig. 476). Hedge G.-Very near G. saxatile, but on a much larger scale. Stems, from a perennial stock, 1 to 2 or 3 feet long, smooth and shining, and more or less branched. Leaves usually 8 in a whorl, varying from obovate to oblong or linear, more or less rough on the edges, and always terminated by a little point. Flowers white and numerous, in large terminal panicles. Corolla varying from 1 to 2 lines in diameter, each lobe bearing a little point, sometimes rather long, sometimes scarcely prominent. Fruit small and smooth, or slightly granulated.

In hedges, thickets, and rich pastures, widely spread over Europe and western Asia, but neither an Arctic nor perhaps a Siberian species. Very common in England, but extends only into the sonthern counties of Scotland, and very rare in Ireland. Fl. summer. In shady situations and rich soils the stems are very straggling, swollen above each node, with broader leaves, and spreading panicles. This is considered by many botanists as the only true G. Mollugo. In drier, more open situations, the stem is more erect, the leaves narrower, the panicles closer, and more oblong, and the points of the corolla more prominent. This form is often described as one or more distinct species, under the name of $G$. erectum, Huds., and G. ariatatum, $\mathrm{Sm}$.

7. G. anglicum, Huds. (fig. 477). Wall G.-Somewlut resembles a very slender $G$. Blollugo, but the root is only annual, and the flowers and fruits are very much smaller. Stems about 6 inches high, the branches almost filiform, spreading, and rough on the edges. Panicles spreading, with filiform pedicels. Corolla white, very minute; the lobes less spreading than in most species, and not pointed. Fruits small, grannlated.

In stony wastes, on old walls, \&c., very common in the Mediterranean region, and eastward to the Caucasus ; less abundant in central Furope 
and barely extending to some of the southern counties of England. $F$. summer. [In former editions of this work, and by many botanists still, this bas been regarded as a smooth fruited form of the continental $G$. parisiense, Linn., in which the fruit is covered with bristles.]

8. G. boreale, Linn. (fig. 478). Northern G.-Rootstock creeping ; the stems more firm and erect, and less branched than in the other species, from $\frac{1}{2}$ to $1 \frac{1}{2}$ feet high, glabrous or slightly hoary. Leaves 4 in a whorl, lanceolate or linear, rather firm, with 3 longitudinal ribs, smooth or scarcely rough at the edges, and often an inch long. Flowers nnmerous, in oblong terminal panicles, white, and rather larger than in $G$. Mollugo, with very short, inflected points to the lobes. Fruit covered with booked hairs or bristles.

On moist rocks, and in mountain pastures, all over northern Europe, Asia to the Arctic regions, and America; confined to mountains in southern Europe and central Asia. Frequent in Scotland, northern England, North Wales, and Ireland. Fl. summer.

9. G. Aparine, Linn. (fig. 479). Clcavers, Goose-grass.-Although an annual, this plant often extends to several feet, serambling over bushes, to which it clings by the recurved asperities or small prickles on the angles of the stem and on the edges and midribs of the leaves. Leaves 6 or 8 in a whorl, linear or linear-lanceolate, often abure an inch long. Peduncles opposite and axillary, rather longer than the leaves, bearing a loose cyme of from 3 to 8 or 10 small, greenish-white flowers, with 3 or 4 leaves at the base of the cyme. Pedicels 2 to 4 lines long, straight and slender, or but slightly recurved and thickened. Fruits usually covered with hooked bristles, forming small, very adhesive burrs, but sometimes almost or entirely without them.

In hedges and thickets, throughout Europe and northern Asia, from the Arctic Circle almost to the tropies, and now spread over North America. Abundant in Britain. Fl. the whole summer, and often in autumn. Slender or short varieties, less hispid, and with smaller fruits, have been distinguished under the names of $G$. Vaillantii, DC., and $G$. spurium, Linn., but the latter name is also given to luxuriant forms of Q. tricorne.

10. G. tricorne, With. (fig. 480). Corn G.-Very near $G$. A parine, but a smaller plant, seldom above a foot long, the leaves shorter, the peduncles shorter than the leaves, with only 1,2 , or 3 flowers, the pedicels of which are rolled back and thickened after flowering, and the fruit is granulated only, withont hooks or bristles.

A much more sonthern plant than $G$. Aparine, very common in waste and cultivated places in the Mediterranean region, and eastward to central Asia; beeomes a cornfield weed in central Europe, and as such extends over most counties of England, but does not extend to Scotland or Ireland. Fl. with the corn, or sometimes later, in the stubble.

\section{ASPERULA. ASPERULE.}

Differs from Galium only in the shape of the corolla, which tapers et the base into a tube at least as long as the lobes, and often several times longer.

The species are less numerous than those of Galium, and the geogra. 
phical range is not so extensive, being limited to Europe, northern Africa, northern and central Asia, and Australia

Leares lanceolate, about 8 in a whorl. Fruit bispld

Leaves linear, opposite or 4 in a whorl. Fruit small, glabrous
1. A. odorata.

2. A. cynanchica.

1. A. odorata, Linn. (fig. 481). Woodrufi.-Rootstock slender and creeping. Stems erect, 6 inches to near a foot high, smooth on the angles. Leaves usually 8 in a whorl (rarely 6,7 , or 9 ), the lowest small and obovate, the remainder oblong-lanceolate, above an inch long, slightly rough at the edges. Peduncles terminal, bearing a few small, white flowers, in a loose, trichotomous cyme. Corollas very fugacions. Fruits globnlar and very hispid. The whole plant has a sweet hay smell in drying.

In woods and shady places, thronghout Europe and Russian Asia, except the extreme north. Abundant in Britain. Fl. spring and early summer.

2. A. cynanchica, Linn. (fig. 482). Squinancyroort.-A smooth and glabrous perennial, the stems sometimes erect and wiry, with few leaves, 6 or 8 inches high, sometimes decumbent or spreading on the ground, in broad, leafy tufts or patches. Leaves narrow-linear, the lower ones 4 in a whorl, the npper ones often 2 only, the 2 others wanting or reduced to small stipules. Flowers white, often with a lilac tinge, forming little clusters at the summits of the branches; the corollas little more than a line long, funnel-shaped, tubular at the base. Fruits small, slightly granulated.

In dry pastures, on warm banks, and stony and sandy places. Abundant in central and southern Europe to the Caucasus, extending northward more sparingly to the Baltic. Common in parts of England and south and west Ireland, but does not extend into Scotland. Fl. summer.

\section{SHERARDIA. SHERARDIA.}

A single species, with the corolla and fruit of an Asperula, and the habit of some sonthern species of that genus, but distinguished both from Asperula and Galium by the calyx, which has a distinct border of 4 or 6 teeth crowning the fruit.

1. S. arvensis, Linn. (fig. 483). Field Madder.-A small annual, seldom above 6 inches bigh. Leaves about 6 in a whorl, the lower ones small and obovate, the upper linear or lanceolate, all rongh on the edges and ending in a fine point. Flowers small, blue or pink, in little terminal heads, surronnded by a broad, leafy involucre, deeply divided into about 8 lobes, longer than the flowers themselves. Corolla with a slender tube, little more than a line long, and 4 small, spreading lobes. Calyx-teeth enlarged after flowering, forming a leafy crown to the fruit.

In cultivated and waste places, in temperate Europe and Asia, extending far to the north as a weed of cultivation. Common in the greater part of Britain, but scarce in the north of Scotland. $M$. the whole summer. 


\section{VALERIANE\&. THE VALERIAN FAMILY.}

Herbs, either annual or with a perennial, sometimes almost bushy stock, opposite leaves, and no stipules. Flowers in terminal corymbs or panicles, usually small and numerous. Calyx adherent to the ovary, the small border sometimes toothed, sometimes scarcely perceptible at the time of flowering, but unrolling afterwards into a feathery pappus. Corolla in the British genera monopetalous, tubular at the base, with 5 spreading lobes. Stamens always fewer than the lobes of the corolla. Fruit small, dry, and seed-like, with a single seed suspended from the top of the cell, with the addition frequently of 1 or 2 imperfect or abortive empty cells.

A natural family, not large, but widely diffused over a great part of the globe. Well characterised among inferior-fruited Monopetals by the seed-like fruit and reduced number of stamens.

Stamen 1. Tube of the corolla spurred at the bsse

Stamens 3. Tube of the corolla slightly swollen at the base, but not spurred.

Perounials. Fruit crowned by a feativery pappus

Annuals, Fruit not crowned by a feathery pappus .

1. Censtanthus.

\section{CENTRANTHUS. CENTRANTH.}

Habit, calyx, and fruit of Valeriana. Corolla with a more slender tube projected at the base into a little spur, and only 1 stamen.

A small genus of the Mediterranean and Caucasian regions.

1. C. ruber, DC. (fig. 484). Red Valerian.-Perennial stock much branched, forming when old an almost bushy, coarse tuft; the whole plant quite glabrous and often somewhat glaucous. Stems stout, 1 to near 2 feet high. Leaves ovate-lanceolate, entire or seareely toothed. Flowers numerous, red or rarely white, in dense cymes, forming a hand. some, oblong terminal panicle. Tube of the corolla 3 or 4 lines long, with a spur of at least a line. Border of the calyx unrolling in the ripe fruit into a little elegant, bell-shaped, feathery pappus.

A native of rocky places in the Mediterranean region, but, long culti. vated for ornament, it has been naturalised on old walls, chalk-pits, \&e., in central Europe, as in many localities in England and Ireland. $\mathrm{Fl}$. all summer.

\section{VALERIANA. VALERIAN.}

Herbs with a perennial stock and nsually ereet flowering stems. Leaves opposite, those of the stem usually pinnately divided or toothed, the lowest often entire. Flowers white or red, small, usually numerous, in terminal corymbs or panicles, sometimes contracted into heads. Caly $\mathbf{x}$ with a prominent border, at the time of flowering rolled inwards and entire, as the fruit ripens opening ont into a little, bell-shaped, feathery pappus. Corolla with a short tube, not spurred at the base. 
and 5 short lobes. Stamens 8. Fruit small, 1-seeded, crowned with the pappus.

A large genus, with the geographical range of the family, but most abundant in mountain regions, where some species ascend to great elevations.

Lower leaves undivided.

Stem 6 to 8 inches high. Radical leaves and segments of the upper ones entire

Stem 2 to 4 feet. Leaves large, broadly cordate, and toothed All the leaves pinnately divided, with several pairs of segments

1. V. dioica.

3. V. pyrenaica. 2. $\boldsymbol{V}$. officinalis.

1. V. dioica, Linn. (fig. 485). Marsh V.-Rootstock emitting creeping running and erect flowering stems, 6 to 8 inches high. Radioal leaves and those of the runners on long stalks, ovate, entire, $\frac{1}{2}$ to 1 inch long; stem-leaves few, mostly pinnate, with one oval or oblong terminal segment and several pairs of smaller and narrow ones, all entire. Flowers very variable in size, and in the size of the stamens, of a pale rose-colour, in terminal corymbs, mostly unisexual; the tube of the corolla short.

A marsh plant, spread over a great part of Europe and eastward to the Himalaya, but most common in the west; extending northward into sonthern Scandinavia. In most English counties and in a few of the southern Scotch ones, but not recorded from Ireland. Fl. early summer.

2. V. officinalis, Linn. (fig. 486). Common V., All-heal.-Rootstock short and thick, with creeping runners, and 1 or rarely more erect stems, 2 to 3 or even 4 feet high, nearly simple, and more or less hairy at the base. Leaves pinnate, with from 9 tu 21, or even more lanceolate segments, 1 to 2 or even 3 inches 1ong, and much varying in breadth, marked with a few coarse teeth, and more or less sprinkled with hairs nnderneath; the upper leaves few and distant. Flowers small, white or tinged with pink, in broad terminal corymbs.

In moist situations, sides of ditches and streams, and damp woods, extending over the whole of Europe and Russian Asia to the Arctic Circle, becoming a mountain plant in the south. Comemon in Britain. Fl. summer. A variety with fewer and broader segments to the leaves has been distinguished under the name of $V$. sambucifolia, Mikan.

3. V. pyrenaica, Linn. (fig. 487). Pyrenean V.-A taller plant even than $V$. officinalis, and much coarser; the leaves broadly beartshaped, coarsely toothed, often 5 or 6 inches long and broad, with more prominent veins than in most Valerians, the lower ones undivided, the npper ones, in addition to the large terminal segment, have 1 or sometimes 2 pairs of smaller ones on the short footstalk. Flowers like those of $V$. officinalis, in large, flat torminal corymbs.

A Pyrenean species, which, having escaped from cultivation, is now well-established in woods and plantations in some parts of central and southern Scotland and western England. Flosummer.

\section{I1I. VALERIANELLA. CORNSALAD. Fredia, Linn,}

Low annuals, with forked branches, narrow, entire or scarcely toothed iseves, and very small white or pale-blue flowers, in little compact 
cymes at the end of the branches or solitary in the forks. Calyx border small, entire or toothed, sometimes enlarging as the fruit ripens, but not feathery. Corolla with a short tube, not spurred at the base, and 5 equal, spreading lobes. Fruit small, convex on the back, but often marked in front with 2 longitudinal ribs or variously shaped projections, which are in fact either imperfect or abortive empty cells.

The species are rather numerous, all much alike in general appearance, and distinguished chiefly by modifications in the form of the little fruits which appear to be constant. They are chiefly natives of the Mediterranean and Caucasian regions, but some are spread as weeds of cultivation over the greater part of the temperate regions of the northern hemisphere.

\section{Fruit without any perceptible projecting border on the top.}

Fruit as broad as long, somewhat laterully compressed, with a slight furrow on each side -

Fruit ovoid, convex on the back, with an oval, concave, or cupshaped appendage on the face . . . . .

Frult crowned by the small, oblique, tooth-like border of the calyx.

Fruit narrow, rather flattened, convex on the back, with 2 longi.

tudinal ribs on the face
Fruit broadly ovoid, showing when cut across 8 cells, $i$ with a seed in it, and 2 consplcuous empty ones

1. V. olitoria.

2. V. carinata.

4. 7 . dentata.

3. $\nabla$. auricula.

1. V. olitoria, Poll. (fig. 488). Cornsalad, Lamb's-lettuce.-A glabrous or slightly downy annual, seldom above 6 inches high, erect or ascending, branching from the base, and repeatedly forked. Radical leaves in a spreading tuft, oblong, $1 \frac{1}{2}$ to 2 inches long, rounded at the top, entire or with a very few coarse teeth, narrowed at the base; stem-leaves narrower, but with a broad base, often clasping the stem, and more frequently toothed. Flowers very small, mostly in little, dense, terminal cymes, $\neq$ to $\frac{1}{2}$ inch in diameter, surrounded by small lanceolate or linear bracts. Fruit abont a line long and at least as broad, somewhat com. pressed, without any perceptible calycine border, and marked on each side with a longitudinal furrow. When cut across, the seed is seen in the centre, with a corky mass on one side, and an empty cell on the other.

A native of sonthern Europe, sften cultivated for salad, and now a common weed in waste places and cornfields in central Europe. Not unfrequent in various parts of the British Isles. Fl. spring and summer.

2. V. carinata, Lois. (fig. 489). Kecled C.-Closely resembles $V$. olitoria in everything but the fruit, which is ovoid, not compressed laterally, but rather from front to back, without any corky mass at the back of the seed, and the empty cell in front is not closed in, but open, in the shape of a little cup-shaped appendage.

More abundant than $V$. olitoria in most parts of continental Europe, but much less frequent in England. I have not met with it in cultivation, although so similar in foliage. Fl. spring and summer.

3. V. Auricula, DC. (fig. 490). Sharp-fruited C.-Stems generally more erect than in the lașt two species, the branches not proceeding from so near the base, more slender and wiry; the leaves small and narrow, the cymes small and, not so compact, often with single flowers in the forks of the stem, and the bracts small and narrow. Fruit broadly ovoid, scarcely compressed, crowned by the little green oblique 
border of the calyx. On being cnt across, it shows 1 small cell occnpied by the seed, and 2 somewhat larger empty ones.

In cornfields and waste places, widely spread over central and sonthern Europe and western Asia. Not unfrequent in Britain, and perhaps truly indigenous. Fl. summer.

4. V. dentata, Poll. (fig. 491). Narrow-fruitcd C.-Habit and foliage precisely those of $V$. A uricula, and the fruit is in the same manner crowned by the oblique border of the calyx, but the fruit is narrower, slightly compressed from front to back, and the seed occnpies the entire cavity withont any empty cells; these are represented by 2 longitudinal ribs on the inner face of the fruit, which, when examined nnder the microscope, will be found to be hollow.

The geographical range appears to be the same as that of $V$. Auricula, with which it is often confounded. $F$. summer. It varies in its fruits more or less hairy, and the calyx-border sometimes cup-shaped, nearly as long as the frnit, and scarcely oblique, which form has been distinguished as a species, nnder the name of $V$. eriocarpa, Desv.

\section{DIPSACEA. THE TEASEL FAMILY.}

Herbs or undershrubs, with opposite leaves, and no stipules. Flowers collected into compact heads or spikes, surrounded by a conmon involucre, with scales or hairs on the receptacle between the florets, as in Composita, but each floret is moreover inserted in a small involucel having the appearance of an outer calyx, sometimes tubular, and complctely enclosing the ovary ; sometimes cup-shaped at its base. Calyx combined with the ovary, with an entire or toothed border; the teeth often terminating in stiff points or bristles. Corolla monopetalous, 4- or 5-lobed, and often oblique. Stamens 4, inserted in the tube; the anthers free, not united as in Composita. Fruit small, dry, and indehiscent, crowned by the border of the calyx, often enclosed in the involucel, which assumes the form of an outer coating. Seed solitary, pendulous.

A small family, spread over the temperate regions of the Old World both in the northern hemisphere and in southern Africa; at once distinguished from Composita by the anthers, from capitate l'mbclliferce by the opposite leaves and the monopetalons corollas.

Scales of the receptacle between the florets prickly.

scales of the receptacle not prickly, op, roplaced by hairs

- 1. Dipsaces.

- 2. Scabiosa.

\section{DIPSACUS. TEASEL.}

Tall, erect biennials, either prickly or bearing very stiff hairs. Heads of flowers oblong or globular; the scales between the florets oblong and prickly. Involucels small and angular, with a very small, thickened border. Caly $\mathrm{x}$ with a small cup-shaped border appearing above the involucel. Corolla oblique, 4-lobed. 
A very small European and north Asiatic genus.

Heads of flowers ovoid or cylindrical, very prickly . . . . 1. D. sylvestrie. Heads of flowers globular, very hairy, and slightly prickly . . 2. D. pilosus.

1. D. sylvestris, Linn. (fig. 492). Wild T.-A stout biennial, 4 or E feet high, with numerous prickles on the stems, the midribs of the leaves, the peduncles, and involucres. Leaves sessile, long and lanceolate, entire or coarsely toothed, the upper ones broadly connate at the base. Heads of flowers at first ovoid, but gradually becoming cylin. drical, near 3 inches long and above $1 \frac{1}{2}$ inches in diameter. Involucre of 8 to 12 long but very unequal, stiff, linear, prickly bracts, usually curved upward. Scales of the receptacle broad and hairy at the base, ending in a fine prickly point, rather longer than the florets. Flowers pale lilac.

On roadsides and waste places, in central and southern Europe, and all across Russian Asia, not extending northward beyond Germany. Common in the southern counties of England, more rare in the north, and in Scotland, and a doubtful native of Ireland. Fl. late in summer, or autumn. The fullers' Teasel (D. fullonum) is believed to be a cultivated variety of this plant, only differing in the scales of the receptacle being hooked at the extremity.

2. D. pilosus, Linn. (fig. 493). Small T.-A branching biennial, 2 to 4 feet high, covered with stiff spreading hairs or bristles, which rarely amount to weak prickles. Leaves with 1 large, ovate, pointed, and coarsely toothed terminal segment, and 1 or 2 pairs of smaller ones on the short leafstalk. Flowers white, forming globular, hispid heads, barely an inch in diameter, on long peduncles. Bracts of the involucre seldom longer than the florets, and passing gradually into the scales of the receptacle, which are ovate, ending in a fine stiff point, about as long as the florets.

In rather moist hedges, thickets, and on banks, in ccntral and southern Europe to the Caucasus, extending northwards to southern Sweden. Occurs in most of the southern and central counties of England, as far north as York, but not in Ireland or Scotland. Fl. summer and autumn.

\section{SCABIOSA. SCABIOUS.}

Jlerbs, either annual or with a perennial stock, becoming shrubby in some exotic species, without prickles. Heads of flowers hemispherical or globular, with an involucre of small, green, not prickly bracts. Involucels various. Corolla 4- or 5-lobed, often oblique. Ovary and fruit crowned by the little cup-shaped calycine border, with 4, 5, or more teeth or bristles.

This, the principal genus of the family, belongs chiefly to the Mediterranean region, a few species extending over the rest of Europe and temperate Asia. Although not very numerous in species, it has been broken up into 4,5 , or 6 genera, the three British species being referred sererally to Succisa, Scabiosa, and Trichera or Kinautia.

Leaves cntire or nearly so. Florets 4-lobed, the outer oncs

scarcely larger than the others
Leaves tuothed or divided. Outer florets of each head usually

1. S. succion. much larger and niore obllque. 
Forets 5-lobed. Involucel with a spreading, scarious border. Fruit crowned by 5 bristles

Forets 4lobed. Involucel very short. Fruit crowned by minuto teeth

2. 5. Columbaria.

3. 8. arvensis.

The annual sweet Scabious (S. atropurpurea) and some other exotic species are occasionally cultivated in our flower-gardens. [S. maritima, I., a south European species, or form of atropurpurea, is completely naturalised on the cliffs at Folkestone.]

1. S. succisa, Linn. (fig. 494). Devil's-bit.-Rootstock short and thick, ending abruptly below as if it had been bitten off. Leaves mostly radical, stalked, ovate or oblong and entire, glabrous or with a few long hairs on the upper surface; those of the stem few and oblong, occasionally marked with 1 or 2 teeth. Stems 1 to 2 feet high, with 1 to 5 heads of deep blue flowers on long peduncles. Bracts of the involncre lanceolate, in 2 or $\mathbf{3}$ rows, the outer ones about as long as the flowers, the inner ones passing gradually into the pointed scales of the receptacle. Florets all nearly alike, 4-lobed, and but little oblique. Involucels tubular, angular, completely enclosing the ovary and fruit, bordered by very small, green teeth. Fruit crowned by the 4 bristles of the calyx, which scarcely project beyond the involucel.

In meadows, heaths, \&c., throughout Europe and Russian Asia, except the extreme north. Abundant in Britain. Fl. summer and autumn.

2. S. Columbaria, Linn. (fig. 495). Small S.-Stock perennial, tufted when old, and sometimes almost woody. Stems 1 to 2 feet high, including the long terminal peduncles, glabrons or slightly hoary. Leaves pinnate, the lower ones crowded, spreading, with an ovate or oblong terminal segment, and several smaller ones; the stem-leaves few, with linear segments, entire or pinnatifid. Flowers of a pale purplish-blue. Involncres short. Scales of the receptacles small and linear. Florets 5 -lobed, the outer ones of each head much larger and more oblique. Involucel enclosing the fruit to near the top, where it is contracted, and then expands into a scarions, sinuate, cup-shaped border, in the centre of which appears the summit of the fruit, crowned by the 5 bristles of the calyx.

In pastures and waste places, very aburuant all over central and southern Europe, extending eastward to the Cancasus, and northward to sonthern Scandinavia. Dispersed over a great part of England, especially near the east coast, along which it extends into west Scotland, but does not occur in Ireland. Fl. summer and autumm.

3. S. arvensis, Linn. (fig. 496). Field S.-A perennial, but of short duration, and often flowering the first year, more or less hairy, especially near the base, from 1 to 2 or even 3 feet high. Leaves very variable; the radical ones nsually lanceolate and stalked; the npper ones broader at the base, and sessile; all coarsely toothed or slightly lobed, but sometimes some or all are deeply cut or pinnate. Heads of flowers large, of a pale lilac-purple; on long peduncles, the outer forets much larger and more oblique than the central ones, as in S. Columbaria, but all are 4-lobed. Involucre short. Receptacle with hairs only between the florets. Involucel very minute. Ovary and fruit angular, crowned by the 8 or 10 radiating teeth or short bristles of the calyx. Knautia arvensis, Coult.

In pastures, open woods, waste and cultivated plases throughous 
Europe and lussian Asia to the Arctic Circle. Abundant in Britain. $\mathrm{Fl}$. all summer.

\section{COMPOSITE. THE COMPOSITE FAMILY.}

Herbs, or in some exotic genera or species, shrubs, with alternate or opposite leaves, without stipules. Flowers or florets collected several together into a head surrounded by an involucre, the whole having the appearance of a single flower, and called by older authors a compound flower, with a common calyx. The receptacle, or enlarged summit of the peduncle on which the florets are inserted within the involucre, either bears chaffy scales and hairs between the florets or is naked. In each floret the calyx is combined with the ovary, either completely so or only appears at its summit as a short border, or more frequently as a pappus: that is, a ring of long, simple or feathery (plumose) hairs or bristles, or of small chaffy scales. Corollas either all tubular, with a 5-toothed (or rarely 4-toothed) border, or all ligulate: that is to say, flat, linear or oblong, forming only a short tube at the base; or else both kinds are in the same head, the central ones tubular, forming the disk; the outer ones ligulate, constituting the ray. In the latter case the head of flowers is said to be radiate, and in contradistinction a head of flowers that has no ray is said to be discoid, and one which has no disk is said to be ligulate. Stamens 5 or rarely 4 , inserted in the tube of the corolla; the antliers linear and united in a sheath round the style. Ovary inferior, with a single erect ovule, and a filiform style divided at the top into two short branches bearing the stigmas. Fruit a small, dry, seed-like nut, usually called an achene, crowned by the pappus or sometimes naked.

The most extensive family among flowering plants, and represented in every quarter of the globe and in every description of station. It is also most easily recognised. The ligular florets are unknown in any other family, and when the florets are all tubular, Composita are distinguished from Dipsacece, and the few others which have similar heads of florets, by the union of the anthers. In Jasione indeed the anthers are slightly united, but there, besides other charncters, the ovary and capsule have two cells with several seeds. The genera are very numerous, and the characters are often taken from differences in the achenes and in the pappus which crowns them, which cannot well be observed until the fruit is ripe. It is therefore particularly necessary, in Composita, in collecting specimens for determination, to gather such as have the most advanced flower-heads, and these will always be found in the centre of the corymb. 
Forets all ligulate (Liovlata)

Florets all tubular.

Florets tubular in the disik or centre of each head, the outer ones either ligulate and forming a ray, or slender and filiform (CORYMBIFrRx)

\& Involucre or leares prickly. Style slightly bulbous under the branches (Criva.

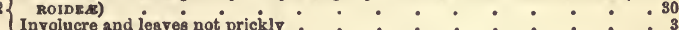

Florets purple, blue, or white $: \quad: \quad: \quad: \quad: \quad: 4$

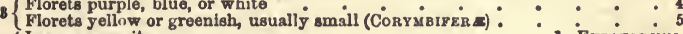

4 Leaves opposite

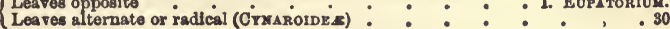

\section{CORYMBIFERE.}

S Leaves opposite

Leaves alternate or radical

Flower-heads emsll, numerous, purple. Pappus of many halrs 1. Euritoriux.

- Flower beads few, rather large, yellow. Pappus of a few bristles.

Flower discold, thet is, all the florets of the head tubular or filiform. 11. BIDENs.

not longer than the central ones

7 Fowers radiate, the outer florets ligulste and spreading, or, if erect, longer thsn the central ones . . . . . . 19

Achenes without a pappus, or crowned by a small cup or short scales : :9

Achenes bearing s pappus of hairs.$\quad 0.42$

Flower-heads monocious, the males with many tubular fiorcts, the femsles

9 forming s thick burr, ending in 2 conical beaks, and enclosing 2 flowers,

Flower-heads sll allke

Receptacle bearing scales between the florets. Plant covered with a dense

:0 white cotton. Leaves entire or toothed . . . . 16. Diotis.

No scales between the florets. Leaves, at least the lower ones, much divided 11

Flower-heads hemlspherical, 3 or 4 lines in diameter, in a large terminal corymb.

11 Achenes sngular, with a flat top 17. TANACETOM.

Flower-hesds emall, often nodding, in a leafy raceme or pantcle. Achenes obovste, contracted at the top . * . . 18. Artemisia.

${ }_{12}$ Bracts of the involucre linear, equal in length, with \& few very amall outer

2 ones of t . . . . . 13

Bracts of the Involucre imbricated In 2 or more rows : . . . . 14

Radical leaves large, brosdly beart-shaped or orbicular. Stem-leares small and

13 uarrow . . . . . 19. Tugsillaco.

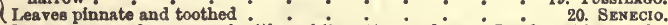

Plants more or less covered with a whits cotton or down. Involucral bracts also

14 cottony, or shining and scarious, or coloured at the edge . . . 15

Plants not woolly. Involucral bracts narrow and green ? : 17

Flower-heads diceclous. Involucral bracts with sprasding tips, st least in the

15 males . * . . . ANTENNARIA.

Flower-heads all with tubular forets in the centre. Iuvolucres not spreading 16

16 A row of scales within the outer row of florets . . . 6. Filaco.

16 Receptacle entirely without scales : : : : 7. Graphaliux.

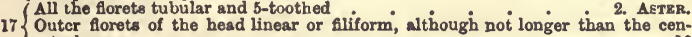

$\left\{\begin{array}{c}\text { Outcr llal ones } \\ \text { tral }\end{array}\right.$

Tall atiff plant. Flower-heads ovold, in a terminal corymb . . Ixvis Conysa.

18 Flowar-heads numerous and small, in a long leafy panicle.

Achenes withont sny pappus, or crowned by a small cup or minute canadense.

Achenes bearing a pappus of hairs

Receptacle bearing ecales between the florets, at least among tho central ones 21

$20\{$ Receptacle naked (without scales between the florets)

Flower-heads rather large, with a convex or conlcal receptacle is. ANTHzisis.

21 Flower-heade small, with s small flat receptacle.

15. ACHILLEA, Involucral bracts all green and of equal length

5. BrLL18. 
$24\{$ kay purple or blue.

Ray yellow

Involucral bracts and fiorela of the ray not numerous, oblong-linear

$25\{$ Involucral bracts and florets of the ray very numerous aud narrow.

3. ERtoeron.
Involucral bracts linear, equal in length, or with a few very amall outer ones 27

Involucral bracts imbrlcated in 2 or nore rows . . . . . 29

Radical leaves large, broadly beart-shaped or orbicular, dintinct from the flower-

27 ing atem. Florets of the ray narrow and very numerous 19. Tussiuado.

Radical leaves none, or at the base of the flowering stem. Florets of the ray linear or oblong . . . . . . . . . . . 28

Achenes of the ray without ang jappus : : $: 21$. DoRonicum.

Achenes of the ray with a pappus like those of the disk : 20 . SkN ECio.

Florets of the riy not more than 10 or 12. Anthers without talls 4. SuLidaco.

29 Florets of the ray very numerous, or at any rate above 20. Anthers with minute fine points or tails at their base. . . . . . 9. INULA.

\section{Cynaroides.}

Bracts of the involucre entire, obtuse or pointed but not prickly . . . 31 30 Bracts of the involucre ending in a long, stiff point, hooked at the extremity.

Bracts of the involucre prickly, or ending in a fringed or toothed appendage 34

31 Haira of the pappus simple . . . . . . . . . . 32

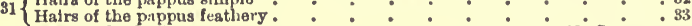

${ }_{32}$ Recptacle chaffy : : : : : : : : $: 23$. SRrRatula.

Receptacle naked : : : : : : 19. Trisiluao.

${ }_{33}$ Leaves entire ur coarsely toothed, not prickly . . : 24. SAUssurea.

$\{$ Leaves either prickly or bordered with minute stiff bristles : 25. CARDUUs.

Bracts of the involucre ending in a simple point or prickle . . . . 35

34 Bracts of the involucre ending in a fringed or toothed appendage, or in several points or prickles, or in a prickle branched at the base . . . . 36

(Receptacle bearing long chaffy bristles between the florets 25 . CARDUUs

33 Receptacle honeycombed, with jagged edges to the eavitles, but not briatly.

26. ONOPORDON.

Inner bracts of the involucre long, linear, shlning and spreading, onter ones

$36\left\{\begin{array}{l}\text { very prickly. Achenea silky } \\ \text { Bracts of the involucre toothed or jagged, not prickly }: \quad 28 \text {. Centa UREA. }\end{array}\right.$

Bracts of the involucre prickly. Achenes glabrous : :

37 Pappns of long, simple or feathery hairs : : : $: 25$. CARDUUS.

Pappus of short, simple bristles or none : : : : 28. Centaurka.

\section{Ligulater}

88 Achenes bearlng a pappus of numerous long hairs . . . . 39 Achenes without a pappus, or crowned by a few short scales : $: \quad: \quad 51$

Pappus with some or most of the haira feathery

Pappus with all the haira slmple.

40 Involnere (very long) with all the bracts of equal length: 29. Traoopocion.

$\{$ Involucre with outer bracts tnuch smaller, or different from the inner ones. 41

Exterual bracta of the involucre 4 or 5 , broadly ovate or heart-shaped.

41 .

External bracts of the involucre amall and unequal .

30. Himinthia.

Receptacle bearing some long chaffy acales between the fiorets.

42

Receptacle naked

83. HYPOCHARIS.

(Stem leafy, branched, several-flowered, with clinging, hooked hairs. Achenes

$43\left\{\begin{array}{c}\text { without a beak } \\ \text { Stem almost leafless, simplo or slightly branched, with } 1 \text { or verj fow fiowor. }\end{array}\right.$ heads. Achenes usually tspering into a short bcak . . 32. LeoNTODON.

(Achenes more or less flattcned. Leaves glabrous, often beailing prickles on

44 the edges or midrib . 45

Achenes cylindrical or angular. Leaves glabrous, hairy, or downy. : 47

45 Achenes tapering into a slender beak bearing the pappus.

Pappus seasile or not supported on a distinct, slendcr beak

$40\left\{\begin{array}{l}\text { Peduncles radical, with a single flower-head } \\ \text { Flowering stems erect, leafy, beartug neveral flower-heads }\end{array}\right.$

85. Sंoncius.

36. TARAXAOUM

34. LaCtuCa 
17 Achenes tapering into s slender beak, bearing the pappus . . . .48

Pappus sessile or not supported on a distinct, slender beak : . . 49

8 Peduncles radical, simple, with a single flower-head .

36. TARAXACUN.

Flowering stenıs branched, bearing several beads . . . . 37. CREPIs

10 $\left\{\begin{array}{l}\text { Achenes strongly striate, and slightly narrowed at the top. Pappus of nume } \\ \text { rous white hairs. Lower leaves frequently pinnatifid. }\end{array}\right.$

Achenes but slightly striate, not narrowed at the top. Pappus of rather stifl bristles, of a dirty white . . . . . . . 50

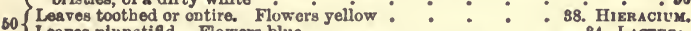

$\{$ Leaves plnnatifld. Flowers blue.

81 Flowers blue. Pappus a small cup formed of short scales : 39. Cickoriux.

1 Flowers small and yellow. No pappus . . . . . . . . 52

Stem 1 to 2 feet, leafy, with several flower-heads $\quad$ 41. Lapsaxa.

$52\{$ Stem leafless, not 6 inches bigh; hollow under the flower-beads. Leaves radical.

Since the earlier editions of this work, the Compositce have undergone a generic revision, and althongh the above three principal divisions or suborders established by Jussien, the Corymbifera, the Cynaroidea, and the Ligulato, may still be convenient for the British or even the European Flora, it has been found necessary for general purposes to distribute the known genera (near eight hundred) into thirteen tribes. Of these the following eight are represented in Britain.

1. EUPATOR1aces. Florets all eimilsr, tubnlar, not yellow. Style branches clubshaped or obtuse. Genus :-1. Eupatorivu.

2. Asteroides. Central fiorets tubular, usually yellow, outer ones ridiating or filiform, rarely wanting. Anthers not tailed at tho base. Style-branches usually flattered and yointed. Genera :-2. Astzr; 3. Eriokron; 4. Solidago; 5. Belli.

8. INDLOIDR. Florets of $\triangle 8 \mathrm{BTEROIDEE}$, but the suthers with fine points or tails at the bese. Style-branches obtuse. Pappus of very slender hairs. Genera:-6. Hilaoo; 7. GNapilaliUM ; 8. ANTENNaria ; 9. InULa.

1. Heurantroides. Central forets tubular, ususlly yellow, outer ones radiating or wantlug. Receptacle with scales. Style-branches truncate or with s pointed appendage. Pappus of rigid bristles, or scales, or nono. Genera:-10. Xaxinuux;

\section{Bipens.}

5. ANтнemidea. Central florets tubular, usually sellow, outer ones radiating, fliform, or none. Style-branches truncate. Yappus none, or of a small ring. Genera :-12. Chrysantermom; 13. Matricaria; 14. Anthemis; 15 . Achillea; 16. Diotis; 17. TANACETUM ; 18. ARTEMisia.

6. Senzcionide $x$ Central florets tubular, uaually yellow, outer ones radiating, or none. Style-branches truncate. Pappus of fine hairs, Genera :-19. Tossiludoo; 20. SENECIO; 21. DORONICOM.

7. Crmaroiden Florets all tubular, rarely yellow. Style cntire, or with short branches, usually swollen below the end. Leaves and involucres usually prickly. Genera:-22. ArctivM; 23. Serratula; 24. Saussurka; 25. CarduUg; 26. ONG. Pordok ; 27. Carlina; 28, Centaurea.

10. Cichoriace $\mathrm{x}$ or Ligulate. Florets all ligulate. Genera:-29. Traoopogon ; 86. Helminthia ; 31 . Picais; 32. Leontodon; 33. Ily pochocris; 34 . Lactuca; 35. Bonchos; 36. Taraxadum; 37. Crepis; 38 . Hieraciom; 39. Cichoridu ; 13. arnoBERIS; 11. LAPBANA.

Among the numerons exotic genera familiar to ns by long or general cultivation may be mentioned the Marigold (Calendula), the Sunflower and Jerusalem Artichoke (Helianthus), the French and African Marigolds (Peruvian species of Tagetes), several Everlastings (Helichrysum, and other Cape and Australian genera), several species of Coreopsis, Rudbeckia, Zinnia, Dahlia, Ageratum, \&c., all belonging to Corymbifera; the Artichoke and Cardoon (Cynara), and the Globe-Thistle (Echinops), belonging to Cynaroidea, and Scorzonera, and Catananche among Ligulate.

I. EUPATORIUM. EUPATORY.

Herbs (or in exotic species, shrubs), with leaves mostly opposite, and 
purplish or white tlowers in terminal corymbs. Receptacles without scales. Florets all tubular and equal. Styles much exserted, with long thickened or club-shaped branches. Achencs angular or striated, with a pappus of simple hairs.

A vast genus, chiefly American, with a few Asiatic species, one of which is also our European one, the only British Composite with opposite leaves, and florets not yellow.

1. E. cannabinum, Linn. (fig. 497). IIcmp Agrimony.-Rootstock perennial, stems erect, 3 or 4 feet high. Leaves 3 to 5 inches long, slightly downy, divided into 3 broadly lanceolate, coarsely toothed lobes, sometimes ayain slightly lobed, a few upper leaves occasionally simple and alternate. Flower-heads numerous, in compact terminal corymbs, of a pale reddish purple. Involucres cslindrical, of very few unequal bracts, and usually containing 5 florets.

On banks and bushy places near water, throughout Europe and central and Russian Asia, except the extreme north. Extends all over Britain. Fl. summer.

\section{ASTER. ASTER.}

Herbs, usually erect, with alternate, entire or toothed leaves, narrow linear in the British species. Flower-heads in terminal corymbs. Involucral bracts imbricated in several rows. Outer florets not very numerous, forming a purple or white spreading ray, but sometimes wanting, those of the disk tubular, 5-toothed and yellow. Branches of the style somewhat flattened and pointed. Antbers without tails. Achenes flattened with a pappus of many hairs.

A very numerous North American genus, with a few species spread over northern Asia, Europe, and some other parts of the world. Several of the North American ones are known among the autumnal plants in our flower-gardens under the name of Michaelmas Daisics. Our China Asters belong to a nearly allied genus from Eastern Africa.

Flower-beads usually radiato. Involucral bracts few, oblong . 1. A. Tripolium. Fluwer-heads witlout rays. Involucral bracts nuncrons, narrow linear.

2. A. Linosyris.

1. A. Tripolium, Linn. (fig. 498). Sea A.-A glabrous perennial, seldom above a foot bigh, erect or decumbent at the base, slightly branched. Leaves linear, entire, somewhat succulent. Flower-heads in a rather compact corymb, the involucral bracts few and oblong. Florets of the ray purplish, numerous or few, and occasionally wanting, those of the disk longer than the involucie; the pappus also longer than the involucre.

In salt-marshes, common in Europe and Russian Asia, except the extreme north. Extends along the British coasts to the north of Scotland. Fl. late in summer or autumn.

2. A. Linosyris, Bernh. (fig. 499). Goldilocks.-A glabrous erect perennial, 6 inches to a foot bigh, with numerous narrow linear, entire leaves, more or less dotted. Flower-heads in a rather comjact terminal corymb, of a bright yellow, without any rays in this country, which had induced older botanists to characterise the plant as a distinct genus, but in Germany it has been found occasionally to bear the rays of an serer. Involucres imbricated, with numerous narrow bracts 
shorter than the florets and the pappus. Achenes compressed and silky as in other Asters. Linosyris vulgaris, Cass.

In clefts of rocks and on stony hills, and especially along gravelly banks of great rivers in south, central, and western Europe, to the Caucasus, not extending into northern Germany, although reappearing on the Isle of Oeland, in the Baltic. In Britain confined to a few limestone cliffs on the southern and western coasts of England and Wales. Fl. end of summer, or autumn.

An Aster with flat lanceolate occasionally toothed leaves, and loosely corymbose radiating flower-heads, has been found on the banks of the Tay, near Perth, and in Wicken fen in Cambridgeshire, and has been referred to $A$. salignus, Willd.; the specimens, bowever, do not appear to me to represent the German plant of that name, but rather a garden variety of $A$. longifolius, Lam., a species long in cultivation, and which probably in the above localities is an escape from some garden. [The true $A$. salignus has, however, been found as an escape from cultivation in Cambridgeshire.]

\section{ERIGERON. ERIGERON.}

Differs from Aster in the involucral bracts very narrow and numerous, and in the outer florets very numerous and much narrower, either forming a short coloured ray, or almost filiform and not projecting beyond the involucre and pappus. The regular, tubular, yellowish florets in the centre often reduced to very few.

Its geographical range is even more extended than that of Aster, for several species are natives of the tropics; some are found in the extreme Arctic regions, or on the summits of the Alps, whilst others spread as weeds nearly all over the globe.

Outer florets almost filiform, not projecting beyond the involucre.

Heads very numerous, and snall

3. B. canadensis. ray.

Annual or blennial. Flower-heads several, or rather long peduncles. Ruy erect, very little longer than the disk .

Pereunial. Flower-heads solitary or very few. Ray spreading, considerably longer than the disk.

1 B. acris.

2. E. alpinus.

Several large-flowered American species are occasionally cultivated in our flower-gardens.

1. E. acris, Linn. (fig. 500). Fleabane E. -An erect annual or biennial, 6 inches to a foot high, slightly branched, and rather rough with short hairs. Leaves linear or lanceolate and entire, the radical ones stalked, but nsually withered away at the time of flowering. Flower-heads rather small, solitary on the peduncles or upper branches, forming a short, loose panicle. Florets very numerous, mostly filiform and short, the outer rows of a pale purple, projecting slightly beyond the involucre and pappus, the tubular ones of the centre very few, of a pale yellow.

In pastures, on banks, roadsides, and waste places, common in the greater part of Furope, from the Mediterranean to the Arctic regions, and in central and Russian Asia. Less frequent in England and Ireland, and rare in Sootland. Fh. summer anul autumn. It varies mucl. 
in stature, in the number and size of the flower-heads, and of the florety of the ray, but these are always smaller and more numcrous than in $E$. alpinus, much larger and fewer than in $E$. canadensis.

2. E. alpinus, Linn. (fig. 501). Alpine E.-Stock perennial, with erect or ascending hairy stems, 2 to 6 or rarely 8 inches high. Radical leaves oblong-lanceolate, tapering at the base; stem-leaves smaller $\mathrm{few}$, and lanceolate. Flower-heads solitary, or rarely 2 or 3 in a loose corymb, each onc at least balf an incli in diameter; the florets like those of $E$. acris, except that the outer pink or purplish ones are longer, more decidedly ligulate, forming a distinct spreading ray. $E$. uniflorus, $\mathrm{Sm}$.

In mountain pastures, in northern Europe, Asia, and America, to the Arctic regions, and in the higher mountain-ranges farther south. In Britain, confined to some of the eastern high mountains of Scotland. Fl. summer, rather late.

3. E. canadensis, Linn. (fig. 502). Canadian E.-A stiff, erect annual, 1 to 2 feet high, glabrous, except a few long, spreading bairs. Leaves narrow, and entire or slightly toothed. Flower-beads very small and nnmerous, forming a long, narrow, leafy panicle. Florets minnte, the outer ones filiform, scarcely longer than the involucre, white or slightly tinged with red; central ones tubular, yellowishwhite.

A native of North America, now established in the greatest abundance as a roadside weed in almost all temperate and hot countries, and appears occasionally as such in England. Fl. summer and autumn.

\section{SOLIDAGO. GOLDENROD.}

IIerbs, usually tall, perennial, and leafy, with numerous rather smalh yellow, radiate flower-heads. Involucres imbricate, in few rows. Receptacle without scales. Outer florets ligulate and few, inner ones tubular, all yellow. Style and anthers of Aster. Achenes cylindrical, with a pappus of many simple hairs.

A considerable North American genus, with a single species spreading over central and northern Asia and Europe. It differs from $A$ ster in the yellow rays and cylindrical achenes, from Inula in the fewer ligulate florets, besides the microscopical but constant character derived from the style and tailless anthers.

Several North American species hare been long cultivated in our flower-gardens, and among them the $S$. lanceolata is said to bave occasionally established itself in their vicinity.

1. S. Virga-aurea, Linn. (fig. 503). Common G.-Stock more or less tufted. Stems crect, stiff, nearly simple, 6 Inches to 2 feet high, glabrous, or minutely downy. Rarlical leaves obovate and stalked, stem-leaves oblong or lanceolate, slightly toothed, shortly tapering at the base. Flower-heads crowded in a narrow-oblong terminal panicle, often leafy at the base, not large, of a bright yellow, each with a spreaning ray of about 10 or 12 florets, and about twice that number of tubular ones in the disk.

In woorls, very common throughout Europe, and central and Russian $\Delta$ sia, and northern America, to the Arctic regions. Abundant in 
Britain. Fl, summer and autumn. [Very variable; S. cambrica, Huds., is a dwarf mountain form with broader ciliate leaves and larger beads.]

\section{BELLIS. DAISY.}

Low herbs, with alternate or radical, entire or toothed leaves. Flowerheads solitary, on radical or axillary peduncles, with a yellow disk and white or pink ray. Involucre hemispherical, with many bracts of equal length, in about two rows, and green, not scarious, at the tips. Receptacle conical, without scales. Achenes compressed, without any pappns. Style nearly that of Aster.

A small genus, extending over the temperate regions of the northern hemisphere.

1. B. perennis, Linn. (fig. 504.) Daisy.-Stock perennial, tnfted. Leaves radical, obovate or oblong, slightly toothed. Peduncles also radical, leafless, bearing single flower-heads. Involucre green, nearly glabrous. Florets of the ray ligulate, white or tinged with pink; those of the disk numerous, small, and tubular.

In pastures, common throughout Europe, except the extreme north, but apparently not extending into Russia, nor ascending high into mountain regions. Abundant all over Britain. Fl. nearly the whole year round.

\section{FILAGO. FILAGO.}

Annuals, covered with the grey or white cottony wool and with the narrow entire leaves of Gnaphalium. Flower-heads numerous, very small, sessile, in lateral or terminal clusters. Involucral bracts cottony outside, shortly dry, and scarious at the tips. Receptacle small, with a row of scales within the outer row of florets, but none in the centre of the head. Florets of the centre tubular, sometimes barren, those of the circumference more numerous, filiform, and fertile as in Gnaphalium, the anthers, style, and achene the same as in that genus.

A genus of few species, widely spread over Europe and Russian Asia, and reappearing in western extratropical America. In the previous editions of this work it was included in Gnaphalium, some species of which it closely resembles, but the general revision of the order has shown the necessity of kecping it distinct.

Clusters of flower-heads few, globular and terminal, each with numerous flower-heads .

1. $F$. germanica.

Clusters numerous, lateral and termiual, with less than 10 heads in each.

Leaves linear-lanceolete

Leaves linear-subulate

1. F. germanica, Linn. (fig. 505). Cudveed.-An erect cottony annual, about 6 to 8 inches high, simple or branched at the base; each stem terminated either by a single globular cluster of flower-heads, or throwing out immediately under it 2 or 3 branches, each ending in a similar cluster. Leaves erect, lanceolate or linear, pointed or obtuse, sometimes spatbulate; those under the clusters shorter or rather longer than the clusters themselves. Flower-heads very small, about 12 to 20 or 30 in each cluster; the involucres ovoid-conical, more or less angular, 
of a pale yellow or brown; the bracts nsually acute. Florets shirter than the involucres; the onter filiform ones mostly concealed among the scales of the receptacle (or inner bracts of the involucre), with a few, chiefly tubular, in the centre, without scales.

In dry pastures, and stony or sandy wastes, over the whole of Europe and western Asia except the extreme north. Abundant in England and Ireland, rather less so in Scotland. $F l$. the whole summer. It has been subdivided into several supposed species, upon characters derived from the shorter or longer, and more or less obtuse or acute floral leaves, from the quantity of cotton on the involucres, and from their obtuse or acute bracts. [Of these $F$. apiculata, G. E., Sm., is a tall variety with purplish boat-shaped bracts; and $F$. spathuluta, Presl., a short one with broader leaves. Both are confined to the east or southeast of England.]

2. F. minima, Willd. (fig. 506). Field $F$. -A much more slender and smaller annual than $P$. germanica, which t t ctherwise resembles in foliage and in mode of growth. It is more irregularly branched at the top, the leaves smaller, the clusters of flower-heads smaller and more numerous, each consisting of from 3 to 10 minute conical heads. Involucres cottony at the base, shining at the tips, and only one or two outer rows of filiform florets are amongst the scales of the receptacle.

In fields, and stony or sandy wastes, with a wider range than that of $P$. germanica, extending all across Russian Asia, and more common in the north, although not an Arctic plant. In Britain it has been observed in various localities, but is perhaps frequently overlooked owing to its small size. Fl. the whole summer.

3. F. gallica, Iluds. (fig. 507). Narrow $P$. - Very near $P$. minima, but much more branched, the leaves almost subulate and much longer, the clusters of flower-heads very numerous and small, the leaves which surround them longer than the involucres, whilst in the last two they are mostly shorter. Involucres very small and conical, containing but very few florets. Some of the outermost rows are embraced as it were each by one of the inner bracts of the involucre, with a row of receptacular scales between them and the next row, thus distinguishing this species from small specimens of Gnaphalium uliginosum, which it sometimes resembles.

In fields and sandy wastes, in western and sonthern Europe, becoming rare in Germany. Very local in Britain, having been chiefly recorded from some of the south-eastern counties of England, and the Channel Islands. Fl. summer.

\section{GNAPHALIUM. CUDWEED.}

Herbs, more or less covered with a grey or white cottony wool; the leaves narrow and entire. Flower-heads small, sessile, often clustered, rarely forming terminal corymbs. Involucral bracts imbricated, cottony outsille, and more or less dry, scarious, and often coloured at the tips, and sometimes spreading, but not in the British species. Receptacle small, without any scales. Florets of the centre tubular, often barren, those of the elrcumference filiform, female, in several rows. Anthers with minnte bristles or hair-like points (tails) at their hase. Stylebranches truncate. Achenes with a pappus of simple hairs. 
A large genus, generally spread over nearly the whole globe from the tropics to the Arctic Circle.

Perennial. Flower-heads in oblong or elongatod leafy spikes.

Achenes not fattened.

Dwarf pereunial. Flower-heads terminal, solitary or very few. Achenes flattened

Annual or biennial. Flower-heads irregnlarly clustered in a terminal corymb. Achenes not flattened

Annual. Flower-heads small and clustered within a tuft of lcaves longer than the beads

2. G. sylvaticum.

8. G. supinum.

1. G. luteo-album

The other species included in Anaphalium in the earliest editions will now be found under Filago and Ariennaria. Most of the composite Everlastings of our gardens belong to the allied genus Helichrysum, of which no specics are British.

1. G. Iuteo-album, Linn. (fig. 508). Jersey C.-An annual or biennial, scarcely a foot high, the stems ercet or ascending and all covered with soft white cotton. Leaves narrow. Flower-heads 2 to 3 lines in diameter, irregnlarly clnstered in a dense corymb. Involncral scales searious at the top, of a pale brown, yellow, or dirty white colour, but not spreading. Florets very numerous, mostly female and filiform, with a few tubular male or complete ones in the centre.

In sandy fields, pastures, and waste places, dispersed nearly all over the temperate and warmer regions of the globe, extending in Europe to the Baltic, but not beyond. In the British Isles, appcaring now and then in the eastern counties and Channel Islands. Fl. summer and autumn.

2. G. sylvaticum, Linn. (fig. 509). Tood C.-Stock perennial, tufted or shortly ereeping, with long-stalked lanccolate leaves. Flowering stems nearly simple, ercct, from 2 to 6 or 8 inches high, with linear leaves, usually cottony on the under side only, but sometimes on both sides. Flower-heads small, cylindrical, or ovoid, either solitary or in little clusters in the axils of the upper leaves, forming a long, leafy spike. Involucres scarcely cottony, with brown, shining bracts; the outer filiform florets more numerous than the inner tubular ones. Achenes slender, nearly cylindrical.

In open woods, heaths, and pastures, in northern and central Europe and Russian Asia, and all round the Arctic Cirele; bccoming a mountain plant in the south, and scarcely reaching the Mediterranean. Extends over the whole of Britain. Fl. summer and autumn. A bigh alpine or Arctic variety, with the leaves cottony on both sides, and the flower-heads darker coloured, in a short terminal spike, has been dis. tinguished as $G$. norvegicum, Gunner., and has been found in Pertl, Forfar, and Abcrdeen.

3. G. supinum, Linn. (fig. 510). Ducarf C.-A small, tufted perennial, with narrow leaves, sometimes resembling dwarf specimens of $G$. sylvaticum, but the stem seldom 2 inches high, bearing only very few flower-heads in a terminal cluster, or only a single one; and sometimes the flower-heads are almost sessile in the centre of the radical leaves. Involucres brown, like those of $G$. sylvaticum, but the filiform florets are mnch fewer, and the achenes broader and evidently flattened.

An Arctic and high alpine plant, extending over the mountain ranges of Europe and western Asia to the Arctic Circle. Not ancommon in the Scotch IIighlands, absent from England and Ireland. $F l$, summer. 
4. G. uliginosum, Linn. (fig. 511). Marsh C.-A much branched, cottony annual, seldom above 6 inches high; the leaves linear or narrow-oblong, the upper ones waved on the edges. Flower-heads small and clustered, many together, within a tuft of rather long leaves at the extremity of the branches. Involucral bracts brown and scarious. Florets about the length of the involucre, the 3 or 4 outer rows fliform, with a very few tubular ones in the centre. Achenes very minute, scarcely compressed, with a very deciduous pappus of distinct hairs.

In fields and waste places, especially in wet, sandy situations, throughout Europe and Russian Asia, from the Mediterranean to the Arctic regions. Common in Britain. Fl. summer and autumn.

\section{ANTENNARIA. ANTENNARIA.}

Cottony perennials, with the characters of Gnaphalium, except that the flower-heads are diocious, those of some individuals having filiform fertile florets without any tubular males, in other individuals having only tubular male florets; and the involucral bracts have more scarious spreading tips, at least in the males.

The species are numerous, almost limited to the mountain regions of the northern hemisphere. They were included in Gnaphalium, in former editions.

Iow plant, with 3 to 6 flower-heads in the terminal corymb . 1. A. dioica. Tall plant, with a large corymb of numerous flower-heads : 2. A. margaritacea.

1. A. dioica (fig. 512). Mountain Everlasting, Cat's-ear,-A small perennial, with a tufted or creeping leafy stalk, and almost simple Howering stems, 2 to 4 or 5 inclics high. Lower leaves obovate or oblong ; upper ones linear, white underneath or on both sides. Flowerheads 3 or 4 together, in compact, terminal corymbs, and diœcious. In the males the inner bracts of the involucre have broad, white, petallike tips, spreading like the ligulate florets of a radiating flower-head; the florets all tubular and short. In the females the inner bracts are narrow, white at the tips, but not spreading, and the florets all filiform, with a long protruding pappus to the achenes.

In mountain past ures, common in northern Europe, Asia, and America, to tbe Arctic regions, and in the great mountain-ranges of central and southern Europe and Russian Asia. Abundant in Scotland, Wales, Ireland, and many parts of England, descending occasionally nearly to the coast level. Fl. summer, rather early.

2. A. margaritacea, Br. (fig. 513). Pearl A.-An erect perennial, 2 to 3 feet bigh. Leaves linear-lanceolate, white and cottony underneath or on both sides. Flower-heads numerous, in flat terminal corymbs, usually diœeious, but less absolutely so than in A. dioica; the involucres of both kinds with several rows of very white, broad, loose, or spreading bracts.

A North American and central Asiatic plant, long cultivated among our garden Evcrlastings, and now apparently naturalised in a few localities in Monmonthshire and in South Wales, Scotland, and the Channel Islands. Fl. end of summer. 


\section{IX, INULA. INULE.}

Herbs, usnally erect, with alternate, entire or toothed leaves. Flowerheads in terminal corymbs or panicles, or rarely solitary. Involncral bracts imbricated in several rows. Florets all yellow, the outer rows ligulate and radiating, or rarely short and concealed by the involucre; those of the disk tubular. Receptacle without scales. Achenes cylindrical or angular, with a pappus of many hairs. Anthers tipped at the lower end by two minute hair-like points called tails.

A numerous European and north Asiatic genus, technically distinguished from Solidago by the tails of the anthers; but these, though constant, are so minute as not to be seen without a careful dissection and good magnifier. The florets of the ray are also very numerous and narrow in Inula, much fewer and broader in Solidago.

Rays considerably longer than the involucre.

Lenves flat, ovate, oblong, or lanceolate.

Flower-heads very large, with broadly ovate involucral bracts 1. 1. Helenium.

Flower-heads less than an inch diameter without the rays.

Glabrous or nearly so. Involucral bracts lanceolate, ciliate Downz plant Involucral bracts narrow.

Leaves narrow, thick, succulent. Plant glabrous, Fower-heads not large

Rays vcry minute, concealed by the involucre, or scarcely longer.

Tall perennial. Flower-heads ovold, in dense corymbs

Annual, scarcely a foot high. Flower-heads brosd, softly downy, in a loose leufy corymb

2. 1. salicina.

5. I. dysenterica.

3. I. crithmoides

4. 1. Conyza.

6. I. Pulicaria.

1. I. Helenium, Linn. (fig. 514). Elecampane.-A coarse perennial, with stout, erect, scarcely branched stems, about 2 feet bigh. Radical leaves often a foot long, oblong, and narrowed into a stalk; the upper ones ovate or oblong, clasping the stem, nearly glabrous above, more or less softly hairy underneath. Flower-heads very large, solitary at the ends of the branches. Involucral bracts broadly ovate and softly hairy. Florets of the ray numerous, long, and linear.

In rich hilly pastures, in central and southern Europe, and eastward to the Caucasus and Himalaya, and, having been much cultivated in former days in herb-gardens, it has established itself in many places farther north. It may therefore be only an introduced plant in Britain, when growing, as it generally does, in the neighbourhood of old castles and gardens; but is also believed to be truly indigenous in Yorkshire, in some parts of southern England, South.Wales, and Ireland. Flo summer and autumn.

2. I. salicina, Linn. (fig. 515). Willow-leaved 1.-Rootstock perennial, with erect stems, scarcely branched, 1 to 2 feet high, the whole plant glabrous or sprinkled with a few hairs especially on the under side of the leaves. Leaves oblong or lanceolate, acute, entire or bordered with small sharp teeth, clasping the stem with rounded auricles. Flowcrheads terminal, solitary or rarely 3 to 5 in a terminal corymb. Involucre hemispherical, about inch diameter; the bracts narrow, ciliate. Florets of the ray numerous, narrow, spreading, yellow.

In moist pastures and along ditches in the outskirts of woods; widely spread over the continent of Europe, and somctimes common, ex. tending northwards to a few localities in Sweden. In the United Kingdom, found only on the margins of Lough Derg, in Galway. Fl. summer.

3. I. critbmoides, Linn. (fig. 516). Golden Sumplire.-A glabrous, 
erect perennial, about a foot high or rather more. Leares numerous, linear, thick and succulent, entire or with 1 or 2 small teeth at the base. Flower-heads not large, solitary on the short branches of a short, leafy panicle. Involncral bracts numerous and narrow. Florets of the ray bright yellow and spreading, not so narrow or so numerous as in the other species, yet twice as many as in Solidago Virga-aurea.

In salt-marshes, in western Europe, and all round the Mediterranean; frequent on the southern and western coasts of Britain up to Kirkcudbright and Wigton, and in the east to Essex, both in salt-marshes and on dry maritime limestone rocks, south-east of Ireland. Fl. summer and autumn.

4. I. Conyza, DC. (fig. 517). Ploughman's spikenard.-A bard, erect biennial, 2 to 3 feet high, covered with a sbort down, rough on the stem, soft and cottony on the under slde of the leaves. Leaves ovate-lanceolate, the lower ones stalked, the upper sessile. Flowerheads numerous, in a terminal corrmb. Involucres ovoid; the bracts numerous, the outer ones tipped with green, the inner linear, reddish, and erect. Outer florets numerous but very small, their purple styles alone protruding beyond the involucre, so that the plant appears at first sight to have no ray.

In hedges and open woods, and roadsides, in central and sonthern Europe to the Caucasus, extending northwards into Denmark, but not into north-eastern Germany. In Britain, as far north as York and Westmoreland, but neither in Ireland nor Scotland. Fl. summer and autumn.

5. I. dysenterica, Linn. (fig. 518). Fleabane 1.-Rootstock perennial, with ascending or erect stems 1 to 2 feet high, loosely branched, and, as well as the foliage, more or less downy or woolly. Leaves oblong, much waved, clasping the stem with rounded auricles. Flower-heads pedunculate in the upper axils or at the ends of the branches, hemispherical, ratber more than half an inch in diameter, with a ray of very numerous, linear, spreading florets of a bright yellow. Involncral bracts also numerons and narrow. Pappus-liairs few and shorter than in the three preceding species, and enclosed at the base in a minute membranons cup. Pulicaria dysenterica, Gxrtn.

In wet pastures, ditches, and roadsides, in central and southern Enrope and western and central Asia, extending northwards to the Baltic. Abundant in southern England and Ireland, becoming rare in the north, and scarcelly found in Scotland. Fl. summer and autumn. This and the following species are sometimes separated as the genus Pulicaria, Gxrtn.

6. I. Pulicaria, Linn. (fig. 519). Small Fleabane-An erect, branching annual, seldom a foot high, with narrower and less woolly leaves

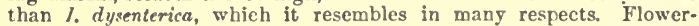
heads much smaller, and the florets of the ray, although very numerous, yellow and spreading, are so short as at first sight to escape observation. The minute outer scales of the pappus are distinct, not forming a little cup as in I. dysenterica. Pulicaria vulgaris, Grertn.

In moist waste places, roadsides, and sandy heaths, ranging over Europe, extending eastward across Russian Asia, and northwurds to sonthern Sweden. In Britain, chiefly in southeastern England, and not known either in Ireland or Scotland. Fl. summer and autumn. 


\section{XANTHIUM. BURWEED.}

Coarse annuals, with alternate leaves, and unisexual, axillary or terminal heads of green flowers. Involucre of the males of several bracts in a single row, enclosing many tubular florets, separated by the scales of the receptacle. Anthers free. Female florets 2 together, combined with the involucre into an ovoid or oblong, prickly burr, terminating in 2 beaks, from which the stigmas shortly protrude.

A genus of two or perhaps three species, from the Mediterranean region to the Levant, but spread as weeds of cultivation over a great part of the globe. Its immediate connection with the remainder of Composites can only be traced through several exotic genera forming the small subtribe of Ambrosice, the general habit and unisexual flowers showing at first sight some analogy to Urticece and some other Monochlamyda.

1. X. Strumarium, Linn. (fig. 520). Burweed.-A coarse, erect annual, 1 to 2 feet high. Leaves on long stalks, rather large, broadly heart-shaped, coarsely toothed or angular, rough on both sides. Flowerheads in axillary or terminal clusters, on short racemes; the upper ones male ; the lower female heads forming, when in fruit, oroid burrs, about 6 to 8 lines long, covered with hooked prickles; the stout, short, conical beaks erect or turned inwards.

In cultivated and waste places throughout central and sonthern Enrope and central Asia, extending, as a weed of cultivation, northwards to the Baltic, as well as into many other parts of the globe. Occasionally found in some of the sonthern counties of England and Ireland, but is not a British plant. Fl. summer. [Two species occur occasionally in Britain, $\boldsymbol{X}$. Strumarium, $\mathrm{L}_{\text {. }}$, with cordate leaves, and usually hooked beaks to the fruiting involucres; and $X$. spinosum, with cuneate bases of the leaves and single straight beaks.]

\section{BIDENS. BIDENS.}

Glabrous herbs, with opposite leares, and hemispherical heads of yellow flowers. Involucres of 2 or 3 rows of bracts, the outer ones often longer and leafy. Florets either all tubular, or the outer ones ligulate and radiating. Receptacle with chaffy scales between the forets. Achenes flattened, crowned by 2 or 3 (very rarely 4 or 5) short, stiff bristles or awns, which are rough, with minute deflexed prickles.

A genus not very numerous in species, but diffused over the whole surface of the globe, some being among the commonest tropical weeds.

Lenves nndivided . . . . . . . . 1. B. cernua

Leaves deeply cut into 3 to 5 segments $\quad: \quad \div \quad$ : 2 B. tripartila

1. B. cernua, Linn. (fig. 521). Bur-Marigold.-A rather stout, erect annual, 1 to 2 feet high, with spreading branches. Leaves lanceolate and serrate, but not divided. Flower-heads drooping, on termina: peduncles, from half an inch to an inch diameter; the florets usually all tubular, but occasionally a few of the outer ones become ligulate. Inner bracts of the involucre broad, and often shining, and yellow on their edges; outer ones more leafy, and often much longer, and spreading. Awns of the achenes 2 or 3 , very rarely 4. 
In wet ditches and marshes, throughout the temperate and northern regions of Europe, Asia, and America. Common in England and southern Scotland. Fl. summer and autunin.

2. B. tripartita, Linn. (fig. 522). Thrte-cleft B.-Only differs from $B$. cernua in the leaves, which are deeply cut into 3 or 5 lanceolate segments, and in the flower-heads rather less drooping.

Its geographical range and stations are the same as those of $B$. cernua, but is rather less common in Britain. Fl. summer and autumn.

\section{CHRYSANTHEMUM. CHRYSANTHEMUM.}

Annual or perennial berbs (or, in some exotic species, shrubs), with alternate toothed or variously dissected leaves, and radiating flowerheads, solitary on terminal peduncles, or in corymbs. Involucres hemispherical, with a few rows of imuricate bracts, more or less scarious on the edges. Receptacle flat or convex, without scales. Achenes angular or striate, without any pappus, but sometimes crowned with a minute raised border. Style nearly that of Senecio.

A considerable genus, extending over Europe, northern and central Asia, and northern Africa. It has been divided by modern botanists into a number of small genera, founcied upon minute, almost microscopical characters, having little relation to general habit. Among them Pyrethrum has been the most generally adopted, although botanists are but little agreed as to the characters or species which should be assigned to it.

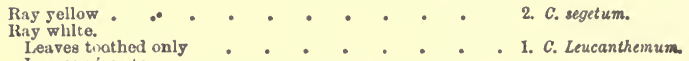

Leaves pinnate.

Flower-heads in corymbs, Segments of the leaves

pinnatifid and toothed. peduncles. Leaves 2 or $\dot{3}$
Flower-hesds on terminal pedures piunate; with narrow linear or filiform lobes .
times

3. C. Partherium.

4. Matricaria inodora.

The old ycllow and white Chrysanthemums of our cottage gardens belong to a north African species (C. coronarium). The late autumnal flowering Chrysanthemums are varieties of the $C$. indicum from China.

1. C. Leucanthemum, Linn.(fig. 523). Ox-eye Daisy.-A perennial, with erect, simple, or slightly branched stems, 1 to 2 feet high, glabrous or slightly downy. Radical leaves obovate and coarsely toothed, on long stalks; stem-leaves narrow, sessile, with a few coarse teeth. Flower-heads solitary on long terminal peduncles, and rather large. Involucral bracts bordered by a brown, scarious edge. Florets of the ray white, more than half an inch long; those of the disk numerous, small, and yellow.

In pastures, on banks, \&c., throughout Europe and Russian Asia, from the Mediterranean to the Arctic Circle. Extends all over Britain. Fl. summer, commencing in spring.

2. C. segetum, Linn. (fig. 524). Corn Marigold.-A glabrous, erect annual, above a foot high, or rather more, with spreacling branches. Lower leaves obovate and stalked; upper ones narrow and stem-claspIng, generally with a few deeply cut teeth at the top. Flower-heads rather large, on terninal peduncles; the involucral bracts broadly 
Bcarions; the florets of the ray, as well as the disk, of a deep golden. yellow.

A cornfield weed, prohably of Mediterranean origin, but now common all over Europe, except the extreme north. Abundant in Britain. Fl. summer and autumn.

3. C. Parthenium, Pers. (fig. 525). Feverfew C.-Stock perennial, shortly branched; the flowering stems erect, branching, a foot high or rather more. Leaves pinnate; the segments ovate or oblong, pinnatifid and toothed. Flower-heads numerous, about balf an inch in diameter, in a terminal corymb; the florets of the ray white, ovate or oblong, those of the disk numerous and yellow. Achenes crowned by a minute toothed border. Pyrethrum Parthenium, Sm.

On roadsides and in waste places, in central and sonthern Europe to the Cancasns, and spread from cnltivation much farther north, as well as to many other parts of the globe. Dispersed over a great part of Britain, but perhaps not truly indigenons; absent from Ireland. Fl. oummer. A very double variety is frequent in our flower-gardens.

\section{MATRICARIA. MATRICARY.}

Habit, foliage, and usually the conical or very convex receptacle of Anthemis, but the receptacle without scales as in Chrysanthemum. Achenes 3- or 5-ribbed on the inner face only, smooth on the back, without pappus, but sometimes crowned with a minute entire or 4-toothed border, and often bearing near the top 2 prominent glandnlar spots.

A small European, northern Asiatic, and North American genus.

Receptacle at first nearly flat, at length ovoid. Achenes 5-ribbed

Recentaclu conical from the frist. Achenes s-ribbed on the inner

\section{M. inodona.}

2. M. Chamomilla.

1. M. inodora, Linn. (fig. 526). Seentless $M$.-An erect or spreading, branched annual, 1 to $1 \frac{1}{2}$ feet high, with the leaves of an Anthemis twice or thrice pinnate, with numerous narrow-linear, almost capillary lobes. Flower-heads rather large, on terminal peduncles. Involucral bracts with a brown, scarions edge, as in C. Leucanthemum. Florets of the ray white, about 7 or 8 lines long; those of the disk nnmerons and yellow. Receptacle convex hemispherical or ovoid, but not so conical nor hollow as in $M$. Chamomilla. Achenes prominently ribbed on the inner face, crowned with a minute, entire or 4-toothed border, and marked outside near the top with 2 glandular spots.

In fields and waste places, common in Europe and Russian Asia, from the Mediterranean to the Arctic regions. Extends all over Britain. Fl. the whole season. M. maritima, Linn., is a maritime perennial variety with the leaves rather succulent.

2. II. Chamomilla, Linn. (fig. 527). IIild Chamomile-Resembles so closely the Anthemis Cotula that it can scarcely be distinguished bnt by the odour and the absence of the scales between the fiorets. It is, like that plant, an erect, branching annual; the leaves twice or thrice pinnate, with short, bnt very narrow linear segments, and the flowerheads rather large, on terminal peduncles. Involucral bracts all nearly of the same length, with scarious edges. Ray-florets white. Receptacle 
much elongated as the flowering advances and hollow. Achenes without any border at the top.

In fields and waste places, in Europe and Russian Asia. Probably diffused all over Britain, but often confounded with Anthemis arvensis or A. Cotula. Fl. the whole season.

\section{ANTHEMIS. CHAMOMILE.}

Ilerbs, with alternate, much cut leaves, and radiating flower-heads, solitary on terminal peduncles, or in a loose corymb. Involueres hemisplherical, with a few rows of bracts more or less scarious on the edges. lieceptacle convex or conical, with scales betreen all or at least tle central florets. Achenes angular or striate, without any pappus, or crowned by a minute border. Style nearly that of Senecio.

A rather large genus, spread over Europe, temperate Asia, and northern Africa; differing from most Chrysanthemums in Labit, and from all in the scales of the receptacle. It has recently been divided into several groups, too technical to be adopted as genera.

Rays yellow .

Rays white.

Florets of the ray withont any style. Erect, glabrous annual . 1. A. Cotula.

Florets of the ray with a style. Plant downy.

Procumbent or creeping perennial. Receptacle-scalcs oblong and obtuse . . . . . . .

Erect or decumbent iranching annual. Receptaclo-scales narrow and pointed

3. A. nobilis.

2. A. arvensis.

1. A. Cotula, Linn. (fig. 528). Fetid C., Stink Mlayweed.-An erect, branching annual, a foot high or rather more, glabrous, but sprinkled with glandular dots, and emitting a disagreeable smell when rubbed. Lower leaves twice or thrice, upper ones once pinnate, with very narrow-linear, sliort pointed lobes, entire or divided. Flower-heads in a loose terminal corymb. Involucre slightly cottony, the inner bracts scarious at the top. Rceeptacle convex from the beginning, lengthening out as the flowering advances into a narrow oblong shape, with a few linear, pointed scales among the central florets. Ray-florets white, without any trace of the style. Achenes rough with glandular dots, without any border.

In cultivated ground, and waste places; a common weed all over Europe and Russian Asia, except the extrcme nortb. Abundant in southern England and Ireland, much less so in the north, and rare in Scotland. $F l$. all summer and autumn.

2. A. arvensis, Linn. (fig. 529). Corn C.-A coarser plant than A. Cutula, sometimes biennial, often decumbent, more or less downy with minute silky hairs, the leafy branches terminating in single flowerheads. Segments of the leaves shorter, and not so narrow as in the last, the flower-heads rather larger, the bracts of the receptacle usually broader, and the florets of the ray have always a style although they do not always perfect their fruit.

Less widely diffused than $A$. Cotula, and chiefly south European, but extends also over a great part of the Continent. Certainly not very common in England or Ireland, and local or rare in Scotland, but so frequently confounded with allied species that its precise distribution os difficult to ascertain. Fl. spring and summer. A maritime variety 
with a more spreading stem and thicker leaves, formerly found on the coast of Durbam, has been figured as A. maritima, Linn., but the true plant of that name is limited to the shores of the Mediterrancan. The Durham plant bas been described under the name of $A$. anglica, Spr.

3. A. nobilis, Linn. (fig. 530). Common C.-A procumbent or creeping, branched perennial; the flowering branches shortly ascending, and leafy. Segments of the leaves fine, and pointed as in A. Cotula, but fewer and more compact. Flower-heads on terminal peduncles, with white rays. Inner involucral bracts more scarious at the top than in the last two species. Scales of the receptacle rather broad, obtuse, and nearly as long as the central florets.

A native, apparently, of western Europe, and chiefly of sandy pastures near the sea, but, having been long cultivated, it has established itself in so many places that its precise area cannot well be made out. Evi. dently indigenous in southern England and Ireland, but decreases rapidly northward, and not a true native of Scotland. Fl. summer and autumn.

4. A. tinctoria, Linn. (fig. 531). Yellow C.-This has much the habit and aspect of $A$. arvensis, but is usually a taller plant, and more downy, the leaves less divided, with pinnatifid or toothed segments, the flower-heads rather larger, and the rays of a bright sellow.

In cultivated and waste places, in central and eastern Europe and Russian Asia, abundant in Denmark and Eastern France, but scarcely farther west. In Britain, it has been found on ballast heaps in some of the eastern counties of England. Fl. cud of summer.

\section{ACHILLEA. ACHILLEA.}

Herbs, mostly perennial, with alternate, much divided, or rarely simple leaves; the flower-heads rather small, in a terminal corymb, with white or pink rays, and a yellow disk. Involucres ovoid or hemispherical, the bracts imbricated, only slightly scarious on the edges. Receptacle small, not convex, with scales between the florets. Achenes without any pappos. Style nearly that of Senecio.

A considerable European, North American, and Asiatic genus, divided by modern botanists into two sections or genera, represented by the two British species, but separated by very trifling characters.

Leaves linear, serrated. Flower-beads few, hemisphericul .

Leaves much divided. Flower-heads numerous, small, and ovoid

1. A. Ptarmica.

2. A. Millefolium.

1. A. Ptarmica, Linn. (fig. 532). Sncezewort.-Rootstock perennial and creeping. Stems erect and glabrous, 1 to 2 feet high, nearly simple. Leaves rather broadly linear, and regularly serrate. Flowerheads few, in a loose terminal corymb. Involucres hemispherical, slightly cottony, smaller than in Anthemis, but much larger than in $A$. Millefolium. Florets of the ray generally from 10 to 15 , short, broad, and white; those of the disk numerous, interspersed with small linear scales.

In moist, chiefly billy pastnres, in northern and central Europe and Asia, becoming a mountain plant in southern Europe, yet not extending to the Arctic regions. Common in Britain. Flosummer, rather late. 
2. A. Millefolium, Linn. (fig. 533). Milfoil or Yarrovo.--Stock perennial, creeping undergound, with numerous short, leafy barren branches, and erect, almost simple flowering stems, about a foot high. Leaves oblong, or linear in their outline, but finely cut into numerons short, but very narrow and deeply pinnatifid segments. Flower-hends numerous, small, ovoid, in a dense terminal corymb. Florets of the ray seldom above 5 or 6 in each head, white or pink.

In pastures, meadows, waste places, \&c., very abundant in Europe and Russian Asia from the Mediterranean to the Arctic Circle, and extends over a great part of North America. It is also one of the commonest of British plants. Fl. the whole summer. It varies with the foliage nearly glabrous, or densely covered with white woolly bairs.

\section{DIOTIS. DIOTIS.}

A single, very cottony species, distinguished from Achillea by the florets, all tubular, with two projecting ears at the base of the corolla, which enclose the achene and remain upon it after the npper part falls off.

1. D. maritima, Cass. (fig. 534). S. Cotton Wecd.-Rootstock perennial and creeping; the stems branching at the base, hard and almost woody, seldom a foot high, covered, as well as the leaves and involncres, with a dense, white, cottony wool. Leaves alternate, oblong, entire or slightly toothed, about half an inch long. Flower-heads nearly globular, abont 4 lines diameter, in dense terminal corymbs. Florets jellow and small. Receptacle convex with scales between the florets. Achenes without pappus or border except the persistent base of the floret.

In maritime sands on the Mediterranean and Atlantic. Extends on the English coasts up to Anglesea on one side and Suffolk on the other; it is found also on the south coasts of Ireland, and the Channel Islands. $\mathrm{Fl}$. end of summer or autumn.

\section{TANACETUM. TANSY.}

Herbs, with mnch divided, alternate leaves. Flower-heads hemi. spherical, in terminal corymbs. Involucral bracts imbricated, scarious at the edges. Receptacle without scales. Florets yellow, all tubular, or the outer ones ligulate but not longer than the others. Achenes angular, with a flat top, without any pappus.

A small genus from the Mediterranean and Caucasian regions, differing from Artemisia technically in the shape of the achene, but more evidently in the larger, more yellow, corymbose, not paniculate, flower. heads.

1. T. vulgare, Linn. (fig. 535). Common T.-A stout, erect per. ennial, 2 to 3 feet high, glabrous or slightly downy, with a strong scent and bitter savour. Rootstock creeping. Leaves rather large, pinnate, with oblong-linear, pinnatifid or toothed segments. Flower-heads numerous, hemispherical, about 4 lines diameter, of a golden yellow, in a large terminal corymb.

On the edges of fields, roadsides, and waste places, in Europe and Russian Asia, from the Mediterranean to the Arctic Circle. Extends ll over Britain, perhaps always where introduced. Fl. end of summer. 


\section{ARTEMISIA. ARTEMISIA.}

Herbs or shrubs, usually highly aromatic, with narrow, alternate leaves, usually much divided, and often white or grey, at least on the under side. Flower-heads small, in terminal leafy racemes or panicles. Involucral bracts imbricated, usually loosely cottony, with slightly scarious edges. Florets the length of the involucrcs, yellow or greenish, either all tubular and 5-toothed, or the central ones tubular, 5-toothed, and male or barren, and the onter ones filiform, or 3-toothed, female, and fertile. Receptacle without scales. Achenes obovate, rounded or narrow at the top, without any pappus.

A numerous genus, often covering vast tracts of land in eastern Europe and central Asia, and extending over nearly the whole of the northern hemisphere from the Arctic regions to the borders of the tropics.

Stem spreading, much branched. Segments of the leaves narrow-linear or subulate.

Stem and leaves cottony white. Involucres narrow-ovold, or

cylindrical, cottony and leaves green or reddish. Involucres ovold, glabrous Flowering stcms or branches tall and erect. Segments of the leaves flat, broadly linear, or lanceolate.

Leaves green above, white underneath, with pointed segments. 3. A. vulgaris.

Leaves silky, whitish on both sides, with obtuse segments - 4. A. Absinthium.

The shrubby Southernwood and the Tarragon of our gardens are species of Artemisia; the latter (A. Dracunculus) is one of the very few species in which the leaves are not dissected.

1. A. campestris, Linn. (fig. 536). Field A.-Stock herbaceous and hard, or shrubby, low, and branched; the annual branches twiggy, very spreading or procumbent, a foot long or more, nearly glabrous, often turning red. Leaves small, once or twice pinnate, with few very narrow-linear segments, green, at least on the upper side. Flowerheads small, ovoid, in numerons loose spikes or racemes, forming a long leafy panicle. Involucre not cottony, containing 5 or 6 outer female florets, and about as many central male or barren ones.

In heaths, and dry, sandy, or stony wastes, widely spread over Europe and temperate Asia, extending far into Scandinavia. In Britain, almost peculiar to a small tract of country in the north-west of Suffolk and adjacent portion of Norfolk. Fl. autumn.

2. A. maritima, Linn. (fig. 537). Sea A.-A much branched, decumbent or nearly erect undershrub, more or less covered with a close white cotton. Leaves twice pinnate, with narrow-linear segments, shorter and more compact than in A. campestris. Flower-heads small, narrow. ovoid or nearly cylindrical, erect or drooping, each containing from 3 to 5 or 6 florets, all tubular and fertile.

In sandy and muddy wastes, generally near the sea, occupying large tracts of country near the Caspian and Black Seas, and extending round the Mediterranean, and along the Atlantic, $\mathrm{pp}$ to the coasts of Britain, as far as Wigton on the west, and Aberdeen on the east; N.E. Ireland, and Channol Islands. Fl. autumn. [Two very different looking forms occur, often intermixed: A. maritima, L., with shortly pedicelled drooping heads; and $A$. gallica, Willd., with nearly sessile spiked heads.]

3. A. vulgaris, Linn. (fig. 538). Mugwort.-Stock thick and woody, 
but short, with erect flowering stems, 2 to 3 feet high. Leaves once or twice deeply pinnatifid, with lanceolate, pointed lobes or segments, coarsely toothed or lobed, green and glabrous above, very white nnderneath. Flower-heads ovoid, with cottony involucres, forming a long terminal panicle, each head containing 12 to 20 complete florets and a few female ones, all fertile.

On roadsides and waste places, either indigenons or introdnced, over nearly the whole area of the genus. Common in Britain. Fl. end of summer, and autumn.

4. A. Absinthium, Linn. (fig. 539). Wormwood or Absinth.-Stock short, but branched and leafy, sometimes almost woody; the flowering stems erect and hard but annual, 1 to 2 feet high; the whole plant of a greyish white, with a very close almost silky down. Leaves almost orbicular in their general outline, but much cnt into oblong, linear, obtuse loles. Flower-heads nnmerous, drooping, nearly hemispherical, and larger than in the other British species; the onter bracts narrowlinear, the inner ones very broad. Central florets numerous and mostly fertile; the outer female ones small and often barren.

On roadsides and waste places, over the greater part of Europe and Russian Asia, but in many cases introduced only, having been formerly much cultivated for its bitter qualities. In Britain, it appears truly indigenous near the sea in many parts of England and Scotland; in the interior it is confined to the neighbourloood of villages and habita. tions; it is a doubtful native of Ireland. Fl. autumn.

\section{TUSSILAGO. COLTSFOOT.}

Herbs, with perennial, creeping rootstocks, and large, broad, deeply cordate radical leaves; the flowering-stems issuing from separate buds with small, narrow, alternate leaves or scales, and terminal flowerheads, either solitary or in a raceme. Involucre of several linear bracts, with a few small outer ones. Outer florets female, either filiform or narrow-ligulate, the inner ones tubular, or sometimes all tubular. Receptacle without scales. Branches of the style cylindrical, or club. shaped. Achenes cylindrical, with a copious pappus of simple hairs.

A genns of very few European or north Asiatic species, easily known among British Compositcs by the peculiar foliage.

The winter IIcliotrope of our gardens, T'ussilago fragrans, often establishes itself near where it has been planted, and spreads widely; it is very near I'. Ptasites, but easily known by its fragrant flowers.

Flower-heads solitary, the external florets yellow and narrow-liguFlower-hesd in a compound raceme, purple or pink, nearly ali tubular, or nearly all small and filiform, not ligulate .

1. T. Farfara.

2. T. Petasiles.

1. T. Farfara, Linn. (fig. 540). Coltsfoot.-Flowering stems simple, but often growing in tufts, erect, about 6 inches high, more or less covered with a loose, white cotton; the small leaves or scales numerous, oblong or linear, entire and erect. Flower-heads solitary, terminal; the florets of the ray numerous, ligulate, very narrow, but not long, of a bright yellow. Radical leaves appearing much later than the flowertems, 4 or 5 inches broad, angular and toothed, covered underneath 
with a loose, white, cottony wool, of which there is a little also on the upper side.

In waste and cultivated ground throughout Europe and central and Russian Asia to the Arctic Circle, and a very troublesome weed in poor, stiff soils. Abundant in Britain. Fl. early spring.

2. T. Petasites, Linn. (fig. 541). Butterbur.-Leaves of T. Farfara, but usually larger. Flowering stems not in tufts, often a foot high when full-grown, with many flower-heads, of a dull, pinkish-purple, in a narrow-oblong terminal panicle, and almost diceions. The male plant has a looser panicle of smaller heads, the florets either all tubular and male (the pistil, although apparently perfect, having no ovule and jorming no seed), or with a few filiform female ones on the outside; the female panicle more compact, the heads larger, the florets all filiform, or with a few tubular male ones in the centre. Petasites vulgaris, Desf.

In sandy meadows, on the banks of streams, or roadsides, in Europe and Russian Asia, but not an Arctic plant. Frequent in England and in Ireland, extending into southern Scotland. Fl. spring. It is often distinguished from Tussilago as a genus, under the name of Petasites.

\section{SENECIO. SENECIO.}

Herbs (or, in some exotic species, shrubs), with alternate, toothed or divided, rarely entire leaves. Flower-heads in terminal corymbs; the florets of the disk yellow and tubular, those of the ray also yellow (or, in some exotic species, blue, purple, or white), spreading, or rarely wanting. Involucre cylindrical or nearly hemispherical, with 1 or 2 rows of linear bracts of equal length, often tipped with brown, usually, but not always, accompanied by a few small outer bracts at their basc. Receptacle without scales. Achenes cylindrical, with a pappus of simple hairs, usually soft and white. Branches of the style truncate at the top, usually with a tuft of minute hairs.

This, the largest of all Composite genera, is spread over every quarter of the globe, although the majority of species occupy each a small area. Several species which have not the small outer bracts to the involucre were distinguished by Linnæus under the name of Cineraria, but the character has proved so uncertain that modern botanists have given it up.

Lesves cut and divided.

Florets of the ray very small and rolled back, or entirely wanting. Root annual.

Ray none. Flower-heads almost sessile, in dense corymbs or clusters

Ray small and rolled back or rarely wanting. Flower-heads stalked, in loose corymbs.

Whole plant very viscid. Involucres broadly cylindrical, of about 20 bracts, with 2 or 3 short outer ones. Achenes glabrous

Plant rarely viscid. Involucres narrow, of about 12 to $14^{\circ}$ bracts; the outer ones scarcely perceptible. Achenes silky th sca

Morets of the ray conspicuous and spreading. "[Rarely absent in $\dot{S}$. Jacobara.]

Root anpual.

1. \&. vulgaris.

2. S. viscosus.

3. S. sylvaticus. 
Rootstock perennial.

Branches spreading. Corymb loose snd Irregular. Achenes all glabrous .

Stem tall and erect. Corymb rather dense and terminal.

5. S aquaticue. Achenes of the disk hairy.

Leaves irregularly pinnate, with a broad terminal lobe. Achenes of the ray glabrous. Rootstock not creeping Leaves pinnate; the lobes all narrow. Achenes all hairy. Rootstock shortly creeping

Leaves undivided, entire or toothed.

Involucres with small, fine outer bracts st the base. Leaves scutely toothed.

Leaves cottony underneath. Ray of 12 to 20 florets . .

Leaves glabrous. Ray of 5 to 8 florets 4 in outer ones. Lesves entire or obtusely toothed.

Annual or biounial. Leaves downy. Achenes glabrous,

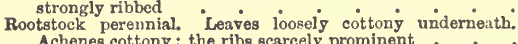

6. S. Jacobara.

7. S. erucifolius.

8. S. paludosus.

9. S. saracenicus
Achenes cottony :

Several exotic species are much cultivated for ornament, especially the double-flowering $S$. elegans from the Cape, $S$. Cineraria from the shores of the Mediterranean, and the numerous varieties of one or two Canary Island species, known to our gardeners as greenhouse Cinerarias.

1. S. vulgaris, Linn. (fig. 542). Groundsel.-An erect, branching annual, from 6 inches to near a foot high, glabrous or bearing a little loose, cottony wool. Leaves pinnatifid, with ovate, toothed or jagged lobes. Flower-heads in close terminal corymbs or clusters. Involucres cylindrical, of about 20 equal bracts, with several outer smaller ones. Florets almost always all tubular, with very rarely any ray whatever. Achenes slightly hairy.

A very common weed of cultivation throughout Europe and Russian Asia, but not extending into the tropics, and less disposed than many others to migrate with man. Abundant in Britain. Fl. all the year round. [A variety, radiata, Koch, with minute rays to the outer florets, is found in the Channel Islands.]

2. S. viscosus, Linn. (fig. 543). Viscous S.-A coarser, harder, and taller annual than $S$. vulgaris, and covered all over with a short, viscons, strong-smelling down, the leaves more deeply divided, with narrower, more jagged lobes, the flower-heads rather thicker, with more florets, and on longer peduncles, forming a loose, terminal corymb. Outer scales of the involucre usually but 2 or 3 , and nearly half as long as the inner ones, of which there are about 20 . Outer florets ligulate, but small, spreading when fresh, but soon withering and rolled back so as at first slght to escape observation. Achenes glabrous.

In waste places, over a great part of Europe, but not common, and does not extend so far eastward or northward as $S$, vulgaris. Scattered over various parts of England, southern Scotland, and Ireland, but very local, and seldom abundant. $F l$. summer and autumn.

3. S. sylvaticus, Linn. (fig. 544). Wood S.-An annual, with the foliage much like that of $S$. vulgaris, but a taller and weaker plant, sometimes 2 feet high or more, slightly downy, or nearly glabrous, not so viscid nor so strong-smelling as S. viscosus. Nlower-heads rather numerous, in a loose corymb, the involucres cylindrical, of from 12 to 15 oqual bracts, with the outer ones very minute or wanting. Outer florets usually ligulate, but small and rolled back as in S. viscosus, and 
sometimes altogether wanting as in $S$. vulgaris. Achenes covered with minute, appressed hairs.

On banks, waste places, and borders of woods, in temperate and southern Europe, from Scandinavia to the Mediterranean. Found occasionally in most parts of Britain, but not generally common. Fl. summer and autumn.

4. S. squalidus, Linn. (fig. 545). Squalid S.-An annual or biennial, or even sometimes forming a stock of two or three years' duration, with the stature of S. vulgaris, but quite glabrous. Leaves rather thick, pinnatifid, with narrow, deeply cut, or jagged lobes. Flower-heads rather large, in a loose corymb, with a bright-yellow, spreading ray, as conspicuous as in S. Jacobcea. Achenes silky-hairy.

A south European species, quite established on walls at Oxford, Bideford, Cork, and a few other localities in middle and southern England and Ireland, but evidently not indigenons. Fl. summer and autumn.

5. S. aquaticus, Huds. (fig. 546). Water S.-Not always easy to distinguish from $S$. Jacoboea, especially from occasional autumnal offsets of the latter, when the main stem has been accidentally destroyed. The foliage is nearly the same, but the plant appears to be of shorter duration, the stem not so tall, seldom attaining 2 feet, more branched and spreading, the flower-heads larger, fewer, on longer peduncles, forming a loose, irregular, spreading corymb, and especially the achenes appear to be always quite glabrous.

In wet places, along ditches, \&c., spread over Europe, extending northward to southern Scandinavia. Common in Britain. Fl. summer.

6. S. Jacobæa, Linn. (fig. 547). Ragwort S.-Rootstock short and thick, without creeping shoots. Stems 2 to 4 feet high, erect, scarcely branched except at the top. Leaves pinnate, with ovate, obovate, or narrow segments, coarsely toothed or pinnatifid, the terminal ones large and confluent, the lower ones smaller and distinct, all glabrous, or with a loose woolly down, especially on the under side. Flowerheads rather large, of a bright yellow, in a handsome, compact, terminal corymb. Involucral bracts tipped with black, the outer ones few, and very small. Florets of the ray from 12 to 15 , linear-oblong and spreading, occasionally but rarely deficient. Achenes of the disk covered with short hairs, those of the ray glabrous.

On roadsides, in waste places, and bushy pastures, all over Europe and Russian Asia, except the extreme north. Very common in Britain. Fl. summer, lasting till late. When checked in its growth, it often assumes the spreading inflorescence of $S$. aquatious, when it can only be distinguished by inspection of the achenes. [The ray-flowers are wanting in the var. S. flosculosus, Jord.]

7. S. erucifolius, Linn. (fig. 548). Narrow-leaved S.-Very near S. Jacobaca. It is fully as tall, and has the same inflorescence and flower-heads, but the rootstock is shortly creeping, the leaves are much more regularly divided into narrower segments, the terminal ones not very different from the others, and the achenes of the ray as hairy as those of the disk. The whole plant is generally more or less covered with a loose, cottony down. S. tenuifolius, Jacq.

The geographical area and stations are about the same as those of 8. Jacobcea. It is rather more common in central and southern Europe. 
but rather less so in Britain, and disappearing north of Lanark and Berwick; east Ireland only. Fl. summer and autumn.

8. S. paludosus, Linn. (fig. 549). Fen S.-Stem erect, 2 to 5 or 6 feet high, scarcely branched. Leaves numerous, narrow-lanceolate, sharply toothed, more or less cottony on the under side. Flower-heads rather large, not very numerous, in a loose terminal corymb. Involucres almost hemispherical, the outer bracts few, short, and subulate. Florets of the ray from 32 to 16 , yellow, linear, and spreading.

In swamps and fens, in temperate Europe, extending northward to southern Sweden, but usually very local. Very rare in Britain, and restricted to a few spots in the fenland tracts of the eastern counties of England and the Channel Islands. Fl. summer.

9. S. saracenicus, Linn. (fig. 550). Broad-leaved S.-An erect perennial, nearly allied to $S$. paludosus, but glabrous or nearly so, and not usually so tall. Leaves broadly or narrowly lanceolate, and more regularly toothed. Flower-heads much more numerous, and smaller than in $S$. paludosus, in a compact corymb. Involucres cylindrical or ovoid, with seldom more than 6 or 7 florets to the ray.

In woods and shady places, almost all over the continent of Europe, extending in Russian Asia to the Arctic regions. although not found in Scandinavia. Very local in Britain, and chicf v in moist meadows and pastures in various parts of England and Scotland, possibly escaped from gardens, where it has been sometimes cultivated. In Ireland, in woods near Bantry. Fl. summer.

10. S. palustris, DC. (fig. 551). Marsh S.-An erect and nearly simple annual or biennial, often covered with a loose grey down, not cottony as in $S$. campestris. Stem hollow, 1 to 2 feet high. Leares lanceolate, sinuate and coarsely toothed or nearly entire. Flowerheads in a dense terminal corymb, approaching to an umbel. In. volucral bracts all equal, without any small outer ones. Florets of the ray about 20, yellow. Achenes glabrous, strongly ribbed, with a copions silky pappus more than twice as long as the involucre.

In wet, muddy places, in northern Europe and Asia, from the Arctic regions to Picardy, the Netherlands, and central Germany. Very rare in Britain, and confined to the fens of the eastern counties of England. Fl. summer.

11. S. campestris, DC. (fig. 552). Field S.-Rootstock short and thick, or slightly crecping. Stem erect, simple, from a few inches to 1 or 2 feet ligh. Radical leaves stalked, oblong or ovate, those of the stem longer and narrower, upper ones few and distant, all entire or toothed, with a loose cottony wool on the under side, as also on the stems, especially in open, dry situations. Flower-lieads like those of $S$. palustris, but only few together, in a small terminal corymb or rather umbel, the peduncles starting from nearly the same point. Achenes downy, with scarcely prominent ribs, and a shorter pappus than in S. palustris.

In meadows and pastures, in most of the mountain-ranges of Europe and Russian Asia to the Arctic regions. In Britain, limited to a few stations on the chalky downs of the central and southern counties of England. Fl. summer. [A tall variety, maritima, Syme. (S. spathulaefolius, Bab.), with broadly toothed leaves, occurs in Micklefell in York. shire, and on maritime rocks in Anglesen.] 


\section{DORONICUM. DORONIO.}

Herbs, with perennial, often crceping stocks, long-stalked, broad radical leaves, and erect flower-stems, bearing a few undivided, alternate leaves, and one, or but few, rather large, yellow, radiating flower-heads. Involucres hemispherical, with linear bracts of equal length. Achenes and florets of Senecio, except that the achenes of the ray have no pappus.

A small genns, extending over central and southern Europe and western Asia, but chiefly restricted to mountain districts.

R:ulical leaves deeply cordate. Stems usually with $\mathbf{S}$ to $\mathbf{5}$ flower-heads Ralical leaves nurrowed or rounded at the base. Stems usually with 1 flower-bead

1. D. Pardalianches. 2. D. plantagineum.

1. D. Pardalianches, Linn. (fig. 553). Leopard's-bane.-Rootstock more or less creeping, often woolly at the crown. Radical leaves broadly ovate and deeply cordate at the base. Stems about 2 feet high, with but few leaves, mostly ovate; the lower ones stalked, but embracing the stem by a broadly dilated base; the upper ones small, essile or embracing the stem. Flower-heads generally 3 to 5 , on long, leafless peduncles; the yellow rays numerous, and narrow.

In woods, and mountain pastures, in central Europe, frequently cultivated in cottage gardens, and readily spreads in their vicinity. In Britain, only as an outcast from gardens, but apparently well established in several parts of England and southern Scotland. Fl. spring and early summer.

2. D. plantagineum, Linn. (fig. 554). Plantain D.-Differs from D. Pardalianches chiefly in the radical leaves, which are never cordate, usually narrowed or wedge-shaped at the base, and rather strongly marked with 3 or 5 ribs; the stem-leaves narrower than in D. Pardalianches; and the flower-head solitary on a long terminal peduncle, or very rarely, when very luxuriant, the stem bears 2 or 3 heads.

In open, sandy woods, in central and southern Europe, from the Atlantic to the eastern frontier, extending in France considerably to the northward of Paris. In Britain, like the last species, only as an escape from cultivation. Fl. spring and early summer. Both the specics vary, either glabrons or hairy, and with their leaves entire or irregularly toothed.

\section{ARCTIUM. BURDOCK.}

A single species, distinguished as a genus from Carduru by the foliage, by the bracts of the involucre ending in a long, stiff point hooked at the extremity, and by the short, stiff pappus.

1. A. Lappa, Linn. (fig. 555). Common Burdock.-A stont, branching, erect biennial, 3 to 5 feet high, the lower heart-shaped leaves very large, sometimes attaining $1 \frac{1}{2}$ fect in length by a foot in breadth; the upper ones much smaller, and broadly ovate; all green and nearly glabrous above, often covered with a short, white, cottony down underneath, bordered by minute teeth, but not prickly. Flower-heads in terminal panicles. Involucres nearly globular, glabrous or covered with a loose, white, cottony wool, catching at anything they come in contact with by the hook d points of their numerous bracts. Florets purple, 
all equal. Anthers with hair-like appendages at their base. Achenes large, with a short pappus of stiff hairs.

In waste places, on roadsides, \&c., over all Europe and Russian Asia, except the extreme north, and naturalised in other parts of the globe. Common in Britain. Fl. summer. It varies much in the size of the flower-heads (from 8 to $1 \frac{1}{2}$ inches diameter), in the breadth of the involucral bracts, in the abundance or deficiency of the cottony wool, in the length of the peduncles; and five distinct species have been described, but it has always appeared to me very difficnlt to ascribe any certain limits, even to the three more generally recognised varieties A. majus, A. minus, and A. tomentosum. [The most conspicuons forms are :-

a. A. majus, Schkuhr., with hollow petioles, green hemispherical heads, and the corolla tube larger than the limb. $-A$. tomentosum is a variety of it with more spherical webbed heads.

b. A. minus, Schkuhr., with more ovoid heads, purplish inner bracts, and the corolla tube equalling the limb; it varies in the breadth of the leaves, the colour of the bracts, and glabrous or cottony beads. $A$. nemorosum, Lej., is a subvariety with narrower coarsely crenate rootleaves, and more globose heads.]

\section{SERRATULA. SAWWORT.}

Herbs, not prickly, but with the general habit and style of Cynaroidece. Involucres ovoid or oblong, the bracts imbricated and pointed, but not prickly. Receptacle with chaffy bristles between the florets. Pappus of numerous simple unequal hairs, longer than the achenes. Anthers without appendages.

Although much reduced by the modern splitting of genera, Serratula still includes several south European and Asiatic species.

1. S. tinctoria, Linn. (fig. 556). Common Sawwort.-A stiff, erect, scarcely branched, and nearly glabrous perennial, 1 to 3 feet high; the lower leaves more or less pinnate, with lanceolate, pointed, and finally toothed segments, the terminal one the largest; the upper leaves toothed only, or with a few lobes at their base. Flower-heads in a terminal corymb, partially diœcious, the male heads rather stouter than the females. Involucres 7 or 8 lines long, with numerous ap. pressed bracts, the inner ones often coloured at the tips. Florets purple.

In open woods, thickets, and bushy pastures, common thronghout temperate Europe, and extending far into Scandinavia, and into western Siberia. Spread over nearly the whole of England, but scarcely penetrates into Scotland, and not recorded from Ireland. Fl. late in summer.

\section{SAUSSUREA. SAUSSUREA.}

Herbs, with the habit and characters of Serratula, except that the hairs of the pappus, or at least the inner ones, are very feathery, and the anthers have at their lower end hair-like appendages or tails.

The species are chiefly numerous in central and Russian Asia. There 
are but few in Europe, confined to mountain regions or high northern latitudes.

1. S. alpina, DC. (fig. 557). Alpine S.-Stem erect and simple seldom a foot high, covered, as well as the involucre and under sides of the leaves, with a loose cotton, which wears off with age. Leaves from ovate to lanceolate, entire or toothed, 2 to 3 inches long. Flower heads ovoid or oblong, nearly sessile, in a small, dense terminal corymb, with purple florets. The soft, feathery pappus projects beyond the Involncres, the inner bracts of which are softly hairy.

In high northern latitndes, or at considerable elevations in the mountain-ranges of Europe, Russian Asia, and Arctic America. Frequent in the mountains of Scotland, and found also in North Wales, in the Lake district of northern England, and in West Donegal, Ireland.

\section{CARDUUS. THISTLE.}

Herbs, with hard stems. Leaves often cut, and usually very prickly. Involucres globular or ovoid, the bracts numerous, closely imbricated, and usually prickly. Receptacle thick, kearing bristles between the florets. Florets all equal and tubular. Achenes glabrous, with a pappus of numerous simple or feathery hairs longer than the achene itself.

The largest and widest-spread genus among Cynaroidece, for although the species are chiefly European and Asiatic, yet there are also several from North America, and the common ones accommodate themselres readily even to a tropical climate. They are usually divided into two genera, Cnicus (Cirsium of some authors) with a feathery pappus, and Carduus proper with a simple-haired pappus; but the distinction is so purely artificial that several botanists now revert to the old natural limits indicated by Linnæus.

Pappus consisting of simple baira (CARDuUs proper).

Bracts of the large involucre very broad at the base, with lateral as well as terminal prickles

Bracts of the involucre lanceolate or li
prickles. Involucres globular, large.

Involucral bracts broadly lanceolate .

Involucral bracts linear

Involucres ovoid or cylindrical : :

Pappus consisting of feathery halrs (Cinicus).

Leaves decurrent along the stem, forming prickly wings.

Flower-heads all peduncled.

Wower-heads few, near $1 \frac{1}{2}$ inches long. Stem winged and prickly. Root biennial.

Flower-heads not an inch long, in terminal corymbs,

Lesves but little decurrent. Rootstock creeping.

Flower-beads small in dense clusters. Stem winged and prickly

Leaves not decurrent, or only very shortly so.

1. C. Marianus.

Hower-heads sessile or on very short peduncles.

Stems stout and branched (about 2 feet). Involucres

large and cottony a dems dwarf, or scarcely any. Involucres not cottony :

Flower-heads all peduncled. Rootstock perennial, often creeping.

Flower-heads in terminal corymbs

Nower-heads growing eingly on long peduncles

5. c. lanceolatus.

7. C. arvensis.

6. C. palustris.

8. C. eriophorws.

12. C. acaulis.

7. C. arvensis. 
I eaves clliate, not prickly, very white underneath

Leaves prickly, green, or with a loose white cotton y. c. heterophyllus. underneati.

Leaves deeply pinnatifd and lobed. Flower-heads usually 2 to 4 .

Leaves toothed, sinuate, or shortly lobed. Flowerheads usually solitary or 2 only

10. C. tuberosus.

-11. C. pratensis.

Very anomalous specimens occur occasionally, especially among the Cnicuses, which are generally believed to be natural hybrids. [These are most frequent between $C$. palustris with heterophyllus and pratensis, and betwecn acaulis with pratensic and arvensis.]

1. C. Marianus, Linn. (fig. 558). Milk T.-An annual or biennial 2 to 3 fect high, not much branched, and glabrons or with but very little cottony wool. Leaves smooth and shining above, and variegated by white veins; the lower ones deeply pinnatifid with broad very prickly lobes; the upper ones clasping the stem by prickly auricles but scarcely decurrent. Flower-heads large, drooping, solitary at the ends of the branches, with purple florets. Bracts of the involucre very broad at the base, with a stiff, spreading, leafy appendage, ending in a long prickle, and bordered with prickles at the base. Hairs of the pappus simple. Silybum MIarianum, Gærtn.

In waste places, in southern Europe to the Caucasus; not indigenous in central Europe, although it occurs here and there as a weed of cultivation. Rare and only introduced into Britain. Fl. summer.

2. C. nutans, Linn. (fig. 559). Musk T'.-A stout species, 2 to 3 feet high, usually slightly covered with loose cottony hairs. Leaves deeply pinnatifid, very prickly, their edges decurrent along the stem, forming narrow very prickly wings. Flower-heads large and drooping, as in C. Marianus, but often 3 or 4 in a loose corymb. Involucral bracts numerous, with a stiff, narrow-lanceolate appendage, ending in a spreading or reflexed prickle, but without lateral prickles. Hairs of the pappus simple.

In waste places, common in the greater part of Europe and temperate Asia, but not spreading to the extreme north. Pretty frequent in southern England, especially on limestone soils, less so in the north, and rare in Scotland. Occurs also in Ireland. Fl. summer.

3. C. acanthoides, Linn. (fig. 560). Welted T'-Much resembles C. nutans, but is usually taller and rather more branched; the leaves narrower and more prickly; and the stem more thickly covererd with prickly appendages, decurrent from the base of the leaves. Flowerneads not so large, though yet globular and slightly drooping; the involucral bracts very numerous and narrow, ending in a linear, spreading or recurved prickle, the innermost of ten of a thinner texture, slightly coloured and scarcely prickly. Hairs of the pappos simple. C. crispus, Linn.

A very common Continental Thistle, extending eastward entirely across Asia, and northward to the Arctic Circle, although in Britain, like many others, it becomes scarce in Scotland. Fl. summer. Three forms are often distinguished as species, C. acanthoides, Linn., with few flower-heads, on long peduncles, and the leaves often nearly glabrous; C. crispus, Linn., with the heads clustered several together on short stalks, and the leaves nsually rather broader and more cottony anderneath; and C. polyauthenıs, Koch., with crowded ovoid heads ; 
but they run too much one into the other to be separable even as permanent varieties.

4. C. pycnocephalus, Linn. (fig. 561). Slender T.-A stiff annnal or biennial, from 1 to 3 or 4 feet high, but not so stout as the last three, and much more covcred, especially the stems and the under side of the leaves, with a white loose cotton. Leaves pinnatifid, with short, kavy, very prickly lobes, and decurrent along the stem, forming waved prickly wings as in $C$. acanthoides. Flower-heads rather numerous, but small and ovoid or oblong, generally in clusters at the top of the stem and branches. Involucral bracts rather broad at the base, ending in a narrow, straight or slightly spreading prickle. Florets pink or whitish. Hairs of the pappus simple. C. tenuiflorus, Curtis.

In waste places and cultivated ground, in western and southern Europe and central Asia, extending north ward to Denmark, but scarcely eastward of the Rhine in central Europe. Not unfrequent in England and Ireland, especially near the sea, and occurs also in the lowlands of Scotland. Fl. all summer.

5. C. lanceolatus, Linn. (fig. 562). Spear T.-A rather stout biennial, 3 or 4 feet high; the stem winged and prickly. Leaves waved and pinnatifid, with short but narrow lobes, the terminal longer and lanceolate, all ending in a stiff prickle, rough on the upper side with sliort almost prickly hairs, white and cottony underneath. Flowerheads few, ovoid, near an inch and a half long when in tlower. Involncral bracts lanceolate, cottony ending in a stiff, spreading prickle. Florets purple. Hairs of the pappus feathery.

In fields, pastures, and waste places, very common throughout Europe and Russian Asia, except the extreme north, and spread with cultivation into other parts of the world. Abundant in Britain. Fl. all summer.

6. C. palustris, Linn. (fig. 563). Marsh T.-A stiff annual or biennial, 4 or 5 feet high, and scarcely branched; the stems quite covered with the prickly decurrent margins of the leaves as in $C$. acanthoides. Leaves narrow, the lower ones 6 or 8 inches long, pinnatifid with numerous ovate, wavy, prickly lobes, with a few rough hairs scattered on both surfaces; the upper leaves small and very narrow. Flower-heads rather numerous, small and ovoid, nsually collected in clusters, forming an irregular terminal corymb. Involucral bracts numerous, with very small somewhat prickly points, the inner ones often coloured. Florets purple. Hairs of the pappus feathery.

In wet fields, and meadows, throughout Europe and Russian Asia, penetrating into the Arctic regions. Frequent in Britain. Fl. summer.

7. C. arvensis, Curt. (fig. 564). Creeping T.-Rootstock perennial and creeping, with erect annual stems 3 or 4 feet high. Leaves narrow, pinnatifid, and very prickly, either embracing the stem with prickly auricles or shortly decurrent. Flower-heads not large, forming rather loose terminal corymbs, and always diœcious; the males nearly globular, with very projecting purple florets; the females with much longer involucres but shorter florets, the copions feathery pappus of the achenes projecting considerably as the fruit ripens; in both, the involucral bracts are numerous, appressed, with very small prickly points.

In cultivated and waste places, the commonest of European and 
Asiatic Thistles, accompanying cultivation to all parts of the world; extending far to the north, though perhaps not quite to the Arctic Circle. Abundant in Britain. Fl. summer. A curious variety, with the leaves almost entire, not decurrent, and scarcely prickly (C.setosus) not uncommon in south-eastern Europe and western Asia, has been found in Orkney, in the county of Fife, and in Ireland; probably always as an introduced plant.

8. C. eriophorus, Linn. (fig. 565). Woolly $T$. - The stoutest of all our indigenous Thistles, and much branched, but not so tall as some others. Leares not decurrent, green and hairy above, white and cottony underneath, deeply pinnate, with narrow lobes ending in very sharp stout prickles. lilower-heads large and globular, clustered 2 or 3 together at the summits of the branches. Involucres covered with a cottony wool, the numerous bracts ending in a narrow prickly point. Hairs of the pappus feathery.

In waste places, in central and soutbern Europe to the Caucasus, but not extending into northern Germany. In Britain, probably confined to the limestone districts of southern England and to some localities in Yorkslire. $F l$. summer.

9. C. heterophyllus, Linn. (fig. 566). Melancholy T.-This species is not prickly like other Thistles, but resembles them in other respects. Rootstock perennial and creeping, stems tall, stout, deeply furrowed, with a little loose cottony wool. Leaves clasping the stem, with scarcely decurrent auricles, lanceolate, glabrous, and green above, very white and cottony underneath, bordered with very small, bristly but scarcely prickly teeth, and sometimes slightly lobed. Flower-heads about the size of those of $C$. lanceolatus, growing singly on long peduncles. Involucral bracts glabrous, lanceolate, obtuse, or with a very minute not prickly point. Hairs of the pappus feathery.

In mountain pastures, in northern Europe and Asia, and in the great central ranges of both continents. Frequent in Scotland, extending into northern England, and North Wales. Fl. summer.

10. C. tuberosus, Linn. (fig. 567). Tubcrous T.-Rootstock woody, nsually shortly creeping, emitting occasionally a few thick, almost woody, tuberous roots, and erect or ascending stems, but little divided, or sometimes simple, about 2 feet high. Radical leaves pinnatifid, the lobes waved and prickly, slightly hairy above, with more or less of a loose cottony wool underneath; the stem-leaves few, less divided, sessile or sometimes very shortly decurrent. Flower-lieads not very large, ovoid, growing singly on long terminal peduncles. Involucral bracts lanceolate, not prickly, with more or less of cottony wool. Hairs of the pappus feathery.

In moist, rich meadows, and marshy, open woods, in western and south central Europe, extending eastwards to Transylvania. In Britain, only in Wiltshire, near Heytesbury, and near Swindon. Fl. summer. [This is regarded by foreign authors as a variety of pratensis.]

11. C. pratexsis, Huds. (fig. 668). Meadow T.-Probably a mere variety of $\boldsymbol{C}$. tuberosus. The roots are less tuberous. Stems 1 to 2 feet high, usually simple, with a single ovoid flower-head, or occasionally divided into 2 or 3 long 1-headed branches. Leaves more cottony than in $C$. tuberosus and much less divided, the radical ones usually 
sinuate or shortly pinnatifid, the stem-leaves lanceolate, bordered only with short, slightly prickly teeth.

In low, wet pastures, boggy meadows, and marshy thickets, chiefly in western Europe. Abundant in some of the southern counties of England and Ireland, more rare in the north. Fl. summer. Luxuriant specimens, with more divided leaves, sometimes slightly decurrent, have been considered as a species under the name of $C$. Forsteri, or as hybrids between this and $C$. palustris. Another luxuriant variety occurs occasionally, approaching C. tuberosus in foliage, but with 2 or 3 flowerheads rather close together, not on long separate peduncles.

12. C. acaulis, Linn. (fig. 569). Dwarf T. - In the common state this is at once distinguished by the almost total want of stem. A thick, woody, perennial stock bears a spreading tuft of very prickly pinnatifid and glabrous leaves, in the midst of which are a few rather large sessile flower-heads. Involucres ovoid, not cottony, with numerous lanceolate, obtuse or scarcely pointed bracts. Florets purple. Hairs of the pappus feathery.

In dry pastures, in temperate Europe and Russian Asia, extending northward to southern Scandinavia. In Britain, only in the sonthern and some central counties of England, where it is often a troublesome weed in pastures. Fl. summer, rather late. In some situations, on the Continent, the stem will grow out to 6 or 8 inches, but this variety is very rare in England.

\section{ONOPORDON. ONOPORD.}

Large-headed, stout, prickly herbs, only differing from Carduus in the receptacle, which, instead of bearing long chaffy bristles between the florets, is honeycombed into a number of little cavities, the jagged edges of which are shorter than the achenes.

There are but few species, natives of the Mediterranean and Caucasian regions, one only of which extends into central Europe.

1. O. Acanthium, Linn. (fig. 570). (Scotch or Cotton Thistle).-A stout, branched biennial, attaining sometimes 6 feet or even more, covered with a loose cottony wool. Leaves coarsely toothed or pinnatifid, waved and very prickly, their broadly-decurrent margins forming prickly wings all down the stem. Flower-heads large, globular, erect, and solitary on the branches of a large irregular panicle. Involucral bracts numerons, ending in a long, lanceolate, spreading prickle. Hairs of the pappus rather longer than the achenes, not feathery, but strongly toothed when seen under a magnifying-glass.

A native of the Mediterranean region and west central Asia, not uncommon also in central Europe and all across Russian Asia, but spreads readily with cultivation, and it is difficult to say how far north it is indigenous. Now found in several parts of England, bat certainly not wild in Scotland, although generally selected to represent the Scotch heraldic Thistle. Fl. end of summer.

\section{CARLINA. CARLINE.}

Low, very prickly herbs. Outer bracts of the involucre very prickly, Inner ones coloured or shining, long, and spreading like the rays of a 
star. Receptacle bearing irregularly cut, chaffy scales between the florets. Acbenes silky-hairy, with a feathery pappus.

A small European and Asiatic genus, easily distinguished by the in. volucral bracts.

1. C. vulgaris, Linn. (fig. 571). Common C.-An erect biennial, seldom above 6 or 8 inches high. Leaves not decurrent, toothed, or pinnatifid, and very prickly ; the lower ones narrow, slightly covered with loose cottony wool; the upper ones broader and nearly glabrous. Flower-heads bemispherical, about an inch in diameter, usually 3 or 4 in a small terminal corymb. Outer involucral bracts broadly lanceolate, bordered with very prickly teeth or lobes; inner ones linear, entire, with very smooth and shining, horizontally-spreading tips.

In dry, billy pastures, and fields, throughout Europe and Russian Asia, except the extreme north. Rather common in England and Ireland, extending into a few Scottish counties. Fl. summer and autumn.

\section{CENTAUREA. CENTAUREA.}

Herbs, with entire or pinnatifid leaves, seldom prickly, and purple, blue, or sometimes yellow flowers. Involucres globular or ovoid, the bracts numerous, ending either in a prickle or in a fringed or toothed appendage. Outer row of florets usually larger than the others, and neuter. Receptacle bearing bristles between the florets. Achenes glabrous, with a short pappus of simple hairs or scales, sometimes very short, or rarely quite wanting.

One of the most numerous genera of Cynaroidece in the Mediterranean and Caucasian regions, with a very few American species. The enlarged outer florets, the most prominent character of the genus, are seldom deficient, and that chiefly in a common variety of nigra. In that case the fringed involucral bracts as readily indicate the genus.

Involucres not prickly, or with very small prickly points to the

bracts.

Involucral bracts with a broad, black, or brown fringed border or appendage.

Leaves mostly entire or toothed. Appendagcs almost conceal-

ing the bracts themselves
Leaves deeply pinnatifid. Involucral bracts showing their green contres with a black fringed border.

Involucral bracts ending in, or bordered by, minute tcoth or prickles.

Outer florets bright blue. An erect cornfield annual - . 3. C. Cyanus.

Florets purple. A spreading Jersey perennial . . . . 4. C. aspera.

Involucral bracts ending in a long, stout prickle.

Florets purple

Florets yellow

C. montana, from central and southern Europe, and a few others, are occasionally cultivated in our gardens, and two species from the Mediterranean, $C$. selmantica and $C$. paniculata, have been found in the Channel Islands, but do not appear to be established there.

1. C. nigra, Linn. (fig. 572). Knapuced or Hardheads.-A perennial, with erect slems, hard and branched, 1 to 2 feet high. Leaves from linear to lanceolate or oblong; the upper ones entire or nearly so, clasping the stem at their base; the lower with a few coarse teeth or short lobes; all green, and rather rough with a few minute bairs, or 
slightly cottony underneath when young. Involucres globular, on terminal peduncles; the bracts closely imbricate, so as only to show their appendages, which are brown or black, and deeply fringed, except on the innermost bracts, where they are shining and usually jagged. Florets purple, either all equal'or the outer row much larger and neuter as in the rest of the genus. Achenes slightly hairy, often apparently without any pappus, but really crowned by a ring of very minute, scaly bristles, occasionally intermixed with a few longer, very deciduous ones.

In meadows and pastures, throughout Europe and western Asia, except the extreme north, extending probably all across Russian Asia. Very abundant in Britain. Fl. all summer. The two forms, with or without the outer row of large florets, are so different in appearance that it has often been attempted to distinguish them as species, but it has been now proved that they are mere varieties, and it is even believed by some that the same plant will appear in some years with and in others without the ray. C. decipiens, Thuill., is a variety, occurring in Sussex, more frequently in some parts of the Continent, with the appendages of the involucral scales of a much paler colour, with a much shorter fringe, or only jagged. This form passes, however, gradually into the common one.

2. C. Scabiosa, Linn. (fig. 573). Greater C.-A stouter plant than C. nigra, more branched at the base; the leaves deeply pinnatifid, with linear or lanceolate lobes, often coarsely toothed or lobed. Flower. heads large, with purple florets, the outer ones always enlarged and neuter. Involucral bracts broad, bordered only with a black appressed fringe, leaving the green centre exposed. Pappus of stiff hairs or bristles nearly as long as the achene.

In pastures, waste places, roadsides, \&c., throughout Europe and Russian Asia, except the extreme north. Rather frequent in England, less so in Scotland, and scarcely indigenous beyond south-eastern Perth and Forfar, local and rare in Ireland. F. summer and autumn.

3. C. Cyanus, Linn. (fig. 574). Bluebottle or Cornflowcr.-An erect, branching annual, about 2 feet high, covered with a loose cottony down. Lower leaves usually toothed or pinnatifid; upper ones, or sometimes nearly all, linear and entire. Involucres solitary, on long terminal peduncles, ovoid; the bracts appressed, often ending in a minute prickle, and bordered by a fringe of very small teeth. Central florets of a bluish purple; outer ones much larger, of a bright blue. Pappus about the length of the achene.

Apparently of south European or west Asiatic origin, but now spread as a cornfield weed over a great part of Europe and Asia. Not uncommon in British cornfields, and formerly much cultivated in flowergardens, where it will sport much as to colour. $F$. all summer.

4. C. aspera, Linn. (fig. 575). Guernsey C.-A biennial or perennial, much branched, very spreading or prostrate, with hard but not thick branches, glabrous, or rough with minute hairs. Leaves narrow; the lower ones pinnatifid, the upper ones entire. Flower-heads solitary at the ends of the branches, with 1 or 2 leaves close under them. Involucres about the size of those of $C$. Cyanus, with appressed glabrous bracts, not fringed, but most or all of them ending in a palmate appen. dage of 5 minute prickles or points. C. Isnardi, Linn. 
In waste lands, not far from the sea; very common on the Mediter. ranean, and extending up the west coast of Europe to Guernsey. Fl. summer and autumn.

5. C. Calcitrapa, Linn. (fig. 576). Star-thistle.-A coarse, green annual, sometimes slightly covered with cottony down, seldom rising to a foot in height, but with very spreading or prostrate branches. Leaves pinnatifid, with a few long linear or lanceolate lobes. Flowerheads sessile among the upper leaves or in the forks of the branches, not large in themselves, but the involucral bracts end in stiff spreading spines, $\frac{1}{2}$ to 1 Lch long, with 1 or 2 smaller prickles at their base. Florets purple. Achenes without any pappns.

In waste places, and on roadsides, in central and especially southern Europe to the Caucasus, and most abundant near the sea. Found occasionally in some of the southern counties of England, but scarcely farther northward. Fl. summer and autumn.

6. C. solstitialis, Linn. (fig. 577). Yellow C.-A stiff, erect annnal, 1 to 2 feet high, with few branches, and covered with a white cottony wool. Radical leaves pinnatifid, upper ones small and linear, decurrent in long narrow wings along the stem. Flower-heads solitary at the ends of the branches, nearly globular; the innermost bracts ending in a small shining appendage; the intermediate ones in a long spreading prickle, with 1 or 2 small ones at its base; the outermost usually with only a few small palmate prickles, as in C. aspera. Florets of a bright yellow.

In waste and cultivated places, in sonthern Europe and western Asia, especially near the sea, and, as a weed of cultivation, widely spread over the world. In Britain, it appears occasionally in cornfields, and sometimes in waste places near the sea. Fl. summer and autumn.

\section{TRAGOPOGON. SALSIFY.}

Biennials or percnnials, with tap-roots, and long, narrow, grass-like, entire leaves, broader and sheathing at the base. Involucre of 8 to 12 bracts, nearly equal, and slightly united at the base, produced into long green points. Achenes narrowed at the top into a long beak, bcaring a pappus of feathery hairs.

A genus not very numerous in species, spread over Europe and temperate Asia, easily known among the British Ligulate by the foliage. In this respect it resembles Scorzonera, a numerous exotic genus, of which one species, the $S$. hispanica, is often cultivated in our gardens for the same purposes as the Sulsify.

Flowers yellow Flowers purple
1. T. pratensis.

2. T. porrifolius.

1. T. pratensis, Linn. (fig. 578). Meadono S., Yellow Goat's-beard. - Stem erect, slightly branched, 1 to 2 feet high. Radical and lower leaves 5 to 8 inches long or even more, shortly dilated at the hase, glabrous and slightly glaucous; upper leaves shorter, with the dilated base longer in proportion. Peduncles long, thickened at the summit, each with a single head of yellow flowers. Involucral bracts narrowlanceolate, 1 to $1 \frac{1}{2}$ inches long. Florets sometimes not half so long, but varying from that to the full length of the involucre. Achenes long 
and striate, the slender beak as long as the achene itself, the hairs of the pappus long and very feathery.

In meadows and rich pastures, throughont Europe and western Asia, except the extreme north. Abundant in Britain, extending far north into Scotland. Fl. early summer. [ $T$. minor, Fries., with small flowers only half as long in the bracts, is by many regarded as a different species.]

2. T. porrifolius, Linn. (fig. 579). Purple S., Salsify.-It is difficult to assign any positive character to distinguish this from $T$. pratensis beyond the colour of the florets, which is of a very decp violet-blue or purple. It is generally of more luxuriant growtb, the peduncles more thickened at the top, the involucres longer in proportion to the florets, and the beak of the achenes and pappus longer.

In meadows and pastures, in the Mediterranean region, but only as an introduced plant in central and northern Europe, having been long cultivated for culinary purposes. In Britain, confined to southern England, where it is established in some localities. Fl. early summer.

\section{HELMINTHIA. HELMINTH.}

Habit and pappus of Picris, from which it only differs in the involucre, of which the outer bracts are broadly cordate and leafy, and in the achenes narrowed at the top into a short beak. [In recent botanical works this genus is reduced to Picris.]

1. H. echioides, Gærtn. (fig. 580). Ox-tongue.-A coarse, erect annual or biennial, 1 to 2 or 3 feet high, rough with numerous short, stiff, almost prickly hairs, often hooked as in Picris. Leaves lanceolate, sinuate or coarsely toothed, very rough; the lower ones narrowed at the base; the npper ones clasping the stem or shortly decurrent. Flower. heads rather small, rather crowded, on short peduncles, forming an irregular terminal corymb. Outer broad bracts of the involucre 4 or 5 , rough like the leaves ; inner ones about 8 , lanceolate, and much thinner. Achenes ending in a beak, with a dense, white, feathery pappus. Picris echioides, Linn.

On hedge-banks, edges of fields, and waste places ; common in central and especially southern Europe to the Caucasus, scarcely extending into northern Germany. Dispersed over England and south-east Scotland; east Ireland rare. F. summer and autumn.

\section{PICRIS, PICRIS.}

Coarse, hispid herbs, with toothed leaves, and rather small heads of yellow flowers, in a loose, irregular corymb. Involucre of several nearly equal, erect, inner bracts, with 2 or 3 outer rows of smaller ones, usually spreading. Achenes transversely striated, not beaked, with a whitish pappus, of which the inner hairs at least are feathery.

A genus containing but few species, natives of Europe and temperate Asia, having much the appearance of Hieracium and Crepis, bat readily distinguished by the feathery pappus.

1. P. hieracioides, Linn. (fig. 581). Ilackweed P.-A biennial, 1 to 2 or 3 feet high, covered with short, rough hairs, most of which are 
minutely hooked at the top, so as to cling to whatever they come in contact with. Leaves lanccolate, the lower ones tapering into a stalk, and often 6 inches or more long, the upper ones clasping the stem. Peduncles rather long and stiff. Involucres scarcely 6 lines long. Pappus of a dirty white, the hairs usually very feathery, except a few of the onter ones of each achene.

On roadsides, borders of fields, and waste places, in sonthern and central Furope, as far as southern Scandinavia, in temperate Russia and central Asia, and now spread as a weed of cultivation to many other parts of the world. Abundant in the greater part of England, extending to Roxburgh in Scotland, absent from Ireland. $\mathrm{Fl}$. summer and autumn.

\section{LEONTODON. HAWKBIT.}

Herbs, with a perennial stock, radical, spreading leaves, simple or slightly branched, usually leafless flower-stems, and yellow flowers. Involneres of several nearly equal, ereet, inner bracts, and 2 or 3 rows of smaller outer ones. Receptacle without bracts between the florets. Achenes more or less tapering at the top into a short beak, sometimes acarcely perccptible. Pappus of all, or at least the central florets, composed of feathery hairs.

A genus not numerous in species, but abundantly spread over Europe and Russian Asia. It was formerly united with Taraxacum, from which it has been separated on acconnt of the feathery pappus.

All the schenes with s pappus of feathery hairs.

Hairy plant, with simple flower-stems, Pappus with an outer

row of minute simple bairs
Plant nearly glabrous. Flower-stems often dlvided, enlarged under the flower-lieads. All the hairs of the pappus of equal

length
Achenes of the outer row of fiorets with a psippus of very short, aimple halrs, Flower-stems simple.

1. L. hispidus.

2. Lo autumnalis.

3. L. hirlus.

1. L. hispidus, Linn. (fig. 582). Common H.-The whole plant more or less bispid with crect, stiff, sbort hairs, often forked or stellate at the top. Leaves long and uarrow, coarsely toothed or pinnatifid. Peduncles 6 inches to a foot or more long, slightly swollen at the top, with a single rather large flower-head. Bracts of the involucre narrow, and always hispid, the inner row much longer than the outer ones. Achenes long, striate, and transversely rugose, slightly tapering at the top, but seldom distinctly beaked. Pappus of about a dozen brown, feathery hairs, about as long as the achene, surrounded by 5 or 6 others not a quarter that length. Apargia hispida, Willd.

In meadows and pastures, very common in Europe, and eastward to the Caucasus and the Ural, except in the extreme north. Abundant in Britain, as far north as Glasgow and Forfar. Fl. the whole summer and autumn. A nearly glabrous variety (L. hastilis), frequent on the Continent, does not appear to bave been found in Britain.

2. I. autumnalis, Linn. (fig. 583). Autumnal H.-Habit nearly of Hypocharis radicata, but with smaller flower-heads, and no scales between the florets. Leaves long, narrow, and pinnatifid, with a few narrow lobes, glabrous, or with a few long, stiff hairs. Flower-stems 
erect, usually with 1 or 2 single-headed branches, having sometimes 1 or 2 narrow, nearly entire leaves near the base; the branches or peduncles nearly glabrous, bearing a few small scales. Involucres oblong, tapering at the base into the enlarged summit of the peduncle, glabrous in the common variety, with closely appressed, imbricated bracts. Achenes long, striate, and transversely wrinkled, tapering into a short beak, scarcely perceptible in the onter ones. Pappus brown and feathery, without the short, outer hairs of $L$. hispidus. Apargia autumnalis, Willd.

In meadows, pastures, and waste places, throughout Europe and Russian Asia, from the Mediterranean to the Arctic regions. Abundant all over Britain. Fl. summer and autumn. L. pratensis, Koch. (Apargia Taraxaci, Horn.), is a northern or alpine variety of dwarf stature, with the flower-stems often simple, and rather large flower-heads, the summit of the peduncle mucls enlarged, and the involucre more or less covered with black hairs. Not unfrequent in the Scotch Highlands. The true $L$. Taraxaci, from the alps of central Europe, is quite a distinct plant.

3. L. hirtus, Linn. (tig. 584). Lesser H.-Usually a smaller plant than the last two, and glabrous, or with a few stiff, mostly forked bairs on the leaves and lower part of the peduncles. Leaves oblong or linear, coarsely toothed, sinuate or shortly pinnatifid. Peduncles seldom above 6 inches high, with a single rather small head of bright yellow flowers. Involucres green, glabrous, thickening at the base after flowering, consisting of 10 or 12 nearly equal bracts, with several small imbricated ones at the base. Achenes of the outer row curved, slightly tapering at the top, with a very short, scaly pappus; the others like those of $L$. hispidus. Thrincia hirta, Roth.

In rather dry open pastures, moors, and waste places in central and southern Europe, scarcely extending to its eastern limits, or northward to the Baltic. Very common in England and Ireland, but fonnd only in the south-east of Scotland. Fl. summer.

\section{HYPOCHCERIS. HYPOCHERE.}

Annuals or perennials, with the habit and pappus of Leontodon, but more frequently branched; the involncres rather more imbricated, and there are a few chaffy scales on the receptacle between the florets, at least among the inner ones.

More numerous in species than Leontodon, it has also a wider geo. graphical range, extending over Europe, Russian Asia, North America, and western and southern South America.

Involueres oblong, nearly glabrous.

Florets scarcely longer than the involucres. Outer achenes usually without a beak . All the achenes ending in a slender beak . . . . . . H. radicata Involucres large, bemispherical, and hairg : $: \quad \vdots \quad: \quad 3 . H_{\text {. maculata }}$

1. H. glabra, Linn. (fig. 585). Glabrous $\boldsymbol{H}$.-Much resembles $\boldsymbol{H}$. radicata, but is a smaller plant, with an annual root, and quite glabrous ; the stems seldom attain a foot in height, with much smaller flower-heads, although the involucres become much elongated after flowering. The schenes are similarly wrinkled, and have the same feathery pappus, 
which, however, is sessile on the achenes of the outer florets, whilst on the central ones it is supported on a slender beak, as in $I I$. radicata.

Although generally spread over central and southern Europe, and naturalised even in distant temperate climates, it is much less common than II. radicata, growing chiefly in sandy situations. Thinly scattered over England, the Scottish stations are still fewer, and not recorded from Ireland. $F l$. summer. [In a variety, H. Balberii, Lois., found in Kent, Shropshire, and the Channel Islands, all the achenes are beaked.]

2. H. radicata, Linn. (fig. 586). Cat's-ear.-Rootstock perennial. Leaves all radical, spreading, narrow, more or less toothed or pinnately lobed, hispid on both sides with stiff hairs. Stems erect and leafless, 1 to 2 feet high, usually divided like Lcontodon autumnule into 2 or 3 long branches or peduncles, slightly thickened upwards, each bearing a few small scales, and terminated by a rather large head of flowers. Involucres near an inch long, narrow but somewliat thickened at the base; the bracts imbricated in several rows, the onter ones smaller, all glabrons, or with a few short hairs on the back. Scales of the receptacle long, narrow, and finely pointed. Achenes transversely wrinkled, all narrowed into a long slender beak with a feathery pappus.

In meadows, pastures, and waste places, throughout Europe, except the extreme north, but scarcely extends into Asia. Abundant in Britain, extending far into the north of Scotland. Fl. summer and autumn.

3. H. maculata, Linn. (fig. 587). Spotted H.-Rootstock perennial. Leaves all or mostly radical, spreading, broadly obovate, or rarely oblong, coarsely toothed or nearly entire, hairy on both sides, and often spotted. Flower-stem erect, 1 to 2 feet high, usually simple, but occasionally bearing a small leaf near the base, and terminated by a single large flower-head; the involucre broad and hairy. The stem is rarely forked, with two flower-heads.

In open pastures, and meadows, widely spread over Europe and Russian Asia, chiefly in monntain districts, although not an Arctic plant. Rare in Britain, but found in a few spots from Westmoreland and North Wales to Essex and Cornwall. Fl. summer.

\section{LACTUCA. LETTUCE.}

Annual or perennial herbs, glabrous or with very few stiff bristles; the stems leafy, erect, and branched, with (in the British species) numerous small heads of yellow or blue flowers. Involucre narrow, of a few imbricated bracts, containing very few florets. Achenes flattened or four-sided, tapering into a slender beak, with a pappus of numerous white and silky (very discoloured, stiff, and bristly) simple hairs.

A genns widely spread over sonthern Europe and central Asia. It has the flattened achenes of Sonchus, from which the only positive distinctive character is the beak of the achenes, but the narrow involucres and few florets generally glve it a different habit.

Learcs thin, on long stalks, with a brond terminal lobe. Panicle slender. Flowers yellow. Beak shorter than the achene itself

Leaves mostly sessile, rather stiff, often prickly. Panicle rigid. Benk as long as or longer than the achene.

Panicle rather loose, oblung or spreading. Beak about the length of the achene

1. L. muralis. 
Panicle almost reduced to a long, clustered spike. Flowers jellow. Beak about twice the length of the achene. 'Flo
Leaves pinnatifid, with a triangular terminal lobe. Flower Beak 0

Our garden Lettuces are luxuriant forms, produced by long cultivation of one or perbaps two southern species, which are not satisfactorily identified, some botanists believing them to be cultivated states of L. Scariola.

1. L. muralis, Fresen. (fig. 588). Wall $L_{0}-A$ glabrous, erect annual or biennial, about 2 feet high, with slender branches, forming a loose, terminal panicle. Leaves few and thin, with a broadly triangular, toothed or lobed, terminal segment, and a few irregular smaller ones along the stalk; the upper leaves narrow, entire or toothed, clasping the stem with prominent auricles. Flower-heads small, on slender pedicels. Involucres about 5 lines long, of 5 equal, linear bracts, with 1,2 , or 3 very small outer ones, containing 4 or 5 florets. Beak of the achenes much shorter than the achene itself.

In woods and shrubby places, in Europe and Russian Asia, extending far into the north, although not an Arctic plant. Not uncommon in England, Perth and Stirling in Scotland, and only known in Wicklow and Louth in Ireland. Fl. summer.

2. L. Scariola, Linn. (fig. 589). Prichly L.-An erect, stiff annual or biennial, 2, 3, or even 4 feet high, of a more or less glaucous green, with short but spreading branches, and quite glabrous, except a few stiff bristles or small prickles on the edges or on the midrib of the leaves. Leaves more or less spreading, but often twisted so as to be vertical instead of horizontal, varying from lanceolate to broadly oblong, either bordered only with small teeth, or with a few short lobes or coarse teeth usually curved downwards, or deeply pinnatifid with few narrow lobes; the upper ones narrow, more entire, and clasping the stem with pointed auricles. Flower-heads in a more or less leafy panicle, sometimes long and narrow, sometimes more branched and spreading. Involucres 4 or 5 lines long, of a few imbricate bracts, the short, broad, outer ones passing gradually into the inner, long, narrow ones. Florets 6 to 10 or 12, of a pale yellow. Achenes much flattened, obovate-oblong, striated, varying in colour from nearly white to nearly black, with a slender beak about the length of the achene.

In dry or stony wastes, on banks and roadsides, in central and southern Europe, extending over a great part of central Asia. Thinly scattered in Britain, from southern England to the low tracts in the south-east Highlands of Scotland. Fl. summer. The name of $L$. Scariola is often limited to the varieties with more erect leaves, with deeper and narrower lobes; and those with broader leaves, toothed only, and not so glaucous, have been considered as a distinct species, under the name of $L$. virosa, Linn.

3. L. saligna, Linn. (fig. 590). Willow L.-Very near L. Scariola, but more slender and twiggy; the leaves upright against the stem, and narrower; the stiff panicles with branches so short that the flowerheads appear clustered in a simple spike; and the beak of the achene from twice to three times its own length. These characters are, however, so variable as to occasion some doubt whether the two species are really distinet. 
The commonest form in the Mediterranean and Caucasian regions, extending to some parts of central Europe. Rare in Britain, and confined to the south-eastern counties from Suffolk to Sussex. Fl. summer.

4. L. alpina, Benth. (fig. 591). Alpine L.-Stock perennial, with erect stems, 2 to 3 feet high. Leaves much like those of Sonchus oleraceus, but with a much larger, broadly triangular, and pointed terminal segment. Panicle oblong, almost narrowed into a raceme, more or less hispid with glandular hairs. Involucres narrow, of but few bracts, containing 12 to 20 deep-blue florets. Achenes oblong, but slightly flattened; the hairs of the pappus of a dirty white, and rather stiffer than in the other species. Sonchus alpinus, Linn.

In moist, rocky situations, in northern and Arctic Europe and Asia, limited in central and southern Europe to mountain ranges. In Britain, only on the Lochnagar and Clova mountains, where it is now becoming very rare. Fl.summer, rather late.

\section{SONCHUS. SOWTHISTLE.}

Erect, leafy herbs, either glabrous or with more or less glandular hairs on the panicles; the leaves usually pinnately lobed or coarsely toothed, and clasping the stem at the base ; the flower-heads in terminal panicles, with numerous yellow florets. Involucre ovoid, with imbricated bracts, and usually becoming conical after flowering. Achenes flattened and striate, not beaked; the pappus sessile, of numerous simple, white, silky hairs.

A considerable genus, spread over the temperate regions of the northern hemisphere, distinguished from Lactuca by the sessile pappus, from Crepis and Hieracium by the flattened achenes.

Perennlals. Flower-heads large. Involucres hairy at the base.

Marsh plant, the auricles of the leaves narrow and acute.

Field weed, the auricles of the leaves short and broad.

2. S. palustria.

1. S. arvensis.

Annuals. Flower-heads rather small and pale. Involucres glubrous 3 . S. oleraceus.

1. S. arvensis, Linn. (fig. 592). Corn S.-Rootstock creeping. Stems 2 to 3 feet high. Leaves long, pinnatifid or sinuate, the lobes lanceolate or triangular, more or less curved downwards, and bordered by small prickly teeth; the lower ones stalked, the upper ones clasping the stem with short, broad auricles. Flower-heads large, of a bright yellow, in loose terminal panicles; the branches, peduncles, and involucres more or less hispid with brown or black glandular hairs. Aclienes striated and transversely wrinkled, with a pappus of copious, white, silky hairs.

A cornfield weed, extending over the whole of Europe and Russian Asia, except the extreme north. Common in Britain. Fl. summer and autumn. [Two forms are recognised as British : S. arvensis proper, with glandular.hispid involucres; and a more robust one (var. glaber, Lond. cat.), with glabrous involucres.]

2. S. palustris, Linn. (fig. 593). Marsh S.-Thls has the large flowers, glandular hairs, and general habit of $S$. arvensis, but is a much taller plant; the rootstock scarcely creeps, and the leaves are narrow, often 8 or 10 inches long, clasping the stem with long, pointed auricles, and either nndivided or with 1 or 2 pairs of long lanceolate lobes.

In marsbes, and the edges of ponds and wet ditches. Said to have 
nearly the geograplical range of S. arvensis, but appears to be more confined to eastern Europe, and nowhere common. In Britain, very rare, the only certain localities being in the marshes of some of the eastern counties of England. Fl. late summer, or autumn.

3. S. oleraceus, Linn. (fig. 594). Common S.-An annual, with a rather thick hollow stem, 1 to 3 or even 4 feet high, perfectly glabrous, except occasionally a very few stiff glandular hairs on the peduncles. Leaves thin, pinnatifid, with a broad, heart-shaped or triangular terminal lobe, bordered with irregular, pointed or prickly teeth, and a few smaller lobes or coarse teeth along the broad leafstalk; the upper leaves narrow and clasping the stem with short anricles. Flower-heads rather small, in a short corymbose panicle, sometimes almost umbellate; the involucres remarkably conical after flowering. Florets of a pale yellow. Achenes flattened, with longitudinal ribs often marked with transverse wrinkles or asperities, the pappus of copions snow-white hairs.

A weed of cultivation, so nniversally distributed over the globe, except perhaps some tropical districts, that the limits of its native conntry cannot now be fixed; probably truly indigenous in Europe and central Asia. Very abundant in Britain. $F l$. the whole season. S. asper, Hoffm, or Prickly $S$., is a marked variety, in which the longitudinal ribs of the achenes have not the transverse wrinkles. The leaves are nsually darker in colour and less divided, but mnch more closely bordered with prickly teeth; and the auricles which clasp the stem are broader, rounded, and more prickly toothed; none of these characters are, however, constant. It is almost always mixed with $S$. oleraceus, and in many places as abundant.

\section{TARAXACUM. DANDELION.}

Herbs, with a perennial rootstock, radical leaves, and radical peduncles, with single heads of yellow flowers. Involucres of several nearly equal, erect, inner bracts, and several imbricated or recurved outer ones. Receptacle withont scales. Achenes tapering into a long slender beak, with a pappus of numerous simple hairs.

A widely diffused genus, of which all the described species may perhaps be considered as varieties of a single one, differing from Leontodon in the simple hairs of the pappus, and from Crepis chiefly in the leafless simple peduncles.

1. T. Dens-leonis, Desf. (fig. 595). Common Dandelion.-The rootstock descends into a thick tap-root, black on the outside, and very bitter. Leaves varying from linear-lanceolate and almost entire to deeply pinnatifid, with broad triangular lobes usually pointing downwards, the terminal one larger, obovate or acute. Peduncles 2 to 6 or 8 inches high. Involucral bracts linear, often thickened towards the top, or with a tooth on the back below the point. Achenes slightly or not at all compressed, striated, marked upwards with short, pointed asperities, the beak two or three times as long as the achene itself. T. officinale, Web.

In meadows and pastures, cultivated and waste places, throughout the northern hemisphere to the Arctic regions, and now a troublesome weed in most parts of the world. Among the numerous forms which 
have given rise to a number of supposed species, the most remarkable British ones are the common $T$. Dens-leonis, with pinnatifid leares and the outer involucral bracts much recurved, and T. palustre with narrow leaves nearly entire or sinuate, and the outer involucral bracts scarcely spreading at the tips.

[There are four principal forms in the British lsles : 1. The common one, with bright green runcinate leaves, recurved outer bracts, and pale achenes; it affects cultivated ground, and is perhaps dependent on it. 2. T. erythrospermum, Andrz., with dull green often glancous runcinate leaves, spreading outer bracts, the inner thickened near the tip, and brown achenes. 3. T. lcevigatum, DC., with dull green pinnatifid leaves, broader erect outer bracts, and pale achenes. These two affect dry uncultivated ground. 4. T. palustre, DC., with very narrow sinuate or pinnatifid green leaves, ovate, erect or spreading outer bracts, and pale acbenes. This inliabits moist moorlands and mountains, and varies greatly in the size of all its parts.]

\section{CREPIS. CREPIS.}

Anuuals or biennials, rarely forming a stock of longer duration, usually glabrous or slightly hairy, with branched, more or less leafy stems, and rather small heads of flowers in loose panicles, yellow in the British species. Involucre of several nearly equal linear inner bracts, with smaller outer oues. Receptacle without scales. Achenes not compressed, angular or striated, more or less narrowed at the top or beaked, with a pappus of copious simple hairs, usually very white.

One of the largest genera of Ligulata in Europe and Asia, with a very few American species, all nearly allied to Hieracium, but mostly distin. guished by habit, as well as by the achenes contracted at the top and the white pappus. There are some species, however, so nearly intermediate betwcen the two genera that they are referred to the one or to the other according to the particular views of individual botanists.

Achenes nurrowed Into a distinct, slender beak (Barkhausia).

All the achenea with a long, alender beak. Outer Involucral bracts lanceolate, whitish at the edgea. ${ }^{2}$, the others with a long beak. Other involucral bracts amall, and very narrow 2. C. fatida.

$\Delta$ chenes contracted at the top, but without a diatinct beak.

Lower leaves pinnatifid, or very narrow. Flower-heads nume. rous. Paplyus very white, and silky.

Outer bructs of the involucre narrow-linear . . . . 3. C. virews.

Outer bracts of the involucre oblong-llnear, with a whitlsh age mostly oblong, coarsely toothed or entire. Flower.ieada

Leaves mostly oblong, coarsely toothed or entire.
fow. Pappus not very white, and rather stiff.

Ieave mostly entire. Achenes with about 20 ribs or strim . 5. C. hieracioides.

Leavea moatly toothed. $\Delta$ chenes with 10 ribs or atrim - 6. C. paludosa.

'The pink Ilawkweed, formerly much cultivated in flower-gardens, is a species of Crepis from south-eastern Europe. C. sctosa, Haller, which bas the long.beaked achenes of $C$. taraxacifolia, but is covered with stiff, spreading hairs, is a south-east European plant, which has occasionally appeared in Britain as a weed of cultivation.

1. C. taraxacifolia, Thuil. (fig. 596). Beaked C.-Much resembles wome forms of $C$. biennis, but is easily known by the pappus. Leaves 
chiefly radical and pinnatifid, with a large, terminal, coarsely toothed lobe, and small ones along the stalk. Stems erect, 1 to 2 feet high, bearing a few small, narrow leaves. Flower-heads smaller than in $C$. fotida, forming a loose, terminal, flat corymb. Involucres scarcely hairy, the outer bracts much shorter than the inner ones, lanceolate, and more or less membranous and whitish on the edges. Achenes all terminated by a slender beak about the length of the achene itself. Barkhausia taraxacifolia, Mœnch.

In rather dry pastures and wet places, in central and especially southern Europe, and eastward to the Caucasus, not extending into northern Germany. In Britain, chiefly in limestone districts of southern England, but extending to Yorkshire: rsther more frequent than $C$. fotida, but frequently confounded with that plant or with $C$. biennis. Fl. summer.

2. C. fœtida, Linn. (fig. 597). Fetid C.-A slight hairy annual or biennial, seldom a foot bigh, witl a few spreading branches. Kadical leaves irregularly pinnatifid, with short lobes, the terminal ones varying from broadly triangular to narrow-oblong; the stem-leaves narrow, the lower slightly pinnatifid, the upper entire or toothed. Flower-heads few, on long peduncles, usually recurved after flowering. Involucres hairy, the outer bracts small, and very narrow. The beak of the outer achenes is very short, often scarcely distinct, whilst that of the inner ones is long and slender, carrying up the whole pappus above the tips of the involucral bracts. Barkhausia foetida, Mœnch.

In rather dry pastures and waste places, in southern Europe to the Caucasus, becomes rare farther north. In Britain only in some of the southern and eastern counties of England. Fl. summer.

3. C. virens, Linn. (fig. 598). Smooth C.-An erect or ascending, branched annual or biennial, from 1 to 3 feet high, usually glabrous or nearly so. Leaves linear or lanceolate, toothed or pinnatifid, with triangular or narrow, but short lobes; the radical ones stalked, the upper ones clasping the stem by pointed, spreading auricles. Flowerhearls small, in loose, often leafy panicles. Involucres often slightly hispid, and become conical after flowering; the outer bracts narrowlinear, and rather close. Achenes narrow-oblong, very slightly contracted at the top, but not beaked, and generally shorter than the pappus, although a few in the same head may be nuch longer than the rest, and longer than their own pappus.

In pastures, on dry banks, roadsides, and waste places, thronghout western and central Europe, from Scandinavia to the ${ }^{\circ}$ Mediterranean; fartlier east apparently replaced by $C$. tectorum. One of the commonest of the British Ligulato. Fl. the whole summer and autumn. It varies much in stature and in the size and number of the flower-heads, but they are always smaller than in any other British species.

4. C. biennis, Linn. (fig. 599). Rough C.-A taller and stonter plant than $C$. virens, more frequently biennial, less branched from the base, but forming a broad, terminal corymb of rather larger flower. heads; the leaves more or less rough with short, stiff hairs; and the outer bracts of the involucre broader, $\mathrm{w}$ ith a whitish, membranous edge. In this respect it resembles the larger forms of $C$. taraxacifolia, but the achenes have the ribs mnch smoother, and althongh narrowed at the top, they do not bear the long, slender beak of that species 
ancl there are often long and short ones in the same head as $C$. virens.

In similar situations with the last three, dispersed over temperate Europe, from Sweden to the Mediterranean. Rare in Britain, and often confounded with $C$. vircus, or with $C$. taraxicifolia, but found in the central and eastern counties of England, and in Aberdeenshire, and Dublin, $\mathrm{Fl}$. summer.

5. C. hieracioides, Jacq. (fig. 600). Hawkveed C.-Like C. paludosa, this has much the habit of a llieracium, but the pappus is almost as white and soft as in other species of Crepis. It is an erect, scarcely brancherl perennial, a foot high or rather more, glabrous or slightly hairy. Leaves entire or with a few minute teeth; the radical and lower obovate-oblong, on long stalks; the upper few, narrow, and clasping the stem. Flower-heads few, in a loose corrmb, like those of $C$. paludnsa, but the achenes are finely striate, with about 20 ribs. $C$. succiscefol ia, Tausch.

In meadows and pastures, chiefly in monntain districts, all acrose central Europe, from the Pyrenees to the Russian frontier, not extend. ing into Scandinavia. In Britain, in a few localities, in Scotland, and northern England, extending from Yorkshire to Banff. Fl. sumnier and antumn.

6. C. paludosa, Mænch. (fig. 601). Marsh C.--This species has almost as much the babit and characters of IIierucium, with which Linnæus associated it, as of Crepis, to which it is referred by modern botanists. It is an erect, scarcely branclied perennial, but of short duration, and nearly glabrous, 1 to 2 feet high. Radical leaves ovate, coarsely toothed, with a few small lobes along the stalk; the stem. leaves from broadly oblong to lanceolate, pointed, toother, especially in the lower part, and clasping the stem by rather large, pointed auricles. Flower-heads yellow, rather large, in corymbs of 8 or 10 ; the involucres more or less hairy with black, spreading hairs. The pappus is of a dirty white, almost like that of a Hieracium, but the achenes are distinctly contracted at the top as in Crepis, and marked with 10 ribs or stria.

In moist, shady situations, in northern Europe, and all across Russian Asia, becoming a mountain plant in southern Europe. Extenils all over Scotland, and southward into the central counties of England, and into South Wales; found also in north lreland. Fl. summer and autumn.

\section{HIERACIUM. HAWKWEED.}

Herbs, with a perennial stock, entire or toothed leaves, and yellow or rarely orange-red flower-heads, either on leafless radical peduncles, or in terminal corymbs or panicles on leafy stems. Involucre more or less imbricated. Receptacle without scales. Achenes angular or striated, not narrowed at the top; with a pappus of simple, generally stiff hairs, of a tawny-white or brownish colour.

A rather numerous European and north Asiatic genus, with a few American species, very nearly allied to Crepis, but the achenes are not perceptibly contracted at the top, and the hairs of the pappus are 
nsually stiffer and never so white. The habit is also different, with the exception of a few species, which are also intermediate in more essential characters. Most of the species are very variable, and specimens are frequently found intermediate between some of the commonest ones. In the attempt to classify these forms, and to give greater exactness to their definitions, modern botanists have distributed them into a large number of supposed species, amounting to 33 for Britain alone; but the difficnlty of distinguishing them appears only to increase with their subdivision.

Peduncles radical, bearing a single flower-head.

Peduncles lenfless. Stems creeping. Lesves whito undorneath. Flower-heads pale yellow . .

Peduncles or flower-stems with 1 or more narrow leaves. No creeping stems. Leaves not white. Flower-heads large, brixht yellow.

Radical leaves ovate. Involucres with short hairs

Radical leaves narrow. Involucres with loug hairs

1. H. Pilosella.

Flowering-stems with more than one flower-head.

Radical leaves mostly persistent at the time of flocering. Stemleaves one or few. Outer involucral bracts few and short.

Stem-leaves ovato and toothed, or small and uarrow, stalked or sessile, scarcely stem-clasping .

Stem-leaves 1 or 2, entire, glaucous, clasping the stem with

No radical leaves at the time of flowering. Sicm leafy. Outer involucral bracts imbricated.

Upper stem-leaves sessile or shortly stalked, not clasping the stem.

Upper stem-leaves all tapcring at the base, usually

nsrrow
Upper stem-lesves short and broad, rounded st the Lase.

Upper stem-lesves clasping the stem.

Auricles of the stem-leaves short and rounded.

Stem-leaves several, ciliate. Pappus dirty-white.

Stem-leaves very fow, glabrous Pappus very wlilte

and soft
Auricles of the stem-leaves long and very pointed, or

5. II. umbellatum.

6. H. subuidum.

3. H. murorum.

2. 1 . alpinum.

\section{H. murorkm.}

4. H. ceriathoides.

7. II. prenanthoides.

Crepis hieracioides.

Crepis paludosa.

1. H. Pilosella, Linn. (fig. 602). Mouse-car H.-Stock perennial, with spreading tufts of radical leaves, and creeping, leafy, barren shoots. Leaves much smaller than in the other British species, oblong or lanceolate, entire, tapering at the base, and often stalked, green above with a few long hairs, white underneath with a short stellate down. Peduncles radical, with a single head of lemon-coloured flowers, often tinged with red on the outside. Involucres and upper part of the peduncle more or less clothed with a minute and cluse whitish down, mixed with short, stiff, spreading black hairs. Achenes shorter in proportion to the pappus than in the other species.

In dry pastures, on banks and roadsides, thronghout Europe and Russian Asia, from the Mediterranean to the Arctic regions. Very common in Britain. $F$. the whole season. In southern Europe it is very variable, but in Britain presents no difficulties. The only other species with creeping runners ever admitted into our Floras is $I$. aurantiacum, L., a native of the mountains of sonthern Europe, which may have spread out of cottage gardens, but is not vaturalised; it has radical peduncles, bearing a corymb of small orange-red flower. heads. 
2. H. alpinum, Linn. (fig. 603). Alpine H.-Rootstock short and thick, sometimes shortly creeping, but without creeping leafy stems. Leaves chiefly radical, oblong or lanceolate, slightly toothed, green, with a few long hairs. Peduncles or flower-stems about 6 inches high, simple or rarely divided into 2 simple branches; they usually bear 1,2, or even 3 small narrow leaves, and a single rather large head of bright yellow flowers. Involucres and peduncles more or less clothed with long rusty hairs; the outer bracts few and small, as in $\boldsymbol{H}$. murorum.

A high alpine or Arctic species, spread over the mountains of northern and Arctic Europe and Asia, and the higher ranges of central and southern Europe. Not uncommon in the Highlands of Scotland, and in the mountains of North Wales, and found also in some parts of north-western England. $\mathrm{Fl}$. summer. In its ordinary state it is easily recognised, but in the Scotch Highlands a variety occurs with broader leaves, longer flower-stems, and less shaggy involucres with black hairs; this, the $H$. nigrescens, Willd., is intermediate between $H$. alpinum and $\boldsymbol{H}$. murorum.

3. H. murorum, Linn. (fig. 604). Wall H.-The short perennial stock bears a spreading tuft of rather large, ovate or oblong leaves, always stalked, sometimes very obtuse and nearly entire, more frequently pointed and coarsely toothed, especially near the base, sometimes tapering into the stalk, sumetimes more or less cordate at the base, usually slightly hairy, and often of a pale glaucous-green underneath. Flower-stems erect, 1 to 2 feet high, rarely quite leafless, usually with 1 ur 2 leaves near the base like the radical ones but smaller, and 1 or 2 smaller narrow ones higher up, but occasionally with several leaves. Flower-heads rather large and yellow, usually 3 or 4 only, but sometimes as many as 20 or 30 , in a loose terminal corymb. Involucres and peduncles more or less clothed with black, glandular hairs, intermixed with a shorter, rusty-coloured down, whilst the stem is glabrous, or bears in the lower part long, white woolly hairs, which are sometimes very dense close to the stock. Scales of the involucres narrow, the inner ones nearly equal, the outer few and much shorter.

On banks and old walls, in meadows and rich pastures, bushy places, and open woods, throughout Europe and Russian Asia, from the Mediterranean to the Arctic regions. Very common all over Britain. $\mathrm{Fl}$. all summer and carly autumn. Exceedingly variable in the shape and teeth of the leaves, in colour and hairiness, in the number of stem-leaves and of flowcr-heads. In alpine situations the leaves are usually much more entire, often obovate. A marked variety, growing in wools and on banks, with a much more leafy stem, has been distinguished as $H$. sylvaticum, Sm., or 1 . vrulyatum, Fries., but it is connected with the more typical form by intermediates which defy classification. From $H$. sabaudum and $H$. umbellatum it may be known by the radical leaves larger than the stem ones, and persistent at the time of flowering, except where they have been accidentally choked by the surrounding herbage, or withered by drought or other accidental causes.

4. $\mathbf{H}$. cerinthoides, Linn. (fig. 605). Honeywort 11 . - The habit and radical leaves are those of the mountain varieties of $H$. murorum, but the whole plant is still more glaucous, and has generally more of the woolly hairs, especially about the stock. The flower-stems bear but few rather large flowers, and 1 or 2 leaves usually entire, and always 
clasping the stem with broad, rounded auricles, and the radical leaves are usually remarkably obovate. $H$. anglicum, Fries.

In western Europe, chiefly in the Pyrenees, more doubtfully extending to the western Alps and Corsica. A very doubtul British plant. The only specimens I have seen which really resemble the Pyrenean ones (in the dried state at least) are from the mountains of the west and north of Ireland. The Scotch and English and most of the Irish ones so denominated are usually varieties of $H$. murorum or of $I I$. sabaudum. [This, the $H$. cerinthoides of Backhouse, is regarded by critical authors, thongh not by Bentham, as different from the Continental (Linnæan) cerinthoides, and is called $H$. anglicum by Fries.]

5. H. umbellatum, Linn. (fig. 606). Umbellnte H.-The perennial stock only forms buds in the autumn, which do not expand into a tuft of spreading leaves as in $H$. murorum, but in the following year grow out into a leafy, erect, rigid stem, 1 to 3 feet high. Radical leaves, if any, few and withering away before the time of flowering. Stem-leaves from narrow-lanceolate to oblong, coarsely toothed or nearly entire; the lower ones stalked, and all tapering at the base. Flower-heads rather numerons, on rather short lateral branches towards the summit of the stem, several of which usually (but not always) start from so nearly the same point so as to form an irregular umbel, and there are often many others lower down in the axils of the upper leaves. Involncres and peduncles glabrous or shortly downy. Leaves glabrous or hairy underneath; the stems usually more or less clothed at the base with long loose hairs. Scales of the involncre more regularly imbricated than in $H$. murorum, the outer ones usually spreading at the tips.

In woods and stony places or banks, throughont Europe and temperate Asia, from the Mediterranean to the Arctic regions. Very common in Britain. Fl. late summer, and autumn.

6. H. sabaudum, Linn. (fig. 607). Savoy H.-Althongh intermediate forms between this species and the last may occasionally be found, yet they are in most cases easily distinguished. $H$. sabaudum, though stout and equally tall with $H$. umbellatum, is less rigid and more hairy ; the leaves larger, broader, and more toothed, the upper ones shorter, always rounded at the base, and sometimes almost clasping the stem; and the flowering branches form a loose corymb, and never an umbel. From $H$. murorum it is distinguished by the more leafy stem, without radical leaves at the time of flowering, and by the more regularly imbricated involncres. II. boreale, Fr.

In woods, under hedges, and in shady places, especially in hilly districts in Europe, extending eastward to the confines of Siberia, and probably still farther into Asia, and northward to the Arctic regions. Distributed over the greater part of Britain, bnt not so frequent as $H$. umbellatum, and especially as $H$. murorum. Fl. late summer, and autumn. [H. sabaudum, Smith, is regarded by most botanists, thongh not by Bentham, as different from the Linnæan sabaudum.]

7. H. prenanthoides, Vill. (fig. 608). Prenanth $I$.-Very near $H$. sabaudum, but the stem-leaves are nsually long, lanceolate, and slightly narrowed near the base, and always clasp the stem by ronnded auricles, and even the stalks of the lower leaves are expanded at the base into the same stem-clasping auricles. The involucres and peduncles have 
usually more ot the short, black, glandular hairs, intermingled with the minute down than either H. sabaudum or $I I$. umbellatum.

In woods, shady places, and rich pastures, and on the banks of streams, in northern Europe and the mountain districts of central Europe, and north and west Asia, and the Himalayas. Rare in the Highlands of Scotland, and in Wicklow county in Ireland, very doubtfully extending into England. Fl. late summer, or autumn.

\section{CICHORIUM. CHICORY.}

Perennials, with the leaves mostly radical, stiff branching stems, and sessile heads of blue flowers. Involucres oblong. Achenes crowned by a ring of minute erect scales.

Besides the British species, the genus only includes the garden Endive, supposed to be a native of India, but it is very doubtful if it be wild even there, and it may be a mere cultivated variety of $C$. Intybus, which yields the chicory of commerce.

1. C. Intybus, Linn. (fig. 609). Succory or Chicory.-Perennial stock descending into a long tap-root. Stems more or less hispid, 1 to 2 or even 3 feet high. Radical leaves spreading on the ground, and, as well as the lower stem-leaves, more or less hairy and pinnatifid, with a large terminal lobe and smaller lateral ones, all pointed and coarsely toothed; the upper leaves small, less cut, embracing the stem by pointed auricles. Flower-heads in closely sessile clusters of 2 or 3 along the stiff spreading branches, and 1 or 2 terminal ones. Involucres of about 8 inner bracts and a few outer ones about half their length; the florets large, of a bright blue. Achenes smooth or scarcely ribbed, closely packed in the hard dry base of the involucre.

In dry wastes, on roadsides, and borders of fields, over the greater part of Europe and Asia, stopping only short of the Arctic regions on the one side, and the tropics on the other. Not uncommon in some parts of England and Ireland, but rare in Scotland. Fl. summer and autumn.

\section{ARNOSERIS. ARNOSERIS.}

A single species, distinguished as a genus from Lapsana, as having a different habit, and the achenes crowned with a minute raised border; and more naturally associated by older botanists with Hyoseris, a Jontinental genus, in which the achenes have a pappus of chaffy scales or bristles.

1. A. pusilla, Gartn. (fig. 610). Dwarf A., Lamb's or Swine's Succory. -Leaves all radical, obovate or oblong, toothed, and glabrous or nearly so. Flower-stalks 4 to 8 inches high, slightly branched and leatless; the erect branches or peduncles enlarged and hollow upwards, each bearing a small head of yellow flowers.

In dry, sandy or gravelly fields, in northern and central Europe, but not an Arctic plant, and apparently rare in the south. Dispersed locally over the eastern counties of England and Scotland, but not recorded from Ireland. Fl. summer. 


\section{LAPSANA. LAPSANE.}

Leafy annual, with small yellow flower-heads. Achenes without any pappus or border whatever.

A genus of few species spread over the northern hemisphere.

1. L. communis, Linn. (fig. 611). Nipplewort.-Stem 1 to 2 or 3 feet high, with a few stiff hairs at the base, branched and glabrous upwards. Leaves thin and usually hairy ; the lower ones ovate, coarsely toothed, with a few smaller lobes along the stalks; the upper ones small, narrow, and entire. Flower-heads on slender peduncles, in a loose panicle or corymb. Involucre about 3 lines long, of about 8 nearly equal scales of a glaucous green, with a few very small outer ones. Achenes slightly compressed, with numerous longitudinal nerves.

A common weed in waste and cultivated places, throughout Europe and Russian Asia, except the extreme north. Extends over Britain, except the northern extremity of Scotland. Fl. summer and autumn.

\section{CAMPANULACER. CAMPANULA FAMILY.}

Herbs, with alternate, entire or toothed leaves, without stipules; the flowers most commonly blue or white, either distinct, or collected into heads with a general involuere. Calyx adhering to the ovary, with a free border of 5 teeth or lobes, sometimes very narrow and almost reduced to bristles. Corolla inserted within the lobes of the calyx, regular or irregular, with 5 teeth or lobes. Stamens 5 , inserted within the corolla at its base, but otherwise free from it. Anthers distinct, or rarely cohering in a ring round the style. Style single, with an entire or divided stigma. Ovary and capsule inferior, divided into from 2 to 5 cells, with several seeds in each (or, in a very few exotic species, reduced to 1 seed).

A rather large family, widely spread over the temperate regions of both hemispheres, especially the northern one, and crossing the tropics chiefly in mountainous districts. The insertion of the stamens within the base of the corolla, and not upon its tube, is pecnliar, among British Monopetals, to this Order and to Ericaceas; and from the latter, Campanulacea are easily known by their herbaceous stems, and the number of stamens always equal to, never double, that of the lobes of the corolla.

Corolla very irregular, split open on the upper side. Anthers closely colieriug

Corolla regular or nearly so. Anthers free or cohering at the base

1. LoBELIA. only.

Segments of the corolla deep and narrow.linear. Flowers in beads or denso spikes.

Anthers united in a ring at the base. Heads small, heml. spherical distinct. Flower-buds cylindrical, curved. Bंeads

Anthers distinct. Flower-buds cylindrical, curved. Heads

Lobes of the corolls broad and ahort

2. JABIONE.

3. Р日 ptecra.

4. Campanula 
Trachclium camulcum, a south European plant of early cultivation in onr flower-garlens, belongs to the same family. The Australian Goodenias, Scarrolas, and their allies, of ten seen in our greenhouses, form a small family, which may almost be considered as a tribe of Campanulacce.

\section{LOBELIA. LOBELIA.}

Flowers in terminal racemes, usually leafless or nearly so. Corrolla very irregular, more or less eleft on the upper side, with 5 lobes usually forming 2 lips; the 2 upper lobes smallest, and erect or recuried: the 3 lower ones sprealing, and less deeply divided. Authers united in a tube round the style, often hairy, or the 2 lower ones bearded at the top.

A numerous genus, widely spread over the globe, and set wanting in the greater part of the continent of Europe and northern Asia. Several North American species, with brilliant scarlet or purple flowers, as well as Cape or Australian ones with blue flowers, are much cultivated.
Aquatic plant. Flowers dronping
Heath pl.unt. Flowers erect

1. L. Dortmanna, Linn. (fig. 612). I'atcr L. -An aquatic peren. nial, with tufts of nearly cylindrical, hollow, radical leaves 1 to 2 inches long, forming a dense green carpet at the bottom of the water, each tuft proceeding from a small thick stock, with filiform creeping runners. Flowering-stems erect and simple, rising about 6 or 8 inches above the surface of the water, almost leafless. Flowers pale blue, 6 or 7 lines long, drooping, in a simple, loose terminal raceme.

In shallows of lakes in northern Europe and America. Common in the lakes of Scotland and Ireland, and in the west of England, descending as far south as Shropsliire and South Wales. Fl. summer. [The leaves are formed of two tubes placed side by side, the flowering stem of one tube.]

2. L. urens, Linn. (fig. 613). Acrid L.-Rootstock perennial, shortly creeping, with obovate or oblong radical leaves. Stems simple or slightly branched, erect, 1 to $1 \frac{1}{2}$ feet high, bearing in the lower half lanceolate, slightly toothed leaves, and in the upper part a long slender raceme of erect, purplish-blne flowers, about the size of those of $L$. Dortmanna.

In moist heaths, in western Enrope, from Andalusia to western and central France. In Britain, only in Dorsetshire and Cornwall. Fl. end of summer and autumn.

\section{JASIONE. JASIONE.}

Flowers blue, in small, terminal, hemispherical heads, surrounded by an involucre of several bracts. Calyx reduced to 5 very narrow, slender lobes. Corolla regular, deeply divided into 5 narrow segments. Anthers nnited at the base into a ring round the long club-shaperl st yle.

Besides our British species, the genus contains 2 or 3 allied perennials, chiefly from the mountains of central southern Europe and western Asia. The flower-heads of this genus show the nearest approach to Composita, from which the many-seeded capsules at once distin. zuish it. 
1. J. montana, Linn. (fig. 614). Sheep's-bit.-Root annual or biennial, bearing in the latter case tufts of radical leaves which live through the winter. Stems sometimes short and decumbent or ascending, sometimes nearly erect, a foot high, with a few spreading branches. Leaves linear or lanceolate, waved on the edges, and more or less hairy. Flower-heads, in the British variety, about half an inch diameter, on long terminal peduncles; the involucral bracts broadly ovate, the flowers or florets small, of a rather pale blue, on short pedicels.

In beathy pastures, on banks, \&c., throughout Europe, except the extreme north, and eastward to the Caucasus. Extends almost all over England and Ireland, but not north of mid Scotland. Fl. summer. On the Continent the size of the flowers and habit of the plant are very variable.

\section{PHXTEUMA. RAMPION.}

Flowers (in the British species) in compact terminal heads or spikes. Corolla when in bud cylindrical and curved, opening more or less into 5 long-linear segments. Anthers free and distinct. Styles cleft at the top into 2 or 3 stigmatic lobes. Capsules crowned by the spreading teeth of the calyx, and bursting at the sides.

A small genua, spread over Europe and western Asia, but chiefly in the great cents al mountain-chains, ascending to great elevations. It is readily knov $a$ by the long, curved flower-buds.

Flower heads g' ubular . - . 1. P. orbiculare. Flower-heads - olong, becoming at length cylindrical : : 2. P spicatum.

1. P. O) oiculare, Linn. (fig. 615.). Round-headed R.-Rootstock thick or , nortly creeping, with simple, erect or slightly decumbent stems, 6 .o 18 inches high. The early radical leaves are ovate and corclat., on long stalks, the suksequent ones and lower stem-leaves stalkf $\mathcal{d}$, but narrow-oblong or lanceolate; the upper ones few, narrow, and sessile. Flowers of a deep blue, in a globular terminal head of nesrly an inch in diameter, surrounded by a few short, broadly lanceolr.te bracts.

In pastures, throughout central and southern Europe, but not extending into Scandinavia. In Britain, only on the chalk downs of southern England, from Kent to Wilts. Fl. summer.

2. P. spicatum, Linn. (fig. 616). Spiked R.-A taller and stouter plant than the last, with longer and broader leaves, the lower ones 2 to 4 inches long and an inch or more in breadth, on stalks of 3 or 4 inches; the upper ones few, smaller and narrower. The flowers form at first an ovoid head, which soon becomes a dense spike 2 inches or more in length. The corollas of a very pale dull blue or yellowishwhite.

In hilly pastures and woods, widely spread over central, and especially south-central Europe, extending northwards into Norway. In Britain, only about Waldron, in eastern Sussex (native ?). Fl. summer. 


\section{CAMPanUla. CAMPANUla.}

Flowers in panicles, racemes, or spikes, sometimes contracted into short leafy heads, or rarely solitary. Corolla regular or nearly so, bellshaped, broadly tubular or rotate, with 5 broad or lanceolate lobes. Anthers distinct. Style 2-, 3-, or 5-cleft at the top. Capsule crowned by the teeth or lobes of the calyx, and opening laterally or at the top.

A numerous genus, widely spread over the globe, chiefly in the northern hemisphere or in the mountain-ranges of the hotter regions, with a few extratropical southern species. Taken as a whole, it is a natural and readily recognised group, but diversities in the opening of the capsule, and minor points, have induced botanists to subdivide it into three or more separate genera. Their characters are, however, so little in accord with their general habit, that, in a local Flora, they may be more conveniently considered as sub-genera or sections.

Calyx-tube and eapsule long and narrow. Corolla rotate (SPECUlakia) . . . . .

Calyx-tube short and broad. Corolla bell-shaped.

Delicate, prostrate plant, with nearly orbicular, angularly toothed leaves. Capsule opening at the top (WAHLEN. BERoin)
Btems erect or ascending. Upper leaves narrow or pointed Capsule opening at the sides. (CaMPanula proper.)

Stem-leaves linear or linear lanceolale, entire or nearly so.

Lobes of the eorolla as long or nearly as long as the tube. Anuual or biennial, with slender spreading branchies and few fluwers. The corolla rather large and very oplen. Ereet, stiff perenvial, with long racemes of rather small flowers

Lobes the ${ }$. stem-leaves ovale lanceolate or heart-shaped and tonthed.

Flowers two or more together in the uppor axils or in tor. minal heads or clusters.

Flowers closely sessile, tn cumpact heads.

Flowers shortly stalked, in rathor loose cluster: terminal racene.

Flowers (inlddle-sized) in a long terminal raceme, with sliort floral léuves

Flowers few and large, the lower oves in the axils of leaves longer than thenselves.

Lower stem-leaves stalked, but tapering at tho base

Lower tem-leaves stalked, and heart-shaped at the buse.

9. C. hybrida

8. c. hederacea.

0. C. patula.

5. C. Rapunculus.

7. C. rotundijolia.

1. c. glomerata

2. C. Trachelium.

4. C. rapunculoides.

8. C. Latifolia.

2. C. Trachelium.

Many species of Campanula have long been garden favourites for the beauty of their flowers; such are the Canterbury-bell ( $C$. medium), $C$. pyramidalis, bctonicafolia, garyanica, carpathica, persictfolia, \&c. 'The latter species widely distributed over the Continent, and nort hern Asia, and, easily maintaining itself when once planted, has been inserted in our Floras, but it has not anywhere spread permanently.

1. C. glomerata, Linn. (fig. 617). Clustered C.-Kootstock short, more or less creeping. Stem firm, erect, a foot high or rather more and hairy. Radical and lower leaves stalked; the remainder sessile, broadly lanceolate, clasping the stem by their cordate base, and roughly hairy. Flowers sessile in small clusters in the upper leaves, the upper ones forming a compact leafy head. Corolla blue, about half an inch long or rather longer. Capsules short and broad, crowned by the 
narrow leafy teeth of the calyx, and bursting open by small clefts at their base.

In rather dry pastures, throughout Europe and Russian Asia, except the extreme north. Extends over the greater part of England, but is rare in the western counties and in Ireland, and is found only in eastern Scotland. $F l$. summer. In very dry soils it often becomes much dwarfed.

2. C. Trachelium, Linn. (fig. 618). Nettle-leaved C.-A variable species, sometimes approaching in appearance the smaller specimens of $C$. latifolia, sometimes with the upper flowers almost contracted into a head or cluster like $C$. glomerata. Lower leaves on long stalks, always broadly heart-shaped and coarsely toothed; the upper ones small and ovate-lanceolate. Flowers large, 2 or 3 together in short leafy racemes in the upper axils or at the summit of the stem, or sometimes solitary, as in C. latifolia ; the calyx stiffly hairy, with broadly-lanceolate segments.

Its stations and geographical range are nearly the same as those of C. latifolia, extending all across Russian Asia, but it appears to be more generally diffused in western Europe. It is also rather common in some parts of England, and found in Scotland as far north as Lanark and Fife ; in Ireland, in Kilkenny only. Fl. summer.

3. C. latifolia, Linn. (fig. 619.) Giant C.-A tall, handsome species, with nearly simple stems; the leaves ovate-lanceolate, pointed and toothed, often 6 inches long and at least 2 inches broad, all narrowed at the base, and the lower ones stalked. Flowers large, blue or white, solitary in the axils of the upper leaves, forming a leafy raceme, the uppermost exceeding their leaves. Capsules short, crowned by the long-lanceolate caly $x$-segments, and opening by short clefts at the base.

In the woods of northern Europe and Russian and central Asia, and extending to the Arctic regions, but rather a mountain plant in southern Europe. Frequent in central and southern Scotland, and northern England, rare in the south, and not a native of Ireland. Fl. summer.

4. C. rapunculoides, Linn. (fig. 620). Creeping C.-Rootstock more creeping than in the other species, with a simple erect stem 1 to 2 feet high. Lower leaves on long stalks, and heart-shaped; the npper ones small, ovate-lanceolate. Flowers drooping, not so large as in the last two species, but varying in size; they grow singly in the axils of small floral leaves, forming long, terminal, simple racemes. Capsules nearly globular, crowned by the linear or narrow-lanceolate lobes of the calyx. and opening by small clefts at the base.

In open woods, in central and southern Europe and western Asia. Having been early cultivated in gardens, and when once planted in genial soil becoming often difficult of extirpation, it is doubtful how far it may be indigenous in the more northern stations given for it. In Britain, admitted as a native of a few localities distantly scattered over England and Scotland, but evidently naturalised. $F l$. summer.

5. C. Rapunculus, Linn. (fig. 621). Rampion, Ramps.-An erect, stiff, but rather slender perennial, more or less covered with stiff white hairs, which almost disappear when cultivated. Radical leaves oblong or ovate, on long stalks, and slightly crenate; the stemleaves narrow and mostly entire. Flowers small, on short peduncles, forming long, simple or slightly branched terminal racemes; the 
corolla divider to about the middle into 5 lanccolate segments, but not near so lirge nor so open as in C. patula. Capsule short and erect, opening in small lateral clefts close under the narrow-linear segments of the calyx.

On banks, roadsicles, and open pastures, in central and southern Europe to the Caucasus, becoming scarcer farther north, and in many places probably only escaped from cultivation. In Britain it used to be commonly raised in kitchen gardens for its tuberous roots, and it is uncertain whether it should be held as a true native in those localities in southern England where it is now established. Fl. summer.

6. C. patula, Linn. (fig. 622). Spreading C.-An erect, but rather slender annual or biennial, about a foot high, and slightly hairy, with spreading branches. Radical leaves obovate or oblong and stalked; the stem ones few, narrow-lanceolate or linear, nearly entire. Flowers few, rather larger than in $C$. rotundifolia, in a spreading panicie; the corolla much more open, of a more purplish colour, and diviled to the middle into 5 broad, pointed lobes. Capsule obconical, erect, and opening in short clefts close under the long, linear segments of the calyx.

Under hedges, on banks, and in bushy pastures, over the whole of Enrope, except the extreme north, extending to the Caucasus and to the Ural. In Britain, chiefly confined to the central and southern counties of England. Fl. summer.

7. C. rotundifolia, Linn. (fig. 623). Ilarebell.-A perennial, with a slender, creeping rootstock, often very intricate; the radical leaves, which mostly die away at the time of flowering, orbicular or heartshaped; those of the stem all narrow-lanceolate or linear, and entire. Stems ascending or erect, 6 to 18 inches high, often branched, with a few elegantly drooping blue flowers in a loose raceme or panicle, or sometimes solitary. Corolla bell-shaped, with 5 broad lobes much shorter than the tube. Capsule ovoid or globular, pendulous, and opening by short clefts close to the base.

In hilly pastures, on heaths, banks, and roadsilles, the comrnonest species in Europe and Russian Asia, from the Mediterranean to the Arctic Circle, and ascending to great elevations; also common in the northern United States ard Canada. Abundant all over Britain. $\mathrm{Fl}$. summer and autumn.

8. C. hederacea, Linn. (fig. 624). Ivy C.-A little graceful, prostrate perennial, witt very slender, thread-like branches, and small delicate leaves, mostly orbicular, or broadly heart-shaped, with a few broad, angular teeth. Flowers on long filiform peduncles, drooping in the bud, nearly erect when fully ont, and often drooping again as the fruit ripens. Corolla not half ar inch long, narrow-bell shaped, of a delicate pale-bluish purple. Capsule almost globular, opening in 3 valves at the top between the calycine teeth, on which account the species is placed by modern botanists in the genus Wahlenbergia, Schrad.

In moist, shady pastures, and woods, chiefly along rills and banks. Abnndant in the extreme west of Europe, extending through central France, eastward to the Rhine. In Britain, common in sonth-eastern I reland and western and sonthern England, as far north as the Isle of Man, and more sparingly in the east, from Sussex in the south to 
Yorkshire in the north; in Scotland it extends from Argyle to Ayrshire Fl. summer und autumu.

9. C. hybrida, Linn. (fig. 625). Corn C.-A nearly simple annual, erect or decumbent, branched at the base, 6 to 8 inches high, and rather hairy. Leaves oblong, much waved at the edges. Flowers sessile in the axils of the upper leaves, remarkable for their long, narrow, triangular ovary and capsule, crowned by the linear of oblong leafy segments of the calyx. Corolla blue, much shorter than the calyx, and very open. The capsule opens by short clefts, close under the segments of the calyx. Seeds very bright and shining. Specularia hybrida, DC.

A cornfield weed, apparently of southern origin, but now widely spread over a great part of Europe. Not uncommon in the cornfields of eastern central and southern England, and appears occasionally in the north and in some parts of Scotland, but has not been found in Ireland. Fl. with tie corn. The Venus's looking-glass of gardens ( $C$. Speculum) is a nearly allied species, common on the Continent, with the same long capsule, but a much larger corolla, flat, and exceeding the lobes of the calyx. These plants are now usually placed in a distinct genus (Specularia, Heist.).

\section{ERICACEÆ. THE HEATH FAMILY.}

Shrubs, sometimes very low, creeping, and almost herbaceous, or occasionally growing into small trees, with entire or toothed undivided leaves, and flowers usually drooping, either solitary or in small clusters or racemes in the axils of the leaves, or forming short, terminal, leafy racemes. Calyx of 4 or 5 divisions, either free or with a tube adhering to the ovary. Corolla inferior or superior, usually ovoid or globular, sonietimes small and campanulate, with 4 or 5 lobes or (in the two last anomalous genera) with 4 or 5 nearly distinct petals. Stamens twice as many, or rarely the same in number as the lobes of the corolla, and inserted within the corolla but distinct from it; anthers opening at the top with two pores, or (in Monotropa) with transverse valves. Ovary having usually as many (rarely apparently twice as many) cells as the lobes of the corolla. Fruit a capsule or berry, with one or several seeds in each cell; the seeds very small, with a fleshy albumen.

A large Order, widely spread over the globe (excepting Australia), especially in the temperate and colder regions, and in hilly districts within the tropics. It is distinguished from all British Monopetals, except Campanulacce, by the insertion of the stamens, and from the latter Order by the shrubby habit, the shape of the flower, and especially by the anthers usually opening in 2 small terminal pores. 
Calyx-tube adherent. Corolls superior. Leaves alternate, of ten toothed

Bepals free. Corolla inferior.

Undershrubs, shrubs or trees. Corolla lobed.

Fruit a berry. Leaves alternate, often toothed.

Tall shrub, or tree. Cells of the ovary with several ovules in each . . . . . . .

Low, creeping shrubs. One ovule in each cell of the

Fruit a dry capsule. Leaves usually simall and entire.

St:mens 5. Leaves very small, opposite . . . . 5. LotSeleuria.

Stamens 8.

Corolla deciduous. Leaves scattered, white underneath $\cdot{ }^{\circ} \cdot \dot{C}^{\circ}$

Corolla persistent, 4-toothed. Leaves opposite or whorled.

Corolla persistent, 4-partite. Leaves opposite

2. Arbutus.

3. ARCTOSTAPEYLOa.

6. Menziesia.

7. Erica.

8. Callena.

Stamens 10. Leaves alternate.

Capsule opening by slits in the middle of the cells. Flowers pink.

Capsule opening by the splitting of the partitions. Flowers purplish-blue.

Herbs. Petals free or nearly 8 .

Iesves radical or nearly so. Scape leafless . . . . 9. Prrola.

Jeaves reduced to seales of the sume colour as the stem $\quad 10$. Mosotkopa.

The Rhododendrons, Azaleas, Kalmias, and other genera of our socalled American gardens, belong also to the Ericacce, which comprises perhaps more ornamental hardy shrubs than any other Order. The Epacrises and allied plants which flower in such perfection in our greenhouses in early spring, form a closely allied family, which replaces Ericacece in Australia.

\section{VACCINIUM. VACCINIUM.}

Low shrubs, with alternate leaves, and flowers usually solitary, or only 2 or 3 together. Calyx with a short tube adhering to the ovary, and 4 or 5 small teeth. Corolla superior, with as many teeth or divisions. Stamens twice as many. Berry globular, with several seeds (or, at any rate, sereral ovules in the young state) in each cell.

A numerous genus in mountainous districts or boggy heaths, over a great part of the globe, now usually considered as forming a distinct family, separated from Ericacea by the inferior ovary; but this character, however important it may be in many cases, is, in this instanee, very artificial. Vaccinium has also been divided into numerons genera, chiefly by the form of the corolla; and many of them, including the brilliant Thibaudias, occasionally grown in our stoves, are now generally adopted.

Stems erect or decumbent at the base. Leaves deciduous, Anthers with 2 littlo awns or points on the back. Berrles black and bluish.

Branches angular. I.eaves toothed

Brunches terote. Le: ves entire

Stems prostrate or creeping. Leaves evergreen. "Anthers with. out awns, Berries red.

Leave obovate, firm. Corolla campanulate

Leave omall, ovate or lanceolito. Stem sleinder. Coroll: epreading, with refloxed lobes.

1. V. Myrtillus.

2. V. uliginosum.

i. V. Myrtilllus, Linnn. (fig. 626).

Bilberry, Blaeberry, Whortlcberry. 
-A small glabrous shrub, with numerous erect or spreading, angular, green branches, 6 inches to a foot high, or rather more. Leaves deciduous, ovate, often slightly cordate at the base, seldom an inch long, bordered with small teeth, and scarcely stalked. Flowers nearly globular, of a pale greenish-white, with a tinge of red, growing singly on short recurved pedicels in the axils of the leaves. Berry globular, nearly black, covered with a glancous bloom, and crowned by the short teeth of the calyx.

In mountain heaths and woods, in northern and central Europe and Russian Asia, restricted to great mountain-ranges in southern Europe, and usually occupying large tracts of land. Common in Britain, with the exception of the eastern counties. Fl. spring.

2. V. uliginosum, Linn. (fig. 627). Bog V.-A smaller plant, more woody and branched than $V$. Myrtillus, with smaller, obovate, or orbicular leaves, quite entire, but thin, deciduous, and much veined, as in that species. The branches are cylindrical, or have scarcely perceptible angles, and are much shorter and not so straight. Flowers rather smaller; the berries very similar in size and colour.

In mountain heaths and bogs, in nort hern and central Europe, Russian Asia, and northern America ; generally restricted to greater elevations than V. Myrtillus. Common in the Highlands of Scotland, and the northern counties of England, but not recorded from Ireland. Fl. spring.

3. V. Vitis-idæa, Linn. (fig. 628). Red Whortleberry, Cowberry.Stems much branched, procumbent, and straggling, with numerous evergreen obovate or oblong leaves, like those of the $B 0 x$. Flowers several together, in short, dense, terminal, drooping racemes. Corolla of a pale flesh-colour, campanulate, with spreading but not reflexed lobes. Berries resembling those of the Cranberry, for which they are somctimes sold.

In dry, rocky moors and heaths, and open woods, in northern and central Europe, Russian Asia, and North America, becoming a mountain plant in southern Europe. In Britain, spread over Scotland, northern and western England, Wales, and Ireland. Fl. early summer.

4. V. Oxycoccos, Linn. (fig. 629). Cranberry.-Stem creeping, and very much more slender and wiry than in any of the preceding species. Leares small, evergreen, ovate or lanceolate, with their edges rolled back, and the under side very glaucous. Flowers drooping, on long, slender peduncles, which have a pair of small bracts below the middle. Corolla deeply divided into 4 lobes, which are very spreading or turned back, exposing the stamens. Berry globular, red, crowned by the 4 short teeth of the calyx.

In peat-bogs, in northern Europe, Asia, and America, and in the high mountain-ranges of central Europe, but not recorded from the Cancasus. In Britain, thinly scattered over the chief part of our islands, but less plentiful than formerly from the drainage of waste lands. Fl. summer. It is often considered as forming a distinct genus on account of the shape of the corolla. 


\section{ARBUTUS. ARBUTUS,}

Shrubs or troes, with alternate, entire or toothed, evergreen leaves; the flowers in terminal panicles. Calyx inferior, of 5 small sepals. Corolla ovoid, enelosing the 10 stamens. Ovary of 5 cells, with several ovules in each. Fruit an indehiscent berry.

A small genus, chiefly American, with 2 or 3 Asiatic species, one of which extends into Europe. The A. Andrachne, from western Asia, and A. proccra, from north-west America, are often planted in our gardens.

1. A. Unedo, Linn. (fig. 630). Arbutus, Strawberry-tree.-An evergreen shrub or bushy tree, the young shoots often hairy, but otherwise glabrous. Leaves shortly stalked, ovate or oblong-lanceolate, toothed, shining on the upper side, 2 or 3 inches long. Flowers in small, drooping terminal panicles, scarcely so long as the leaves, of a greenish white, often tinged with pink. Berry red, globular, and granulated, so as at a distance to resemble a strawberry, but without flavour.

Frequent in lilly districts of southern Europe, extending eastward almost if not quite to the Caucasus, and along the western coast of Europe to Ircland, where it is abundant about the lakes of Killarney and near Glengariff, but not indigenous to any part of Great Britain. Fl. autumn.

\section{ARCTOSTAPHYLOS. BEARBERRY.}

Low, creeping, or straggling shrubs, with alternate, entire or toothed leaves, and rather small flowers, 2 or 3 together, in short terminal racemes. Calyx, corolla, and stamens of Arbutus, but the ovary has but 1 ovule in each cell. Fruit a berry, with 5 or fewer seeds.

A considerable American genus, with a very few Asiatic and European species.

Leaves evergreen, shining, and Box-like . . . . . . 1. A. Uva-ursi. Lenves strongly veined, withering away at the end of tue year 2. A. alpina.

1. A. Uva-ursi, Spreng. (fig. 631). Common B.-The plant has some resemblance to the Cowberry, but is at once known by the free ovary and fruit, the sepals being at the base of the berry, not crowning it. The procumbent stems form large masses with numerous shining evergreen, obovate or oblong leaves, quite entire, and seldom an inch long. Flowers much like those of the Arbutus, but smaller, from 4 to 6 together, in compact, drooping terminal racemes. Berries globular, of a bright red, smooth and shining.

On rather dry, heathy, or rocky hills, often covering considerable tracts of ground, and extending over a great part of central and northern Europe, Asia, and America, to the Arctic Circle. In Britain, confined to Scotland, northern England, and lreland. Fl. spring.

2. A. alpina, Spreng. (fig. 632). Black B.-A low, creeping shrub, with shorter and more herbaceous branches than those of the last apecies; the leaves rather narrower, and very different in consistence, being thin, strongly veined, toothed at the top, and withering away at the end of the season. Young shoots surrounded by the scales of the las-bzds, which remain long persistent. Flowers small, usually 2 or 8 togather, on short, drooping pedioes. 
A high alpine or Arctic plant, common in the mountains of northern Europe, Asia, and America, and at high altitudes in the central chains of the two former continents. In Britain, only in the central and northern mountains of Scotland, extending to Shetland. Fl. spring.

\section{ANDROMEDA. ANDROMEDA.}

3mall shrubs or herb-like undershrubs, chiefly growing in peat-bogs, Ath the flowers of an Arbutus, but a dry capsular fruit opening in as many entire valves as it has cells, by slits placed in the middle of the cells, not by the splitting of the partitions as in Menziesia, each cell sontaining several seeds.

A small genus, limited by some modern botanists to the single British species, but nsually extended so as to comprise several other North American, as well as Asiatic and European species.

1. A. polifolia, Linn. (fig. 633). Marsh A.-A low, brancling, herb-like shrub, seldom above 6 inches high, and quite glabrous. Leaves alternate, $\frac{1}{2}$ to 1 inch long, oblong-lanceolate, evergreen, with their edges rolled back, and very glaucous underneath. Flowers on rather long pedicels, in short, terminal racemes or clusters; the calyx small, deeply 5-lobed; the corolla pale pink, ovoid, enclosing the 10 stamens.

In peat-bogs in northern Europe, Asia, and America, to the Arctic regions, and in the great mountain-chains of central Europe. In Britain confined to central and northern England, southern and central Scotland and Ireland, but absent from the Scotch Highlands, where the plants of similar Continental distribution are usually found. $F l$. all summer.

\section{LOISELEURIA. LOISELEURIA.}

A low, trailing shrub, with small opposite leaves. Sepals 5. Corolla tampanulate, 5-lobed. Capsule free, with 2 or 3 cells, opening in as many valves by the splitting of the partitions, and containing several seeds.

The single species of which this genes consists was included by Linnæus among his Azaleas, and some botanists retain that name for it, proposing to give that of Anthodendron to the showy shrubs so well known as Azalcas in our American gardens, but such a change would entail great useless confusion in synonjmy, and the name of Loiscleuria is now generally adopted, at least by Continental botanists. [Moreover the name Azalea was applied by Linnæus primarily to the Indian plant of that name, and has been retained by almost all succeeding botanists for it and its allies, which only differ from many Rhodoclendrons in their deciduous leaves. Loiseleuria differs from all these in its opposite leaves, and in its anthers opening by lateral slits.]

1. I. procumbens, Desv. (fig. 634). Loiselcuria.-Leaves numerous, evergreen, only 2 or 3 lines long, ovate or oblong, shining on their upper side, with the edges rolled back. Flowers small and rosecoloured, in short terminal clusters. Valves of the capsule usually shortly split at the top. Azalea procumbens, Linn. 
On mountain moors, in northern and Arctic Europe, Asia, and America, and in the high alpine chains of central Europe. In Britain only in the Highland mountains from Ben Lomond northwards, Flo spring.

\section{MENZIESIA. MENZIESIA.}

Heath-like, low shrubs, with scattered leaves, and blue or pink flowers, in terminal racemes. Sepals 4 or 5 . Corolla deciduous, ovoid, with 4 or 5 short lobes. Stamens 8 or 10 . Capsule free, with 4 or 5 cells, opening in as many valver, by the splitt: «ag, of the partitions.

A small northern and west European genus, artificially distinguished from Andromeda by the manner in which the capsule opens, from Erica by the deciduous corolla, from Loiseleuria by the number of stamens. It has been divided into almost as many genera as there are species.

Flowers pink, with 4 lobes. T,eaves white underneath . . 1. Mr. polifolia. Flowers blue, with 5 lubes. Leaves green on both sides : . . 2. M. carulea.

1. M. polifolia, Sm. (fig. 635). St. Dabcoc's Ileath.-A low shrub, rather straggling at the base, with ascending flowering branches, clothed with short, rather viscid hairs. Leaves small, the lower ones ovate, the upper ones narrow, all green above, and very white underneath. Flowers very elegant, nearly 6 lines long, pink, or sometimes white, drooping from short pedicels, in a loose terminal raceme. Corolla with 4 very short, spreading lobes. Stamens 8. Capsule 4-celled. Dabeocia polifolia, Don.

A strictly west European plant; common on the heathy wastes of the Asturias and south-western France, and extending up to Connemara in Ireland, but unknown in Great Britain. Fl. summer.

2. M. cærulea, Sm. (fig. 63b). Blue M. -A small, much branched shrub. Leaves evergreen, crowded, linear, green on both sides, and bordered with minute glandular teeth, scarcely visible without a magnifying-glass. Flowers of a purplish blue, on long pedicels, clustered 3 or 4 together, in very shart terminal racemes or umbels. Corolla 4 or 5 lines long, with 5 very short lobes. Stamens 10 . Capsule 5 . celled. Phyllodoce taxifolia, Salisb.

On mountain heaths, in northern and Arctic Europe, Asia, and America, In Britain only on the mountain, called the Sow of Atbol, in Perthshire, where it is exceedingly rare. Fl. summer.

\section{ERICA. HEATII.}

Much-branched shrubs, usually low, but in some species attaining 8 or 10 feet, with small, entire leaves, usually in whorls of 3 or 4 , but sometimes opposite or scattered, and almost always rolled back on their edges. Flowers either axillary or in short terminal racemes or clusters, mostly drooping. Sepals 4 , shorter than the corolla. Corolla ovoid, globular, or campanulate (in some exotic species tubular), more or less 4-toothed or lobed, and persisting round the capsule till its naturity. Stamens 8. Capsule free, with 4 cells, opening down tho back of the cells, each cell with several seeds 
A genus of about 400 genuine species, besides the innumerable garden hybrids and varieties. Its geographical range is eminently Atlantic. The greater number of species come from sonth-western Africa, where few extend to the eastward. In Europe also Ileaths are strictly western, with the exception of two or three species which extend eastward along the sandy wastes of northern Europe, or round the Mediterranean to the frontiers of Asia. The genus is other. wise unknown in Asia, America, or Australia.

Anthers ineluded within the corolla.

Corolla nearly inch long, obliquie at the mouth. Anthers without awns

Corulla about $\frac{1}{t}$ inch long, straiglit at the mouth. Anthers with 2 awns, or little appendages at the insertion of the filament.

Leaves 3 in a whorl. Flowers, numerous, in oblong or elongated racemes . .

Leaves 4 in a whorl. Flowers few in terminal clusters or umbels

3. B. eiliaris.

Anthers protruded from the corolla, withoit a wns or appen: dages.

Corolla campanulate or nearly globular. Sepals sloort. An-

thers short, with slender filanents. Antliers oblong, with
Corolla narrow-ovoid. Sepals linear. Ants

1. B. einerea.

2. F. Tetralix.
5. E. vagans.

4. E. carnea.

1. E. cinerea, Linn. (fig. 637)。 Bell Ileather.-A small bush. Leares linear, finer and more pointed than in any of our other Heaths, and usually 4 in a whorl, with clusters of small leaves in their axils. Flowers numerons, of a reddish purple, in very showy, dense terminal racemes. Sepals small and nariow. Corolla ovoid, about 3 lines long, straight at the mouth, with 4 very small lobes or teeth. Stamens enclosed in the corolla, with small toothed appendages at the insertion of the anther on the filament.

Common in western Europe, from southern Spain to Norway. Ranges over Britain, covering immense tracts of country on the Scotch, Irish, Welsh, and some English moors. Fl. summer and autumn.

2. E. Tetralix, Linn. (fig. 638). Cross-leaved II.-Generally a lower plant than $E$. cinerea, bushy at the base, with rather short, ercet, flowering branches; the leaves in fours, shorter and less pointed than in that species, and ciliate with short stiff hairs, besides a short whitish down, which often clothes the branches and npper leaves. Flowers about the size of those of $E$. cinerea, but more pink in colonr, and forming little terminal clusters or close umbels. Appendages to the anthers entire, awnlike, and often nearly as long as the anthers themselves.

A strictly western species in southern Europe, but in northern Europe extends over Sweden and northern Germany to Courland and Livonia, but never so gregarious as $E$. cinerea. Ranges all over Britain, and very common in the west. Fl. summer, rather late. A very marked variety, with shorter and broader lcaves of a darker green, from Connemara, in Ireland, and also from the Asturias, has been distinguished nnder the name of Mackaiana (Bab.) as a species, and was formerly adopted as such by myself, but the numerous intermediate specimens I have since scen induce me now to consider it as a mere variety. Intermediate forms between this and $E$, ciliaris observed in Cornwall and Dorset, are natural hybrids. 
3. E. ciliaris, I.lnn. (fig. 639). Ciliated H.-A very handsome species, readily known br its raceme of highly coloured rosy flowers, of the size of those of Menzicsia polifolia. It is a straggling shrub, ciliated with short stiff hairs. Leaves 3 in a whorl, ovate. Flowers in short pericels in the axils of the upper leaves. Sepals small and ciliate. Corolla about 5 lines long, with a small, very oblique, 4-lobed mouth. Stamens enclosed in the corolla, without any appendages to the anthers.

A western species, on the Continent confined to west France, Spain, and Portugal. Also found in Cornwall, and Dorsetshire. Fl. early summer.

4. E. carnea, Linn. (fig. 640). Mediterrancan $I I$.-I.caves in fours or rarely in threes, linear but obtuse, firmer and thicker than in E. cinerea. Flowers axillary, forming leafy racemes either terminal or below the ends of the branches. Sepals linear-lanceolate and coloured. Corolla narrow-ovoid, about 3 lines long, of a reddish flesh-colour. Anthers protruding slightly from the mouth of the corolla, oblong, inserted by their lower ends on somewhat flattened flaments, without appendages.

The geographical range is different from that of most lleuths, being scattered here and there on the lower hills along the great central range of European mountains, from Switzerland to the Balkan, where it is usually, but not always, a rather low, almost straggling shrub. Descending to the shores of the Atlantic, it is there more erect, with rather smaller flowers, a form considered by many as a distinct species, $E$. meditcrranea, Linn. It reappears in boggy heaths of Mayo and Galway in Ireland, in a form intermediate between the extreme Continental varieties. It is not wild in Great Britain, but frequently cultivated. Fl. early spring.

5. E. vagans, Linn. (fig. 641). Cornish $I I$.-A rather low species, the leaves linear, in fours or sometimes in threcs, as in E. carnea. Flowers very numerous, axillary, on slender pedicels, forming tcrminal, oblong or elongated leafy racemes. Sepals short and obtuse. Corolla pink or almost white, rather small, campanulate when it first expands, but becoming nearly globular. Anthers very small, appearing double, protruding beyond the corolla upon slender filaments, withont appendages.

A gregarious species, often occupying large tracts of open country like $E$. cinerea; ranging all round the Mediterranean from Spain to Greece, Turkey and Egypt, and ascending along the Atlantic to Cornwall, but never penetrating very far inland. Fl. summer, rather early.

\section{ViII. CALLUNA. LING.}

A much branched, low shrub, with minute, imbricating, decussate leaves, and axillary small pinkish flowers, with 2 pairs of small blacts at their bases. Flowers as in Erica, but the calyx is as long as the corolla, which is cleft to the base into 4 segments, and the capsule opens by slits opposite the partitions. Cells 1 or 2-seeded.

1. C. vulgaris, Salisb. (fig. 642). Ling.-A straggling shrub, 1 to 3 feet high. Leaves very short, a little prolonged at the base below their insertion. Flowers often very pale or evep white, on short pedicels 
along the upper branches, forming irregular leafy racemes. Calyx coloured like the corolla, and concealing it. C. Erica, DC.

The most widely distributed of all the /leaths, extending over central and northern Europe to the Arctic Circle, eastward to the Ural, and westward to the Atlantic. Also occurring in the Azores, Grecnland, and very rarely in north-eastern Amcrica, in Labrador and Massachussets. In Britain very abundant. $F l$. summer. It varies in the same spot, either quite glabrous or more or less downy, or even hairy.

\section{PYROLA. WINTERGREEN.}

Low herbs, with a slender, shortly creeping stock ; orbicular or ovate, nearly radical leaves; and white or greenish, drooping flowers, either solitary or several in a short raceme, on leafless, erect j/ccluncles. Sepals 5, small. Petals 5, distinct or slightly joined at the base, forming at first a spreading cornlla, which persists round the young capsule, assuming a glohular shape. Stamens 10. Capsule 5-celled, opening by slits in the middle of the cells.

A small genus, confined to the northern hemisphere both in the New and the Old World, allied to Ericacece in all essential characters, although so different in habit and foliage. It has been divided by modern botanists into almost as many genera as it has species.

Flowers aolitary

Flowers scveral in a raceme.

l.eaves ovite, puinted. Fowers small, in a close, one-sided racerne :

Leaves ovate or
usually few.

Strle much longer than the corolla, and curved - . . 2. P. rotunulijolia.

Style longer than the corolla, and straight $\quad$ : $\quad 3$. P media.

Style not longer than the corolla . . . . . 4. P. minor.

1. P. uniflora, Linn. (fig. 643). One-flowered W.-Leaves of $P$. minor, but rather smaller. Flower rather large, always solitary on the peduncle, drooping, nearly white, and very fragrant; the petals ovate, slightly connested at the base. 'The pores of the anthers form little protruding tubes much more prominent than in the other species, although they are sometimes observable even in $P$. minor. Style nearly straight, with a broad 5-lobed stigma. Moneses grandiflora, Salisb.

In wools, in northern and Arctic Europe, Asia, and America, and along the high mountain-ranges of central Europe. In pine woods from Perth and Aberdeen northwards, found only in Scotland. $F$. summer.

2. P. rotundifolia, Linn. (fig. 644). Larger W.-A larger plant than $P$. minor, with larger and whiter flowers, and the petals more spreading, but chiefly distinguished from it by the long, protruding, much curved style, usually at least twice as long as the capsule, with a much smaller stigma, with short, erect lobes.

In similar situations and with nearly the same range as $P$. minor; extending farther into central Asia, even to the Himalaya, but not so frequent in Europe. Rare in Britain, though occurring in isolated spots between Kent and Inverness, and at Westmeath in Ireland. Fl. summer. [A remarkable variety ( $P$. maritima, Ken.), with smaller lesves, many 
practs on the peduncle, and broader sepals, is found on sandhills in Lancashire.]

3. P. media, Swartz. (fig. 645). Intermediate W.-Perhaps a mere variety of $P$. minor, and sometimes passing almost into $P$. rotundifolia. It difiers from the former chiefly by the style, which is considerably longer, although nearly straight, and never so curved as in $P$. rotundifolia. 'The size of the flower is variable.

The geographical range is much more restricted than that of any other of the species; it is confined to Europe, and in England is not found south of Warwick and Worcester, whence it extends to Shetland; it also is found in the north and west of Ireland.

4. P. minor, Linn. (fig. 646). Common IV.-Stock perennial, slightly creeping, retaining a few leaves during the winter intermixed with scales produced at the base of each year's shoot. Leaves on rather long stalks, collected 3 or 4 together in 1 or 2 tufts at the top of the stock, broadly ovate or orbicular, rather thick, entire or slightly crenated, with a minute tooth or gland in each notch, scarcely visible without a glass. Peduncle erect, from 4 or 5 inches to twice that height, leafless or with 1 or 2 small scales. Flowers drooping, in a short, loose raceme, not turned to one side as in the following species, each one in the axil of a small, narrow bract. Sepals short and broad. Petals ovate or orbicular, quite free, but concave and closing over the stamens, usually of a pale pink. Stamens shorter than the corolla. Style scarcely protruding or even shorter than the corolla, straight or nearly so, with a broad, 5-lobed, spreading stigma.

In woods and moist shady places, in Europe, northern Asia, and the extreme north of America, becoming a mountain plant in southern Europe and the Caucasus. Frequent in Scotland, northern England, more local in southern England; rare in Ireland. Fl. summer.

5. P. secunda, Linn. (fig. 647). Serrated W.-Leaves ovate, more pointed, and often more distinctly toothed and more prominently veined than in $P$. minor. Flowers smaller, more numerous and crowded, and all remarkably turned to one side. Sepals very small. Petals free, of a greenish white. Style long and nearly straight.

The geographical range is nearly that of $P$. minor, but it is more local, and generally more northern or more alpine, being rarely found in central and southern Europe out of the ligher mountain-ranges. In Britain it is vers local, but found in Monmouthshire, and from Yorkshire northward to Ross-shire. It is very rare in the north-east of Ireland only. Fl. summer.

\section{MONOTROPA. MONOTROPE.}

Simple, erect, rather succulent herbs, of a pale brown or yellowish colour, leafless with the exception of small scales of the colour of the stem, resembling Orobanche, and probably parasitical on the roots of trees. Sepals 4 or 5 , free or united at the base. Petals as many, free or united at the base. Stamens twice a many. Anthers opening by transverse slits or valves, not by pores as in the rest of the family. Capsule of 4 or 5 cells, opening by slits opposite the middle of the cells Style single, with a broad terminal stigwa. 
A genus of very few species, inhabiting the woods of Kurope, Asia, and America, obviously allied to Pyrola, but readily distinguished by the want of green leaves. As in the case of Pyrola, it has been divided Into almost as many genera as there are species.

1. M. Hypopithys, Linn. (fig. 648). Y'ellow Bird's-nest.-Stem about 6 or 8 inches high, often rather downy in the upper part, bearing oblong or ovate concave scales instead of leaves. Flowers few, in a short terninal raceme. Sepals and petals nearly of the same size, ovate or oblong, glabrous or slightly downy inside, persisting round the capsule. Anthers small, on slender filaments, opening by transverse valves. Thie terminal flower has its parts in fours, the lateral ones in fives. The whole plant is of a pale yellowish-brown colour, turning black in drying. Ilypopithys multiflora, Scop.

In fir, birch, and beech woods, in Europe, north Asia and North America, becoming a mountain plant in southern Europe, but extends neither to high northern latitudes nor to great elevations in the Alps. Scattered over nearly the whole of England, but only found in some of the southern counties of Scotland, and very rare in Ireland. $F l$.

summer.

\section{PRIMULACEE. THE PRIMROSE FAMILY.}

Herbs, with leaves undivided except when under water; the flowers either axillary or in terminal racemes or umbels. Calyx usually of 5 , sometimes 4,6 , or 7 divisions or teeth. Corolla regular, more or less deeply divided into as many lobes or teeth as divisions of the calyx, or rarely wanting. Stamens as many as the lobes of the corolla, inserted in the tube opposite the centre of the lobes, or where there is no corolla, alternating with the lobes of the calyx. Capsule single, 1-celled, containing several seeds attached to or immersed in a free central placenta, which is often thick and globular. Style single, with a capitate stigma.

A widely spread family, inhabiting chiefly the northern hemisphere, and especially high mountains, often at very great elevations. A few species reappear in the Antarctic regions, and even within the tropics, but the group is there represented chiefly by the Myrsinacee, which scarcely differ, except in their arboreous or shrubby growth. Both these families are chiefly distinguished from other regular-flowered Monopetals by the stamens being opposite to, not alternate with, the lobes of the corolla. This character requires some care in observing it, especially in those species of Lysimachia which have a deeply divided, rotate corolla, and the stamens erect in the centre of the flower.

Aquatic plant, with the leaves all submerged and pluuate, with linear lobes

Terrestrial plants, leaves undivided.

Leaves opposite, whorleal or rarely alternate Flowers axillary or

1. Hotrunla. rarely terminal. 
Stamens aud divisions of the flower in fours

8. Centunculus

Stamens and divisions of the flower in fives.

No corolla. Calyx pink ish

Both caly $x$ and corulla.

Capsulo opening at the top. Flowers yellow

Capsule opening transversely. Flowers blue or red

Leaves allernate or ralical, or the upper ones irregularly whorled. Flowers terminul.

Lesves all radical. Flowers solitary or umbellate, on radical peduncles. Tube of the corolla distinct.

Tube of the corolla cylindrical, lobes spre:iding. No tuber.

Tube of the corollia nearly globular, lobes refiexed. Rootstoek tuberous

2. Primula.

3. CrClasign. Btem leafy.

leaves in one termin:sl whers, with a few alternate ones below. Peduncles few, terminal, 1-flowered. Corolla

Leaves all siternate. Flowers small, white, in a terminal raceme

The Dodecatheon, or American Covslip, of our gardens, belongs also to Primulacece. The allied family of Myrsinacece, mentioned above, is com. monly represented in our greenhouses by a spccies of Ardisia.

\section{HOTTONIA. IIOTTONIA.}

Aquatic herbs, with submerged, pinnatifid leaves, and flowers in whork forming a terminal raceme; differing from Primula in the more deeply divided calyx, and in the eapsule, which opens by lateral slits instead of terminal teeth.

Besides our own species, the genus only comprises a single North American one.

1. H. palustris, Linn. (fig. 649). Waler Violet, Featherfoil.-Stock perennial and creeping, with whorled leafy branches entirely submerged ; the leaves alternate and deeply pinnatifid, with narrow-linear lobes. From the centre of the whorl a single, erect, leafless flower-stem arises out of the water, bearing at intervals whorls of from 3 to 5 of b handsome, pale-purple flowers, on short pedicels, each with a small bract at its base. Caly $\mathrm{x}$ of 5 deep, linear divisions. Corolla with a straight tube, rather shorter or scarcely longer than the calyx, and a broad, 5-lobed limb.

In pools and channels, in central and northern Europe, but not extending to the Aretic Circle. Very local in western England, more common in the central and eastern districts; in Ireland, County Down only, and not found in Scotland. Fl. early summer.

\section{PRIMULA. PRIMROSK.}

Heabs, with radical leaves; the flowers either solitary or in a terminal nmbel, on leafless, radical peduncles. Calyx tubular or campanulate, with 5 teeth or lobes not reaching to the base. Corolla with a straight tube, and a spreading, 5-lobed limb, each lobe often notched or 2-cleft. Capsule opening at the top in 5 teeth.

A genns widely spread in Europe and northern and central Asia, containing many alpine, especially Chinese and Himalayan species, with nnly two or three North American, and one in Antarctic America 
Leaves rather large, wrinkled, light green. Lobes of the corolls slightly notched

Peduncles apparently radical, snd i-foriered * * • •

Peduncles bearing an umbel of several flowers.

Limb of the corolla small and concave

Limb of the corolla broad and flat $\quad: \quad \vdots \vdots:$ Var. c. Oxlip.

Leaves small, not wrinkled, covered underneath as well as the calyx with a white meal. Corolla small, the lobes deeply notched. .

1. $P$. veris.

Var. a. Primrose.

2. P. farinosa.

1. P. veris, Linn. (figs. 650,651 ).-Stock perennial and tufted. Leaves ovate or oblong, usually about 3 inches long, of a pale green, slightly toothed and much wrinkled. Calyx tubular, half an inch or rather more in length. Corolla usually yellow or straw-coloured; the tube nearly as long or longer than the calyx; the limb deeply 5-lobed, each lobe shortly notched. Stamens included in the tube.

In meadows, open woods, and hedge-banks, in Europe and Russian Asia. Fl. spring. It occurs commonly in tbree different forms, originally united by Linnæus under one botanical species, but since his days considered by most botanists as so many distinct and constant species, although more recent investigation has shown that Linnæus's views were correct. The Polyanthuses of our gardens are cultivated varieties of the same species. The three indigenous raves [which are supposed to hybridise with one another] are:-

a. The Primrose ( $P$. vrulgaris, Huds., $P$. acaulis, Liun.) (fig. 650). More or less hairy. Peduncles apparently all radical, as long as the leaves, each bearing a single large flower, with a broad flat limb. Calyx-teeth narrow and pointed. If closely examined, the peduncles will, however, be seen really to spring from an umbel, of which the common stalk is so short as to be concealed by the base of the leaves.-On hedge-banks and in rather open woods; particularly abundant in Britain, and extends over central Europe and some mountainous districts of southern Europe, wanting in north-eastern Europe, and not rccorded from the Altai or from Siberia.

b. The Conoslip, or Paigle (P. veris, Linn.) (fig. 651). Not hairy, but often covered with a minute, pale down. Flower-stalks rising above the leaves, bearing an nmbel of flowers. Calyx-teeth usually broad and obtuse. Corolla with a concave or cup-shaped limb, very much smaller than in the Primrose, but varying in size.-In meadows and pastures, over nearly the whole of Europe and Russian Asia to the Caucasus and Altai, and extending much farther over southern Europe than the other varieties. Not, however, an Arctic plant, and, in Britain, not so common in Scotland as in England.

c. The Oxlip (P. elatior, Jacq.), including all the intermediate forms which have the limb of the corolla broader and flatter than in the Covslip, but the flowers in an umbel raised above the ground, and usually above the leaves, on a common peduncle. Calyx and hairiness partaking sometimes of those of the Primrose, sometimes of the Cowslip.-Usually in moister and more luxuriant meadows and pastures than the Conosi ip, in less shady situations than the Primrose, but frequently intermixed with either, or with both, and passing gradually into the one or the other. Geographical range nearly that of the Cowslip, but much less abundant, except in some parts of central Europe. It is now generally believed that there is a distinct species, $P$. elatior, Jacq., closely resembling the hybrid Oxlip, but differing in the more villous caly $\mathrm{x}$, paler flower, 
and the absence of folds usually to be seen in the orifice of the corolla in the Primrose and Cowslip, a Continental plant occurring in some of the eastern counties of England; but the distinctness is scarcely proved satisfactorily.

2. P. farinosa, Linn. (fig. 652). Bird's-eye P.-Stock tufted as in the last, but the leaves much smaller, often not an inch long, glabrous above, and nsually covered underneath with a white, mealy, minute down, also observable on the peduncle and calyx, and only disappearing on a few very luxuriant specimens grown in the shade. Peduncle much longer than the leaves, with a compact umbel of small pale-lilac flowers, with a yellow eye; the lobes of the corolla rather narrow, and deeply notched.

In mountain pastures, in all the great mountain-ranges of Europe and Asia, penetrating far into the Arctic regions; found also in Greenland and the northern United States. Not uncommon in northern England, more rare in Scotland, but not recorded from Ireland. A small form from northern Scotland, with broader leaves, and shorter and broader lobes to the corolla, is the $P$. scotica, Hook.

\section{CYCLAMEN. CYCLAMEN.}

Perennials, with a globular, tuberous rootstock, and radical leaves, and 1-flowered peduncles. Calyx 5-lobed. Corolla with a campanulate tube, and 5 lobes closely reflexed over the calyx. Capsule globular, opening in 5 valves.

A very distinct genus, comprising bnt few species, from southern Europe and western Asia, many of which are in cultivation.

1. C. europæum, Linn. (fig. 653). Common C., Sowbread.-Rootstock forming a tuber, varying from $\frac{1}{2}$ to near 2 inches in diameter, according to age and station. Leaves on long stalks, heart-shaped, more or less angular and toothed; often of a purple or violet colour underneath. Peduncles radical, spirally rolled inwards after flowering, so as to bury the capsules in the earth. Flower rather large, white or rose-coloured, fragrant or scentless, drooping from the summit of the peduncle, with the oval or oblong lobes of the corolla turned upwards. C. hederafolium, Willd.

In woods, on banks, and under rocks, in southern Europe and western Asia, and, having been long cultivated in flower-gardens, has established itself in a few localities in Kent and Sussex. Fl.autumn. In its native country it varies much in foliage, in the precise shape of the orifice of the tube and of the lobes of the corolla, as well as in the time of flowering; and it is believed that two at least of the supposed species founded upon these differences have been gathercd in England appar. ently wild.

\section{LYSIMACHIA. LYSIMACHIA.}

Perennials, with erect or trailing stems, opposite or whorled leaves; the flowers usually yellow, either solitary on axillary pedicels or collected in terminal or rarely axillary racemes or clusters. Calyx deeply 5-cleft. Corolla rotate or campanulate, deeply 5-lobed. Stamens 5. Capsule opening in 6 or 10 valves. Occasionally the parts of the flower are in wires insteed of fives. 
A considerable genus, spread over the northern hemisphere in thurope, Asia, and America.

Stems erect. Peduncles many-flowered.

Leaves ovate-lanceolate. Flowers in short terminal panicles.

Lobes of the corolla broad
Leaves lanceolate. Flowers in axillary racemes. Lobes of the corolls narrow and short
Stems procumbent or trailing. Peduncles 1-flowered, axilliary.

Flowers small, rotate. Calyx-segments very narrow

Flowers large, almost campanulate. Calyx-segments brosd :

1. L. vulgaris.

2. L. thyrsiflora.

4. L. nemorum.

3. L. Nummularia

Besides the above, L. ciliata, Linn., a North American species, has been gathered apparently wild in Cumberland and near Dumbarton. It is an erect plant, like $L$. vulgaris, but with fewer flowers on longer pedicels, the corolla more rotate and paler coloured, fringed at the edge, and the stamens free and spreading.

1. I. vulgaris, Linn. (fig. 654). Common L., Loosestrife.-Stem erect, branched, 2 to 3 feet high, and more or less downy. Leaves nsually in whorls of 3 or 4 , rather large, broadly lanceolate or nearly ovate. Flowers in short, compound racemes, or panicles, in the npper axils and at the summit of the branches, forming a terminal, leafy panicle. Segments of the calyx lanceolate and pointed, varying much in breadth, and more or less ciliate on the edges. Corolla yellow, rather campanulate than rotate, deeply divided into 5 broad lobes. Stamens connected at the base into a cup enclosing the ovary.

On shady banks, and along streams, in Europe and Russian Asia, from the Mediterranean and the Cancasus to the Arctic Circle. Frequent in England, local in Ireland, rare in Scotland. Fl. summer, rather late. L. punctata is a marked variety of this species, not uncommon in Germany and south-eastern Europe, and occurring, mixed with the common form, in north-western England and south-western Scotland. It has the pedicels usually 1-flowered in the axils of the stem-leaves, the sepals rather narrower, and the lobes of the ccrolla fringed with minute glandular hairs; but none of these characters are constant.

2. L. thyrsiflora, Linn. (fig. 655). Tufted L.-Stem erect, simple, 1 to 2 feet high, sometimes slightly downy. Leaves sessile, lanceolate, 2 to 3 inches long. Flowers small and yellow, in dense axillary racemes, more or less pedunculate, but always shorter than the leaves. Sepals and petals narrow, the stamens and styles very prominent, and all the parts of the flower as often in sixes as in fives.

On wet banks, and along streams, in central and northern Europe, and northern Asia and America, extending to the Arctic Circle. In Britain, confined to northern England and central Scotland. Fl. summer.

3. I. Nummularia, Linn. (fig. 656). Moneywort, Creeping Jenny.Stems prostrate, trailing to the length of 1 to 2 feet, often rooting at the nodes. Leaves opposite, broadly ovate or rounded, very obtuse, on short stalks. Flowers yellow, large and handsome, on axillary peduncles not so long as the leaves; the divisions of the calyx broadly ovate and pointed; the corolla concave, deeply divided into 5 ovate lobes. Stamens erect in the centre, with the filaments slightly connected at the base.

On banks, under hedges, and in moist pastures, all over Kurope, except the extreme north, and eastward to the Caucasus, Not uncommon is 
Kngland ; from York and Durham southward; not indigenous in Scotland or Ireland. Fl. summer and autumn.

1. I. nemorum, Linn. (fig. 657). Wood L.-A procumbent plant, with the habit and rotate corolla of Anagallis arvensis, but with the yellow flowers and the eapsule of a Lysimachia. Stem slender, often rooting at the base, 6 inches to a foot long. Leaves opposite, broadly ovate, on short stalks. Pedicels slender, axillary, rather longer than the leaves, each with a single, rather small flower. Calyx-segments narrow and pointed. Corolla rotate, of a briglit yellow. Stamens quite free, with slender filaments. As the capsule rịpens, the pedicels roll round, as in Anagallis arvensis.

In woods and shady places, not uncommon in westeru Europe, extending far northward in Scandinavia, and eastward through central Europe to Transylvania. Generally distributed over Britain. $F$. all summer.

\section{TRIENTALIS. TRIENTALE.}

A single species only distinguished from Lysimachia by a somewhat different habit, and by the parts of the flower being usually in sevens instead of in fives, although these numbers are not quite constant.

1. T. europæa, Linn. (fig. 658). Trientale,-Rootstock perennial and slightly creeping. Stems erect, simple, 3 to 6 inches high, bearing at the top a tuft or irregular whorl of 5 or 6 leaves, varying from obovate to lanceolate, usually pointed, the largest near 2 inches long, with 2 or 3 small alternate leaves below the whorl. From the centre of the leaves arise from 1 to 4 slender pedicels, abont as long as the leaves, each terminated by a single flower, white or pale pink, with a yellow ring, rather larger than in Lysimachia nemorum. Calyx-segments narrow. Corolla rotate. Stamens with slender filaments, and short, recurved anthers.

In woods, in northern and Arctic Europe, Asia, and America, reappearing here and there in mountain woods of eentral Europe. Local in the Scoteh Highlands, more rare in the north of England, and unknown in Ireland. Pl. early summer.

\section{GLAUX GLAUX.}

A single species, distinguished from all Primulacea by the absence of any real corolla, the coloured campanulate calyx assuming the appearance of one, the stamens alternating with its lobes. Capsule opening in 2 or 4 valves.

1. G. maritima, Linn. (fig. 659). Sea Milkwort, Black Saltwort.A low, decumbent, branching perennial, glabrous and often slightly succulent, from 3 to 4 or 5 , rarely 6 inches high, with a more or less creeping rootstock. Leaves small, mostly opposite, sessile, ovate, oblong or almost linear, and entire. Flowers of a pale pink colour, not 2 lines long. Calyx deeply 5-lobed. Stamens about the same length, with slender filaments and small anthers.

Wn sands, salt-marshes, and muddy places, near the sea, in Kuropo. 
northern Asia, and America, extending to the salt tracts and inland seas of central Asia. Common on the British coasts. Fl. summer.

\section{ANAGALLIS. PIMPERNEL.}

Procnmbent or creeping herbs, with opposite leares, and opposite axillary flowers on slender pedicels. Calyx deeply cleft into 5 narrow segments. Corolla 5-cleft, rotate or campanulate. Stamens 5. Capsnle opening transversely by a circular fissure aoross the middle.

A small genus, chiefly from the Mediterranean region and central Asia, with one South American species.

Annual. Corolla rotate, blue or red . . . . . . . 1. A. arvensis. Pereunial. Corolla cumpanulate, of a delleate pale pink : $:$ 2. A. tenella.

1. A. arvensis, Linn. (fig. 660). Common P., Shepherd's or Poor Man's Weather-glass. - A neat, much branched, procumbent annual, 6 inches to near a foot long, with opposite, broadly ovate, sessile, and entire leaves. Pedicels considerably longer than the leaves, and rolled back as the capsule ripens. Calyx-divisions pointed. Corolla rotate, nsually of a bright red within, but occasionally pale pink, or white, or bright blue.

A very common weed of cultivation, in cornfields, gardens, waste places, \&c., all over Europe and Russian Asia, except the extreme north, and has accompanied man in his migrations over a great part of the globe. $F$. the whole season. The blue variety (A. carulea, Sm.) is as common in central and sonthern Europe as the red one, but with us it is rare.

2. A. tenella, Linn. (fig. 661). Bog P.-A delicate, slender, creeping perennial, only a few inches long, with very small, orbicular, opposite leaves. Flowers very elegant, of a pale pink, on long slender pedicels. Segments of the calyx pointed but short. Corolla narrow campanulate, of a very delicate textnre, and deeply 5-cleft. Stamens erect in the centre, with very woolly filaments.

On wet, mossy banks, and bogs, chiefly along rivulets, throughout western Europe, extending eastward to north-western Germany, Tyrol, and here and there round the Mediterranean. Spread over the greater part of Britain, but chiefly in the west from Cornwall to Shetland, and in Ireland. Fl. summer.

\section{CENTUNCULUS. CENTUNCLF.}

Small, slender annuals, with minute axillary flowers, differing from Anagallis in their alternate leares, and in the parts of the flower being in fours instead of in fives.

Besides our own species, the genus contains but very few, all from America.

1. C. minimus, Linn. (fig. 662). Chafficeed.-Stem often under an inch and seldom 3 inches high, branched at the base only. Leaves ovate, 1 to 2 lines long. Flowers almost sessile, shorter than the leaves. Calyx-divisions linear. Corolla pink, very minute. Capsule opening transversely as in Anagallis.

In moist, saxily or gravelly places, ranging over Kurope, Russian 
Asia, northern and even tropical America, and Australia, but everywhere thinly scattered, or frequently overlooked. Local, but in. dicated in many localities in England, and Scotland; rare in Ireland. Fl. summer.

\section{SAMOLUS. SAMOLE.}

Herbs, with alternate leaves and flowers, in terminal racemes. Calyx campanulate, partially adhering to the base of the ovary, with 5 teeth or lobes. Corolla with a short tube, 5 spreading lobes, and a small scale between each lobe, alternating with the stamens. Capsule inferior, opening in 5 valves.

A small genus, belonging, with the exception of our own species, exclusively to the southern hemisphere.

1. S. Valerandi, Linn. (fig. 663). Brookwced. A glabrous, bright green annual or perennial, with a tuft of obovate and spreading radical leaves. Flowering stems 3 or 4 inches to near a foot high, slightly branched, bearing a few obovate or oblong leaves, and loose racemes of small white flowers. Pedicels rather long, with a green bract a little above the middle. Capsules small, globular, crowned by the short broad teeth of the calyx.

Generally diffused over all parts of the world, most abundant in maritime sands and marshes, but in many countries found also far inland. In Britain, almost always near the sea, and chiefly along the west coast. Fl. summer and autumn.

\section{XLVII, IENTIBULACEÆ. THE PINGUICULA FAMILP.}

Marsh or aquatic plants, with radical or floating leaves (or sometimes none), and very irregular flowers, either solitary or several in a raceme, on leafless, radical, or terminal peduncles. Calyx variously divided. Corolla 2-lipped, projecting at the base into a pouch or spur. Stamens 2. Ovary and capsule 1-celled, with several seeds attached to a central placenta.

A family of very few genera, dispersed over the greater part of the globe. Their spurred flowers have a general resemblance to those of Linaria in Scrophulariacece, next to which they might perhaps be better placed, although the ovary and capsule are those of Primulacea, with which botanists more generally associate them.

Calyx 4- or 5-lobed, Leaves entire, radical • . . . . 1. Pinguicula. Calyx 2-lobed. Losves floating, much divided : : : 2. UtriculariA

\section{PINGUICULA. BUTTERWORT.}

Plants growing in bogs or on wet rocks, with radical, entire leaves, and yellow or purple flowers, on leafless radical peduncles. Calyx with 4 or 5 teeth or lobes, arranged in 2 lips. Corolla spurred, with a broad, open mouth; the npper lip short, broad, and 2-lobed; the lower one asually longer, broadly 3-lobed. Capsule opening in 2 or 4 valves.

The genns is limited to the northern hemisphere, with the exception of one Fuegian species. 
Flowers violet-purple, often large. Spur long, slender, and nearly straight .

Flowers yellow or pale-coloured. Spur smsll, contcal or curved.

Bpur very short, nearly straight. Niddle lobe of the lower lip of the corolla much larger than the others. Upper lip short

Bpur curved. Lobes of the lower lip of the corolla nearly equal, and scarcely longer than the upper lip

1. P. vulgaris.

2. P. alpina.

8. P. lusitanica,

1. P. vulgaris, Linn. (fig. 664). Common B.-Leaves spreading, ovate or broadly oblong, of a light green, somewhat succulent, and covered with little crystalline points, which give them a wet, clammy appearance. Flower-stalks 3 to 5 inches high, with a single handsome, bluish-purple flower; the broad, campanulate throat of the corolla attached laterally to the receptacle, and projected below into a slender spur about its own length; the lobes broad, the 2 upper ones (next the calyx) considerably shorter than the 3 lower ones. Capsule ovate, longer than the calyx.

Among mountain rills and on wet rocks, in northern Europe, all round the Arctic Circle, and along the mountain-ranges of central and southern Europe and Russian Asia. In Britain, chiefly in the western billy districts of England and Scotland, and in Ireland. Fl.summer, commencing very early. A large-flowered and very handsome variety, with broader lobes, and a long spur to the corolla, and a more obtuse capsule, $\boldsymbol{P}$. grandifloro, Lam., occurs in the bogs of south-western Ireland, and here and chere in the western parts of the continent of Europe, where, however, it passes gradually into the commoner form. [It has been naturalised in the vicinity of Penzance.]

2. P. alpina, Linn. (fig. 665). A lpine B.-Generally a smaller plant than $P$. vulgaris, with much smaller flowers, of a pale yellow or slightly purplish colour. The spur is short and obtuse, the lobes of the corolla nnequal and broad, the middle one of the lower lip much longer and broader than the two lateral ones.

A very northern or high alpine plant, common in the Arctic regions of Europe and Asia, and along the higher ranges of central Europe and north Asia. In Britain it has only been found in Skye and Ross-shire. Fl. early summer.

3. P. lusitanica, Linn. (fig. 666). Pale B.-Leaves of $P$. vulgaris, but smaller. Peduncles very slender, with a pale yellow flower, tinged with lilac, still smaller than in $P$. alpina; the spur always much curved, rather larger in proportion than in $P$. alpina, but much shorter than in $P$. vulgaris; the lips of the corolla nearly equal in length, and the lobes of the lower one almost equal in breadth. Capsule globular.

A west European plant, common in the bogs of Portugal and western Spain, and France, and extending to Ireland, the sonth and south-west of England, and west of Scotland. Fl. all summer.

\section{UTRICULARIA. BLADDERWORT.}

Some exotic species are marsh plants, either leafless or with entire radical leaves and 1-flowered peduncles; the European ones are all floating plants, without real roots at the time of flowering, but with long, root-like capillary branches or rootstocks, all submerged; their leaves divided into short capillary segments, interspersed with little bladders or vesicles, full of air. Flowers in the terminal raceme, on a 
leafless flower-stem arising out of the water from a tuft of the floating branches. Calyx deeply 2-lobed. Corolla spurred as in I'inyuicula, but the mouth is closed or nearly so by the convex palate, the lobes of the lips being turned back. Capsule globular, opening in 2 valves.

A considerable genus, dispersed over nearly the whole world.

Bladders intersperged with the leaves.

Flowers of a rich yellow, about 6 to 8 lines long. Spur conical. 1. U. vulgaris.

Flowers of a pale yellow, not 4 lines long. Spur very short . 2. U. minor.

Bladders on separate branches from the leaves . : . 3. U. intermedia.

1. Utricularia vulgaris, Linn. (fig. 667). Common B.-The rootlike floating branches extend to a length of 6 inches to a foot or more, bearing numerous capillary, much divided leaves, from $\frac{1}{2}$ to 1 inch long, and more or less interspersed with little green vesicles. Flower-stems 6 to 8 inohes high, bearing a few rather large yellow flowers. Bracts at the base of the pedicels, and lobes of the calyx, broad and thin. Corolla with a short, conical, more or less curved spur, and a broad convex palate; the upper lip very short, scarcely projecting beyond the palate; the lower lip much longer, thrown back from the palate; the lateral lobes turned downwards.

In deep pools and water-channels, in Europe, Asia, and America, from the Arctic Circle to the tropics. Widely distributed over Britain, although not a common plant. $F$. summer. A slender variety, $U$. neglecta, Lehm., with long pedicels remaining erect after flowering, and the upper lip of the corolla projecting beyond the small palate, has been found in the south-eastern counties of England.

2. Utricularia minor, Linn. (fig. 668). Lesser B.-Differs chiefly from $U$. vulgaris in the small size of all its parts. The floating branches are very slender, those of the flowering plant usually 2 or 3 inches long, but when barren often longer, and intricately branched; the leaves small, very fine, very few forked lobes, and seldom more than 1 or 2 bladders to each, or often without any. Flowers scarcely more than half the size of those of $U$. vulgaris, of a pale yellow, with the lower lip much flatter; the spur usually reduced to a short, broad protuberance.

Appears to be as widely spread over northern and central Europe, Russian Asia, and northern America as $U$.vulgaris, but not extending so far to the southward. Rather common in Britain. Fl. summer.

3. Utricularia intermedia, Hayne (fig. 669). Intermediate B.Intermediate in size between $U$. vulgaris and $U$. minor, and distinguished from both by the leaves crowded into tnfts at the ends of branches without bladders, the bladders being few, and placed at the ends of leafless branches. Flowers of a pale yellow, larger than in U. minor, with a much more prominent spur.

In central and western Europe, much more rare than the preceding species. Local in Britain, indicated in Dorsetshire, Hants, Norfolk, and Westmoreland, whence it extends to the north of Scotland; found also in Ireland. Fl. summer.

The Snowdrop-tree (IIalesia) from North America, and the Styrax from south-eastern Europe and western Asia, both occasionally to be met. with in our shrubberies and plantations, belong to the small Styrar 
family, which is entirely exotic. It consists of trees and shrubs, with the calyx often partially adherent to the ovary, the corolla monopetalous, and stamens, although inserted on the corolla, usually more or less united together.

\section{OLEACEE. THE OLIVE FAMILY.}

\section{(Jasminacea, 1st edit.)}

Trees, shrubs, or tall climbers, with opposite (or in a very few exotic species alternate) leaves, entire or pinnate, and flowers usually in terminal panicles or clusters. Calyx and corolla regular, each of 4 or 5 divisions, or in a few species entirely deficient. Stamens 2. Ovary and fruit 2-celled, each cell containing 1 or 2 seeds.

An Order widely spread over nearly the whole of the globe, readily known by the 2 stamens inserted at the base of the corolla, without reference to the number of its divisions. It is commonly divided into two:-Oleacea proper, with the divisions of the corolla 4 or 2 , and usually valvate in the bud, which comprises the two British genera, as well as the Olive (Olea) and the Lilac (Syringa), Filarea (Phillyrca), Chionanthus, and Forsythia of our shrubberies ; and Jasminece, consisting of Jasminum (Jessamine) and some other small exotic genera, which have 5 or more divisions to the corolla, overlapping each other and obliquely twisted in the bud. The seeds also have usually a considerable albumen in the one tribe and little or none in the other, but this difference is not constant.

Trees, with pinnate leaves, and a dry, oblong, linear fruit . . 1. Fraxinus. Shrubs, with simple leaves, and a berry

2. Ligustruy.

\section{FRAXINUS. ASH.}

Trees, with pinnate leaves, and a dry fruit produced at the top into an oblong, rather firm wing, and divided at the base into 2 cells, each containing a single seed. Caly $\mathrm{x}$ and corolla either none, or in some exotic species 4-lobed.

A small genns, limited to the northern hemisphere, without the tropics. Several American species are to be met with in our plantations.

1. F. excelsior, Linn. (fig. 670). Common Ash.-A tall, handsome tree, with opposite, deciduous, pinnate leaves, consisting of from 7 to 11 ovate-lanceolate, toothed segments. The flowers open before the leaves, and appear at first sight like clusters of stamens issuing from opposite buds along the last year's shoots, each cluster surrouniled by a few small, woolly scales. On examination it will be found to consist of a number of pedicels, arranged in a short raceme, each pedicel bearing a pair of sessile anthers, with an ovary in the middle, ending in a straight style with a thickened stigma. The capsules, commonly called keys, are, including the wing, about an inch and a half long.

In woods, throughout temperate Europe and western Asia, extending northwards into Scandinavia, but generally replaced in southern Europo 
by a closely allied but perhaps distinct species. Common in Britain, and truly wild excepting in the northern parts of Scotland, where, how. ever, it bears the climate in plantations. Fl. spring. A garden variety with solitary leaflets is the $F$. heterophylla.

\section{LIGUSTROM. PRIVET.}

Shrubs, with opposite, simple leaves, and small white flowers. Calyx slightly 4 -toothed. Corolla 4-lobed, with a short tube. Stamens short. Fruit a berry, with 2 cells and 1 or 2 seeds in each.

Besides our own, the genus contains but a small number of species, chiefly from eastern Asia, some of which are in cultivation in oup gardens.

1. L. vulgare, Linn. (fig. 671). Common P.-A shrub, attaining 6 to 8 feet in height, with long, slender branches. Leaves nearly ever. green, lanceolate or oblong, quite entire, and shortly stalked. Flowers in short, compact panicles at the ends of the branches. Berries black, globular or somewhat ovoid.

In bedges and thickets, over the greater part of Europe and western Asia, penetrating far into Scandinavia, but so much planted that its natural limits cannot well be traced. In Britain, common in southern England, and has been considered as truly wild in chalk districts and coast cliffs as far north as Durham and Yorkshire; in Ireland it is considered indigenous only in the south of the island. Fl. summer.

\section{APOCYNACE正. THE PERIWINKLE FAMILY.}

A large tropical Order, distinguished from Gentianacece chiefly by the ovary completely divided into 2 cells, or more frequently into 2 distinct carpels, whilst the style, or at least the stigma, is entire.

It is limited in Britain to the single genus Vinca, but is represented in our planthouses by the Oleander (Nerium), from southern Europe; the Manderilla, Allamandas, Lipladenias, \&c., from South America; and others from tropical Asia. The closely allied A sclepias family, which is entirely exotic, but includes the Periploca, Stapelias, Hoyas, Stephanotus, \&c., of our gardens and planthonses, differs chiefly in the curious manner in which the anthers are connected with the stigma.

\section{VINCA. PERIWINKLE.}

Herbs, with opposite, entire leaves, and blue, pink, or white flowers, growing singly on axillary pednncles. Caly $x$ free, deeply divided into 5 narrow divisions. Corolla with a cylindrical or almost campanulate tube, and a flat, spreading limb, with 5 broad, oblique segments, twisted in the bud. Stamens 5 , enclosed in the tube. Ovaries 2, distinct at the base but connected at the top by a single style, terminating in an oblong stigma, contracted in the middle. Fruit consisting of 2 oblong or elongated capsules or follicles, each of a single cell, of a greenish colour, diverging as they ripen, and opening by a longitudinal slit on 
the inner side. Seeds several, withont the seed-down of many exotic genera of the Order.

Leaves broadly ovate, and segments of the calyx eiliate on their margins. Flowers large - . D. major. Leaves narrow-ovate, and calyxes quite giabrous. Flowers smali $\quad$ 2. V. minor.

The $V$. rosea, a tropical species with erect stems, is often cultivated In our hothouses.

1. V. major, Linn. (fig. 672). Larger P.-A perennial, with a creeping rootstock, long, trailing, barren shoots, and nearly erect, simple flowering stems, about a foot high. Leaves broadly ovate, evergreen, and shining, but bordered by minute hairs. Pedicels shorter than the leaves. Calyx-segments narrow, ciliate on the edges. Corolla large, blue; the tube broad, almost bell-shaped, though slightly contracted at the mouth; the lobes broad, almost angular.

In woods and shady banks, in south-central and southern Europe to the Caucasus, but, having been long cultivated for ornament, and spreading with great rapidity by its rooting stems, it has established itself much farther north, and in many parts of England, where, however, it seldom, if ever, ripens its seed. Fl. spring.

2. V. minor, Linn. (fig. 673). Lesser P.-Differs from the last in its smaller size, more trailing habit, with short, erect flowering stems; in its narrower, ovate or oblong leaves, which are perfectly glabrous; in its smaller flower, with a more open tube to the corolla, and shorter and broader segments to the calyx, withont any hairs.

Its geographical range is more extended than that of $\nabla$. major, being undoubtedly wild much farther northwards, and more abundant in England, but yet, like that species, it is probably with us an introduced, not a truly indigenous plant. Flo spring and summer.

\section{GENTIANACEE. THE GENTIAN FAMILY.}

Herbs, more or less bitter, usually glabrous, with the exception of a few exotic species; the leaves usually opposite and entire, without stipules; the flowers in terminal, dichotomous cymes or panicles, with a single flower in each fork. Calyx of 4,5, or rarely 6 to 8 divisions. Corolla regular, with a straight or open tube, sometimes very short, axd a spreading limb of as many divisions as the calyx, usually twisted in the bud. Stamens as many as the divisions of the corolla, and alternating with them. Ovary of a single cell, or partially divided into 2. Capsule opening in 2 valves, with many seeds.

A rather large and very natural Order, extending nearly all over the world, but chiefly in temperate or mountain regions, some species ascending to the utmost limits of vegetation.

Leaves opposite. Terrestrial plants.

Stamens and divisions of the corolla 4

Muwors vory small, yellow. .

Flowers rather largo, ulue

1. Cicendia.

Gomtiana campestria. 
Stamens and divisions of the corolla 5 (sometime with 5 additional smaller lobes).

Flowers pink or red. Calyx divided to the base. Style deciduous.

Flowers blue. Calyx not divided beluw the middle. Style remalning long after the flowering is over. Stamens and divisions of the corolla usually 8 . Corolla jellow, rotate

Leaves alternate. Water plants.

Leaves entire, orblcular. Flowers yellow

Leaves with 3 leaflets. Flowers white, fringed within:

2. Ertthrak.

3. Gentinan.

4. ChLORA.

6. LIMNANTIEMUM. 5. MenYanthes.

\section{CICENDIA. CICENDIA.}

Very small annuals, differing from Gentiana in their decidnous style, and from Erythraza in the short, broad tube of the corolla, with the parts of the flowers in fours instead of fives. The ferv species are all European, and some botanists limit the genus to the single C. pusilla, regarding the $C$. filiformis as generally distinct under the name of Vicrocala.

Stems simple or with few erect branches. Calyx-teeth broad and

short
Stems much branched. Caly $\mathbf{x}$-segments linear:

1. C. Aliformis. 2. C. pusilla.

1. C. filiformis, Reichb. (fig. 674). Slcnder C.-A slender annual, about 2 inches high, with a few pairs of small, narrow leaves, chiefly near the base of the stem, and either simple and 1-flowered or divided into 2 or 3 branches, each with a single small yellow flower. Calyx campanulate. with 4 broad, short lobes; limb of the corolla also 4 -cleft. Capsule globular, 1-celled. Microcala filiformis, Link.

In moist, sandy situations, common in western France and Spain, extending northward to Denmark, and eastward in southern Europe to Sicily and some other parts of the Mediterranean. In Britain, only in the south-western counties of England, and in the extreme south-west of Ireland. Fi. summer.

2. C. pusilla, Griseb. (fig. 675). Dwarf C.-Usually a smaller plant than C. filiformis, and much more branched, but chiefly distin. guished by its pink, white, or pale yellow flowers, with the calyx divided to the base into narrow segments, instead of the short, broad teeth of $C$. filiformis.

In moist, sandy situations, in France, Spain, and here and there in the west Mediterranean region, and has been found in the Channel Islands. Fl. summer.

\section{ERYTHRIAA. CENTAURY.}

Annuals, with pink, or, in some exotic species, pale yellow flowers differing from Gentiana by their more deeply divided calyx, their deciduous style, their anthers, which become more or less spirally iwisted after shedding their pollen, and by the capsule, in which the seed-bearing edges of the valves meet in the centre, so as to divide it more completely into 2 cells than in most others of the family.

1. E. Centaurium, Pers. (fig. 676). Common Centaury.-An erect annual, from an inch or two to a foot high, usually much branched in the upper part. Lower leaves usually broadly ovate, forming a spreading radical tuft; the upper ones in distant pairs, varying from ovate or oblong to narrow-linear. Flowers pink or red, usually numerous, in 
a terminal, repeatedly-forked cyme or panicle. Calyx-segments 5, narrow-linear. Corolla with a slender tube, and a spreading, 5-cleft limb.

In dry pastures, and sandy places, on banks, roadsides, \&c. ; widely spread over Europe and central Asia, extending northward to south Sweden. Common in Britain, excepting in the north of Scotland, where it is almost confined to the coast. Fl. all summer. It varies much in the size and breadth of the foliage and flowers, and has been subdivided into 2,3 , or even 6 or 7 supposed species, which, however, run into one another so much that no precise limits can be assigned them. The most prominent forms or varieties in Britain are :-

a. Large-flowered $C$. Tall, not much branched, with a compact cyme and large flowers; the tube of the corolla long and the lobes ovate.

b. Common C. (E. pulchella, Fries.). More branched, with numerous flowers; the tube of the corolla not much longer than the calyx, and the lobes of the limb narrow.

c. Broad-leaved $C$. (E. latifolia, Sm.). Including all the dwarf forms with ratber large flowers and broad leaves.

d. Linear C. (E. littoralis, Fries. ; E. linarifolia, Pers.). MIuch branched, usually small, with very narrow leaves and rather large flowers. The last two varieties are most frequent near the sea, where they both, as well as the small-flowered varieties, often dwindle down to a simple stem half an inch high, with a single flower.

[e. Capitate C. (E. capitata, Willd.). Very dwarf, with the flowers in a dense head, and the stamens inserted at the base of the corolla-tube, a position so unusual in the Order as to suggest this being rather an abnormal state than a variety.-Downs, Isle of Wight, and Eastbourne.]

\section{GENTIANA. GENTIAN.}

Herbs, with opposite, entire leaves, and (in th€ British species) blue flowers, either solitary and terminal or in pyramidal or oblong panicles, the lower ones often axillary. Calyx tubular, of ten strongly angled, with 5 , rarely 4 lobes, seldom reaching below the middle. Corolla with a cylindrical or narrow-campanulate tube, and spreading limb, divided into 5 or rarely 4 lobes, and occasionally 5 additional ones in the angles. Style remaining attached to the capsule after the flower fades. Capsule 1-celled, the placentas not meeting in the centre.

A numerous genus, spread over the northern hemisphere, especially in mountainous districts, and, in the higher ranges of both the New and and old World, penetrating into the tropics. One very common Swiss species, as well as several other exotic oncs, have yellow flowers, but blue is the prevailing colour in the genus.

Corolla fringed at the throat with long hairs.

Calyx-lobes 4, 2 of them broadly ovate . . . 6. G. campestris.

Calyx-lobes 5, all narrow-lanceolate or linear. : : 4. G. Amarella.

Corolla not fringed at the throat.

Stem 6 inches to a foot high. Corolla tube above an inch

long
stem dwarf, seldom sbove 3 or 4 inches Corolia an inch
long or less, with small lobes between the larger ones.

Tufted perennial, with 1-flowered stems and a broad limb to the corolla

Branched apnual, with several flowers and a smati limb to tho cosella. . . . . .

1. G. Pnewmonanthe.

2. G. verna

1. *imali. 
The Gentianella of our gardens is the Gentiana acaulis, a mountain species, very common in central Europe, but not a native of Britain.

1. G. Pneumonanthe, Linn. (fig. 677). Marsh G.-Rootstock perennial. Stems simple, erect, 6 inches to a foot or more high. tower leaves oblong-lanceolate, the upper ones nearly linear, all obtuse and rather thick. Flowers nearly sessile, in opposite pairs in the axils of the upper leaves, with a terminal one close between the last pair. Lobes of the calyx narrow. Corolla an inch and a half or more long, of a deep blue within, with 5 grecnish, broad lines outside; the tube with. out hairs at the throat; the lobes rather short, broad and spreading.

In moist heaths and pastures, chiefly in hilly districts, throughout Europe and Russian Asia, except the extreme north. Local in Britain, more frequent in northern than in central or southern England, but not a native of Scotland or Ireland. Fl. summer.

2. G. verna, Linn. (fig. 678). Spring G.-Stock perennial and leafy, densely tufted, often spreading to 4 or 5 inches in diameter, with ovate or oblong leaves. Flower-stems simple and numerous, sometimes so short that the flowers appear sessile on the tufts of leaves, sometimes 1 or 2 inches long, bearing 1 or 2 pairs of small leaves, and a beautiful bright-blue terminal flower. Calyx very angular, with lanceolate teeth or lobes. Corolla-tube cylindrical, nearly an inch long; the limb broad and spreading, with 5 ovate lobes, and smaller 2-cleft ones between them.

One of the most common species, in mountain pastures, in central and southern Europe to the Caucasus and the Altai, but scarcely extending into northern Germany. Rare in Britain, apparently confined to a few localities in northern England and western Ireland. Fl. spring or early suminer.

3. G. nivalis, Linn. (fig. 679). Small G.-A slender, erect, leafy annual, sometimes single-flowered and only an inch high, but more frequently 2 to 4 inches high and more or less branched; each branch bearing a single blue flower, much like that of $G$. verna, but considerably smaller. The tube of the corolla is but little more than 6 lines long, and the lobes of the limb not 2 lines, broadly ovate and pointed, with very small 2-cleft ones between them.

A high alpine plant, not uncommon in the higher mountain-ranges of central Europe as well as in the extreme north, but not recorded with any certainty as extending into central Asia. Very rare in Britain, and only on a few of the higher Scotch mountains. Fl. summer.

4. G. Amarella, Linn. (fig. 680). Autumn G.-An erect, much. branched annual, 3 or 4 inches to near a foot high, often assuming a livid-green or purplish tinge. Leaves ovate or lanceolate ; the flowers numerous, sometimes much crowded, sometimes forming a loose, oblong, leafy panicle of a pale purplish-blue, and varying much in size. Calyx divided to the midale into 5 narrow-lanceolate, equal or slightly unequal lobes. Corolla-tube broad, the limb spreading, divided into 5, rarely 4, ovate or oblong lobes, without any smaller ones between them, but furnished within, at the mouth of the tube, with a fringe of hairs half as long as the lobes.

In rather dry hilly pastures, in Europe and Russian Asia, extending to the Arctic Circle, but becoming ratler a inountain plant in southern Europe. Diffused over the greater part of Britain. Fl. end of summer 
and autumn. The flowers (including the limb) vary with is from 6 to o lines in length, more rarely attaining an inch, whilst in some Continental specimens they are sometimes yet longer.

[a. germanica, Willd., is a stont, large-flowered variety with more unequal calyx lobes and shorter corolla-tube ; it is confined to England. Another variety, $G$. uliginosa, Willd., has 4-merous flowers. These seem to unite $G$. A marella with campestris.]

5. G. campestris, Linn. (fig. 681). Field G.-An erect annual, much resembling at first sight $G$. Amarella, but usually rather stonter, more branched, and with more crowded leaves and flowers, though seldom above 6 inches high; and it is easily known by the parts of the flower being in fours, not in fives, and by 2 of the lobes of the calyx being broadly ovate, overiapping the 2 other narrow ones. The blue fringe of the mouth of the corolla is very conspicuous.

In open pastures, and commons, chiefly in limestone districts, in central and northern Europe, but not recorded from the Caucasus or eastward of the Ural. More frequent in Britain than the last species. Fl. autumn.

\section{CHLORA. CHLORA.}

Glancous annuals, with yellow flowers. Calyx deeply divided as in Erythraza, but into 8 lobes. Corolla-tube very short; the limb spreading, 8-lobed. Stamens 8. Style persisting on the capsule as in Gentian. Besides the British species, the genus includes a few European ones.

1. C. perfoliata, Linn. (fig. 682). Yellowoort.-An erect, rather stiff annual, 2 or 3 inches to a foot high, of a pale glaucous green. Radical leaves in a spreading tuft, those of the stem in distant pairs, broadly connected together at the base, so that the stem appears to pass through them, whence the specific name. Flowers of a bright yeliow, in rather loose terminal cymes; the corolla nearly rotate. Blackstonia perfoliata, Huds.

In dry pastures, and waste places, generally confined to limestone districts, in western, central, and southern Europe to the Caucasus. In Britain, limited to England, where it is local, and Ireland. Fl. summer.

\section{MENY ANTHES. BUCKBEAN.}

A single species, distinguished as a genus from Limnanthemum by its compound leaves and the capsule opening in 2 valves.

1. M. trifoliata, Linn. (fig. 683). Buckbean, Marsh Trefoil.-An aquatic herb, with creeping rootstock and densely-matted roots. Stem short, creeping or floating, with a dense tuft of leaves, consisting eaoh of a long stalk, sheathing at the base, and 3 obovate or oblong leaflets, 1 to $1 \frac{1}{2}$ inches long. Flowers white, tinged externally with red, in an oblong raceme, on a peduncle of 6 inches to a foot, proceeding from the base of the tuft of leaves. Caly $\mathrm{x}$ short, with rather broad green lobes. Corolla campanulate, deeply 5-lobed, and elegantly fringed on the inside with white filaments.

In wet bogs, and shallow ponds, in Europe, Russian and central Asia, and North America, extending into the Arctio regions. Diffused all sver Britain. Fho oummer, rather early. 


\section{LIMNANTHEMUM. LIMNANTH.}

Aquatic plants, with simple, broad, floating leaves and yellow flowers. Caly $x$ 5-cleft. Corolla nearly rotate, 5-cleft, slightly fringed within at the base. Capsule bursting irregularly when ripe.

A small genus, represented by some species or variety in the fresh waters of most of the temperate or tropical parts of the world.

1. L. nymphæoides, Link. (fig. 684). Common L.-The long stems creep and root at the base, branch and ascend to the surface of the water, bearing a single leaf at each upper branch, and a terminal floating tuft of leaves and peduncles. Leaves on long stalks, and deeply cordate, like those of a Waterlily on a small scale. Peduncles as long as the leafstalks, each with a single, rather large, yellow flower. $L$. peltatum, Gmel., Villarsia reniformis, Linn.

In ponds and still waters, tbroughout Europe and central and Russian Asia, except the extreme north; extending eastward to China. Found in the eastern counties and Oxford, and scarcely even uaturalised in Scotland and Ireland. Fl. summer.

\section{POLEMONIACEE. THE POLEMONIUM FAMILY.}

Herbs or rarely shrubs, the flowers usually in terminal eymes or panicles. Calyx 5-eleft or 5-toothed. Corolla regular, 5-lobed, the lobes twisted in the bud. Stamens 5, inserted in the tube, and alternating with the lobes. Ovary single, 3-celled, with several or rarely a single seed in each cell, inserted in the inner angle. Style simple, with 3 stigmatic lobes. Capsule 3-celled, opening in 3 valves by slits opposite the middle of the cells.

A small family spread over northern Asia and America, and western South America. Besides the European genus, it incluries the Plloxes, Gilias, and Collomias of our flower-gardens, as well as the shrubby Cantuas and climbing Cobceas of our planthouses.

\section{POLEMONIUM. POLEMONIUM.}

Herbs, with pinnate leaves, and blue or white flowers in terminal corymbs. Calyx 5-lobed. Corolla with a very short tube, and a broad, open, 5-cleft limb. Stamens oblique, their filaments dilated into hairy scales. Capsule with several seeds.

A small genus, extending all round the northern bemisphere, chiefly in high latitudes.

1. P. cæruleum, Linn. (fig. 685). Greek Valerian, Jacob's Ladiler.Stock perennial, the radical leaves forming dense tufts, their common stalk 6 inches long or more, bearing from 11 to 21 lanceolate, entire segments or leaflets of a tender green. Stems erect, $1 \frac{1}{2}$ to 2 feet high, bearing a few smaller pinnate leaves, and a rather showy terminal corymb or panicle of flowers.

Widely diffused over the higher northern latitudes of Europe, Asia. 
and America, extending also in the mountain-regions of central Europe, and Asia. In Britain it is found apparently indigenous in several parts of the north of England, but has been so long cultivated in cottage gardens, and seeds so readily, that it cannot be pronounced with certainty to be truly indigenons. Fl. summer.

\section{CONVOLVULACE⿸广 CONVOLVULUS FAMILY.}

Herbs usually twining or prostrate (rarely, in some exotic species, erect or shrubby), with alternate leaves, or leafless and parasitical; the flowers, often very showy, growing singly or several together on axillary peduncles. Calyx of 4 or 5 distinct sepals, often very unequal. Corolla usually campanulate (but varying in form in exotic species), plaited in the bud, with 4 or 5 lobes, or nearly entire. Stamens 4 or 5 , attached near the base of the corolla. Ovary and capsule containing 2, 4, or 6 seeds, and often divided into 2,3 , or 4 cells, the partitions very thin, and remaining attached to the central column, and not to the valves, when the capsule bursts. Style simple, with 2 or rarely 3 stigmatic lobes, or 2 distinct styles.

An Order rather numerous in species, and widely spread over the warmer and temperate parts of the globe. The exotic genus Ipomae. including Pharbitis and Quamoclit, often separated from it, supplies some of our most beautiful greenhouse and hothouse climbers.

Stem leafy. Corolla campanulate - . . . . . 1. Convocvurus. Stem thrond-like, without leaves, parasitical on other plants. Corolien nearly globular

2. Coscuta.

\section{I. convolvolus. Convolvulus, Bindweed.}

Twiring or prostrate herbs (or in some exotic species erect), with altern t,e leaves. Sepals 5. Corolla campanulate. Style single, with 2 oblong or linear stigmatic lobes. Capsule with 4 seeds in 1 or 2 cells.

A Lurge genus, having the geographical range of the family, but more wspecially abounding in the Mediterranean region.

Bracts small, and placed on the peduncle at some distance from

th $\rightarrow$ flower. Stigma narrow-linear

1. C. arvensis.

Bracts large, close under the calyx. Stigma ovate or oblong.

Sten climbing. Leaves angular at the base. . . . . 2. C. sepium.

Stom prostrate. Leaves tbick, rounded : : . 3. C. Soldanella.

The common blue Convolvulus minor of our gardens ( $C$. tricolor of botanists) is a south European species; the so-called Convolvulus major is the Ipomaea or Pharbitis purpurea, a widely-spread species over the hotter parts of the world, probably of American origin.

1. C. arvensis, Linn. (fig. 686). Lesser Bindweed.-Rootstock lander, creoping underground to a great extent. Stems twining, 
but prostrate or scarcely climbing, seldom attaining above 2 feet in length. Leaves stalked, ovate-sagittate, $1 \frac{1}{2}$ inches long; the lobes of the base spreading and pointed, or angular. Peduncles axillary, nsually 2-flowered, with 2 small bracts at their fork, and a third on one of the pedicels, at some distance from the flower. Sepals small and broad. Corolla of a delicate pink, or nearly white, an inch or rather more in diameter. Lobes of the style narrow-linear. Capsule divided into 2 cells by a thin partition.

In fields and pastures, throughont Europe and central and Russian Asia, except the extreme north. Common and often a troublesome weed in England and Ireland, but local in Scotland. Fl. all summer.

2. C. sepium, Linn. (fig. 687). Larger B.-Rootstock creeping as in $C$. arvensis; the twining stems climb to the length of many feet over hedges and bushes. Leaves broadly ovate or triangular, pointed, with broad, angular lobes at the base. Peduncles bearing a single large flower of a pure white, with a pair of large, leafy bracts immediately under the calyx, and completely enclosing it. Stigmas obovate-oblong. Capsule without any partition between the seeds. Calystegia scpium, $\mathrm{Br}$.

In hedges and bushy places throughont Europe and Russian Asia, except the extreme north, and in North and South America and Australia. Abundant in England and Ireland, but local in Scotland. $F l$. summer. This and the following species are, on account of their large bracts, often removed from Convolvulus as a distinct genus, under the name of Calystegia.

3. C. Soldanella, Linn. (fig. 688). Sea B.-Rootstock creeping. Stems short, prostrate and scarcely twining. Leaves small, thick, broadly rounded or kidney-shaped, with broad, rounded or angular lobes at the base. Peduncles 1-flowered, with the 2 large bracts of C. sepium. Corolla nearly as large as in that species, of a light pink colour, the stigmas longer and more pointed than in $C$. sepium, but shorter and broader than in C. arvensis. Calystegia Soldanella, Br.

In maritime sands, in the temperate regions of both the northern and southern hemispheres, scarcely penetrating into the tropics. Not uncommon on the coasts of England, Ireland, and southern Scotland. Fl. summer.

\section{CUSCUTA. DODDER.}

Annnal, parasitical, leafless herbs, with twıning, thread-like stems, attaching themselves to the plants on which they grow by minute tubercles; the small, nearly globular flowers in lateral heads or clusters. Calyx coloured like the corolla, deeply 4- or 5-cleft. Corolla with a broad tube, and 4 or 5 usually spreading lobes, and as many small scales inside the tube. Styles 2, distinct from the base, or, in some exotic pecies, united to near the top. Capsule globular, with 4 seeds in 2 cells.

A genus widely spread over the globe, comprising a considerable nnmber of species, and still more numerous varieties, remarkable as showing great general similarity of aspect, but much diversity in minute 
characters derived chiefly from the size and form of the corolla and of the scales. Corolla more than a line in diameter, with short, broad lobes,
and inconsplcuous, appressed scales.

Calyx shorter than the corolla-tube, which is not much swollon when first flowering.

Calyx as long as the globular corolla-tube. Plant growing on flax only

Corolla usually less than a line in diameter, with pointed, spread. ing lobes; the scales prominent, and nearly closing the tubo.

1. C. europaca.

2. C. Bpilinum.

3. C. Bpithymum.

1. C. europæa, Linn. (fig. 689). Greater D.-The whole plant is of a pale greenish-yellow, tending more or less to redden in many situa: tions. Flowers in sessile, globular clusters, 4 or 5 lines in diameter; each flower a little more than 1 line in diameter, sessile or borne on an exceedingly short pedicel. Sepals broad and rounded. Tube of the corolla at first broadly cylindrical, longer than the calyx, with broad and short lobes, and very minute, scarcely perceptible scales inside. Styles and stamens usually enclosed in the tube. As the capsule enlarges, the tube of the corolla becomes nearly globular.

Parasitic on a great variety of plants, more especially on herbaceous stems, in Europe and the temperate parts of Asia. Not very abundant in England, nor found north of York, nor in Ireland. Fl. summer.

2. C. Epilinum, Weihe. (fig. 690). Flax D.-Differs sliglitly from C. europica in its flowers rather larger and more succulent but fewer in number, the calyx rather longer, the corolla-tube globular even when young, and the lobes still shorter in proportion.

Said to grow exclusively on flax, in Europe and Russian Asia, and introduced into Britain with the cultivation of that plant.

3. C. Epithymum, Linn. (fig. 691). Lesser D.-The threadlike stems are much finer than in C. europaca; the heads of flowers small, globular, and very compact. Flowers often considerably less than a line in diameter, and very seldom attaining that size; the calyx smaller in proportion; the lobes of the corolla pointed, spreading, and about as long as the tube; the scales of the inside more prominent, almost closing the tube, and the style and stamens usually slightly protruding, though shorter than the lobes.

In open, sunny situations, chiefly on thyme, heath, and other small shrubby plants, in Europe and temperate Asia. More frequent in England than C. europcea, and extending into southern Scotland, but nnknown in Ireland. $F l$. summer. C. Trifolii, Bab., is a variety found in clover fields, with smaller distant scales on the corolla.

\section{BORAGINEÆ. THE BORAGE FAMILY.}

Herbs, usually rough with coarse hairs (rarely shrubs or even trees, in some exotic genera), with alternate, simple, usually entire leaves; the flowers in 1-sided spikes or racemes, rolled back when young, and usually forked or dichotomous. Calyx of 5 divisions or teeth. Corolla regular or slightly irregular, monopetalous, with a 5-cleft limb. Stamens 5, inserted in the 
tube of the corolla, and alternating with its divisions. Ovary deeply 4-lobed (or, in some exotic gencra, 2-lobed), with a simple style inserted between the lobes. Fruit consisting of as many small, 1-seeded nuts, having the appearance of sceds, and enclosed within or currounded by the calyx.

A numerous family in the northern hemisphere, with a few represen. tatives in the tropics or in the southern hemisphere; easily distinguished $y$ the 4 seed-like nuts from all but Labiatce, and from these by their aiternate leaves and more regular flowers.

Tube of the corolla open, without any scales or valves at its orifice.

Stamen protruding beyond the corolla.

Corolla oblique and more or less irregular, with erect, or scarcely spreading lobes Corolla regular, with a straight tube and spreading liwb

Stamens included in the tube of the corolla. Calyx tubular, the lobes not rcaching to the middle Calyx divided to the base. Nuts very bard

shbe or centre of the corolla more or lces clesed at its orifice by scales or valves, or stimens.

Corolla tubular, with 5 small teeth forste, the anthers erect, forming i cone in thie

Corolla (small) with silightly bent tube, and rather oblique, spreading limb

Corolla with a straight tube, and regular spreading limb.

Caly $\mathrm{x}$ broad, and somowhat flattened, enlarged after flower-

ing, with small teeth between the large ones. . . 10. Asreroco.

Caly $x$ regularly 5-cleft.

Nuts depressed, ovate or round, muricated and burr-like. 11. Crxoctossum. Nuts ovold, ercet, anooth or wrinkled.

Nuts wrinkled. Spikes with a bract under each flower. Nuts smooth and shining. Racemes without bracts. Flowers usually small .

1. Ecrives.

3. HIERTENSIA.

2. Pulmonaria.

4. Lithopserarum.

8. SrмpHYTUM.

9. Borago.

7. Lrcopsia

6. A NCFU8A.

5. Mrosotis.

Among exotic genera, Echinospermum Lappula, a south European annual, which has all the appearance and the small fiowers of a Myosotis, but with triangular, very rough nuts, has been occasionally found in isolated localities in England, when accidentally introrluced with Continental weeds. The well-known swect lleliotrope of our gardens belongs to a large exotic genus, truly Boragineous, though somewhat anomalous in the closer union of the nuts. The Nemophilas and Eutocas of our flower-gardens belong to the small allied Hydrophylum family, which has the inflorescence and flowers of Boraginea, but the fruit is a capsule, and the leaves often divided.

\section{ECHIUM, ECHIUM.}

Coarse biennials, or, in exotic species, half-shrubby perennials, with blue or purple flowers. Caly $x$ deeply divided. Corolla with a broad, open mouth to the tube, and an oblique limb, with 5 erect or scarcely spreading unequal teeth or lobes. Stamens protruding from the tube, and nnequal in length. Style 2-cleft. Nuts wrinkled.

A rather numerous genus in the Canary Islands and western and sonthern Africa, with a few European and west Asiatic species? 
Bturus very erect. Corolla-tube narrow to the top of the calyt. Longest stamens longer than the corolla

Stems ascending. Corolls tube broadly campanulate. Longesit stamens not longer than the lower lobes of the corolla .

1. B. vulgare.

2. B. plantaginewm.

1. E. vulgare, Linn. (fig. 692). Viper's Buyloss.-Stem erect, 1 to 2 feet high, covered with stiff, spreading, almost prickly hairs. Radical leaves stalked and spreading, but often withered away at the time of flowering; the stem-leaves linear-lanceolate, several inclies long. Flowers showy, at first of a reddish purple, turning afterwards bright blue, in numerous 1-sided spikes, forming a long terminal panicle. Corolla about 7 lines long, the narrow part of the tube about as long as the calyx, the limb very oblique, the longest stamens longer than its lower lobes.

On roadsides and waste places, throughout Europe and western Asia, except the extreme north. Dispersed orer a great part of Britain, abunilant in some parts of southern England, but becomes rare in the north; in Ireland chiefly near the east coast. Fl. all summer.

2. E. plantagineum, Jinn. (fig. 693). Purple E.-Radical leaves broader and more permanent than in $E$. vulgare; the stems branched from the base, and more spreading; the flowering spikes fewer and much longer; the flowers highly coloured, much larger, often an inch long; the narrow part of the tube very short, spreading into a bread campanu. late throat, with a very oblique limb ; the lower lobes rather longer than the longest stamens. $E$. violaceum, Hook. and Arn., not of Linnæus.

In waste places, chiefly near the sea, in southern Europe, extending up the western coasts to Jersey, and has also been found near Penzance in Cornwall. Fl. summer.

\section{PULMONARIA. LUNGWORT.}

Perennial herbs, with a creeping rootstock and rather large blue or purple flowers. Calyx tubular-campanulate, 5-toothed or cleft to the midllle only. Corolla with a straiglit tube open at the mouth, without seales, and a spreading 5 -lobed limb. Stamens included in the tube. Nuts smooth.

A European genus, limited to a very few species.

1. P. officinalis, Linn. (fig. 694). Common L.-Radical leaves in distinct tufts, ovate-oblong or nearly linear, on long footstalks, and coarsely hairy, usually much spotted. Flowering stems from 6 inches to a foot high, with shorter, alternate, mostly sessile leaves, the lowest sometimes reduced to scales. llowers in a terminal, forked cyne. Calyx very hairy, little more than 4 lines long at the opening of the flower, but twice that length when in fruit, the teeth or lobes not reaching to the middle. Limb of the corolla broadly spreading, with short lobes.

In woods, in central and southern Europe to the Caucasus, extending northwards into Scandinavia. Rare in Britain, the only really wild stations are in Hampshire and Dorset. Fl. spring. The British specimens belong to a variety $P$. angustifolia, Linn., with narrow leaves, rarely spotted, but in many parts of the Continent the two forms pass very gradually one into the other. 'The broad-leaved variety has been long cultivated in cottage-gardens, and has here and there strayed into adjoining woods. 


\section{MERTENSIA. MERTENSIA.}

Perennial herbs, nearly glabrous, differing from Pulmonaria in their short, open, deeply 5.cleft calyx, in the stamens protruding slightly from the tube of the corolla although shorter than the limb, and in their slightly fleshy nuts.

Besides the British species there are several nearly allied to it from North America and Siberia.

1. M. maritima, J)on. (fig. 695). Sea M.-A procumbent leafy perennial, almost succulent, covered with a glancous bloom. Leaves obovate, entire, rather thick, and of en wavy ; the lower ones stalked, the upper ones sessile. Flowers rather small, of a beautiful purple-blue, forming a loose terminal cyme; the pedicels nearly 6 lines long. Segments of the calyx ovate, very broad after flowering, but scarcely longer than the nuts.

A seacoast plant, common in northern Europe and Asia and northwest America, at high latitudes, and descending along the coasts of Scotland to Berwick, North Wales, and Ireland. Fl. spring and early summer.

\section{LITHOSPERMUM. GROMWELL.}

Annuals, perennials, or, in some exotic species, undershrubs, more or less hairy; with leafy stems, and blue or whitish flowers, in leafy cymes or 1-sided spikes. Calyx deeply 5-cleft. Corolla with a straight tube, not closed by scales, and a spreading, shortly 5-lobed limb. Stamens included within the tube. Nuts very hard and stony.

A considerable genus, widely spread over Europe and northern Asia, although most of the species belong to the Mediterranean region.

Flowers sinall, white, or pale yellow. Stems erect.

Stock perennial. Nuts smooth.

Annual. Nuts wrinkled $\cdot: 0^{-}$. 1. $L$. arvense.

Flowers showy, of a bight blue. stoms long and strag. gling .

1. I. arvense, Linn. (fig. 696). Corn G., Bastard Alkanet.-An erect, usually branched annual, about a foot high, and more or less hoary with appressed hairs. Leaves narrow-lanceolate, or nearly linear. Flowers small and white, sessile, in leafy terminal cymes; the segments of the calyx nearly as long as the corolla. Nuts shorter than the calyx, conical, very hard, and deeply wrinkled.

In cultivated and waste places, in Europe and western and central Asia, not extending to the Arctic regions, but carried out as a cornfield weed to various parts of the world. Rather frequent in Britain. Fl. spring and summer.

2. L. officinale, Linn. (fig. 697). Common G.-Stock perennial, with a stouter and taller stem than that of $L$. arvense, which this species otherwise much resembles. Flowers ratber smaller, of a jellowish white; the calyx shorter in proportion. Nuts hard and white, very smooth and shining, without any wrinkles unless dried before they are ripe.

In waste places, on roadsides, \&c., diffused over the whole of Europe and liussian Asia, except the extreme north, and established in many 
parts of North America. Common in England and Ireland, but rare in Scotland. Fl. spring and summer.

3. I. purpureo-cœruleum, Linn. (fig. 698). Creeping G.-Stock perennial, with procumbent, leafy stems, often 2 feet long or more, and shorter ascending or nearly erect flowering stems, ending in a leafy forked cyme. Leaves lanceolate and hairy. Hlowers uearly sessile, of a rich blue, rather large, but usually shorter than the leaves; the calyx segments narrow. Nuts smooth and shining.

In thickets and open woods, in central and southern Europe, from the Atlantic to the Caucasus. Rare in Britain, and only in Wales and some of the southern counties of England. Flo summer.

\section{MYOSOTIS. MYOSOTE.}

Annual or perennial, low or rather weak herbs, with oblong or linear stem-leaves; the radical ones broader, shorter, and stalked; the flowers small, blue or white, in 1-sided racemes, either forked or simple, withont bracts at the base of the pedicels. Calyx 5-toothed or 5-cleft. Corolla with a small, straight tube, lalf-closed at its mouth by 5 short scales, and a spreading, flat or concave, 5-lobed limb. Stamens included in the tube. Nuts smooth and shining, compressed or triangular attached by their small base.

A numerous genus in Europe and northern Asia, scarce in North America, but reappearing in Australia. Although the characters which separate it from Anchusa appear slight, it is very distinct in habit.

Some exotic species are cultivated in our tlower-gardens, together with varieties of $\boldsymbol{M}$. palustris, $M$. sylvatica, and $\boldsymbol{M}$. collina.

Calgx-teeth short or not divided beyond the middle. Hairs of the

caly $x$ appressed

Calyx deeply cleft, tho hairs spreading or hooked.

Pedicels as long or longer than the culyx, 3 to 6 luches loug when in frult.

Perennial with rather large flowers, Limb of the corolla fitt .

Annual or biennial, with small flowers. Limb of the corolla often concave ${ }^{\circ}$ line long, usually shorter than the caly $\dot{x}$.

\section{Pedicels not
Annuals.}

8tem ascending or branched from the base. Calyx usually open after flowering. Corolla al ways blue .

Btem erect, simple at the base. Calyx alwayo closed after nowering. Corolla at first yellow, afterwards blue .

1. B. palustrie.

2. M. sylvatica

3. M. arvensis.

1. M. palustris, With. (fig. 699). Water M., Forget-me-not.-Perennial, stock usually slightly creeping; the stems weak, ascending, from 6 to 18 inches high, often nearly glabrous, but sometimes rather thickly clothed with spreading hairs. Leaves glabrous or with appressed hairs. Flowers of a bright clear blue, with a yellow eye, very variable in size, but usually rather large for the genus. Calyx never divided below the middle, whilst in all other British species it is deeply cleft.

In wet ditches, and by the sides of streams, in Europe, Russian Asia, N. India, and northern America, extending into the Arctic Circle. Abundant in Britain. Fi, the whole summer. Modern botanists divide It into three: the true Porget-me-not, which is often nearly glabrous, - :th a broad flat corolla, and short broad teeth to the calyx; M. repene 
Don., which is more hairy, with narrower lobes to the caly $\mathrm{x}$, reaching to about the middle; and $M$. caspitosa, Schultz, with a smaller corolla, with the limb often slighty concave; the first is more common in the south, the last in the north, but they all three run so much one into another as not to be distinguishable with certainty even as varieties.

2. M. sylvatica, Hoffm. (fig. 700). Wood $M$. - A perennial, like $\boldsymbol{M}$. palustris, but with a more tufted stock, and rather roughly hairy. Calyx cleft nearly to the base, with narrow segments, erect when in fruit; its hairs more or less spreading, and crisped or hooked when seen through a lens. Corolla as large as or even larger than in the $M$. palustris, with the limb spread out tlat.

In mountain pastures and shady situations, common in the far north of Europe and Asia, as well as in the great central chains from the Pyrenees to the Caucasus and the Altai. Not frequent in Britain, nor occurring north of Forfarshire. Fl. summer. It varies much in size and stature ; in lower shady situations, and in our gardens, the stems will attain a foot or more in length, with rather small flowers. The alpine form, with larger flowers, is by some distinguished as a species, under the name of $M$. alpestris, Schmidt. It is extremely rare, and confined to the high mountains of Perthshire, Teesdale, and Westmoreland.

3. M. arvensis, Hoffm. (fig. 701). Ficld M.-An annual or sometimes biennial, with a weak stem often above a foot long. It has the hairy foliage and deeply cleft calyx of $M$. sylvatica, but the corolla, although variable, is much smaller, with a short concave limb. Calyx shorter than the pedicels, or scarcely so long even when in fruit, with narrow segments, erect when in fruit.

On hedge-banks, in cultivated ground, the edges of woods, and bushy places, throughout Europe and central and northern Asia, and in North America. The most common species all over Britain. Fl. all summer and autumn. Some of the large-flowered specimens are difficult to distinguish in the dried state from the smaller-Howered ones of $M$. sylvatica, but when fresh $I$ have never observed any really internediate forms.

4. M. collina, Hoffm. (fig. 702), Early M.-A low, much branched, hairy annual, seldom attaining 6 inches ; the leaves mostly collected in radical tufts, with a few at the base of the flowering branches, which consist chiefly of the slender racemes; the pedicels seldom above a line long. Calyx, when dry, exactly like that of $M$. arvensis, but in the living plant its segments are spreading, not erect, after flowering. Corolla very small, of a bright blue, with a small, concave limb.

On dry, open places, in central and soutinern Europe, to the Caucasus and the western Himalaya. Not frequent in Britain, but apparently more so in the south of England than further to the north, and is also found in eastern Ireland. Fl. early summer, and dies soon after. A white-flowered and more permanent variety, M. Mittenii, is often cultivated. Occasional intermediate forms excite some doubts as to whether this be really specifically distinct from $M$. ervensis.

5. M. versicolor, Pers. (fig. 703). Changing M.-A little hairy unnual, with a more simple and erect stem than any of the fore- 
going, from a few inches to near a foot high, with a spreading tuft of radical leaves, and a few erect ones along the stem. Flowers small and nearly sessile; the calyx-segments quite closed over the fruit after flowering; the corolla small, at first pale yellow, and turning blue as it fades.

On banks, in meadows and pastures, in central and southern Enrope and western Asia, extending northwards into Scandinaria. Abundant in Britain. Fl. spring.

\section{ANCHUSA. ALKANET.}

Coarse, hairy biennials or perennials, with rather large blue flowers, in 1-sided spikes, with a bract nnder each flower. Calyx deeply 5-cleft. Corolla with a straight tube, often slightly enlarged at the top, and closed at the mouth by nsually hairy scales; the limb spreading and 5-lobed. Stamens included in the tube. Nuts rather large, wrinkled, angular, attached by their broad, concave base.

The species are numerons in southern Europe and western Asia, a very few extending far to the north.

Leaves lanceulnto. Flowers in terminal forked panicles

Leaves broadiy ovate. Flowers in short sxillary spikes

1. A. officinalis.

2. A. sempervirens.

1. A. officinalis, Linn. (fig. 704). Common A.-A biennial, about 2 feet high, with coarse, stiff hairs; the root thick and hard. Radical leaves long and stalked; the lower stem-leaves lanceolate, broad and narrow, from 2 to 5 or 8 inches long; the npper ones gradually smaller. The 1 -sided forked spikes lengthen considerably as the flowering advances, and form a kind of terminal panicle. Flowers nearly sessile, with a small, leafy bract at the base of each; the calyx very stitly hairy, with narrow divisions; the corolla of a rich blue, and rather large, but varies in size.

In waste places, on roadsides, \&c., all orer the continent of Europe, except the extreme north, and eastward to the Caucasus. In Britain only on ballast hills, and very rare. Fl. summer.

2. A. sempervirens, Linn. (fig. 705). Green A.-Stock pereunial, the stems more straggling than those of $A$. officinulis, but covered with the same coarse, stiff hairs. Leaves broadly ovate; the flowers In 1-sided, short spikes, leafy at the base, and placed in the axils of the stem-leaves. Corolla of a rich blue, with a shorter tube than in A. officinalis. Nuts expanded at the base on the inner side into a small convex appenduge.

In waste places, on roalsides, \&c., in western Europe, scarcely extending eastward along the Muditerranean, and not reaching the Rhine. Scattered over several parts of Britain, but not truly wild. Fl. spring and summer.

\section{LYCOPSIS. BUGLOSS.}

A small European and north Asialic genus, distinguished from $\Delta$ nchusa by the curved tube of the corolla. The species are all annuals, with small flowers.

1. L. arvensis, Linn. (fig. 706). Small B.-A coarse, spreading 
annnal, covered with very stiff hairs. Stems procumbent at the base, branched, 1 to 2 feet long. Leaves lanceolate or oblong-linear, waved on the edges, and often toothed; the lower ones often stalked, the npper ones sessile or stem-clasping. Flowers in simple or forked, terminal, 1-sided spikes. Calyx deeply 5-cleft, and nuts wrinkled as in Anchusa. Corolla pale blue, with the tube always curved in the middle.

A common European and north Asiatic weed of cultivation, carried out witb European crops to North America, and other parts of the world. Extends all over Britain. Fl. summer.

\section{SYMPHYTUM. COMFRKY.}

Rongh, hairy perennials, with yellow or purple drooping flowers, in short, terminal, forked cymes, and no bracts under the pedicels. Calyx deeply 5-cleft. Corolla tubular, but enlarged above the middle, where it is closed inside by 5 lanceolate scales, and terminates in 5 very small spreading teeth or lobes. Stamens shorter than the corolla. Nuts ovoid, smooth, attached by their base.

The genus contains but few species, nearly resembling each other, and extends over Europe and northern Asia.

Stem 2 or 3 feet high, branched, mure or less winged by the decurrent base of the leaves
stem simple, about a foot high. Leaves stalked or scarcely de-

current . . . . . . . . . 2. S. tuberosum.

1. S. officinale, Linn. (fig. 707). Common C.-Rootstock thick, with stout, erect, branching, annual stems, 2 or 3 feet high. Leaves broadly lanceolate, often 8 or 9 inches long or more, tapering into a long point, and rough with short, stiff hairs; the lower ones stalked, the upper ones sessile and decurrent along the stem to the next leaf below or even lower down. Flower cymes stalked above the last leaf, once or seldom twice forked; the branches forming short, 1-sided racemes. Flowers all pedicellate, 3 lines long, either pale yellow or a dark dingy-purple.

On moist banks, the borders of meadows, \&c., in Europe and western Asia, extending northward into southern Scandinavia. Frequent in England and Ireland, but less so in Scotland, and not wild north of Aberdeen or Glasgow. Fl. spring and summer.

2. S. tuberosum, Linn. (fig. 708). Tuberous C.-A mucb smaller plant than the common species, seldom above a foot high, and not branched. The rootstock forms a short woody tuber. Leaves mostly ovate and stalked; the upper ones nearly sessile, and very slightly decurrent. Cymes small and few-flowered, the flowers themselves about the size of those of $C$. officinale.

In woods, and on shady banks, in central and sonthern Europe, but scarcely extending into northern Germany. In Britain, not found south of North Wales and Bedford, being more frequent in southern scotland than in England; absent from Ireland. Fl. summer.

\section{BORAGO. BORAGE.}

Kough, halry annuals or biennials, with blue flowers in loose forked cyucs. Calyx deeply 6-cleft. Corolla rotate; the tabe exceedingly 
short; the mouth closed by short scales. Stamens 5; the filaments very short and forked; the anthers forming an erect cone in the centre of the flower. Nuts attached by their excavated base, and free from the style.

A genus of few species, chiefly from north-eastern Europe and western Asia.

1. B. officinalis, Linn. (fig. 709). Common B.-Stem erect, with spreading branches, a foot high, or rather more. Lower leaves obovate or oblong, narrowed at the base into long stalks; the upper ones more shortly stalked, and narrower. Flowers on long pedicels, drooping, of a clear blue or sometimes white; the dark anthers very prominent in the centre.

In waste gronnds, indigenous to the east Mediterranean region, long cultivated in European gardens, and naturalised in many parts of central and western Europe, and in several counties of England. $F$ all summer.

\section{ASPERUGO. ASPERUGO.}

A single species, allied to Anchusa, but universally admitted as a genus on account of the peculiar calyx and habit.

1. A. procumbens, Linn. (fig. 710). Madicort.-A weak procumbent annual, rough with short, stiff, almost prickly hairs, many of them curved or hooked so as to be very adhesive. Leaves oblong or lanceolate, narrowed at the base, the lower ones stalked, those under the flowers often nearly opposite. Flowers small and blue, 1 to 3 together in the axils of the npper leaves, on very short, recurved pedicels. The broadly campanulate calyx enlarges immediately after flowering, becomes much flattened, veined, and divided to the middle into 5 lanceolate lobes, with 1 or 2 small ones between each. Corolla that of a very small Anchusa. Nuts ovoid, with a granulated surface.

In cultivated and waste places, over nearly the whole of Europe and northern Asia short of the Arctic Circle. Occurs as a weed of cultivation in many parts of England and Scotland, but not in Ireland. Fl. oummer.

\section{CYNOGLOSSUM. HOUND'S-TONGUE.}

Stout, erect biennials, clothed with rough hairs, which are, however, more appressed and hoary than in most Boragineous plants; with long, narrow leaves, and rather small, blue or purplish-red flowers, in simple or forked 1-sided racemes. Calyx deeply 5-cleft. Corolla with a short tube, closed at the mouth by prominent scales, and a spreading, 5-lobed, regular limb. Nuts rather large, depressed, attached laterally to the base of the style, and covered with short, hooked prickles, so as to make them very adhesive burs.

A European and Asiatic genus, rather numerous in species, especially if considered as including the little blue-flowered Omphalodes and the white-flowered $C$. linifolium. These two species, formerly frequent in our flower-gardens, are, however, now generally distinguished with some others as a genus by the nuts, which instead of being muricated all over, have a raised, more or less toothed border. 
Leaves hoary with rather soft appressed halrs. Flowers dull purple-red

Leaves green, rough with scittered halrs, Flowers bluish-purple

1. C. officinale.

2. C. montanum

1. C. officinale, Linn. (fig. 711). Common $H$.-Stem stout, erect, and branched, abont 2 feet high, with rough hairs. Leaves lanceolate, or often the radical and lowest ones oblong, stalked, and sometimes near a foot long; the others gradually shorter, with shorter stalks, the uppermost sessile and clasping the stem; all of them hoary with a dense, rather soft, appressed down. Racemes numerous, mostly simple, forming a terminal leafy panicle; the pedicels short, without bracts. Calyx-segments broadly lanceolate. Corolla rather small, of dull purplish-red. Nuts flattened and bur-like, often above 3 lines dianeter. The whole plant has a disagreeable smell.

On roadsides and waste places, in Europe and Russian Asia, extend. ing far into Scandinavia. Not unfrequent in Britain from Forfar Bouthwards; but confined to the south-east of Ireland. Fl. summer.

2. C. montanum, Lam. (fig. 712). Green $H$.-Much like $C$. officinale, but generally not so stout, much grcener; the hairs of the leaves fewer, more scattered and stiffer; the upper leaves broader at the base, and the spikes more slender, with fewer and smaller flowers, of a dull bluish. purple tinge. C. sylvaticum, Haenkr.

In woods and shady places, chiely in the forests and mountain districts of the continent of Europe, extending eastward to the Caucasus. Not common in Britain, occurring in the southern and some of the central or eastern counties of England, Dublin only in Ireland, not known in Scotland. Fl. sunmer.

\section{SOLANACEE. THE SOLANUM FAMILY}

Her'ss, shrubs, or soft-wooded trees, witl alternate leaves without stipules, but sometimes accompanied by a smaller leaf at their base; the flowers solitary or in forked cymes, on lateral or terminal peduncles. Calyx usually with 5 teeth, lobes, or secments. Corolla monopetalous, with 5 or rarely 4 teeth or lubes, regular or nearly so, and folded in the bud. Stamens as nany as the lubes of the corolla, and alternating with its divisions. Ovary 2-celled, rarely incompletely 4-eelled, with several ovules in each cell. Fruit a berry or rarely a capsule, with several seeds.

A numerous family in the tropical and warmer parts of the globe, only represented in northern regions by a few stragglers from more southern latitudes. A large proportion of the species contain a narcotic, poisonous principle, although several are important articles of food.

Fruit a capruie.

Corullis large, with a long tube. Capsule prickly, 4-valved.

curolla obliquely campanulate, with a short tube Capsule sinooth

rruit a berry.

1. Datuka.

2. II roecramun 
Corolla rutate. Ant'ters close together, in a projecting cone, opening by pores at the top

Corolla campanulate. Anthers distinct, opening by longitu-

8. Botanux. dinal slits

Several Solanacec belonging to exotic genera are cultivated for use or ornament, among which may be mentioned Lycium barbarum, often called Tea-plant, a straggling or climbing shrub, with small lilac flowers, often to be seen in cottage gardens, and established in hedges in some of the eastern counties; the Tobacco (Nicotiana), and the closely allied ornamental genera Petunia and Nierembergia, the Mandrake (Mandragora), the Winter-cherry (Physalis), the Cayenne Pepper (Capsicum), as well as the Cestrums and Fabianas and even Nolanas of our gardens, which, although somewhat anomalous, belong to Solanacca.

\section{DATURA. DATURA.}

Coarse annuals or soft-wooded shrubs. Corolla long, funnel-shaped and regular. Capsule large, opening in 4 valves, and partially divided into 4 cells.

A small genus, spreading over the warmer regions of the globe. The large shrubby Daturas, of ten distinguished as Brugmansias on account of their smooth, not prickly capsules, are from South America.

1. D. Stramonium, Linn. (fig. 713). Thorn-apple.-A coarse, glabrous or slightly downy annual, 1 to 2 feet high, with spreading, forked branches. Leaves rather large, ovate, with irregular, angular or pointed teeth or lobes. Flowers solitary, on short pednncles, in the forks or at the ends of the branches. Calyx loosely tubular, about $1 \frac{1}{2}$ inches long, and falls off after flowering, leaving a small rim under the capsule. Corolla above 3 inches long, bordered with 5 narrow, distant teeth, usually white, but occasionally (especially in hot conntries) purple. Capsule nearly globular, very prickly, with numerous wrinkled seeds.

A common roadside weed, in southern Europe and all over the warmer parts of the globe, extending northward into southern Sweden. Appears not unfrequently in sonthern England, but can scarcely be considered as naturalised. Fl. summer and autumn.

\section{HYOSCYAMUS. HENBANE.}

Coarse, usually hairy annuals or biennials. Corolla obliquely campanulate or shortly funnel-shaped, 5-lobed. Capsule enclosed in the enlarged calyx, bursting when ripe round a circular raised ring immediat ely below the hardened top.

A Mediterranean genus, extending from the Canary Islands to central A sia.

1. H. niger, Linn. (fig. 714). Common H.-A coarse, erect, branching annual, 1 to 2 fcet high, more or less hairy and viscid, with a nauseous mell. Leaves rather large, sessile; the upper ones clasping the stem, ovate, and irregularly pinnatifid. Flowers very shortly stalked; the lower ones in the forks of the branches; the upper ones sessile, in 1. sided leafy spikes, rolled back at the top before flowering. Caly $x$ short when in flower, but persists round the fruit, and then an inch long, 
strongly veined, with 5 stiff, broad, almost prickly lobes. Corolla above an inch long, pale, dingy-yellow, with purplish veins. Capsule globular, with numerous small seeds.

In waste, stony places, on roadsides, \&c., in central and southern Europe and western Asia, and having been formerly much cultivated for its medicinal properties, has spread far into northern Europe. In Britain, chiefly on rubbish and waste places, about villages and old castles, in England, sonthern Scotland, and Ireland. Fl. summer.

\section{SOLANUM. SOLANUM.}

Herbs, shrubs, or, in exotic species, low trees; the flowers usually in cymes, on short, lateral, or terminal peduncles. Caly $x$ of 5 or rarely more divisions. Corolla rotate, 5 -lobed, with scarcely any tube. Anthers almost sessile, closed or joined together in an erect cone round the style in the centre of the flower, each anther opening by a small pore at the top. Fruit a berry, with several seeds.

A very large genus, widely spread over the globe, but chiefly in tropical regions, and more especially in Sonth America. The enltivated speeies include the Potato (S. tulicrosum), the T'omato or Love-apple (S. Lycopersicum), the Egg-plant or Brinjall (S. Melongcna), and several ornamental ones.

Climher, shrubby at the base. Leaves slightly cordate or 3-lobed 1. S. Dulcamara. Erect anumal or biennial. Leaves uvate, angularly tothed. . 2. S. nigrum.

1. S. Dulcamara, Linn. (fig. 715). Bittersweet, Nightshade,-Stem shrubby at the base, with climbing or straggling branches, of ten many feet in length, but dying far back in winter. Leaves stalked, ovate or ovate-lanceolate, 2 or 3 inches long, usually broadly cordate at the base and entire, but sometimes with an additional smaller lobe or segment on each side, eitber quite glabrous or downy on both sides as well as the stem. Flowers rather small, blue, with yellow anthers, in loose cymes, on lateral peduncles shorter than the leaves. Berries small, globular or ovoid, and red.

In hedges and thickets, in moist shady situations, all over Europe, except the extreme north, represented all across temperate Asia by a closely allied species, or perhaps a mere variety. Generally diffused over England and Ireland, but more rare in Scotland. Fl. summer. [A maritime variety (marinum, Bab.), with a prostrate branched stem and fleshy habit, occurs on the south coast of England.]

2. S. nigrum, Linn. (fig. 716). Black S.-An erect annual or biennial, with very spreading branches, about a foot high; in Britain usually glabious or nearly so, but on the Continent often hairy or rough on the angles. Leaves stalked, ovate, with coarse angular teeth. Flowers small and white, in little cymes almost contracted into umbels, on short, lateral peduncles. Berries small, globular, usually black, but sometimes, especially on the Continent, green, yellow, or dingy-red.

One of the widest spread weeds over every part of the globe, except the extreme north and south; varying so much in warmer regions as to have been described under more than forty names. Common in some parts of England, but local in Scotland and Ireland, and only 
when accidentally introdnced with cultivation.

Flo the whole summes and autumn.

\section{ATROPA. ATROPA.}

Calyx broadly campanulate, deeply 5-lobed. Corolla campanulate, regular. Fruit a berry.

A genus confined by some to the single European species, but extended by others to include several herbs or shrubs from warmer climates, of no interest to the British botanist.

1. A. Belladonna, Linn. (fig. 717). Drale, Belladonna, Dcadly Nightshade.-An erect, glabrous or slightiy downy herb, with a perennial rootstock and branching stem. Leaves stalked, rather large, ovate and entire, with a smaller one nsually proceeding from the same point, often 80 small as to look like a stipule. Flowers solitary, on short peduncles, in the forks of the stem or in the axils of the leaves. Corolla pale, purplish-blue, nearly an inch long, with 5 broad short lobes. Stamens shorter, with distinct filaments. Berry rather large, globular.

In waste, stony places, in sonthern Europe and west central Asia, extending over central Europe, chiefly about old castles and ruins. In Britain, it is only found in similar localities in southern England, and a few stations farther north, or in Ireland, probably the remains of former cultivation. Fl. summer.

\section{OROBANCHACEA. THE BROOMRAPE FAMILY.}

Herbs, of a brown or purplish colour, passing into yellow or blue, but never green, always parasitical on the roots of other herbs or shrubs; the stems simple or rarely branched, erect, bearing scales of the same colour instead of leaves, and a terminal spike of flowers, each in the axil of a bract, similar to the scales of the stem, and accompanied often by a pair of smaller bracts at the base of the calyx. Calyx variously divided, usually into 2 or 4 lobes or sepals. Corolla broadly tubular or campanulate, often curved, the lobes more or less 2-lipped. Stamens 4, in 2 pairs. Anthers 2-celled, the cells parallel, and usually pointed at the lower end. Style single, with a 2-lobed stigma. Ovary and capsule 1-celled, the latter opening in 2 valves, with numerous small seeds attached to parietal placentas.

A small Order, spread over the greater part of the globe, but chiefly in temperate climates, and more abundant in the old World than in America. The floral characters are nearly those of the Scrophularia family, with the exception of the ovary and capsule, which are never rivinad into cells, the placentas not joining in the centre. The absence 
of green leares at once distinguishes it from all British species of that family.

Calyx deeply divided into 2 or 4 pointed sepals .

Calyx with 4 broad, short teeth or lobes

1. OROBANOHR.

2. LATHRAA.

\section{OROBANCHE. BROOMRAPE.}

Calyx divided to the base on the upper side, and often also on the lower side, so as to form 2 lateral sepals, either entire or 2-cleft, either distinct from each other, or more or less connected at the base on the lower side, and sometimes on the upper side also by the intervention of a fifth lobe, and always pointed. Habit and other characters those of the family.

It is the principal genns of the Order, extending over the whole of its geographical range. The species are in general difficult to characterise. Some appear to thrive only on the roots of one species, or at most two or three closely allied ones, whilst others will grow on a great variety of plants of the most remote natural affinities. But as the particular stock the plant feeds on may occasion some modification in the habit of the parasite, it is in many cases a matter of great doubt whether the differences observed are owing to this circumstance or to real specific distinction. It is not therefore improbable that some of the speeies here arlopted, although much less numerous than those usually distinguished, may on a mere careful observation prove to be mere rarieties of each other.

One bract only under each flower. Plant with llttle or no blue.

Stout plant, 1 to 3 feet high, with numerous flowers in a dense spike.

Plant dingy-brown, on shrubby Leguminosa. Stamens

glabrous below
Plant more or less yellow, on Centaurea and other herbs. Stamens hairy below
seldom above a foot high. Spike short, or with the

Plant seldom above a foot
lower flowers distant.

Plant of a dingy-brown, or wlth a recldish tint. Tube of the corolla broad.

Calyx of 2 entire or unequally divlded sepals. Plaut red-brown, on Thyme.

Calyx of 2 equally divlded sepals. Plant liglit or ilarkbrown, on Galium

Plant of a llght yellowish-brown or purplish, the fiowers often tinged with blue. Tube of the corolla narrowed above the base

Three bracts to each flower, one underneath, and a smail one on each side. Plant often bluish.

Stem always simple. Calyx 5-toothed or lobel

Stem often branched. Calyx 4 -toothed or -lobed

1. O. major.

4. O. elatior.
3. O. rubra.

2. O. caryophyllacen

5. 0. minor.

1. O. major, Linn. (fig. 718). Great B.-This, our largest species, is first of a pale yellow, but soon assumes in every part a dingy purplish-brown. Stem simple, stout, from 1 to $1 \frac{1}{2}$ or 2 feet high, much thickened at the base, with lanceolate scales, which are much shorter and broader at the base of the plant. Flowers closely sessile, with 1 bract to each, forming a dense spike at least half the length of the whole plant. Calyx more or less deeply divided into 2 or 4 lanceolate lobes. Corolla \& to 1 inch long; the tube nearly as broad as long, curved with a very oblique limb; the upper lip entire or shortly 2-lobed, the lower one 3-lobed, with the middle lobe usually, 
Imst not always larger than the lateral ones, and all the lobes toothed snd wavy, although less so than in many species. The upper part of the style and stamens are usually covered with short glandular hairs, which are usually wanting in the lower parts. O. Rapum, Thuill.

On the roots of the shrubby Leguminous plants, scattered over nearly the whole of Enrope. Not uncommon in some parts of England, extending to Dumfriesshire, chiefly on Broom, more rarely on Furze, rare in Ireland. Fl. early summer.

2. O. caryophyllacea, Sm. (fig. 719). Clove-scented B.-The colour of the plant and size of the flowers are those of 0 . major, but the stem is seldom above 8 or 9 inches high; the flowers are much fewer, and farther apart; the tube of the corolla is not quite so broad; the upper lobes scarcely spreading, and the lower ones nearly equal, and the stamens more hairy at the base. The flowers are usually sweet. scented.

Said to grow exclusively on Galiums; common on the continent of Europe, extending across the whole of Asia. In Britain limited hitherto to a very few of the southern counties of England. Fl. early summer.

3. O. rubra, Linn. (fig. 720), Red B. - A rather smaller plant than 0 . caryophyllacea, which it resembles in the shape of the flowers, but these are nearer the size of those of $O$. minor, and the whole plant assumes a very red-brown colour. Calyz usually divided into 2 entire sepals with narrow points, but these are sometimes again divided, although very unequally, or nnited in front at the base, as in 0 . minor, and other species.

On the roots of Thyme, in central and southern Europe. In Britain, only on the basalt and trap-rocks in Scotland and Ireland. $F$. summer.

4. O. elatior, Sutt. (fig. 721). Tall B.-Closely resembling $O$. major in statnre and flowers, of which it is probably a mere variety. It retains longer its pale yellow colour; the lobes of tho corolla are less unequal and more toothed, and the stamens are hairy in their lower part, and nearly glabrous above.

On Centaurea and not on Leguminous shrubs; said to be more abundant than 0. major iis eastern Europe, in Britain it inhabits chiefly the eastern and sonthern connties, but has occurred in South Wales. Fl. summer.

5. O. minor, Linn. (fig. 722). Lesser B.-Often small, and always more slender than any of the preceding, with smaller flowers. Generally of a light brown or yellowish colour, with more or less of bluishpurple in the flowers, although not running into the deep purple-blue of the two following species. It is usually from 6 to 9 inches high, although some of the larger specimens exceed a foot; the lower flowers of the spike are at some distance from each other. Segments of the calyx ending In long slender points. Tube of the corolla contracted in the middle, much curved; the lobes of the limb larger in proportion, and more wavy than in 0 . major and 0 . caryophyllacea. Stamens more or less hairy in their lower part.

One of the widest spread species over Europe and Russian Asia, growing on a great variety of plants. In Britain, not uncommon in southern and central England, and southern Ireland. $F l$. all summer. 
It varies according to station, and the plant it affects. Many of these varieties are considered as species, and three are commonly admitted into the British Flora:-O. picridis, F. Schultz, a tall, very palecoloured variety, growing on Picris hieracioides; 0. amethystea, 'Thuill., assuming a bluer tint than any of the others, and growing on Eryngium; O. Hederce, Duby, not uncommon on $1 v y$ in the south of England and Ireland, as on the Continent; it is said to differ from the common form in the yellow, not purple, stigma, and other trifling characters, which, however, do not appear to be constant.

6. O. cærulea, Vill. (fig. 723). Blue B.-Stem simple or rarely branched, 6 to 9 inches high, with a light bluish tint. Flowers of a deep purplish-blue, with 2 small bracts at its base, 1 on each side, besides the larger bract common to all Orobanches. Calyx usually closed at the back by a fifth tooth or lobe, much shorter and broader than the others. Corolla-lobe rather long and curved; the 5 lobes, although arranged in 2 lips, are less unequal, and less wavy than in the preceding specles.

Chiefly, if not exclusively, on Achillea MIIllefolium; not uncommon on the continent of Europe, and in west-central Asia. In Britain, only in grassy pastures near the sea, in the eastern and southern counties, and in the Channel Islands. $F$. carly summer. The O. arenaria, Borkh., a larger plant, of a paler blue, with hairy anthers, parasitical on Artcmisias in light, sandy soils, has been found in Alderney.

7. O. ramosa, Linn. (fig. 724). Branched B.-Very much smaller than $O$. carulca, of a pale straw-colour, with smaller pale-blue flowers. Stem often branched, seldom above 6 inches high. Flowers shaped like those of $O$. carulea, and, like them, they have 2 small lateral bracts besides the larger one; but the calyx is split at the back, and has only 4 lobes, as in the brown Orobanches.

On Hemp, Lucern, and some other crops, chiefly in southern Europe, and has been found, though very rarely, in some of the southern and eastern counties of England. Fl. summer.

\section{LATHRAA. TOOTHWORT.}

A small genus closely allied to Orobanche, but the flowers are less irregular, the calyx broadly campanulate or inflated, with 4 short, broad, erect lobes, the upper lobe of the corolla forming a more or less distinct npper lip, and the 4 placentas to which the seeds are attached in the capsule are more fleshy, and more distinctly united in pairs.

1. I. squamaria, Linn. (fig. 725). Common T. $\rightarrow$ A pale rose-coloured plant, with flesh-coloured or slightly bluish flowers, streaked with purple or dark red. Rootstock fleshy and creeping, covered with close-set, short, thick, fleshy scales. Flowering stems erect, from 3 or 4 inches to wear a foot high, with a few broad, orbicular, much less fleshy scales, pasing gradually into the bracts. Flowers numerous and nodding, in a dense spike, or sometimes shortly stalked. Calyx about 5 lines long. Corolla half as long again, the upper lip entire or slightly notched. Stamens and style nearly as long as the corolla, or sometimes, especially the style, projecting beyond it.

On the roots of trees, especially the Hazel, throughout Kurope and 
central and Russian Asia, except the extreme north. Not uncommon in England and Ireland, and extends into the central counties of Scotland. Fl. early spring.

\section{SCROPHULARINE压. SCROPHULARIA FAMILY.}

Herbs, or in some exotic species shrubs, with opposite or alternate leaves and no stipules. Calyx persisting round the fruit, usually with 5 teeth or segments, sometimes fewer. Corolla monopetalous, usually 2-lipped, but sometimes nearly regular, with 4,5 , or rarely more lobes, always overlapping one another in the bud. Stamens usually 2, or 4 in 2 pairs, very rarely 5 , inserted in the tube of the corolla. Ovary and capsule divided into 2 cells, with several seeds in each cell. Style simple, usually ending in a 2-cleft stigma.

A numerous family, widely diffused over the globe, from the Arctic Circle to the tropics, although more abundant in temperate regions than in the extremes of heat or cold, and, generally speaking, well-marked by the 2-lipped or personate corolla, the stamens in pairs, and the several seeds in each cell of the capsule; but there are some anomalous genera in which these characters are much modified, and two large and natural exotic families, the Bignonia and Acanthus families, are only to be accurately distinguished from Scrophularinea by an attentive study of minute characters. To the first of these belong the Bignonias and Tecomas of our hothouses, as well as the Catalpa, often planted in our gardens, and (if taken in its most extended sense) the numerous hothouse Gesnerias, Gloxinias, Achimenes, \&c. The Acanthacea include Justicias, Ruellias, and many modern hothouse genera, besides the European Acanthus, which gives its name to the family.

Curolla rotate or concave, with a very short tube.

Stamens 2. Corolla 4-cleft, never yellow.

Stamens 4 or more.

Tall, coarse, erect plants. Stamens 5, often woolly .

Small or creeping plants. Stamens 4 , glabrous.

Glabrous, almost stemless plant, with radical leaves and minute subsessile flowers

Slender, creeping, hairy plant, with orblcular, aiternate leaves, and axillary, stalked, minute flowers .

Corolla with a distinct tube.

Tube of the corolla with a spear or protuberance at the base, the mouth closed by a projecting paiate.

Tube of the corolla spurred

Tube of the corolla straight at the base, the mouth open (except in Melampyrum).

Calyx with 5 lobes or teeth, or 2 or 3 leafy jagged lobes.

Corolla nearly globular, small, dingy, with 5 unequal

Corolla more than an inch long, with a broad tube, and flat, spreading lobes.

Inowers red or white, in a long terminal raceme. Leaves alternate

Fowers yellow, on axillary peduncles. Leaves opposite Cormlla less than an Inch long, the tube slender or short.

9. VERONICA.

1. Verbascum.

6. LIMOSELIA.

7. SIBTHORPIA.

3. LINARIA.

2. ANTIRrhindM.

\section{SCROPEJUARIA.}

8. Digrtalis.

5. Mrmulus. 
Caly Inflated after flowering. Upper lip of the corolla laterally compressed

13. Pedicularis.

Calyx tubular or campanulate. Upper lip of the corolla with 2 spreading lobes.

Calyx with 4 lobes or teeth.

Upper lip of the corolla arched or with sprcaling lobes. Anther-cells pointed at the lower end.

Upper lip of the corolla nearly entire, arched or concave 10. BARTSIA.

Upper lip of the corolla 2-lobed, spreading . . . 11. EUPHRASIA.

Upper lip of the corolla much compressed laterally. Anther-cells obtuse.

Calyx much inflated, the teeth small

11. Fuphrasia.

Calyx tubular or campanulate, toothed or lobed.

- 12. Rhinanthus.

. 14. MELAMPYRUM.

These British genera belong to two of the three principal Tribes or Suborders of the family, viz:-

Tribe Antirrhinea. Upper lip or outer lobe of the corolla outslde the others in the bud. Geneta:-1. VBRBASCUM; 2. ANTIRRHINUM; 3. LiNARIA; 4. SCropiluLARIA; and 5. MIMULOS.

Tribe Rhinanthea. Upper llp or upper lobe of the corolla wholly or partlally inslde the others in the bud. Genera:-6. LIMOSELLA; 7. SIBTHORPIA; 8. DIGItalis; 9. Veronica; 10. Bartsia; 11. EUPHRASIA; 12. RHINANTHUS; 13. PediCULARIS; and 14. MELAMPYRUM.

Among the exotic genera cultivated in onr gardens may be mentioned, Browallia, Brunsfelsia, Salpiglossis, and Schizanthus, belonging to the wholly exotic tribe Salpiglossidea, now generally transferred to Solanacea; and Calceolaria, Alonsoa, Angelonia, Maurandia, Lophospermum, Paulownia, Collinsia, Pentstemon, Torcnia, and several others of the tribe Antirrhinea. The exotic genera of Rhinanthea, with the exception of a few allied to Veronica and Digitalis, are mostly parasitical, and therefore, although very handsome, not in cultivation. The south-west European Erinus alpinus, allied to Veronica, but with a 5-lobed corolla with a slender tube, is established as an escape from gardens, on old walls, especially on the Roman Wall, on the borders of Yorkshire and Lancashire.

\section{VERBASCUM. MULLEIN.}

Tall, erect, stiff herbs, often woolly ; with coarse, alternate leaves, more or less toothed; and yellow, white, or rarely purple flowers, either solitary under each bract or in short dense cymes or branches, forming terminal, simple spikes or branched panicles. Calyx deeply 5 -cleft. Corolla rotate, or concave, with a very short tube, and 5 broad, rounded lobes. Stamens 5, with all the filaments woolly or the two lower ones glabrous. Capsule ovoid, opening at the partition in 2 valves, with very numerous small seeds.

The genus extends over Europe and northern and central Asia, but is most abundant in the Mediterranean region, where the species vary much, besides frequently producing natural hybrids, so that their dintinction has become very complicated. [In the case of the British species, $\boldsymbol{V}$. nigrum hybridises with Thapsus, pulverulentum, and Lychnitis, end $V$. Thapsus with Lychnitis.]

Leaves decurrent on the stem, very woolly. Flowers in a dense, simple spike

Leaves not decurrent, or the upper ones very slightly so.

1. V. Thapens.

Floners in a raceme or panlcle.

Phas glabrous or slightly glandular-hairy. Two stamens unuker than the othera, with long anthers. How cre 
large, one or few to each bract. (Raceme usually simple.)

Pedicels mostly longer than the calyx .

2. V. Blattaria.

Pedicels shorter than the calyx . 3. V. virgatum.

Plant with more or less white cottony down or wool, especially on the calyx and under side of the leaves. Flowers rather small, several to each bract.!

Lower leaves cordate at the base. Raceme nearly simple. Hairs of the flaments yellow.

Lower leaves narrowed at the base. Raceme panicled. Hairs of the flaments white.

Down short and powdery. Upper side of the leaves

nearly glabrous
Down a nealy wool, easily rubbed off, on both sides of
the leaves

4. V. nigrum

5. F. Lychnitis.

6. V.pulverulentum

1. V. Thapsus, Linn. (fig. 726). Great M.-A stout, erect biennial, simple or branched, 2 to 4 feet high, clothed with soft woolly hairs. Leaves oblong, pointed, slightly toothed, narrowed at the base into 2 wings running a long way down the stem; the lower ones often stalked, and 6 or 8 inches long or more. Flowers in a dense, woolly terminal spike, sometimes a foot or more long. Corolla yellow, usually 6 to 9 lines diameter, slightly concave; 3 of the filaments are covered with yellowish woolly hairs, and have short 1-celled anthers; the 2 longer stamens glabrous or nearly so, with longer anthers adnate to the filaments. Capsule thick, rather longer than the calyx.

Common on roadsides and waste places, all over Europe and temperate Asia to the Caucasus, Altai, and Himalasa, and now naturalised in America. Frequent in Britain, extending as far north as Aberdeen. Fl. summer. A variety with a much larger and flatter corolla and longer anthers to the long stamens, not uncommon on the Continent, where botanists give it the name of $\boldsymbol{V}$. thapsiforme, but which is believed by some to be the original form described by Linnæus, is said to have been found also in Kent.

2. V. Blattaria, Linn, (fig. 727). Moth M.-A tall biennial, not quite so stout as V. Thapsus, sometimes branched, and either glabrous or with a few glandular hairs in the upper part. Leaves oblong, coarsely toothed or sinuate; the lower ones stalked, the middle ones sessile, the upper ones clasping the stem or shortly decurrent. Flowers yellow or rarely white, in a long, loose, simple raceme; the pedicels from 3 to 6 lines long, either solitary or rarely 2 together in the axil of a green bract. Hairs of the filaments purple.

On banks and edges of fields, in central and southern Europe, Russian and central Asia, and naturalised in North America, but not extending into Scandinavia. Indicated in several counties of England south of Norfolk and Stafford, and in sonthern Ireland, but generally regarded as an introduced plant, except perhaps near the southern coast. Fl. summer and autumn.

3. V. virgatum, With. (fig. 728). Twiggy $M$. - This may be a mere variety of $\boldsymbol{V}$. Blattaria, but the glandular hairs are more abundant, and the pedicels of the flowers are very short, usually from 2 to 6 together under each bract.

Apparently limited on the Continent to western and central Europe, and generally less common there than $V$. Blattaria, but established as a weed of cultivation in northern as well as tropical America and other distant lands. Rather more frequent in England than $V$. Blettario, 
but very rare, and probably introdnced only in Ireland. $F$. summer and autumn.

4. V. nigrum, Linn. (fig. 729). Dark M. - Stem sparingly clothed with woolly hairs, 2 to 3 feet high, ending in a long, simple or slightly branched raceme. Leaves crenate, nearly glabrous on the upper side, slightly woolly underneath; the lower ones large, cordate-oblong, on long stalks; the upper ones nearly sessile, small, and pointed. Flowers numerous within each bract, more or less stalked, smaller than in the last three species. Corolla yellow, with bright-purple hairs to the filaments.

On banks and waysides, all over Europe and western Asia, except the extreme north. Truly indigenous in central and southern England, but naturalised only in northern England and southern Scotland, and not indicated in Ireland. Fl. summer and autumn.

5. V. Lychnitis, Linn. (fig. 730). White $M$.-About the size of $\boldsymbol{V}$. nigrum, or rather taller. Stem-leaves nearly sessile, the lower ones narrowed into a short footstalk, all nearly glabrous above, but covered nnderneath with a short, white, powdery down, which is also sprinkled over the stem, and more conspicuous on the calyxes. The racemes form a narrow, branching panicle, with erect branches. Flowers numerous, pale yellow or nearly white, the size of those of $V$. nigrum. Hairs of the filaments white.

On banks and waysides, in Europe and western Asia, extending northwards into Scandinavia. In Britain, scattered over several parts of central and southern England, but local. Fl. summer.

6. V.pulverulentum, Vill. (fig. 731). Hoary $M$.-A stately species, often growing to the height of 3 feet or more, terminating in a long, stiff, pyramidal panicle, with spreading branches, and remarkable for the mealy white wool which clothes the whole plant, but is easily rubbed off. Leaves sessile, or the lower ones narrowed into a short footstalk, broadly oblong and crenate. Flowers numerous, in small clusters, about the size of those of the last two species, yellow, with white hairs to the filaments.

On roadsides, and dry, stony wastes, in central and especially southern Europe, not extending so far east as the preceding species, nor into northern Germany. In Britain, apparently confined to Norfolk and Suffolk. Fl. summer.

\section{ANTIRRHINUM. SNAPDRAGON.}

Herbs, with the lower leaves often opposite, the upper ones alternate, and the flowers, often showy, solitary in the axils of the upper leaves, or forming terminal racemes. Calyx deeply 5-cleft. Corolla with a broad tube, slightly protrnding below the calyx on the lower side, but not spurred as in Linaria; the divisions of the limb arranged in 2 lips, with a projecting palate closing the mouth. Capsule oblique, 2-celled, opening at the top by 2 or 3 pores.

The species are not numerous, chiefly confined to the Mediterranean regions, or more especially to sonth-western Europe.

Perennial, with showy flowers. Sepals broad and short .

annual. Sepals narrow, as loug as the corolla

1. A. majnts.

2. 4. Orontium 
1. A. majus, Linn. (fig. 732). Great S.-Stem perennial at the base, forming a leafy tnft; the flowering branches erect, 1 to 2 feet high, glabrous or slightly downy, often branched. Leaves narrow-lanceolate or linear, entire. Flowers large, purplish-red (or, in gardens, white or variegated). Segments of the caly $x$ broad and obtuse, not above 3 lines long. Corolla above an inch long, the so-called palate opening when the tube is pressed laterally between the finger and thumb, whence the popular name.

In clefts of rocks, old walls, and stony places, in the Mediterranean region, but being much cultivated in gardens, it has become natnralised mucb farther north, and is frequently fcund on old walls in England and Ireland. Fl. summer and autumn.

2. A. Orontium, Linn. (fig. 733). Lesser S.-An erect annual, seldom above a foot high, much more slender than $A$. majus, with narrower leaves. Flowers scarcely 6 lines long, mostly in the axils of the upper leaves; the narrow, unequal segments of the calyx as long as or longer than the corolla.

Apparently indigenous in southern Europe, and widely spread is a weed of cultivation over the greater part of Europe and ccntral Asia, and carried out to other countries. In Britain, it extends over Fingland and sonthern Ireland. Fl. summer.

\section{LINARIA. LINARIA.}

This genus only differs from Antirrhinum in the tube of the corolla, which is projected at the base into a conical or cylindrical spur. The species are more numerous, and the geographical range rather wider, but still the greater number are from southern and especially sonthwestern Europe.

Stems erect or ascending. Leaves linear, oblong or rarely ovate, entire.

Flowers yellow.

Stems 1 to 3 feet high, erect from the base . . . . 1. L. vulgaris.

Stems scarcely 6 inches high, diffuse at the base ${ }^{*}$ : 4. L. supina.

Flowers biue or purplish or striped.

Perennial. Flowers on short pedicels, in terminal racemes. Spur short and conical

Annual. Flowers on short pedicels, in a short terminal

raceme. Spur long and slender
Annual. Flowers small, on long axiliary pedicela. Spur

short and conical
Btems trailing. Leaves ovate, orbicular, or anguiar.
Plant quite glabrons. Leaves 5.lobed, with palmate nerves .

Plant hairy. Leaves ovate or angular, with pinnate nerves.

Leaves ovate or orbicular, very hairy. Peduncles hairy. Sepais broad

Leaves angular or hastate at the base, slightly hairy. Pe. duncles glabrous and slender. Sepals narrow . 8. L. Elatine.

L. purpurca, a tall Italian species, with narrow leaves and a long raceme of small purple flowers, has become almost naturalised in the south of the Isle of Wight, and several other species, such as L. triphylla and bipartita, cultivated in our flower-gardens, will occasionally sow themselves in the vicinity, but soon disappear.

1. L. Vulgaris, Mill. (fig. 734). Toadfax,-Rootstock shortly creeping. Stems erect, 1 to 3 feet bigh, of a glaucous green, and usually 
glabrous, except a few glandular hairs amongst the flowers. Leaves crowded, linear, or narrow-lanceolate. Flowers large and yellow, forming a short but handsome terminal panicle. Calyx small. Spur of the corolla long and pointed; the projecting palate of the lower lip of a bright orange colour, completely closing the tube. Capsule large and ovoid, with numerous rough seeds, surrounded by a narrow, scarious border.

In hedges, and on the borders of fields, in Europe and Russian Asia, and has been carried out with European crops to other parts of the world. Abundant all over the British Isles excepting the Scotch Highlands, where it is more rare. Fl. summer and autumn. A singular deformity, called Peloria, occurs sometimes, in which the corollas are regular, with 5 spurs. Varieties are also occasionally found with smaller flowers, either yellow or striped, and without the border to the seeds. They are very rare, and supposed to be hybrids between this and the following species. [There are two recognised British forms, the common one, with faintly 3-nerved leaves, a glandular raceme, and ovate-lanceolate calyx segments; and var. latifolia, Bab., with 3-nerved leaves, glabrous raceme, leafy bracts, and lanceolate calyx segments.]

2. L. repens, Ait. (fig. 735). Pale L.-Rootstock slender, and creeping to a considerable extent; the stems erect or decumbent at the base, from 8 or 10 inches to above 2 feet high, and glabrous. Leaves crowded or whorled at the base of the stem, scattered in the upper part. Flowers rather small, but pretty and slightly sweet-scented, forming short racemes, usually arranged in a terminal panicle. Corolla under 6 lines long, nearly white, but striped with bluish or purple veins; the spur usually very short and conical, but variable in length. Seeds wrinkled, without any scarious border.

In stony wastes, in southern and central Europe to the Caucasus, scarcely extending into Germany. Fare in Britain, occurring here and there in England and Ireland, or farther north only as a straggler from gardens, where it was formerly cultivated. Fl. summer and autumn.

3. L. Pelisseriana, Mill. (fig. 736). Pelisser's L.-An erect, glabrons, slender annual, scarcely branched, with very narrow linear leaves, few and distant. Flowers small, in a short terminal raceme; the corolla purple, with dark vcins, and a long slender-pointed spur.

In bushy wastes, and pastures, in western and southern Europe, along the Mediterranean region to the Caucasus, extending bere and there into central Europe, and has been gathered in the Isle of Jersey. Fl. June.

4. I. supina, Desf. (fig. 737). Supine L.-Percnnial stock short, with numerous branches, seldom 6 inches long, decumbent at the base, simple or nearly so, glabrous or with a slight glandular down. Leaves lincar; the lower ones and those of the barren stems whorled. Flowers yellow, in a short terminal raceme, rather smaller than in $L$. vulgaris, with a long, slender spur. Seeds nearly flat, with a scarious wing.

In sandy or st ony places, especially near the sea, in western Europe and the west Mediterranean region. Very abundant in sonthern France and Spain, extending up the western coast to the Channel, and occasionally found in Devonshire and Cornwall on ballast heaps. Fl. summer. 
5. L. minor, Desf. (fig. 738). Lesser $L_{\text {. }}-\mathbf{A}$ much branched, erect annual, 3 or 4 inches high, with a slight, glandular down. Leaves, although linear, yet broader and more obtuse than in any of the preceding species, and narrowed at the base. Flowers very small, on long axillary peduncles; the corolla scarcely exceeding the calyx, of a pale purple or violet colour, with a short blunt spur. Seeds small, not bordered.

In waste and cultivated places, in temperate and southern Europe, extending northward far into Scandinavia and eastward to the Cancasus. In Britain, not unfrequent as a weed of cultivation in southern England, more rare in the north, in Ireland, and in Scotland. $F$. summer.

6. L. Cymbalaria, Mill. (fig. 739). Ivy L.-A perfectly glabrous, trailing perennial, with slender stems, often rooting at the nodes. Leaves stalked, broad, almost reniform, broadly 5-lobed, rather thick, and faintly marked with 3 or 5 palmate veins. Flowers small, solitary, on recurved axillary peduncles, of a pale lilac, with a rather short spur; the palate yellowish, closing the tube. Capsule nearly globular, containing several warted but not winged seeds.

On rocks, old walls, and stony places, in the Mediterranean region, and now naturalised in many parts of central and even northern Europe. In Britain, perfectly established in many places. Fl. the whole season.

7. I. spuria, Mill. (fig. 740). Round-leaved L.-A very hairy annual, with slender, branchlng, prostrate stems, 2 or 3 inches to a foot or more long. Leaves nearly sessile, broadly ovate or orbicular. Flowers solitary, on hairy peduncles, in the axils of the upper smaller leaves. Sepals ovate or broadly lanceolate. Corolla very small, yellowish, with a purple upper lip; the spur slender and recurved. Seeds warted, without wings.

In waste and stony places, in the Mediterranean reglon, and as a weed of cultivation in central Europe, but not extending so far north as $L$. Elatine. In Britain, only in cultivated places, in southern and central England, and South Wales. Fl. the whole season.

8. L. Elatine, Desf. (fig. 741). Pointcd $L_{0}-$ A prostrate annual, with the stem and leaves hairy, but less so than in $L$. spuria, which this plant resembles in most respects; the branches are, however, more slender, the leaves angular or hastate at the base, the peduncles much more slender, glabrous, and spreading at right angles, the sepals narrowlanceolate, and the spur of the corolla straight.

In open woods, and heaths, in cult Ivated and waste places, in Europe and western and central Asia, extending northwards into southern Sweden. In Britain, chiefly as a weed of cultivation, but probably truly indigenous in southern England and Ireland; rare in the north, but unknown in Scotland. $F l$. the whole seasom.

\section{SCROPHULARIA. SCROPHULARIA.}

Herbs, usually erect, with angular stems, opposite leaves, and rather small flowers, of a dingy purple or yellow, in loose cymes forming a terminal panicle. Calyx more or less dceply 5-cleft. Corolla nearly 
globular, with short, broad lobes; the 2 upper ones erect and nnited into an upper lip; the 2 lateral ones often shorter and erect; the lowest one turned downwards. Stamens 4, turned downwards, with 1-celled anthers; a fifth barren stamen usually forming a scale nnder the upper lip. Capsule 2-eelled, opening at the partition in 2 valves.

The species are numerous, having their great centre in the Mediterranean region, and in central Asia, a few only extending over the rest of Europe, northern Asia, and a part of North America. The shape of the corolla readily distinguishes the genus from all others.

Leaves glabrous. Panicle almost leafless.

Stem acutely angled but not winged, with numerous knotty tubers at its base. Leaves acute. Border of the sepals very narrow

Stem 4-winged, without tubers at the base. Leaves usually ob. tuse. Sepals with a conspicuous scarious border.

Leaves downy. Panicle leafy at the base, or cymes all axillary.

Leaves cordate-triangular. Flowers dull purple, with a scale

under the upper lip.
Leaves orbicular or broadly cordate. Kowers yellow, wlthout any scale under the upper lip.

1. S. nodosa.

2. S. aquatica.

3. S. Scorodonia.

4. S. vernalis.

1. S. nodosa, Linn. (fig. 742). Figwort.-A coarse, erect perennial, 2 to 3 feet high, glabrous or nearly so, with a disagreeable smell; the short stock emitting a number of small green knots or tubers. Stem sharply quadrangular. Leaves large, broadly ovate or heart-shaped, pointed, and doubly crenate or serrate. Panicle loosely pyramidal or oblong, usually sprinkled with minute glandular bairs. Lobes of the calyx rounded, with a very narrow, often scarcely perceptible, scarious border. Tube of the corolla of a pale greenish purple, twice as long as the calyx; the upper lip more deeply coloured, much longer than the lateral lobes.

In rather molst cultivated and waste grounds, in Europe, Russian Asia, and some parts of North America. Extends all over Britain. Fl. all summer.

2. S. aquatica, Linn. (fig. 743). Water S.-Very variable in size, but is generally taller and rather less branched than $S$. nodosa, which it much resembles in habit and in flowers. The angles of the stem project into narrow wings, there are no tubers at its base, and the leaves are not so broad, and more obtuse. Panicle long and narrow. Lobes of the calyz surrounded by a scarious border, much more conspicuous than in S. nodosa. Corolla of a dull purple.

In wet places, along ditches and sides of streams, in Europo and Russian Asia. Abundant in England, from Berwick southwards. Fl. summer. It varies in the shape of the scale or barren stamen under the upper lip of the corolla, in station, and in the more or less acute teet b of the leaves, and two species have been generally distinguished: $S$. Ehrharti, Stevens, is a more luxuriant and leafy plant, with the scale reniform, much broader than long, and the capsule nearly globular; and $S$. Balbisii, growing in drier situations, the leaves more pointed, tho scale often nearly orbicular, and the capsule more ovoid and pointed; but these differences in foliage and capsule do not always correspond with those of the shape of the scale, which will often rary in different flowers of the same plant. 
3. S. Scorodonia, Linn. (fig. 744). Balm-leaved S.-Very nearly allied to $S$. aquatica, in all essential characters, and distinguished chiefly by its downy, wrinkled leaves, and by the panicle more leafy at its base. It is also usually a rather smaller plant, and the angles of the stem are never expanded into wings, and sometimes scarcely perceptible.

A west European species extending southwards to Madeira, and northwards to Jersey, the extreme south-west of England, and Kerry in Ireland. Fl. summer.

4. S. vernalis, Linn. (fig. 745). Yellowo S.-A hairy perennial, very different in aspect from the three preceding species, and not near so coarse. Stems seldom 2 feet high ; the leares nearly orbicular, cordate at the base, coarsely toothed, and of a light green colour. Peduncles almost all axillary, bearing a small cyme of jellow flowers; the 4 upper lobes of the corolla nearly of equal size, without any scale or barren stamen inside; the lowest lobe rather larger. Stamens longer than the tube of the corolla.

On roadsides, and waste or stony places, in the hilly districts of Europe, extending from France to the Caucasus. Occasionally found in England, but introduced. Fl. spring.

\section{MIMULUS. MIMULUS.}

Herbs, with opposite leaves, and sellow, purple, or pink flowers, growing singly on axillary peduncles. Calyx tubular, with 5 prominent angles, and 5 short teeth. Corolla with a broad tube, and 5 flat lobes arranged in 2 lips; the upper one 2-lobed and sometimes erect; the lower one spreading and 3-lobed, the central lobe often notched. Stamens 4. Capsule opening in 2 valves in the middle of the cells.

An American genus, which, besides the species now naturalised in Europe, comprises the Musk Mimulus and some others occasionally cultivated in our gardens.

1. M. luteus, Willd. (fig. 746). Yellow Mimulus.-A perennial, with a shortly creeping rootstock, and erect or ascending stems, either glabrous or slightly downy, seldom above a foot high. Leaves ovate, coarsely toothed, glabrous. Peduncles 2 inches long or more, bearing a showy yellow flower, above an inch long, usually marked inside with several small purple spots at the mouth of the tube, and sometimes with a large purple-red or pink spot upon each lobe.

On the banks of streams, and in moist, shady places, in north-western America and Chili; long cultivated in our flower-gardens, and now naturalised in boggy places in many parts of Britain. Fl. all summer.

\section{LIMOSELLA. LIMOSEL.}

Small, tufted or floating annuals; the leaves and minute flowers mostly radical. Calyx 5-toothed or lobed. Corolla regular, campanu. late, 5-lobed. Stamens 4. Anthers 1-celled. Capsule globular, with a very thin pericarp, scarcely dehiscent.

Besides our European species the genus comprises but very few from gouthern Africa and Asia.

1. L. aquatica, Linn. (fig. 747). Common Limosel.-A glabrous 
annual, forming little tufts of 1 or 2 inches diameter. Leaves on long stalks, oblong and entire, all radical as well as the minute flowers; or occasionally a few slender stems are developed among the leaves, abont an inch long, and bearing at thcir summit a similar tuft of leaves and flowers. Corolla of a pale rose-colour, scarcely longer than the calyx.

In wet mud, or in places where water has stood, throughout Europe and a great part of Asia, Africa, and North America. Thinly scattered in England, and very local in Scotland, absent from Ireland, but from its small size it may be frequently overlooked. Fl. summer.

\section{SIBTHORPIA. SIBTHORPIA.}

Slender, hairy, trailing herbs, with alternate leaves, and small, axillary, yellow or pinkish flowers. Calyx of 4 or more divisions. Corolla nearly rotate, with 5 lobes, or 1 more than the calyx. Stamens of the same number as, or 1 less than the lobes of the corolla. Anthers 2-celled. Capsule compressed, divided into 2 cells, and opening in the middle of the cells in 2 valves.

Besides the British species there is one from the Canary Islands, with larger jellow flowers, often cultivated in our gardens under the name of Disandra prostrata, and two from the Andes of South America.

1. S. europæa, Linn. (fig. 748). Common Sibthorpia.-A perennial, with a small stock, and very slender creeping stems rooting at the nodes. Leaves small, on slender stalks, orbicular, deeply cordate at the base, crenate, and hairy. Flowers very minute, on short, axillary stalks. Calyx with 4 narrow segments. Corolla scarcely longer, the 2 upper lobes yellowish, the 3 lower broader and pink.

In moist, shady places, along the western coasts of Europe, penetrating eastward to a very few stations round the Mediterranean, and extending northwards to the Channel Islands, southern Ireland, South Wales, and the south-west of England. Fl. summer.

\section{DIGITALIS. FOXGLOVE.}

Biennials or perennials, with stout, erect, usually simple stems, alternate leares, and showy flowers, in long, terminal, one-sided, simple racemes. Calyx of 5 unequal sepals or segments. Corolla tubular, contracted above the base, then much inflated, with the limb shortly 4- or 5-lobed; the lateral lobes outside the upper one in the bud, and the lowest usually the longest. Stamens 4. Capsule pointed, opening at the partition in 2 valves, with numerous small seeds.

A European and north Asiatic genus, of which several species besides our own are occasionally cultivated in flower-gardens, especially the yellow $D$. grandiflora.

1. D. purpurea, Linn. (fig. 749). Purple F.-Root usually biennial, but sometimes forming a stock, which flowers a second or even a third time. Radical leaves on long stalks, ovate or ovate-lanceolate, 6 inches long or more, coarsely veined and downy. Flowerlng stems 2 to 4 feet high, with a few alternate shortly-stalked leaves in the lower part, the upper part occupied by a long stately raceme of purple 
flowers, each $1 \frac{1}{2}$ inch long. Four of the calyx-segments broad and leafy, the fifth upper one much narrower and more pointed. Corolla beautifully spotted inside, with 4 short lobes, the lowest about twice the length of the others and hairy inside.

On dry, hilly wastes, and roadsides, in many parts of western and central Europe, extending northwards into Scandinavia, but almost nnknown in limestone districts. Abundant in Britain. Fl. spring and summer.

\section{VERONICA. SPEEDWELL.}

Herbs (or shrubs in a few exotic species), with opposite stem-leaves, and small flowers, usually blue or white, sometimes arranged in spikes or racemes, or in the axils of alternate floral leaves. Calyx 4- or 5. cleft. Corolla with a very short tnbe, the limb rotate, deeply 4-cleft, the lower segment the narrowest. Stamens 2. Capsule more or less flattened laterally (at right angles to the partition), and opening round the edges in 2 valves. Seeds few.

A numerous genns in the northern hemisphere, with a few species spreading into the tropics and far into the southern hemisphere, whilst a few are peculiar to Australia, and very many to New Zealand, where the genus forms a dominant feature throughout the island. Among the latter the $\boldsymbol{V}$. speciosa, salicifolia, Lindleyana, and other shrubby or half-shrubby ones, are much cultivated in our gardens. Several species occasionally have two forms of flowers, one large and blue, the other smaller and pinkish.

Perennlals, with the flowers in leafless spikes or racemes.

Spikes or racemes terminal.

Stem erect, with a long dense, terminal spike of flowers

Stems diffuse or very short. Racemes loose, few-flowered.

Stem shrubby at the base

Stems herbaceous.

Stem erect or scarcely creeping at the base, 2 or 3 inches high. Flowers very few, in a short spike or head. stem creeping, and rooting at the base. Flowers in loose, often leafy spikes . . . . . . Racemes axillary.

Plant glabrous.

Leaves linear or lanceolate. Stem diffuse. Racemes few and slender. Capsule very flat, broader than long

Leaves lanceolate or oblong. Stems erect. Racemes nume: rous. Capsule as long as or longer than broad

Leaves oblong or ovate, rather thick and obtuse. Stem diffuse.

Plant more or less hairy.

Leaves much narrowed at the base. Flowers sessile or almost sessille . . . . .

Leaves ovate, broad or cordate at the base. Flowers rather large and pedicellate.

Stem hairy all round. Capsule broadest in the middle. Stem with 2 opposite lines of long hairs. Capsule broadest towards the top Annuals. Flowers all,
axils of the leaves.

Upper flovers forming a raceme. The upper leaves reduced to bracts.

Plant glabrous, creeping, and rooting at the baso. Seeds ovato .

1. V. spicata.

2. V. saxatiis.

3. $V$. alpina.

4. V. serpyllifolia.

8. V. scutellata.

6. V. anagallis.

7. V. Beccabunga.

5. V. officinalis.

9. V. montana.

10. V. chamadrys. 
Plant downy or hairy, erect or procumbent, but not creep. lug. Seeds cup-shaped.

Leaves ovate, coarsely toothed. Pedicels shorter than the calyx.

Leaves deeply cut.

Stems erect. Pedicels sliorter than the calyx . . 15. V. verna.

Stems decumbent. Pedicels as long as or longer than the calyx

All the flowers axillary. "The upper leaves like the lower ones, but

14. V, arvensis.

16. V. triphyllos. smaller. Stems procumbent. Seeds flat or nearly so.

Sepals heart-shaped at the base. Leaves rather thick, often long-stalked. Capsule 2- to 4-seeded

Sepals ovate or lanceolate. Leaves short-stalked. Capsule several seeded.

Capsule twice as broad as long. Flowers rather large

Capsule but little broader than long. Flowers small

11. V. hederafolia

13. V.Buxbaumii.

- 12. V. agrestis.

1. V. spicata, Linn. (fig. 750). Spiked S.-Stock shortly creeping, hard, and almost woody ; the stems ascending or erect, 6 inches to a foot high, usually simple. Leaves oblong or the lower ones ovate, downy and slighty crenate. Flowers of a clear blue or sometimes pale pink, in a dense terminal spike; the lobes of the corolla narrower and less spreading, and the tube more apparent than in any other British species.

In hilly pastures, cliefiy in limestone distriets, over the greater part of the continent of Europe, and northern Asia, sliort of the Arctic regions. Rare in Britain, and chiefly in Suffolk and Cambridgeshire, and Wales. Fl. summer. A large and broader-leaved variety, V. hybrida, Linn., occurs in Somersetshire and in some other western counties; and numerous varieties of this and the allied $V$. paniculata and longifolia have long been cultivated for ornament in cottage-gardens.

2. V. saxatilis, Linn. (fig. 751). Rock S.-A low, spreading perennial, glabrous in all its parts except a slight glandular down in the upper part, branching and often woody at the base, with spreading or ascending flowering branches, 3 or 4 inches long. Leaves small, obovate or oblong, entire or nearly so, and rather firm. Racemes short, of a few rather large, bright-blue flowers, on tiort pedicels. Capsules ovate.

On alpine rocks, often at great elevations, in most of the great mountain-chains of Europe, extending northwards to the Arctic Circle, but scarcely into Asia. In Britain not very abundant, and only in the high mountains of Perthsliire and some adjoining counties of Scotland. $F l$. summer. A variety with smaller pink flowers has been distinguished under the name of $V$. fruticulosa, but it is very rare, and probably merely accidental.

3. V. alpina, Linn. (fig. 752). Alpine S.-Stock shortly creeping, but never woody as in $V$. saxatilis, and much less branched than in $V$. serpyllifolia. Flowering branches often solitary, always simple, ascending from 2 to 4 or even 5 inches high, and slightly hairy. The raceme, when young, forms a short, slightly hairy head, and even in fruit is but little elongated, consisting of 4 or 5 rather small blue flowers, varying occasionally, as in other species, to a pale pink or flesh-colour.

In alpine situations, in most of the great chains of Europe, Asia, and North America, extending into high northern latitudes. In Britain, only near the summits of the higher mountains of Scotland. Fl. summer.

L. V. serpyllifolia, Linn. (fig. 753). Thyme-leaved S.-Stems shortly 
creeping, very much branched, forming a small, flat, dense, leafy tuft ; the flowering branches ascending, 2 to 4 or 5 inches high. Leaves nearly sessile, ovate, seldom half an inch long, very slightly crenate, and usually glabrous as well as the rest of the plant. Flowers very small, of a pale blue or white, with darker streaks, sessile or shortly stalked, in terminal spikes or racemes; but the bracts, especially the lower ones, are rather large and leaf-like, so as to give the inflorescence much the appearance of that of the annual Veronicas. Capsule broad, and often rather deeply notched.

In pastures, fields, and waste places, in Europe and Russian and central Asia, from the Mediterranean to the Arctic Circle, and ascending to high alpine summits. Abundant in Britain. Fl. spring and summer. A variety, $V$. humifusa, Dicks., with slightly downy stems, occurs occasionally in the Scotch mountains.

The American $V$. peregrina, an annual otherwise much resembling some varieties of $V$. serpyllifolia, has occasionally appeared in England ond Ireland as an introduced weed.

5. V. officinalis, Linn. (fig. 754). Common S.-Stems perennial at the base, much branched, creeping, and rooting at the nodes, extend. ing sometimes to a foot or more, but usually about half that length. Leaves obovate or oblong, toothed, and hairy. Spikes or racemes like those of the preceding species, but hairy, and they are axillary, not terminal; for although sometimes proceeding from the other axils, they may appear terminal before the end of the branch has grown out, yet they are never really so. Flowers nearly sessile, rather small, pale blue or rarely flesh-coloured. Capsule obovate or obcordate, broader than it is long.

In woods, and rather dry bushy pastures, throughout Europe and Russian and central Asia, and now naturalised in North America. Extends over the whole of Britain. Flo the whole summer. [V. hirsuta, Hopk, is a small hairy form, with narrower leaves, found in Ayrshire.]

6. V. Anagallis, Linn. (fig. 755). Water S.- Tootstock shortly creeping, the stems erect and branching, from 6 inches to 2 feet high, often thick or succulent, glabrous as well as the whole plant. Leaves lanceolate, broad or narrow, sessile or clasping the stem at the base, more or less toothed. Racemes unmerous, axillary, and opposite (in the axils of both leaves of each pair). Flowers rather small, pedicellate, pale blue. Capsules ovate, less flattened than in some species, and slightly notched at the top.

In wet ditches, and along streams and ponds, over Europe, Russian and central Asia, and North America, but not an Arctic plant. Extends all over Britain, to the northern extremity of Scotland. Fl. summer.

7. V. Beccabunga, Linn. (fig. 756). Brooklime.-Stems procumbent or floating at their base, rooting at the nodes; the flowering branches ascending, thick and succulent, and, as well as the whole plant, quite glabrous. Leaves shortly stalked, ovate or oblong, obtuse, slightly toothed, and rather thick. Flowers small, blue or rarely pink, in opposite axillary racemes, often scarcely longer than the leaves. Capsule shorter than the calyx, broad and rather thick, and notched at the top.

In wet ditches, and along streams and ponds, in Kirope, Russian and 
central Asia, and northern Africa, but scarcely extending to the Arctio regions. Common in Britain. Fl, the whole summer.

8. V. scutellata, Linn. (fig. 757). Marsh S.-Rootstock slender and perennial, emitting creeping runners; the stems slender, ascending or spreading, seldom above 6 inches high, glabrous or rarely downy. Leaves linear-lanceolate, glabrous, entire or scarcely toothed. Flowers few, in very slender racemes, proceeding alternately from one axil only of each pair of leaves. Pedicels filiform. Corolla rather small, of a pale pinkish-blue or white. Capsule very that, broad, and rather deeply notched.

In marshes, ditches, and wet places, in northern and central Europe, Russian Asia, and North America. Extends almost all over Britain. Fl. summer.

9. V. montana, Linn. (fig. 758). Mountain S.-The foliage is nearly that of $V$. Chamcedrys, but the stem is more trailing, rooting at the nodes, and hairy all round; the leaves are on longer stalks ; the racemes are looser and more slender, with fewer flowers, which are usually rather small, and the capsule is very flat, abont 4 lines broad, and only 3 lines long, regularly orbicular, the broadest part being in the middle, notched at the top, and often minutely toothed and ciliate round the edge.

In moist woods, over the whole of temperate Europe, from sonthern Sweden to southern Russia, but not so frequent as $V$. officinalis and $V$. Chamadrys. Not unfrequent in most parts of England and Ireland, as well as in several Scotch counties. Fl. spring and summer.

10. V. Chamædrys, Linn. (fig. 759). Germander S.-Stems weak, creeping at the base, then ascending, often above a foot long, and remarkable by the hairs collected into two opposite lines down the stem from between each pair of leaves to the leaf next below, whilst the rest of the stem is glabrons or nearly so. Leaves shortly stalked, ovate-cordate, crenate, and hairy. Racemes axillary, one only from each pair of leaves, much longer than the leaves, with rather larger bright blue, or rarely smaller pinkish flowers, on rather long pedicels. Calyx 4-cleft. Capsule flat, very broad, and notched at the top, narrowing towards the base.

In woods, pastures, hedge-banks, roadsides, \&c.; very common all over Europe and Russian Asia, from the Mediterranean to the Arctic Circle. Extends all over Britain. Fl. spring and summer.

11. V. hederæfolia, Linn. (fig. 760). Ivy S.-An annual, nsnally not so hairy as $V$. agrestis; the leaves of a thicker and smoother consistence, more distinctly stalked, broadly orbicular, with 5 or 7 coarse teeth or short lobes, the middle one broad and rounded; bnt the chief distinction is in the calyx, the divisions of which are broadly heart-shaped, not narrowed at the base. Corolla and capsule nearly those of $V$. agrestis, but there are usually but 1 or 2 seeds in each cell.

In waste and cultivated places, in Europe and Russian Asia, extending as a weed of cnltivation over nearly the same area as $V$. agrestis, but generally less abundant. In Britain, not near so common as $V$.agrestis. Fl. all summer.

12. V. agrestis, Linn. (fig. 761). Procumbent S.-A more or less hairy, much branched annual, with procumbent or prostrate stems, from 8 to 8 or 10 inches long. Leaves shortly stalked, ovate and toothed? 
the lowest opposite, withont flowers, but the greater number alternate, each with a pedicel in its axil, usnally shorter than the leaf, bearing a single small, blne, or pinkish-white flower. Sepals ovate or oblong, usually longer than the corolla. Capsule composed of 2 ovoid, erect lobes, each containing a small number of seeds, which are rough and convex on the outside, and hollowed out into a cup on the inner face.

In waste and cultivated places; a very common weed all over Europe and Russian Asia, and introdnced into North America and other countries. Very abnndant in Britain. Fl. the whole season. It varies in the shape of the sepals, and the size and colour of the corolla, and has been divided into three more or less marked varieties or races :$\vec{V}$. agrestis, with oblong sepals, and white or pink flowers; $\boldsymbol{V}$. polita, Fries, with ovate sepals, and larger blue flowers; $V$. opaca, Fries, with spathulate sepals and fewer seeds; but none of the characters have sufficient constancy to justify their maintenance as distinct species.

13. V. Buxbaumii, Ten. (fig. 762). Buxbaum's S.-This closely resembles $\boldsymbol{V}$. agrestis, but is much larger in all its parts; the pedicels are longer, the flowers larger, of a bright blne, and the lobes of the capsule are broad and divaricate, so that the whole capsule when ripe is about 4 lines broad and only 2 long. $\nabla$. persica, Poir.

A weed of cultivation, like the other annual species, but much more abundant in southern Europe and central Asia than in central or northern Enrope. Occurs rather frequently in Britain, but probably introduced with clover or other seeds. $\mathrm{Fl}$. all summer.

14. V. arvensis, Linn. (fig. 763). Wall S.-A little, hairy annnal, seldom 6 inches high, and often much smaller; the stems sometimes erect and simple, sometimes diffuse and branching at the base. Leaves almost sessile, opposite, ovate, and toothed, but not cut; the upper floral ones small, alternate, lanceolate, and entire. Flowers small and sessile, forming terminal, leafy racemes ; the sepals oblong or lanceolate, unequal in size; the corolla very small, blue or nearly white. Capsule broad, much flattened, notched, each cell containing a small number of broad, flattened seeds.

In cultivated and waste places, banks, old walls, \&c., thronghont Europe and Russian Asia. Abundant in Britain. Fl. the vhole season.

15. V. verna, Linn. (fig. 764). Vernal S.-A small, erect annual, seldom above 2 or 3 inches high, closely allied to $V$. arvensis, of which it has the almost sessile flowers; but the stem-leaves are deeply cut into 3,5 , or 7 narrow lobes as in $V$. triphyllos.

A more southern species than $V$. arvensis, widely spread over central and southern Europe, and south Russian Asia to the Altai, but rare in the north. In Britain, it has been found in a few sandy fields in Norfolk and Suffolk. $F l$. spring and summer.

16. V. triphyllos, Linn. (fig. 765). Fingered S.-Stem spreading, or almost trailing, as in $\nabla$. agrestis and $V$. hedercefolia; but the leaves are deeply cut into 3,5 , or 7 digitate lobes, and the capsule and seeds are more like those of $\nabla$. arvensis. Flower-stalks rather longer than the floral leaves, which are much smaller and less divided than the stem-leaves. Corolla small, of a deep blue. Capsule broad, with several thin but concave seeds.

In cultivated and waste places, widely spread over central and southern Kurope and western Asia, extending northward into southern 
Sweden. Rare in Britain, having been only found in a few localities in Suffolk, Norfolk, and Yorkshire. Fl. spring and summer.

\section{BARTSIA. BARTSIA.}

Herbs, usually balf parasitical on the roots of other plants, with erect stems, opposite leaves, and yellow or purple flowers in terminal spikes. Calyx tubular or campanulate, 4-cleft. Corolla with a distinct tube ; the limb 2-lipped; the uprer lip erect, concare, entire or notched, but withont spreading lobes. Stamens 4 , in pairs; the cells of the anthers pointed at the base. Capsule opening in 2 valves in the middle of the cells. Seeds many, more or less striated or furrowed.

Rather a large genus, chiefly European, north African, and west Asiatic, but also with a considerable number of South American species. It has been divided into three or four distinct genera, distinguished chiefly by the seeds; but it appears to me a more natural course to consider these as sections of one genus, distinguished from Euphrasia by the corolla.

Spikes panicled. Flowers pink. Seeds few, pendulous .

3. B. Odontites.

Spikes slmple or nearly so. Seeds numerous.

Spikes short. Flowers dull-purple. Calyx campanulate. Seeds

deeply furrowed
spikes long. Flowers yellow. Calyx tubular. Seeds scarcely striated

\section{B. alpina.}

2. B. viscosa.

1. B. alpina, Linn. (fig. 766). Alpine B.-A hairy perennial, with a short rootstock, and erect stem 6 to 8 inches high. Leaves sessile, ovate and crenate, the floral ones rather smaller. Flowers in a short, leafy spike. Calyx deeply 4-lobed. Corolla of a dull livid-purple, 8 or 9 lines long, with a tube much longer than the calyx, and very short lobes to the lower lip. Anthers very hairy. Capsule ovate, longer than the calyx, with several deeply furrowed, almost winged seeds.

In mountain pastures, in the bigher chains of central and northern Europe, to the Arctic regions. Rare in the higher mountains of Scotland and the north of England, and unknown in Ireland. $\mathrm{Fl}$. summer.

2. B. viscosa, Linn. (fig. 767). Viscid B.-An erect, rigid annnal, often above a foot high, more or less clothed with a short, glutinous down; the root-fibres hard and wiry. Leaves lanceolate, coarsely toothed, the floral ones alternate. Flowers yellow, in a long terminal spike; the calyx tubular, 6 lines long, with 4 lanceolate lobes; the corolla half as long again, with the lower lip longer than the upper one. Anthers hairy. Capsule oblong, with very numerous, minute, scarcely striated seeds. Eufragia viscosa, Griseb.

In fields and pastures, chiefly near the sea, in western Europe, and round the whole Mediterranean region, and has established itself in the Canary Islands and South America. In Britain, at present confined to some of the southern and the western maritime counties of England, to sonthern Ireland, and south-western Scotland. Fl. summer and autumn.

3. B. Odontites, Huds. (fig. 768). Red B.-An erect, branching annual, seldom a foot high, slightly downy, and not glutinous. I,eaves lanceolate and toothed. Flowers of a purplish red, numerons in 1 . sided spikes; the calyx campanulate, 4-cleft; the upper lip of the 
corolla longer than the lower one. Anthers scarcely sairy. Capsule oblong, with a few pendnlons, furrowed seeds, as in Euphrasia, bnt with the general habit and corolla of a Bartsia. Euphrasia Odontites, Linn.

In fields and waste places, all over Europe and Russian Asia, except the extreme north. Generally distributed over Britain. F. summer. [There are three principal forms of this species in Britain : verna, with ascending branches, leaves rounded at the base, bracts longer than the flowers, and calyx-teeth equalling the tube; serotina, with flexnous npcurved branches, leaves narrow at the base, bracts shorter than the flowers, and calyx-teeth equalling the tube; and divergens, with many widely spreading branches.]

\section{EUPHRASIA. EYEBRIGHT.}

Erect annuals, or, in some exotic species, perennials, closely allied to Bartsia, and differing chiefly in the corolla, which has the upper lip much less concave, with 2 lobes spreading laterally or turned back, and the lobes of the lower lip are more spreading, and usually notched. Seeds few, pendulous, and furrowed.

There is probably but one species of the genns in the northern hemisphere, but several others are natives of Anstralia and South America.

1. E. officinalis, Linn. (fig. 769). Common E.-A little, much branched annual, varying wonderfully in size, station, shape of the leaves, size and colour of the flowers, \&c., and believed to be half parasitic on the roots of grasses. It is most frequently from 2 to 6 inches high, glabrons or slightly downy. Leaves small, sessile, opposite, ovate, deeply toothed, the teeth of the lower ones obtuse, of the upper ones finely pointed. Flowers in loose, terminal, leafy spikes; the calyx with 4 or 5 pointed teeth; the corolla white or reddish, streaked with purple, and a yellow spot in the throat, the tube usually shorter than the spreading lobes. Capsule oblong. Sometimes, especially in high alpine regions, the whole plant is but 1 inch high, with minute, almost yellow flowers; when luxuriant attains 8 inches, with flowers nearly half an inch long. The leaves in some varieties are all broad, obtuse, almost orbicular, and the npper ones closely imbricated ; in others they are all narrow, very pointed, and distant.

In pastures, throughont Europe and Russian and central Asia, from the Mediterranean to the Arctic regions and the highest alpine summits. Abundant in Britain. Fl. summer and autumn. The numerous varieties are referable to two principal races-the $E$. officinalis, with a more glandular down, especially on the calyx, the teeth of the leaves obtuse, or the upper ones shortly pointed, the capsule broadly oblong, and the seeds ovoid ; and $E$. nemorosa, Pers., which is never glandular, the teeth of the upper leaves at least ending in a fine point, the capsule very narrow, and the seeds spindle-shaped; but many forms occur in which these characters are variously combined, or pass into each other. [Another division of the British forms is into $E$. officinalis proper, with broad-based bracts and a long lower lip of the corolla; E. gracilis, Fries, more slender, with narrow-based bracts, and lower corolla lip shorter than the tube; and var. maritima, with the capsule far exceeding tho calvx. The latter from Shetland only.] 


\section{RHINANTHUS. RATTLE.}

A genus limited to the single species described below, distinguished from Pedicularis chiefly by the calyx and capsule.

1. R. Crista-galli, Linn. (fig. 770). Commun R.-An erect, glabrous or slightly hairy annnal, with a shortly branched, fibrous root, which attaches itself to the living roots of grasses and other plants by means of slightly enlarged suckers. Stem from a few inches to a foot high, simple or slightly branched. Leaves opposite, lanceolate, and more or less coarsely toothed ; the floral ones broader, shorter, and more cut at the base. Flowers in a loose, leafy spike; the calyx nearly orbicular, inflated, but compressed, contracted at the month, with 4 small teeth. Corolla jellow, often with a purple spot on the upper, or upon both lips; the tube longer than the calyx; the upper lip laterally compressed, with a tooth or lobe on each side in front; the lower lip shorter, with 3 spreading lobes. Stamens 4, in pairs, with obtuse, hairy anthercells. Capsule orbicular, flattened, with a few large, flat, nsually winged seeds.

In meadows and pastures, in Europe and Russian Asia, from the Mediterranean to the Arctic regions. Abundant in Britain, often causing much injury to the herbage. Fl. summer, or sometimes later. It varies much in stature, in the breadth of the leaves, in the size of the flower, and in the form of the teeth of the npper lip; and botanists have distinguished three supposed species $-R$. major, Ehrh., with large flowers; $R$. minor, Ehrh., with small flowers ; and $R$. angustifolius, with linear leaves; but further observation has shown that these forms are neither constant, nor indications of permanent races. [Other characters have been taken from the seeds, which are broadly winged, var. platyp. ter ; narrowly winged, in var. stenoptera; or wingless, var, aptera.]

\section{PEDICULARIS. PEDICULARIS.}

Herbs, with leaves alternate, or, in a very few species, whorled or nearly opposite and pinnately lobed, toothed, or divided; and, in the British species, purple flowers, in leafy spikes or racemes. Calyx broadly tubular, inflated after flowering, with 2 to 5 irregular, often jagged teeth or lobes. Corolla with a distinct tube; the upper lip laterally compressed, entire or with a small tooth in front on each side. Stamens 4 , in pairs, the anther-cells not pointed. Capsule flattened, more or less oblique at the top, with a few large seeds attached to the lower part.

A numerous genus in the mountains or colder regions of the northern hemisphere, extending far into the Arctic Circle, and found also in some of the tropical mountain-ranges. It is always readily known by tie foliage and calyx.

Stems 1 to 2 feet high. Calyx with 2 short, broad, Jagged lobes. Upper lip of the corolla with a tooth on each slde, at or below the middle

Stems prostrate or spreading, not $6^{\circ}$ inches long. Calyx 4- or $5^{\circ}$ toothed. Upper lip of the corolla without any teeth at or below the midule

1. P. palustris

1. P. palustris, Linn. (fig. 771). Red Rattle-A nearly glabrous annual, with a rather thick root; the stems erect, or, in dry situations, 
decumbent at the base, much branched, about a foot high, or in water as much as 2 feet. Leaves often opposite, pinnate, with short, ovate, crenate or deeply cut segments; the floral ones alternate, and often twice pinnate. Flowers almost sessile in the axils of the upper leaves, of a deep purple red. Calyx broad, with 2 broad, short, irregularly cut or jagged lobes. Upper lip of the corolla with 2 minute teeth on its inner edge just below the point, and 2 others below its middle. Capsule oblique, the short point projecting beyond the calyx.

In marshes, wet meadows, and watery ditches, in northern and central Europe, and Russian Asia, from the Altai to the Arctic regions. Generally spread over Britain, but not so common as the following species. Fl. all summer.

2. P. sylvatica, Linn. (fig. 772). Lousewort.-Rootstock perennial, with prostrate or spreading, branching stems, seldom above 6 inches long. Leaves alternate, pinnate, with deeply cut, small segments. Flowers sessile in the upper axils, pink-red or rarely white. Calyx broadly oblong, with 5 nnequal teeth or short lobes, the longer ones often toothed. Tube of the corolla much longer than the calyx, the upper lip with 1 minute tooth on each side, under the point.

In moist pastures, and meadows, all over western, central, and northern Furope, but disappearing in the south and the east. Common in Britain. Fl. spring and summer.

\section{MELAMPYRUM. COWWHEAT.}

Frect or spreading herbs, probably semi-parasitical like Rhinanthus, with opposite leaves and branches; the floral leaves often passing into coloured bracts ; the flowers yellow, purple or variegated, either axillary or in terminal leafy spikes. Calyx tubular or campanulate, with 4 teeth. Corolla with a distinct tube; the npper lip compressed, entire or with a small tooth or lobe on each side in front; the lower lip spreading, with 3 short lobes, and a more or less projecting palate closing the mouth of the tube or nearly so. Capsule ovate, oblique, with from 1 to 4 oblong seeds.

A small but distinct genus, confined to Europe and northern Asia.

Flowers variegated with pnrple, in short leafy spikes.

Spikes closely imbricated, 4-Bided. Foral leaves broadly cor.

date and finely toothed - Floral leaves ovate, acuminate,

with long slender teeth
Flowers yellow, In distant axillary pairs, all tnrned one way.

Upper floral leaves toothed at the base. Flowers pale yellow, 6 lines long or more

1. M. cristatum.

2. M. arvense.

Floral leaves all entire. Flowers deep yellow, 3 or 4 llnes long

3. M. pratense.

1. M. cristatum, Linn. (fig. 773). Crested C.-Stem simple or with a few broadly-spreading opposite branches 8 inches to a foot high. Leaves lanceolate or linear and entire, or the npper ones toothed at the base. Flowers in a densely imbricated 4 -sided spike, 1 to $1 \frac{1}{2}$ inches long; the floral leaves or bracts under each flower short and broad, finely but shortly toothed, and of a clear pink or purplish colour at the base. Corolla yellow, more or less variegated with purple, about 6 lines long.

In woods and thirkets, over nearly the whole of Rurope and Russlam 
Asia, but not so common as some other species. In Britain, chiefly confined to eastern England. $F l$. summer.

2. M. arvense, Linn. (fig. 774). Purple C.-A taller and handsomer plant than $M$. cristatum, and usually covered with a very short close down. Leaves lanceolate, toothed at the base. Flowers in a long, loose, leafy spike, beautifully variegated; the bracts often longer than the flowers, at first pink, turning green as they advance, and bordered by long slender teeth. Calyx purplish green, with similar long teeth. Corolla 6 to 8 lines long, with a pink tube, a bright yellow throat, and deep-red lips.

In cornfields, in temperate Europe, from south Sweden to the Can. casus, often proving very injurious to the crops. In Britain confined to a few localities in south-eastern England and in Norfolk. Fl. summer.

3. M. pratense, Linn. (fig. 775). Common C.-Stem erect or ascending, 6 inches to a foot high, with very spreading, opposite branches, usually glabrous or nearly so. Leaves lanceolate, the floral ones distant from each other, short, and often toothed at the base. Flowers pure yellow, in distant axillary pairs, all turned one way, and about 6 to 8 lines long; the teeth of the calyx usually erect and shorter than the tube, but they vary much both in length and direction.

Chiefly in woods, througliout Europe and Russian Asia. Abundant in Britain. $F l$. summer and autumn.

4. M. sylvaticum, Linn. (fig. 776). Small-flowered C.-Very near M. pratense, and not always easy to distinguish from it. It is usually a smaller plant, with the floral leaves almost always entire, and the flowers very much smaller, of a deep yellow; the calycine teeth are more conspicuous, and the lower ones spreading. Corolla seldom above 4 lines long.

A high northern and alpine plant, not unfrequent in the woods of northern Europe and Asia, and in the high mountain-ranges of central Europe, the Caucasus, and Altai. In Britain, apparently limited to Scotland, northern England, and north-eastern Ireland. Fl. summer.

\section{LABIAT压. THE LABIATE FAMILY,}

Herbs, or rarely shrubs, with quadrangular stems or branches, and leaves always opposite. Flowers in the axils of the upper leaves or bracts, rarely solitary in each axil, more frequently in cymes, often so closely clustered that the two opposite eymes appear like one whorl of 6,10 , or more flowers (sometimes called a verticillaster or false whorl), the whole forming usually n terminal compound spike, raceme, or panicle (more strictly termed a thyrsus). Besides the pair of floral leaves or bracts under the whorls, there are often smaller bracts to each flower in the whorl. Calyx 5-toothed, or rarely 2- or 3-lobed. Corolla with a distinct tube and a more or less irregular 4- or 5-lobed limb, usually forming two lips. Stamens 2, or 4 in 2 pairs. Orary 4-lobed, with 1 erect ovule in each lobe, and a single 
style rising from the centre, and shortly cleft at the top into 2 stigmatic lobes. Fruit enclosed in the persistent calyx, separating into 4 small, 1-seeded and seed-like nuts.

A vast family, spread over every quarter of the globe, and readily known from all Monopetals, except Boraginea, by the 4-lobed ovary and the 4 small nuts resembling naked seeds in the bottom of the calyx; and from Boraginea by their opposite leaves, the want of the fifth stamen, and usually by the more irreguiar flowers. Most of the species have also a peculiar strong scent, either highly aromatic in many of our potherbs, or as disagreeable in several species of Stachys. Distinct, however, as the whole family is, the genera into which it has been divided are much less so than could be wished. Those especially which are allied to Stachys are separated from it by slight differences in the shape of the calyx and corolla, which are not always easy to appreciate.

(Stamens, at least the longer ones, longer than the npper lip of the corolla $\quad 12$

1 Stamens in pairs, or 2 only, under the upper lip of the corolla.

Stamens concealed within the tube of the corolla $\quad . \quad: \quad . \quad 16$

Calyx regularly 5 -toothed. Stamens always $4.0 \quad: \quad: \quad 3$

2 Calyx distinctly 2-lipped, the upper teeth more or less united into an upper lip, the 2 lower ones united or distinct. Stamens 4 or 2 .

$\{$ Calyx with 15 parallel ribs. Outer stamens the shortest : $: 7$. N RPRis.

8 Calyx with 5 or 10 principal ribs or veins. Outer stamens the longest

Lower leaves deeply divided. Upper lip of the corolla very hairy, almost

4 woolly . 15. LEONURUS. Lower leaves coarsely toothed. Upper lip of the corolla glabrous or hairy . 5 Anthers opening by transverse valves, one valve fringed with small hairs.

Anthers opening by longitudinal valves

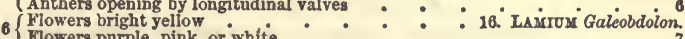

Klowers purple, pink, or white

Nuts flat and angular at the top. Lateral lobes of the lower lip of the corolla

7 either very small and tooth-like or pointed. Anthers hairy . 16. LAMIUM.

Nuts rounded at the top. Lateral lobes of the lower lip usually obtuse. Anthers glabrous $8\left\{\begin{array}{l}\text { Calyx funnel-shaped, the teeth ovate, spreading with a fine point } 14 \text {. BALLTA. } \\ \text { Calyx tubular or campanulate, with narrow-pointed teeth }\end{array}\right.$ Calyx of 2 entire lobes, the upper one with a concave scale on the back.

9. SCUTELLARIA.

Calyx with the upper lip more or less toothed or lobed, the lower one 2-cleft to the base (Stamens 2 (the flaments branched, one branch with a perfect anther-cell, the

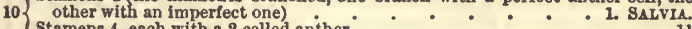
Stamens 4, each with a 2-celled anther. : 11 (Calyx broadly campanulate, veined, with 4 or 5 obtuse lobes or teeth.

Calyx upper-lip fiat and angular, with 3 small teeth. Filaments with a small

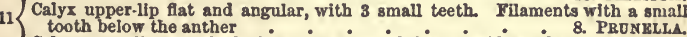
Calyx upper-lip 3-toothed, the tube 13-nerved, hairy inside at the top.

6. CanAMintha.

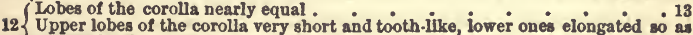
Upper lobes of the corolla very short and tooth-1ike, lower ones elongated so as Stamens 2

Stamens 4 Corolla nearly regular,
4-lobed. Calyx equally is-toothed, scarcely hairy in the

14 throat Upper lip of the corolla erect. Calyx very hairy in the throat ${ }^{\circ}$. 3. MrNTHA. 
(Low, procumbent plant, with small leaves. Calyx distinctly 2-lipped.

15 Erect plant. Flowers in leads, intermixed with bracts in a terninal panicle. Calyx nearly equally 5 -toothed .

16 Calyx with 10 recurved teeth. Stamens all perfect : 11. MARRUBium.

$16\{$ Calyx with 5 teeth. Stamens mostly barren

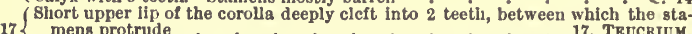

17 mens protrude . 17. TEUCRIUM.

short tooth-like upper lip entire or notched, behind the stamens - 18. AJUGA.

The genera of Labiates have been distributed into eight Tribes, of which the five following are represented in Britain.

1. MON $\triangle R D E$. T. Two ascending stamens, in which one cell of each anther is either wanting or separated from the other. Genus-1. SALvis.

2. SATUREINEE Two or four spreading or ascending stamens. Upper lip of the corolla with the lubes usually flat. Genera:-2. LycopUs; 3 . MENTHA; 4. THYMUs; 5. ORiganum; and 6. Calamintha.

8. NEPETER. Four ascending stamens, of which the upper or middle pair are the longest (project above the others), while in the preceding and two following tribes the lower or outer pair are the longest. Genus-7. NEPETA.

4. ST $\triangle C H Y D E E$. Four ascending stamens. Upper lip of the corolia usually con. cave or arched. Genera:-8. Pronella; 9. Scutellaria; 10. Melittis; 11. Mar RUBIUM ; 12 STACHUS; 13. GALEOPSIS; 14. BALlOTA ; 15. LEONURUS; and 16. LAMIUM.

5. AJUGOIDEs. Stamens ascending (4 in the British genera). Corolla apparently 1-lipped. Genera:-17. TrUORIUM; and 18. AJUOA.

Among Labiate genera entirely exotic, the sweet Basil (Ocymum), Lavender (Lavandula), Rosemary (Rosmarinus), Balm (Melissa), Savory (Satureia), and Hyssop (Hyssopus), are cultivated among our culinary potherbs; several species of Coleus, including the Patchouly, in our hothonses; the shrubby Phlomis and Leonotis, and the herbaceous Perillas, Monardas, and Dracocephalums, and others, in our flower-gardens.

\section{SALVIA. SAGE.}

Herbs, or, in some exotic species, shrubs, with the flowers usually in whorls of 6 or more, forming terminal racemes or spikes, the floral leaves all or most of them reduced to mere bracts. Calyx 2-lipped, the npper lip entire or with 3 small teeth, the lower one 2-cleft. Corolla with the upper lip erect, concave, or arched; the lower spreading, 3-lobed; the middle lobe often notched or divided. Stamens really 2, although easily mistaken for 4 , for the anthers have a long slender connective, having the appearance of a filament, fastened by the centre to the very short real filament, and bearing at one end a perfect anther-cell under the upper lip of the corolla, and at the other end a small cell, almoșt always empty, and usually much deformed.

A very large genus, widely spread over the temperate and warmer regions of the globe, although within the tropics the majority of species are mountain plants. The structure of the stamens readily distinguishes them from all other Labiata.

Leaves mostly radical. Corolla large, near thrice as long as the calyxy. Corolia small, not twice the length of the calyx. : I. S. Pratensis.

Many exotio specles are cultivated in our gardens, the common or garden Sage (S. officinalis) from southern Europe, as a potherb, and ceveral Aucrican ones for the beauty of their flowers. 
1. S. pratensis, Linn. (fig. 777). Mcarlow S.-Stock perennial, with a spreading tuft of shortly stalked radical leaves, ovate, heartshaped, or oblong, 2 to 6 inclies long, coarsely toothed, and very much wrinkled. Stems 1 to $1 \frac{1}{2}$ feet high, slightly downy, with only a few narrow leaves near its base. Flowers in a long and handsome, terminal, simple or scarcely branched spike, composed of whorls of about $C$ flowers, at regular distances. Upper lip of the calyx minutely 3-toothed. Corolla near thrice as long, of a rich blue, with a long, arched upper lip.

In dry pastures, roadsides, and waste places, in central and southern Europe to the Cancasus, extending northwards into Sweden and to the French side of the Finglish Channel. Very rare in England, and con. fined to Oxford, Cornwall, and Kent. Fl. summer.

2. S. Verbenaca, Linn. (fig. 778). Wild S.-A coarse, more or less hairy, erect perennial, 1 to $1 \frac{1}{2}$ or rarely 2 feet high, and slightly branched. Lower leaves stalked, ovate, coarsely toothed or lobed, and much wrinkled; the upper ones sessile, broader and shorter; bractlike floral leaves small, heart-shaped and entire. Flowers small, blue, in whorls of about 6 , forming terminal hairy spikes; the corolla seldom twice the length of the calyx.

In waste places, on roadsides, \&c., in northern and central Europe and Russian Asia. Scattered over Fngland, Ireland, and southern Scotland as far as Edinburgh. Fl. summer. In southern Europe it is replaced by the small-flowered S. clandestina, a marked variety or perhaps species, on a smaller scale, with narrower, more cut leaves, and smaller flowers, which occurs in the Channel Islands.

\section{LYCOPUS. LYCOPUS.}

Herbs, with the habit and flowers of Mentha, but with only 2 stamens snd the nuts surrounded by a thickened, somewhat corky border.

Besides the British species there are but very few, dispersed over Europe, Asia, and North America, together with one in Australia. Perhaps indeed all but one may be mere varieties of the common one.

1. I. europæus, Linn. (fig. 779). Gipsywort.-A tall, erect, and branching perennial, slightly hairy, with a shortly creeping rootstock. Leaves shortly stalked, lanceolate, or almost ovate, deeply toothed or pinnatifid. Flowers small and very numerous, in dense axillary whorls or clusters, seldom exceeding the leafstalk. Calyx-teeth 5, stiff and pointed. Corolla scarcely exceeding the calyz-teeth, and nearly equally 4-lobed. Stamens rather long.

In wet ditches, and marshes, throughout Kurope, northern Asia, and North America Abnndant in England and Ireland, extending into Scotland, but becoming rare as it advances northward. $F$. oummer.

\section{MENTHA MINT.}

Perennial herbs, usually downy or hairy, with rather small flowers in dense whorls or clusters, which are either collected in terminal 
heads or spikes, or axillary and distant. Calyx of 5 teeth, regular or slightly 2-lipped. Corolla with a short tube and a campanulate 4-lobed limb, the upper lobe rather broader and sometimes slightly notched. Stamens 4, equal and erect, the anthers 2-celled. Nuts smooth, not bordered.

A natural genus, not numerous in species, but widely diffused over the greater part of the globe without the tropics, and most of the species, from the variety of situations to which they will adapt themselves, vary so much as to render their exact definition almost hopeless. Many of them also propagate so readily from suckers, that individual varieties are perpetuated so as to assume the appearance of species. Almost all the species vary in the stamens, in some individuals much longer than the corolla, in others included within the tube, and often barren; and in several species individuals occur with all the leaves crisped and cut, and have been published as distinct, under the names of $M$. crispa or crispata. Hybrids also probably occur, and may have been the origin of some supposed species, such as $M$. gentilis, Sole., which are not now to be found wild. [No fewer than fourteen species, with twenty-one varieties, are admitted into the London Catalogue of British Plants (1886.)]

Whorls of flowers in terminal spikes or heads.

Leaves mostly sessile. Flowers in spikes.

Leaves and stem downy or hairy.

Leaves narrow-ovate or lanceolate _ . . . . 1. M. silvestris.

Leaves broadly ovate or orblcular

Leaves and stem glabrous

Leaves all shortly stalked.

Flowers in cylindrical or elongated spikes

Flowers in terminal, globular or ovold heads (rarely with a few dense clusters below the terminal one) .

Whorls of flowers all axillary, the last (terminal) pair of leaves

having no flowers or only a very small whorl.

Howering stems ascending or erect. Leaves coarsely cre. nate.

Throat of the calyx not closed with hairs.

Calyx tubular, with narrow teeth

Calyx campanulate, with shotiva.

Calyx campanulate, with short teeth
Flowering stems prostrate. Leaves small. Throat of the calyx closed with hairs .

7. M. arvensis

8. Mr. Pulegium.

1. M. silvestris, Linn. (fig. 780). Horse M.-Rootstock, as in most Mints, more or less creeping, the stems 1 to 2 feet high, erect, slightly branched, and, as well as the whole plant, more or less hoary with a short close down. Leaves closely sessile, broadly lanceolate or narrow. ovate. Flowers small and numerous, in dense cylindrical spikes, 1 to 2 inches long, usually several together, forming an oblong terminal panicle.

In wet pastures, and waste places, along ditches, \&c., in temperate and southern Europe and Russian and central Asia, but does not extend far north. In Britain, it is a doubtful native, and rare in the northern counties. Fl. summer, rather late.

2. M. rotundifolia, Linn. (fig. 781). Round-leaved M. - An erect perennial, like $M$. silvestris, but coarser, greener, and more hairy. Leaves broadly ovate or orbicular, much wrinkled, green above and whitish underneath. Spikes of flowers terminal and cylindrical, more slender than in the last, 1 to 2 inches or rather more in length, forming 
a leafy, somewhat spreading panicle. Flowers small, pale pink, or sometimes white.

Nearly as widely diffused over Europe and temperate Asia as the last, but rather more of a western plant. It spreads also more readily as an accompaniment of cultivation. In Britain, rather more common than $M$. silvestris, but, except in the southern counties, introduced. $F l$. summer, rather late. Specimens occur so nearly intermediate between these two species that it is difficult to say to which they belong.

3. M. viridis, Linn. (fig. 782). Spear M. -An erect or ascending perennial, with the narrow leaves sessile or nearly so, and the cylindrical terminal spikes of $\boldsymbol{M}$. silvestris, but the stem and leaves are green and glabrous, although there are often hairs on the calyx and bracts.

Chiefly known in Europe, Asia, and North America, as the common Mint of gardens, and only found apparently wild in countries where it has been long cultivated. Occurs occasionally in Britain under similar circumstances. Fl. end of summer. It is not improbably a mere variety of $M$. silvestris, of garden or accidental origin, rendered perpetual by its ready propagation by suckers.

4. M. piperita, Huds. (fig. 783). Pepper M.-A perennial, less erect than $M$. viridis, glabrous like that species or nearly so. Leaves more stalked and broader. Spikes fuller, consisting of larger whorls; the lower ones often distant, showing an approach to the character of $\boldsymbol{M}$. aquatica.

The common pungent variety appears to be of garden origin, occasionally spreading in wet places in several parts of Europe. Indicated in several localities in England and Ireland. Fl, end of summer. It may possibly prove to be a mere variety of $M$. aquatica.

5. M. aquatica, Linn. (fig. 784). Water M. - Usually a rather coarse perennial, 1 to $1 \frac{1}{2}$ feet high, much branched, and almost always softly hairy, although some varieties become nearly glabrous. Leaves stalked, ovate or slightly heart-shaped. Flowers larger than in M. silvestris and $\boldsymbol{M}$. rotundifolia, in dense, terminal, globular or oblong heads, of more than half an inch in diameter, with occasionally 1,2 , or more additional whorls in the axils of the upper leaves. Calyx tubular, about $1 \frac{1}{2}$ lines long, with fine pointed teeth.

In wet ditches, and marshes, and on the edges of streams, throughout Europe and Russian Asia, and now naturalised in many other countries. Abundant in Britain generally, but, like the two following, becomes rarer in the north of Scotland. Fl. summer and autumn. [A variety, $M$. pubescens, Willd., with narrower sharply serrate leaves and stout crlindric spikes, occurs in the midland and southern counties of Eingland.]

6. M. sativa, Linn. (fig. 785). Whorled M.-Intermediate, as it were, between $M$. aquatica and $M$. arvensis, this plant has the foliage and calyx of the former, but the stem is less erect and often low and spreading, as in $M$. arvensis, and the flowers, as in the latter species, are all in distinct axillary whorls, without any terminal bead or spike, or with only a very few flowers in the axils of the last pair of floral leaves. Its chief difference from $M$. arvensis is in the more tubular, longer calyx, and larger flowers ; but intermediate forms are so numerous, connecting it on the one hand with $M$. arvensis, and on the other with $M$. aquatica, that many botanists have considered it as a mere variety of the one or 
of the other. These points cannot be determined without a long course of experiments and observations made on a succession of seedlings, which are as rare in this as in other species of the genus.

As widely spread as $M$. arvcnsis, all over temperate and northern Europe, and Russian Asia, but growing usually in moister situations and richer soils. Common in Britain. Fl, summer and autumn. [This includes many distinct British varieties, distinguished as species by some botanists, as $M$. rubra, Sm., with the nerves of the leaf purple; Mf. gracilis, Sm., a very slender form with narrow floral leaves; $\boldsymbol{M}$. pratensis, Sole., with drooping leaves rounded at both ends; and $\boldsymbol{M}$. gentilis, Linn., with large floral leaves, the uppermost flowerless.]

7. M. arvensis, Linn. (fig. 786). Corn M.-Usnally a low, spreading, branched perennial, more or less hairy, with a creeping rootstock, and annual stems, from 6 inches to a foot long, rarely rising erect to the height of 1 or 2 feet. Leaves stalked, ovate, and toothed, 1 to 2 inches long, or the upper ones smaller. Flowers all in axillary whorls, mostly shorter than the leafstalks; the last pair of leaves without any or with only very few flowers. Calyx campanulate, seldom above a line long, with short teeth. Corolla twice as long.

In fields and moist places, in temperate and northern Europe and Russian Asia ; rarer to the southward, but introduced with cultivation into many other parts of the globe. Abundant in Britain, although less so than $M$. aquatica, and, like that species, becomes rarer towards the north of Scotland. Fl. summer and autumn. It varies much in stature, in lıairiness, in the size of the leaves, \&c.

8. M. Pulegium, Linn. (fig. 787). Pennyroyal.-A prostrate, much branched perennial, with the leaves very much smaller than in any other Mentha, being seldom above half an inch long, and quite entire or seldom slightly crenate; the floral ones still smaller, and often recurved. Flowers in dense axillary whorls, like those of $M$. arvensis, except that the calyx-teeth are less regular, with the mouth closed by hairs, and the upper lobe of the corolla is more evidently notched, thus showing a slight approach to the characters of Thymus.

In wet ditches, and marshy places, most abundant in the Mediterranean region, but extending over Europe and western Asia, and introduced into other parts of the world. Scattered over the greater part of England, Ireland, and the south of Scotland. Fl. end of summer.

\section{THYMUS. THYME.}

Low, much branched, spreading or procumbent nndershrubs or herbs with small leaves, usually entire, and flowers in terminal leafy heads or loose spikes. Calyx 2-lipped; the upper lip 3-toothed, the lower 2-cleft, the mouth closed with hairs after flowering. Corolla with the npper lip erect, nearly flat; the lower spreading, broadly 3-lobed. Stamens (when perfect) 4, the lower ones diverging, as long as or longer than the corolla.

A genus of several species, chiefly from the Mediterranean region and central Asia, whore they are very variable and difficult to determine. In northern Europe, however, there is but one species wild. The garden I'kyme, cultivated as a potherb, is $T$. vulgaris, from southern Europe. 
1. T. Serpyllum, Linn. (fig. 788). Wild Thyme-Stems procumbent, slender, very much branched, perennial, and hard bnt scarcely woody at the base, forming low dense tufts; from a few inches to near a foot in diameter, and often almost covered with the purple flowers. Leaves very small, ovate or oblong, fringed at the base by a very few long hairs on each side; the floral leaves similar but smaller. Flowers usually 6 in the whorl, without any other bracts than the floral leaves, forming short, terminal, loose, leafy spikes. Calyx usnally hairy, and the whole plant sometimes covered with short, rather stiff, hoary hairs.

On banks, and dry, hilly pastures, throughout Europe and northern and central Asia. Very abundant in Britain. Fl. the whole summcr. [There are two very distinct forms of the wild Thyme.

a. T. Serpyllum proper. Flowering branches ascending from trailing shoots, whorls in one head, upper lip of corolla oblong.

b. T. Chamadrys, Fries. Branches all ascending from the rootstock, whorls in axillary heads, npper lip of corolla short broad.]

\section{ORIGANUM. MARJORAM.}

Herbs or nndershrubs, with the principal characters of Thymus, but of taller growth, and especially differing in inflorescence. The flowers are in compact heads, with a bract under each flower at least as long as the calyz, the whole forming terminal corymbs or panicles. The calyx is also variable, in our species more regular than in Thymus, in some exotic ones quite as decidedly 2-lipped as in that genus, and the lips somctimes entire.

Besides our common species, the greater number of Origanums are east Mediterranean, including the sweet Marjoram of our gardens.

1. O. vulgare, Linn. (fig. 789). Wild M.-Rootstock perennial, shortly creeping; the annual stems erect, 1 to 2 feet high, more or less hairy. Leaves stalked, ovate or ovate-lanceolate, an inch or more long, and slightly toothed. Flowers purple or rarely white, in globular compact heads, forming a terminal trichotomous panicle. Bracts ovate, about the length of the calyx. Calyx very hairy inside the mouth, with short, nearly equal teeth. Corolla twice as long as the calyx, with 4 broad, nearly equal lobes, of which the upper one is broader and nearly erect. The two longest stamens, and sometimes all four, project beyond the corolla.

On the edges of woods, roadsides, and hilly pastures, especially in limestone districts, thronghout Europe and Russian Asia, except the extreme north. In Britain, spread over England and Ireland, rarer in Scotland. Fl. summer. [O. megastachyum, Link, is a form with larger 4-angled spikes.]

\section{CALAMINTHA. CALAMINT.}

Branching, erect or ascending herbs, with ovate, toothed leaves, and purplish flowers in axillary cymes, sometimes forming dense whorls, sometimes loose and paniculate. Calyx tubular, with 13 longitudinal parallel ribs ( 2 between the midribs of the lower teeth, and 1 only between the midribs of the upper teeth), and 5 pointed teeth; the $\&$ 
upper teeth more or less connected at the base into an upper lip; the month more or less closed with hairs. Corolla-tube usually longer than the calyx; the upper lip erect and slightly concave; the lower one spreading, with 3 broad lobes. Stamens 4 , in pairs nnder the npper lip, the outer ones the longest, but not spreading beyond the corolla.

A considerablegenus, spread over the temperate regions of thenorthern hemisphere, both in the New and the Old World. It is distinguished from Thymus and Origanum chiefly by the longer corolla and the stamens not diverging, from all the following genera by the arrangement of the ribs or nerves of the calyx.

Annual. Calyx-tube enlarged at the base on the lower slde.

Flowers in axlllary whorls of six

Perennials. Calyx-tube not enlarged at the base.

Cymes axlllary, many-flowered, forming dense whorls, with linear bracts as long as the calyxes

Cymes loose, axillary, and few-flowered or loosely panlculate. Bracts small, or none besidea the floral leaves

1. C. Acinos.

3. C. Clinopodiun.

2. C. oflcinalis.

An American Calamintha with red flowers is occasionally cultivated in our gardens. The common Balm (Melissa officinal is), which often establishes itself for a time as an outcast from gardens, in the southern districts of England, much resembles a Calamintha; it is, however, a coarser plant, and is distinguished as a genus chiefly by a slight curve upwards in the tube of the corolla.

1. C. Acinos, Clairv. (fig. 790). Field C., Basil-Thyme-A more or less branched annual, 6 or 8 inches high, and slightly downy. Leaves stalked, rather small, narrow-ovate, pointed, slightly toothed. Flowers pale-purple, or white, in axillary whorls of about 6 , on short, erect pedicels, without bracts. Calyx strongly ribbed; the tube much enlarged on the under side at the base, contracted again at the mouth; the teeth short and fine. Corolla in the common variety but little longer than the calyx, although occasionally near twice as long. $O$. arvensis, Lam.

In waste places, or more frequently as a weed of cultivation, in Europe and western Asia, extending northward into Scandinavia. Dispersed over England, and a portion of Scotland, very rare in Ireland. Fl. summer.

2. C. officinalis, Mœnch. (fig. 791). Common C.-A more or less hairy perennial; the rootstock often creeping; the stem ascending or erect, with straggling branches, 1 to 2 feet high or even more. Leaves stalked, ovate, and toothed. Flowers very variable in size, usually turned to one side, in loose cymes, which are sometimes all axillary, with 6 to 10 flowers in each, sometimes looser, on peduncles as long as or longer than the leaves, and forming terminal, 1-sided leafy panicles. Calyx tubular, ribbed, not swollen at the base; the teeth finely pointed, those of the lower lip finer and longer than the upper ones.

In woods, hedges, roadsides, and waste places, in central and southern Europe and Russian Asia, but scarcely extending into northern Germany. Frequent in England and Ireland, but not in Scotland. Fl. summer. The following marked varieties have been usually considered as species, but they run so much into one another that many botanists unite them :- 
a. C. Nepeta, Clairv. Rootstock scarcely creeping. Leaves abou half an inch long, nearly entire. Flowers about 6 lines long, the cymes contracted into loose whorls of about 10, the corolla half as long agair. as the calyx. On dry, open, sunny banks. Abundant on the Continent and not uncommon in England.

b. C. officinalis. Leaves larger than in the last, and more toothed. Flowers nearly twice as long as the calyx. Intermediate between the two other varieties, and not quite so common as either.

c. C. sylvatica, Bromf. Rootstock more creeping. Stem taller. Leaves often 2 to 3 inches long. Cymes loose. Flowers showy, often an inch long, the corolla fully twice as long as the calyx. In woods, and under hedges, common on the Continent, especially in the south, extending in Britain to the Isle of Wight, Hampshire, and Devonshire.

3. C. Clinopodium, Benth. (fig. 792). Hedge C., Wild Basil.Rootstock shortly creeping. Stems annual, erect or ascending, branched, and softly hairy, 1 to 2 feet high. Leaves stalked, ovate, slightly toothed, almost 2 inches long, soft and hairy. Flowers purple, in dense cymes, forming compact whorls or heads in the axils of the upper leaves, or at the ends of the branches, and surrounded by subulate, hairy bracts. Calyx abont 3 lines long, with subulate, hairy teeth, the 3 upper ones shortly nnited by their broad base. Tube of the corolla rather longer than the calyx-teeth.

Under hedges, and on the borders of woods, throughout Europe and Russian Asia, except the extreme north. Rather frequent in England and southern Scotland, rare in Ireland. Fl. summer.

\section{NEPETA. NEPETA.}

Creeping or erect herbs, with flowers usually blue, in axillary whorls or terminal spikes. Calyx tubular, 15-ribbed, its month oblique and 5-toothed, the upper teeth usually the longest. Corolla with a rather long tube, the throat enlarged; the upper lip erect, slightly concave, notched or 2-lobed; the lower lip spreading and 3-lobed. Stamens 4, in pairs under the upper lip, the upper or inner pair the longest.

An extensive European and Asiatic genus, the great centre of which is in western Asia. With a few other exotic genera, it forms a tribe among Labiata, known as well by the ribs of the calyx always 15, not 13 as in Calamintha, nor 10 or 5 as in the generality of Labiato, as by the stamens, of which the upper or central pair project above the outer ones, whilst in most Labiatce the outer ones project above the inner ones.

Stem creeping or prostrate. Howers axillary .

Stem tall and erect. Flowers in terminal spikes or clusters .

1. N. Glechoma.

The $N$. Nepetella, from continental Europe, and one or two eastern species, are occasionally cultivated in flower-gardens.

1. N. Glechoma, Benth. (fig. 793). Ground-Ivy.-A more or less hairy perennial, creeping and rooting at the base, often to a considerable length; the flowering stems shortly ascending. Leaves orbicular, orenate, deeply cordate at the base, the lower ones on rather long stalks. Flowers blue, from to near an inch long, in axillary whorls 
of about 6 ; the tube of the corolla at least twice as long as the calyx. Glechoma hedcracea, Linn.

Under hedges, on banks, edges of woods, and waste places, throughont Europe and central and Russian Asia, excepting the extreme north, extending eastward to Japan. Very sbundant in Britain. Fl. early spring.

2. N. Cataria, Linn. (fig. 794). Catmint.-An erect, branching perennial, 2 feet high or more, of a pale green, or somewhat hoary with minute down. Leaves stalked, ovate-cordate, pointed, and coarsely toothed, often whitish underncath. Flowers rather small, pale blue or nearly white, crowded in compact cymes, forming short, oblong spikes at the ends of the branches, with frequently 1 or 2 clusters a littlo lower down. Calyx softly downy, nearly as long as the tube of the corolla.

In hedges, on roadsides and waste places, thronghout Europe and central and Russian Asia, except the extreme north. Tolerably frequent in the south and centre of England, and in Ireland, less so in the nort?, and not a native of Scotland. Fl. summer, rather late.

\section{PRUNELLA. PRUNELLA.}

Low, branching, hairy perennials, with the flowers in whorls of 6 , but collected into dense terminal heads, with broad, bract-like floral leaves under each whorl, and no real bracts. Calyx 2-lipped, the npper lip flat, the lower deeply 2-lobed, the mouth not closed with hairs. Upper lip of the corolla erect, concave, short, broad, and nearly entire; the lower one spreading, 3-lobed. Stamens 4, in pairs under the upper lip, each filament with a small tooth below the anthers.

A very distinct genus (often spelled Brunella), containing, besides the British one, but two species, both natives of the continent of Europe; one of which, $P$. grandiflora, chiefly distinguished by the large size of its flowers, is often cultivated in cottage-gardens.

1. P. vulgaris, Linn. (fig. 795). Prunella, Self-heal.-Stem procumbent or creeping, and rooting at the base, with ascending flowering branches, sometimes 2 or 3 inches, rarely near a foot high. Leaves stalked, ovate, and nearly entire. Spikes of flowers at first very short, but lengthening out to 1 or even 2 inches, with a pair of leaves close under it. Corolla usually of a violet purple, about 6 lines long, but varying much in size and depth of colour; the upper lip bends over the lower one, which is scarcely longer, with a broad, finely-toothed middle lobe.

In pastures, on banks, \&c., especially in rather moist situations, throughout Europe, north and central Asia, and North America, penetrating into the Arctic regions, and into the tropical mountains of America and Asia, and reappearing in Australia. Abundant in Britain. $\mathrm{Fl}$. summer and autumn. In some conntries it varies much more than in Britain, in stature and foliage, as well as in the size and colour of the flowers.

\section{SCUTELLARIA. SKULLCAP.}

Herbs (rarely shrubby in some exotic species), usually rather weak or straggling, with the flowers always solitary in the axil of each leat. 
either all in distant axillary pairs, or, in some exotio species, forming terminal spikes or racemes. Calyx divided into 2 lips, both entire; the upper one bearing on its back a bollow, scale-like protuberance. Corolla with a rather long tube, and small, nearly closed lips, the npper one concave, the lower one 3-lobed. Stamens 4, in pairs, the anthers of the lower pair 1-celled. Nuts raised on a short, oblique or curved stalk.

A rather large genns, widely distributed over the temperate anc some of the warmer regions of the globe, and easily recognised, either by its inflorescence, calyz, stamens, or ovary and fruit.

8 tem nsually 8 inches to a foot high. Flowers blue, rather large 1. S. galericulata Stem usually under 6 inches. Flowers pink, and small . . 2 s. minor.

Some of the Mexican or Sonth American half-shrubby species, with scarlet flowers, are occasionally cultivated in our planthouses.

1. S. galericulata, Linn. (fig. 796). Common S.-A weak, slightly downy perennial, with a slender, creeping rootstock, and slightly branched, ascending stems 8 inches to a foot high. Leaves nearly sessile, ovate-lanceolate, slightly toothed. Flowers nearly sessile, opposite, in axillary pairs along the greater part of the stem, and all turned to one side; the corolla more than 6 lines long, of a rather dingy blue ; the tube very slender below, considerably enlarged at the throat.

In wet, shady, or stony places, in Europe, northern Aria, and northeast America, extending from the Himalaya and the Cancasus to the Arctio Circle, but rarer in the Mediterranean region. Tolerably frequent in England and Scotland, less so in Ireland. F. summer. [A hybrid occurs at Virginia Water, Surrey, which unites the characters of this and $S$. minor.]

2. S. minor, Linn. (fig. 797). Lesser S.-A very small, and usually more glabrous plant than $S$. galericulata, with slender stems, seldom 6 inches long. Leaves of the same shape, but nearly entire. Flowers shortly stalked, scarcely above 3 lines long, of a pale pink.

In moist heaths or marshy sands, chiefly in western Europe, more rare in central Europe, extending, however, across northern Germany into Russia and central Asia, but neither a high northern, nor scarcely a Mediterranean plant. In Britain, chiefly in western England, Ireland, and south-western Scotland. Fl. summer.

\section{MELITTIS. MELITTIS.}

A genus limited to a single species, differing from the long-flowered species of Stachys chiefly by its large calyz, nsually 3-lobed, and by its axillary flowers.

1. II. Melissophyllum, Linn. (fig. 798). Balm.-An erect and slightly hairy perennial; the stems nearly simple, 1 to $1 \frac{1}{2}$ feet high. Leaves stalked, heart-shaped, and coarsely toothed, about 2 inches long. Flowers pink, or variegated with white and purple, in axillary whorls of 2 to 6 , shorter than the leaves. Calyx of a thin texture, broadly canpanulate, with 3 broad, rounded lobes, of which the upper one is sometimes 2- or 3-toothed. Corolla with a broad tube, near an inch long : the upper lip thrown back and slightly concave; the lower lip largn, 
spreading, and 3-lobed. Stamens 4, in pairs, projecting slightly from the tube. M. grandiflora, Sm.

In woods and shady places, in temperate and southern Europe and western Asia, not extending into northern Germany. In Britain, confined to a few localities in southern and south-western England. $\mathrm{Fl}$. summer.

\section{MARRUBIUM. HOREHOUND.}

Perennial herbs, usually cottony or woolly, with much wrinkled leaves and rather small flowers in axillary whorls or clusters. Calyx with 5 or 10 ribs, and as many equal pointed teeth. Corolla with a short tube; the npper lip erect, usually notched; the lower lip spreading and 3 lobed. Stamens 4, included within the tube of the corolla, all the anthers 2-celled. Nuts rounded at the top.

A rather numerous genus in southern Europe and western Asia, readily distinguished amongst British Labiata by the included stamens, and in that respect allied to the extensive south European genus Sideritis, which, however, has different anthers.

1. M. vulgare, Linn. (fig. 799). White H. -Stem rather thick, a foot and a half high, with spreading branches, thickly covered with a white cottony wool. Leaves stalked, orbicular, soft, and much wrinkled. Flowers in dense whirls or clusters in the axils of the upper leaves, small, of a dirty white. Calyx with 10 small, hooked teeth. Upper lip of the corolla narrow, erect, and 2-cleft.

On roadsides and waste places, in temperate and southern Europe and central and Russian Asia, extending northwards into Scandinavia, and now naturalised in several parts of America and other countries. Not a common plant in England or Ireland, and still more rare in Scotland; although found in abundance at particular localities. [It is a doubtful native, except in the Isle of Wight.] Fl. summer and autumn.

\section{STACHYS. STACHYS.}

Rather coarse, hairy herbs (or, in some exotic species, low shrubs), with the leaves often cordate, and flowors, in the British species, in whorls of 6 or more, forming terminal racemes, spikes, or heads. Calyx 5- or 10-ribbed, with 5 nearly equal, erect or spreading, pointed teeth. Corolla with the upper lip erect, concave, and entire; the lower lip longer, spreading, 3 -lobed, the lateral lobes often reflexed. Stamens 4, in pairs under the upper lip. Nuts smooth, rounded at the top.

A numerous genus, spread over nearly the whole world, but within the tropics limited to mountain districts.

Erect perennials, 1 to 3 feet high.

Plant thiekly covered with a white silky wool. Flowers numerous, in erowded whoris.

Plant green, more or less hairy.

Nlowers many in each whorl, forming a close, oblong, terminal spike. Leaves mostly radical a

2. S. germanica

Flowers 6 to 10 in each whorl, forming a long, loose, terminal

1. S. Betonice npike. Stem leafy. 
Lower leaves long-stalked, ovate, deeply cordate .

Leaves short-stalked or sessile, oblong or lanceolate, scarcely cordate

Low, weak, or spreading annual, with small flowers

8. S. sylvatica.

4. S. palustris.

5. S. arvensis.

The S. annua, Linn., a low, erect, south European annual, with yellow flowers the size of those of $S$. palustris, has been inserted in some British Floras, probably from having appeared among the weeds ir. some cornfield. The S. coccinea, from Mexico, with red flowers, and a few other exctic species, are occasionally cultivated in flower-gardens.

1. S. Betonica, Benth. (fig. 800). Betony.-A perennial, 1 to 2 feet high, more or less downy or hairy, but not woolly. Leaves mostly radical, oblong, coarsely crenate and cordate at the base; the upper ones few and distant, on short stalks or quite sessile, narrower, and not cordate. Flowers in several dense whorls, collected in a close, terminal, oblong head or spike, with an ovate or lanceolate bract under each calyx. Calyx-teeth erect, very pointed, almost prickly. Tube of the corolla considerably longer than the calyx; the upper lip ovate, erect, and slightly concave, about the length of the lower one. Anthercells more distinct and less divergent than in the rest of the genus, or almost parallel. Betonica officinalis, Linn.

In woods and thickets, all over Europe and Russian Asia, except the extreme north. Abundant in England, extending, but rarely, into the counties of Scotland, and into southern Ireland. Fl. summer.

2. S. germanica, Linn. (fig. 801). Woundwort._-An erect, branching perennial, 1 to 3 feet high, remarkable for the long, whitish, silky hairs which cover its stems and leaves, and especially the upper portion of the plant and the calyxes. Leaves shortly stalked, oblong-ovate or lanceolate, slightly cordate at the base, soft and silky. Flowers numerous, in dense whorls or clusters, all distinct, the lower ones sometimes rather distant, but all forming a long terminal spike, with numerous small, narrow bracts, close under the flowers. Calyx-teeth often almost prickly. Corolla-tube shorter than the calyx, the upper lip very silky outside.

In waste places, and on roadsides; very common in central and southern Europe and western Asia, where it is very variable. In Britain it has appeared in some limestone districts of Hampshire, Oxford, and Kent, but it is perhaps not indigenous. Fl. summer.

3. S. sylvatica, Linn. (fig. 802). Hcdge S.-A green, coarsely hairy perennial, with a disagreeable smell; the rootstock emitting short, thick, creeping scions; the stem stout, erect, and branching, 2 to 4 feet high. Leaves all stalked, rather large, ovate, cordate, and crenate. Flowers in whorls of 6 to 10, distant from each other, forming long terminal spikes, without any bracts except the floral leaves. Calyxteeth spreading and pointed, but not prickly. Corolla of a dark reddish-purple, the tube longer than the calyx, the lower lip variegated with white on the upper side.

In ditches, on shady banks, and the edges of woods, throughout Europe and Russian Asia, from the Caucasus and Altai to the Arctic Circle. Very abundant all over Britain. Fl. summer.

4. S. palustris, Linn. (fig. 803). Marsh S.-Resembles S. sylvatioa in its creeping rootstalk and tall, stout stems, but the hairs are shorter and not so coarse, the smell is not so bad, and the leaves are much 
narrower; they are very shortly stalked, oblong or lanceolate, slightly cordate at the base, 2 to 4 inches long. Flowers of a palc bluish-purple, in whorls of 6 or 8 , forming shorter and more crowded spikes than in S. sylvatica; the calyx-teeth long and pointed, but not prickly. Corollatube rather shorter, with a broader and somewhat shorter lower lip than in $S$. sylratica.

In ditches, and on moist banks, in Europe, Russian Asia, and northern America, generally a more northern plant than $S$. sylvatica. Abundant in Britain. $F l$. summer and autumn. S. ambigua, Sm., is a hybrid with $S$. sylvatica; it has rather broader and longer-stalked leaves, and a rather longer tube to the corolla.

5. S. arvensis, Linn. (fig. 804). Ficld S.-A slender, hairy annnal, very different in aspect from the preceding species; the stems branched, decumbent, or slightly ascending, from an inch or two to nearly a foot long. Leaves small, ovate, scarcely cordate. Flowers small, of a pale purple, in whorls of 2 to 6 or 8 , forming loose, leafy spikes. Calyxteeth as long as its tube. Corolla scarcely longer than the calyx.

In fields and waste places, spread over Europe and Russian Asia, except the extreme north, and carried out with our crops even to tropical countries. Common in England, rare in Ireland and Scotland. Fl. the whole season.

\section{GALEOPSIS. GALEOPSIS.}

Erect, or slightly decumbent annuals, with spreading branches and flowers in dense whorls in the upper axils or at the summit of the branches. Calyx nearly regular, with 5 pointed teeth. Corolla with a tube longer than the calyx; the upper lip erect, concave and entire or slightly notched; the lower spreading and 3-lobed. Stamens 4, in pairs ; the cells of the anthers opening by a transverse slit, bordercd with hairs.

A small genus, consisting of European and north Asiatic weeds of cultivation, distinguished from Stachys chiefly by the anthers.

Hairs of the plant short and soft. Calyx-teeth not longer than the tube. Stems not swollen under the nodes.

Flowers purple.

Flowers yellow:

Hairs of the plant long and stiff. Calyx-teeth long and almost prickly. Stems swollen under the nodes.

1. G. Ladanum. 2. G. ochroleuca.

1. G. Ladanum, Linn. (fig. 805). Red G.-An annual, seldom above 8 or 9 inches high, with very spreading, almost decumbent branches, and covered with a very short, soft down. Leaves shortly stalked, narrow-ovate or lanceolate, coarsely toothed. Flowers purple, 6 to 10 together, in dense whorls in the upper axils, the upper ones forming a terminal head. Calyx-teeth usually very pointed, but shorter and less prickly than in $G$. Tetrahit, the tube of the corolla considerably longer than the calyx.

In cuitivated and waste places, all over Europe and Russian and western Asia. Frequent in southern England, decreasing in Scotland, local in east Ireland. Fl. summer and autumn. It varies much in the breadth of the leaf, from ovate to nearly linear; in the degree of hairiness, and in the size of the flower. [G. angustifolia, Ehr., is a 
narrow-leaved form with the leaves sometimcs cntire, closer whorls of flowers, and a longer corolla-tube.

2. G. ochroleuca, Lam. (fig. 806). Downy G.-Very much like G. Ladanum, but more densely covered with soft almost silky hairs, which give the upper part a whitish hue, and the flowers are very numerous, considerably larger, often above an inch long, and of a pure yellow colour. G. dubia, Leers.

In cultivated and waste places, in temperate Europe, from Spain to Scandinaria, and eastward to south Russia. Confined to the central and northern countios of England and north Wales. Fl. summer and autumn. It is very doubtful whether it be more than a variety of G. Ladanum, and it is even said that the one has been raised from the seeds of the other.

3. G. Tetrahit, Linn. (fig, 807). C. Ilemp-nettle,-A coarse annual, 1 to 2 feet high or even more, although sometimes very dwarf, with n few spreading branches, green, with stiff, spreading hairs, and the stems swollen under the nodes. Leaves stalked, ovate, very pointed, and coarsely toothed. Flowers numerous, in close whorls in the axils of the upper leaves. Calyx-teeth long and almost prickly. Corolla, in the common variety, pale-purplish or white, exceedingly variable in size, sometimes not longer than the calycine teeth, more frequently twice that length, and sometimes much longer.

In cultivated and waste places, and occasionally also in woods, extending all over Europe and Russian Asia. Frequent in Britain. $F l$. summer and autumn. G. versicolor, Curtis (speciosa, Miller), is a marked variety, often considered as a distinct species. It is usually a larger plant, with larger yellow flowers with a purple spot on the lower lip; but, as in the purple variety, the size of the flower is very variable, and in some localities it passes into $G$. Tetrahit.

\section{BALLOTA. BALLOTA.}

This genus, closely allied to the shorter-flowered Stachyscs, differs chiefly in the calyx, which is enlarged at the top, so as to be nearly funnel-shaped, and in several exotic species has 10 or even more teeth. The corolla, stamens, and nuts are nearly as in Stachys.

The exotic species belong almost exclusively to the Mediterranean region and western Asia.

1. B. nigra, Linn. (fig. 808). Black H.-A coarse, erect, hairy, branching perennial, 2 to 3 feet high, softly hairy all over, with a strong, disagreeable smell. Leaves stalked, ovate or cordate, coarsely toothed. Flowers in dense axillary clusters, often slightly stalked, and turned to one side, assuming less the appearance of whorls than in Stachys, usually shorter than the floral leaves, and accompanied by a number of stiff, linear bracts. Calyx 4 or 5 lines long, green or purplish, with 10 prominent ribs, and 5 broadly ovate teeth, each terminating in a fine stiff point. Corolla purplish, with an oblong or oval, concave and somewhat arched upper lip, scarcely shorter than the 3-lobed, spreading lower lip. $B$, ruderalis, Sm.

On roadsides, nnder hedges, and in waste places, thronghont Enrope and Russian Asia. In Britain it extends over England, Ireland, snd 
the south of Scotland, but usually as an escape from cultivation. $\boldsymbol{F}$. summer and autumn. It varies considerably in the precise form of the teeth of the calyx, and in the length of their point. [B, alba, Liun., is a stout form, with spinous spreading or reflexed tips of the calys. teeth.]

\section{LEONURUS. LEONURUS.}

Erect herbs, with leaves more or less lobed, and rather small flowers in close axillary whorls, forming long, terminal, leafy spikes. Calyx with 5 prominent ribs, and 5 equal, spreading, almost prickly teeth. Corolla with a rather short tube; the upper lip erect, concave, and entire; the lower spreading, and 3-lobed. Stamens 4, in pairs. Nuts flat, angular at the top.

A small genus, containing a few European and Asiatic species, differing from Stachys chiefly in the shape of the nuts, which is the same as in Lamium.

1. L. Cardiaca, Linn. (fig. 809). Motherwort.-A tall, coarse, stiff, slightly hairy or downy perennial, 2 to 4 feet high. Leaves stalked, the lower ones broad, deeply and irregularly cut into 5 or 7 coarsely toothed lobes; the floral leaves narrow, 5-lobed, or nearly entire, their stalks as long as the flowers. Flowers 6 to 15 together, in close axillary whorls, forming a long interrupted terminal, leafy spike. Calyx-teeth almost prickly. Corolla pink or nearly white, like that of a Stachys, with a rather short tube, and very hairy upper lip.

In waste places, hedges, on roadsides, \&c., in Kurope and central and Russian Asia; not extending, however, far to the northward. Indicated in several parts of England, Scotland, and Ireland, but with considerable doubts as to its being indigenous. $F$. end of

summer.

\section{LAMIUM. DEAD-NETTLE.}

Hairy herbs, either annual or perennial, decumbent at the base; the lower leaves always stalked, ovate or orbicular, and toothed; the flowers in close axillary whorls, or the upper ones in a leafy head. Calyx as in Stachys. Corolla tube slender at the base, much enlarged at the throat; the upper lip erect or arched, slightly coneave, entire or slightly notched; the lower spreading, with a broad middle lobe; the two lateral ones either smaller and pointed, or more often reduced to a small tooth. Anthers hairy in all the British species except $L$. Galcobdolon.

A genus of several species, chiefly south European or central Asiatic, generally distinguished either by the long, arched upper lip, or by the smallness of the lateral lobes of the lower lip of the corolla.

Lnnuals, with small flowers, in few, nearly terminal, leafy whorls.

Floral leaves sessile, orblcular, obtusely crenate .

1. L. amplexicaule

Floral leaves shortly stalked, ovate, often pointed.

Yerennials, with rather large flowers in axillary whorls.

2. L. purpurcumn 


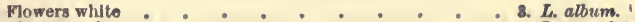

Flowers red.

Flowers yellow

1. I. amplexicaule, Linn. (fig. 810). Henbit.-A low, decnmbent, much branched annual, a few inches, or, when very luxuriant, near a foot long. Lower leaves small, orbicular, on long stalks; the floral ones closely sessile, broadly orbicular, and deeply crenate or cut. The flowers form 1,2, or 3 compact whorls. Calyx softly hairy, with short teeth. Corolla about half an inch long, of a purplish red, with a slender tube; the lateral teeth of the lower lip scarcely perceptible.

In cultivated and waste places, throughout Europe and central and Russian Asia, except the extreme north. Extending all over Britain. $F l$. the whole scason. A variety, $L$. intermedium, Fries, with rather longer teeth to the calyx, and more distinct lateral teeth to the lower lip of the corolla, is occasionally found mired with the common one, especially in the more northern localities.

2. I. purpureum, Linn. (fig. 811). Red D.-A spreading annual, like $L$. amplexicaule, and the lower leaves are likewise small and orbicular, on long stalks; but the upper leaves, even the floral ones, are all shortly stalked, and ovate, heart-shaped, or triangular, often pointed, and, in the common variety, less deeply toothed. Calyx-teeth fine, and spreading. Corolla of a purplish red, shorter than in $L$. amplexicaule, with a broader, more open tube, and a more hairy upper lip; the lower lip with a short fine tooth on each side.

In cultivated and waste places, throughont Enrope and western Asia, except the extreme north. In Britain more common than L. amplexicaule, especially as a garden weed. $F l$. the whole season. A variety with the upper leaves deeply cut, which occurs in western Europe, and has been found in England and Scotland, is the L. incisum, Willd. (hybridum, Vill.).

3. I. album, Linn. (fig. 812). White D.-A rather coarse, hairy perennial, with a shortly creeping stock, and decumbent or ascending, branching stems, seldom above a foot high. Leaves stalked, coarsely crenate. Flowers pure white, in close axillary whorls of 6 to 10 or more Calyx-teeth long, fine, and spreading. Tube of the corolla curved upwards. and longer than the calyx, with an oblique contraction near the base, corresponding with a ring of hairs Inside; the npper lip long and arched; the lateral lobes of the lower one slightly prominent, with a long, fine tooth.

Under hedges, on banks, and waste places thronghout Europe and Russian Asia, except the extreme north. Extends all over Britain, although becoming rare in the Scotch Highlands. Fl. the vhole season. The leaves are occasionally marked by a white line or spot in the centre, but less frequently so than in the following species.

4. I. maculatum, Linn. (fig. 813). Spotted D.-Closely resembles $\boldsymbol{L}$. album in every respect except in the colour of the flower, which is purple-red instead of white, and in the ring of hairs in the tube of the. corolla, which is transverse instead of oblique. The leaves are also more frequently marked in the centre with a broad white line or spot. It is still very doubtful whether it may not be a mere variety of $\boldsymbol{L}_{\mathrm{n}}$ album, with which I had formerly united it.

With nearly the same geographical range as $L_{0}$ album, it is, however, 
rather more southern. In Britain it is rare, and only introduced, as it has long been cultivated in cottage gardens, and spreads readily by its offsets. Fl. summer.

5. I. Galeobdolon, Crantz. (fig. 814). Yellow Archangel.-Stock perennial as in the last two species, but the stems are longer and less branched, often a foot and a half high. Leaves stalked, ovate, toothed, but scarcely cordate. Flowers bright yellow, in dense axillary whorls; the calyx-teeth short; the tube of the corolla scarcely longer than the calyx; the upper lip long and arched; the lateral lobes of the lower lip narrow, but not much smaller than the central one. Anthers glabrous as in some exotic species, not hairy as in the other British ones. Galeobdolon luteum, Huds.

In woods and shady places, in Europe and western Asia, extending northwards into southern Scandinavia. Not uncommon, but local in England and the east of Ireland, but found in Scotland. Fl. spring and early summer.

\section{TEUCRIUM. GERMANDER.}

Herbs or undershrubs, varying much in habit; the flowers few in each whorl, usually turned to one side. Calyx of 5 teeth, often arranged in 2 lips. Corolla apparently without an upper lip; the 2 upper lobes forming 2 small teeth, one on each side of the base of the lower lip, which has thus 5 lobes, the middle one large and concave. Stamens 4, protruding between the 2 upper teeth of the corolla.

A numerous genus, spread over all parts of the world, and always known by the shape of the corolla.

Flowers in terminal 1-sided spikes or racemes.

Flowers pale yellow, 2 to each whorl. Calyx with 1 broad and 4 small teeth.

Howers purple-red, 1 to 6 in each whorl. Calyx-teeth nearly equal

Flowers all axlliary. 'Calyx-teeth nearly equal.

Softly hairy perennlal. Leaves sessile, or nearly so, oblong, toothed

Pubescent annual. Leives stalked, deeply divided lnto narrow lobes

1. T. Scorodonia.

4. T. Chamadrye.

2. T. Scordium

8. T. Botrys.

1. T. Scorodonia, Linn. (fig. 815). Wood-sage-Rootstock creeping, the stems ascending or erect, hairy, about a foot bigh, slightly branched, hard and almost woody at the base. Leaves stalked, ovate or lanceolate, coarsely toothed, much wrinkled, downy, and green on both sides. Flowers of a pale yellow, in pairs, with a small bract under each pedicel, forming terminal and axillary l-sided racemes. Upper tooth of the caly $x$ very broad and turned back, the 4 lower teeth small. Tube of the corolla slender, twice as long as the calyx; the lip almost as long, with a terminal concave lobe and 2 small lateral teeth on each side.

In woods and hedges, thronghout Europe and Russian Asia, except the extreme north. Abundant in Great Britain. Flo oummer and nutumn

2. T. Scordium, Linn. (fig. 816). Water G.-A low, branching perennial, procumbent and rooting at the base, or twitting creeping 
ocions, and usually covered with short, soft hairs. Leaves oblong, $\frac{1}{2}$ to 1 inch long, coarsely toothed, usually narrowed at the base, but larger and cordate in luxuriant specimens. Flowers of a pale purplish-red, all axillary, turned to one side, in whorls of 6 or fewer, the pediceds very slender. Calyx small, with 5 nearly equal teeth.

In wet, marshy places, generally dispersed over Europe and central and Russian Asia, except the extreme north. Rare in Britain, having been only found in a few English counties, chiefly eastern; very rare in Ireland. $F$. summer.

3. T. Botrys, Linn. (fig. 817). Cut-lcaved G.-An erect or decnmbent branching annual of 6 to 9 inches, more or less pubescent. Leaves stalked, rhomboidal in ontline, $\frac{1}{2}$ to $\frac{3}{4}$ inch long, deeply divided into linear entire or lobed segments. Flowers of a purplish-red, all axillary, in whorls of 6 or fewer. Calyx broad, 3 to 4 lines long, very gibbous, almost saccate on the under side at the base, with 5 short lanceolate nearly equal lobes or teeth.

In waste places and borders of fields, in central and sonthern Europe, from Spain to Silesia, extending northwards to Normandy, and in Britain found in a few localities in Surrey. Fl. summer.

4. T. Chamædrys, Linn. (fig. 818). Wall G.-Stock perennial, almost woody; the stems rarely branched, ascending, hairy, 6 to 8 inches high. Leaves ovate, deeply toothed, wedge-shaped at the base, green, and more or less hairy on both sides. Flowers reddish-purple, in whorls of 2 to 6 , forming a short, rather loose, terminal, 1-sided raceme. Calyx loosely tubular, with 5 almost equal, pointed teeth.

On stony banks, and old walls, over the greater part of central and southern Enrope and western Asia, but not extending into Scandinavia. In Britain, it has been found only in a few localities, on old walls, having, although now well established, escaped from gardens; in Ireland it has been found in sandy fields, but very rarely. Fl. summer.

\section{AJUGA. BUGLE.}

Low herbs, with purplish-blue or yellow flowers, in close whorls in the upper axils, often forming terminal leafy spikes; the corolla withering but remaining attached after flowering. Calyx 5-cleft. Corolla with a distinct tube; the upper lip rarv short, erect, and entire or nearly so; the lower lip longer and spreading, as in Germander. Stamens in pairs, projecting beyond the upper lip or tooth of the corolla. Nuts rongh or wrinkled.

A rather extensive genns, spread over Europe, Asia, Africa, and Anstralia, but unknown in America, differing from Germander in the tooth-like upper lip of the corolla, and still more in habit.

Ieaves entire, or coarsely toothed. Flowers blue or ash-coloured.

Plant glabrous, or slightly hairy, with creeplng scions

Plant very hairy, without creeping scions. . . 2. A. genevensis.

1. A. reptans.

Leaves deeply divided into linear lobes. Flowers yellow . : 8. A. Chamapitys.

1. A. reptans, Linn. (fig. 819). Creeping B.-The whole plant is glabrous, or with a fow hairs chiefly amongst the flowers. The short stock emits creeping scions and a tuft of radical leaves, which are obovate. 1 to 2 inche lnng, entire or broadly crenate, and narrowed 
into a stalk nearly as long as the leaf. Flowering stems crect, often only 2 or 3 inches, rarely near a foot high, with short, ovate or obovate, nearly sessile leaves; the upper ones often coloured, small, and bract. like. Flowers in close whorls in the axils of nearly all the leaves; the npper ones forming a cylindrical leafy spike. Corolla blue, or rarely flesh-colour or white, with the tube much longer than the calyx.

In pastures and woods, throughout Europe and western Asia, except the extreme north. Abundant in Britain. Fl. spring and early summer.

2. A. genevensis, Linn. (fig. 820). Erect B.-Much like A. reptans, but has no creeping scions, and is much more hairy; the stock bas a tuft of rather large, spreading radical leaves, and one or more erect or ascending flowering stems, with the leaves often coarsely toothed. Calyx very hairy. Floral leaves in the pyramidal variety, the only one found in Britain, broadly ovate, longer than the flowers, and crowded with them in a pyramidal or quadrangular leafy spike.

The species has a very wide range over Europe, and central and Russian Asia, to the Himalayas and China, although not an arctic plant. Fl. early summer. The pyramidal variety, common in northern Europe and the great mountain-ranges of central Europe, is the only British form; it occurs but rarely in the Scotch Highlands, and in the great island of Aran, off the coast of Ireland. This variety is usually dis. tinguished as a species (A. pyramidalis, Linn.), but its peculiarities appear to be owing to station, and it is never more marked than in recently burnt pastures.

3. A. Chamæpitys, Schreb. (fig. 821). Yellow B., Ground Pine.A low, much-branched, hairy annual. Leaves much crowded, and deeply divided into 3 linear lobes; the lateral ones sometimes again divided. Flowers yellow, in axillary pairs, always shorter than the leaves.

In dry, cultivated, and waste stony places, roadsides, \&c., chiefly in limestone soils, in central and southern Europe and western Asia, extending northwards over the greater part of Germany. In Britain, limited to some of the south-eastern or eastern counties of England. Fl. the whole season.

\section{VERBENACE\&. THE VERVEIN FANILY.}

Herbs, shrubs, or trees, with opposite or rarely alternate leaves. Flowers of Labiatce, except that the ovary is entire, with the style proceeding from the top. Fruit dry or succulent, usually shorter than the persistent calyx, 2- or 4-celled, with 1 seed in each cell.

A large family, chiefly American or from the warmer regions of Asia and Africa. Besides the numerous cultivated species of Verbena, several exotic genera, such as Lantana, Vitex, \&c., are familiar to our gardeners.

\section{VERBENA. VERVEIN.}

Herbs or rarely shrubs, with opposite stem-leaves, and alternato Howers in terminal spikes. Caly 5 5-toothed. Corolla with a distinct tube, and a rather unequally 5-cleft, spreading limb. Stamens 4, or 
rarely only 2 , included in the tube. Fruit enclosed in the calyx, dividing into 41 -seeded nuts.

A genus confined in Europe to one or two species, but comprising numerous American ones, which have been still more multiplied in our gardens by the more or less permanent varieties or races produced by cultivation.

1. V. officinalis, Linn. (fig. 822). Common V.-A nearly glabrous, erect perennial, 1 to 2 feet high, with long, spreading, wiry branches. Lower leaves obovate or oblong, stalked, and coarsely toothed or cut; the npper ones few, sessile, and lanceolate. Flowers very small, in long, slender spikes, the lower ones becoming distant as the spike lengthens, each one sessile in the axil of a small bract.

On roadsides and on waste places, in central and southern Europe and Asia, extending northwards into southern Sweden. Frequent in the southern counties of England, rare in the north and in Ireland, nnknown in Scotland. Fl. summer and autumn.

\section{PLUMBAGINEÆ. THE PLUMBAGO FAMILY.}

Herbs, or rarely undershrubs, usually hard and stiff; the leaves mostly or entirely radical; the flowers in terminal heads, spikes, or panicles. Calyx tubular, often enlarged and petallike at the top. Corolla of 5 petals, often united at the base. Stamens 5, inserted at the base of the corolla or between the petals. Ovary single, with 1 cell, and a single, suspended ovule, but bearing 5 styles, either quite distinct or united below the middle. Capsule either indehiscent or opening irregularly, and enclosing a single seed.

A small family, extending over most parts of the world, but chiefly within the influence of the sea-air, or occasionally on high mountains. Besides the two British genera, some speciss of Plumbago or Leadwoort (which gives its name to the family) are cultivated as ornamental plants.

- Howers in terminal panicles or spikes. Styles glabrons . . . 1. STATICE. Flowers in globular heads. Styles hairy at the base $: \quad: 2$ ARMERIA.

\section{STATICE. STATICE.}

Flowers solitary or 2 or 3 together, in little spikelets within 2 bracts, these spikelets forming 1 -sided spikes, arranged either in a dichotomous or trichotomous panicle, or, in some exotic species, forming a single spike. Calyx more or less expanded at the top into a dry, membranous, coloured, and slightly 5-lobed limb, each lobe traversed by a green or dark nerve. Petals slightly nnited at the base, the stamens inserted at their point of union. Styles glabrous.

The geographical range is the same as that of the family, of which this genus includes the great majority of species.

Loaves usually several Inches long, the veins pinnate (when

vislble). Panicle very spreading and corymbose

1. S. Limonisn. 
Leaves ustrally not above an inch, with 1 or 3 ribs, and no plnnate veins. Panicle elongated, usually 1 -sided.

Branches all, or nearly all flowering .

Short, flowerless, intricate branches very numerous

2. S. auriculefolia 3. S. reticulata.

Several exotic species are occasionally cultivated in our flower-gardens or planthouses.

1. S. Limonium, Linn. (fig. 823). Sea Lavender.-Stock short and thick, with tufts of radical leaves from 2 to 5 or 6 inches long, obovate or oblong, quite entire, glabrous, and narrowed at the base into a long stalk; the midrib is alone prominent when fresh, but when dry the lateral reticulate veins branching from it distinctly appear. Flowerstem erect, leafless, 6 inches to a foot or even more high, repeatedly forked, 80 as to form a broad corymbose panicle, with a membranous bract at each division. Flowers numerous, in slort, rather loose spikes at the ends of the branches, with a green bract, coloured at the edge, under each flower. Calyx green at the base, dry. scarious, and of a pale purple in its upper part, with 5 short, broad teeth, which are often slightly toothed or jagged. Petals of a bluish purple, at the time of flowering rather longer than the calyx, but the latter becomes subsequently much enlarged, so as to assume the appearance of a corolla concealing the real one.

In maritime sands and salt-marshes, on the coasts of western Europe, the Mediterranean, and western Asia, and apparently the same species on the South American and Californian sea-shore. Frequent on the coasts of England and Ireland; eastern Scotland only. Fl. summer and autumn. A small variety, with less compact spikes, has been described as a species, under the name of $S$. bahusiensis, Fries, or $S$. rarifora, Drejer. It grows in the same situations, and is often very difficult to distinguish, even as a variety.

2. S. auriculæfolia, Vahl. (fig. 824). Rock S.-Resembles in many respects $S$. Limonium, but the tufted stock is more branched and compact. The leaves are much smaller, usually scarcely 1 and rarely 2 inches long, with shorter stalks, and, when dry, often show a lateral nerve on each side of the midrib, but never any diverging veins. Stems about 6 to 10 inches high. Spikes more compact, with rather larger flowers than in S. Limonium, but the spikes themselves are fewer and more distant, forming an elongated, not a corymbose panicle. The bracts are greener and longer. S. bincrvosa, G. E. Sm. S. intermedia, Syme, S. Dodartii, Gir., and S. occidentalis, Lloyd.

On dry, rocky, maritime banks, or more rarely in sands, on the shores of western Europe, penetrating also far along the Mediter. ranean. In Britain, it extends up the west coast to Wigtonshire, but not beyond Lincolnshire on the east coast, and occurs in Ireland. Fl. summer.

3. S. reticulata, Linn. (fig. 825). Mattcd S. -This is a still smaller plant than the last, with leaves often not more than 6 lines long; the lower branches of the panicle numerous, very much branched, and nsually without flowers, whilst the central ones bear numerous short spikes of small flowers, with the bracts white and scarious nearly from the base. S. bellidifolia, Gouan.

In maritime sands, all round the Mediterranean and in western Asia, extending more sparingly up the west coast of France. In 
Britain only in the counties of Norfolk, Suffolk, and Cambridge. Fl. summer.

\section{ARMERIA. THRIFT.}

Flowers in a terminal, globular head, intermixed with scarious scales, of which the outer ones form a kind of involucre, and the 2 outermost of all are lengthened below their insertion into appendages forming a sheath round the upper part of the peduncle. Calyx usually drier and more scarious than in Statice, the petals scarcely united at their very base, and the styles hairy in the lower part.

A genus of very few species, separated from Statice chiefly on acconnt of their inflorescence, which gives them a peculiar habit.

Leaves narrow-linear, 1-nerved. Teeth of the calyx short.

Leaves lanceolate-linear, 3- or 4-nerved. Teeth of the calyx long and fine

1. 4. vulgaris.

2. A. plantaginea.

1. A. vulgaris, Willd. (fig. 826). Common T., Sea pink.-The stock forms perennial tufts, with numerons radical leaves, all narrow-linear, entire, with a single prominent midrib. Flowering stems simple and leafless, glabrous or shortly downy, 3 or 4 inches to twice that height, each bearing a globular head of pink or sometimes white flowers; the petal-like border of the calyx crowned by 5 very short, slender teeth.

On muddy or sandy sea-shores, and on maritime rocks, in the northern hemisphere, from the Arctic regions to near the tropics, reappearing in the southern hemisphere beyond the tropics, and also at considerable elevations in the high mountain chains of Enrope and Asia. Abundant on our British coasts and on the tops of some of the Scotch mountains. $F$. summer. ['The mountain form has rather broader leaves, and is var. planifolii, Syme.]

2. A. plantaginea, Willd. (fig. 827). Plantain T.-Very near the last, and perhaps one of its numerous forms, but the leaves are much broader, usually marked with 3 or 5 parallel nerves, the flower-stalk is often a foot high or more, and the slender teeth of the caly $x$ are much longer than in A. vulgaris.

On sandy heaths and wastes, in western Europe, extending northward to the English Channel and eastward to the Rhine. In onr flora only in Jersey. Fl. summer.

\section{PLANTAGINEA. THE PLANTAIN FAMILY.}

Herbs, with radical, tufted or spreading leaves, and leafless flower-stalks, bearing a simple spike or a single terminal flower (the stem in some exotic species becoming elongated, branched, and leafy). Sepals 4. Corolla small, scarious, with an ovato or cylindrical tube; and 4 spreading lobes. Stamens 4 , alter. nating with the lobes of the corolla, and usually very long. Ovary 1-, 2-, or 4-celled, with 1 or more ovules in each cell, and 
terminating in a long, simple style. Capsule opening trans. versely or indehiscent.

A small Order, widely spread over the globe, but most abundant in the temperate regions of the Old World.

Flowers hermaphrodite, in terminal heads or spikes

Flowers unisexual, solitary, or 2 together, the males stalked, the

1. Plantago.

females sessile amongst the leaves

2. LITTORELLA.

\section{PLANTAGO. PLANTAIN.}

Flowers hermaphrodite, in heads or spikes on a leafless peduncle. Capsule 2- or 4-celled, with 2 or more seeds.

The genus comprises the whole family, with the exception of the single species of Iittorella.

Leaves ovate or lanceolate, strongly ribbed.

Leaves very broad, stalked. Spike long. Capenl, severalseeded ovate, almost sessile. Spike cylindrical. capsule 1 -

Leaves ovate, almost sessile. Splke cylindrical. Capsule 1seeded.
Sikes lanceolate. ovold, or shortly cylindrical. Capsule 2-seeded

Lcaves liuear, entire or plnnatifid.

Leaves entire, or very slightly toothed. Ovary 2-celled . . 4. P. maritima.

Leaves deeply toothed or pinnatifid. Ovary 4-celled . . . 5. P. Coronopus.

1. P. major, Linn. (fig. 828). Greater P.-Rootstock short and thick. Leaves erect or spreading, broadly ovate, often 4 or 5 inches long and nearly as broad, entire or toothed, glabrous or downy, marked with 7 (rarely 9 or only 5) prominent, parallel ribs, converging at the base into a rather long footstalk. Peduncles usually longer than the lcaves, bearing a long, slender spike of sessile flowers, smaller than in the two following species. Sepals green in the centre, scarious on the edges. Stamens longer than the corolla, but shorter than in the two following species. Capsule 2-celled, with from 4 to 8 seeds in each cell.

In pastures, on roadsides, and in waste places, throughout Europe and liussian and central Asia, and has spread with cultivation over almost every part of the globe. Very abundant in Britain. Fl. summer and autumn. It varies much in size; the spike of flowers is seldom less than 2 inches, sometimes as much as 6 inches long. $[P$. intermedia, Gilis., is a dwarf downy form with ascending scapes.]

2. P. media, Linn. (fig. 829). Hoary P.-Rootstock thick, almost woody, and branched as in $P$. lanceolata. Leaves ovate, sessile, usually closely spreading on the ground, more or less hoary with a short down, and marked with 5 or 7 ribs. Peduncles long and erect, bearing a dense cylindrical spike, shorter and much thicker than in $P$. major, bnt yet longer than in $P$. lanceolata, varying from 1 to near 2 inches in length. Flowers and capsules of $\boldsymbol{P}$. lanceolata, except that the 4 sepals are free, the corolla more silvery, and the stamens pink or purple. Ovary with 2 seeds in each cell, but they often do not all ripen, and the capsule has then but 3 or 2 altogether.

In dry, close pastures, chiefly in limestone districts, in most parts of Europe and western Asia. Abundant in similar situations in England 
and sonth of Scotland, but not in Ireland, except where introduced. Fl. early summer, and often again in autumn.

3. P. lanceolata, Linn. (fig. 830). Ribwort P.-Rootstock short, but thick and woody, and often much branched, bearing tufts of woolly hairs among the leaves. Leaves erect or spreading, lanceolate, varying much in size, but usually 2 to 4 inches long, slightly hairy, with 3 or 5 ribs, and more or less tapering into a stalk at the base. Pednncles longer than the leaves, erect and angular. Spike ovoid or oblong, nsually 6 lines to near an inch long, but sometimes very small and globular, or, in very luxuriant specimens, becoming cylindrical, and exceeding an inch. Sepals scarions, marked with a prominent green rib; the two lower ones often combined into one. Stamens more than twice as long as the corolla, with slender white filaments and yellow anthers. Capsule with 2 hemispherical seeds attached to the partition by their inner face.

In meadows, pastures, and waste places, with the same widely extended geographical range as $P$. major, and equally abundant in Britain. $F$. the whole season. [A variety, P. Timbali, Jord., with broad silvery margins of the bracts and sepals, occurs in fields, \&c., but is not indigenous.]

4. P. maritima, Linn. (fig. 831). Sea P.-Stock often more branched than in the preceding species, with some long hairs in tufts among the leaves. Leaves narrow-linear, thick and fleshy, pointed, entire or slightly toothed, with scarcely prominent ribs. Peduncles cylindrical, longer than the leaves. Spike cylindrical, 1 to 2 inches long, not so dense or so thick as in the two preceding species. Flowers rather smaller than in $P$. lanceolata. Sepals all usually distinct. Capsules with 2 seeds only.

On muddy sea-shores, and in salt-marshes, in Europe, central Asia, at the northern and western extremities of America, and in South Africa. It occurs also occasionally inland, especially in the principal mountain-ranges of Europe. Frequent on the British coasts and on some of the Scotch and Yorkshire mountains. Fl. late in summer and autumn.

5. P. Coronopus, Linn. (fig. 832). Bucks-horn P.-Rootstock short and thick, scarcely branched. Leaves spreading, in a dense tuft, linear or linear-lanceolate, or pinnatifid with linear segments, more or less hairy, with scarcely prominent ribs. Spikes cylindrical, 1 to 2 inches long. The flowers rather smaller than in P. maritima; the sepals broad and ciliate. Ovary with 4 cells, each with a single ovule, but it often happens that only 1 or 2 in each capsule attain their maturity.

In dry, stony, or sandy situations, especially near the sea, in Europe, north Africa, and western Asia. Common in Britain. Fl. summer and autumn

\section{IITTORELLA. LITTOREL.}

A single species, distinguished generally from Plantago by the inflorescence, the monceious flowers, and a 1-seeded, indehiscent fruit.

1. L. lacustris, Linn. (fig. 833). Littorel.-The small perennial rootntock hears a tuft of bright green, narrow-linear, entire radical leaves, 
from $1 \frac{1}{2}$ to 3 inches long. Male peduncles radical, about an inch long, with a single or rarely 2 terminal flowers, and a small bract lower down. Sepals narrow. Corolla like that of a Plantago, but with small lobes. The stamens, which form the most conspicnous part of the plant, have slender filaments, full half an inch long, terminated by large, ovate anthers. Female flowers concealed amongst the leaves, consisting of a sessile calyx, split into 3 or 4 unequal sepals, enclosing a small ovary, with a long thread-like style. Fruit a small nut.

In mud and wet sand, on the margins of pools, in northern Enrope, extending far into the Arctic regions, but chiefly confined to mountains in central and southern Europe. Appears to be widely distributed in Britain, though seldom observed, for it often remains under water without flowering, when its leaves become longer and grass-like. Fl. summer.

\section{ILLECEBRACEE. THE ILLECEBRUM FAMILY.}

Low herbs, either annual or with a perennial, sometimes woody stock, and annual flowering branches, usually spreading or decumbent; opposite or rarely alternate leaves; small scarious stipules (rarely deficient); and small, often granula: flowers, in terminal or axillary cymes or bunches, rarely solitary. Calyx shortly or deeply divided into 5 , rarely 4 or 3 lobes or segments. Petals either as many, inserted at the base of the sepals, or represented by as many small filaments, or none. Stamens as many as the sepals, rarely fewer, inserted between the petals. Ovary and capsule 1-celled. Styles or sessile stigmas 2 or 3 . Seeds solitary, with a curved embyro, and mealy albumen.

A small Order, widely diffused over the globe, intermediate between Caryophyllacea and Amarantacea, to which it appears on the whole the most nearly allied, for the petals, except in Corrigiola, are reduced to small filaments, which may be considered as imperfect stamens, or are altogether wanting as in $A$ marantacea, thus placing the family amongst Monochlamydce.

Leaves arternate. Leaves opposite.

Calyx with a distinct ovold or globular tube .

Calyx divided almost to the base.

Flowers green. Calyx without points.

Nowers white. Calyx with 5 points.

1. CORriatora.

4. Solrranthog.

2. IIRRNIARIA.

3. ILLRCEBRUM

\section{CORRIGIOLA. STRAPWORT.}

Annuals, with alternate leaves, and small white flowers in terminal cymes. Calyx of 5 divisions. Petals 5 , oblong or oval. Stamens 5 . Stigmus 3, sessile. Seed solitary, in a small nut, enclosed in the caly $\iota_{4}$ 
Besides the British species there are two or three others in southern Europe, Africa, and South America, all seacoast plants.

1. C. littoralis, Linn. (fig. 834). Strapwort.-Stems numerous, procumbent or ascending, slightly branched, slender, and glabrous. Leaves linear or oblong, obtuse, tapering at the base, with a minute scarious stipule on each side. Flowers crowded in little heads or cymes at the ends of the branches; the white, ovate or oblong petals barely protrnding beyond the calyx, whose divisions, however, are white and petal-like on the margin, and green in the centre only. Nuts enclosed, when ripe, in the scarcely enlarged calyx.

On the sandy seashores of western and southern Europe, and northern Africa, extending sparingly into the east Mediterranean region, and western Asia, occurring here and there more inland in west-central Kurope. In Britain, confined to the coasts of Devon and Cornwall. Fl. rummer and autumn.

\section{HERNIARIA, RUPTURE-WORT.}

Herbs, either annual or with a perennial stock of short duration ; with prostrate, much branched, annual stems ; opposite leaves; very minute, scarcely visible scarious stipules; and small, green, granular flowers, crowded in little axillary cymes. Calyx of 5 dirisions. Stamens 5, alternating with 5 small filaments. Stigmas 2. Sced solitary, in a thin, indehiscent capsule enclosed in the calyx.

A genus of very few species, all growing in sandy places, chiefly near the sea, in sonthern Europe, central Asia, and Africa.

1. H. glabra, Linn. (fig. 835). Common $R$. - The very much branched stems spread along the ground to the length of a few inches, and are usually crowded from the base with their little green flowers intermixed with small, opposite, oblong, obovate, or rarely orbicular leaves. The whole plant is glabrous, with the exception of a few usually recurved hairs at the edge of the leaves.

In sandy places, in temperate and southern Europe and Russian Asia, extending into Scandinavia, but not to high latitudes. In Britain, it occurs in several counties of southern and central England. Fl. summer. It varies with the clusters of flowers all crowded into a leafy spike, or, in $H$. ciliata, Bab., the lower ones separated by considerable intervals.

[H. hirsuta, Linn., distinguished by having narrow hirsute leaves, is a very common Continental and west Asiatic species, and has lately been found near Christchurch, in Hampshire.]

\section{ILLECEBRUM. ILLECEBRUM.}

Calyx of 5 thickish white divisions, hooded at the top, with a subulate point. Stamens 5 , alternating with 5 small filaments. Stigmas 2, sessile. Seed solitary, in a capsule enclosed in the calyx, but opening at the base in 5 or 10 valves, which remain cohering at the top.

A genus now reduced to a single specles, but which formerly included several south European ones, now forming the genus Paronychia.

1. I. verticillatum, Linn. (fig. 836). A small, glabrous, much branched annual, prostrate and spreading at the base; the branches 
ascending, from 1 to 3 inches in height, covered in their whole length with the shining white whorls of flowers, in the axils of opposite, obovate, green leaves. Sepals somewhat enlarged after flowering, but even then but little more than half a line long, green on the inner edge, but thickened and of a pure white on the back, with a fine point, giving the whole calyx a 5-ribbed form, something like the capsule of a Sedum. Petals, stamens, and ovary very minute.

In sands, and especially in sandy marshes, in central and southern Europe, from the west coast to the Russian frontier. In Britain, only in Devonshire, Cornwall, and the Channel Islands. Fl. summer.

\section{SCLERANTHUS. KNAWEL.}

Small, much branched herbs, with opposite narrow leaves, connected by a narrow, transparent edge at the base; and numerous small, green flowers, in crowded terminal cymes. Calyx-tube ovoid or campanulate, the limb 5-lobed. Stamens 5, alternating with 5 small filaments, all inserted at the top of the calyx-tube. Styles 2. Seeds solitary in $n$ little nut, enclosed in the somewhat hardened tube of the calyx.

Besides the two British species, the genus comprises two or three from southern Europe, closely resembling them, and perhaps mere varieties.

Root annual. Calyx-lobes pointed . - 1. S. annuus. Btock perennlal. Calyx-lobes obtuse, edged with whito : $\quad$ 2. S. perennis.

1. S. annuus, Linn. (fig. 837). Annual $K$. - A mnch branched, ereet or spreading annual, 2 to 3 inches high, glabrous or very slightly downy. Leaves very narrow, 2 to 3 lines long. Calyx enlarged after flowering to about $1 \frac{1}{2}$ lines in length; the lobes stiff, erect, narrow, pointed, about equal in length to the tube.

In fields and waste places, over the whole of Europe and western Asia, except the extreme north. Abundant in England, Ireland, and southern Scotland, but scarce in the north. Fl. all summer.

2. S. perennis, Linn. (fig. 838). Perennial K. - This species so much resembles $S$. annuus, that it is by some considered as a mere variety. but the root and tufted lower part of the stem will last two or three years. The flowering stems, usually about 2 inches high, are more rigid, the flowers more densely collected in terminal cymes, and the caly $\mathrm{x}$ is rather smaller, with obtuse divisions, bordered by a much more conspicuous white edging.

With nearly the same general range in Europe and Asia as S.annuus, it is everywhere more local. In Britain it appears to be confined to eastern and sonthern England. Fl. all summer.

\section{CHENOPODIACEE. THE GOOSEFOOT FAMILY.}

Herbs or undershrubs, often succulent, sometimes leafless, more usually with alternate or rarely opposite leaves, and no stipules; the small, herbaceous flowers usually in sessile clusters, either in axillary or terminal spikes or panicles, and often 
unisexual. Perianth single, calyx-like, deeply divided into 5, or in some flowers fewer segments. Stamens 5, opposite the perianth-segments, rarely fewer. Ovary free, with a single ovule. Styles 2 or 3, either free or united at the base. Fruit consisting of a single seed, enveloped in a very thin or sometimes succulent pericarp, and enclosed in the persistent perianth, which is sometimes enlarged or altered in form. Seed. usually orbicular and flattened; the embryo curved or spirally twisted, with or without albumen.

The Order is spread over the greater part of the world, and is rather numerous in species, especially in maritime situations, or within the influence of a saline soil or atmosphere, where they sometimes, in combination with Artemisius, give a general grey aspect to the countrs. They are not easily confounded with any other British Order, but approach very near to Amarantacex, an exotic family, chiefly distinguished by the presence of 2 or 3 small bracts under each flower, and by the tendency of the perianth to become scarious or coloured.

stem succulent and jointed, without leaves. Stamens 1 or 2 . 1. SAlicorria.

Btem leafy, not jointed. Stamens 5 .

Leaves narrow, semi-cylindrical (as thick as broad).

Leaves rather succulent and linear, not prickly. Fruiting

perianth not altered
Leaves prickly. Fruiting perianth encircled by a scarions wing

Leaves flat.

Perianth mostly 5.cleft and regular, even when in fruit.

Fruiting perianth succulent, enlarged, with prominent ribs or protuberances

Fruiting perianth scarcely enlarged, herbaceous : :

Perianth of the male flowers 5-cleft and regular. Fruiting perianth (from female flowers) flat, consisting of 2 much enlarged segments .

\section{SURDA.}

3. Salsota.

The Spinach of our gardens (Spinacia oleracea), probably from western Asia, forms a genus closely allied to Atriplex, but with a differently shaped fruiting perianth, and 4 styles. One or two species of Amarantus belonging to the above-mentioned Amarantacere have occasionally appeared amongst garden weeds in the neighbourbood of London, but do not appear to have anywhere established themselves in Britain. The Amarantacea include also the Love-lies-bleeding and Princes-feather (both species of Amarantus), the globe Amaranth (a species of Gomphrena), the Cock's-comb (Celosia), \&c., of our gardens. [A marantus retroflexus, Linn. and A. Blitum, Linn., very common warm country European and Asiatic weeds, occur here and there as outcasts from gardens, where they bave been introduced with foreign seeds.]

\section{SALICORNIA. MARSH SAMPHIRE.}

Succulent, jointed berbs, sometimes hard and woody at the bese, without leaves. Flowers immersed in the upper articles (or internodes) forming terminal, succulent, cylindrical spikes, each article having 6 flowers, 3 in a triangle on each side. Perianth succulent, flat, and nearly closed at the top; the stamens (usually 2 or only 1) protruding through the minutely 3- or 4-toothed orifice. Style included in the 
perianth, divided into 2 or 3 stigmas. Nut enclosed in the unchanged succulent perianth. Seed ovoid, without albumen. Radicle bent back over the cotyledons.

A genus of very few species, ranging over the salt-marshes of all parts of the world.

1. S. herbacea, Linn. (fig. 839). Marsh Samphire, Glasswort.-In its simplest form this is a glabrons, bright green, succulent, erect annual, scarcely 6 inches high, with few erect branches, each one terminated by a spike, $\frac{1}{2}$ to 1 inch long. When luxuriant, after the first flowering, branches shoot out from every joint or node as well as from the spike itself, the lower ones become hard, and often procumbent, rooting at the nodes, and the whole plant will extend to a foot or more; and in favourable situations a few plants will outlive the winter, so as to have the appearance of nndershrubs, but probably do not last beyond the second year.

[A very variable plant. The British varieties, procumbens, ramosissima, and pusilla, indicate these characters. A very different form usually recognised as a species, is $S$. radicans, Sm., with perennial woody creeping stems; it is confined to western Europe, and in Britain to the coasts from York to Devon.]

\section{SUADA. SUEDA.}

Herbs or undershrubs, with rather small, linear, semi-cylindrical, succulent leaves. Flowers and fruit of Chenopodium, except that the embryo of the seed is coiled into a flat spiral, with little or no albumen.

A genus of very few species, ranging over the seacoasts of most parts of the globe, readily distinguished amongst British Chenopodiacea by the foliage as well as by the seed.

Stem shrubby at the base. Styles 3 . . . . . . . 1. S. fruticosa. Stem annual, much branched, or diffuse. Styles 2 . : 2. S. maritima.

1. S. fruticosa, Forsk. (fig. 840). Shrubby S.-A branching perennial, more or less shrubby at the base, sometimes erect, and 1 to 2 feet high, sometimes low and spreading. Leaves numerous, linear but thick, nearly cylindrical and succulent, 3 to 5 or rarely 6 lines long, of a pale green. Flowers small, and solitary or 2 or 3 together, closely sessile in the axils of the leaves. Styles 3, rather longer than the perianth.

In maritime sands, and salt marshes, all round the Mediterranean, in central Asia, and up the western coasts of Europe to Holland, occurring also here and there in America. In Britain, very local, and confined to the eastern and southern coasts of England. Fl. autumn.

2. S. maritima, Dumort. (fig. 841). Herbaceous S.-A low, much branched annual, or sometimes biennial, of a green or reddish colour, seldom a foot high, and often not above 2 or 3 inches. Leaves linear and succulent as in $S$. fruticosa, but usually longer and sometimes more pointed; the lower ones often an inch long, the upper ones 3 to 6 lines. Flowers small, green, and sessile, solitary or 2 or 3 together in the axils of the leaves. Styles usually 2 only.

In salt-marshes and maritime sands, in Kurope and central Asia, extending northward to the shores of Scandinavia and the Baltic. Common all round the British Isles, $F$. summer and autumn. 


\section{SALSOLA. SALTWORT.}

Herbs, with semi-cylindrical, succulent or prickly leaves. Perianth regular, 5-cleft, and enclosing the fruit when ripe, as in Chenopodium and Suceda; but the segments have then a small appendage at the top, forming a horizontal, scarions wing round the perianth. Stamens 5. Styles 2 or 3, often combined at the base, as in Chenopodium. Embryo coiled into a spiral, with little or no albumen, as in Suceda.

The genus comprises a considerable number of maritime species, chiefly from the Mediterranean and western Asia.

1. S. Kali, Linn. (fig. 842). Prickly S.-A procumbent, glabrous annual, with a hard, much branched stem, 6 inches to near a foot long. Leaves all ending in a stont prickle, the lowest semi-cylindrical, linear, slightly enlarged at the base; the uppermost shorter and broader, nearly triangular. Hlowers sessile in the upper axils. The appendage of the perianth spreads horizontally over the fruit, but is usually shorter than the surrounding floral leaves or bracts.

In maritime sands, and salt-marshes, in Europe and western Asia, extending northwards to Scandinavia and the Baltic. Frequent on the coasts of England and Ireland, and Scotland. Fl. summor and autumn.

\section{CHENOPODIUM. NOOSEFOOT.}

Herbs, either glabrous or covered with a mealy dust; the leaves flat and alternate; the flowers small and green, in little sessile clusters, collected into spikes in the axils of the upper leaves, or forming large terminal panicles. Perianth of 5 (rarely fewer in a few flowers) equal segments, which enclose the ripe fruit without appendages or alteration, excepting a slight enlargement or thickening. Stamens 5 (rarely fewer). Styles 2 or 3, often connected at the base. Embryo of the seed curved or forming a ring round the albumen.

The species are rather numerous, widely distributed over the globe, with fewer strictly maritime ones than in most other genera of the Order. When young they much resemble the Atriplexes, but as the flowering advances they can be always known by the want of the peculiar fruiting perianth of that genus.

Perennial, with a thick, fleshy root, and broadly triangular, dark green leaves.

Annuals. Leaves green or grey.

Leaves all quite entire. Stems procumbent.

Plant mealy and whitish, with a nauseous smell when rubbed.

Tlant green and scentless
Leaves, at least the lower ones, sinuate, or toothed, or lobed, or angular.

Leaves obtusely toothed or sinuate. Plant more or less mealy-white.

Plant usually erect. Upper leaves narrow and entire, whitish on both sides

Plant procumbent. Leaves all sinuate, green above, white underneath. hown leaves broad, irregularly and coarsely toothed or
cobed. Plant green (exiept sometimes C. murale)

9. C. Bonus-Henricua.

3. C. album.

4. C. glasecurat

1. C. Vulvaria.

2. C. polyspernnum 
Lower leaves broadly cordate or truncate at the base. Clusters of flowers chlefly in a loose, terminal, leafy panicle

\section{C. hybridum.}

Lower leaves wedge-shaped, or narrow at the base. Clusters of flowers in axillary spikes, or in a short, terminal, leafy panicle.

Axillary spikes erect, simple, or but little branched. Seeds horizontal ? . . . . 6. C. urbicum. Seeds vertical. $\quad . \quad \div \quad$ - $\quad$ 5. C. rubrum.

Axillary spikes forked Into spreading cymes . $\quad$. 7. C. murale.

1. C. Vulvaria, Linn. (fig. 843). Stinking G.-A procumbent or spreading, much branched annual, seldom a foot long, covered with a granular mealiness, and remarkable for a strong, stale-fish smell when rubbed. Leaves small, ovate, all quite eutire, on rather long stalks. Clusters of flowers small, in short axillary and terminal racemes, often branched, but not much exceeding the leaves in length. C. olidum, Curt.

Under walls, in waste and rubbishy places, in Europe and western Asia, extending northwards into southern Scandinavia. Occurs in various parts of England and southern Scotland, more rare in the west, and in Ireland. Fl. summer and autumn.

2. C. polyspermum, Linn. (fig. 844). Many-serded G.-Usnally a procumbent or spreading, much-branched annual, with all the leaves quite entire, as in C. Vulvaria, but without the granular mealiness or the nauseous smell of that species. It is also sometimes erect, a foot high, with numerous branches, ascending from the base. Leaves usually rather thin, green, ovate, $\frac{1}{2}$ to 2 inches long. Clusters of flowers small, in short axillary spikes; the upper ones forming an irregular terminal spike or narrow panicle. Calyx-segments thin, green, not corering the fruit as in $C$. album.

In cultivated and waste places, dispersed all over Europe and Russian Asia, except the extreme north. In Britain, limited to England and the Channel Islands. Fl. summer and autumn.

3. C. album, Linn. (fig. 845). White G.-A tough annual, usually erect, 1 to 2 feet high, of a pale green, or more or less mealy-white, especially the flowers and the under side of the leaves. Leaves stalked, the lower ones ovate or rhomboidal, more or less sinuately toothed or angular, the upper ones usually narrow and entire. Clusters of flowers in short axillary spikes, either dense or interrupted, simple or slightly branched; the upper ones forming a loug panicle, leafy at the base. Fruit entirely enclosed in the perianth, and seeds all horizontal.

In cultivated and waste places, throughout Europe and central and Russian Asia to the Arctic regions, and carricd out with cultivation to nearly all parts of the globe. The commonest species in Britain. Fl. all summer and autumn. Specimens may sometimes occur with almost all the leaves entire, but they have not the smell of C. Vulvaria, are usually more erect, and if perfect, the lower leaves at least will always show a tendency to the angular or sinuate form. [C. ficifolium, Sm., included by Bentham under $C$. album, is a very marked form with oblong-hastate leaves, and smallor dotted seeds which are not keeled. C. vi-idle, Linn., is a variety with green not mealy leaves and long lax spikes.]

4. C. glaucum, Linn. (fig. 846). Glaucous a.-Sometimes a low, procumbent plant, like c'. I'ulvariu, sometimes more erect, but not so 
much so as $C$. album, and more branched. Leaves narrow-ovate or oblong, sinuately toothed, bat more regularly so than in any other species, green above, mealy-white underneath. Clnsters of flowers small, mostly in axillary, nearly simple spikes. Perianth green or slightly mealy, almost closing over the fruit, of which the seed is usually erect, as in C. rubrum, or horizontal only in a few flowers.

In cultivated and waste places, dispersed over Europe and central and Russian Asia, except the extreme north. Occurs occasionally in varions parts of England, bnt not jet detected in Ireland or Scotland. Fl. summer and autumn.

5. C. rubrum, Linn. (fig. 847). Red G.-Very near C. urbicum, of which it has the foliage and inflorescence, and only differs in that most of the flowers have only 2 or 3 segments to the perianth, with the seed erect, not horizontal, and usually much smaller. The whole plant is more apt to turn red, especially near the sea.

On roadsides, and in waste places, especially near the sea, thronghont Furope and Russian Asia, except the extreme north. Dispersed over England, Ireland, and southern Scotland. Fl. summer and autumn. [A variety with subentire more fleshy and triangular leaves is $C$. botryodes, Sm.]

6. C. urbicum, Linn. (fig. 848). Upright G.-An erect, rather stout, slightly branched annual, 1 to 2 feet high, usually green, without the mealiness of C. album. Lower leaves on long stalks, broadly ovate, triangular or rhomboidal, almost always nartowed or wedge-shaped at the base, coarsely and irregularly toothed or lobed, 2 or 3 inches long, the upper ones narrower and more pointed. Clusters of flowers small and numerous, in crowded axillary spikes, nsually erect and slightly branched, more slender than in C. album. Perianth small and green, not completely covering the fruit; the seed is always horizontal.

Under walls, on roadsides, and in waste places, throughout Europe and central and Russian Asia, except the extreme north. In Britain, chiefly near habitations, in England and Ireland. Flo summer and autumn.

7. C. murale, Linn. (fig. 849). Nettle-leaved G.-An erect or decumbent and much-branched annual, a foot high or rather more, either green like $C$. urbicum, or with a slight, whitish meal. Leaves broadly ovate and coarsely toothed, as in C. urbicum, and the inflorescence is also chiefly axillary, but the spikes are much branched, forming spreading cymes. Caly $x$ usually slightly mealy, almost closing over the fruit. Seeds all horizontal.

Under walls, on roadsides, and in waste places, in temperate Europe and Asia, as far northward as sonthern Sweden, and in some other countries. Found, but rarely, near habitations, in England and very rarcly in Ireland, bnt does not extend into Scotland. Fl. summer and autumn.

8. C. hybridum, Linn. (fig. 850). Maple-leaved G.-An erect, branching annual, 1 to 2 or 3 feet high, green and glabrous. Leaves líke those of Spinach, rather thick, stalked, ovate, coarsely toothed, sinuate or with a few broad lobes, the larger ones 2 or 3 inches long and broadly cordate at the base, the upper ones narrower. Clusters of flowers in forked cymes, forming a loose terminal panicle, scarcely leafy at the base. Perianth green, leaving a considerable part of the fruit exposed. 
In cultivated and waste places, dispersed over Europe, central and Russian Asia, and North America. In Britain it occurs rarely, and only in England as a weed of cultivation. Fl. summer and autumin.

9. C. Bonus-Henricus, Linn. (fig. 851). Good King Henry, AUgood. -Distinguished from all the preceding by its perennial stock, with a thick, fleshy root, like that of a Rumex. Stems about a foot high, scarcely branched. Leaves like those of Spinach, stalked, broadly triangular, often above 3 inches long, sinnate or slightly toothed, rather thick, and of a dark green; the upper ones smaller, and nearly sessile. Flowers numerous, in clustered spikes, forming a narrow terminal panicle, slightly leafy at the base. Frnit completely concealed by the perianth. Seeds vertical.

On waste ground, near villages and sheepfolds, in the mountain districts of Europe and Russian Asia, except the extreme north. In Britain, chiefly on roadsides, near villages and dwellings, but in many places introduced only, having been formerly much cultivated as a potherb. Fl. spring and all summer.

\section{BETA. BEET.}

Inflorescence and flowers of Chenopodium, except that each flower has 3 small bracts at its base, and that the ovary and fruit are im. mersed in the succulent base of the perianth, which thickens and hardens as it ripens, becoming angular, and often toothed or prickly.

The species are very few, extending along the coasts of Europe, western Asia, and Africa.

1. B. maritima, Linn. (fig. 852). Wild B.-The wild Beet has a short, hard stock of a few years' duration, with erect or spreading branched stems about 2 fect high. Lower leaves large, broad, rather thick, and green, the upper ones small and narrow. Flowers green like those of Chenopodium, single or clustered, in long, loose, terminal spikes, often branching into a leafy panicle. The ripe perianth forms a hard, angular, often prickly mass, enclosing a single horizontal sced like that of a Chenopodium.

On rocks, and in muddy sands by the seashore, in Europe, western Asia, and northern Africa, extending northwards to the Baltic. Not uneommon on the British coasts, south of Fife and Argyle. Fl. summer and autumn. The white and red Beets, and the Mlangel Wurzd (Root of scarcity), are cultivated varieties of this specics.

\section{ATRIPLEX. ORACHR.}

Herbs or undershrubs, often covered with a grey or white scaly meal , the leaves flat and alternate, or the lower ones rarely opposite. Flowers small and numerous, clustered in axillary spikes or terminal panicles as in Chenopodium, but always of two kinds; in some, which are usually males only, the perianth is regular, and 5-cleft as in Chenopodium, with 5 stamens; in the females the perianth consists of 2 flat segments (or rather bracts, replacing the real perianth), either free or more or less united at the edges, enclosing the ovary. After flowering this false perianth enlarges, is often toothed at the edge, and covered with wart- 
like excrescences. Seed usually vertical. In some species there are also a few regular female real perianths, which ripen without enlarging, and contain a horizontal seed, as in Chenopodium. Embryo curved round the albumen.

A considerable genus, widely spread over the maritime or saline districts of the globe, scarcely any species besides the common one being ever found inland, or away from the saline inflnence.

8cgments of the fruiting perianth nnited nearly to the top.

Leaves all entlre, and mealy-white.

Perennlal, or shrubby at the base. Fruiting perianth ses-

Annual - Fruiting perianth distinctly staiked: $:$ 1. A. portulacoides. segments of the fruiting perianth not united above the middle. Annuals. Leaves either toothed or hastate, or, if entire, narrow and green.

Segments of the fruiting perianth thin, and quite free. Plant

segments of the fruiting perianth thickish, and partlally 2. A. pedunculata. united. Plant not above 3 feet, erect, or procnmbent.

Moral leavea nearly sessile. Fruiting perianths mostly

axillary, white and scaly .
Lesves almost all stalked. Fruiting perianths mostly mired with the male flowers, green, or alightly mealy

\section{4. hortensis.}

5. A. rosea.

4. A. patula.

The shrubby A. Halimus, from the shores of the Mediterranean, is often cultivated in gardcns, especially near the seacoast.

1. A. portulacoides, Linn. (fig. 853). Sea Purslane.-A low, stragg. ling, much branched shrub or undershrub, often shortly creeping, and rooting at the base, 1 to $1 \frac{1}{2}$ feet high, corered with a grey 8caliness closer than in other species. Leaves obovate or oblong, tapering at the base, or the upper ones linear, seldom abore an inch long, and always entire. Flowers in short, interrupted spikes, forming a terminal panicle. Fruiting perianth small and thick, triangular or nearly orbicular; the segments united very nearly to the top, where they are more or less toothed.

On the seacoasts of Europe, western Asia, and northern Africa, extending northwards to the Baltic. Common on maritime cliffs and marshes from Ayr and Northumberland southwards; very rare in Ireland. Fl. summer.

2. A. pedunculata, Linn. (fig. 854). Stalked $0 .-$ Resembles A. portulacoiles in its entire, thickish leaves, scaly-white on both sides, but is an annual only, with spreading branches, seldom a foot high; the leaves usually broader, the lower ones ovate or obovate. Fruiting perianth always borne on a pedicel of 2 or 3 lines; the segments wedge-shaped, united at the top, where the two angles often project into little recurved points.

In the saline districts of central and south Russian Asia, on the shores of the Black Sea, the Baltic, and the North Sea, as far west as Belgium, but apparently absent from the Mediterranean and the Atlantic coasts. In Britain, only on the eastern shores of England. Fl. summer and autumn.

3. A. hortensis, Linn. (fig. 855). Garden O.-An erect, stout annual, attaining 4 or 5 feet in height. Leaves broadly triangular, cordate or hastate, or the upper ones narrow, green or slightly white and mealy underneath. Flowers very numerous and crowded, in a long, terminal 
leafy panicle. Fruiting perianths of 2 broad, flat segments, distinct nearly from the base, 3 or 4 lines long, quite entire, thin and net-veined, closely clasping the flat vertical seed; intermixed with them are also several small, regular 5-cleft perianths, half closed over the fruit as in Chenopodium. Seed horizontal.

Of east European or west Asiatic origin, but has long been cultivated in kitchen-gardens, and was formerly much used as spinach, and has established itself as an escape from cultivation in several parts of Europe. In Britain, said to be tolerably abundant on the seacoast near Ryde, in the Isle of Wight. Fl. end of summer and autumn. The Ryde specimens are much nearer to the common garden form than to the east European wild variety often distinguished under the name of $\boldsymbol{A}$. nitens, Rebent.

4. A. patula, Linn. (fig. 856). Common 0.-A most variable plant in stature, in the shape of the leaf, and in the fruiting perianth. It is an annual, erect or prostrate, dark or pale green, or more or less mealy. white, but never so thickly frosted or scaly as $A$. rosea. Leaves all stalked; the lower ones usually hastate and sometimes opposite; the upper ones often narrow and entire, or coarsely toothed. Flowers clustered in rather slender spikes, forming narrow, leafy, terminal panicles; the females mixed with the males, or a few in separate axillary clusters. Segments of the fruiting perianth nnited to about the middle, usually ovate or rhomboidal and pointed, often toothed at the edge and warted or muricate on the back, but very variable in size and shape, often of two kinds, a larger and a smaller, on the same plant.

On the seacoasts of Europe, Asia, and Africa, extending to the Arctic regions, besides being very common inland as a weed of cultivation. Abundant in Britain. Fl. the whole scason except early spring. The principal forms, which have been distinguished as species, although they run very much one into another, are the following :-

a. A. hastata, Linn. (deltoidea, Bab., Babingtonii, Woods). Erect or spreading. Lower leaves broadly triangular or hastate, often coarsely and irregularly toothed.

b. A. erceta, Huds. Stem erect. Leaves lanceolate, the lower ones broader and hastate.

c. A. angustifolia, Sm. Stem spreading or decumbent. Leaves mostly lanceolate or the upper oncs linear.

d. A. littoralis, Linn. Stems prostrate. Leaves still narrower than in the last, often toothed.

All these varictios have maritime forms, with thicker succulent leaves, in some specimens very green and shining, in others more or less mealy. white, especially the variety dcltoidea.

5. A. rosea, Linn. (fig. 857). Frosted O.-Resembles some of the maritime varieties of $A$. putula, but is much more covered with a white scaly meal; the leafstalks are much shorter, the floral leaves almost sessile, and the female perianths are mostly clustered in the axils of the leaves, whilst the male flowers are in rather dense spikes, forming short terminal panicles. Leaves usually broadly triangular or rhomboidal, and coarsely toothed. Fruiting perianths always mealy-white, rather thick, rhomboidal or orbicular, often warted; the segments united to above the middle, but not so high as in A. portulacoides. A. laciniata, Linn. A. arenaria, Woods. A. jarinosa, Dumort. 
On the seacoasts and in the saline districts of Europe, Asia, and Africa, but not extending to the Arctic regions. Not uncommon round the British Isles. Fl. summer and autumn.

\section{POLYGONACE压. THE POLYGONUM FAMILY.}

Herbs, or in some exotic species, shrubs, with alternate leaves, and thin, scarious stipules, forming a sheath or ring round the stem within the leafstalk. Flowers small, herbaceous or sometimes coloured, clustered in the axils of the leaves or in spikes or racemes, forming terminal panicles. Perianth of 6,5 , or fewer segments, regular and equal, or the inner ones enlarged. Stamens variable in number, never more than 8 in the British species. Ovary free, with a single ovule, but with 2,3 , or more styles or stigmas. Fruit a small, seed-like nut, enclosed in the persistent perianth. Embryo of the seed straight or curved, in a mealy albumen.

A considerable Order, dispersed over every part of the globe, from the hottest tropical plains. to the extreme Arctic regions, or to the highest mountain summits, close to the limits of perpetual snows. Some tropical species are tall, woody climbers, or erect shrubs, but the majority of the Order are berbs approaching Chenopodiacea in character, and sometimes in habit, but always readily known by their sheathing stipules, even when reduced to a narrow ring or a mere line surrounding the stem. They also very seldom acquire any of the mealiness of Chenopodiacca.

Fruiting perianth of 6 segments, 3 inner ones often enlarged . . 1. RUMEx.

Frulting perianth of 4 segments, 2 inner ores enlarged : : 2 OxYRIA.

Fruiting perianth of 5 nearly equal segmint . . : : 8. POLYGONUM.

The Rhubarbs of our gardeners and druggists are species of the genns Rheum, belonging to Polygonacea.

\section{RUMEX DOCK.}

Herbs or shrubs, the British species all perennials, with a thick rootstock, and erect, furrowed annual stems; the thin sheathing stipnles never fringed on the edge, but soon becoming torn or jagged. Lower ieaves stalked and often large. Flowers numerous, small, herbaceons, though often turning red, usually pedicellate, in whorl-like clusters, axillary or in terminal raccmes, often branching into panicles. Perianth deeply 6-cleft; when in fruit the 3 inner segments become enlarged and close over the triangular nut. Stamens 6 . Styles 3 , very short with often tubercled, fringed stigmas.

A considerable genus, spread over the greater part of the world, very readily distinguished from the rest of the Order, but the species vary so much in appearance that it is often very difficult to fix their real limits. They can also seldom be determined without the fruiting perianth, from which most of the characters are taken. They 
may be readily distributed into two distinct sections, Rumex proper and Acetora.

Leaves never hastate at the base (though often cordate, with obtuse auricles). Flowers mostly hermaphrodite (RV. MEX.)

Inner perianth-segments entire, or with one or two scarcely perceptible teeth.

segments broadly ovate, more or less cordate. Panicle narrow and crowded when in fruit.

No tubercle on any of the perianth-segments - . 1. $R$. aquaticus.

A tubercle on one at least of the perianth-segments . 2. $R$. crispus.

Segments ovate, not cordate.

Tall water-plant. Lower leaves above a foot long. Panicle erect. A tubercle on all three perianthsegments

Plant seldom above 3 feet. Lower leaves not a foot. Panicle very spreading. Perianths small.

A tubercle on all three perianth-segments

A tubercle on one segment only
Inner perianth-segments toothed on the edge, one at least of the teeth ending in a fine point.

Panicle erect. Pedicels longer than the perianth .

Panicle very spreading. Pedicels shorter than the fruitlng perianth.

Leaves chiefly radical. Pedicels thickened. Teeth of the perianth-segments stiff and short.

Panicle leafy. Perianths densely clustered with long fine teeth to the segments

Leaves, at least the lower ones, hastate (with acute auricles). Flowers mostly unisexual (SORRELS).

Leaves oblong or broadly lanceolate. Inner segments of the fruiting perianth enlarged and orbicular .

Leaves narrow lanceolate or linear. Inner segments of the fruiting perianth not enlarged

\section{R. Bydrolapathum}

5. $R$. conglomeratus.

6. R. sanguineus.

3. $R$. obtusifolius.

7. R. pulcher.

8. R. maritimus.

9. $R$. Acetosa.

10. R. Acetosella.

Besides the above, $R$. alpinus, Linn., from the mountains of continental Europe, formerly cultivated for its root, a very broad-leaved species of true kumex, with entire, grainless perianth-segments, and the French Sorrcl ( $R$. scutatus), also a common plant in Continental mountains, sometimes cultivated as a Sorrel, have both been met with occasionally in Scotland or northern England, near the gardens from which they had escaped, but neither of them appears to be really established in Britain.

1. R. aquaticus, Linn. (fig. 858). Smooth-Fruiled D.-Closely re. sembles the larger and denser-flowered forms of $R$. crispus, of which it may be a luxuriant variety. The leaves are usually not so much crisped, sometimes nearly flat, and often 9 or 10 inches long and full 3 inches broad; the panicle long and much crowded; but the chief difference is in the inner segments of the fruiting periantls, which are of the same sliapc, but have no tubercle, although a slight thickening of the midrib may be sometimes observed.

In rather rich and moist situations, in northern and Arctic Europe, Asia, and America, and in the mountains of central Europe. In Britain, confined to Scotland and the north of England. Fl. summer.

2. R. crispus, Linn. (fig. 859). Curled $D$. - Stem 2 to 3 feet high, with but few branches, usually short, and seldom spreading. Radical leaves long and narrow, usually much waved or crisped at the edges, and abont 6 to 8 inches long, but varying much in size; the upper one smaller and narrower gradually passing into mere biats, Whorls of 
flowers numerous, and when in fruit much crowded in a long narrow panicle, although the slender pedicels are really longer than the pcrianths. Inner segments of the fruiting perianth broadly ovate, more or less cordate, one of them bearing on the midrib an ovoid or oblong, coloured tubercle, whilst the others have the midrib only a little thickened, except in the southern varieties, where all three have often a tubercle.

On roadsides, in ditches, pastures, and waste places, throughout Europe and Russian Asia, except the extreme north, and (probably naturalised) in many other parts of the globe. Abundant in Britain. Fl. summer. Specimens are occasionally found with the leaves rather broader and the perianth-segments very slightly toothed, $R$. conspersus, Hartm., showing an approach to $R$. oblusifolius. These are by some believed to be hybrids between the two species, by others considered as a distinct species, $R$ acutus, Linn.

3. R. obtusifolius, Linn. (fig. 860). Broad D.-Stem 2 or 3 feet high, and but slightly branched, as in $R$. crispus, which it much resembles. It differs, however, in the broader leaves, the radical ones often 8 or 9 inches, by 3 or 4 , rounded at the top, and cordate at the base, the npper ones narrower and more pointed; in the looser and more distinct whorls of flowers, and the less crowded panicles, although not near so spreading as in $R$. sanguineus; and especially in the inner segments of the perianth, which, although often broadly ovate, are never cordate, and are bordered below the middle by a few small teeth, nsually ending in a fine point. As in $R$. crispus, one or all three segments have a small tubercle at the base.

In the same situations and at least as widely spread and as common as $R$. crispus, with which and $R$. sanguineus it is usually mixed. Very abundant in Britain. Fl. summer. A variety of this species, R. sylvestris, Wallr., has nearly entire fruiting perianth segments.

4. R. Hydrolapathum, Huds. (fig. 861). Water D.-Stem 3 to 5 feet high, slightly branched. Leaves long, lanceolate or oblong, usually pointed, and flat or only very minutely crisped at the edges; the lower ones often 1 or 2 feet long, narrowed at the base into a long erect footstalk. Panicle long and rather dense, leafy at the base, the branches scarcely spreading. Inner perianth-segments ovate, not so broad as in $\boldsymbol{R}$. crispus, and never cordate, entire or scarcely toothed, with a large oblong tubercle on all three, or rarely wanting on one of them.

On the edges of streams and pools, and in watery ditches, in central and northern Europe and Russian Asia, but not an Arctic plant. Generally dispersed over England, Ireland, and southern Scotland. Fl. summer. $A$ variety with the margins of the petioles raised and truncate or cordate inner perianth-segments has been distinguished under the name of $R$. maximus, Schreb., $\boldsymbol{R}$. latifolia, Borrer.

5. R. conglomeratus, Murr. (fig. 862). Clustered D.-Resembles in many respects $R$. sanguineus, of which it may be a tall, luxuriant variety, showing some approach to $R$. Hydrolapathum. Stem 2 or 3 feet bigh. Leaves often pointed, as in $R$. Hydrolapathum, but more waved on the edges, and the lower ones often rounded or even cordate at the base. Panicle with spreading branches and distinct whorls, as in $R$. sanguineus, bnt larger. Inner perianth-segmencs narrow-ovate, rather larger than in $R$. sanguiness, and usually all equal, with an oblong tubercle upon each. 
In meadows, and waste places, nsually in richer and wetter situations than $R$. sanguineus, widely spread over Europe and central and Russian Asia, except the extreme north, and apparently naturalised in many other parts of the world. Generally distributed over Britain, but not always readily distinguished from $R$. sanguineus. $F l$. summer. [An erect maritime variety, with narrower root-leaves, tapering panicle, fewer narrower bracts, and larger fruiting sepals, occurs on all the sonthern coasts, and is the $R$. rupestris, Le Gall.]

6. R. sanguineus, Linn. (fig. 863). Red-veined D.-Stem not so tall as in most of the preceding species, seldom above 2 feet, and more branched. Radical leaves oblong or lanceolate, sometimes cordate at the base, waved on the edges, and sometimes narrowed in the middle as in $R$. pulcher. Panicle leafy at the base, with stiff, thongh slender, very spreading branches; the whorls of flowers all distinct. Pedicels shorter than in the foregoing, but longer than in the following species. Fruiting perianths small; the inner segments narrow, and entirely or scarcely toothed, one about $1 \frac{1}{2}$ lines long, with a large tubercle, the two others nsually smaller, without any or only a very small tubercle.

On roadsides, in ditches, pastures, and waste places, throughout Europe and Russian Asia, except the extreme north, usually accompanying $R$. crispus and $R$. obtusifolius. Abundant in Britain. Fl.summer. It varies considerably, and often assumes a red tint, especially on the leafstalks and panicle.

7. R. pulcher, Linn. (fig. 864). Fiddle D.-A rather low species, often not a foot high, and seldom 2 feet, with stiff, very spreading branches. Leaves chiefly radical, oblong, cordate at the base, and often narrowed in the middle. Whorls of flowers all quite distinct, forming very compact clusters; the fruiting pedicels thickened and recurved, shorter than the perianth. Inner segments toothed, as in $R$. obtusifolius, but narrow-ovate, all 3 , or only 1 or 2 of them bearing a tubercle, which is often itself tubercled.

On roadsides and in waste places, in central and sonthern Europe and western Asia, very common in the Mediterranean region, but not extend. ing into northern Germany. In Britain, chiefly in southern England, but occurs as far north as Nottingham and North Wales. Fl. summer.

8. R. maritimus, Linn. (fig. 865). Golden D. - Stem 1 to $1 \frac{1}{2}$ feet high, often much branched. Leaves narrow-lanceolate or linear. Flowers very small and very numerous, densely crowded in globular axillary whorls, even the upper floral leaves being much longer than the flowers. Pedicels slender but short. Inner segments of the fruiting perianth lanceolate or triangular, fringed with rather long fine teeth, and with a narrow-oblong tubercle upon each segment. The whole plant, and especially the perianth, often assumes a yellowish hue.

In marshes, chiefly near the sea, in temperate Europe and Russian Asia, extending northwards into Scandinavia. In Britain, apparently confined to England and Ireland. Fl. summer. A more luxuriant variety, with the whorls more distant, and rather shorter points to the teeth of the perianth-segments, has been distinguished as $R$. palustris, Sm.

9. R. Acetosa, Linn. (fig. 866). Sorrel D.-Stems scarcely branched, 1 to 2 feet high. Leaves chiefly radical, oblong, 3 to 5 inches long, sagittate at the base with broad pointed auricles, of a bright green, and very acid; the stem-leaves few. on shorter stalka Flowers diccious 
or sometimes monœeious, in long, terminal, leafless panicles, usually turning red. Inner segments of the fruiting perianth enlarged, orbicular, thin and almost petal-like, quite entire, without any tubercle, but each with a minute scale-like appendage at the base, which, as well as the small outer segments, is turned back on the pedicel.

In meadows and moist pastures, in Europe, central and Russian Asia, in northern America, from the Mediterranean to the Arctic Circle, ascending high into mountain-ranges, and reappearing in the southern hemisphere. Extends all over Britain, and has long been in cultivation. Fl. summer.

10. R. Acetosella, Linn. (fig. 867). Sheep-sorrel-A slender plant, from 3 or 4 inches to nearly a foot high, acid like $R$. Acetosa, and often turning red. Leaves all narrow-lanceolate and linear, and some at least of every plant sagittate, the lobes of the base usually spreading and often divided. Flowers small, diccious, in slender terminal panicles. Segments of the perianth small, broadly ovate or orbicular, entire, and thin; the inner ones closing over the nut as in the other species, but scarcely enlarged; the onter ones erect, not reflexed as in $R$. Acelosa.

In pastures, especially in dry open places, over the greater part of the globe without the tropics, penetrating far into the Arctic regions, and ascending high upon alpine summits. Abundant in Britain. $F l^{\circ}$ from spring till autumn.

\section{OXYRIA. OXYRIA.}

A single species, with the habit of a small Rumex of the Acetosa group, separated from that genus because the perianth has only 2 inner and 2 outer segments of the perianth, and the ovary has only 2 stigmas.

1. O. reniformis, Campd. (fig. 868). Kidncy Sorrel.-A glabrous perennial, seldom above 6 inches high, of an acid flavour. Leaves chiefly radical, cordate-orbicular or kidney-shaped, usually less than half an inch, but sometimes an inch broad Stem slender and almost leafless, terminating in a simple or slightly branched raceme. Flowers small, in clusters of 2 or 3 , on slender pedicels; the inner segments of the periantb slightly enlarged, but shorter than the nut. Stamens 6 . Nut flat, orbicular, about 2 lines in diameter, including a scarious wing, which surrounds it, and is entire or notched at the top and base. $O$. digyna, Hill.

A bigh alpine plant, in all the great mountain-ranges of Europe and Asia, descending to a lower level in the north, and extending far into the Arctic regions. Frequent in the mountains of Scotland, northern England, and North Wales; rare in Ireland. Fl. summer.

\section{POLYGONUM. POLYGONUM.}

Herbs, varying much in habit, but not so stiffy erect as the Docks, and sometimes prostrate, floating, or twining; the scarious stipules usually sheathing the stem, and often fringed at the edge; the leaves. alternate. Flowers small, pale-green or red, clustered or rarely solitary in the axils of the upper leaves, or in terminal heads, spikes, or panicles. Perianth of 5 (rarely fewer) segments, either all equal or 2 or 3 outer 
ones enlarged. Stamens 8 or sometimes fewer. Styles 3 or 2, some. times united at the base, the stigmas entire. Nut triangular cr flattened, enclosed in or surrounded by the persistent perianth.

A large genus, widely spread over every part of the globe.

stems much branched, wiry, often prostrate. Fiowers axillary.

Annual. Nuts scarcely above a line long, opaque, dotted, or wrinkled

Perennlal. Nuts about 2 lines long, very smooth and shining

stems twining. Flowers in loose racemes.

Fruiting perianth triangular, scarceiy winged

Fruiting perlanth with 3 white, scarious wings

steins usually ascending or ercct, or floating. Fiower in terminal splkes.

Rootstock perennial. Spikes solitary or rarely 2.

Leaves oblong-linear. Spike slender and linear.

Leaves ovate or oblong.lanceolate. Spike dense, oblong or cylindrical.

Styles 3 . Leaves chlefly radical. Stem-leaves few and small . . . . .

Styles 2 Stems floatlng or ascending, with large, oblong,

stalked leaves
Annuals. Stems branched with several spikes.

Bpikes dense, seldom above an inch long.

Pediceis and perianths quite smooth. Stlpules usually

Pedicels and perianth rough with glands " stipules

usually entire
Splkes long and slender; the clusters of fiowers, at least

1. P. aviculare.
2. P. maritimum.

8. P. Convolvulus.

4. P. dumetorum. the lower ones, distinct.

Perianth covered with raised dots. Taste bitins .

- 10. P. Hydropiper.

Perianth without raised dots. Taste not biting

6. P. Bistorta.

7. $P$. amphibium

B. $P$. viviparum.

8. P. Persicaria.

9. P. Lapathifolium.

The tall Persicaria of our gardens is an east Asiatic Polygonum ( $P$. orientale), and several other Asiatic species bave been recently intro. duced into our flower-gardens. The Buckwheat of agriculturists, occasionally found on the margins of fields where it had been cultivated, is also an Asiatic plant, included by some in Polygonum (P. Fagopyrum), by others separated into a distinct genus under the name of Fagopyrum.

1. P. aviculare, Linn. (fig. 869). Knotweed, Knotgrass.-A much branched, wiry annual, prostrate when in the open ground, erect when drawn up amongst corn or grass, often a foot or two long. Stipules white and scarious, becoming ragged at the edges. Leaves narrow. oblong, small, very rarely attaining an inch in length. Flowers small, :hortly stalked, in clusters of 2 to 5 in the axils of most of the leaves. Styles 3. Fruiting perianths but little more than a line long; the seg. ments white on the edge, green in the centre. Nats triangular, seldom exceeding the perianth, not shining, and, when seen through a strong glass, minutely granulated or wrinkled.

In cultivated and waste places, almost all over the globe, from the tropics to the Arctic regions. Abundant in Britain. Fl. almost the whole season. It varies much in its branches, sometimes very long and slender, with very few distant leaves, sometimes short and densely matted, with the small leaves much crowded. A maritime variety, distinguished as $\boldsymbol{P}$. littorale, Link., with rather thicker leaves and larger flowers and nuts, has been confounded with $\boldsymbol{P}$. maritimum, but has not the shining nuts of that species.

2. P. maritimum, Linn. (fig. 870). Sea P.-When flowering the 6r: rear of its growth, or when luxuriant, this species is distinguished 
from $\boldsymbol{P}$. aviculare by its thicker stems, larger and thicker, more glaucous leaves, larger scarious stipules, brown and much veined at the base, larger flowers, and especially by the nuts, often 2 lines long, projecting beyond the perianth, and very smooth and shining. Older specimens, grown in drier sands, have a woody, perennial stock, with short, thick branches, completely covered by the stipules, the internodes being all very short.

In maritime sands, on most of the seacoasts of the northern hemisphere, and here and there also in the sonth. Common on the south coast of England and the Channel Islands. Fl. end of summer and autumn. The $P$. Robcrti, Loisel, or $P$. Raii, Bab., is rather a young or a luxuriant state of this plant than a distinct variety, although those names are sometimes given to the maritime variety of $P$. avioulare.

3. P. Convolvulus, Linn. (fig. 871). Black Bindweed.-A glabrous annual, with a twining stem as in Convolvulus. Stipules short. Leaves stalked, heart-shaped or broadly sagittate, and pointed. Flowers in little loose clusters; the lower ones axillary, the upper ones forming loose, irregular terminal racemes. Styles 3. Fruiting perianth not 2 lines long; the 3 outer segments closely surrounding the triangular nut, and sometimes sharply kceled on the midrib, but rarely winged.

In cultivated and waste place, throughout Europe, in central and Russian Asia, and North America, to the Arctic regions. Frequent in Britain. Fl. summer and autumn. [The var. pseudo-dumetorum, Wats., has broad wings on the outer sepals.]

4. P. dumetorum, Linn. (fig. 872). Copse P.-Stem, foliage, and inflorescence of $P$. Convolvulus, of which it may be a mere variety; but it is more luxuriant, and the 3 angles of the fruiting perianth are more or less expanded into a white, scarious wing, which is often decurrent on the pedicel, the whole perianth being often 3 lines long. The nut is also usually more shining.

In hedges, open woods, or rich, cultivated places, in Enrope, Russian Asia, and North America, but not so common, nor extending so far northward, as $P$. Convolvulus. In Britain, chiefly in the southern counties of England. $F l$. end of summer, and autumn.

5. P. viviparum, Linn. (fig. 873). Viviparous $P$.- Stock perennial and tuberous, with simple, erect, slender stems, 4 to 6 or rarely 8 inches high. Radical leaves on long stalks, narrow-oblong or linear; stem. leaves few, nearly sessile or clasping the stem. Spike solitary and terminal, slender, $1 \frac{1}{2}$ to 3 inches long. Flowers, when perfect, pale flesh-coloured, and small, with 3 styles, but the lower ones, and sometimes all, are converted into little red bulbs, by which the plant propagates.

In alpine pastures, often at great elevations, in all the great mountainranges of Europe and Asia, descending to lower levels in the north, and penetrating far into the Arctic regions. Frequent in the Highlands of Scotland, and occurs also in northern England and North Wales, and on Ben Bulben, in Ireland. Fl. summer.

6. P. Bistorta, Linn. (fig. 874). Bistort, Snakewoed.-Perennial rootstock thick, and often spreading considerably. Radical leaves in broad patches, on long stalks, ovate-lanceolate or cordate, often 3 to 6 inches long. Stems simple and erect, 1 to 2 feet high, with a few nearly sessile leaves, and terminating in a single, dense, oblong, or cylindrical flower- 
spike, 1 to 2 inches long. Perianth pink or rarely white. Styles 3. Stamens longer than the perianth.

In moist pastures, and meadows, chiefly in hilly districts, in Europe, central and Russian Asia, and northern America, extending into the $A$ rctic regions. Occurs in various parts of Britain, chiefly in the north of England and south of Scotland, but is local, and in some instances a straggler from gardens. Fl. summer.

7. P. amphibium, linn. (fig. 875). Amphibious P.-A glabrons perennial, usually floating in water, and rooting at the lower nodes. Leaves oblong or lanceolate, rather thick, 3 to 6 inches long, spreading on the surface of the water. Spikes terminal, solitary or rarely 2 together, supported on short peduncles above the water, dense and cylindrical, 1 to $1 \frac{1}{2}$ inches long, of a rose-rect. Stamens usually 5 . Styles 2. Nuts flattened.

In ponds and ditches, in Europe, central and Russian Asia, and northern America, to the Arctic regions. Extends all over Britain. Fl. summer. When growing in dried-up ponds or muddy ditches the stems are creeping at the base, then shortly erect, and the leaves are often downy.

8. P. Persicaria, Linn. (fig. 876). Persicaria.-An erect or sprearl. ing, branched annual, glabrous or slightly hoary, and often turning red, 1 to 2 feet high. Leaves lanceolate, stalked, or the upper ones sessile; the larger ones 3 to 5 inches long, and an inch broad or rather more, often marked in the centre with a dark spot. Stipules more or less fringed at the top with short fine bristles. Spikes terminal, rather numerous, oblong or cylindrical, and seldom above an inch long, dense, but not so regular as in $P$. amphibium, and there is often a cluster of flowers a little below. Flowers reddish or sometimes green, not dotted. Stamens nsually 6. Styles usually 2. Nuts flattened but rather thick, smooth and shining, and often concare on one side. Occasionally there are 3 styles, and the nut is then triangular.

In ditches, on roadsides, in cultivated and waste places, throughout Furope and central and Russian Asia to the Arctic regions. Abundant in Britain. Fl. all summer and autumn. It varies much in stature and in colour, in the number and density of the spikes, and in the achenes more or less concave or convex on one or both sides.

9. P. lapathifolium, Linn. (fig. 87i). Pale P.-Closely resembles $P$. Persicaria, and is probably a mere variety, distinguished by the pedicels and perianths dotted with small prominent glands. The colour of the plant is usually pale green, the stipules seldom fringed, and the nuts usually concave on both sides, but these characters are not constant.

In cornfields and waste places, with nearly the same range as $P . P_{c r}$. sicaria, but usually in richer soils, and does not extend so far north. In Britain not uncommon. Fl. summer and autumn. Specimens agreeing with $P$. Persicaria in everything but the glandular dots bave been described as a third species under the name of $P$. laxum or $P$. nodosum.

10. P. Hydropiper, Linn. (fig. 878). Watcrpepper P.-Stature and foliage nearly as in P. Persicaria, but a more slender plant, often decumbent or even creeping at the base, the stipnles more fringed at the top, the leaves narrower, and the flowers in slender spikes, often 2 or 3 inches long, more or less nodding, the clusters of flowers almost 
all distinct, and the lower ones often distant and axillary. Perianths, and often the bracts and stipules or other parts of the plant, dotted with small glands, and the whole plant is more or less acrid or biting to the taste.

In wet ditches, and on the edges of ponds and streams, throughout Europe and central and Russian Asia to the Arctic regions. Abundant in England and Ireland, more rare in the Scotch Highlands. $\mathrm{Fl}$.summer and autumn.

11. P. minus, Hnds. (fig. 879). Slender P.-Very near P. IIydropiper, and probably a mere variety. It is usually a smaller plant, with rather smaller flowers, in closer, although slender spikes, and has neither the glandular perianths nor the biting flavour of that species.

In ditches and waste places, on roadsides, \&c., over the whole range of $P$. Hydropiper. In Britain, not so common as that species, and scarcely extends beyond the middle of Scotland. Fl. summer and autumn. The smaller, most distinct form is usually found in drier situations. When growing in richer, wet sitnations, it can only be distinguished from $P$. IIydropiper by the absence of the glands on the perianth. This form has been publishel under the name of $P$. mite, Schrank, and is confined to England. It is not improbable that further observation may show that this and the last three Polygonums are all varieties of one species.

\section{THYMELEACE疋. THE DAPHNE FAMILY.}

A family limited in Britain to the single genus Daphne. The exotic genera associated with it differ chiefly in the number of the stamens and in the number and form of the divisions of the perianth, or in the consistence of the fruit.

The species are rather numerous in sonthern Africa and Australia, including among the latter the Pimeleas of our grcenhouses, with a few from the tropics or the northern hemisphere.

\section{DAPHNE. DAPHNE.}

Shrubs, or, in some exotic species, trees, with alternate or rarely opposite entire leaves, and no stipules; the flowers either coloured or sometimes green, either lateral, or, in exotic species, terminal. Perianth inferior, deciduons, with a distinct tube and a spreading 4-cloft limb. Stamens 8 , inserted in the top of the tube. Ovary free within the tube, 1-celled, with a single pendulous ovule. Style exceedingly short, with a capitate stigma. Fruit a berry or drupe, the endocarp forming a slightly crustaceous, 1-seeded stone.

A considerable genus, widely spread over the northern hemisphere, with a few species extending into the tropics.

Leaves declduous. Flowers purple, below the leaves . . . 1. D. Mezereum. Leaves evergreen. Flowers green, axillary : : : 2, D. Laureola.

Several exotic species are cultivated for the beanty or the perfume of their flowers, especially $D$. odora, $D$. pontica, $D$. Cneorum, \&c.

1. D. Mezereum, Linn. (fig. 880). Mezereon.-An erect, glabrous shrnb, of 1 to 3 feet, with few, erect branches, each terminated by a 
tnft or shoot of narrow-oblong or lanceolate, decianous leaves, abont 2 or 3 inches long. Before these leaves are fully out, the flowers appear in clusters of 2 or 3 along the preceding year's shoot; they are purple and sweet-scented. Perianth-tube 3 or 4 lines long, and slightly hairy, the lobes rather shorter. Berries red.

In woods, chiefly in hilly districts, spread over nearly the whole of Europe and Russian Asia to the Arctic regions. In Britain, however, believed to be truly wild only in some of the southern counties of England. Fl. early spring.

2. D. Laureola, Linn. (fig. 881). Spurge Laurel.-An erect, glabrons shrub, of 2 to 4 feet, with few erect branches, and evergreen, oblong or lanceolate leaves, crowded towards their summits. Flowers in clusters or very short racemes of $\mathbf{3}$ to 5 in the axils of the leaves, rather smaller than in $D$. Mezcreum, green and scentless, and accompanied by more conspicuous bracts. Berries bluish-black.

In woods, in sonthern and western Europe, scarcely extending into Germany. Not nncommon in England, doubtfully indigenous in southern Scotland, and unknown in Ireland. Fl. spring.

The large and important tropical family of Laurinex, remarkable amongst Monochlamyda for the peculiar mode in which the anthers open (like those of the Barberry), is represented in our gardens by the BaySwet (Laurus nobilis), which is the Laurel of the ancients and of poets.

\section{ELEAGNACEE. THE ELEAGNUS FAMILY.}

Shrubs or trees, more or less covered with minute, silvery or brown, scurfy scales, differing from Thymeleaceos in the erect, not pendulous, ovule and seed.

An Order of very few genera, dispersed over the northern hemisphere. The principal one, Elocagnus, has not the clustered male flowers so peculiar in our Hippophae. One or two of its species, from south-eastern Europe and Asia, are not uncommon in our shrubberies.

\section{HIPPOPHAE. HIPPOPHAE.}

Shrubs or small trees, distinguished as a genus by their diocions flowers; the males in axillary clusters, with a perianth of 2 small seg. ments and 4 stamens; the females solitary, with a tubular perianth, minutely 2-lobed, which becomes succulent, forming a berry round the true fruit. The reduced perianth and clustered flowers show considerable affinity with Myrica.

1. H. rhamnoides, Linn. (fig. 882). Sallow-Thorn, Sea Buckthorn. -A willow-like shrub, covered with a scaly scurf, very close and silvery on the under side of the leaves, thin or none on the upper side, dense and more or less rusty on the young shoots and flowers; the axillary shoots often ending in a stont prickle. Leaves alternate, linear, and entire. Male flowers very small, in little clusters resembling catkins. Females crowded, although solitary in each axil; the perianth about 2 lines long, contracted at the top, with the style shortly protruding, form. ing when in fruit a small yellowish or brown berry. 
In stony or sandy places, especially in beds of rivers and torrents, in central and eastern Enrope and central and Russian Asia, also occasionally near the seacoasts of the Baltic and the North Sea. In Britain, very local, and only near the seacoasts of some of the eastern and southern counties of England. Fl. spring.

\section{SANTALACE尽. THE SANDALWOOD FAMILY.}

A family limited in Britain to a single species, but comprising several exotic genera, chiefly tropical or southern, differing from Thymeleacece in the perianth combined with the ovary at its base, in its valvate, not imbricate, lobes, and in minute but important particulars in the structure of the ovary.

\section{THESIUM. THESIUM.}

Low herbs or undershrubs, with alternate entire leaves, no stipules, and small flowers. Perianth adhering to the ovary at the base; the limb divided into 4 or 5 lobes or segments, valvate in the bud. Stamens 4 or 5 , opposite the lobes of the perianth. Ovary inferior, 1-celled, with 2 ovules suspended from a central placenta. Style short, with a capitate stigma. Fruit a small green nnt, crowned by the lobes of the perianth. Seed solitary, with a small, straight embryo in the top of the albumen.

A considerable genus, widely spread over Europe and temperate Asia, but chiefly abundant in sonthern Africa. Some of the Kuropean species have been ascertained to be partially parasitical on the roots of other plants, to which they attach themselves by means of expanded suckers, like Rhinanthus and some others of the Scrophularia family.

1. T. linophyllum, Linn. (fig. 883). Bastard Toadflax,-A glabrons, green perennial, forming a short, woody rootstock, with several annnal, procumbent or ascending, stiff stems, usually simple, 6 or 8 inches long, but sometimes near a foot. Leaves narrow-linear, or, when very luxuriant, rather broader, and above an inch long. Flowers small, in a terminal raceme, leafy, and sometimes branching at the base; each flower on a distinct peduncle, with 3 linear bracts close under it. Perianth cleft almost down to the ovary; the tube of a greenish-yellow colour; the segments white, waved or almost toothed on the edges, and rolled inwards after flowering. Nuts small, ovoid, marked with several longitndinal veins or ribs. T. humifusum, DC.

In meadows and pastnres, attaching itself to the roots of a great variety of plants, generally dispersed over temperate Europe and Russian Asia, but not extending into Scandinavia. In Britain, only in the chalky pastures of the southern counties of England. Fl. all summer.

\section{ARISTOLOCHIACE疋. THE ARISTOLOCHIA FAMILY.}

Herbs, or, in exotic species, tall climbers, with alternate leaves, and often leafy stipules; the flowers brown or greenish. 
Periunth combined with the ovary at the base, either 3-lobed or very irregular. Stamens usually 6 or 12 , inserted on the summit of the ovary within the perianth. Ovary and fruit in. ferior, 3- or 6-celled, with several seeds in each cell. Albumen fleshy, with a minute embryo.

A small family, widely spread over the globe, chiefly in the tropics. The principal genus, Aristolochia, remarkable for the tubular perianth, often curved, terminating in an oblique, entire limb, is not British; but the tall, climbing A. Sipho, and some other species, are cultivated in our gardens; and A. Clematitis (Eng. Bot. t. 398), from southern Europe, has been found in some parts of England, as an escape from gardens. It is an erect perennial, of about $1 \frac{1}{2}$ feet, with broadly cordate leaves, and slender, yellowish-green flowers clustered in their axils.

\section{ASARUM. ASARUM.}

Perianth campanulate, regular, 3-cleft. Stamens 12.

A genus of very few species, dispersed over Europe, temperate Asia, and North America.

I. A. europæum, Linn. (fig. 884). Asarabacca.-A low perennial, with a shortly creeping rootstock, and very short, inconspicuous stems. Leaves nsually 2 only, almost radical, on long stalks, orbicular-cordate or kidney-shaped, I to 2 or even 3 inches broad. Between them is a single greenish-brown flower, about half an inch long, on a short, recurved stalk; the perianth divided to the middle into 3 broad, pointed lobes.

In woods and shady places, in central and southern Europe and tem. perate Russian Asia, extending northwards into southern Scandinavia. Rare in Britain, but believed to be a true native in a few localitics in the north of England and in Wiltshire, Fl. May.

\section{EUPH'JRBIACEÆ. THE SPURGE FAMILY.}

Herbs, shrubs, or trees, much varied in foliage and inflorescence. Flowers always unisexual, with or without a perianth. Stamens various. Ovary consisting of 3 (rarely 2 or more than 3) united carpels, each with 1 or 2 pendulons ovules. Styles as many as carpels, entire or divided. In the fruit these carpels separate from each other and from a persistent axis, and ustally open with elasticity in 2 valves. Seed with a large embryo usually enclosed in fleshy albumen.

A vast family, chiefly tropical, so varied in aspect that no general idea can be formed of it from the three genera which represent it in Britain, nor is the connection between these three genera easily ux.4erstood without a comparison with intermediate exotic forms. The structure of the ovary and fruit is peculiar to this family among anisexual plants. 
Beveral male flowers (looklng like single stamens) and one stalked ovary collected in a small Involucre, which has the appearance of a cup-shaped perlanth

Male and female flowers distluct.

Herbs, with thin leaves. . . . . . . 2. Mrercuriahts.

Shrubs, with shinlng, evergreen leaves. : : : : 3. BuxUs.

The Poinsettia and the red-flowered Jatrophas of our hothouses remarkable for their brilliant red bracts, and the coloured leaved Crolons, belong to this family, but generally speaking the tropical Euphorbiacece are not ornamental enough for cultivation.

\section{EUPHORBIA. SPURGE.}

The European species are herbs, abounding in milky juice; the lower part of the stems simple, with alternate leaves (except in $E$. Lathyris). Flowering branches or peduncles axillary, the upper ones in a terminal umbel of 2 to 5 or more rays, each ray or axillary peduncle usually several times forked, with a pair of opposite floral leaves at each fork, and a small green, apparent flower, really a head of flowers, between the branches. 'These flower-licads consist of a small, cup-shaped involucre (looking like a perianth), with 4 or 5 very small teeth, alternating with as many horizontal yellowish or brown glands. Within are 10 to 15 stamens, each with a jointed filament, and a minnte scale at its base, showing that they are each a distinct male flower. In the centre is a single female flower, consisting of a 3-celled ovary, supported on a stalk projecting from the involucre and cnrved downwards. Style 3-cleft. Fruit of 3 carpels, each with a single seed.

A very large genus, extending over most parts of the globe, including many tropical species, and leafless, succulent ones in southern Africa.

Prostrate plant, with all the leares at the time of flowering

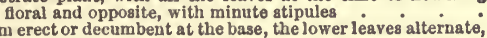

1. E. Peplis.

Btem erect or decum
and no stipules.

Glands of the involucre rounded on the outer edge.

Annuals or biennials. Lezves finely toothed.

Leaves obovate, very obtise. Capsules smooth

Stem-leaves oblong, usually pointed Capsules more or less warted

Perennials. Leaves entire.

Umbel compact. Capsule glabrous, much warted . 4. E. hiberna.

Umbel loose. Capsule smooth, or rough with small

glaudular dots, often hairy .

Glands of the involucre crescent-shaped, the two points turned outwards.

Floral leaves of each pair united at the base

Floral leaves all distlnet.

Umbel of 3 or 4 rays.

Low, green annuals, seldom above 6 lnches high.

Stem-leaves linear.

Stem-leaves broadly obovate, stalked :

Tall, very glaucous biennial, with large capsules .

Umbel of 5, rarely 6, rays.

Leaves crowded, thick and leathery. Umbel compact.

Seeds smooth . Umbel spreading. Seeds pitted :
Leaves rather thln.

Umbel of 8 or more rays

12. E. amygdaloiles.

2. E. Helioscopta.

3. E. platyphyllos.

7. B. exigua.

6. E. Peplus.

8. K. Lathyris.

10. E. Paralia.

9. B. reyetalis

- 11. E. Ésula. 
E. Characias, a tall, south European species, with a handsome, oblong, crowded, leafy panicle, variegated by the contrast of the purple glands of the involncre and the green bracts, has been often cultivated in gardens, and where once planted will remain many years, but does not permanently establish itself. A tropical shrubby species with scarlet involucres, called Poinsettia, is cultivated in our hothouses, and several South African succulent ones may be met with in cactus-houses.

1. E. Peplis, Linn. (fig. 885). Purple S.-A glabrous annual, of a glaucous or purple hue; the very short main stem loses all its leaves before flowering, and divides close to the base into an umbel of 3 or 4 rays, so that the whole plant appears to consist of the repeatedly forked flowering branches, closely prostrate on the sand, and forming patches of 6 inches to a foot or more in diameter. Floral leaves opposite, numerous, very oblique, broadly oblong, very obtuse and rather thick, with minute stipules at their base. Flower-heads very small. Glands of the involucre expanding into small, whitish or purple scales. Capsule glabrous and smooth. Seeds not pitted.

In maritime sands, all round the Mediterranean, and op the western coasts of Europe to the English Channel. In Britain, only in South Wales, and on the southern coasts of England, where it is now becom. ing scarce; county Waterford, Ireland. Fl. summer and autumn.

2. E. Helioscopia, Linn. (fig. 886). Sun S.-An erect or ascending annual, 6 or 8 inches to a foot high, simple or with a few branches ascending from the base. Stem-leaves obovate or broadly oblong, and narrowed into a short stalk; floral leaves broadly obovate or orbicular, all very obtuse and minutely toothed. Umbel of 5 rays, each ray ouce or twice forked at the end, but the branches so short that the flowers and floral leaves appear crowded into broad, leafy heads. Glands of the involucre entire and rounded. Capsules glabrous and smooth. Secds pitted.

In cnltivated and waste places, in Europe and Asia, extending farther north than most species, jct not an Arctic plant. Common in Britain, $\mathrm{Fl}$. the whole season.

3. E. platyphyllos, Linn. (fig. 887). Broad S.-An erect annual or biennial, sometimes slender and only 6 inches high, but usually 1 to 2 feet, glabrous or very slightly downy. Stem-leaves oblong or almost lanceolate, most,ly pointed, and very finely toothed; floral leaves broadly cordate or orbicular, often with a yellowish tint. Umbel of about 5 (rarely 4 or 3 ) rays, besides several flowering branches from the axils of the upper stem-leaves; these rays are slender, usually divided into 3,4 , or even 5 secondary, simple or forked rays. Glands of the involucres entire or rounded. Capsule smaller than in most species, more or less warted, glabrous or hairy. Seeds not pitted.

In cultivated and waste places, in central and southern Enrope and western Asia, but not extending into Scandinavia. In Britain only from Yorkshire and Gloncester southwards, and here and there as a weed of coltivation farther north. Fl. summer and autumn. [Two species were recognised by Linnæus and others.

a. $\boldsymbol{E}$. platyphyllos, L., with bracts $\frac{1}{2}$ in. long, capsule with rounded warts and olive brown seeds.

b. $E$. stricta, L., with bracts $\frac{1}{4}-\frac{1}{3}$ in. long, capsule smaller with conical warte and small red-brown seeds.] 
4. E. hiberna, Linn. (fig. 888). Irish S.-A perennial, with several ascending or nearly erect stems, 1 to $1 \frac{1}{2}$ feet high, either glabrous or the stems and under side of the leaves more or less softly hairy. Leaves broadly oblong, entire, often 2 inches long or more. Umbel compact, of 5 rays, once or twice shortly forked, and but little longer than the leaves immediately under it. Floral leaves large and ovate, often yellowish. Glands of the involucre entire and rounded. Capsule rather large, strongly warted, but not hairy. Seeds not pitted.

In woods and mountain pastures, in western Europe, and chiefly in the Pyrenees, in western and central France, and in south and west Ireland, and in a few localities in Devonshire. Fl. early summer.

5. E. pilosa, Linn. (fig. 889). Hairy S.-A perennial, somewhat resembling $E$. hiberna, but more erect, either softly hairy, especially on the under side of the leaves, or nearly glabrous in a Continental

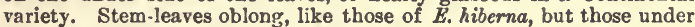
the nmbel shorter. Umbel usually of 5 rays, with a few axillary branches below it; the rays much longer and more branched than in $E$. hiberna. Capsules rather smaller, thongh much larger than in E. platyphyllos, not really warted, but usually covered with small, raised, glandular dots, glabrous or hairy. Seeds not pitted. E. palustris, Forst.

In moist woods and thickets, on shady banks, in central and southern and especially eastern Europe, and western Asia, but not approaching nearer to Britain than the Loire. It has, however, long been known apparently wild near Bath, and has been recently found by Mr. Hemsley near Westmeston in Sussex. Fl. early summer.

6. E. Peplus, Iinn. (fig. 890). Petty S.-An erect or decumbent, glabrous annual, 6 inches to a foot high, branching from the base. Stem-leaves obovate, entire, shortly stalked. Umbel of 2 or 3 repeatedly forked rays, often occupying the greater part of the plant. Floral leaves broadly ovate or cordate. Flower-heads small. Glands of the involucre crescent-shaped, with long points. Capsule glabrous and smooth, with a longitudinal rib or narrow wing to each carpel. Seeds pitted.

In cultivated and waste places, throughout Europe and Russian Asia, except the extreme north. Abundant in England, Ireland, and a great part of Scotland. Fl. the vole summer, and autumn.

7. E. exigua, Linn. (fig. 891). Dwarf S.-A slender, glabrous annual, with several erect or ascending stems, from 1 or 2 to 6 or 8 inches high. Stem-leaves numerous, small and narrow. Umbels of 3 or 4 , rarely 5 rays, sometimes contracted into terminal heads, more frequently elongated and forked. Floral leaves usually lanceolate. Glands of the involucre crescent-shaped, with fine points. Capsules small, smooth or slightly warted at the angles. Seeds slightly wrinkled.

In cultivated and waste places, in central and sonthern Europe and western Asia, extending northwards to southern Sweden. Abundant in most parts of England, rare in Scotland, and local in Ireland. Fl. the whole season.

8. E. Lathyris, Linn. (fig. 892). Caper S.-A tall, stont annual or biennial, often 3 feet high or even more, very smooth and glaucous. Stem-leaves narrow-oblong, the upper ones broader, especially at the 
base, often 3 or 4 inches long, and all opposite, not alternate as in other Euphorbias. Umbels of 3 or 4 long rays, once or twice forked, with large ovate-lanceolate floral leaves, Glands of the involucre crescentshaped, the points short and blunt. Capsules large and smooth. Seeds wrinkled.

A native of southern Europe and west central Asia, probably wild in Somerset and Sussex; long since cultivated in cottage gardens, and often establishes itself as a weed in their vicinity. $\mathrm{Fl}$. summer.

9. E. segetalis, Linn. (fig. 891). Portland S.-An inland southern variety is annual or biennial, the British maritime form lasts probably seven years, becomes hard at the base, with several decumbent or aseending stems, a few inches to near a foot high. Stem-leaves narrow, of a pale green or glancous, but not thick and leathery as in the sea $S$. Umbel of 5 repeatedly forked rays, the floral leaves all very broadly cordate. Glands of the involucre crescent-shaped, with fine points. Capsule smooth or with small raised dots on the angles. Seeds pitted. $\boldsymbol{E}$. portlandica, Linn.

In sandy or stony, waste or cultivated places, especially near the sea. Very common in the Mediterranean region, the strictly maritime perennial variety extending also up the western coasts of Europe to the Channel. In Britain, along the southern and western coasts of England up to Galloway in Scotland, and also in Ireland. Fl. summer and autumn. The northern specimens are usually shorter and more compact, with shorter and more obtuse stem-leaves than the southern ones, but a very gradnal passage may be traced from the one to the other.

10. E. Paralias, Linn. (fig. 894). Sea S.-A perennial, with a short, hard, almost woody stock; the stems ascending or erect, 6 inches to near a foot high, crowded with short, concave, rather thick and leathery leaves, of a very pale green. Umbel compact, of 5 more or less forked rays, and often a few axillary flowering branches below it. Lower leaves narrow, but passing gradually into the broad, ovate-cordate floral leaves. Glands of the involucre crescentshaped, with short points. Capsules smooth. Seeds smooth or slightly warted.

In maritime sands, round the Mediterranean and up the western coasts of Europe to Holland. In Britain along the southern coasts, np to Dublin in Ireland, and to Cumberland and Suffolk in England. Fl. autumn.

11. E. Esula, Linn. (fig. 895). Leafy S.-A glabrous perennial, readily distinguished from all the preceding species by the terminal umbel of 8 to 12 or more rayș. Stems 1 to $1 \frac{1}{2}$ feet high, the leaves vary. ing from oblong-lanceolate to linear, of a glaucous green. Floral leaves broadly cordate or orbicular, often yellow. Glands of the involucre crescent-shaped, and rather pointed. Capsules minutely granulated, but not warted. Seeds not pitted.

On river-banks and hilly wastes, in central and especially southern Europe, and western Asia, extending, however, north wards into southern Scandinavia. Probably not indigenous in Britain, but is said to have established itself in Forfar, near Edinburgh and Alnwick. Fl. summer. Starved, narrow-leaved states of this plant have been taken for $\boldsymbol{E}$. Cyparissias, a more southern Continental swecies. 
12. E. amygdaloides, Linn. (fig. 896). Wood S.-Stock perennial and almost woody, with several erect, often reddish stems, 1 to 2 feet high, glabrous or slightly hairy. Stem-leaves rather crowded towards the middle of the stem, lanceolate or narrow-oblong; the upper ones more distant, and shorter. Umbel of 5 long rays, not much divided, with a few axillary peduncles below it. Floral leaves of each pair always connected into one large orbicular one, of a pale yellowish-green. Glands of the involucre crescent-shaped, with rather long points. Capsules and seeds smooth.

In woods and thickets, in temperate and southern Europe and western Asia, but not extending into Scandinavia. In Britain, common over the greater part of England, rare in northern England, in Ireland only near Bandon and Donegal; unknown in Scotland. Fl. spring.

\section{MERCURIALIS. MERCUIRY.}

Frect herts: with opposite leaves, and small green flowers in little clusters, either sessile, stalked, or spiked in the axils of the leaves, the males and females distinct, on the same or on separate plants. Perianth of 3 segments. Male flowers with 9 to 12 stamens. Females with a sessile 2-celled ovary, crowned by 2 simple styles, and surrounded by 2 or 3 small filaments. Capsule 2-celled, otherwise like that of Spurge.

A small genus, spread over the temperate regions of the southern as well as the northern hemisphere, and nearly connected with several more tropical genera of weed-like, uninteresting plants.

Rootstock perennial. Stems simple. Fowers all in loose spikes . 1. M. perennis. Root annual. Stems branched. Female flowers sessile or shortly stalked

2. M. annua.

1. M. perennis, Linn. (fig. 897). Dog's Mercury.-Rootstock slender and creeping. Stems erect, simple, 6 or 8 inches, or rarely nearly a foot high. Leaves rather crowded in the upper half, oblong or ovatelanceolute, 2 to 4 or 5 inches long, usually pointed, crenate or serrated, and rough or shortly hairy. Flowers diœcious, on slender axillary peduncles, often nearly as long as the leaves; the males in little clusters, the females singly or 2 together. Ovaries larger than the perianth, with rather long, spreading styles. Capsules more or less covered with warts or soft prickles.

In woods and shady places, throughout Europe and Russian Asia, except the extreme north. Abundant in England and Scotland, less so in Ireland. Fl. early spring, commencing before its leaves are fully out.

2. M. annua, Linn. (fig. 898). Annual M. -An erect, glabrous annual, 6 inches to a foot high, with opposite branches. Leaves stalked, ovate or oblong, rather coarsely toothed, of a thin texture. Male flowers clustered, as in $M$. perennis, along slender peduncles nearly as long as the leaves. Females 2 or 3 together, either sessile or shortly stalked, in the axils of the leaves, usually on separate plants from the males.

In cultivated and waste places; very common in central and sonthern Europe and eastward to the Caucasus, more rare towards the north, and only as an introduced weed of cultivation in Scandinavia. Not generally common in England or Ireland, very local and doubtfully indigenous in 
Scotland. Fl. the whole summer and autumn. A variety with more sessile leaves and flowers, the latter often monceious, has been described as a species, under the name of $M$. ambigua. It is not common, even on the Continent, bnt has been found in Jersey and in the south of England.

\section{BUXUS. BOX.}

Flowers monccious, the males and females clnstered in the same axil, but not enclosed in a common involucre. Perianth small, of 1 segments. Stamens 4 in the male flowers. Styles 3 in the females. Capsule 3-celled, with 2 seeds in each cell.

A genus limited to a single European, and a few exotic species.

1. B. sempervirens, Linn. (fig. 899). Common Box.-A glabrous, much branched, evergreen shrub, attaining 6 or 8 feet in height when left uncut. Leaves opposite, entire, thick and shining, varying from ovate to oblong, $\frac{1}{2}$ to 1 inch long. Flowers small, green and sessile, usually several males and 1 or 2 females in the same axillary cluster, the former with one small bract under the perianth, the female with 3 bracts. Capsule sessile, ovoid, of a hard consistence, about 3 or 4 lines long, ending in 3 stiff, short beaks.

In hilly, rocky, chiefly limestone districts, in western and southern Europe, extending eastward to the Himalaya and Japan, and northward into many parts of central and western France. In Britain, only in some localities in southern and contral England. Fl. spring. The Box nsed for edging in gardens is a dwarf variety.

\section{EMPETRACE压. THE EMPETRUM FAMILY.}

A family of six or seven European or North American species, whose affinities have not been satisfactorily made out. The structure and position of the seeds prevent its union with Euphorbiacea, to which it might in other respects be technically referred. [Some authors place this Order near Ilicinece, and others near Ericacea.]

\section{EMPETRUM. CROWBERRY.}

Low, creeping, beath-like shrubs, with small, crowded, entire, evergreen leaves, and minute, axillary, diœcions flowers. Perianth of 6 scales in 2 rows, with 6 external, similar, but smaller bracts. Stamens 3 in the male flowers. Style in the females very short, divided into 6 or more radiating and toothed or divided stigmas. Ovary with as many cells as stigmas, and a single erect ovule in each. Fruit a small berrylike drupe, containing several small 1-seeded stones. Embryo slender, in a copious albumen.

1. E. nigrum, Linn (flg. 900). Cronoberry. $\rightarrow$ A glabrous plant, forming spreading thickly branched tufts, like those of Loiseleuria, often a foot in diameter; the crowded evergreen leaves scarcely 2 lines long with their edges rolled back as ia Hcaths. Ilowers sessile, very minute, tha 
stamens of the males protruding from the perianth on slender filaments. Fruit black, globular, about the size of a pea.

In mountain heaths and bogs, in Europe, Asia, and North America, very abundant at high northern and Arctic latitudes, and quite alpine in southern Europe and central Asia, and a red-berried variety abounds in the Falkland Islands. Common in Scotland, in northern and western England, and in Ireland. $F l$ spring.

\section{OALLITRICHINEE. THE CALLITRICHE FAMILY.}

Aquatic, floating herbs, with opposite or whorled leaves, and minute unisexual flowers in their axils. No perianth. Ovary and fruit either 1-seeded or 4-lobed, with 1 seed in each lobe.

Two genera, each of a single species. Allied in many respects to Haloragea, they are sometimes placed next to or amongst them; but there is no perianth, and they are therefore more frequently enumerated amongst anomalons Monochlamyda. [These genera are regarded by others as forming two families, of which Callitrichinece have been reforred both to Euphorbicca and to Haloragea. 'The position of Cerato. phyllum is quite uncertain.]

\section{CERATOPHYLLUM. HORNWORT.}

Leaves whorled and dissected. Stamens several. Style 1. Ovary and fruit entire, with a single seed.

1. C. demersum, Linn. (fig. 901). Hornwort.-A glabrous perennial, the stems floating like those of a Myriophyllum, and the leaves are whorled in the same manner, but instead of being pinnately divided they are twice or thrice forked, with linear often fine and subulate segments, usually slightly toothed on the edge. Flowers small, sessile in the axils of the leaves, each one surrounded by a whorl of minute bracts, but without any real perianth; the males consisting of 12 to 20 sessile oblong anthers, the females of a small ovary with a simple style. Fruit an ovoid, slightly compressed nut, 2 to 3 lines long, either two sharp species (C. demersum proper), or with a few tubercles or prickles ( $C$. sub. mersum, Linn.), either scattered over the surface or united in a slightly prominent wing round the edge.

In pools, slow streams, and shallow margins of lakes, dispersed almost all over the globe. Not uncommon in Britain. Fl. summer, but only in shallow water.

\section{CALLITRICHE. CALLITRICHE.}

Leaves opposite entire. Stamens solitary. Styles 2. Ovary and fruit 4-lobed and 4-seeded.

1. C. aquatica, Sm. (fig. 902). Common C. or Water Starwort.-A glabrous, slender perennial, either floating in water or creeping and rooting in wet mud, flowering young so as to appear annual, varying in length according to the depth of the water. Leaves either all obovate or 
oblong, 1 to 6 lines long, or the lower submerged ones narrow-linear, and obtuse or notched at the top; the upper ones obovate, and spreading in little tufts on the surface of the water, or all submerged and linear. Flowers minute, usually solitary in each axil, bet ween 2 minute bracts vary. ing much in size and sometimes wholly wanting. Male flowers consisting of a single stamen with a conspicuous filament ; the females of a sessile or stalked ovary, with 2 erect or recurved styles. Fruit from $\frac{1}{2}$ to 1 line in diameter, the lobes either rounded or keeled or winged on the edge.

In shallow waters or wet mud, dispersed all over the globe. Abundant in Britain. $F l$. the whole season. It has been variously divided into from 2 to about 20 supposed species, from slight differences in the size and form of the fruits, the direction of the styles, in the bracts, \&c., or from the presence or absence of the upper obovate leaves; but the distinctive characters which have been given all fail when applied to a large number of specimens collected in different parts of the world. [The British forms generally recognised as species or varicties are six, of which the first five have usually floating leaves, bracteate flowers, and the fruit-lobes broadly connate.

a. C. verna, Linn. (aquatica, Sm.). Fruit subsessile, its lobes turgid, sharply keeled.

b. C. platycarpa, Kuetz. Fruit large, subsessile, its lobes flattish, sliarply keeled. Often grows prostrate on mud, and is the $C$. stagnalis, Scop.

c. C. hamulata, Kuetz. Fruit subsessile, its lobes flattish, shortly broadly keeled.

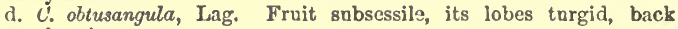
obtusely trigonous.

e. C. ped unculata, DC. Leaves linear. Fruit sessile or stalked, its lobes flattish, sharply keeled.

f. C. autumnalis, linn. Leaves all submerged and linear, truncate. Fruit larger, stalked or sessile, its lobes keeled or winged, connate only at the axis. Rare and local.]

\section{URTICACE\&. THE NETTLE FAMILY.}

Herbs, or, in exotic genera, trees or shrubs, with leaves usually rough or stinging, more or less conspicuous stipules, and small, herbaceous, unisexual flowers. Perianth in the males regular and simple. Stanens as many as segments of the perianth and opposite to them, or rarely fewer. Perianth of the females often less divided. Ovary free or rarely adherent to the perianth, with a single ovule, and 1 or 2 styles or stigmas. Fruit small, 1-sceded, dry or rarely succulent. Seed with or without albumen, the radicle pointing upwards.

A very large Order, chiefly tropical, of which the few British species give a very inadequate 1dea. It is readily distinguished from Euphorbincece by the single-seeded fruit, from Amentacce by the regular perianth of the male flowers. 
Frect herbs. Leaves npposite

Erect or procumbent herb. Leaves aiternate:

Tall twiner. Leaves opposite

1. URTICA.

2. PARIETARIA.

3. HUMULUS.

Among exotic genera in cultivation may be mentioned the (Cannabis), which, although an erect herb, is in many respects allied to the Hop; the Fig (Ficus), in which the flowers are collected in great numbers withinside a succulent receptacle, popularly called the fruit; and the Mulberry (Morus), in which the flowers are collected in heads on the outside of a receptacle, and become succulent as the fruit ripens.

\section{URTICA. NETTLE.}

Erect herbs, with stinging hairs and opposite leaves. Flowers in axillary clusters or spikes; the males with a perianth of 4 segments and 4 stamens; the females with a perianth of 2 segments, or, if 4 , the 2 inner ones larger. Fruit a flattened seed-like nut, enclosed in the perianth. Stigma single, sessile, and tufted.

A considerable genus, generally distributed over the globe.

Annual and moncecious. Flowers in nearly sessile short clusters . 1. U. urens. Annual and moncecious. Male flowers in loose spikes. Females in stalked, globular heads

Perennial, usually diocious. Flowers in branched spikes

2. $U$. pilulifera.

1. U. urens, Linn. (fig. 903). Small N.-An erect, branching annual, seldom above a foot high and often only a few inches, glabrous with the exception of the stiff, stinging hairs. Leaves ovate or elliptical, deeply and regularly toothed, more tender than in the two other species. Flowers male and female intermixed, in small, loose, almost sessile axillary clusters.

In cultivated and waste places, especially in rich soils, throughout Europe and temperate Asia, and carried sut as weed of cultivation to other parts of the world. Common in Britain. Fl. the whole season.

2. U. pilulifera, Linn. (fig. 904). Roman $N$.-An annual like the last, but coarser and taller, attaining 2 feet, and very stinging. Leaves ovate or heart-shaped, deeply and regularly toothed. Male flowers in little, distinct clusters, along peduncles often as long as the leaves; the females in globular heads, on the summit of a peduncle from $\frac{1}{2}$ to 1 inch long. When in fruit these heads are 4 or 5 lines in diameter, and thickly beset with stinging bristles.

On roadsides, and in waste places, in soutbern Europe. Farther north only as an introduced weed in the neighbourhood of habitations, and as such occurs occasionally in the east of England. $F l$ summer and autumn. $U$. Dodartii, Linn., is a variety with nearly entire leaves.

3. U. dioica, Linn. (fig. 905). Common N.-Rootstock perennial and creeping. Stems erect, 2 or 3 feet high, the whole plant of a dark green, and more or less downy, besides the copious stinging bristles. Lower leaves cordate-ovate, the npper ones more or less lanceolate, narrowed at the point, coarsely toothed. Flowers nsually diœcions, both the males and females clustered in axillary, branched, spreading spikes, usually about the length of the leaves.

Along hedges, on roadsides, and in waste places thronghout Europe and Russian Asia, from the Mediterranean to the Arctic regions, and carried out as a. weed to other parts of the globe. Common in Britain. $F l$ summer and autumn. 


\section{PARIETARIA. PELLITORY.}

Herbs, with alternate, often entire leaves, and not stinging. Flowers in small axillary clusters, surrounded by a few bracts, often united into a small involucre. Male flowers like those of Urtica, but usually very few. Females with a tubular or campanulate, 4-lobed perianth, enclos. ing the ovary and adhering to the seed-like fruit. Stigma single, tufted, sessile or with a distinct style. Besides these there are a few hermaphrodite flowers, which become enlarged after flowering, but seldom ripen their seed.

A genus of several species, chiefly from the Mediterranean region and central Asia, with one American one, widely spread over a great part of the world.

1. P. officinalis, Linn. (fig. 906). Wall P.-A small, branching perennial, erect the first year, afterwards usually diffuse or procumbent, 6 inches or rarely a foot long, more or less downy with short soft hairs. Leaves stalked, varying from ovate to oblong, quite entire. Flowers in sessile clusters, the involucre very small, consisting of 2 or 3 divided bracts. P. diffusa, Koch.

On old walls, and in waste, stony places, throughout Europe and Russian Asia, except the extreme north. Common in Britain, but rare in the north. Fl, the whole summer.

\section{HUMULUS. HOP.}

A single species, differing from all other Urticacece by its twining habit, by the inflorescence, and by the seed, which contains a flat, spirally coiled embryo, without albumen.

1. H. Lupulus, Linn. (fig. 907). IIop.-Rootstock perennial, the stems annual, but twining to a considerable height over bushes and small trees. Leaves opposite, stalked, broadly heart-shaped, deeply 3or 5-lobed, and sharply toothed, very rough but not stinging. Flowers dioccious, the males in loose panicles in the upper axils, small, and of a yellowish grcen. Perianth of 5 segments. Stamens 5. Female flowers in shortly stalked, axillary, ovoid or globular spikes or heads, conspicuous for their broad, closely-packed bracts, each with 2 sessile flowers in its axil. Perianth a concave scale enclosing the ovary. Stigmas 2, long and linear. After flowering, the scales of the spike (often called a cone) become much enlarged, quite concealing the seedlike fruits.

In hedges, thickets, and open woods, all over Europe and central and Russian Asia, except the extreme nortb. Extends over most of England, and is naturalised in Ireland and Scotland, having long been in general cultivation. Fl. summer.

\section{ULMACEA. THE ELM FAMILY.}

Trees or shrubs, differing from Urticacea in their flowers mostly hermaphrodite, and the ovary generally 2-celled, although the fruit has but 1 seed. 
Besides Ulmus there are but very few genera, either tropical or from the warmer parts of the northern hemisphere.

\section{ULMUS. ELM.}

Trees, with alternate, deciduous leaves, and small flowers in clnsters, appearing before the leaves on the preceding year's wood. Perianth campanulate, with 4 to 6 short lobes or teeth, and as many stamens. Ovary flat, with 2 short, diverging styles, and divided into 2 cells, each with a single pendulons ovule. Fruit flat, thin, and leaf-like, slightly thickened in the centre, where it contains 1 pendulous seed.

A small genus, spread over the temperate regions of the northern hemisphere.

Fruit slightly notched at the top, the seed-bearing cavity placed considerably below the notch
Fruit deeply notched, the notch almost reaching the seed-bearing cavity

1. U. montana.

2. U. campestris.

1. U. montana, Sm. (fig. 908). Scotch or Wych E.-A tree of considerable size and picturesque form; the large branches spreading from near the base unless when drawn up in its youth. Leaves nearly sessile, broadly ovate, bordered with double teeth, and very nnequal or oblique at the base, usually rough on the upper side and downy underneath. Flowers reddish, in dense clusters, surrounded by brownish bracts, which soon fall off; the pedicels scarcely as long as the perianth. Fruits green and leaf-like, broadly ovate or orbicular, 6 to 9 lines long, with a small notch at the top; the seed suspended in a small cavity near the centre of the fruit.

Chiefly in hilly districts, in northern and western Europe and Asia. In Britain, it is the common wild $E l m$ of Scotland, Ireland, and northern and western England; it is rare in south-eastern England, where a variety of $U$. campestris is often called wych Elm. Flo early spring, before the leaves.

2. U. campestris, Sm. (fig. 909). Common E.-Very near U. montana, and many botanists consider the two races as forming but one species. The $U$. campestris appears, however to be generally, if not constantly, distinguished by the fruit, which is deeply notched, the top of the seed-bearing cavity almost reaching the notch. It is usually also a taller and straighter-growing tree, attaining in rich soils above a hundred feet; the young branches are more slender, and the leaves usually smaller and less coarse; but all these characters are very variable.

Widely spread over central, sonthern, and eastern Europe, and western Asia, and the most generally planted species. In Britain, it is the most frequent one in fields and hedge-rows. It is nowhere indigenous in Britain, where it rarely ripens seed, but increases rapidly by root suckers. $F l$. early spring, before the leaves. It varies with the leaves nearly smooth and glabrons, and the bark becomes corky (U. suberosa, Ehrh.), even on the young branches, more frequently than in U. montana; but the supposed species established on these characters do not come true from seed. 


\section{AMENTACE\&. THE CATKIN FAMILY.}

Trees or shrubs, with alternate flat leaves, usually with stipules, and small, unisexual flowers, in cylindrical, oblong, or globular spikes, called catkins, which are usually dense with closely packed, scale-like bracts, rarely loose, or with minute deciduous scales. Stamens in the male catkins 2 or more (rarely united into 1) within each scale, usually accompanied by 2 or more smaller scales, either distinct or forming in a few cases an irregular or oblique perianth, or rarely entirely deficient. Female catkins either like the males, with 1, 2, or 3 flowers within each scale, or reduced to a sessile bud, with 2 or 3 flowers in the centre, surrounded by the lower empty scales of the catkin; within each scale are also usually 2 or 3 inner scales. Perianth none, or closely combined with the ovary, with a minute, free, or entire toothed border. Ovary 1-celled or several-celled, with 2 or more styles, always resulting in a 1-celled fruit, which is either a 1-seeded nut, or a several-seeded capsule opening in 2 valves. The catkin-scales, or the inner scales, or both, usually persist, and are sometimes enlarged into an involucre, either around or under the fruit. Seeds without albumen, at least in the British genera.

An extensive family, widely distributed over the globe, but chiefly in the temperate regions of both hemispheres, where it often constitutes a large proportion of the forest-trees. Minor differences, chiefly in the female flowers, have required its division into several independent families, but for the purposes of this work it forms a natural as well as a distinct group. Among the few British plants that have their inflorescence at all resembling catkins, Hippophae is readily distinguished by the berry-like fruits and scurfy foliage, Ulmus by its hermaphrodite flowers, Humulus by its opposite leaves, and Coniferce by their peculiar foliage, independently of the important character of the naked seeds.

\section{Tree or shrub, in flower.}

Scales of the male catkins broad, Imbricated. Anthers longer than their flamente.

Male and female catklns short, sessile, and erect . .

1. MIYRICA.

Male catkins cylindrical, usually pendulous.

Three distinct flowers, each with 4 stamens, under each scale of the male catkins. Female catkins small, ovoid

2. ALNU8.

Btamens 6 to 12 within each scale, not in distinct llowers.

Scales of the male catkins stalked. Female catkins cylindrical 8. BEToLA.

Scales of the catkins sessile.

Btamens at the base of the scale. Female catking loose, with narrow scales.

Btamens on the scale Itself Female catking minute, ses-

Scales of the male catkins narrow-linear, or divided, or very minute.

4. Carpinua

6. Cosyun.

An hers small, on slender fllaments.

Floners diacidus. Catkins both wale and female, cylisulrical, connvact, and usually silky-hairy 
Catkin-scales entire. Stamens 2, rarely 3 to 5, with 1 or 2 glanc-

like inner scales
Catkin-scales jagged. Stamens several, in an oblique, cup-
shaped perianth.

8. SALIX.

9. Populus.

Flonoers monoecious.

Malo catkins slender and interrupted. Female flowers in small, sessile or shortly-stalked clusters

Male catkins globular, on pendulous stalks. Females erect, globular, softly hairy Tree or shrub, in fruit.

7. QURRCUS.

a. TAGUS.

Capsules (in catkins) opening in 2 valves. Seeds minute, with a tuft of long, cottony hairs.

Scales of the catkin entire. Leaves on short or rather stiff stalks . Scales of the catkin jagged. Leaves on long stalks, very broad, Nuts 1-seeded. shaking with the wind.

Nuts small, in compact catkins.

Nuts slightly succulent, and resinous outalde .

Nnts flat and quite dry.

Scales of the catkins thin and deciduous. Nuts winged . Scales of the catkins hard, remaining after the nuts have

Nuts solitary, or in elusters, or in loose spikes, wholly or partially enclosed in an involucre.

Nuts small, in loose spikes, each in a 3-lobed, leafy involucre

Nuts solitary or clustered, each in an involucre adhering to it at the base, with leafy, jagged lobes

Nuts (acorns) projecting irom a short, cup-shaped involucre :

Nuts completely enclosed in a prickiy involucred involucro Q. QUERCUS.

These nine genera are distribnted by modern botanists into four tribes or orders: MYRICACEA, limited to Myrica; BETULACEs, including Alnus and Betula; CUPUlfirra, comprising Carpinus, Corylus, Fagus, and Quercus; and SALICINEM, for Salix and Populus.

Among trees generally planted in Britain, belonging to exotic genera of Amentacea or their allies, are the Spanish Chestnut (Castanea), with the flowers nearly of an Oak, but the nuts completely enclosed in a prickly involucre, as in Fagus; the Planes (Plantanus), with both male and female catkins globular and pendulous, the flowers intermixed with bristly hairs, and differing slightly from the family in their albuminous seeds; and two or three species of Walnut (Juglans), which in their pinnated leaves and more perfect perianth show an approach to Terebinthacece. [Of the above the Chestnut seeds and reproduces itself freely in parts of Surrey and elsewhere, and may fairly slaim the position of a naturalised plant.]

\section{MYRICA. GALE.}

Shrubs, with resinous, dotted leaves. Flowers diœcious, in short, sessile catkins; the scales imbricated, without inner scales. Male catkins with 4 or 8 stamens within each scale, the anthers nearly sessile, and no perianth. Females with 2 ovaries within each scale; perianth adhering to the base of the ovary, with two lateral, projecting lobes. Stigmas 2, linear. Fruit a small, resinous or nearly drupe-like, globular nut, with 1 erect seed.

A genus of several species, dispersed over the temperate regions of the globe, or the monntainous parts of the tropics. Associated with two or three small North American or South African genera, it forms a distinct tribe, approaching Hippophae in the 2-lobed female perianth and almost drupe-like nut. 
1. M. Gale, Linn. (fig. 910). Sueet G.-An erect shrub, of 2 or 3 feet, fragrant when rubbed. Leaves deciduous, cuneate-oblong or lanceolate, slightly toothed towards the top, and often rather downy underneath. Catkins sessile along the ends of the branches; the males scarcely 6 lines long, with spreading concave, shining scales; the females much shorter, the long styles protruding from the scales. Fruiting catkins somewhat lengthened; the globular, resinous nuts scarcely above a line in diameter.

In bogs and wet moors in northern and Arctic Europe, Asia, and America. Abundant in Scotland, northern England and Ireland, rarer in the south and east of England. Fl. spring, before the leaves are out.

\section{ALNUS. ALDER.}

Flowers monocious, the males in cylindrical catkins, usually pendnlous, with broad, almost sessile scales. Stamens 12 within each scale, the anthers on very short filaments, with a small scale under each, usually forming 3 distinct, nearly regular, 4-cleft periantlis. Female catkins short, closely imbricated; the scales entire, with 2, rarely 3 , smaller inner scales. Ovaries 2 within each scale, 2 -celled, with a pendulous ovule in each cell. Styles 2. Fruiting catkin ovoid, the scales (formed of the catkin-scale, with the 2 inner ones combined) hard, almost woody, remaining after the nuts have fallen. Nuts small and seed-like, without wings.

A small genus, confined to the northern bemisphere, closely connected with Betula through some intermediate exotic species.

1. A. glutinosa, Linn. (fig. 911) Common A.-A moderate-sized tree, of a dark hue. Leaves stalked, troadly ovate or orbicular, sharply toothed, and occasionally lobed, glabrous or with a little down in the axils of the veins on the under side. Catkins 2 or 3 together, in terminal clusters or small panicles; the males long, loose, and drooping; the females not half an inch long, with the styles slightly protruding. In the fruiting catkin the scales are not unlike those of a miniature fir-cone.

In wet woods, borders of streams, and wet pastures, in Europe and western Asia, not extending to the Arctic Circle. Abundant in Britain. Fl. eurly spring, before the leaves are fully out, the cathins having been formed the previous autumn.

\section{BETULA. BIRCH,}

Flowers moncelous, the males in cylindrical cat kins, usually pendulous, with broad, shortly stalked scales. Stamens 8 to 12 within each scale, the anthers on very short filaments, the cells distinct, some with a small scale underneath, and all irregularly arranged in 3 flowers. Female catkins cylindrical and compact, each scale with 2 small scales inside, and 3, rarely more, flowers. No perianth. Ovary flat, with 2 styles and 2 cells, with a pendulous ovule in each. In the fruiting catkin the scales (formed of the catkin-scale, with the 2 inner ones combined) are somewhat enlarged and 3-lobed, falling off with 
the nuts, which are small and seed-like, flat, surrounded by a scarious wing.

A small genns, confined to the northern hemisphere, and not reaching the tropics.

Tree, with broadly ovate, usually polnted leaves . . . . . 1. B. alba. Shrub with small, orbicular leaves $\cdot \quad \cdot \quad 0^{-} \quad 2_{2}$ B nana.

1. B. alba, Linn. (fig. 912). Common B.-An elegant tree, with slender, often gracefully drooping branches, the white bark of the trunk readily peeling off in layers. Leaves usually broadly ovate, taper-pointed, and toothed, but varying from rhomboidal to triangular or broadly cordate, often trembling on their slender stalks like those of the Aspen, glabrous and shining, with minnte glanditar dots when young. Male catkins drooping, 1 to 2 inches long; the females shortly stalked, about 6 inches long when in flower. Fruiting catkins 1 to $1 \frac{1}{2}$ inches, the scales wedge-shaped, fully 2 lines long, broadly 3 -lobed.

In woods, in northern and central Europe, north Asia, and North America, more limited to mountain districts in southern Europe. Extends all over Britain. Fl. spring, before the leaves are fully out. [In the ordinary $B$. alba the side lobes of the fruiting bracts are spreading; in var. glutinosa they are more erect; in the latter the twigs are glabrous or pubescent, and the leaves more or less glutinous.]

2. B. nana, Linn. (fig. 913). Dvarf B.-Usually a small shrub, but sometimes attains 20 feet. Leaves very shortly stalked, nearly orbicular, seldom above half an inch long, and not pointed. Carkins small and sessile, the males oblong or shortly cylindrical, the females scarcely above 3 lines long. Fruiting catkins abont 6 lines long, the scales not so thin, nor so deciduous as in $B$. alba.

In moors and bogs, in northern Europe, Asia, and America, and in the monntains of central Europe. Not uncommon in the Highlands of Scotland, but rare in the north of England, and unknown in Ireland. Pl. spring.

\section{CARPINUS. HORNBEAM.}

Flowers monœcious, the males in cylindrical catkins, with broad, sessile scales. Stamens about 12 within each scale, without inner scales or perianth;' the anther-cells distinct, on very short, forked filaments. Female catkins slender, the scales lanceolate and deciduous. Flowers 2 within each scale, each enclosed in a hairy, unequally 3 -lobed inner scale. Perianth combined with the ovary at the base, with a minute toothed border. Ovary 2-celled, with a pendulons ovule in each cell. Styles 2. Fruiting catkin much elongated, the inner scales enlarged into long, leafy, unequally 3 -lobed bracts, each enclosing at its base a small nut.

There are but very few European, Asiatic, or North American species, differing slightly from each otber in the shape of the fruiting bracts.

1. C. Betulus, Linn. (fig. 914). Common H. - A small tree, with numerous short, slender branches. Leaves stalked, ovate, pointed, doubly toothed, with parallel veins diverging from the midrib, usually downy in their axils nnderneath. Male catkins sessile, about $1 \frac{1}{1}$ inches long, less drooping than in the allied genera; the anthers crowned by 
t $\mathrm{nfts}$ of hairs. Female catkins slender, the fruiting ones often several inches long, and conspicuous for their long, leaf-like bracts; the central lobe lanceolate, 1 to $1 \frac{1}{2}$ inches long. Nut small, ovoid, with prominent ribs.

In central and south-eastern Europe, extcnding eastward to the Caucasus and nort liwards to southern Sweden. In Britain it is everywhere planted, and is indigenous only in Wales, and central and southern England. Fl. spring, as the lcarcs come out.

\section{CORYLUS. HAZEL.}

Flowers monœcious, the males in cylindrical cat kins, with broad, sessile scales, each with 2 small lobes or adherent scales inside. Stamens about 8 , irregular!y inserted on the scale itself, without any perianth; the anther-cells distinct, on very short, forked filaments. Female catkins very small, forming a sessile bud, with closciy packed, narrow scales, the outer ones empty. Flowers 2 within each scale, crowded in the upper part of the catkin, each one enclosed in a minute jagged inner scale. Perianth combined with the ovary at the base, with a minute toothed border. Ovary 2-celled, with a pendulous ovule in each cell. Styles 2. Fruits nsually clustered, each consisting of a hard nut, nearly enclosed in a leafy involucre, unequally lobed and jagged, formed of the very much enlarged inner scales of the catkin.

A genus of but very few species, spread over the temperate regions ol the northern hemisphere.

1. C. Avellana, Linn. (fig. 915). Common 11 . or Nut. -A shrub, or sometimes a small tree. I Leaves broadly obovate or orbicnlar, doubly oothed or slightly lobed, coarse and downy on both sides. Male cat. kins drooping, $1 \frac{1}{2}$ to 2 inches long; the females resembling small leafbuds, with shortly protruding, red stigmas. After flowering the minute inner bracts enlarge very rapidly, so as to form the leafy involucre commonly called the husk of the nut.

In woods and thickets, throughout Europe and central and Russian Asia, except the extreme north. Abundant in Britain. Fl. early spring, before the leaves are out.

\section{FAGUS. BEECH.}

Flowers monøcious, the males in globular, pendulous catkins; the scales small, and falling off very early. Perianth campanulate, shortly stalked, 4- to 6-lobed (formed of the inner scales within each catkinscale), containing 8 to 12 stamens, with long protruding filaments and small anthers. Female catkins globular, almost sessile, the scales lincar, with numcrous, closely packed filiform inner scales, all empty except the uppermost, and forming an involucre round 2 or 3 flowers, sessile in the centre of the catkin. Perianth combined with the ovary at its base, bordered by 4 or 5 short lobes. Ovary 3-celled, with 2 pendulous ovules in each cell. Styles 3. Nuts 2 or 3 , enclosed in a hard, prickly involucre, composed of the combined outer and inner cales of the catkin, and opening in 4 valves.

Besides the single northern species, the genus comprises several from Chili, Fuegia, Tasmania, and New Zealand. 
1. F. sylvatica, Linn. (fig. 916). Common B.-A tall tree, with a straight, smooth trunk, and large, dense head. Leaves shortly stalked, ovate, entire, or obscurely toothed, silky when young, glabrous when full-grown. Catkins or flower-heads softly silky-hairy, the males 4 to 6 lines diameter, on slender, drooping peduncles 1 to $1 \frac{1}{2}$ inches long, consisting of about a dozen flowers. Female catkins nearly as large, but on a very short, erect peduncle. Fruiting catkin about inch diameter; the prickles rather soft and silky, containing 2 or 3 triangular nuts, called masts.

In temperate Furope, extending eastward to the Cancasus and northward into southern Scandinavia, becoming rather a mountain plant in southern Europe. Extensively planted in Britain, establishing itself readily as a naturalised tree, but indigenous only in England. $\boldsymbol{F l}$. spring.

\section{QUERCUS. OAK.}

Flowers monocions, the males in slender, pendulous catkins or spikes, nsually interrupted, without any o: with only very small catkin-scales. Stamens 6 to 12 , with similar filaments, surrounded by about as many narrow scales, sometimes united into an irregular perianth. Female flowers solitary or clustered, each one surrounded by an involucre of small imbricated scales. Perianth adherent to the ovary at its bese, with a short toothed border. Ovary 3-celled, with 2 pendulous ovules in each cell. Style 3-lobed. Nut or acorn oblong, ovoid, or globular, protrnding from a woody cup or involucre formed by the enlarged scales.

A very numerous genus, extending over nearly the whole of the northern hemisphere, excepting the extreme north, but only penetrating into the tropics along the chain of the Andes or in the Moluccas. Many exotic species have evergreen or entire leaves, or are mere shrubs, but are all readily recognised by the fruit, in which the involucre never so completely encloses the nut as in the Chestnut and Beech. Among the most frequent in our plantations may be mentioned the evergreen or Ilex $O$. (Q. Ilex) from southern Europe, the Cork-tree (Q. Suber) from south-western Europe, the Turkey or moss-cupped O. (Q. Cerris) from south-eastern Europe, the red $O$. (Q. rubra), and some others, from North America.

1. Q. Robur, Linn. (fig. 917). British 0.-A stately trce, one of the largest and longest-lived natives of our islands. Leaves deciduous, although in some varieties they remain through a great part of the winter, usually obovate or oblong, irregularly sinuate or almost pinnatifid; the lobes usually ebtuse, glabrous or (rarely in Britain) downy underneath. Cup very much shorter than the acorn, with short, obtuse, closely imbricated, often scarcely distinct scales.

Extends over the whole of Europe, except the extreme north, penetrating along the chain of the Caucasus a considerable way into central Asia, although farther north it does not cross the Ural. Fh spring, as the leaves are coming out. It varies considerably in foliage and inflorescence, and throughout its range two remarkable forms appear so definite and usually so permanent that many of the most acnte botanists regard them as distinct species. The question of their 
specific identity has been much discussed, but the arguments adduced on each side are not absolutely conclusive in favour of the view here adoptcd, which is nevertheless the result of a close investigation, carried on for many years in various parts of Europe. The following are the two British races :-

a. Q. pedunculata, Ehrh. Leaves sessile or shortly stalked. Fruits either clustered or spiked, above the middle of the pednncle 1 to 6 inchès long. The commonest Oak over the greater part of England, Ireland, and the lowlands of Scotland. In the hilly parts of the west and north it is less abundant and less constant in its characters, and sometimes absent.

b. Q. sessiliflora, Salisb. Leaves on footstalks to 1 inch long. Fruits solitary or clustered, either closely sessile on the branch or borne on a short peduncle an inch long. Frequently scattered in woods of the pedunculate variety, and then pretty constant in its characters, rarely constituting the mass of oak-woods in the lower parts of Britain, but in North Wales and the hilly parts of northern England it is the commonest of the two, and much more variable; in Ireland said to be rare and local.

\section{SALIX. WILLOW.}

Leaves variable, but not triangular nor rhomboidal. Stipules often very conspicuous, but sometimes small or deficient on other branches of the same plant. Flowers diœcious, in cylindrical, usually silky-hairy catkins, with small, entire scales. Stamens in the males 2 , rarely 3,5 , or even more, or united into one, with slender filaments, and small anthers, and a gland-like scale either between the stamens and the axis, or more rarely between the stamens and the catkin-scale, or two scales, one on each side, but no perianth. Female flowers solitary within each scale, with a gland-like inner scale between the ovary and the axis. Ovary conical, sessile or stalked, 1-celled, with several ovules inserted on 2 short parietal placentas. Style forked, each lobe entire or shortly 2-lobed. Fruit a conical capsule, opening in 2 valves. Seeds several, minute, with a tuft of long, white, silky hairs.

A vast genus, widely spread over the world, but particularly abundant in the northern hemisphere, from the tropics to the Arctic zone, ascending high upon alpine summits and in low countries chiefly inhabiting wet or sandy situations. The great variations in the shape of the leaves of many species, and the difficulty of matching the male and female specimens, or the young and old leaves of those species which flower before the leaves are out, have produced a multiplication of supposed species, and a confusion amongst them, beyond all precedent. Eightcen of these are ennmerated in the stndent's British Flora, thirty in Babington's Mannal; the following fifteen are, however, all that appear to me to be truly distinct among the British ones; at the same time, reliable observations are wanting on the variation of particular charecters, especially amongst the mountain species, and intermediate forms between very dissimilar species are not nnfrequent in herbaria. These are in some cases taken from trees or shrubs much altered by cultiva. tion, others have been proved to be natural hybrids; in neither case can they be considered as botanical species. 
Male catkins sessile. Females sessile or on very short peduncles, with or without leafy bracts.

Stamen 1 withln each scale, entire or forked. Leaves narrow, glabrous or whitish underueath. Anthers usually purple

8tamens 2, distinct. Anthers usually yellow. Leaves very silky and white, at least underneath.

Stems erect, twiggy. Leaves long, lanceolate or Inear . Stems creeping underground. Leaves small, ovate, oblong or lanceolate

\section{Leaves glabrous, dovny or cottony.}

Leaves wrinkled, usually with a short, crisp or cottony down, especially underneath. Capsules pedicellate.

Male catkins very silky, oblong. Capsules 3 to 4 lines long. Leaves ovate or oblong

Male catkins cylindrical, rather sllky. Capsules 2 to $\dot{3}$ lines long. Leaves mostly obovate . . .

Leaves not wrinkled, glabrous and downy when young. Catkins rather slender. Capsules pedicellate

Leaves not wrinkled, downy or woolly, quite entire. Catkins dense and very silky.hairy. Capsules sessile.

Catkins silky-white. Capsules abont 2 lines long .

Catkins golden-yellow. Capsules about 3 lines long

5. S. purpurea.

6. S. viminalis.

10. S. repens.

and female catkins on short, leafy shoots.

Male and female catk
T'rees or tall shrubs.

Stamens about 5. Leaves dark-green and shining .

Stamens 3. Leaves green above, white underneath

Stamens 2.

Leaves ashy-grey or sllky-white. Capsules nearly sessile

Leaves green or glabrous. Capsules pedicellate . Low, spreading or prostrate, or creeping shrubs.

Catkins at the end of short, leafy shoots, without buds. Stems procumbent, ascending, or forming low bushes.

Leaves silghtly toothed. Male catkins nearly sessile. Capsules pedlcellate ${ }^{\circ}$ cating

Leaves finely toothed. All the catkins on leafy stalks.

Capsules almost sessile
Catkins on short peduncles, at the last leaf of a branch,
with a bud in the angle. Stems rrostrate or creeping.

Leaves entire, wrinkled, white underneath

Leaves finely toothed, not wrinkled, green on both sides 15. S. herbacea.

7. S. Caprea.

8. S. aurita.

9. S. phylicifolia.

11. S. Lapponum.

12. S. lanuta.

1. S. pentandra.

4. S. amygdalina.

3. S. alba.

2. S. fragilis.

9. S. phylicifolia.

13. S. Myrsinites.

The well-known weeping Willow (S. Babylonica) is of Asiatic origin. The S. daphnoides, from continental Europe, with the male catkins like those of S. Caprea, but with lanceolate, pointed, green or glaucous leaves, is occasionally planted, and has been seen apparently wild near Cleveland in Yorkshire; and some other Continental or North American species have been described as British from planted specimens. Many of the British species are also natives of North America.

1. S. pentandra, Linn. (fig. 918). Bay W.-A shrub or small tree, from 6 to 20 feet high, glabrous or rarely slightly silky on the young shoots, the twigs green or yellow. Leaves broadly lanceolate or oblong, pointed, finely toothed, thicker and more smooth and shining than in any other species. Catkins cylindrical and loose, on short, lateral, leafy shoots; the males $1 \frac{1}{2}$ to 2 inches long, less hairy than in most species. Stamens nsually 5 but sometimes more, and there are almost always 2 or even more entire or divided gland-like scales at their base. Ovaries glabrous, nearly sessile or stalked. Capsules 2 to 3 lines long, of a yellowish-green.

In damp, open woods, and along streams, chiefly in hilly districts, extending all over Furope and temperate Asia to tha Arctic regions 
In Britain, chiefly in northern England and soutbern Scotland, rare in Ireland. $\mathrm{Fl}$. spring, rather late.

2. S. fragilis, Linn. (fig. 919). Crack W.-Very near S. alba, but nsually a more bushy though equally large tree, and the foliage green and glabrous, or very slightly silky when young; the catkins are rather longer and looser, the flowers larger, the capsules more distinctly pedicellate and much more tapering at the top.

Widely distributed, like S. alba, over Europe and Russian Asia, and extensively cultivated, with nearly the same geographical limits. In Britain, believed to be indigenous in England, and doubtfully in Ireland and Scotland. Fl. spring.

3. S. alba, Linn. (fig. 920). White or Common W.-A tree of considerable height, the foliage of an ash-grey or whitish colour; the young twigs green, purplish, or bright yellow. Leaves mostly narrow janceolate, pointed and toothed, but not so finely as in S. pentandra, and when young silky-white on both sijes, or at least underneatb, often glabrous when old, but never of a bright green. Catkins cylindrical and loose, on short, lateral shoots, or leafy peduncles. Stamens always 2 , usually with 2 glandular scales. Capsule glabrous, sessile or nearly so, shortly tapering at the top.

In moist meadows, in marshes, along streams, \&c., thronghout Europe and temperate Asia, except the extreme north, and extensively planted. Common in Britain. Fl. spring. The golden Osier (S. vitellina, Linn.), is a variety, with bright-yellow branches, cultivated as an Osier. [ $S$. carulea, $\mathrm{Sm}$., is another, with olive-green twigs and leaves glaucous blue beneath.]

4. S. amygdalina, Linn. (fig. 921). Almond or French W.-A moderate-sized tree, often flowering as a shrub. Leaves rather narrow, lanccolate, either paler or more frequently nearly white underneath, but not silky. Catkins cylindrical and loose, on very short, leafy shoots, like those of $S$. alba, but in the males there are al ways 3 stamens within each scale, and in the females the scales are more persistent, remaining often till the fruit is ripe. Capsules seldom 2 lines long, glabrous, usually pedicellate, and but little tapering at the top.

In moist or marshy places, all over Europe and Russian Asia, except the extreme north, and much cultivated for basket-making. Frequent in parts of England, Scotland, and Ireland. Fl. spring.

5. S. purpurea, Linn. (fig. 922). Purple W.-A slirnb, decnmbent at the base, or a small tree; the branches twiggy, glabrous, yellow, green or purple. Leaves usually long and narrow, varying to oblong, green and glabrous above, usually whitish or slightly silky underneath. Catkins appearing before the leaves, the males at least closely sessile along the twigs, with only very small bracts at the base, narrow-cylindrical but closely packed, seldom an inch long when in flower, shortly silky; the scales sbort, obtuse, and tipped with purple. Stamens united into an entire filament with a double anther, or the filament forked, with an anther on each branch. Capsules cottony-white, 1 to $1 \frac{1}{2}$ lines long, usually sessile, and very obtuse. The female catkins, especially when in fruit, are sometimes shortly stalked, with a few leafy bracts at their base.

In marshy places, and on river-banks, in temperate and sonthern Furope, extending across Asia; some varieties cultivated as Osiers. 
Spread over England, Ireland, and southern Scotland, but a doubtful native. Fl. early spring. The broader-leaved varieties, commonly designated as S. purpurea or S. Helix, Linn., appear to be the most common, the narrower-leaved $S$. rubra, Huds., chiefly cultivated.

6. S. viminalis, Linn. (fig. 923). Osier.-A shrub, with long, twiggy branches, nsually slightly downy, sometimes growing into a small tree. Leaves long and narrow, often 4 or 5 inches, of a silvery white underneath, with the silky down more copions than in any other long-leaved species. Catkins cylindrical, sessile or nearly so, with a few bracts at the base, an inch long or rather more, with rather long, silky hairs. Stamens 2, as in all the following species. Capsnles downy, about 2 lines long, tapering towards the top.

In wet places, throughout Europe and Russian Asia, except the extreme north, and the most commonly cultivated Osier. Frequent in Britain. Fl. spring. S. Smithiana, Willd., or S. mollissima, Sm., is a broader-leaved variety [or hybrid with Caprea], with the capsules more distinctly pedicellate.

7. S. Caprea, Linn. (fig. 921). Sallow.-A tall shrub or bushy tree. Leaves ovate or oblong, often rather large, seldom tapering at the top, either narrow, rounded, or broadly cordate at the base, usually of a greyish green, more or less wrinkled, and whitish nnderneath with a short crisp down not silky, entire or toothed, especially when old. Stipules usually conspicuous, broad and oblique. Catkins sessile, the males usually closely so, with a few broad, scale-like bracts at the base, oblong-cylindrical, an inch long or rather more, and very silky-hairy; the females not quite so close; the bracts often more leafy, and when in fruit 2 inches long or more. Capsules downy-white, pedicellate, 3 or 4 lines long, tapering into a long beak.

In woods, thickets, and hedges, along streams, \&c., thronghont Europe and temperate Asia to the Arctic Circle. Common in Britain. Fl. early spring. It varies very much in the size and shape of the leaves, the amount of down, \&c., but it is generally distingnished from all the preceding species by the cottony, not silky down, and wrinkled leaves, from most of the following by its larger size. The grey Sallow (S. cinerea, Linn.) is distinguished by some as being more downy, by others as less so, with the leaves nsually smaller, and the catkins not quite so thick and silky.

8. S. aurita, Linn. (fig. 925). Round-eared W.-Allied to S. Caprea and perhaps a variety, but more bushy; the leaves smaller, usually obovate, about an inch long, but varying from orbicular to oblong, and then often 2 inches long; they are also more wrinkled than in $S$. Caprea, waved on the edges, grey and downy, especially on the under side; the stipules very conspicnons. Male catkins closely sessile, but smaller than in $S$. Caprea, and the silky hairs less prominent; the females about half an inch long when in flower, an inch when in fruit, on a short stalk, with small leafy bracts. Capscles pedicellate, 2 to 3 lines long, tapering at the top.

In woods and thickets, in Europe and Russian Asia, from the Mediter. ranean to the Arctic regious. Common in Britain. Fl. carly spring.

9. S. phylicifolia, Linn. (fig. 926). Tca-leaved W.-A bushy shrub, very variable in its folliage, some of the larger forms coming very near S. Caprea, whilst the smaller ones appear to pass gradually into $S$. $M y$ m. 
sinites. Young shoots and leaves often downy, when old usually glabrous. Leaves ovate-oblong or rarely lanceolate, usually 1 to 2 inches long, and pointed, not wrinkled, but the veins rather prominent above, often toothed at the edge, and glaucous or whitish underneath, but not closely silky. Catkins more slender and less silky than in $S$. Caprea, the males nearly sessile, with a few broad, or sometimes leafy, bracts at the base; the females more stalked, with the bracts more leafy, usually under an inch long when in flower, 1 to 2 inches when in fruit. Capsules shortly stalked, glabrous or silky or cottony, 2 to 3 lines long when ripe.

In woods, thickets, and waste places, near streams, in northern and Arctic Europe and Asia, and in the mountain districts of central and southern Europe. In Britain, chiefly in northern England, in Scotland, and northern Ireland. Fl. spring and carly summer. Among the numerous varieties published as species, often from spccimens altered by cultivation, two are generally recognised as distinct types, S. nigricans, Sm., which turns black in drying and is usually larger, and $S$. phylicifolia, which preserves its colour better and has usually a smaller and neater foliage.

10. S. repens, Linn. (fig. 927). Creeping.-A low straggling shrub; the stems creeping extensively underground and roting at the base, ascending to the height of about a foot or more, erect and taller when cultivated in rich soils; the foliage and young shoots more or less densely silky-white. Leaves oblong or lanceolate, under an inch long, rarely shortly ovate, or in luxuriant shoots narrow-oblong, and $1 \frac{1}{2}$ inches long, usually entire or nearly so, and silky on both sides. Catkins cylindrical, usually about 6 lines long, and sessile when in flower, with a few leafy bracts at the base; when in fruit the peduncle lengthens, and the catkin often attains an inch. Capsules pedicellate, usually silky, seldom 2 lines long.

On heaths, moors, and sandy places, in Arctic, northern, and central Europe, and Russian Asia, more rare in southern Europe. Common in Britain. Fl. sping. Varieties rather less creeping, with the leaves somewhat wrinkled, and the white down rather more cottony, distinguished under the name of $S$. ambigua, Elirh., showing in some respects a connection between $S$. aurita and S. repens, are asserted by German botanists to be accidental hybrids between those two species.

11. S. lapponum, Linn. (fig. 928). Downy W.-A spreading, much branched shrub, usually low and scrubby, sometimes attaining 2 or 3 feet or more in rich valleys. Leaves oblong or lanceolate, pointed, and entire, covered on both sides with a white cottony down, or, when old, becoming nearly glabrous above. Catkins closely sessile, with a few deciduous bracts at their base ; when in flower about an inch long, thick, with long dense silky hairs; when in fruit lengthening to $1 \frac{1}{2}$ or 2 inches. Capsules sessile, cottony, about 2 lines long.

In monntains, pastures, and wet, bushy places, in northern and Arctic Europe, and Asia, and in the mountains of central Europe. In Britain, only in the mountains of Scotland. El. summer. It varies much in sta. ture and the size of the leaves, but is always distinguished from $S$. repens by the stem not creeping underground, and the much larger catkins, more like those of $S$. Caprea, and from the latter species by the entire leaves and sessile capsules, 
12. S. lanata, Linn. (fig. 929). Wooly W.-A stont, much branched shrub, attaining abont 2 feet in height, allied to $S$. Lapponum, but the leaves are usually ovate, covered on both sides with a thick, soft, silky wool, and the catkins longer, clothed with dense, long, silky hairs, of a fine golden yellow; in fruit near 3 inches in length. Capsules sessile, cottony, tapering at the top, more than three lines long.

A high northern and Arctic species, both in Europe and Asia. In Britain, confined to a few rocky alpine glens in Scotland. Fl. early summer. [S. Sadleri, Syme, a dwarf species referred in former editions to $S$. Myrsinites, is confined to a single spot in the mountains of Forfarshire, and is believed to be a starved extipulate form of $S$. lanata.]

13. S. Myrsinites, Linn. (fig. 930). Whortle W.-A low, scraggy, much branched shrub, sometimes closely procumbent, though not creeping underground, sometimes rising to the height of a foot or more. Leaves small, orbicular, ovate or lanceolate, bright green, with prominent veins, and finely toothed; usually with long, silky hairs when young, becoming glabrous when old. Catkins loosely cylindrical, $\frac{1}{2}$ to 1 inch long in flower, $1 \frac{1}{2}$ to 2 inches when in fruit, always borne on short, leafy shoots or peduncles. Capsules nearly sessile, about 2 lines long, more or less hairy.

In the mountains of northern, central, and Arctic Europe and Asia. In Britain, only on the mountains of mid-Scotland and of Sligo in Ireland. Fl. early summer. Under the name of S. Arbuscula, Linn., the British Floras include several plants which appear to be either varieties of S. Myrsinites, of rather larger growth, with short peduncles to the catkins, and the leaves rather glaucous underneath, or perhaps smallleaved varieties of $S$. phylicifolia, showing in their more toothed leaves and more leafy peduncles an approach to S. Myrsinites. [S. Arbuscula, Linn., is a generally admitted species, a native of the Scotch mountains, differing from $S$. Myrsinites, in the leaves shining above and pale or glaucous beneath. It has many forms.]

[S. Grahami, Borr., a Sutherland plant, only known from female specimens introduced into the Edinburgh Botanical Gardens, appears to me to be a form of S. Myrsinites, with smaller catkins, paler scales, and a glabrous capsule on a silky pedicel. A similar plant has been found in Donegal.]

14. S. reticulata, Linn. (fig. 931). Reticulate W.-A prostrate, much branched shrub, often spreading, but not rising above 5 or 6 inches from the ground; the branches glabrous or hairy when young. Leaves obovate or orbicular, quite entire, $\$$ to 1 inch long and broad, green, glabrous, and much wrinkled above, white underneath. Catkins on rather long, leafless peduncles, at the ends of short branches, opposite to the last leaf; both males and females cylindrical, $\frac{1}{2}$ to 1 inch long, shortly downy but not silky-hairy. Capsules cottony, about $1 \frac{1}{2}$ lines long.

In the mountains of northern, Arctic, and central Europe, nortb Asia, and America. In Britain, confined to the loftiest Scotch mountains. Fl. summer.

15. S. herbacea, Linn. (fig. 932). Dwarf W.-The smallest of British shrubs, the half-underground stems creeping and rooting sometimes to a considerable extent, the branches seldom rising above 2 inches from the gronnd. Leaves obovate or orbicular, above half an 
Inch long, finely crenated, green, glabrous, and veined like those of S. Myrsinites, or sometimes slightly silky-hairy when young. Catkins very small, ovold, and few.flowered, on very short, leafless peduncles, or almost sessile, opposite the last leaf of the young shoots. In fruit they sometimes attain half an inch. Capsules nearly glabrous, fully 2 lines long.

In alpine pastures, in northern and Arctic Europe and Asia, and in the Alps and Pyrenees. Common at high elevations in the mountains of Scotland, northern England, North Wales, and Ireland. Fl. nummer.

\section{POPULUS. POPLAR.}

Leaves usually broadly triangular or cearly orbicular, on slender stalks, the scales of the leaf-buds often covered with a resinous varnish. Catkins cylindrical, usually silky-hairy, the scales irregularly toothed or lobed at the top. Perianth (or inner united scales) a small, flat, oblique cup. Stamens in the males from about 8 to near 30, with slender filaments and small anthers. Ovary in the females 1-celled, with several ovules inserted on short, parietal placentas. Styles 2, with deeply forked stigmas. Fruit a capsule, opening in 2 valves. Seeds several, minute, with a tuft of long, silky hairs.

A small genus, confined to the temperate regions of the northern hemisphere, very near the Willows in flowers and fruit, but distinct in habit and foliage, and in the presence of an apparent perianth.

Under slde of the leaves and young shoots very white and cottony 1. P. alba. Unter side of the leaves green and glabrous.

Leaves ovate-triangular, tapcring at the top, with small, regular

teeth
Leaves smali, orblcular or rhomboidal, irregularly and rather coarsely toothed

3. P. nigra.

2. P. tremula.

The Tacamahae or balsam Poplar (P. balsamifera), the Carolina Poplar $(P$. angulata), and other North American species, are of ten planted.

1. P. alba, Linn. (fig. 933). White P., A bele.-A tall and handsome tree, with a light-grey or ash-coloured bark, the young shoots, as well as the under side of the full-grown leaves, covered with a close, very white cotton. Leaves orbicular or very broadly ovate, irregularly sinuate or shortly lobed, more or less cordate at the base. Catkins sessile, about 2 inches long, the membranous scales jagged at the top, very deciduous, hairy in the males, less so in the females. Stamens usually about 8 . Loves of the stigmas linear.

Along streams,-antd in open, moist woods, dispersed over central and southern Europe and temperate Asia. In Britain, very generally planted, and probably also indigenous. $\quad F l$. spring. $P$. canescens is a variety [or hybrid with $P$. trcmula] with rather smaller leaves, seldom lobed, and not so white.

2. P. tremula, Linn. (fig. 934). Aspen.-A smaller tree than our two other Poplars, of slower growth, the branches more slender. Leaves nearly orblcular, like those of $P$. alba, but smaller, often not an inch broad, less deeply toothed, scarcely cordate, of a thinner texture, without any white cotton, although sometimes very pale underneath; the leafstalks particularly slender, so that the blade trembles with the dightest motion of the air. Catkins much smaller than in $P$. alba, the 
scales as well as the stigmas more deeply divided. Stamens usually 6 to 8.

In woods and forests, thronghout Europe and Russian Asia, from the Mediterranean to the Arctic Circle. In Britaln, apparently more frequent in Scotland and Ireland than in England. Fl. early spring.

3. P. nigra, Linn. (fig. 935). Black or Italian P.-A tall, quick-growing tree, readily assuming a somewhat pyramidal form, quite glabrous, with very glutinons buds. Leaves broadly rhomboidal or nearly triangular, tapering at the top, the lower angles rounded, the edge crenated or serrated, green on both sides. Catkins loose, about 2 inches long, the scales hairy only at the tips. Stamens more numerous than in $P$. $a l b a$ and $P$. tremula, and the lobes of the stigmas shorter and broader.

In moist places, the borders of streams, \&c., in central and southern Europe, and temperate Russiar Asia. In northern Europe it has been much planted, and is now common in Scandinavia as well as in Britain, but it is not indigenous in England. Fl. early spring. The Lombardy Poplar is a cultivated variety ( $P$. fastigiata), of Eastern origin.

\section{CONIFERE. THE PINE FAMILY.}

Trees or shrubs, mostly with resinous juice. Leaves stiff, and in the European genera always entire, either subulate or linear, or short and scale-like. Flowers monœcious or diœcious, in cylindrical or short catkins, with closely-packed scales, or the females rarely solitary. Stamens inserted either on the axis of the catkin within the scales, or the anther-cells sessile on the inside of the scales themselves, which then form a part of the stamens. Ovules and seeds naked, that is, without ovary, style, or pericarp, either inserted within the catkin. scales, or solitary and quite exposed.

An extensive Order, spread over the whole globe, although within the troplcs chiefly confined to mountainous districts. In the northern hemisphere Conifers often form vast forests, and include some of the loftiest trees known. A large number of exotic species are generally planted, and some to such an extent as to cover large tracts of country. The very pecnliar structure of the flowers and the seeds of this and the adjoining small family of Cycadea, has referred them to a separate class (Gymnosperms) distinct both from Dicotyledons and Monocotyledons.

Male catkins cylindrical, with 2 anther-cells to each scale. Fruit a dry cone, with 2 winged seeds within each scale

Male catkins small, with 4 anther-cells to each scale. Fruit small and succulent, containing 2 or 3 hard seeds .

1. Pinus.

Male catkins small, wlth 3 to 8 anther-cells to each of the upper scales. Fruit a single seed, half-immersed in a succulent cup .

2. JUNIPRRUS.

3. TAXUB.

The most commonly planted Coniferce, not belonging to the above genera, are species of Cypress, resembling Junipers in foliage and male Howers, but the fruit is larger and woody, with few or many small 
seeds; or of Thuia, very near Cypress, but with flattened branches, and small, ovate, dry cones, with few seeds; or of Taxodium, with deciduous leaves, and a small cone near that of Cypress; besides the Sequoias (including the Wellingtonia) of California, Cryptomeria from Japan, Araucaria of Chili, Cedars of Lebanon and India (Deodara), anc others.

\section{PINUS. PINE.}

Trees, with linear or subulate leaves. Male catkins closely imbricated, with 2 adnate anther-cells on the inside of each scale (at least apparcntly so, for in fact the scale is the connectivum of the anther, and the whole catkin thus consists of nothing but closely imbricated anthers). Female catkins short, consisting of closely imbricated scales, with 2 ovules on the inside of each; the foramen, or open pore at the top of the ovule, turned downwards. Fruit a cone, consisting of more or less hardened, imbricated scales, each one covering 2 winged seeds.

A large genus, constituting the great mass of the Coniferce of the northern hemisphere, scarcely penetrating into the tropics, and nnknown in the southern hemisphere.

The cultivated species are very numerous, belonging to four principal sections or genera, viz.:-1. The true Pines, with subulate evergreen leaves, in clusters of 2,3 , or 5 , and hard cones with persistent scales, including, besides the Scotch $P$., the Pinaster or maritime $P$., the Weymouth P., the Roman P., \&c. 2. The Spruces (Picea), with shorter, flattened or angular leaves, arranged singly and often in two opposite ranks, and with thin persistent scales to the pendulons cones, including the common or Norway Spruce, now almost naturalised in Britain, the Hemlock Spruce, and the Douglas Fir, \&c.-3. The Firs (Abics), with flattened leaves and large erect cones with deciduous scales, as the silver Fir. 4. The Larches (Larix), with short, fine, deciduous leaves, in dense clusters, and small erect cones with thin persistent scales; and 5. The Cedars of Lebanon, and Deodara (Ccdrus), with short, evergreen, subulate leaves, clustered as in Larix, and large, erect, hard closely packed cones with deciduous scales. [The so-called "Scotch Fir" is no Fir, but a Pine p:oper.]

1. P. sylvestris, linn. (fig. 936). Scolch, Norway, or Riga.-A tree of considerable size; the main trunk simple or forked, with a reddish bark, and a rather dense head, but less so than in many other species. Leaves stiffly subulate, evergreen, seldom above 2 inches long, in pairs, sheathed by short, scarious scales. Cones sessile, ovoid, conical, recurved when young; the scales hard and woody, much thickened upwards, with a short, thick point, often turned backwards in the lower scales of one side of the cone, but generally disappearing as the cone ripens. Seeds with an obliquely lanceolate, obtuse wing, 2 or 3 times as long as the seed itself.

Widely distributed over northern and central Europe and Russian Asia, chiefly in granitic or sandy soils, and in the mountains of southern Furope and the Caucasus. Indigenous in the Scotch Highlands, and formerly in Ireland; planted all over Britain, and quite naturalised. R. spring. 


\section{JUNIPERUS. JUNIPIFR.}

Shrubs or small trees, with evergreen leaves, either small and scalelike, or spreading, stiff, and pointed, or both kinds on the same shrub. Flowers usually dicecious, in minute axillary catkins; the males consisting of broad, shield-shaped scales, with 3 to 6 anther-cells attached to their lower edge, the females with imbricated, empty scales at the base, and 3 to 6 fleshy ones at the top, coalescing into one, and enclosing as many ovules, with their foramen os open pore turned upwards. Fruit a small berry, formed by the succulent scales, enclosing 1 or 2 hard seeds.

A numerous genus, almost as widely spread as the $P$ ines.

1. J. communis, Linn. (fig. 937). Common J.-A much branched, evergreen shrub, sometimes procumbent, sometimes ascending or erect, 2 to 5 , or even 20 feet high. Leaves in whorls of 3 , linear, spreading, ending in a prickly point, not above 6 lines long, of a bright green underneath, glaucous and concave above. Catkins scarcely above a line long. Berries globular, of a dark purple blue, the size of a large pea.

On rather dry, barren hills, in Europe, from the Mediterranean to the Arctio regions, and in northern Asia and America. Dispersed over the British Isles, but more common in the north than in the south. Fl. spring. A dwarf variety, occurring on the mountains of North Wales, Westmoreland, and in Scotland, with rather shorter, less prickly leaves, is the J. nana, Willd.

The cultivated species include, amongst others, the American red or pencil Cedar (J. virginiana, Linn.), and the south Kuropean Savin ( $J$. Sabina, Linn.).

\section{TAXUS. YEW.}

Trees or shrubs, with evergreen linear leaves. Flowers mostly dicecions. Catkins small, with empty, imbricated scales at the tase; the males terminating in a cluster of stamens, each consisting of 3 to 8 anther-cells, within a shield-like scale or connectivam; the females of a single erect ovule, with a small cup-shaped disk round its base. Fruit a hard seed, partly imbedded in a pulpy, berry-like cup.

A small genus, extending all round the northern hemisphere.

1. T. baccata, Linn. (fig. 938). Common Yew.-A densely branched, dark, evergreen tree, not lofty, but attaining a great age, with a thick trunk and hard wood. Leaves 6 to 9 lines long, inserted all round the branches, but spreading in one plane in 2 opposite ranks, convex and shining on the npper side. Catkins very small, in the axils of the leaves. Fruits, though small, conspicuous by their bright red, half-transparent, juicy cups.

Dispersed over Europe, north and central Asia, and North America. Common in Britain, having been much planted in early times; indigenous in hilly districts in England, southern Scotland, and northern Ireland. Fl. spring. The Irish or Florence-Court Yew ( $T$. fastigiata), a shrub with erect branches, is a garden variety of $T$. baccata. 


\section{Class II. MONOCOTYLEDONS.}

Stem not distinguishable into pith, wood, and bark, but consisting of bundles of fibres, irregularly imbedded in cellular tissue, and in woody species a firmly adherent rind outside. Seeds with one cotyledon, the embryo undivided, the young stem being developed from a sheath-like cavity on one side.

Besides the above positive characters, Monocotyledons may be generally known by their simple, entire, alternate or radical leaves, with simple parallel veins, the base usually encircling or sheathing the stem or the base of the next leaf; and the parts of the flower are most frequently in threes, the calyx and corolla, when present, being generally similar in appearance, forming a single perianth of 6 parts. In several families, however, the perianth is entirely wanting, or reduced to a very few small scales ; in Aroidece, in Tamus, and Paris, the leaves are somewhat netted-veined; and in some Naiadece, and in Puris, and some Convallarias, they are opposite or whorled.

\section{TYPHACE\&. THE REEDMACE FAMILY.}

Reed-like marsh or aquatic herbs, with long, linear leaves. Flowers monceious, in dense spikes or globular clusters, without any perianth. Ovary tapering into a slender simple style. Fruit a small, seed-like nut, with a single pendulous seed. Embryo straight, in a copious albumen.

\section{A family limited to the two British genera}

Klowers in long, dense, cylindrical splkes.

Flowers in distinct globular heads

1. TYPHA.

2. SPARGANIUM.

\section{TYPHA. REEDMACE.}

Flowers in a long, very dense, cylindrical and simple spike, terminating the stem, the upper part consisting of stamens only, intermixed with hairs, the lower part more dense, with minute ovaries, surrounded by numerous hairs. Nuts very small, enveloped in a copious down.

A small genus, spread over the greater part of the globe.

Male flowers close above the females, In an uninterrupted spike 1. $\boldsymbol{T}$. latifolia. Male and female parts of the spike separated by a short interval without flowers

2. T. angustifolia.

1. T. latifolia, Linn. (fig. 939). Great R., Cat's.taih-Rootstock shortly creeping, with erect, reed-like stems, 3 to 6 feet high. Leaves very long, erect and linear, sheathing at the base, but flat in the greater part of their length. Flowers in a continuous spike, often more than a foot long, the upper male portion rather thicker when in flower, yellow with the very numerous, closely packed, linear anthers; the minute ovaries of the lower part as closely packed, and enveloged in 
tufts of soft, brownish hairs. When in fruit, the npper part of the spike is a bare stalk, whilst the lower part has thickened by the enlargement of the nuts, still enveloped in the rusty down.

On the margins of ponds, lakes, and watery ditches, nearly all over the north temperate zone. Abundant in Britain. Flo summer. [Often, but erroneously, called Bull-rush.]

2. T. angustifolia, Linn. (fig. 940). Lesser $R$.-Differs from $T$. latifolia chiefly in the interruption in the spike between the male and the female flowers, for a space varying from a few lines to an inch in length. It is also usually smaller, with narrower and stiffer leaves, more concave on the upper side, and the spikes are more slender, but all these characters are very variable.

Accompanies $T$. latifolia over the greater part of its area, but is not so common, and scarcely extends so far north. In Britain, it occurs locally from Fife and Lanark sonthwards, and rarely in east Ireland. Il. summer.

\section{SPARGANIUM. SPARGANIUM.}

Flowers in globular heads, placed at a distance from each other along the summit of the stem, with leaf-like bracts under the lower ones. Upper heads all males, consisting of stamens with minute scales irregularly interposed; the lower heads larger, all females, consisting of sessile ovaries, each one surrounded by 3 to 6 scales, forming an irregular perianth.

A small genus, dispersed over the northern hemisphere without the tropics.

Inflorescence branched, each branch bearing more than one head. 1. S. ramosum. Inflorescence simple.

Stems and leaves erect . . . . . . . . 2 S. simplex.

Stem weak. Leaves floating : : : . : : 3. S. minimum.

1. S. ramosum, Huds. (fig. 941). Branched S., Bur-reed.-Stems erect, simple or branched, 2 feet high or more, sheathed below by the long, linear leaves, which usually far surpass the inflorescences. These form a kind of panicle at the summit of the stem, with 3 or 4 to 6 or 8 simple branches, each bearing 6 to 12 or even more male heads, about the size of a pea till the stamens expand, when they are about 4 lines in diameter; the lower female heads are fully 6 lines in diameter, glabrous, with the long linear points of the stigmas very prominent.

On the margins of ponds, lakes, and streams, almost all over Enrope and Russian Asia, and a portion of North America, bnt scarcely reaching the Arctic Circle. Extends all over Britain. $F l$ summer.

2. S. simplex, Huds. (fig. 942). Simple S.-Rather smaller than $S$. ramosum, with narrow leaves ; the flower-heads mnch fewer, at considerable distances from each other along the simple summit of the stem; all sessile except the lowest female, which is often on a peduncle of 1 to 2 inches. Flowers as in $S$. ramosum.

In similar situations, and nearly as widely tistributed as $S$. ramosum, but not quite so common. Not unfrequent in Britain. Bl. summer. A floating variety, S. natans, Linn., found occasionally, but rarely, in deeper water, has the weak stems and long floating leaves nearly of $\dot{S}$. minimum. 
It is a larger plant, and has the long styles or points of the fruit of $\boldsymbol{S}$. simplex.

3. S. minimum, Fries. (fig. 943). Small S.-An aquatic plant; the weak stems ascending to the surface of the water on which the long, narrow leaves float. Flower-heads very few, with long, linear bracts ; the 2 or 3 lowest ones female, and often shortly stalked. Fruiting heads smaller than in the last two species, and the styles or points to the fruits very much shorter.

In lakes and pools, in northern Europe, Asia and America; and is the high mountains of southern Europe and central Asia. In Britain, more frequent in Scotland than in England; unknown in Ireland. $F$ summer. [S. minimum is usually regarded as a slender variety of $S$. natans, Linn., with the lower leaf sheaths not inflated, few male flower. heads, and obovoid fruits; the true $S$. nalans ( $S$. affine, Schn.) has inflated sheaths, several male flower-heads, and spindle-shaped drupes Both are British.]

\section{AROIDER. THE ARUM FAMILY.}

Herbs, with the rootstock often tuberous but not bulbous; the veins of the leaves sometimes branched or even netted, almost as in Dicotyledons. Flowers closely packed in a dense spike, called a spadix, with a leaf-like or coloured bract at the base, called a spatha. The stamens and ovaries in different parts of the spike or mixed together, without any periauth, or separated by small scales, which sometimes form a small, regular perianth. Ovary with 1 or several cells, each with 1 or more ovules. Fruit a berry. Seeds rarely without albumen.

A considerable family, chiefly from the tropical and warmer parts of the globe, where many acquire a considerable size, or climb up the stems of trees. The large spatha and broad leaves are at once characteristic of the majority of species; a few, however, come near to Typhacea in habit, but are distinguished usually by their succulent fruit, and in most cases by the seeds, or at least the ovules, not solitary.

Leaves broad. Spatha large . . . . . . . . 1. ARUM.

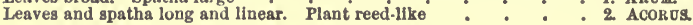

\section{ARUM. ARUM.}

Spatha large, convolute (the edges rolled over each other) at the base. No perianth. Pistils of female flowers at the base of the spike. Stamens or male flowers above them; the club-shaped summit of the axis without flowers. Berry with 1 or very few seeds.

A genus sometimes limited to a very few species, from Europe and temperate Asia.

1. A. maculatum, Linn. (fig. 944). Common A., Cuckoo-pint, Wake Robin, Lords-and-Ladies. - Rootstock an acrld, white tuber. Leaves on long, radical footstalks, ovate-hastate ; the lobes of the base straight or shortly diverging, of a dark, shining green, sometimes spotted with purple or marked with pale-whitish veins. Spatha 6 to 8 inches long, 
obliquely campanulate, tapering to a point at the top, the convolnte part contracted above the base. Spike balf concealed in the spatha, the club-shaped yellow or purplish top alone appearing above the convolute part. Berries bright red, in a short spike, on a naked peduncle, the leaves and spatha having died away before they are ripe.

In woods and thickets, nnder hedges, \&c., chiefly in central Europe, from northern Italy and Spain to sonthern Scandinavia. Frequent in England and Ireland, doubtfully wild in Scotland. Fl. spring. [The closely allied $A$. italicum, Miller, which occurs in several places on the south coast of England, differs in its greater size, longer spatbe, yellow spadix, larger berries, and in the leaves appearing in winter.]

\section{ACORUS. ACORUS.}

A single species, distinguished as a genns by the leaf-like spatha not enclosing the spike, and by the numerous hermaphrodite flowers consisting of a perianth of 6 short scales, 6 stamens, and a 2-or 3-celled ovary, all closely packed in a dense, cylindrical spike.

2. A. Calamus, Linn. (fig. 945). Sweet Flag, Sweet Sedge.-A highly aromatic, reed-like plant, with a thick, shortly creeping rootstock. Leaves linear and erect, 2 or 3 feet long, about half an inch broad. Flowering-stems simple and erect, the long, linear, leaf-like spatha forming a flattened continnation, with the spike sessile at its base so as to appear lateral ; it is cylindrical, very dense, 2 to 3 inches long, of a yellowish-green colonr.

On the edges of lakes and streams, all over the north temperate zone. In Britain, believed to be indigenous only in some of the eastern connties of England, but has been introduced elsewhere, and in Ireland and Scotland. Fl. summer.

\section{LEMNACEA. THE DUCKWEED FAMILY.}

A single genus, united by some with Aroidece, but anomalous in its mode of vegetation and very reduced flowers.

\section{LEMNA. DUCKWEED.}

Floating plants, witbout distinct stems or real leaves, but consisting of small, leaf-like fronds, either separate or cobering two or three together by their edges, emitting in most species one or more fibres from their nnder surface into the water, and multiplying by similar fronds growing ont of their edges. Flowers very rare, appearing from a fissure in the edge or on the upper surface of the frond, and consisting of a minute membranous bract or spatha, enclosing 1 or 2 stamens, and a single 1-celled ovary, with 1 or more ovales, a sbort style, and no perianth.

A small, widely distributed genus.

Roots in clusters. Fronds above 8 lines diameter . . . . 4. L. polyr-kiza

Roots solitary.

Fronds very thin, oblong or narrowed one end (the young ones unualy projecting on osch side at right angles)

1. Is trisulos. 
Fronds broadly ovate, nnder 3 lines diameter.
Fronds rather thick, slightly convex underneath

Fronds very thick and convex underneath
Roots none. Fronds minnte, with the flowers on the upper surface.

1. I. trisulca, Iinn. (fig. 946). Ivy-leaved D.-Fronds very differently shaped from those of the othor species, and much thinner. They are usually near 6 lines long and about half that breadth, thin, narrow, and minutely toothed at one end, and ending in a little stalk at the other, with 2 young ones usually growing from opposite sides near the base, and a single root from underneath. Flowers of $L$. minor.

On ponds and still waters. One of the common species on the Continent, but less so in Britain, especially in the north. Fl. summer, but very rarely.

2. L. minor, Linn. (fig. 947). Lesser D.-Fronds nsually about 2 lines long, broadly ovate or orbicular, cohering 3 or 4 together, with 1 root under each but without any stalk, quite entire, and of a rather thick consistence. Ovary with a single ovule.

On ponds and still waters, throughout the range of the genus, and generally the commonest species, often covering the water to a great extent. Fl. summer, commencing early, and more found in that state than any other spccies. [The flowering patches may be discerned by their yellowish bue.]

3. I. gibba, Linn. (fig. 948). Gibbons D.-Fronds shaped like those of $L$. minor, but rather larger and much thicker, flat above, spongy, and almost hemispherical underneath, with a single root to each. Stamens 2. Ovary with 2 or more ovules.

With the station and range of $L$. minor it is everywhere less common. Local in England and Ireland, and rare in Scotland. Fl. summer, very rarely.

4. L. polyrrhiza, Linn. (fig. 949). Greater D.-Fronds larger than in any other species, attaining 3 or 4 lines diameter, broadly ovate or orbicular, rather thick, with a cluster of roots under each one. Flowers of L. gibba.

As widely dispersed as the other species, and rather more frequent than L. gibba, except in Scotland. The flowers have never been observed in Britain.

5. L. arrhiza, Linn. (fig. 950). Rootless D.-Fronds rather thick and swollen on the underside, but much smaller than in any other British species, only half a line long and rarely emitting any root. Anther solitary, globose, sessile. Ovary with a single ovule, the flower and fruit issuing from the upper surface, not from the edge of the frond as in the other species, on which account this one has been separated as a genus under the name of Wolfia.

On ponds and still waters, common in the warmer regions of Asia and Africa, and perhaps in South America, more rare in Europe. In Britain flowerless, and confined to the south-eastern countiea. F. summer. 


\section{NAIADEE. THE NAIAD FAMILY.}

Floating, or submerged or marsh plants; the leaves either sheathing at the base or accompanied by sheathing stipules, alternate or sometimes opposite. Flowers axillary, inconspicuous, solitary or spiked, often proceeding from a sheathing bract. Perianth none, or inferior and consisting of 4 or 6 small, scale-like segments. Stamens $1,2,4$ or 6 . Ovaries either of 2,4 , or 6 distinct carpels, each with a single ovule and a separate stigma, or single, with 1 ovule and 2 to 4 stigmas. Fruit consisting of $1,2,3,4$, or 6 seed-like nuts, each with one seed, without albumen.

An Order not numerous in species, but of very varions habit, abundantly diffused over all parts of the world, in the sea as well as in fresh waters.

Water-plants. Stems creeping in sand or mud under salt-water.

Leaves very long and linear. Flowers within the base of

long, linear bract, like the stem-leaves

Ovaries simple, with 1 style and 2 or 3 stigmas. Lonves opposite or whorled, and often toothed

Ovaries of 4 carpels, each with a separate stigma.

Flowers and carpels axillary and sessile. Lesves opposite, very slender.

Flowers usually 2, on an axillary peduncle. Carpels stalked, pear-shaped. Leaves alternate, very slender.

Fowers in pedunculate splkes or heads. Carpels sessile. Leaves alternate or rarely opposite .

Marsh-plants. Stems erect Leaves rush-like. Flowers in

1. ZosTERL.

2. NAIA8.

8. ZANNIOHELIA.

4. RUPPLA.

5. POTAMOGRTON.

spikes or racemes.

Flowers bracteate. Anthers long - . . . 6. SCHEUCHzRRIA Flowers ebracteate. Anthers short: : : : 7. TriglochiN.

\section{ZOSTERA. GRASS-WRACK.}

Marine herbs, the stem creeping and rooting in the sand or mnd, with long, grass-like, alternate leaves. Flowers enclosed in a sheath near the base of leaves similar to the others, but usually smaller. Within this sheath is an oblong or linear, thin, leaf-like peduncle, on one side of which are arranged in 2 rows a few sessile anthers, with 3 or 4 sessile or nearly sessile ovaries, tapering into a deeply 2 -cleft, linear style. Embryo split longitudinally, with a deep groove forming 2 valves, which fold over the long, curved, linear cotyledonar end.

A genus hitherto limited to the two British species.

Leaves seldom a foot long. Ripe seeds smooth . . . 2 Z. nana. Leaves usually more than a foot long. Ripe seeds furrowed $\quad:$ 1. Z. marina.

1. Z. marina, Linn. (fig. 951). Grass-wrack.-Creeping stems or rootstocks often very long and rather fleshy. Leaves varying from near a foot to several feet in length, and from 2 to 3 or 4 lines in breadth, with 3,5 , or even 7 more or less distinct parallel nerves. Flowering sheath near the base of the floral leaves, from 1 to $1 \frac{1}{2}$ or near 2 inches long. The flattened peduncle narrow-linear, and said to be always withont the horizontal appendages of $Z$. nana. Seeds oblong. marked by longitudingl furrows. 
Common near the sandy or muddy edges of the sea, in temperate regions of the world, usually at or below low-water mark, and often thrown up in great quantities by the tide. Abundant round the British Isles. Fl. summer, or, according to some, in spring only.

2. Z. nana, Roth. (fig. 952). Dwarf G.-Closely resembles the smaller forms of $Z$. marina, of which it may be a variety. The leaves are usually from a few inches to near a foot long, very narrow, with only 1 or rarely 3 distinct nerves; the flowering sheath about half an inch long, and the flattened peduncle inside has to every ovary a little transverse appendage or band. Seeds shorter than in Z. marina, perfectly smootb.

On sandy shores, nsually between high-and low-water marks, in various parts of the world. Common in western Europe, and has been found on several points of the British coasts. Flo summer and autumn. The seeds appear certainly distinct in the two species; the constancy of the other characters is doubtful. I have examined only the dwarf species in a living flowering state.

\section{NAIAS. NAIAD.}

Slender, branching, submerged plants, with linear, opposite or ternate, entire or toothed leaves, often crowded into whorls or clusters. Flowers small and sessile, often clustered with the branch-leaves in the axils, and diœcious or rarely monœcions; the males consisting of a single, nearly sessile anther, enclosed in 2 bracts; the females of a single ovary, sessile in the sheathing base of the leaf, with 2 to 4 subulate stigmas. Fruit a small, seed-like drupe Embryo straight.

A genus of few species, widely spread over a great part of the globe.

1. N. flexilis, Rostk. (fig. 953). Slender N.-Leaves narrow-linear, nsually in whorls of 3 , or sometimes opposite, often clustered in the axils, abont 6 or 8 lines long; the teeth few and very minute. Stigmas usually 5 , sometimes 4. Fruit oblong, about a line long.

A common North American species, observed in a few scattered localities in Europe, and found in Perthshire, Skye, and Connemara in Ireland. $\mathrm{Kl}$. summer.

[2. N. marina, Linn. (fig. 954). Holly-leaved N.-Stems with here and there toothed wings. Leaves opposite and ternate, linear, strongly spinular-serrate. Fruit ellipsoid, $f$ of an inch long.

Common in the tropical and some temperate regions of the old World. In Britain, found only in Hickling Broad, Norfolk. Fl. summer.

3. N. graminea, Del. (fig. 955). Grassy N.-Leaves in clusters at the nodes, narrowly linear, less than an inch long, serrulate. Stigmas 2. Fruit linear-oblong.

A native of stagnant waters in the hotter regions of Asia, which has been introduced into Italy, Austria, and Lancashire.]

\section{ZANNICHELLIA. HORNED PONDWEED.}

A genus limited to a single species; differing from the narrow-leaved Potamogetons by the monqecious flowers sessile in the axils and without 
perianth, from Ruppia in the usually opposite leaves, in the single stamen, and in the shape of the fruit.

1. Z. palustris, Linn. (fig. 956). Common Z.-Stems slender, branched and floating. Leaves finely. linear, bright green, 1 to 2 inches long, mostly opposite, with a small, sheathing, membranous stipule embracing the stem withinside. At the time of flowering there are usually about 4 oraries together, almost sessile within the stipule, each with a short style and a broad, disk-shaped stigma, and a solitary stamen with a slender filament in the same or in a separate axil; the anthers 2- or 4-celled. When ripe the carpels are 1 to $1 \frac{1}{2}$ lines long, sessile or shortly stalked, somewhat curved and flattened, tipjed by the remains of the style; the ribs on the back often crenated, warted, or slightly winged.

In ponds, or lagoons of fresh, or brackish or even salt water; dispersed over a great part of the globe. Common in Britain. Fl. the whole summer.

[There are four well-marked forms of this.

a. Z. palustris proper. Stamens long; anther 4-celled. Carpels 2-4, sessile, style half as long, stigma small.

b. Z. brachystemon, Gay. Stamens short; anther 2-celled. Carpels 2-4, subsessile, their bracts crenated; stigma large.

c. Z. pedunculata, Reichb. Stamens short; anther 2-celled. Carpels pedicelled, their backs muricate; stigma large.

d. Z. polycarpa, Nolte. Stamens very short ; anther 2-celled. Carpels 1-6, subsessile, their backs smooth; stigma large.]

\section{RUPPIA. RUPPIA.}

A single species, distinguished from Zannichellia by the alternate leaves, 2 sessile anthers, and the ripe carpels all stalked and ovoid.

1. R. maritima, Linn. (fig. 957). Sea R.-A slender, branched, floating plant, much resembling Potamogeton pectinatus. Leaves almost capillary, with a sheathing base. Peduncles axillary, at first very short, bearing 1 or 2 flowers, each consisting of 2 almost sessile anthers, with 2 distinct cells, and 4 carpels, at first nearly sessile. As the fruit ripens, the carpels become little, obliquely pointed nuts, 1 to $1 \frac{1}{2}$ lines long, on pedicels from 2 or 3 lines to an inch in length, the common peduncle often becoming spirally coiled, and also lengthening.

In salt marshes, lagoons, and shallow creeks and bays, dispersed over nearly the whole globe. Common round the British Isles. Fl. summer and autumn. [There are two British forms usually regarded as species.

a. $R$. maritima proper. Sheaths inflated. Fruiting peduncles spiral.

b. $R$. rostellata, Koch. Sheaths not inflated. Fruiting peduncles short, flexuous. Nut beaked, gibbons.]

\section{POTAMOGETON. PONDWEED.}

Aquatic herbs, with a perennial rootstock, long, floating, usually forked stems, and alternate or rarely opposite leaves, either dilated and sheathing at the base, or having all or some of them a sheathing, scarioụs stipule in their axil. Flowęrs small, sessile in a spike or head 
on an axillary peduncle rising above the water. Perianth of 4 scale. like segments. Stamens 4, opposite the segments; the anthers sessile and 2-celled. Capsules 4, each with a very short style or a sessile stigma. Nuts small and seed-like, sessile, usually laterally compressed. Seed much curved or almost coiled round an obovoid projection of the endocarp.

A considerable genus, most of the species spread over the greater part of the globe, chiefly in fresh water, but some accommodating themselves also to salt water, and many of them very variable in foliage. In the species with axillary stipules, these are sometimes only to be seen nnder the peduncles or under the branches of the stem.

Upper leaves on long stalks, floating on the surface of the water.

Lower submerged leaves stalked or reduced to mere leat. stalks

Lower submerged leaves sessile or nearly so.

Lower aubmerged leaves linear, 1-nerved or slightly 3 .

Lowers submerged leaves lanceolate, with 5 , 7 , or more nerves.

All the leaves under water and sesille.

Leaves all opposite

Leaves alternate, except under the peduncles or forks.

Leaves broadly ovate, clasping the stem all round

Leaves ovate-lanceolate or oblong, broad at the base and clasping the stem

Leaves lanceolate or linear, tapering at the base, or not atem-clasping.

Leaves broadly linear or lanceolate, flat and entlre, with

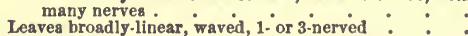

1. P. natans.

Leaves narrow-linear, not waved, 1- or 3-nerved.

Leaves not dilated at the base, with a scarious stipule in most axils.

Leaves 1 to 2 lines broad. Nuts 1 llnes long.

Leaves obtuse or Bcarcely acute. Splkes usually 1

inch long . Leaves very acute. "Spikes short and few-fiowered : Leaves under 1 line broad. Nuts under 1 line long
eaves dilated at the base into a sheath, scarious at the

Leaves dilated at the base into a sheath, scarious at the
edges .

2. P. heterophyllus.

8. P. lucens.

7. P. denors.

ס. P. perfoliatus.

4. P. pralongus.

8. P. lucens.

6. P. crispus.

8. P. obtusifolius.

9. $P$. acutifolius.

10. P. pusillus.

11. P. pectinatus.

[The Potamogetons, like so many water plants, are very difficult of discrimination, and nearly thirty species are enumerated in the London Catalogue of 1886 as British, many of them distinguished by very variable or minnte characters. I have been unable to reduce these satisfactorily to the leading types which Bentham has confined himself to describing.]

1. P. natans, Linn. (fig. 958). Broad P.-One of the largest of our Potamogetons. Leares stalked, the upper ones floating on the surface of the water, of a thick, opaque texture, ovate or oblong, 2 to 4 inches long by 1 to $1 \frac{1}{2}$ broad, usually rounded at the base but sometimes cordate or tapering, marked by several longitudinal nerves, with a few cross veins often branched or slightly netted; the submerged leaves thinner and narrower, but stalked like the floating ones or reduced to a mere stalk. Axillary stipules closely sheathing, often an inch long. Spike dense and cylindrical, often an Inch long or more, on a stout peduncle of several inches. Nuts ovold, above a line long, slightly com. 
pressed, nearly straight, the inner edge ronnded outwards, with 1 or sometimes 3 dorsal ribs.

In stagnant or running waters, deep or shallow, sunny or shaded, in almost all parts of the world, and varies accordingly in the size, shape, and texture of the foliage, the size and number of the flowers, fruit, \&c. Abundant in Britain. Fl. summer.

[This includes the true $P$. natans with coriaceous floating leaves, no true submerged ones, and keeled nnts; $P$. poylgonifolius, Pourr., with more membranous floating leaves, lanceolate submerged ones, and nuts with a rounded back; and $P$. plantagineus, $\mathrm{Du} \mathrm{Croz}$, with most of the leaves broader, and all submerged and translucent, and short broad obtuse stipnles.]

2. P. heterophyllus, Schreb. (fig. 959). Various-leaved $P$.-Usually much smaller than $P$. natans, which it resembles in the long stalk and the ovate or oblong shape of its floating leaves, but these are only 1 to 2 inches long, and the submerged leaves are all narrow-lanceolate or linear, with the few veins of $\boldsymbol{P}$. pusillus, tapering at both ends but not distinctly stalked. Spikes and fruits as in smaller forms of $P$. natans.

Chiefly a North American species, not common in Europe, where it appears to be rather a western plant. Occurs in many parts of Britain. $F l$. summer. Sometimes the floating leaves are not developed, and then it is scarcely to be distinguished from $P$. pusillus except by its larger size, with a denser spike, and generally a firmer consistence.

3. P. lucens, Linn. (fig. 960). Shining P.-A large species, the leaves usually all thin and under water, sessile or nearly so, tapering at both ends or scarcely obtuse, 2 or 3 to near 6 inches long, seldom above half an inch broad, marked with 2 or 3 well-defined longitudinal nerves on each side of the midrib, besides several intermediate fainter ones, and a few transverse reticulations. Flowers as in $P$. natans.

In ponds and rivers, usually rather deep, generally distributed over the globe, except the extreme north. Not uncommon in Britain. $F$. summer. $\boldsymbol{P}$. rufescens, Schrad., is a variety with the npper leaves floating on the surface and shortly stalked, either lanceolate or oblong, $\boldsymbol{P}$. lanceolatus, Sm., appears to be a smaller state. which is always to be distinguished from $P$. natans and $P$. heterophyllus by the sessile, many. nerved lower leaves.

[P. Lonchites, Tuckerm., is an American form lately found in the river Boyne, distinguished by its very long 7-9-nerved leaves.]

4. P. prælongus, Wulf. (fig. 961). Long P.-A large species, with the leaves all submerged and thin, with numerous longitudinal veins, and a few transverse reticulations, like $P$. hucens, but the leaves are broader, all closely sessile, and half clasping the stem by their rounded base, usually 3 or 4 inches long, obtuse at the tip, and concave, so as to split in drying. Stipules very prominent. Peduncles long and stont, with the flowers and acutely keeled fruits usually larger than in $P$. natans, in a rather close spike.

In pools and rivers of the north temperate zone. In Britain, not 80 common as $P$. lucens. Fh. summer.

P. perfoliatus, Linn.(fig. 962). Perfolvate P.-Leaves all submerged, thin and many-nerved as in $P$. proelongus and $P$. lucens, but much shorter, usually ovate, obtuse, completely clasping the stem; the auricles often enited on the opposite side. so that the leaf appears to be pierced 
through; from 1 to $1 \frac{1}{2}$ inches long by fully an inch broad. Stipules as in the preceding species, but soon disappearing. Spike of fiowers seldom above 6 or 8 lines long.

In rivers and ponds, all over the northern hemisphere, and in Australia, Generally distributed in Britain. $F l$. summer.

6. P. crispus, Linn. (fig. 963). Curly P.-One of the most marked of the alternate-leaved species. Leaves all submerged and thin, narrowoblong or broadly linear, obtuse, shortly tapering at the base, 1 to 2 inches long, 3 to 5 lines broad, always waved and sinuated on their edges, and marked by 1 strong midrib and 2 parallel slender nerves at some distance from it, but connected with it by a few transverse veins. Spikes small, consisting of about 3 to 6 flowers, at some distance from each other.

In ponds, streams, and ditches of the northern bemisphere, except the extreme north, and in Australia. Common in Britain. Fl. summer.

7. P. densus, Linn. (fig. 964). Opposite P.-Readily known by its numerous short leaves, all opposite, and arranged in 2 rows on the opposite sides of the stems; they are all submerged and thin, broadly lanceolate, 6 to 9 lines long, folded and clasping the stem at their base, with a strong midrib and 2 fainter parallel nerves, connected by a few transverse veins. Stipules only under the peduncles or branches. Pedun. cles very short, turned down after flowering, bearing a head of 2 or 3 flowers only. Ripe carpels rather large, rounded, and smooth.

In shallow pools, and ditches, of Europe, except the extreme north, temperate Asia and America. Common in Britain. Fl. summer.

8. P. obtusifolius, Mert. and Koch. (fig. 965). Obtuse P.-Stems slender. Leaves all submerged, alternate except under the branches, $1 \frac{1}{2}$ to 3 inches long, and 1 to 2 lines hroad, obtuse or scarcely acute, usually 3-nerved, with a very few transverse veins. Sheathing scarions stipules often persistent under the branches, but sometimes mostly fallen away. Peduncles not long. Spikes usially $\frac{1}{2}$ inch or rather longer, not very dense. Nuts broadly ovoid, about $1 \frac{1}{2}$ lines long, nearly smooth or with a prominent often rugose dorsal rib and straight beak. Seed much curved.

In pools, ditches, and still fresh waters, over a great part of the globe. Common in Britain. Fl. summer. The Linnean names P. gramineus and $P$. comprcssus have been so varionsly applied by their author and others, to this and the following species, and to some states of $P$. heteropkllus, that the names given by German botanists are now generally adopted.

9. P. acutifolius, Linn. (fig. 966). Acute P.-Very near P. obtusifolius, with the same habit and stipules. Leaves as in that species, narrow-linear, but semi-amplexicaul and very acute, with 1 prominent central nerve, and often 1 on each side not connected by transverse veins, bnt occasionally nnmerons exceedingly fine longitudinal ones may be seen nnder a lens. Splkes nsually shorter than in $P$. obtusifolius. Nuts the same, but with a recurved beak.

Appears to be as generally spread as $P$. obtusifolius, and perhaps more common in Britain. Fl. summer. Both this and the preceding species were included in early editions as robust varieties of $R$. pusillus.

[P. zosterifolius, Schum., is a very closely allied plant with broad almost winged stems, abruptly acuminate leaves, and 3-ribbed nuts.]

10. P. pusillug. Linp. (fig. 967). Slender P.-Distinguished from 
all the preceding species by the thread-like stems, and very narrow linear leaves like those of Zannichellia or Ruppia, and from the following by the scarious sheathing stipules, always observable in the axils of those leaves at least which are under the branches or peduncles. Leaves veined as in $\boldsymbol{P}$. pectinatus, 1 to 3 inches long and very seldom a line broad. Peduncles slender, with a short, close spike of small flowers. Nuts ovoid, under 1 line long, almost pointed, with a more or less strongly marked dorsal rib.

In pools, ditches, and still waters, fresh or salt, generally spread at least in the northern hemisphere. Common in Britain. Fl. summer.

[P. trichoides, Cham, and Schl, a European species found in the eastern counties of England and in Ireland, is a form with capillary stems, setaceous leaves, and very few flowers with solitary carpels.]

11. P. pectinatus, Linn. (fig. 968). Fennel P.-Stems thread-like, with very narrow, grass-like leaves, usually 2 or 3 inches long, most of them dilated at the base into a rather long sheath, which is scarious at the edge and often projecting at the top into 2 small scarions lobes (stipules adhering to the base of the leaf); the sheathing stipules of the other species either absent or very rare under the peduncles. The midrib of the leaf sometimes separates into longitudinal, netted veins, only visible when magnified, and there are usually 2 faint longitudinal nerves at some distance from it. Peduncles usually bearing several distant clusters of 2 or 3 flowers, forming a slender interrupted spike, rarely reduced to a single, small terminal cluster. Nuts as in P. pusillus.

In pools, ditches, and still waters, fresh or salt, almost all over the world. Generally distributed over Britain. Fl. summer.

$[P$. fliformis, Nolte, a widely distributed species, in the north and south hemispheres, has capillary leaves, flowers in whorls, and much larger nuts. It is not uncommon in Scotland, and has also been found in Anglesea and Ireland.]

\section{SCHEUCHZERIA. SCHEUCHZERIA.}

Frect marsh plant with few linear leaves, and a short, loose terminal raceme. Perianth-segments 6 , small and equal, with an anther sessile at the base of each one. Carpels 3 to 6, each containing 1 or 2 seeds, and opening Inwards by longitudinal slits.

The genus is limited to the single British species, nearly related to Triglochin, and with it forming the distinct tribe of Juncaginece, by some regarded as a separate family.

1. S. palustris, Linn. (fig. 969.) Marsh S.-A rush-like perennial, with a creeping rootstock, and an erect stem about a foot high. Leaves few, linear, sheathing at the base, then narrowed, and nearly cylindrical; the lower ones often longer than the stem; the upper ones passing into short, sheathing floral bracts. Flowers few, rather small, on pedicels sbout 6 lines long, forming a short, loose terminal raceme Perianth slightly coloured, of 6 spreading or reflexed segments Stamens 6 . Carpels 3, rarely 4 to 6 , nearly 3 lines diameter when ripe, opening by a longitudinal slit, and containing 1 or 2 seeds.

In bogs and peaty marshes, in northern and Arctic Europe, Russian 
Asia, and North America, and here and there in the mountains of central Europe. In Britain, only in northern England, in Shropshire, and Methuen, near Perth. Fl. summer, rather early.

\section{TRIGLOCHIN. ARROW-GRASS.}

Tufted herbs, with linear, semi-cylindrical radical leaves, and leafless flower-stems, bearing a slender raceme or spike of small greenish flowers without bracts. Perianth of 6 nearly equal segments. Stamens 6. Ovary and fruit of 3 or 61 -seeded carpels, each bearing a separate, small, feathery stigma, all united at first round a central axis, but separating from it when ripe.

A small genus, chiefly maritime, but widely distribnted over the globe. Ripe fruit linear, with 3 carpels . . . . . . 1. T. palustre. Ripe fruit ovoid or oblong, with 6 carpels . $\quad$ - . 2, T. maritimum.

1. T. palustre, Linn. (fig. 970). Mursh A.-The tufted stock emits a few slender, creeping runners. Leaves slender, but rather succulent, varying from 2 to 8 inches in length, dilated and sheathing at the base. Flower-stems from 6 to 12 inches high, bearing in their upper half a slender spike of small, yellowish-green flowers, which are at first sessile, but as the fruiting advances the pedicels lengthen to 1 or 2 lines. Perianth-segments broadly ovate, the feathery stigmas just appearing above them. After they fall off, the fruit lengthens to about 3 lines by less than a line broad, tapering at the base; when ripe it separates from the base upwards into 3 carpels, leaving a central axis.

In wet meadows, and marshes, and on the shallow edges of streams, more especially in maritime districts, in Europe, central and Russian Asia, and North America, extending from the Mediterranean to the Arctic regions. Common in Britain. Fl. all summer.

2. T. maritimum, Linn. (fig. 971). Sea A.-Very near T. palustre, but usually rather stouter, with more succulent leaves, the flowers nearly similar; but even in that state the ovary is broader, with 6 cells, and the ripe fruit is not more than 2 lines long, more than a line broad, and divides into 6 carpels.

Generally more restricted to the vicinity of the sea than T. palustre, but equally abundant with that species in the salt marshes of the northern hemisphere. Common in Britain. Fl. from spring till autumm.

\section{ALISMACE无. THE ALISMa FAMILY.}

Marsh or water plants, with radical leaves and leafless flowerstems. Flowers in terminal umbels, panicles, or racemes. Perianth of 6 segments, either all similar, or 3 outer sepal-like and 3 inner ones larger and petal-like. Stamens 6, 9, or indefinite. Ovary of 3,6 , or many carpels, either distinct from the first or separable when in ripe fruit, each with 1,2 , or many ovules. Seeds consisting, within the trata, of a large, straight or hooked embryo without albumen. 
1 The genera are not numerous, but several of them are dispersed over the greater part of the world.

Perianth-gegments all nearly equal, large and coloured. Fowerstem tall, with a large terminal umbel

Perianth-segments 3 small and herbaceous, 8 large and coloured. Flowers opposite or whorled, in a terminal raceme, umbel, or panicle.

Carpels and stamens numerous. Leaves sagittate

Carpels numerous. Stamens 6 . Leaves ovate or narrow

Carpels 6. Stamens 6. Leaves ovate or oblong .

1. Butougs.

\section{BUTOMUS. BUTOME.}

A single species, distinguished from Alisma as a genns, or by some botanists as an independent family, chiefly on account of the ovary, which has several ovules in each carpel.

1. B. umbellatus, Linn. (fig. 972). Flowering Rush.-A perennial, with a thick, creeping rootstock, and long, erect, sedge-like triangular radical leaves, broad and sheathing at the base. Flower-stem leafless, 2 to 4 feet high, thick and rush-like, bearing a large nmbel of showy, rose-coloured flowers, with 3 lanceolate, thin bracts at its base. Pedicels 3 to 4 inches long, often 20 to 30 in the umbel. Perianth fully an inch diameter, of 6 ovate, spreading, nearly equal segments. Stamens 9. Carpels 6, erect, tapering into short styles, seeds numerous minute.

In watery ditches, and still waters, over Europe and temperate Asia, except the extreme north. Central and southern England, rare in England, introduced only in northern England and Scotland. $F l$. summer.

\section{SAGITTARIA. ARROWHEAD.}

Aquatio herbs, differing from Alisma in their unisexnal flowers, the males with numerous stamens, the females with very numerous small carpels in a dense head.

Besides the common species, there are several from North and South Ameriea, and eastern Asia.

1. S. sagittifolia, Linn. (fig. 973). Common A.-A perennial, with a creeping rootstock, forming bulb-like tubers. Leaves radical, rising out of the water on very long stalks; the blade 6 to 8 inches long, sagittate; the lobes of the base nearly as'long as the terminal one, all pointed, but varying much in width. Flower-stem leafless, erect, longer than the leaves, bearing in its upper part several distant whorls of rather large, white flowers; the 3 inner segments of the perianth twice as long as the 3 outer green ones; the upper flowers usually males, on pedicels $\frac{1}{2}$ to 1 inch long; the lower ones females, on shorter pedicels.

In watery ditches, and shallow clear ponds and streams, dispersed over the greater part of Europe and temperate Asia, to the Arctic regions. In Britain, limited to England and Ireland, naturalised in Scotland. $F l$. summer and autumn. 


\section{AIISMA. WATER PLANTAIN.}

Aquatic herbs, erect or rarely floating, with radical, long-stalked leaves; the flowers either in a terminal nmbel, with or without whorls of pedicellate flowers below it, or in a panicle with whorled branches each bearing a similar umbel. Perianth of $\mathbf{3}$ outer, small, herbaceous segments, and 3 much larger inner ones, petal-like, and very delicate. Stamens 6. Carpels numerous, small, and 1-seeded, either arranged in a ring round the axis, or irregularly in a globular head.

A genus comprising several species, chiefly American, but some of them distributed over nearly the whole world.

Nowers numerous, in a loose panicle. Carpels forming a ring round the axis of the flower.

sinwers few, in a single umbel. Carpels irregularly arranged

in a globular head.

Stems erect or creeping. Carpels with 1 or 5 prominent

stems floating. Carpels with 12 to 15 slender ribs :

1. 4. Plantago.

1. A. Plantago, Linn. (fig. 974). Common W.-Rootstock perennial, becoming almost bulbous by the thickened sheathing bases of the leafstalks. Leaves radical, varying from ovate to narrow-lanceolate. Flower-stem 1 to 3 feet high, with whorled branches, nnequal in length, forming a loose, pyramidal panicle. Flowers rather small, of a pale rose-colonr, fon long whorled pedicels. Fruit of 20 to 30 carpels, arranged in a single ring round a broad, flat, central axis.

In watery ditches, ponds, and edges of streams; common in Europe, temperate Asia, and North America, extending to the Arctic regions, and reappearing in Anstralia. Abundant in Britain. Fo all summer.

2. A. ranunculoides, Linn. (fig. 975). Lesser W.-The leaves and peduncles form annual tufts, but will occasionally emit runners for a succeeding year. Leaves narrow-lanceolate, or sometimes reduced to a linear leafstalk. Flower-stems, in the ordinary state, simple, with a single terminal umbel, or rarely a second whorl below it. Flowers larger than in $\mathbf{A}$. Plantago, sometimes near an inch diameter. Carpels irregularly arranged in a globular head in the centre of the flower.

In wet ditches and marshes, over the greater part of Europe, but rare in the east. In Britain, as widely dispersed as $\mathbf{A}$. Plantago, but not near so frequent. $F l$. summer and autumn. In var. repens the flowering-stem bends down, and forms roots and leafy tufts at each whorl of flowers.

3. A. natans, Linn. (fig. 976). Floating W.-Stems slender, and floating on the surface of the water, producing at every node a tuft of small ovate or oblong, stalked leaves, and 1 or 3 small flowers, whilst the radical leaves of the original tuft are all reduced to a linear leafstalk, scarcely dilated towards the top. Carpels in a globular head, like those of A. ranunculoiles, but much more pointed, and marked with 12 to 15 slender longitndinal ribs.

In ponds and still waters, in western and some parts of central Kurope. In Britain very rare, and confined to western England, Wales, and western Ireland. ['The subsolitary flowers, floating habit, and position of the ovules, separate this from Alisma, under the name of Elioma, Buchenan.] Fl. summer and autumn. 


\section{DAMASONIUM. DAMASONIUM.}

Herbs, only differing from Alisma in the carpels, which are few, larger, usually 2-seeded, and cohere by the base to the central axis of the flower.

Besides the European species, the genus comprises two others from Australia and California.

1. D. stellatum, Pers. (fig. 977). Star D.-A tufted, glabrous annual Leaves all radical, on long stalks, ovate or oblong, often cordate at the base. Flower-stems erect, from 3 to 9 inches high, usually bearing 1 terminal nmbel, and 1 to 3 whorls of rather small flowers lower down. Inner segments of the perianth very delicate, white, with a yellow spot at the base. Carpels 6, tapering into a long point, and radiating horizontally, like a star. Actinocarpus Damasonium, $\mathrm{Br}$.

In watery ditches, and pools, in western and southern Europe, and west-central Asia, but not extending into Germany or Scandinavia. In Britain, only in some of the southern and eastern connties of England. Fl. summer.

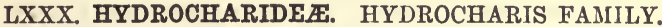

Aquatic herbs, with undivided leaves, and mostly diœcious flowers, enclosed when young in an involucre or spatha of 1 to 3 leaves or bracts. Perianth of 3 or 6 segments, either all petallike or the 3 outer ones smaller and herbaceous, with a tube adherent to the ovary at its base in the females, without any tube in the males. Stamens in the males 3 to 12 . Ovary in the females inferior, 1-celled, with 3 parietal placentas, or divided into 3,6 , or 9 cells. Styles 3,6 , or 9 , with entire or 2 -cleft stigmas. Fruit small, ripening under water, indehiscent. Seeds several, without albumen.

A small Order, widely diffused over the globe.

stem floating and branched, with small opposite or whorled leaves. Female perianth-tube long and thread-like. Stigmas 3

Stem root-like, with floating tufts of orblcular leaves Femaie perianth-tube short, on a slender pedicel. Stigmas 6
stem scarcely any. Leaves tufted, succulent, radical. Female perianth-tube short, on a stout pedicel. Stigmas 6

1. Elodra.

2. HYDROCHARIS.

3. STRATIOTES.

\section{ELODEA. ELODEA.}

Stems submerged, branched and leafy. Flowers sessile, the males with 3-9 stamens, the females with a long, thread-like perianth-tube. Style adherent to the tube, with 3 notched or lobed stigmas. Ovary 1 . celled, with 3 parietal placentas.

A small genus, temperate and tropical

1. E. canadensis, Michx. (fig. 978). Water-thyme-A dark green, much branched submerged perennial. Leaves numerous, opposite or in whorls of 3 or 4 , sessile, linear-oblong, transparent, 3 or 4 lines long. Flowers sessile in the upper axils, in a small, 2-lobed spatha; the slender perianth-tube of the female often 2 or 3 inches lono, so as to attain the 
surface of the water, where it terminates in 3 or 6 small, spreading segments. Anacharis Alsinastrum, Bab.

In ponds, canals, and slow streams, abundant in North America, and introduced from thence into Britain, where it was first observed in 1847 in Yorkshire, Leicestershire, and near Berwick. It has since spread with great rapidity, and there are now but few counties without it. [Generally known as the American Water-wecd.] Fl.summer and autumn.

\section{HYDROCHARIS. FROGBIT.}

A single species, distinguished as a genus from Stratiotes and others more by its habit than by any very marked characters in the flower.

1. H. Morsus-ranæ, Linn. (fig. 979). Frogbit.-Stems floating, resembling the runners of creeping plants, with floating tufts of radical leares, peduncles, and submerged roots. Leaves stalked, orbicular, entire, cordate at the base, rather thick, about 2 inches diameter. Peduncles of the male plant rather short, bearing 2 or 3 rather large flowers on long pedicels, enclosed at the base in a spatha of 2 thin bracts. Outer segments of the perianth pale green, shorter and narrower than the inner white ones. Stamens 3 to 12. Female spatha sessile among the leaves; the flowers like the males, but with the pedicel enlarged at the top into a short perianth-tube enclosing the ovary. Styles 6, with 2-cleft stigmas. Fruit dry, 6-celled, with several seeds.

In ditches and ponds, dispersed over Europe and central and Russian Asia, but not extending to the Arctic Circle. Occurs in many parts of England and Ireland, not indigenous in Scotland. Fl. summer.

\section{STRATIOTES. WATER-SOLDIER.}

A single species, with the flowers nearly of Hydrocharis, but with a succulent fruit, and a very different habit.

1. S. aloides, Linn. (fig. 980). Water-soldier.-Rootstock creeping in the mud, producing at the bottom of the water tufts of sessile, long and narrow, more or less succulent leaves, bordered by small, pointed teetl. Peduncles rising from among the leaves to a few inches above the water, much thickened at the top, bearing a spatha of 2 bracts, about an inch long. Male flowers several in the spatha, stalked, much like those of IIydrocharis, but rather larger, with nsually 12 or more stamens. Female flowers solitary, and sessile in the spatha, with a rather long tube, swollen below the middle. Ovary and stigmas nearly as in IIydrocharis, but the fruit is ovoid and somewhat succulent.

In lakes and watery ditches, dispersed over Europe and Russian Asia, except the extreme north. Oommon in the fens of eastern England, occurs also in Lancashire and Cheshire, and naturalised in Ireland and Scotland. F. summer. 


\section{ORCHIDACEE. THE ORCHID FAMILY.}

Perennial herbs, with the roots or stock often thickened into tubers, entire and parallel-nerved leaves, and irregular flowers, either solitary or in snikes, racemes, or panieles, each one in the axil of a bract. Perianth superior, irregular, with 6 usually petal-like segments; the 3 outer ones, called sepals, and 2 of the inner ones, called petals, of ten nearly alike; the third inner one, called the lip or labellum, differing from the others in shape or direction. Opposite to the lip, in the axis of the flower, is the column, consisting of 1 or rarely 2 stamens, combined with the pistil ; the 2-celled anther or anthers being variously situated on the style itself. Pollen rarely granular, more frequently cohering into 1 or 2 pairs of oblong or globular pollen-masses, tapering at one end into a point. Ovary inferior, 1-celled, with 3 parietal placentas. Capsule 3-valved, with innumerable minute seeds, resembling fine sawdust.

A very extensive Order, spread over all parts of the globe. Our own species, and generally those of temperate regions, are terrestrial, bnt a large proportion of the tropical ones are epiphytes, growing upon the stems and branches of trees, but without penetrating into their tissues. Numbers of these are now extensively cultivated for the singularity of the forms assumed by the flowers, as well as for their great beauty. The genera are distinguished chiefly by the form and relative arrangement of the anther-cells, the pollen masses, and the stigma, and the shape and direction of the lip, characters which, however essential, are in many cases as difficult to describe clearly as to observe accurately, especially in dried specimens. For the beginner, therefore, I have endeavoured in the following table to select such prominent features as may guide him to the British species, independently of the more minute characters, which may be reserved for gubsequent study.

gtem without any leaves, except short scales.

Lip with a spur underneath. Flowers fow, rather large - 8. FPIPOaUM.

Lip without a spur. Flowers small.

Plant green. Howers white, In a spirally-twisted spike . 9. SPIRANTHes.

Plant and flowers brown or yellowish-white. Flowers in a raceme.

Lip entire, not so long as the sepals.

• • 3. Corallorhiza. Plant with 1, 2, or more green leaves.

Perianth with a spur or pouch at the base of the lip . . 11. ORCHIs (and

Perianth without any spur or pouch*

Lip hanging, longer than the sepals, very narrove or divided into narrono lobes. Flowers yellowish-green.

stem with 2 opposite, broad leaves. Hlowers pedicellate. Rootstock fibrous

12. HABEN ARIA)

6. IISTERA.

- A single speclmen has been occasionally found of species of Orchis and Habenaria, in which the flowers are all deformed, without any spur, but such instances are very rare. 
Stem leafy at the base. Flowers sessile. Rootstock tuberous.

Sepals arching over the column. Lobes of the lip

linear.
Sepals spreading. Lobes of the lip oblong : $: \quad$ 13. ACERAs.

Lip hanging, very convex or large, brown or spotted.

Flowers 1 or 2 ouly, very large. Lip inflated, above an inch long

Flowers several. Llp convex, not above haif an inch

Lip erect or spreading, not longer than the sepals, concave or flat.

Howers rather large, In a loose, leafy spike. Stem leafy, usually a foot high or more.

Flowers pedicellate, drooping

Flowers sessile, erect

16. CY PRIPEDIUX.

15. OPHRYS.

Fowers small (white or greenish-ycllow). Stem seldom above 6 inches high.

Flowers pedlcellate, erect. Stem bulbous at the base. Sepals broad-lanceolate, about 1 line long . . Sepals narrow-linear, fully 2 lines long .
Flowers sessile, horizontal or drooping. Stem not bulbous.

Flowers greenlsh-yellow, all round the splke. Root-

Fowers greenish-whlte. Spike one-sided, straight. Rootstock creeplng, flbrous
wers white. Spike one-sided, spiral. Rootstock almost tuberous
4. EPIPACTIS.
5. Ceplatianthera.

\section{MALAXIS. BOG ORCHIS.}

A single species, distinguished as a genus from Liparis by the proportion of the petals, and by the pollen-masses, which are club-shaped, in 2 pairs, both suspended from a gland which terminates the column.

1. M. paludosa, Sw. (fig. 981). Bog Orchis.-A delicate plant, 3 or 4 inches in height, the rootstock producing a small solid bulb out of the ground like many exotic epiphytes, and 3 or 4 ovate or oblong radical leaves. Flowers very small, of a greenish yellow, in a loose slender raceme. Sepals ovate or broadly lanceolate, about a line long, two of them erect, the third turned down; petals similar, but not half the size, and spreading laterally. Lip erect, shorter than the sepals, but longer than the petals, ovate, concave at the base, where it embraces the very short column.

In spongy bogs, in northern Europe and Russian Asia, from the north of France to the Arctic regions, and in some monntain districts in central Europe. Spread over the greater part of Britain, but very sparingly, and always difficult to find. Fl. summer, rather late.

\section{LIPARIS. LIPARIS.}

Delicate herbs, with radical leaves, and small, greenish.yellow flowers, in a terminal raceme. Sepals and petals nearly alike. Lip much broader, erect or spreading and entire. Column erect or curved, with a lid-like terminal anther ; the two pairs of pollen-masses attached by their summits, but spreading laterally into the 2 anther-cells.

Besides the European species, the genus contains a considerable number from the warmer regions of both the New and the Old World. several of them true epiphytes. 
1. L. Loeselii, Rich. (fig. 982). Two-leaved L.-The stock forms a small bulb for the following year by the side of the stem. Leaves 2 , about half the length of the stem, narrow-oblong or broadly lanceolate, with a shorter outer sheath. Stem from 2 or 3 to near 6 inches high. Flowers from 3 to 10 in the raceme; the sepals and petals very narrow, about 2 lines long or rather more; the lip broadly ovate, erect at the base, turned back at the tip. Column much shorter. Sturmia Loeselii, Reichb.

In bogs and wet places of central Europe, from southern Scandinavia and western France to the Russian frontier. In Britain, only in the eastern counties. Fl. summer.

\section{CORALLORHIZA. CORALROOT.}

Brown or yellowish herbs, without green leaves; the flowers in a loose terminal spike. Sepals and petals nearly alike, the lip larger, often with 2 lateral lobes and 2 projecting ridges on the surface. Colnmn short, with a terminal lid.like anther, and 2 pairs of globular pollen. masses, attached horizontally.

Besides the European species, the genus comprises a small number from North America and eastern Asia.

1. C. innata, Br. (fig. 983). Spurless C.-A slender plant, 6 to 9 inches high, of a light brown or pale yellow colour, slightly tinged with green in the lower part, with a few short, sheathing scales instead of leaves; the rootstock forming a number of short, thick, fleshy, clubshaped fibres, densely interwoven, and nearly white. Flowers small, of a yellowish green ; the sepals narrow-lanceolate, about 2 lines long; the petals rather shorter; the lip oblong, white, and hanging.

In moist woods, widely diffused in Europe from northern Italy to the Arctic regions, in North Asia, and America. In Britain, only known in a few localities in east Scotland. Fl. summer.

\section{EPIPACTIS. EPIPACTIS.}

Herbs, with a leafy stem, and purple brown, or whitish flowers, rarely inged with red, in a loose raceme. Perianth spreading; the petals horter than the sepals but otherwise similar; the lip free from the column, thick and concave at the base, the terminal portion broad and petal-like, with 2 protuberances at its base. Column short; the anthers terminal; the pollen very loosely cohering in the pollenmasses.

A small genus, ranging over the temperate regions of the northern hemisphere.

Raceme long and leafy. Flowers distant, dull green or purplish . Raceme rather loose but short. Sepals pale purplish-green; the lip white, tinged with pink.

1. Iatifolia.

2. B. palustris.

1. E. latifolia, Sw. (fig. 984). Broad E.-Rootstock shortly creeping, with rather thick fibres. Stems usually 2 to 3 feet high. Leaves strongly ribbed; the lower ones ovate and stem-clasping ; the upper ones narrower, lanceolate, and pointed, gradually passing into the linear bracts 
of which the lower ones are often longer than the flowers. Flowers pendulous, in a long, 1-sided raceme, varying in colour from green to a dingy purple. Sepals ovate-lanceolate, about 3 or 4 lines long. Petals rather smaller. Lip rather small, the lower portion very short.

In woods and shady places, dispersed over Europe and temperate Asia, except the extreme north. Not unfrequent in Britain, but often appearing only in single specimens. Fl. summer, rather late. [The upper leaves, colour of the flowers, and the form of the terminal lobe of the lip are all very variable in Britain, giving rise to many varietal or specific names, as viridiflora, Hoffm. ; purpurata, Sm. ; media, Fries ; violacea, Bor. ; atrorubens, Iloffm. ; ovalis, Crantz ; and rubiginosa, Crantz.]

2. E. palustris, Sw. (fig. 985). Marsh E.-Not so tall as E. latifolia, the leaves narrower, usually lanceolate, and the bracts all shorter than the flowers. Racemes loose, but much closer than in E. latifolia, and not 1 -sided ; the flowers larger, slightly drooping. Sepals lanceolate. of a pale greenish-purple. Petals rather shorter, white, more or less streaked with pink at the base. Lip of the colour of the petals, but longer even than the sepals, distinctly divided into two portions, the lower one thick and half-clasping the column.

In moist and marshy places, especially in limestone districts, and near the sea, in Europe and Russian Asia, except the extreme north. Widely spread over Britain, and abundant in particular spots, yet not a common plant, and rare in Scotland and Ireland. Fl. summer.

\section{CEPHALANTHERA. HELLEBORINE.}

Habit and foliage of Epipactis, but the fiowers are sessile, erect, and usually larger, white or red, the petals and sepals not so spreading, the lip has no protuberances at the base of the upper portion, the column is longer, and the anther is shortly stalked.

A small European and north Asiatic genus, united by some with Epipactis, whilst others place it in a different tribe of Orchids on account of the slight difference in the position of the anther.

Fluwers white or cream-eolour.

Leavos broad. Lower bracts longer than the flower, and all

lunger than the ovary
narrow. All the braets shorter thin the ovary : : Flowern red :

1. C. pallens, Rich. (flg. 986), Large or White H.-Rootstock fibrous. Stem 1 to $1 \frac{1}{2}$ feet high. Leares prominently veined as in Epiractis; the lower ones broadly ovate, the upper ones rather broadly lanceolate. Flowers rather large, of a yellowish white or creamcoloured, in a loose, leafy spike, all the bracts being longer than the ovary, and the lower ones quite leaf-like and longer than the flowers. Sepals 6 to 8 or even 9 lines long, oblong, and usually obtuse, rather open. Petals rather shorter, close over the column. Lip small, of two distinct portions, the lower one embracing the column, the terminal one recurved at the tip. C. grandiflora, Bab.

In woods and thickets, in Europe, extending northward to Denmark. In Britain, scattered over various parts of England. Fl. early summer.

2. C. ensifolia, Rich. (fig. 987). Narrow 11 . - Very near $C$. granditora. 
but the leaves are narrower, the lower ones broadly oblong, the upper ones long and narrow-lanceolate; the bracts very short, mostly 1 to 2 lines long, or the lowest rarely as long as the ovary. Flowers pure white; the sepals narrower and more pointed than in C. pallens.

Stations and geographical range of $C$. grandiflora, but extending into temperate Asia. It is local in Britain, occurring in various counties from Mull and Perth southwards, and rare in Ireland. Fl. early summer.

3. C. rubra, Rich. (fig. 988). Red $I I$.-Stature and foliage of $C$. ensifolia. Bracts rather longer, but not so long as in C. pallens. Ovaries and axis of the raceme minutely downy. Flowers rather larger than in $C$. ensifolia, of a pink red, with a narrow, white lip.

Stations and geographical range of the last species. In Britain extremely rare, having been only seen in Gloucestershire and Somerset. Fl. summer.

\section{LISTERA. TIVAYBLADR}

Herbs, with 2 leaves at some distance from the ground, placed so near together as to appear opposite, and small, green flowers in a slender raceme. Sepals broader than the petals, otherwise all nearly alike, short, and spreading; the lip longer, linear, and 2-cleft. Anther fixed by its base in a cavity at the top of a short column; the pollen as in Epipactis.

A small European, north Asiatic, and North American genus, readily known among the small-flowered, spurless Orchids by the foliage.

Leaves orate, narrowed at the base, 2 to 4 inches long . . . . 1. L. ovata. Leaves broad or cordate at the base, not an inch long . . . . 2. L cordata.

1. L. ovata, Br. (fig. 989). Common T.-The rootstock has a mass of clustered, thickish fibres, but not near so succulent as in Neottia Nidus-avis. Stem 1 to near $1 \frac{1}{2}$ feet high, with 2 or 3 sheathing scales at the base, and at about 6 inches from the ground a pair of broadly ovate, green leaves, 2 to 4 inches long. Raceme rather long and slender. Sepals and petals about $1 \frac{1}{2}$ to near 2 lines long; the lip twice as long, ending in 2 linear lobes.

In moist pastures and woods, throughout Europe and Russian Asia. Frequent in Britain. $F l$. spring and summer.

2. L. cordata, Br. (fig. 990). Lesser T.-A much smaller and more slender plant than $L$. ovata, usually about 6 inches high. Leaves seldom above $\frac{8}{4}$ inch long, very broad, and sometimes slightly cordate at the base. Flowers very small, in a short raceme; the lip linear, 2-cleft, with 2 minute teeth at its base.

On mountain heaths, in northern and Arctic Europe, Asia, and America, extending to the Alps and the Caucasus. In Britain, most common in Scotland, the north of England, and some parts of Ireland. Fl. summer.

\section{NEOTTIA. BIRD'S-NEST ORCHIS.}

A genus of very few European and north Asiatic species, distinguished from Listera by the brown stems with sheathing scales instead of leavos, and by a rather longer column in the flower. 
1. N. Nidus-avis, Linn. (fig. 991). Common B.-The rootstock consists of a dense mass of thick, rather succulent fibres. Stem a foot high or rather more, of a pale-brown colour, as well as the few loose sheathing scales which replace the leaves. Spike rather dense, 3 or 4 inches long, with a few distant flowers below it, all dingy-brown. Sepals broadly ovate, almost acute, about $2 \frac{1}{2}$ to 3 lines long; petals more rounded; lip twice as long, deeply cleft at the extremity into 2 oblong, diverging lobes.

In woods of Europe and western Siberia, extending eastward to the Caucasus, although never a very common plant. In Britain, it is found in many parts of England, Ireland, and southern and central Scotland. Fl. spring and early summer

\section{EPIPOGUM. EPIPOGUM.}

A single species, leafless like Corallorhiza and $N$ cottia, but with a very different spurred flower.

1. E. aphyllum, Sw. (fig. 992). Leafless E.-The rootstock produces a number of short, thick, fleshy branches, like those of Corallorhiza. Stem about 6 inches high, of a pale colour, with a few short, sheathing bracts. Hlowers 3 or 4 in the raceme, rather large, of a pale yellowish hue, pendulous, with the lip upwards. Sepals and petals narrow-lanceolate; lip large, ovate, somewhat concave, marked with raised dots on the surface, with an oblong lobe on each side at its base, and a thick, projecting spur underneath. Column short, with a shortly stalked terminal anther.

Among rotten leaves, in woods and shady places, scattered over Europe and central and temperate Asia, but every where very scarce. In Britain, found only once or twice at Tedstone Delamere, in Herefordshire. Fl. August.

\section{SPIRANTHES. LADY'S TRESSES.}

Rootstock producing a few oblong tubers or thickish fibres. Stem leafy, or sometimes the flower-stems with scales only, and radical leaves by its side. Flowers small, in a more or less spirally-twisted spike. Sepals and petals nearly alike, erect or only spreading at the tips; the lateral sepals oblique, covering the base of the lip; the upper sepal cohering with the petals. Lip oblong, concave at the base, dilated and spreading at the extremity. Column arching, with the anther attached to the back.

An extensive genus, spread over the greater part of the globe, and readily known by the spirally twisted spikes.

Leaves radical, ovate, or oblong; the stems bearing short scales only Leaves all narrow, near the base of the flowering stem.

Spike 2 to 3 inches long, the flowers in one row

Spike dense, 1 to $1 \frac{1}{2}$ inches long, the flowers in three rows

1. S. autumnalis.

1. S. autumnalis, Rich (fig. 993). Common $L$-The rootstock pro. duces every year 2 or 3 thick, oblong tubers, and a tuft of 3 or 4 broadly ovate or oblong, spreading radical leaves, seldom above an inch long. Nlowering stems by the side of the tuft of leaves, 6 to 8 inches high, 
green, with short, sheathing, pointed scales, very seldom growing out into vers short, linear leaves. Flowers white, with a sweet smell of almonds, in a rather close spiral spike of about 2 inches, all diverging horizontally to one side, whilst the bracts remain erect on the opposite side.

On dry, hilly pastures, all over Europe, except the extreme north, extending eastward to the Caucasus. In Britain it is not found farther north than Westmoreland and Yorkshire, but occurs in central and south Ireland. Fl. autumn.

2. S. æstivalis, Rich. (fig. 994). Summer L.-Rootstock more horizontal than in $S$. autumnalis, with longer, more cylindrical tubers. Leaves radical, or on the flower-stem near the base, narrow-lanceolate or linear. Stem rather taller than in the common $L$, and the flowers rather larger.

In bogs and marshes, chiefly in southeru Europe, extending over France and into Belgium. The only known British stations are in Hampshire, Worcester, and the Channel Islands. Fl. late in summer.

3. S. Romazoviana, Cham. (fig. 995). Drooping L.-Rootstock producing a cluster of thin cylindrical tubers. Stem leafy, attaining 6 to 9 inches. Lower leaves at the base of the stem lanceolate or spathulate, 2 to 3 inches long, spreading, the upper ones smaller, erect, sheathing at the base. Spike dense, 1 to 2 or even 3 inches long, the flowers white, packed in 3 rows, much larger than in the other two species, with a broader lip. S. Gemmipara, Lindl. S. cernua of early editions.

A native of Kamtschatka and North America, unknown in Europe, except in meadows at Bantry Bay, Ireland. $F l$. August and September.

\section{GOODYERA. GOODYERA.}

Very near to Spiranthes, but the spike is not spiral, and the lip does not embrace the column, and is contracted at the top into a recurved point.

The species are very few, all from the northern hemisphere, and generally from high latitudes or alpine sitnations.

1. G. repens, Br. (fig. 996). Creeping G.-Rootstock shortly crecping, with a few thick fibres. Flowering stems 6 inches to near a foot high, with a few ovate stalked leaves near the base. Spike 1-sided as in Spiranthes autumnalis, but straight, with rather smaller fowers of a greenish-white; the lateral sepals rather shorter, and more spreading than the npper sepal and the petals.

In moist woods, and forests, in northern and Arctic Europe, Asia, and America, and the higher monntains of central Europe and Asia In Britain, confined to Cumberland and several counties of Scotland, where it is rare and local. Fl. end of summer.

\section{ORCHIS. ORCHIS.}

Rootstock producing each year a fleshy tuber by the side of the decaying one of the preceding year, the following year's stem shooting from the top of the new tuber. Stem leafy at the base, with a terminal spike 
of flowers, usually red or purple. Sepals and petals nearly equal. Lip turned downwards, usually 3 to 5-lobed, or mucli dilated at the extremity, and produced underneath at its base into a sjur or pouch. Anther on the face of the column, with 2 erect cells cunverging together at the base, each cell containing a pollen-mass, cont racted below into a short stalk, terminating in a gland that is concealed in a pouch.

A considerable genus, chiefly European and north Asiatic, with a very few north American species. The allied genus Habenaria is separated by technical characters so difficult for the beginner to appreciate that the species of both genera are included in the following table.

Spur of the perianth very slender, and longer than the onary.

Flowers white, rather large, in a loose spike. Two leaves unly at the base of the stem . . . . . . . 1. II. bifolia.

Flowers usually red, rather small, in a dense spike. Leaves several, narrowed.

Tubers of the rootstock entire. Spike ovate or pyramidal, very dense divided. Sptke cylindrical, at length rather

9. 0 pyramidalis. loose . 2. II. conopsea.

Spur from half the length to about the length of the ovary.

Sepals all converging and arching over the column and petals in the form of a helmet. Tubers entire.

Flowers few, in a loose splke. Lip broadly and shortly 3 .

Flowers numerous, in a dense or long spike. Lip with $\dot{2}$ lateral, smaller lobes, aud a large 2 -cleft middle one

Sepals, at least the lateral ones, spreading. Petals, eith
or with the upper sepal, arching over the columu.

spike long or loose. Tubers entire.

Bracts 1-nerved. Upper sepals arching over the petals 4. 0 . mascula.

Bracts with several veins. All 3 sepals spreading : . 5. O. laxiflora.

Spike dense. Tubers lobed.

Bracts shorter than the flowers. Llp irregnlarly 3-lobed . 6. 0. maculata.

Lower bracts longer than the flowers. Lip toothed or

8carcely lobed
Spur exceedingly short, or reduced to a small pouch or cavity.
Lip linear, 3-lobed, the middle lobe morn than an inch long

- 7. 0. latifulia.

Lip not above a quarter of an inch long.

spike rather loose. Flowers green, rather small, with an oblong hanging lip, rather longer than the sepals.

Spike dense, with numerous small flowers, the lip not longer than the sepals.

Flowers purple before expanding. Lip white, 4-lobed (3lobed, with a 2-cleft middle lobe)

Fowers pink or pale purple. Lip 3-lobed • • • . 3. O. ustulata

Flowers white. Sepals ovate. Llp 3-lobed : $:$ : 4. H. allida.

Flowers greenish-yellow. Sepals and petals very narrow. Lip 3-lobed

8. 0. hircina.

5. I. viridis.

. HERIINIOM.

1. O. Morio, Linn. (fig. 997). Grcen-winged O.-Tubers entire. Stems seldom above 6 or 8 inches high, with a few rather narrow, almost radical leaves, and 2 or 3 loose, sheathing scales higher up. Flowers about 6 to 8 , in a loose spike. Bracts thin and rather pink, about the length of the ovary. Sepals purplish, arching over the much smaller petals and column in the form of a helmet. Lip longer than the sepals, convex, broadly and shortly 3-lobed, of a pinkish purple, pale in the middle, with darker spots. Spur very obtuse, nearly as long as the ovary.

In meadows and pastures, very common in central and southern Europe, and temperate Asia, rarer towards the north, although extending into southern Scandinavia. Abundant in southern England, and Ireland, scarcer northwards, and wanting in Scotland. Fl. early summer. 
2. O. militaris, Linn. (fig. 998). Military 0.-A handsome species, 1 to 2 feet ligh, with entire tubers. Leaves in the lower part of the stem varying from broadly oval to oblong, usually 3 to 5 inches long. Flowers numerous, in a dense oblong spike, with short bracts. Sepals usually purple, converging over the petals and column in the shape of a helmet as in 0. Morio. Lip rather longer, of a pale colour, more or less spotted with purple, and 4-lobed, or, in other words, 3-lobed, with 2 lateral entire lobes and a third middle one more or less divided into 2 , with a small tooth in the cleft or notch. Spur not half the length of the ovary.

In hilly pastnres, and on borders of woods, dispersed over the greater part of temperate Europe and 's assian Asia, chiefly in limestone districts, extending northwards to Guthland. In Britain, limited to the counties bordering on the Thames from Oxford to Kent and Sussex. Fl. sprin. Among the numerous varieties observed, chiefly in the colour and form of the lip, the three following, often distinguished as species, have appeared in Englaud :-1. O. purpurea, Huds. ( fusca, Jacq.), robust, with dark purple, rather obtuse sepals; the lip variegated with: purple, its middle lobe broad and short. 2. O. Simia, Lamk. (tepheceanthos, Vill., not precisely the same as the Continental variety so named), more slender, with pale purple or crimson, spotted flowers; the middle lobe of the lip long and narrow, like the lateral ones. 3. The true 0. militaris, Linn., intermediate between the two others. [Another and perhaps better disposition of the above is the retention of 0 . purpurea, Huds., (O. fusca, Jacq., O. militaris, Sm., not Linn.) as a species, characterised by its robust habit, and broad obcordate crenate mid-lobe of the lip; and of 0 . militaris, Linn., not Sm. (O. Simia, Lamk, O. tephrosanthos, Vill.), as another species, of slenderer habit, with the mid-lobes of the lip divided into 2 narrow up-curved segments with an intermediate tooth.]

3. O. ustulata, Linn. (fig. 999). Duarf O.-Rather a small species, seldom above 6 to 8 inches high, and remarkable for the dense spike of small flowers, the deep purple of the nnexpanded ones giving it a burnt or scorched appearance. 'Tubers entire. Leaves few, oblong or lanceolate. Spike 1 to 2 inches long, with small bracts. Sepals deep purple, pointed, converging over the column and the very small, narrow petals. Lip white, with a few purple spots, 4-lobed, or, in other words, deeply 3-lobed, with 2 lateral lobes and the middle one divided into 2 spreading obtuse, more or less notched lobes. Spur very short.

On dry, hilly, open pastures, in central and southern Europe, extending eastwards to the Caucasus, and northwards to southern Scandinavia. Occurs in many parts of England, but neither in Scotland nor in Ireland. Fl. spring or early summer.

4. O. mascula, Linn. (fig. 1000). Early 0.-Stem 1 to $1 \frac{1}{2}$ feet high, with numerous showy flowers, in a loose spike 3 to 6 inclies long, varying from a bright pinkish-purple to flesh-colour or even white. Tubers entire. Leaves rather broad and often spotted. Bracts coloured, nearly. as long as the ovary, with a single nerve. The upper sepal and petals converging over the ovary, but the lateral sepals spreading, or turned back. Lip scarcely longer than the sepals, of ten slightly downy in the centre, reflexed on each side, with 3 short lobes, the middle one the largest and more or less notched. 
In moist woods, meadows, and shady places, in central and southern Curope, extending to the Caucasus and northward to southern Scandinavia. Generally distributed orer Britain. Fl. spring and early summer.

5. O. laxiflora, Lam. (fig. 1001). Loose O.-Near O. mascula, but the leaves are narrow-lanceolate or linear; the flowers rather larger, of a rich red, in a much looser spike; the bracts broader and always more veined; and the 3 sepals are spreading or reflexed, the petals alone converging over the column.

In moist meadows, common in southern Europe, extending into central Germany and over the greater part of France and Belgium. In the British Isles, confined to Jersey and Guernsey and ballast heaps at Hartlepool. Fl. spring and early summer.

6. O. maculata, Linn. (fig. 1002). Spotted O.-Tubers rather flat, and divided into 2 or 3 finger-like lobes. Stem usually about a foot high. Leaves varying from nearly ovate to narrow-lanceolate, and often marked with dark spots. Flowers in a dense oblong spike, 2 or 3 inches long, usually of a rather pale pink, but varying much in depth of colour. Bracts marked with several veins, the lowest almost always longer than the ovary, the upper ones shorter. Sepals about 3 lines long, either all or the 2 lateral ones only spreading, whilst the petals arch over the column. Lip broadly orbicular, either flat or the sides reflexed, usually more or less toothed and irregularly 3-lobed, variously spotted or variegated with a deeper colour, the middle lobe usually small. Spur rather slender, a little shorter than the ovary.

In meadows, pastures, and open woods, throughout Europe and Russian Asia, from the Mediterranean to the Arctic regions. Abund. ant in Britain. Fl. spring and early summer. It varies very much in the breadth of the leaves, the size of the bracts, the colour of the flower, and the shape of the lip, sometimes approaching very near to O. latifolia.

7. O. latifolia, Linn. (fig. 1003). Marsh O.-Very near O. maculata, and by some botanists considered as a mere variety. It is usually more luxuriant, the stem more hollow, the leaves larger and not always spotted, the spike longer and more leafy, the lower bracts, and sometimes nearly all, as long as or longer than the flowers, the flowers are nsually deeply-coloured and less variegated, the lip toothed only or very obscurely 3-lobed, and the spur thicker; but these characters are not constant.

With the same geographical range as $O$. muculata, it is usually found in moister situations or richer soils. Frequent in Britain. $\mathrm{Fl}$. spring and early summer. A variety with narrow unspotted leaves, more regularly tapering from the base, is $O$. incarnata, Linn.

8. O. hircina, Scop. (fig. 1004). Lizard 0.-A stout species, 1 to 5 feet high, with entire tubers and a leafy stem. Spike dense, 4 to 8 inches long; the flowers rather large, of a dirty greenish-white, with a disagreeable smell, and remarkable for their long, linear lip; the 2 lateral lobes short, the middle one more than an inch long, rolled in. wards in the bud, entire or notched at the tip; the sepals converging over the column, and the petals small. Loroglossum hircinum, Rich.

Widely spread over central and sonthern Kurope, but everywhere scarce, and often in single specimens, extending into Belgium. Kx. 
tremely rare in Britain, and confined to Kent, Surrey, and Suffolk. $F l$. summer.

9. O. pyramidalis, Linn. (fig. 1005). Pyramidal 0.-Tubers entire. Stem a foot high or rather more, with lanceolate leaves, usually narrow and pointed. Spike very dense, ovoid or oblong, 2 to 3 or even 4 inches long; the flowers not very large, but of a rich rose or purplish-red, either scentless or with a disagreeable odour, and remarkable for their very slender spur, longer than the ovary, although that is long in proportion to the rest of the flower. Sepals lanceolate, spreading. Petals converging over the column. Lip broad, 3-lobed, the lobes equal or the middle one narrower. Anacamptis pyramidalis, Rich.

On rather dry banks, and pastures, chiefly in limestone districts, in central and southern Europe, extending eastward to the Cancasus and northward to Denmark. Abundant in several parts of England and Ireland, and occurs in a few localities in southern Scotland. Fl. all nummer.

\section{HABENARIA. HABENARIA.}

Foliage, inflorescence, and spurred flowers of Orchis, but the anthercells, instead of converging at the base, are either parallel or diverging, each terminating in a gland which is more or less exposed.

An extensive genus, chiefly distributed over Asia and America. The table of species is included above in that of Orchis.

1. H. bifolia, Br. (fig. 1006). Butterfly H.-Tubers entire. Stem 1 to $1 \frac{1}{2}$ feet high, with 2 rather large leaves at its base, varying from broadly ovate to oblong; the outer leaves very few, and usually re. duced to sheathing scales. Flowers pure white or with a slight greenish tinge, rather large, and sweet-scented, in a loose spike from 3 to 6 or 8 inches long, with lanceolate bracts about the length of the ovary. Two lateral sepals spreading, the upper one arching over the column with the petals. Lip linear and entire, rather longer than the sepals, and usually greenish at the tip. Spur slender, twice as long as the ovary. Platanthera, Rich.

In moist pastures, and meadows, on grassy slopes and open places in moist woods, throughout Europe and Russian Asia, from the Mediterranean to the Arctic Circle. Generally distributed over Britain. Fl. all summer. It varies much in the breadth of the leaves and the parts of the flower, and the name of $I I$. chlorantha, Bab., is given to one in which the flowers are large, nsually very white (although the name means "green-flowered"), and the anther-cells are broadly diverging at the base. But intermediates passing gradually from the broad to the narrow forms have been frequently seen in great nnmbers at High Force in Teesdale in 1865.

2. H. conopsea, Linn. (fig. 1007). Fragrant H.-Tubers palmate as in 0 . maculata. Stem 1 to 2 feet high, with linear or narrow-lanceo. late leares. Spike oblong or cylindrical, not so dense as in C. pyramidalis. Flowers much like those of that species, but smaller, sweet-scented, and the slender spur is still longer. Gymnadenia conopsea, $\mathrm{Br}$.

In heaths and pastures, throughout Europe and Russian Asia, especially in the north, extending to the Arctio regions; in the south of 
Europe more confined to mountain districts. Dispersed all over Britain, and very abundant in Scotland and Ireland. Fl, all summer.

3. H. intacta, Benth. (fig. 1008). Dense-spiled H.-Tubers entire. Leaves broadly oblong or lanceolate, often spotted. Flowers pink, pale purple or white, often twisted to one side. Sepals pointed, converging over the column and over the narrow petals. Lip 3-lobed, not exceeding the sepals, the central lobe entire or notched Spur very short. Tinea cylindracea, Biv.; Neotinca intacta, Reichb. f.

In open pastures, chiefly in limestone districts, widely distributed over the Mediterranean region and western Europe. In the British Isles only found in Mayo and Galway. Fl. summer. This species has been referred to several genera, and even raised to the rank of a genus.

4. H. albida, Br. (fig. 1009). Small H.-In stature, and its small flowers with very short spurs, this species approaches Orchis ustulata, but the flowers are white, and the anthers are more like those of JIabenaria than of Orchis. The rootstock produces several thickened fibres, sometimes uniting into a deeply divided tuber. Stem 6 to 8 inches high, with a few oblong leaves. Spike dense, cylindrieal, 1 to 2 inches long, with numerous small, sweet-scented flowers. Sepals concave, but open, scarcely above a line long; the lip about their length, with 3 entire lobes, the middle one the longest. Gymnadenia albida, Rich.

In mountain pastures, in northern and Arctic Europe, and in the mountains of central Europe. Abundant in Scotland and northern England; found also in Sussex, North Wales, and Ireland. Fl. summer.

5. H. viridis, Br. (fig. 1010). Grcen H., Frog Orchis.-Tubers more or less lobed. Stem 4 to 8 inches high, with a few ovate or oblong leaves, and a rather close spike of yellowish green flowers, rather larger than in $I I$. albida, but with the same very short spur or pouch. Bracts usually longer than the ovary. Sepals converging over the column and petals, about $2 \frac{1}{2}$ or 3 lines long. Lip longer and hanging, oblong, with nearly parallel sides, and 3 or sometimes only 2 very short lobes at the tip.

In hilly pastures, in Europe, from the Mediterranean to the Arctic regions, but rather a mountain plant in the south, Russian Asia, and North America. Frequent in Scotland and Ireland, less so in southern England. Fl. summer.

\section{ACERAS. MAN ORCHIS.}

Flowers and habit of an Orchis, except that there is no spnr whatever to the lip.

A genus of very few species, from Europe, Asia, and northern Africa.

1. A. anthropophora, Br. (fig. 1011). Man Orchis.-A rather small species, seldom above 8 or 9 inches bigh, with entire tubers; the leaves varying from ovate to oblong or nearly lanceolate. Spike slender, 2 to 4 inches long. Flowers of a dull yellowish-green; the sepals converg. ing over the column and petals as in Orchis hircina, but very much smaller. Lip narrow-linear, twice as long as the sepals, and fancifully compared to a hanging man, the lateral lobes representing his arms, and the middle one, which is longer and 2-cleft, his body and legs. 
In dry pastures, in sonthern Europe, rarer in western Germany and France. In Britain, only in eastern England. Flo early summer.

\section{HERMINIUM. MUSK ORCHIS.}

Small-flowered plants, nearly allied to Habenaria, but the perianth has no spur, the anther-cells are distant at their bases, and the glands of the stalks of the pollen-masses protrude below the cells as in that genus.

A genus of very few species, from the bigh northern or alpine regions of Furope and Asia.

1. H. Monorchis, Br. (fig. 1012). Musk Orchis.-A slender plant, seldom above 6 inches high, with 2 or very seldom 3 oblong or lanceolate, radical leaves. Tubers nearly globular, like those of an Orchis, but the new one, instead of being produced close to the stem, is formed at the end of one of the fibres proceeding from the crown, thus forming a creeping rootstock. Spike slender, with numerous, small, yellowishgreen flowers. Sepals erect or scarcely spreading, and narrow. Petals narrower and rather longer, instead of being shorter as in most British Orchids. Iip scarcely longer, erect, hollowed into a kind of pouch at the base, but not spurred, with 3 narrow entire lobes.

In hilly pastures, in central, northern, Arctic, and the mountains of southern Europe, and in temperate Asia. Very local in Britain, chiefly in the southern and eastern counties of England, and nnknown in Scotland or Ireland. $F l$. summer.

\section{OPHRYS. OPHRYS.}

Habit, tubers, and foliage of an Orchis, but the flowers have no spur, and the lip is usually very convex, resembling more or less the body of an insect. Anther-cells distant at the base, protruding below the rest of the anther in 2 distinct little pouches enclosing the glands of the pollen-masses.

A small genus, chiefly from the Mediterranean region, with a very few species spreading into central Europe. The forms assumed by the lip and its markings are so very variable that the accurate distinction of species, especially of the southern ones, is a matter of great doubt and difficulty.

Lip of the perianth as broad as long or nearly so, and scarcely

longer than the sepals.

Fnd lobe of the lip much turned nnder. Sepals nunally pink . 1. O. apifera.

Lip slightly lobed, the edges scarcely turned under. Sepals Lip of the perianth oblong, considerably longer than the sepals : 3. O. muscifera.

2. O. aranifera

1. O. apifera, Huds. (fig. 1013). Bee O.-Tubers entire. Stem 9 to 18 inches high, with a few oblong or lanceolate leaves near the base, and from 3 to 6 rather large, distant flowers, in a iong, loose spike, each with a bract at least as long as the ovary. Sepals ovate, pink, pale green, or white, but always tinged with pink, very spreading or reflexed. Petals smaller, usually narrow, nearly erect. Lip broad, very convex, of a rich velvety brown, downy on the sides, smooth in the middle, and variously marked by paler lines or spots; the lobes small 
and all turned down, 2 lateral ones very downy, 3 terminal ones con. cealed ander the lip, the middle one often again turned upwards, but very variable in length. Column erect, with a distinct beak above the anther. $O$. T'rollii, Heg.

In dry pastures, usually in limestone districts, in central and southern Europe, not farther north than central Germany and Belgium. In Britain, chiefly in the southern and eastern connties of England, occurring more sparingly in other parts of England and in Ireland, but not in Scotland. Fl. early summer. [O. arachnites, Hoffm., is a variety with broader petals and a longer lip.]

2. O. aranifera, Huds. (fig. 1014). Spider O.-Much like O. apifera, but the sepals are green with less of pink, the petals very short, the beak of the column is straight, and the lip is broader, of a dull brown, variously marked with paler spots in the centre, convex as in 0 . apifera, but the edges obscurely or very shortly lobed, and either not turned under or but very slightly so.

In dry pastures, with nearly the same range as 0 . apifera, rather more common in southern Europe, less so northwards. Much more rare in England than O. apifera, and unknown in Ireland. Fl. spring and early summer. [O. fucifera, Sm., is a variety with the petals downy within, and usually entire tip.]

3. O. muscifera, Huds. (fig. 1015). Fly 0.-A much more slender plant than the two preceding species, with narrow leaves, and a slender spike of 3 or 4 flowers. Sepals oblong or narrow-ovate, greenish. Petals very narrow-linear. Column short, without any beak. Lip much longer than the sepals, oblong, convex, of a purplish brown, with pale-blue or white marks in the centre; the 2 lateral lobes turned down, the central one larger, with a deep notch.

On dry pastures in central Europe, extending farther east than the two last species, but not near so common in the south. In Britain, spread over England, and abundant in some of the eastern and southeastern counties; very rare in Ireland; not in Scotland. Fl. spring and early summer.

\section{CYPRIPEDIUM. LADY'S SLIPPER.}

Rootstock fibrous. Leaves large. Flowers few, with a large inflated lip. Column terminating in a dilated, incurved, thickish, petal-like lobe, below which are 2 distinct anthers, 1 on each side.

A considerable and very distinct North American and Asiatic genus, with one species extending into western Kurope.

1. C. Calceolus, Linn. (fig. 1016). Lady's Slipper.-Stem It feet high, with large, ovate, pointed leaves, the upper ones lanceolate, and 1 or rarely 2 large showy flowers on long peduncles. Upper sepal opposite the lip, broadly lanceolate, $1 \frac{1}{2}$ inches long, a similar one (formed of the 2 lateral ones combined into 1 ) under the lip; the 2 petals nearly as long, linear and spreading; all of a brown-purple. Lip very large and inflated, compared to a slipper, yellow, variegated with purple. Column very much shorter than the petals.

In woods, in northern Asia and eastern Europe, almost to the Arctio Circle, rarer over western Europe. In Britain, found only in Durham nd Yorkshire. Flo early summer. 


\section{IRIDEZE. THE IRIS FAMILY.}

Perennial herbs, with a bulbous, tuberous, or shortly creeping rootstock, and leaves usually either radical or equitant, that is, arranged on opposite sides of the stem, and vertically, not horizontally flattened, opening towards the base in a sheath which embraces the stem. Perianth superior, with 6 petal-like segments. Stamens 3. Ovary inferior, 3-celled, with many ovules. Style 1, with 3 stigmas (or stigmatic lobes), sometimes dilated and petal-like or fringed.

A rather large family, widely spread over the globe, but particularly abundant in southern Africa and other dry sunny climates. It differs from the Amaryllis family in the number of stamens, and, in most cases, in the position of the leaves.

Leaves on the stem, equitant.

Perlanth with 8 outer large segments, and 8 inner emall ones. Stigmas large and petal-like, arching over the stamens.

Perianth with 6 nearly simllar segments, but oblique, and arranged almost in 2 lips $\quad$ Perianth-segments nearly equal

Lesves radical,
and regular.

Rootstock tufted or fibrous. Flowers 2 or more in a terminal cluster or umbel. Stígmas entire

Rootstock bulbous. Scapes l-flowered.

Perlanth-tube very short. Stigmas deeply 8-cleft . . 4. Royulen.

Perianth-tube longer than the segments. Stigmas jagged or much divided. . . . Crocus.

The Ixias, Tigridias, and many others of the smaller South African bulbs, formerly much more cultivated than they now are, belong to the Iris family.

\section{IRIS. IRIS.}

Rootstock thick and horizontal, or rarely bulbous. Leaves equitant. Flowers large and showy; the 3 outer perianth-segments large, spreading or reflexed; the 3 inner ones much smaller, and erect. Stigmas 3, enlarged, each with a petal-like appendage, which arches over the corresponding stamen and the onter segment of the perianth.

A considerable genus, widely spread over the northern hemisphere.

Fowers bright yellow. Inner perianth-segments scarcely as long as the claw of the outor ones
Fowers violet-blue or yellowish-whlte. Inner segments two.

thirds as long as the outer ones . . . . . . 2. I. fatidissima

Several continental European species are frequent in our flowergardens, and occasionally escape into neighbouring waste places, especially the large-flowered 1 . susiana and $I$. germanica, the dwarf 1. pumila, the bulbons-rooted I. Xiphium and I. xiphioides, the I. tuberosa, \&c.

1. I. Pseudacorus, Linn. (fig. 1017). Yellow 1., Yellow Flag.-Rootstock thick, horizontal, with numerons fibres. Stem abont 2 feet high. Lower lesves often much longer, and 1 or 2 inches broad, stiff and erect, of a pale glaucous-green; the upper ones much shorter. Flowers 2 or 3 , 
each proceeding from a sheathing bract, large, erect, of a briglit yellow. Outer perianth-segments spreading, broadly ovate, fully 2 inches long, contracted at the base into an erect, broad claw ; inner segments oblong and erect, scarcely longer than the claws of the others. Petal-like stigmas rather longer than the inner segments, 2-cleft at the top, with a short, scale-like appendage inside at the base of the lobes. Capsule green, 2 to 3 inches long, with numerous pale-brown seeds.

In marshes, and along watercourses throughout Europe and Russian Asia, except the extreme north. Abundant in Britain. Fl. summer. [A well-marked variety, A acoriformis, Bor., has darker-coloured sepals and shorter stigmas.]

2. I. fœtidissima, Linn. (fig. 1018). Fetid 1., Gladdon, Roastbeefplant. - Not so large a plant as 1 . Pseudacorus, the leaves narrower, 1 or 2 only overtopping the stem, and the whole plant of a deeper green, smelling disagreeably when bruised. Flowers rather smaller, several together, of a violet-blue or rarely pale-yellowish white. Outer perianthsegments narrow-ovate, the inner ones reaching to about two-thirds their length. Petal-like stigmas scarcely so long. Seeds bright orange or scarlet.

In woods and shady places, in western Kurope. Abnndant in many parts of southern England, scarce or local in the north, and only naturalised in Scotland and Ireland. Fl. summer, commencing early.

\section{GLADIOLUS. GLADIOLUS.}

Rootstock bulbous, the onter coating fibrous and more or less netted. Stems leafy, with a terminal, 1-sided spike of flowers. Perianth oblique, the segments obovate or oblong, narrowed into a claw, and united in a tube at the base, the 3 upper ones and the 3 lower ones almost arranged in 2 lips. Stamens ascending under the uppermost segments. Stigmas 2, slightly expanded, and entire.

A numerous genns, chiefly South African, with a few species in the Mediterranean and Caucasian regions.

1. G. communis, Linn. (fig. 1019). Common G.-Stem $1 \frac{1}{\frac{1}{2}}$ to near 2 feet high. Leaves linear-lanceolate, shorter than the stem. Spike of 4 to 6 or 8 red flowers, all turned to one side, and sessile between 2 lanceolate bracts. Perianth about $1 \frac{1}{2}$ inches long, the expanded part of the segments oblong-lanceolate, the uppermost one broader and rather longer than the others. Anthers linear, shorter than their filaments. Capsule short, depressed at the top, with 3 prominent angles.

In meadows, woods, and grassy heaths, in central and southern Kurope, not reaching nearer us on the Continent than the Loire and the Rhine. In Britain, found in the New Forest, near Lyndhurst, among the Brakes, and in the Isle of Wight, but possibly introduced. Fl. early summer. The true Cornflag ( $G$. segctum), a cornfield weed, is a rather more sonthern species, differing chicfly in its larger flowers, with the anthers longer than their filaments. [The British plant is referable to one of the Continental varieties of $G$. communis, called illyricus, Koch.] 


\section{SISYRINCHIUM. SISYRINCHIUM.}

Rootstock tufted or fibrous. Leaves grass-like or lanceolate, entirely or most radical. Flowers of a delicate blue. Perianth-segments 6, all nearly equal, similar and spreading, the tube short and broad. Stamens united in a tube. Stigmas 3, filiform, undivided, rolled in wards.

A considerable genus, almost excluslvely American.

1. S. angustifolium, Mill. (fig. 1020). Blue-eyed Grass.-Leaves narrow, grass-like, sheathing at the base, shorter than the stem. Stem 6 inches to 1 foot high, 2-edged, or with 2 narrow acute wings, rather broader under the erect bracts. Flowers 1 to 4 together in a terminal cluster, the filiform pedicels almost concealed within 2 sheathing lanceolate bracts, of which the outer one often ends in a leafy tip exceed. ing the flowers, but occasionally both are nearly equal. Fruit a small globular capsule. S. bermudiana of former editions.

In moist meadows, woods and grassy places, very common throughout North America. In Britain near Kerry and Galway, in Ireland, where there seems no ground to suppose that it can have been introduced by human agency. $F l$. sumnier.

\section{ROMULEA. ROMULEA.}

Small bulbous plants, with the foliage and flowers of Crocus, except that the perianth-tube is very short, and the short stigmas are deeply 2-cleft.

A genus of very few species, chiefly from the Mediterranean region.

1. R. Columnae, Seb. and Maur. (fig. 1021). Common R.-Bulb small, with shining brown coats. Leaves very narrow and grass-like, spreading, 3 or 4 inches long, sheathing at the base. Flower-stalk not half so long, with a single erect terminal flower, almost sessile in a sheathing bract, and of a pale purplish-blne, with a yellow centre. Perianth near $\frac{8}{4}$ inch long, the segments half-spreading and rather pointed. Trichonema Bulbocodium of former editions.

In heaths and sandy places, chiefly near the sea, nearly all round the Mediterranean, and up the western coasts of Europe, to the Channel Islands and Dawlish in Devon, where it abounds at the Warren. Fl. spring.

\section{CROCUS. CROCUS.}

Rootstock bulbons, the outer coating fibrous, and more or less netted, or rarely membranous. Leaves radical, narrow-linear. Flowers almost sessile among the leaves, with a very long tube, and a campannlate limb of 6 nearly equal segments. Stigmas dilated and coloured at the top, and often cnt or fringed, but not petal-like. Capsule buried amcng the leaves.

A south Enropean and west Asiatic genus, a few species extending into central Europe, and several, long since cultivated for ornament, and one for saffron collected from the stigmas, have established themselves in a few localities still farther north. 
Fiowers in spring, with the leaves. Stigmas wedgo-shaped, and slightly fagged.

Flowers in autumn, without leaves, stigmas cut into a niany-
lobed fringe

1. C. vernus.

2. C. nudiflorus.

1. C. vernus, All. (fig. 1022). Spring or Purple C.-Leaves enclosed at the base in a tube of 2 or 3 thin, scarious sheathing scales. Flowers solitary within the leaves, of a bluish-purple; the ovary sessile on the bulb, the long tube enclosed at the base in a sheath similar to that of the leaves. Stigmas of a rich orange, dilated at the top, and slightly jagged, but not deeply fringed.

In meadows, in the hilly districts of central and southern Europe, not farther north than central France. In Britain, naturalised in meadows of Nottingham, Suffolk, and Middlesex. Fl. early spring.

2. C. nudiflorus, Sm. (fig. 1023). Autumnal C.-Flowers rather larger than in 0 . vernus, appearing after the leaves of the year have withered, and before those of the following year have developed. They somewhat resemble the flowers of Colchicum autumnale, but are readily distinguished by the 3 , not 6 , stamens. Tube very long, enclosed halfway $\mathrm{np}$ in the sheathing scales. Stigmas deeply cut into an elegant orange fringe or tassel.

In meadows and pastures, in south-western Europe, but not nearer to ns than south-western France. Naturalised in the meadows of several of the midland counties. Fl. autumn.

\section{AMARYLLIDEE. THE AMARYLLIS} FAMILY.

Rootstock bulbous, except in a very few exotic genera. Leaves radical and parallel-veined. Perianth petal-like, with 6 segments. Stamens 6 , the anthers turned inwards. Ovary inferior or adherent to the perianth-tube, 3-celled. Fruit a capsule, with several sceds, opening in 3 valves.

A large Order, widely distributed over the globe, chicfly in dry, sunny countries; differing from the Lily family in the inferior ovary, from the Iris family in the 6 stamens.

Perianth tubular at the base, the limb spreading, with a eupshaped or tubular erown at the mouth of the tube

Perianth divided to the ovary, without any erown.

Three outer perianth-segments larger than the inner ones . 2. Galanthos.

Perianth-segments all equal . . . . : 8. Levcorum.

Mnny of the most showy exotic bulbous plants grown in our garden and planthouses belong to this family, including the genera A maryllis, Alstrameria, Crinum, Nerine sarniensis (callcd Guernsey Lily, from an erroneons inpression that it was a native of Guernsey), and others, besides the gigantic Agave americana, commonly called Aloe, but not a cungener of the true Aloes of botanists, which are Liliaceous plants 


\section{NARCISSUS. NARCISSUS.}

Flowers either solitary or several together, from a terminal spatha. Perianth with a distinct tnbe above the ovary, and 6 usually spreading segments, with a cup-shaped or tubular, coloured crown inside, round the orifice of the tube.

A well-defined and very natural genus, chiefly south European, not extending into Asia beyond the Cancasus, and probably containing but few real species, although some botanists, availing themselves of the most trifling characters, observed chiefly in cultivated varieties, have proposed the breaking it up into 15 or more genera, with above a hundred species.

Flowers solitary, the crown broadly tubular, as long as the

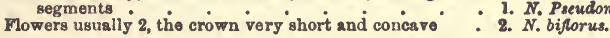

Several other cultivated species have occasionally established themselves for a time in the vicinity of gardens, particnlarly $N$. poeticus, from the Mediterranean region, which is near $N$. biflorus, but has usually a solitary flower, of a pure white, except the crown, which is yellow, often edged with orange or crimson.

1. N. Pseudonarcissus, Linn. (fig. 1024). Daffodil, Daffy-dovndilly, Lent Lily.-Bulb rather large. Leaves usually 2 or 3, seldom a foot long, from 4 to 6 lines broad, of a bluish green. Stem rather taller, with a single large, scentless, yellow flower. Perianth-tube about an inch long, wider at the top ; the segments ovate or oblong, of the length of the tube; the crown very conspicuons, broadly tubular, often longer than the segments, and slightly 6-lobed, or waved at the edge.

In meadows and mountain pastures, dispersed over the greater part of temperate Europe, especially France and Spain. Abundant in many parts of England, but often only as an escape from cultivation, as it soon establishes itself in great quantities in a meadow where it was once introduced; in Scotland and Ireland only where introdnced. Flo early spring. It varies much in size and intensity of colour of the flower, and the relative size of the crown.

2. N. biflorus, Curt. (fig. 1025). Primrose Peerless.-Much resembles the Daffodil in stature and foliage, except that it is ratber stouter and taller. Flowers usually 2 together, of a pale straw-colour, or nearly white, and sweet-scented. Perianth-tube slender, about an inch long; the segments rather shorter, oval or oblong; the crown very short, concave or broadly cup-shaped, yellow, slightly crenate at the edge.

In meadows, in southern and western Europe, chiefly Spain and western France. In Britain, much cultivated in cottage gardens, and naturalised in some western and southern counties. Fl. spring.

\section{GALANTHUS. SNOWDROP.}

A single species, distinguished as a genus from Leucoium by the inner perianth-segments being shorter than the outer ones, and by the finely pointed antliers opening at the top only.

1. G. nivalis, Linn. (fig. 1026). Common S.-Bulb rather small 
Leaves 2 or rarely 3 , narrow-linear, short at the time of flowering, but lengthening considerably afterwards. Stem 6 inches to near a foot high, with a single drooping, sweet-scented flower, shortly pedicellate above the terminal bract or spatha. Perianth-segments quite distinct down to the ovary, the 3 outer ones pure white, oblong, about 8 or 9 lines long, the 3 inner about half that length, and usually tipped with green.

In woods and shady pastures, in central and southern Europe, extend. ing eastwards to the Caucasus and northward into Holland. In Britain, probably not indigenous, but long cultivated, and now naturalised in England, Scotland, and Ireland. Fl. early spring.

\section{LEUCOIUM. SNOWFLAKE.}

Flowers solitary or several together, from a terminal spatha. Perianthsegments 6 , nearly equal, distinct down to the ovary or slightly cohering at the base. Anthers obtuse, opening in longitudinal slits.

A genus of very few species, chiefly south European, and distributed by some garden botanists into almost as many genera.

1. L. æstivum, Linn. (fig. 1027). Summer S.-Bulb larger than that of the Snowdrop. Leaves few, a foot long or more, like those of a Narcissus. Stem 1 to $1 \frac{1}{2}$ feet high, with a terminal cluster of 2 to 6 broadly bell-shaped flowers, on pedicels from 1 to 2 inches in length, arising from a sheathing entire bract or spatha. Perianth-segments ovate, about 6 lines long, of a pure white, with a short, sometimes greenish tip.

In meadows, in central and southern Europe, extending eastward to the Caucasus, and northward rather farther than the Snovdrop. Considered indigenous in several of the south-eastern counties of England. Fl. spring, rather late. [The Spring Snouflake (L. vernum, Linn.), a common Continental plant, smaller than the Summer $S$. , with a bifid spatha, is naturalised in Dorsetshire.]

\section{DIOSCORIDE⿸厂 THE YAM FAMILY.}

Climbing plants, with tuberous or woody rootstocks, alternate leaves with netted veins between the ribs, and small unisexual flowers. Perianth of 6 divisions. Stamens in the males 6 . Ovary in the females inferior, 3 -celled, with 1 to 3 ovules in each cell. Styles or stigmas 3 . Seeds with a minute embryo in a hard albumen.

An Order consisting of bnt very few gencra, but with a considerable number of species, dispersed over the warmer ref ins of the globe. They include the cultivated Yain, and several South African and Mexican plants grown in our greenhonses as curiosities on account of their massive woodv root.stocks, contrasted with the slender, climbing annual stems 


\section{TAMUS. BLACK BRYONY.}

A single or perhaps two species, distinguished as a genus in the Order by the fruit, which is a berry, not a dry capsule.

1. T. communis, Linn. (fig. 1028). Black Bryony.-An elegant climber, twining to a considerable length over hedges and bnshes, easily known by its bright, shining, heart-shaped leaves, with a tapering point, and sometimes almost 3 -lobed bnt otherwise entire. Flowers small, of a yellowish-green; the males in slender racemes, often branched and longer than the leaves; the females in much shorter and closer racemes. Berries scarlet, often very numerons.

In hedges, and open woods, and bushy places, in west-central and sonthern Europe, extending eastward to the Caucasns, and northward to Belgium. Dispersed over nearly the whole of England, and common in some counties, but not fonnd in Scotland, and in Ireland confined to the banks of Lough Gill, in Sligo. Fl, spring and early summer.

\section{LILIACE无. THE LILY FAMILY.}

Perennial herbs, with a creeping, wulbous, or clustered rootstock, and either radical leaves and peduncles, or annual biennial, or, in a few exotic species, perennial, leafy flowering-stems. Flowers hermaphrodite or rarely unisexual. Perianth inferior, petal-like, with 6 divisions. Stamens 6 . Ovary free, 3-celled, with several ovules or rarely only one ovule in each cell. Styles single, with an entire or 3-parted stigma. Fruit a capsule or berry. In a very few cases the parts of the flower are reduced to 4 , or increased to 8 .

A large Order, widely distributed over every part of the globe, and supplying several of the most gorgeons ornaments of our flowergardens. It is easily distinguished from Alismacee by the carpels nnited into a single ovar: and fruit, from Amaryllidea by the free or superior ovary, from Juncece by the petal-like, coloured perianth. It is nsually divided into two or more Orders, varionsly circumscribed according as the character is taken from the foliage, the fruit, the seed, or the stock, none of which taken alone give a very natural demarcation. A more natural arrangement appears to be to preserve the whole as one large family, divided into suborders, of which five. enumerated below, are represented in Britain.

stem leafy.

Stem branching. Frult a berry.

Leaves short, subulate, and clustered. Flowers axillary . L. AsPARAGCR

Leaves ovate, stiff, and prickly. Flowers on the middle of the leaves.

stems simple.

Pruit a berry.

Leaves net-velned, in a single whorl of 4 or rarely 5 . 1. PARIS.

Leaves parallel-velned, alternate or radical.

Flowers axillary

Nlowers in a terminal raceme.

Perianth bell-shaped. Leaves radical . . 8. CONvALLARMA 
Perfanth spreading, divided to the base. Leaves altcr-

Fruit a capsule.

Rootstock not bulbous.

Flowers of a brownish white, paniculate

Flowers yellow, in a raceme or spike.

Style simple.

Styles 3 Stlgmas capitate: - .

Stigmas 3 , sessile, feathery : $: \vdots$ TRIGLocHIN (p.

Rootstock bulbous.

Flowers in a terminal umbel or head.

Flowers solitsry, or in a terminal raceme.

4. MatanthemUM.

Perisnth-segments spreading.

Perianth white, with pink stripes. Hlowers usually solitary .

Perianth yellow. Flowers in a corymb-like ra-

ceme
Perianth-segments converging into a bell-shape.
Segments chequered, the inner ones with a cavity near the base

Segments not chequered, without any cavities :

stem leafless. Leaves all radical, sometimes sheathing the stem.

Rootstock creeping. Fruit a berry .

Rootstock bulbons. Fruit a capsule.

Flowers radical, with a very long tube commencing under-

ground
Flowers in a terminal umbel or head:

Flowers in a terminal raceme.

Perianth of 1 piece, with 6 minute teeth . . . . 13. MUduscarI.

Perianth of 6 segments.

Flowers blue or pink. (Fllaments flattened or not) . Flowers white or greenish. Flaments flattened.

Flowers yellow. Filaments not tlattened

15. SIMETHIS,

16. NARTHECIUM.

17. TOFIRLDIA.

TRIGLOCHIN (p. 430)

14. ALITUM.

\section{LLOTDU.}

10. Gagra.

7. Fritillaria.

8. TULIPA.

3. Convaluaria.

18. CoLcrincuM.

14. Alliom.

12. ScILLA.

11. ORn ITHOGalem.

10. G $\triangle Q \mathrm{EA}$.

The above Genera belong to the following Suborders :-

1. Trillidrs. Fruit a berry. Leaves with netted velns. Styles free. Genus : -1. PARIS.

2. Convallarir.z. Fruit a berry. Leaves with parallel veins. Styles united. Testa of the seed membranous. Genera:-2. Polfgonatum; 3. Convallaria; - mainanthimum.

3. ASP $\triangle R A G E$ F. Frult a berry. Leaves with netted veins, Styles united. Testa of the seed hard and black. Genera:-5. AsParagus; 6 . RUScus.

4. Liliez. Fruit a capsule. Styles united. Genera:-7. Fritiluaria; 8 TUlipa ; 9. Lloy dia ; 10. Gagra ; 11. ORnithogale ; 12. ScIlla ; 13. MUSCARI; 14. Alliom ; 15 . Simeturs; 16. Narthrcium.

5. CoLchicz ג. Fruit a capsuie. Styles distinct. Genera:-17. Tormedra; 18 COLCHICUM.

Among the exotic Genera most familiar by long or general cultivation may be mentioned the Hyacinth, Asphodel, Yucca, Lilium, Calochortus, Erythronium or Dog-tooth Violet, Hemerocallis, Tuberose (Polyanthes), Agapanthus, Funckia, \&c., and some of their species, especially of Lilium, occasionally appear almost wild in the neighbourhood of gar. dens. The Pincapple and some showy Pourretias and Tillandsias, occasionally seen in our hothouses, belong to the nearly allied family of Bromeliaccer.

\section{PARIS. HERB-PARIS.}

Rootstock creeping. Stem simple, with a single whorl of nettedveined leaves, and a single terminal flower. Perianth of 8 or rarely 10 narrow segments in two series. Stamens as many. Ovary with 4 or rarely 5 cells, and as many distinct styles or stigmas. 
A genus consisting of the European and a few Asiatic species.

1. P. quadrifolia, Linn. (fig. 1029). Herb-Paris.-Stem 9 inches to a foot high, with a whorl of 4 broadly-ovate or obovate leaves, 2 to 3 or 4 inches long. Peduncles rising to 1 or 2 inches above the leaves. Perianth of a yellowish-green colour; the 4 outer segments narrowlanceolate, about an inch long; the 4 inner ones linear and rather more yellow. Anthers linear, on slender filaments. Berry of a bluish-black colour. Sometimes, but rarely, there is a fifth leaf, with the addition of a fifth to each of the parts of the flower.

In woods and shady places, dispersed over Enrope and temperate Asia, from the Mediterranean to the Arctic Circle, but not generally very common. Scattered over several parts of Britain, but local and not found in Ireland. Fl. spring or early summer.

\section{POLYGONATUM. SOLOMON-SEAL.}

Stems annual, erect and leafy, with a thick horizontal rootstock. Leaves parallel-veined. Flowers axillary, drooping. Perianth tubular, shortly 6-cleft. Stamens 6, inserted on the perianth. Ovary 3-celled, with 2 ovules in each cell. Style slender, with an entire stigma. Frnit a small berry.

A small genns, spread over the northern hemisphere without the tropics, easily known by its foliage and inflorescence.

Leaves whorled, narrow .

Leaves alternate.

Flowers usually several in each axil. Filaments hairy . . 2. P. multiflorum.

Fowers 1 or rarely 2 in each axil. Fllaments glabrous : 8 . P. officinale.

1. P. verticillatum, All. (fig. 1030). Whorled S.-Stem about 2 feet high. Leaves numerous, in whorls of 3,4 , or 5 , narrow-lanceolate, 2 to 3 inches long, of a bright green. Flowers usually several in each axil, on short branching peduncles or rarely solitary. Perianth about 4 lines long, white, with greenish tips. Berries red.

In woods and shady places, in the monntain districts of Europe and temperate Asia, extending far into Scandinavia. Very rare in Britain, being only known from near Bellingham in Northumberland, and in Forfarshire and Perthshire, on the banks of streams flowing from the Gramipians into the Tay. Fl. June.

2. P. multiflorum, All. (fig. 1031). Common S.-Stems near 2 feet high, erect or rather Inclining to one side. Leaves alternate, ovate or oblong, 3 or 4 inches long, all usually turning to one side. Flowers 2 to 7 or 8 together, on short branching peduncles, usually turned to the lower side of the stem away from the leaves. Perianth 7 or $\$$ lines long, white, with greenish tips. Filaments and style hairy, all included within the perianth. Berries of a dark blue, or red according to Godron.

In woods and shady places, almost all over Europe and Russian Asia, except the extreme north. Occurs in several parts of England, not indigenous in Scotland or Ireland. Fl, spring or carly summer.

3. P. officinale, All. (fig. 1032). Angular S.-Very near P. multiflorum, but of smaller stature, seldom exceeding a font in height, the flowers 
rather larger and especially thicker, solitary or 2 only in each axil, and the filaments of the stamens quite glabrous.

With nearly the same geographical range as $P$. multiflorum, but generally in more open and rocky situations, and more common in the limestone districts of southern Eurcpe. In Britain, more scarce, but undoubtedly wild in several localities in England and South Wales. Fl. spring and early summer.

\section{CONVALLARIA. CONVALLARIA.}

A single species, separated from Polygonatum by the leafless flowerstem bearing a terminal raceme, and by the short bell-shaped perianth, with the stamens inserted near $\mathrm{jts}$ base.

1. C. majalis, Linn. (fig. 1033). Lily-of-the-Falley.-Rootstock creeping. Leaves radical, usually 2 together in a scaly sheath; their long footstalks enclosed one within the other so as to appear like a stem; the blade oblong, tapering at both ends, 4 to 6 inches long. Flower-stem leafless, radical, shorter than the leaves. Flowers droop. ing, bell-shaped, pure white, sweet-scented, in a loose receme. Berrics globular, red.

In woods, dispersed over Europe and Russian Asia, from the Mediter. ranean to the Arctic Circle, and very common in some localities, especially towards the centre and north, but totally wanting in other districts. Abundant in some counties of England, very local or wanting in others, and not indigenous in Scotland or Ireland. Fl. spring.

\section{MAIANTHEMUM. MAY LILY.}

Rootstock usually creeping, with annual erect stems. Leares alternate. Flowers small, in a terminal simple raceme or narrow panicle. Perianth deeply divided into 4 or 6 nearly equal spreading segments. Stamens 4 or 6 , inserted at the base of the perianth-segments. Ovary 2- or 3-celled, with 2 ovules in each cell. Style short, with a 2- or 3. lobed stigma. Fruit a small berry.

A small genus, di gersed over Europe, temperate Asia, and north America.

1. M. Convallaria, Roth. (fig. 1034). May Lily.-Rootstock slender, creeping. Stems 6 to 9 inches high. Leaves 2, alternate, shortly stalked, ovate, deeply cordate. Flowers small, white, in a terminal raceme about an inch long, not branched, but the short, slender pedicels usually clustered. Perianth of 4 divisions. Stamens 4. Ovary 2-celled. Berries small, red. Smilacina bifolia, Desf.

In woods, and occasionally in pastures; dispersed over Europe, Russian Asia, and North America, and often very common. Rare in Britain, and omitted in the first edition of this Handbook, in the beliet that the few localities assigned to it were only where it had been planted. It is, however, stated to be nndoubtelly indigenous and abundant near Harkness, 6 miles from Scarborough. Fh early summer. 


\section{ASPARAGUS. ASPARAGUS.}

Herbs, with a creeping, matted rootstock, and annual branching stems, with clusters of fine, short, subulate leaves (theoretically shown to be deformed branches called cladodes), in the axils of short scarious scales (the true leaves). Flowers small, axillary. Perianth of 6 distinct segment3. Stamens 6. Ovary 3-celled, with 2 ovules in each cell. Styles single, with a 3-lobed stigma. Fruit a berry.

A considerable genus, chiefiy African, with a few south European or Asiatic species, all readily known by the foliage.

1. A. offinalis, Linn. (fig. 1035). Common A.-Stems erect and much branched, usually 1 to 2 feet high in the wild state, attaining 4 to 5 feet when cultivated, and elegantly feathered by the numerous clusters of fine subulate cladodes, about half an inch long. Flowers small, of a grueaish white, hanging on slender pedicels, 2 or 3 together in the axils of the principal branches, many of them with stamens only. Berries small, red, and globular.

In maritime sands, or in sandy plains, in central and western Asia, all round the Mediterannean, and up the western coasts of Europe to the English Channel. In Britain, confined to the western and south western shores of England, and to the coast of Wexford and Waterford in Ireland. $F l$ summer.

\section{RUSCUS. RUSCUS.}

Shrub-like herbs, with a perennial rootstock, hard, green, branching stems, and alternate, stiff, evergreen, parallel-veined leaves (theoretically shown to be short leaf-like branches, cladodes), in the axils of minute, often microscopical scales (the real leaves). Flowers small, mostly unisexual, apparently sessile on the middle of the leaf. Perianth of 6 distinct segments. Stamens united in a tube, with 3 or 6 anthers. Ovary 3-celled, with 2 ovules in each cell. Style simple, with an nndivided stigma. Fruit a berry.

A small European and North African genus, easily known among European Monocotyledons by its stiff, shrub-like habit.

1. R. aculeatus, Linn. (fig. 1036). Butcher's Broom.-A rigid, dark green, much branched plant, 2 to 3 fcet high; the stems said to be biennial, although apparently shrubby. Cladodes numerous, ovate, all terminating in a prickly point. Flowers small and white, apparently sessile in the middle of what is really the upper surface of the cladode, though it is usually turned downwards by a twist of the cladode at its base; and a close examination will show that the flower is in fact borne on a pedicel arising from the axil of the cladode and closely adnate to its surface, with a minute bract under the flower. Berries red.

In woods and bushy places, in west central and southern Enrope, extending eastward to the Caucasus and northward to Belgium, but not into Germany. Abundant in some of the sonthern counties of England, but not truly wild in northern England, Scotland, or Ireland. Fl. spring. 


\section{FRITILLARIA. FRITILLARY.}

Bulbous herbs, with a leafy stem, and 1 or more rather long, droopIng flowers in a terminal raceme. Perianth bell-shaped, with distinct segments as in Tulipa, but the 3 inner segments have near their base a nectariferous cavity. Stamens inserted at the very base of the perianth, the anthers attached a little above their base. Capsule as in Tulipa.

An elegant genus, chiefly North Anierican and Asiatic, with 2 or 3 species extending into Europe.

1. F. Meleagris, Linn. (fig. 1037). Common P., Snake's head.-Stem a foot high or rather more, with 3 or 4 linear or somewhat lanceolate leaves, and a single terminal drooping flower, usually of a dnll red, marked inside with more highly coloured, chequered lines and spots; the segments oblong, narrowed at both ends, about $1 \frac{1}{2}$ inches long, the cavity of the inner ones oblong or linear.

In moist meadows, and pastures, and occasionally in woods, all across central Europe, from France and southern Scandinavia to the Caucasus, replaced in southern Europe by a closely allied species or variety. Occurs in several parts of England, but perhaps truly wild only in some of the southern and eastern counties, and not in Scotland or Ireland. Fl. spring. It varies occasionally with white or yellowish Howers.

\section{TULIPA. TULIP}

Bulbous herbs, with a leafy stem, and a single terminal flower (or very rarely 2), usually large and erect when fully out. Perianth bellshaped; the segments free from the base, without any depression in the centre. Stamens free from the perianth; the anthers erect, attached by their base. Style very short, thick, or 0 ; stigma 3-lobed. Capsule 3 -celled, with several flattish horizontal seeds in each cell, their testa pale and thin.

A splendid genus, chiefly south European and west Asiatic, including the Tulips of our gardens, which are most of them varieties of $T$. Gesneriana.

1. T. sylvestris, Linn. (fig. 1038). Wild T.-Stem about a foot high, with 1,2 , or rarely 3 linear-lanceolate leaves, and a single terminal yellow flower, drooping in the bud, nearly erect when fully out, and with a faint fragrant smell. Perianth-segments narrowed at the base and at the top, about $1 \frac{1}{2}$ inches long, the inner ones rather broader than the outer. Stamens about half as long, with a tuft of hairs at the base of the filaments.

In fields, pastures, and waste places, in central and southern Europe, extending eastward to the Caucasus and northward to Holland. Indigenous in some of the eastern and southern counties of England, intro. duced in some others. Fl. spring. 


\section{LLOYDIA. LLOYDIA.}

A single species, with most of the technical characters of Tulipa, but with a slender style, and the small spreading perianth of the following genera.

1. L. serotina, Reichenb. (fig. 1039). Mountain L.-Bulb small, with 2 or 3 almost filiform leaves, 3 or 4 inches long, and a slender stem, about the same height, bearing 2 or 3 short narrow leaves and a single terminal white flower. Perianth-segments about 4 or 5 lines long, spreading, broadly oblong, marked inside with 3 longitndinal reddish lines, and a small yellow spot at the base. Stamens shorter than the perianth, and inserted at its very base. L. montana, Salisb.

In rocky mountains, in northern and Arctic Kurope, Asia, and America, and in the high mountain-ranges of Europe and Asia. Very rare in Britain, and only on the Snowdon range. Fl. June.

\section{GAGEA. GAGEA.}

Bulbous herbs, with 1 or 2 radical leaves, and a short stem, with a terminal raceme of yellow flowers flattened into a corymb, with a leaflike green bract under each pedicel, and sometimes a leaf below the flowers. Perianth spreading, with distinct segments. Stamens inserted at their very base, with filiform, not flattened filaments. Seeds of Ornithogalum.

A small European and Asiatic genus, closely allied to Ornithogalum, with which it was formerly united, but distinguished by the stamens, the yellow flowers, and more leafy bracts.

1. G. lutea, Ker. (fig. 1040). Yelloio G.-Bulbs small, forming nsually two new ones every year, one on each side of the old one. Leaves 1 or very rarely 2, linear, pointed and curved like those of a Tulip. Stem slender, rarely 6 inches high. Flowers 3 or 4 , in a flat raceme, almost contracted into an umbel; the leaf-like bracts as long as the pedicels or longer. Perianth-segments about 6 lines long, very spreading, narrow-oblong, yellow, with a green back. G. fascicularis, Salisb.

In meadows and fields, especially in sandy soils, over the greater part of Europe and temperate Asia, except the extreme north. Occurs in several parts of England, and the Lowlands of Scotland, but rarely, and not found in Ireland. Flo spring. Continental botanists distinguish as species several forms, according as to whether there are 1, 2, or 3 bulbs at the time of flowering (if 1 only, it is the old bulb still remaining entire, the new ones commencing only, or not yet visible; if 3 , the 2 new ones are fully formed, spreading out horizontally before the old one is absorbed; if 2 , the old one is fully absorbed, leaving only a shrivelled stem between the 2 new ones), and some slight differences in the breadth, and obtuse or pointed ends of the perianth-segments, and it is probable that similar variations may be found in the British specimens. 


\section{ORNITHOGALUM. ORNITHOGALUM.}

Bulbous herbs, with the leaves all radical and not sheathing the stem. Flowers white or partly grcen, in a terminal raceme, with a scarious bract under each pedicel. Perianth very spreading, with distinct seg. ments, remaining persistent after fading. Stamens almost free from the perianth, with flattened filaments. Seeds few, black, nearly globular.

A considerable genus, chiefly European, west Asiatic, and African, only distinguished from Scilla by the more persistent perianth, without any blue or pink in its colour.

Raceme flattened into a corymb, the lower pedicels mnch longer than the upper

Racemes elongated, the pedicels of nearly equal length.

Flowers few aud large, the segments near an inch long . . 2. 0. nutans.

Flowers small and numerous, the segments about 4 lines long. 3. 0. pyrenaicum.

1. O. umbellatum, Linn. (fig. 1041). Star-of-Bethlchem.-Bulb ovoid, full of a clammy juice, like that of the Bluebell. Leaves long and narrow, weak and flaceid. Stem from a few inches to near a foot high. Raceme flattened into a corymb, the lower pedicels being lengthened so as to bring their flowers at least to the level of the inner ones. Perianth-segments very spreading. varying from 6 lines to near an inch in length, white, with a broad, green, central line outside.

In waste and cultivated places, in central and southern Europe, from France and Holland to the Caucasus. In Britain, not indigenous, but established in many parts of England. Fl. spring and early summer.

2. O. nutans, Linn. (fig. 1042). Drooping O.-A handsome species, a foot high or more, with a raceme of 5 or 6 large nodding flowers on very short pedicels. Perianth-segments about an inch long, less spreading than in the other species, white within, green in the centre outside. Filaments very broad and petal-like.

In waste and cultivated places, in most parts of central and southern Europe, extending northwards to southern Scandinavia. In Britain, not indigenous, but established in some parts of England. Fl. spring.

3. O. pyrenaicum, Linn. (fig. 1043). Spiked O.-Bulb ovoid, with few long, linear leaves. Stems $1 \frac{1}{2}$ to 2 feet high, with a long raceme of small, greenish-white flowers, on slender pedicels varying from 3 to 6 lines in length, with a bract about as long under each one. Perianth. segments very spreading, about 4 lines long. Stamens rather shorter.

In woods and pastures, in western and southern Europe, extending eastward to the Caucasus, and northward into Belgium, but only into southern Germany. Rare in Britain, but has been found in several of the southern counties of England. Fl. early summer. [The young stems are sold at Bath as a vegetable, and called "French Asparagus."

\section{SCILLA. SQUILL}

Bulbous herbs, with radical leaves. Flowers nsually blne or rarely pink, in a terminal raceme, sometimes flattened into a corymb. Perianth-segments deciduons, free or slightly cohering at the base, either spreading or forming a bell-shaped or tubular flower, and then spread- 
ing at the top only. Stamens inserted on the perianth, below the centre of the segments. Seeds of Ornithogalum.

A considerable genus, chiefly from the Mediterranean and Caucasian regions, distinguished from Ornithogalum chiefly by the colour of the flowers and deciduous perianth, from Hyacinthus by the segments distinct from the base or very nearly so.

Fiowers erect, the perianth-segments spreading.

Flowers in spring, with a bract under each pedicel

Howers in autumn, without bracts

Fowers nodding, narrow bell-shaped

Two or three Mediterranean species, with corymbose racemes of bright-blue flowers, are cultivated in our flower-gardens.

1. S. verna, Huds. (fig. 1044). Spring S.-A delicate little plant, with a small bulb, and narrow-linear leaves, 2 to 4 inches long. Flowerstem seldom 6 inches long, with several small, erect blue flowers, in a short terminal raceme, almost flattened into a corymb, with a linear bract under each pedicel. Perianth-segments scarcely above 3 lines long, spreading, but not so much so as in Ornithogalum. Stamens inserted close to their base.

In stony and sandy wastes, and pastures, especially near the sea, in western Europe, reappearing farther east in Denmark, on the Rhine, and in Sardinia. In Britain, it occurs at intervals, but in abundance on the east coast of Ireland, the western and northern coasts of Great Britain, the east of Scotland, and very locally in north-eastern England. Fl. spring.

2. S. autumnalis, Linn. (fig. 1045). Autumnal S.-Bulb rather larger than in S. verna. Flower-stems 6 to 9 inclies high, or more when very luxuriant, appearing after the leaves have withered away. Flowers small, erect, of a pale violet-blue, or somewhat pink, in a raceme short at first, but which will lengthen out to 2 or even 3 inches, all the pedicels remaining of the same length, and without bracts. As the flowering advances, a tuft of leaves, similar to those of $S$. verna, shoots out by the side of the stem for the following year.

In rocky wastes of southern Europe, from Spain to the Cancasus, extending northward into central France, and up the western coast to the English Channel, reappearing on the Rhine. In Britain, confined to some of the southern counties of England. Fl. autumn.

3. S. nutans, Sm. (fig. 1046). Bluebell.-Bulb white, full of a clammy juice. Leaves linear, shorter than the flower-stem, 4 or 5 lines broad. Stem about a foot high, angular, with a terminal, one-sided raceme of drooping blue flowers, each with a small narrow bract at the base of the pedicel. Perianth about 6 lines long, almost tubular, the segments spreading at the top only, although distinct, or very shortly nnited at the very base. Stamens inserted above the base of the segments, but below the middle. Hyacinthus nonscriptus, Linn.

In woods, hedges, and shady places, in western Europe, from Spain to Britain, extending eastward only into central France, and here and there along the Mediterranean to Italy. Very abundant in Britain. Fl. spring. Originally placed in the genus Hyacinthus, on account of the general form of the perianth, it was removed to Scilla as having the segments distinct or nearly so, and is now often considered as forming 
a distinct genus [Agraphis, Link., Endymion, Dumort.], cither alone or with other species which connect it with the other Scillas.

\section{MUSCARI. MUSCARI.}

Bulbous herbs, with radical, linear leaves, and a terminal raceme of nodding flowers, nsually blue or brown. Perianth globular or ovoid, contracted at the mouth, with 6 minute teeth.

A small genns, chiefly from the Mediterranean region and western Asia, separated from Hyacinthus on account of the form of the perianth.

1. M. racemosum, Mill. (fig. 1047). Grape Hyacinth.-Bulb rather large. Leaves narrow-linear, rather thick, but not stiff, from 6 inches to a foot, or when very luxuriant $1 \frac{1}{2}$ feet long. Stem nsually shorter, with a close terminal raceme or head of small dark-blue flowers, looking almost like little berries; a few of the uppermost of a paler blue, erect, much narrower, and withont stamens or pistil.

In cultivated and waste places, heaths and pastures, in central and southern Kurope, extending eastwards to the Caucasus and northwards over a great part of Germany. In Britain, it occurs in the eastern counties of England; formerly much cultivated in flower. gardens. Fl. spring.

\section{ALLIUM. ALLIUM.}

Bulbous herbs, with radical leaves, sometimes sheathing the stem to a considerable height. Flower-stem otherwise leafless, bearing a terminal umbel or head of flowers, surrounded by a spatha of 2 or 3 thin, whitish or scarious bracts. Perianth of 6 segments, distinct from the base, either spreading or bell-shaped. Stamens inserted on their base, either all alike or the 3 inner ones broad and 3-cleft; the middle lobe bearing the anther. Capsule with 1 or 2 black seeds in each cell.

An extensive genus, ranging over Europe, Africa, northern Asia, and North America Most of the species possess the peculiar, well-known onion or garlic smell.

Leaves flat or keeled.

Umbels flat or convex, of few very white fowers. Leaves quite radical.

Leaves more than an inch broad, on long stalks

Leaves not inch broad, not stalked.

Umbels nearly globular, with numerous purple or pale flowers (or bulbs). Leaves sheathing the stem at their base.

Leaves very narrow, and thick. Stamens all similar and entire

Leaves flat or keeled. Inner stamens broad and s-cleft. Stamens longer than the perlanth. Umbels large, rarely with bulbs Stamens not longer than the perlanth. Umbels with Leaves cylindrical or nearly so, very narrow. Uimbels 7. A. ursinum. 8. A. triquetrum.

8. A, oleraceum.

1. A. Ampeloprasum.

2. A. Scorodoprasum. globular.

Stamens all similar and entire.

- Flowers on long pedicels, usually intermixed with bulbs. 8paths-bracts with long green points .

Nowers in compact heads, without bulbe Spatha-bracto whort.

8. A olenacesm.

4 A. schanopranem 
Three inner stamens flattened, and 3-eleft. Spatha-bracts short.

Flowers intermixed with bulbs .

Flowers without bulbs

6. A. vineale.

b. A.sphcerocephalum.

The genus comprises also the Garlic (A. sativum), the Onion (A. Cepa), the Shallot (A. ascalonicum), the Leck (A. Porrum), now believed to be a cultivated variety of $A$. Ampeloprasum, and a few species occasionally cultivated for ornament.

1. A. Ampeloprasum, Linn. (fig. 1048). Wild L.-Stems 2 to 3 feet high. Leaves rather broadly linear, flat, but usually folded lengthwise and keeled underneath, from a few inches to above a foot long, their sheaths enclosing the lower part of the stem. Flowers very numerous, of a pale purple, on long pedicels, forming large globular heads, with a spatha of 1 or 2 bracts, often tapering into a green point, but shorter than the flowers. Perianth bell-shaped, 2 to $2 \frac{1}{2}$ lines long. Stamens protruding from the perianth, the 3 inner ones with flattened, 3-cleft filaments.

In cultivated and waste places, in southern Europe and western Asia. In Britain, indicated as an introduced plant in two or three spots in western England, and said to be more abundant in the Channel Islands, and perhaps indigenous on the coast of Galway, in Ireland. Fl. summer. The A. Babingtonii, Borr, is a variety with sessile bulbs in the nmbel in lieu of most of the flowers, a character which it loses by cultivation, and our garden Leek (A. Porrum, Linn.), is a cultivated variety of the same species.

2. A. Scorodoprasum, Linn. (fig. 1049). Sand L.-This has the flat leaves, short spatha, bell-shaped perianth, and flat, 3-cleft inner st amens of $A$. Ampeloprasum; but the nmbel is nsually smaller, seldom (if ever in this country) withont bulbs, and the stamens are not longer than the perianth. It is also nsually not so stout a plant, the bulb smaller, with the young offsets on slender stalks, and the umbel is occasionally reduced to a head of bulbs without any flowers. A. arenarium, $\mathrm{Sm}$.

In sandy pastures, and waste places, and occasionally in woods, scattered over northern and central Europe, but not an Arctic plant, and not common in the south. In Britain, chiefly in northern England, southern Scotland, and some parts of Ireland. Fl. summer. It may possibly prove to be a bulbiferous variety of the Continental $A$. rotundum.

3. A. oleraceum, Linn. (fig. 1050). Field L.-Stems 1 to 2 feet high, with a rather small bulb. Leaves narrow-linear, nearly flat, but rather thick, 1 to $1 \frac{1}{2}$ lines broad, their sheathing bases covering the stem a considerable way np. Spatha of 2 broad bracts, with long, green, linear points, one of which, at least, is mnch longer than the flowers. Umbel much looser than in the allied species; the flowers pale brown, on pedicels from $\frac{1}{2}$ to above 1 inch long, always (in Britain) intermixed with bulbs. Filaments all simple, rather shorter than the perianth.

In cultivated and waste places, dispersed over all Europe and tem. perate Asia, except the extreme north. In Britain, it occurs on the borders of fields in east Scotland and many connties of England, but not in Ireland. Fl.summer. In southern Europe it occnrs occasionally without bulbs in the umbel. With ns the nmbel has often bulbs only, 
and then it is distinguished from $A$. vineale by the long points of the spatha-bracts. [A. complanatum, Bor., is a broad-leaved form.]

4. A. Schœnoprasum, Linn. (fig. 1051). Chives.-Stems about a foot high, often several together. Leaves very narrow, but cylindrical and hollow, only one of them sheathing the stem at its base. Umbel contracted into a dense globular head of rather large, purplish flowers, without bulbs. Spatha of 2 or 3 broad, coloured bracts, much shorter than the flowers. Perianth-segments 3 to 4 lines long, very pointed. Stamens all alike and simple, considerably shorter than the perianth.

In rocky pastures, throughout temperate and northern Europe and Russian Asia, and in the mountain districts of southern Europe. Rare in Britain, being only recorded from Northumberland, Lancashire, Brecon, and Cornwall. Fl. summer. [A. sibiricum, L., is a large form with recurved leaves, found at Kynance Cove.]

5. A. sphærocephalum, Linn. (fig. 1052). Round-headed L.-Stems 1 to 2 feet high. Leaves few and short, very narrow, nearly cylindrical, and hollow, their sheathing bases corering the lower half of the stem. Umbel globular, rather dense, with numerous purplish flowers, without bulbs. Spatha of 2 bracts, shorter than the flowers. Perianth about 2 lines long. Stamens usually longer than the perianth, the 3 inner filaments broad and 3-cleft.

In cultivated and waste places, in central and southern Europe, extending eastward to the Caucasus and northward over a great part of Germany and Belgium. In Britain, confined to the neighbourhood of Bristol, and the Channel Islands. Fl. summer.

6. A. vineale, Linn. (fig. 1053). Crow Garlic.-Very near A. spharocephalum, and perhaps only the bulb-bearing form of that species. The stature, foliage, and flowers are the same, except that the perianth is usually much paler and greener, and the inner filaments are said to be rather more deeply cleft. The umbel always bears bulbs intermixed with the flowers, or bulbs only without flowers. In the latter case it is distinguished from $A$. oleraceum most readily by the want of the long points to the spatha-leaves.

In cultivated and waste places, over the greater part of Europe, and more common in the north than A. spharocephalum, extending far into Scandinavia. Local in England, Ireland, and Scotland. Flo early summer.

7. A. ursinum, Linn. (fig. 1054). Ramsons.-Readily distinguished by the thin, flat, spreading leaves, 6 to 8 inches long and above an inch broad, on long stalks, not sheathing the stem above-ground. Flowerstem not a foot high, bearing a loose nmbel of about a dozen white flowers ; the spatha-bracts usually falling off before the flower expands. Perianth-segments lanceolate, very spreading. Stamens shorter, all simple.

In woods and shady places, in central and southern Europe, extend. ing all across Russian Asia, and northward to southern Scandinavia. Dispersed all over Britain, and in some places very abundant, but not everywhere common. $\mathrm{Fl}$. spring or early summer.

8. A. triquetrum, Linn. (fig. 1055). Triquetrous L.-Leaves broadly linear, flat but folded and keeled, only sheathing the stem at its very base, and sometimes very long. Flower-stem not a foot high, bearing a loose, slightly drooping umbel of rather large white flowers. 
Spatha-bracts short. Perianth-segments oblong, not spreading. Stamens $\mathrm{ab}$ ut half their length, all simple.

In molst, shady places, in the Mediterranean region, from Spain to Greece, unknown in France, except the extreme south. In Britain confined to Cornwall and the Island of Guernsey. Fl. May and June.

\section{SIMETHIS. SIMETHIS.}

A single species, differing from all British capsular-fruited Liliacca except Narthecium in its rootstock not bulbons, and from Narthecium in its panicled flowers, deciduous perianth, and few seeds. It was formerly comprised in the exotic genus Anthericum, but has been isolated on account of a different habit, accompanied by slight differences in the stamens, and the number of seeds.

1. S. bicolor, Kunth. (fig. 1056). Variegated S.-Rootstock short, with a tuft of thick fibrous roots. Leaves all radical, long, linear, and grass-like. Stem leafless, usually under a foot high, branching in the upper part, with a bract under each branch, the lowest bracts often linear and leaf-like. Flowers erect, in a loose terminal panicle. Perianth spreading, of 6 oblong segments, abont 4 lines long, white inside, purplish outside, especially near the tip. Stamens shorter than the perianth-segments, inserted near their base, the filaments very woolly. Style entire. Capsule 3-valved, with 2 shining black seeds in each cell.

On heaths and open wastes, in the extreme west of Europe, from north-western Africa and Italy to Kerry, in Ireland, and formerly fonnd in plantations, near Eastbourne, in Dorsetshire, possibly introduced with the seeds of the Pinaster. Fl. early summer.

\section{NARTHECIUM. NARTHECIUM.}

A single species, with the grass-like vertical leaves, simple racemes, and persistent yellow perianth of Tofieldia, but with the bearded filaments and simple style of Simethis, differing from both in its minnte seeds, with a thread-like point at each end. The consistence of the perianth, firmer than in the generality of Liliacece, shows an approach to Juncacece, with which many botanists associate it.

1. N. ossifragum, Huds. (fig. 1057). Bog or Lancashire Asphodel.Pootstock shortly creeping. Stem stiff and erect, 6 inches to a foot high or rarely more. Leaves shorter than the stem and near its base linear, vertically flattened and sheathing at their base in 2 opposite ranks as in Iridec; the upper ones rednced to short scales. Flowers in a stiff terminal raceme, of a bright yellow. Perianth-segments spreading, lanceolate and pointed, 3 or 4 lines long, green on the back and persistent as in Ornithogalum. Stamens rather shorter, their filaments covered with a white wool. Capsule very pointed, longer than the perianth.

In bogs, in western and central Europe, and North America, but not an Arctic plant; a rare instance of a species common to Europe and North America without extending over Asia. In Britgin, abnndant in bogs and wet moors. Fl. summer. 


\section{TOFIELDIA. TOFIELDIA.}

Herbs, with creeping rootstocks, grass-like, chiefly radical leaves, vertically flattened and sheathing on opposite sides as in Iridece, and small yellowish green flowers in terminal spikes. Perianth of 6 distinct segments persistent round the capsule. Stamens inserted at their base. Ovary 3-lobed, with 3 distinct styles. Capsules small, 3-lobed, with several small oblong, brown seeds.

A small genus, chiefly North American, extending along the Andes to tropical America, and westward across northern Asia to Europe.

1. T. palustris, Huds. (fig. 1058). Scottish Asphodel.-Radical leaves an inch or rarely $1 \frac{1}{2}$ inches long. Flower-stem about 6 inches bigh, with 1 or 2 short leaves at its base, and terminated by a little globular or ovoid spike or head; the perianth not quite a line long. The very short pedicels are each in the axil of a minute bract, and within the bract is a still smaller 2-lobed or 3-lobed one, sometimes quite imperceptible, but never placed at the top of the pedicel as in the larger species which is common in central Europe.

In the bogs of northern Europe, Asia, and America, and of the great mountain-ranges of central Europe, but always at high latitudes or in alpine situations. Not uncommon in the mountains of Scotland and northern England, but not found in Ireland. Fl. summer.

\section{COLCHICUM. COLCHICUM.}

Bulbous herbs, with radical leaves, and the large, almost radical, long-tubed flowers of Crocus. Stamens 6. Ovary undergronnd, but within the tube of the perianth, not below it. Styles 3 , very long and thread-like. Capsule 3-valved, with many seeds.

A small genus, chiefly Mediterranean and West Asiatic, with the habit of Crocus, but very different stamens, ovary, and styles.

1. C. autumnale, Linn. (fig. 1059). Common C., Meadov Saffion.-At the time of flowering there are no leaves; the brown bulb ending in a sheath of brown scales, enclosing the base of the flowers, whose long tube rises to 3 or 4 inches above ground, with 6 oblong segments of a reddish-purple or rarely white, and near $1 \frac{1}{2}$ inches long. Soon afterwards the leaves appear and attuin in spring a length of 8 or 10 inches by about 1 or $1 \frac{1}{2}$ inches in breadth. 'The capsule is then raised to the surface of the ground by the lengthening of the peduncle, soon after which the leaves wither away.

In moist meadows, and pastures, over the greater part of Europe, but rare in the north, and scarcely extends into Asia. Very abundant in some parts of England, rare in Ireland, and naturalised only in Scotland. Fl. autumn.

\section{JUNCACEÆ. THE RUSH FAMILY.}

Herbs, usually stiff, with cylindrical or narrow and grasslike leaves, and small, herbaceous or dry flowers, in terminal or apparently lateral elusters or panicles. Perianth regular, dry, and calyx-like, of 6 segments. Stamens 6 or rarely 3 only. the 
anthers opening iuwards. Siyles single, with 3 slender stigmas. Capsule 1- or 3-celled, opening in 3 valves, with few or many small seeds.

A small family, abundantly spread over the whole surface of the globe, with almost all the technical characters of the Lily family except the consistence of the perianth, whilst the general aspect brings it nearer to the Sedges and the Grasses.

Capsule 3-celled, with many seeds. Leaves cylindrical, at least at their

tips, or rarely faxt .

Capsule 1-celied, $x^{2}$ th 3 seeds. Leaves flat and grass-like $\vdots \quad \vdots \quad 2$ LuzuLA.

\section{JUNCUS. RUSH.}

Leaves stiff and glabrous, cylindrical, at least at the tips, or terete and grooved, or very rarely flat and grass-like. Flowers either distinct or in little clusters, usually arranged in irregular panicles; the branches very unequal in length, with a dry sheathing bract (like the glumes of Sedges and Grasses) under each ramification, cluster, or flower; the outer bract or bracts often ending in a long leaf-like point, in some species appearing like a continuation of the stem. Stamens 6, rarcly 3. Capsule 3.celled, with numerous small seeds.

The principal genus of the Order, and co-extensive in its geographical range. The species are almost all inhabitants of marshy, boggy, or wet ground, and several are almost cosmopolitan.

Stems quite leafless, except the brown sheathing scales at the base, which have no leafy tips. Howers in a lateral cluster.

Stems soft and pliable.

Flowers very numerous. Perianth about 1 line long

Howers few, about halfway up the stem. Perianth about $\dot{z}$ lines long

Stems rigid.

Stems tufted, rather slender. Panicle loose. Perianth-seg.

ments very narrow
Stems very stiff. Rootstock creeping. Panicle many-flowered. Perianth segments neariy ovate

Leaves (sometimes cylindrical and stem-like) either on the stem or under the panicle, or forming leafy tips to the sheathingscales at the base of the stem.

Leaves cylindrical and hollow, but with internal cross partitions, which make them look jointed when dry.

Perianth-segments more or less pointed .

Perianth-segments all obtuse
Leaves and outer bracts cylindrical, very stiff, with prickly points.

Capsule much longer than the perianth . . . . . 13. J. acutus. Capsule not longer than the perianth $\quad . \quad 12 . J$ maritimus.

Leaves neither jointed nor prickly (usually channelled, or slender, or spreading).

Leaves all radical or nearly so (except the onter leal-like bract), and much shorter than the stem. Flowers not clustered, in a loose panicle Flowers in 1 or 2 terminal heads.

Heads solitary, with 2 to 4 flowers

Heads 1 or 2 , with 6 to 8 flowers in each

5. J. articulatus.

6. J. obtusiflorus.

2. J. glaucus.

4. $J$. balticus.

1 or 2 leaves on the stem below the panicie. small annuals. Flowers pale-coloured.

Fowers distinct, in a mnch branched, leafy panicle, occupying the greater part of the plant ? ? 10. J. Bufomise Fiowers collected in 1 or few terminal heads. 
l'erlanth segments 2 to $2 \frac{1}{3}$ lines long, scarcely poiuted. Capsule narrow . . . . . 11. J. pygmaus.

Perianth-segments under 2 lines, with a fine, often recurved point. Capsule short and broad . . . 12. J. capitatus. Perennials. Flowers brown.

Flowers several, distinct, in a loose panicle. Outer bract short

Flowers many, in terminal cymes. Bracts long : :

Flowers very few on each stem, distinct. Outer bracts very long and slender

7. J. compressus. 8. J. tenuis.

• 15. J.trifius.

Flowers 6 or 8 together in terminal heads . : : 16. J. castaneus.

These species are well distributed into two sections. In the one, comprising the first ten of the following species, the seeds are ovate or oblong, scarcely pointed. In the second section, to which belong the last five species (11 to 15), the testa of the seed is extended at each end into a little tail-like appendage.

1. J. communis, Mey. (fig. 1060). Common R.-The shortly creeping matted rootstock bears dense tufts of cylindrical leafless stems with solid pith, 2 to 3 feet high or even more, erect, but soft and pliable, sheathed at the base by a few brown scales. Some of these stems remain barren so as to resemble leaves; others bear, on one side, at 4 to 6 or 8 inches below the top, a densely-clustered panicle of small green or brown flowers; the very numerous peduncles vary from a line or two to above an inch in length, the central smaller ones have but 2 or 3 flowers, the others a considerable number in irregular cymes. Perianth-segments about a line long, very pointed. Capsule about as long, very obtuse or even notched. Stamens usually 3 only.

In wet situations, almost all over the northern hemisphere and in many parts of the southern one. In Britain, one of the commonest species. Fl. summer. Two extreme forms are usually distinguished as species, $J$. conglomeratus, Linn., with the flowers densely packed in close clnsters of about an inch diameter, usually brown; and J. effusus, Linn., with the panicles much looser, often 2 to 3 inches diameter, and paler coloured; but every gradation may be observed between them in this respect, as well as in other minute characters which have been assigned to them respectively.

2. J. glaucus, Ehrh. (fig. 1061). IIard R.-Resembles J. communis in its main characters, but the stems are seldom 2 feet high, and although thinner, yet harder and stiffer, darker green, striate and often glaucous, pith chambered; the panicles but 2 or 3 inches below the top; the flowers rather larger, in a much looser and less branched panicle. Capsule of a shining brown, never flattened or hollowed at the top, but rounded or almost pointed. Stamens usually 6.

Spread over Europe and Russian Asia, but not quite so abundantly as J. communis. Extends all over Britain. Fl. summer. [J. diffusus, Hoppe, is a hybrid with $J$. effurus, having less glaucous leaves and imperfect seeds.]

3. J. fliformis, Linn. (fig. 1062). Thread R.-Stems as soft as in $J$. communis, but very slender, and seldom much above a foot high. Clusters of flowers small, usually not above halfway up the stem; the flowers few, much larger than in J. communis; the perianth-segments abont 2 lines long. Capsule shorter, obtuse, with a short distinct style. Stamens usually 6.

In wet situations, in northern and central Eirope and Russian .1sis, 
and the mountain districts of southern Europe. In Britain, only known on the margins of lakes in northern England and Kincardine in Scotland. Fl. summer.

4. J. balticus, Willd. (fig. 1063). Baltic $R$.--Rootstock more creeping than in any of the foregoing. Stems very stiff and hard, 1 to 2 feet high or more, often prickly at the end. Panicle lateral, more erect and much more dense than in $J$. glaucus, the flowers larger, usually dark-brown. Perianth-segments broader and not so pointed, especially the inner ones, which are often quite obtuse. Capsule about the same length, obtuse, with a short style. Stamens 6.

Chiefly near the sea, at high northern latitudes, in Enrope, Asia, and America. Spread all round the Baltic and along the eastern coasts of the North Sea. In Britain only in the north-eastern connties of Scotland. Fl. summer. It is probably a luxuriant variety of the $J$. arcticus, a common plant in the extreme north of Europe and Asia, and reappearing at great elevations in the mountain-ranges of central Europe.

5. J. articulatus, Linn. (fig. 1064). Jointed $R$.-An exceedingly variable species in habit and size, but readily known by its leaves, which sheath the stem below, and are cylindrical npwards, and hollow, but divided inside by cross partitions of pith, which give them, especially when dry, the appearance of being jointed. Flowers in little clusters of from 3 or 4 to 8 or 10 or more, arranged in more or less compound terminal panicles; the outer bracts, and sometimes one or two of the others, ending in a short, fine leaf. Perianth-segments about the size of those of $J$. communis, either all pointed or the inner ones obtuse. Capsule more or less pointed, varying from the length of the perianth to half as long again.

Throughout Europe and Russian Asia, from the Mediterranean to the Arctic regions, and at high latitudes in North America. As abundant in Britain as J. communis. Fl. all summer. In rich, moist, deep soils the stems form dense tufts 2 or 3 feet high, with loose, very compound, brown or green panicles 5 or 6 inches diameter. In driedup sandy or muddy places the rootstock is more creeping, with ascend. ing stems, from a few inches to a foot or more, with much less branched panicles of a rich brown. On the edges of ponds and watery ditches the stems will spread over the water, rooting in it at the joints, often covering it to a great extent with dense floating masses. At high elevations the stems are often short and erect, with small panicles of 4 or 5 clnsters of dark brown flowers. [The principal recognised British forms are: 1. J. articulatus proper (acutiflorus, Ehrh.); tall with jointed leaves, and dense clusters of dark chestnut-coloured flowers, 6 stamens and an acuminate capsule. 2. J. supinus, Mœnch. (uliginosus, Sibth.), with flaccid often floating stems rooting at the inflorescence, obscurely jointed slender leaves, 3 stamens, and an obtuse mncronate capsule. 3. J. lamprocarpus, Ehrh., with a compressed stem, jointed leaves, 6 stamens, and a narrow beaked glossy capsule.]

6. J. obtusiflorus, Khrh. (fig. 1065). Obtuse R.-Probably to be added to the numerons varieties of $J$. articulatus, only differing from the csmmon larger erect form in having all the segments of the perianth obtuse or nearly so, and about as long as the very pointed cepsule. 
Mixed with $J$. artaculatus on the continent of Europe, and in some localities as common. Not uncommon in marshy places from midScotland southwards, and in Ireland. Fl. summer. [Considered to be very different from any form of articulatus, not only in the obtuse perianth-segments, but in the ovold mucronate capsule and tall stout habit.]

7. J. compressus, Jacq. (fig. 1066). Round-fruited R.-Stems 1 to $1 \frac{1}{2}$ feet high, erect and rather slender, slightly compressed at the base, with a few nearly radical leaves shorter than the stem, and 1 or 2 higher up, all very narrow and channelled or grooved. Flowers arranged singly or scarcely clustered, in a rather loose terminal panicle, of a shining brown. Perianth-segments obtuse, scarcely above a line long. Capsule as long or longer, with a short style.

In wet, marshy places, especially near the sea, in Europe and Russian Asia, from the Mediterranean to the Arctic regions. In Britain not so generally spread as some other species, and rare in inland districts. Fl. all summer. J. Gerardi, Loisel., is a variety with a narrower mucronate capsule, found in salt marshes.

[8. J. tenuis, Willd. (fig. 1067). Slender Rush.-Rootstock tufted. Leaves few, nearly all radical, very slender, channelled and deeply striate, base membranous. Flower-stems very slender, 6 to 15 inches high, cylindric, wiry. Flowers in terminal panicles, sessile or pedicelled. Perianth-segments pale, lanceolate, acuminate. Capsule shorter, ovoid, obtuse or pointed.

In wet sandy places of north-western Europe, France, Holland, and Germany, and the western United States; quite recently found in Herefordshire, Carnarvon, and in Kerry in Ireland. Fl. summer.]

9. J. squarrosus, Linn. (fig. 1068). Heath $R$-Leaves all radical or nearly so, numerous at the base of each stem, and not half its length, very narrow, grooved, stiff, but spreading, rarely longer and more erect. Flower-stem usually under a foot high, rigid, with a terminal, compound but not much branched panicle. Flowers usually distinct, not clustered. Perianth-segments about 2 lines long, rather broad, of a glossy brown, with broad, scarious edges. Capsule about the same length.

On moors and heaths, in drier situations than most Junci, in central and northern Europe and Asia, but scarcely an Arctic plant, although in southern Europe chiefly confined to moorlands. Abundant in Britain. Fl. summer.

10. J. bufonius, Linn. (fig. 1069). Toad R.-A small, pale-coloured annual, with numerous stems, often forming dense tufts, from 1 or 2 to 6 or 8 inches high, branching and flowering almost from the base. Leaves chiefly radical, short and slender. Flowers solitary or rarely 2 or 3 together along the branches, with the lower bracts leaf-like but short. Perianth-segments narrow and pointed, above 2 lines long, of a pale green, with scarious edges, 3 outer ones longer than the 3 others. Capsule oblong, shorter than the perianth.

In wet places, widely spread over the greater part cf the world. Abuntant in Britain. Fl. all summer.

11. J. pygmøus, Rich. (fig. 1070). Droarf $R$.-A tufted annual, I to 3 inches high, with the flowers collected in terminal clusters as in $J$. capitatus, but there are usually 3 to 5 clusters on each stem, sessile 
at the base of the branches or peduncles bearing the others. Perianth longer than in J. capitatus, the segments scarcely acute, striate. Capsule narrow, and longer than in J. capitatus. Seeds more distinctly ribbed.

In moist, sandy situations, in western and southern Europe, from Sicily and Portugal, over the greater part of France, reappearing in soutl-western Scandinavia, and near the Lizard and Kynance Downs in Cornwall. Flo summer.

12. J. capitatus, Weig. (fig. 1071). Capitate R.-A slender, tufted annual, 2 or 3 inches high, resembling the smaller specimens of $J$. bufonius, but the flowers are smaller, collected in terminal clusters of 6 or 8 , with very rarely a second or third cluster lower down. Perianth-segments under 2 lines long, ending in a fine, often recurved point. Capsule very much shorter, obovoid. Stamens usually 3.

In sandy situations, in western and southern Europe, and again in the Netherlands, north Germany, and southern Scandinavia. In the British Isles only recorded from West Cornwall and the Channei lslands. Fl. summer.

13. J. maritimus, Sm. (fig. 1072). Sea $R$.-Stems 2 to 3 feet high, in large tufts, very rigid, terminating in a prickly point, the sheathing scales at their base also terminating each in a stiff, cylindrical, stemlike, prickly leaf, shorter than the real stems. Flowers rather numerous, in little clusters, forming a loose, irregularly compound panicle; the outer bract at its base erect and nearly as long as or longer than the panicle, but more dilated at the base and looking less like a con tinuation of the stem than in J. communis. Perianth-segments about 1t lines long. Capsule rather shorter, or scarcely longer.

In maritime sands, widely spread along the shores of the Atlantic, from North America and Europe far into the southern hemisphere, and along the Mediterranean to the Caspian Sea, but not penetrating far into the Baltic, and not an Arctic plant. Occurs on many parts of the English and Irish coasts, but rare in Scotland. Fl. summer, rather late.

14. J. acutus, Linn. (fig. 1073). Sharp R.-Very near J. maritimus, but more rigid and prickly, the flowers rather larger, not so numerous, in closer panicles, and usually browner, and the stout capsule is considerably longer than the perianth-segments.

In maritime sands, along the shores of the Atlantic, and up the Mediterranean to the Caspian Sea, but not on those of the North Sea or the Baltic, nor yet recorded from the southern hemisphere. Rather more frequent than $J$. maritimus, but confined to the southern coasts of England, from Wales to Norfolk, rarer than that species in Ireland. Fl. summer, rather early.

15. J. trifidus, Linn. (fig. 1074). Highland R.-Perennial stock densely tufted, formed of a shortly creeping rootstock and the persistent bases of the numerous stems and closely sheathing brown scales. Stems slender, not 6 inches high, with 2 or 3 slender filiform leaves or bracts in their upper part, 2 or 3 inches long, the 1 or 2 uppermost having at their base a single sessile flower or a cluster of 2 or 3 . Perianth-segments very pointed, rather longer than the capsule.

In rocky and gravelly situations, in northern and Arctic Europe, Asia, and North America, and in the higher mountains of central Furope. In Britain, only in the Highlands of Scotland, where it is trequent on stony summits. Fl. summer. 
16. J. castaneus, Sm. (fig. 1075). Chcstnut R.-The rootstock emits creeping runners. Stems 6 inches to a foot high, with a few rather short, grass-like, and channelled radical leaves, and 1 or 2 on the stem itself, all ending in a fine, nearly cylindrical tip. Flowers rather large, dark brown, in 1, 2, or 3 clusters at the top of the stem; the outer bract rather longer than the flowers. Perianth-segments pointed, nearly 2 lines long. Capsule oblong, brown and shining, often nearly $t$ wice the length of the perianth.

In wet, rocky places, in the mountains of northern Europe, Asia, and America, extending all round the Arctic Circle, and at great elevations in the principal mountain-chains of Europe and Asia. In Britain, confined to the Scotch Highlands, where it is very local. Fl. summer.

17. J. biglumis, Linn. (fig. 1076). Two-flowered $R$.-Leaves radical, sheathing the base of the stem, short and grass-like. Stems tufted, 6 to 8 inches high, each with a single terminal cluster of 2 , 3 , or rarely 5 or 6 rather large, brown flowers; the outer bract seldom longer than the flowers. Perianth-segments obtuse, scarious on the edges, $1 \frac{1}{2}$ to 2 lines long. Capsule as long or longer, more or less obtuse.

In mountain bogs, in northern and Arctic Europe, Asia, and America, and at great elevations in the mountain-ranges of central Europe. In Britain, not unfrequent in the Scotch Highlands, extending into northern England and North Wales. F. summer. Two forms of this plant have been distinguished as species, the two-flowered variety ( $J$. biglumis, Linn.), chiefly A rctic, usually with only 2 flowers, a small leafy tip to the outer bract, and a short, very obtuse [turbinate, 3-lobed] capsule, [not longer than the perianth]; and the more common three-flowered variety (J. triglumis, Linn.), with 3 or more flowers, no leafy tip to the bract, and a longer, less obtuse [ellipsoid-beaked] capsule [much longer than the perianth]; but each of these characters will be found to vary occasionally in the same tuft, and not always to correspond with each other. [As all other botanists regard these forms as species, I have added in [] other important characters to those given by Bentham. J. biglumis is a very rare Scotch mountain plant, 2 to 6 inches high, with leaves septate within and sheaths not auricled. $J$. triglumis is not uncommon in Wales, north England and Scotland, grows 6 to 18 inches high, with leaves formed of 2 tubes, and auricled sheaths.]

\section{LUZULA. WOODRUSH.}

Perennial herbs, differing from Juncus in their softer, flatter, grasslike leaves, often fringed with long, white hairs, and in their capsules, not divided into 3 cells, and containing only 3 much larger erect seeds.

A genns widely distributed over both hemispheres, usually in woods, meadows, and pastures, in drier situations than the Rushes.

\section{Klowers pantcled.}

Flowers single on each pedicel

Nowers in clusters of 2,3 , or 4 on each pedicel.

Plant 2 or 3 feet high, with numerous flowers in a compound

pantcle
Alpine piant, not 6 inches high, with 3 or 4 small clusters of

1. L. pilosa.

towera

2. L. rylvatica.

3. L. arousth. 
Flowers in compact, ovold heads.

Flower-heads 8 or 4 , the outer ones pedicellate . . 4. L. campestris.

Flower-heads nearly sessile, forming a dense terminal spike : 5 . L. opicata.

1. I. pilosa, Willd. (fig. 1077). Hairy W.-Stock branched and tufted, with creeping offsets. Stems slender and erect, 6 inches to a foot high. Leaves chiefly radical or near the base of the stem, linear and grass-like, 2 or 3 inches long, more or less fringed with long, white hairs. Flowers all distinct, or very rarely $\mathbf{2}$ together; the central one nearly sessile, the others on slender peduncles, either simple and 1-flowered or more or less branched, forming an irregular terminal panicle. Each flower has 2 or 3 scarious bracts at its base. Perianth-segments very pointed, of a shining brown. Capsule longer or scarcely shorter than the perianth. Seeds with a soft, loose, oblique or curved appendage at the top.

In woods and on banks, common in Europe and Russian Asia, from the Mediterranean to the Arctic regions, and in North America. Extends all over Britain. Fl. spring. It is usually divided into two species, L. pilosa, (L. vernalis, DC.), with an obtuse capsule and the appendage of the seed decidedly curved, and $L$. Forsteri, DC., witb an acuminate capsule and the appendage straight or nearly so, but the character of the appendage is very variable, and does not correspond with the differences in habit which it is sometimes sup. posed to do. The var. Forsteri is confined to the southern half of England.

2. I. sylvatica, Gand. (fig. 1078). Great W.-Easily known among British species by its large size; the stems attaining $1 \frac{1}{2}$ to 2 feet or more, and the leaves a breadth of 3 or 4 lines and a length of above a foot. Flowers in little clusters of 2 or 3 , in a large, loose, compound panicle. Perianth rather smaller than in $L$ pilosa, the segments broader but with a fine point. Capsule nearly of the same length. Seeds without any appendage. L. maxima, DC.

In woods, chiefly in hilly districts, in western, southern, and central Europe, as far as central Germany and western Scandinavia. Extends all over Britain. Fl. early summer.

3. I. arcuata, Hook. (fig. 1079). Curved W.-A small species, seldom attaining 6 inches, with the leaves channelled almost as in Juncus, and without the white hairs of our other Luzula. The panicle consists of 3 or 4 clusters or heads of 3 or 4 flowers each, about half the size of those of $L$. pilosa; the central cluster sessile, the others on rather long, slender, curved peduncles. Capsule nearly globular, shorter than the perianth. Seeds withont any appendage.

A high northern species, frequent in Arctic Europe, Asia, and America. In Britain only on the summits of some of the highest Scotch mountains, Fl. summer.

4. I. campestris, Br. (fig. 10s0.) Field W.-The foliage, stature, and white hairs are those of $\boldsymbol{L}$. pilosa, but the flowers, instead of being single, are collected 6 to 8 or more together in close ovoid heads or clusters, of which from 3 to 6 form a small terminal panicle ; the central cluster sessile, the others on slender peduncles varying from a line or two to an inch in length. Perianth-segments very pointed, brown, with light-coloured shining edges, abont $1 \frac{1}{2}$ lines long. Capsules shorter and obtuse. 
In dry pastures, woods, and heaths, throughout the northern hemisphere without the tropics, and in some parts of the southern hemisphere. Abundant in Britain. Fl. spring. In some specimens, $L$. crecta, Desv. (multiftora, Lej.), the peduncles are so shortened as to give the inflorescence the appearance of that of $L$. spicala, but the outer clusters are never quite sessile, and the perianth is always much larger than in $L$. spicata.

5. I. spicata, DC. (fig. 1081). Spiked W.-Rather smaller than $L$. campestris, and the flowers considerably smaller (about $\$$ line long), in dense clusters, all sessile, forming an ovoid or oblong terminal spike, $\frac{1}{2}$ to near 1 inch long, and more or less drooping, the lowest 1 or 2 clusters often a little apart from the others, but always sessile within a short leafy bract.

An alpine species, common in northern and Arctic Europe, Asia, and America, and in the high mountain-ranges of central and southern Europe and Asia. Abundant in Scotland, very local in northern England and North Wales, and unknown in Ireland. Fl. summer.

\section{ERIOCAULE无. THE ERIOCAULON FAMILY.}

IIerbs, differing from Juncacece in their minute unisexal flowers, in involucrate heads, membranous perianth, with the inner segments inserted in a tube or in the female flower replaced by a pencil of hairs, and in their ovules and seeds always solitary in each cell of the ovary or capsule, and suspended from the top, not erect from the base as in Luzula.

An Order, containing several genera and many species, for the most part Sonth American. In former editions of this work it was regarded as included under Restiacece.

\section{ERIOCAULON. ERIOCAULON.}

Aquatic or marsh plants, with tufted leaves. Peduncles leafless, with a terminal globular head of minute flowers; the central ones chiefly males, the outer ones chicfly females ; all intermixed with small bracts, of which the outer ones are rather larger, forming an involucre round the head. Perianth very delicate, of 4 or 6 segments, the 2 or 3 inner ones in the males united to near the summit. Stamens in the males as many or half as many as the perianth-segments. Capsule in the females 2- or 3-lobed, and 2- or 3-celled. Style single, with 2 or 3 stigmas.

A large genus, widely distribnted over the globe, numerous in South America, and extending over that continent to the Arctic Circle, general in tropical Asia, Africa, and Australia, but wholly wanting in Russian Asia and Europe, with the exception of the single British station.

1. E. septangulare, With. (fig. 1082). Jointed $\boldsymbol{B}$.-The slender rootstock creeps in the mud under water, emitting numerous white, jointed fibres, and tufts of linear, very pointed, soft and pellucid 
leaves, 1 to 3 inches long. Peduncles from a couple of inches to above a foot high, enclosed at the base in a long sheath. Flower-heads 2 to 4 lines diameter, with very numerons minnte flowers. Bracts and perianths of a leaden colour, tipped with a few minute crafi-like hairs. Perianth-segments 4, with a minnte black gland on the 2 inner ones. Stamens in the males 4. Stigmas and lobes of the ovary in the females 2.

A North American species, found in lakes of the isles of Skye, Coll, a few of the neighbouring Hebrides, and the west coast of Ireland, but not elsewhere in Enrope. Fl. August.

\section{CYPERACEE. THE SEDGE FAMILY.}

Herbs, resembling in aspect Juncacece, or more frequently Graminece, but usually stiffer than the latter, with solid [usually 3-ang!ed] stems, and the sheaths of the leaves closed all round. Flowers in little green or brown spikes, called spikelets, which are either solitary and terminal or several in a terminal (or apparently lateral), simple or compound cluster, spike, umbel, or panicle. Each spikelet is placed in the axil of a scale-like or leafy outer bract, and consists of several scalelike, imbricated bracts, called glumes, each containing in its axil one sessile flower. Perianth either none or replaced by a few bristles or minute scales. Stamens 3 or rarely 2. Ovary (in the same or in a distinct glume) simple, l-celled, the style more or less deeply divided into 2 or 3 branches or linear stigmas. Fruit a small, seed-like nut, flattened when the style is 2-cleft, triangular when it is 3-cleft, containing a single seed.

A large family, abundantly distributed all over the globe, but more especially in moist situations or on the edges of waters. It is intermediate as it were between Restiacece and Graminece, distinguished from the former by the absence of any regular perianth, from Graminea generally by the want of an inner scale or palea between the flower and the axis of the spikelets; by the simple, not feathery, branches of the style ; besides that in most cases the two families are readily known by the sheath of the leaves closed round the triangular stem in Cyperacece, slit open on the side opposite to the blade in Graminea. The glumes are also most frequently brown in the former, green or purplish in the latter.

Flowers unisexual, the atamens and ovaries within separate glumes, either in the same or in separate spikelets.

Ovary enclosed in a little bottle-shaped utricle, the atylo protruding through a small apertnre at the top

Ovary partially enclosed in 1 or 2 glume-like scales, open at the side.

Flowers hermaphrodite, the atamens and ovaries within the

9. Carrx.

8. KOBRESL same glume.

Glumes in each spikelet arranged in twoo opposite rows.

All the glumes in each spikelet, except one outer one, containing flowers. Spikelets many, in a compound numbel

1. CTPERUS. 
Several of the lower glumes of each spikelet smaller and empty. Spikelets closely sessile, in compact heads . Glumes in each spikelet imbricated all round the axils.

Spikelets sessile, in a terminal spike, arranged in 2 opposite rows

Spikelets solitary, or. in heads, clusters, umbels, or panicles.

Several of the lower glumes of each spikelet smaller and empty. Only 2 or 3 flowers at the top of each spikelet.

Spikelets very numerous, in a compound panicle. Style-branches 3 . $\dot{2}$ terminal or pedunculate

Spikelets few, in 1 or 2 terminal or pedunculate clusters. Style-branches 2 . All the glumes of the spikelet, excepting one outer
larger one, containing flowers.

Hypogynous bristles (within the glume round the flowers) projecting far beyond the glumes and forming long cottony or silky tufts

Hypogynous bristles shorter than the glumes or none

2. SCHOKNOS

5. BLYSMUS.

\section{Cladiux.}

4. RnYNCHOSPOR.

7. ERIOPHOROY

6. SCIRPUS.

\section{CYPERUS. CYPERUS.}

Stems triangular, leafy at the base. Spikelets in clusters or heads, usually several together, one of them sessile, the others stalked, in a terminal, irregular, umbel-like panicle, with an involucre of 1 or more leaf-like outer bracts. Glumes several in each spikelet, regularly arranged in 2 opposite rows, all nearly equal, with 1 flower in each glume. Stamens and ovary under the same glume, without hypogynous bristles.

A very large tropical genus, represented by very few species in temperate regions, and quite disappearing in the extreme north and south. The regular arrangement of the glumes gives the spikelets a flattened appearance readily recognised.

Stem above a foot high. Spikelets numerous. Involucral leaves very long a foot high. Spikelets in a small cluster. Involucral

leaves not above 3 inches . . - . - . . 2. C. fuscus,

1. C. longus, Linn. (fig. 1083). Galingale.-Rootstock creeping. Stems stout, 1 to 3 or even 4 feet high, with a few leaves at the base, usually shorter than the stem. Involucre of about 3 leaves, very unequal in length, the longest often attaining a foot or more. Umbel simple or compound, the central ray very short, the others varying from 1 to 2 or even 3 inches, each bearing a simple or branched cluster of 6 to 12 or more spikelets: these are linear, pointed, flattened, about half an inch long. Glumes numerous, obtuse, of a bright chestnut colour, with a green keel. Styles 3-cleft.

In wet meadows, and pastures, common in southern Europe and central Asia, extending more sparingly into central France, and along the western provinces to the Channel. In Britain, very local and only in South Wales ard some southern counties of England. Fl. summer, rather late.

2. C. fuscus, Linn. (fig. 1084). Frown C.-A much smaller plant than the last, forming grass-like tufts a few inches in height, or very rarely nearly a foot. Leaves shorter than the stem, those of the in. volucre unequal, the longest from 2 to 4 inches. Clusters compact, either in a small terminal hcad or in an nmbel, of which the longest 
rays are under an inch. Spikelets much flattened, obtuse, not above 3 lines long, with dark-brown glumes, not near so closely imbricated as in C. longus.

In meadows and waste places, widely distributed over central and southern Europe and northern Asia, extending northward to southern Scandinavia. In Britain, formerly found (naturalised) at Chelsea, now confined to Shalford Common in Surrey, and Jersey. Fl. Late in summer

\section{SCHCENUS. SCHOENUS.}

Herbs, usually stiff and rush-like. Glumes arranged, as in Cyperus, in 2 opposite rows, but not more than 4 of the uppermost have flowers in their axils, the 3 or 4 lower ones rather shorter and always empty. There are also occasionally from 3 to 6 bristles round the ovary.

A small genus; most of the species are from the southern hemisphere.

1. S. nigricans, Linn. (fig. 1085). Black S., Bog-rush.-A tufted perennial, with stiff, rush-like stems about a foot high. Leaves short and stiff, almost radical, their sheaths often of a dark, shining brown. Spikelets several, of a dark, shining brown, almost black, closely sessile in compact terminal heads about half an inch in diameter, with an involucre of 2 or 3 broad, brown bracts, one of which at least has a stiff, erect, leaf-like point $\frac{1}{2}$ to 1 inch long. Glumes nearly 8 lines long, pointed, with a prominent keel, and rough on the edge. [Bristles at the base of the nut, minute or 0.]

In bogs and marshes, chiefly near the sea, in central and sonthern Kurope, extending northward to the Baltic and to north Asia. Spread over a great part of Britain, but chiefly in the west. Fl. summer.

[2. S. ferrugineus, Linn. (fig. 1086). A widely distribnted continental species has been quite recently discovered in Perthshire. It is distinguished from $S$. nigricans by its paler colour, shorter subulate leaves and involucral bracts, fewer spikelets and much longer bristles which exceed the nut.]

\section{CLADIUM. CLADIUM.}

Distinguished from Rhynchospora chiefly on account of the thick texture of the frnit. Its habit is very different from that of our Rhynchospora, but comes very near to that of some exotic species of that genus.

1. C. Mariscus,'Br. (fig. 1087). Prickly C.-A tall, rush-like plant, with a creeping rootstock, and leafy stems, 3 to 6 feet high. Leaves nearly erect, the lowest nearly as long as the stem, smooth and sheathing at the base, then keeled, and ending in a long triangular point; the keel and edges very rongh and cutting, being bordered by minute, sharp teeth. Spikelets of a pale brown, in small but very numerous clusters, arranged in somewhat corymbose panicles in the upper axils, the whole forming a terminal, more or less leafy, oblong panicle, often above a foot long. Each spikelet is 2 or 3 lines long, rather pointed, with the glumes imbricated all round the axis, containing usually one perfect flower in the innermost glume, an incomplete one in the next, the 4 or 5 outer glumes gradually shorter and always empty. Stamens 
nsually 2. Style branches 3 . Nut tapering at the top, the outer coating thick and fleshy when fresh, brittle when dry. C. germanicum, Schrad.

In deep bogs and marshy places, in most temperate and some tropical regions of the globe, extending northward in Europe to southern Scandinavia. In Britain, thinly scattered over England, frequent in the west of Ireland, and very rare in Scotland. Fl. late in summer.

\section{RHYNCHOSPORA. BEAKSEDGE.}

Spikelets several, in 1 or more cluster, forming terminal or axillary heads or panicles. Each spikelet obloug, more or less pointed; the glumes imbricated all round the axis, 1 to 3 of the upper or inner ones containing each a flower, the lower or outer ones shorter and empty. Stamens 3 or rarely 2. Hypogynous bristles 6 or sometimes more, shorter than the glumes. Nuts globular or laterally flattened, tapering into a 2-cleft style.

A considerable genus, widely dispersed over the surface of the globe, formerly united with Schcenus, but well distinguished by the glumes imbricated all round the axis, not arranged in 2 opposite rows.

Spikelets brown. Outer bract projecting an inch beyond the flowers. 1. R. susca. Spikelets white. Outer bract shorter or scarcely longer than the flowers.

1. R. fusca, Linn. (fig. 1088). Brown B.-Near R. alba. but rather firmer, with a creeping rootstock. Stem 6 to 10 inches bigh, with a few short, erect, subulate leaves; the floral ones or bracts projecting an inch or more beyond the flowers. Spikelets brown, usually forming 2 rather loose clusters, one terminal, the other on a slender pedicel, in the axil of the next leaf ; each spikelet about $2 \frac{1}{2}$ lines long, containing usnally 2 flowers, with 3 or 4 empty outer glumes. Hypogynous bristles about 6 , small and very unequal.

In bogs, chiefly in northern and western Europe, in the mountains of central Europe, and in North America, In Britain, confined to southern and western England and Ireland. $F l$. summer.

2. R. alba, Vahl. (fig. 1089). White B.-Stems 6 to 9 inches high, slender, forming dense, grass-like tufts, without any creeping rootstock. Leaves chicfly radical, short and subulate; the floral bracts scarcely exceeding the flowers. Spikelets nearly white, in a small, loose terminal cluster, often with 1 or 2 smaller clusters on slender pednncles in the axils of the next leaves. Each spikelet 2 to $2 \frac{1}{2}$ lines long, with 1 or 2 flowers, and 2, 3, or 4 empty glumes before them. Hypogynous bristles about 12, more apparent than in $R$. fusca, being nsually rather longer than the nut, although shorter than the glume.

In bogs, in northern and central Europe, northern Asia, and North America. Generally distributed over Britain. Fl. summer and autumn。

\section{BLYSMUS. BLYSMUS.}

Spikelets and flowers of Scirpus, but the spikelets are sessile, in 2 opposite rows, along the axis of a short terminal spike.

$A$ genus limited to the two European species, often united with Scirpus. 
Bpikelets chestnut-brown, o- to 8-flowered, and longer than the

gplikelets dark-brown, \&- to 4 -flowered, almost enclosed in the long giume-like bract at thelr base? .

1. B. compressus, Panz. (fig. 1090). Broad B.-Stems 6 to 8 inches high, with a creeping rootstock. Leaves much like those of the common Carex panicea, shorter than the stem, 1 to $1 \frac{1}{2}$ lines broad, flat or kceled. Spike terminal, about an inch long, consisting of about 10 or 12 oblong spikelets, closely sessile on opposite sides of the axis, each one about 3 lines long; the broad, brown, glume-like outer bract shorter than the mature spikelet. Glumes about 8 , imbricated all round the axis of the spikelet, the lowest one of all often empty. Stamens usually 3, with 3 to 6 small hypogynous bristles. Nuts somewhat flattened, tapering into the two-cleft style. Scirpus Caricis, Retz.

In bogs and marshes, in Furope and Russian Asia, not extending to the extreme north, and yet a mountain plant in southern Europe and the Cancasus. Occurs in many parts of England, and southern Scotland. Fl. summer.

2. B. rufus, Link. (fig. 1091). Narrow B.-Stems 6 inches to near a foot high, rather stiff but slender, wlth a few very narrow leaves near the base, shorter than the stem, erect and cbannelled or nearly cylindrical. Spike terminal, 6 to 9 lines long, consisting of about 6 sessile spikelets, of a dark, shining brown, almost black, each containing only 2 to 4 flowers, and almost concealed by the outer bracts, which are dark brown, thin, and shining, about 3 lines long. Glumes of the spikelet imbricated all round the axis, the lowest one often empty. Stamens 3 ; the hypogynous bristles minute or wanting. Nut rather larger than in B. compressus. Scirpus rufus, Wablb.

In marshy places, especially near the sea, in northern Europe and all across temperate Asia, extending from northern Germany nearly to the Arctic circle. In Britain, particularly abundant in Scotland and northern England, descending to North Wales and Lincolnshire; not uncommon in northern Ireland. $F l$. summer.

\section{SCIRPUS. SCIRPUS.}

Spikelets either solitary and terminal or several together, forming one or more heads or clusters, or an irregular panicle, either terminal or apparently below the top of the stem. Glumes several in each spikelet, imbricated all round the axis, all containing a perfect flower in their axil except sometimes the lowest one. Hypogynous bristles either 6 , or fewer and shorter than the glume, or altogether wanting.

A large genus, widely distributed over the whole world, and, like other large genera of Cyperacece, containing species very nnlike each other in general habit. It has been repeatedly endeavoured to divide it into several, with characters derived from the hypogynous bristles, the shape of the base of the style, the number of its parts, \&c., but the smaller groups so formed still include species as unlike each other as those of the original genus, whilst species closely resembling each other in every other respect have become widely separated. The genus is therefore here retained in its integrity, distinguished from Rhynchorpora by the glumes all bearing flowers except the lowest, from Cyperus by the 
arrangement of the glumes, and from Blysmus by the arrangement of the spikelets.

Splkelets solitary on each stem.

Stems branched, leafy, floatling In water or in matted tufts on its edge .

Stems simple, erect or ascending.

Outer bract of the spikelet without any leafy tip.

Stems very slender, not 3 Inches hlgh. Styles 3-cleft. Spikelet dark brown, scarcely more than 1 line long . spikelet pale-coloured, usually $1 \frac{1}{2}$ lines long or rather

more
Stems rather stlff, 8 or $\dot{4}$ lnches to a foot high or more.
Styles mostly 2-cleft . Styles mostly 3-cleft.

Sheaths at the base of the stem obtuse or obllque at the top, wlthout any leafy tip. Spikelets oblong.

Flowers numerous in each spikelet, the thickened base of the style rather bulb-shaped.

Fowers 8 to 6 in each spikelet, the thlckened base of the style gradually tapering from the nut.

Sheaths at the base of the stem with a short leafy tip. Splkelet ovold .

Outer bract of the spikelet with a leafy tip as iong as the spikelet or longer.

Stems rather firm, 6 inches to a foot high, wlth numerous sheaths at the base, each with a short polnt

stems very slender, 1 to 6 Inches high, with 1 or 2 subulate leaves.

Nut marked with longltudinal rlbs and furrows

Nut without ribs or furrows
8plkelets 2 or more, in a cluster or umbel below the summit of 7. S. fuitans. the stem.

Stems very slender, 1 to 6 lnches high, with 1 or 2 subulate leaves.

Nut marked with longitudinal rlbs and furrows .

8. S. setaceus.

Nut without ribs or furrows . . . . . 9. S. riparius.

Stems firm, 1 to 2 feet high or more.

Stems leafless, or with 1 or 2 short, stiff leaves at the base.

Stems acutely triangular from near the base.

Splkelets all sessile, in a close cluster. Leaf-blade narrow, 2 or 3 Inches long

8pikelets more or less pedicellate, in a compound clus-

ter. Leaf-blade very short
Stems cyllndrical, or scarcely angular at the top.

Spikelets very small but very numerous, densely packed in one or more small, globular heads $\quad .10 . S$. Holoschcenus.

Splkclets rather large, in a cluster or Irregular umbel . 13. S. lacustris.

Stems bearing several long iteves.

Splkelets large, brown, in a sessile cluster or close com.

pound umbel
splkelets small, greon, very numerous, in a large, loose,
compound panlcle

14. S. maritimus.

15. S. sylvaticus.

1. S. acicularis, Linn. (fig. 1092). Needle S.-A little slender tufted plant, with the appearance of an annual, but emitting thread-like, reeping rootstocks; the fine subulate stems scarcely 2 inches high, with short sheaths at their base, and most of them bearing a single terminal oblong spikelet, not 2 lines long, of a dark-brown colour, the outer bract similar to the glumes. Flowers usually 6 to 8 in the spikelet. Hypogynous bristles 3 or 4 . Styles 3-cleft. Not obovoid, slightly triangular. Eleocharis acicularis, Br.

In wet, sandy places, the margin of lakes, \&c., widely spread ovex 
Europe and central and Russian Asia, and North America. Not uncommon in Britain. Flo summer and autumn.

2. S.parvulus, Roem and Sch. (fig. 1093). Small S.-A small tufted plant emitting creeping rootstocks, very closely allied to $S$. acicularis, but the thread-like stems nsually rather stouter and the spikelet rather larger and pale-coloured. Flowers, hypogynous bristles, style and nut the same as in $S$. acicularis, of which this may be a maritime variety. Eleocharis parvula, Hook.

In wet, sandy places, chiefly in salt marshes in western Europe. Coasts of Devon, Dorset and Hants, and of Wicklow in Ireland. Fl. summer.

3. S. palustris, Linn. (fig. 1094). Creeping S.-Rootstock often creeping to a considerable extent, with numerons erect stems, often densely tufted, and not 6 inches high at the edge of the water, more distant, and a foot high or more when in the water; all leafless, except one or two short sheaths at their base, without leafy tips. Spikelets, solitary and terminal, oblong, 4 to 6 lines long. Glumes nnmerous, closely imbricated, brown, with scarious edges, and green on the midrib; the outer bract only differing from the glumes in being rather larger. Hypogynous bristles usually 4. Style 2-cleft. Not obovate, crowned by a little conical tubercle, being the persistent base of the style. Elcocharis palustris, $\mathrm{Br}$.

On the edges of pools and watery ditches, throughout the northern hemisphere, and in some parts of the southern one. Frequent in Britain. Fl. all summer. Specimens with the outer bract rather broader, so as almost to enclose the base of the spike, are the $S$. uniglumis, Link. and Watsoni, Bab.

4. S, multicaulis, Sm. (fig. 1095). Many-stalked S.-Very much like the last, and perhaps a mere variety, but smaller, forming dense tufts, with a few creeping offsets; the stems more slender, often slightly decumbent at the base, many of them barren and leaf-like. Spikelet rather smaller. Styles usually, but not always, 3-cleft, the nut becoming obovoid and triangular. Hypogynous bristles usually 6 . Eleocharis multicaulis, Br.

In similar situations to $S$. palustris, and often mixed with it, but not so much in the water; recorded chiefly from northern and western Europe. Not unfrequent in Britain. Fl. summer.

5. S. pauciflorus, Lightf. (fig. 1096). Fcw-flowercd S.-In appearance much like a starved, slender state of $S$. palustris, whilst the nut is nearer that of $S$. caspitosus. Stems slender and many of them barren, not 6 inches high, the sheaths without leafy tips. Spikelet small, not containing above 5 or 6 flowers. Hypogynous bristles, 3-cleft style, and obovoid nnt, as in S. multicaulis, but the thickened base of the style is considerably narrower, forming a tapering point to the nut, not a conical tubercle.

In moorlands, and the edges of pools, in northern and central Europe, Asia, North America, and the mountains of southern Europe, but scarcely an Arctic plant. In Britain, more frequent in Scotland. Ireland, and northern England than in the south. Fl. summer.

6. S. cæspitosus, Linn. (fig. 1097). Tufted S.-Stems 6 inches to a foot high, densely tufted, covered for an inch or two at their base with closely imbricated sheaths, the outer ones brown, the inner ones green, 
with narrow, leafy tips, 1 to 2 lines long. Spikelets solitary and terminal, ovoid, brown, scarcely above 2 lines long; the outer bract like the glumes but larger, with an almost leafy tip, about the length of the spikelet. Flowers usually 6 to 8 in the spikelet. Hypogynous bristles about 6 . Style 3-cleft, the persistent base very minute. Eleocharis caspitosa, Link.

In moorlands and bogs, common in northern and Arctic Europe, Asia, and America, but restricted to mountain ranges in central and southern Europe, and not recorded from the Caucasus. Frequent in Britain, excepting some of the southern counties of England. Fl. summer.

7. S. fluitans, Linn. (fig. 1098). Floating S.-Easily known by its long, slender, branching stems, either floating on the water, or forming soft, densely matted masses on its margin, with linear-subulate leares, $\frac{1}{2}$ to 2 inches long. Spikelets solitary and terminal, oblong greenish, not 2 lines long, the outer bract without any leafy point. Flowers without hypogynous bristles. Styles 2-cleft. Isolepis fluitans, Br.

In pools and still waters, generally distributed over Europe, and reappearing in the southern hemisplere, but not recorded from Asia or America. Scattered over the whole of Britain, but not very common. Fl. summer.

8. S. setaceus, Linn. (fig. 1099). Bristle S.-Stems slender, 2 or 3 inches high, forming little dense tufts, with 1 or 2 short, subulate leaves, on each stem, sheathing it at the base. Spikelets solitary, or 2 or 3 together in a little cluster, appearing lateral, the subulate point of the outer bract forming a continuation of the stem. Each spikelet is ovoid, seldom 2 lines long; the glumes broad and short, dark brown, with a green mid-rib. No hypogynous bristles. Style 3-cleft. Nut very small, marked with about 8 longitudinal ribs and furrows, only visible under a magnifying-glass. Isolepis sctacea, $\mathrm{Br}$.

In gravelly and sandy places, on the margins of pools, \&c., in Europe and Russian Asia, from the Mediterranean nearly to the Arctic circle. Generally distributed over Britain. Fl. summer.

9. S. Savii, Seb. and Maur. (fig. 1100). Savi's S.-Very like S. setaceus, but usually still more slender, although sometimes attaining 6 or 8 inches; the point of the outer bract scarcely exceeds the spikelet, and the nut has not the longitudinal ribs and furrows of $S$. setaceus. $S$. riparius, Spreng; Isolepis Suviana, Sch.

In marshes and edges of pools, chiefly near the sea, frequent in the sonthern hemisphere, and in the Mediterranean region and west of France. In Britain, in several counties from Wales and Suffolk southwards, also in Lancashire, the west of Scotland, and Ireland. $F$. summer.

10. S. Holoschœnus, Linn. (6ig. 1101). Clustered S.-A stiff, rushlike plant, with a stout, creeping rootstock, and cylindrical stems, 1 to 2 feet high or even more, with 1 or 2 stiff leaves sheathing the base. Spikelets very numerous and small, closely packed into one or more globular lieads, forming a lateral clıster or umbel, the largest stiff outer bract forming an apparent continuation of the stem. The largest heads are sclitom above 4 or 5 lines diameter, and contain upwards of 30 spikelets, of a light-brown colour, each containing many tlowers. No hypogynous bristles. Style 2-cleft or rarely 3-cleft.

In sandy places, chiefly near the sea in the Mediterranean region 
extending into central Asia, and in western Europe to the Loire and Belgium, and here and there into central Europe. In Britain, only in North Devon and the Channel Islands. Fl. late in summer.

11. S. pungens, Vahl. (6g. 1102). Sharp S.-Very near S. triqueter, but a rather smaller plant; one or two of the sheaths bear narrow, keeled leaves 1 to 3 inches long, the spikelets are few (usually 3 to 6 ), all sessile, in a close cluster; the stiff, triangular, outer bract continuing the stem as in $S$. triqueter.

In bogs, marshes, and on the margins of pools, chiefly in North America and the West Indies, but occurs in western Europe, and is found on the sandy banks of St. Ouen's Pond, in Jersey. Fl. summer, rather late.

12. S. triqueter, Linn. (fig. 1103). Triangular S.-Rootstock creeping. Stems acutely triangular, 2 or 3 feet high, leafless, except that the one or two loose sheaths at the base bear a short lanceolate blade, from a couple of lines to near an inch long. Spikelets usually 8 or 10 or even more, the central ones sessile, the others stalked, forming a compound lateral cluster or umbel; the stiff, triangular outer bract continuing the stem for an inch or more. Each spikelet is ovoid, 4 or 5 lines long; the glumes brown, broad, usually notched or fringed at the top, with a minute point. Hypogynous bristles about 5. Style 2-cleft. Nut smooth and shining.

In marshes, and edges of pools, in central and southern Europe, extending eastward to eastern Asia and Australia, and northward chiefly in western Europe to Denmark; also found in America. Rare in Britain, and limited to the banks of tidal rivers from the Thames to Cornwall. Fl. late in summer.

13. S. lacustris, Linn. (fig. 1104). Lake S.-Rootstock creeping, with stout, erect stems, from 2 or 3 to 6 or 8 feet high, cylindrical at the base, gradually tapering npwards, and sometimes obtusely triangular near the top, with a single short leaf near the base. Spikelets ovoid or oblong, 3 to 6 lines long, rather numerous, in a compound lateral nmbel or cluster, the outer bract continuing the stem. Glumes numerous, broad, brown, fringed at the edge, notched at the top, with a little point in the notch. Hypogynous bristles 5 or 6 . Style 2- or 3-cleft. Nut smooth.

On the margins of lakes and ponds, and in watery ditches, in Arctic, temperate and tropical regions over the globe. Abundant in Britain. $\mathrm{Fl}$. summer. Two varieties are often distinguished as species, S. lacustris, with a 3-cleft style and smooth glumes, and S. Tabernamontani, Gmel. (S. glaucus, Sm.), with a 2-cleft style and raised dots on the glumes; but these characters are very inconstant, and there are often 2-cleft and 3 . cleft styles in the same spikelet. The name of $S$. Duvalii or S. carinatus, Sm., is sometimes given to a variety of $S$. lacustris with the stems rather more triangular at the top, sometimes to a slight variety of $S$. triqueter. [There are three principal British forms of this species, S. lacustris proper, with terete green stems, leaves often floating, ciliate anthertips and compressed nuts; $S$. Taberncemontani, Gmel., with glaucons terete stems, scabrid glumes, glabrous anther-tips, and 3-gonous nuts; S. carinatus, Sm., with green stems obtusely three-angled above, glabrous anther-tips, and compressed nuts. This last occurs on tidal river banks in the sonth of England only.]

14. \& maritimus, Linn. (fig. 1105). Sea S.-Rootstock creeping. 
Stems sharply triangular, 2 to 1 or even 5 feet high, with long, flat, pointed leaves, often far exceeding the stem. Spikelets of a rich brown, ovoid or lanceolate, about 9 lines long, sometimes only 2 or 3 in a close sessile cluster, more frequently 8 to 10 in a compound cluster, the outer ones stalked. The leaf-like outer bract continues the stem, and sometimes one or two other bracts bave leafy points. Glumes notched, with a fine point. Style 3-cleft. Hypogynous bristles few.

In salt marshes, and occasionally up the banks of large rivers in most north temperate regions, though less frequent within the tropics. Common all round the coasts of Britain. Fl. summer.

15. S. sylvaticus, Linn. (fig. 1106). Wood S.-Stems triangular, 2 or 3 feet high, with long, grass-like leaves. Spikelets ovoid, of a dark slining green, not above 2 lines long, very numerous, in clusters of 2 or 3 together, forming a terminal, mueh branched, compound umbel or panicle, with an involcure of 2 or 3 linear leaves. Glumes keeled and pointed. Hypogynous bristles usually 6. Styles 3-cleft.

In moist woods, and on grassy banks of rivers, throughout Europe and Russian Asia, except the extreme north, and North America. Abundant in some localities, over England, Ireland, and central and southern Scotland, but not generally common. Fl. summer.

\section{ERIOPHORUM. COTTONSEDGE.}

Habit and character of Scripus, except that the hypogynous bristles, as the flowering advances, protrude to a great length beyond the glumes, forming silky-cottony tufts, which have given to these plants the name of Cotton-rushes or Cotton-grass. The style is usually 3-cleft.

A genus of few species, all bog plants, restricted to the northern hemisphere, and most abundant ins ligh latitudes or at considerable elevations.

S pikelets solitary.

Spikelets 2 or 3 lines long, oblong, and brown. Hypogynous

bristles 6 to each flower.
spikelets above 6 lines long, ovold, of a dark olive-green. Hypogynous bristles very
splkelets several to each stem

1. E. alpinum.

2. E. vaginatum.

3. $\boldsymbol{E}$. polystachion.

1. E. alpinum, Linn. (fig. 1107). Alpine C.-In everything but the long bristles this plant precisely resembles Scirpus cospitosus. It has the same densely tufted stems, 6 to 10 inches high, with imbricate sheaths at the base; the inner ones with very short leafy tips, and small, brown, solitary and terminal spikelets. After flowering the hypogynous bristles, about 6 to each flower, form a silky tuft attaining an inch in length.

In bogs, in the high mountain-ranges of Europe and Russian Asia, or at bigh latitudes all round the Arctic circle. Formerly found in a bog near Forfar, now extinct. Fl. summer.

2. E. vaginatum, Linn. (fig. 1108). Sheathing C.-Stems tufted, a foot high or more, covered at the base with a few loose ragged sheaths, one or two of which bear linear, almost subulate leaves, shorter than the stem, and one or two of the upper sheaths inflated, withcut uny or only a very short blade. Spikelet solitary, terminal, ovoid, 6 to $\varepsilon$ lines long, of a deep olive-green. Hypogynous bristles very numerous 
to each flower, forming at length very dense cottony tufts, nearly globular, about an inch in diameter.

In bogs and wet moors, in northern and central Europe, northern Asia, and North America, and in the mountains of southern Europe. Extends all over Britain. $F l$. summer.

3. F. polystachion, Linn. (fig. 1109). Common C.-Rootstock creeping. Leaves few, mostly radical, much shorter than the stem, more or less triangular, or channelled at the top or all the way along, those on the stem often very short. Stems about a foot high, with a terminal umbel of 2 or 3 to 8 or 10 or even more spikelets; the inner ones sessile, the outer ones more or less staiked and often drooping; the 1 to 3 outer bracts more or less leafy. Each spikelet ovoid or oblong, 5 or 6 lines long; the glumes thin, of an olive-green, with scarious edges, or sometimes altogether brown. Hypogynous bristles very numerous, forming dense cottony tufts, often attaining 1 to $1 \frac{1}{2}$ inches in length.

In bogs and wet moors, the commonest species in Europe, Russian Asia, and North America. Frequent in Britain. Flo summer. It is usually divided into 3 species, $E$. latifolium, Hoppe, with leaves flattened the greater part of their length; $\boldsymbol{E}$. gracile, Koch., with very slender leaves, and few, almost erect spikelets ; and $B$. angustifolium, Roth., with intermediate leaves and more numerous spikelets. Other characters, derived from the smoothness or roughness of the peduncles, or from the length of the cottony bristles, do not appear to be near so constant as has been supposed. [The usual limitation of these forms is as follows: $E$. polystachion proper. Rootstock long, stems not tnfted, 6olid, leaves channelled, glumes ovate, nut mucronate. $B$. latifolium, Hoppe. Rootstock short, stems tufted, slender, 3-gonous, hollow, leaves flat, glumes lanceolate, nut mucronate. E. gracile, Koch. Stem very slender 3-gonous, leaves short, very narrow 3-gonous, glumes broad obtuse, nut very narrow obtuse. Very rare; and found only on the banks of the Blackwater river in Surrey.]

\section{KOBRESIA, KOBRESIA.}

Perennial herbs, with grass-like leaves, radical or sheathing the stems at the base. Spikelets sessile in a terminal spike, simple or rarely branched at the base, with a glume-like bract under each spikelet. In each spikelet the lowest glume encloses an ovary with a long trifid style, the next one or rarely two glnmes enclose 3 stamens, and there is often a small rudimentary glume or awn terminating the axis. Some spikelets have only one glume enclosing an ovary, and some, near the end of the spike, have only one glume with 3 stamens.

Besides the British species the genns comprises one or two from the continent of Europe.

1. K. caricina, Willd. (fig. 1110). Kobresia.-A low, carex-like plant, forming dense tnfts seldom above 6 inches high; the leaves radical or sheathing the stems at the base, spreading, and much shorter than the stem. Spikelets 4 or 5, short and brown, closely sessile in a short terminal spike. In each spikelet the lower flowers are female, consisting within the glume of an ovary with a 3-cleft style. The upper terminal spikelets of the spike, and usualiy one 
terminal flower of the lateral spikelets are males, cousisting of 3 stamens within the glumes. Sometimes the lower spikelets are slightly compound or branched.

In moors and wet places, in the mountains of northern and central Europe, the Caucasus, Greenland, and the Rocky Mountains of America. In Britain, only in a few localities in Argyll and Perthshire and in the north of England. Fl. summer.

\section{CAREX CAREX.}

Herbs, mostly perennial, with grass-like leaves, chiefly radical or on the lower part of the stem. Spikelets solitary or several in a terminal spike, or the lower ones distant or stalked, or rarely forming a short compound spike or dense panicle. Flowers unisexual, the stamens and pistils always in separate glumes, either in separate spikelets or in different parts of the same spikelet, which is then called mixed or androgynous. Glumes imbricated all round the axis. Stamens in the males 3 , or rarely 2 , without bristles or inner scales. Ovary in the females enclosed within a bottle-shaped or inflated sack or utricle, contracted at the top, with a small opening through which protrudes the 2-cleft or 3-cleft style. This sack persists round the nut, forming a compressed, angular or bladdery outer covering to the seed-like fruit. It is by some botanists considered as a perianth, but its analogy to that organ in more perfect flowers is very doubtful.

A very large and well-defined genus, widely spread over the northern hemisphere, the mountain-ranges of the tropics, and the extratropical southern hemisphere. The great conformity of the essential characters of the genus renders it difficult to break it up into well-marked sections, and the main divisions are usually taken from the relative position of the male and female spikelets or of their male and female portions. These characters are readily appreciated when the plant is in flower, but when in fruit, a state in which it is necessary to procure it in order to determine the species with accuracy, it requires some attention not to overlook the few male flowers at the base or at the top of the mixed spikes, as, the stamens having fallen away, they then appear like empty glumes.

$1\left\{\begin{array}{l}\text { Spikelct solitary and terminal } \\ \text { Spikelets several, the terminal one mixed, the rest female or mixed } \\ \text { spikelets aeveral, the terminal one or more male (rarely with a very tew } \\ \text { female flowers at the base), the others female or mixed. }\end{array}\right.$ Spikelet solitary, terminal.

$2\left\{\begin{array}{l}\text { Splkelet wholly male or wholly femalo. } \\ \text { spikelet mixed male at the top, female at the base : }\end{array}\right.$

$8\left\{\begin{array}{l}\text { Mlale and female spikelets on different plants } \\ \text { Female spikelet on a long ped uncle arising from the base of the male stem. }\end{array}\right.$

24. C. humilis.

Splkelet above 6 lines long. Stigmas 2. Frults tapering to a point.

- Splkelet above 6 lines long. Stigmas 8. Frults obovold, obtuse \&. C. rupestris. sptkelet not above 4 lines. Flowers very fow. Stigmas s. Fruit tapering.

Sptkelets several, the terminal one mixed.

4. C. paucifora.

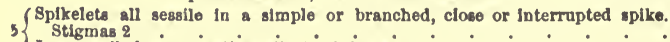

$5\left\{\begin{array}{c}\text { Stigmas } 2 \\ \text { Lower spikelets generally staiked. stigmas } 3: \vdots: \vdots: \vdots 20\end{array}\right.$ 
( Terminal splkelet male at the base. Spike simple .

Terminal splkelet male at the top. Spike often branched or compo und. 13

(Spikelets forming $a$ terminal spike withqut leafy bracts, or with only a small

7 one to the lowest spikelet . . . .

Spikelets very distant, the lower ones each in the axil of a long leafy bract .12

(Splkelets ovoid, close together. Fruits tapering to a polnt, erect or scarcely

$8\{$ spreading

Spikelets, at least the lower ones, at some distance from each other

9. Frults winged at the edges. Stems usually a foot high or more 5. C. ieporina.

Fruits not winged. Stems usually 8 or 9 inches high . 6. C. lagopina.

Fruits tapering to a point or beak considerably longer than the glume . . 11

10 Fruits erect, ovate, with a minute point. Stems a foot or more. Splkelets pale green . . . . . . C. canescens. Ripe spikelets nearly globular, with very spreading beaked fruits. Sten 6 or

118 inches. 8 . C. stellulata. Ripe spikelets oblong, with rather spreading pointed fruits. Stem 1 to 2 feet.

All the spikelets simple, sessile, and distant

12 Lower spikelets branched or 2 or 3 together. Upper ones rather near together.

13 Stems tufted, without creeping rootstocks

13 Rootstock long and creeping.

Spike compound or branched. Stems i to 4 feet (usially 2 to 3 feet) : . 15

14 Spike simple or the lower spikelets slightly compound. Stems not a foot or very slender. Spike or panicle dark brown, rather loose. Fruits obtusely 3-angled.

$15\{12$. C. paniculata.

Spike cylindrical, often green, densely crowded. Fruits mnch flattened, with acnte angles. Stem acutely triangular .

Spikelets near together, in a terminal brown spike about an inch long.

Lower spikelets distant, all pale brown or green. . . . 17

Fruiting splkelets globular, no male flowers at thelr base. 14. C. muricata.

17 Fruftlng spikelets oblong, a few males at the base of some of them. Fruits

flattened . . . . . 11. C. axillaris.

(Spikelets rather large, ovold, In a spike of 1 or 2 inches. Fruits with a very

18 thin or winged edge $\quad .15$. C. arenaria.

Spikelets short, in a splke of about $\frac{1}{2}$ inch. Fruit very convex, not winged 19

Spike ovold, the spikelets distinct. Stem slender, erect . 16. C. divisa.

19 Spike nearly globular, very dense. Stem short, curving downwards.

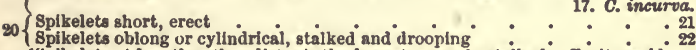

Spikelets at length rather distant, the lowest scarcely staiked. Fruit ovold,

21 obtuse 22 C. Buxbaumii spikelets close together, the lowest stalked. Fruit angular, shortly beaked.

Splkelets oblong, very black. Fruit triangular, with a short beak 23. C. alpina.

22 Spikelets cylindrical, green. Glumes and fruits with long subulate points.

43. C. Preudocyperus.

Spikelets several, one or more terminal ones wholly mala.

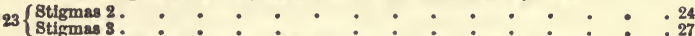

Spikelets small, green, and distant, lower one branched or clustered. - . 27

24\{

Spikelets cylindrical or oblong, few, dark-brown or black.

$25\{$ Fruits very convex or inflated

Glumes mostly obtuse. Splkelets if to $\dot{2}$ inches long : : : 19. c. caespitosa.

26 Glumes mostly narrow and polnted. Femake spikelets 3 inches or more.

Bracts sheathing, withont leaty tips. (Fruits obtuse, slightly downy) acuta.

27 Bracts, at least the lower ones, leafy, with or without sheaths . : 20

Stems shorter than the leaves. Female spikelets short, distant, bali-Incinded

98 In the sheaths

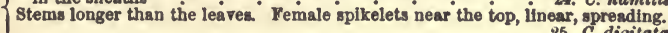

25. C digitata. 


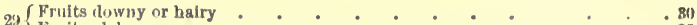

29 Fruits glabrous

30 Female spikelets short and compact, close under the males : : : $: 31$

31 Lowest bract shortly sheathing, with a short leafy point . : 26. C. pracex.

31 Lowest bract shortly leafy, without any sheath - : : 32

32 Fruits not above a line long, very shortly downy : : 28. C. pilulifera.

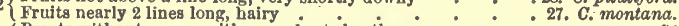

Bracts without any or with very short sheaths

33 Bracts with long sheaths. Fruits hairy, beaked, 2 lines long. 'Splkelets very

$34\left\{\begin{array}{l}\text { distant } \\ \text { Spikelets rather distant, very compact. Fruits not a line long, and not beaked. } \\ \text { 29. C. tomentosa. }\end{array}\right.$

$34\{$ Spikelets very distant. Fruits nearly 2 lines long, tapering into a beak.

One terminal male spikelet (rarely with a smaller one close under it). Female spikelets erect. Bracts leafy, with sheaths . . . . 36

35 One terminal male spikelet. Females more or less drooping." Bract with or

rarely without sheaths
Two or three male spikelets. Bracts without sheaths, or rarely the lowest one

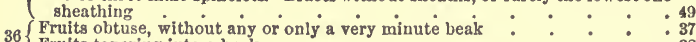

36 Fruits tapering into a beak.

$\left\{\right.$ Female spikelets short, oblong, paie. Fruit very obtise $\dot{3}_{32 .}$ C. pallescens.

$37\{$ Female spikelets cylindrical. Glumes dark. Fruit often with a minute beak.

3. Female spikelets compact, nearly sessile $\quad 37$. C. panicea.

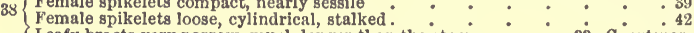

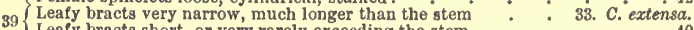

Leafy bracts short, or very rarely exceeding the stem . . . . . 40

$40\left\{\begin{array}{l}\text { Female spikelets short, yellowish-green, mostly near the top of the stem. } \\ \text { Fruits very spreading } \\ \text { Female spikelets oblong, brown, very distant. Fruits with an erect or slightly }\end{array}\right.$

Female spikelets oblong, brown, very distant. Fruits with an erect or slightly
spreading beak

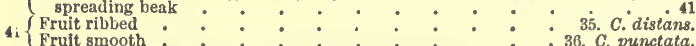

42 Female spikelets green. Fruits with a long beak $\dot{0}:$ 36. C. punctata.

42 Female spikelets brown. Fruits with a very short beak: - 37. C. panicea.

43 Peduncles of the lower spikelets very long . . . . 41. C. sylvatica.

43 Peduncles of the lower spikelets short :

44 Female spikelets short, or very brown (seldom above an inch): . . . 45

Female spikelets greenish, 1 to 6 Inches long 46

Female spikelets light brown, loose. Lower bracts leafy, with long sheaths. Fruits beaked . . . . . 38. C. capillaris.

Female spikelets pale green, oblong. Lower bracts leafy, with short sheaths.

$45\left\{\begin{array}{l}\text { Fruits not beaked } \\ \text { a }\end{array}\right.$

Female spikelets dark brown. Bracts almost without sheaths. Fruits compressed, not beaked . - 39. C. limosa.

Female spikelets brown, cylindrical. Sheaths variable. Fruits ovold, not beaked. 40. C. glauca.

46 Female spikelets distant, not crowded. Stems weak and lealy $\dot{0}$. C.glauca.

46 Female spikelets not very distant. Flowers crowded. Stems stont, 3 to 5 ft. 48

$\int$ Female spikelcts about an inch, on slender stalks. Fruits rather long beaked.

47 Female spikelets about 2 inches, very slender. Stalks almost concealed in the sheaths. Fruits short-polnted. 42. C. strigosa.

$48\left\{\begin{array}{l}\text { Female splkelets about } 2 \text { inches, on slender stalks. Glumes and fruits spreading, } \\ \text { with long points }\end{array}\right.$

Female spikelets 4 to 6 inches. Stalks almost concealed in the sheaths. Fruits small, scarcely beaked . . . . . . 4. C. pendula.

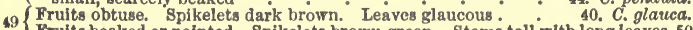

Fruits beaked or pointed. Spikelets browu-green. Stems tall with long leaves 50

Fruits much flattened, pointed .

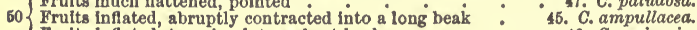
Fruits Inflated, tapering Into a short beak - . . . 46. C. vesicaria.

1. C. dioica, Linn. (fig. 1111). Dicecious C.-A slender diœcious 
plant, seldom above 6 or 8 inches high, with a crecping rootstock; the leaves very narrow, much shorter than the stem, the radical ones locsely tufted. Spikelets brown, solitary on each stem; those of the male plant linear, about 6 lines long ; the female's much shorter, and ovoid. Fruits longer than the glumes, contracted into a point, and more or less spreading when ripe. Styles 2-cleft.

In spongy bogs, in northern and Arctic Europe, Asia, and America, and in the mountain ranges of central Europe. Common in Scotland, northern England and Ireland, but rarer in the south. $\mathrm{Fl}$. early summer.

[C. Davalliana, $\mathrm{Sm}$., alluded to in former editions under this species, is a very distinct one, formerly found near Bath, but now extinct.]

2. C. pulicaris, Linn. (fig. 1112). Flea C.-A small tufted species, not creeping, 3 to 6 inches high, the leaves narrow, almost subulate, shorter than the stem. Spikelet solitary and terminal, about 9 lines long, male in the upper half, 3 to 7 of the lower flowers female. Style 2-cleft. Fruit ovate, sessile, and erect when young, becoming oblong, pointed, contracted at the base, and horizontally spreading when ripe, and then nearly 2 lines long.

In wet meadows and bogs, or moist hilly pastures, in northern Europe and Asia, and in the mountains of central and southern Europe to the Caucasus. Generally spread over Britain. Fl. early summer.

3. C. rupestris, All. (fig. 1113). Rock C.-Rootstock creeping. Leaves in loose tufts, broader and flatter than in $C$. pulicaris, but ending in a long fine point. Stems 3 to 6 inches high, with a linear, mixed spikelet like that of $C$. pulicaris, but the style is 3-cleft, and the fruit is shorter, obovoid, not pointed, and not so spreading. The lower glumes often bear a fine deciduous point.

On wet rocks, and moors, in the ruuntains of northern and Arctic Europe and Asia, and North America, and the higher ranges of central Europe. In Britain, limited to the higher mountains of Scotland. $F l$. rummer.

4. C. pauciflora, Lightf. (fig. 1114). Fevo-flowered C.-A slender species, with long, creeping runners, and a loosely branched stem, decumbent at the base, or rarely forming dense tufts, and not above 6 inches high. Leaves narrow, the upper ones sheathing the stem to nearly the middle, and often nearly as long. Spikelet solitary, pale brown, 3 or scarcely 4 lines long, with few flowers, the 2 or 3 uppermost male, the 2 or 3 lower female, with 3 cleft styles. Fruits narrow and pointed, nearly as long as the whole spikelet, spreading or reflexed when ripe.

In moors and swamps in northern and Arctic Europe, Asia, and America, and in the higher mountain ranges of central Europe. Rather frequent in the Highlands of Scotland, more local in northern England, and not recorded from Ireland. $F$. summer.

5. C. leporina, Linn. (fig. 1115). Oval C.-Stems loosely tufted at the base, forming at length a short, horizontal rootstock, and attaining a foot or more in height. Leaves usually considerably shorter. Spikelets 4 to 6 , sessile, distinct but very close together, ovoid, brownish-green and shining, about 4 lines long, consisting chiefly of female flowers, with a few males at the base of each spikelet. Outer bracts like the glumes or the lowest rarely with a short, leafy 
point. Styles 2-cleft. Fruits flat, with a scarious wing or border. C. ovalis, Good.

In moist meadows, and pastures, over the whole of Europe and tem. perate Asia, found also in the Rocky Mountains of North America. Generally diffused over Britain. Fl. summer, rather early.

6. C. lagopina, Wahlenb. (fig. 1116). Hare's foot C.-Very near C. leporina, but a smaller plant, seldom above 8 or 9 inches high, forming rather dense tufts, with the leaves about balf the height of the stems. Spikelets usually 3 or 4, very close together, of the shape of those of $C$. leporina, but rather smaller, and the fruits, thougl tlat, are not winged.

An Alpine plant, not unfrequent in northern Europe, Asia, and America, at high latitudes, and in the higher mountain ranges of sentral and southern Europe. In Britain, only on the loftiest mountains of Aberdeen, and there extremely rare. Fl. summer.

7. C. elongata, Linn. (fig. 1117). Elongated C.-When first flowering this plant has the appearance of tall, luxuriant specimens of $C$. canescens, often attaining 2 feet, but the spikelets are browner, and the ripe fruit attains near 2 lines, tapers into a point, and spreads more or less from the axis, projecting far beyond the glumes. 'The spikelets are longer, narrower, and not near so close as in C.leporina, and the fruits are not at all winged.

In marshes, in central and northern Europe, and northern Asia, from northern Spain and Italy almost to the Arctic circle, and in NorthWest America. Rare in Britain, although it has been found in several counties of England, in the south of Scotland, and in Antrim in Ireland. Fl. early summer.

8. C. echinata, Murr. (fig. 1118). Star-headed C.-A tufted species, rarely above 6 or 8 inches high, with the leaves mostly shorter than the stem. Spikelets 3 or 4 , at soree distance from each other (except sometimes the 2 uppermost), oval-oblong, and about 3 lines long when they first come out; but as the flowering advances, the long-beaked fruits spread in every direction, giving the spikelets a nearly globular form. The male flowers occupy the lower lalf of the terminal spikelet, and a small portion of the base of the two others. Styles 2 . cleft. Fruits about 2 lines long, and edges slightly rough. C. stellulata: Gooden.

In marshy places, especially in monntain districts, in Europe and Russian Asia, from Spain and Italy to the Arctic regions, and in North America. Frequent in Britain. Fl. spring or early summer.

9. C. canescens, Linn. (fig. 1119). Whitish C.-Stems tufted, a foot high or rather more, with rather long leaves. Spikelets 4 to 6 , at some distance from each other, or the nppermost closer, 3 or 4 lines long, of a pale green. Fruits not longer than the glumes, rounded at the top, with a small point, not tapering into a beak as in the last three species. Styles 2-cleft. Male flowers generally very few, at the base of most of the spikelets. C. curta, Good.

In bogs and marshy places, in northern and Arctic Europe and Asia, and in the mountains of central and southern Europe to the Caucasus, and in North America. Spread over many parts of Britain, and abundant in some bogs, but not very general. $F l$. early summer. An alpine variety, with smaller spikelets, has been distinguished under 
the name of C. alpicola, Wahlb. (C. vitilis, Fries., or C. Persoonii, Sieb.).

10. C. remota, Linn. (fig. 1120). Remote C.-Distinguished from all other British species, with mixed spikelets male at the base, by the small pale spikelets at considerable distances from each other, the outer bracts of the 3 or 4 lower ones always very long and leaf-like. Stems slender, a foot high or more. Spikelets smaller than in $C$. canescens. Fruits tapering into a point, but not so long as in $C$. elongata. The terminal spikelet has male flowers in the lower half, the others only a few at the base, and the lowest is often entirely female.

In woods, and moist, shady places, generally dispersed over Europe and central and Russian Asia, except the extreme north, and North America. Frequent in England and Ireland, less so in Scotland. Fl. early summer.

11. C. axillaris, Gooden. (fig. 1121). Axillary C.-A rather tall species, with leafy stems often 2 feet high, allied on the one band to C. remota, but the spikelets are not so distant, and the lowest is either branched, or there are 2 or 3 together, either sessile or very shortly stalked, and only one or two of the lower bracts are leaf-like. On the other hand, the clnstered lower spikelets show an approach to $C$. paniculata, and, as in that species, there are a few male flowers at the top of the terminal spikelets; but the inflorescence is much more slender, the spikelets much more distant, and there are nsually a few male flowers at the base of most of them. From the remote-flowered forms of $C$. muricata it differs in the longer spikelets, the much more leafy lower bract, and the fruit flatter, with very acute edges.

Generally distributed over Europe and Russian Asia, except the extreme north, but not very common. Very local in England and Ireland, and not known in Scotland. Fl. early summer. [C. axillaris is supposed to be a hybrid between $C$. remota and $C$. muricata; and C. Bœnninghauseniana, Weihe, is another between remota and paniculata.]

12. C. paniculata, Linn. (fig. 1122). Panicled C.-A stout species, forming large tofts; the stems attaining from 1 to 3 or even 4 feet in height, and more or less triangular, but never so much so as in $C$. vulpina; the leaves in luxuriant specimens longer than the stem, and 3 or 4 lines broad, in poorer specimens much shorter and narrower. Spikelets numerons, brown, crowded into a compound spike or panicle, sometimes 4 or 5 inches long, with the lower branches spreading and an inch long, sometimes contracted into a spike like that of $C$. vulpina, but more slender. The individual spikelets are sessile, mostly with a few male flowers at the top, the outer bracts scarious at the edges, the lowest sometimes with short fine points. Styles 2-cleft. Fruits ovate, beaked, marked on the inner face with several longitudinal ribs or veins.

In marshes and bogs, throughout Europe and Russian Asia, except the extreme north, and in North America. Generally distributed over Britain. Fl. early summer. It varies much in the degree of development of the inflorescence, as well as in the nerves or ribs of the fruit. A small variety. C. teretiuscula, Good, has the panicle almost contracted Into a squke of about an inch, but much more slender than in $C$. vulpina, aud the fruit, although the longitudinai riks are scarcely 
prominent, is very convex, not flattened as in the latter species. This variety is connected with the more common state of $C$. paniculata, by numerous intermediate forms, often considered as a species under the name of $C$. paradoxa, Willd.

13. C. vulpina, Linn. (fig. 1123). Fox C.-A short, tufted plant, 2 to 3 or even 4 feet high, with rather broad but not very long leaves, ending in a fine point, and a sharply-triangular stem, with broader sides than in C. paniculata. Spikelets numerous, green or pale brown, densely crowded into a terminal spike of 1 to 2 inches, always more or less compound and interrupted as the base, but the branches never elongated. The outer bracts of the lower clusters of spikelets have a fine leafy point. The individual spikelets are ovoid, many-flowered, all male at the top. Styles 2-cleft. Fruits much flattened, spreading when ripe, with a green or pale brown, rather broad beak.

In marshes and wet meadows, throughout Europe and Rnssian Asia, except the extreme north, and in North America. Frequent in England and Ireland, more scarce and chiefly a coast plant in Scotland. $F l$. early summer.

14. C. muricata, Linn. (fig. 1124). Prickly C.-A much smaller plant than the last two, seldom attaining a foot in height, with rather narrow leaves shorter than the stem. Spikelets about 6 , rather short, brown or shining green, all mixed, having a few male flowers at the top of each, either all simple and crowded in a terminal spike of about an inch, or the lower ones rather more distant and sometimes slightly compound. Outer bracts mostly terminating in short fine points. Styles usually 2-cleft. Fruits rather large, 2 lines long when ripe, pointed and spreading as in C.echinata.

In marshy and gravelly pastures, throughout Europe, temperate Asia, except the extreme north, and North America. Not uncommon in England, Ireland, and southern Scotland. Fl. éarly summer.

C. divulsa, Gooden., appears to be a variety of muricata growing in less open situations, with longer stems and leaves, and paler, more distant spikelets, forming an interrupted spike of 2 or 3 inches; the lowest spikelet occasionally compound, with a rather long, leafy outer bract. It is distinguished from $C$. elongata, by the shorter nearly globnlar spikelets, without any male flowers at the base, and the fruits much less flattened.

15. C. arenaria, Linn. (fig. 1125). Sand C.-Rootstock crecping often to the length of many feet, emitting small tufts or single stems from a few inches to 1 or $1 \frac{1}{2}$ feet in height and leafy at the base. Spikelets rather large, ovoid, all simple and sessile, crowded 8 or 10 together in a terminal spike of 1 to 2 inches, or 1 or 2 lower ones occasionally more distant. Outer bracts all glume-like, or the lowest with leafy points. Male flowers often numerous in the upper, and especially in the intermediate spikes, very few at the top of the lowest. Fruits much flattened, tapering into a beak, and winged as in C. leporina, from which this species differs in the creeping rootstock and in the male flowers at the top, not at the base of the spikelets.

In maritime sands, on the coasts of Europe and northern Asia. Abundant all ronnd Britain. Fl. all summer.

C. intermedia, (rooden. ( . disticha, 11 uls.), appears to be an inland rariety, not uncommon in marshy ground and wet meadows, in Eurowe 
and Russian Asia, and North America, as also in various parts of England, Ireland, and southern Scotland. It is usually taller and more slender and leafy, and the fruits are generally, but not always, longer and less distinctly winged. [C. ligerica, Gay, is a more slender form with female spikelets at the top, fonnd in the Scilly Islands.]

16. C. divisa, Hnds. (fig. 1126). Divided C.-Rootstock creeping. hard, and almost woody; the stems usually short, but always more slender than in $C$. arenaria. Spikelets few and short, crowded into an ovoid or oblong spike or head, seldom above half an inch long, all, especially the upper ones, with several male flowers at the top. Styles 2-cleft. Fruits scarcely flattened, not winged, varying much in the length of their beak.

Chiefly a sea-coast plant, but found occasionally inland in marshes and swamps, in sonthern Europe, extending eastward to the Caucasus and Himalaya, and np the western coasts to the English Channel. In Britain frequent on some of the coasts of England, but not extending to the north, and only near Dublin in Ireland. Fl. early summer.

17. C. incurva, Lightf. (fig. 1127). Curved C.-Rootstock creeping; the stems not above 2 or 3 inches high, often cnrved as well as the rush-like leaves, which are nsually abont the same length. Spikelets 3 or 4, closely packed into a broadly ovoid, brown head, each with a few male flowers at the top. Styles 2-cleft. Fruits broad, rather inflated, tapering into a short beak projecting beyond the glumes.

A northern, chiefly Arctic species, in Europe, northern and central Asia, and North America. In Britain, only on the sandy sea-shores from Holy Isle to Shetland, but rare. Fl. summer.

18. C. saxatilis, Linn. (fig. 1128). Russet C.-Rootstock creeping ; the scaly runners ending in tufts of leaves. Stems nsually shortly decumbent at the base, 8 inches to a foot high or rather more, and leafy. Spikelets about 3 or 4 , distant from each other; the terminal one or two cylindrical and small; the lower 3,2 , or 1 female, ovoid, of a dark brown, about 6 or 8 lines long; the lowesi on a slender stalk, with a leafy bract at its base. Style 2-cleft. Fruit ovoid, inflated, longer than the glume, with a very short point or beak.

Limited to the Arctic and high northern regions of Europe. In Britain, only in the higher Scotch monntains. Fl. summer. [This includes $C$. Grahami, Boott, and pulla, Gooden., and is regarded by many authors as a variety of $C$. vesicaria.]

19. C. cæspitosa, Linn. (fig. 1129). Tufted C.-A very variable species, but (with the following $C$. acuta) readily known among all the British species with distinct male and female spikelets, by the 2-cleft styles and almost flat fruits. The rootstock has creeping runners, but the stems are often densely tufted, enclosed at the base by the brown sheaths of the leaves, the outer ones often without blades and worn into ragged fibres. In dry soils the stems are scarcely 6 inches high, and the leaves still shorter; in rich swamps the stems attain 4 feet, with the leaves almost as long. Spikelets 3 to 6 , each from $\frac{1}{2}$ to $1 \frac{1}{2}$ inches long, the terminal one and the npper portion or the whole of the next male, the remainder female ; the lowest usually shortly stalked, and 1 or 2 of the outer bracts leafy. Glumes dark brown or black, midrib often green.

In pastures, meadows, and marshes. Common in Europe and Russian 
Asia, from the Mediterranean to the Arctic regions, and in North America. Fl. spring and summer. The principal forms occurring in Britain, often considered as species, are:-

a. C. rigida, Good. A dwarf alpine form, scarcely 6 inches high, with short, flat, and rigid leaves. In exposed situations, at great elevations, or at bigh northern latitudes.

b. C. caspitosa, Sm. (vulgaris, Fries., Goodenovii, Gay). Usually 1 to 3 feet high, loosely tufted, with narrow leaves, including many intermediate forms passing gradually into the preceding and following varieties. Abundant throughout Britain.

c. C. stricta, Good. Usually about 2 feet high, more glancous and tufted than the last variety, with narrow leaves, rather long spikelets, the fruits more distinctly arranged in 8 or 9 rows, and their nerves more strongly marked. Equally commor, with the last variety, but usually in more open situations.

d. C. aquatilis, Wahl. A very tall, leafy form, with slender spikelets, approaching $C$. acuta. In bogs and marshes in Scotland, rare.

[e. C. trinervis, Degl. A short, stont plant, with narrow rigid leaves, the margins of which are involute. Confined to the shores of N.W. Europe, and recently found in wet, sandy places on the Norfolk coast.]

20. C. acuta, Linn. (fig. 1130). Acute C.-This may again be a mere luxuriant variety of $C$. cospritosa. It attains 2 or 3 feet, with long, flaccid leaves, and leafy bracts; the female spikelets are often 3 inches long or more; the glumes all narrow and acute, and the fruits themselves narrower than in most varieties of $C$. ccespitosa.

In wet meadows, and marshes, generally distributed over the area of C. caspitosa, and not uncommon in Britain. Fl. spring and early summer.

21. C. alpina, Sw. (fig. 1131). Alpine C.-A rather slender species, 5 inches to a foot high, tufted or shortly creeping, with short leaves. Spikelets about 3, ovoid, black or dark brown; the terminal one mixed, hairy, a few male flowers at its base; the 2 others female, one close to the terminal one, the other a little lower down, on a short stalk, in the axil of a leafy bract. Styles 3-cleft. Fruit green, obtusely triangular, shortly beaked, and projecting beyond the glume. C. Vahlii, Schk.

On mountain-rocks, in northern Europe and Asia. In Britain only in two localities on the Clova mountains of Scotland. Fl. summer.

22. C. Buxbaumii, Wahlenb. (fig. 1132). Buxbaum's C.-Rootstock shortly creeping, but the stems often densely tufted, 1 to 2 feet high, with rather long leaves. Spikelets usually 3 , in a loose spike, the terminal one male at the base, the others all female and sessile, or the lowest on a very short stalk. Lowest bract, and sometimes the next also, leafy. Glumes dark brown, mostly pointed. Styles 3-cleft. Fruits of a pale colour, much resembling those of $C$. coespitosa, usually as long as or longer than the glumes, rather obtusely angled, and not beaked.

In bogs, in northern and Arctic Europe, Asia, and North America, in the mountains of central Europe, and in Australia. In British Islands only known from Lough Neagh, in Ireland. Fl. July.

23. C. atrata, Linn. (fig. 1133). Black C.-Stems loosely tufted, to 11 feet high; the leaves broad and flaccid, with loose sheaths. Spikelets 3 or 4, black or dark brown, cylindrical, 8 or 9 lines long; 
the terminal one with a few male flowcrs at the base, or irregularly mixed, not all male as in the Arctic $C$. ustulata, which closely resembles this species in other respects; the spikes entirely female or nearly so, stalked, erect when young, drooping when ripe. Onter bracts leafy. Glumes rather large, pointed. Styles 3-cleft. Fruits dark and shining, flat when young, very acntely triangular when ripe, with a short point or beak.

A common species, in northern, alpine, and Arctic Kurope, Asia, and Nortb America. Not unfrequent in some of the Scotch mountains, and found also, but sparingly, on Snowdon in North Wales, but not in Ireland. FJ. summer, rather early. [C. ustulata, Wahlb., mentioned above, is included in some British floras, and in the "London Catalogue" on the anthority of the late G. Don, who believed that he had found it in Glen Lyon nearly a century ago, but if so it has never been refound.]

24. C. humilis, Leyss. (fig. 1134). Dwarf C.-Tufts short and very dense, with narrow, radical leaves, broadly sheathing at their base, and considerably longer than the flower-stems. These are from 3 to 5 inches high, with a terminal male spikelet about 9 lines long, and 3 or 4 much smaller female ones, placed at intervals along the stem almost from its base, and, although stalked, scarcely protruding from the white scarions sheaths of the leafless bracts; the glumes of both the male and female spikelets are also scarious on the edges. Styles long and 3-cleft. Fruits ovoid, obtnse, more or less ribbed, and slightly downy. C. clandestina, Good.

On downs and stony wastes, chiefly in limestone districts, in central and southern Europe, extending eastward far into South Russian Asia, and northwards into most of the calcareous districts of France and Germany. In Britain, only in Wilts, Somerset; Gloncester, Hereford, Dorset, and Hampshire connties. Fl. spring.

25. C. digitata, Linn. (fig. 1135). Fingered C.-A densely tnfted species, 6 inches to a foot high, with short leaves. Male spike about 6 lines long, and really terminal although exceeded by the npper female spike, which is placed close under it ; there are also 2 or 3 other female ones rather lower down, all shortly stalked, longer than the male and more or less spreading, so as to give the whole spike a digitate appearance; the flowers in each spikelet at some distance from each other. Bracts brown and sheathing, without leafy points or only a very short one. Styles 3-cleft. Fruits obovoid and minntely downy.

In the woods of limestone mountains, in central and sonthern Europe and temperate Russian Asia, extending northward into Scandinavia. Rare in Britain, and only in the hilly districts of western and northcentral England. Fl. spring. [C. ornithopoda, Willd., is a variety with distant female spikelets, and fruit longer than the glumes, found in Derbyshire and Yorkshire. C. ericetorum, Poll., with the habit of C. digitata, has keeled leaves and smaller shorter crowded spikes. A native of dry banks in Europe and North Asia, found in Britain in the eastern counties on chalk-hills only.]

26. C. præcox, Jacq. (fig. 1136). Vernal C.-Near C. pilulifera and C. tomentosa, but with shorter, stiffer leaves; the inflorescence is less compact than in the former, more so than in the latter, and the bract of the lowest spikelets forms a short sheath with a small leafy point. 
The male spikelet is larger, and the glumes more obtuse, but with a distinct fine point. Fruits ratber small, shortly beaked, covered with a minute down.

In dry pastures, and heaths, common in Europe and Russian Asia, except the extreme north, and naturalised in North America. Generally distributed over Britain. $F l$. spring.

27. C. montana, Linn. (fig. 1137). Mountain C.-Very near C. pilulifera, but the bracts have scarcely any leafy points; the female spikelets are shorter, with much darker glumes; and the fruits are twice as long, with acute angles, and are rather hairy than downy.

In pastures and heaths with $C$. procox, in central and southern Europe and western Asia, and exterding northward into Scandinavia. In Britain, found in a few western and southern counties. Fl. spring.

28. C. pilulifera, Linn. (fig. 1138). Pill-headed C.-Stems 6 inches to a foot high, forming broad and sometimes loose tufts, but scarcely creeping at the base. Leaves shorter than the stem, weak and flexible. Female spikelets 2 or 3 , short and compact, close under the terminal male one. Bracts leafy, usually short, without sheaths. Glumes brown, more or less pointed. Styles 3-cleft. Fruits small, obovoid, or nearly globular, scarcely beaked, covered with a minute down.

In hilly pastures, and moors, generally distributed over Europe, and the same, or a closely allied species, across Russian Asia and in North America. Common in Britain. Fl. carly summer.

29. C. tomentosa, Linn. (fig. 1139). Downy C.-Rootstock creeping. Stems erect, slender, a foot high or more. Leaves narrow, erect, much shorter than the stem. Terminal male spikelet about an inch long; females 1 or 2 , at some distance from it, oblong, erect, and nearly sessile, rather more than $\frac{1}{2}$ inch long, compact, with small brown glumes. Lower bracts leafy, without any sheath. Styles 3-cleft. Fruits small, ovoid, or nearly globular, not beaked, downy.

In moist meadows, in central and southern Europe, extending east ward to the Caucasus, and northward to the Baltic. In Britain, only known from a single locality near Merston in Wiltshire. Fl. early summer.

30. C. flliformis, Linn. (fig. 1140). Slender C.-The habit is near that of $C$. distans, or of $C$. extensa, but it differs in its downy fruits. Rootstock creeping. Stems 1 to 2 feet high, with long, narrow leaves; the leafy bracts are also long and narrow, almost as in C. extensa, but without or almost without sheaths. Male spikelets usually 2 or even 3, the terminal one often $1 \frac{1}{2}$ inches long; females 1 or 2 , remote from them, nearly sessile, 6 to 9 lines long. Styles 3-cleft. Fruit near 2 lines long, ovoid, shortly beaked, and very downy.

In wet ditches, and marshes, in northern and central Europe, and Russian Asia, from the Arctic regions to central France and the Alps, and in North America. Not common in Britain, occurring chiefly in Scotland, northern England and Ireland. Fl. spring.

31. C. hirta, Linn. (fig. 1141). Hairy C.-Rootstock creeping. Stems weak, leafy, 1 to 2 feet high, and, as well as the leaves, more or less hairy. Lower bracts long and leafy, with long sheaths. Terminal male spikes 1 or 2 . Females very distinct, cylindrical, rather loose, an inch long or more, much like those of $G$. sylvatica, and the fruits, as in that species, taper into a long beak, but they are also covered with short spreading hairs. 
In woods and wet pastures, common in Europe and Russian Asia, except the extreme north. Frequent also in Britain, excepting the north of Scotland. Fl. spring and early summer.

32. C. pallescens, Linn. (fig. 1142.) Pale C.-The general aspect and pale yellowish-green fruiting spikelets are like those of $C$. flava, but the fruits are obtuse, without any prominent beak. Stems tufted, leafy at the base, seldom above a foot high. Terminal spikelet male, light brown, about 6 lines long. Female spikelets 2 or rarely 3 , shortly stalked, erect or slightly drooping, oblong, shorter than the male one, and all near under it. Bracts leafy, with a short, sheathing base, or the lowest scarcely sheathing. Styles 3-cleft. Fruits glabrous.

In marshy places, extending over Europe and Russian Asia, from the Mediterranean to the Arctic regions, and often very common, and in North America. Frequent in Scotland and Ireland, but certainly less so in England. Fl. early summer.

33. C. extensa, Gooden. (fig. 1143). Long-bracted C.-A tufted rather slender species, 1 to 2 feet high, with narrow, often convolute stiff and erect leaves. Spikelets nearly sessile, and near together at the top of the stem, or only the lower one distant, as in C. flava, but all oblong and of a brown-green, as in C.distans, although usually not so long, and differing from both in the long, narrow, leafy bracts, the lowest usually much exceeding the stem. Styles 3-cleft. Fruits as in C. distans, ovoid, triangular, strongly nerved, and tapering into a conical beak.

Very common in brackish marshes round the coasts of Europe, ex. tending to the Baltic, temperate Asia, and North and South America. It is general also round the British Isles. Fl. early summer.

34. C. flava, Linn. (fig. 1144). Yellow C.-Usually densely tufted and leafy, seldom attaining a foot in height, and acquiring frequently a jellowish hue, especially the fruiting spikelets. Leaves flat. Male terminal spikelet 6 to 9 lines long. Females 1, 2, or 3 , sessile or shortly stalked and very near the male, and often one much lower down on a longer stalk; all erect, ovoid or oblong, or when ripe nearly globular. Bracts all leafy and sheathing at the base. Styles 3-cleft. Fruits ovoid, distinctly nerved, with a prominent beak, always very spreading or reflexed.

In turfy bogs and marshy pastures, very common in Europe and temperate Asia, from the Mediterranean to the Arctic regions, and in North America. Generally diffused over Britain. Fl. spring arid summer. It varies much in the distance of the lower spikelets from the upper ones, and in the size of the fruits; but the small-fruited forms with short beaks ( $C$. Ederi, Ehrh.) are very inconstant in their characters.

35. C. distans, Linn. (fig. 1145). Distant O.-Stems more or less tufted, slender, 1 to 2 feet high, with flat but rather narrow leaves, much shorter than the stem. Spikelets few and far apart; the terminal one male (sometimes with a small one close under it), the others female, oblong-cylindrical, $\frac{1}{2}$ to 1 inch long, stalked, but often appearing sessile from the stalks being enclosed in the long sheaths of the leafy bracts. Glumes brown. Styles 3-cleft. Fruits usually rather dark-green, but sometimes yellowish, erect, rather strongly nerved or ribbed, tapering into a rather long beak.

In warshes and wet moors, or sometimes in drier pastures, especially 
near the sea, in Europe and western Asia, from the Mediterranean to Scandinavia, and in North America, although not an Arctic plant. Common in Britain. Fl. summer. It varies much in the length of the stalks of the lower spikelets and in the prominence of the ribs of the fruit. The following are the principal varieties, which are often considered as species :-

a. C. fulra, Good., with short, pale-coloured spikelets, and a rathe1 long beak to the fruit.

b. C. depauperata, Good., with only 4 or 5 fruits to the spikelet, but each one larger, somewhat inflated, with a very long beak. [Very rare and confined to dry woods from Kent to Somerset.]

c. C. binervis, Sm., with darker spikelets and more angular fruits.

d. C. laevigata, $\mathrm{Sm}$., like the last, but the slender green spikelets often 1 to $1 \frac{1}{2}$ inches long, much like those of $C$. sylvatica, but erect, not drooping.

36. C. punctata, Good. (fig. 1146). Dotted C.-Very much like the common sea-coast form of $C$. distans, of which it may be a mere variety ; but the fruits appear to be entirely withont longitudinal ribs, except the 3 angles, which are slightly prominent.

Marshy places in Europe westward of Italy, extending into Norway. In Britain it is local and confined to Wales and the southern half of England, the south of Ireland, and Kirkcudbright in Scotland. Fl. summer.

37. C. panicea, Linn. (fig. 1147). Carnation C., Carnation-grass.Stems tufted, but emitting creeping runners from the base, 1 to $1 \frac{1}{2}$ feet high, with rather short, erect, flat leaves, more or less glancous. Spikelets nsually 3 , the terminal one male, the others female, distant, erect, stalked, cylindrical, $\frac{1}{2}$ to 1 inch long, often loosely imbricated; the flowers, especially in the lowest one, at some distance from each other. Bracts shortly leafy, with rather long sheaths. Glumes brown. Styles 3-cleft. Fruits ovoid, without ribs except the 3 angles, obtuse, with a very short beak or point, like those of $C$. glauca, from which plant this species differs chiefly in the more erect, loose female spikelets, and in the male spikelet always solitary.

In meadows and moist pastures, one of the commonest species throughout Europe and temperate Asia, occurring also in North America. Com. mon in Britain. Fl. early summer. An alpine variety, not uncommon in high northern latitudes, and at considerable elevations in the mountains of central Europe, and in some of the Highlands of Scotland, with the sheaths of the bracts looser, the spikelets darker-coloured and fewflowered, and the fruits more decidedly tapering into a beak, is $C$. vaginata, Tausch. An alpine Aberdeenshire plant, which has been referred to the alpine and Pyrenean C. frigida, All., appears to me, from the specimen I bave seen, and from the figure in Trimen's "Journal," to be rather a form of this $C$. vaginata, with the beak of the fruit still longer.

38. C. capillaris, Linn. (fig. 1148). Capillary C.-Stems slender, densely tufted, without creeping runners, 4 to 9 inches high, longer than the leaves. Terminal spikelets male, and small. Female spikelets 2 or 3 , much lower down, but on long, thread-like peduncles, so as sometimes to exceed the male, of a rather pale-colonr, loose-flowered, but seldom 6 lines long. Bracts shortly leafy, the lower one with a 
rather large sheath. Glumes very scarious on the edge. Styles 3-cleft. Fruits 10 to 12 in each spikelet, tapering into a pointed beak.

In alpine meadows, and on moist rocks, in northern and Arctic Enrope and Asia, in the high ranges of central and sonthern Europe, North Asia, and North America. On the mountains of the north of England and Scotland, but rare and local; not in Ireland. Fl. summer.

39. C. limosa, Linn. (fig. 1149). Mud C.-Rootstock creeping. Stem slender, from 3 inches to a foot high, with narrow leaves, sometimes as long as the stem, sometimes much shorter. Terminal male spikelet $\frac{1}{2}$ to near 1 inch long. Females 1 or 2, on slender stalks, drooping, rather loose, 6 to 8 lines long. Bracts leafy, withont sheaths, or with a short, scarious one. Glumes rather dark-brown, ovate, the upper ones pointed. Styles 3-cleft. Fruits rather large, roundish, compressed, scarcely pointed, and not distinctly beaked. C. irrigua, Hoppe.

In bogs and mountain marshes, in northern and Arctic Europe, North Asia, and North America, and in the higher ranges of Central Europe. Local in Britain, chiefly in the north, but extending to Dorset and Hants. Fl. summer. The C. variflora, Sm., is a high northern or Arctic variety, with the glumes almost black, and more obtuse, and only 5 or 6 fruits in each spikelet. It occurs, but rarely, in the highest Scotch mountains. [It is generally admitted to be a very distinct species.]

40. C. glauca, Murr. (fig. 1150). Glaucous C.-The creeping rootstock, glaucons foliage, and most of the characters, are those of $C$. panicea, but there are generally 2 or 3 male spikelets, the female ones are rather more compact, on longer stalks, and more or less drooping when ripe, and the sheaths of the leafy bracts are usually shorter. Stems, in dry situations, 6 or 8 inches high, with short, curved leaves; in rich meadows, 1 to $1 \frac{1}{2}$ feet, with erect leaves as long as the stems. Female spikelets 2 or 3 , varying from to above 1 inch in length. Glumes dark-brown. Styles 3-cleft. Fruit ovoid, not ribbed except the 3 obtuse angles, and without any beak.

In meadows and marshes, in Europe, extending eastward into temperate Asia and north ward far into Scandinavia. Abundant in Britain generally, although in the north less so than C. panicca. Fl. early summer.

41. C. sylvatica, Huds. (fig. 1151). Wood C.-Stems weak, tufted, leafy, 1 to 2 feet high. Leaves and leafy'bracts flaccid, the latter with long sheaths. Terminal spikelet male, about an inch long. Lower spikelets 2 to 4 or rarely more, all female, or occasionally 1 or 2 of the upper ones partially or even wholly male, the females distant, cylindrical, looseflowered, about an inch or rather longer; on slender stalks, and at length more or less drooping. Glumes green, narrow, and very pointed. Styles 3-cleft. Fruit glabrous, ribbed, tapering, into a long beak.

In woods, common in Europe and Russian Asia, except the extreme north, although in the south it is rather a mountain plant. Frequent in Britain, except the north of Scotland. Fl early summer.

42. C. strigosa, Hnds. (fig. 1152). Thin-spiked C.-Very near $C$. sylvatica, but the female spikelets are much longer, and more slender, usually above 2 inches long, the flowers at some distance from each other, the peduncles much shorter, almost concealed in the long sheaths of the bracts. Glumes green and lanceolate. Fruits tapering to a point. bat not iptc s long beak as in C. sylvatiog. 
In mountain woods, dispersed over north and central Europe; ex. tending from France and Denmark to the Cancasus, but nowhere very common. Occurs in many parts of England and Ireland, but not in Scotland. Fl. early summer. It is probable that varieties of $C$. sylvatica are often mistaken for it.

43. C. Pseudocyperus, Linn. (fig. 1153). Cyperus-like C.-Stems tall, stout, and triangular, with long, broad leaves, as in $C$. pendula, but the spikelets are not above 2 inches long, more crowded at the top of the stem, on longer stalks, and remarkable for the very narrow, pointed, green glumes, and the narrow, striated, spreading fruits, ending in a long, pointed, slender beak. The spikelets droop when in fruit, as in C. pendula. The terminal male one has often a few female flowers at the top, or sometimes in the whole npper half. Styles 3-cleft.

In marshes and wet ditches, in central and southern Europe, extend. ing eastward to the Caucasus, and northward into southern Scandinavia, and in North America. Scotland, sonth of the Caledonian Canal. Spread over a great part of England and Australia and Ireland. Fl. early summer.

44. C. pendula, Hod. (fig. 1154). Pendulous C.-One of the largest of our Carexes. Stems stont, triangular, leafy, 3 to 5 feet high. Leaves long, and often near $\frac{1}{2}$ inch broad. Spikelets 4 to 6 inches long, more or less drooping, the terminal one male; females 3 or 4 , at some distance from the male, their stalks almost concealed in the sheaths of the long, leafy bracts. Glumes ovate-lanceolate, brown, with a green centre. Styles 3-cleft. Fruits small, crowded, ovoid, with a very short beak.

In woods and shady places, in central and sonthern Europe, extend. ing eastward to the Caucasus and northward to the Channel, but scarcely into northern Germany. In Britain, scattered over England, Ireland, and southern Scotland. Fl. early summer.

45. C. ampullacea, Gooden. (fig. 1155). Bottle C.-A stont, tufted spccies, the stems scarcely angled, 1 to 3 feet high, with long leaves. Spikelets 1 to 2 inches long or even more; males 2 or 3 , the terminal one longer than the others; females 2 or 3 , erect, cylindrical, compact, the lowest shortly stalked. Leafy bracts rather long, without sheaths. Styles 3-cleft. Fruits ovoid, inflated, pointed, with a rather long beak, spreading horizontally. C. rostrata, Stokes.

In bogs and marshes, in central and northern Europe, and central and Russian Asia, from northern Spain and Italy to the Arctic regions, and in North America. Generally spread over Britain. Pl. carly summer.

46. C. vesicaria, Linn. (fig. 1156). Bladder C.-Very near C. ampullacea, but the stem is more angular, the spikelets rather shorter, and the fruits, although inflated as in that species, are more conical, tapering more gradually into the beaks.

The geographical distribution is nearly the same as that of $C . a m m u$. lacer, extending from Spain to the Arctic regions, and all across Russian Asia into North America. In Britain, however, it is less frequent, and does not extend so far north. Fl, sming and early summer. [As observed under $C$. saxatilis (p. 495), that plant has been regarded by various anthors as a variety of vesicaria. Wliether as forms or distinct species they may be distinguished by the following characters:-C. vesicaria (incluāing $U$. involuta, Bab.); stems 1 to 2 feet, fruit elongate-ribbed. 
with a long slender beak and 3 styles. C. saxatilis, Linn. (pulla, Good. and Grahami, Boott); stems 4 to 10 inches, spikelets smaller, fewer, fruits nearly smooth with a short beak and 2 styles. Lofty Scotch mountains.]

47. C. paludosa, Gooden. (fig. 1157). Marsh C.-A stont, long-leaved species, with a creeping rootstock and triangular stems, 2 to 3 feet high. Male spikelets 2 or 3 , above an inch long, and sessile. Female spikelets 2 or 3 , rather distant, cylindrical, often 2 inches long, sessile, or the lowest shortly stalked. Bracts leafy, without sheaths. Glumes more or less pointed. Styles 3-cleft. Fruits ovate, slightly 3-angled, but much flattened, tapering into a very short, spreading point or beak.

In wet meadows, and marshes, throughout Europe and central and Russian Asia, except the extreme north, and North America. Frequent in England, Ireland, and southern Scotland, less so in the north. $F$. spring and early summer. A taller variety with longer female spikelets, on longer stalks, more pointed glumes, and a more distinct beak to the fruit, has been distinguished as a species nnder the name of $C$. riparia, Curtis. It is also said to have the minute point on the anthers more distinct; but all these characters apnear to be too variable to be relied upon as specific. It grows with the smaller form, and is rather more frequent in Britain.

\section{GRAMINEA. THE GRASS FAMILY.}

Herbs, with stems usually hollow, except at the nodes, and alternate, narrow, parallel-veined, entire leaves, sheathing the stem at their base, but the sheaths are usually split open on the side opposite to the blade, and terminate, within the base of the blade, in a small scarious appendage called a ligule. Flowers in spikelets, arranged in terminal spikes, racemes or panicles. Each spikelet consists usually of 3 or more chaff-like, concave scales or bracts, called glumes, arranged alternatcly on opposite sides of the spikelet, their concave faces towards the axis; the 2 lowest, or first and second glumes, usually empty, nearly opposite to each other, and often differently shaped from the others. The succeeding, or flowering glumes, enclose each a rather smaller scale called a palea, usually thinner, and with $\mathbf{2}$ longitudinal ribs or veins, placed either between the gloom and the axis of the spikelet, with its back to the axis, or apparently opposite the glume at the end of the axis. Where there are more than 3 glumes, the third, or lowest flowering glume is usually close to the second, its flower is sometimes imperfect, or it is even quite empty, and it is often intermediate in shape between the outer empty ones and the succeeding flowering ones, which are inserted on the axis at distinct intervals. Within the palea, or apparently between the flowering glume and the 
palea, is the real flower, consisting usually of 2 minute, almost microscopical scales called lodicules, of 3 (rarely 2 or 6 ) stamens, and of a 1-celled, 1-ovuled ovary, crowned by 2 more or less feathery styles. The name of flower, however, is here, as in other works, generally meant to include the flowering glume and palea. Fruit 1-seeded and seed-like, called a grain or caryopsis, consisting of the real seed and pericarp, either free or adhering to the persistent palea, or enclosed in the more or less hardened flowering glume and palea, or in the outer glumes. Embryo small, at the base of a mealy albumen.

Such is the general plan upon which the flowers of Grasses are arranged, but there are many variations which require to be carefully attended to in discriminating the genera of this most natural, but somewhat difficult family. When the spikelet contains but one flower, its flowering glume and inner palea appear often almost opposite to each other, like an inner pair of glumes within the outer empty ones. Sometimes there are three or even more outer, empty glnmes, either passing gradually into the slape of the flowering ones, or one or two, very differently silaped (usually much smaller), are placed between the onter empty pair and the flowering one; or the axis of the spikelet terminates in one or more rudimentary, empty glumes. Occasionally one flower, either below or above the perfect one, bas stamens only, and some exotic species are always monoccious or diœeious. Frequently the midrib of the flowering glumes alone, or of the intermediate empty ones alone, or of all the glumes, is prolonged into a bristle, sometimes very long, called an awn, and the awn is either terminal, proceeding from the point of the glume or from a notch at the top, or is inserted lower down, on its back, or at its very base. Sometimes the whole spikelet contains only two glumes, one empty, the ot her flowering, with or even without a palea, or is reduced to a single flowering glume and palea, and in a very few l-flowered spikelets it may be doubtful whether the 2 inner scales should be considered as a glume and a palea, or as 2 glumes without any palea. Many botanists restrict the name of glume to the outer empty pair, calling both the flowering glumes and their palea, palcas or ylumellas, and giving the name of sterile florets to all other empty glumes in the spikelet, or even to a small prolongation of the axis which is often observable at the outer base of the palea of the terminal flowers. The leaves of some Grasses are described as convolute, that is, rolled inwards on the edges, but the character is often very deceptive in dry specimens, for in many species the leaves are perfectly flat when growing, but roll inwards in drying immediately on being gathered.

Grasses are abundantly diffused over the whole world, from the utmost limits of phrnogamous vegetation towards the Poles or on alpine summits, to the burning plains of the Equator. In temperate regions they form the principal mass of the green carpeting of the soil, whilst in tropical regions some species (the Bamboos) attain the height of tall trees. They supply us with one of the most important articles 
of food for man, in the shape of grain, and for cattle as constituting the chief portion of meadows and pastures.

1 Spikelets 1-flowered

1 Spikelets containing 2 or more flowers

Spikelets arranged along one slde of a slender, simple, linear spike

2 Spikelets arranged along one side of the simple, linear branches of the panicle 5

Splkelets arranged in a close, cylindrical or ovate splke or spike-like panicle . ?

Spikelets arranged in a loose, branching panicle... . 16

Spikelets 1-/oroered, in one-sided linear spikes.

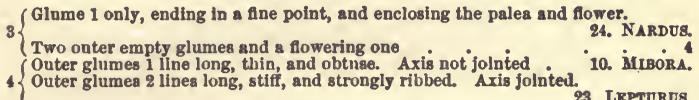

$5\left\{\begin{array}{l}\text { Spikelets in pairs or clusters along the branches } \\ \text { Spikelets single along the branches }\end{array}\right.$

23. LRPTURUS.

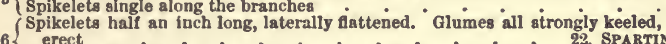

$6\{$ ereet 22 SPARTINA.

Spikelets about a line long. Outer glumes spreading . . 21. CrNodon.

Spikelets 1-flonored, in a dense spike or spike-lile panicle.

$7\{$ Outer glumes without awns. Flawering glumes with or without awns . . 8

All the glumes awned a : 13

Only 2 nearly equal empty glumes enclosing the flower : $:$;. Pircis

An additional small empty glume outside the 2 equal ones

Two additional small, awned, empty glumea, withinside the two equal ones.

$9\left\{\begin{array}{l}\text { 5. ANTHOXANTHUM. } \\ \text { Outer glumes swollen and shlning at the base. 8pikelets rather small. } \\ \text { 14. GASTrIDIOM. }\end{array}\right.$

Outer glnmes keeled or boat-shaped

(A tuft of halrs at the base of the flower, withln the onter glume. Reed-like $10\left\{\begin{array}{l}\text { grass with a very long spike } \\ \text { No tuft of hairs outsile the flawer within the outer glumes. Splkelets fiat . I1 }\end{array}\right.$

11 Flowering glume with a fine awn on its back (sometimes shorter than the

Flowering glumes withont swns. Inner pales present • * 9. ALOPEOURCS.

12 Keel of the outer glumes expanded into a flat whing : $:$ i PHALARIS.

Keel of the outer glumes not winged 8 PHLEuM.

Spikelets 3 together on each tooth of the simple, close, cylindrical spikes, $13\left\{\begin{array}{l}1 \text { or } 2 \text { of each cluster rediced to a pair of enypty glumes. } \\ \text { Spikelets small and numerous, in a cluse spike-like panicle, all containing }\end{array}\right.$ flowers

$14\left\{\begin{array}{l}\text { Flowering glumes without awns } \\ \text { Flowering glumes awned as well as the onter ones : : : PHLkuM. }\end{array}\right.$

15 Spike ovate, with long softly silky hairs : : : : i1. LAGOROS.

Spike cylindrical or branched, not hairy : $: \vdots: 12$. Polrrocon.

Spikelets 1-foroered, in a loose panicle.

16 Spikelets ovate, obtuse or scarcely acuto . • . • • . . . 17

Spikelets lanceolate, pointed
Spikelets very flat, consisting of only 2 glumes, both keeled : : irsis 19

17 Splkelets scarcely fiattened. Two outer empty glumes about the size of the

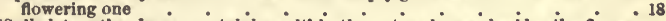

Spikelets rather large, containing within the outer glumes, besides the flower,

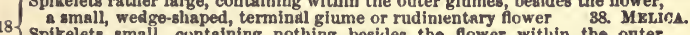

Spikelets small, cuntaining nothing besides the flower within the onter glumes

$19\left\{\begin{array}{l}\text { Small tufts of hairs or hairy appendage st the base of the flower within the } \\ \text { outer glumes }\end{array}\right.$

(No halrs or hairy appendage at the base of the flower within the onter ginmes 21

(No awns. A small hairy appendage at the base of the flower on esch side.

20 Flowering glume with a short fine awn. A tuft of hairs at the base of the flower ? 
(Awns to all the glumes

12. PoLTPOGON.

21 A wns (often very smali) to the flowering glume only, cr none. Outer glumes pointed but not awued

22 Awns jointed, with a tuft of hairs at the joints

Awns not jointed

23 Outer glumes swollen and very shining at the base

. 22

22

Splkelets all sessile, in a simple.

$\left\{\begin{array}{l}\text { Splkelets all sessile, in a simple spike (branched only in sccidental } \\ \text { luxuriant specimens) }\end{array}\right.$

Spikelets single or clustered, in 8 loose and spreading or close and spike-like panicle.

$25\left\{\begin{array}{l}\text { Awns to some or all the glumes } \\ \text { Spikelets entirely without awns }\end{array}\right.$

Spikelets 3. or more floncered, sessile in a single spike.

(Two spikelets to each tooth of the spike

26 . Splkelets all aolitary

Spikelets clustered along the axis of the splic

Spikele with their side to

27 Spikelets with their sides to the main sxis of the spike. . . 28

Splkelets with one edge (the backs of the glumes) to the main axis . . . 29

Outer glumes neariy equal. Splkelets very closely aessile, or indented.

Outer glumes unequal. Spikelets almost sessile . . 29. BRACHYPODIUM.

(One empty glume at the base of each spikelet (except the terminal one).

29 Spikelets indented in the axis 28. LOLIUM.

Two empty glumes at the base of each spikelet. Spikelets almost sessile . 30

$30\{$ Perennial. Splkelets 6 lines long or more . * . . FnstucA elatior.

$30\{$ Annual. Spikelets not above 3 linea long : : : : . POA loliacea.

Spikelets 2-or more flowered, panicled, auned.

31 Flowering glumes all awned .

$\{$ Spikelets with 1 awnless perfect flower, and 1 awned male flower $:$ (Awus inserted on the back of the flowering glumes, near or below the centre.

IIairs on the axis between the flowers short

82 Awns terminal. Flowering glumes surrounded by hairs longer than them.

Awns terminal or neiry "Axis the spikelet withont hair

33 Spikelets 2-flowered

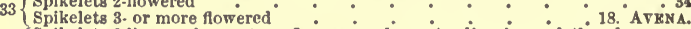
$34\left\{\begin{array}{l}\text { Splkelets } 2 \text { lines or less. Awn fine, scarcely protruding beyond the glumes. } \\ \text { 17. AIRA }\end{array}\right.$

Splkelets 3 or 4 lines long. Awn exscrted. One of the flowers male only.

setimes rednced to a very short polnt

36 Spikelets crowded in a close spike or dense clusters : . . . . . . 37

36 Panicle loose or contracted into a long one-sided spike : 81 . Frstúca.

37 Outer spikelet of each cluster consisting of empty glumes only 33. CYNosurus.

37 All the spikelets contaituing flowers . - 32. DACTXLIS.

38 One terminal awnless flower and s lower male flower awned - 8. PANICUM.

38 Awniess flower the lowest, with a terminal awned male one : . . 39

(Outer glumes 2 to 3 lines, completely enclosing the flowers and their awns.

39 Outer glumes 3 to 5 lines, the flowers or at least their awns protruding.

20. HoLCU8.

19. ARRHEN ATHRRUM.

Spikelets 2-or more flowered, awnless, panicled or in a compound spike.

(Spikelets 2 or 3 together to each notch of an apparently simple spike.

.0 Spikelets sessile, In close clusters in an apparently simple splke or apike-like

Spikelets more or less stalked, in s lonse or contracted panicle.

A small bract at the base of the spikelets or clusters . 41. SESLRRIA.

1. Outer spikelet of each cluster consisting of empty glumes. 33. CYNOSURU8.

Splkeiets all containfing flowers without bracts at the base of the clusters $\quad$. 8 
Splke cylindrical or slightly Interrupted. Mowering glumes white and mem0 branous 13 Clusters one-sided, in an irregular spike or close panicle Glumes herbaceons and rigid

13 Outer glumes enclosing the fiowers or nearly so : : : : .

43 Outer glumes ahorter than the flowers.

Glumea obtuse, coloured. Two flowers with wedge-shaped rudimentary

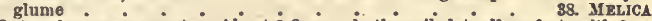

44 Outer glumes very acute. Abont 3 flowers in the splkelet, all perfect, with 3 . toothed glumes

Glumes all acute. Two male flowers and 1 smaller perfect one in the splkelet.

First onter glume very amall, second broadly truncate at the top , Hind ocklor.

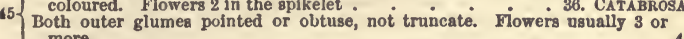
$46\left\{\begin{array}{l}\text { mpikelets broadiy ovate or orbicular. Glumes closely packed and very apread. } \\ \text { ing }\end{array}\right.$

6 ing.

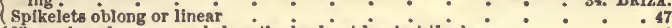

47 Flowering glumes rounded on the back, at least at the base : : : $: 48$

7 Flowering glumes keeled on the back :

48 Flowering glumes obtuse or rather acute $\quad$ : : : 35. POA.

8 Flowering glumea very pointed or ahortly awned

Flowering glumea very polnted. Flowers about 3 , with a bristle-like continua-

49 tion of the axil . . . . . • • . 37. MIOLINIA. Flowering glumes obtuse or acute. Flowers 3 or more, the last terminal 35. POA.

The limits of the nnmerons genera into which Grasses are divided are as yet fa: from being definitely fixed. Some are by no means natural, and those which are so have not always any definite characters. They have also been variously distributed into tribes, according to the special views of their structnre entertained by different botanists. Amongst those which appeared to be the most generally adopted, eight tribes were, in the first editions of this work, distinguished as being represented in Britain. Since then a detailed study of a considerable part of the Order, in connection with the Australian Flora, has suggested some modifications in the general gronping of the genera, but as the new tribes cannot yet be considered as definitely settled, the sequence adopted in the first edition is here left nndisturbed. A general sketch, however, of the proposed arrangement as affecting British genera is now added, observing at the same time that here and there an exceptional species may not be in strict conformity with the tribal cliaracter; but fewer, it is believed, than in the case of any other method hitherto proposed.

* Pedicel articulate belono the outer glumes. Spikelet with 1 terminal fertile foncer, the male or barren floucer (if any) or empty glumes belono it. (PANICACEA.)

1. PANICE.r. Flowering glume of a firmer texture than the empty onea below it :-3. PANICUM.

2. ANDROPOGONEz. Flowering glnme much thinner and smaller than the empty one below It, and often bearing a twisted awn :-12. POLYPOGON.

The above two tribes, so sparingly represented in Britain, comprise a very large proportion of tropical GRAMIN F.e.

* Articulation, when present, under the flovoering glumes, but above the twoo outer ones. Spikelets with one or more flovers and frequently a male fower or empty glume above them, the male flower rarely below them. (POACEA.)

3. Phatarmex. Glumes normally 6, 2 below the articulation, 2 inmedlately above It, usually small and empty or with a male flower in each, 2 upper nearly Equal, encloaing a single perfect flower. No true palea (the lower glumes occa. siunally deficient):-1. I.EERSIA ; 9. A loprcurus; 6. PHALARIS; 7. DIaraphis;

b. Anthoxanthum; 4. Hikrochlok.

4 STREPTATHER 4 . Spikelets with 1,2 , or rarely more perfect flowers. Howering 
glume bearing usually a bent or twisted often dorsal awn; palea 2-nerved, usually thin or small. Sub-tribe Agrostridece : Spikelet 1-flowered, truiting glume and small palea usually very thin :-10. MIBORA; 13. AGROSTIS; 14. GASTRIDIOX; 11. LAGORUS; 16. Ca lamagostis; 16 . Psama. Sub-tribe Avenacae: Spikelet 2- or few-flowered, rarely 4-flowered, fruiting glnme and palea more developed and flrmer than in Agrostidece. 8. PhleUM; 20. Holcus; 17. AirA; 18. AVRNA; 19. Arrhena. THERUM.

5. ASTREPTA. Splkelets with several, more rarely 1 or 2, perfect flowers. Flowering glumes unawned or terminating in straight awns; pales prominently 2nerved or 2-keeled, nsually as long or neariy as long as the giume. Sub-tribe Miliea : Spikelets paniculate, 1- or 2-flowered, the rachis not produced beyond the flower :-2. MInIOM. Sub-tribe Chloridea: Spikelets 1-or several-flowered, sessile along the simple branches of the panicle:-21. CYNODON; 22. SPARTINA. Sub-tribe IIordeinea : Splkelets 1- or several-flowered, sessile in the notches of a simple spike:-23. LEPTURUS; 24. NARDUS; 25. ElYMUS; 26. HORDEUM; 27. AGROPYRUM; 28. LOLIUM ; 29. BRACHY PODIUM. Sub-tribe Festucece: Spikelets severai-flowered,

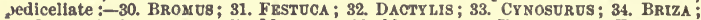
35. PoA ; 36. Catabrosa ; 37. Molinia ; 38 . Mrlica ; 39 . Trionia ; 40. Kosleria ; 41. Sesleria ; 42. ARdNDO.

Among the exotic genera occasionally cultivated in our fields or gardens may be mentioned Rye (Sccale cereale), the Maize or Indian Corn (Zea Mays); and the Feather-grass (Stipa pennata), a native of southern Europe, once supposed to have been found in Westmore. land.

\section{LEERSIA. LEERSIA.}

Spikelets loosely panicled, 1-flowered, flat, consisting of only 2 glumes both of them keeled, without any inner 2-nerved palea. Stamens in the British species 3 , in most exotic ones 6,2 , or 1 .

A small genus, chiefly American, with 2 or 3 of the species spread over the warmer regions of the Old World and Australia. This genus appears to be a Phalaridca reduced to the terminal pair of glumes. In the adjoining genus Oryza (the Rice) the intermediate small empty pair is present, in both the outer empty pair below the articulation is deficient.

1. L. oryzoides, Sw. (fig. 1158). Common L. - Stems about 2 feet high, the leaves, especially their sheaths, rcry rough. Panicle, when fully developed, loosely branched, spreading, 6 or 8 inches long, but in the British specimens usually much shorter, and partially included in the sheath of the last leaf. Spikelets numerous, all serund, 2 to nearly 3 lines long; the first glume rather broad, with 2 nerves on each side of the keel ; the second much narrower, with 1 faint nerve on each side.

In wet places, ditches, and marshes, common in North America, extending over a great part of Asia, and more sparingly across central Europe to France and Denmark, reappearing in the tropics of both worlds. In Britain found only in Hampshire, Sussex, and Surrey. Fl. autumn.

\section{MILIUM. NILIUM.}

Spikelets loosely panicled, 1-flowered without awns. Fmpty glumes 2, concave nearly equal. Flowering glume concave, of a firmer texture, hard and shining when in fruit.

A genus of very few species, but widely dispersed over the globe, usually placed amongst Panicea, on account of the hardened fruiting 
glume, but there is no articulation of the pedicel, and it seems better to unite it with a few other exotic genera in a tribe or sub-tribe of Poacere.

1. Milium effusum, Linn. (fig. 1159). Sprcading M.-A tall, slender Grass, often 4 or 5 feet bigh, with rat her short, flat leaves, and a long, loose, slender, and spreading panicle of small, pale green or purple spikelets. Empty glumes concave but not keeled, 1 to $1 \frac{1}{2}$ lines long, nearly smooth. Flowering glume almost as long, very smooth and shining. Palea nearly similar but rather smaller, faintly 2-nerved, and notched at the top.

In moist woods, widely spread over Europe, Asia, and North America, extending from the Mediterranean to the Arctic Circle. Common in Britain. $F l$. summer.

\section{PANICUM. PANICUM.}

Spikelets either in a loose or close and spike-like panicle, or along one side of the simple branches of a panicle, usually small, 1-flowered, rarely awned. Outer glumes usually 3 ; the first or lowest small, sometimes very minute, the next always empty, the third empty or with an imperfect or male flower in its axil. Flowering glume concave, of a firmer texture, hard when in fruit. Palea like the flowering glume, but rather smaller, and more or less 2-nerved.

A vast genus, chiefly tropical or North American, with a very few species spreading into Russian Asia and Europe, including most of the cultivated Millets of southern Europe, Africa, and Asia It is in most cases easily recognised by the small outer glumes, although in some species reduced to an almost microscopical scale. Many botanists remove the following species into three separate genera distinct from the true tropical Panicums.

Spikelets 2 together, along one side of the linear, digitate branches of the panicle. (DIGrtaria.)

Spike-like branches of the panicle 2 to 4 inches long. - . 1. P. sanguinale.

Spike-like branches not above an inch iong : 2 P. glabrum.

spikelets crowded in a sinple or branched, spike-1lke panicle.

Spike-like panicle cylindrical, the spikelets intermixed with numerous, iong, awn-like bristles. (SRTARIA.)

Bristles rough with reversed hairs, felt as the spike is drawn

downwards through the hand. $\dot{b}^{\text {Bistles rough with erect hairs, felt as the sike is pushed }}$ upwards through the hand.

Nowering glume marked with transverse wrinkles . . 4. P. glaucum.

Flowering glume not wrinkled $\quad$ 5. $P$. viride.

Panicle pyramidal, without awn-like bristles, but the spikelets

sometimes coarsely awned (ECHINooHLOA) - . . Q. P. Crus-galli.

1. P. sanguinale, Linn. (fig. 1160). Fingered P. - An annnal, with stems from 1 to 2 feet long, more or less spreading or creeping at the base, then ascending or erect. Leaves flat, more or less hairy. The panicle consists of 2 to 6 , or rarely more, simple, slender branches, 2 to 4 inches long, and all spreading from nearly the same point at the top of the peduncle, so as to appear digitate. Spikelets in pairs along one side of these branches, one sessile, the other shortly stalked, each about 1 line long. First glume very minute, almost microscopic; the second concave, and about half the length of the third, which is nearly 
flat, and 5-nerved. Flowcring glume, about the same length, very smooth and awnless. Digitaria sanjuinalis, Scop.

One of the commonest weeds in all tropical and warm countries, becoming less frequent in central Europe. In Britain, only as an introduced weed of cultivation in the south of England. $\mathrm{Fl}$. the whole season.

2. P. glabrum, Gaud. (fig. 1161). Glabrous $P$.--Very much like $P$. sanguinale, but a much smaller plant; the panicle has only 2 or 3 spikelike branches, each scarcely above an inch long, and the spikelets are fewer. The first glume is, as in the last species, very minute, but the two next empty ones are both about the same length as the flowering glume. Digitaria humifusa, Pers.

A weed of warm climates, like the last, but rather less tropical, more generally spread over central Europe, extending northward to southern Scandinavia, and better established in the south of England. Fl. summer and autumn.

3. P. verticillatum, Linn. (fig. 1162). Rough P.-A glabrous erect annual, 1 to 2 feet high, with flat leaves, rough on the edges. Spikelets small, crowded into a cylindrical but rather loose, compound spike (or rather, spike-like panicle), 1 to 2 lines long, interspersed with numerous bristles, 2 or 3 lines long, inserted under the spikelets, but projecting beyond them. These are rough with minute hairs, reversed so as to cling to the hand when the spike is drawn downwards through the fingers. First glume very small, the two next about the length of the flowering one. Setaria verticillata, Beauv.

In cultivated and waste places, very common in southern Euope, and generally spread over central Europe to the Baltic, and into Asia, but much rarer in hot countries than the two following species. In Britain, it occurs in the south apd ast of England. Fl. summer and autumn.

4. P. glaucum, Linn. (fig. 1163)。 Glaucous P.-An erect annual, very much like $P$. verticillatum, but of a paler green; the spike or spikelike panicle more compact and regularly cylindrical, 1 to $1 \frac{1}{2}$ inches long, with very numerous projecting bristles. These are but slightly rough with minute erect teeth, so as only to be felt as the spike is pushed upwards through the fingers. Spikelets rather larger than in $P$. verticillatum, the second glume rather shorter than the third, the flowering one marked with numerous transverse wrinkles, visible especially as the seed ripens. Setaria glauca, Beauv.

One of the commonest weeds of cultivation throughout the warmer regions of the globe, abundant in southern Europe, less so in central Europe, not extending into Scandinavia. In Britain, only occasionally introduced. $F l$. all summer and autumn.

5. P. viride, Linn. (fig. 1164). Green P.-Closely resembles P. glaucum, but the second and third glumes are both about the same length, and the flowering one has no transverse wrinkles. Setaria viridis, Beanv.

With the same geographical range as $P$. glaucum, this is, however, much less common in tropical conntries, but more so in central Europe, extending eastward all across Asia, and northward into southern Scandinavia. In Britain, it is also rather better established than the other species, except P. glaucum. Fl. summer and autumn.

6. P. Crus-galli, Linn. (fig. 1165). Cockspur P.-A coarse, decum. 
bent, rather broad-leaved annual. Panicle 4 to 6 inches long, irregularly pyramidal, and rather one-sided; the spikelets larger than in the preceding species, crowded or clustered along the spike-like branches, the lowest of which are I to 2 inches long, diminishing gradually to the top. Lowest glume very short and broad, the next about the length of the flower, empty and awnless, the third about as long, ending in either a short point or a long, coarse awn, and has often a thin palea in its axil. Flowering glume awnless, smooth and shining. Echinochloa Crus-galli, Beauv.

A common and widely-spread weed of hot countries, especially in the Old World, and abundant in temperate Europe and Russian Asia, extending northwards to southern Scandinavia. In Britain, occasionally only, as a weed of cultivation in southern England. Fl. summer and autumn.

\section{HIEROCHLOE. HOLYGRASS.}

Panicle loose and spreading (in some exotic species narrow and crowded). Spikelets with 1 perfect terminal flower and 2 lower flowers male only, with 3 stamens. Glumes 6 , all scarious, boat-shaped, keeled, and pointed; the 2 outer empty ones as long as the flowers, below the articulation of the rachis ar:d persistent, 2 intermediate ones enclosing the male flowers; the upper pair smaller, but both keeled, without any 2-nerved palea.

A genus of several species, spread over the colder regions of both the nort bern and southern hemispheres, and closely allied to Anthoxanthum, differing only in the intermediate glumes enclosing male flowers.

1. H. borealis, Rom. et Sch. (fig. i166). Northern H.-A perennial, from $\frac{1}{4}$ to $]_{\frac{1}{2}}$ feet high, with a creeping rootstock, and flat leaves, osually short, scented like Anthoxanthum. Panicle spreading, about 2 inches long, with slender branches. Spikelets ovate, of a shining brown; the outer empty glumes very pointed, nearly 3 lines long, and glabrous. Two intermediate glumes attaining to the length of the outer ones, but rough on the outside with short hairs, and each enclosing a 2-nerved palea and 3 stamens. Uppermost pair of glumes smaller and nearly glabrous, the innermost enclosing 2 stamens and the pistil.

In mountain pastures and waste places, at high latitudes, in northern and Arctic Europe, Asia, and America, descending southwards to northern Germany, and to the monntains of south-eastern Germany. In Britain, only near Thurso, in Caithness. Fl. summer.

\section{ANTHOXANTHUM. ANTHOXANTH.}

Spikelets 1-flowered, narrow, pedicellate, but crowded into a cylindrical spike or spike-like panicle. Glumes 6, all boat-shaped and keeled, the 2 onter ones unequal, pointed but not awned; the 2 next also empty, shorter than the onter ones, narrow, hairy; one with a small awn on its back, the onter with a longer awn arising from its base; the upper pair still shorter, obtuse and awnless, without any true palea. Stamens only 2. 
The genus consists of but few species.

1. A. odoratum, Linn. (fig. 1167). Vernal Grass.-A rather slender, erect perennial, 1 to 2 feet high, and quite glabrous. Spike-like panicle 1t to 2 inches long. Outer glumes very pointed; the second about 3 lines long, the first seldom above half that length. Intermediate and upper glumes usually quite included in them, or rarely the longest awn slightly protrudes.

In meadows and pastures, throughout Europe and temperate Asia, from the Mediterranean to the Arctic regions. Abundant in Britain, imparting a sweet scent to new-made hay. Fl. spring and early summer, and often again in autumn. [A. Puelii, Leeoq. and Lam., a native of southern and central Europe, has of late been introduced into several fields in England and Scotland, and may be recognised by its very slender annual habit, and long, exserted awn.]

\section{PHALARIS. PHALARIS.}

Spikelets 1-flowered, broad and very flat, densely crowded into an ovoid or cylindrical spike or spike-like panicle as in Phleum, but there are usually 6 glumes, the 2 outer ones, below the articulation, have the keel projecting into a scarious wing, the intermediate pair small and empty, or one of them occasionally deficient, the upper pair, under the flower, flattened and complicate like the outer ones, but smaller and thinner, with the central nerve or keel short and scarcely conspicuous, or wanting in the inner one, which leares it doubtful whether it be really a glume or a palea.

A small genus, chiefly from the Mediterranean region and central Asia.

1. P. canariensis, Linn. (fig. 1168). Canary Grass.-An erect, leafy annual, 2 to 3 feet high, with a densely imbricated, ovoid, spike-like panicle, 1 to $1 \frac{1}{2}$ inches long, variegated with green and white, and quite glabrous. Outer glumes very flat, 3 to 4 lines long, acnte but not awned, white on the edges, with a broad green line down each side, the intermediate empty ones short and lanceolate. Upper glumes much shorter, narrow and pointed, smooth and shining, but usually villous, hardening round the seed as it ripens.

A native of southern Europe or northern Africa, much cultivated as Canary-seed in Europe, and frequently appearing as a weed of cultivation. In Britain, occasionally found as such. Fl. summer. [Another species, $\boldsymbol{P}$. paradoxa, Linn., is to be found entered into some British floras, but it has no claim to be considered even as a weed of cultivation, being only a very rare and fugitive garden escape.]

\section{DIGRAPHIS. DIGRAPHIS.}

A single species, often united with Phalaris, of which it bas tho rudimentary glumes immediately under the flowering ones, but it is very different in inflorescence, and the onter glumes are not winged on the keel. 
1. D. arundinacea, Trin. (fig. 1169). Reed-grass.-A perennial, 2 to 3 feet high, with rather broad, long leaves, the lower ones forming a dense tuft at its base. Spikelets very numerous, in a panicle 6 to 8 inches long, rather compact, but not closely imbricated nor spike-like as in Phalaris, the lower branches often spreading. Outer glumes about 2 lines long, lanceolate and pointed, but not awned, keeled but not winged, pale-green or whitish with green nerves, the intermediate empty ones reduced to minute linear hairy scales. Flowering glumes smooth and shining, and, as in Phalaris, hardened round the seed. Phalaris arundinacea, Linn.

On river-banks and in marshes, in Europe, Asia, and North America, extending from the Mediterranean to the Arctic regions. Common in Britain. $F l$. summer. A variety with variegated leaves is often cultivated in gardens under the name of Striped-grass or Ribbon.grass.

\section{PHLEUM. PIILEUM.}

Spikelets 1-flowered, flat, and crowded into a cylindrical or oroid spike or spike-like panicle. Outer glumes boat-shaped, their keels projecting iuto a point or very short awn. Flowering glume shorter, very thin, awnless, or with a very short awn on the back. Palea very thin, sometimes with a minute bristle at its base outside, which is the continuation of the axis of the spikelet.

A small genus, widely spread over the temperate and colder regions of the northern hemisphere, distinguished from Alopecurus chielly by the presence of the palea.

Onter glumes truncate and broadly scarious below the point.

Spike long and cylindrical. Points of the outer glumes not hall 80 long as the glume itself.

8 plke short, ovold, or oblong. Polnts or awns of the outer glumes nearly as long as or longer thau the glume itself . . 2. P. alpinum. Outer glumes tapering into a uinute point.

Perennial. Outer glumes linear-lauceolate . . . . . S. P.Buehmeri.

Annual.

Outer glumes wedge-shaped, less than a llne long; the lateral ribs inconspleuous. Splke long and slender. . . P. asperum.

Outer glumes lanceolate, strongly ciliated on the keel, if lines long; the lateral ribs promiuent. Spike sliort - . . 5. P. arenarium.

1. P. pratense, Linn. (fig. 1170). T'imothy-grass, Cat's-tail.-A perennial, 1 to 3 feet high; the leaves rather soft, although rough on the edges. Spike (or spike-like panicle) cylindrical and very compact, from 1 to 3 or even 4 inches long, with very numerous small spikelets. Outer glumes about a line long, with broad, scarious edges, truncate at the top; the green keel slightly ciliate and projecting into a point shorter than the glume itself. Flowering glume entirely included in the outer ones and closely covering the palea; the stamens and styles protruding from the top.

In meadows and pastures, in Europe and temperate Asia, from the Mediterranean to the Arctic regions. Abundant in Britain. Flo early rummer, and often again in autumn. [ $P$. nodosum, Linn., is a recumbent form, with narrower leaves and slender spike.]

2. P. alpinum, Linn. (fig. 1171). Alpine P.-Pcrennial like the 
last, but usnally of much lower stature; the sheaths of the npper leaves very loose or inflated. Spike ovoid or oblong, seldom an inch long, nsually assuming a purplish hne. Outer glumes truncate as in $\boldsymbol{P}$. pratense, but the keel lengthened into an awn, varying from 1 to 2 lines in length.

In alpine pastnres, in northern and Arctic Europe, Asia, and America, and in their monntain chains, reappearing in Antartic America. In Britain, only in the higher Scottish mountains. Fl. summer.

3. P. Bœhmeri, Schrad. (fig. 1172). Bœhmer's $P$.-An erect perennial, like $P$. pratense, but usually smaller, with shorter leaves, the sheaths not enlarged. Spike cylindrical, 1 to 3 inches long, not quite so dense as in $P$. pratense. Outer glumes narrow-lanceolate, tapering into a minute point, without hairs on the keel, and with a narrow, scarious edge. Flowering glume much smaller. Palea with a minute bristle at its base outside. P. phalaroides, Koel.

In dry fields, and waste places, generally dispersed over Europe and Russian Asia, except the extreme north. Rare in Britain and chiefly found in the eastern counties of England. Fl. summer, rather early.

4. P. asperum, Jacq. (fig. 1173). Rough P.-An annual, 6 to 12 inches high, with a cylindrical spike like that of $P$. Bceltmeri, but the spikelets are smaller and more numerous. Outer glumes less than a line long, of a firm texture, smooth or scarcely rough, narrow at the base, enlarged npwards, and contracted rather suddenly into a very short point, the lateral nerves scarcely prominent. Flowering glume very small.

In dry fields, and waste places, in central and sonthern Europe, extending eastward to the Caucasus, and northward into eastern France and central Germany. Rare in Britain, where it has been found casually, chiefly in the ea tern counties. $F l$. summer.

5. P. arenari: $/ \mathrm{m}$, Linn. (fig. 1174). Sand P.-An erect annual, 6 to 8 inches high, with short leaves. Spike to 1 inches long, dense and nearly cylindrical, but more or less tapering at the base. Spikelets about $1 \frac{1}{2}$ lines long. Outer glumes lanceolate, tapering into a short point ; the keel ciliate with stiff hairs, and a very prominent nerve on each side. Flowering glume not one-third the length of the outer ones.

In maritime sands, chiefly in western Europe, extending, however, far along the shores of the Baltic in the north, and the Mediterranean in the south. Common on the coasts of England and Ireland, but only in the east of Scotland. Fl. spring and early summer.

\section{ALOPECURUS. FOXTAIL,}

Splkelets 1-flowered, flat, and densely crowded into a cylindrical spike or spike-like panicle Outer glumes boat-shaped, with a prominent keel, but not awned. Flowering glnme shorter, with a very slender awn inserted on the back (sometimes concealed under the outer glumes). Palea entirely wanting.

A small genus, widely spread over the temperate and colder region. of both the northern and sonthern hemispheres, resembling Phleuw babit, but easily distinguished by the absence of the pales. 
Annual. Outer glumes 3 lines long, nnited to the middle, gla brous or nearly 80

Perennials or rarely annuals. Onter glumes less than 3 lines,

1. A. agrestis. free or united at the base only ; the keel hairy.

Spikes long. Awns more or less prominent.

Stem erect or nearly so. Outer glumes lanceolate, about 2 lines. Awns twice as long.

Stems procumbent at the base. Outer glumes not $1 \frac{1}{2}$ lines. Awns not twice as long

Spikes short. Awns scarcely exceeding the onter glumes .

2. A. pratensis.

3. A. geniculatus.

4. A. alpinus.

1. A. agrestis, Linn. (fig. 1175). Slender F.-An annual, 1 to 2 feet high, erect or slightly decumbent at the base. Leaves rather short, with long, not very loose sheaths. Spike 2 to 3 inches long, thinner and more pointed than in the other species; the spikelets fewer, longer (abont 3 lines), not so flat nor so closely imbricated, and usually quite glabrous; the two onter glumes united to about the middle, the hairlike awn of the flowering one projecting 2 or 3 lines beyond them.

In waste places, on roadsides, \&c., in central and southern Europe and across Russian Asia, extending northward to southern Scandinavia. In Britain, frequent in the south of England, decreasing northwards; in Scotland and Ireland only where introdnced. Fl. the whole season.

2. A. pratensis, Línn. (fig. 1176). Meadow $F$.-Rootstock perennial and shortly creeping, the stems erect or scarcely decumbent at the base, 1 to 2 feet high. Sheaths of the upper leaves rather loose. Spike 2 to 3 inches long, very dense, rather obtuse; the spikelets very numerons and flat, 2 to nearly 3 lines long. Outer glumes free or scarcely united at the base, with short hairs on the keel, which give to the spike a soft, hairy aspect. The hair-like awns project 2 to 4 lines beyond the outer glumes.

In meadows and pastures, throughont Kurope and central and Russian Asia from the Mediterranean to the Arctic regions, and naturalised in several parts of the globe. Abundant in Britain. $\mathrm{Fl}$. spring and summer.

3. A. geniculatus, Linn. (fig. 1177). Marsh $P_{0}-\mathrm{A}$ perennial like A. pratensis, or sometimes annual. Stems nsually procumbent at the base, bending upwards at the lower nodes. Sheaths of the upper leaves rather loose. Spike 1 to 2 inches long, closely imbricated like that of $A$. pratensis, but more slender, with much smaller spikelets. Outer glumes hairy on the keel, not so pointed as in A. pratensis, and scarcely above a line long, the hair-like awns not projecting above a line beyond them.

In moist meadows, and marshy places, throughont Europe and temperate Asia from the Mediterranean to the Arctic regions, and naturalised in other parts of the globe. Abundant in Britain. F. all summer. A slight variety, with still shorter awns, has been described under the name of 4 . fulvus, Sm.; and in some localities, especially near the sea, the stems thicken at the base into a kind of bulb, which state has also been distinguished as a species, under the name of $A$. bulbosus, Gonan.

4. A alpinus, Sm. (fig. 1178). Alpine $F$.-Rootstock creeping and stems erect, as in A. pratensis, but nsually not so tall, and the sheaths of the upper leaves looser. Spike ovoid or shortly cylindrical, seldom above an inch long unless cultivated, and softly silky with the rather fong hairs which cover the glumes. Spikelets closely imbricated, 
rather smaller than in 4. pratensis; the awns either included within the outer glumes or scarcely projecting beyond them.

A high northern plant, extending from east Arctic Earope across Arctic Asia and America, and reappearing in South Chili. In Britain, it occurs in the higher mountains of Scotland, although unknown in Scandinavia. Fl. summer.

\section{MIBORA. MIBORA.}

A single species, differing from Agrostis chiefly in the inflorescence, which is a simple spike nearer that of the Hordeinece, altho ing the spikelets are not closely sessile enough to remove it to that tribe.

1. M. verna, Adans. (fig. 1179). Mibora.-A little, tufted annual, seldom 3 lnches ligh. Leaves short and narrow, with very thin sheaths. Spikelet small, purplish, almost sessile in a simple slender spike about balf an inch long. Outer glumes nearly equal, obtuse, about a line long. Flowering glume shorter, very thin and scarious, hairy outside, jagged at the top, but not awned. Palea small or sometimes none. Kruppia agrostidea, Sm. Chanagrostis minima, Bork.

In sandy pastures, and waste places, in western Europe, not extend. ing in central Europe much to the eastward of the Rhine, although in the south it reaches as far as Greece. Rare in Britain, and apparently confined to the coasts of Anglesen and the Channel Islands. F. spring.

\section{LAGURUS. HARE'S-TAIL}

A single species, with the characters nearly of Calamagrostis, except the inflorescence, which is condensed into an ovoid, softly hairy head or spike as in Alopccurus.

1. L. ovatus, Linn. (fig. 1180). Hare's-tail.-An erect annual, from a few inches to above a foot bigh; the leaves hoary with a soft down, their sheaths rather swollen. Spikelets l-flowered, very numerous, and closely crowded into an ovoid or oblong, softly hairy bead, $\frac{1}{2}$ to 1 inch long. Outer glumes subulate or slightly dilated at the base, about 4 lines long, feathered with long soft hairs. Flowering glume much shorter, and thin, cleft into 2 awn-like points about the length of the outer glumes, and bearing on its back a long, hair-like, bent awn, usually at least $t$ wice the length of the spikelet.

In maritime sands, and waste places, common all round the Mediterranean, and extending up the west coast of Europe to Guernsey; also found, but not wild, in Suffolk. $F l$. eurly sumımer.

\section{XiI. POLYPOGON. BRARDGRASS.}

Spikelets 1-flowered, densely crowded in a spike-like or slightly branched panicle, the pedicel articulate below the glumes. Outer glumes ending in a fine, straight awn. Flowering glume thinner and smaller, with a fine twisted and bent or minute and straight awn, in a tetuinal notch, or on the back. 
A genus of very few species, but widely spread over a great part of the globe.

Awns three or fonr times as long as the spikelets . - . 1. P. monspeliensis. Awus scarcely longer than the glumes themselves :

2. P. littoralis.

1. P. monspeliensis, Desf. (fig. 1181). Annual B.-An annual, procumbent at the base or rarely erect, 1 to $1 \frac{1}{2}$ feet high, with flat, rather flaccid leaves. Panicle contracted into a cylindrical or slightly branched spike, 2 to 3 inches long, of a yellowish shining green, and thickly bearded with the numerous straight and very smooth awns. Outer glumes nearly equal, notched at the top; the fine awn proceeding from the notch, and 3 or 4 times as long as the glume itself. Flowering glume shorter, often with a short, very fine awn. Palea smaller and awnless.

In fields and waste places, on roadsides, \&c., especially near the sea, common in the Mediterranean region and Asia, extending up the west coast of Enrope to Holland. Rare in Britain, and only in some of the south-eastern counties of England. Fl. stummer.

2. P. littoralis, Sm. (fig. 1182). Perennial B.-A procumbent perennial, with rather short, narrow, flat leares. Panicle more branched than in $\boldsymbol{P}$. monspeliensis, the glnmes longer, narrower, tapering into an awn scarcely longer than the glume itself. Flowering glume small, the awn rednced to a minute point. In habit almost intermediate between Polypogon and Agrostis, but the articulation of the pedicel, as well as some other characters, show the close generic affinity with Arundinella in the exotic tribe Andropogonere.

In salt marshes, scattered here and there along the seacoasts of western Europe, the Mediterranean, and North America. In Britain, very local on the coasts of Norfolk, Essex, Kent, and Hampshire. Fl. summer.

\section{AGROSTIS. AGROSTIS.}

Spikelcts small, 1-flowered, and numerous, in an elegant panicle, with slender branches often proceeding several from the same point, and either erect forming a narrow, almost spike-like but loose panicle, or spreading, at least at the moment of flowering. Outer glumes narrow, boat-shaped, pointed, but without awns. Flowering glume shorter, often bearing a fine straight awn on the back below the middle. Palea much smaller or altogether wanting. The axis of the spikelet within the outer glumes glabrons or very shortly hairy.

The genns, as now limited to the exclusion of the more tropical Sporobolus, is chiefly spread over the temperate regions of the globe. Some species are commonly called Bents in some parts of the country, a name giren by others more especially to the Cynosurus cristatus. A wn 2 to t times as long as the spikelets. Second glume longer than the lowest 4. A. Spica-venti. A wn none, or not twice as long as
equal, or the lowest the longest.

Leaves fiat (broad or narrow).

Fowering glnmes awnless or with a very short awn at its

base. l'alea athnt half its length
Fowering glume with a short awn below the middile. Falea minute or none

Legres very fine and oubulate

1. A. abab.

2. A. canina.

3. 4 . setoces 
1. A. alba, Linn. (fig. 1183). Fiorin-grass.-An elegant but most variable perennial grass; in dry mountain pastures often densely tufted, and not above 2 or 3 inches high; in rich moist soils creeping and rooting at the base, often to a considerable extent; the flowering stems erect, 1 to 2 feet high, with a slender panicle usually very spread. ing when in full flower, especially in fine weather, sometimes contracted both before and after flowering. Leaves flat, rather short, but narrow. Spikelets scarcely a line long. Outer glumes nearly equal or the lowest rather the largest. Flowering glume very thin, awnless or rarely with a minute awn arising from its base. Palea nsually about half its length.

In pastures and waste places, wet or dry, thronghout Europe, temperate Asia, and northern America, penetrating far into the Arctio regions, and ascending high upon Alpine summits, and reappearing in the southern hemisphere. Abundant in Britain. Fl, the whole summer. Besides the great differences in size and stature, it varies in the more or less spreading panicle of a light-green or purplish colour, in the length of the ligula of the leaves, in the degree of prominence of the nerves of the glumes and the roughness of their keel, and in other minute particnlars; but all attempts to combine these characters so as to show distinct species, or even to separate marked and permanent varieties, have hitherto failed. [The usually recognised forms are $\boldsymbol{A}$. alba, Linn. (including A. stolonifera, Iinn.), with a long acute ligula and contracted panicle, and A vulgaris, With. (including A. pumila, Linn. and nigra, With.), with a short trnncate ligula and spreading panicle.]

2. A. canina, Linn. (fig. 1184). Bent-grass.-Very near A. alba, but the leaves are rather finer, the panicle is less spreading, the outer glumes longer and more pointed; the flowering one bears on its back below the middle a fine awn, which slightly protrudes beyond the outer glumes, and the palea is very minute or wholly wanting.

With $\boldsymbol{A}$. alba, of which it may be a variety, and having nearly the same geographical range, but not generally so common except perhaps in some mountain districts. Spread over the whole of Britain. Fl. summer.

3. A. setacea, Curt. (fig. 1185). Bristle A.-A perennial, with densely tufted leaves, mostly radical, and very finely subulate. Stems erect, 1 to 2 feet high, with a narrow, slender panicle, always contracted except during the moment the flowers are expanded. Glumes narrow, and more pointed than in $A$. alba, the lowest always longer than the second, the flowering one with a fine awn at its base, usually slightly protruding beyond the outer glumes. Palea very minute.

On dry heaths, in western Europe, from Spain and Portugal to Holland. In Britain, only in the south-western connties of England, extending eastward to Surrey. Fl. summer.

4. A. Spica-venti, Linn. (fig. 1186). Silky A.-A rather tall, slender, and most elegant annual, with rather narrow, flat leaves. Panicle long, and usually spreading, with very slender hair-like branches, and little shining spikelets, scarcely a line long, without the awns. Outer glumes narrow, very pointed, the second rather larger than the lowest one. Flowering glumo with a hair-like awn, 3 or 4 times as long as the spikelet. Palea small with a minute, almost microscopic appendage at its base, which is the prolongation of the sxis of the spikelet. Apera Spica-venti, Adana. 
In fields and sandy pastures, in Europe and Russian Asia from the Mediterranean to the Arctic regions. In Britain, confined to some of the eastern counties of England, from York to Hampshire. Fl. summer. The A. interrupta, Beauv., is a slight variety, with the spikelets more crowded, in a narrow panicle, with nearly erect branches. The anthers are also said to be shorter, but that character is very variable. It is often found with the common form passing gradually into it.

\section{ULBIALIOM. NITGRASS.}

A single specits, sepurated from Agrostis on account of the smooth, shining, enlarged base of the outer glumes.

1. G. lendigerum, Beanv. (fig. 1187). Nitgrass.-An elegant, erect annual, 6 to 8 inches high, with flat leaves. Panicle contracted into a loose tapering spike, 2 to 3 inches long, of a pale green, shining with a satiny or silvery lustre. Spikelet very crowded. Outer glumes nearly 2 lines long, narrow, and very pointed, with a short, very shining enlargement at the base, the second glume shorter than the lowest. Flowering glume very short, broad, and thin, often bearing below the summit an awn about the length of the outer glume, but as often without it. Palea nearly as long.

In fields and waste places, especially near the sea, but occasionally also inland along the valleys of large rivers. Very common in the Mediterranean region, extending up western France, and in Britain, to Sonth Wales, Warwickshire, and Norfolk. Fl. summer.

\section{PSAMMA. MARAM.}

A single species, sometimes united with Calamagrostis, but more frequently considered as a distinct genns, characterised by the inflorescence, the firmer consistence of the glumes, without any awn to the flowering one.

1. P. arenaria, Beanv. (fig. 1188). Maram, Sea Matweed.-Rootstock creeping. Stems stiff, erect, 2 to 3 feet high, with narrow, stiff, erect, and glaucous leaves, concave, or rolled inwards on their edges. Panicle contracted into a close, narrow-cylindrical spike, 5 or 6 inches long, tapering to the top. Spikelets crowded, 4 or 5 lines long, the outer glumes lanceolate, compressed, stiff, and chaffy. Flowering glume rather shorter, but equally stiff, with a tnft of hairs outside on the axis of the spikelct. Palea nearly as long, with a minute hairy bristle, or prolongation of the axis at its base. Ammophila arundinacea, Host.

On maritime sands, common on all the coasts of Europe, except the extreme north, and in North America. Frequent on the British seacoasts. Fl. summer. [P. baltica, $\mathrm{R}$. and $\mathrm{S}$., is a variety or closely allied species found on the Norfolk and Northumberland coasts, with a larger interrupted panicle and more lanceolate and acuminate glumes.] 


\section{CALAMAGROSTIS. SMALLREED.}

Tall grasses, with a more or less open panicle, and numerous 1-flowered spikelets. Outer glumes nearly equal, keeled and pointed. Flowering glume much smaller, very thin, with a very slender and short, hair-like, st raight awn on its back, and a tuft of long silky hairs at its base, on the axis of the spikelet. Palea usually smaller.

A considerable genus, widely distributed over the globe, formerly nnited with Arundo, from which it is distinguished chiefly by the 1. flowered spikelets.

Hairs within the spikelet longer than the flowering glume.

Spikelets nearly 3 lines long, crowded in a narrow panicle. Onter glumes very narrow, almost subulate.

Splkelets about 2 lines long, in a loose panicle. Outer glumes
narrow-lanceolate Hairs within the spikelet shorter thai the flowering glume:- $:$. C. lancenlata.

1. C. Epigeios, Roth. (fig. 1189). Wood S.-Rootstock creeping. Stems 3 or 4 feet high, erect, and rather firm, with long, narrow, somewhat glancons leaves. Panicle branched, but not spreading, except whilst in full flower, from a few inches to near a foot long, with numerous crowded spikelets, often assuming a purplish tint. Outer flumes very narrow-lanceolate and pointed, almost subulate, both nearly 3 lines long. Flowering giume thin, its awn very short and slender, inserted some nay from the top, and scarcely distinguishable from the long silky hairs which envelop the flower.

In moist, open places in woods and thickets, and amongst bushes, spread over the greater part of Europe and temperate Asia from the Mediterrancan to the ctic regions. Abundant in some parts of southern England, but not generally common, and rare in Scotland and Ireland. Fl. summer.

2. C. lanceolata, Roth. (fig. 1190). Purple S.-A tall grass, like the last, and not always readily distinguished from it. It is usually more slender, with flat flaccid leaves. Panicle much looser, 5 or 6 inches long, with slender branches, and more often assuming a shining purple colour. Onter glumes about 2 or sometimes $2 \frac{1}{2}$ lines long, narrowlanceolate, but broader than in $C$. Epigeios. Flowering glume nearly as in that species, but the awn is inserted close to the cleft summit.

In moist woods, and shady places, in northern and central Europe, and Russian Asia, from the Alps to the Arctic regions. Dispersed over several parts of England, and unknown in Ireland or Scotland. Fl. summer.

3. C. stricta, Nutt. (fig. 1191). Narrow S.-A more erect plant than C. lanceolata, $1 \frac{1}{3}$ to 3 feet high, with stiffer, narrow leaves. Panicle very narrow, 4 to 6 inches long. Spikelets smaller than in the last species, the onter glumes broader. Hairs of the axis considerably shorter than the following glume, which has an awn inserted rather below the middle, and reaching to about its own length. There is also at the base of the palea a rudimentary prolongation of the axis, in the shape of a minnte bristle, with a tuft of hairs. In this respect, as in the shortness of the hairs of the axis, it approaches Deycuxia, to which genus it is referred by some botanists, as $D$. neglecta, Kunth.

In bogs and marshes, in northern and Arctio Europe, Asia, and America, not reaching southward of northern Germany. Very rare in 
Britain, having been formerly found in Scotland, and more recently in the moors round Oakmere in Cheshire, and a variety, Hookeri, Syme, about Lough Neagh, in Ireland. Fl. summer.

[4. C. strigose, Hartm. (fig. 1192). An Arctic and subarctic species, has very recently been discovered in Caithness; it most closely re. sembles $C$. stricta, but has larger spikelets and more acuminate glumes.]

\section{AIRA. AIRA.}

Very near Avena in all essential cliaracters, but the spikelets are much smaller, usually with two flowers, only or rarely a single one, the flowering glumes thinner and more scarious, not projecting beyond the outer glumes, and the hair-like awn on their back much shorter than in Avena.

The species are few, chiefly European and north Asiatic, a very few extending into North America, or reappearing in the soutlern hemisphere.

Panicle very loose, with caplllary, spreading branches.

Stems 2 to 4 feet high. Lesves in large tufts, flat and rough. Awns shorter than the glumes

1. A. carpitosa. fecting from the outer glumes

Stens 4 to 6 inches. Leaves fine and short. Arins sliortly protruding . . . . . 5. 4. caryophyllea.

Panicle dense and narrow. Stems 3 to 6 inches.

Spikelets about 2 lines long. Awus thickened at the top, shorter thsn outer glunes

8pikelets rather more than 1 line. Awn halr-like, shortly protruding

3. A. canescens.

1. A. cæspitosa, Linn. (fig. 1193). Tufied A.-A tall perennial, forming large, dense tufts, with rather stiff, flat leaves, very rough on the upper surface. Stems 2 to 4 feet, bearing an elegant panicle 6 inches to near a foot long, with spreading, slender, almost capillary branches. Spikelets silvery-grey or purplish, about $1 \frac{1}{2}$ lines long. Outer glumes rather unequal, lanceolate and pointed. Flowering glumes scarcely projecting from the outer ones, minutely toothed or jagged at the top, with a fine, hair-like awn inserted near their base, and not so long as the glume itself. Deschampsia caspitosa, Beauv.

In moist, sliady places, throughout Europe, from the Mediterranean to the Arctic regions, and the temperate and mountain regions of the northern and southern hemispheres. Abundant in Britain. Fl. summer. A. alpina, Linn., is a variety which in its least altered form only differs in its lower stature, with shorter leaves, with the glumes more or less enlarged, the awn adhering to it so much the higher as the glume is more altered. The whole panicle is usually viriparous, all the glumes being elongated, foliaceous, withont awns, and containing very imperfect flowers or none. It frequents considerable elevations, or high latitudes, and is common in the higher mountains of Scotland.

2. A. flexuosa, Linn. (fig. 1194). Wavy A.-A much smaller and more slender plant than the ordinary form of $A$. caspitosa, from 1 to 1 t feet high, with very narrow leaves rolled inwards on the edges, and almost subulate. Fanicle spreading, but not sobvẹ \& or 3 ịchẹs long; 
the spikelets much fewer than in A. caspitosa, but larger, being usually 2 to 3 lines long, very shining, with the fine, hair-like awns protruding beyond the glumes. Deschampsia flexuosa, Beauv.

On heaths and hilly pastures, throughout Europe and temperate Asia, North America, and in South Chili and Fuegia. Generally distributed over Britain. Fl. summer. [A.montana, Huds., is a subalpine form with larger purple glumes, and A. setacea, Huds. (uliginosa, Weihe, discolor, R. and S.), one with slender leaves.]

3. A. canescens, Linn. (fig. 1195). Grey A.-A small, tufted perennial, of a glaucous or slightly purplish tinge, seldom above 6 inches high, with fine convolute leaves. Panicle dense and narrow, 1 to 2 inches long. Spikelets above 2 lines long, the outer glumes pointed, quite concealing the small flowering ones. These are remarkable for their awns, which are jointed in the middle, with a tuft of minute hairs at the joint, and slightly thickened towards the top, the whole awn not projecting beyond the outer glumes. Corynephorus canescens, Beauv.

In sandy situations, in central and southern Europe, extending eastward to North Asia and the Caucasus, and northward to southern Scandinavia. In Britain, only known for certain on the sandy seacoasts of Norfolk and Suffolk, and in the Channel Islands. Fl. summer.

4. A. præcox, Linn. (fig. 1196). Early A.-A slender, densely tufted annual, 3 to 6 inches high, with short very fine leaves. Panicle contracted, $\frac{1}{2}$ to 1 inch long. Spikelets rather more than a line long, the outer glumes very scarious. Flowering glumes small, cleft at the top, and slightly hardening, as in Avena; the short, hair-like awns shortly protruding beyond the outer glumes.

In sandy and hilly pastures, in central and southern Europe, and western Asia, extending into Scandinavia, but not far to the north. Generally spread over Britain, to the northern extremity of Scotland. Fl. spring.

5. A. caryophyllea, Linn. (fig. 1197). Silvery A., Hair-grass.A slender, graceful, tufted annual, seldom above 6 inches high, with short, fine leaves, as in $A$. procex, but the panicle is loose and spreading, with long, capillary branches, usually in threes, often occupying half the whole height of the plant. Spikelets and glumes as in $A$. praceox.

In sandy and hilly pastures, with the same area as A. procex, and fully as common in Britain. Fl. summer, rather early.

\section{AVENA. OAT.}

Spikelets several-flowered (usually with 3 to 5 flowers, rarely more, $a r$ 2 only), in a loose panicle. Glumes scarious, at least at the top; the outer empty ones lanceolate and tapering to a point; the flowering one smaller, 2-cleft at the top, each lobe tapering into a point, with a long, twisted, and bent awn on the back of the glume. The terminal glume of the spikelet often small and empty or rudimentary. Axis of the spikelet hairy nnder the flowering glumes.

A considerable genus, widely spread over the temperate and colder 
regions of both hemispheres, or in the higher mountains within the tropics.

Annual. Spikelets hanging, 8 to 10 lines long.

Perennial. Spikelets erect or spreading.

spikelets about 6 lines long

Spikelets about 3 lines long

1. A. fatua, Linn. (fig. 1198). Wild O.-An erect, glabrous annual, 2 to 3 feet high, with a loose panicle of large spikelets, hanging from filiform pedicels of unequal length, arranged in alternate bunches along the main axis. Outer glumes nearly $\frac{g}{4}$ inch long, pale-green or purplish, tapering to a thin, scarious point. Flowering glumes 2 or 3 , scarcely so long as the outer ones, of a firm texture at the base, and covered outside with long, brown hairs, thin and cleft at the top, each lobe tapering into a short point. Awn fully twice as long as the spikelet, twisted at the base, abruptly bent about the middle.

A common weed of cultivation in all corn countries, and generally confined to cornfields, so that its origin is as yet doubtful, but probably a native of the east Mediterranean region. Abundant in Britain. Fl. with the corm. A variety with the flowering glumes larger and more like the outer ones, hairy only below the middle, and terminating in 2 almost awn-like points, has been distinguished as $A$. strigosa, Schreb., and it is said that the cultivated Oat is but a variety of the same species, readily degenerating into the wild form. This, however, requires proof.

2. A. pratensis, Linn. (fig. 1199). Perennial 0.-An erect perennial, with a tufted or shortly creeping rootstock, 1 to $1 \frac{1}{2}$ feet high, with narrow leaves in dry pastures, but in rich mountain meadows attaining often 3 feet high, the leaves then broader, with much flattened sheaths. Panicle either slightly compound or reduced to a simple raceme. Spikelets erect, usually 3 or 4 -flowered, glabrous and shining. Glumes all scarious at the top; the outermost empty one about 6 lines long, tapering to a point; the second similar but rather longer; the flowering ones gradually smaller, shortly cleft at the point, with an awn on the back fully twice their length.

In meadows and pastures, especially in hilly districts, throughout Furope and Russian Asia, except the extreme north. Widely distributed over Britain, but not very common. Fl. summer, rather early. A. alpina, $\mathrm{Sm}$., is a luxuriant mountain form, with more or less flattened sheaths to the leaves, formerly confounded with the Continental A. planiculmis, Schrad. A more marked variety, not uncommon in dry districts, is $A_{0}$ pubescens, Huds.; it has the leaf-sheaths more or less downy, rather smaller spikelets, and the hairs on the axis of the spikelet between the florets much longer.

3. A. flavescens, Linn. (fig. 1200). Yellow O.-An erect perennial, 1 to 2 feet high. Panicle oblong, 3 to 5 inches long, with slender, somewhat spreading branches and pedicels. Spikelets erect, shining, and often of a yellowish hue, not half the size of those of 4 . pratensis. Glumes all scarions, the 2 onter empty ones very nnequal. Flowering glumes nsually 4 or 5 , cleft into 2 points; the awn twisted and bent as in the last two species, but short, and very fine and hair-like. Trisetum Siavescens, Beanv.

In xpther dry meadows and pastures, in temperate and southern 
- Enrope and temperate Asia, extending northward into southern Scan. dinavia. Frequent in England, much less so in Scotland and Ireland. $\boldsymbol{F l}$. summer. Like A. pratensis, it varies in the glabrous or hairy leafweaths, and in the length of the points of the glumes.

\section{ARRHENATHERUM. FALSE-OAT.}

A single species, separated from Avena as having the lower flower of each spikelet male only. At the same time a minute rudimentary prolongation of the axis above the npper flower shows its general affinity with the Poacea, not with the Panicacce, to which it might be technically referred. The articulation is also above the outer glumes as in Poacea.

1. A. avenaceum, Beauv. (fig. 1201). False-Oat.-An erect Grass, 2 or 3 feet in height, perennial, long branching knotted rootstocks. Leaves few and flaccid. Panicle narrow and loose, 6 or 8 inches long, spreading only whilst the flowers are open. Spikelets 3 to 4 lines long, 2flowered, the 2 outer empty glumes thin and pointed, the sccond ncarly as long as the flowers, the outermost rather shorter. The lowest flowering glume has a fine bent awn on the middle of the back about twice its own length, and contains stamens only; the upper flower is perfect, with a minute awn near the top of the glume or none at all.

In meadows, hedges, and thickets, throughont Furope and western Asia, except the extreme north. Common in Britain. Fl. summcr. [A most troublesome pest in light soils, often called Couch.]

\section{HOLCUS. HOLCUS.}

Panicle somewhat open, but with numerons crowded spikelets, all 2flowered; the upper flower male only, its glume bearing a short awn; the lowest hermaphrodite, its glume usually awnless. Outer glumes boat-shaped, compressed, enclosing the flowers. Axis of the spikelet without hairs.

A genus limited by most botanists to the two European species, allied on the one hand to Digraphis, from which it differs in the presence of an upper male flower and the want of the rudimentary scales below the perfect one ; on the other to Arrhcnatherum, but with a different habit, and the male flower above, not below, the perfect one.

Outer glumes about 2 lines long, rather obtuse, concealing the awn 1. II. lanatus. Outer glumes nearly 3 lines long, very pointed, the awn projecting

beyond them

1. II. lanatus.

1. H. lanatus, Iinn. (fig. 1202). Woolly $I$. -A perennial Grass, with a creeping rootstock and ascending stems, 1 to 2 feet high, more or less clothed, as well as the lcnves, with a very short down, which gives to the whole plant a pale, soft appearance. Panicle 2 to 3 inches long, of a pale-whitish colour or sometimes reddish. Outer glumes about 2 lines long, obtnse, but often bearing a short point just below the tip. Lowest flowering glume awnless, smooth and shining; the upper one thinner, its awn seldom reaching the length of the outer glumes 
In meadows, pastures, and waste places, throughout Europe and probably Russian Asia, except the extreme north. One of the commonest British grasses. Flo all summer.

2. H. mollis, Linn. (fig. 1203). Soft H.-Very near H. lanatus, and by some considered as a mere variety. It is not generally so downy, although the hairs on the joints are rather more conspicuous, the spikelets are larger, the outer glumes taper to a fine point, and the awn of the upper flowering glume usually projects beyond the outer ones.

In similar situations with $I$. lanatus, and with nearly the same geographical area, but much less common. Generally distributed over Britain, but not abnndant, and in some parts rare. Fl. summer.

\section{CYNODON. CYNODON.}

Spikelets 1-flowered, awnless, sessile along one side of the simple, spike-like branches of the panicle, which all proceed from nearly the same point, so as to appear digitate. At the base of the palea is a small bristle or prolongation of the axis, sometimes bearing a very minute rudimentary glume.

A genus of very few species, perhaps all varietics of a single one, readily known by the digitate spikes from all British Grasses except the Digitaria set of Panicums, and from them by the spikelcts arranged singly, not in pairs, along the spikes.

1. C. Dactylon, Pers. (fig. 1204). Creeping Cynwdon.-A prostrate Grass, often creeping and rooting to a great extent; the flowering stems shortly ascending, with short leaves of a glancous green. Panicle of 3 to 5 slender spikes, each 1 to $1 \frac{1}{2}$ inches long. Spikelets less than a line long; the outer glumes nearly equal, open, narrow and pointed. Flowering glume rather longer and much broader, becoming hardened when in fruit, smooth on the sidcs, rather rough on the keel and edges. Pibichia umbellata, Koch.

In cultivated and waste places, especially near the sea, very common in sonthern Europe and in all hot countries [where it is known as Bermuda Grass], extending sparingly into northern France and central Germany. In Britain, on the sandy southern coasts of England. Flo summer and autumn.

\section{SPARTINA. SPARTINA.}

Spikelets I-flowered, much flattened, and awnless, sessile along one side of the simple branches of a long, spike-like panicle. Glumes long and narrow, strongly keeled, the palea as long as or longer than the flowering glame.

A small genus, chiefly American, and almost confined to seacoasts.

1. S. stricta, Sm. (fig. 1205). Cordgrass.-A stiff, erect Grass, with a creeping rootstock, and rather short, erect leaves, flat excepting at the top when fresh, the edges always rolled inwards when dry. Panicel 8 or 4 inches long, consisting of from 2 to 4 erect, spike-like branches: ayikelets arranged alternately in 2 rows along these branches, sessile 
in a groove on the axis, all erect but turning to one side, each spikelet 6 to 8 lines long. Glumes thin but stiff, pointed or rather obtuse; the first empty one 3 or 4 lines long; the second abont half an inch, and often bairy; the flowering glume simllar but scarcely so long; the palea again rather longer. The smell of the plant is strorg and dis. agreeable.

In muddy salt-marshes, along the shores of the Atlantic; common in North America, less so in western Kurope, and very local on the Mediterranean as well as the North Sea. In Britain, only on the southern and eastern coasts of England. Fl. summer and autumn. A luxuriant variety, with long leaves, long slender spikes, and nearly glabrons glumes, has been described as $S$. alterniflora, Loisel. [and another with shorter leaves and a flexuous tip to the rachis as $S_{\text {。 }}$ Townsendii, Groves], but in North America these pass gradually into the more common form. In Britain, these varieties have been found on the coast of Hampshire and Kent.

\section{LEPTURUS. LEPTURUS.}

Spikelets 1-flowered (or, in some exotic species, 2-flowered), awnless, inserted singly in notches on alternate sides of a simple slender spikc, the axis jointed at each notch. Outer glumes 2, hard and ribbed; flowering glume or glumes very thin. Stamens 3 and styles 2, as in most genera of Grasses.

A genus of very few species, chiefly seacoast plants, widely dispersed over the greater part of the globe.

1. L. incurvatus, Trin. (fig. 1206). Curved L.-An annual, decumbent and much branched at the base; the flowering stems curved upwards or erect, a few inches, or when very luxuriant, nearly a foot bigh, with short fine leaves, the uppermost one close under the flowers. Spike 2 to 4 inches long, usually curved; the spikelets imbedded as it were in the axis, which breaks off readily at every notcl. Outer glumes about 2 lines long, stiff and pointed, with strong green ribs; the flowering glume and palea rather shorter, of a very delicate transparent texture. L. filiformis, Trin.

In salt-marshes and maritime sands and pastures, on the western consts of Europe; abundant all round the Mediterranean, extending eastward to the Caspian and northward to the English Channel. In Britain, it occurs on the shores of England, Ireland, and of Scotland, south of Fifeshire, but is not generally common. Fl. summer.

\section{NARDUS. MATGRASS.}

A single species, differing from all other genera of British Grasses in the very simple structure of its spikelets.

1. N. stricta, Linn. (fig. 1207). Matgrass.-A densely tufted, erect, wiry perennial, 6 inches to near a foot high. Leaves fine, but very stiff and bristle-like. Spikelets 1-flowered, sessile, alternately arranged in 2 rows on one side of an erect, slender, simple spike, often assuming a 
purplish hue. Each spikelet has a single narrow glume, 3 or 4 lines long, ending in a fine point, and enclosing a palea, 3 stamens, and a simple style.

On moors, heaths, and hilly pastures, in northern and Arctic Europe and Russian Asia, and in the mountains of central and southern Europe to the Caucasus. Common in Britain. Fl. summer.

\section{ELYMUS. LYMEGRASS.}

Spikelets 2- to 4-flowered, awnless, sessile in pairs (or, in exotic species, 3 or 4 together) in the notches of a simple spike."

A small genus, spread over the temperate and cooler parts of the northern hemisphere, differing from Hordium in that all the spikelets contain more than one flower.

1. E. arenarius, Linn. (fig. 1208). Lymegrass.-A stiff, glancous perennial, 2 to 4 feet high, with a long creeping rootstock. Leaves stiff, rolled inwards on the edges, ending in a hard point. Spike some. times rather dense, 3 or 4 incles long, sometimes lengthening to 8 or 9 inches, with the spikelets in rather distant pairs, each containing 3 or 4 flowers. Glumes lanceolate, stiff, downy or rarely glabrous; the outer ones 8 or 9 lines long, and very pointed; the flowering ones gradually shorter, broader, and less pointed.

In maritime sands, common in the temperate and colder regions of the northern hemisphere, more local on the Mediterranean and in hotter climates, and occurring occasionally in inland central Europe, North Asia, and North America. Fl. summer. A singular variety, with the spike much elongated, the spikelets distant, and the glumes often enlarged and abruptly bent down, has been distinguished under the name of $\boldsymbol{E}$. geniculatus, Curt. It is met with on the coasts of Holland and Scandinavia, and was formerly on the 'Thames below Gravesend.

\section{HORDEUM. BARLEY.}

Spikelets 3 together, sessile on alternate notches of a simple spike, 1 or 2 of them consisting each of 2 glumes, either empty or with male or rudimentary flowers, the 2 or 1 others containing each 1 perfect Hower; the empty glumes of the 3 spikelets often reduced to mere awns, and forming a kind of involucre round the flowering glume.

A genus of few species, dispersed over the temperate regions of both hemispheres, chiefly in maritime districts, and rare in the tropics. The rigin of the 2 or 3 cultivated species has not been as yet satisfactorily made out.

Flowers of the 2 lateral spikelets perfect; of the central one

male, or rudimentary, or none.
Nowers of the central spikelet perfect; of the lateral ones malc, or rudimentary, or none.

Outer glumes of all the spikelets awn-llke from the base .

Outer glumes of the central splkelet lanceolate, and cillate at the base; of the others awn-like from the base

1. H, sylvaticum.

2. $U$. pratense.

8. H. murinum 
Outer glumies of all the spikelets slightly dilated at the base, not ciliate, and one of each lateral spikelet broader than the rest

4. H. maritimum.

1. H. sylvaticum, Huds. (fig. 1209). Wood B.-An erect perennial, about 2 feet high, with flat leaves, usually hairy on the sheaths. Spike cylindrical, not very dense, about 3 inches long. The central spikelet of each notch is reduced to 2 narrow-linear glumes, either quite empty or rarely containing a rudimentary or male flower, the 2 lateral spikelets have each 1 perfect flower, and sometimes a second. either rudimentary or male; the outer glumes like those of the central spikelet, but rather broader and longer, and placed side by side; the tlowering glume shorter, but terminating in a long awn.

In woods and thickets, in central and sonthern Europe, extending eastward to the Cancasus and northward to southern Scandinavia. In Britain, not rare in some of the midland and northern counties of England, but not found in Scotlend, and only near Dublin in Ireland. Fl. summer.

2. H. pratense, Huds. (fig. 1210). Meadow B.-An erect or decum. bent annual or perennial, often 2 feet high, and tufted or bulbous at the base. Leaves glabrous and rather narrow. Spike $1 \frac{1}{3}$ to 2 inches long, close and cylindrical. To each notch are 3 pairs of awn-like rough glumes; within the central pair is a flowering glume, lanceolate, but completely rolled round the flower, and tapering into an awn as long as itself; within each of the 2 lateral pairs is usually an inner glume smaller than the central one, either empty or enclosing a male or rudimentary flower.

In moist meadows, and pastures, in central and sonthern Europe, extending eastward all across Russian Asia and into north-west India, and North America, and nortbward to sonthern Scandinavia. Frequent in England, very local in Ireland, and Berwick only in Scotland. Fl. early summer.

3. H. murinum, Linn. (fig. 1211). Wall B.-A rather coarse, tufted Grass, the stems decumbent at the base, 1 to 2 feet long. Leaves often hairy. Spike dense and cylindrical, 3 or 4 inches long, thickly beset with the long rough awns. Outer glumes of the 3 spikelets all awn. like, but those of the central spikelet somewhat broader at the base and ciliate. Inner glume of each spikelet lanceolate and rolled inwards at the base, ending in a long awn ; that of the central spikelet enclosing a perfect flower, and a short awn-like empty glume at the back of the palea; those of the lateral ones empty or with a very imperfect male flower.

In waste places, on roadsides, \&c., in central and southern Europe and western Asia, extending nortliwards to southern Scandinavia, and now naturalised in many parts of the world. Frequent in England, confined to the east of Scotland, and very rare in Ireland. $F$. all summer.

4. H. maritimum, With. (fig. 1212). Sea B., Squirrel-tail Grass.Very near $H$. murinum, but smaller and somewhat glaucous, the spikes smaller, with shorter awns, and 3 pairs of outer glumes all lanceolate at the base but not ciliate, and one of each of the lateral pairs a little broader than the others.

On the seacoasts of western Enropc, and all round the Mcditerranean 
extending northward to Denmark, but not into the Baltic. Abundant on several of the eastern and southern English coasts, absent in Waler Scotland, and Ireland. Fl. summer.

\section{AGROPYRUM. AGROPYRUM.}

Spikelets several-flowered, closely sessile, and single in each notch of a simple spike, the side of the spikelet or edge of the glumes being next the axis of the spike. Outer empty glnmes 2, similar to the flowering ones.

The genus consists of few species, all perennials, widely spread over the temperate regions both of the northern and southern hemispheres. They were formerly included in Triticum, a genus founded on the cnltivated Wheats, all annuals, supposed to have been of Oriental origin. These are allied to Agropyrum, but, it is believed, still nearer so to Egylops, a Mediterranean genus believed to have been the parent of the Wheats.

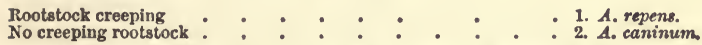

1. A. repens, Beauv. (fig. 1213). Couch or Quitch.-A perennial, with an extensively creeping rootstock, and stiff, ascending or erect stems, 1 to 2 or even 3 feet high; the whole plant varying from a bright green to a pale glaucous colour. Spikelets $\delta$ to 10 or more, at regular distances on alternate sides of a spike varying from 2 or 3 inches to twice that length, each one containing 5 or 6 flowers. Glumes all alike in shape, narrow and stiff, marked with 5 or more nerves, and usually pointed or terminating in an awn, sometimes exceedingly short, sometimes as long as the glume itself; the outer empty glumes about 4 lines long; the flowering ones gradually shorter, with less prominent nerves; the terminal one usually small and empty or quite rudimentary.

In fields and waste places, throughont Europe and Russian Asia, from the Mediterranean to the Arctic regions, and in North and South America. Abundant in Britain. Fl. summer. Triticum junceum, Beauv., and T. laxum, Fries. (T. acutum, R. and S., and T'. pungens, R. and S.) appear to be maritime varieties of the same species, much stiffer and more glaucous, with the leaves almost pungent, and the glumes often obtuse. They are frequent on seacoasts throughout the range of the common $A$. repens, and have been often observed to pass gradually into it.

2. A. caninum, Beauv. (fig. 1214). Fibrous A.-In the s'mucture of the spikelets and their arrangement this species closely resembles $\boldsymbol{A}$. repens, but the stems are tufted, without any creeping rootstock, more leafy, and not so glaucous. Glumes rather thinner, with 5 very prominent ribs, and terminating in a rather long awn; the outer empty ones usually smaller than the flowering ones, with shorter awns, and often only 3 ribs.

In woods and shady places, in Kurope and temperate Asia, from the Mediterranean to the Arctic regions, and in North America. Generally distributed over Britain. Fl. summer. 


\section{LOLIUM. LOLIUM.}

Spikelets several-flowered, closely sessile, and single in each notch of the simple spike, the edge of the spikelet (or the backs of the glumes of one row) next the axis of the spike. One or rarely 2 outer glumes empty, differing but little from the flowering ones.

A genus of very few species, natives of the temperate regions of the northern hemisphere, some of them found also, either indigenous or perhaps introduced, in the southern hemisphere, and even within the tropics.

Outer glume shorter than the spikelet. Awns short or none Outer glume as long as or longer than the spikelet. Some of the

glumes with awns as long as themselves.

1. $L$. perenne.

1. L. perenne, Linn. (fig. 1215). Ryegrass.-An erect, or slightly decumbent Grass, either annual or often lasting for several years, 1 to 2 feet high, leafy only in the lower part. Spike 6 inches to a foot long, the spikelets at a considerable distance from each other. Outer glumes of the lateral spikelets empty, stiff, and strongly nerved, usually much larger than the others, yet seldom attaining 6 lines and never so long as the whole spikelet. Flowering glumes 8 to 16 or even more, obtuse or pointed, or sometimes ending in a short awn. In the terminal spikelet the second glume is usually empty, and sometimes also in the lateral spikelets.

In meadows, pastures, and waste places, throughout Europe and liussian Asia, except the extreme north, and naturalised in other parts of the world. Abundant in Britain. Flo the whole season. It varies much in duration, and in the precise shape and proportion of the glumes, as well as in the presence or absence of awns. The Italian Ryegrass ( $L$. italicum, Braun), is a variety raised by cultivation, most probably from seeds originally exported from England. In rich meadows abnormal varieties, or rather, luxuriant states, occur occasionally with a branched spike, or with an increased number of variously deformed empty glumes.

2. L. temulentum, Linn. (fig. 1216). Darnel.-Closely allied to L. perenne, but the root is always annual, the outer glume of the spikelets usually as long as the spikelet itself, the flowering glumes shorter and broader than in $L$. perenne, and some of them at least have an awn longer than themselves.

In fields and waste places, in central and southern Europe, and central Asia, extending more or less into northern Europe as a weed of cultivation, and as such generally dispersed over Britain, but not common. $F l$. summer. The Tares of Scripture have been supposed to refer to this species.

\section{BRACHYPODIUM. FALSE-BROME.}

Spikclets many-flowered, long, in a single spike as in Agropyrum, but not so much flattened as in that genus, and not quite so closely sessile, the axis of the spike not being indented to receive them, yet not so distinctly stalked as in Festuca.

A genus of very few species, chiefly from the temperate regions of the old World, and intermediate, as it were, between Agropyrum. 
Pestuca, and Bromus, with one or other of which genera they have often been nnited.

I wns as long as or longer than the flowering glumes. Spikelets usually drooping
Awns shorter than the fiowering glumes. Spikelets erect or nearly so

1. B. sylvaticum.

1. B. sylvaticum, Beauv. (fig. 1217). Slender $P$. - A rather slender, erect Grass, 2 to 3 feet high, with a perennial tuft, and slightly creeping rootstock. Leaves flat, and rather long. Spikelets usually 6 or 7 in a loose spike, more or less drooping, or rarely erect, each one attaining an inch or even more in length, nearly cylindrical when young, and flattened when in fruit, containing from 8 to twice that number of flowers. Glumes glabroas or pubescent, the outer ones pointed, the flowering ones ending in an awn usually as long as or longer than the glume itself. Palea fringed with a few hairs on the edges.

In woods, hedges, and thickets, throughout Europe, and central and Russian Asia, except the extreme north, also found in the Western Himalaya. Common in Britain. Fl. summer.

2. B. pinnatum, Linn. (fig. 1218). Heath $P$.-Perhaps a mere variety of $B$. sylvaticum growing in more open situations. The rootstock is more creeping, the spikelets more erect, the flowering glumes rather smaller, and more open, and the awn is very much shorter.

In pastures and stony wastes, with nearly the same geographical range as $B$. sylvaticum, but not extending so far north, nor into the Himalaya, and more common in southern and easte: $=$ Europe. In Britain, scattered over the eastern and central couns but nnknown in Scotland and Ireland. Fl. summer.

\section{XXX, BROMUS. BROME.}

Spikelets several-flowered, rather large, erect or drooping, in a branched, loose, or compact panicle. Outer glumes unequal, usually keeled and awnless. Flowering glumes longer, rounded on the back, scarious at the edges, with an awn inserted just below the notched or cleft summit. Palea ciliate on the nerves. Ovary usually bairy, the style inserted on one side of the summit.

A considerable genus, widely spread over the northern hemisphere, chiefly in the Old World, with a few American or southern species. It is also a natural one if made to include $B$. giganteus, referred by some to Festuca on account of the glabrous ovary and more central style. By others the species here included are distributed into two, three, or four distinct genera.

Flowering glumea oblong, turgid. Outer ones distinctly nerved Howering glumes narrow-lanceolate. Outer ones obscurely nerved.

Flowering glumes abont 3 lines long. Ovary glabrous .

Flowering glumes 5 lines long or more. Ovary hairy.

Awns shorter or not longer than the glumes. Leaf-sheaths with long hairs.

Panicle loose and drooping . . . . . . . 2. E. asper.

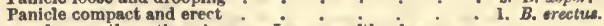

Awns longer than the glumes. Leaves softly downy or gixbrous.

6. B. arvensis.

7. B. giganteus. 
Panicle loose and drooping

3. B. stcrilis.

Panicle compact and erect.

Spikelets, together with the awns, more than 3 inches long

spikelets with the awns not $\dot{2}$ inches long

4. B. maximus.

5. B. madritensis.

1. B. erectus, Huds. (fig. 1219). Upright B.-An erect perennial, 2 feet high or more, with a slightly creeping rootstock. Leaves narrower than in most Bromcs, especially the radical ones, with a few long hairs on their sheaths. Panicle about 3 to 5 inches long, much more compact than in $B$. slerilis, the branches erect, or nearly so. Spikelets not numerous, $\frac{1}{2}$ to $1 \frac{1}{2}$ inches long, containing 6 to 10 or even more flowers. Flowering glumes lanceolate, with closely appressed hairs on the back, the lateral nerves scarcely prominent, the awn straight, and scarcely half its length.

In fields and waste places, in temperate and southern Europe to the Caucasus, extending northward into southern Scandinavia. In Britain, chiefly in southern and eastern England, very local in Wales, Ireland, and Scotland. Fl. summer.

2. B. asper, Murr. (fig. 1220). Hairy B.-An annual, or sometimes perennial, 3 to 5 or even 6 feet high. Leaves long and flat, with long, spreading, or reflexed hairs on their sheaths. Panicle loose, with long, drooping branches, bearing a few loose spikelets, each above an inch long, containing 6 to 10 or more flowers. Flowering glumes nearly cylindrical, slightly hairy or glabrous, with a straight, fine awn, shorter than the glume itself.

In hedges and thickets, and on the edges of woods, in temperate and southern Europe, extending eastward to the Caueasus and Siberia, and northward to southern Scandinavia. Frequent in England, Ireland, and the lowlands of Scotland. $F l$. summer.

3. B. sterilis, Linn. (fig. 1221). Barren B.-An erect annnal or biennial, 1 or 2 feet high or rather more; the leaves softly downy, but less so than in B. arvensis. Panicle 6 inches long or more, with numerous more or less drooping branches, many of them as long as the spikelets or longer. Spikelets linear-lanceolate, with 6 to 8 or more flowers, attaining more than 2 inches in length, including their awns. Flowering glumes rough on the back, distinctly 7-nerved, with a straight awn much longer than the glume itself.

In moist places, on waysides, \&c., throughout Europe and Russian Asia, except the extreme nortb. Abundant in England, Ireland, and the lowlands of Scotland. Fl. summer, commencing early.

4. B. maximus, Desf. (1222). Great B.-Very near B. sterilis, but the panicle is more erect and compact, only a few of the branches attaining the length of the spikelets without their awns, and the flowering glumes are longer and broader, with very long awns, the whole spike. let, including the awns, being often $3 \frac{1}{2}$ inches long.

A native of the Mediterranean regions, which appears to have estab. lished itself in Jersey. Fl. early summer.

5. B. madritensis, Linn. (fig. 1223). Compact B. -A much smaller plant than $B$. sterilis, seldom above a foot high, less downy, and with narrower leaves. Panicle erect or nearly so, very compact, and often of a parplish tint, the branches much shorter than the spikelets. Awns as in the last two species, longer than the flowering glumes; but 
the whole spikelet, including the awns, is seldom 2 inches long. The flowers have, like other Bromes, sometimes only 2 stamens, $B$. diandrus, Curt.

On roadsides, and in waste places, thronghont southern Europe, extending up the west coasts to the English Channel. In British Isles only in the southern counties of England, and Tipperary, Ireland. $\mathrm{Fl}$. early summer.

6. B. arvensis, Linn. (fig. 1221). Ficld B.-An erect annual or biennial, varying much in size, from 1 to 2 or 3 feet high, more or less softly downy, or sometimes quite glabrous. Panicle sometimes small, slender, elongated or compact, and nearly erect, bat more frequently more or less drooping, yet never so large nor so loose as in $B$. asper and $B$. sterilis; and amidst all its variations the specles is always distinguished from the four preceding ones by its short, oblong, or ovoid, turgid flowering glumes, 3 to 4 lines long, and more closely packed, giving a broader an'? fuller shape to the spikelet. Awn slender, usually about the length of the glumes, straight or spreading when dry, but not in so marked a marner as in the south European $B$. squarrosus, said to have ar-eared occasionally in our cornfields.

In cultivated and waste places, meadows and pastures, throughout Europe and Russian Asia, except the extreme north. Abundant in Britain. Fl. the whole season, especially spring and early summer. Many of the forms assumed by this ubiquitous species, difficult as they are to distinguish, and passing gradually one into another, have been recognised as species, although with characters very differently marked out by different authors. The most prominent among the British ones are :-

a. B. secalinus, Linn. A tall cornfield variety, with a loose, more or less drooping panicle, the flowers not so closely imbricated, becoming quite distinct and spreading when in fruit, most of these differences arising from being cultivated with the corn.

b. B. mollis, Linn. One of the commonest forms in open, waste places, with a more erect panicle, either short and compact, or long and slender, and the whole plant softly downy.

c. B. racemosus, Linn. (commutatus, Schrad.). Like the last variety, but much more glabrous.

d. B. multiflorus, $\mathrm{Sm}$., includes any of the preceding varicties, when the flowers are more numerous than nsual in the spikelet.

7. B. giganteus, Linn. (fig. 1225). Tall B.-An erect, glabrous perennial, 3 or 4 feet high, with a long, loose, more or less drooping panicle, much resembling $B$. asper, but known at once by the smaller spikelets and slender awns. The spikelets, withont the awns, are 7 or 8 lines long, and contain from 3 to 6 flowers. Outer glumes unequal, the lowest 1-nerved, the second 3-nerved. Flowering glumes lanceolate, almost nerveless, about 3 lines long; the fine awn fully twice that length, usually inserted a little below the tip, as in Bromus. Ovary glabrous, as in Festuca. Festuca gigantea, Vill.

In heriges and woods, over the greater part of Europe and Russian Asia, except the extreme north. In Britain, not generally as commo as $B$, asper, and still less in Scotland. $F l$ sumer. 


\section{FESTUCA. FESCUE.}

Spikelets several-flowered, usually numerous, in a compact or slightly spreading panicle (in one variety reduced to a simple spike). Outer glumes unequal, keeled. Flowering glumes lanceolate, convex on the back, pointed or tapering into an awn, scarcely scarious at the edges. Ovary glabrous, rarely downy, with the styles terminal. Grain usually adnate to the palea.

A genus widely distributed over the temperate regions of the globe, and numerous in forms if not in species. It differs from Poa only in the longer, more pointed, or awned glnmes; from Bromus in the inflorescence, in the more terminal points or awns, the edges of the glumes less scarious and scarcely, if at all, extended beyond the commencement of the awn, as well as in the glabrous ovary and more terminal styles of most of the species.

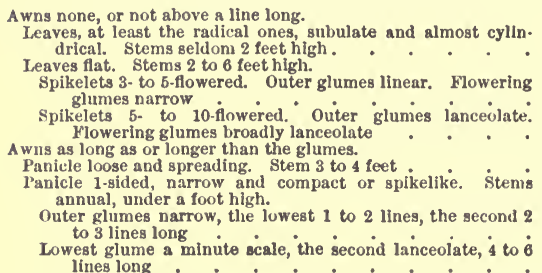

1. F. ovina.

3. F. sylvatica.

2. F. elatior.

Bromus giganteus.

\section{F. Myurus.}

5. F. uniglumis.

1. F. ovina (fig. 1226). Sheep's F.-A densely tufted or more rarely shortly creeping perennial, 6 inches to near 2 feet high. Leaves chiefly radical, very narrow, and almost cylindrical, the few stem ones more rarely flattened. Panicle rather compact and slightly 1 -sided, from $1 \frac{1}{2}$ to 4 inches long. Spikelets smaller than in $F$. elatior; the glumes narrower, glabrous or downy, very faintly nerved, and almost always bearing a fine point or awn about a line long.

In hilly pastures, most abundant in dry, open situations, more rarely in moist places, throughout Europe and Asia, from the Mediterranean to the Arctic regions, and in North America and Australasia. Abundant in Britain. Fl. summer. In mountain pastures it is very apt to become viviparous, the glumes becoming elongated and leaf-like, and this state has been described as $F$. vivipara, Sm. The following British varieties are sometimes ranked as species:-

a. Common $F$. ovina. Stem not a foot high, with dense tufts of subulate leaves. In dry, hilly pastures. F. glauca, Sm.

b. $\boldsymbol{P}$. duriuscula, Linn. Taller but tufted, the radical leaves subulate, 1 or 2 stem ones usually flattened. In moister and more luxuriant pastures.

c. $F$. sabulicola, Duf. (rubra, Linn.). Rootstock more or less creeping, all the leaves subulate. In light sandy or loose stony places, attaining sometimes, especially near the sea, above 2 feet in height.

2. F. elatior, Linn. (fig. 1227). Meadow $P_{\text {. }}$-A perennial, varying 
from about 2 to 4 or 5 feet in height, either tufted or with a shortly creeping rootstock. Leaves flat, but varying much in breadth. Panicle sometimes reduced to a simple spike, with almost sessile, distant spikelets, more frequently branched, bnt always erect and narrow, from 5 or 6 inches to near a foot long. Spikelets 6 lines to near an inch long, containing from 5 to 10 or even more flowers. Flowering glumes, when the panicle is nearly simple, rather broad, scarious at the edge, scarcely pointed, and distinecly 5-ribbed; but the more the panicle is branched the narrower and more pointed are the glumes, with less distinct ribs, and sometimes witl a distinct but exceedingly short awn.

In meadows and moist pastures, on banks and riversides, throughont Europe and temperate Asia, except the extreme north. Common in Britain. Fl. summer, rather early. The most marked British forms, often considered as species, are the following :-

a. $P$. loliacea, Curt. Spikelets almost sessile, in a simple spike. Grows with the common form, always passing gradually into it.

b. $F$. pratensis, Hnds. Panicle slightly branched but close. In meadows and pastures.

c. $\boldsymbol{P}$. arundinacea, Schreb. A taller, often reed-like plant, with broader leaves, the panicle more branched and spreading. On banks of rivers, and in wet places, especially near the sea.

3. F. sylvatica, Vill. (fig. 1228). Reed $P$.-A tall, reed-like perennial, with rather broad, flat leaves, and a rather compact panicle, 4 to 6 inches long. Spikelets numerous, smaller even than in $\vec{P}$. ovina, seldom containing more than 4 or 5 flowers. Outer glumes much narrower than in the two preceding species, and often almost subulate. Flowering glumes about 2 lines long, tapering into a fine point, but not distinctly awned. P. calamaria, Sm.

In monntain woods, in central Europe, from central France and northern Italy to southern Scandinavia, and eastward to the Russian frontier. Thinly scattered over Great Britain and Ireland, most prevalent in northern England, but unknown in the north of Scotland. Fl. summer.

4. F. Myurus, Linn. (fig. 1229). Rat's-tail P.-A tufted annual, usually about a foot high. Leaves narrow and convolute as in $F$. ovina. Panicle slender and 1-sided, 2 to 6 inches long, contracted, sometimes spike-like or even rednced to a simple spike; the branches always short and erect. Spikelets of the size of those of $P$. ovina, but the glumes narrower, the outer ones very nnequal, the flowering ones ending in an awn at least as long as themselves. Vulpia Myurus, Gmel.

In waste places, on walls, roadsides, \&c., in central and southern Enrope, extending eastward to the Caucasus and northward into sonthern Scandinavia. In Britain, rather frequent in England and Ireland, less so in Scotland. Fl. early summer. There are two marked varieties often considered as species, the true $\boldsymbol{F}$. Myurus (including $\boldsymbol{F}$. ambigua, Le Gall.), with a panicle of about 3 inches, the flowering glumes nearly as long as their awn, the lowest empty glume abont 2 lines long, the second at least 3 lines, and both very pointed; and $\boldsymbol{F}$. bromoides, Sm. (sciuroides, Roth.), with a panicle much longer and more slender, the flowering glumes smaller, thinner, and much shorter than their awns, the outermost empty glume not 1 line long, the second 
about 2 lines. In some localities, however, the two torms run much one into the other.

5. F. uniglumis, Soland. (fig. 1230). One-glumed $P$.-A tufted annual, with convolute leaves like the last, but seldom above 6 inches high, and the leaf-sheaths much looser. Panicle 1-sided and spikelike, 2 inches long or rather more. Spikelets much crowded, on short erect pedicels, thickened at the top. Outermost glume reduced to a minute almost microscopic scale; the second lanceolate, 4 to 6 lines long, scarious on the edges, ending in an awn-like point. Flowering glumes 3 or 4 , rather shorter, but ending in an awn usually longer than themselves. Vulpia uniglumis, Reichb.

On sandy seacoasts, common round the Mediterranean and western Europe. In British Isles, on the eastern coasts of Ireland, and western, southern, and south-eastern England. Fl. early summer.

\section{DACTYLIS. COCK'S-FOOT,}

A single species, with all the characters of Pestuca, except that the spikelets are densely crowded in thick, 1-sided clusters, arranged in an irregular short spike or slightly branched panicle.

1. D. glomerata, Linn. (fig. 1231). Cock's-foot Grass.-A coarse, stiff Grass, 1 to 2 feet high, the perennial stock forming at length dense tufts. Leaves flaccid, but rough on the edges. Clusters of spikelets dense and ovoid, sometimes collected into a close spike of about an inch, sometimes in a broken spike of several inches, or on the branches of a short, more or less spreading panicle. Each spikelet much flattened, ovate, 3- to 5-flowered. Glumes lanceolate, strongly keeled, ciliated on the back and pointed at the top, the flowering ones more so than the outer ones, the point often lengthened into a short awn.

In meadows, pastures, woods, and waste ground, thronghout Europe, central and Russian Asia, except the extreme north. Abundant in Britain. Fl. the whole season.

\section{CYNOSURUS. DOG'S-TAIL.}

Spikelets in sessile clusters, forming a 1-sided spike or head, the outer spikelet of each cluster consisting of several glumes, all empty ; the other spikelets containing 2 to 5 flowers; the glumes pointed or awned as in Festuca.

As now limited, the genus comprises but one Mediterranean species besides the two British ones.

spike semi-cylindrical. Glumes polnted . . . . . . 1. C. cristatus.

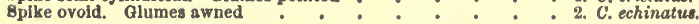

1. C. cristatus, Linn. (fig. 1232), Crested D.-A slightly tufted perennial, with short, narrow leaves, mostly radical, and a slender, often wiry erect stem, from under a foot to near 2 feet high. FlowerIng spike semi-cylindrical, oblong or nearly linear, 1 to 3 inches long; the clusters regular, and all turned to one side; the outer elegantly 
pinnate empty spikelets being the most conspicuous, and forming a kind of involucre to each cluster, within which are 1 or 2 fertile spikelets, each with 3 to 5 flowers. The glumes, whether empty or tlowering, all terminate in a very short point.

In rather dry, hilly pastures, and downs, throughout Europe and western Asia, except the extreme north. Abundant in Britain. Flo summer. The dry stalks, rejected by sheep, and remaining all the autumn, are called Bents in many parts of the country.

2. C. echinatus, Linn. (fig. 1233). Rough D.-An annual, much less stiff than the last, with flaccid leaves. Spike ovoid and less regular; the glumes, both of the empty and of the flowering spikelets, all ending in an awn at least as long as themselves.

In fields and waste places, common in southern Europe and eastward to the Caucasus, extending np the west of Europe to the Channel Islands. In the main islands of Britain it only appears occasionally on the coasts, probably when introduced with ballast. Fl. summer.

\section{BRIZA. QUAKEGRASS.}

Splkelets several-flowered flat, broad, and short, hanging (in the British species) from the slender branches of a loose panicle. Glumes all broad, concave, but not keeled, obtuse, scarious on the edges, closely imbricated, and spreading. Grain loosely enclosed in the very concave glume and much smaller flat palea.

A small genus widely spread over the temperate regions of the northern hemisphere, and as weeds into the tropics and the sonthern hemisphere.

Perennial. Ligula of the leaves very short . . . . . . 1. B. media. Annual. Ligula of the upper leaves 3 to 6 lines iong : $\quad$. $_{2} \mathrm{~B}$. minor.

$B$. maxima, a south European species, with the spikelets above half an inch long, is frequently cultivated in our flower-gardens, and has been introduced into some Floras as a British plant.

1. B. media, Linn. (fig. 1234). Common Q.-An erect, rather stiff, but very elegant perennial, from near a foot to $1 \frac{1}{2}$ feet high, with a tufted or slightly creeping stock. Leares flat but narrow and few, except at the base of the stem, their ligules very short. Panicle 2 to 4 inches long, very loose and spreading. Spikelets hanging from the long, slender branches, at first orbicular, then ovate, 2 to 3 lines long, variegated with green and purple, containing about 6 or 8 flowers. Glumes all nearly similar, the outer pair empty, the upper ones gradually smaller.

In meadows and pastures, thronghont Europe and Russian Asia, except the extreme north. Common in the greater part of Britain, but becoming scarce in the north of Scotland. Fl. early summer.

2. B. minor, Linn. (fig. 1235). Lesser Q.-An erect annual, from 2 or 3 inches to near a foot high, with shorter and broader leaves than $B$. media, and much longer ligules. Panicle like that of $B$. media, but more branched and still more slender, the spikelets more numerous. 
smaller though rather broader in proportion, seldom attaining 2 lines in length.

In fields and waste places, in southern Europe, and eastward to the Caucasus, extending up the west coast of Europe to the English Channel. In Britain, in the southern counties of England, and has been occasionally found near Cork and Kinsale in Ireland. Fl. summer, ralker eurly.

\section{POA. POA.}

Spikelets several-flowered (rarely only 2-flowered), awnless, numerous, in a spreading or compact panicle. Outer glumes rather unequal, usually keeled. Flowering glumes obtuse or pointed, but not awned, scarious at the top, either keeled from the base or at the top only, or rounded to the top without any prominent keel. Grain usually but not always free from the palea.

A large genus widely spread over most parts of the world. Although in many respects a natural one, its characters and limits are far from precise. It differs from $P_{\text {estuca }}$ only in its glumes, without awns or decided points, and some species have been placed in either genus. The first seven species are frequently formed into one, two, or more genera, characterised by minute differences in the nerves of the glumes or in the shape of the minute floral scales, or of the seed; and on the other hand, Catabrosa, Molinia, Triodia, Dactylis, and Koleria, although universally admitted, are distinguished by characters of very little more value.

[Although Mr. Bentham would in future editions of his Handbook have probably adhered to the above limitation of $P_{o} a$ in respect of the British species, as best suited for beginners, I think it right to give his latest view regarding them, formed upon a study of the genera of Grasses of the whole world, and published in the "Genera Plantarum " (1883). According to that work the following thirteen species would be referred to three genera characterised as follows :-

GLYckRIA.-Flowering glumes convex, obtuse, tips nerveless, awnless. Sp. 1-4.

Fistuca.-Flowering glumes convex, tips nerved, acute or awned. Sp. 5, 6, 7 (together with the other Festucas of this work).

POA.-Flowering glumes compressed, keeled, tips nerved, awnless. Sp. 8-13.]

Tail, aquatic plants. Spikelets not much flattened. Flowering glumes rounded on the back, with prominent veins, but not distinctly keeled.

Panicle large and spreading. Spikelets 3 to 5 lines long .

Panicle long and narrow. Spikelets erect, 6 linea to an inch long .

Piants not aquatic.

Panicle 1-8ided and stiff. Flowering glumes rounded on the back, at least at the base.

Panicle rather loose, 4 to 6 inches long. Glumes almost nerve. less. Stock perennial.

Stem creeping at the base. Klowering glume about if lines long.

Leaf-sheaths much flattened

Leaf-sheaths not flattened .

stems tufted. Flowering glumes abont 1 line long -

Panicle compact, seldom 3 inches long. Spikelets crovidai.

1. P. aquatica.

2. P. ftuitans.

Rost annual.

9. P. compressa

3. P. maritima

1. P. distans. 
Spikelets abont 3- or 4-flowered. Fowering glumes

strongly nerved
spikelets 6- or more flowered. Fiowering glumes faintly

Panicle reduced to a single spilke, with the lover spikelets occa. sionally clustered. Root annual . . .

Panicle scarcely 1-sided, the branches and pedicels slender.

Nowering glumes all keeled, with minute silky hairs on

the keel or sides.

Root annual. No hairs on the axis of the splkelet

Stock perennial. Minute woolly hairs on the axis under the flowering glumes.

Panicle ovate or oblong, more or less crowded.

Stem creeplng at the base. Leaf-stalks much fiattened. 9. P. compressa.

Stock tufted. Stems and lower sheaths thickersd at the base.

Stems bulbous at the base. Panlcle contracted

Stems scarcely bulbous. Panicle rather looso

6. $P$. procumbens.

C. $P$. rigida.

7. $\boldsymbol{P}$. loliacea.

8. P. annua.

Panicle loose or very long.

Glumes polnted. Flowers about 3.

Panicle long. Spikelets oblong or lanceolare.

Stems weak. Leaves narrow and flaccld. Panicle slender . . . .

Stems tall. Leaves long and stiff. Panicle very long and rather stiff . with slenoer branches, and few, rather large, ovate spikelets. (Alpine plant.). 13. P. laxa.

Flowering glumes rather obtuse. Panlcle spreading, with numerous spikelets.

Rootstock with creeping sclons. Klowers about 4 in the splkelet. Lateral nerves of the flowering glumes very faint ${ }^{2}$.

15. P. bulbosa.

14. P. alyina.

let. Lateral nerves of the flowering glumes conspicuous

10. P. pratensis.

-11. $P$. trivialis.

1. P. aquatica, Linn. (fig. 1236). Reed P.-A stout, reed-like perennial, 4 to 6 feet high, with a creeping rootstock. Leaves flat and very rough on the edges. Panicle much branched, spreading, nearly a foot long. Spikelets numerous, with 5 to 8 or 10 flowers. Outer glumes nnequal, thin, and 1-nerved. Flowering glumes about $1 \frac{1}{2}$ lines long, loosely imbricated, strongly 5- or 7-ribbed, rather obtnse, and scarious at the top. Glyceria aquatica, Sm.

In wet ditches, and shallow waters, throughont Europe and temperate Asia, except the extreme north, and in North America. Frequent in Fngland and Ireland, rarer in Scotland. Flo summer.

2. P. fluitans, Scop. (fig. 1237). Floating P.-An aquatic perennial, often 2 or 3 feet high or more, with rather thick but weak stems, creeping at the base; the leaves often floating on the surface of the water. Panicle erect and slender, a foot long or more; the branches few and usually erect. Spikelets few, $\frac{1}{2}$ to 1 inch long, with from about 8 to near 20 flowers. Outer glumes nnequal, thin, and 1-nerved. Flowering glumes loosely imbricated, $1 \frac{1}{3}$ to near 3 lines long, strongly 5- or 7 -ribbed, scarions at the top, obtuse or slightly pointed. Glyceria fluitans, $\mathrm{Br}$.

In wet ditches, and stagnant or slow-running waters, throughout Europe and Rassian Asia, except the extreme north, and in North America. Common in Britain. Fl. all summer. [G. plicata, Fries., is a variety with flowering glumes, twice as long as broad, and divaricate truiting spikelets.] 
3. P. maritima, Huds. (fig. 1238). Sea P.-A perennial, with a creeping rootstock and decumbent or erect stems, attaining about a foot in height. Leaves rather short, narrow, and usually convolute. Panicle erect, rather stiff, 3 or 4 inches long, or sometimes more; the branches erect, or the lower ones spreading. Spikelets not numerous, shortly stalked, all turned to one side of the branches, each about 6 lines long, and containing about 6 or 8 flowers. Glumes nearly $I_{\frac{1}{2}}$ lines long, all rounded on the back, obtuse and scarious at the top, and faintly 5-nerved, the lowest outer one rather smaller. Glyceria maritima, Wahlb., Sclerochloa maritima, Lindl.

In maritime sands, common on the coasts of Europe and western Asia. From the Mediterranean to the Arctic Circle, and in North America. Frequent all round the British Isles. Fl. summer.

4. P. distans, Linn. (fig. 1239). Reflexed P.-Very near P. maritima, of which it may possibly prove to be a mere variety. The stock is tufted or the stems scarcely creep at the base; the leaves are flatter, the stems taller and more slender, the panicle much more spreading, with long, slender branches, and the spikelets smaller, the glumes not above a line long. Glyceria distans, Wahlb. Sclerochloa distans and Borreri, Bab.

In sandy pastures, and waste places, chiefly near the sea, in Europe and western Asia, from the Mediterranean to the Arctic Circle, and in North America. In Britain, in the maritime counties of England, Ireland, and southern Scotland. Fl. summer.

5. P. procumbens, Curt. (fig. 1240). Procumbent P.-A tufted annual, with decumbent stems, 6 or 8 inches long, or very seldom attaining a foot. Leaves flat. Panicle branched and 1 -sided as in the last two species, but much more compact, seldom above 2 inches long. Spikelets rather crowded, nearly sessile along the branches, abont 4tlowered. Glumes as in P. maritima, but rather smaller, stiffer, with the nerves more conspicuous. Glyceria procumbens, Dumort. Sclerochloa procumbens, Beauv. Festuca procumbens, Kunth.

In waste ground near the sea, in western Europe, from the Spanish Peninsula to Holland, temperate Asia, and North America. Occurs on varions parts of the coasts of England, and Ireland, rare. Fl. sunımer.

6. P. rigida, Linn. (fig. 1241). Hard P.-A tufted annual, usually about 6 inches high, with stiff stems, erect or slightly decumbent at the base. Panicle lanceolate, 1-sicled, about 2 inches long, rather crowded; the branches slightly spreading. Spikelets on short, stiff pedicels, linear, about 3 lines long, each with about 6 or 8 flowers. Hlowering glumes scarcely a line long, rather obtuse. with very faint lateral nerves, the outer empty pair more pointed and more distinctly nerved. Glyceria rigida, Sm. Sclerochloa rigida, Linn. Festuca rigida, Kunth.

In waste, dry, or stony places, in central and sonthern Europe, not uncommon on dry rocky and stony places in England, Scotland, and Ireland. Fl. summer.

7. P. loliacea, Huds. (fig. 1242). Darnel P.-A tnfted annual, like the last, but usually smaller and stiffer; the panicle reduced to an almost simple spike, along which the spikelets are almost sessile, in 2 rows, on alternate sides of the axis, but all turning one way; the lower ones often 2 or 3 together in a sessile cluster. Each spikelet is about 
8 lines long, with 6 to 8 flowers. Glumes abont a line long, more or less keeled, especially at the top, with faint lateral nerves and scarions edges, obtuse or slightly pointed; the onter empty pair nearly similar to the flowering ones, but more strongly nerved. Sclerochloa loliacea, Woods.

On sandy sea-shores, common on the Mediterranean and up the western coasts of Europe to the English Channel. Scattered here and there along the coasts of England and Ireland, and very local in Scotland. Fl. summer. This species has been successively transferred by different botanists from Triticum, where it was originally placed by Smith, to Brachypodium and Festuca, with all of which it has consider. able affinity, or with $P$. rigida it has been made one of the small genera Sclerochloa, Catapodium, or Scleropoa, more recently established.

8. P. annus, Linn. (fig. 1243). Annual P.-A tufted annual, usually about 6 inches high, with flat, flaccid, bright-green leaves. Panicle loose and spreading, $1 \frac{1}{2}$ to 3 inches long, with slender branches. Spikelets all stalked, oblong or linear, each with from 3 to 6 or rarely more flowers. Flowering glumes scarions at the top, keeled from the base; the lateral nerves also slightly prominent when dry withont woolly hairs on the axis of the spikelet, but very minutely silky-hairy on the keel.

In cultivated and waste places, most abundant in the temperate regions of the northern hemisphere, but extending into almost every part of the globe. Very common in Britain, and a chief ingredient in the grass of some of the London parks. Fl. ncarly the whole year round. It will often germinate, flower, seed, and die in the course of a few weeks.

9. P. compressa, Linn. (fig. 1244). Flattened P.-A perennial, seldom above a foot high, with a creeping rootstock, and erect stems more or less flattened at the base. Leaves rather short, with flattened sheaths, and a short, obtuse ligula. Panicle oblong, 2 to 3 inches long, slightly spreading, but rather crowded, with many of the spikelets sessile, and the branches turned towards one side, but not so much as in $P$. procumbens and $P$. maritima. Spikelets ovate-oblong, usually 4- to 6-flowered, with occasionally a few woolly hairs on the axis. Flowering glumes about a line long, with minute silky hairs on the keel; the lateral nerves not prominent.

On dry, barren, waste ground, and frequently on walls, in temperate and southern Europe, in Russian Asia, and North America, extending far into Scandinavia, but not an Arctic plant. Frequent in England and Scotland, but less so farther north, and rare in Ireland. Fl. all summer.

10. P. pratensis, Linn. (fig. 1245). Meadow P.-A perennial, 1 to 2 feet high, with a more or less creeping rootstock or emitting creeping scions aboveground. Leaves rather narrow, with a short, obtuse lignla. Panicle 2 to 3 Inches long, with slender, spreading branches. Spikelets numerous, ovate or oblong, all or nearly all stalked, each with about 4 flowers. Flowering glnmes rather more than a line long, with minute silky hairs on the keel; the lateral nerves scarcely prominent.

In meadows and pastures, throughont Europe and central and Russian Asia, from the Mediterranean to the Arctic Circle, in North America, and reappearing in the sonthern hemisphere. Abundant in Britain. Fl. nummer, commencing early.

11. P. trivialis. Lynn (fig. 1246). Roughish P. - Very near P.pratensis, 
but there are no creeping scions; the stems are usually taller and more slender; the ligula of the leaf longer; the panicle more slender, often 6 inches long, with slender, spreading branches; the spikelets have seldom more than 3 flowers, and usually only 2 . Flowering glumes as in $\boldsymbol{P}$. pratensis, except that the lateral nerves are much more conspicuous.

In meadows and pastures, with the same geographical range as $P$. pra. tensis, and at least as common. Abundant also in Britain. Fl. summer, commencing early.

12. P. nemoralis, Linn. (fig. 1247). Wood P.-A perennial, 1 to 2 feet high, tufted, or slightly creeping at the base, erect, but weaker and more slender than the last two species, with narrower leaves, their ligules very short. Panicle contracted or spreading, with slender branches. Spikelets compressed, lanceolate or ovate, with 2 to 5 flowers in each, and scarcely any woolly hairs on the axis. Flowering glumes rather more than a line long, lanceolate, more pointed than in the last two species, with a line of small silky hairs on each side and another on the keel. [P. Parnellii, Bab., P. Balfourii, Parn.. and P. glauca, Sm., are mountain forms.]

In woods and shady places, and on moist mountain rocks, throughout Europe and Russian Asia from the Mediterranean to the Arctic regions. Frequent in Britain. $F l$. summer. A mountain variety, P. coesia, Sm., has the stems usually shorter, the panicle less branched, and the spikelets rather longer, but it passes gradually into the common form.

13. P. laxa, Hænke (fig. 1248). Wavy P.-A tufted or slightly creeping perennial, seldom a foot high, near $P$. alpina, but more slender, with narrower and more numerous leaves. Panicle loose, with few spreading branches. Spikelets rather larger than in P. alpina, from 1 to 3 on each branch of the panicle, ovate, each with 3 or 4 flowers. Glumes about 2 lines long, more pointed than in most Poas. P. minor, Gaud.

Confined to high northern latitudes, or to great elevations in the mountains of Europe, Asia, and North America. In Britain, only on Ben Nevis and Lochnagar, in Scotland, where it is usually in a viviparous state, and then not easily distinguished from $P$. alpina. I myself have seen no Scotch specimens that I could refer with certainty to $\boldsymbol{P}$. laxa. [P. laxa includes two forms or species: one, P. laxa, Hænke (minor, Gaud.), with channelled leaves, concave at the tip, and the panicle open in flower, and closed in fruit; the other, $P$. stricta, Lindb., with leaves flat to the tip, and the panicle open in flower, and spreading in fruit.]

14. P. alpina, Linn. (fig. 1249). Alpine P.-Stems tufted, often swollen at the base, but not so much so as in $P$. bulbosa, 6 inches to a foot high. Leaves short, rather broad, mostly radical or nearly so, and when perfect have a short inflected point. Panicle ovoid, about 2 inches long, rather spreading, with short but slender branches. Spikelets crowded, ovate, 3- to 5-flowered. Flowering glumes pointed and keeled; the lateral nerves not prominent, with a few minute silky hairs on the keel and edges, but with little or no wool at their base on the axis of the spikelet.

In alpine pastures, common in all the great mountain-ranges of Kurope and central and Russian Asia, and at high latitudes in North America. On the higher mountains of Scotland, northern Fingland very rarely 
those of west of Ireland, frequently in a viviparous state, the spikelets being converted into leafy bulbs. Fl. summer.

15. P. bulbosa, Linn. (fig. 1250). Bulbous P.-A low, tufted perennial, seldom above 6 inches high, and remarkable for the bulbs formed by the swollen base of the stems and leaf-sheaths. Leaves short, the ligula of the upper ones prominent and acute. Panicle ovoid or oblong, spike-like or scarcely spreading, not much above an inch long. Spikelets ovate, 3 - or 4 -flowered. Flowering glumes about a line long or rather more, pointed and keeled; the lateral nerves not prominent, with minute silky hairs on the keel and edges, and a few short woolly ones at their base on the axis of the spikelet.

In dry waste places, on roadsides, \&c., especially near the sea, in tem. perate and southern Europe, and across Russian Asia, extending north. wards into southern Scandinavia. In Britain, chiefly near the sea, and only in the southern and eastern counties of England. Fl. spring.

\section{CATABrosa. CATABROSK.}

A single species, closely allied to $P$ oa, but the spikelets have usually only 2 flowers, the glumes broad and truncate at the top or slightly jagged.

1. C. aquatica, Beanv. (fig. 1251). Water C.-A glabrous, tender, pale-green perennial; the stems procumbent, and creeping or floating at the base, rooting at the nodes, and often 2 or 3 feet long; the flowering branches erect. Leaves short, flat, and flaccid. Panicle 4 to 6 inches long, consisting of many sets of half-whorled, unequal, slender, and spreading branches. Spikelets 1 to near 2 lines long. Outermost glume very short and small, the second larger, broad, and truncate at the top like the flowering ones, but much shorter : these are scarious, and slightly toothed or jagged at the top, with very prominent ribs. Paleas similar but rather smaller, with only 2 ribs.

In shallow pools and ditches, in Kurope and temperate Asia, from the Mediterranean to the Arctic regions, and in North America. Generally, although thinly, scattered over Britain. Fl. early summer.

\section{MOLINIA. MOLINIA.}

A single species, very near Poa and Pestuca, differing from the former in the much more pointed glumes, from Festuca in the smaller and rather less flattened spikelets. There is also, at the base of the palea of the uppermost flower, a small, bristle-like appendage, being a continuation of the axis of the spikelet, and bearing sometimes the rudiment of another flower, although less conspicuous than in Melica. This rudimentary terminal flower, however, occasionally occurs in most of the allied genera.

1. M. cærulea, Mœnch. (fig. 1252). Purple M. -A rather coarse, stiff perennial, often 3 feet high, with the leaves chiefly radical, forming large tufts, long and flat, rather stiff, and slightly hairy on the upper side. Panicle narrow but loose, 6 inches to above a foot long, green or porplish; the branches erect or scarcely spreading. Spikelets 
erect, narrow and pointed, 2 to 4 lines long, nsually with about 3 flowers. Glnmes acute, the outer ones shorter than the flowering ones, and rather unequal.

In wet heathy places, moors, woods, and waste places, throughout Europe and temperate Asia, from the Mediterranean to the Arctic regions. Common in Britain, except where destroyed by cultivation. Fl. late in summer, or autumn. [M. depauperata, Lindl., is a 1-flowered state.]

\section{MELICA. MELICK.}

Spikelets awnless, rather large, and a few in a slender panicle, each with 1 or 2 flowers, besides a small, terminal, wedge-shaped glume, enclosing 1 or 2 more minute or rudimentary ones. Glumes broad and several-nerved, but not keeled; the outer empty ones thin, the flowering ones of a rather firmer texture.

A small but natural and widely dispersed genus, readily known by the small, terminal, empty glumes, much more conspicuous than in any of the allied genera.

Spikelets drooping, 2-flowered . . . . . . . 1. Mr. nutans.

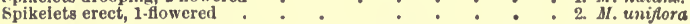

1. M. nutans, Linn. (fig. 1253). Mountuin M.-A slender erect perennial, 1 to 2 feet high, with erect, flat leaves. Panicle onc-sided, 2 to 3 inches long; the short but slender branches usually erect, so as to give it the appearance of a simple saccme. Spikelets about 10 to 15 , drooping, 3 to even 4 lines long, 2-flowered; the outer glumes brown or purple, with scarious edges, the flowering ones scarcely protruding beyond them; the inner imperfect glume mucli shorter, broadly wedgeshaped.

In woods, and shady rocky places, in hilly districts, extending all over Europe and Russian Asia, to the Arctic zone. In Britain, only in Scotland and the west of England. Fl. early summer.

2. M. uniflora, Linn. (fig. 1254). Wood M.-An elegant perennial, 1 to 2 feet high, more slender even than $M$. nutans, with longer and narrower leaves. Leaf-shcath quite closed, opposite to the blade as in C'yperacce, and produced into a small green point. Panicle sometimes reduced to an almost simple raceme with only 3 or 4 spikelets, sometimes with a few long, slender, distant branches, each bearing several spikelets. Each spikelet near 3 lines long, coloured as in $\boldsymbol{M}$. nutans, but erect and containing but one flower; the imperfect inner glume oblong, stalked, and reaching to the height of the flowering one.

In woods and shady places, in central and southern Europe, extend. ing eastward to the Caucasus and northward into Scandinavia. Frequent in England and Ireland, quite local in Scotland. Flo early summer.

\section{TRIODIA. TRIODIA.}

Spikelets awnless, rather large, and few in a panicle, contracted almost, into a simple raceme, and few-flowered. Outer glumes pointed, 
as long as the flowering ones or longer; flowering glumes with 3 very minnte teeth at the top.

A small genus, chiefly Australian, differing from Avena and its allies chiefly in the absence of any awn, from Pestuca in the onter glumes usually exceeding the flowering ones.

1. T. decumbens, Beauv. (fig. 1255). Decumbent T.-A tufted perennial, 6 inches to a foot high. Leaves narrow, with a few long soft hairs on their sheaths and eages, and a tuft of hairs in the place of their ligula. Spikelets seldom more than 5 or 6 , erect, containing 3 or 4 flowers. Outer glumes of a firm consistence, but nearly scarious towards the edges, 4 or 5 lines long, concave but keeled, very pointed and glabrous; flowering glumes deeply concave, ending in 3 minute teeth, the central one more pointed, but all 3 often scarcely prominent. Sieglingia decumbens, Bernh.

On dry heaths, and hilly pastures, in central and northern Europe and western Asia, extending from northern Spain and Italy|far into Scandinavia, but not an Arctic plant. In Britain, generally distributed and rather common. Fl. summer.

\section{KCELERIA. KCELERIA.}

Spikelets few-flowered, in nearly sessile clusters, crowded into an oblong or nearly cylindrical spike-like panicle; the glumes keeled, scarious on the edges, pointed, or in some exotic species, awned.

A small genus, chiefly European and Asiatic, with a few species from the southern hemisphere, all closely allied to Poa and Festuca, from which they differ chiefly in inflorescence, which is nearer to that of Phleum or Phalaris.

1. K. cristata, Pers. (fig. 1256). Crested $K$.-A perennial, usually about 6 inches high, with a dense tuft of short leaves, chiefly radical; but in luxuriant specimens the stems attain a foot, with leaves almost as long. Spike cylindrical, 1 to 2 inches long or even more, the lower clusters more or less distant. Spikelets usually 2- or 3-flowered; the glumes $1 \frac{1}{2}$ to 2 lines long, and very pointed; the outer ones unequal, and scarious on the edge only; the flowering ones white and scarious, except the green keel, giving the spike a variegated and shining silverygrey aspect.

In dry pastures, in central and sonthern Europe, extending more sparingly northwards into Scandinavia, in both north and sonth temperate regions. Widely distributed over Britain, and abundant in some parts, but rare or wholly wanting in others. Fl. summer.

\section{SESLERIA. SESLERIA.}

Spikelets few-flowered, in nearly sessile clusters, crowded into an ovoid or cylindrical spike-like panicle, as in Koleria, but there is nsually a glume-like bract on the main axis, at the base of the lower spikelets. Outer glumes nearly equal and pointed, the flowering ones 3- or 5-toothed at the top, the central tooth lengthened into a point, or (in exotic species) into a short awn. 
A small genus, chicfly south European and west Asiatic, differing from $\mathrm{Poa}$ in the inflorescence, and in most species by the presence of an outer bract under the spikelets, which is analogous to those of Cyperacece.

1. S. cærulea, Ard. (fig. 1257). Blue S.-A perennial, 6 inches to nearly a foot high, with a shortly creeping rootstock, and densely tufted, short, and rather stiff radical leaves. Spike (or spike-like panicle) ovoid or oblong, $\frac{1}{2}$ to $\frac{s}{4}$ inch long, often assuming a bluishgrey hue. Spikelets not numerous, but closely packed, generally in pairs, one sessile, the other shortly stalked; the lower ones with a broad, glume-like bract at their base. Glumes about 2 lines long, the flowering ones usually 2 in each spikelet, shortly protruding beyond the onter ones, their central tooth forming a short point.

In mountain pastures, especially in limestone districts, in Europe, and from the mountains of Spain and Italy to Scandinavia. In Britain, confined to Scotland, the north of England, and the north and west of Ireland. Fl. spring and early summer.

\section{ARUNDO. REED.}

Very tall, erect, perennial Grasses, with long, broad leaves, and a large, crowded panicle. Spikelets several-flowered, with long, silky hairs on the axis, enveloping the flowers.

'The species, though not numerous, are very conspicuous in all tem. perate and warm climates, and form a natural genus if considered as including, as well as our northern species (often separated under the name of Phragmiles), the South American Pampas Grass, the latter generically distinguished under the name of Gynerium, on account of its flowers being usually (but, it is said, not always) diocious. The genus differs from $P_{8 a m m a}$ and Calamagrostis chiefly in having more than one flower in the spikelet.

1. A. Phragmites (fig. 1258). Common R.-A stout perennial, usually 5 or 6 feet high, but sometimes twice as much, with a long, creeping rootstock, and numerous long leaves, often an inch broad, all the way up the stem. Panicle from a few inches to a foot long, with numerous branches, more or less drooping, of a purplish-brown colour. Spikelets very numerous, narrow, above 6 lines long. Ontermost zlume lanceolate, concave, about $1 \frac{1}{2}$ lines long, and empty; the second jarrower, and twice that length; the third still longer, and also empty, or with 1 or 2 stamens only; and all 3 without hairs outside. Above are 2 or 3 flowering glumes about the same length, but narrower, ending in an almost awn-like point, and surrounded by silky hairs, which lengthen much as the seed ripens, giving the panicle a silvery ppearance. Phragmites communis, Trin.

In wet ditches, marshes, and shallow waters, almost all over the world, from the tropics to the Arctic zone. Common in Britain. FE end of summer, and autumn. 


\section{CuAss III. CRYPTOGAMS.}

No real flowers, that is, neither stamens, nor pistils, nor true seeds, the fructification consisting of minute, often highly microscopic granules, called Spores, variously enclosed in sessile or stalked Spore-cases (Sporangia) often called capsules, or imbedded within the substance of the plant, the spore-cases themselves sometimes so small as to be scarcely visible without the aid of a microscope.

The few British Cryptogams which are included in the present volume have all of them roots, and stems or rootstocks as in flowering plants, and in a few the leaves are somewhat similar, but in most the leaves are more or less converted into fruiting branches, bearing the fructification on their surface, base, or edges, and are therefore now generally distinguished from true leaves by the name of fronds. In the remaining families of Cryptogams, called Cellular, such as the Charas, Mosses, Hepatica, Lichens, Fungi, and Algo, there is either no distinct stem, or the stem does not contain any fibrous or vascular tissue. None of these can be readily determined without the use of high magnifying powers, and the assistance of carefully executed plates. However great, therefore, may be the interest attached to them, they are beyond the scope of the present Flora.

\section{LYCOPODIACEE. THE CLUBMOSS FAMILY.}

Stem or rootstock bearing leaves, either linear, or small and 1-nerved, or reduced to minute scales. Spore-cases solitary, sessile in the axils of the leaves or of the bracts of a terminal spike, 2-valved. Spores all similar.

\section{LYCOPODIUM. CLUBMOSS.}

Perennials, with a branched, usually creeping stem, crowded with small, moss-like, entire or minutely serrated leaves. Spore-cases sessile in the axils of the upper stem-leaves, or of bracts usually smaller or thinner and broader than the stem-leaves, forming an erect, cylindrical terminal spike, each spore-case opening by a transverse slit in 2 valves, and either all filled with minute powdery graniles, or some containing larger grains.

A large genus, widely spread over every part of the globe.

5pore-cases in the axils of the stem-leaves. Stems tufted, scarceiy

Bpore-cases in terminal spikes. Stems creeping or prostrate.

Creeping stems long and hard. Fruiting branches forked or clustered.

Leaves about 1 line long, closely imbricated in 4 rows

Leaves 2 or 3 lines long, spreading, with fine points. Spikes pedunculate, usually 2 or 3 together.

Spikes solitary and sessile above the last stem-leaves

Creeping or prostrate stems, slender, 1 to 3 inches long. ing, branches simple

4. L. Selago.

3. L. alpinum.

1. L. clavatum.

2. L. annotinum

C. L. inundatum 
1. L. clavatum, Linn. (fig. 1259). Common C.-Stems hard, creeping, 1 to 2 feet long, with ascending forked branches, 1 to 2 inches long, all completely covered with the crowded, moss-like, bnt rather stiff leaves, which are linear, 2 to 3 lines long, including their fine, hair-like points; those on the creeping stem all turned npwards; those on the branches imbricated all round. Spikes 1 to $1 \frac{1}{2}$ inches long, scattering their yellow dust in great profusion, 2 or sometimes 3 together, on a peduncle at least as long, bearing small, narrow, yellowish leaves or scales, about half as large as the stem-leaves.

In hilly pastures and heaths, in central and northern Europe, Russian Asia, and North America, extending from the Pyrenees and the Alps to the Aretic regions, and in the southern hemisphere. Generally distributed over Britain, but more common in the north. Fr. summer and autumn.

2. I. annotinum, Linn. (fig. 1260). Interrupted C.-The long, hard, creeping stems, with short ascending branches all covered with leaves, are the same as in $L$. clavatum, but the leaves are much stiffer, more spreading, fully 3 lines long, without any hair-like point, and the spikes, seldom an inch long, are always solitary and closely sessile at the extremity of the leafy branches.

In mountain heaths, woods, and stony places, in central and northern Europe, Russian Asia, and North America, extending from the Alps to the Arctic regions. In Britain, only in the mountains of Scotland, northern England, and North Wales. Fr. summer and autumn.

3. L. alpinum, Linn. (fig. 1261). Alpine C.-The stems creep as in the last two species, and sometimes attain a considerable length, but the ascending branches are much more divided, forming close clusters or tufts, 2 to 3 inches high. Leaves scarcely above a line long, few on the creeping stems, numerons on the branches, and closely imbricated in 4 rows. Spikes about $\frac{1}{2}$ inch long, closely sessile, and solitary at the extremity of the leafy branches.

In mountain pastures, in Europe and eentral and Russian Asia extending from the Pyrenees and Alps to the Arctic regions. In Britain, common in the mountains of Scotland, northern Ireland, and northern and central, but very rare in southern England. $F r$. summer.

[ $L$. complanatum, Linn., is a form which affects warmer climates, and is distinguished by its longer, less crowded, flattened branches, and several peduncled spikes. It has been found in Gloucestershire and Worcestershire.]

4. I. Selago, Linn. (fig. 1262). Fir. C.-Dtems scarcely creeping, though slightly decumbent and rooting at the base; the forked branches forming dense, level-topped tufts 3 or 4 inches high, completely covered with their crowded but spreading dark-green leaves, all lanceolate, 3 or 4 lines long, with a short fine point. Spore-cases in the axils of the upper leaves, not forming a distinct spike; they are sometimes replaced by little pedicellate leafy bulbs.

In hilly pastures, in the cold and temperate countries of both hemispheres. Frequent in all billy parts of Britain, except some of the southern counties of England. Fr. summer and autumn.

5. L. inundatum, Linn. (fig. 1263). Marsh C.-Stems slender and creeping, scarcely branched, seldom above 2 inches long, with narrow. linear leaves, about 2 lines long, all turned upwards. Fruiting branches 
solitary, simple and erect, $1 \frac{1}{2}$ to 3 inches high, with leaves like those of the stem, but loosely scattered all round. The upper end of the branch is thrckened into a fruiting spike, from $\frac{8}{4}$ to 1 inch long; the bracts very like the stem-leaves, but broader at the base.

In heathy bogs and sandy swamps, dispersed over the greater part of the world, but not recorded from the Arctic regions. Irregularly distributed over various parts of Scotland and Ingland, very rare in Ireland. Fr. summer and autumn.

\section{SELAGINELLACE正.}

Prostrate herbs, with minute imbricating leaves often of two forms, or stemless water-plants with slender leaves. Sporecases of two forms; in the former case in the axils of the scales of a spike, in the latter at the bases of the leaves. Spores of two forms; those in the spike consisting of a minute, powdery dust, the lower containing larger grains.

[This Order includes one of the Lycopodiums of former editions of this work, together with the genus Isoetes, with which it agrees in the most important character of having two kinds of spores, thus differing from Lycopodiacece.]

A prostrate moss-like plant. Spore-cases in the bracts of a terminal spike.

1. SELAGIN ELLA. stemless plants with long subulate leaves. Spore-cases in the dilated bases of the leaves.

2. ISOETES.

\section{SELAGINELLA, Beauv.}

Prostrate or ascending, often tufted and moss-like plants with leafy branches. Leaves small, either uniform and imbricating, or of two forms, one large and distichous, the other small and placed on one side of the stem. Spore-cases spiked.

A very large tropical genus, rare in temperate climates.

1. S. selaginoides, Gray (fig. 1264). Common S. or Lesser Club Moss. - Stems slender, prostrate, much branclied, forming moss-like patches 3 or 4 inches in diameter. Leaves spreading, lanceolate, pointed, 1 to $1 \frac{1}{2}$ lines long, not densely crowded. Fruiting branches ascending or erect, solitary and simple, with rather longer leaves; those of the spike or fruiting part fully 2 lines long, lanceolate, and bordered with a few fine teeth. Spike to $\frac{3}{4}$ inch long. Lycopodium selaginoidcs, Linn.

In moist monntain pastures, and wet, stony places, in Europe, Asia, and North America, extending from the Alps and Pyrenees to the Arctic regions. Not nncommon in Scotland, northern and central England, Wales, and Ireland. Fr. summer and autumm.

\section{ISOETES. QUILLWORT.}

Stock very short, rooting at the base, bearing a tuft of linear leaves, the whole plant usually under water. Spore-cases more or less enclosed 
within the enlarged base of the leaves, those of the inner leaves filled with minute powdery granules, those of the outer leaves containing larger grains, at first cohering in fours.

A small genus, widely spread over the greater part of the globe.

1. I. lacustris, Linn. (fig. 1265). European Q.-A perennial, of a bright green, forming dense tufts under the water. Leaves narrow. linear, thick, and nearly terete or 4-angled, much like those of several Monocotyledons, varying from 2 to 6 inches long, their enlarged bases giving the plant often a bulbous appearance.

In mountain pools, and shallow lakes, in central and northern Europe, northern and Arctic Asia, and North America. In Britain, in the mountainous parts of Scotland, northern England, Wales, and Ireland. $F r$. summer and autumn. [I. Morei, Moore, is a variety with leaves 18 inches long, found in Wicklow.] Modern botanists distinguish as I. echinospora, Durieu, a form found in our mountain lakes, often growing with the common one, but said to be only where the soil is peaty. It differs chiefly in the larger spores covered with acute tubercles instead of being granulate only or smooth on the surface. A more distinct form referred to I. Hystrix, Durieu (fig. 1266), occurs in moist sandy hollows on Laucresse Common in Guernsey. The rootstock is covered, outside the tuft of leaves, with a number of small, imbricate, toothed or jagged brown scales, which are the persistent remains of old leaves, and which are never observed in the common under-water forms. It remains to be seen how far this difference may be owing to situation.

\section{MARSILEACE臣. THE MARSILEA FAMILY.}

No true leaves. Fronds, as in Filices, proceeding from the rootstock and rolled inwards at the top, barren ones either reduced to a narrow-linear stipes, or in an exotic genus bearing 4 digitate leaflets; fertile ones sessile or on a short stipes, bearing a globular or ovoid utricle, usually called an involucre, and formerly considered as analogous to the spore-cases of Lycopodiacece, but which is really the recurved fertile lamina with the margins united. Real spore-cases of two kinds, larger and smaller, as in Selaginacea, but arranged, as in Filices, inside the involucre, that is, on the under surface of the recurved frond, in sori enclosed in membranous indusia, dividing the involucre into as many cells.

The Order was formerly supposed to be closely connected with Lyeopodiacee, in which the only British genus was included in our first editions, but its still nearer relation to Filices has been well pointed out chiefly by German botanists. It contains only one genus besides the British one.

\section{PILULARIA. PILLWORT.}

Rootstock creeping under water, with subulate, barren fronds, almost solitary at the nodes. Involucres (or fertile fronds) almost sessile on the 
stock, globular. Sori 2 to 4 , vertically adnate, their indusia dividing the involucre into 2 to 4 cells, and each consisting of numerous sporecases, the lower ones few and larger, the upper ones numerous, minute, and powdery.

Besides the European species, which is also in the sonthern hemi. sphere, there is a distinct North American one.

1. P. globulifera, Linn. (fig. 1267). Creeping P.-The slender rootstock often creeps to a considerable length, rooting at every node. Barren fronds filiform, of a bright green, like the leaves of Isoetes, varying from 1 to 3 inches in length. Involucres like little pills, nearly 2 lines diameter, covered with short hairs.

In the shallow edges of pools and lakes, in Europe north of the Alps. Widely distributed over England and Scotland, and in some places not uncommon, but often overlooked, very rare in Ireland. Fr. summer and autumn.

\section{EQUISETACE正. THE EQUISETUM FAMILY.}

A family consisting of a single genus, distinguished from all others as well by the articulate and whorled stems, only resembling some of the larger fossil plants now extinct, as by the fructification.

\section{EQUISETUM. EQUISETUM.}

Leafless herbs, with a perennial, usually creeping rootstock, and erect, rush-like, hollow, and jointed stems, marked with longitudinal strixe or furrows, with a sheath at each joint which encloses the base of the next internode, and is bordered with short or elongated teeth, nsually as many as the strix of the stem. These stems are either simple or have at each node, from the base of the sheath, a whorl of jointed branches, similar to the stem, but with fewer strix, and always simple, except in $\boldsymbol{E}$. sylvaticum. Fructification an ovoid or oblong terminal spike, consisting of several whorls of peltate, shield-shaped, shortly-stalked scales (usually brown or black), under each of which are several (about 6 or 7 ) spore-cases, filled with minute spores and opening down the inner side. Under the microscope there will be seen to be attached to each spore at its base 4 thread-like filaments, club-shaped at the top, rolled spirally round the spore when moist, nncoiling elastically when dry.

The species are not numerous, althongh widely diffused over the temperate and colder regions of the northern hemisphere, extending more sparingly into tropical countries. Some of them accommodate themselves to a great variety of stations and become very variable. To determine them it is not only necessary to have the fruiting stem, but also to observe whether the plant bears or not barren fronds at the same time, and whether these are similar or dissimilar to the fruiting ones. Accidental variations must also be guarded against. The side branches sometimes bear spikes, or shoots similar to these side branches may arise from the stock, and if gathered alone, without observing the more ordinary state of the stems, may become very puzzling. 
Fruiting stems, in spring, simple, thick, with long loose sheaths, and withering before the barren ones appear.

Sheaths of the fruiting stems more than an inch long, with numerous subulate teeth

Sheaths under an inch, distant from each other, with about $\dot{8}$ or 10 lanceolate teeth

Fruiting stems appearing in or lasting till summer, at the same time as the barren ones, and nearly similar to them.

Spikes very obtuse.

Sheaths with 3 to 5 large teeth. Lower branches recurved and again branched

Sheaths with 14 to 20 long subulate teeth. Branches ail un: divided

Sheaths with 6 to 20 minute teeth. Branches few.

Stem smooth, not grooved, 10-20 striate. Sheaths cylindric appressed.

Stem rough, with io to 18 grooves. Upper sheaths subcampanulate

Stem rough, with 5 to $12^{\circ}$ grooves. Sheaths cylindric appressed

Spikes acute or apiculate.

Stem with 8 to 12 grooves. Sheaths cylindric, at length black; teeth slender

Stem with 14 to 20 grooves. Sheaths cylindric, appressed, at length biack, teeth slender, tips deciduous

Stem very slender, 4- to 10-grooved. Sheaths cylindric, teeth short obtuse membranous

1. E. Telmateia.

2. E. arvense.

3. E. sylvaticum

4. . pratense.

5. E. limosum.

6. E. littorale.

7. E. palustre.

9. Es. trachyodon.

8. $\boldsymbol{E}$. hyemale.

10. $E$. variegatum.

1. E. Telmateia, Ehrh. (fig. 1268). Great E.-The fruiting stems appear alone early in spring, they are quite simple, 8 or 10 inches high, as thick as a finger, of a pale-brown colour; the sheaths rather loose, an inch long or more, completely covering the stem from one joint to the next, of a dark brown, marked with 20 to 30 or more longitudinal striæ, and fringed with as many long, subulate teeth, or half as many, these teeth being often joined 2 and 2 together. Spike fully 2 inches long, the lower whorls of scales often distinct. Barren stems appearing after the fruiting ones have withered away, often several feet high, white, with the tips of the sheaths black; the long, crowded, slender branches very numerous in each whorl. $E$. maximum, Lamk.

In marshy, shady, wet, or gravelly places, in temperate Europe, not extending northward into Scandinavia, nor perhaps southward into Spain, but eastward to Greece and the Caucasus, and thence all across Russian Asia, and in North America. Occurs over the greater part of England, Ireland, and western and south-eastern Scotland. Pr. early spring.

2. E. arvense, Linn. (fig. 1269). Field E., Common Horsetail.Fruiting stem simple, thick, 8 or 10 inches high, and dying before the barren ones appear, as in $E$. Telmateia, but the sheaths are seldom above 8 or 9 lines long, at a considerable distance from each other, and have seldom more than about 10 lanceolate teeth, and are dark only in the upper part. Barren stems 1 to 2 feet high, with slender spreading sranches, about 10 to 12 in each whorl; these are sometimes slightly branched, but never regularly so as in $E$. sylvaticum.

In field 3 and waste or moist places, throughout Europe and temperate Asia, from the Mediterranean to the Arctic regions, and in North America. Abundant in Britain. Fr. spring.

3. E. sylvaticum, Linn. (fig. 1270). Wood E.-Fruiting stems at first nearly simple, and about a foot high, but soon branched, like the 
barren ones. Sheaths about half an inch long, divided into atout 6 to 8 lanceolate, scarious lobes, broader than in our other Equisetums. Spike about 6 to 8 lines long, obtuse. Branches, both of the barren and fertile stems, 10 to 16 or more in a whorl, very slender, but not above 2 or 3 inches long, and remarkable for bearing, at the lower nodes at least, whorls of 2,3 , or more smaller branches, which give the plant a very elegant tufted appearance.

In wet woods, and shady places, in temperate and northern Europe and Asia, from northern Italy and the Caucasus to the Arctic regions, and in North America. Spread all over Britain, bnt more abundant in Scotland and northern England and Ireland than in the south. $F r$. summer, or commencing in spring.

4. E. pratense, Ehrh. (fig. 1271). Shady E.-Allied to $E$. sylvaticum In stature and mode of growth; the fruiting stems at first simple, producing whorls of branches after the spike is developed; but the branches of both fruiting and barren stems are always simple, and the spike is larger. The fruiting stems at first resemble those of $E$, arvense, but are much more slender. The sheaths have seldom less than 14, and usually about 20 striæ, and long, subulate teeth. $E$. umbrosum, Willd.

In moist woods, and shady places, generally distributed over the range of $E$. sylvaticum, in Enrope, Asia, and North America, but probably nowhere so common. Has been found in various parts of Scotland, northern and central England, and northern Ireland. Fr. late in spring and summer.

5. E. limosum, linn. (fig. 1272). Smooth E.-Stems mostly fruiting, 1 to 2 feet high or more, all, including the barren ones, simple, or with few short, simple branches at the middle or npper nodes; the striæ usually about 12 to 20 , not prominent. Sheaths abont 3 or 4 lines long, with shortly subulate or pointed teeth. Spike about 6 to 8 lines long, obtuse.

In marshy places, wet ditches, or shallow waters, throughout Europe and temperate Asia, from the Mediterranean to the Arctic regions. Common in Britain. Fr. summer.

[6. F. littorale, Kühlew. (fig. 1273). Bog E.-Intermediate between $E$. limosum and palustre, with both of which it agrees in habit, but differs from the former in the roughish stem with 10 to 18 distinct deep grooves, and in the upper sheaths having dilated mouths, and from $E$. palustre in the larger more hollow stems, with 10 to 18 grooves, and in the dilated months of the npper sheaths.

In sandy bogs of Denmark, north and central Germany, and central Russia. In Britain hitherto found only in similar situations at Bisley Common, in Surrey, but is probably overlooked elsewhere, from its similarity to $E$. palustre.]

7. E. palustre, Linn. (fig. 1274). Marsh E.-Stems mostly fruiting, but all nearly similar, erect, about 1 to $1 \frac{1}{2}$ feet high, much thinner than in $E$. limosum, and marked with only about 6 to 8 prominent strix or angles, and deep furrows; the branches but few in a whorl, not very long, and not so thin as in some species Sheaths 3 or 4 lines long, with as many pointed or shortly subulate teeth as striæ. Spike as in E. limosum.

In marshes and spongy bogs, in Europe, temperate Asia, from the Mediterranean to the Arctic regions, and in North America. Common in Britain. $\mathrm{Pr}$. summer.

8. E. hyemale, Linn. (Cg. 1275). Rough $E_{\text {, }}$ Dutch Rush,-Stems 
mostly fruiting, but all similar and simple, or rarely with very few branches, 1 to 2 feet high or more, faintly marked with 15 to 20 strix, and rough to the touch. Sheaths 3 to 5 lines long, white, with black rings round the top and the base; the teeth very minute and blunt, or rarely shortly subulate. Spike 6 to 9 lines long, with a little conical point on the rounded top.

In marshes and wet woods, in northern Europe, Asia, and America, extending from Spain and Italy to the Arctic regions. In Britain, chiefly in Scotland, and northern and central England; rare in Ireland. Pr. summer, rather late.

[E. Moorei, Newm., is an annual variety found near the sea in Wicklow, with looser sheaths, and truncate teeth.]

9. E. trachyodon, A. Braun. (fig. 1276). Long $E$.-Very near $\boldsymbol{E}$. hyemale, with the same little conical point to the spike, and very probably a mere variety, differing only in its slender stems, with only 8 to 12 or seldom more striæ; the sheaths have seldom any black ring round the base, though they often turn black altogether, and the teeth have usually lanceolate, subulate points. The stem terminating the stock has usually a few long branches, especially from the lower whorls, and varies from 1 to 2 feet high or more ; the lower stems are simple, slender, and shorter, all usually bearing a spike. $E$. ramosum of former editions. $E$. Mackaii, Newm.

In sandy, moist places, generally dispersed over Europe, Russian Asia, and North America. In Britain, apparently confined to Scotland and north-east Ireland. Fr. summer, rather late.

10. E. variegatum, Schleich. (fig. 1277). Variegated E.-This is again considered by some, and perhaps correctly, as a variety of $E$. hyemale. Stems slender, all simple, or very rarely branched, usually in several tufts, 6 to 8 inches high, but the terminal or central one sometimes lengthened out to 1 or 2 feet, with only 8 to 10 strix; the sheaths short, with a conspicnous black ring, and short teeth. Spike seldom half an inch long, with a conical point as in $E$. hyemale.

In maritime sands, or on the sandy banks of rivers, sometimes quite in water, in the maritime or mountain districts of Europe and Russian Asia, especially in the north, and in North America. In Britain, chiefly in Scotland, Ireland, and the coasts of northern England. Fr. summer, rather late.

\section{FILICES, THE FERN FAMILY.}

Herbs, with a perennial, short, or tufted, or creeping rootstock (in some exotic species growing up into a tall, woody stem), or rarely annual; with radical or alternate leaves, which, as they also partake of the nature of branches, are distinguished by the name of fronds. In most genera these fronds are, when young, rolled inwards at the top, and the rootstock, and sometimes also the stalks of the fronds, are more or less covered with brown, scarious, usually pointed scales. Fructification consisting of capsules, called spore-cases (sporangia), sometimes small 
and almost dust-like, arranged either in clusters, called sori, on the under surface of the frond, and often covered, when young, with a thin membrane, called the indusium, or in little involucres on the margin of the frond; sometimes rather larger, in spikes or panicles at the top of the frond, which has, lower down, either leafy branches or one leaf. These capsules open in various ways to discharge the minute, usually microscopical spores.

A very large Order, abundantly diffused over the whole surface of the globe, especially in moist climates, although some species may be found in the chinks of the hottest rocks. The elegance of their foliage has of rate years attracted as much interest in them, on the part of cultivators and amatenrs, as has their fructification and germination on the part of the physiologist. It has long been known that they can be reproduced from their spores, but it has only lately been ascertained that these spores when sown develop minute, green, leafy expansions, called prothalli. On the prothallus are produced minute bodies, which have been compared to stamens and pistils, from whence the young Fern is subsequently developed.

The limitation of genera and species in the Ferns has always been a matter of great difficusty, and of late years their splitting and changing has been carried to such a degree as to throw the whole nomenclature into a state of utter confusion. The best characters are taken from the form and arrangement of the sori and of their indusium; and some large genera, such as Adiantum, Asplenium, \&c., are natural, and readily recognised; but in Polypodium, Aspidium, Cystopteris, \&c., there is nothing in habit to serve as a guide, and the indnsium of the two latter genera is often so evanescent that it requires the most careful examination of specimens, in exactly the proper state, to ascertain its existence. I have been induced, therefore, with a view to assist the beginner in the determination of the British species, to include in the following Table of Genera the species also of the most difficult ones, endeavouring to lead to them by more prominent characters, without reference to the more minute, although essential ones, which distinguish the genera. It must be recollected, however, that to determine Ferns they must be in fruit. It is hopeless to attempt to find ont by books to what species a barren frond belongs; and monstrous developments, and deformed fronds, now common in cultiration, and found occasionally wild, are here wholly passed over.
Fructification in a terminal spike or panicle. The frond either leaf-like, or bearing a leaf in the lower part. Fructification in a little cup or involucre at the edge of the frond . : Fructification on the back or under side of some or all the fronds .
Fronds twice pinnate, usually 2 or more feet high, the fructiflcation forming a $2\{$ panicle at their extremity . 3, OSMUNDA. Fronds stem-like, not 6 inches high, with a terminal spike or panicie . . 3

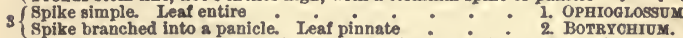
Fronds numerous, scarcely 2 inches high, pinnate, with few deeply-lobed seg- 4 ments. Involucre ovate, 2-lobed - 17. HYMkNOPHYLLUM. Fronds 6 or 8 inches high, 2 or 3 times pinnate, with crowded segments. Invo. iucre cup-shaped.
16. TRICHOMANES. 
Fronds tufted, of 2 sorts, the central ones erect, fruiting, the outer ones barron,

$5\{$ usually shorter, with broader lobes. . . .

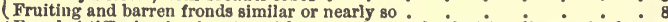

Fronds (atiff) simpiy pinnate, with entire lobes, the fruiting linear, the barren

6 lanceolate 0.11 . BLECHNOM.

Fronds (delicate) nuch divided, with small, obovate or oblong, toothed lobes 7

7 Sorl formlng a line ciose to the margin of the frond . . 5. Allosorus.

7 Sori oblong, scattered on the surface of the frond : : 6. Grammitis.

Fructification concealed by, or intermixed with, chaffy scales or hairs . . 9

Fructification in lines along the margin of the fronds, the indusium a membrane

$8\{$ attached to the margin

Fructification in circular, oblong, or linear sori, on the under surface, wlthout

chaffy scaies . . . . . . . . . . . 11

Fronds deeply pinnatifi, with entire segments. Sorl linear, conceaied by the

9 scales. . . . . 10. CETERACH.

Fronds twice pinnate, with small segments. Sorl circular, with chaffy hairs Intermixed . 15. WOODSIA.

Tall, erect, stiff fern, ternately divided, with pinnate branches and sessile

$10\left\{\begin{array}{l}\text { iobes } \\ \text { T. 12. PTERIs. }\end{array}\right.$

Delicate fern, not a foot high, much divided, with broad, wedge-shaped lobes on capiliary stalks . . . . 13. ADIANTUM.

Sori oblong or linear, covered (when young) with a membrane attached along the

Sori circular, either without any indusium, or covered (when young) with 12 membrane attached by the centre or by a lateral point. .. .13

Frond entire. Indusium opening in a slit along the centre 9. Scolopendrium.

12 Frond pinnate or much divided. Indusium opening along the inner side.

8. Asplenium,

13 Fronds simply pinnate, with entire or toothed segments or plnnas .

13 Fronds pinnate, with plnnatlfid prlmary divisions or pinnas, or twice or thrice pinnate* *. . 15

(Segments narrow lanceolate, rather thick, attached to the stalk by a broad base, and confluent. Sori golden yellow, without any indusium.

14 Segmenta distinct or stalked, ovate-falcate, prickly-toothed, with a prominent angie or lobe at the base on the inner side. Sori with a smali circular indu. sium . 7 (1). ASPIDIUM Lonchitis.

Segments smali, obovate. Induslum attached laterally 1 8. AsplenIum.

Lower pair of pinnas much larger than the others, giving the frond a broadiy

15 trianguiar or rhomboidal form . . . 16

Lowest pair, or several lower pairs of pinnas, decreasing lin size or not larger than the rest. Frond ovate or lanceolate in outline . . . . . 17

Fronda once,pinnate, with pinnatifld segments 4 (2). POLYPODIO M Phegopteris.

16 Fronds twice pinnate, the pinnaa mostly opposite 4(4). POLY PODIUM Dryopteris.

Fronds twice pinnate, the pinnas mostly alternate ? . 14. CrstopTERIs.

Fronds delicate, seldom a foot high, without any brown scarions scales (or very
few at the base of the staik), twice plnnate, with staiked plnnas

17 Fronds stiff, 1 to 3 feet high or more (except in Polypodium Phegopteris). The stalk more or less shaggy beiow the leafy part, with brown scarious scales (except in Aspidium Thelypteris)

Segments with fine pointed teeth .

Segments oblong or lanceolate, nearly sessile, with obtuse teeth or lobes.

Segments small, obovate, stalked, with obtuse teeth. Delicate annual.

14. Cystopteris.

6. GRAMMITIS.

19 Fronds pinnate, the pinnas deeply pinnatifld, the lobes entire or obtuse, and

Fronds twice pinnate, the segments sharply toothed or pinnatifid : $: \quad$ : 24

20

Pinnas (ail but the lowest pair) attached to the stalk by their broad base.

Pinnas attached by thelr midrlb only 4(2). POLYPODIUM Phegopteris.

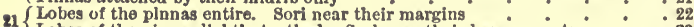

Lobes of the pinna slightly toothed. Sorl near their base or centre : : 23

- In all twice or thrice pinnate lesves or fronds the prlmary divlsions on each dde of the main stalk are called pinnas, the ultimate divisions retaining the name of segments. 


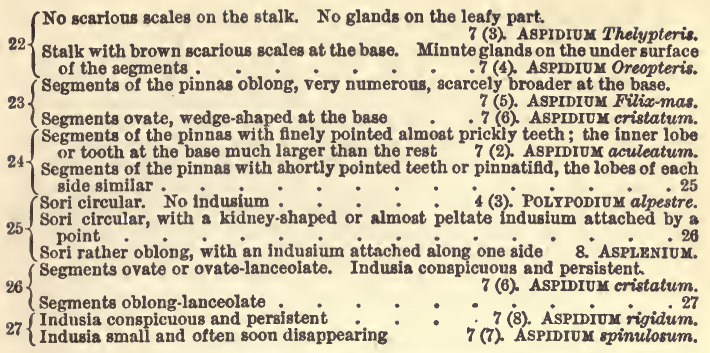

\section{OPHIOGLOSSUM. ADDER'S TONGUE.}

Stem simple, bearing a single leaf-like barren frond in the lower part, and a simple terminal fruiting spike. Spore-cases rather large, closely sessile, in two opposite rows, each opening by a transverse fissure.

A genus of very few species, but widely distributed over most parts of the globe.

1. O. vulgatum, Linn. (fig. 1278). Adder's-tongue.-Rootstock very small, but apparently perennial. Stem (combined stipes of the barren and fertile frond) solitary, from a few inches to near a foot high, with an ovate or oblong entire leaf-like barren frond, nsually 2 to 3 inches long, narrowed at the base into a shortly sheathing footstalk, and usually attached below the middle of the stem. Spike terminal, $\frac{8}{4}$ to about an inch long, bearing on each side from about 15 to 25 closely sessile spore-cases.

In moist meadows, and pastures, thronghout Europe, Asia, except the extreme north, North America, and apparently also in the southern hemisphere as well as within the tropics. Generally distributed over Britain, but more common in some parts of England and in Ireland than in the north of Scotland. Fr. summer. O. lusitanicum, Linn., is now believed to be a mere variety, only differing from the common form in its small size, the slender stems varying from 1 to 3 inches, the leaf or barren frond linear or lanceolate, narrowed into a stalk, and seldom above $1 \frac{1}{2}$ inches long. It is usually to be found only in winter near the sea, along the west coast of Europe to Guernsey, but not on the main British Isles.

\section{BOTRYCHIOM. MOONWORT.}

Stem of Ophioglossum, but the leaf-like barren frond is divided, the terminal spike is branched, forming a panicle, and the spore-cases are globular, and, although sessile, quite distinct.

A small genus, distributed over the temperate regions of the northern hemisphere, and more sparingly in the southern one. 
1. B. Lunaria, Sw. (fig. 1279). Moonwort.-Rootstock very small, bearing a single erect stem, 3 to 6 or 8 inches high, surrounded at the base by a few brown sheathing scales. The leaf or barren frond about the centre of the stem, 1 to 3 inches long, pinnate, with from 5 to 15 or even more obliquely fan-shaped or halfmoon-shaped segments, of a thick consistence, and entire or crenate. Panicle 1 to near 2 inches long, of a narrow pyramidal shape, the branches all turned towards one side.

In dry, hilly, or mountain pastures, in northern and Arctic Europe, Asia, and America, in the mountains of central and southern Europe, and reappearing in south temperate regions. Widely diffused over Britain, but not generally common. Fr. spring or early summer.

\section{OSMUNDA. OSMUND.}

Fronds once or twice pinnate, the leafy part barren; the fructification consisting of clustered spore-cases, either in a panicle at the end of the frond, or, in exotic species, in some other part of the frond, but always distinct from the leaf-like part; each spore-case opening by a vertical fissure.

A genus of few species, natives chiefly of the temperate regions of both hernispheres, especially the northern one.

1. O. regalis, Linn. (fig. 1280). Fern Royal.-The perennial stock often forms a trunk rising perceptibly from the ground, and sometimes to the height of a foot or more. Fronds growing in tufts, erect, from a foot or two in dry poor soils, to 8 or 10 feet when very luxuriant, twice pinnate, with lanceolate or oblong segments, 1 to 2 inches long, rather stiff, prominently veined, either entire or obscurely crenate. Fructification forming a more or less compound panicle at the top of the frond, usually bipinnate, each spike-like branch representing a segment of the frond.

In moist or boggy places, in western, central, and some parts of southern and south-eastern Europe, extending northwards to southern Scandinavia; also in central Asia, North and South America, and southern Africa. In Britain, chiefly in the western counties of England and Scotland, in Wales, and Ireland, apparently very local in other parts of England, and entirely absent from several counties. Fr. end of summer, or autumn.

\section{POLYPODIOM. POLYPODY.}

Fronds (in the British species) either pinnate or ternately divided, with the branches pinnate. Spore-cases minute, collected in circular clusters or sori on the nnder side of the segments, withont any indusinm or involucre; each spore-case (as in all the following genera) encircled by an elastic jointed ring, and bursting irregularly on one side, having then, under a microscope, the appearance of a little helmet.

A large genns, widely distributed over the globe, only differing from Aopidium in the absence of any indusinm or membrane covering the 
sori even when young. For the Table of Species, see the Generic Table above, p. 554, n. 13.

1. P. vulgare, Linn. (fig. 1281). Common P.-Rootstock thick, woody, and creeping. Fronds about 6 inches to a foot high, of a firm consistence, without any scales on their stalk, broadly oblong-lanceolate or somewhat ovate in their general outline, simply pinnate or deeply pinnatifid; the linear-oblong segments adhering to the main stalk and usually connected with each other by their broad bases. Sori rather large, of a golden yellow, in two rows along the under side of the upper segment. When bearing fruit these segments are usually entire or nearly so, and obtuse; when barren they are often slightly toothed; and monstrous states not nnfrequently occur with the segments varionsly lobed or branched.

In sheltered places, on trunks of old trees, walls, moist rocks, and shady banks, throughout Europe and temperate Asia, from the Mediterranean to the Arctic regions, and in North America and Sonth"Africa. Common in Britain. Fr. summer and autumn. [P. cambricum, Willd. is a Welsh form with pinnatifid segments.]

2. P. Phegopteris, Linn. (fig. 1282). Beech Fern.-Rootstock creeping. Fronds rather slender, 6 inches to a foot high or rather more, including their long stalks, broadly ovate-lanceolate and acuminate in their general ontline, once pinnate; the segments deeply pinnatifid, narrow-lanceolate, gradually diminishing from the base to the end of the frond, and all, except sometimes the lowest pair, adhering to the main stem by their broad base. The midrib, principal veins, and margins of the frond more or less hairy on the under side, by which this species may be readily distinguished from the smaller specimens of Aspidium Thelypteris, which it sometimes resembles. Sori rather small, near the margins of the lobes. Phegopteris polypodioides, F'é.

In moist situations, in hilly districts, in Europe and Western Asia, from the Pyrenees and Alps to the Arctic regions, and in North America. In Britain, in western and northern England, Scotland, and Ireland. Fr. summer and autumn.

3. P. alpestre, Hoppe. (fig. 1283). Alpine P.-Stock short, often forming several crowns. Fronds tufted, 1 to 3 feet high, twice pinnate ; the segments numerous, oblong or lanceolate, deeply pinnatifid, and sharply toothed, the larger ones usnally about half an inch long. Sori circular, withont any indusinm whatever; this character alone distinguishes this plant from the smaller states of Asplenium Filix-fomina and from some forms of Aspidium spinulosum, which it closely resembles in all other respects. Athyrium alpestre, Milde.

In the monntains of Europe and western Asia, from the Alps and the Cancasns to the Arctic regions. In Britain, only in the Highlands of Scotland. Fr. summer. [P. flexile, Moore, is a variety found in the Forfarshire mountains, with very short stalks and segments.]

4. P. Dryopteris, Linn. (fig. 1284). Oak Fern.-Rootstock creeping, rather slender. Fronds slender but erect, on long stalks, broadly triangular or rhomboidal in their general outline, the leafy part 4 to 6 inches long and at least as broad, twice pinnate, or rather, in the first instance, ternate; the lower pair of branches or pinnas on slender stalks, each often as large and as much divided as the rest of the frond; the others mnch smaller and less divided, the terminal ones reduced to 
A lobes. Segments thin, light green, obtuse, slightly crenate, quite Arous. Sori near the margins of the segments. Phegopteris Dryopsis, Fée.

In rather dry woods, in Europe and temperate Asia, from the Medi. terranean to the Arctic regions, and in North America. Not nncommon in western, central, and northern England and Scotland, rare in North Ireland. Fr. summer and autumn. P. calcareum, Sw. (P. Robertianum, Hoffm.) is a variety of rather stouter growth, usually with rather less difference in size between the lower pair of pinnules and the succeeding ones, and is covered with a glandular meal. It occurs here and there, in more open rocky situations than the common form, and especially in limestone districts.

\section{ALLOSORUS. ALLOSORUS.}

Delicate Ferns, with tufted, mnch divided fronds; the central ones erect and fruiting; the outer ones barren, with broader segments. Sori circular, but so close as to form compact lines along the margins, covered over when young by the thin edge of the frond itself.

A small genus, confined to the mountainous or northern districts of the northern hemisphere.

1. A. crispus, Bernh. (fig. 1285). Rock Bracken, Parsley Fern.Stock densely tufted with brown scarious scales. Fronds 2 or 3 times pinnate, ovate or oblong in their general outline, on slender stalks almost without scarious scales; the outer barren ones about 5 or 6 inches high, somewhat resembling Parsley-lcaves, with numerous small, obovate or wedge-shaped and deeply-toothed segments. Fruiting fronds 8 to 1 foot high, with equally numerous oblong or linear segments, the thin membranous edges turned down over the sori. Cryptogramme crispa, $\mathrm{Br}$.

In the mountains of Europe, from the Pyrenees and Apennines to the Arctic regions, usually local, but often very abundant in particular spots. In Britain, chiefly in Scotland and northern England, but occurs also in ccntral and western England; very rare in Ireland. Fr. summer.

\section{GRAMMITIS. GRAMMITIS.}

Fronds much divided. Sori lincar or oblong, simple or forked, nut marginal, and without any indusium.

A considerable genus, chiefly tropical, inclnding many of those elegant Ferns often seen in our hothouses, with a golden or silvery dust on the under side of the fronds. The generic name Grammitis, Swartz, has the right of priority over that of Gymnogramma, Desv.

1. G. leptophylla, Swartz (fig. 1286). Small G.-A delicate little Fern, resembling at first sight very small specimens of Allosorus crispus. Fronds in little tufts, although the whole plant is nsually annual; the outer fronds short, with few broadly obovate or fan-shaped segments, often barren; the others erect, 2 to 6 inches high, with slender black stalks, twice pinnate, with numerons small, thin, obovate, deeply. toothed or lobed segments. Sori oblong, at length nearly covering the under surface of the segments, Gymnogramma leptophylla, Desv. 
On moist shady banks, in the Muditerranean region and western Europe, extending eastward into central India, and northward up western France to Jersey, the only st tion within our Flora. It reappears in the southern hemisphere. $F_{7}$. spring and summer.

\section{ASPIDIOM. SHIELDFERN.}

Fronds (in the British species) once, twice, or thrice pinnate, with a stiff erect stalk, usually bearing, at least at the base, numerous brown scarious scales. Sori circular as in Polypodium, but covered when young by a membrane or indusium, attached by the centre or by a point neas one side, so that, when raised all rond by the growth of the sporecases, it becomes either peltate or kidney-shaped.

A very large genus, ranging over every part of the globe, only distin. guished from Polypodium by the indusinm. In modern British Fernbooks it is usually divided into two, Lastrea and Polystichum, according to whether the attachment of the indusium is central or towards the margin, a minute character, unconnected with habit, often difficult to appreciate, and sometimes inconstant. The 'Table of Species will be found under the Generic Table above, p. 556, n. 13.

1. A. Lonchitis, Sw. (fig. 1287). Holly Fern.-Stock short and thick. Fronds tnfted, usually 6 inches to a foot high or rather more, stiff, linearlanceolate in their general outline, simply pinnate, leafy from the base, the common stalk very scaly below. Segments mostly broadly lanceolate or almost ovate, curved, prickly-toothed, enlarged at the base on the inner or upper side into a toothed angle or lobe, all nearly sessile, but attached by the midrib only, stiff, glabrous above, with a few scals hairs underneath ; the central ones about an inch long; the lower ones smaller and broader, often ovate. Sori circular, rather large, with a not very conspicuons peltate indusinm in the centre. Polystichum Lonchitis, Roth.

In the clefts of rocks, in all the great mountain regions of Europe and central and Russian Asia, from Spain and Italy to the Arctic regions, and in North America. In Britain, only in the mountains of Scotland, northern England, North Wales, and Ireland. Pr. summer and autumn.

2. A. aculeatum, Sw. (fig. 1288). Prickly S.-Fronds tufted, arising from a short thick stock, 1 to 2 feet or rather more high, stiff, twice pinnate, broadly lanceolate in outline, with the lower pinnas decreasing in length; the stalk below the leafy part 1 to $G$ inches long, very shaggy with brown, scarious scales. Primary branches or pinnas shaped like the whole frond of $A$. Lonchitis in miniature, being pinnate, with their segments shortly ovate-lanceolate, curved and prickly-toothed, with a prominent angle or lobe on the inner or upper side; the lower ones, or gometimes nearly all, attached by their midrib, the upper ones decurrent on the stalk or united at the base. Sori rather small, with a central but not very conspicnous indusium. A. lobatum, Sm. Polystichum aculeatum, Roth.

On hedge-banks and in shady places, in temperate and southern Europe, from the Mediterranean to Scandinavia, extending eastward into central Asia; in North and South America, and generally in the southern hemisphere. Frequent in Britain. Fr. summer and autumn. 4. angulare, Willd, is a rather larger, more luxuriant, and less stiff 
variety, usually more divided, with more distinct segments, the lower ones evidently stalked.

3. A. Thelypteris, Sw. (fig. 1289). Marsh S.-Rootstock creeping, with single, not tufted, erect fronds as in Polypodium Phegopteris, to which this fern bears corsiderable resemblance. It is taller, usually 1 to 2 feet high, quite glabrous, with a rather slender but stiff stalk, without scarious scales. The leafy part lanceolate, pinnate, with deeply pinnatifid pinnas, which are not crowded, and the lowest rather distant and smaller; all attached to the central stalk by their midrib or by a very short stalk; the lobes or segments entire, obtuse or scarcely pointed. Sori in lines near the edges, distinct at first, with an indusium attached near the edge, but soon covering nearly the whole under surface and eoncealing the indusium. Lastrea Thelypteris, Presl. Nephrodium Thelypteris, Desv.

In boggy or marshy places, throughout Europe and Russian Asia, except the extreme north, and in North America and New Zealand. In Britain local, but dispersed over England, Ireland, and southern Scotland. $P r$, summer and autumn.

4. A. Oreopteris, Sw. (fig. 1290). Mountain S.-The stature, mode of growth in circular tufts, and the general shape of the fronds are those of A. Filix-mas, from which it may be distinguished by a lighter colour, especially of the stalk, and by the lobes or segments of the pinnas all quite entire, with the small sori in a line near the margin as in A. Thelyp. teris. From the latter it differs in its larger size, the stalk bearing brown scarious scales, the pinnas so closely sessile as almost to lap over the central stalk; and from both this species may be known by the minute resinous or glandular dots on the under side of the fronds, from whence a fragrant smell is imparted to the plant when rubbed. Lastrea Oreopteris, Presl. Nephrodium Oreopteris, Desv.

In mountain heathy districts, and moist open woods, in temperate Europe, from northern Spain and Italy to Scandinavia, and eastward to Moscow. Generally dispersed over Britain, especially in Scotland, northern and western England, and in Ireland. Fr. summer and autumn.

5. A. Filix-mas, Sw. (fig. 1291). Male Pern.-Rootstock short but thick, woody, and decumbent, or rising sometimes obliquely a few inches from the ground. Fronds handsome, in a large circular tuft, 2 or 3 feet high, stiff and erect, broadly lanceolate, with the lower pinnas decreasing, as in most Aspidiums, regularly pinnate, the pinnas deeply pinnatifid or pinnate; the segments regularly oblong, slightly curved, very obtuse, slightly toothed, connected at the base or the lowest ones distinct; the main stalk very shaggy with brown scarious scales. Sori rather large, near the base of the segments, with a conspicuous, nearly peltate or kidney-shaped indusinm. Lastrea Filix-mas, Presl. Nephrodium Filixmas, Rich.

In woods and shady situations, along moist banks, \&c., thronghont Europe and central and Russian Asia, from the Mediterranean to the Arctic regions, and in Africa and the Andes. One of the commonest and most variable of British Ferns. Fr. summer and autumn. The barren fronds of young plants often resemble those of $A$. spinulorum, but the fruiting ones are almost always very distinct.

6. A cristatum, Sw. (fig. 1292). Crested S.-Resembles in some resjects 4 . Filix-mas, but the frond is less erect, the pinnas less regular 
the segments broader, thinner, more wedge-shaped on the lower side, much more toothed, and the lower ones sometimes almost pinnatifid, the plant then forming some approach to A. spinulosum, from which it differs in the much narrower frond, with the segments much broader and much less divided. Sori large as in A. Filix-mas, with a conspicuous indusium. Lastrea cristata, Presl. Nephrodium cristatum, Desv.

In moist or boggy places, in temperate Europe and western Asia, from the Pyrenees and northern Italy to Scandinavia, and in North America, but. not generally common. In Britain, very local, but has been found in Nottinghamshire, Yorkshire, Cheshire, and Renfrewshire in Scotland. Fr. summer and autumn. Some specimens appear almost to connect it with $A$. Filix-mas, whilst others are difficult to distinguish from $\boldsymbol{A}$. spinulosum. [Lastraea uliginosa, Newm., is a variety with more divided frond and more acnte pinnules.]

7. A. spinulosum, Sw. (fig. 1293). Broad S.-The most variable of all our Aspidiums, allied to A. Filix-mas, but generally not so tall, of a paler green, and very much broader; the general outline nearly ovate, 1 to 2 feet long or rarely more, the lowest pair of pinnas not much shorter, or even longer than the others. The frond is also more divided, either twice pinnate, with the segments of the pinnas oblong-lanceolate and deeply toothed, or pinnatifid, or thrice pinnate; it then closely resembles Asplenium Filix-famina and Polypodium alpestre, but may be generally distinguished by the lower pinnas not decreasing so much in size, and more accurately by the sori, which are circular, with a kidneyshaped indusium as in A. Filix-mas, although much smaller, and when mature the indusium often disappears.

In sheltered, shady places, on moist banks, in open, moist woods, \& $\mathrm{c}_{\eta}$ common in Europe and Russian Asia, from northern Spain and Italy to the Arctic regions. Abundant in Britain. Fr. summer and autumn. [More than twenty varieties of this species have received distinct names, and the following four have been considered as species, but have no tangible characters to separate them; they are,-

a. A. spinulosum, Swartz. Frond oblong-lanceolate, glandular beneath, pale-green. Lastrea spinulosa, Presl.

b. A. dilatatum, Willd. Scales denser, narrower, with a dark-brown centre. Frond large, broader, dark green, glandular beneath. $L$. dilatata, Presl.

c. A. remotum, Brann. Rachis of frond scaly. Frond glandular beneath, oblong-lanceolate, pinnules cut halfway down. Windermere only. Lastrea remota, Moore.

d. A. comulum, Sw. Frond triangular, glandnlar beneath, concave and curved upwards, smelling of hay. Local in Britain. Nephrodium foenisecii, Lowe.]

8. A. rigidum, Sw. (fig. 1294). Rigid S.-Very near A. spinulosum, of which it has the deeply toothed or pinnatifid, oblong-lanceolate segments, but the frond is stiffer and not so broad, and the sori are much larger, the two rows often occupying nearly the whole breadth of the segments, their indusinms conspicuons and persistent as in A. Filix-mas and A. cristalum. Lastrea rigida, Presl. Nephrodium rigidum, Desv.

In rocky situations, especially in limestone districts, in temperate Europe, from the Pyrenees to Norway, extending eastward into central Asia, and in North Americo In Britain, chiefly in the limestone 
districts of northern England. Fr. summer and autumn. Some botanists regard this and the two preceding species as varieties of A. Filix-mas, into which they appear (when seen growing in profusion' to pass, through numerous intermediate forms.

\section{ASPLENIUM. SPLEENWORT}

Fronds (in the British species) once, twice, or thrice pinnate or forkec nsually rather stiff, though slender, and often small. Sori oblong or linear, on the under surface, nsually diverging from near the centre of the segments, covered when young by a membrane or indusium, which opens outwards, being attached lengthwise along the outer side.

Widely dispersed over the globe, and one of the most natural among the large genera of Filices, for although a few of the larger species are scarcely to be distinguished from some species of Aspidium and Poly. podium, except by the sori, the great majority have a peculiar, dark green, smooth appearance, which makes them easy to recognise.

Fronds twice or thrice pinnate, with numerous primary pinnas,

the lowest or several lower pairs decreasing in size.

Frond 2 or 8 feet lilgh, the longer pinnas 3 to 6 inches or

Frond not a foot high, the longer plnnas seldom 1 i

1. A. Filix-fomina. inches.

Broadest part of the frond above the middle. Ulti. mate segments 1 to 1 lines long

Broadest part below the middle. Ultimate segments broad, 2 to 3 lines long pinnate, with numerous segments, the lover pairs

Fronds once pinnate,
decreasing in sise.

Segments thick, ovate, or lanceolate, 1 to 1 inch long or more

Segments thin, ovate or orbicular, under 5 lines long.

Stalk black

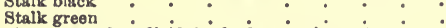

Fronds more or less divided, the lonest pinnas larger, on longer stalks, or more divided than the others.

Frond 6 inches to a foot, shining green, with numerous lanceolate plnnus and sessile segments

Frond 8 or 4 inches, with s few small, stalked segments.

Segments obovate

Segments narrow-oblong

Segments linear

2. A. fontanum.

3. A. lanceolatum.

1. A. Filix-fœmina, Bernh. (fig. 1295). Lady Fern.-A most elegant Fern, with the short woody rootstock and circular tuft of fronds of Aspidium Filix-mas, but more divided, the stalk less scaly, and the sori different. Fronds usually 2 to 3 feet high, broadly lanceolate, twicc pinnate, the lower pairs of pinnas decreasing in size, the segments oblong-lanceolate and pinnatifid, with pointed teeth. Sori shortly oblong, diverging from the centre of the segments, with the indusium attached along one side as in other Aspleniums, but shorter, and the lower ones of the segment often slightly kidney-shaped, showing some approach to those of Aspidium. Athyrium Filix-famina, Bernh.

In molst, sheltered woods, hedge-banks, and ravines, throughout Kurope and central and northern Asia, from the Mediterranean to the Arctic regions, and in North America Abundant in Britain. Fr. 
summer and autumn. It varies much in size, and in the degree of division of its fronds, and between 30 and 40 forms have received names as varieties.

2. A. fontanum, Bernh. (fig. 1296). Rock S.-Fronds densely tnfted, 3 to 5 inches high, or near twice as much when very luxuriant, smooth and shining, oblong-lanceolate in their general outline, but the broadest part above the middle, twice pinnate; the longest primary pinnas seldom above half an inch long, their segments 1 to $1 \frac{1}{2}$ lines, obovate, and deeply notched with 2 or 3 pointed teeth. Sori generally 2 or 3 only on each segment, shortly oblong, like those of A. Filix-fomina.

On rocks and walls, in monntain districts, in central and southern Europe, extending probably into western Asia, but scarcely northward of the Jnra, except as as inrecoduced plant. In Britain it has been found on walls in England, bus culy where planted. Fr. summer and autumn.

3. A. lanceolatum, Huds. (fig. 1297). Lanceolate S.-A low, tnfted Fern, with twice-pinnate fronds, lanceolate in their general outline like the last, but with much larger zegments. Fronds usually 3 to 6 inches high, rarely attaining a foot when luxuriant, the longest pinnas, rather below the middle of the frond, 1 to $1 \frac{1}{2}$ inches long; the segments obovate or broadly oblong, narrowed at the base, but almost sessile, notched with a few pointed teeth. Sori 2 to 4 on each segment, oblong and distinct when young, but when old united in an irregular mass, covering the upper part of the segment.

On rocks and walls, in western Europe, chiefly near the sea, extending sonthward to Madeira, and northward to the English Channel. In Britain, it is found in Yorkshire, Wales, and the western and southern counties, and near Cork in Ireland. Fr. summer and autumn.

4. A. marinum, Linn. (fig. 1298). Sea S.-Fronds tufted, nsually 6 inches to near a foot high, narrow-lanceolate in general outline, but coarser than in A. lanceolatum; the stems usnally black, and only once pinnate. Segments obliquely lanceolate or nearly ovate, rather thick, obtuse, crenate, especially on the upper edge, narrowed at the base into a short stalk, the longer ones, in the middle of the frond, about an inch long. Sori several on each segment, linear, often above 2 lines long.

On rocks and walls, near the sea, in western Enrope, extending southward to the Canary Islands, and eastward to several spots along the Mediterranean, and to North America. In Britain it is common on the sonth and west coasts and north to the Shetlands, but no farther south than Yorkshire on the east coast. $F r$. the whole season.

5. A. Trichomanes, Linn. (fig. 1299). Common S.-A neat little tufted Fern, usually 2 to 6 inches high, simply pinnate; the slender stalk nsually black; with numerons obovate, orbicular, or broadly oblong segments, nearly equal in size, those of the middle of the frond rather the largest, 2 to 3 or rarely 4 lines long, more or less toothed. Sori several on each segment, oblong-linear and distinct when young, but often nniting in a circular mass when old.

On walls and rocks, throughont Europe and central and Russian Asia, except the extreme north. Common in Britain. $F_{r}$. the whole peason. [A. anceps, Sol. is only a large form; A. Clermonta, Syme, found 
on a garden wall at Newry, is almost certain:y a hybrid with A. Rutamuraria.]

6. A. viride, Huds. (fig. 1300). Green S.-Very near A. Trichomanes, and considered in the first edition of this Handbook as a variety of it. It is osually less rigid, the segments rather shorter and broader especially on the npper side, and the stalk is either entirely green or brown at the base only.

Among rocks in the mountains of central and northern Europe, Asia, and America. Not uncommon in most mountainous districts of Britain. F'r. the whole season.

7. A. Adiantum-nigrum, Linn. (fig. 1301). Black S.-Fronds tufted, usually 6 inches to a foot high, including the rather long, dark-brown or black stalk, the leafy part triangular or broadly lanceo. late, of a dark shining green, and firm consistence, twice pinnate, or the lower part three times; the pinnas gradually decreasing and less divided, from the lowest pair to the point; the segments varying from lanceolate to ovate or even obovate, sharply toothed or cut. Sori narrow-oblong or linear, sometimes, when old, covering nearly the whole surface.

On sandy hedge-banks, rocks, and old walls, in eentral and southern Europe and western and central Asia, extending northwards to southern Scandinavia. Common in Britain. Fr. all summer and autumn.

8. A. Ruta-muraria, Linn. (fig. 1302). Wall-Rue.-Fronds densely tufted, usually 2 to 3 inches long, rather dark-green, but not shining; the stalk more or less pinnately divided; the lower pinnas usually oearing 3 segments, the upper ones simple; the segments all stalked, obovate or broadly oblong, seldom above 2 lines long, and usually minutely toothed. Sori shortly linear, becoming united into broad patches when old.

On old walls and rocks, throughout Europe and central and Russian Asia, except the extreme north, and in North America. Common in Britain, except in some of the eastern districts. Fr. the uhole season.

9. A. germanicum, Weiss. (fig. 1303). German S,-Very near A. Ruta-muraria, and perhaps a variety; but the segments are much narrower, usually narrow wedge-shaped or oblong, on short stalks; the whole frond narrow, usually simply pinnate, with the lower segments 3 lobed, or very rarely bearing 3 distinct segments; the segments entire or toothed at the summit. Sori few, long and narrow. A. alternifolium, Wulf.

On rocks and old walls, dispersed over the greater part of Enrope, from Spain to Scandinavia, and in the Himalaya and China Has been found in isolated localities in western and northern England and central and southern Scotland. Fr. summer and autumn.

10. A. septentrionale, Hoffm. (fig. 1304). Forked $S_{\text {. }}$-This again is allied to $A$. Ruta-miraria, and has similar tufted fronds, 2 to 5 or 6 inches high; but the whole frond usually consists of a stalk, forked wowards the top, each branch bearing a single, linear, entire or 2-lobed segment, about half an inch long, the lincar sori occupying the whole ander surface except the narrow pointed extremity. Some fronds have but a single entire or 3-lobed terminal segment, and a few have 3 distinct segments.

On rocks and old walls, in the mountainous districts of the greates 
part of Europe and central and Russian Asia, from Spain to Scandinavia, and in the mountains of North America. In Britain, in several of the western and northern connties of England and in Scotland, bnt not in Ireland. Fr. summer and autumn.

\section{SCOLOPENDRIUM. HART'S-TONGUE.}

Fronds entire or lobed, with linear diverging sori as in Asplenium, but the indusium is attached along both sides, opening in 2 valves by a longitudinal fissure along the centre.

The few species associated with our British one are from the tropics or the Mediterranean region.

1. S. vulgare, Sm. (fig. 1305). Hart's-tongue-Fronds tufted, undivided (except in monstrous forms), broadly linear or narrow-oblong, cordate at the base, with rounded auricles, usually about a foot long and $1 \frac{1}{2}$ to 2 inches in the broadest part, of a firm consistence, smooth and shining on the upper surface, with a brown or greenish foot-stalk of about 2 to 4 or 5 inches. Sori numerous, transverse and parallel, in 2 rows, one on each side of the midrib, usually of very different lengths, but never reaching either to the midrib or to the edge of the frond.

On shady banks, rocks and walls, in ravines, \&c., in temperate and southern Europe, west central Asia, Japan, and north-west America, extending from the Mediterranean to the Baltic. Common in Britain. Fr. the whole season. It varies much in size from 6 inches to near 2 feet, and in the fantastic forms assumed by the barren fronds when monstrous, especially under cultivation. No less than 58 of these forms are named in Moore's Handbook.

\section{CETERACH. Ceterach.}

Fronds pinnatifid or pinnate. Sori linear and diverging as in Asplenium, but without any distinct indusinm, and usually ahmost concealed onder the scales of the under surface of the fron.t.

The genus is now limited to the European species and a second larger one from the Canary Islands.

1. C. officinarum, Desv. (fig. 1306). Ceterach.-Fronds tufted, spreading, about 2 to 6 inches long, deeply pinnatifid or pinnate, with broadly oblong or rounded lobes or segments attached by their broad base, green and glabrous on the upper side, but the under side thickly covered with brown scarious scales, which completely conceal the sori until they become very old. Asplenium Ceterach, Linn.

On rocks and old walls, in central and southern Europo and west central Asia, extending northward to Holland. In Britain, common in many parts of England, especially western, and in Ireland and western Scotland. Pr. summer and autumn.

\section{BLECHNUM. BLECHNUM.}

Sori linear, one on each side of the midrib of each segment and parallel to it. Indusinm attached along the outer edge of the sorux, croning outwards from the inner side. 
A small genus, spread over many parts of the world, but chiefly tropical.

1. B. Spicant, Roth. (fig. 1307). Blechnum.-Fronds simply pinnate, tufted, of two kinds, the outer barren ones spreading, usually 6 inches to near a foot long; the segments lanceolate, curved, entire, attached by their broad base; those in the centre of the frond 1 to $1 \frac{1}{2}$ inches long, gradually decreasing towards each end. Frniting fronds in the centre of the tuft, erect, 1 to $1 \frac{1}{2}$ feet high; the segments of the same dength as in the barren ones, but all narrow-linear; the under side entirely occupied by the 2 linear sori. B. boreale, Sw. Lomaria spicant, Desv.

In woods, and rather moist stony places and heaths, generally dis. tributed over Europe, extending from the Mediterranean far into Scandinavia, and nccurs in north-cast Asia and north-west America. Common in Britain. Fr. summer, rather late, and autumn.

\section{PTERIS. PTERIS.}

Fronds usually stiff, often large, lobed, or pinnately divided. Veins of the segments branching from the midrib. Sori linear, close along the margin of the frond, with an indusium attached along its outer edge to the margin of the frond, and opening on the inner side.

A large genus, widely distributed over the globe, and if not very natural, at any rate easily recognised.

1. P. aquilina, Linn. (fig. 1308). Bracken.-A tall, erect, stiff Fern, with a thick, hard, creeping rootstock. Fronds 1 to 2 feet ligh in poor soils, 8 to 10 feet high when luxuriant, twice or thrice pinnate; the primary pinnas in pairs at some distance from each other; the lowest pair much larger, the others decreasing in size and successively developed, giving the whole frond, especially when young or small, a broadly triangular outline. Secondary pinnas numerous, linear-lanceolate, deeply pinnatifid or pinnate, always ending in an undivided, crenate, blunt point. Segments ovate or oblong, obtuse and entire, attached by their broad base of a firm consistence, glabrous above, often hairy underneath. Sori in continuous lines along the margins of the upper segments and summits of the secondary pinnas.

In woods and thickets, on heaths and waste places, dry or moist, but not swampy, in almost every part of the globe, except the extrome north and south. Very abundant in Britain. Pr. autumn.

\section{ADIANTUM. MAIDENHAIR.}

Fronds usually delicate and divided, the segments more or less wedge. shaped, with diverging forked veins, usually without a midrib. Sori oblong or linear, transverse, at the ends of the lobes on the under side, with an indusium formed from the edge of the frond and opening in. wards.

A considerable and well-marked genus, chiefly tropical.

1. A. Capillus-Veneris, Linn. (fig. 1309). Maidenhair.-A very delicate tufted Fern. Fronds 6 inches to near a foot long, twice or tbrice pinnate, usually brogdly ovate in general outline, their slender 
stalk of a shlning brownish-black. Segments obovate or fan-shaped, 4 to 8 lines broad, all narrowed at the base into a short, slender stalk, more or less divided into wedge-shaped, obtuse lobes, thin, and of a bright green, without any midrib, but numerous forked veins converging at the base. Sori conspicnons, occupying the extremities of most of the lobes of the segments.

In the fissures of moist rocks, at the entrance of caves and wells, and other situations sheltered from cold, as well as from sun and drought, in most of the tropical and warmer parts of the globe, common in southern Europe, extending northward over the greater part of France, but scarcely into Germany. In Britain, only in the southern and western counties of England, in South Wales, the Isle of Man, and Ircland. Fr. all summer.

\section{CYSTOPTERIS. BLADDERFERN.}

Delicate Ferns, with twice or thrice pinnate fronds. Bori small circular, on the nnder surface, enclosed, when young, in a very thin, globular, or hood-shaped membrane, which opens out irregularly into a cup under one side, and often disappears early.

A small genns limited to the colder or mountainons rcgions of both hemispheres.

Fronds oblong-lanceolate, the lowest pinnas decreasing in size Fronds broadly triangular or rhomboidal, the lowest pair of pinnas

the largest

1. C. fragilis, Bernh. (fig. 1310). Brittle B.-Rootstock shortly creeping. Fronds tufted, usually under a foot long, oblong-lanceolate in their general ontline, twice pinnate; the longest primary pinnas towards the middle of the frond, 1 to $1 \frac{1}{2}$ inches long, decreasing towards both ends. Stalks slender, withont scales. Segments lanceolate, deeply pinnatifid, or the lower ones pinnate, with small, oblong, more or less crenate lobes, all obtuse, not pointed as in Asplenium fontanum, to the larger specimens of which this plant bears some resemblance.

On rocks and old walls, spread over the greater part of the globe, especially in monntainous districts, extending far into the Arctic regions. Dispersed over all Britain, and common in the hilly districts. Fr. summer and autumn. A variety from the Alps and Pyrenees, C. alpina, Desv., with a 3-4- pinnate frond, is found in Teesdale. [Another variety is $C_{\text {. dentata, }} \mathrm{Sm}$., with ovate-lanceolate obtuse segments, and submarginal sori.]

2. C. montana, Bernh. (fig. 1311). Mountain B.-Rootstock creeping. Fronds growing singly, twice or thrice pinnate, broadly triangular or rhomboidal in general outline, the pinnas of the lowest pair being considerably larger and more divided than the others, as in Polypodium Dryopteris, which this plant much resembles. It is, however, of a more delicate textare, only 6 or 8 inches or rarely a foot high, including the long slender stalk; the pinnas are mostly alternate, with more divided, smaller segments, and the slender indusinm over the sori is easily seep upder a magnifying-glass when young. 
In moist, alpine situations, in northern and Arctic Europe, Asia and America, and in their great mountain-ranges. In Britain, only on few of the lofty mountains of Scotland. Pr. summer.

\section{WOODSIA. WOODSIA.}

Small, tufted, pinnately-divided Ferns, with brown scarions scales or hairs on the under surface. Sori circular, surrounded by or intermixed with a fringe of chaffy hairs, proceeding from the minute indusium concealed under the sorus.

A small genus, still more strictly confined than the last to high northern or southern latitudes, or to great elevations.

1. W. ilvensis, Br. (fig. 1312). Alpine W.-Stock densely tufted. Fronds spreading, 2 to 4 or rarely 6 inches long, twice pinnate, oblonglanceolate in outline; the longer primary pinnas in the middle of the frond, 6 to 9 lines long, the lower ones decreasing; all pinnate or pinnatifid, with small obtuse segments, rathes thick, green and glabrous, or hairy above, more or less covered nnderxesth with brown scarious scales or chaffy hairs.

On alpine rocks, in northern and Arctic Europe, Asia, and America, and on their great mountain-chains. Rare in Britain, and only in the mountains of Scotland, northern England, and North Wales. Fr. summer. W. hyperborea, Br., usually considered as a distinct species, but probably only a variety of $W$. ilvensis, differs in its more tender texture, a greener colour, the segments shorter and less deeply divided, with more rounded lobes, and the scarious scales less numerous, narrower and paler-coloured. Its range is nearly the same as that of the ordinary form, but it is generally more rare.

\section{TRICHOMANES. BRISTLE FERN.}

Delicate, half-pellucid Ferns, usually of a dark green. Fructification consisting of little cup-shaped involucres, sessile upon or partly immersed in the edge itself of the frond. In the centre of the involucre is a little bristle, often projecting beyond it, round the base of which are attached the minute capsules or spore-cases.

A large genus, widely spread over the warmer regions of the globe, but more especially in tropical America.

1. T. radicans, Sw. (fig. 1313). European B.-Rootstock creeping, often to a considerable extent. Fronds usually 6 to 8 inches high, including the rather long stalk; broadly ovate-lanceolate in general outline, twice or thrice pinnate, of a dark green, with rather stout stalks and branches. Segments numerous and crowded, thin, pellucid, oblong, more or less toothed, narrowed at the base. Involucres in the axils of the small ultimate segments or lobes, cylindrical, about a line long, the central bristle projecting $\frac{1}{2}$ to 1 line more.

In moist, sheltered, shady places, widely distributed over the tropical and hotter regions of both hemispheres, but in Europe only in a few 
localities in western Spain, South Wales, Yorkshire, Argyleshire, and Killarney in Ircland. $P r$. summer. [T. Andrewsii, Newm., is a pretty form with a narrower frond, many-winged involucres, and larger receptacles.]

\section{HYMENOPHYLLUY, FILMY FERN.}

Half-pellucid Ferns, closely resembling Trichomanes, but usually smaller; the involucres deeply divided into 2 lobes, and the bristle or receptacle usually concealed within them.

A large genus, with nearly the same range as Trichomanes.

1. H. tunbridgense, Linn. (fig. 1314). Tunbridge $F$.-Rootstock very slender, creeping, and much branched with numerous fronds, forming broad, dense, almost moss-like patches. Fronds pinnate, scldom above 2 or 3 inches long, lanceolate in general outline; the stem very slender; the segments deeply divided into 3 or 8 or more oblong-linear lobes, which appear minutely toothed when seen through a lens. Involucres at the base of the segments or their lobes, on their inner edge, ovate, about a line long, deeply divided into 2 flattish lobes, often minutely toothed round the edge.

In moist, rocky, or shady situations, dispersed over most of the warmer mountain districts of the Old World, especially in the southern hemisphere, more rare in America, extending from the Canary Islands and western Europe to Belgium and Norway, but not recorded from eastern Europe or any part of the Russian dominions, nor from North America. Generally distributed over the greater part of Britain, but more frequeut in Scotland, northern and western England, and Ireland, than in eastern England. Fr. summer and autumn. A variety with the valves of the involucre entire, not toothed, is usually distinguished as a species, under the name of $\boldsymbol{H}$. unilaterale, Willd. (fig. 13i5), or $\boldsymbol{H}$. Wilsoni, Hook, but the other characters, said to accompany this one, sach as the narrow involucres, the different direction of the lobes of the fronds, \&c., do not appear to me to be so constant as they are supposed to be; and the teeth of the valves, when present, are very variable. The entire-valved form is the most common in Scotland and Ireland, but the two are often intermixed. 


\section{INDEX OF SUBSTANTIVE NAMES,}

ORDINAL, GENERIC, AND POPULAR.

\begin{tabular}{|c|c|c|c|c|c|c|c|c|c|c|}
\hline & & & & & & & & & & \\
\hline & & & . 414 & Alaternns . & & & - 99 & American Cow & wslip & \\
\hline & & & . 416 & & • & & . 139 & & • & \\
\hline & & . & . 242 & & . & & . 139 & Ammophila & & \\
\hline & & & - 85 & & . & & . 404 & & & \\
\hline & & & . $10 \mathrm{I}$ & anders & & . & .202 & lex & . & \\
\hline & & & $\cdot 3^{23}$ & $=$ & . & & . 547 & $2 \operatorname{lug}$ & - & \\
\hline & & & - 96 & na.. & & & . 432 & ptis & . & \\
\hline & & & - 96 & a Fain & & & . 430 & An & & \\
\hline & . & & .446 & & . & - & . $43^{\circ}$ & is . & & \\
\hline & & & .239 & & & & . $3^{13}$ & & . & \\
\hline & & & $\cdot 323$ & & & & & eda. & & \\
\hline & & & $2,12,13$ & & - & & - 3 & gonex & & \\
\hline & & & .13 & 1 & . & & . 217 & . & . & \\
\hline & & & - $42 \mathrm{I}$ & & & & & m. & & \\
\hline & & & . 14 & . & & • & . 464 & . & • & . 19 \\
\hline & & & .433 & as . & & & . 560 & ia. & . & \\
\hline & & & - 557 & & & & & & & \\
\hline & & & . 568 & & & & - 128 & Pea & . & $\cdot 12$ \\
\hline & & & & . & . & . & . 404 & is & . & \\
\hline & & & .206 & & & & 452 & lem . & & \\
\hline & & & .529 & & & & & & - & $\cdot 23$ \\
\hline & & & .182 & & & & 14 & & & \\
\hline & & & . 96 & & & & 67 & Iron & & \\
\hline & . & & . 190 & ove & & - & . 114 & & & $\cdot 5$ \\
\hline & us . & & .456 & & & & - 452 & thuin & & \\
\hline & & & $.45^{2}$ & & & & . 86 & & & \\
\hline & & & .225 & & & - & 25 & & - & . II \\
\hline & & & . I & & & & & & . & \\
\hline & & & 141,226 & & & & . 371 & inum. & & \\
\hline & & & - $\quad 529$ & & & - & - 371 & is . . & • & .25 \\
\hline & & & . 64 & & & & & & & \\
\hline & & & . 517 & & & . & & & & \\
\hline & & & $\cdot 5^{2}$ & & & & . $45^{2}$ & naces . & - & \\
\hline & & & & & & & & & & \\
\hline & & & & 67 & & & & ? & & \\
\hline
\end{tabular}




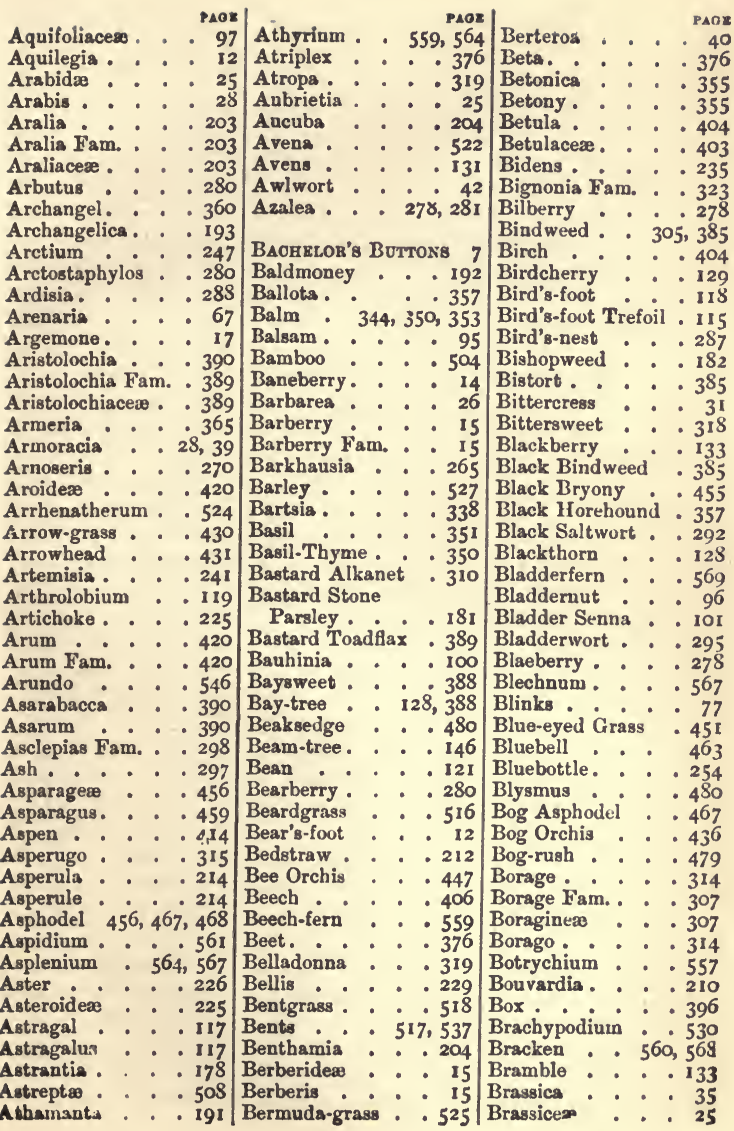




\begin{tabular}{|c|c|c|c|c|c|c|c|c|}
\hline & & & $\begin{array}{l}\text { PAOR } \\
\text { 318 }\end{array}$ & & & PAGE & & \\
\hline tle-fern & & & - 3 IS & Calendula . & & . 225 & Cancalis : & - 199 \\
\hline $\begin{array}{l}\text { 3ristle-tern } \\
\text { Biza . }\end{array}$ & n & - & - 570 & Calliandra. & - & . 100 & Cauliflower & - $\quad 37$ \\
\hline roccoli & - & - & - 537 & Callitriche. & $\bullet$ & - 397 & Cayenne Pepper & - 317 \\
\hline $\begin{array}{l}\text { Broccoli } \\
\text { Brome. }\end{array}$ & - & - & - $\quad 37$ & Oallitriche F & am. & - 397 & Ceanothus. & - 99 \\
\hline $\begin{array}{l}\text { Brome } \\
\text { Bromeliace }\end{array}$ & - & - & . $53 \mathbf{I}$ & Calitrichineæ & . & - 397 & Cedar . & $\cdot 416$ \\
\hline neliace & & • & . $45^{6}$ & Calluna . & - & . 284 & Celandine . & 8,19 \\
\hline is. & - & - & . 531 & Calochortus & - & - $45^{6}$ & Celastraceæ & - \\
\hline lime. & & - & - 335 & Caltha .. & - & . $\quad$ I I & Celastrus Fam. & - 9 \\
\hline weed & & . & . .294 & Calycanthus & . & .148 & Celery . . & - 18 \\
\hline n. . & & - & 101, 104 & Calystegia. & . & . 306 & Celosia. . & - 371 \\
\hline arape & & & . 320 & lina. & . & . 42 & Centaurea. & . 254 \\
\hline rape & & am. & - 319 & linero & . & . 25 & ury . & . 300 \\
\hline llia. & & - & . 324 & Campanula & & - 274 & Centranth. & . 216 \\
\hline ansia & & . & - 317 & Campanula 1 & Fam & .271 & ranthus . & . 216 \\
\hline & & & - $35^{2}$ & $\mathrm{Ca}$ & ex & - 271 & cle. & . 293 \\
\hline elsia & & & . 324 & jion . & - & - 62 & anculus . & . 293 \\
\hline & - & . & . . 157 & Canary-grass & & . 512 & Cephalanthera & - $43^{8}$ \\
\hline y. . & - & - & 157,455 & -seed & - & 512 & t. . . & - 70 \\
\hline ean. & & & . 303 & ytuft. & - & . 44 & Cerastium . & - 70 \\
\hline zshorn & & . & . .367 & is . & $D^{\circ}$ & - 399 & Ceratophyllum & - 397 \\
\hline horn & & & $99,3^{88}$ & oury 1 & & - 274 & $\operatorname{cis} \cdot$. & - 100 \\
\hline horn & & & . $\quad 98$ & Car & - & - 304 & Cestrum & - 317 \\
\hline Bnckwned & & - & - $3^{84}$ & Caprifoliace: & & . 205 & Ceterach : & . 567 \\
\hline & - & • & - 361 & $1 \quad$ & - & - 45 & ophyllum & - 197 \\
\hline 083 & - & . & $309,3^{1} 3$ & la & - & - 45 & eed.. & . 293 \\
\hline ce. & - & & .129 & sicum . & - & - 317 & Chamagrostis & $\cdot 5^{\mathbf{I}}$ \\
\hline & - & · & 184,198 & ana. & - & . IOI & mile. & 237,23 \\
\hline ver. & - & - & . .186 & y. & . & - 184 & ceæ . & - .547 \\
\hline Bupleurum & & - & .186 & Cardamine & ${ }^{\circ}$ & - 31 & lock & - \\
\hline ck. & & & . 247 & on. & & . 225 & Cheiranthus & 26 \\
\hline Larige & ol & & .235 & 48 & . & . 249 & gium. & . 19 \\
\hline t. . & - & . & . 140 & Carex . & . & . 488 & podiacere & - 370 \\
\hline eed & - & - & . 419 & ina. & . & . 253 & podium & - 373 \\
\hline & $\dot{0}$ & - & .235 & e. . & - & $.25 j$ & leria.. & . . 67 \\
\hline tcher's I & $\mathrm{Br}$ & 001 & - 459 & ion. & • & - 59 & Cherry. & 129,317 \\
\hline & - & - & - 431 & Carnation-g? & ass & - 500 & Chervil. & . $\quad 197$ \\
\hline ns. & - & . & . 431 & aus. & . & . 405 & nut & - 403 \\
\hline rbur. & & . & - 243 & rot. & . & . 200 & kweed 70,7 & $3,74,77$ \\
\hline up . & & · & - 9 & $\mathrm{Ca}$ & . & .183 & ry : . & . .270 \\
\hline rwort & & • & - 294 & phyllac & $e x$ & - $5^{8}$ & onanthus & - 148 \\
\hline Buxus • & & . & - 396 & ia.. & . & - 100 & ianthus & - 297 \\
\hline $\mathbf{G R}$ & & & & ea & & & Chives . & \\
\hline сељ & & & .158 & Cat & & $\begin{array}{l}543 \\
323\end{array}$ & Chorozema & - \\
\hline Cresalpinia & & • & .100 & nche & - & .225 & Christmas Rose & \\
\hline & & & - $4^{8}$ & dium & - & . $54 \mathrm{I}$ & anthemum & . 236 \\
\hline aagros & st & & . 520 & & - & - 61,62 & osplene. & . 169 \\
\hline oint . & & - & - 349 & Catkin Fam. & - & - 402 & Chrysosplenium & - 170 \\
\hline nth & & & - 349 & int . & - & 52 & Cicely & - 196 \\
\hline & & - & . 76 & Cat'g-ear & - & 232,260 & Cicendia . & - 300 \\
\hline olaria & & . & . 324 & Cat's-tail . & - & 418,513 & Cichoriaceie & .225 \\
\hline
\end{tabular}




\begin{tabular}{|c|c|c|c|c|c|c|c|c|c|c|}
\hline & & & & & & & PAOK & & & \\
\hline ium. & - & & . 270 & Convolvulus & & & - 305 & Croton . & & . 391 \\
\hline & & & - 180 & lorhiza & & & - 437 & Crosswort . & • & . 212 \\
\hline ineraria . & & & . 244 & alroot. & & $3^{2}$ & , 437 & Crowberry. & - & . 396 \\
\hline inquefoil. & & & . 136 & choras. & &. & - 128 & Crowfoot & . & . 9 \\
\hline a. & & & . 154 & ass. & - & . & - 525 & Cruciferæ . & • & 22 \\
\hline $\mathrm{am}$ & & & . 249 & sis. & & . & .225 & Crucifer Fam. & & . 22 \\
\hline as. & & & - 99 & der. & . & . & . 202 & Cryptogams & & 547 \\
\hline $\operatorname{ces}$ & - & & 51 & Arum & & & . 202 & gramm & & 560 \\
\hline 8 . . & & & 51 & ree : & - & . & . 407 & eria & - & . 416 \\
\hline s Fam & & & 51 & Co & . & . & . 204 & Cucko & & - $3 I$ \\
\hline & & & .479 & Cockle & & & . 64 & Cuckoo-pint & - & . 420 \\
\hline a & & & . 149 & & & . & . 205 & lus. & - & . 59 \\
\hline nia. & & & & Fam. & & & . 204 & er. & $\bullet$ & .157 \\
\hline & & & . 214 & $\mathrm{ag}$ & - & - & . $45^{\circ}$ & Cucurbitacere & & . .157 \\
\hline & & & & ver & - & & . 254 & Cu & & 229,230 \\
\hline us . & & & . IOI & lad. & & & .217 & Cuphea. & . &.$\quad 155$ \\
\hline diun & & & . $35^{1}$ & . . & & & . 204 & Cupuliferæ & . & - 403 \\
\hline erry & & & . 135 & $11 \mathrm{a}$. & - & . & - IOI & nt . & & . 164 \\
\hline Pink & & & & phorus & & & - 522 & $a$. & & . 306 \\
\hline & & & - 109 & ; & - & . & - 96 & Cyclamen . & - & .290 \\
\hline & & & . 547 & ola. & & & - $3^{68}$ & Cy & - & . .225 \\
\hline & & & - 547 & al. & & & . 22 & ideæ & & 224,225 \\
\hline - & & & . 249 & dalis . & & & - 22 & odon . & & . .525 \\
\hline & & & - 304 & $\therefore$ & . & . & . 406 & glossum & & - 315 \\
\hline aria. & & & - $3^{8}$ & iferæ & & & . 223 & osurus. & & - 536 \\
\hline$-\mathrm{com}$ & & & . 371 & aster & & & - 148 & eraceœ & - & . 477 \\
\hline foot & & & - 536 & rass & & & . 486 & erus . & & . 478 \\
\hline & & & . 146 & rush & - & & . 486 & Cyphel . & & - 67 \\
\hline & & & & sedge & & & & Cypress . & - & . 415 \\
\hline & - & & . 210 & Thiot & & & . 253 & ripedium & & . 448 \\
\hline сеæ . & & & . 456 & weed & & & . 240 & pteris & . & . 569 \\
\hline um. & & & & edon. & & & . 159 & Cytisus. . & . & . 104 \\
\hline & - & & 344 & . & $\therefore$ & & - 529 & & & \\
\hline & & & - $3^{24}$ & ne & & & . 180 & OIA. & & . 282 \\
\hline & & & - 304 & erry . & & & . 279 & tylis . & & . 536 \\
\hline pot. & & & - 342 & & & : & . 289 & Daffodil & . & .453 \\
\hline & & & . 12 & leat. & & & . $34 I$ & Dahlia . & & . 225 \\
\hline & & & $\therefore$ IOI & pple & . & & . 146 & Daisy . & & 9,236 \\
\hline & & & - 37 & & & . & - 49 & ssonium & & - 433 \\
\hline am. & & & . 139 & & & & 279 & & & - 33 \\
\hline & & & 314 & & & & & nson . & & - 129 \\
\hline sitso & & & & & & - & 158 & Dandelion. & - & - 263 \\
\hline & & & 22 & & & - & - 158 & wort . & - & - 207 \\
\hline & - & & & асеæ & & & - 158 & hne : & & - $3^{87}$ \\
\hline$r æ$ & & & & & & • & - 147 & hne Fan & & - 387 \\
\hline & & & & & & & - $29 I$ & Darnel . & - & - 530 \\
\hline & & & & & & & - 264 & Datura. & & - 317 \\
\hline laria & & & & & & & & & & .200 \\
\hline & & & & & & & . $45^{2}$ & & & . 319 \\
\hline & & & 305 & & & & - 193 & & & - $35^{8}$ \\
\hline & & & & & & & & hininm & & \\
\hline
\end{tabular}




\begin{tabular}{|c|c|c|c|c|c|c|c|c|c|c|}
\hline & & & PAOE & & & & PAOE & & & \\
\hline $\operatorname{tra}$ & & & - 32 & Echium & & & - 308 & Eupatorium & - & . 225 \\
\hline Deodara & & & $.4 J 6$ & Edwardsia & - & - & . 101 & Eupatory . & - & .225 \\
\hline Deschamps & & & .521 & Egg-plant . & - & - & - 318 & Euphorbia & - & - 391 \\
\hline tzia & & - & . 165 & Elæagnace» & - & - & - 388 & Euphorbiace & & - 390 \\
\hline Devil's-bit & & • & . 221 & Elæagnus . & - & - & - 388 & Euphrasia. & - & - 339 \\
\hline berry & & - & . 134 & Elæagnus F & aw. & . & - 388 & Eutoca . & & - 303 \\
\hline xia & - & - & . 520 & Elatinaceæ & • & - & . 78 & Evening Prit & $\mathrm{mr}$ & .153 \\
\hline Dianthus & - & . & . 59 & Elatine . & . & • & - 78 & Everlasting 2 & 22 & 31,232 \\
\hline ra & & - & - 21 & Elatine Fam & n.. & • & - 78 & asting 1 & $\mathrm{Pe}$ & .125 \\
\hline ledo & ons & . & - I & Elder - & - & - & - 206 & Evonymus & - & . \\
\hline 18 & & - & - 96 & Elecampane & - & - & - 233 & Eyebright. & - & - 339 \\
\hline & & & - 21 & Eleocharis. & & & - $4^{8} 3$ & & & \\
\hline lis & & & - $33^{2}$ & Elm . . & 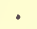 & - & . 401 & NA. & - & - 317 \\
\hline ria & & - & . 510 & Elm Fam. . & - & , & - 400 & Fagopyrum & - & - 384 \\
\hline his & & - & . 512 & Elodea . & - & • & . 433 & Fa & - & . 406 \\
\hline ea & & . & . 190 & Elymus . & & - & . 527 & False-Brome & - & - 530 \\
\hline & & - & . 454 & Finpetracea & e. & - & . 396 & False-Oat . & . & - 524 \\
\hline & & & - 96 & Empetruun & & - & . 396 & erfoil & . & . 288 \\
\hline & & . & . 240 & Einpetrum & Fam & n. & - 396 & Feathergrass & 3. & - 508 \\
\hline denia & & - & . 298 & Euchanter's & & igl & & Fedia . & - & . 217 \\
\hline & & - & - 36 & ade. & - & & - 154 & Fennel. & - & - I90 \\
\hline Dipsacea & - & . & .219 & Endive. & & 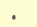 & .270 & Fern Fain. & - & - 554 \\
\hline & - & - & . 219 & Epacris. & - & . & .278 & Royal & . & - $55^{8}$ \\
\hline & & - & - 332 & be . & • & . & . 149 & $1 e \cdot$. & - & - 534 \\
\hline nder & & & - 46 & Epilobium. & & & . 149 & Festuca & - & - 5 \\
\hline & & - & - 379 & dium & - & . & . 15 & Fibichia & - & - $5^{2}$ \\
\hline er. & & & - 306 & tis. & • & . & - 437 & Ficoider & & - \\
\hline the & & & - 288 & Epipogum . & & & . 440 & Ficus - & - & - 399 \\
\hline & & & - 395 & etaceæ & . & - & . $55 \mathrm{I}$ & Field Madd & & \\
\hline 's-tail & & & . 536 & eturn & & - & - 551 & Fig . . & & $\therefore 399$ \\
\hline Dug-tooth & & & . 456 & petum & Fat & & - 551 & Figwort & - & - 8,33 \\
\hline & & & . 205 & Eranthis . & - & - & & Filago . & - & . .2 \\
\hline & & & . 247 & Erica . & - & . & - $2 \mathrm{Sz}_{2}$ & Filarea. & - & . 2 \\
\hline icum & & & - 247 & Ericacea . & . & & . 277 & Filices : & & . 554 \\
\hline . & & & - 40 & Erigeron & - & & . 227 & Filmy Fern & - & - 5 \\
\hline & & & - 344 & lus . & . & . & - 324 & Fiorin-grass & - & - 513 \\
\hline rort & & & 1 jo, 188 & aulea & & & . 476 & Fir . . & • & $\cdot .4$ \\
\hline & & &.$\quad 17 \mathrm{I}$ & aulon & - & . & . 476 & Flag. . & - & $42 I, 449$ \\
\hline aces & & & .171 & lorum & . & . & . 486 & Flax. & - & . : \\
\hline L & & & .131 & liumn . & . & • & . 93 & Flax Fam. & - & - $\mathrm{S}_{3}$ \\
\hline weed & & & - 421 & Erophila . & - & . & & Fleabane . & - & 227,234 \\
\hline & & & - 421 & trum & - & . & - 36 & sweed & & - 34 \\
\hline $\mathrm{cb}$. & & & 553 & gium. & - & - & - 179 & Flowering Ru & & - 431 \\
\hline ale & & & - 319 & Kryngo. . & - & - & - 179 & Fœniculum & - & - 190 \\
\hline & & & & um. & - & . & & Fool's Parsle & & \\
\hline & & & 184,1 & conium & m & . & . 456 & Forsythia. & . & 297 \\
\hline & & & .58 & llonia. & & & . 165 & Foxglove. & & - 3 \\
\hline & & & - 511 & & & - & - 17 & Foxtail . & - & - 514 \\
\hline & & & . 225 & Bufragia & - & - & & Fragaria . & - & . 135 \\
\hline & & & & & & - & & ankenia. & - & - \\
\hline
\end{tabular}




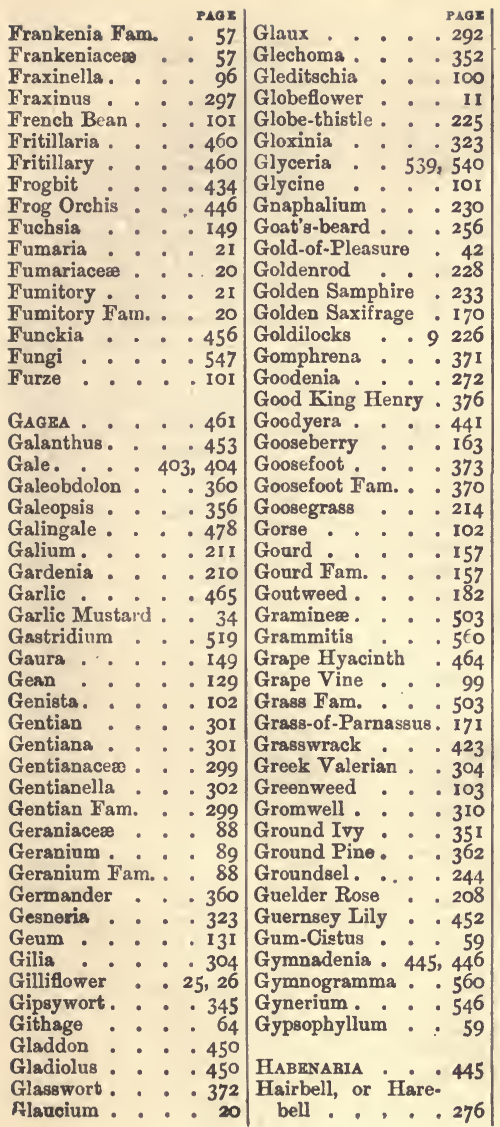

PAGE

Hairgrass . . . 522

Halesia. . . . 296

Halorageæ . . 172

Hardheads . . 254

Hare's-ear . . 35, I87

Hare's-tail . . 516

Hart's-tongue . . 567

Hartwort . . . 196

Hawkbit . . 258

Hawkweed . . 266

Hawthorn. . . 14t

Hazel . . . 406

Hazel-nut . . . 406

Heartsease - . 55

Heath • . . 57, 282

Heath Fam. . 277

Hedera . . . 203

Hedysarum . 101, 120

Helianthemum . 5I

Helianthoideæ . . 225

Helianthus . . 225

Helichrysum . . 225

Heliotrope . 242, 308

Hellebore . . I II

Helleborine . . 438

Helleborus : . . 11

Helminth . . 257

Helminthia . . 257

Helosciadium . . 180

Hemerocallis . . . 456

Hemlock . . 180, 201

Hemp . . . 399

Henbane . . . 317

Henbit . . . 359

Hepatica . . . 4

Hepaticæ . . 547

Heracleum . . 195

Herb-Bennet . . 13I

Herb-Christopher . I4

Herb-Gerard . . I82

Herb-Paris . . 456

Herb-Robert . . 91

Herminium . . 447

Herniaria . . 369

Hesperis - . 33

Hibiscus . . 84,87

Hieracium. . . 266

Hierochlue . . . 511

Hippocastanem . . 96

Hippocrepis . . . I19

Hippophæ. . . 388 


\begin{tabular}{|c|c|c|c|c|c|c|c|c|c|}
\hline & & $\mathbf{F}$ & & & & & K & & \\
\hline Hog's Fenne & & . 174 & Illecebrum & & & & $\begin{array}{l}\text { Koweria } \\
\text { Koleria }\end{array}$ & & \\
\hline Iogweed. & & $\begin{array}{l}\text { - } 194 \\
. \\
\text { I95 }\end{array}$ & Illecebruin & $\mathrm{F}_{\mathrm{al}}$ & - & $\begin{array}{r}309 \\
\cdot 368\end{array}$ & Kœniga & & - 545 \\
\hline Iolcus . & & .524 & Impatiens. & . & & & Kohlrabbi . & & $\begin{array}{l}40 \\
37\end{array}$ \\
\hline olly . . & & 97,179 & Indian Corn & & & .508 & & & \\
\hline olly Fam. & - & . $\quad 97$ & an Pink & $\mathbf{k}$ & . & & ATE . & & - 342 \\
\hline olly Fern & • & - $.56 \mathrm{I}$ & go . & . & & . IOI & ate Far. & & 342 \\
\hline lyhock. & - & - 87 & Inula . & & - & . 233 & num & - & IOI \\
\hline Im & • & . 70 & le $\cdot$ & & - & - 233 & ca $:$ & & 60 \\
\hline ass. & - & - 5 II & Inuloideæ . & - & - & .225 & es' Bedst & & 12 \\
\hline enya & & - 67 & cea. & - & - & - 305 & Fern & . & . 564 \\
\hline ty : & & . . 25 & Irideæ . & & . & 449 & 's-fingers & & 116 \\
\hline oneysuckle & & IOI, I20, & Iris . & - & - & - 449 & 's-mantle & & - 139 \\
\hline ysuckle & & in. . 205 & Isatis & & . & $\begin{array}{r}449 \\
\cdot \quad 48\end{array}$ & Lady's-smock & & $\begin{array}{r}418 \\
-\quad 3 I\end{array}$ \\
\hline$\therefore$. & & . 400 & rdia & & & . 153 & y's-tresses & & . 410 \\
\hline Lordeum . & &.$\quad 527$ & Isoetes . & 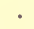 & . & . 549 & La & - & - 51 \\
\hline and & & 354,357 & Isolepis. & & - & . 484 & & & .2 \\
\hline eam & & . 405 & Isopyrum & & - & & \& Suc & & . 270 \\
\hline & & - 397 & Ivy . & - & - & . 203 & $m$ & & - $35^{8}$ \\
\hline hestr & & . 96 & Ixia. & & - & 449 & - & 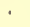 & \\
\hline dish & & - $\quad 39$ & & & & & na & 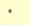 & 271 \\
\hline & & - 552 & $J_{A C O B}{ }^{\prime} L_{A I}$ & $\mathrm{E}$ & & 04 & ane & - & \\
\hline nia. & & - $28 S$ & Jasione. . & & & . 272 & . & . & \\
\hline -tong & & - 315 & ninaceæ & & & -7 & in & - & - 4 \\
\hline & & - 162 & wateo & & . & $2 y$ & spur & - & \\
\hline , & & - 298 & num. & & . & .29 & a. & - & $I, 56$ \\
\hline ulus . & & - 400 & ha. & & & & cea & - & . \\
\hline nsia & & - 45 & $\mathrm{~m}$ & & & & yrus & - & $-\circ$ \\
\hline th 4 & & 3,464 & ne & & & & l. & - & 128,38 \\
\hline hus & - & - 463 & $\mathrm{Ch}$ & & & & $8:$. & & $128,3^{8}$ \\
\hline & &.$\quad 165$ & & & & $\begin{array}{r}49 \\
. \\
.\end{array}$ & stinus & - & - \\
\hline arid & & $\cdot .433$ & $J u$ & & $\cdot$ & & dula & - & - \\
\hline aris & & - 434 & aceze & & . & $\cdot 4$ & $\mathrm{ra}$ & - & - \\
\hline 10 & & - 433 & & & • & . 469 & der & - & 44,36 \\
\hline tyle & & 177 & Juniper & & • & $4 \mathrm{I}$ & ort. & - & \\
\hline I & & n. 308 & perus & & - & - 417 & - & & \\
\hline phy & lun & . 571 & Justicia & & & & is. & - & - \\
\hline & - & - 317 & & & & & te & - & \\
\hline & • & . 270 & & & & & . . & - & - \\
\hline ineas & - & - 79 & & & & & aceæ & - & \\
\hline $\mathrm{um}$ & & 79 & Kalmia . & - & - & - 278 & bulacefe & & . 2 \\
\hline & & - 79 & dya. & - & - & . IOI & ily . & - & .453 \\
\hline & • & - 259 & & & - & - 128 & tis . & . & - 344 \\
\hline peris & - & - 259 & ey Vet & & & & don & - & \\
\hline & - & - 287 & & & - & . 51 & 3. & - & - 358 \\
\hline . & - & - 344 & reed & & - & . 25 & d's-ba & ge & - 247 \\
\hline & & - 344 & & & & & neæ. & - & - 2 \\
\hline & & & ass . & & & & $\mathrm{nm}$ & • & : \\
\hline & & & eed. & & & & & & \\
\hline
\end{tabular}




\begin{tabular}{|c|c|c|c|c|c|c|c|c|c|}
\hline & & & & & & & & & \\
\hline & & & & ucern. & & .106 & Marsileaceæ & & \\
\hline $\mathrm{m}$ & . & . & . 454 & & - & - 210 & & & \\
\hline & a & - & & igia & & .153 & 88. & & \\
\hline & - & • & - 191 & & - & & & & \\
\hline & - & • & - 547 & & . & . 309 & & & \\
\hline & & & . 224 & . . & . & . 101 & & - & . 237 \\
\hline & n & & - 191 & & - & . 474 & & & \\
\hline & 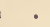 & . & . 298 & & . & - 63 & & & - 32 \\
\hline & - & . & . 297 & & . & - 317 & & & \\
\hline & & & .455 & & & & & & \\
\hline & & - & .4 & & . & & d . & & \\
\hline & & & .455 & & - & - 313 & $t$. & - & .21 \\
\hline & -Vall & & & & . & & Rue. & & \\
\hline & & . & - 87 & ass & & & & & .46 \\
\hline & & & - 87 & & . & . 290 & reet & & .13 \\
\hline & & & - 304 & & & & & & \\
\hline & & & . 304 & & . & . & 0 . & & . 10 \\
\hline & & & . $33 \mathrm{I}$ & & & . I & - . & & .10 \\
\hline & & & $\cdot 331$ & & & & & & . 14 \\
\hline & & & . 82 & & . & .210 & rum. & & \\
\hline & & . & . 327 & & - & 5 & & & \\
\hline & & & & & & & maceic & & \\
\hline & & • & . 209 & & & .12 & & & 34 \\
\hline & & & .2 & & & & & & \\
\hline & & & 83 & & & & & & \\
\hline & & . & & & & & 18 . & & 10 \\
\hline & & . & $.43^{6}$ & & - & . 508 & & & \\
\hline & - & & & & & & & & \\
\hline & & . & & & - & 43 & & & \\
\hline & & & & & & & & & \\
\hline & & & & & & & & & \\
\hline & & - & - I60 & & & 85,8 & & & \\
\hline & & & . 461 & & & & lis & & \\
\hline & & & & & & & & & \\
\hline & & . & . & & & & ia. & & \\
\hline & & & & & & & lus. & & \\
\hline & & & & his & & .446 & & & \\
\hline & & . & . 25 & & & . 295 & . . & & 19 \\
\hline & & & . 169 & & & & eon. & & \\
\hline & & & & & & & M & & \\
\hline & & & . 208 & & & & cala. & & \\
\hline & & & & & & & & & \\
\hline & & & .3 & & & & & & \\
\hline & & & . $2 \mathrm{O}_{3}$ & Tribe & & & ette $\mathrm{F}$ & & \\
\hline & & & & & & & & & \\
\hline & & & & & & & & & \\
\hline & - & • & & & & & & & \\
\hline & & & & & & & ort Fan & & \\
\hline & & & & & & & & & \\
\hline & & & & & & & tia & & \\
\hline & & & & & & & Mimosa & & \\
\hline
\end{tabular}




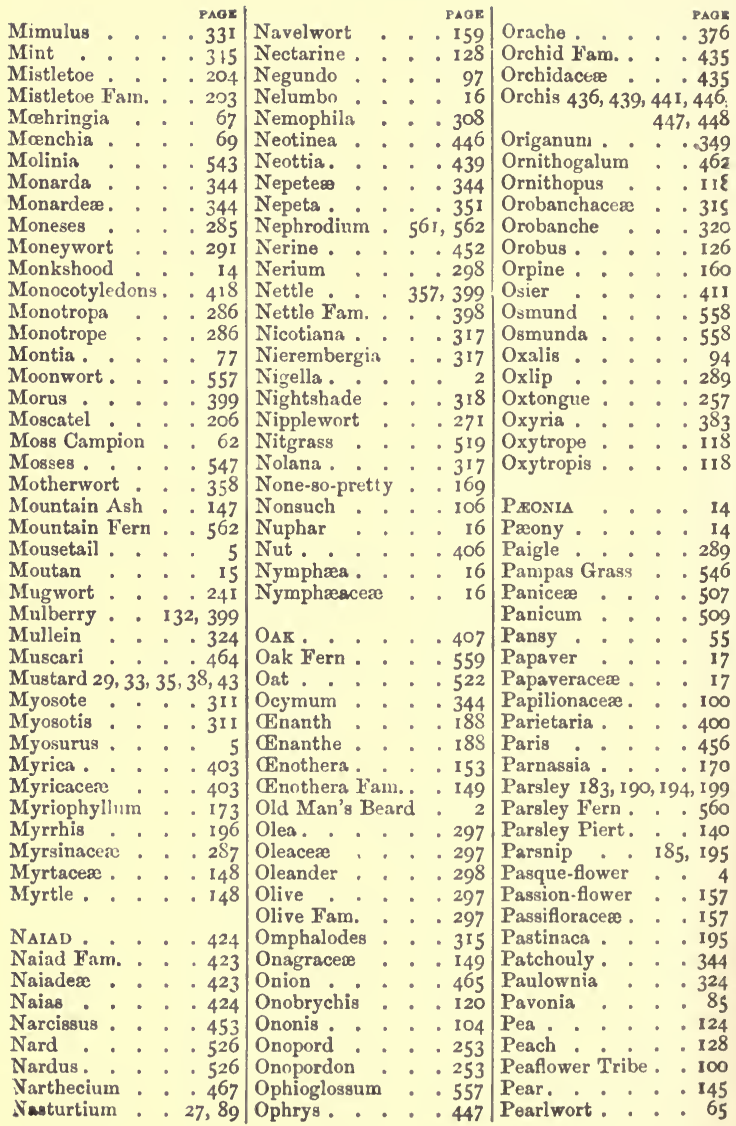




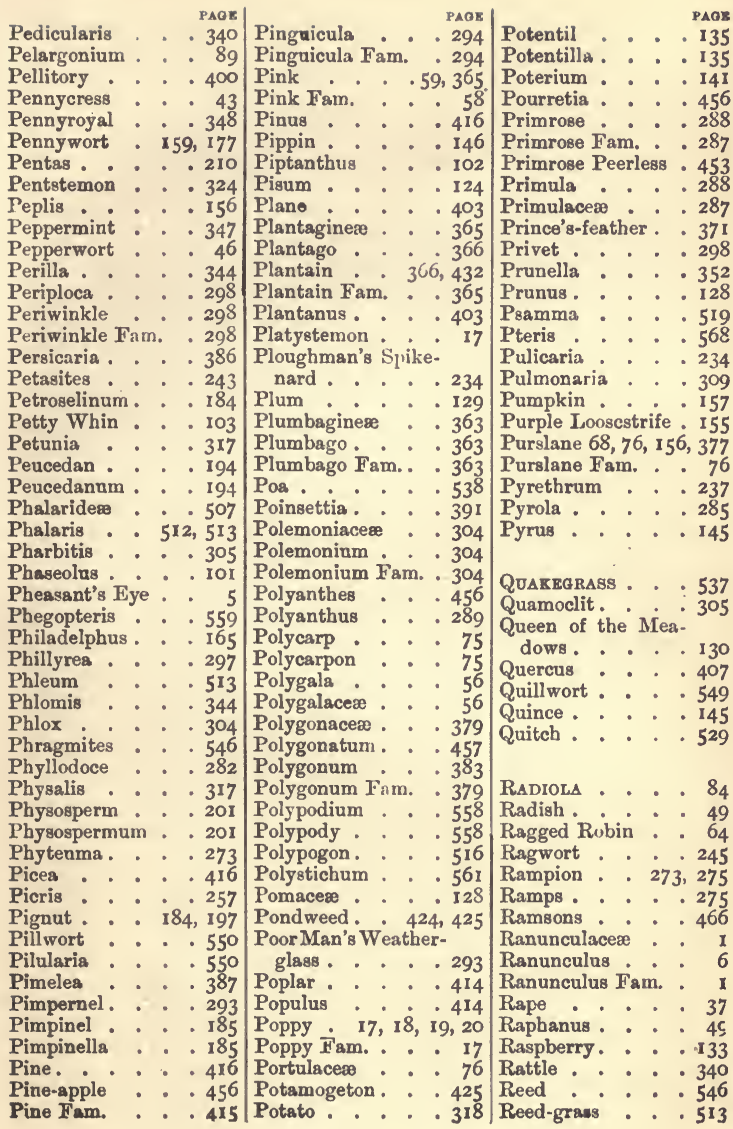


PAGT

Reedmace . . 418

Reedmace Fam. . . 418

Reseda . . . :50

Resedaceæ . . 50

Restharrow . . IO4

Restiaceæ . . . 476

Rhamanceæ . . . 98

Rhamnus . . . 99

Rheum . . . 379

Rhinantheæ . . 324

Rhinanthus . . . 340

Rhododendron . . 278

Rhubarb . . . 379

Rhus . . . . 100

Rhynchospora

Ribbon-grass .

Ribes

Ribes Fam.

Ribesiaceæ

Ribwort

Roastbeef-plant .

Robinia

Rochea .

Rockcist

Rock-cress 480

513 163

163

163

367

450

IOI

158

Rocket $26,33,36,48,50$

Rock-rose . . . 5 I

Rœmeria . . . . 19

Romulea . . . .45I

Root of Scarcity . 376

Rosa . . . . I 142

Rosaceæ . . . 127

Rose . . . . 142

Roseæ . . . . 128

Rosebay . . . I50

Rose Campion . . 64

Rose Fam. . . . 127

Rosemary . . . 344

Roseroot . . . . 160

Rosmarinus . . 344

Rowan-tree . . 147

Rubia . . . .210

Rubiaceæ . . . 210

Rubns . . . . 132

Rudbeckia . . .225

Rue . . . . . 96

Ruellia . . . 323

Rumex . . . 379

Ruppia . . . . 425

Rupture-wort . 369

Ruscus . . . .459
PAGR

Rush . . . . 469

Rush Fam. . . . 468

Ruta . . . . 96

Rye . . . . 508

Rye-grass . . 530

SAFFroN . . 468

Sage . . . 344

Sagina . . . 65

Sagittaria. . . 43I

Sainfoin . . . I20

St. John's-wort . . 80

St. Patrick's Cabbage . . . . 169

Salad-Burnet. . . 14 I

Salicineæ . . . 403

Salicornia . . . 371

Salix . . . . 408

Sallow . . . . 411

Sallow Thorn . . $3^{88}$

Salpiglossis . . 324

Salsify . . . 256

Salsola . . . 373

Saltwort . . . 373

Salvia . . . 344

Sambucus . . . 206

Samole. . . . 294

Samolus . . . 294

Samphire . 193, 371

Sandalwood Fam. . 389

Sandspurry . . 74

Sandwort . . . 67

Sanguisorb . . I40

Sanguisorba . . 140

Sanicle. . . . 178

Sanicula . . . 178

Santalaceæ . . 389

Sapindaceæ . . . 96

Sapindus Fam. : . 96
Saponaria . . 61

Sarothamnus . . 104

Satureia . . . 344

Satureiner . . 344

Sauce-alone . . . 34

Saussurea . . . 248

Savin . . . 417

Savory . . . . 344

Sawwort . . 248

Saxifraga . . . 165

Saxifragaccæ . . 165

Saxifrage $165,186,192$
PAgK

Saxifrage Fam. . 165

Scabiosa . . 220

Scabious . . . 220

Scævola . . 272

Scandix . . . 196

Scarlet Runner . IOI

Scheuchzeria . . 429

Schizanthus . . 324

Schœnus . . . 479

Scilla . . . 462

Scirpus. . . . $48 \mathrm{I}$

Seleranthus . . 370

Sclerochlon . . 540

Scleropos . . . 541

Scolopendrium . 567

Scorzonera - 225, 256

Scrophularia . . 329

Scrophularia Fam. . 323

Scrophularineæ . 323

Scurvy-grass . . 39

Scutellaria . . 352

Seakale. . . 49

Secale. . . 508

Sedge . . . . 421

Sedge Fam. . . . 477

Serum . . . I 59

Selaginella . . 549

Selaginellaceæ . 549

Selfheal . . . 352

Selinum . . . 177

Sempervivum . . 162

Senebiera . . . 47

Senecio. . . 243

Senecionidere. . 225

Sensitive-plant . . 100

Sequois . . . 416

Serratula . . . 248

Service-tree . . 146

Seseli . . . . 191

Sesleria . . . 545

Setaria . . . 510

Setter-wort . . I2

Shallot. . . . 465

Sharnrock . . . II

Sheep's-bit . . 273

Shepherd's-needle . I96

Shepherd's-purse - 45

Shepherd's weatherglass . . . . 293

Sherardia . . . 215

Shieldfern . . . $56 \mathrm{I}$ 


\begin{tabular}{|c|c|c|c|c|c|c|c|c|}
\hline & & & & & & & & \\
\hline & & $.13^{8}$ & Spindle-tree . & & . $\quad 98$ & Taoamahao & & $\cdot 414$ \\
\hline Crab & & .145 & & & . 130 & Tagetes . & & .225 \\
\hline & & - 332 & thes & & . $44^{\circ}$ & Tamarise & . & \\
\hline & & . 545 & wwort & & . 564 & se Fan & $\mathrm{am}$. & - \\
\hline & & . 192 & & & .416 & iscinex & & \\
\hline & & - $6 \mathrm{I}$ & ge . & & . 39 I & Tamarix . & . & \\
\hline weed & & - 138 & Spurge Fam. . & & . 390 & Tamu & . & . 45 \\
\hline & & .250 & & & & etum & & \\
\hline & & - 467 & & & . 462 & s Pea & a. & \\
\hline & & . 35 & & & . 215 & & . & . 240 \\
\hline & & . 181 & tail $\mathbf{G}$ & & 3. 528 & gon. & & . $24 \mathrm{I}$ \\
\hline & & . 25 & & & & cum & & \\
\hline $\mathrm{um}$ & & . 33 & & . & & & - & .121 \\
\hline & & . $45^{1}$ & Sts & & . 298 & dium. & & 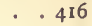 \\
\hline & & .185 & & & & & & \\
\hline & & - $35^{2}$ & ethleb & & . 462 & ant . & & • \\
\hline & & . 128 & & & . 72 & & & .21 \\
\hline & & . 520 & Wat & & - 397 & Fam. & & $.2 \mathrm{I}$ \\
\hline & & $.45^{8}$ & & & - 363 & & & . \\
\hline & & .20 & & & - 72 & & & . \\
\hline & & . 106 & & & . 210 & hace & & \\
\hline & & o & Tribe & & . 210 & & & $\cdot 36 c$ \\
\hline & & & & & . 2 & & & \\
\hline & & .326 & & & - 508 & $\mathrm{Im}$ & & \\
\hline & & .2 & & & & & & $3^{8}-x-1$ \\
\hline & & .20 & & & & lia. & & \\
\hline & & . 453 & & & & & & \\
\hline & & .2 & & & & & & \\
\hline & & . 454 & & - & 434 & leø & & - \\
\hline & & - $6 \mathrm{I}$ & & & & pple & & \\
\hline & & $\cdot 316$ & $y$-tre & ee . & . 280 & & & \\
\hline & & & ræ . & - . & . 507 & & & - \\
\hline $\mathrm{F}$ & & - 3 & rass & & & $\operatorname{tax}$ & - & \\
\hline & & & & & & & & \\
\hline sea & & . 457 & - & & & & & \\
\hline & & . 2 & & & & eaces & & \\
\hline & & $3^{80}, 3_{3}^{8}$ & a. & & & & & - \\
\hline wood & & & & & - 220 & dia & & \\
\hline & & . 2 & & & .2 & & & \\
\hline & & & -weed & & & $\mathrm{Ti}$ & & • \\
\hline & & . 419 & & & . 100 & & & \\
\hline & & - . 52 & & & . I & & & \\
\hline & & IOI, IC & $\mathrm{gm}$ & & & hy-gras & & \\
\hline & & & & & . 225 & Tir & & \\
\hline & & . 277 & & & & & & \\
\hline & & - 3 & $\operatorname{liam}$ & & & & & \\
\hline & & & & & & To & & \\
\hline & & & & & & & & \\
\hline & & . 192 & & & & ort. & & \\
\hline & &, $3 t$ & & & & am. & & \\
\hline & & & & & & & & \\
\hline
\end{tabular}


PAOR

Torilis . . . . 199

Tormentil . . . 137

Touch-me-not . 95

Towercress . . 29

Trachelium . . 272

Tragopogon . . . 256

Traveller's-joy . . 2

Trefoil . 109, 115, 303

Trichera . . . 222

Trichomanes . . 570

Trichonema . . 45 I

Trientale . . . 292

Trientalis . . . 292

Trifolium . . . . 109

Triglochin . . . 430

Trigonel . . . . I08

Trigonella. . . 108

Trillideæ . . . 456

Trinea . . . . 182

Triodia. . . . 544

Trisetum . . . 523

Triticum . . . 529

Trollius . . . II

Tropæolumı . . 89

Tuberose . . . 456

Tulip . . . . 460

Tulipa . . . . 460

Tulip-tree . . . 15

Turnip . . . . 37

Turritis . . . 29

Tussilago . . . 242

Tutsan . . . . 80

Twayblade . . 439

Typha . . . .418

Typhace» . . . 418

ULEX . . . . IOI

Ulınaceæ . . . 400

Ulinus . . . . 401

Umbellate Fam. . 174

Umbelliforæ . . I74

Urtica . . . 399

Urticaceæ. . . 398

Utricularia . . 295

VACOLNIUM
PAOE

Valerian . . .216

Valeriana . . . 216

Valerianeæ . . 216

Valerian Fam. . . 216

Valerianella . . . 217

Vegetable Marrow . 157

Venus's-comb . . 196

Venus's lookingglass.

Verbascum

Verbena

Verbenaceæ

Vernal-grass

Veronica $\cdot 5^{12}$

Vervein 333

Vervein Fam. : 362

Vetch. . 117, 120

Vetchling . . . 124

Viburnuin . . . 207

Vicia . . . . 120

Victoria . . . 16

Villarsia . . 304

Vincs . . . . 298

Vine . . . . 99

Viola . . . . 53

Violace.. .553

Violet 33, 53, 54, 288, 289

Violet Fam. . . . 53

Virginian Crecper . 99

Viscaria . . . 64

Viscum. . . . 204

Vitace» . . . . 99

Vitex . . . . 362

Vitis . . . 99

WAHLRNBERGIA . . 274

Wake-robin . . 420

Wallcress . . . 30

Wallflower . . 26

Wall-pepper . . 161

Wall-rue . . . 566

Walnut. . . . 403

Wartcress . . . 47

Water Chickwced . 77

Watercress . . 27

Waterlily . . . 16
PAOE

Waterlily Fam. . . I6

Watermelon - . 157

Water Pepper $78,3^{86}$

Water-soldier ... 434

Wayfaring tree . . 208

Weigela . . . 206

Weld . . . 50

Wellingtonia . . . 416

Wheat . . . . 527

Whin . . . . 102

White-rot . . . 177

Whitethorn . . I 47

Whitlow-grass . . 42

Whortleberry . . 278

Willow . . 150, 408

Willow-herb . . 150

Wintercress . . 26

Wintergreen . . 285

Wistaria . . . IOI

Woad . . . . 48

Wolffia . . . . 422

Wolfsbane . . 14

Woodbine. . . 209

Woodruff . . . 215

Woodrush . . . 474

Wood-sage . . 360

Woodsia . . . 570

Wormwood . . . 242

Woundwort . . 355

XaNTHIUM . . 235

YAM . . . 454

Yam Fam. • . 454

Yarrow . . . 240

Yellow Weed . 50

Yellow-wort . . 303

Yew. . . . 417

Yucca . . . 456

Zanniohelda . . 424

Zauschneria . . I49

Zea . . . . 508

Zinnia . . . . 225

Zostera. . . 423 



\section{Date Due}

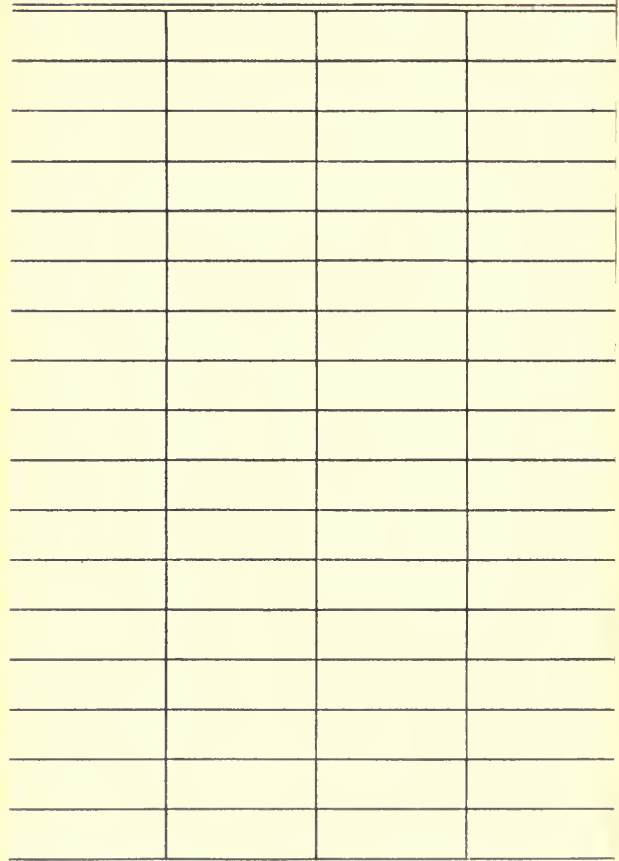

Demco 293-5 
QK306

B45

1892
Bentham, George

A $000640312 \quad 5$

Handbook of the British flora: a description of the flowering plants and ferns indigenous to. or naturalian
QK306

$B 45$.

1892
Bentham, George

Handbook of the British flora: a description of the flowering plants and ferns indigenous to, or naturalised in, the

\section{AGRICULTURAL LIBRARY}

UAV: "ITY OF CAIIFORIIA

CITRUS FESEARCH CENTER MMD AGRICULTUIAL EXPERINEITT SIATION

RIVERSIDE, CALIFORNIA 


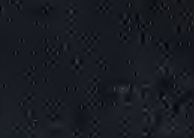

fing 8 is

$\sin x$ 